
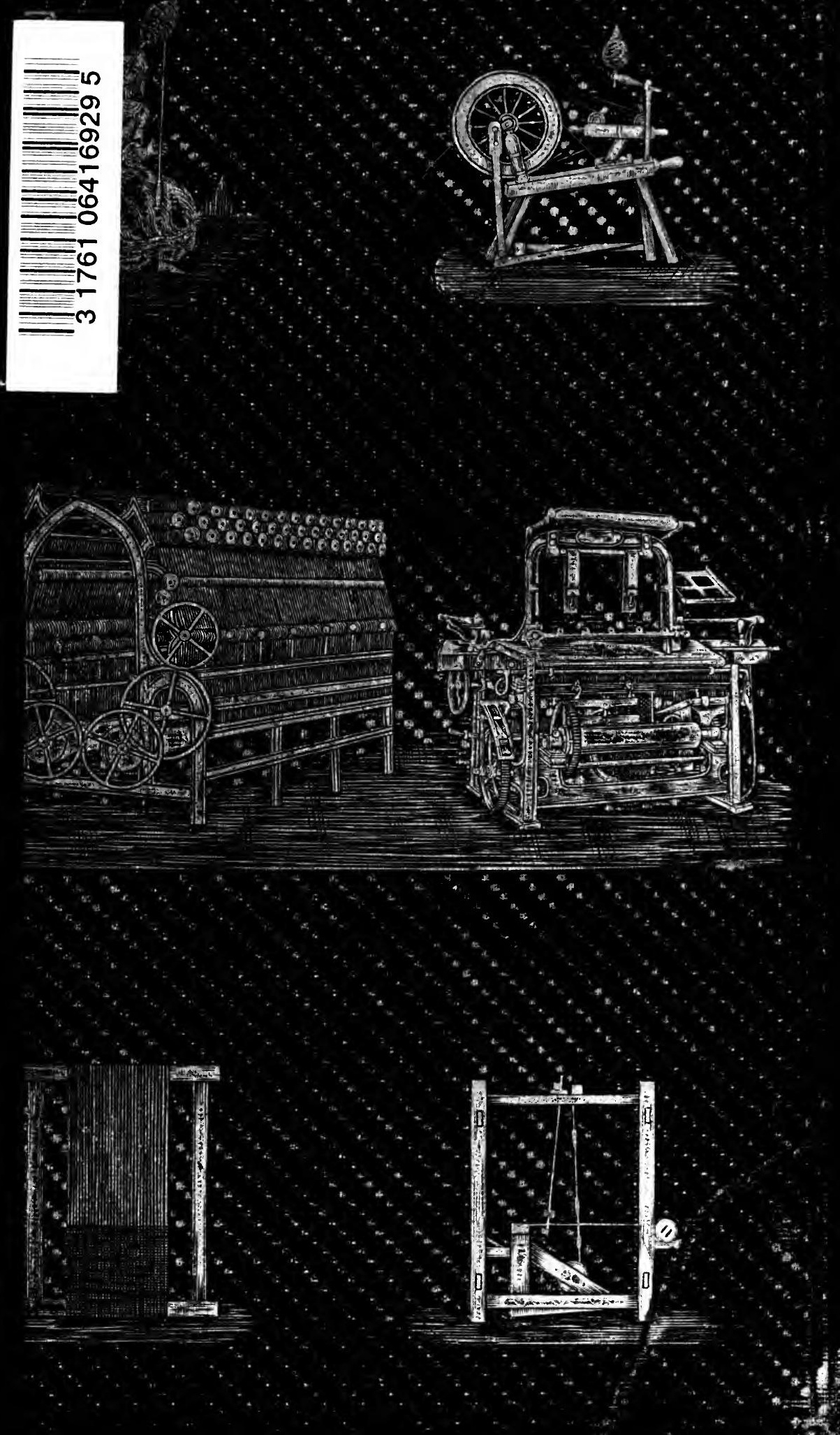


Digitized by the Internet Archive in 2007 with funding from Microsoft Corporation 


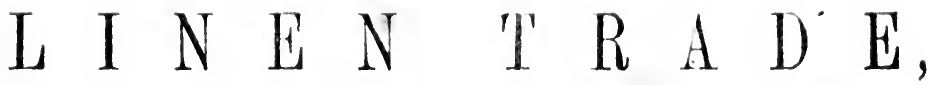

\section{ANCIEN'I' AND MODERN.}

\author{
BY \\ A L EX. J. W A R D E N \\ MERCHANT, DUNDEE.
}

\section{SECOND EDITION.}

\section{ONDON :}

LONGMAN, GREEN, LONGMAN, ROBERTS \& GREEN. 1867. 


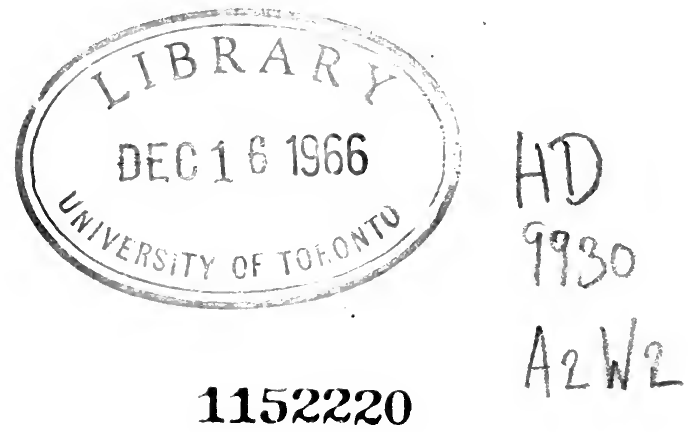

PRINTED BY CHARLES ALEXANDER AND COMPANY, DUNDER. 
THIS WORK

IS

BY PERMISSION,

K E S P E C T F UL L Y DE D I CA T E D

ro

\section{THE PRESIDENT,}

VICE-PRES I D E T, D I R ECT T RS,

AND

M E M B E R S

OF THE

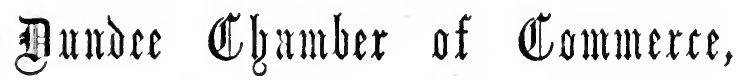

BY

THE AUTHOR. 


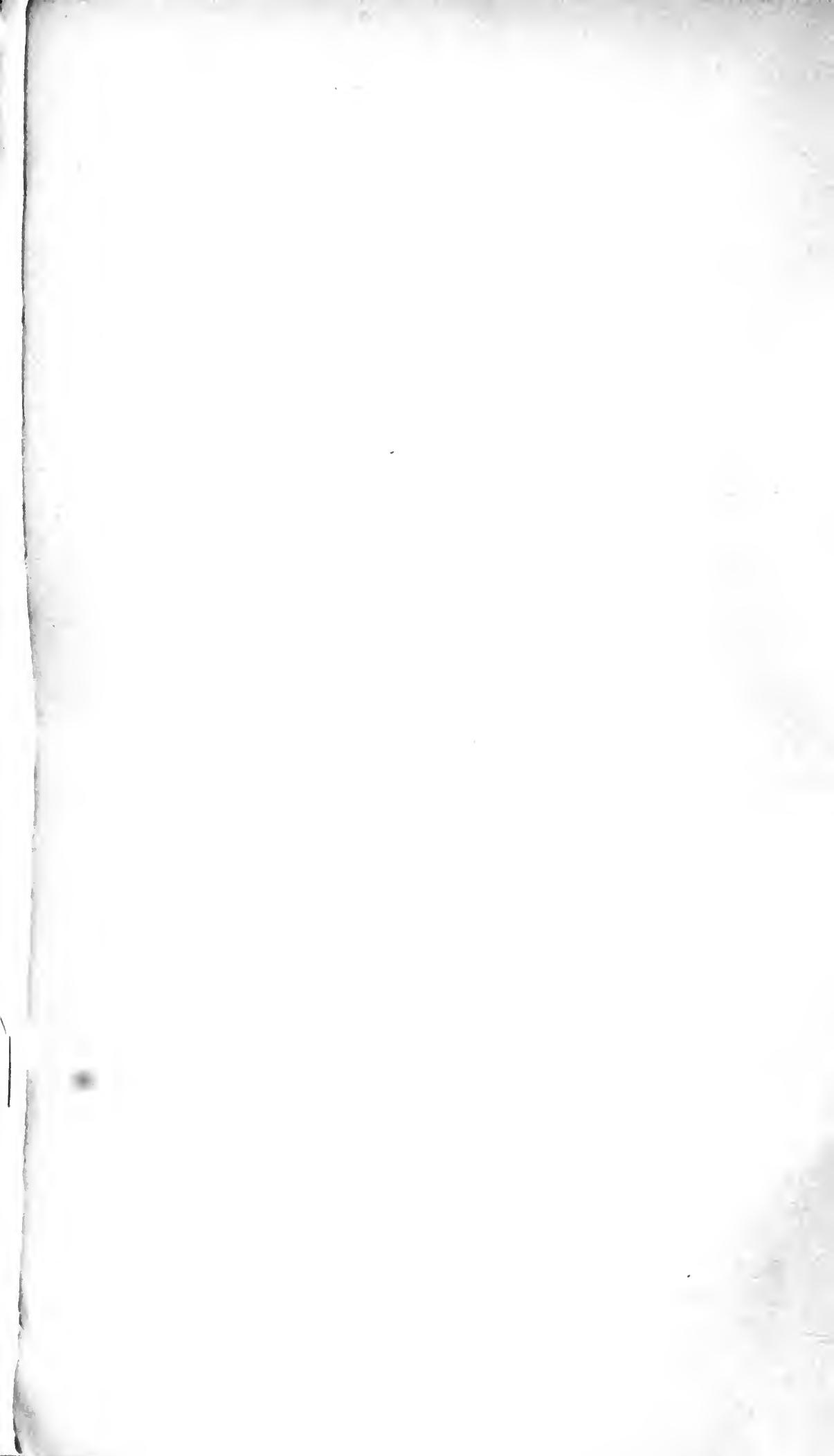




\section{PREFACE.}

IT is somewhat surprising that the history of so ancient and important a manufacture as that of Linen, and of the commerce connected with it, has not long before this time been placed in a comprehensive form before the world. It is one of the axioms of Political Economy, as it is held at the present day, that "demand creates supply," but, up to the present time, that has not in this instance been verified. The feeling that such a work was needed has often been expressed, both by the general public and by those immediately concerned in the Trade, but without, until now, having the effect of bringing forth one. Perhaps that is to be accounted for by our system of "division of labour." Books are generally written by literary and scientific men; but probably very few of either of those classes possess anything like that practical knowledge of the details of the subject, which it would be difficult to obtain without having been actually engaged in the business. That is the only way in which it appears possible to explain the fact that a generally acknowledged want has been suffered to remain unsatisfied, and that it has been left for me to attempt the performance of a task which should have been committed to abler hands. But whatever the deficiencies I may be sensible of with respect to mere literary qualifications, I have the advantage of an intimate practical acquaintance with the Linen Trade in all its branches-the result of having been for many years engaged in it; and I may venture to hope that the following pages will be found to contain evidence that I have industriously endeavoured to collect information from all accessible sources. Conscious that that is the case, I may ask that faults of style, of which I fear there are many, may be indulgently regarded, and that the Book may be received and judged of, not as a literary effort, but as an attempt to compile a full and reliable record of the rise, progress, and present condition of an important department of manufacture and commerce. 
Great care has been given to the preparation of the Statistical Tables, and to ensure the correctness of the figures which are scattered through the work ; and the letter-press has been mainly compiled from the writings of historians and authorities, ancient and modern, with the view of making the work trustworthy and complete as a Book of Reference.

In the course of my labours I have been indebted to many gentlemen in Dundee and other places, for information which would, but for their help, have been inaccessible to me, and I have gratefully to acknowledge their kindness. The names of some of my benefactors are mentioned in the work; and to those and others who are not specially alluded to, I beg to present my sincere thanks.

To Sir John OgILvy, Bart., M.P. for Dundee, I am under great obligations for the kindly interest he has taken in my efforts, and for the readiness with which he has supplied information on several points.

Mr John Leng, Proprietor of the Dunaee Advertiser, in the most handsome manner placed at my disposal the entire file of the Advertiser from its commencement in $\mathbf{1 8 0 1}$ to the present time. I went over every paper for the first forty years, and many of later date. From them $I$ gathered much interesting and curious matter, and (as mentioned at p. 610), the data for the Dundee Prices Current for many of the earlier years. Mr CHarles Alexander, of the Courier (commenced in 1815), and $\mathrm{Mr}$ Robert PARK, of the Northern Warder (begun in 1841), also gave me access to their files, and I am indebted to their courtesy for considerable advantages. The Directors of the Dundee Chamber of Commerce obligingly granted me the use of the valuable collection of books in the Library of the Chamber, and thus enabled me to give a number of the statistical details contained in this volume. As a small mark of my appreciation of their kindness, and of my respect. for the Incorporation which watches over the interests of the staple trade of Dundee, I have dedicated this book to the President, Directors, and Members of the Chamber.

ALEX. J. WARDEN.

Dundee, July 16. 1864. 


\title{
C ONTENTS.
}

\author{
SECTION I.
}

\section{THE RAW MATERIAL,}

Page.

Chap. I. Flax Culture,

II. HeMP Do.

III. Jute Do.,

1. The Culture of Jute in the Field, . . 49

2. Do. do. in the Factory, . . 66 Tabular Statements regarding Jute, . . $\quad 84$

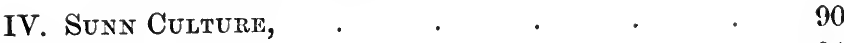

V. VARIOUS Fibres, . $\quad$. $\quad$. $\quad$. $\quad$. 94

The Nettle, . $\quad . \quad$. $\quad . \quad$. 95

China Grass, . $\quad$. $\quad$. $\quad$. $\quad$. 95

New Zealand Flax, $\quad$. $\quad$. $\quad$. $\quad$. 98

Manila Hemp, . . . . . . 100

The Lime Tree, \&c., . . . . . 103

Noble's Prices Current, . . . . 108

Tabular Statements regarding Flax, \&c., $\quad$. 110

SEC'LION I I .

A N C I E T L I N E , 118

Chap. I. Bible Linen, . . . . . . 120

II. Egyptian Do. . . . . 145

III. Phoenictan Do. - . . $\quad$. 176

IV. Carthagenian and Babylonian Do. . . 180

V. Colchican Do. . . . . . 183

VI. GRECIAN Do. . . . . . 185

VII. Roman Do. . . . . . 198

S E C T I O N I I I.

THE LINEN MANUFACTURES OF THE OLDEN TIME, 209 
SECTION I V.

M ODER N L I N N .

PART I.

CONTINENTAL LINEN.

Page.

248

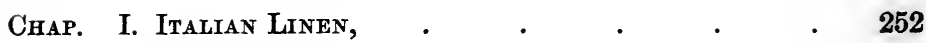

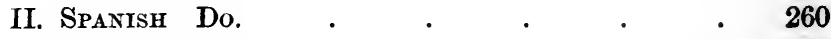

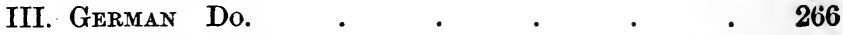

German Fairs, $\quad . \quad$. $\quad$. $\quad$. $\quad$. 280

Hanseatic League, ․ $\quad$. $\quad$. $\quad$. 282

IV. Austrian Linen, $\quad$. $\quad$. $\quad$. $\quad$. $\quad$ - 285

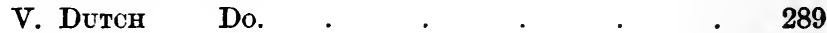

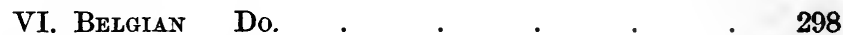

VII. French Do., . . . . . . 303

VIII. Russian Do., $\quad$. $\quad$. $\quad$. $\quad$. $\quad$. 319

IX. Various Countries-

Denmark, Norway, and Sweden, . . . 339

Portugal, . $\quad$. $\quad . \quad$. $\quad . \quad 340$

Switzerland, $\quad . \quad$. $\quad . \quad . \quad$. 342

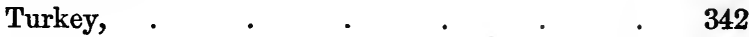

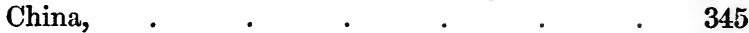

The United States of America, . . . $\quad 345$

PAR T I I.

THE UNITED KINGDOM, 351

Chap. I. English Linen, . $\quad$. $\quad$. $\quad 252$

II. IRISH Do., $\quad$ - $\quad$. $\quad$. $\quad$. 388

III. Scotch Do., $\quad$ - $\quad$ - $\quad$. $\quad$. $\quad$ - 421

British Linen Company, . . . . 442

Board of Trustees for Manufactures, . . 444

The Stamp Act, . $\quad$. $\quad$. $\quad$. 465

Tabular Statements of Linens Stamped,. . 476

Rural Districts- $\quad$. $\quad . \quad$. 483

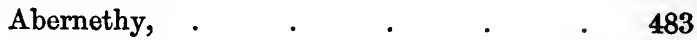

Abernyte, . $\quad$. $\quad$. $\quad$. $\quad$. 483

Alyth, . $\quad$. $\quad$. $\quad$. $\quad$. 484

Arbirlot, . $\quad$. $\quad$. $\quad$. $\quad$. 485

Auchterarder, . . . . $\quad 485$

Auchtermuchty, . $\quad$. $\quad$. $\quad$. 485

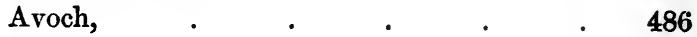

Banff, . $\quad$. $\quad$. $\quad . \quad 486$

Barry, . $\quad$. $\quad$. $\quad$. $\quad$. 487

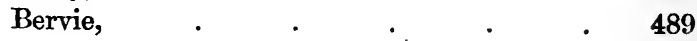


RuRal Distrets-

Page.

Bendochy, . $\quad$. $\quad$. $\quad$. $\quad$. 491

Benholın, . . . . . . 491

Birsay and Harray, . . . 491

Blair-Athole, . . . . 491

Cairnie, . . . . . . 491

Cambuslang, . $\quad$. $\quad$. $\quad$. $\quad . \quad 492$

Caputh, . . . . . . 492

Ceres, . . . . . . 493

Cluny, . . . . . . 493

Comrie, . . . . . . 493

Coupar-Angus, . . . . . 494

Crail, . . . . . . 494

Crieff, . . . . . 495

Cupar-Fife, . . . . . 495

Cullen, . . . . . . 496

Deer, . $\quad . \quad$. $\quad . \quad 497$

Dowally, . . . . . $\quad . \quad 497$

Dunkeld, . . . . . 497

Dunottar, . . . . . 498

Dunnichen, . . . . . 498

Dysart, $\quad . \quad$. $\quad$. $\quad$. $\quad$. 498

Elgin, . . . . $\quad$. 501

Falkland, . . . . . 501

Fordoun, . . . . . 502

Fordyee, . . . . . 502

Forgan, .. . . . . 502

Forres, . . . . . 503

Galston, . $\quad$. $\quad$. $\quad$. 503

Glamis, . . . . . 504

Glasgow, . . . . . 504

Grange, . . . . 505

Greenock, . . . . $\quad 505$

Huntly, . . . . 506

Inverary, . . . . . 506

Inverness, . . . . . 506

Keith, . . . . . 507

Kemback, . . . . . 507

Kenmore, . . . . 508

Kettle, . . . . . 508

Kilbride, . . . 508

Kilchoman, Isla, . . . $\quad 509$

Killin, . . . 509

Kilwinning, . . . 509

Kinghorn, . . . . 510

Kinloch, . . . . 511 
Rural Districts-

Page.

Kinnettles, .

Kinross,

Kirkden,

Kirkwall and St Olda,

515

Largo,

515

Leslie,

Lethendy,

Leuchars,

515

516

516

Little Dunkeld, $\quad . \quad$. $\quad$. $\quad$. $\quad 517$

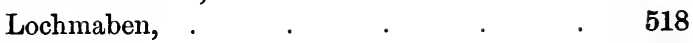

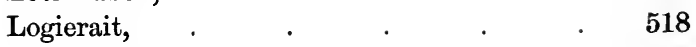

Logie Pert, . $\quad . \quad 5 \quad$. $\quad$. 518

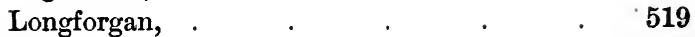

Mains,

Markinch, . . . . $\quad .520$

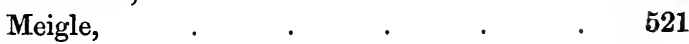

Melrose, . $\quad . \quad 5 \quad$. 521

Menmuir, . $\quad . \quad 5 \quad . \quad 5 \quad . \quad 522$

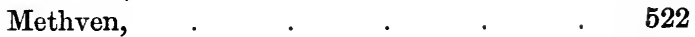

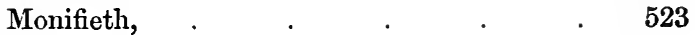

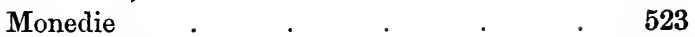

East Monkland, . $\quad$. $\quad$. $\quad$. 523

West Monkland, $\quad . \quad 5 \quad$. $\quad$. $\quad$. 523

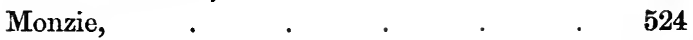

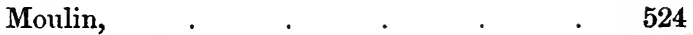

Newburgh, Fife, . $\quad . \quad . \quad . \quad 525$

North Yell and Fetlar, . . . $\quad 527$

Orphir, . . . . $\quad$. 527

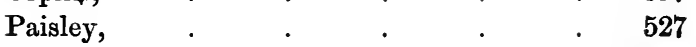

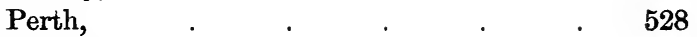

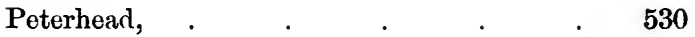

Rathen, . . . . . . 531

St Boswells, . $\quad . \quad 5 \quad . \quad 5 \quad . \quad 532$

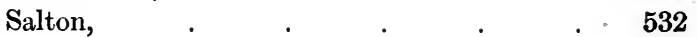

Scoonie, $\quad . \quad$. $\quad . \quad 5 \quad . \quad 532$

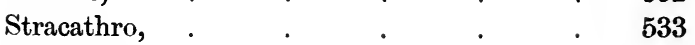

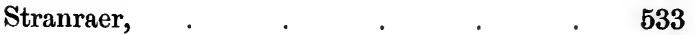

Strathdon, . $\quad . \quad 6 \quad . \quad 533$

Strathmiglo, . $\quad . \quad$. $\quad . \quad 5 \quad$. 534

Strichen, . $\quad . \quad$. $\quad . \quad 534$

Thurso, $\quad . \quad$. $\quad . \quad 5 \quad$. $\quad 534$

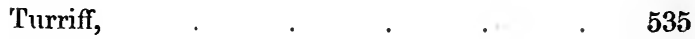

Weem, . . . . $\quad . \quad 535$

Wemyss, . . . . . . 535

Wick, $\quad . \quad$. $\quad . \quad . \quad . \quad 537$ 


\section{Distriet Trade-}

Page.

Aberdeen, . $\quad$. $\quad . \quad 5338$

Arbroath, . . . . . 541

Blairgowrie, . . . . 548

Brechin, . . . 551

Dunfermline, . . . . . . 554

Forfar, . . . . . . 558

Kirkcaldy, . . . . . 561

Kirriemuir, . . . . $\quad 567$

Lochee, . . . . . 570

Montrose, . . . . . $\quad 574$

DUNDEE- $\quad . \quad 2 \quad . \quad 5 \%$

Tabular Statements-Imports and Exports, . 633

Prices Current, $\quad . \quad 6 \quad$. $\quad .639$

Tabular Statements of Power, Sc., . . $\quad 654$

Chap. IV. United Kingdom, - . $\quad$. 658

Linen Bounty, . $\quad$. $\quad$. $\quad$. 663

Factory Laws, . $\quad . \quad$. $\quad .670$

Tabular Statements of Exports of Yarn and Linen, $\quad 673$

Do. do. of Factory Returns, . $\quad 680$

\section{SECTION V.}

MANUFACTURING OPERATIONS,

I. Flax-Spinning, $\quad$. $\quad . \quad 6 \quad$. $\quad$. $\quad 683$

II. Linen Weaving, . . . . 700

III. Liney Bleaching, . . . . 716

Appendix, . . . . . . . . . 724

INDEX, . . . . . 734

ERRAT A.

Page.

76-Line 9 -For 1823 read 1832.

85 " 5-For ton read ewt.

187 , 17-For Alexandira read Alcandra.

197 -Heading-For Roman read Grecian.

584-Line 28 -For 1762 read 1792.

34 "34-For weavor read wearer. 



\section{PREFACE TO THE SECOND EDITION.}

The impression of the work on The Linen Trade consisted of fifteen hundred copies. The first issue of these, (one thousand) copies, has now been disposed of. To meet the demand which still exists for the book, it has been resolved to issue the remainder of the impression. In order to make the volume as complete as possible, a supplement will be given with the new issue, containing a continuation of the most important of the statistical tables, and other information of an interesting character bearing on the present position of the Linen Trade.

The author is very grateful for the laudatory manner in which The Linen Trade was noticed by so many of the leading journals of the day. He returns his cordial thanks to the numerous subscribers to the work, and to the many gentlemen who purchased copies of it when published and subsequently

Prior to the publication of The Linen Trade in July 1864, the calls for the volume were so numerous and so urgent, that the author was compelled to issue the work before it was possible to go over the typography and note all the errata. As might have been expected in such a work, many errors exist besides those noticed in the few errata given in the volume. An enlarged list of errors, typographical and otherwise, is now supplied.

Dundee, October, 1867. 



\section{SUP P L E M E N T.}

WHEN the volume on the Linen Trade was published in July 1864 , the trade was in a very flourishing state, not only in the United Kinglom, but also in the other linen manufacturing countries of Europe. The demand, stimulated by the enormous consumption of Linens by the belligerents on both sides during the American War, was most active, and the trade highly renumerative. This induced spinners and manufacturers in many districts to build new works, or make great additions to old ones, in order to increase their production and supply the wants of consumers. The American War terminated, and the roid caused by the War was filled up. Again trade returned to its normal position, and manufacturers were left to supply the ordinary every day wants of the world. The vastly increased production, induced by the then exceptional demand, appears to be at present quite up to, if not beyond, the legitimate consumption, and a sickly demand with low prices for Linens is the natural consequence.

Unfortunately for the Flax branch of the Trade, the cultivation of the Flax plant has not kept pace with the extensiun of machinery, and the supply of the Raw Material is not now equal to the requirements of the Trade. For some years past the price of Flax has been high, but high prices have not been inducement enough to stimulate the farmers in the Flax growing countries of Europe sufficiently to extend the acreage under the plant. A short supply of Flax is, and mustbe, disastrous to the Linen producing countries; and it is a problem, the solution of which is of the greatest importance,-by what means to get the supply of Flax kept up with the increased and still increasing consumption.

Russia is the great Flax producing country of Europe, and, according to the pamphlets published by the Russian Government for the Paris Exhibition, upon the productive power of that 
country, it is grown to some extent in almost every Government of that great empire, both in Europe and Asia. The Governments where Flax is most largely cultivated, and the quantity of fibre and seed produced in each, are as under:-

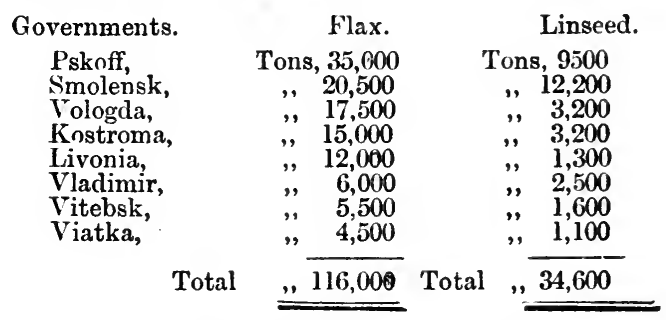

No statement of the quantity of Flax produced in any of the other Governments is given, but, as nearly all of them grow nore or less of it, the estimate of 150,000 tons, given in page 319 , is now probably considerably under the quantity actually raised.

Although the cultivation of Flax in Russia may have been increased of late years, the quantity available for export cannot be much, if any, greater than it was, because the local Linen manufacture of the country has been extending year by year for some time past. The various branches of the Flax trade, from raising the plant to weaving the Linen, occupy the first rank among the textile industries of Russia, and so general is the trade, that the Government has not been able to make up correct statistics regarding it, but the following is a near approximation to the truth. Pskoff and Livonia export nearly all they grow, and there, as well as in other districts, improvements have lately been made in the cultivation and preparation of the fibre, but the processes employed still leave much to be desired. On the banks of the Volga and in Yaroslav and Kostroma, many works have recently been erected for spinning flax. In 1864 more than 5000 people were employed in the mills there, and the value of the yarn spun was more than half a million pounds sterling; since then considerable extensions have been made, and the increase still goes on. In Vologda, Vladimir, Kostroma, Yaroslav, Novgorod, Twer, and Archangel powerloom weaving has made great progress of late. Yaroslav is famed for its fine Linens, made in imitation of Irish goods; Kostroma for fine linens, and for damasks and other table linen; and Vladimir and Novgorod for 
ravens-duck, and for bed sheeting, \&c. In 1864 there were 73 powerloom works in these Governments, with 13,000 workers, and producing goods to the value of about three quarters of a million pounds sterling, and they have been greatly extended since. It is estimated that $3,000,000$ people are employed in spinning Flax, and 500,000 in weaving Linen, in both branches chiefly by hand, in Russia. The annual value of the Flax Trade in all its branches in Russia, is estimated at nearly twenty million pounds sterling. The importance of the trade to Russia is therefore immense, but the introduction and constantextension of machinery for spinning and weaving consumes at home larger and larger quantities of the Flax grown, and curtails the supply available for export.

It thus appears that adequate supplies of Flax to meet an extending consumption in this and in other countries cannot be expected from Russia. Hopes were at one time entertained that sufficient supplies might be raised in India, but hitherto almost no Flax has been imported from that country, and at the present time it is difficult to see whence an abundant supply of strong coarse Flax can be got.

Canada has both a suitable soil and climate for Flax, and the plant has been cultivated successfully there, but it is doubtful if it can be grown largely, as the population is small, and thinly spread over the country, and it would be difficult to get people at the precise time to conduct the various operations when required. Australia hasalso been experimenting on the cultivation of Flax, and practical good may yet result, but hitherto there has been little, if any, exported to this country.

The cultivation of Flax is extending in France and Belgium, but the increasing consumption there keeps pace with the enlarged supply, and no more is available for exportation.

Consul John Goodwin, in his report to the Government, for the year 1866, dated Palermo, 9th May, 1867, mentions that Sicily has ceased to grow wheat, and is now cultivating Flax and rice instead, and that both have been abundant. Little benefit may be derived by this country from that circumstance, but it is pleasant to hear of the raising of Flax extensively in any land where little had been grown before. 
Supplement to Statement on Page 111.

Total Quantities of Flax and Tow Imported into the United Kingdoy IN EACH YeAR, FROM 1862 to 1866, AND to 31st AUgust 1867.

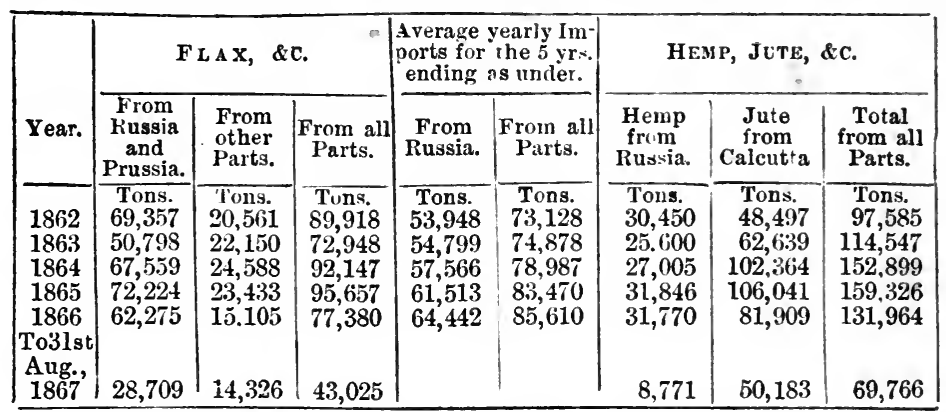

The cultivation of Jute is almost entirely confined to the deltas of the Ganges and Rrahmapootra, but there is sufficient field there to raise greatly more than supply the present demand, large though that undoubtedly is. The competing crop is rice, and as the relative prices of Jute and Rice regulate the quantity of each sown, a rise of a few pounds per ton might increase the supply almost indefinitely. Hitherto the Jute grown has been sufficient to meet the increased consumption, and the great fluctuations which frequently occur in the price are the fruit of speculation, rather than the result of scarcity.

Quantity of Jute, Jute Cuttings, Gunny Cloth, and Gunny Bags, Exported from Calcutta in the Years Undernoted.

(From Toulmin and Co's Reports.)

\begin{tabular}{|c|c|c|c|c|c|}
\hline & $\begin{array}{r}\mathbf{J} \text { U T } \\
\text { Bales of } 3\end{array}$ & & $\begin{array}{c}\text { Jute Cuttings. } \\
\text { Bales of } 225 \\
\text { lbs. }\end{array}$ & $\begin{array}{c}\text { GUNNY ClOTH. } \\
\text { Pieces weighing } \\
66 \text { lbs. }\end{array}$ & $\begin{array}{c}\text { GUNnY BaGS } \\
\text { Bags. }\end{array}$ \\
\hline 1852 & $\begin{array}{c}\text { Great Britain. } \\
47,865\end{array}$ & $\begin{array}{l}\text { Total. } \\
\mathbf{5 4 , 9 8 6}\end{array}$ & Total. & $\begin{array}{l}\text { Total. } \\
561,086\end{array}$ & $\begin{array}{c}\text { Total. } \\
13,262,946\end{array}$ \\
\hline 1853 & 81,267 & 92,594 & 53,409 & 382,298 & $15,287,148$ \\
\hline 1854 & 123,807 & 164,538 & 7 & 293,138 & $12,672,624$ \\
\hline 1855 & 203,303 & 245,241 & . & 494,826 & $17,135,076$ \\
\hline 1856 & 284,651 & 326,338 & مמב & $1,234,907$ & $20,659,702$ \\
\hline 1857 & 242,770 & 301,100 & 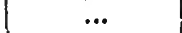 & 427,448 & $15,845,764$ \\
\hline 1858 & 197,441 & 261,372 & "• & 673,192 & $35,265,122$ \\
\hline 1859 & 391,741 & 449,698 & $\cdots$ & 901,532 & $13,570,745$ \\
\hline 1860 & 360,725 & 398,346 & $\ldots$ & 869,509 & $12,653,061$ \\
\hline 1861 & 301,798 & 356,0 & $\cdots$ & 250,662 & $18,408,900$ \\
\hline 1862 & 365,505 & 419,665 & $\cdots$ & 214,196 & $18,550,852$ \\
\hline 1863 & 707,078 & 745,547 & 47,617 & 24.091 & $21,403,289$ \\
\hline 1864 & 552 & 738,759 & 45,397 & 24,3 & $19,599,813$ \\
\hline & 754,714 & 818,777 & 95,124 & 152,696 & $31,155,142$ \\
\hline 1866 & 536,970 & 607,158 & 31,750 & 536,795 & $30,065,407$ \\
\hline To 3lst & & & & & \\
\hline 1867 & 329,226 & 362,302 & 14,359 & 347,938 & $13,582,874$ \\
\hline
\end{tabular}


Supplement to Statement on page 726.

Comparatje Statement of Clearances and actual Sailungs of Jute. from Calcutra to Great Batain in the Twelve Monthy of the Seas'on 1863.4.

Reported Clearances.

Actual Shipinents.

\begin{tabular}{|c|c|c|c|c|c|c|}
\hline \multirow{2}{*}{\multicolumn{2}{|c|}{$\left.\begin{array}{l}\text { For details of the } \\
\text { eight montlis, Sep- } \\
\text { tember to April, } \\
\text { - See Page 7:26. }\end{array}\right\}$}} & \multicolumn{2}{|r|}{ Jute and Cuttings. } & Jute. & Cuttings. & Tutal. \\
\hline & & Bales, & 640,459 & 583,942 & 45,574 . & 629,516 \\
\hline Nay, & (ס) & " & 29.720 & 30 & 6,740 & 27.500 \\
\hline & ? & ," & 39, & & & 26,632 \\
\hline & . & ", & & & 6,2 & 41,252 \\
\hline gust, & . & $"$ & 36,410 & 25,417 & 600 & 26,1117 \\
\hline & Total & , & 777,125 & 87,843 & $\overline{63,074}$ & 750.917 \\
\hline
\end{tabular}

SEASON 1864-5.

Reported Clearances. Actual Shipments.

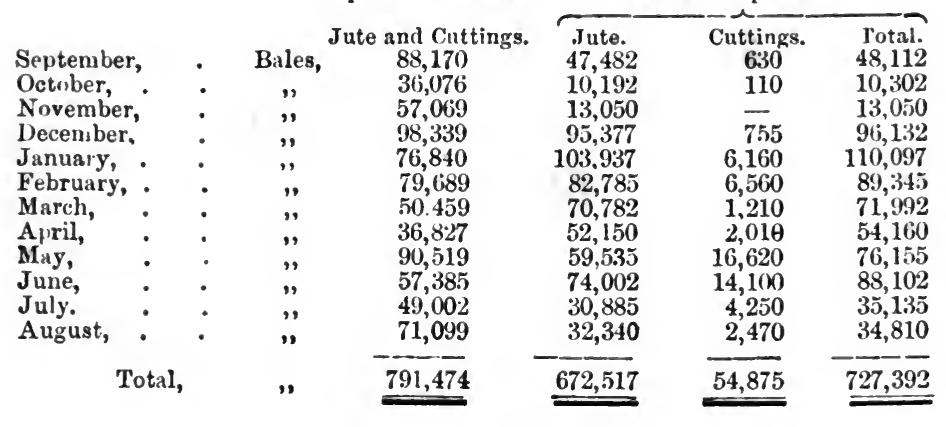

SEASON 1865-6.

Reported Clearances.

\begin{tabular}{|c|c|c|c|c|c|c|}
\hline & & & 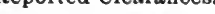 & & & \\
\hline \multirow{2}{*}{$\begin{array}{l}\text { September, } \\
\text { Octolser, }\end{array}$} & . & Bales, & $\begin{array}{c}\text { Jute and Cuttings. } \\
81,300\end{array}$ & $\begin{array}{l}\text { Jute. } \\
82,308\end{array}$ & $\begin{array}{l}\text { Cuttings. } \\
10,630\end{array}$ & Total. \\
\hline & • & , & 53,730 & 20,032 & 4,470 & 24,502 \\
\hline November, & - & $"$, & 99,997 & 69.555 & 17,510 & 87,065 \\
\hline December, & - & , & 76,975 & 88,148 & 6,870 & 95,018 \\
\hline January, & • & ," & 70,767 & 60,157 & 9,050 & 69,207 \\
\hline February, & 6 & ", & 45,827 & 55,402 & 7,140 & 62,542 \\
\hline March, & - & $"$ & 45,301 & 73,463 & 2,424 & 75,887 \\
\hline April, & - & " & 18,069 & 19,566 & - & 19,566 \\
\hline May, . & - & , & 7,003 & 17,430 & 30 & 17,460 \\
\hline June, & - & ", & 26,412 & 11,340 & - & 11,340 \\
\hline July, & - & $"$ & 23,021 & 31,736 & - & 31,736 \\
\hline August, & • & " & 29,344 & 27,107 & 109 & 27,216 \\
\hline & Total, & "' & 557,746 & 556,244 & 58.233 & 614,477 \\
\hline
\end{tabular}


Comparative Statement of Clearances and Actual Sallings of Jute from Calcutta to Great Britain for Season 1866-7.

\begin{tabular}{|c|c|c|c|c|c|}
\hline \multirow[b]{2}{*}{$\begin{array}{l}\text { September, } \\
\text { October, } \\
\text { November, } \\
\text { December, } \\
\text { January, } \\
\text { February, } \\
\text { March, } \\
\text { April, } \\
\text { May, } \\
\text { June, } \\
\text { July, } \\
\text { August, }\end{array}$} & & $\begin{array}{l}\text { Reported Clearances. } \\
\text { Season 1866-67. } \\
\text { Jute and Cuttings. }\end{array}$ & \multicolumn{3}{|c|}{$\begin{array}{l}\text { Actual Shipments. } \\
\text { Season } 1866-67 \text {. }\end{array}$} \\
\hline & 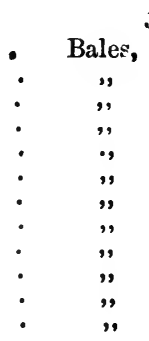 & $\begin{array}{c}\text { Jute and Cuttings. } \\
62,927 \\
73,702 \\
107,822 \\
59,262 \\
35,485 \\
77,017 \\
65,555 \\
36,560 \\
22,870 \\
31,005 \\
63,977 \\
48,010\end{array}$ & $\begin{array}{r}\text { Jute. } \\
49,626 \\
41,811 \\
57,731 \\
99,643 \\
55,761 \\
35,316 \\
87,421 \\
50,691 \\
31,581 \\
24,993 \\
44,928 \\
48,000\end{array}$ & $\begin{array}{c}\text { Cuttings. } \\
100 \\
2,900 \\
4,431 \\
3,145 \\
= \\
1, \overline{0} 8 \\
1,555 \\
1, \overline{040} \\
1,572\end{array}$ & $\begin{array}{r}\text { Total. } \\
49,726 \\
44,711 \\
62,162 \\
102,788 \\
55,761 \\
35,316 \\
88,449 \\
52,246 \\
31,581 \\
26,033 \\
46,500 \\
48,000\end{array}$ \\
\hline Tota & ", & 684,182 & 627,502 & 15,771 & 643,273 \\
\hline
\end{tabular}

The progress of the Linen Trade of the country is best shown by the Board of Trade Returns, as they give, in a condensed form, the Imports of the Raw Material, Flax, Hemp, and Jute, and the Exports of Yarns and Linens. The Returns for 1864, 1865 , and 1866, and for the first eight months of 1867 are as follows :-

Sapplement to Page 678.

\begin{tabular}{|c|c|c|c|c|}
\hline \multirow{2}{*}{$\begin{array}{l}\text { F L A X, } \\
\text { (Dressed and Undressed) and Tow } \\
\text { or CoDILLA of FLAX. }\end{array}$} & \multicolumn{3}{|c|}{ For the 12 Months ending 31st Dec. } & \multirow{2}{*}{$\begin{array}{l}\text { For Eight } \\
\text { Months } \\
\text { ending 31st } \\
\text { Aug., 1867. }\end{array}$} \\
\hline & & & 1866 & \\
\hline \multirow{2}{*}{$\begin{array}{l}\text { Russia and Prussia, } \\
\text { Holland, } \\
\text { Belgium, } \\
\text { Other countries, } \\
\text { Total, }\end{array}$} & 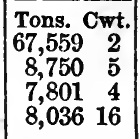 & $\begin{array}{r}72,2 \\
8,4 \\
10,1 \\
4,8\end{array}$ & $\begin{array}{r}\text { To } \\
62 \\
3 \\
7 \\
4\end{array}$ & $\begin{array}{rr}9 & 5 \\
1 & 4 \\
8 & 15 \\
35 & 14\end{array}$ \\
\hline & $2,147 \quad 7$ & $95,656 \quad 12$ & & 3418 \\
\hline \multirow{2}{*}{$\begin{array}{l}\text { H E M P. } \\
\text { (Dressed and Undressed) and Tow } \\
\text { or CoDILLA of HEMP. }\end{array}$} & \multicolumn{3}{|c|}{ For the 12 Months ending 31st Dec. } & \multirow{2}{*}{$\begin{array}{l}\text { For Eight } \\
\text { Nonths } \\
\text { ending 31st } \\
\text { Aug., 1867. }\end{array}$} \\
\hline & & & & \\
\hline \multirow{3}{*}{$\begin{array}{l}\text { From Russia, } \\
\text { Austrian Territolies and } \\
\text { Venetia, } \\
\text { British East Indies, } \\
\text { Philippine Islands, . } \\
\text { Other Countries,. }\end{array}$} & $\begin{array}{l}\text { Cwt. } \\
13\end{array}$ & $6 \quad 9$ & Tor & 718 \\
\hline & \begin{tabular}{r|}
19 \\
2 \\
3 \\
11
\end{tabular} & $\begin{array}{r}4 \\
38 \\
7 \\
26 \\
3 \\
5\end{array}$ & $\begin{array}{r}6 \\
15 \\
8 \\
16\end{array}$ & $\begin{array}{rr}5,586 & 7 \\
272 & 16 \\
2,976 & 0 \\
1,976 & 0\end{array}$ \\
\hline & $50.534 \quad 8$ & $53,285 \quad 5$ & 50 & 11 \\
\hline & & & & 00,18 \\
\hline
\end{tabular}




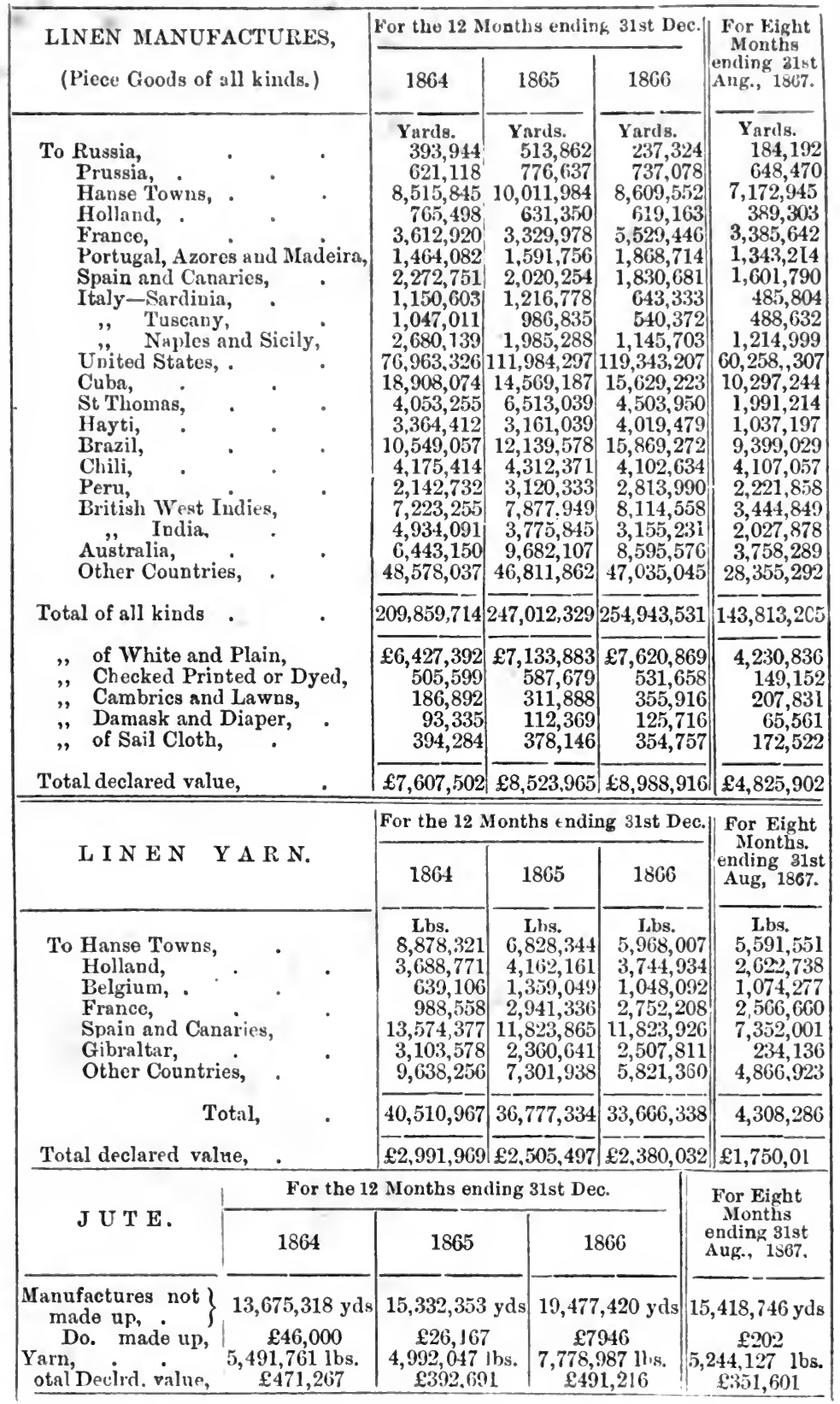


Supplement to Page 673.

Linen Manufactures, Thread, \&C., and Yarns Exported yrom the United Kingdom for 1864, 1865, 1866, AND to 31st August, 1867.

\begin{tabular}{|c|c|c|c|c|c|}
\hline \multirow{3}{*}{ Years. } & \multirow{2}{*}{\multicolumn{2}{|c|}{$\begin{array}{l}\text { Linen Manufactures. } \\
\text { Entered by the Yard. }\end{array}$}} & \multirow{3}{*}{$\begin{array}{c}\text { Thread, Tapes } \\
\text { and Small } \\
\text { Wares. }\end{array}$} & \multirow{2}{*}{\multicolumn{2}{|c|}{ LINEN Y YRN. }} \\
\hline & & & & & \\
\hline & Yards. & |Declr'd. Value. & & Lbs. & Declr'd Value \\
\hline $\begin{array}{l}1864 \\
1865 \\
1866\end{array}$ & $\begin{array}{l}209,859,714 \\
247,012329 \\
254,943,531\end{array}$ & $\begin{array}{r}£ 7,607,502 \\
8, \pi 23,965 \\
8,988,916\end{array}$ & $\begin{array}{r}£ 565,312 \\
630,666 \\
587,247\end{array}$ & $\begin{array}{l}40,510,967 \\
36,777,334 \\
33,666,338\end{array}$ & $\begin{array}{r}£ 2,991,959 \\
2,505,497 \\
2,380,032\end{array}$ \\
\hline To 31st & & & & & \\
\hline 1867 & $143,813,205$ & $4,825,902$ & 249.591 & $24,308,286$ & $1,750,031$ \\
\hline
\end{tabular}

The Linen Trade has grown rapidly in Prussia, in Austria, in France, in Belgium, and in other Continental countries, during the past few years; and spinning and weaving by power has made immense progress. The Jute branch of the trade has been largely dereloped in France, and extensions are still being made there and in other countries. London is the great depot for Jute for European consumption, and the export of the article from the United Kingdom shows the progress of the trade there. It is as follows: -

EXPorts OF JUTE FroM THE UNITED KINGDOM IN 1864, 1865, 1866, AND For Eight Months, anding 31st A Ugust, 1867.

$\begin{array}{cccc}1864 & 1865 . & 1866 . & \text { To 3lst Aug., } 1867 . \\ \text { Tons, 13505 } & \text { Tons, 20,899 } & \text { Tons, 20,818 } & \text { Tons, 13,384 }\end{array}$

Flax spinning and weaving by power has made little progressin England during the last few years, but several works have lately been erected in various parts of that country for spinning and weaving Jute. The spindles and powerlooms on Flax do not now vary much, on the gross, from the numbers given in page 680, but the spinning of Jute was scarcely begun in England when that Return was made up. At the present time there may be about 12,000 spindles and 500 power-looms employed on Jute in England, and the trade appears to be increasing.

In Ireland an amazing increase has been made to the number of spindles and powerlooms employed, since the details given in page 681 were made up. The following abstract made up by the Linen Trade Committee shows the numbers at the periods named It is in continuation of the Tables in page 420 and 727 :- 
FLAX SPINNING MILLS AND POWER-LOOM FACTORIES (LINEN)

IN IRELAND,

From Reports Rendered by Propriftors to Linen Trade Commitee. 1st-Spinning Mills.

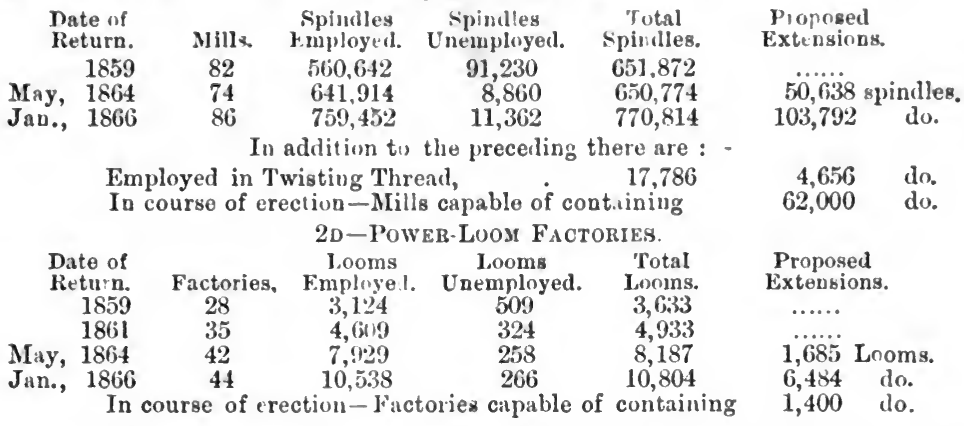

Mr Wm. Ewart, Jun., in a paper read by him before the Social Science Association in Belfast, on 19th Septenuber, 1867, mentions that there were then in operation in Ireland 800,000 spindles, and 12,000 power looms.

Many of the private spinning and weaving establishments in Ireland have merged into limited liability companies, and they are now carried on by managers and bodies of directors. The great development of the Linen trade in France is also due to the establishment of joint stock companies there, many of the works being now owned by them. Several limited liability companies have been formed in Glasgow, and the larger Linen works there are now carried on by them, but the principle has not yet been adopted in or around Dundee, the business being still left to the enterprise of individuals or private firms.

The following table gives the statute acres under Flax in the provinces and counties in Ireland in the years specified. It is a continuation of the tables given in pages 411 and 412 . The Scutching Mills in 1866 are also given :-

FLAX GROWN IN IRELAND IN 1864, 1865, 1866, \& 1867.

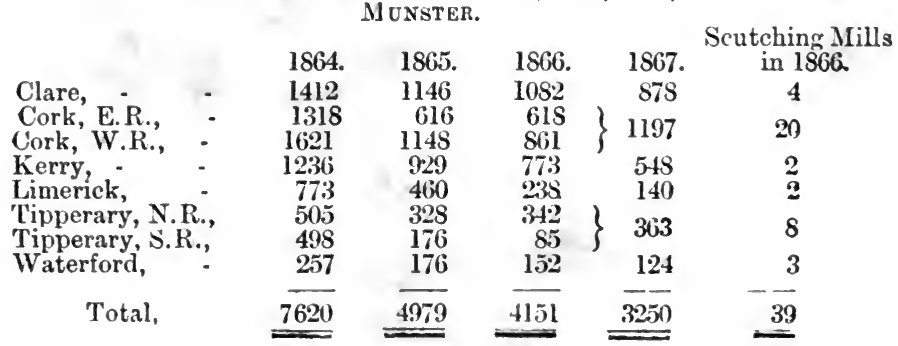




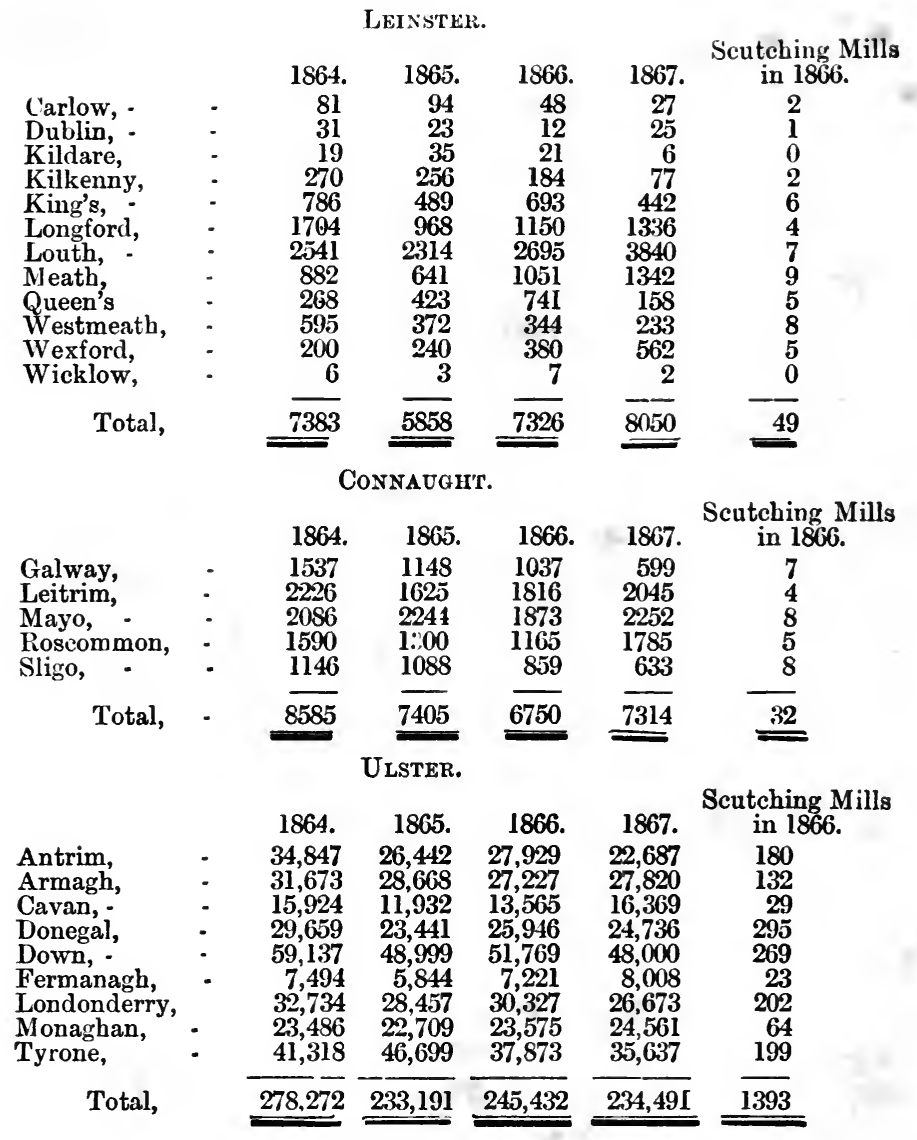

ABstract.

\begin{tabular}{|c|c|c|c|c|c|c|}
\hline \multirow{6}{*}{$\begin{array}{l}\text { Munster, } \\
\text { Leinster, } \\
\text { Connaught, } \\
\text { Ulster, - }\end{array}$} & & \multirow{3}{*}{$\begin{array}{c}\text { Scutching Mills } \\
\text { in } 1866 . \\
39\end{array}$} \\
\hline & & 1864. & 1865. & 1866. & 1867. & \\
\hline & - & 7620 & 4979 & 4151 & 3250 & \\
\hline & - & 7383 & 5858 & 7326 & 8050 & 49 \\
\hline & - & 8585 & 7405 & 6750 & 7314 & 32 \\
\hline & - & 278272 & 233191 & 245432 & 234491 & 1393 \\
\hline otal Ireland, & & 301,860 & 251.433 & 263,659 & 253,105 & 1,513 \\
\hline
\end{tabular}

The following interesting table is taken from the Belfast Nerus Letter. It exhibits the total acreage under crop in Ireland for each year from 1850 to 1866 inclusive; also the portion thereof under Flax-the total produce of Flax in tons, and the produce of Flax per statute acre in stones and pounds for same years. 


\begin{tabular}{|c|c|c|c|c|c|}
\hline Year. & $\begin{array}{l}\text { Total Acreage } \\
\text { under Crop. }\end{array}$ & $\begin{array}{l}\text { Acreage under } \\
\text { Flax. }\end{array}$ & $\begin{array}{l}\text { Produce of } \\
\text { Flax in } \\
\text { Tons. }\end{array}$ & \multicolumn{2}{|c|}{$\begin{array}{l}\text { Produce } \\
\text { per } \\
\text { Acre. }\end{array}$} \\
\hline 1850 & 5758292 & 91040 & 22427 & 39 & 5 \\
\hline 1851 & $5 \$ 58951$ & 140536 & 33561 & 38 & 8 \\
\hline 1852 & 5739214 & 137008 & 35462 & 41 & 6 \\
\hline 1853 & 5696951 & 174579 & 43862 & 40 & 3 \\
\hline 1854 & 5570610 & 151403 & 35606 & 37 & 9 \\
\hline 1855 & 5685836 & 97075 & 23428 & 38 & 9 \\
\hline 1856 & 5753547 & 106311 & 18791 & 28 & 4 \\
\hline 1857 & 5859117 & 97821 & 14475 & 23 & 10 \\
\hline 1858 & 5852052 & 91646 & 17583 & 30 & 9 \\
\hline 1859 & 5862605 & 136282 & 21576 & 25 & 5 \\
\hline 1860 & 5970139 & 128595 & 23760 & 29 & 8 \\
\hline 1861 & 5890536 & 147957 & 22563 & 24 & 6 \\
\hline 1862 & 5753610 & 150070 & 24253 & 26 & 3 \\
\hline 1863 & 5662487 & 214099 & 42646 & 31 & 12 \\
\hline 1864 & 5676321 & 301693 & 64506 & 34 & 6 \\
\hline 1865 & 5648403 & 251433 & 39561 & 25 & 2 \\
\hline 1866 & 5519678 & 263659 & No ret & & \\
\hline
\end{tabular}

This table shows that during these years the acreage under Flax fluctuated greatly, but the last few years exhibit a decided increase over the previous ones. It also shows that the produce of Flax per acre is decreasing, the average for the first eight years being almost 36 stones per acre, while for the latter eight it was little more than 28 stones $6 \mathrm{lbs}$ per acre.

Great efforts have been made to extend the cultivation and improve the quality of Flax in Ireland, but the success, although considerable, and so far very gratifying, is not at all equal to what it ought to be. Prejudices against the raising of Flax still prevail, even among people otherwise intelligent. The failure of some parties, from ignorance and want of care, to raise and prepare a really merchantable fibre that will bring a fair price in the market has deterred others from sowing Flax. In this way the cultivation of Flax is retarded, and both the agricultural and manufacturing portions of the people are losers in consequence.

No trouble should be spared to find out the cause of the diminution of the produce of Flax per acre, and to discover and apply an effectual remedy. Should this not be done, both grower and consumer will suffer, as it will deter farmers from cultivating Flax, and the want of a sufficient supply of the raw material will stop farther extensions, and interfere with the proper working of the present spinning and weaving machinery.

On 16th August, 1867, an Association was formed in Belfast for the extension of the cultivation and improvement of the quality of Flax in Ireland, and as an influential committee was 
formed to carry ont the objects contemplated, it is expected that the result will be beneficial to the entire Flax-spinning trade.

At the period when The Linen Trade was published (July 1864), the trade of Dundee, and of the district around, was in a prosperous state, and it so continued for some time thereafter. The halcyon days which prevailed during the latter part of the American war, and for some time subsequent thereto, have left their mark on the district. Cld mills were rebuilt and extended, and new ones erected; power-loom factories sprung up in all directions, and for a time builders and engineers had the entire command of the position. The result has been to transform and beautify and extend towns previously prosperous, and to vivify and invigorate others which were fast falling into decay.

Many of the spinners and manufacturers in Dundee and Lochee, especially those engaged in the Jute branch of the trade, realized handsime fortunes during these prosperous years. Abundant evidence of this is to be seen in the magnificent and gorgeously furnished mansions which they have recently erected-in the picturesque and beautiful gardens by which they are surrounded-in the noble conservatories, filled with the choicest plants, which adorn these grounds-in the splendid equipages and spirited horses which enliven the streets-and in the other refinements and luxuries which meet the eye on every side, and which wealth alone can procure.

It is difficult to ascertain the actual progress made in any branch of the trade in any particular town or district, or even in the entire district, as the ramifications are so multifarious and so intertwined that it is impossible to unravel them. An estimate of the general progress in the district may be formed from the following statements of the Imports into and Exports from Dundee, which are made up to the most recent date.

Supplement to Statement on Page 633.

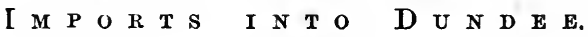

\begin{tabular}{|c|c|c|c|c|c|c|c|c|c|}
\hline \multirow[b]{2}{*}{ Year. } & \multirow[b]{2}{*}{ Flax. } & \multirow{2}{*}{$\begin{array}{c}\text { Flax } \\
\text { Codilla. }\end{array}$} & \multirow[b]{2}{*}{ Hemp. } & \multirow{2}{*}{$\begin{array}{l}\text { Hemp } \\
\text { Codilia }\end{array}$} & \multirow{2}{*}{$\begin{array}{l}\text { Total } \\
\text { Tons. }\end{array}$} & \multicolumn{3}{|c|}{ J U T E. } & \multirow{2}{*}{$\begin{array}{c}\text { Total } \\
\text { rons im } \\
\text { ported. }\end{array}$} \\
\hline & & & & & & By Sea. & By $R \cdot$ il. & Total & \\
\hline 186 & & & & & & 35, & 20 & & \\
\hline 18 & & & & & & & & & \\
\hline 1866 & 34,5 & 8,000 & 2,328 & 176 & 45,065 & 33,291 & 18,888 & 52,179 & 97,244 \\
\hline Aug. & 23,123 & 2351 & 615 & & 26.089 & 34,520 & 13,257 & 47.777 & 73.866 \\
\hline
\end{tabular}




\begin{tabular}{|c|c|c|c|c|c|c|c|c|c|}
\hline & & 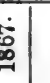 & 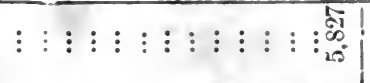 & 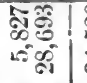 & 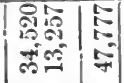 & 焉 & & 180 & \\
\hline & & & : 点 & $\mid$ & 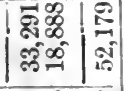 & 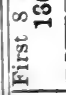 & & ît & \\
\hline & & 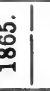 & 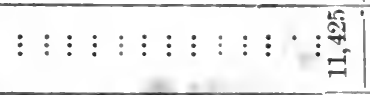 & $\mid$ & 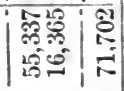 & & W & $1=0.2$ & \\
\hline & & 葸 & : : : : : : : & $\mid$ & 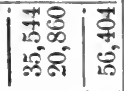 & 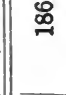 & ज़ & Eิ & \\
\hline & & & $::$ & $\mid$ & 管电 & 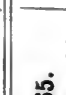 & $=\varepsilon$ & $1 \%$ & \\
\hline & $\dot{\square}$ & 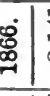 & $\vdots$ & 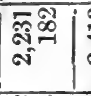 & 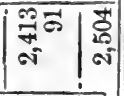 & $\stackrel{\infty}{ \pm}$ & काष & $\because$ & \\
\hline & 兽 & 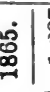 & $: 1$ & & $\mid$ & & 18 & ఇ్.ి & \\
\hline & & 离 & 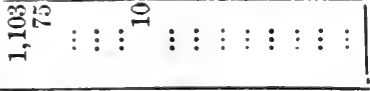 & $\left|\begin{array}{l}\infty \\
\infty \\
\hdashline \\
\hdashline\end{array}\right|$ & $\mid$ & $\stackrel{\infty}{\sim}$ & \%क & $\sigma=$ & \\
\hline & & & 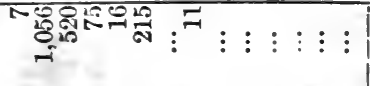 & $\mid$ & 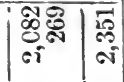 & & & & \\
\hline & 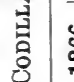 & 离 & 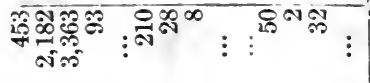 & 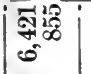 & |옳 & & & & \\
\hline & 紊 & 悉 & : $:$ : & 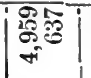 & 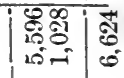 & & 害 & & \\
\hline & $\begin{array}{lll}0 \\
\end{array}$ & 总 & ${ }^{\infty}:^{\mathbb{R}} \vdots^{\mathbb{N}}$ & $\mid$ & 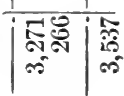 & & & & \\
\hline & & & $a^{\infty}$ & $\mid$ & 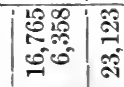 & & 恖 & & \\
\hline & $\dot{x}$ & ڤ & 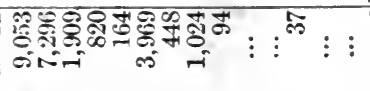 & 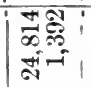 & 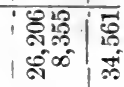 & & 崖 & 氮 & \\
\hline & 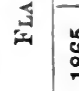 & & 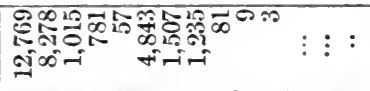 & $\mid$ & 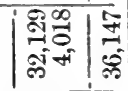 & & & & \\
\hline & & ֻ & 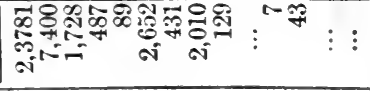 & $\mid$ & 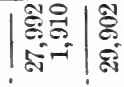 & & 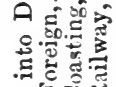 & & \\
\hline & 勉 & & 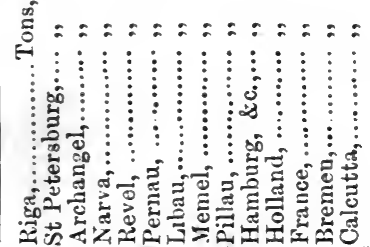 & 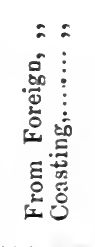 & 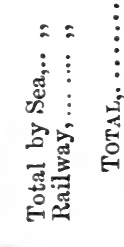 & & 要 & & \\
\hline
\end{tabular}




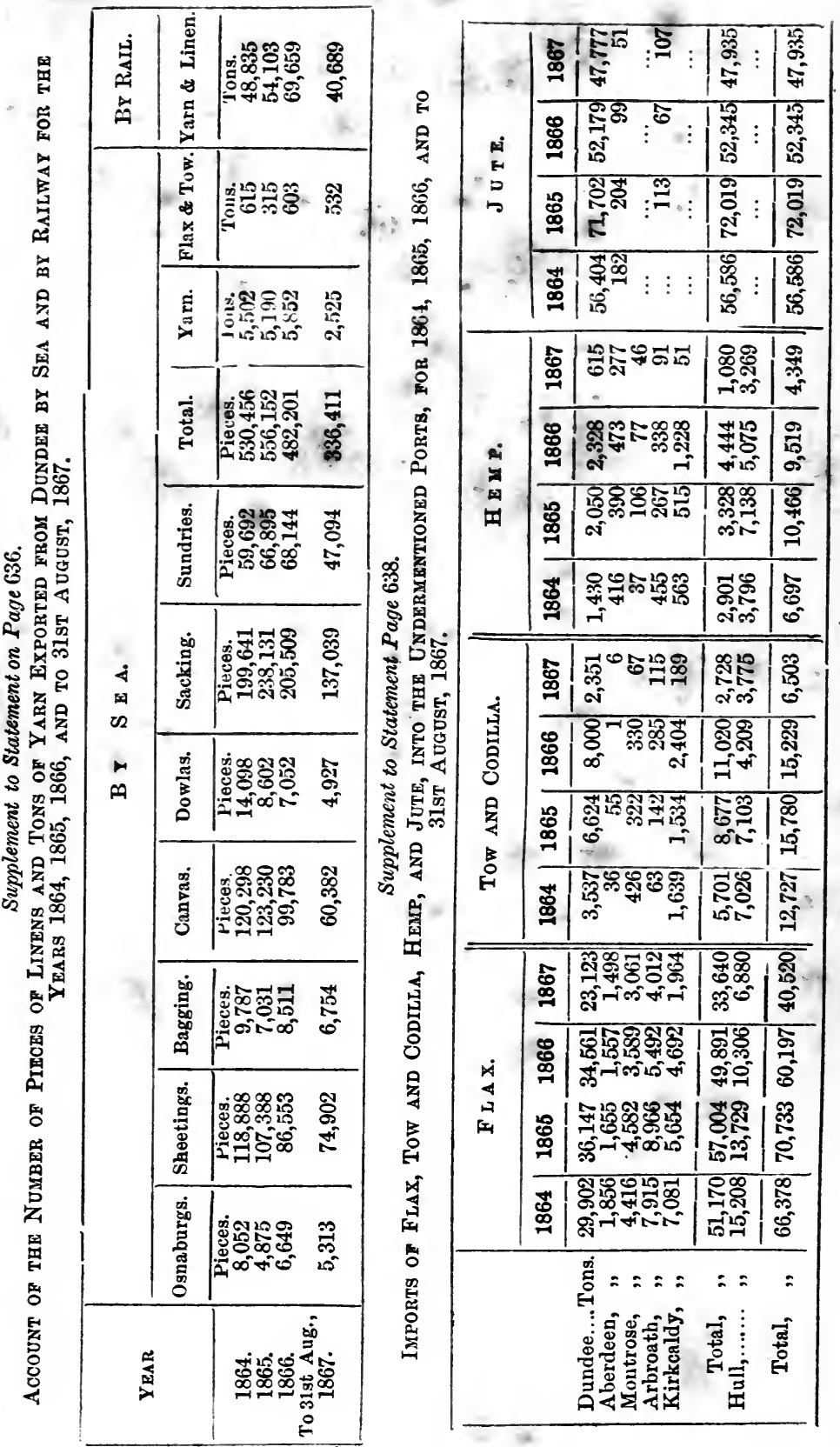




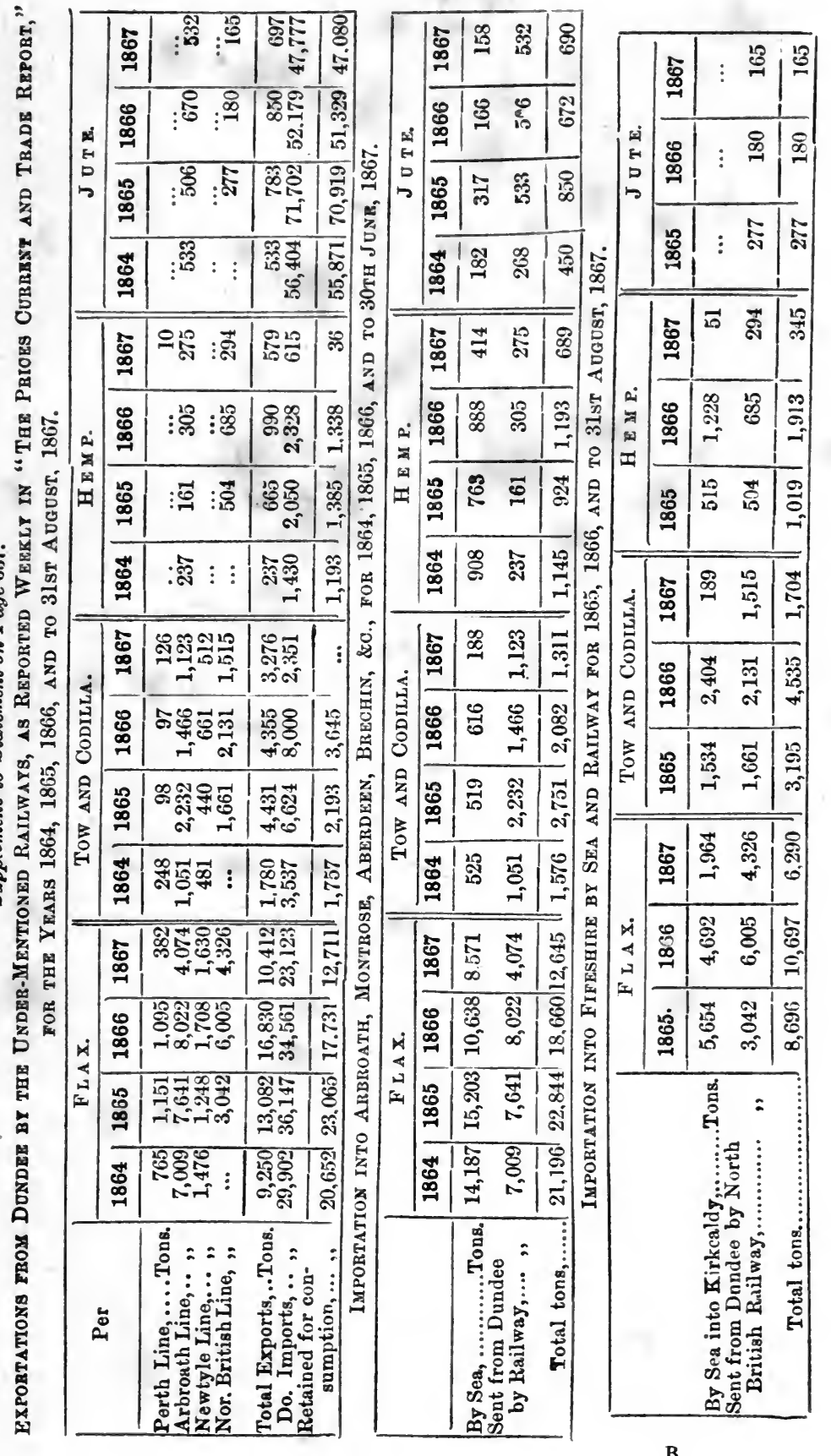


From these statements it appears that the present annual consumption of Flax and Tow in Dundee is about 24,000 tons, of Hemp about 1000 tons, and of Jute about 65,000 tons, in all 90,000 tons.

The Harbour Trustees and the Railway Companies make up their returns in different ways, and it is impossible to tell, from the returns furnished, either the total weight of the goods sent off, or the number of pieces of each, or of any kind. If the weight, as well as the pieces of the goods shipped was given, the total weight sent from Dundee could be ascertained, and this would be useful information to all connected with the trade.

For many years the staple trade of Dundee was spinning and weaving Flax. Since the introduction of Jute into the manufactures of the town, that fibre has gradually insinuated itself into the trade. Until within a year or two, one or two firms confined their operations entirely to Flax; but now Jute is used to a greater or less extent in every establishment in town, and a large proportion of the works are entirely upon that fibre.

The principal articles manufactured in Dundee are enumerated in page 630, and since then few new fabrics have been introduced. The coarser descriptions of Jute goods are chiefly used as wrappering, either as pack-sheet or as bags for nearly every description of goods, and by almost every nation in the world. The eheapness of Jute fabrics, and their sightly appearance, are their great recommendation to general favour, and hitherto no material used in the textile industries of the country has been able to compete successfully with them.

For a long period Dundee had the monopoly of the Jute manufacture, but of late other districts have taken up the trade, and there are already numerous works in operation in various parts of the country. Some of these are of large extent, especially one in Glasgow, which consumes nearly as much Jute as even the larger mills in Dundee. The works in and near London and Liverpool have the advantage of being beside the emporiums for Jute and a market for their productions, but Dundee has compensating advantages which place works in that town on a level with those even in the most favourably situated localities. Dundee will therefore have little difficulty in main. taining the hold which she has so long possessed of the Jute trade. 
Great improvements have of late years been made in spinning and weaving machinery, especially in that intended for Jute. Every machine has been made stronger than formerly, and thus better suited than the slim machinery of former days for such a fibre as Jute. Softening machines, and shell breaker carding engines, and other novelties, now soften and subdivide the fibres, and make them pliable and easily spun. By the use of these machines the quality of the yarn is improved and the production increased. A new mode of spinning Jute has been recently tried. The Jute is softened and cut into lengths, and then by one operation the yarn is drawn into a sliver and spun into yarn. In this way Roving and other processes are saved, and the waste is reduced; but this mode has been tried for too short a time to put the principle to a thoroughly practical test. Variousimprovements have also been introducedin cope and warp winding, in weaving, and in other processes in the manufacture of Linen. The object of these improvements is to cheapen the cost of labour, lessen the space occupied by the machinery, save waste, and produce better yarn and cloth than was formerly done, and in many instances the desired result has been attained.

The improved external appearance of the recently erected mills and factories in Dundee and throughout the entire district is very marked, but the internal sanatory and economic arrangements for preserving the health, and adding to the comforts of the operatives employed, are still more noteworthy and important, and a visit to some of the newer works is not more interesting than pleasant and instructive.

The Author was instructed by the Local Industries Committee of the British Association, to prepare a paper on the Flax, Jute, and Hemp Trades, with the view of having it published, along with papers on kindred subjects, by the Committee, previous to the meeting of the Association in Dundee. In furtherance of these iustructions he made application to the proprietors of all the Flax, Jute, and Hemp Spinning Mills and Power-Loom Factories in Scotland for certain details of their respective works, with the view of making up an abstract of the whole to be included in the paper. The publication of the volume was subsequently delayed by the Committee until after the Meeting of the Association, and the Author was requested 
instead to read a short Paper on the Linen manufacture before one of the Sections of the British Association. This he did before section F, presided over by M. E. Grant Duff, Esq., M.P., on Monday, 9th September, 1867. The Paper was most favourably received by the Association, and the Author, in addition to the thanks of the President given after it was read, received, at the concluding meeting of the Section, a special vote of thanks for the Paper, and a copy of it was requested that it might be published in the Statistical Journal. The details of the various works were collected with considerable care, and from the returns, furnished in almost every case by the proprietors of the respective works (in the one or two instances where this was not done they have been estimated as correctly as possible), the following Tabular Statement has been very carefully prepared, it is therefore nearly, if not absolutely, correct. It contains the nominal horse power, the number of spindles and power-looms, and the number of operatives employed in all the Flax and Jute Spinning Mills, and Linen Power-Loom Factories in Scotland. The names of the proprietors of the respective works are not given, as identification of the several works by parties not directly interested in them seems unnecessary, but each proprietor will know his own Establishment. All the works of each firm are given together, excepting in two or three cases where parties have establishments in different towns widely separated, and these are entered as distinct works. The whole are arranged according to the horse-power employed, beginning with the largest and ending with the smallest-the extremes being 785 and 6 horse-power. The relative sizes of the various establishments are shown by the Table. Several of the works are not yet wholly filled with machinery, and in these the power seems out of proportion to the machinery presently in operation, but this is a usual proceeding, power being generally provided at first for the prospective extent of the mill or factory. An Abstract is appended containing the summation of the several details of each town district, and also the totals of each county or district of the country. 
SUPPLEMENT TO THE LINEN TRADE.

Return of the Flax, Jute, and Hemp Spinning Mills and Power-Loom

Factories in Scotland, in September 1867.

\begin{tabular}{|c|c|c|c|c|c|c|c|c|c|}
\hline 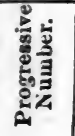 & 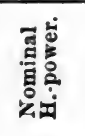 & 农 & 通 & 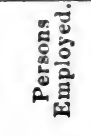 & 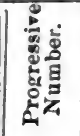 & 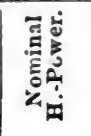 & 范 & $\mid$ & 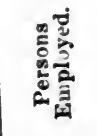 \\
\hline & & & & & $\begin{array}{l}\text { Bro't } \\
\text { For'd }\end{array}$ & 10,326 & 371,237 & 9,549 & $51,6 \pm 0$ \\
\hline 1 & 785 & 16,814 & 428 & 2,175 & 51 & & & 570 & 720 \\
\hline 2 & 75 & 23,816 & & 1,584 & 52 & 80 & 1,600 & 50 & 250 \\
\hline 3 & 7 & 22,000 & 1,200 & 4,000 & 53 & 75 & 3,080 & & 450 \\
\hline 4 & & 18.000 & 600 & 3,500 & 54 & 72 & …... & 400 & 600 \\
\hline 5 & 5 & 11,500 & 660 & 3,300 & 55 & 70 & 2,266 & 100 & 450 \\
\hline 6 & 3 & 18,476 & 600 & 2,500 & 56 & 70 & 3,000 & 40 & 400 \\
\hline 7 & & 10,216 & 435 & 1,7 & 57 & 70 & 3,318 & & 424 \\
\hline 0 & 3 & 16,000 & & 1,750 & 58 & 65 & 2,100 & 110 & 350 \\
\hline 9 & 290 & 4,080 & 203 & 1,300 & 59 & 65 & 2,300 & 149 & 520 \\
\hline 10 & & 16,000 & & 12 & 60 & 65 & 3,500 & $\ldots$ & 330 \\
\hline 11 & 2 & 13,332 & ï20 & $\mathbf{I}, 393$ & 61 & 65 & 2,200 & ... & 150 \\
\hline 12 & 26 & 16,970 & & 1,600 & 62 & 65 & 2,540 & ... & 160 \\
\hline 13 & & & 788 & 982 & 63 & 60 & 2,800 & $\ldots$ & 220 \\
\hline 14 & 22 & 5,000 & 510 & 2,100 & 64 & 60 & 2,000 & & 250 \\
\hline 15 & 20 & 12,228 & & 798 & 65 & 60 & 2,892 & 112 & 500 \\
\hline 16 & 2 & 5,200 & 300 & 960 & 66 & 60 & 1,650 & 65 & 350 \\
\hline 17 & 20 & 4,348 & 20 & 500 & 67 & 60 & 3,290 & 59 & 600 \\
\hline 18 & & 4,200 & 243 & 750 & 68 & 60 & 3,200 & & 400 \\
\hline 19 & 1 & 8,964 & & 780 & 69 & 60 & 1,660 & 16 & 160 \\
\hline 20 & 16 & 6,000 & 120 & 1,000 & 70 & 60 & 4,038 & $\cdots$ & Standg. \\
\hline 21 & 160 & 9,500 & & 700 & 71 & 60 & 1,700 & ... & 220 \\
\hline 22 & 15 & 3,550 & 165 & 1,060 & 72 & 60 & $2,8: 36$ & & 230 \\
\hline 23 & 14 & 4.050 & 140 & 665 & 73 & 60 & 732 & 48 & 170 \\
\hline 24 & 140 & 7,800 & 122 & 750 & 73 & 56 & & 247 & 360 \\
\hline 25 & 1: & 1,700 & 448 & 707 & 75 & 5 & 2.500 & & 240 \\
\hline 26 & 132 & 3,600 & 136 & 1,000 & 76 & 5 & 1,004 & 12 & 240 \\
\hline 27 & 130 & & 520 & 750 & 77 & 5 & 1,800 & 50 & 3 \\
\hline 28 & 120 & 4,896 & $\cdots$ & 350 & 78 & 50 & 2,100 & 160 & 500 \\
\hline 29 & 120 & 13,000 & & 800 & 79 & 5 & 1,810 & 78 & 328 \\
\hline 30 & 120 & 4,006 & 56 & 40 & 80 & 5 & & 200 & 200 \\
\hline 31 & 120 & 10,294 & & 90 & 81 & 5 & 2,360 & ... & 170 \\
\hline 32 & 114 & 0 & $\ddot{8} 6$ & 5 & 82 & 5 & 2,160 & ... & 290 \\
\hline 33 & 110 & 500 & 136 & 80 & 83 & 5 & 2.000 & .. & 120 \\
\hline 34 & 1 & 060 & & 50 & 84 & 4 & 812 & 81 & 250 \\
\hline 35 & 11 & 7,030 & 32 & 6 & 85 & 4 & 1,950 & 100 & 400 \\
\hline 36 & i) & 5,400 & & 5 & 86 & 4 & .... & 260 & \\
\hline 37 & 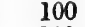 & 4,600 & 72 & 7 & 87 & 4 & $\cdots$ & 300 & 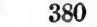 \\
\hline 38 & 10 & 4,500 & .. & 30 & 88 & 4 & & 186 & 225 \\
\hline 39 & 1 & 3,775 & .. & 30 & 89 & 40 & 1.500 & 67 & 250 \\
\hline 40 & 1 & 7,008 & $\cdots$ & $5 ?$ & 90 & 4 & 1,400 & 60 & 25 \\
\hline 41 & 100 & 2,000 & 400 & 50 & 91 & 4 & & & 130 \\
\hline 42 & 100 & 4,6 & $\ldots$ & 5 & 92 & 4 & 1,124 & 12 & 1 \\
\hline 43 & 100 & 4, & 150 & 5( & 93 & 4 & 1,716 & 51 & 2 \\
\hline 44 & 96 & 2,8 & 106 & 44 & 94 & 4 & 1,542 & ... & 110 \\
\hline 45 & & 3,3 & 140 & & 95 & 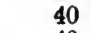 & 1,700 & & 1 \\
\hline 46 & 9 & 2,9 & 32 & 25 & 96 & 40 & & 200 & 2 \\
\hline 47 & 8 & 2,3 & 281 & 59 & 97 & 40 & 2,350 & 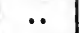 & 200 \\
\hline 48 & 0 & 3,000 & 100 & 55 & 98 & 40 & 1,500 & ... & lc \\
\hline 49 & 80 & 2,400 & 40 & 33 & 99 & 40 & 1,100 & 130 & 320 \\
\hline 50 & 80 & 2,672 & 160 & 460 & \multirow{3}{*}{$\begin{array}{c}100 \\
\text { Carry } \\
\text { For'd }\end{array}$} & 40 & 706 & 38 & 180 \\
\hline \multirow{2}{*}{$\begin{array}{l}\text { Carry } \\
\text { For'd }\end{array}$} & 10,326 & 1,237 & 9 & 690 & & 13,044 &, 433 & 13,500 & 66,280 \\
\hline & & & & & & & & & \\
\hline
\end{tabular}


Rerori of the Flax, JUTe, aNd Hemp FaOtorigs in SoOthand.-Continued.

\begin{tabular}{|c|c|c|c|c|c|c|c|c|c|}
\hline 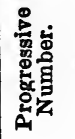 & 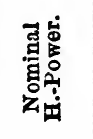 & 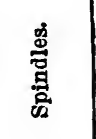 & 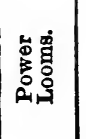 & 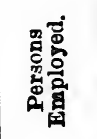 & 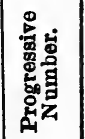 & 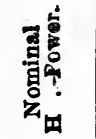 & $\begin{array}{l}\stackrel{g}{0} \\
\text { : } \\
\text { : }\end{array}$ & 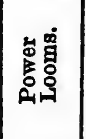 & 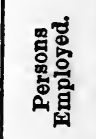 \\
\hline $\begin{array}{l}\text { Bro't } \\
\text { For'rd } \\
101 \\
102 \\
103 \\
104 \\
105 \\
106 \\
107 \\
108 \\
109 \\
110 \\
111 \\
112 \\
113 \\
114 \\
115 \\
116 \\
117 \\
118 \\
119 \\
120 \\
121 \\
122 \\
123 \\
124 \\
125 \\
126 \\
127 \\
128 \\
129 \\
130 \\
131 \\
132 \\
133 \\
134 \\
135 \\
136 \\
137 \\
138 \\
139 \\
140 \\
141 \\
142 \\
143 \\
144 \\
145 \\
146 \\
147 \\
110\end{array}$ & 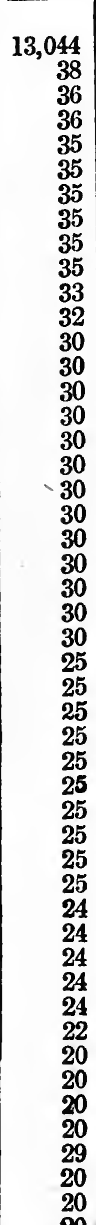 & 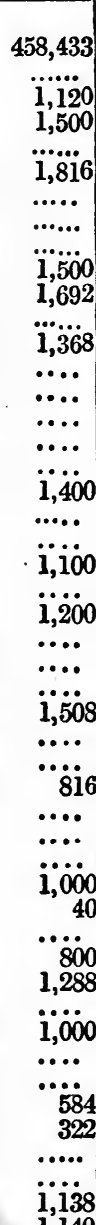 & 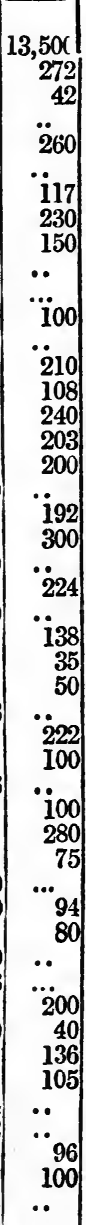 & $\begin{array}{r}66,280 \\
350 \\
250 \\
90 \\
330 \\
190 \\
136 \\
300 \\
200 \\
120 \\
138 \\
180 \\
120 \\
360 \\
180 \\
366 \\
300 \\
250 \\
132 \\
205 \\
400 \\
95 \\
220 \\
70 \\
250 \\
60 \\
80 \\
80 \\
29 \\
295 \\
130 \\
50 \\
100 \\
260 \\
80 \\
43 \\
150 \\
140 \\
70 \\
75 \\
200 \\
180 \\
150 \\
150 \\
36 \\
61 \\
106 \\
112 \\
100 \\
70\end{array}$ & \begin{tabular}{|c|} 
Bro't \\
Fordd \\
151 \\
152 \\
153 \\
154 \\
155 \\
156 \\
157 \\
158 \\
159 \\
160 \\
161 \\
162 \\
163 \\
164 \\
165 \\
166 \\
167 \\
168 \\
169 \\
170 \\
171 \\
172 \\
173 \\
174 \\
175 \\
176 \\
177 \\
178 \\
179 \\
180 \\
181 \\
182 \\
183 \\
184 \\
185 \\
186 \\
187 \\
188 \\
189 \\
190 \\
191 \\
192 \\
193 \\
194 \\
195 \\
196 \\
197
\end{tabular} & $\begin{array}{r}14,411 \\
18 \\
16 \\
16 \\
16 \\
16 \\
16 \\
16 \\
16 \\
16 \\
16 \\
16 \\
16 \\
15 \\
15 \\
15 \\
12 \\
12 \\
12 \\
12 \\
12 \\
12 \\
12 \\
12 \\
10 \\
10 \\
10 \\
10 \\
10 \\
10 \\
10 \\
10 \\
10 \\
10 \\
10 \\
10 \\
8 \\
8 \\
8 \\
8 \\
8 \\
8 \\
8 \\
7 \\
7 \\
6 \\
6 \\
6 \\
6\end{array}$ & 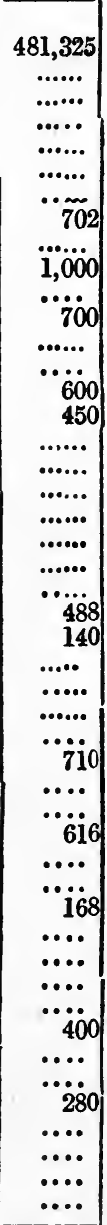 & 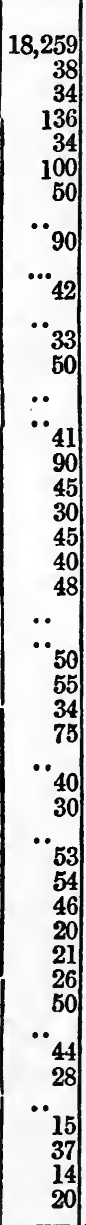 & $\begin{array}{r}74,498 \\
51 \\
40 \\
170 \\
50 \\
100 \\
60 \\
50 \\
140 \\
50 \\
50 \\
40 \\
38 \\
60 \\
25 \\
20 \\
70 \\
140 \\
50 \\
32 \\
50 \\
65 \\
70 \\
18 \\
45 \\
80 \\
80 \\
68 \\
120 \\
44 \\
75 \\
68 \\
27 \\
55 \\
58 \\
77 \\
30 \\
30 \\
35 \\
80 \\
45 \\
50 \\
27 \\
14 \\
30 \\
60 \\
30 \\
30 \\
\end{array}$ \\
\hline $\begin{array}{r}148 \\
149 \\
150 \\
\text { Carry }\end{array}$ & $\begin{array}{l}20 \\
20\end{array}$ & $\begin{array}{c}1,140 \\
560 \\
\cdots . .\end{array}$ & $\begin{array}{l}{ }^{*} \\
{ }_{60}\end{array}$ & $\begin{array}{r}50 \\
140\end{array}$ & Total, & 14,952 & 487,679 & 19,917 & 77,195 \\
\hline & 14,411 & 481.325 & 18,259 & 74,498 & & & & & \\
\hline
\end{tabular}


Abstract of the foreging Returns of Flax, JUte, and Heyp factories in SCOTLAND - -SePtembeb 1867.

1st.-FORFARSHIRE.

\begin{tabular}{|c|c|c|c|c|c|}
\hline Districts. & $\begin{array}{c}\text { No. of } \\
\text { Works. }\end{array}$ & $\begin{array}{l}\text { Nominal } \\
\text { H.-Power. }\end{array}$ & $\begin{array}{c}\text { No. of } \\
\text { spindles. }\end{array}$ & $\begin{array}{l}\text { No, of Power } \\
\text { Looms. }\end{array}$ & $\begin{array}{c}\text { Persons } \\
\text { Employed }\end{array}$ \\
\hline $\begin{array}{l}\text { Dundee, } \\
\text { Arbroath, \&c. } \\
\text { Montrose, \&c. } \\
\text { Forfar, } \\
\text { Brechin, } \\
\text { Carnoustie, }\end{array}$ & $\begin{array}{r}72 \\
18 \\
6 \\
6 \\
4 \\
2\end{array}$ & $\begin{array}{r}5,822 \\
892 \\
495 \\
232 \\
190 \\
84\end{array}$ & $\begin{array}{c}202,466 \\
36,732 \\
33,966 \\
\dddot{0}, 400 \\
\ldots \ldots\end{array}$ & $\begin{array}{r}7,992 \\
830 \\
122 \\
1,401 \\
539 \\
445\end{array}$ & $\begin{array}{r}35,310 \\
4,941 \\
2,483 \\
1,865 \\
1,322 \\
650\end{array}$ \\
\hline & 108 & 7,715 & 278,564 & 11,329 & 46,571 \\
\hline $\begin{array}{l}\text { Kirkcaldy, \&c. } \\
\text { Dunfermline, } \\
\text { Leven Distric } \\
\text { Eden Do., } \\
\text { Tayport, }\end{array}$ & $\begin{array}{r}18 \\
5 \\
9 \\
16 \\
3\end{array}$ & $\begin{array}{l}2 \mathrm{~b} .- \\
909 \\
410 \\
856 \\
444 \\
72\end{array}$ & $\begin{array}{r}\text { SHIRE. } \\
28,670 \\
1,100 \\
32,350 \\
10,478 \\
2,060\end{array}$ & $\begin{array}{r}1,612 \\
1,858 \\
252 \\
1,271 \\
45\end{array}$ & $\begin{array}{r}3,887 \\
2,410 \\
3,044 \\
2,038 \\
200\end{array}$ \\
\hline & 51 & 2,691 & 74,658 & 5,038 & 11,579 \\
\hline $\begin{array}{l}\text { Blairgowrie, } \\
\text { Coupar Angus, } \\
\text { Alyth, } \\
\text { Perth, \&o., }\end{array}$ & $\begin{array}{l}9 \\
3 \\
2 \\
3 \\
\end{array}$ & $\begin{array}{c}3 \mathrm{D} .-\mathrm{P} \\
562 \\
62 \\
42 \\
181\end{array}$ & $\begin{array}{c}\text { SHIRE. } \\
18,296 \\
1,268 \\
\dddot{1,000}\end{array}$ & $\begin{array}{l}393 \\
224 \\
178 \\
553\end{array}$ & $\begin{array}{r}2,050 \\
467 \\
315 \\
908\end{array}$ \\
\hline - & 17 & 847 & 21,064 & 1,348 & 3,740 \\
\hline $\begin{array}{l}\text { Forfarshire, } \\
\text { Fifeshire, } \\
\text { Pertbshire, } \\
\text { Kincardinesbir } \\
\text { Abordeen,. }\end{array}$ & $\begin{array}{r}108 \\
51 \\
17 \\
\quad \quad 5 \\
\end{array}$ & $\begin{array}{c}\text { GenERA } \\
7,715 \\
2,691 \\
847 \\
74 \\
785\end{array}$ & $\begin{array}{r}\text { BSTRAOT. } \\
278,564 \\
74,658 \\
21,064 \\
2,818 \\
16,814\end{array}$ & $\begin{array}{r}11,329 \\
5,038 \\
1,348 \\
\because \ddot{428}\end{array}$ & $\begin{array}{r}46,571 \\
11,579 \\
3,740 \\
120 \\
2,175\end{array}$ \\
\hline $\begin{array}{l}\text { Total, } \\
\text { Other parts } \\
\text { Scotland, }\end{array}$ & $\begin{array}{r}182 \\
15\end{array}$ & $\begin{array}{r}12,112 \\
2,840\end{array}$ & $\begin{array}{r}393,918 \\
93,661\end{array}$ & $\begin{array}{r}18,143 \\
1,774\end{array}$ & $\begin{array}{l}64,185 \\
13,010\end{array}$ \\
\hline Grand Total, & 197 & 14,952 & 487,579 & 19,917 & 77,195 \\
\hline
\end{tabular}

In Dundee the increase during the three years which have elapsed since the toble given in pages 656 and 657 was made up, both in spindles and in power-looms, is about 19 per cent, showing that the relative proportion of spindles to powerlooms has been maintained during these years. The increase in the other towns in Forfarshire, taken together, is, in spindles 19 per cent, and in power-looms 90 per cent. As no account of the spindles and power-looms for the whole of Fifeshire was made up in 1864, the per centage of increase has not been ascertained. By comparing the returns now given with those made up about six years ago, and presented to the House of 
Commons on 11th February, 1862, (see pages 680, 681, and 682 ), the increase during this period will be seen. In Forfarshire it is 48 per cent. in spindles, and 105 per cent. in power-looms; in Fifeshire, 37 per cent. in spindles, and 176 per cent. in powerlooms; and in the whole of Scotland 56 per cent. in spindles and 133 per cent. in power-looms.

The operatives employed, as enumerated in the Tables, are those engaged in and about the Spinning mills and Powerloom factories. There are also many persons employed in hand-loom weaving and winding, sewing sacks and bags, and in other departments of the Linen manufacture, as well as in the auxiliary branches of the trade, but the number of these has not been ascertained. It is estimated that the total number of persons engaged in the Linen Trade in Dundee at the present time cannot be much, if at all, under 55,000, or nearly 20,000 more than are directly employed in the mills and factories under the Factory Act. The total number of persons engaged in the Linen Manufacture of Scotland, in allits branches, may be estimated at from 100,000 to 110,000 .

In Dundee, and in the district around, there are several mills and factories in course of erection, and when these are completed, as they will probably be within a few months, the total number of spindles in Scotland will considerably exceed 500,000, and the power-looms will number nearly 21,000 .

The estimated quantity of yarn spun annually in Dundee is now about 31 million spindles, which, at the average rate of $2 \mathrm{~s} 3 \mathrm{~d}$ per spindle, is $£ 3,487,500$; and in the district around 29 millions, which at same rate is $£ 3,262,500$, making the total value of the yarn spun in the district $£ 6,750,000$. The number of yards of Linen manufactured, either in Dundee or in the district, has not, for want of available data, been ascertained ; but the total annual value of the Yarn and Linen made cannot be estimated at less than $£ 8,000,000$. The value of the Linen manufactures of the other districts of Scotland is about $£ 2,000,000$. The total value of the Linen manufactures of Scotland, at the present time, is therefore about $£ 10,000,000$ annually.

The capital invested in the Flax and Jute Factories in Dundee is estimated at about $£ 2,500,000$; in the district of which that town is the centre $£ 2,200,000$; and in the other districts of 
Scotland $£ 1,000,000$; making the total capital laid out in Mills and Factories in Scotland $£ 5,700,000$. In the bleach works, calenders, and otlier auxiliary branches of the trade, there is a farther sum invested of about $£ 1,300,000$, being a total of

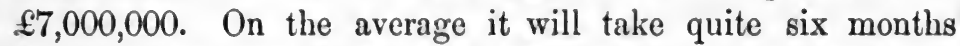
from the purchase of the raw material before it can be manufactured and the proceeds received. The average value of the stock-in.trade in the hands of spinners, manufacturers, and merchants cannot, therefore, be less than $£ 5,(000,000$. The total capital required to carry on the Linen manufacture of Scotland is thus about $£ 12,(100,000$.

Dundee has made immense advances in various ways during the last quarter of a century. and if the Jute manufacture, which is now the great staple of the town, makes as much progress during the next decade as it has done in the past (and the probabilities are that it will do so, as the trade, although already large, is only yet in its infancy), the annual consumption of Jute will then exceed one million of bales, and the population will have increased to 150,000 . The prospects of Dundee, notwithstanding the gloom and depression which at present hang over the trade of the town and district, are therefore promising.

The following statement of the wages paid to Mill and Factory operatives, \&c., in Dundee in 1866 was compiled for the Government by the Secretary of the Chamber of Commerce, and it appears in a Blue Book published this year. Since that statement was made up a reduction in the wages has taken place, amounting to from sixpence to one shilling, or in some cases two shillings per week. The wages of the operatives in the Linen Trade, as in other trades, are regulated by the supply and demand, and changes in the rates paid are, therefore, not unfrequent, but of late years the wages have gradually risen, and it is only recently they have begun to fall again.

Wages Paid in Dunde in 1866, Compiled by the Secretary of the Chamber of Comarerce.

Linen aNd FlaX MaNUfactures.

Spinsing.

Preparers for spinning,

Spinners, Do., Girls,

Twisters, .
MaLes.

$486 \mathrm{~d}$ to $8 \mathrm{~s} 0 \mathrm{~d}$

-
FRMaLR.

$6 \mathrm{~s} 0 \mathrm{~d}$ to $10 \mathrm{~s} 0 \mathrm{~d}$

8 s $6 \mathrm{~d}$ to $14 \mathrm{~s} 6 \mathrm{~d}$

$3 \mathrm{~s} \mathrm{0d}$ to $7 \mathrm{~s} \mathrm{Od}$

8. $6 \mathrm{~d}$ to 128 Od 
W AGES PAID IN DUNDER IN 1866.-Continued.

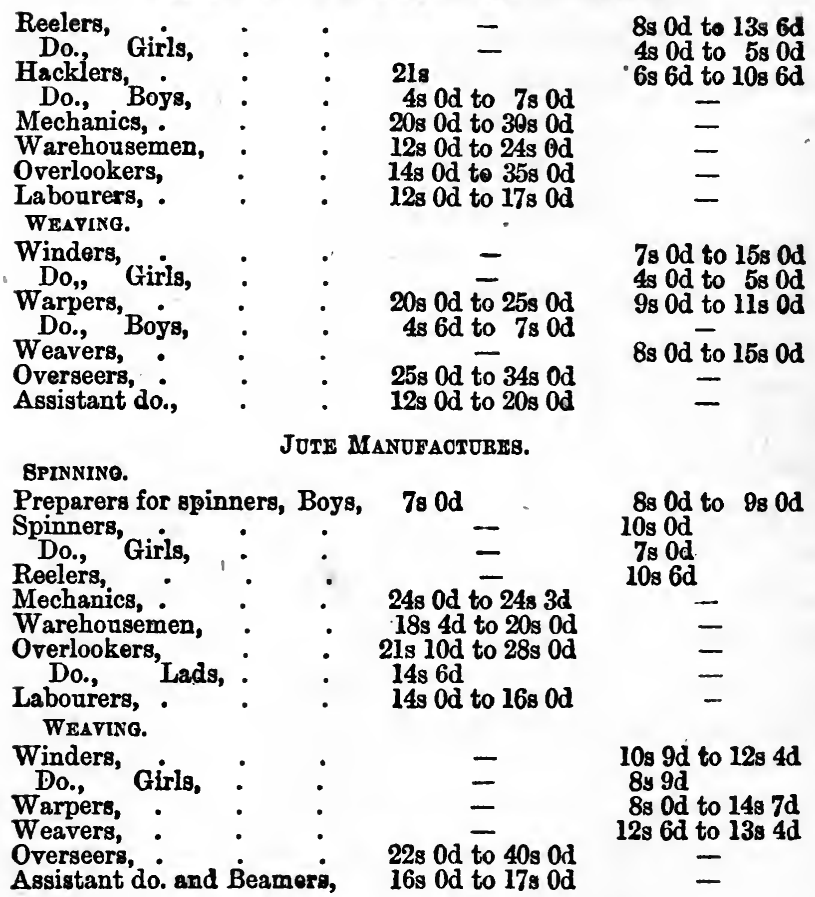

ShIPboILding aNd RopI aNd Sarimakers.

SErpburhding (OP WOOD.)

Shipwrights,

Ship Smiths

Strikers om, Helpers

Sawyers, :

Joiners,

Ship Carpenters,

Foremen

Skilled Workmen,

Apprentices,

Labourers, .

Platers and Boilermakers,

Angle Iron Smiths,

Rivetters

Holders Up

KOPE AND TWIME SPINNRRS.

Rope Y ard Spinners,

Twine Spinners, .

Apprentices,

ROPE, SAIL, AND SAIL CLOTH MaKerg.

Rope Maker, . . 19s 0d

Sail Maker, . $\quad 21 \mathrm{~s}$ 0d

Weaver, $\quad 4 s$ ld to $4 \mathrm{~s} 7 \mathrm{~d}$ per bolt.

Warpers and Winders, : $\quad 0 s 21 \mathrm{~d}$ per bolt.

Warpers, Females, : Os ld per spl. 24s 0d and 26̂s 0d

$24 \mathrm{~s} 0 \mathrm{~d}$ to $30 \mathrm{~s}$ Od

$16 \mathrm{~s} \mathrm{0d}$

$24 \mathrm{~s} 0 \mathrm{~d}$

$23 \mathrm{~s} 0 \mathrm{~d}$

24s 0d and 26s 0d

$30 \mathrm{~s} \mathrm{Od}$ to $35 \mathrm{~s} \mathrm{Od}$

$18 \mathrm{~s} 0 \mathrm{~d}$ to $22 \mathrm{~s} 0 \mathrm{~d}$

$6 \mathrm{~s} 0 \mathrm{~d}$ to $12 \mathrm{~s} \mathrm{Od}$

$13 \mathrm{~s} 0 \mathrm{~d}$ to $15 \mathrm{~s} 0 \mathrm{~d}$

27s 0d

28s 0d

23s 0d

$15 \mathrm{~s} 0 \mathrm{~d}$

19s od

$19 \mathrm{~s} 0 \mathrm{~d}$

$386 d$ to $9 s 6 d$ 
Dunder Prices Current-Last Week in October 1864, 1865, and 1866, and Skoond Wegk in Uctober 1867.-Continued from Page 653.

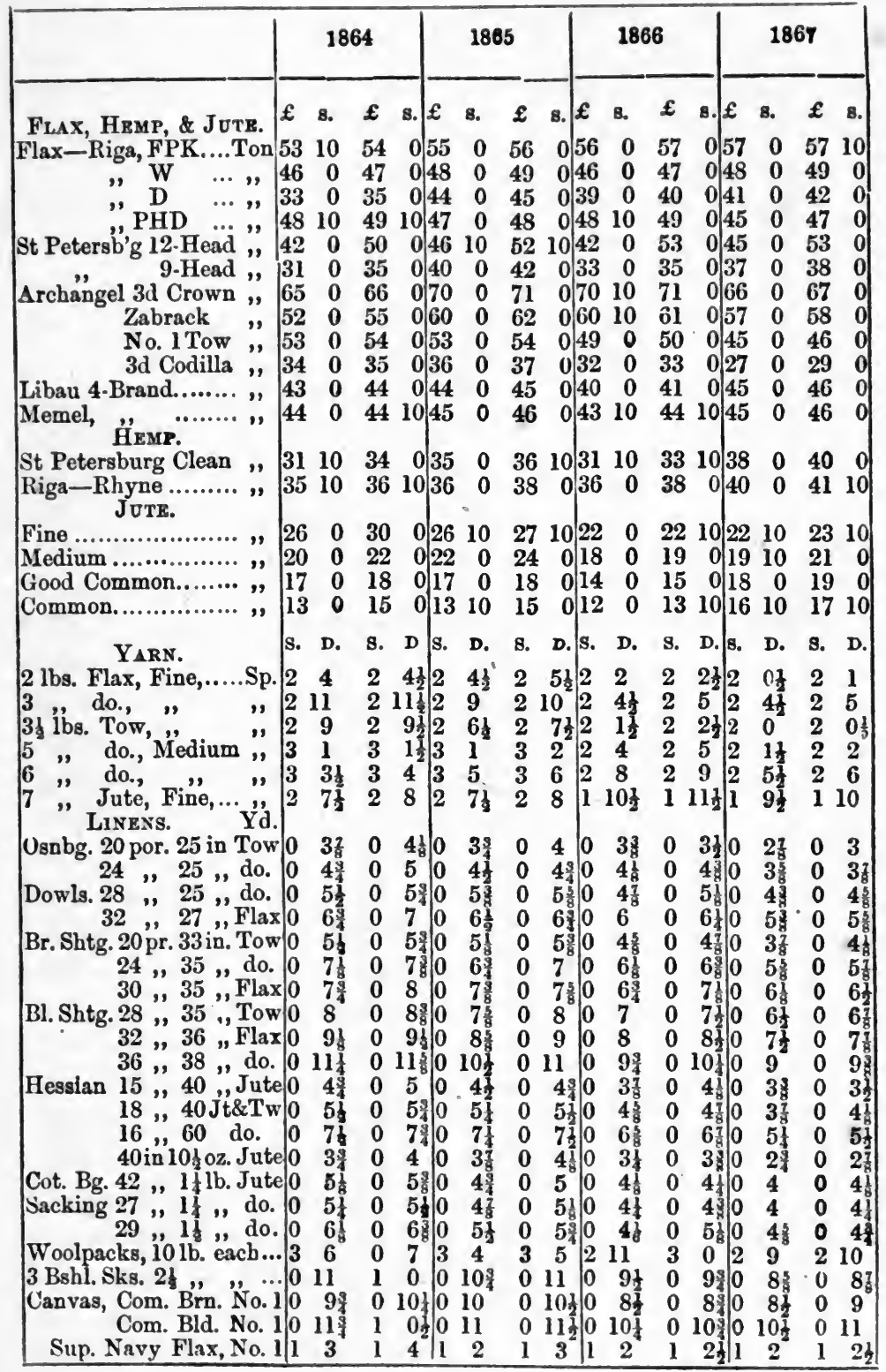


The progress made in the district, of which Dundee is the centre, during the last few years has been remarkably great. Mills and Factories have been erected in various towns previously without them. In some towns, the works formerly in operation have been enlarged and improved, and in others many new Factories have been put up, and old ones extended. The great increase is in Power Loom Weaving, which in some places has all but superseded the hand loom.

Alyth has now its two Power Loom Factories, one of which is of considerable extent. Arbroath, in the extent of its Linen manufactures, is second only to Dundee. The increase since 1864 in the spindles employed exceeds twenty per cent, but the number of power looms remains without much change.

Blairgowrie has added both to its spindles and power looms; the increase in the former being about forty per cent., and on the latter nearly sixty per cent. Brechin is now alive with power looms. The small work erected a dozen years ago has lately been doubled in size, and two new Factories of large extent have recently been erected, and are now in full operation.

Coupar Angus, Phœnix like, has risen into new life. A few years ago it was rapidly falling into decay, but the erection since then of two Spinning Mills, and three Power Loom Factories, one of the works being already of no small extent, has given it new vitality, and the little town has now a bustling appearance, and wears a cheerful look not seen before. Cupar Fife has now two Power-Loom Factories, one of which is extensive, and employs many people. Carnoustie has now also two Power Loom Works. The one erected about ten years ago has recently been enlarged to twice its original size, and it is now one of the most extensive Factories in the district.

Power Loom Weaving has made much progress in Dunfermline of late years. The town now contains four large Factories, two of which rank among the greatest in the country. Other two are in course of erection, and it is probable that one or two. more may soon be added. The erection of these large works is changing the character of the trade of the place, and ere many years elapse hand loom weaving will be a thing of the past.

There are now four Yower Loom Factories in the parish of Falkland, three of which are in the village of Freuchie, 
and one of these is an extensive work. When Power Loom Works were tried in Forfar, it was found that they were well adapted for the fabrics made there, and within a short period thereafter several works were erected. In September 1867, when the returns which are given in pages 21 to 23 were made up, there were eight works belonging to six firms in the town. Since then another factory has been started, and there are now nine works belonging to seven firms in operation, being in the aggregate of 267 horse power, and containing about 1500 power looms. These factories produce the greater part of the cloth required, and hand loom weavers have now difficulty in getting employment, and are fast dying out.

The extensions in Kirkcaldy, Dysart, and neighbourhood, embrace both spinning and power-loom weaving, and within the last three years the increase in both departments is about one hundred per cent. At the present time some other factories are in course of erection, and, when these are started; which will probably be shortly, Kirkcaldy will, after Dundee and Arbroath, take the third place among the Linen manufacturing towns of the district. Some of the manufacturers in Kirriemuir have been proposing to erect power-loom factories, but there is a difficulty in getting suitable ground having a supply of water. This has hitherto delayed operations, and the weaving is still entirely performed by hand there.

The increase in Montrose is confined to the spindles, and is equal to about sixteen per cent. during the last three years.

Two Power-Loom Factories and one Spinning Mill have been erected in Tayport since 1864, and another Factory is to be put up shortly. Power-loom works have recently been erected at Auchtermuchty, Kingskettle, Ladybank, Strathmiglo, and in other parts of Fifeshire, and considerable additions have been made to several of the spinning mills on the Leven and in the Eden district. A spinning mill has also been started in Perth, and a large addition has been made to the power-loom factory formerly in operation in that City.

In Glasgow and in the district around some extensive works have been put up within the last few years, both for spinning and weaving Flax and Jute. Two of the establishments are now owned by Limited Liability Companies. 


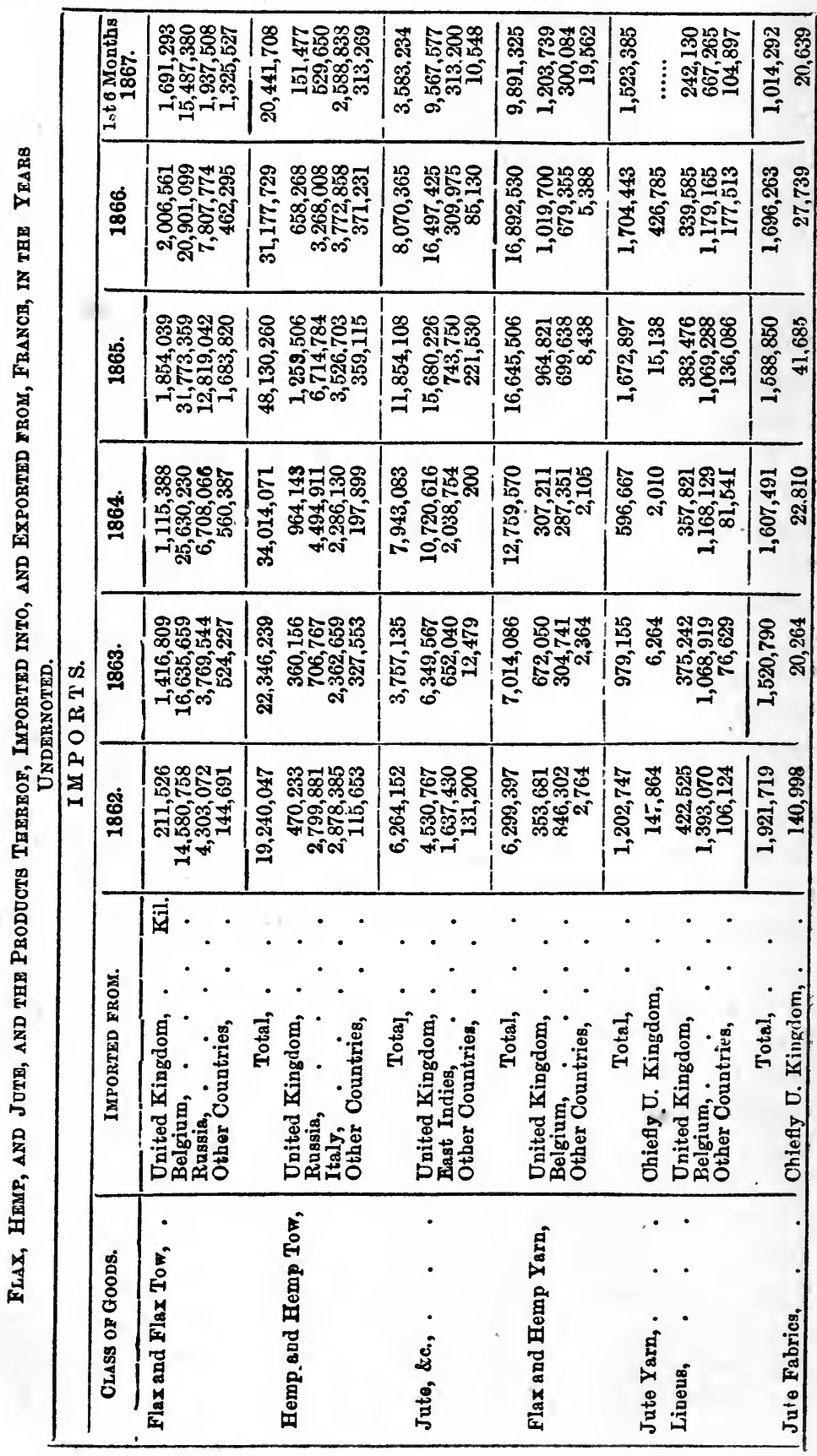




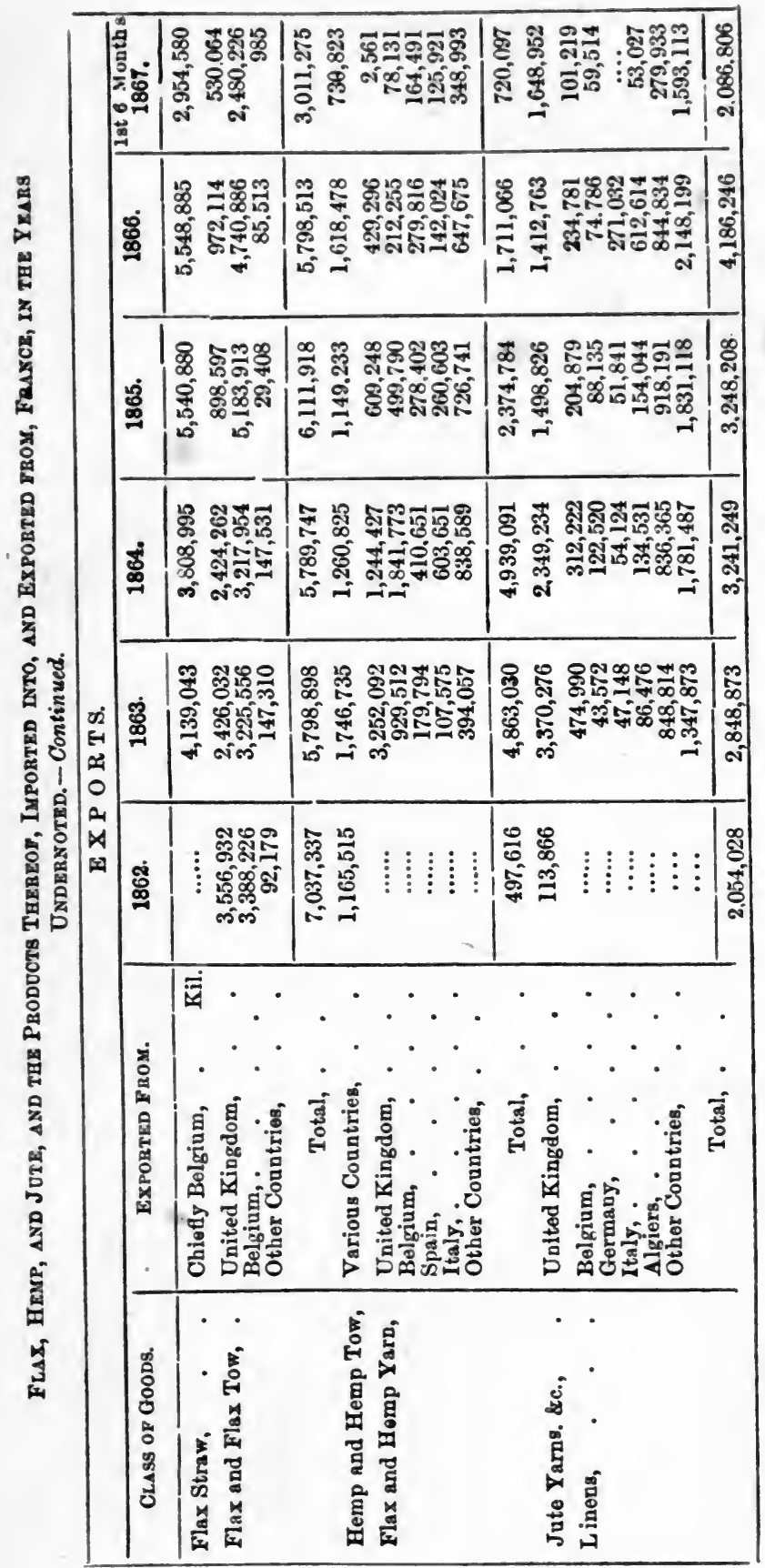


Stock of Jute in and Afloat to London and Liverpool; with Pricks of same and of First Class 7-lb. Jute Yarns at Dundee, a t the UNDER-MENTIONED DATES.

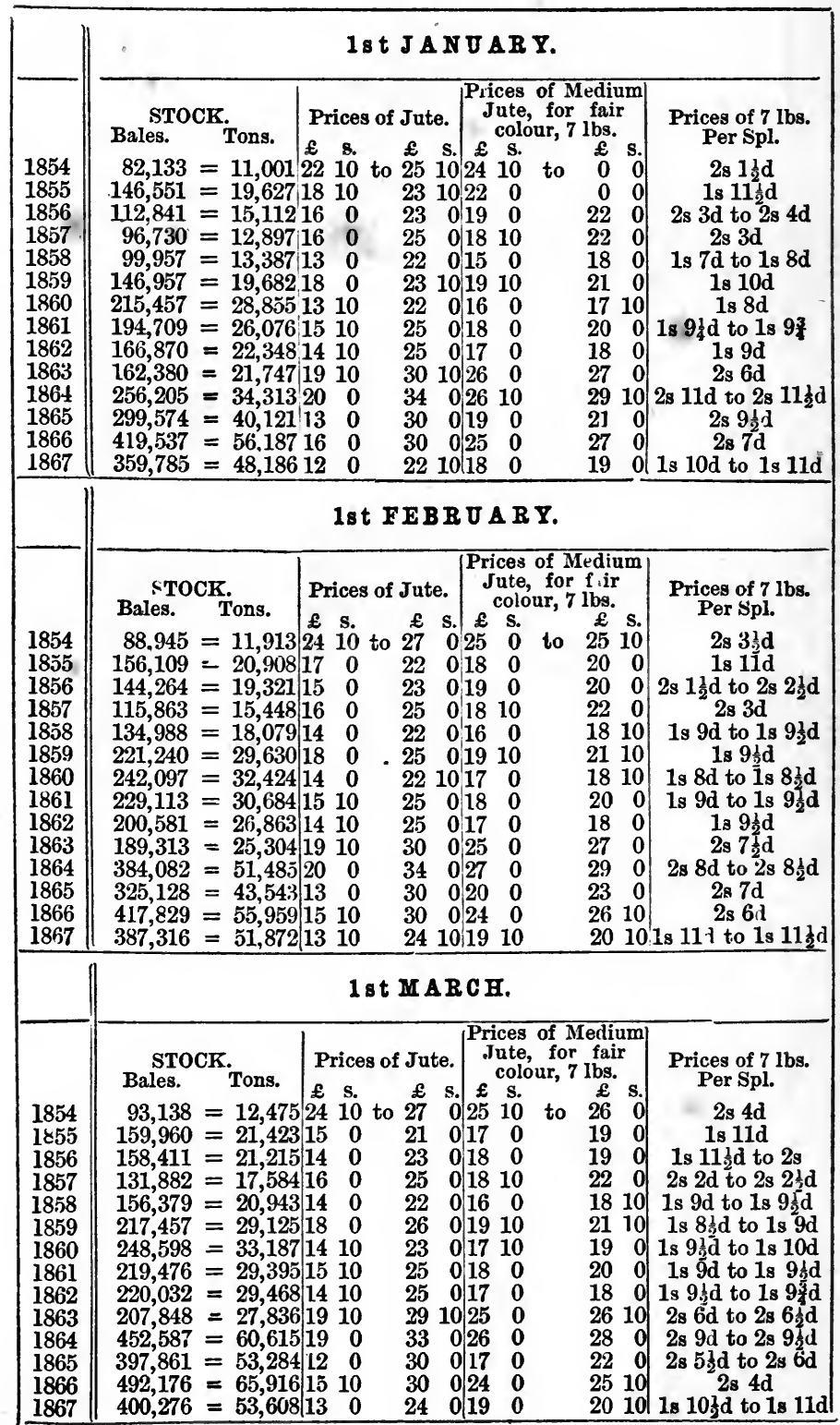


Stock of JUtx IN AND A flo.tT to LoNdoN AND Liverpools-Continued.

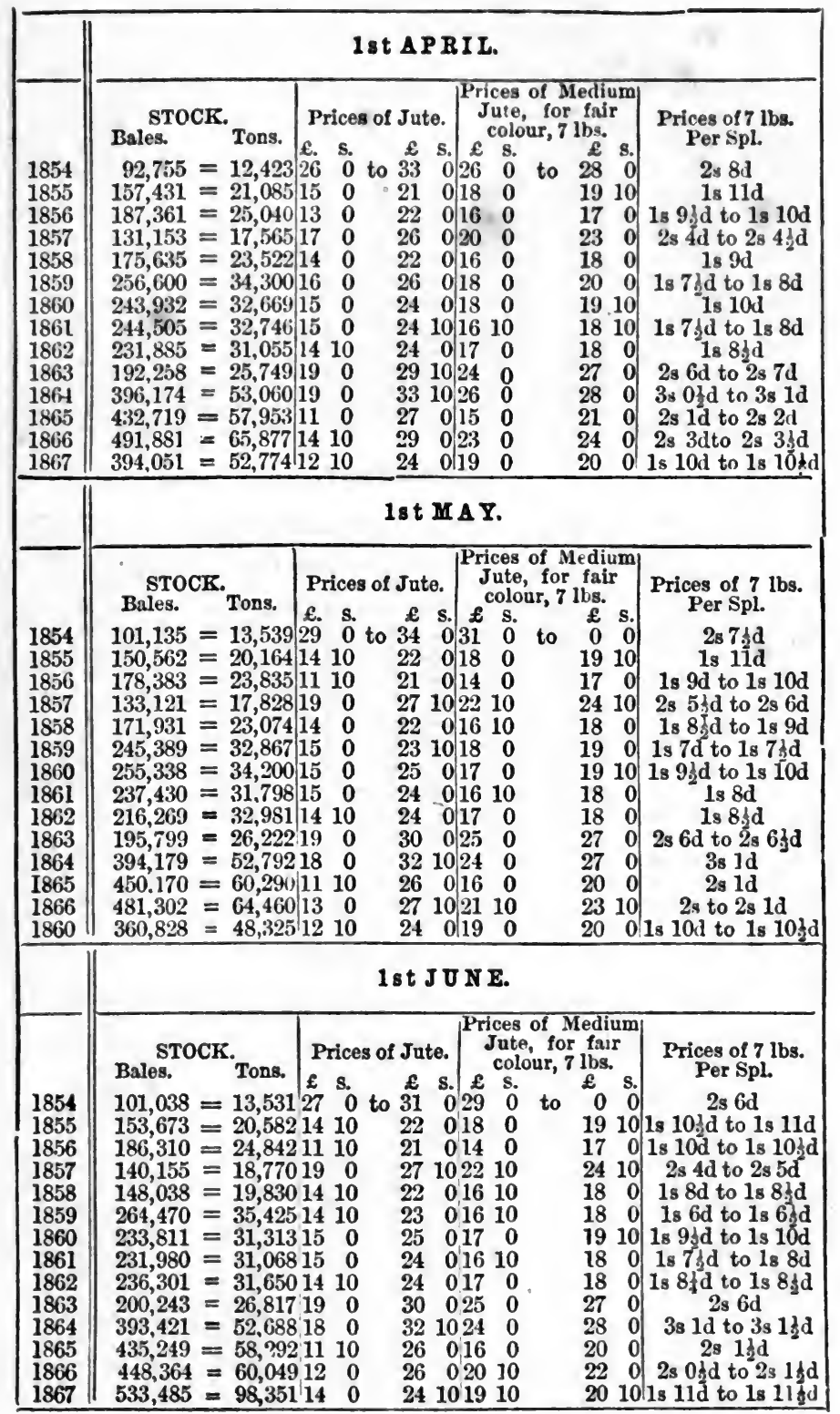


Imports of JUte IN AND AFLoat to London and Liverpoor. - Continued.

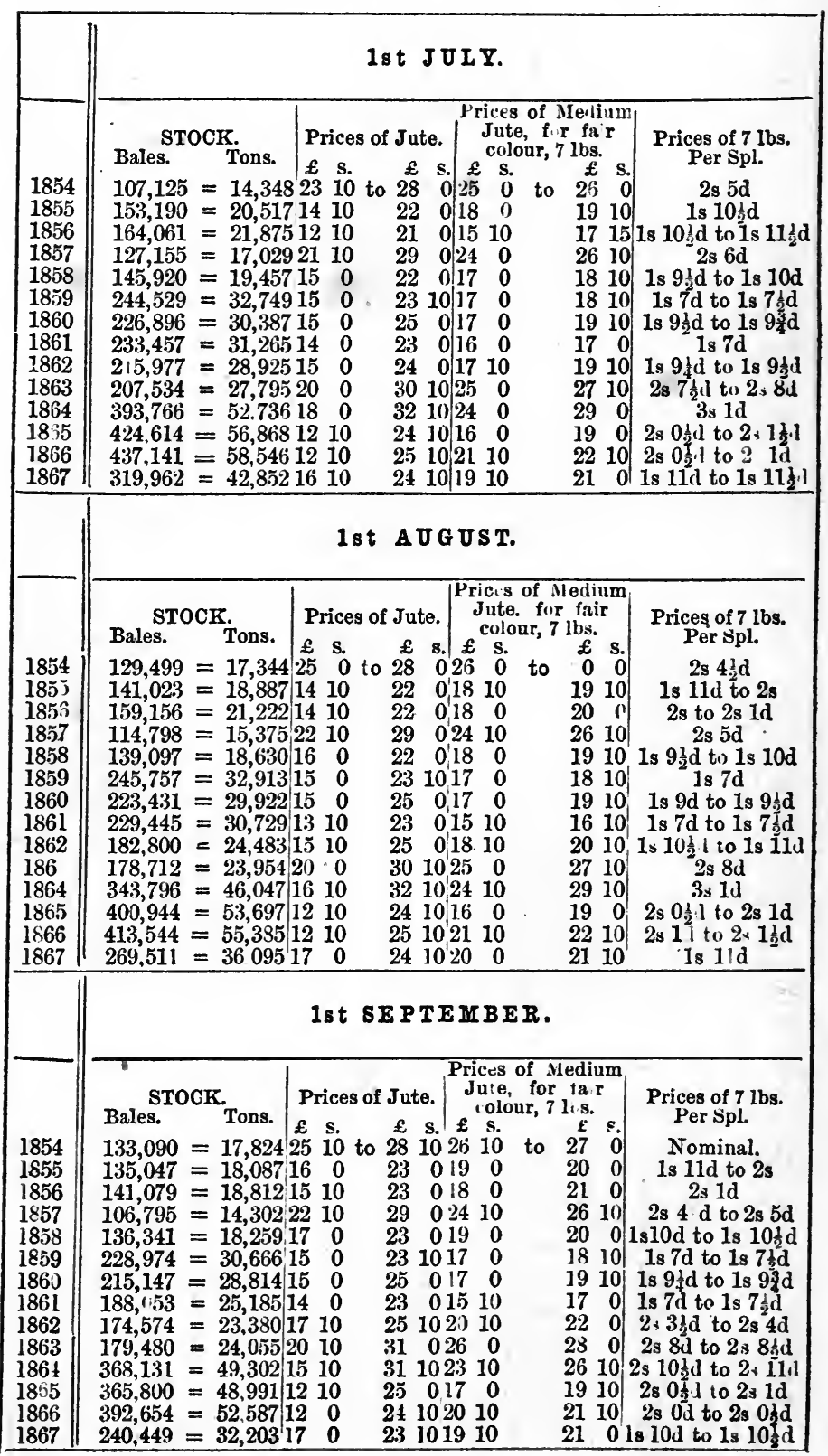




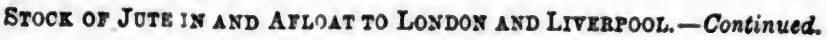

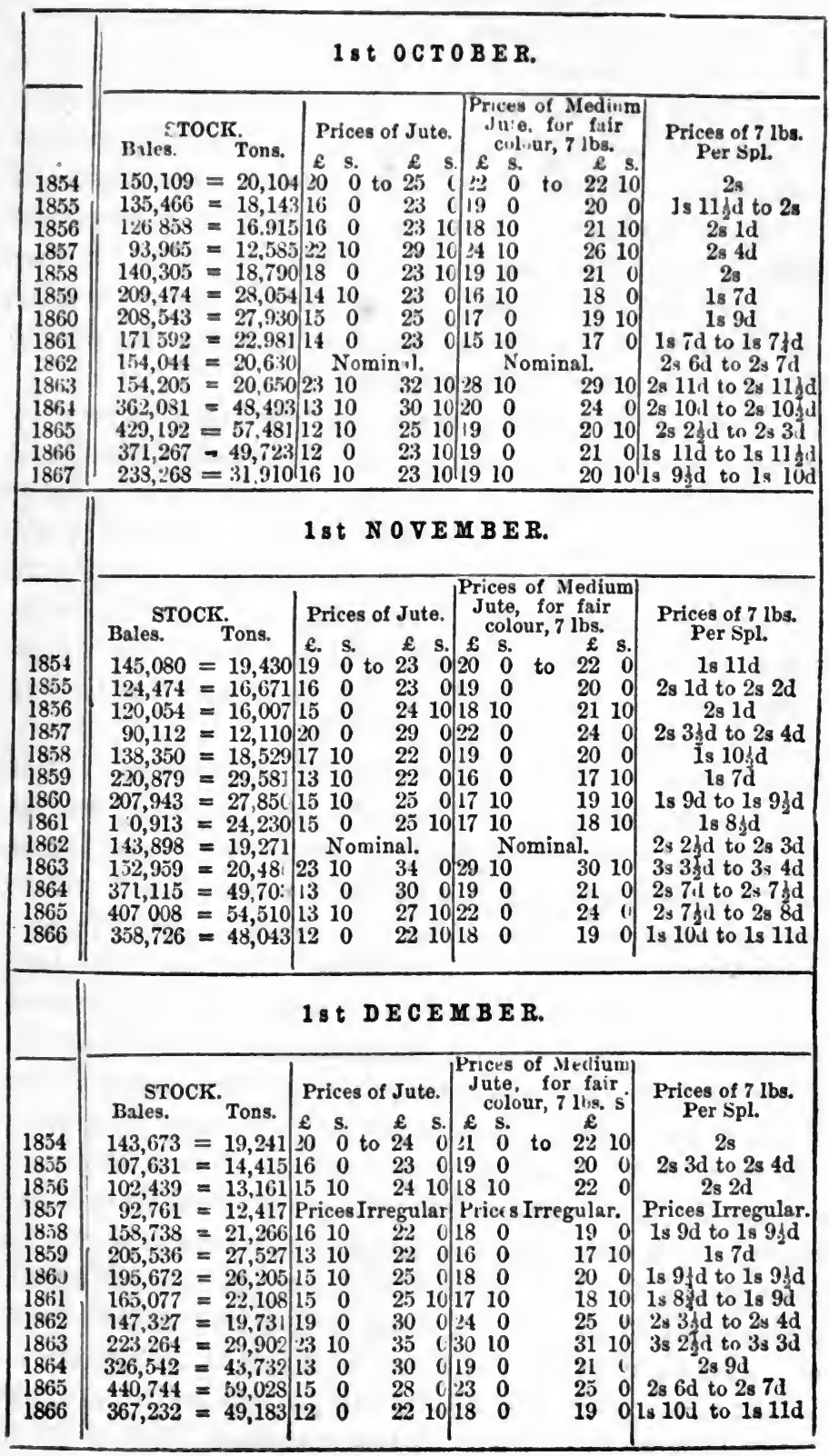


The following interesting notes are taken from the Official Report, by John Stevelly, Esq., on the Flax and Jute Yarns and Linens in the French International Exhibition of 1867 :-

There are 621 Exhibitors of these goods, and the show of Linens is very extensive and varied. France has devoted a larger space to her Linen manufactures than to any other of her industries, and the series is very complete. The Linens of France have nothing in common with our makes, or consistent with our ideas of what she would find most profitable, but they are no doubt suitable for and preferred by the French, and the qualities and finish should be imitated by those who wish to sell their manufactures in that country.

The Exhibition confirms, what was previously known by experience, the fact that the United Kingdom, although no doubt the largest linen manufacturer in the world, is by no means a great consumer. Continental nations, on the other hand, are large consumers of Linen goods, and in some countries the quantity used is enormous ; indeed, in many places the wearing of a cotton blouse, or a cotton shirt, has long been a mark of exceptional poverty. In France the consumption of Linen is estimated at 250,000,000 yards annually.

It is, therefore, of great importance for manufacturers of this, or other countries, who are desirous of having the Linen consuming nations on the Continent for customers, to make themselves thoroughly acquainted with the description and style of the Linen consumed there. Unless this be done, and Linens in imitation of the favourite native fabrics made, neither a large nor a profitable business need be expected. The Belgians well understand this, and, as they have been careful to adapt their Linens to the taste of their French neighbours, they and they only have been able to sell their goods to advantage in France.

Neither Scotch, English, nor American Linens are represented in the Exhibition, and the absence of Great Britain, in a department for which she is so famous, is very noticeable. The reason probably is, that the manufacturers did not consider the benefits likely to accrue equal to the trouble and cost of exhibiting. The Jute Spinners and Manufacturers of Dundee did not consider it advisable to exhibit their productions in a country from which, by an unjust, because one-sided tariff, they are 
practically excluded, as they would have been only paying to show their rivals what they were doing, without receiving a single compensating advantage in return.

The present French tariff, passed in 1860 , was an experimental measure, and it has since then been abundantly.proved that the French Flax and Jute Spinners and Manufucturers require no high protective duties to enable them to prosecute their trade profitably; it is, therefore, high time that these protective duties were abolished, and the duty limited to the fiscal wants of the country, and to that only.

On 1st January, 1866, France had at work 266 mills, containing 705,350 spindles. In the Department du Nord alone, there were 4305 power looms at work, and this number has since been so largely increased there, that the power looms now working in France cannot be estimated at fewer than 8000 .

At the beginning of the present century, during the wars of the Empire, each household only grew what Flax it required for its own use, and little or none was exported. In 1822 about 35,000 acres were under Flax, but in 1845 the area had fallen to 11,000 acres in consequence of France having been slow to adopt spinning by machinery. After that period Flax culture and mill spinning increased simultaneously year by year, and in 186445,000 acres were grown in the Department du Nord alone. It is estimated that in 1866 France had 60,000 acres under Flax, besides importing 31,210 tons Flax, 7400 tons Hemp, and 16,900 tons Jute; and the exports were 7400 tons Flax and Hemp. The Flax, \&c., grown and imported not being adequate for the consumption, a Company was formed some years ago for the cultivation of Flax in Algiers, where the plant is indigenous, and already some success has been attained as the Company sold 1000 tons last year. The Flax produced in Algiers is of good quality and very suitable for spinning into medium sizes of yarn, and the seed is also excellent for sowing, as the plant is nearly a foot longer than from Riga seed, and the fibre finer. Flax, the produce of Algiers, may yet become of great consequence to the Flax spinner, as the country is large and might produce it extensively, and cheaply, possessing as it does great facilities for its successful cultivation.

Normandy was the cradle of family linens and sheetings 
under the name of "Cretonnes," and they are still made there, but these fabrics are now copied largely and well by power in Lille. Blouse Linens, blue, slate, and drab, are leading fabrics in France. Heary shirtings, and sheetings of good quality, are used largely in the agricultural districts; and the sailcloth made in Dunkirk and elsewh re, for the Royal Navy of France, is equal to any made in Dundee.

In France, Linens are used largely in the Naval and Military services, as well as in the Hospitals, Prisons, and other public departments, and various fabrics are made specially for these purposes, all of which might, if they were admitted at a fiscal duty only, be imitated in Britain with a fair chance of competing with native manulactures there.

Hemp is used largely in France for shoe thread and cloth. Hempen fabrics and coarse Linens are steeped in a preparation of sulphate of copper to make them waterproof, and made into cart and waggon covers, and universally used. The Hemp grown in the Valley of the Loire is the best in the world, but fine Hemp is also grown in other districts.

Jute yarns are spun largely, and they are made into sacking and hessians, and such like fabrics. Roubaix near Lille, and Laval in Mayenne, make drills of all qualities very largely, and these goods form a large item in the Linen exports of France. In the Cholet district, light Linen and Linen handkerchiefs employ 20,000 looms. Checked Madras handkerchiefs, dyed in the yarn, are also made there, and exported to Spain, Wales, and other countries where snuff-taking still lingers. Cambrai is famed for finer handkerchiefs and fine Linens, and also for its "batistees," and other fabrics. The Damask trade has made immense progress in France during the last ten years, and the goods now made are very beautiful, and unsurpassed either in the designs produced, in the whiteness of the bleach, or in the superiority of the texture.

Belgium shows many Linens in common with the Lille district of France. The foundation of the Linen manufacture in this part of the Continent is attributed to certain barbarous tribes from the region of the Caspian Sea, who are said to have settled in this district some 300 years before the Christian era. Whether there be truth in this legend or not, it is certain that Flanders Linen 
can be traced back to a very early period. At the time of the first invasion of Gaul by the Romans, these Northern people wore the "sagum," or blouse, which is still the national dress.

Belgium offers many advantages for the development of the Linen trade. The climate is very suitable for the growth of Flax, and so is the water for steeping it. The people are industrious and well-trained in its cultivation and preparation, and the quality of the Belgian Flax is greatly esteemed. In 1840 the quantity grown was estimated at 21,000 tons, and in 1864 at 25,000 tons. The finer descriptions are exported to England and Ireland, and the coarser sorts to Lille, or consumed at home by the 250,000 spindles which are in operation in Belgium. Yarn to the value of $£ 1,000,000$, and Linens to the extent of $£ 1,600,000$, were exported in 18ti4. Belgian Linens embrace shirtings and sheetings; blouse Linen, of which an enormous quantity is made; drills, damasks, hessians, sacking, sail cloth, and other fabrics; and the quality of many of the goods shown in the Exhibition is very superior, and quite equal to the productions of Belfast or Dundee of a like kind. Specimens of excellent yarns are also exhibited, and there are some samples of hand spun yarns ranging up to 1600 lea, or fully 33 spindles in one pound weight. The blind, aided by their fine sense of touch, succeed best in this delicate manipulation. There are some large establishments in Belgium; one in Brussels having 750 power looms, and nearly twice that number of hand looms, and employing 4000 workers, and producing over $11,000,000$ yards of Linen annually.

The Linens shown in Holland are of poor quality.

Prussia and the German States are large exhibitors. The region around Bielefeldt has from time immemorial been celebrated for its fine plain Linens, and it still retains its well merited reputation. In addition to many old established hand spinning and hand loom weaving concerns, there have recently been erected eight or ten large Flax Spinning Mills, on the model of those in the United Kingdom, averaging 20,000 spindles each, and many of them have large Power Loom Factories attached. Osnaburg still manufactures the fabric of that name, and Hanover makes almost every description of Linens from fine shirting to common hessians. 
Saxony, the classic land of Damasks, has a very creditable show of these goods, and also drills, handkerchiefs, and many plain power-loom fabrics. Specimens of the products of the "Kramsta," one of the largest houses in Germany, if not in the world; and also of the King of Prussia's fine model Flax Mill, are exhibited. The former concern had only 17,000 spindles on Flax, and 500 power-looms on Linen goods, but, including their Cotton and Linen manufactures, they give employment to 10,000 persons, and buy yearly 420,000 bundles of English yarn. At the latter work 4,000 persons are employed, the fabrics made being drills, diapers, and family Linens. Prussian Silesia has long had, and still has, a high reputation for her Linens.

The Linens of Austrian Silesia bear so great a resemblance to those of Prussian Silesia as clearly to point to the common origin of the manufactures on both sides of the mountains. The quantity of Austrian Linen shown is not extensive, but some of the specimens from Silesia, Moravia, and other districts, are very good indeed. Since the recent war in these countries, many new mills have been or are in course of erection. Wirtemberg also exhibits some light Linens of more than ordinary merit. Switzerland shows few Linens worthy of note. Spain, by poor samples of manufacture, shows the effect of a long-continued system of protection. Portugal has only some of the very coarsest towelling, hessians, sailcloth, \&c. to exhibit. Italy has a good display of embroidered towels, but with this exception she produces little to entitle her to retain the high rank her Linen manufactures formerly held. Sweden shows sailcloth that might have come from Dundee, but her damasks and plain Linens appear as if they had been made a century ago. The primitive appearance of the Turkish Linens shown are their principal merit. Russia is advancing. She employs good materials, and some of the samples of yarn and cloth are excellent. The native manufactures in white shirting, hessians, \&c. are interesting; and the various fabrics used in their naval and military services, exhibited by the Russian Government, are of good quality, and very suitable for the purposes intended.

The United States do not even put in an appearance. They are too intelligent, says Mr Stevelly, not to feel that, even with 
their natural advantages and Saxon industry, their protective system prevents their competing on an equal footing with European nations, and they are too proud to figure by the side of Spain or Italy.

Belfast has nobly sustained the reputation of the British Empire, her unrivalled exhibition of Linens embracing every article which can be made from Flax, from nail-bags made of Scutchers Tow to the finest Linens and Damasks, and each unsurpassed.

The extraordinary advance of this industry, and the enormous importance which it has now acquired, may be gathered from the following figures:-In Belfast and within a radius of seven miles, the value of the Spinning Mills, including buildings, steam engines, and machinery, is estimated at $£ 2,700,000$, and the Power-looms at $£ 300,000$. The imports of Flax-seed, Flax, Tow, Linen Yarn, and Thread, to this district amounted for the year 1866 to $£ 2,117,500$; and the exports for the same period to $£ 7,150,000$.-Extracted from the Supplement to the Belfast Linen Trade Circular, No. 807, dated $22 d$ October, 1867.

In an article on Flax cultivation in the Northern Whig of 24th August, 1867, it is said that in the reign of Edward the Sixth, the Bishop of Dromore held an annual exhibition for the display of the finest parcels of Flax, and the lest "bunches" of yarn. Many prizes were distributed, and eager was the competition between the farmers and spinners on these festive occasions. Lord Strafford did much to extend the culture of Flax during his administration of affairs in that country. In a letter, dated 25th July, 1636, he says-" The Irish earth, is apte for bearying Flax, and I have, therefore, sente to Hollaynde to procure seede, that being better than the sorte we have. This year I have sowne a thousande poundes weight of this seede." Pretty accurate accounts are kept of the breadth of the land under Flax in Ireland during the eighteenth century, and from the data given, it would appear that the area rarely exceeded 50,000 acres, plantation measure, and was often only about half that extent. In 1809 Ulster had nearly 23,000 acres sown, and the other provinces only about 12,000 acres so occupied.

A very interesting and for a time a very successful experi- 
ment was made to introduce the Linen manufacture into the south of Ireland by Sir Richard Cox, Bart., in the middle of last century. An account of this patriotic experiment was given in a letter from Sir Richard to Thomas Prior, Esq., "showing from Experience a sure method to establish the Linen manufacture, and the Beneficial Effects it will immediately produce." Dublin: Printed for Peter Wilson in Dame Street, 1752.

Sir Richard's grandfather, in the latter part of the seventeenth century, undertook to fix an English colony, and to erect a seat for his family in the parish of Fanlobbus, near the source of the river Bandon, in Cork. When Sir Richard succeeded to the property in 1733 little progress had been made by the new colony, and his account of the condition and habits of the people might have been written at the present time, so truly does it describe what now exists. At first Sir Richard encouraged horse-racing, but this made bad worse, and in a happy moment he was led to think of making his people industrious by starting a manufacture among them. At first he thought of the Woollen manufacture, but various considerations, detailed in the letter, induced him to try Linen instead.

In 1735 Sir Richard commenced by growing Flax, he then instructed the people to spin it, and afterwards to weave the yarn into Linen. At first he was the manufacturer himself, but afterwards he thought it better to get the people to manufacture on their own account, and with this view offered premiums of various kinds to encourage them in the work. The result was very gratifying. In 1746 the quantity manufactured was 11,174 yards of Linen, value $\mathfrak{E} 67616 \mathrm{~s} 2 \mathrm{~d}$, and by 1750 , the last year for which the record of the experiment is given in the pamphlet, the quantity had been increased to 26,841 yards of the value of $£ 173018 \mathrm{~s} 8 \mathrm{~d}$.

These figures may appear small to those who are accustomed to the large production of Linens in modern days, but, looking to the time, and the place, and the circumstances in which the experiment was tried, they represent great and noble and gratifying results. The effect of this experiment upon the habits of the people was most wonderful. The beggar was changed into the industrious artizan, the morals of the people were greatly improved, and, instead of squalor and wretchedness, 
comfort and content then reigned throughout the district; indeed, the transformation was complete, and in every respect creditable to Sir Richard and to his people.

This letter might with great propriety be reprinted at the present time, when attempts are being made to ameliorate the condition of the people in the south and west of Ireland, by introducing manufactures among them, and I commend it to the careful consideration of all who have the welfare of that country seriously at heart. What was done by a good landlord in 1737 might be done again in 1867, and experiments of a similar class, but suited to the altered circumstances of the country, might, with great propriety, and with every prospect of success, be once more tried.

Norz. - The Statement of lmports into and Exports from France, given in pages 30 and 31, are taken from the Linen Trade Circular of Lille. 


\section{E R R $\dot{A}$ T A.}

Page.

11-Line 17-For this read these.

12 " 22-For 10,010 read $10,000$.

48 , 38-For eud read end.

65 . 39-For loose read lose.

85-Summation of arrivals 1844-For 8,324 read 28,324.

88-Line 16-For baled cuttings read bales cuttings.

92 "29-For differrent read different.

125 ", 19-For inhabtants read inhabitants.

134 " 27-For covering read coverings.

160 , 39-After cloth insert by.

163 . 11-After it insert at.

163 "39-For a stringent read astringent.

164 " 89-For Lincere read Sincere.

165 " 1-For Lincerus read Sincerus.

165 ," 2-For Line Cera read Sine Cera.

180-Title, chap. iv-read Carthagenian and Baby!onian Linen.

182-Line 35-After have insert been.

204, 6-For holders read heddles.

219 "18-For skillful read skilful.

262 " 5-For after read afterwards.

262 " 11-For previous read previonsly.

314 "32-For Belgium read Belgian.

317. , 28-For sets read set.

344 " 3-For Linens read Linen.

353 . "10-After as insert the.

429 " 26-After success, paragraph in page 430 , beginning with " In 1646 ,

should have been inserted.

$431 \quad$ \27-For in read by.

433 " 7-After of insert the.

440 "27-After Journal insert 1863.

442 "24-For 1846 read 1746.

462 " 15-For everything read every time.

477, , 14-Year 1748 read $£ 54,452$ 1s $6 \mathrm{~d} \frac{1}{2}$.

477-For average price 11 read 11 4-12-Do., do., 97 read 9 7-12.

480-Average price 728-For 11 read 11 4-12.

550-Line 22-For 1,4'0 read 14,000.

$582 \quad$, 5-For 1727 read 1707.

601 ", 26-For tons read tuns.

604 "19-For yarns read yards.

606 "35-For to read by.

617 " 29-For 1816 read 1826.

621 " 29-For or read and.

631 "25-After total insert annual

639 " 15-For yd. read sp., and line 24, after Osnaburgs, insert yd.

640 " 22-After 10 to $20 \mathrm{lb}$. do., do. insert lb.!

641 " 20-After 6 lb. shorts do. insert lb.

652 and 653 -Line 42-For lb. each read oz.

670-Underneath exports insert Great Britain over first column, and Ireland, over second column.

673-Line 13-For and Flax read \&c.

689 " 8-For antomatic read automatic.

691 " 8-For Kendrews read Kendrew.

69: " 18-For overcomes read overcome.

694 " 9-After Dundee insert vide page 690.

695 "33-For placing read passing.

716 , 12-For are read is.

721 " 12-Delete which. 


\title{
THE LINEN TRADE.
}

\author{
SE C T I O N I.
}

\section{I'HE RAW MATERIAL.}

THE Linen Manufacture is of undoubted antiquity. Portions of Linen are still in existence which were fabricated more than four thousand years ago. In the dawn of civilization the cultivating, spinning, and weaving of Flax occupied the anxious minds and employed the active hands of many of the world's inhabitants. The product of this celebrated plant finds a place in the early pages of the Sacred record, the oldest and most authentic history extant. The Father of Historians speaks with admiration of the wonderful productions of the Egyptian loom, and the spindle and distaff were not unworthy of Homeric lays.

Since the days when the children of the Nile first learned to spin and weave the world renowned Linen of Egypt, many revolutions and mighty changes have happened on the earth's surface. Men have risen from obscurity to greatness, have exchanged the shepherd's crook for the kingly sceptre, have graced a throne, and died. Monarchs who marched with triumphant legions through subdued kingdoms, and wept because they had no more world's to conquer, had at last to yield to a greater conqueror, and go down to the grave, leaving only a name and fame behind. Dynasties, which for ages dazzled the world with their prowess and glory, at last waned and disappeared for ever. Mighty nations have been born, attained manhood, lived to a good old age, passed away, and been forgot- 
ten. Not so the manufacture of Linen. It has outlived the reign of kings, it has survived the fall of nations, and while warriors have come and gone, this useful art, this gentle handmaid of industry and skill remains with us still.

In the seat of its birth, or its early childhood, it attained a ripe maturity. Sometimes its progress was prosperous, but it also had its seasons of adversity and distress. At one time the favoured of kings and priests, at another the object of their direst hate. Now sending forth vigorous shoots to bud and blossom in other lands, and anon lopped of its branches, with little left but a lifeless trunk. Its history is an eventful one, and pregnant with instruction.

Unfortunately the peaceful arts and sciences offer few striking incidents to attract the notice of historians, and while wars and rumours of wars, strife and carnage, are pompously recorded, little is said of aught that makes life valuable. Manufactures, trade, and commerce, are only mentioned incidentally by ancient authors, and few of them give an intelligible account of this important branch of manufacture. Detached sentences or short paragraphs on the subject are here and there to be found, and little more. It is only by collecting and arranging these that information is elucidated, as one passage throws light on another, and from the whole some notion of the trade in the various countriesis obtained.

Even in mediæval times there are few data left to form a connected history of the Linen trade, and in many cases it is only by adopting a similar course that much information can be got. This mode will generally be adopted throughout the volume. Sometimes the ideas, and at other times the words, of the various authorities, will be given, without note or comment where they appear to be sufficiently plain of themselves. Where that is not the case, they will be, as far as possible, explained and made intelligible.

It is proposed that each country and each subject shall, as far as practicable, be treated of in distinct chapters; but from the intimate connection between many of them it will not be possible to keep them from occasionally running into and trenching upon each other Repetitions will, however, be introduced as seldom as is consistent with the proper elucidation of the subject. 
In an account of the Linen trade it appears proper to begin at the beginning, and with that view the culture and preparation of the various fibres employed demand the first place. In every branch of manufacture, the raw material is of primary importance, as it is the foundation of the completed fabric-the superstructure upon which the whole process rests. Flax holds the first rank in the trade; indeed to its product is the term Linen alone properly applicable, and to it accordingly is the priority given.

\section{CHAPTER I.}

FLA X C ULT URE.

The beasts of the field and the fowls of the air in a state of nature require no artificial covering. The great Creator has clothed each with a natural dress, beautifully adapted to the nature of the animal, and to the life it was intended to lead. Hair, fur, scales, feathers, or other covering, is provided, suitable to the clime and element in which the animal is placed, whether that be the arctic regions or the torrid zone.

Man has no such natural covering, but GoD, in His great goodness, has endowed him with a mind to invent, and furnished him with hands to prepare, artificial clothing to protect his body alike from the cold of winter, and the heat of the summer sun. Nature abounds with substances suitable for such a purpose, and she has placed them within the easy reach of man. For cold climates warm clothing is absolutely necessary, and it is abundantly provided from the fleece of the flock. Warmer regions require a cooler material, and it is liberally supplied by the plants of the field.

The fibrous or stringy texture is very prevalent in many vege- 
table substances. In some cases it is found in the bark and wood of trees, in others in the stalks of green or herbaceous plants, and the leaves both of plants and trees abound with it. In all such plants and leaves the fibres are held or cemented together by a glutinous, mucilaginous, and azotized compound, which must be removed before the fibrous parts can be made practically useful. Those plants, the fibrous parts of which are most easily freed from this extraneous matter, and the fibres of which, when so freed, are strongest and most flexible, are naturally the most valuable. Of all the plants with which civilized nations are acquainted, the one combining these properties in the highest degree is Flax. Early in the world's history this valuable plant was known to man, and since then he has not failed to apply it to his own use as an article of clothing, and for other and kindred purposes. There can be no doubt that it has added much to his comfort, and that the facility for changing body linen has greatly conduced both to health and longevity.

Flax, (Ger., Flachs ; Du., Vlasch ; Rus., Len; Fr., Lin ; It. and Sp., Lino ; Lat., Linum), belongs to the Natural Family of Linaceæ, its botanical name being Linum usitatissimum. Its native country is unknown, but it has been cultivated from the earliest ages by civilized nations, and it is probably a native of Oriental regions, from which it has travelled westward and northward into Europe.

Flax is an annual, rising on a single stalk, according to the quality of the soil, climate, and other circumstances, to the height of from twenty to forty inches. The stem is smooth, simple, and erect, of an elegant green colour, and, when at its full height, it is crowned with a number of small, bright, blue flowers, of very delicate texture, and beautifully formed. The leaves are alternate, sessile, linear-lanceolate, and smooth, and the flowers are arranged in a corymbose panicle. The sepals, or green outer leaflets of the flower, are five in number, ovate acute, slightly ciliated, and nearly equal to the capsule in length. The five petals are obscurely crenate, comparatively large, and deciduous. The stamens are alternate with the petals, and have their filaments united together near their base into a sort of ring. The orary or young seed vessel is divided into five cells, surmounted by five stigmata, and the capsule or 
boll is roundish, but rather pointed at the apex, divided into five cells, each subdivided into two, thus forming ten divisions, each of which contains one seed. The seeds are of an oval shape, plump, smooth, and shining, generally brown externally but white internally, the seed coat mucilaginous, and the kernal oily and farinaceous. The stem consists of a pith and woody part, with the layer of bast fibres, covered with cuticle, on the outside. When carefully cultivated for the fibre, there are only two or three seed vessels to each stalk, and few or no branches, but any there are spring from near the top of the stem.

Shortly after flowering the appearance of the plant becomes changed; and the handsome flowers give place to the small rough-cased globules or bolls, filled with seed. When Flax is in bloom it is highly ornamental, and nothing in nature can be more beautiful than the appearance of a field of it, undulating in long waves under the pressure of a gentle breeze. Certainly no crop which the farmer can produce is more graceful during the stages of its growth than Flax, nor will the other products of his fields at all compare with it in beauty.

Besides other species of the same genus, there are some varieties of the true Flax plant known, but they are not so numerous as is the case with other long cultivated plants. Dr Lindley describes two different forms. The Linum humile or crepitans, a plant shorter and more inclined to branch, and with larger capsules (which burst with considerable elasticity when ripe) than the true winter flax already described, and the capsules of which firmly retain their seeds. The Indian plant, called Ulsee or Tesee, has acquired certain characters from the peculiarities of soil, of climate, and of culture. It is always short, rising from twelve to sighteen inches in height, much branched, and loaded with bolls which are filled with large plump seed. Until within the last few years the plant was cultivated solely for its seed throughout India, the fibrous part being considered of no value in that country. Probably by thick sowing and careful cultivation the plant might change its habit, and become assimilated to the common European variety.

Although Flax requires careful nurture to produce it of a superior quality, it is not difficult to rear, and it is capable of 
being grown throughout a great range of latitude. No doubt it thrives best in a temperate climate, but it is also grown extensively and profitably in the northern districts of Russia, and in the sunny plains of Egypt and of India. By careful cultivation it will flourish in every country, and its products are sought for and valued by every race. Its culture would therefore appear to be as universal as its utility.

The climate most suitable for the growth of the plant is one having a regular supply of genial moisture in spring, without an excess of wet in autumn, and where the temperature is pretty equable throughout the season. A severe drought, with a hot sun, after the plant has risen two or three inches above the ground, is very detrimental to it. The delicate leaves are then unable to exclude the scorching rays from the surface of the soil, and as the roots have not had time to penetrate sufficiently deep to secure a supply of moisture, the plant droops, turns a whitish yellow, and, if the drought continues long, it dies. In such a case Flax may be beneficially watered, and a regular water cart will go over an acre a-day. Long continued droughts are therefore a great enemy to the Flax grower, and as these are less frequent in the British Islands than on the Continent, they would appear to be the more suitable places for its cultivation. When the plant thoroughly covers the ground dry weather does little injury; but occasional gentle showers are very requisite to stimulate its growth, from the germinating of the seed until the Flax attains maturity. Alternate showers and sunshine make the most vigorous plant, and produce both quantity and quality of fibre.

Short hot summers induce too rapid a growth, and, although the quantity of fibre produced is large, the quality is never fine. In Egypt, though the plant attains great luxuriousness in the rich alluvial soil of the Nile, and great efforts have of late been made to improve its culture and preparation, yet the fibre does not attain the degree of fineness and softness requisite for spinning into very small sizes of yarn. The hot summers of Russia and Prussia are also inimical to fineness of fibre, and the bulk of the Flax grown in these countries is dry and brittle, and wants that elasticity, pliancy, and oiliness which are found in the produce of more temperate countries. There is, however, less care bestowed 
upon the cultivation of Flax in these countries than in Belgium or Ireland, and perhaps this, as well as the hotter climate, may tend to produce a coarser fibre.

The Flax plant is not valuable for its fibre alone, its seed also being an article of great importance. In many districts, and even in whole countries, it is only grown for its seed, and tho fibre is considered so worthless that it is thrown aside and lost. The kernel or almond of the seed contains much fixed oil, and is extensively crushed for the purpose of extracting it. The oily matter expressed from the seed is called linseed oil, and is an article of considerable commercial importance. The refuse is valuable for feeding cattle, and it is used very extensively for that purpose. It is generally compressed into hard flat pieces, and sold as linseed cake. The sceds, or even the cake, ground into meal, is a favourite emollient with medical men, and has often proved a great relief to suffering humanity; but for this purpose the meal of the ground seed is best, as it contains valuable properties which the cake wants.

The yield of oil from a bushel of East Indian seed is from $14 \frac{3}{4} \mathrm{lb}$. to $16 \mathrm{lb}$; of Egyptian, $15 \mathrm{lb}$; of Sicilian, from $14 \frac{1}{2} \mathrm{lb}$. to $15 \frac{1}{2} \mathrm{lb}$. ; of Russian, from $11 \mathrm{lb}$. to $13 \mathrm{lb}$; and of Scotch, English, or Irish, from $10 \frac{3}{4} \mathrm{lb}$. to $12 \mathrm{lb}$. Sometimes the oil is cold drawn, but it is usually expressed after the seeds have been subjected to a heat of 200 degrees. It has the property of drying into a hard transparent varnish, and this peculiarity is increased by boiling the oil, either alone or with some of the preparations of lead.

In India, as already mentioned, and in some parts of North America the Flax plant is cultivated almost entirely for its valuable seed. Very large quantities of Flax seed, linseed, and of oilseed cake, are imported into Great Britain. The crushing seed was principally imported from Russia, but India now furnishes a very considerable quantity. Of $2,052,258$ bushels of linseed imported in $1829,1,505,861$ were from Russia, 79,611 from Prussia, 33,123 from the Netherlands, 199,607 from Italy, 156,373 from Egypt, 68,710 from the United States, \&c. In 1833 the quantity imported was $2,229,323$ bushels. In 1834 it was $2,230,502$ bushels. In 1860 and 1861 the importation was as follows:- 
Flax Seed, chiefly for Sowing.

1860.

\begin{tabular}{|c|c|c|c|c|c|c|c|}
\hline \multirow{5}{*}{$\begin{array}{l}\text { Russia, } \\
\text { Holland, } \\
\text { Other parts, }\end{array}$} & & \multicolumn{3}{|c|}{1860.} & \multicolumn{3}{|c|}{1861.} \\
\hline & & Qrs. & 25,045 & $£ 67,135$ & Qrs. & 11,419 & $£ 30,831$ \\
\hline & • & ," & 10,230 & 25,890 & " & 9,746 & 26,313 \\
\hline & . & " & 284 & 734 & ", & 2,995 & 8,086 \\
\hline & & Qrs. & 35,549 & $£ 93,759$ & Qrs & 24,160 & $£ 65,230$ \\
\hline
\end{tabular}

\begin{tabular}{|c|c|c|c|c|c|}
\hline Russia, . & Qrs. 631,452 & $£ 1,575,150$ & Qrs. & 502,010 & $£ 1,305,201$ \\
\hline Prussia, & 71,038 & 162,191 & , & 49,930 & 114,529 \\
\hline Hamburg, & 7,269 & 17,462 & $"$ & 3,122 & 7,289 \\
\hline Belgium, . & $\ldots \ldots$ & .......... & " & 3,947 & 9,793 \\
\hline Two Sicilies, & 1,705 & 5,168 & $"$ & 11,969 & 32,075 \\
\hline Egypt, . & 4,419 & 10,863 & $"$ & 10,967 & 26,398 \\
\hline British S, Africa, & 5,538 & 15,888 & $"$ & 3,300 & 8,745 \\
\hline British E. Indies, & $, 565,710$ & $1,493,039$ & $"$ & 544,256 & $1,520,376$ \\
\hline Other Parts, & 7,933 & 18,418 & $"$ & 6,609 & 18,419 \\
\hline
\end{tabular}

Oil from Seed, chiefly Linseed.

\begin{tabular}{|c|c|c|c|c|c|c|}
\hline Prussia, & Tuns & 2289 & $£ 98,288$ & Tuns & 1715 & $£ 72,330$ \\
\hline Hamburg, & , & 1620 & 68,716 & $"$ & 1440 & 62,107 \\
\hline Holland, & " & 1706 & 73,292 & ", & 1672 & 74,262 \\
\hline Beigium, & , & 1043 & 43,994 & 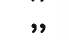 & 695 & 27,617 \\
\hline France, & " & 3810 & 156,451 & , & 1709 & 58,834 \\
\hline Portugal, & , & 818 & 33,819 & , & 420 & 18,455 \\
\hline British E. Indies, & , & 1136 & - 47,591 & ", & 783 & 29,420 \\
\hline \multirow[t]{2}{*}{ Other Parts, } & " & 573 & 24,023 & $"$ & 439 & 17,495 \\
\hline & & & 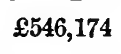 & n: & s 8873 & $£ 360,520$ \\
\hline
\end{tabular}

Oil Seed Cake, chiefly Linseed.

\begin{tabular}{|c|c|c|c|c|c|}
\hline \multirow{3}{*}{\multicolumn{2}{|c|}{ Russia, $\quad$ Tuns }} & 2,499 & $£ 21,533$ & Tuns 4,027 & $£ 33,557$ \\
\hline & & $\ldots \ldots .$. & $\ldots . . .$. & , 1,528 & 12,675 \\
\hline & & 9,386 & 78,315 & , 5,618 & 46,398 \\
\hline Prussia, &, & 11,754 & 96,540 & , 7,445 & 61,040 \\
\hline Hanover, & $"$ & 2,414 & 20,330 & , & ......... \\
\hline Hamburg, . & ", & 10,878 & 91,220 & , 2,161 & 17,788 \\
\hline Belgium, . & $"$ & 8,536 & 71,896 & , .......... & ....... \\
\hline France, & , 1 & 19,823 & 165,667 & $, .22,332$ & 214,507 \\
\hline Italy, & $"$ & 965 & 7,800 & , 1,673 & 16,674 \\
\hline Austria, & $"$ & 197 & 1,574 & ,, 466 & 4,263 \\
\hline United States, & , & 37,303 & 314,319 & $, 32,367$ & 331,432 \\
\hline British N. America, & $a,$, & 573 & 4,793 & 462 & 4,960 \\
\hline Other Parts, & $"$ & 4,498 & 36,853 & "1,143 & 10,103 \\
\hline $\mathrm{Tu}$ & & & 840 & Tuns 79,222 & ,397 \\
\hline
\end{tabular}

It is thus seen that Flax seed is imported both for sowing and for crushing, and it is used very largely for both purposes. The 
two valuable parts of the Flax plant are thus its fibre and its seed. Both can be produced at once from the same crop, but great care is required that the one be not sacrificed to the other. To produce either in perfection the crop must be cultivated for the one object alone, and then the finest fibre or the finest seed will be got. When sown in order to produce a good crop of seed, it must be put into the ground thinly, so that the plant may grow up with a strong and full stem, fit to support the seed bolls, and bring them to perfect maturity, and it must not be pulled until it is fully ripe. When sown sparingly the seeds produce stronger plants, with great branching tops loaded with the seed capsules, but the quality of the Flax is generally found to be deteriorated, and always coarser than when the seed is sown thick. Where the saving of the seed is the primary object, the Flax should at once be tied up in bundles without rippling, and piled up in long, narrow rows thinly put together, that it may obtain the full benefit both of sun and air. When dry, after probably a week's exposure, the bundles should be put up into ricks in an open stackyard. During the winter the seed must be carefully taken off, and if so it is then highly suitable for sowing, as its reproductive powers remain unimpaired. It is also very suitable for crushing when so prepared. After the removal of the seed the Flax must be re-stacked until spring, when it can be watered and grassed in the usual -way. By this mode the fibre of Flax grown in Belgium and some other distriets is said not to be deteriorated. In other countries where this system has been tried it has not been found so beneficial, as the fibre has been undoubtedly impaired, although not to a serious extent.

When the bolls are first taken off the Flax they are rather soft and green, and must be dried thoroughly to make them keep. If to be used for feeding purposes they may be at once removed to a kiln, and gently dried there. For feeding, the chaff is a very useful auxiliary, and may be left on, as it contributes a good deal to the efficiency of the bolls. If the bolls are destined for seed or for crushing, they should be dried outside on sheets, when the weather admits, or indoors in airy lofts, over which they must bo 
thinly spread This leaves the rich juices in the seed, and is therefore the best system, even for feeding, as the seed is more nourishing than when dried on a kiln. When sufficiently dry the bolls for crushing must be thrashed, and the seeds separated from the husks and carefully preserved. When the Flax is wanted principally for the fibre it must be sown as thickly as can with safety be done, for the purpose of drawing up long thin stems, and thereby gaining a fine quality of fibre. It is the fibrous part of the Flax which goes to form linen, and in view of this the history of the plant will now be detailed.

The success of the Flax crop depends much on the seed employed ; the greatest care is therefore requisite in selecting it, and none but the very finest quality ought to be used. Dutch seed is in the highest estimation for sowing, because it not only ripens sooner than any other imported, but produces larger crops of the finest quality of Flax. The produce from American seed is not so large as from Dutch seed, but the Flax is good. Riga seed is perhaps used more extensively than any other for sowing, and, when of the finest quality, it is well adapted for this climate. It ought to be from the previous year's crop only, because if older, it, to a great extent, loses its germinating power, and is then only fit for crushing. To prevent deception, the year of its growth is stamped on the barrel by sworn inspectors called "brackers." The first cost of inferior seed is less than of the finest, but it is a poor saving to use it, as it will prove most disappointing when the crop is reaped. The interchange of. seeds is no doubt beneficial for Flax as well as for other crops, but perhaps too much importance is attached to foreign seed. Excellent crops have been grown in Ireland from seed saved from the Russian, and perhaps a change of seed every second or third year may produce as good crops as any other; the intermediate years being sown with seed saved from the crop of the previous year. In Norfolk and Essex although good crops have been grown year after year from seed produced in the country, there is no doubt that, unless the seed be occasionally changed, the quality of the fibre will degenerate. It is not necessary that the change should at all times be to foreign, as home-grown from a different district of the country will do quite as well, but an occasional change to Dutch, Belgian, or Riga will be beneficial. 
Riga seed is imported in barrels containing $3 \frac{1}{2}$ bushels, and as the seed usually contains from 10 to 15 per cent. of weeds it ought to be carefully sifted before sowing. Dutch seed comes in old wine hogsheads, containing 7 bushels each, and is seldom adulterated. Although Riga seed is preferred by many, Dutch seed is by some thought preferable, especially for heavy soils and in sheltered situations. American seed is not generally approved in the United Kingdom, but it has done well in India.

In the north of Ireland the average produce of a statute acre of air-dried Flax straw, with bolls, is about two tons, which by the rippling machine is reduced to about thirty cwt., and after scutching the yield in dressed fibre is from four to five cwt. The linseed produced is from 12 to 16 bushels. Prof. Hodges, Queen's College, Belfast, had a quantity of Flax air-dried, which in that state weighed $77 \% 0 \mathrm{lbs}$; after passing it between two iron rollers to bruise out the seed there was of Flax straw $5824 \mathrm{lbs}$. or $52 \mathrm{cwt}$., and husks and refuse $1946 \mathrm{lbs}$. This produced $910 \mathrm{lbs}$. of clean seed. The straw lost in steeping 13 cwt., and the 39 cwt. of steeped straw produced 6 cwt. 1 qr. and $2 \mathrm{lbs}$., or 702 lbs. of marketable fibre, or rather more than 9 per cent. of the gross weight of dried straw with the bolls, rather more than 12 per cent. of the dried straw without the bolls, and rather more than 16 per cent. of the dry steeped straw.

Of 100 tons of air-dried Flax straw treated by Schenck's process the yield at the steeping works at Cregagh was-

1. By Seeding -33 tons of seeds and husks, leaving of seeded Flax, 67 tons.

2. By Steeping -67 tons of seeded Flax yielded of steeped straw, 39.50 ,"

3. By Scutching -391 tons of steeped straw yielded of dressed flax, 5.90 ", And of tow and pluckings, . . . 1.47",

An experiment on ordinary Flax straw taken from the bulk of the stock at Messrs Leadbetter's works, and treated by Watt's process, gave the following results:- Weight of straw with the seed on experimented upon, $13 \frac{3}{4} \mathrm{cwt}$; ; after removal of the seed, which on being cleaned thoroughly from the chaff measured $3 \frac{3}{4}$ imperial bushels, the straw was reduced in weight to $10 \mathrm{cwt} .1$ qr. 2 lbs. It was then placed in the vat, and subjected to the steaming process for about eleven hours. After steeping, wet rolling, and drying, it weighed 7 cwt. 0 qr. $11 \mathrm{lb}$., and on being scutched, the yield was $187 \mathrm{lbs}$. of Flax, $12 \mathrm{lb} .6 \frac{1}{2} \mathrm{oz}$. of fine tow, and $35 \mathrm{lb} .3 \mathrm{nz}$. of coarse scutching tow. The yield of 
fibre, in the state of good Flax, was therefore at the rate of $13 \frac{1}{2}$ lbs. from the cwt. of straw with seed on; $18 \mathrm{lb}$. from the cwt. of straw without the seed; and $26 \frac{1}{4} \mathrm{lb}$. from the cwt. of steeped and dried straw.

Having selected the finest seed, which, generally speaking, is of a bright brownish or brilliant golden colour, oily to the feel, heary and quite fresh, the next process is the sowing of it.

It is of essential importance to the practical agriculturist to make himself acquainted with the composition of the plant he is to cultivate, and the soil most suitable for its production. Without this knowledge he must necessarily proceed in a hap hazard manner, perhaps as his father may have done before him, but without any degree of certainty whether the result will be favourable or the reverse. Master of his subject he proceeds on well defined laws, and he is encouraged to look for as successful a return a sthe variable nature of the climate will admit.

The chemical composition of Flax, according to Professor Hodges of Belfast, is,

\begin{tabular}{llllrr} 
Water, & $\cdot$ &. &. & 63.852 & Dry. \\
Organic Matter, & $:$ & $\cdot$ &. & 34.732 & 96.08 \\
Ash, & $\cdot$ & $\cdot$ & $\cdot$ & 1.416 & 3.92 \\
\hline
\end{tabular}

And of the stem of the plant

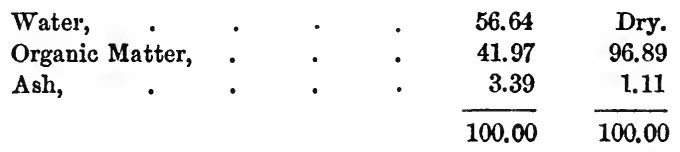

Ash per cent, dried at 212 degrees Fahr, 3.20. One hundred parts of Irish Flax straw give 0.53 of nitrogen, and the capsules 1.26 per cent. The ash of the dry straw and of the capsules contain :-

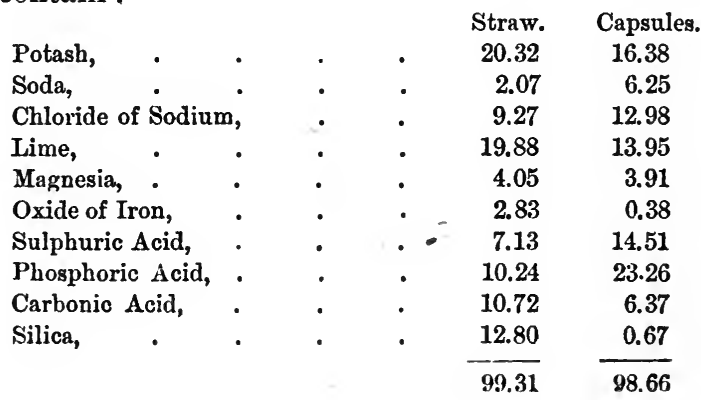


The analysis of Sir Robert Kane differs a little from the above in the proportion of some of the substances, but the difference is not important.

Mr Wilson, in his endeavours to ascertain the relative proportions of the produce, and also of the distribution of the inorganic matter in Flax straw, confirms Dr Hodges' experiments. The Flax employed had been steeped in the ordinary way, and was found to contain 1.73 per cent. of ash. Of the air-dried straw, $4000 \mathrm{lbs}$. weight was taken, which produced-

These Products contained

Of dressed fibre, $500 \mathrm{lb}$. In the dressed flax, $4.48 \mathrm{lb}$. of ash

. fine Tow, 132 ., "fine Tow, . 2.08 ".

". coarse Tow, 192, " coarse Tow, 2.56 "

Of fibre in all, $824 \mathrm{lbs}$. Or in the whole of

the fibre, $\quad 9.12 \mathrm{lb}$. of inorganic matter.

So that of $69.20 \mathrm{lbs}$. of ash which the crop had withdrawn from the soil, 60.08 remained in the straw, or useless portion, while only 9.12 were carried off in $824 \mathrm{lbs}$. of the dressed fibre and tow.

The following is the analysis by Sir R. Kane, of three kinds of Irish soil, and one of Belgium, which some members of the Royal Flax Improvement Society of Ireland considered to bo highly favourable for Flax :-

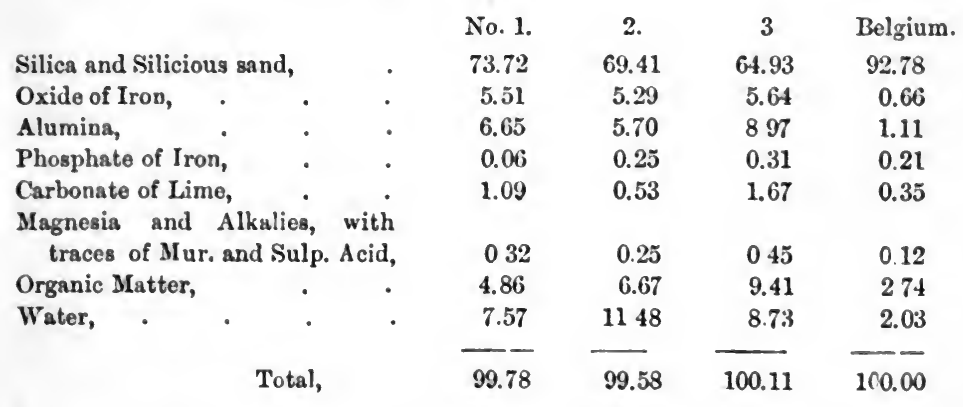

As the organic matter in these soils was rich in nitrogen, their fertility is, from the analysis, easily understood.

The following analysis of celebrated flax soils from Russia, Belgium, Holland, and Ireland is interesting :- 


\begin{tabular}{|c|c|c|c|c|c|}
\hline Per cent. of & $\begin{array}{l}\text { Russia. } \\
\text { Average of } \\
2 \text { samples. }\end{array}$ & $\begin{array}{l}\text { BELGIUM. } \\
\text { Arerage of } \\
2 \text { samples. }\end{array}$ & $\begin{array}{l}\text { HoLLAND. } \\
\text { One } \\
\text { sample. }\end{array}$ & $\begin{array}{l}\text { IRELAND. } \\
\text { Average of } 2 \\
\text { samples L.derry } \\
\text { and Armagh. }\end{array}$ & $\begin{array}{l}\text { IRELAND. } \\
\text { Slob land of Lough } \\
\text { Foyle recently re- } \\
\text { claimed from Sea. }\end{array}$ \\
\hline Silica, & 82.21 & 83.93 & 60.94 & 69.32 & 79.36 \\
\hline Lime, & 00.45 & 00.35 & 00.36 & 2.36 & 1.19 \\
\hline Alumina, & 6.93 & 1.29 & 5.66 & 7.81 & 3.31 \\
\hline Iron, & Traces. & Traces. & 6.04 & 00.45 & 7.49 \\
\hline
\end{tabular}

The best soil for Flax is a nice dry, sandy loam, or an alluvial soil, not too light, but of medium weight, with a strong subsoil, but not of a clayey nature. With care a good crop may be got off other soils, although they are not so well adapted for the purpose; but where it is possible to sow it in soil of one of the above descriptions, it will be found advantageous to do so. While the soil ought to be such that water may permeate, and the roots spread through it in every direction, yet it ought to be able to retain sufficient moisture to benefit the plant, and not let it run off at once, as some open soils do. The treatment of the soil depends much on its quality, but the land should be thoroughly drained, much damp being injurious to the crop. It should also be completely freed from weeds, because noxious plants rising with the Flax will seriously check its perfect development. The great object of the farmer in sowing Flax is to have a fine, dry, deep, and clean bed for the seed, and the skilful agriculturist will know how this may be best attained.

In Belgium, Flax is usually sown after oats, but in Ireland it is thought best to sow it after wheat, and it grows well after lea. Perhaps the best rotation is the following:-1st year, lea ; $2 \mathrm{~d}$, oats ; $3 \mathrm{~d}$, potatoes and turnips ; 4th, wheat, one-half sown out with grass ; 5th half hay, one-fourth Flax, and one-fourth beans. More or less Flax than this may be safely grown at the discretion of the farmer, but Flax ought never to be raised on the same soil oftener than once in ten years. If sown the first year after a potato crop, the Flax grows too rank to thrive, and besides this, the farmer loses the intermediate very profitable crop of wheat without having any real benefit to counterbalance the sacrifice. When sown after wheat in the manner mentioned, it is really an extra crop, grown without manure, and is in no way an exhaustive or severe crop, but quite the reverse. If grown oftener than once in ten years; it 
is no doubt a severe crop, but there is no reason why this should be done. In poor soils not fit for growing wheat, Flax may be sown after potatoes with advantage. It would thus appear to be a great mistake in proprietors to prohibit the cultivation of Flax, because it is really not more exhausting when properly managed, and not too frequently grown on the same soil, than the other crops they are permitted to raise.

In light soils it is considered best to plough the stubble in February, or early in March, so as to allow it to get a little frost. It should be well harrowed before sowing and the weeds carefully removed. The ground should be made as even as possible, in order to insure uniformity of length in the stems of the plant when at maturity. Depth of tillage in Flax cultivation is of great importance, because in sustaining so tall a stem, and providing the ingredients necessary for its proper growth, the small but numerous fibrous roots have to penetrate deeply in search of the required nourishment. Should the downward course of the roots be checked from any cause, the vigour of the plant will be much impaired.

The seed should be sown up and down the rig, immediately after the harrowing in the end of March, or the beginning of April, and a fine seed harrow and light roller then passed over the field to cover the seed, which should be about an inch below the surface, and to finish the ground. Sowing at this early season is recommended, because it is followed by slow and steady growth, which is indispensable for obtaining a fine fibre; and it enables the crop to be gathered in before the regular cornharvest. If sown later in the season vegetation is more rapid, and the fibre grows quicker, and has not time to fine and mellow. Much, however, depends on the country and on the district, as what would be the best season for sowing in one place may not be so in another, and the most suitable time will be best known by intelligent farmers themselves. Mr Wilson considers that even autumn sowing might be suitable in some localities, as he says is sometimes done in Austria and in the North of Europe, where the snow lies too long on the ground to admit of early tillage in the spring. It has not been the custom in this country to sow Flax seed in autumn, and it may be doubted if the practice would be adrantageous. In 
Ireland the best time for sowing is said to be from 20th April to 10th May, but a few days earlier in sheltered situations.

The quantity of seed usually sown upon a statute acre is from two to two and a half bushels. The latter quantity, or about 130 lbs. of clean seed, may perhaps be the most profitable, because the greater the number of stems, the yield of fibre will be increased in proportion. If a crop of seed be the principal object, then six pecks an acre is sufficient.

In medium soils the wheat stubble should be ploughed pretty deeply in autumn. In spring it should be cross ploughed and well harrowed, to make the soil free from lumps. Should the land be damp, the ridges ought to be made high in the centre, and the furrows well cleaned out, that the water may be carried off quickly during the winter months. Heavy soils are not well adapted for a Flax crop; but, should it be tried on such, more frequent harrowing and rolling will be necessary to break the clods, pulverise the ground, and bring it to the required smoothness.

In Belgium the farms generally vary from eight or ten to twenty or thirty acres, and every farmer grows Flax sufficient to keep his people employed when not at work on the land. There the cultivation of Flax is conducted with the greatest care, the ground being well ploughed, rolled, enriched with liquid manure, and harrowed. The seed is then sown, harrowed in with a light harrow, the surface rolled, and the fields when thus prepared, display much neatness and smoothness. The liquid manure consists of the urine of cattle, in which rape cake has been dissolved, and in which the cleansings of privies from the neighbouring towns and villages have been mixed. It is collected in subterranean vaults of brick work, and about 2800 gallons, beer measure, are allowed to the imperial acre.

Manure in many soils is useful, but in others, or when too much is applied, the Flax is apt to grow coarse, and will not yield a fine fibre. It would seem to succeed best after a corn crop which has been manured, or on ground recently turned up.

The elementary principles of which Flax fibre, as well as cotton, sugar, \&c., consist, are now known to be derived almost entirely from the atmosphere. Therefore, by taking away only 
the fibre, and returning the other products of the plant to the soil, it will be less impoverished than by almost any other crop, and there is no difficulty in accomplishing this. The seeds can be used in feeding cattle on the farm, the steep water can be pumped up, and by means of a water cart spread over the ground, and the shive or woody part of the stem can be mixed with the manure in the farm-yard. The restoration of these will serve to renovate the soil, and preserve its undiminished fertility ; it must therefore be short-sighted policy, arising from ignorance, that could wilfully throw away such highly valuable ingredients. With proper cultivation, and careful preservation and giving back to the soil the (to the Flaxspinner) useless parts of the plant, Flax is the very reverse of an exhaustive crop, and landlords might, with great propriety, revoke the clauses prohibiting its growth, which stand as monuments of ignorance in so many of their leases in various parts of the country.

After the Flax has been sown as directed, it must be watched to prevent the weeds from injuring the crop. If the land has been well cleaned and prepared before sowing the seed, as it certainly ought to be, few weeds will appear. Any that do grow up, however, must be carefully removed when the plant is from five to six inches in height. If done earlier a second weeding may be required, and if done later the plants would be injured by the weeders, as they would not recover their upright position again. The weeders should not be allowed to wear clogs, or nails in their shoes, as is done in some places, and they ought to work with their faces towards the wind, always pressing the stems one way, and the breeze will help to make it rise again. If the plants are twisted they cannot rise again, and therefore will be lost.. After the Flax has fairly started into growth, it may be rolled with advantage, but this should be done only on a dry day.

In order to produce a fine fibre the plant must be pulled before it is quite ripe. The best time for gathering it is between the falling of the flower and the formation of the seed, because the fibre is finer and more solid then than at any other time. If pulled too early the fibre will be flimsy, and if too late it will be coarse ; the time for pulling is therefore a subject of the greatest imporiance. The common rule is to let about two-thirds of the stalk to become yellow, and not to allow the seed capsules to becon:e more than slightly tinged with brown. Perhaps the best time 
for pulling is when the stalk is stripped of its leaves for half or two-thirds its length from the root. No doubt the exact period for pulling the Flax, as for reaping all grain crops, requires some judgment, but the intelligent farmer will soon learn the proper time to do so, and act accordingly. It is of great importance to have the operation performed on a fine day, and care should be taken, if possible, to select one for the pulling process. If the previous day or two has been fine the fibre will be firmer than it would otherwise have been.

If good seed is required for future sowings, a little of the Flax should be allowed to remain after the bulk of the crop is pulled, that it may ripen fully, and yield seed with the germinating principle really in it.

In the "Library of Entertaining Knowledge" it is said that low grounds which have received deposits left by the occasional overflowing of rivers, or where water is found not very far from the surface, are most favourable for the culture of Flax. It is attributed to the latter circumstance that Zealand produces the finest Flax grown in Holland. There two or three bushels of seed are required for each acre of ground for Flax for ordinary purposes ; but when it is to be manufactured into lawn or cambric, double the quantity of seed is sown on the same space of ground. The plants, when growing nearer to each other, have a tendency to shoot up into long slender stalks, and as the same number of fibres are usually found in each plant, these will, of course, be finer in proportion.

If the crop grows short and branchy, it is then most valuable for its seed, and the plants should be allowed to grow to maturity. But if the stalks grow straight and long, then all care of the seed becomes a secondary consideration, and the Flax should be pulled at the most favourable time for obtaining good fibre. Experience has shown that when the bloom has just fallen, when the major part of the stalks begin to turn yellow, and before the leaves fall, the fibres are softer and smaller than if left standing until the seed is quite matured, and it is better to pull the Flax a day too early than one too late. Although the Flax be pulled at this stage, the seeds will ripen sufficiently, if not detached from the parent plant until dry, as the sap which it contains contributes towards further nourishing and perfecting the seed. 
The Dutch avail themselves of this fact with regard to their crop, and stack the Flax after pulling it. The seed, by this means becomes ripe. while the fibres are collected at the most favourable period of their growth. They thus obtain both of the valuable products from their plants, and supply their less careful neighbours and others with the seeds. If they can do this there is no good reason why it may not be done in Ireland and in other Flax growing countries. The only objection is that the Flax cannot be got so soon ready for market; but surely the extra value of the seed would far more than compensate for the want of the money for the Flax for a few weeks or months.

In pulling, the long and short stems should be kept separate as much as possible, and the lower ends even. A small quantity should be held with the left hand, and pulled with the right hand, placed about half way down the stalks. The handfuls should be neatly placed over each other, so as to remain distinct, and no earth or clay should be allowed to remain on the roots.

Some parties prefer to steep the Flax with the bolls upon it, supposing that the oil of the seed is beneficial in assisting fermentation, but there is no good reason for such a supposition. The most approved mode is to remove the seed capsules before steeping, the more so as they can then be made arailable for feeding eattle, and in that way will much more than pay the cost of removing them. The Flax bolls contain more nourishment than linseed cake, from which the oil has, of course, been expressed ; and they form a valuable addition to the warm food prepared during winter for either horses or cattle. In addition to the fattening properties of the bolls, they give the animal a sleek appearance, and, owing to their slightly pur.gative properties, assist in warding off internal disease. It is therefore a great mistake to steep, and thus waste so valuable a commodity, and none but ignorant or prejudiced people would do so.

Warnes says the wily Dutch were certainly the first to pro. mulgate the notion that it was impossible to obtain both fibre and seed at the same time. This notion, however absurd, regulated the practice in the United Kingdom till the year 1841, many parties asserting that the steeping of the stalks with the seed tended to improve the quality of the Flax. This is now 
found to be an erroneous opinion, because Flax itself contains oleaginous matter that requires extraction instead of addition.' Warnes' practice on the farm of Trimingham in Norfolk, invariably was to remove the seed, as it was highly valuable for feeding: cattle, the culture of the Flax being very profitable, although grown for the seed for feeding purposes alone. Certainly the cogent arguments which he adduces place this beyond a doubt. and the wonder is that the plant is not far more extensively cultivated, not only in England and Scotland, but in Ireland also. When both fibre and seed are made available, as they ought invariably to be, the plant is as profitable as any which can be grown.

The box system of feeding cattle with a mixture of linseed and other compounds, introduced by Warnes, has risen into favour wherever known, and in many districts of England no farm is considered complete without it. In his lifetime he did much for the encouragement of the cultivation of the "golden crop" (as it is called in Belgium) in England, and his system might be advantageously introduced into Ireland, as it would make the crop much more profitable to the farmers in that country than it has hitherto been.

When the Flax is pulled it should be made up into small sheaves or bundles, tied slack to let the air have free action through them. These should be set up in stooks of twelve sheaves, with the bolls up, and allowed to remain from two to four days, to ripen and firm. In very sunny weather little time is required for this purpose, but if the crop has been heavy and lodged, it will require a little extra time, as it should under such circumstances be pulled a little sooner than if it had been standing.

When the bolls are to be removed preparatory to steeping, and this ought always to be done, as they are very valuable before being steeped, but worthless after steeping, the plants after being laid in handfuls, as mentioned, should then be handed to the "ripplers," who pass the tops of the plant through a large comb, with wooden frame and iron teeth, called a ripple. The best ripples are made of $1 \frac{1}{2}$ inch square rods of iron, placed with the angles of iron next to the ripplers, 3-16ths of an inch asunder at the bottom, half an inch at the top, and 18 inches 
long, to allow a sufficient spring, and to save much breaking of Flax. The points should begin to taper three inches from the top. Two ripplers sit opposite each other on the frame of the machine, with a large sheet on the ground below it; and the bundles of Flax, after being drawn throngh the ripple, and the seed taken off, should be bound up with rushes in small sheaves and taken to the watering pool, previously made ready to receive them. It is better to leave some of the seed on than ripple the Flax too closely, because there is a risk of splitting or bruising the delicate fibres about the top of the stem.

The stem of the Flax plant, as already stated, consists of a central wood-like part, called shove or boon, and of the tough fibres, called bast or harl, covered by cuticle, cemented together by gummy compounds. These parts are so closely adherent to each other, and the fibres to one another, and to the cellular tissue of which all fibres are formed, that they are with difficulty separated from each other, and the fibres obtained for use. If green vegetable matter be exposed to the continuous influence of wet or of drought, disunion of the adherent parts takes place, and they may then be readily separated from each other. The same effect is produced if some of the constituent parts are dissolved by a chemical solvent, or by water at different temperatures; the rest being set free, the fibres may then be easily separated. All these methods have been and aro employed for the separation of Flax fibre in different localities, and it is a matter of vast importance to know which mode is the most economic of the fibre, both as to quantity and quality. Much scientific skill has at different times been made to bear on this subject, and many schemes have been brought forward with this view, which after a fair trial have been found wanting in some essential points, given over and forgotten, and the old modes again resorted to. Some of the most promising plans for this object will be noticed hereafter.

It may be proper here to refer to Lee's system of preparing and scutching Flax, which was brought forward in 1810, and which for several years raised great expectations, but which in the end were not realised. $\mathrm{Mr}$ Lee not only patented his invention, but obtained an Act of Parliament, by which the specification was ordered to be deposited 
in the Court of Chancery, to be kept secret from the public for fifteen months, and then to be produced only by order of the Lord Chancellor, and by him to be examined whenever occasion required. Indeed, his discovery was thought of such importance, that Parliament granted him the peculiar privilege, that the time for the specification of his patent should be extended from six months to seven years. The Irish Linen Board was dazzled by the scheme, and for several years they paid large sums for the patent machines, and offered premiums for cloth manufactured from Flax prepared in the new mode, but all in vain. After many careful and extensive experiments, made by Mr Williamson, of Lambeg House, one of the most intelligent merchants of his day, he reported to the Linen Board, and the report was confirmed by many of the leading spinners, manufacturers, and bleachers of Belfast, that the system was found unsuited to the linen manufacturers of Ireland.

It was also tried for a considerable period at Kirkland Works in Scotland, and although the proprietors of the works thought highly of it at first, yet after a fair and impartial trial, they found its promised advantages altogether delusory, and, in January 1816, wrote a letter to the Dundee Advertiser detailing its defects, and cautioning others from being led away by the fair, but illusory promises of the patentee and his agents. They stated that the glutinous matter of the plant was not extracted from it by Lees' method; that, although the Flax was greatly improved by being put through fluted rollers. after being slightly broken, the process was slow and expensive, and that bleaching the Flax was impracticable on a large scale. The same year the Board of Trustees in Scotland also pronounced judgment against the machines, both as to the small quantity and inferior quality of the Flax cleaned by them.

The system proposed was to do away with steeping or waterretting, and the ordinary mode of scutching, and to substitute in their stead a thrashing machine, a breaking machine, a cleansing machine, and a refining machine, and to bleach the Flax fibre before being spun. The cumbrous and expensive machinery was enough of itself to condemn this mode of preparing Flax, but, in addition, the fibre was too much broken, and, being cut transversely, it did not join well in spin- 
ning, and this defect was also shown in the dressing and weaving operations, both warp and weft being weak, and giving way with the least strain. The failure of Lee's system cannot be ascribed to any unwillingness in those interested to improve, but rather to its own inherent defects, as it got a fair trial in various places, and from parties who were most desirous that it should succeed.

The steeping process is one of the most important in the preparation of Flax. The odour produced during fermentation is very pungent and fotid, and the offensive smell is felt at a considerable distance from the place in which the plant is steeped. It is well known that all plants imbibe carbon through the fibrous roots, after it has been dissolved in the soil by water, and that it is retained to give firmness and solidity to the plant. In the fermentation or putrefaction of vegetable matter, and in steeping Flax, a putrid fermentation takes place, carbonic acid and nitrogen is produced, which act like a narcotic poison to animal life. The disagreeable smell arising from a Flax steeping pond results from the evolution of various odorous compounds of valerianic acid, butyric acid, \&c. Indeed, the noxious effluvia constantly oxhaled, like marsh miasma, carry with them the germs of painful diseases, which attack both animals and men.

Courtrai in Belgium has long been famous for the quality of its Flax, and there the straw is steeped in tho river Lys, the water of which is remarkably pure, and very suitable for the purpose. The mode adopted in the Courtrai district is as follows:-The Flax is placed perpendicularly into wooden crates or frames, about twelve feet long, eight wide, and three deep, tied up in small sheaves, bound round with three bands. It is packed close together, the sheaves standing on the butt end, which prevents any damage to the top. The Flax is well covered with straw, and the crates are then launched into the river Lys, and kept under the water with large stones. It is never allowed to sink to the bottom of the river, because the mud would damage the fibre, and the nearer it is kept to the top of the water the better, as the heat of the weather quickens the process. When the necessary change has taken place, which is known by the woody part pulling out of the fibre for six or eight inches, thecrates are hauled on shore, where the Flax is unpacked 
and carted to the grass. The sheaves are then placed on the butt end to dry, and after this is thoroughly done, which it will be in two or three days, if the weather be favourable, they are ready for stacking. The process of bleaching or stacking is performed by the farmer at his leisure, but March is a favourite month for this operation, and it is often done then as it is considered the best bleaching time.

Steeping is a regular trade to many men, and two or more unite in the possession of a number of crates adapted to a given expanse of water, for which they pay no rent, and the Government protects them from the interference of shipping. For many miles along both banks of this celebrated river the steeping process is conducted, and farmers send their Flax long distances, in some cases forty miles by land, to be steeped. Some send it by water longer distances than that, indeed, it is sent even from Holland for this purpose. Stacking the Flax for some time after it is steeped is said to enhance the value, particularly with respect to colour.

Those parties who require the money for their Flax before spring, sell it while growing to factors, at a price per acre. When the finest qualities of Flax are wanted this is the more necessary, because it must be kept in the straw all winter, steeped next summer, again stacked, and only grassed and scutched the following spring, so that the fibre is not available for the market until the second season after it is grown, which would be a heavy trade to any farmer who is not wealthy. The great care which the Belgians have bestowed upon the cultivation of Flax has raised them from a state of poverty to affluence, and this shows the vast benefits to be derived from the cultivation of so valuable a plant.

In some parts of Ireland Flax is also steeped in a river or stream, and it is a strange fact that fermentation should proceed successfully in a running stream of fresh water. It would thus appear that the process of fermentation must go on in the glutinous matter which connects the woody stem with the pure fibre of the plant, and that its elements are loosened from their former conditions of combination, gradually dissolved, and carried off by the stream, as the water has no time to become decomposed in passing through the bundles of Flax. To put fresh slaked lime into the water in which Flax is steeped would 
absorb the carbonic acid, and remove the offensive smell, but it would retard fermentation, and perhaps spoil the Flax. Pure soft water, free from lime and other minerals, is therefore the best for steeping Flax, as it allows the fermentation to go on freely, and thus loosens the adherence by dissolving some parts, and setting the others free.

The most common mode of steeping Flax is in holes cut near a river, from six to twelve feet wide, three or four feet deep, and of the length required. The water ought to be, and is generally, put in a few days before the Flax is to be immersed. The sheaves of Flax should be carefully placed in the water in layers, and covered at top with straw or wicker-work, on which stones are placed to keep all firmly under water. The pools ought to be very clean, and this is a point the Belgians are very particular about, and great care is taken in putting in the Flax, so as to preserve the colour, fibre, \&c.

In some states of the weather ten days may be sufficient time for steeping the Flax, and at other times fourteen days may be required, but nothing save practical experience will prevent mistakes in this operation. Generally the Flax should be taken out when, on breaking the stem of the plant, the fibre separates freely from the woody part, because then the fermentation appears to have performed its part. The Flax ought then to be taken out of the water by men standing in it, and after the bundles have been allowed to drain on the bank for a short time, it should be removed to the field and spread out upon the grass. The steep water is an excellent liquid manure, and ought to be lifted out and applied to the neighbouring grass fields. This water contains much of the nitrogen and other inorganic matter which the plant drew from the soil, consequently it is the most speedy restorative for exhausted Flax ground that could be applied, and is therefore well worth the trouble and expense of the application.

By allowing the water to run off before the remoral of the Flax from the hole, the scum and dirt are left among the plants, the bundles are pressed on the sides of the pit and dirtied, the valuable liquid manure is lost, and the noxious fluid, passing into the river in the drought of summer, renders it unfit for domestic use, and poisons the fish therein. These are formicl- 
able objections to such a mode, and there is not a single reason which can be adduced in its favour. Fools cut in stiff clay answer best for the purpose of steeping or retting, and it is an objection to have them shaded by trees, as they are most suitable when exposed to the sun and to the atmosphere.

For spreading the Flax upon, nice meadow or grass land, mown close, should always be chosen, but not clover, as it grows so fast that it might rot the Flax. The situation should be sheltered from storms, and yet get the benefit of both sun and air. If spread too thick it requires turning after having undergone a few days' exposure, in order that both sides may be bleached alike, but turning is not necessary when it is spread thin. The time required on the grass depends much on the state of the weather, but generally, if thin spread, from three to four nights will be sufficient. Under watered Flax will require a little extra grassing to correct the deficiency in the former process, but even then six nights is quite enough, as any longer time will waste the Flax and make it towy.

When the Flax appears dry and brittle in the woody part of the stem, it should be lifted carefully, and the fibres kept as straight as possible. It should then be tied up in bundles and removed to the scutch mill, or stacked like grain, in a dry open position. The only safe system of drying is in the open air, as artificial means is apt to damage the Flax.

Dew retting, that is grassing the Flax when pulled, instead of steeping it first, is still resorted to in the Archangel districts of Russia, in some parts of Germany, and in the United States of America. Though an effectual, it is always an uncertain and very tedious process, requiring from three weeks to a month for its completion. Flax so prepared is very apt to heat when exposed to moisture, and when kept in a close place with little fresh air. The fibre, however, is soft and silky, and well adapted for spinning into small sizes of yarn, and it requires a shorter time for bleaching, and therefore it is largely used. It is very doubtful if the quality be so good as it would have been if it had undergone the usual process of steeping in water, instead of exposure to the action of the atmosphere, the sun, and the nightly dews and rains.

Other modes of retting Flax have been proposed, and perhaps 
the best of these is the improvement on the common retting process, patented by Shenck. The principle of his plan is simple and easily understood. It consists in substituting water, heated to a given temperature under cover, so as to hasten the fermentation necessary to separate the pure fibre from the woody and gummy portions, for the uncertain and irregular action of the common steeping ponds. This plan was at one time in high favour, but it was found to be too costly, and therefore it has been nearly given over. This is not a new process, as it has long been practiced in Sumatra, and in the district of Rungpore, where the vatives not only use warm water, but sometimes chemical substances, to assist in separating the fibre of various plants.

By Watt's process, boiling and crushing are substituted for fermentation, by which means the unpleasant smell arising from the Flax while in process of retting is avoided. It is not yet proved whether the process of fermentation be absolutely essential to the separation of the fibre, or whether an equally good fibre cannot be got without it. Watt said it could, and that by subjecting the straw to the action of steam, and afterwards putting it through heavy metal rollers, more fibre, and that of finer quality, is obtained than by the usual method of steeping. Watt died a few years ago, and perhaps since then his system has not been fairly tested, but some of the experiments made during his lifetime seemed to produce favourable results. Professor Wilson said that it possessed the following advantages:Saving of time; economy of fibre ; avoidance of nuisance; and beneficial application of waste products. All very important, if really attainable.

Buchanan's process is said to be an improvement on Watt's. In it the solvent power is due to the hot water occasioned by the condensation of steam, the steeping being effected by repeated immersions in a tank of heated water, kept at a temperature between $150^{\circ}$ and $180^{\circ}$. The process is described as quite automatic, requiring only four hours for the operation, and saving much labour.

Pownall, in his experiments on Flax straw, discovered that if the straw be taken out of the steep water after fermentation, and instantly, bofore drying, subjected to severe pressure and a 
stream of cold water, the pressure pressed out almost all the gluten not removed by the fermentation, and the water washed it away. This removes the difficulty of hitting the happy mean between over and under fermenting the straw. Some of these may be valuable improvements, but practical experience for a length of time alone can test them, and until this be done it would be wrong to laud any of them.

In retting Flax, the water, by rotting the straw, makes it separate easily from the fibre, but it does not separate the fibres of the Flax from each other. The grassing accomplishes this, and by opening or breaking up the fibre, adapts it the better for being spun into the finer sizes of yarn. Steeping and grassing are therefore both highly essential to the production of a fine fibre, and any system that dispenses with either process is liable to grave objections. No doubt neither nor both of these processes will convert naturally coarse Flax into a fine fibre, but they do improve the spinning properties of even coarse Flax, and therefore both are best, and both should be practised where it is possible to do so.

Sometimes the finer sorts of Flax in Germany are steeped four or five days in a warm mixture of milk and water, and in this way the desired degree of fermentation in the stems is produced. Sometimes lea of wood ashes, and other chemical agents have been tried to facilitate the separation of the fibres; but indeed the action of water and the production of fermentation in the ordinary way, may truly be considered chemical operations, and if rightly conducted, this is perhaps the best and safest mode for accomplishing the desired object.

The practice of steeping green is carried on to a large extent in the Waes district in Belgium, and elsewhere, and it is by many considered the best, as it certainly is the quickest mode of obtaining the fibre. The other and usual mode is to dry the straw, and stack it in the field or stack yard. In winter the seed is carefully taken off and preserved, the straw again stacked till spring, when it is retted, grassed, and scutched in the usual way.

Steeping Flax is no doubt liable to various objections. The stems in a field do not all come to maturity at the same time, nor have they all the same volume or power of resistance, and yet in the retting pit they are all treated alike. As a natural 
consequence some stems are imperfectly retted, and yield harsh and brittle fibres, while others, offering little resistance, yield soft and enervated fibres. Even supposing it were possible to steep and ret only similar stems together, the different positions in which they are placed in the pit would lead to modifications in the putrefaction, and produce like results. In order to separate the filaments properly, the retting must be fully carried out, and this is apt to cause the fibre to lose part of its tenacity and cohesion, and thus injure it. 'To obviate these objections various modes have been tried of scutching the Flax direct from the field on which it is grown, and many machines have been patented with this object, some of which have been mentioned above; but hitherto, it is believed, no scheme has been discovered which, practically, will preserve the fibre in all its perfection, while superseding retting.

It is now well known that the fibre of all unsteeped Flax is white, or only tinged with a yellow colour, immediately soluble in water. The colouring matter in unsteeped Flax is easily discharged, whether it be in the state of F'lax, yarn, or cloth, and Lee's mode accomplished this; but the expense was too great to be of practical use. Perhaps some method may yet be discovered for preparing Flax without retting, and at the same time preserve the fibre and all its requisite spinning qualities intact. The discoverer of such a system will confer a boon on both the growers and manufacturers of the fibre, and be a benefactor to his country.

The next stage of the process is scutching or cleaning the Flax, that is, separating the fibre from the woody portion of the stalk, and a most important one in the preparation and preservation of the fibre it certainly is. Many schemes have from time to time been brought forward for transforming the straw into Flax expeditiously, cheaply, and beneficially, both as to the quantity and the quality of the fibre. Some of them have been talked of, and forgotten without even a trial. Others have been tested and found unsuitable from various causes, and quickly thrown aside. While others again have had lengthened trials, with every advantage which money could procure, and every encouragement which high patronage could offer, but in the end were found to be practically worthless. Sometimes valuable re- 
sults have been produced without lengthened investigation, and, as it were, by chance, but generally really beneficial improvements have to be worked out, and are discovered gradually. A wonderful theory, however attractive on paper, must stand the unromantic test of much practical experience before it can be trusted and adopted with safety, or it may in the end turn out a "dazzling but illusory experiment." The truth of this has been well exemplified in the many futile attempts which have been made to improve the scutching machines in general use.

The primitive mode of scutching Flax is to twist a bundle of stalks or stems in the hand, so as to break the woody part, taking care not to ravel or entangle the fibre. The fragments of the stalks are then shaken or beaten off by a wooden knife several inches broad, and the fibre thus cleared is the undressed Flax of commerce. Various other modes of scutching by hand with the aid of simple instruments have also been in use, but these have now, and for a long period, given way to a great extent to mill scutching. The fibre is better cleaned by. the scutch mills than can possibly be done by hand, and it commands a higher market value in consequence. Any hand scutching process must naturally be slow and telious, and now it is only practised where labour is cheap or where prejudice is strong.

The cost of scutching Flax in Ireland is about a penny a pound, including cartage to and from the scutch mill. This is considered a high charge, and were the scutch mills to have employment during the whole year, instead of working only the winter six months, it might be done at perhaps three farthings a pound and yet pay the scutcher well. The produce of a ton of good average quality of dry Flax straw, fairly scutched, is about four hundredweight of Flax fit for market, and perhaps one hundredweight of codilla. Both the quantity of Flax and of Codilla will vary with the quality of the straw, and with the description of mill, and the care bestowed upon the Flax during the operation of scutching.

The system now generally adopted in the best and most approved scutch mills is, to pass the Flax, well dried, between a set of rollers, which bruise it so thoroughly as to make the 
after separation of the straw an easy process, and the better it is bruised the greater will be the yield of fibre at the mill. The Flax is then suspended from an opening in the top of a machine in which a horizontal shaft, with wooden blades about twelve inches in length attached thereto, revolves and acts on the Flax vertically, and care should be taken to make the shaft travel at the rate of 250 revolutions a minute. By a recent improvement spring stocks have been introduced, which give a little in the operation of scutching. This prevents the Flax from being injured by too severe action from the blades, and the Flax so scutched is increased in value, because the fibre is left in a better and sounder state.

Generally speaking, the less scutching Flax undergoes the better, and if the straw be thoroughly dry and then well broken, little scutching will be required, as the straw will separate very easily from the fibre. Flax is the proper product of the plant, and the tow taken off it is produced by the injury the fibre receives in the process of separation from the woody matter of the stem. The less the fibre is broken the greater will be the yield of Flax, and the less codilla will be produced. It is therefore of the highest importance to preserve the fibre entire, and the scutcher who best accomplishes this is the first man in his trade and worthy of all encouragement.

The cost of the machinery of a small scutching mill, with four stands, is about $\mathfrak{E 6 0}$, and of a large one, with twelve stands, about $£ 150$. A new scutching machine, recently patented, and which is said to answer admirably, can be got for

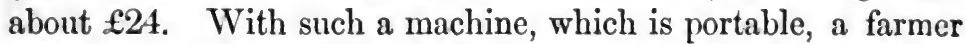
could scutch his own Flax. This is an object of first-rate importance in encouraging the growth of Flax in any district, as the want of scutch mills has hitherto kept many farmers from trying it.

The operation of scutching Flax brings it into a marketable state, the long fibres being known in commerce as Flax, and the tow, which is taken off in the process of scutching, is called scutching tow or codilla.

The following directions for the proper management of the Flax crop, issued by the North-Eastern Agricultural Association of Ireland, may fitly conclude the chapter on Flax culture, 
as they have been prepared with great care, and to the Flax grower are truly invaluable :-

\section{Soil and Rotation.}

By attention and careful cultivation, good Flax may be grown on various soils; but some are much better adapted for it than others. The best is a sound, dry, deep loam. It is almost essential that the land should be properly drained and subsoiled; as, when it is long saturated with either underground or surface water, a good crop need not be expected. The subsoiling should be executed the year of the green crop, so as to be completed at least two years before the Flax is grown.

The best rotation is to grow after wheat, on average soils ; but in poor soils, where wheat does not succeed, it is often better to grow after potatoes. Flax should on no account be grown oftener than once in five years, and once in seven, or even ten, is considered safer.

Any departure from this system or rotation is likely to cause loss and disappointment.

\section{Preparation of the Soil.}

One of the points of the greatest importance in the culture of Flax is by thorough draining, and by careful and repeated cleansing of the land from weeds, to place it in the finest, deepest, and cleanest state. 'This will make room for the roots to penetrate, which they will often do to the depth equal to onehalf the length of the stem above ground.

After wheat, one ploughing may be sufficient on light, friable loam, but two ploughings are better; and on stiff soils three are advisable —one immediately after harvest, across the ridges, and two in spring, so as to be ready for sowing in the first or second week of April. Much will, of course, depend on the nature of the soil, and the knowledge and experience of the farmer. The land should be so well drained and subsoiled that it can be sown in flats, which will give more even and much better crops. But, until the system of thorough draining be general, it will be advisable to plough early in autumn to the depth of six or eight inches. Throw the land into ridges, that it may receive the frost and air; and make surface drains to carry off the raius of 
winter. Plough again in spring, three or four inches deep, so as to preserve the winter surface for the roots of the Flax. 'The spring ploughing should be given some time before sowing, to allow any seeds of the weeds in the land to vegetate, and the harrowing in of the Flax-seed will likely kill them, and save a great deal of after weeding. Following the last harrowing, it is necessary to roll, to give an even surface and consolidate the land, breaking up this again with a short-toothed or seed-harrow before sowing, which should be up and down, not across the ridges, or anglewise. These operations can be varied by any skilful farmer, to suit peculiar soils or extraordinary seasons. 'The object is to have clean, fine soil, as like as possible to what a garden soil should be.

The rotation we recommend is :-

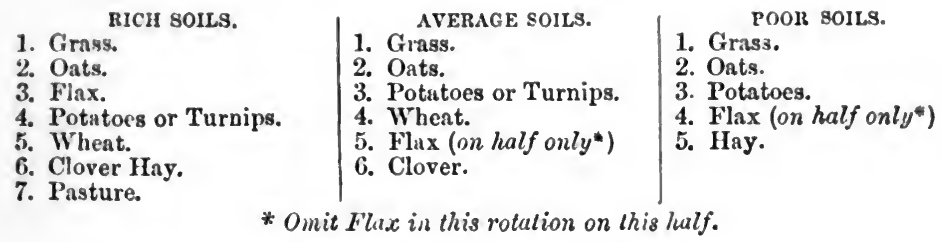

\section{Sowing.}

The seed best adapted for the generality of soils is Riga, although Dutch has been used in many districts of the country for a series of years with perfect success, and generally prodnces a finer fibre, but not so heavy a crop as Riga. In buying seed, select it plump, shining, and heavy, and of the best brands, from a respectable merchant. Sift it clear of all the secds of weeds, which will save a great deal of after trouble, when the crop is growing. This may be done by farmers, and through a wire sieve, twelve bars to the inch. These sieves can be had in Belfast. Home-saved soed has produced excellent crops, yet it will be best, in most cases, to use the seed which is saved at home for feeding, or to sell it for the oil mills. The proportion of seed may be stated at one Riga barrel, or three and-a-half imperial bushels, to the Irish or plantation acre; and so on, in proportion to the Scotch or Cunningham, and the English or statute acre, viz. :-about two and a half bushels for the Scotch acre, and about two for the statute acre. It is better to sow rather 
too thick than too thin ; as with thick sowing the stem grows tall and straight, with only one or two seed capsules at the top ; and the fibre is found greatly superior, in fineness and length, to that produced to thin sown Flax, which grows coarse and branches out, producing much seed, but a very inferior quality of fibre. The ground being pulverised and well cleaned, roll, harrow, and sow. If it has been laid off without ridges, it should be marked off in divisions, eight to ten feet broad, in order to give an equable supply of seed. After sowing, which should be done by a very skilful person, as the seed is exceedingly slippery, and apt to glide unevenly from the hand, cover with a seed harrow, going twice over it-once up and down, and once across or anglewise, as this makes it more equally spread, and avoids the small drills made by the teeth of the harrow. Finish with the roller, which will leave the seed covered about an inch-the proper depth. The ridges should be very little raised in the centre, when the ground is ready for the seed, otherwise the crop will not ripen evenly; and when land is properly drained there should be no ridges. Rolling the ground after sowing is very advisable, care being taken not to roll when the ground is so wet that the earth adheres to the roller.

\section{Weeding.}

If care has been paid to cleaning the seed and the soil, few weeds will appear ; but if there be any, they must be carefully pulled; or cut with a knife, when the weeds happen to be large or when potato stalks appear. It is done in Belgium by women and children, who, with coarse cloth round their knees, creep along on all-fours. This injures the young plant less than walking over it (which, if done, should be by persons whose shoes are not filled with nails). They should work, also, facing the wind, so that the plants laid flat by the pressure may be blown up again, or thus be assisted to regain their upright position. The tender plant, pressed one way, soon recovers; but, if twisted or flattened by careless weeders, it seldom rises again. The weeding should be done before the Flax exceeds six inches in height.

\section{Pulling.}

The time when Flax should be pulled is a point of much 
nicety to determine. The fibre is in the best state before the seed is quite ripe. If pulled too soon, although the fibre is fine, the great waste in scutching and hackling renders it unprofitable; and if pulled too late, the additional weight does not compensate for the coarseness of the fibre. It may be stated that the best time for pulling is when the seeds are beginning to change from a green to a pale brown colour, and the stalk to become yellow for about two-thirds of its height from the ground. When any of the crop is lying and suffering from wet, it should be pulled as soon as possible, and kept by itself. So long as the ground is undrained, and imperfectly levelled before sowing, the Flax will be found of different lengths. In such cases, pull each length separately, and, if possible, keep it separate in the pool. Where there is much second growth, the Flax should be caught by the puller just underneath the bolls, which will leave the short stalks behind. If the latter be few, it is best not to pull them at all, as the loss from mixture and discoloration by weeds would counterbalance the profit. If the ground has been thorough drained, and laid out evenly, the Flax will likely be all of the same length. It is most essential to talio time and care to keep the Flax even, like a brush, at the root ends. This increases the value to the spinner, and, of course, to the grower, who will be amply repaid by an additional price for his extra trouble. Let the handfuls of pulled Flax be laid across each other diagonally, to be ready for the

\section{Rippling,}

Which should be carried on at the same time, and in the same field with the pulling. If the only advantage to be derived from rippling was the comparative ease with which rippled Flax is handled, the practice ought to be adopted; but, besides this, the seed is a very valuable part of the crop, either for the oil mill or for feeding purposes at home. The apparatus is very simple. The ripple consists of a row of iron tecth screwed into a block of wood. This can be procured in Belfast, or made by any handy blacksmith.* It is to be taken to the field, where the

- The best ripples are made of half-inch square rods of iron, placed with the angles of iron next the ripplers, 3-16ths of an inch asunder at the bottom, half an inch at the top, and 18 inches lnng, to nllow a sufficient spring, and save much breaking of flax. The points should begin to tuper 3 inches from the top. 
Flax is being pulled, and screwed down to the centre of a ninefeet plank, resting on two stools. The ripplers may either stand or sit astride at opposite ends. They should be at such a distance from the comb as to permit of their striking it properly and alternately. A winnowing sheet must be placed under them, to receive the bolls as they are rippled off; and then the ripplers are ready to receive the Flax just pulled, the handfuls being placed diagonally, and bound up in a sheaf. The sheaf is laid down at the right hand of the rippler and untied. He takes a handful with one hand, about six inches from the root, and a little nearer the top with the other. He spreads the top of the handful like a fan, draws the one half of it through the comb, and the other half past the side; and, by a half-turn of the wrist, the same operation is repeated with the rest of the bunch. Some, however, prefer rippling without turning the hand, giving the Flax one or two pulls through, according to the quantity of bolls. The Flax can often be rippled without being passed more than once through the comb. He then lays the handfuls down at his left side, each handful crossing the other, when the sheaf should be carefully tied up and removed. The object of crossing the handfuls so carefully, after rippling, when tying up the beets for the steep, is that they will part freely from each other when they are taken to spread out on the grass, and not interlock and be put out of their even order, as would otherwise be the case. If the weather be fine the bolls should be kept in the field, spread on winnow-cloths, or other contrivances for drying; and if turned from time ts time, they will soon dry. Passing the bolls first through a coarse riddle, and afterwards through fanners, to remove straws and leaves, will facilitate the drying. If the weather be moist, they should be taken in-doors, and spread out thinly and evenlyon a barn floor, or on a loft, leaving windows and doors open to allow a thorough current of air, and turned twice a-day. When nearly dry, they may be taken to a corn kiln (taking care not to raise it above summer heat), and carefully turned until no moisture remains. By the above plan of slow drying, the seed has time to imbibe all the juices that remain in the husk, and to become perfectly ripe. If it be taken at once from the field, and dried hurriedly on the kiln, these juices will be-burned up, 
and the seed will become shrivelled and parched, little nutritious matter remaining. In fine seasons, the bolls should always be dried in the open air, the seed threshed out, and the heaviest and plumpest used for sowing or crushing. The light seeds and chaff form most wholesome and nutritious ficeding for cattle. Flax ought not to be allowed to stand in the field, if possible, even the second day; it should be rippled as soon as pulled, and carried to the water as soon as possible, that it may not harden.

\section{Watering.}

This process requires the greatest care and attention. River water is the best. If spring water must be used, let the pond be filled some weeks before the Flax is put in, that the sun and air may soften the water. That containing iron or other mineral substances should never be used. If river water can be had, it need not be let into the pond sooner than the day before the Flax is to be steeped. The best size of a steep pool is 12 to 18 feet broad, and $3 \frac{1}{4}$ to 4 feet deep. Place the Flax loosely in the pool, in one layer, somewhat sloped, and in regular rows, with the root end underneath; the tie of each row of sheaves to reach the root of the previous one; cover with moss sods, or tough old lea sods, cut thin, laid perfectly close, the sheer of each fitted to the other. Before putting on the sods, a layer of rushes or ragweeds is recommended to be placed on the Flax, especially in new ponds. As sods are not always at hand, a light covering of straw may do, with stones laid on it, so as to keep the Flax just under the water ; and as the fermentation proceeds, additional weight should be laid on-to be removed as soon as the fermentation ceases, so as not to sink the Flax too much in the pool. Thus covered, it never sinks to the bottom, nor is affected by air or light, A small stream of water, allowed to run through a pool, has been found to improve its colour. It will be sufficiently steeped, in an average time, from eight to fourteen days, according to the heat of the weather and the nature of the water. Every grower should learn to know when the Flax has had enough of the water, as a few hours too much may injure it. It is, however, much more frequently under-watered than over-watered. The best test is the following:-'Try some stalks, of average thickness, by break. 
ing the shove, or woody part, in two places, about six or eight inches apart, at the middle of the stalk; catch the broken bit of wood, and if it will pull freely out, downwards, for that length, without breaking or tearing the fibre, and with none of the fibre adhering to it, it is ready to take out. Make this trial every six hours after fermentation subsides, for sometimes the change is rapid. Never lift the Flax roughly from the pool, with forks or grapes, but have it carefully handed out of the Flax drain by men standing in the water. It is advantageous to let the Flax drain twelve to twenty-four hours after being taken from the pool, by placing the bundles on their root ends, close together, or on the flat, with the slope; but the heaps should not be too large, otherwise the Flax will be injured by heating.

The Flax water can be either used as liquid manure for meadows, or kept in the pool till the first flood-it should not be run off into the river when the water is very low, as the odour is very unpleasant, and the water thus impregnated is poisonous to fish, and contrary to law-see Fisheries Act, 5 and 6 Vic., c. 106.

\section{Spreading.}

Select, when possible, clean, short, thick pasture ground for this operation; and mow down and remove any weeds that rise above the surface of the sward. Lay the Flax evenly on the grass, and spread thin and very equally. If the directions under the head of rippling have been attended to, the handfuls will come readily asunder without entangling. Some people recommend turning it on the grass with a long rod, which is not, however, generally done in Ireland.

\section{Lifting.}

Six to eight days, if the weather be showery or ten to twelve if it be dry, should be sufficient on the grass. Ten days may be taken as a fair average in ordinary weather. A good test of its being ready to lift is to rub a few stalks from the top to the bottom; and when the wood breaks easily, and separates from the fibre, leaving it sound, it has had enough of the grass. Also when a large proportion of the stalk are perceived to form a bow and string, from the fibre contracting and separating from 
the woody stalk. But the most certain way is to prove a small quantity with the hand-break, or in a Flax mill. In lifting, keep the lengths straight and the ends even, otherwise great loss will occur in the rolling and scutching. If heavy dews or damp weather prevail, don't lift after three o'clock p.m. Let it be set up to dry for a few hours, and afterwards tie it up in small bundles; and if not taken soon to be scutched, it will be much improved by being put in small stacks, loosely built, with stones or brambles in the bottom to keep it dry, and allow a free circulation of air. Stacks built on pillars would be the best.

\section{Drying}

By fire is always most pernicious. If properly steeped and grassed no such drying is necessary; but to make it ready for breaking and scutching, exposure to the sun is sufficient. In some districts it is put to dry on kilns in a damp state, and is absolutely burned before it is dry, and the rich oily appearance of the Flax is always greatly impaired

\section{Breaking and Scutching,}

If done by hand, try the Belgian system, which is considered superior to that practiced in Ireland. If by milling, the farmer will do well to select those mills in which good machinery has been introduced; and it is to be hoped that, ere long, by further improvements, increased economy in these establishments will be attained.

\section{The Courtrai System.}

This mode of preparation requires to be very carefully executed, as inattention will reduce the value of the straw and yield inferior fibre. When made up for drying in large sheaves, the straw is much injured, the outside stalks being much discoloured by the heat of the sun before the inside of the sheaf is dry. The Flax stems should be put together in bunches, about one-half larger than a man can grasp in one hand, spread a little, and laid on the ground in rows after each puller; the bunches laid with tops and roots alternately, which prevents the seed-bolls from sticking to each other in lifting. It should be stooked as soon after pulling as possible, and never 
allowed to remain overnight unstooked, except in settled weather. The stooking should go on at the same time as the pulling, as, if Flax is allowed to get rain while on the ground, its colour is injured. A well-trained stooker will put up the produce of a statute acre or more in good order in a day, with two boys or girls to hand him the bunches. The Flax should be handed with the tops to the stooker. The handfuls, as pulled, are set up, resting against each other-the root ends spread well out, and the tops joining like the letter $\mathrm{A}$. The stooks are made eight to ten feet long, and a short strap keeps the ends firm. The stooks should be very narrow on the top, and thinly put up, so that they may get the full benefit of the weather. In six or eight days at most, after being pulled, the Flax should be ready for tying up in sheaves of the size of corn sheaves. It is then ricked and allowed to stand in the field until the seed is dry enough for stacking. To build the rick, lay two poles parallel on the ground, about a foot asunder, with a strong upright pole at each end. The Flax is then built the length of a sheaf in thickness or breadth. The bottom poles should be laid north and south, so that the sun shall get at both sides of the rick during the day. In building, the sheaves should be laid tops and roots alternately, built seven to eight feet high, and on the top a single row of sheaves lengthwise, or across the others, and then another row as before, but with the tops all the same way, which gives a slope to throw off rain; finish by putting on the top a little straw tied with a rope. In this way, if properly built, it will stand secure for months, or it can be put in a barn, if preferred; in either case, the seed is to be taken off during the winter, and the flax steeped in the following May. 
Vanious fibres are known in commerce under the common name of Hemp, but the true Hemp plant has characteristics peculiarly its own.

Hemp, (Ger., Hauf ; Dan., Kanip or Kinnep ; Swe., Hampa; Du., Hennip ; Fr., Chanvre ; It., Canape ; Rus., Konopel ; Pol., Konope; Erse., Canail ; Anglo-Saxon, Haenep ; the Cannabis sativa of botanists), is supposed to be a native of India or some other Eastern country, but it has long since been naturalized in Europe. It is an anuual, rising to the height of from 3 or 4 to 10 or 12 feet, according to soil and climate; the root is white and furnished with fibres. If the plants are grown apart they are branched, even from the bottom, but when crowded they are erect and simple, and covered with fine but rough pubescence. The stem is hollow or filled with a soft pith, which is surrounded by a tender brittle substance, called the reed or shive. Over this is the thin bark, composed of fibres, extending in a parallel direction along the whole stalk. The English word Canvas has the same origin as Hemp, and hence also comes camp, canopy, \&c., meaning cloth made of Hemp.

Hemp is one of the few plants cultivated in Europe which has the male and female flowers in different plants. Those bearing flowers only are called male Hemp, and those bearing the fruit or seed the female. The leaves are opposite or alternate, on long petioles, composed of from five to seven narrow, lanceolate, sharply serrated leaflets, of which the lower are the smallest, all tapering at the apex into an entire point. The fruit grows in great abundance on the stem of the female Hemp. It is not preceded by any corolla, but by a membranacious hairy calyx, terminating in long points, enclosing the pistil, the base of which becomes the seed. The male is quicker in growth than the female, and generally rises half a foot higher, by which pro- 
vision of nature, the farina or pollen from the stamina, or the fecundating dust which conveys fertility to the seed, is readily shed on the lower plant.

Hemp has been cultivated in Bengal from the remotest antiquity, but not, as in Europe, for its fibre. It secretes a resinous principle in its leaves, as well as in the churrus collected from off the young tops of the stem and flowers, which is highly esteemed in all eastern countries, on account of its exhilarating and intoxicating properties. In the Hindoo economy this serves as a substitute for malt, the favourite intoxicating liquor called banga or bhang, being produced from it. On this account chiefly it is cultivated in India, Egypt, Arabia, \&c., and in these lands it is grown very extensively. The Arabs call it the " increaser of pleasure," the "cementer of friendship," and similar names; and it is called Hasheesh in Syria and the adjoining countries.

When cultivated for this purpose in India, Hemp is sown thinly by the natives, who afterwards transplant the young plants, and place them at distances of nine or ten feet from each other. In this way they are exposed more freely to light, heat and air, which enables the plant to produce its secretions in a more complete manner. The more perfect these secretions are, the stronger and more intoxicating is the bhang or hasheesh extracted from this famous plant.

The use of Hemp among the ancients was very limited. It is never mentioned in Scripture, and not often by the heathen writers of antiquity, and Theophrastus takes no notice of it.

According to Herodotus, garments were made of Hemp by the Thracians. He says " they were so like linen that none but a very experienced person could tell whether they were of Hemp or Flax; one who had never seen Hemp would certainly suppose them to be Linen." The coarser kinds of Linen would, it is certain, be difficult to distinguish from the finer kinds of Hempen cloth. To the present day Hemp is produced abundantly in the vicinity of the countries occupied by the ancient Thracians. The men who drive the horses which drag the boats upon the Danube between Pesth and Vienna now wear coarse tunics of Hemp.

The next writer who mentions Hemp is Moschion, rather 
more than 200 years B.c. He states that the magnificent ships of Syracusia, built by command of Hiero II., were provided with Hemp from the Rhone for making ropes. The common materials for such purposes were the Egyptian Papyrus, the bark of the Lime tree, of the Hemp-leaved Mallow, and of the Spanısh Brown, and probably also the Stipa Tenaciosina of Linnæus.

Hemp as well as Flax was grown abundantly in Colchis. It was brought to the ports of the Aigean Sea by the Ionian merchants, who were intimately connected with the northern and eastern coasts of the Euxine through the medium of their Milesian colonies.

It is probable that Hemp was not the natural growth of either Italy, Greece, or Asia Minor, but that it was confined in a great degree to countries lying to the north of these regions. The intimate connection of the Romans with the Greek colony of Marseilles may have brought it among the Sabines, in the same manner as the trade between the Euxine and Miletus may have introduced it into Caria.

Pliny says that towards the end of the first century Hemp was in common use among the Romans for sails, ropes, \&c., but probably during the dark ages which succeeded the downfall of Rome it had been little cultivated or used.

In many countries of Europe, particularly Russia, Italy, and France, Hemp is now cultivated most extensively, and forms an article of primary commercial importance. It is also grown in other European countries to a small extent, in some counties of England, and more extensively in some of the States in North America.

When Hemp is grown for its fibre it is sown thick, and shade and moisture are advantageous for promoting this object. If for cordage, the Hemp should be sown in drills, as a strong and coarse fibre is required, and it is best produced in that way. When it is wanted for weaving purposes, it ought to be sown broad-cast, as the stems rise more slender and finer in proportion to their proximity, provided they are not so near each other as to choke and impede the growth. For whatever purpose Hemp is grown there should never be a smaller interval than a foot botween each plant. 
When sown broad-cast three bushels of seed is the ordinary allowance for an acre. If in drills, from one and a half to two bushels are sufficient, but if the soil be very rich, a little less should be sown whether it be broadcast or in drills. After the sowing great vigilance should be used to keep off the birds, or they will play sad havoc with the seed, and leave little to germinate and produce a crop. The ground requires very little after care or labour till the Hemp is fit for pulling, as the plant is never overrun with weeds, but, on the contrary, has the remarkable property of destroying their vegetation. Agriculturists sometimes take advantage of this well known fact, and by sowing a crop or two of Hemp on the rankest soils, they subdue all noxious weeds, and entirely cleanse the ground from these troublesome intruders.

Seed from Holland is most esteemed, because it ripens soon, and yields abundant crops of Hemp of a fine quality. Well grown English seed also produces a good quality of fibre, and is very suitable for sowing. Although Indian seed looks well, it is not so much liked for sowing, as it does not yield so good a crop of fibre in the first year. The seed should be of a bright gray colour and plump. If it has undergone heating in any way the germinating principle will be lost, but this can be known by the taste, which, if fit for sowing, should when bitten be sweet, but if unfit it will be bitter or acrid.

Hemp, like its sister Flax, will grow in almost any country, but it seems to thrive best in temperate regions. The Italians have a saying that Hemp may be grown everywhere, but it cannot be produced fit for use, either in heaven or earth, without manure. Rich moist earth is considered most favourable to its growth, with a fair portion of sand to keep the soil open and light to allow the roots to spread. It seldom thrives on a stiff cold clay soil, and poor land will yield but a scanty crop, although of fine quality. If the soil be over rich the plant grows too luxuriantly, and produces a strong coarse fibre. Poor soils may be made to produce a good crop by a plentiful supply of manure, and if a sufficient quantity of manure be applied Hemp nay be grown year after year on the same spot.

In Lincolnshire, where strong and heavy Hemp is grown, the hemp gardens are small and near the houses of the growers. 
These gardens absorb vast quantities of manure, and produce Hemp every year, without any alternation of the crops. Sometimes when the Hemp is pulled early a few turnips are sown for a stubble crop. In Italy, Hemp is sown in their best lands, which are rich and strong loams, and are made fine and friable. In Romagna, where the best Hemp is produced, it may be grown anywhere with manure. When a fine quality of fibre is wanted, the most suitable soil is selected, cultivators being regulated in their choice of soil by the description of Hemp they wish to raise. In England the generality of soil will require a dressing of ten tons of well rotted farmyard dung per acre, ploughed and harrowed in early in April.

The best time for sowing in England is from the beginning to the middle of May, but it may be done up to the first week in June, although late sown plants are apt to grow thin and weak. In Russia it is sown from the middle of May to the end of June, and some farmers think the latter the better time, as the frosts injure the early sowings. There the season of reaping is from the beginning to the end of September; it is thereforo between thirteen and fourteen weeks in a state of vegetation. The male plants, or white Hemp, come to maturity about three or four weeks before the female. 'They are known to be ripe by the flowers fading, the farina falling, and the stems turning partially yellow. The Russian summer though short is regular while it lasts, and the temperature is sufficiently high to bring the Hemp to full perfection. There the male plants are pulled before the female. In Lincolnshire, in Italy, and in other parts, the male plant is gathered a month earlier than the female, and small paths are made at intervals through the fields, to enable the persons employed to pull the plants which are ripe without trampling down those which are to remain.

The ripeness of the female Hemp is known by the same indications as those of the male, and also by the calyx partially opening, and its seed beginning to change colour. In Suffolk, both the male and female plants are gathered at the same time, and where seed is not wanted this may be done, without seriously injuring the fibre. They are both less injured by being pulled too soon than too late, but if too young the fibres though fine, are not so lasting as when the plants are gathered in a more 
matured state. If allowed to stand until they are quite ripe, the fibres adhere so tenaciously to the reed as not to be readily separated, and they become so coarse that no subsequent process can reduce them to a proper degree of fineness. Some plants are, therefore, preserved for seed, and these require no particular cultivation ; but some male Hemp should also be left to attain maturity, and shed its farina or pollen upon the seedbearing plant. Forty plants raised in the common way, yielded only a pound and a-half of seed, whereas, from a single plant which grew by itself, seven pounds and a-half were obtained.

During its season of rapid growth, the plant necessarily requires moisture, and irrigation is sometimes practised. The climate of Italy being remarkable for its clearness, regularity, dryness and warmth, irrigation is essentially necessary for much of its agriculture, especially for Hemp. The Italian Hemp is fine, soft, light coloured and strong, as well as long in the staple, which is partly owing to its careful culture, and partly to the soil, climate, \&c.

Each plant is pulled up singly by the root, care being taken not to break or cramp the stem in the hand. Before the plants are taken from the field the leaves and flowers, and sometimes the roots, are taken off with a wooden sword, and these are left on the ground, as they greatly contribute to enrich it for the succeeding crop. The stalks are then arranged as nearly as possible in equal lengths, the root ends being all laid on the same side of each handful or bundle, which is tied round with one of the stalks. It is then set up in shock for a week or so to dry, and if intended to be kept till spring it is tied in larger bundles, stacked and thatched.

When the female Hemp is gathered, it is allowed to stand eight or ten days exposed to the air, to allow the seed to dry and ripen, the tops being covered with undergrowth to keep off the birds, after which the heads are cut off, and the seed gently thrashed and separated in the same manner as linseed. The female plant is generally stacked auring the winter, and not steeped till the spring. Some parties say that instead of drying the hemp in the sun for a short time, it should be steeped as speedily as possible after being pulled. In this state it is said to require only four days, but where it has been dried, eight days 
of steeping Others approve of drying first, but the question which is best, has not been definitely settled, and, until it has been, use and wont may be the rule.

The object sought to be attained by steeping Hemp, as in the case of Flax, is by a slight degree of fermentation to enable the epidermis, or outer skin, to separate readily from the bark, and this from the boon or reed. It is generally steeped in the same manner as Flax, the bundles of Hemp being laid at the bottom of the water in the pond or ditch, and covered with straw and stones to keep all down. It is desirable to make a small stream of water pass through the steeping place, as putrid water, although it is said to make the fibres soft, gives them a disagreeable colour.

The length of time to keep Hemp in the steep is readily ascertained by taking out one of the steeped stems, and, holding it by the root end, draw the thumb nail up the stem to the top. If the fibre split up the stem, it has been sufficiently retted.

When the Hemp is sufficiently steeped, it is taken to a field of grass, hence called grassing, which is clean and free from cattle. It is there spread out very evenly, and allowed to lie for three or four weeks, in order to bleach and to free the fibre from the root. During that period it must be carefully turned over with light long poles every three or four days. When pink spots appear on the stem it is sufficiently bleached, and when dry it is tied up in bundles again, and carried to the barn or stack. Dew retting is another mode of preparation, in which the stems, after being pulled, are allowed to stand in the stook or shock for two or three days to dry, and then spread out on land where grass is plentiful. It may require to lie for six weeks, being frequently turned during that period. When the pink spots appear, it must be taken up at once and formed into bundles to dry, but the fibre will not sustain any damage until they appear Snow retting is practised in Russia and Sweden. After the first fall they spread the Hemp, already dried, on the snow, and leave it there to be corered with other falls of snow until spring, when it is usually found to be sufficiently retted. In Livonia the Hemp is steeped in a series of basins, one above the other, but the French have given over this mode of steeping.

After being steeped or otherwise retted, the Hemp is passed 
through between fluted rollers to break it, and then scutched much in the same way as Flax, and it is then in a marketable state, and fit for being heckled preparatory to spinning, or for being made into cordage. The heckles used are sornewhat coarser than those for Flax, the teeth of the coarsest being usually about an inch in circumference at bottom, tapering gradually to a sharp point, and they are set about two inches apart frnm each other.

The produce of an acre of land sown with Hemp usually averages from four to six hundredweight of scutched Hemp, and from sixteen to twenty-four bushels of seed. Hemp-seed affords a very useful oil, similar in its qualities to linseed; also cake which is largely imported into Great Britain, and sold to farmers for feeding purposes.

Hemp, as already mentioned, is largely cultivated in Russia, almost every province of that great country producing more or less of it For a very long period it has been one of the most important articles of export, St Petersburg and Riga being the two great shipping ports. When it is brought from the interior to the port of shipment, in the spring or summer, it is selected and made up into bundles by sworn brackers, who generally act impartially, and assort it with considerable care. At St Petersburg it is assorted into clean or firsts, outshot or seconds, and half clean or thirds. At Riga the three qualities are distinguished as Rhyne, Outshot, and Pass. In both places the refuse is called Codilla. Tickets are attached to each bundle as selected, and the different qualities are well known to the various purchasers by these names. Particular care is taken to ship Hemp in fine weather, as it is apt to heat on the voyage if it gets wet, and so become totally spoiled. The quality of Russian Hemp is admirably adapted for cordage, and it has long been largely used for that purpose in this and in other countries.

Hemp is grown both in the plains and on the high mountain ranges of India. In Bengal, where the land is so low as to remain moist during the dry season, it is cultivated and thrives luxuriantly during the cold season. There it only occupies the ground for about eighty days, or from the beginning of June to the eud of August. It thrives well in the Himalayas at an elevation of trom 6000 to 7000 feet, and it is grown there both 
for its intoxicating properties and for its fibre. It also grows in the northern districts of Nepaul, and in the southern and western provinces of India. The quality, for want of knowledge and care in the culture, is not particularly fine, but it is strong and suitable for many purposes. It might be produced in almost unlimited extent, and at less cost than Russian Hemp ; and perhaps the day is not far distant when it may supersede other Hemps in this country.

In former times Hemp was largely used in the manufacture of Linens, but very little of it is now consumed in that way. The fibre is too strong and harsh for the finer class of goods, and it is difficult to spin it into small sizes of yarn; indeed it must undergo some process to soften it before it can be properly spun over machinery at all. For twines, cordage, and similar articles, it has long been deservedly popular, and, from its strength and peculiar adaptation for ropes, these seem to be the purposes to which it ought to be applied. When Flax is dear and Hemp cheap, which occasionally happens, Riga Hemp, being softer and finer fibred than St Petersburg, is often used for the manufacture of sail-cloth, but for this purpose it is not so pliable as flax-cloth, and not so well liked by practical seamen. It was also largely manufactured into bagging, sacking, \&c., and it is still used to some extent in this way, but these goods have been nearly superseded by its cheap rival Jute.

\section{CHAPTER III.}

\section{JUTE CULTURE.}

\section{1.-The Culture of Jute in the Field.}

INDra abounds with fibre-yielding plants, some of which have been long known to, and manufactured into cloth, twines, \&c. by the natives of that country. Until a comparatively recent 
period very little was known in this country of almost any of these fibres, and scarcely any of them were employed by us in the manufacture of textile fabrics. So long ago as 1792 the Directors of the East India Company directed enquiry to be made by the collectors of districts in Bengal regarding substitutes for Hemp, and a good deal of useful information was then got respecting the culture of Sunn Hemp in India. In the years 1796 to 1798 great losses were sustained by the Company in their endeavours to introduce some of the fibres of India into this country, as their expenditure upon that object exceeded the amount of the sales by more than $£ 45,000$. The accounts of the exports of these fibres from India are imperfect, but by the reports on the affairs of India, given in to the-Committee of the House of Commons in 1831, it appears that in the official year 1796-7, only 591 maunds (not quite 22 tons) of Flax, Hemp, and twine were exported from Calcutta to the United Kingdom, and 2883 to the United States of America. At the same period 521 maunds of Jute were exported to the United Kingdom, 159 to America, and 1100 to Hamburg, being about 65 tons in all Besides these fibres, 34,000 gunny bags, made of Jute, were exported from Calcutta to America in the year 1796, and considerable quantities to Penang, China, New South Wales, \&c.

The East India Company, finding the trade so unprofitable, discontinued the importation of fibres into Great Britain until 1800, when differences occurred between this country and the Northern Powers of Europe, which induced the Government to look elsewhere than to Russia for Hemp. In that year the Directors sent out a person to India to establish the cultivation of Hemp, and the experiment was continued for some time, it is said, in an expensive manner.

In a letter, dated 4th February 1803, from the Lords of the Privy Council for. Trade and Plantations, to the Court of Directors of the East India Company, they were recommended to encourage as much as possible the growth of strong Hemp in such parts of their dependencies as were best suited for the production of that article. The Court, on 23d of same month, replied that they would take the needful measures for accomplishing the object of their Lordships' wishes.

Farms were accordingly taken for the cultivation of Hemp 
and of substitutes for it, and a scientific gentleman was appointed to take charge of one of them. He cultivated a great variety of the fibrous plants of India, made experiments with the fibres, and sent specimens of them to this country. Among the fibres subjected to experiment were the Brown Hemp of Bombay, the Sunn of Bengal, and different sprecies of Jute. Considerable quantities of the different kinds of Sumn and Jute were from time to time imported into this country by the East India Company. The experiments were finally discontinued in 1811 , but much raluable information was obtained regarding those and other fibrous plants during the time they were carried on.

After this period, the Company, still desirous to introduce some of these fibres into the manufactures of Britain, now and agrain imported them. Sometimes they discontinued the importation for a time, and again resumed it, and had the fibres tried by ropemakers and others in London, but with little practical result. In the case of Jute, ignorance and prejudice, and the want of having it thoroughly tested by properly qualfied parties, long kept its valuable properties from being known. As these were gradually discovered, prejudice gave way to reason, and the despised and calumniated article rose into farour, and soon took high rank among fibrous substances.

Jute is the fibre of plants of the Corchorus family, and is said to be derived from two species of it, viz.:-Corchorus olitorius and Corchorus capsularis. Both plants are common in almost every part of India, and, from the following description of them, they scem to bear considerable resemblance to each other, both in appearance while growing and in their several products.

Corchorus olitorius, Pot Herb, or Jew's Mallow, is an herbaceous annual, which in India grows to the height of from five to ten, or, under favourable circumstances, twelve or fourtecn feet. The stem is erect, smooth, cylindrical, and more or les branched toward the top. The leaves are smooth, and of a lively green colour, alternate on fout stalks, oral or oro-lanceolate in shape, with the margin dentate, and with the two lower dentilures terminated by a slender filament. The stipules are simple, awl-shaped, and of reddish colour at the base; and the peduncles or flower-stalks are one or two fluwered. The flowers 
are small, having the calyx consisting of five pieces or sepals, the corolla of five yellow petals, and the stamens numerous. Torus or nectary cup-shaped, with glands at the base of the petals. Ovary solitary, ripening into a long, nearly cylindrical capsule, ten-ribbed, six to eight times longer than it is broad, five-celled, and formed of five valves, with five terminal points. Seeds numerous, with nearly perfect transverse partitions between them.

Corchorus capsularis, or Capsular Corchorus, is also an herbaceous annual, with a straight, smooth, and cylindrical, afterwards branched stem, of from four or five, to eight, ten, or twelve feet in height. The leaves have long footstalks, and are oval, acuminate, thin, of a light green, and serrated at their margins, with the two lower serratures terminating in narrow filaments. The flowers are small, yellow, and like those of the other species in the number of their parts. The capsules are short and globose, wrinkled, and muricated, with five cells, and composed of five valves; seeds few in each cell, and without transverse partitions. Both plants flower in the rainy season, and the fruit is ripe in September and October.

The two plants are easily distinguished by the capsules or seedvessels, the one being elongated and cylindrical, and the other short and globular. The name Corchorus is from the Korkhorus of the Greeks, which was a pot-herb, and is by many supposed to have been the first described of these plants. It is still cultivated in the neighbourhood of Aleppo, and is said to be eaten as a pot-herb in Egypt and Arabia, as well as in Palestine. Ranwolf saw the Jews about Aleppo using the leaves as a potherb, hence the name of Olus Judaicum in old authors, which, by the French, is translated Mauve de Juif, and in English Jew's Mallow. It grows to the height of a couple of feet in the dry soil of Syria, and it is supposed to be the plant alluded to in Job xxx. and 4.

Dr Buchanan says he was informed that it was the latter species the young leaves of which were eaten by the natives as a sort of spinach. It would appear, however, from the best information which has been obtained on the subject, that in India the leaves of both are used as pot-herbs, and that the stems of both yield the fibre known in commerce by 
the name of Jute; and farther, that the plants are there cultivated on both of these accounts. The young leaves of the plants, though eaten and apparently relished by the natives, Hindoos and Mussulmans, as a pot-herb, have a coarse, weedy flavour, little suited to European palates.

In Sanscrit the plants are called Putta; in Bengalee the first is called Pat or Paut, the second Ghi-nalita Pat, and the fibre of both Jute. Cloth made of the fibre is called Tat, Megila, and Chotee or Choti, whence probably the name Jute has been derived. The plant or plants is by far the most extensively cultivated of all the fibrous family throughout the delta of Bengal. Its easy culture, rapid growth, and comparatively large produce, present advantages not to be overlooked by that eminently practical and economical people, the natives of Bengal.

It is generally grown, during the rainy season, on high land, or land not subject to submersion like rice land. The seeds are sown in April or May, when there is a sufficient quantity of rain to moisten the ground, on land which has been well ploughed and smoothed, and the seeds, which are sown broadcast, are then harrowed in the same manner as paddy or rice land. If sown very thick, the fibre is soft and silky, but the plants do not attain a great height, and the yield is thus lessened. When sown very thin, the plants are long and strong, and the fibre harsh. A medium between too thick and too thin sowing would thus appear best, as it yields both quantity and quality of fibre. No plant is more grateful for good cultivation than Jute, and it thrives best in a good loamy soil, well manured, or which has been well manured under a former crop. A hot and moderately rainy season suits it best, but excessive rains or bad drainage injure or deteriorate it. In this respect it is a precarious and delicate crop, but otherwise it presents the advantage of affording a more valuable return from land at that season than any other crop the cultivator can grow. It requires to be carefully reeded when young, the best time being when the plants are about a foot and a half high, after which it acquires strength enough to keep down all intruders. A poor crop, or one which has suffered from excessive rains, will only attain a height of from three to six feet, but 
with heat and a due quantity of rain, in a good well manured soil, it attains a height of from ten to twelve or even fourteen feet. The stems vary from one to two inches in circumference, and some of them, under very favourable circumstances, even exceed this thickness.

Heat and moisture are the great provocatives to a luxuriant crop, and in many districts appliances are adopted by the natives to increase both. The lands in which Jute is grown are generally nearly level, and in order to conserve the rain it is divided into small plots by miniature mud dykes, from six to nine or twelve inches in height. After the crop has risen about three or four feet above the ground, and after the weeding is finished, the gaps in the dykes are filled up, and the rain is retained and allowed to run over the top of the embankments. The heat of the sun raises the temperature of the water in these artificial reservoirs to perhaps 100 degrees or more, the while retaining considerable heat in the soil below. This forces on the growth of the plant with great rapidity, and makes it attain a height which, under less favourable circumstances, it never could have reached. Before the plant is cut the water is run off and the land allowed to dry.

Where the soil is naturally damp and cold this irrigation is not needful ; indeed it would be injurious to the Jute, and retard rather than encourage its growth. Should the rains be excessively heavy, the water flows over the banks so quickly that it has no time to become heated, and it sours the ground, and seriously injures the plant. Even when more than usually heavy, although not excessively so, there is not enough heat produced to stimulate the growth of the crops sufficiently, and little benefit accrues. When the season is very dry, the little reservoirs do not retain depth of water to keep the temperature of both the water and the ground. below it uniform night and day, and the full advantage of the system is not realized. Moderate rains and a warm summer suit Jute best, and are highly favourable to this mode of culture, and fortunately they are the rule and the extremes the exception.

The practice of forcing on the growth of Jute in this manner has its defects as well as its advantages. Much of the Jute imported inio this country has a root end, in many cases both 
long and harsh, which is not easily softened and broken down, and without this it is difficult to spin it into the lighter sizes of yarn. Some parcels have also what are called runners, that is, hard stems, the fibres of which are not easily separited, and therefore much disliked by the spinner. The little pools or reservoirs are the cause of both. 'The lower part of the stem of the plant which has been under the water, or in close proximity to it, imbibes a mucilaginous matter from the water, which hardens the natural gluten of the plant and cements the fibres together. 'This does not come off in any of the subsequent processes, and it remains of a dark brown colour, and is what is called the root, although it is not really the root of the plant, having been grown above the ground, but under the water. When any of the plants get bent by wind or other cause and fall down in the water (and sometimes quantities of it may be wholly bent or broken down and lodged in the water), the portions which are so immersed become saturated with the mucus in the water, which fastens the gum in the plant, glues the fibres together, and forms runners. This cause accounts for the fact that sometimes only a single runner or two are found in a bale, and at other times whole strikes of them are met with. Sometimes they extend down only a portion of the fibre, and at other times throughout its whole length. When the stalk is bent the juices eannot ascend properly to perfect the plant, and the fibres do not attain maturity. Such stems are not so good as others, even although there was no mucilage upon them; but were some simple means adopted to remove the glutinous matter, it would probably improve their quality.

The crop being ripe for cutting, the plants are cut down close to the roots, their tops clipped off, and they are tied up in bundles of from fifty to a hundred. Ten, fifteen, or more of these bundles are then laid in a shallow tank or reservoir of water, or in some neighbouring ditch, over them a quantity of turf or clods are placed to make them sink in the water, and to keep them covered until they are sufficiently retted. Thiey are generally allowed to remain in the water for eight or ten days, and sometimes longer, according to the state of the weather, during which time they are visited daily by the cultivator, who tries the bark with his nails, until he finds that decomposition has arrived at the proper point. 
In preparing Jute intended for export, the water retting process is pushed to its utmost limits, short of actually destroying the fibre by excessive putrefaction. This is done in order to obtain that thoroughly detached silky character of fibre, which is so much valued in this country. When the bark separates easily, and the stalk and fibres become soft, it is ready for being removed from the water. If steeped too long the Jute always suffers more or less in strength, and an extra day or two would totally destroy it. Jute prepared for native consumption is darker coloured and not so clean, but it is more durable than that which is grown specially for shipment. It is, however, cheaper, as the yield per acre is said to be much larger.

The proper time for removing the Jute from the steep having arrived, the weight upon the stalks is removed and the bundles untied. The native operator, frequently a boy or a young man, takes as many of the stems or plants in his hand as he can grasp, and removing a small portion of the bark from the ends next the roots, and grasping them together, he strikes them gently against a board placed before him in a slanting position, and with a little management he strips off the whole from end to end, without breaking either stem or fibre. Having thus got a certain quantity into this half prepared state, he next proceeds to wash off. This is done by taking a large handful, and, swinging it round his head, the while, standing up to the middle in water, he dashes it repeatedly against the surface of the water, drawing it through towards him, to wash off the impurities; then with a dexterous throw he fans it out on the suriace of the water, and carefully picks off all remaining black spots or other extraneous matter. It is now wrung out so as to remove as much water as possible, and then hung up on lines prepared on the spot, or over bamboos, to dry in the sun. The Jute is afterwards cleaned, and made up in bundles of from one to two maunds for the market, and that it is well cleaned is generally acknowledged, very little of the husk or stalk being ever left upon the Jute.

The produce per acre is variously stated at from 400 to 700 lb., but it is very probable that the latter quantity is nearest the truth, if not short of it. Were the land sufficiently enriched with manure suited to the nature of the plant, and properly pre- 
pared for the seed bed, the best seed selected and sown, and the cultivation in every respect intelligently attended to, there is no doubt that the rich soil of the delta of the Ganges, Burhampooter, and other rivers where the plant is chiefly grown, might be made to yield a greater return. So in like manner, by the same means, the staple might be improved greatly in colour, strength, and fineness of fibre, and the root ends better freed from the hard woody bark which is so detrimental to its spinning properties. Hitherto little has been done to instruct the natives in the cultivation of the plant, and they still grow it much in the same way as their ancestors did a thousand years ago. The preference which a strong, well cleaned silky parcel gets in the bazaars, and the relatively higher price which it brings, so far stimulates the growers to produce such Jute; but this is not sufficient to obtain the desired end, although there is no doubt some improvement has taken place of late.

Some of the Jute imported is found, on opening the bales, to be greatly discoloured, and so much weakened as to be scarcely fit for spinning. To a great extent this is caused by carelessness in the preparation. After the fibre has been freed from the stem and washed, it ought to be immediately hung up to dry, and never packed up into bundles until thoroughly dried. Too often, however, the handfuls, after being washed, are laid down wet on the damp ground, and allowed to lie there for a day or two, and sometimes longer. In this stage the great warmth of the climate speedily causes the wet fibre to heat, and this weakens and discolours it. It may not be practicable in all cases to have it removed direct from the stream or pond in which it is washed to the drying lines, but when possible this should invariably be done to preserve the fibre.

Sometimes on opening the bales the Jute is found to be very much soiled with clay or other earthy matter. This is caused partly by laying it down on the wet soil after washing, and before hanging it up to dry ; but oftener by washing it in muddy water. It may not be possible at all times to get a sufficient quantity of pure water in which to wash the Jute, but every effort should be made to keep it clean in the various processes it undergoes. Earthy matter on the fibre greatly injures the machinery in the operation of spinning, and it is therefore 
seriously objected to by the spinner, and lessens the market value of the Jute.

Jute has now become an article of prime necessity in the manufactures of this country, and everything ought to be done to increase the production, and to improve the quality, that money and skill can accomplish. There are many wealthy houses in Calcutta who have a deep interest in the trade, and it is their duty, and it would be greatly for their interest, at once to take steps to instruct the natives in the cultivation of the plant, and the preparation of the fibre. The merchants who are buying it daily must know how this could be best done, but done it ought to be, and that without delay What is wanted from the growers is a fine pearly white colour, uniform throughout the whole length of the strike, a finer fibre combined with greater strength, and an abundant supply.

In order to get the best quality of fibre, the Jute must be cut shortly after it has flowered, which is from the middle of July to the middle of September. It generally attains this stage in about 100 days after being sown, but of course, it is to some extent dependent on the weather, which is not uniform in India any more than here. Some plants are allowed to stand to ripen the seed for a future crop, and then cut down after they have attained maturity. After the removal of the Jute from the ground, the fields are prepared for a winter crop, such as tobacco, mustard, or other plants, for which, from their elevation and the nature of the soil, they may be most suitable.

Specimen plants of Jute have been grown in Dundee and neighbourhood. About ten years ago, James Crichton of London sent a few seeds to Alexander Easson, Dundee, and to others. Mr Easson raised some plants in his green-house, and exhibited them in the Baltic or Exchange Reading Room there for some days. They grew to the height of three or four feet, were graceful plants and much admired by all who saw them.

The fibre is not the only valuable part of the Jute plant, as the stalks or stems, which are applied to a multitude of uses by the natives, are of great importance to them. They are somewhat like willow switches, beautifully white, straight, and light, though rather brittle. They are made into charcoal for gunpowder and freworks, and they are used for fences, especially 
for the basket-work enclosures in which the betel-pepper vine is cultivated, and which is universally consumed by all, nabob and peasant alike. 'These stallis are also used largely in supplyingr fuel for burning the myriads of worms which infest the bottoms and sides of the native craft, and which, if not so destroyed, would speedily render these frail vessels nothing but riddles.

Jute, when first prepared, is of a beautiful pearly white, the very colour which is most prized by spiuners, but it gradually changes to fawn, and then to light brown. 'The causes of these changes are more or less inherent in the fibre itself, and to this is ascribed the difficulty there is in bleaching Jute. If this property could be changed it would make the article much more valuable in Dundee, but perhaps it could not be altogether obviated. It has been suggested that the water-retting should be dispensed with, and a process adopted of preparing the fibre without steeping. This might accomplish the desired result, at all events it is well worth trying, as it could be done without risk to the fibre, and at trifling cost.

A very large proportion of the Jute grown in Bengal is made into cloth in the districts where it is cultivated, and this industry forms the grand domestic manufacture of all the populous eastern districts of Lower Bengal. It pervales all classes, and penetrates into every household, almost every one, man, woman, and child, being in some way engaged in it. Boatmen, husbandmen, palankeen carriers, domestic scrvants, every one in fict, being Hindoos-for Mussulmans spin cotton only-pass their leisure moments, distaff in hand, spinningr gunny twist. It is spun by the takur and dhara, the former being a kind of spindle, which is turned upon the thigh or the sole of the foot, and the latter a reel, on which the thread, when sufficiently twisted, is wound up. Another lind of spinning machine, called a ghurghurea, is occasionally used. A bunch of the raw material is hung up in every farmer's house, or on the protruding stick of a thatched roof, and, every one who has leisure forms with these spindles some coarse pack-thread, of which ropes are twisted for the use of the farm. The lower Hindoo castes from this pack-thread spin a finer thread for being made into cloth, and, there being a loom in nearly every house, very much of it is woren by the women of the lower 
class of people. It is especially the employment of the Hindoo widow, as it enables her to earn her bread without being a burden on her family.

The cloth thus made is of various qualities, such as clothing for the family, especially the women, a great proportion of whom on all the eastern frontier wear almost nothing else, coarse fabrics, bedding, rice and sugar bags, sacking, packsheet, \&c., \&c. Much of it is woven into short lengths, and very narrow widths, two or three of which are sometimes sewed into one piece before they are sold. That intended for rice and sugar bags is made about six feet long, and from 24 to 27 inches wide, and doubled. A considerable quantity of Jute yarn is dyed and woven into cloth for various local purposes, and some of it is also sent out of the district.

The principal places where Chotee, or Jute cloth for gunny bags is made, are within a radius of perhaps 150 to 200 miles around Dacca, and there both labour and land are remarkably cheap. The short staple, common Jute, is generally consumed in the local manufacture, the finer and long stapled being reserved for the export trade. These causes enable gunny cloth and bags to be sold almost as cheap as the raw material, which creates an immense demand for them in nearly every market of the world.

The portion of the stem next the root, which is held in the hand while removing the fibre from the stalks, is more or less contaminated with bark and other impurities. About nine inches is generally cut off on this account, and these ends are either sold to the papermakers, or made into a coarse cloth, which used to be sent in large quantities to America, for cotton bagging and similar purposes. The manufacture of Jute whisky from these ends was tried experimentally, by subjecting them to the process of conversion into sugar with sulphuric acid, and afterwards fermenting. The produce had much resemblance to grain whisky. Some of these ends or roots are now regularly imported into Britain.

The Jute intended for sale in Calcutta, is taken from the districts where it is grown in boats of various kinds, tied up, as already mentioned, in bundles of one or two maunds. From some of the districts the voyage is long and tedious, but in a 
short time the trausit will bo much facilitated by the opening up of railways. Already one is opened for 110 miles to Kooshtee, on the Ganges, which brings Dacea nearer to Calcutta by five days, and it is proposed to run a steamer from Kooshtee to Serajgunge, which is one of the great Jute districts. On the way to Calcutta very little care is taken of the Jute, and it frequently gets wet in the boats, which does it material injury by weakening the fibre. On its arrival there it is removed from the boats to the bazaars, and built up in tiers ready for sale.

The business in the bazaars is all done through brokers, very much as the sale of produce is carried on by the brokers in Mincing Lane, London. A merchant cannot himself meet the ryots or sellers, but must employ a broker to purchase what ho wants, but he has no brokerage to pay, this being done by the seller. After the Jute is purchased, what is intended for export is removed from the bazaars to public packing establishments, of which there are numbers in Calcutta. There it is carefully selected by inspectors employed by the merchants for this purpose, and assorted into such classes as may be wished. All the larger houses have distinguishing marks of their own for each quality, and great care is generally taken to have each mark as uniform throughout as possible. Of course, if the crop has been a bad one, or if the Jute is generally inferior, the firstclass, although bearing a relative proportion to the other classes of the same season's Jute, will be much inferior to the same class in a scason when the crop is superior. Before a buyer can therefore judge of the quality by the mark, it is absolutely necessary to know the character of the season's crop; but, this known, a pretty correct judgment can then be formed regarding the quality of the standard marks.

After selection, the Jute is packed into bales of about 300 lbs. each, the strikes being carefully laid with both roots and crops inside. The pressure is applied by powerful screws, generally placed in a loft over the press, and worked by manual labour. When sufficiently hard pressed, and the ropes put round, the bales are turned out to make way for others. The packer is usually taken bound to compress the bales until five of them do not exceed a ton of 52 cubic feet in bulk, and if this is not done he is charged with the extra freight, which the loose packing involves. After being packed the bales are sent direct 
to the ship, or warehoused until they are wanted for shipment. Some Jute is packed in the country before being brought down to Calcutta, where it can be done cheaper than in that city, and it is known as native packed. Sometimes the quality of this Jute turns out pretty well, but no dependence can be placed upon its uniformity, it not being so well selected nor not so carefully packed as what is done in the regular way. In consesequence of this it is not so well liked in this market, and it commands a proportionally lower price.

About 1300 of the bundles of Jute, as brought down to Calcutta, are required to pack 300 of the bales as exported. Although the bales as packed only weigh about $300 \mathrm{lb}$. each, it requires about $340 \mathrm{lb}$. of the bazaar or rough Jute to make one of them, the balance being rejections, refuse, waste, \&c.

Hydraulic presses would pack the Jute well, but they have not yet been generally adopted for this purpose, as labour is so cheap in India, and it is difficult to get native customs changed. There is little doubt, however, that at no distant day they will be generally used, as they would compress the Jute better, are far less cumbrous, and much more convenient than the hitherto almost universal screw.

The greater part of the Jute for this country has hitherto been shipped either to London or Liverpool, which are the great depôts for the article. Sometimes orders are sent out to Calcutta by merchants or spinners, who get the Jute sent direct to them, but the great bulk of the quantity exported is brought on ship's account, being bought to fill up, or to put the vessel into proper sailing trim. Entire, or almost entire, cargoes are sometimes brought, but it is too light for a full cargo, and some dead weight is required to steady the ship, and put her into good sailing trim. Much of the Jute imported into London and Liverpool is sold by brokers, who are the medium between the importers and the purchasers. In both cities parcels are occasionally sold to arrive, when they are transferred direct from the ship to the buyer if the purchase money has been settled. The bulk of the importation is, however, warehoused, the bales being weighed and labelled by the employees of the Dock Companies as landed, which weight is taken in the sale of the parcel, even although, as is frequently the case when it is long in warehouse, the weight should go in considerably. 
Parcels are frequently sold privately by the brokers, some. times to speculators and sometimes to the trade direct, but very much of the Jute imported is sold at the public sales, which take place almost every week, in Lonlon on Wednesday, and in Liverpool generally on 'Thursday. In London the public sales are held in a sale room in Mineing Lane, and they are conducted by the respective brokers who have the sale of the Jute, and who are licensed anctioneers. Cantalogues of the parcels to be exposed, made up in lots of ten bales, are sent round among the agents and merchants a day or two before the sale. The Jute is on show before the sale, and the warchouse in which it is stored is stated in the catalogue, to enable intending buyers to inspect it, make up their mind as to its value, and come prepared to operate. 'The terms are stated in the catalogue, and they are usually three months prompt, which means that the Jute may remain for that period in warehouse frec of expense to the purchaser; but it must be paid for in full before remoral, and delivery can be got at any time during the currency of the prompt. Immediately after the sale fifteen per cent of the purchase money must be paid as a deposit, in security for the fulfilment of the bargain, and when the balance is paid the dock warrants, which were given to the importer when the Jute was warehoused, are handed over to the purchaser, and these transfer the ownership of the Jute to the holder of them.

The auction sales are conducted with great regularity and rapidity, on certain rules well understood between the selling and buying brokers, the whole business being done by them. Any merchant may buy, but the deposit must be then and there paid down, and as the selling broker charges him a buying commission or brokerage, the merchant has no saving by not employing a broker to purchase for him. The whole business is therefore transacted by the brokers, and as they are appointed by the Corporation of the city, and their number limited, the trade is a very profitable one when they get into a good con. nection.

The buying and selling brokers each charge a commission of one-half per cent., and when the one broker, as is frequently the case, acts in both capacities, he gets both commissions, or one per cent. on the transaction. 
In London, the Jute sold by auction is generally in lots of ten bales, and on this one shilling of lot money is usually charged. A draft of one pound a bale is allowed on the Jute bought there.

In Liverpool the terms are cash, and there is no charge made for brokerage on the Jute bought, either at auction or by private sale. Five pounds a bale of tare, and one pound a bale of tret, are allowed on all Jute bought there; the terms are therefore more favourable to the buyer than those of London.

Both in London and Liverpool there are a number of agents who, on receiving orders to purchase from their constituents in Dundee and elsewhere, examine the parcels on sale, and buy from the selling broker privately, or through the medium of another broker at the public sales. For this they charge a commission of one per cent. with fourpence a bale in Liverpool, and five shillings a ton in London. Some of them do not confine themselves to the regular agency business, but become merchants, and buy on their own account when prices are considered cheap, in the hope of selling at a profit farther on. This they are enabled to do in London without much capital, through the instrumentality of the system of prompts; but the practice is disliked by the trade in Dundee, as it induces speculation, and frequently raises the price unnecessarily to the consumer. It would therefore be more for the interest of all parties that the agents were agents in fact as well as in name, as it would increase confidence between them and their constituents, and keep the trade in its proper channel.

Many of the leading Dundee spinners now purchase their supplies direct from London or Liverpool, but others prefer to see the Jute before they buy it, because they can thus get a parcel of the precise quality wanted. This they cannot make sure of otherwise, scarcely any of the marks being uniformly the same throughout the entire season, although the larger Calcutta shipping houses try to have them as nearly alike as possible. Some spinners, from necessity or other reasons, usually purchase in that market from dealers or agents, who buy in England on their own account, or who get it sent for sale by the merchants there. These sellers are generally content with so very small a profit, that in many cases consumers are, taking everything into 
account, better to buy on the spot thun to send their money to the south to purchase there.

The better way and the most profitable, both for importers and consumers, would be to have the Jute brought direct from Calclitta to Dundee, as it would save intermediate charges, amounting on the average to about two pounds a ton.

About the year 1840, the "Selma," belonging to Dundee owners, arrived from Calcutta with a cargo of Jute and other produce, being the first Jute which was ever brought from Calcutta to Dundee direct. Since then, Allan Edward, and David Martin and Co., merchants, and Gilroy, Brothers, and Co., spinners there, have imported various cargoes direct, and one cargo belonging to Messrs Martin, and intended for Dundee, was burned on the voyage. Had these merchants received sufficient encouragement they would have prosecuted the trade, but spinners were callous and indifferent, and they discontinued it. About twenty years ago, Balfour and Meldrum, merchants, Dundee, ordered a considerable quantity of Jute from Calcutta, and had it brought into London. It was sold there in the usual way, but the result was not satisfactory, and the order was not repeated. Other Dundee parties have from time to time bought Jute in Calcutta, and brought it to Great Britain, but the total quantity so imported has not been great. Of late considerably more business has been done in this way for Dundee account, which has resulted well for the importers. This season (1863), several complete cargoes of Jute from Calcutta to Dundee have already arrived there, and others are on their way to that port. 'The high price at which the article has ruled in Britain throughout the year has made these direct shipments profitable speculations to the importers. Many of the spinners in Dundee are now large consumers of Jute, and several of them are possessed of sufficient capital to enable them to import a great part of what they require for their own consumption. The profits made on the direct importations this season will probably be a sufficient stimulus to those who have embarked in the trade to prosecute it more extensively, and also to induce others to enter into it. If so, the character of the trade will in a few years be completely changed, and the London and Liverpool branches of it loose much of their present importance. 


\section{2.-The Culture of Jute in the Factory.}

Having now given an account of the culture of Jute; and traced its progress from the time it is sown in the rich soil and sunny clime of India, until it is deposited in the works of the consumers, a short sketch of its introduction into Dundee, and subsequent history in connection with the trade of the district,-in short, of its culture in the Factory, may not be uninteresting. Although its introduction is of very recent date, there is some doubt about the precise period when the first bales were received, but as they can scarcely be said to have been spun, this is of the less importance. The date and the mode of its first incorporation into the staple trade of the town have been ascertained with more accuracy, and are believed to be correct.

The East India Company, as already mentioned, imported Jute in small quantities so long ago as 1796-7, and they also sent some of it to Hamburg and to America at the same period. After that date the Company imported it now and again, mostly in small quantities, but for many years it made no progress in the manufactures of this country, and remained comparatively unknown. This is the more surprising when its adaptation for textile fabrics was so well known in Bengal many ages ago, and when gunny cloth and bags made of it there were exported from Calcutta to New South Wales, China, America, and other places, nearly seventy years ago. At that period the Company, having become more alive than they had previously been to the importance of the fibres of India, experimented upon them in several places and in various ways. If they had then got some intelligent manufacturers of coarse linens in Dundee to experiment upon Jute in a thoroughly practical manner, its value might have been sooner known, but that was not done. The early importations of it were mostly consumed in the neighbourhood of London, having been made into door mats, ropes, and other articles, for which it was found to be very suitable.

Some of this Jute found its way at an early period to Abingdon in Oxfordshire, a town which for centuries has been famous for its sacking, twines, \&c. There it was spun by hand, or by 
what is called shade-spinning, and used to a small extent in the manufactures of the town. At Abingdon woollen carpeting was also manufactured, and seeing that Jute yarn had some resemblance to wrollen yarn, the manufacturers there had it dyed, and made into carpeting. So far as known they were therefore the first in this comntry to spin and manufacture Juto into cloth, and although the date when they first began to use it has not been ascertained, it must be abont forty years ago, and it may have been even a few years earlier.

In 1823, or early in 1824, the late Thomas Henry of London, sent a bale or two of Jute to the late George Leighton, Dundee, but any experiments which may have been made with it produced no practical result. About the same period a few bales (perhaps of same parcel) of Jute of fine quality, imported into London by Gilmore and Co., was sent by A. B. Auderson, merchant there, to his brother William, then one of the most extensive and intelligent manufacturers of fine and coarse Linens in Dundee. $\mathrm{Mr}$ Anderson had previously had experience of East India Hemps, more especially Sunn, which he had manufactured largely in contract with Maberly and Co., for Government. His mother, like most of the old ladies in those days of hand-spinning, was fond of her wheel, and as she was a capital spinster, he got her to test the spinning qualities of the Jute. On being well heckled, she found it capable of being spun into yarn of about a pound a spindle, or 48 lea, but she was sadly rexed at its want of strength. The tow she was unable to form into a thread at all satisfactory to herself, the fibres being so hard and dry that they resisted all her efforts to combine them thoroughly. Indeed, the first tow could only be twisted into yarn or weft to the coarsest fabrics.

At that period all the Baltic Hemp longs and tows, and much of the coarser Flax tows, were spun entirely by hand. $\mathrm{Mr}$ Anderson had this Jute heckled in his Factory, as was then usual with both Hemp and Flax. The better to test it, he had part of the heckled Jute shade-spun in a rope-walk, and part was given to several spinners to be spun on the common hand-wheel. The tow was spun from the waist, as was then customary with Hemp tow and other coarse fibres, and not from a distaff. The longs. or line yarn he used for weft to low priced padding canvas, and 上 2 
the tow yarn for weft to nail bagging and other heavy fabrics. Mr Anderson did not lose sight of the fibre. On the contrary, his nephew, James Crichton, of London and Dundee, states that he occasionally had small quantities of it spun by hand, and made into sacking and such fabrics. Considerable difficulty was then experienced in the sale of goods suspected to have Jute in them, without a warranty that they were entirely free from it. Part of this dislike arose from the mistaken notion that cloth made of the fibre will not stand water, an idea not yet wholly extinct among certain parties, although it is a well ascertained fact that Jute goods resist wet longer than almost any other textile fabric.

It must not be forgotten that, even at this late period, Flax spinning by power was comparatively in its infancy, and that efforts were then making to perfect it. The new fibre, Jute, wanted strength to render it suitable for being used as a substitute for either Flax or Hemp. Sunn, it was known, lost much of its strength when wet, and it was supposed that Jute, being also an East India fibre, would be of a like nature, and have the same tendency. It only appeared in limited quantity, and as the bad reputation of Sunn was reflected on Jute, it was not thought worthy of much attention, and, so far as can be ascertained, it was not tried by any mill-spinner on flax spinning machinery until a later period, some account of which will now be given.

Thomas Neish, now one of the oldest merchants in Dundee, received a small consignment of Jute from London, he thinks about the year 1822. He endeavoured to induce some of the spinners to try it over their machinery, but could not get them to make the attempt. It lay in his warehouse for a long time without buyers at any price, until at length he got Bell and Balfour, flax-spinners, to consent to take it at $£ 11$ a ton. They experimented upon it to a small extent, perhaps in 1825 or 1826 , but were unable to spin it into yarn, and the bulk was ultimately disposed of for the purpose of being made into door mats and such articles. The nature of Jute was unknown, and the spinning machinery then in use was ill adapted for such a fibre. Had an intelligent mind been perseveringly applied to it, the difficulties which the imperfect machinery of the 
day presented might have been gradually overcome. Juto did not yet possess much importance, the trials made of it were superficial, and, as might have been expected, they ended in failure. Some years elapsed before any farther attempts were made to spin Jute by machinery, and again the sume parties were to some extent the pioneers of the manufucture.

About the beginning of 1832, Mr Neish got another consignment of Jute from James Scott of London, and this parcel may be called the foundation of the Jute manufacturo in Dundee. He offered the Jute to many of the spinners in that town, but so prejudiced were they in farour of existing materials, and so averse to introduce a new and comparatively unknown fibre, that he could not prevail upon them to try it. $\Lambda$ t length, after repeated efforts, he succeeded in getting Balfour and Meldrum, successors to Bell and Balfour, who had tried the fibre before, to take a little of it, and they experimented upon it in Chapelshade Works. These experiments were not made on an extensive scale, but they were this time persevered in assiduously, and ultimately proved successful. From about the end of that year the firm span a little Jute regularly, and the progress they made with it will be subsequently referred to.

The great instrument, however, in the introduction of Jute into the trade was James Watt, jun., merchant. Mr Neish got him to make trial of ten bales, and it was invoiced to him on 24th July 1832, at $£ 19$ a ton, less $2 \frac{1}{2}$ per cent. discount for cash. In $1833 \mathrm{Mr}$ Neish received other parcels of Jute for sale, and from that period he has continued in the trade, often dealing largely in the article. He was thus the first merchant who had Jute for sale in Dundee, and it was through his persevering efforts to get parties to make trial of the fibre that it was introduced into the trade of the town. The bantling of 1832-3 has in thirty years attained a goodly stature, and Mr Neish and Mr Watt have good reason to look with pride on the now prodigious extent of a trade which they were so instrumental in establishing.

Mr Watt was a large buyer of linens, and he endearoured to get some of the spinners and manufacturers to try the Jute, but the great length of the fibre was thought to be an insuperable barrier in the way of its being spun over Flax spinning machi- 
nery, and none would so much as attempt it. Mr Watt was a sagacious, intelligent man, and from a careful examination of the fibre, he was convinced of its being suitable for the manufacture of cotton bagging, then an important article in the trade of the town, and for similar fabrics. He therefore got a person to erect an old breaker card at Liff, where he sent the Jute in bales, and had it torn down and returned teased, or formed into tow, for which process he paid at first about $£ 5$ a ton. $\mathrm{Mr}$ Watt gave out portions of this teased Jute to several spinners, most of whom reported unfavourably of it.

These repeated rebuffs and disappointments did not, however, discourage $\mathrm{Mr}$ Watt. Indeed he was not the man to be baffled where his judgment told him he was right, and the experiments he had made only convinced him the more of the admirable adaptability of Jute for some of the manufactures of the district. Instead, therefore, of giving it up in despair, as many might have done, he went into it with spirit, showing that he had strong confidence in its ultimate success. How fortunate for the trade of Dundee that such a man as Mr Watt took Jute by the hand, and carried it through the shoals and quicksands of its early days! But for his shrewdness, his energy, and his indomitable perseverance, the obstacles which ignorance, prejudice, and indifference, threw in the way of the introduction of this invaluable fibre might have triumphed, and Dundee still have been without its Jute. Had this been the case the town would have made comparatively slow progress, as sufficient Flax material could not have been got to employ anything like the extent of machinery which is now at work. Providence had determined otherwise, and there is never an instrument wanting to work out its decrees.

In the autumn of 1832, Mr Watt bought from Robert Baxter of London, 53 bales of Jute, which he brought to Dundee. It was teased in the same way as the ten bales had been, and with better results in the spinning. He then bought from Trueman and Cook of London, 1351 bales, half of which was invoiced at $£ 1510$ s, and half at $£ 16$ a ton. It was landed at Dundee in October and November of that year.

By this time Mr Watt had got several of the spinners to try his teased Jute, and it would appear that the late William 
Boyack, then the most extensive spinner in Dundee, must have thought well of the article, as he bought 502 bales from $\mathrm{Mr}$ Watt on 17 th Nov. 1832 , at $£ 1910$ s a ton. He was therefore the first spinner who went heartily into the trade, and who span Jute on an extensive scale. On 28th Nov. the late John Halley bought 200 bales, and on 7th Dec. John Haddon

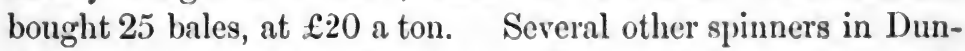
dee, and James Aytoun of Kirkaldy, shortly afterwards took small parcels of it at same price, and within a short time $\mathrm{Mr}$ Watt appears to have disposed of the whole quantity.

Mr Watt went into the market again in the beginning of 1833, having bought from David Campbell of Liverpool, 1639 bales of Jute, 526 of which were invoiced at $£ 1410$ s, and 1113 at $£ 1415$ s a ton. It was brought to Dundee, and landed in March 1833. On 24th April Mr Boyack bought 300 bales of this parcel at $£ 175$ s, and same day Mr Halley bought 102 bales at $£ 18$ a ton. On 31st August Andrew Low and Son bought 140 bales at $£ 1610$ s a ton, and subsequently the late Daniel Duff and others bought part of it. Mr Watt the while continued to have part of his Jute teased as before, and this he had spun and manufactured into bagging and other fabrics. This parcel did not, however, go off well, and part of it remained on hand for a considerable time.

On 13th January 1835, a large warehouse in Dock Street, Dundee, belonging to $\mathrm{Mr}$ Watt, took fire, and was burned down. He had about 300 tons of material, chiefly Jute, stored in the warehouse. Unfortunately he was not insured, and his loss by this calamity was very heavy. The débris of the fire turned out about 130 tons of Jute.

Mr Boyack, Mr Halley, and others, who first bought Jute from Mr Watt, had it teased, and span it, mixed with Flax codilla, into the heavier sizes of yarn for weft to bagging and sacking. The late James Grimond of Oakbank, Blairgowrie, made trial of Jute early. He tore it down on the heckle and succeeded in spinning it mixed with tow into 6 or $7 \mathrm{lb}$. yarn for weft to Osnaburgs, Hessian Sheetings, \&c., and long continued to use a little of it in this manner. 'The yarn spun from the mixture was not liked, and did not find a ready market. Most people shook their head at it, declared the process a. 
fraud and declined to use the mixed yarn. The presence of Jute in yarn was considered objectionable, and manufacturers unanimously disapproved of it. Some of the parties who first span the Jute used it sparingly and by stealth, and a considerable quantity of mixed yarn was in this way used unwittingly. In every instance where the yarn was known to have any of this fibre in it, it was disliked, if not altogether declined. It will thus be seen that the introduction of Jute was uphill work to all who tried it, and for a time, from the bad odour of the mixed yarn, it was generally unprofitable to those who first began to spin it.

In the beginning of 1833 the late Alexander Rowan of Dundee, brought from London some specimens of Abingdon hand-spun Jute line yarn, and of cloth made therefrom, and he got the late James Taws to spin Jute yarn in imitation of these samples, which was sent in small quantities to London. Mr Taws began to spin pure Jute in the summer of 1833, and perhaps he was the first spinner who did so. After commencing to spin it he continued afterwards to do so to a greater or less extent. In the early days of his Jute spinning he bought Jute at about $£ 12$ a ton, and span it into $24 \mathrm{lb}$. yarn, for which he got $4 \mathrm{~d}$ a pound-a very handsome return for his capital and labour.

Mr Rowan had strong faith in Jute, and he was in no small degree instrumental in getting it introduced into Dundee. Towards the autumn of 1833 he got Balfour and Meldrum to spin Jute line yarn, and to make it into twofold and threefold twist for him. These gentlemen, as already mentioned, had commenced to experiment upon it the previous year; but, although they persevered, they did not prosecute the subject on a large scale. Ultimately they succeeded in spinning from 4 to $6 \mathrm{lb}$. Jute line yarn; and they were the first to do so and to make Jute twist in Dundee. Perhaps to this circumstance may be attributed the introduction of the manufacture of Jute carpeting into the town.

Some of the yarn spun in Abingdon, of which Mr Rowan brought samples tọ Dundee, was dyed, and among the specimens of cloth were carpeting made of the dyed Jute yarn. The Abingdon manufacturers appear therefore to have been not only the first 
makers of plain Jute cloth in this country, but also of Jute carpeting.

From a very remote period some of the Jute yarn spun in India has been dyed, and it is probable that some of the yarn or cloth dyed in India may have found its way to London and been seen by the Abingdon people. In this way the conception of Jute carpeting may have been suggested to them; but, however got, they were not slow to follow up the idea and turn it to practical account.

Jute is one of the most easily dyed fibres known, and the colours it takes on are bright and beautiful. The common dyes are quickly applied, but they are very fugitive, and when exposed to the sun's rays soon become faint and dull. By the common process the colouring matter strikes little more than the outside of the fibre, and, as it were, paints it, and this mode of dyeing requires little material, and is done at small cost. The fibres of Jute do not subdivide so minutely as Flax, and they are of a hard dry nature, and to a considerable extent impervious to moisture. It therefore requires a more complex process to make the colouring materials thoroughly penetrate the fibre, so as to make the dye lasting. This can, however, be accomplished, and the better class of goods made of dyed Jute undergo this process, which makes the colours both brighter and faster. It is hardly possible to make every colour perfectly fast, although some of them are as durable as those upon other materials.

Jute is very readily brougint to a rich cream colour either in the fibre, in yarn, or in cloth. It is, however, very difficult to bring it to a full white without injuring the strength of the fibre. Many experiments have from time to time been made to bleach Jute, but at best they have been only partially successful, and it may be said that a perfect white has never yet been attained without impairing strength. Fresh sound Jute of fine quality can, without danger, be brought to a moderate degree of whiteness; but, as the fibre gets older, exposure to the atmosphere changes it to a browner tinge, and it then becomes more difficult to bleach. To describe the materials employed, or the mode of dyeing or bleaching Jute yarn, is unnecessary. The latter does not differ much from the bleaching of linen yarn elsewhere detailed, and it is dyed into so many colours that a description of the 
process of each would take up too much space. Nearly every dyer employs a method of his own, and therefore a general description would be unprofitable.

Towards the end of 1833 the samples of the Abingdon manufacture, and the progress which had then been made in spinning the fibre here, caused James Neish of "The Laws," then a manufacturer in Dundee, to turn his attention to the manufacture of Jute carpeting. A consignment, composed of some of his earliest productions, was sent to New York; but his agents neglected it for about a year, and then sent it to an auction sale. At the sale, cloth 18 inches in width brought the very handsome price of 60 cents a yard, which would return him a profit of from four to five hundred per cent. Notwithstanding the profitable return from the first American consignment of Jute carpeting, the progress of the manufacture was slow and uncertain. No one in Dundee understood the dyeing of the yarns for fine colours, and they were sent to Glasgow to be dyed and then taken back to Dundee to be woven, which greatly increased the cost of the carpeting. The demand came in fits and starts, being at one time active and at another and for long periods quite stagnant. The manufacture was thus at times flattering, and at others very discouraging, but Mr Neish persevered and was ultimately rewarded with a splendid success.

The author began the manufacture of Jute carpeting in May 1835. On 20th April he bought 19 bales of Jute from the late Hugh Samson, at $£ 1415 \mathrm{~s}$ a ton, and on 18th May a farther quantity of 42 bales at $£ 145 \mathrm{~s}$. He had it heckled, and sold the produce to the late David Lindsay, flaxspinner, the dressed longs at $£ 236 \mathrm{~s} 8 \mathrm{~d}$, and the tow at $£ 17$ a ton, taking back the yarn at $4 \mathrm{~s} 9 \mathrm{~d}$ a spindle for $11 \mathrm{lb}$. line, and $5 \mathrm{~d}$ a pound for $8 \mathrm{lb}$. line twisted two-fold. The Jute weft for the carpeting then cost from $3 \frac{1}{2} \mathrm{~d}$ to $4 \mathrm{~d}$ a pound, depending on the size and quality.

Shortly after the introduction of Jute, attempts were made to leckle it, with the view of mixing the longs with Flax, or of spinning it into yarn by itself. The great length of the Jute made heckling difficult, and when the fibre came to the frames it was found that it did not amalgamate readily with the Flax, and that they did not spin well together. It was also found equally difficult 
to spin it alore, and thus very little success attended the first efforts to make line yarn either wholly of Jute or of a mixture of Flax and Jute. The yarn into which it was attempted to be spun was about $3 \mathrm{lb}$. a spindle, or $16 \mathrm{lea}$, a size used in many of the fabrics then, and still made there. When the mixed yarn came into the loom it would not work, and it was found to be quite unsuitable for warp, and many chains made of it had to be cut out of the looms. These difficulties, added to the previous bad repute of Jute, and tended to retard its progress in the trade.

For the first year or two very little pure Jute yarn was spun, excepting Jute line for twist, and some heavy sizes for weft to sacking or carpeting; but by the beginning of 1835 various sorts of yarn spun of entire Jute were regularly sold in the market. On 1st April 1835, $11 \mathrm{lb}$. pure Jute yarn cost $4 \frac{1}{8} \mathrm{~d}$ a pound. It was used for weft to 25 inch cloth, then being made for Charles Norrie, merchant, Dundee. The cloth was charged at $3 d$ a yard, while the same fabric wefted with tow yarn was charged $3 \frac{1}{2} \mathrm{~d}$. On and after that year the price of Jute and of $7 \mathrm{lb}$. Jute yarn will be found in the prices current given hereafter. It was not until 11th Nov. 1836, that the price of Jute is quoted in the

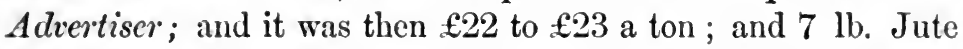
yarn appears there for the first time on 19th July 1844, at 1s 11d to $2 \mathrm{~s}$ per spindle. In Aug. 1835, and again in Nov. of that year, $8 \mathrm{lb}$. to $16 \mathrm{lb}$. Jute yarn cost $4 \mathrm{~d}$ a pound; $22 \mathrm{lb}$. yarn and also rove, $3 \frac{1}{2} \mathrm{~d}$; and $14 \mathrm{lb}$. Jute line twist $5 \frac{1}{2} \mathrm{~d}$ a pound.

For years after its first introduction the principal spinners refused to have anything to do with Jute, and cloth made of it long retained a tainted reputation. Indeed it was not until Mr Rowan got the Dutch Government, about 1838, to substitute Jute yarn for those made from Flax tow in the manufacture of the coffee bagging for their East Indian possessions, that the Jute trade in Dundee got a proper start. 'That fortunate circumstance gave an impulse to the spinning of the fibre which it never after lost, and since that period its progress has been truly astonishing.

No account of the importation of Jute into Dundeo was kept until 1838, and the quantity for that and succeding years will be giren subsequently in the table of imports into that town. Previous to that date Jute was included under the head of Hemp 
imported coastivise, the total of which from 1832 onwards was as follows:-

$$
\begin{array}{rrrrrrr} 
& 1832 . & 1833 . & 1834 . & 1835 . & 1836 . & 1837 . \\
\text { Tons } & 182 & 300 & 828 & 1222 & 16 & 171
\end{array}
$$

For some years following 1837, when the Jute imported was given separately, there was no Hemp imported coastwise, so that it may not be far wrong to suppose that the whole, or nearly the whole, of the above noted quantities were Jute. Prior to 1823 the importation of Jute was trifling, and the quantity in that year seems to have been only what belonged to $\mathrm{Mr}$ Watt. In 1833 his importation comprised three-fourths of the total quantity. The importations for 1834 and 1835 appear to have been in excess of the requirements of the trade, and little more was needed for the following two years.

Since 1837 the increase has been steady, and so rapid that last year the importation was more than 220 times greater than it was that year, or within a quarter of a century. For the period which has gone of 1863 , the increase is even in a greater ratio.

To show the bad odour of Jute in Dundee in January 1835, it is mentioned in the Advertiser of that date that it was then difficult to get good Flax yarn, bona-fide Flax, unmixed with Jute or Hemp. In a comparison of the price of material, yarn, and linens, for 1833 and 1834, given in that paper of 6th Feb. 1835 , it is said that " in consequence of the great rise in Flax, from the failure of the Flax crop, substitutes had begun to be used. But the mischief is that were Linens to advance as much as Flax had done, cotton would come into competition, and thus the manufacturer was precluded, unless at a great sacrifice, from pursuing his trade honestly, and obliged to use substitutes. Of these the most common was Jute Hemp, an Eastern production, which, from being a drug in the London and Liverpool markets, was then worth about $£ 17$ a ton, an advance within a few months of from 40 to 50 per cent. This article, is weak, of a reddish brown colour, very soft and silky, but totally destitute of moisture. The use of this and other substitutes would tend to lower the character of our manufactures very much, though it is to be hoped the necessity for using them will not continue long enough to ruin it altogether." The same article was repeated in the Advertiser 
the following week, the reason assigned being, because it had given so much satisfaction the week before.

As already mentioned, great difficulty was experienced in getting Jute at first introduced into the manufactures of the town, and this arose from various causes. Spinner, manufacturer, and consumer, were alike prejudiced against it, and all eschewed the disreputable fibre-the two former classes, because they did not know the nature of the material, nor how to use it, and the latter because it had got a bad name from people who were ignorant of its merits. 'The spinner, perhaps had some cause to be cautious, because, having been tried, it was found that the machinery then in use was not well adapted for spinning it. Many of them were disiuclined to alter their machinery, it being doubtful whether, after all, Jute might in the end be found suitable. The probable future supply and price were unknown, and any movement in it was, as it were, taking a step in the dark as to future consequences, but perfectly clear as to present cost. Those who did go into the trade with spirit and persevered, soon discovered its advantages, and ultimately they were rewarded for all their labour and anxiety with a brilliant success.

The loug strikes of Jute intended for line yarn were cut of a proper length for heckling, and the teaser was erected to tear down and make into tow what was designed to be so spun. The cards were altered to suit the new fibre, and the preparing and spinning machinery strengthened and enlarged, the better to turn it into yarn. The application of oil softened the material, made it more pliable, and gave it better spinning properties. These were still more improved by spreading out the strikes, saturating them thoroughly with oil and water, and allowing the Jute to remain in the batch for several days before being spun. This operation was first performed in a thorough manner by William Taylor at Ruthven Mill, and it has added greatly to the spinning qualities of the material, improved the appearance of the yarn, and materially lessened the waste and consequent cost of spinning. After the preparing and spinning machinery was properly adapted for Jute, and after the appliances of oil and water had been judiciously laid on, the difficulties in the way of spinning the fibre were removed. The bad odour which 
it had at first was then forgotten, and profitable returns made it smell fragrantly to the spinner.

When first tried, Jute had no name or standing in the place, and little note was then taken of the time or the manner in which the calumniated and untried stranger was introduced. The first spinners of the fibre have almost all passed away, and as most of them were, from its evil reputation, ashamed to own their bantling, and in a great measure compelled to use it stealthily, little public notice was for a time taken of it. Some, even among those who first used Jute, are unable to tell the date when they did so, because the quantity was so small and unimportant that little note of it was kept. So in like manner with the changes which, in its younger days, were constantly making in the manipulation of the fibre, and in the machinery for converting it into yarn. These were effected gradually year by year, and so quietly that the dates when many improvements were originated were unnoted and remain unknown. The information regarding its first introduction detailed above is, however, substantially correct. The greater part of it has been taken from the books of the parties themselves, supplemented by oral statements from such of them as remain, or by their contemporaries, and little better or more reliable information on the subject can now be got.

As already stated, the only attempts to spin Jute longs into small sizes of yarn, either in combination with Flax or by itself, of a quality suitable for warp purposes, entirely failed. It was not then possible to get off a fair spin of either entire Jute or of mixed yarn, and neither when spun would work as warp. The long dry fibres of the Jute, instead of having a tendency to twist and combine with each other as some other fibres do, stand out from the body of the thread ready to catch or to be caught by anything with which it comes in contact. The friction caused by the rubbing of the threads upon each other, and upon the camb, reed, \&c., in the process of weaving, drew out these loose fibres, and broke the yarn. This rendered the weaving tedious; and the cloth, if cloth was formed, unmerchantable. The Jute yarn, both line and tow, was therefore only used as weft, with the exception of such of it as was twisted two-fold, and it was chiefly made into carpeting. The warp of sacking and other 
fabrics formed of single Jute yarn was therefore all sized or starched before being weaved, and this slow and tedious process greatly retarded the production of this class of goods.

In September 1848, Peter Smith, manufacturer, Dundee, instructed James Aytoun, of Kirkaldy, to make some sacking chains of very fine Jute, with the yarn well twisted. On trying these chains he found they wrought admirably without starch. Gilroy, Brothers, and Co., hearing of this successful experiment, improved the quality of the material of their chains, twisted harder, and wrought them green. Other spinners shortly followed their example, and starching sacking chains made of Jute was immediately discontinned. As long as Jute chains required starching, the production of the cloth was much restricted, the process being slow, and the starching accommodation limited. This discovery gave a great impulse to the manufacture of such fabrics, and largely increased the consumption of Jute.

The sightly nature of Jute, the regular and even thread which, by the improved machinery, is formed of it, and the smooth, tidy, and clean appearance of Jute cloth, are all pleasing to the eye, and therefore attractive. These qualities combined with its cheapness, have served to recommend it to consumers, and bring it into general use. Now, instead of being used stealthily by spinners as of old, it is the only material spun by several of the leading firms in Dundee. The collossal proportions of some of the works devoted solely to spinning and weaving Jute may be imagined, when it is stated that the consumption in several of them exceeds 500 bales each a week, and one or two of them each cut up about 1000 bales weekly.

The various descriptions of Jute goods now manufactured are legion-sackings, baggings, hessians, sheetings, hop pocketing, Osnaburgs, ducks, carpeting, \&c., \&c., \&c. The major portion of the Jute cloth is made of yarn in the green or natural state, but in many sorts the yarn is milled and improved, creamed, or dyed, and in some it is bleached. In addition to the fabrics composed wholly of Jute, many sorts of Unions are made. Flax and tow yarns, and cotton and wnollen yarns, are incorporated with Jute in many ways, and in this manner an endless variety of fabrics are formed. Every effort is made to suit the 
taste and the requirements of the people in all lands, and the present extent of the Jute trade testifies to the success of these efforts. What it may become hereafter it is impossible to foretell, but judging from the progress made since its introduction, little more than thirty years ago, it is not too much to suppose that it will have a glorious future.

For a long period nearly all the Jute consumed in the kingdom was in Dundee and neighbourhood, but the manufacture is now extending in various places. In London and the district around, it is used to a considerable extent for various purposes. A small quantity of fine Jute is cut up in Yorkshire, and used in the formation of woollen fabrics. In Lancashire several works have of late years been started for spinning and weaving the fibre.

Establishments for the manufacture of Jute have been erected in Glasgow, and in Greenock, and the consumption at both places is on the increase. Jute was early spun in Fifeshire, but it has not made much progress there. In Arbroath and in Blairgowrie Jute has been spun for years, and the consumption of the article in both towns is on the increase, although in neither has it yet attained to great proportions.

On the Continent of Europe, Jute spinning has been carried on in some countries for years, but it has not hitherto made much way in any of them. In the statement of the export of fibres from the United Kingdom, a detailed account is given of the countries to which Jute was sent in the years named, and the quantity and value to each. That statement shews the progress of the trade in these States, as they draw their supplies chiefly from this country, and import very little from Calcutta direct. France imports from the United Kingdom, and also direct from Calcutta. The total importation into that country for the years 1861 and 1862, taken from the monthly circular of G. and J. A. Noble of London, for February 1863, is therefore given.

JUTE IN FRANCE.

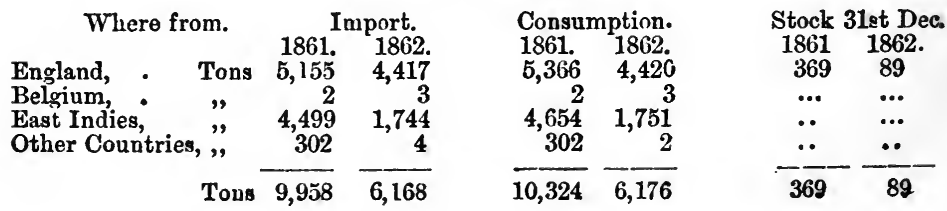


The Jute imported into France from 1st January to 31st May was: -

1861. Tons 3795 1862. Tuns 2709 1863. Tous 1670

On 31st May 1863, the Stock of Jute in France was insignificant.

It would appear from these statistics that the Jute trade in France is not in a prosperous state, as the consumption has decreased materially during these years, and it seems to be still on the decrease. This supposition is strengthened by the fact that large quantities of Jute yarns were, in the beginning of 1863 , sent from France to Dundee for sale, which would not have been the case had the trade there been in a healthy condition. This anomaly no doubt arises from exceptional causes, but it is curious.

For a long period the United States of America has been an importer of Jute direct from Calcutta, and a little has occasionally been sent firom this country. The consumption there has been progressive, but it has not yet attained to great magnitude, and a considerable part of the Jute imported from India has been re-exported to the United Kingdom.

Two factories for Jute spinning and weaving have been in active operation in the neighbourhood of Calcutta for several years past. A third is shortly to be started, and the Borneo Company are now making a very large addition to their establishment, which, when completed, will vie with some of the larger works in Dundee. The steam power of the work will be about 270 horses, driving fully 3500 spindles, and 350 looms, with all the necessary preparing and finishing machinery. 'Thomas Duff, the managing partner of the Company, who is a native of Dundee, employed the machine makers there to make the engines and machinery required for the extension of their works, and the machinery for the new spinning mill is also being made in Dundee.

The establishment of these works at Calcutta has not hitherto had an injurious effect upon the trade in Dundee. The goods they manufacture have come more into competition with the productions of the native looms, as they have been chiefly nsed for bags for rice and other produce of the country, which was 
formerly shipped in gunny cloth. The consumption of cloth for this purpose is immense, and constantly on the increase, and it will be some time before the production can exceed the demand. The manufacturing establishments at Calcutta are reported to have yielded a handsome return to the proprietors, and the knowledge of this will probably stimulate the erection of other works of a similar kind there. Should this be done they may in time supply the Australian market with corn sacks and wool packs, and thus interfere with the manufactures of Dundee; but this day may yet be far distant.

Last year a proposal was made to cottonize Jute, or to bleach, soften, and break it down, so as to adapt it for being spun over cotton machinery. For a short time the idea was eagerly seized upon by holders of Jute in England, and speculation speedily ran it up to the fabulous price of about $£ 40$ a ton for the finest qualities, and $£ 30$ for common. Those who were practically acquainted with the nature of the fibre had no faith in Jute cotton, well knowing that it would be about as easy to make the leopard change his spots as to impart to Jute the spinning qualities of cotton.

After some fruitless attempts to accomplish the object sought to be attained, the project died a natural death. The dazzling promises proved illusory, and the poor speculators got out of their Jute as they best could, poorer if not wiser men.

It is not at all probable that Jute, as now imported into Great Britain, will ever by any process be rendered suitable as a substitnte for, or even for being spun with cotton. It may be possible, by some means not yet discovered, so to improve the cultivation and preparation of Jute as to produce a stronger and yet finer and softer fibre; but until radical changes are made in these respects it is vain to expect Jute-cotton. A machine has recently been introduced by Sandford and Mallory, an American firm, for softening and increasing the spinning qualities of Jute, but the most that can be expected from any such machine is to render the fibre more suitable for the purposes to which it has hitherto been applied, an l nothing farther need be looked for.

Jute from its appearance more resembles wool than cotton, and there appears to be nothing so Quixotic in the idea of Jute- 
wool. Indeel for a while past fubrics of Jute and wool have been made in some districts of England, but not hitherto to a very great extent. This trade may increase, but not to such a point as to deprive Dundee of its Jute.

According to 1)r J. Forbes Watson, the growth of Jute in India is at least 300,000 tons annually. Of this there is now exported in the raw state from 50,000 to 60,000 tons, and perhaps from 80,000 to 100,000 tons are used as grunny bags and bagging, the balance being required for local consumption. It appears from the sime authority, that the better qualities are mostly retained for home use, and that the production admits of unlimited extension. It is natural therefore to expect that the late active demand and high prices will stimulate in a great degree the cultivation of Jute, and that the supplies will keep pice with the ever increasing consumption in this country.

In M'Culloch's Commercial Dictionary, it is said that Jute consists of the fibre of two plants, Choricle and Isbund (C.O. and C.C.), extensively cultivated in Bengal, and forming the material of which guuny cloth is made. It comes into competition with Flax, Tow, and Codilla in the manufacture of stair and other carpets, bagging for cotton and other goods, and such-like fabrics, and is extensively used for those purposes in Dundee; but it is most unsuitable for cordage from its snapping when twisted, and rotting in water. When first introduced into this country in 1815 , the price varied from $£ 35$ to $\mathfrak{E 4 0}$ per ton. It was then, however, very little used, and did not begin to come into general use as bagging till 1827 or 1828 .

That description is incorrect in various particulars. Jute has never come into competition with Flax, 'Tow, or Codilla, in the manufacture of stair and other carpets. Carpeting was made of wool, and not of any of these fibres, and the Jute car pets were made in imitation of woollen carpets. Jute yarn spun with an ordinary twist does not snap readily, and it is not more weakened thereby in proportion to its original strength than other fibres. It stands water better than Flax material. In various instances cioth of Flax, or Flax tow warp and Jute weft, has been immersed in water, both salt and fresh, for days and weeks, and, on being taken out, it has been found that the Jute weft came through the ordeal less weakened than the Flax 


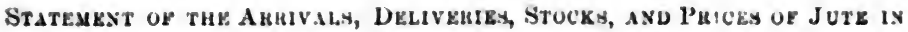
Loxdos is tre Y Yalls NaMED.

\begin{tabular}{|c|c|c|c|c|c|c|c|c|}
\hline \multirow{15}{*}{$\begin{array}{l}\text { Jan. } \\
\text { Feb. } \\
\text { Mar. } \\
\text { Apr. } \\
\text { May. } \\
\text { June. } \\
\text { July. } \\
\text { Aug. } \\
\text { Sept. } \\
\text { Oct. } \\
\text { Nov. } \\
\text { Dec. }\end{array}$} & \multicolumn{4}{|c|}{1840} & \multicolumn{4}{|c|}{1841} \\
\hline & Arrivale & Delifreries. & stueks. & Prices. & Arrisale & Delliveries. & stoeks. & Prices. \\
\hline & Bales. & Bales. & Bales. & Per 'Ton. & Bales. & Bales. & Bales. & Yer Ton. \\
\hline & & 3,512 & \multirow{2}{*}{\multicolumn{2}{|c|}{$\begin{array}{l}20,70010 / 3 @ 11 / 3 \\
21,20010,0 \Leftrightarrow 11 / 0\end{array}$}} & 789 & 1,450 & \multirow{2}{*}{$\begin{array}{l}8,5901: \\
8,0001:\end{array}$} & \multirow{2}{*}{$\begin{array}{ll}3 / 9 & @ 14 / 6 \\
3 / 6 & , .146\end{array}$} \\
\hline & 1,939 & 1,419 & & $10,0,11 / 0$ & 790 & 1,300 & & \\
\hline & 254 & $\begin{array}{l}1,840 \\
+49\end{array}$ & \multirow{2}{*}{\multicolumn{2}{|c|}{ 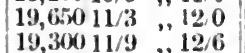 }} & 273 & 1,350 & 6,9501 & $13 / 6,14 / 3$ \\
\hline & 1,$4 ; 0$ & 1,774 & & & 2,405 & 1,75 & 7,600 & 16, \\
\hline & 661 & 1,450 & \multicolumn{2}{|c|}{ 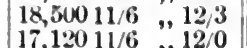 } & 1,722 & 1,952 & 7,3301 & $13 / 3,, 14 / 3$ \\
\hline & & 1,380 & 17,120 & $11 / 6,, 12 / 0$ & 623 & 1,835 & 6,150 & \multirow{2}{*}{6} \\
\hline & 1,600 & 2,020 & \multicolumn{2}{|c|}{$16,700120, " 126$} & 213 & 1,060 & \multirow{2}{*}{5,25011} & \\
\hline & 287 & 1,000 & \multirow{2}{*}{\multicolumn{2}{|c|}{$\begin{array}{ll}16,00012 / 6 & , 136 \\
13,50014 / 6 & , 16 / 0\end{array}$}} & 600 & 925 & & \multirow{2}{*}{ / } \\
\hline & $\ldots$ & 2,600 & & & 965 & 1,311 & $\begin{array}{l}4,95016 \\
4,60016\end{array}$ & \\
\hline & $\ldots$ & 1,900 & 11,600 & 146,156 & 543 & 1,843 & 3,300 & $18 / 6,19 / 0$ \\
\hline & 703 & 1,003 & 11,300 & $140,15 / 0$ & 711 & 1,600 & 2,400 & $\left\{\begin{array}{l}19,6 \\
, 200\end{array}\right.$ \\
\hline & $\cdots$ & 1,950 & 9,250 & $14 / 0,, 15_{i}^{\prime} 0$ & 457 & 1,100 & 1,000 & $20 / 0,20 / 6$ \\
\hline & 6,894 & 21,848 & & & 10,091 & 17,521 & & \\
\hline & & & 1842 & & & & 843 & \\
\hline Jan. & 6.59 & 580 & 1,075 & (a) $20 / 6$ & 3,033 & 2,073 & 7,960 & $16 / 0 @ 18 / 6$ \\
\hline Feb. & $1,0: 38$ & 913 & 1,200 & $19 / 0,19 / 6$ & 2,125 & 1,385 & 8,700 & $14,0,18 / 0$ \\
\hline Mar. & 1,325 & 1,025 & 1,500 & $18 / 0,18 / 6$ & 3,858 & 1,700 & 10,850 & $13 / 0,18 / 0$ \\
\hline Apr. & 2,158 & 1,858 & 1,800 & $18 / 6,, 19 / 6$ & 2,685 & 2,660 & 10,850 & $13 / 0,, 17,0$ \\
\hline May. & 1,708 & 2,450 & 1.050 & $16 / 0,17 / 0$ & 6,160 & 3,100 & 13,900 & $0,12 / 0, " 16 / 0$ \\
\hline June. & 2,856 & 1,106 & 2,800 & $16 / 0, " 17 / 0$ & 750 & 3,450 & 11,200 & $1110, " 150$ \\
\hline July. & 2,063 & 2,563 & 2,300 & $15 / 3,15 / 9$ & 400 & 1,450 & 10,150 & $11 / 6,150$ \\
\hline Aug. & 745 & 1,265 & 1,780 & $15 / 6, " 16 / 0$ & 2,242 & 1,652 & 10,750 & $12,0,150$ \\
\hline Sept. & 6,634 & 1,314 & 7,100 & $15 / 0, " 15 / 9$ & 950 & 1,190 & 10,50 & $130 ", 150$ \\
\hline Oct. & 1,197 & 2,747 & 5,550 & $16 / 0,17,0$ & 5,226 & 1,476 & 14,250 & $140,, 166$ \\
\hline Nov. & 4,981 & 1,600 & 8,950 & $16 / 6 \quad . .18 / 6$ & 6,855 & 1,250 & 19,850 & $14 / 0,160$ \\
\hline Dec. & 850 & 2,800 & 7,000 & $17 / 3,19 / 0$ & 950 & 958 & 19,825 & $13 / 9,16.0$ \\
\hline & 26,206 & 20,221 & & & 35,207 & 22,336 & & \\
\hline & & & 1844 & & & 8 & 45 & \\
\hline Jan. & 752 & 1,200 & 19,300 & 136 (c) $16 / 0$ & 7,161 & 2,150 & 25,500 & $11 / 0 a$ \\
\hline Feb. & 2,479 & 1,425 & & $136,, 160$ & $3,7 \div 8$ & $3,530)$ & 25800 & $111 / 9,150$ \\
\hline Mar. & 1,637 & 2,087 & 19,900 & $12 / 0,, 15 / 6$ & 8,863 & 1,463 & 33,200 & $11 / 9,150$ \\
\hline Apr. & 3,973 & 2,703 & 20,950 & $11 / 6,, 140$ & 6,744 & 3,944 & 36,000 & $0110,15 / 0$ \\
\hline May. & 510 & 3,650 & 17.800 & $11 / 3,140$ & 3,220 & 5,220 & 34,000 & $11 / 0,, 15 / 0$ \\
\hline June & 1,349 & 2,149 & $\$ 17,000$ & $11 / 3, \| 110$ & 3.928 & 3,628 & 34,300 & $11 / 3 ., 150$ \\
\hline July. & 4,589 & 2.889 & 18,700 & $11 / 9, " 146$ & 2,345 & 3,345 & 33,300 & $11 / 6,15 / 0$ \\
\hline Aug. & 3,553 & 3,775 & 18,450 & 130,156 & $8: 31$ & 3,231 & 30,900 & $011 / 6,15 / 0$ \\
\hline S pt. & 2,344 & 2,722 & 18.10 & $12 / 6,160$ & 1.000 & 2.000 & 29,200 & $011 / 6,140$ \\
\hline Oct & 4,137 & 2,707 & $19,5: 30$ & $116,, 160$ & 1.465 .5 & 2,315 & 28.350 & $0119,, 15 / 4$ \\
\hline Nov. & 1,516 & 1,346 & 19,700 & $11 / 6,, 15 / 6$ & $4,3 \leqslant 3$ & 3,233 & 29,500 & 123,156 \\
\hline Dec. & 1,495 & 595 & 20,600 & $11,6,15,0$ & 1,521 & 2,921 & 28,100 & $012 / 0,, 15 / 6$ \\
\hline & 8,324 & 27,248 & & & 4,159 & & & \\
\hline
\end{tabular}




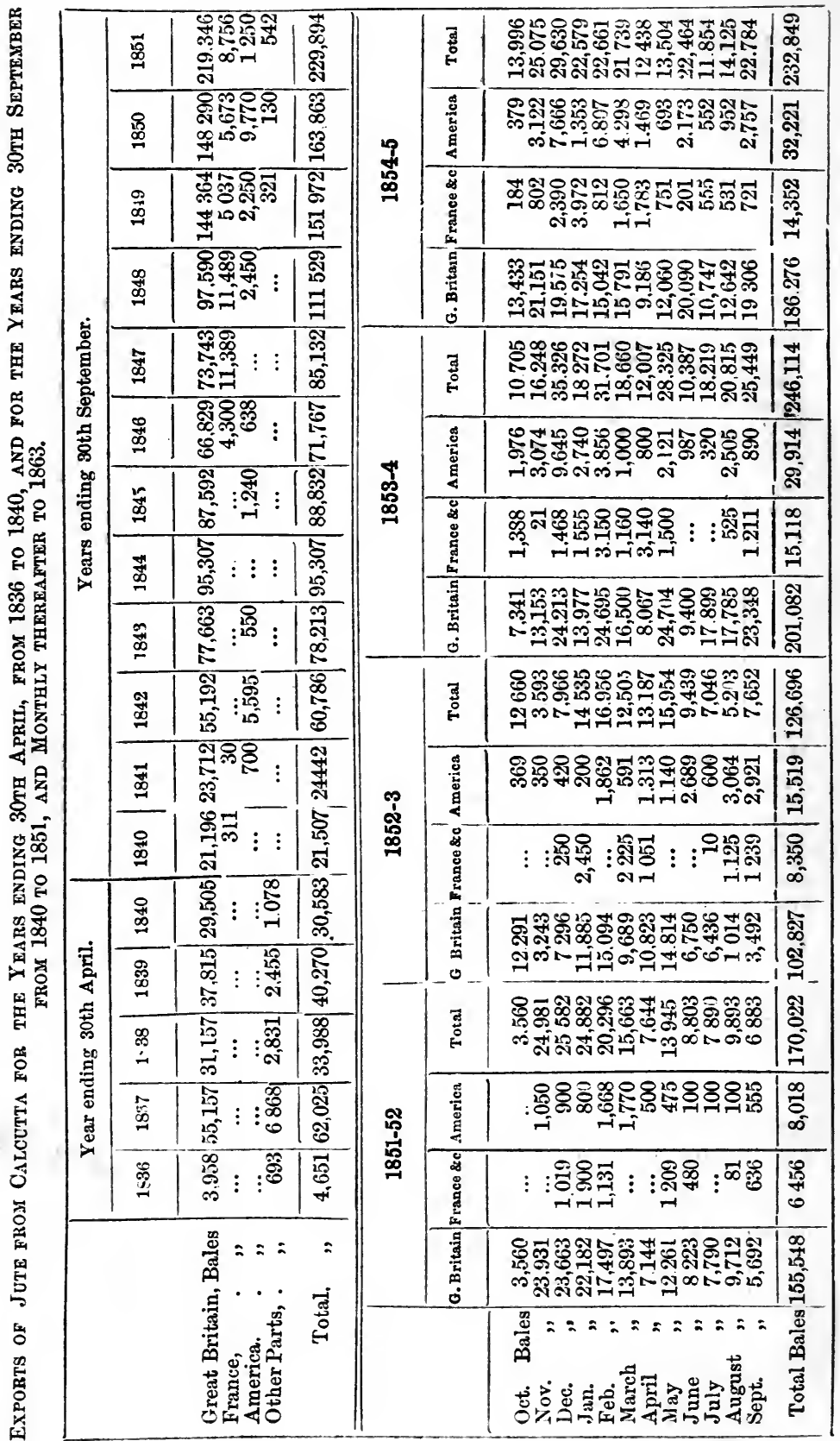




\begin{tabular}{|c|c|c|c|c|c|c|}
\hline \multirow{4}{*}{ 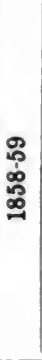 } & 공 & 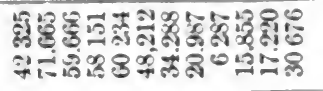 & 赵 & \multirow{4}{*}{ శ్ } & 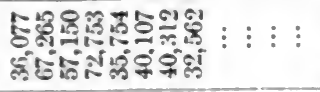 & 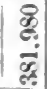 \\
\hline & $\frac{8}{4}$ & 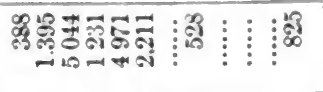 & 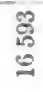 & & : & :5 \\
\hline & 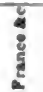 & 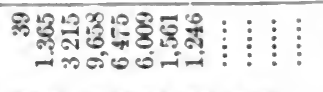 & $\begin{array}{l}3 \\
3 \\
\text { की } \\
\text { है }\end{array}$ & & $\vdots: \vdots 0^{1}$ & $\stackrel{\bullet}{\circ}$ \\
\hline & 竞 & 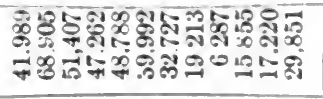 & $\frac{8}{9}$ & & 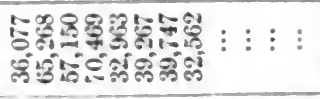 & לֶ. \\
\hline \multirow{4}{*}{ 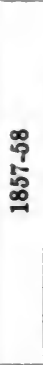 } & 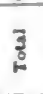 & 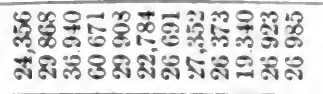 & $\overrightarrow{\vec{a}}$ & \multirow{4}{*}{ 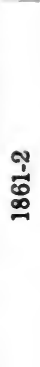 } & 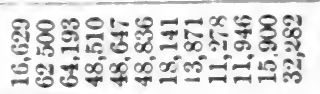 & 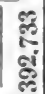 \\
\hline & $\frac{8}{8}$ & 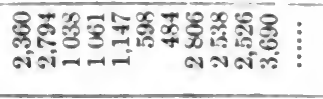 & क्ष & & 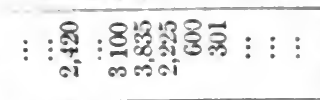 & 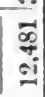 \\
\hline & 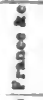 & 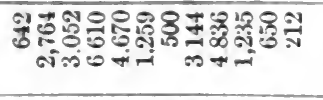 & 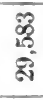 & & 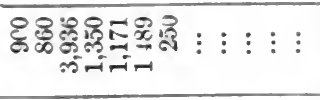 & 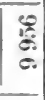 \\
\hline & 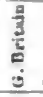 & 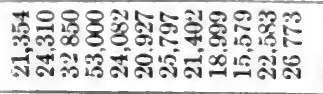 & 党 & & 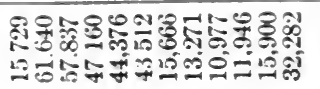 & $\begin{array}{c}\xi_{i} \\
\sum_{0}\end{array}$ \\
\hline \multirow{4}{*}{ 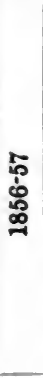 } & इ & 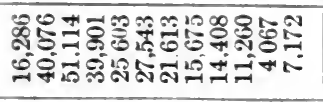 & 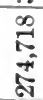 & \multirow{4}{*}{$\begin{array}{c}\tilde{\delta} \\
\dot{0} \\
\infty\end{array}$} & 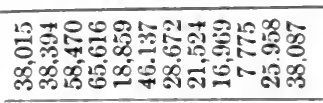 & $\frac{1}{2}$ \\
\hline & 远 & 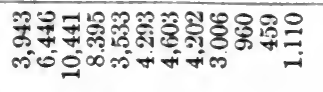 & กับ & & 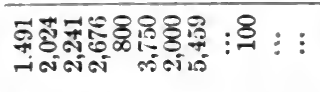 & हो \\
\hline & 递 & 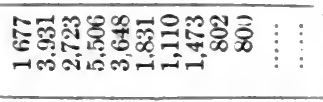 & 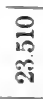 & & 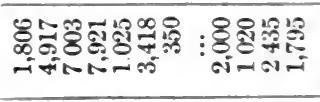 & $\begin{array}{l}\mathscr{d} \\
\text { ๙ి } \\
\end{array}$ \\
\hline & 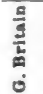 & 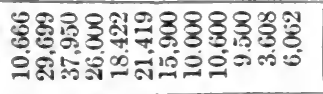 & 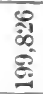 & & 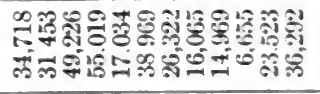 & 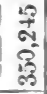 \\
\hline \multirow{5}{*}{ 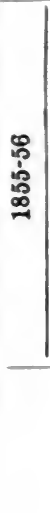 } & รั่ & 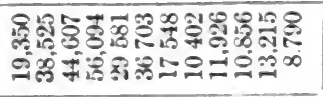 & 蛋 & \multirow{4}{*}{$\begin{array}{l}0 \\
0 \\
0 \\
0 \\
0 \\
0\end{array}$} & 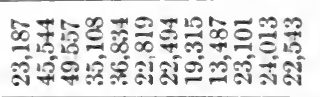 & हें \\
\hline & 焉 & 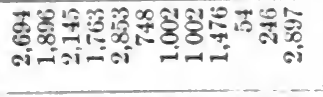 & 电 & & 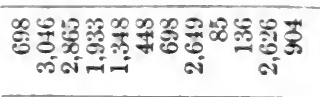 & $\stackrel{2}{\stackrel{2}{*}}$ \\
\hline & 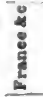 & 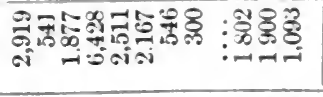 & $\begin{array}{l}\text { के } \\
\text { ลें } \\
\text { ลi }\end{array}$ & & 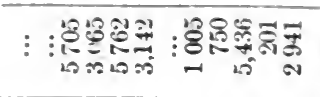 & 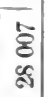 \\
\hline & 亳 & 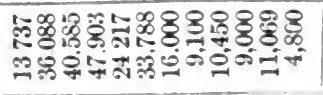 & 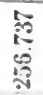 & & 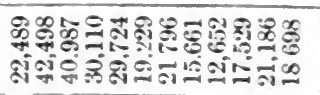 & 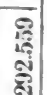 \\
\hline & & 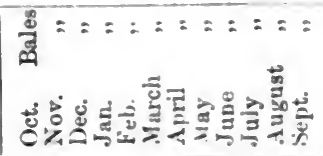 & 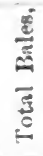 & & 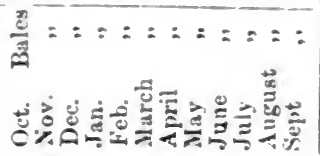 & | \\
\hline
\end{tabular}


THE RAW MATERIAL.

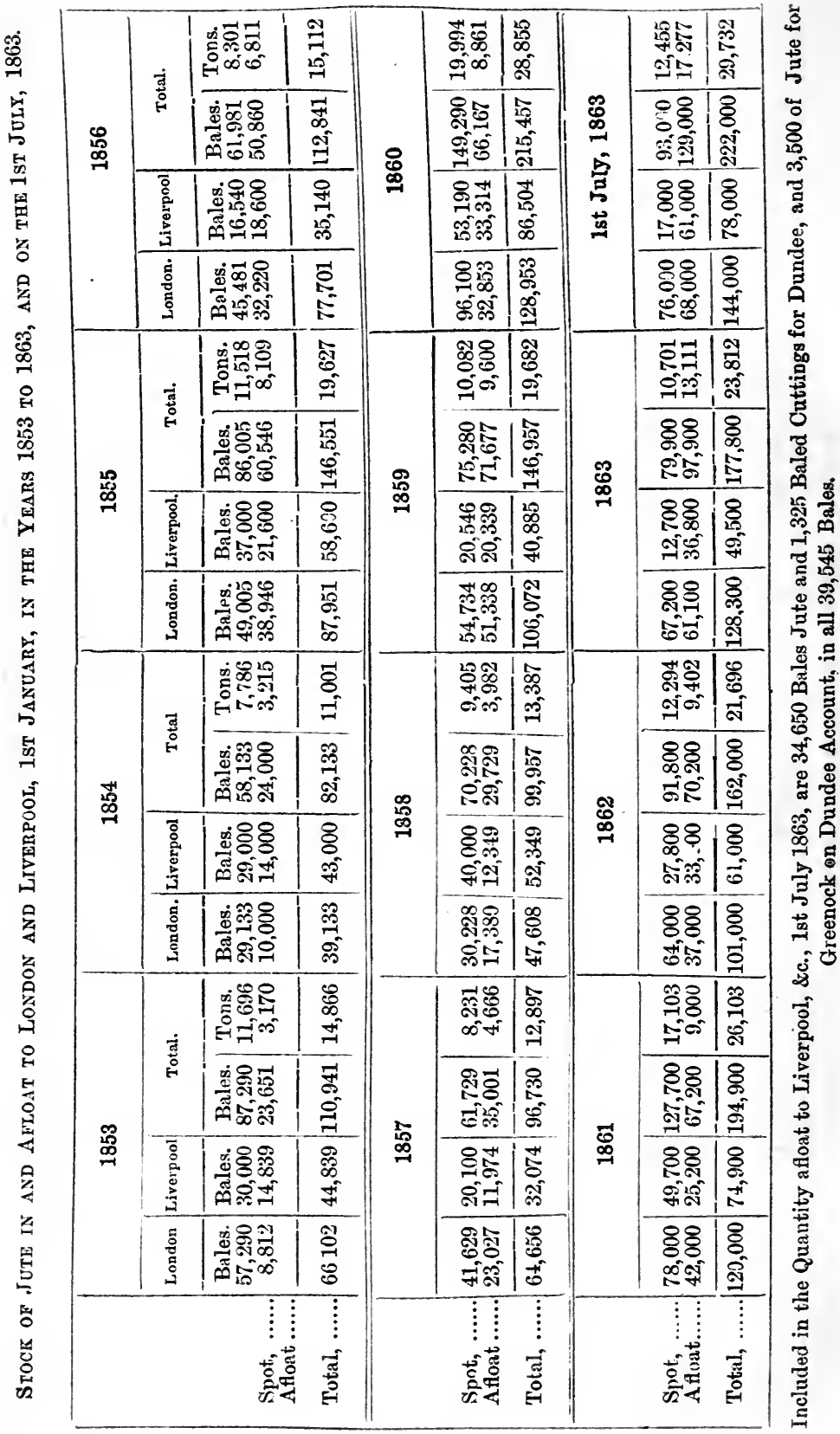




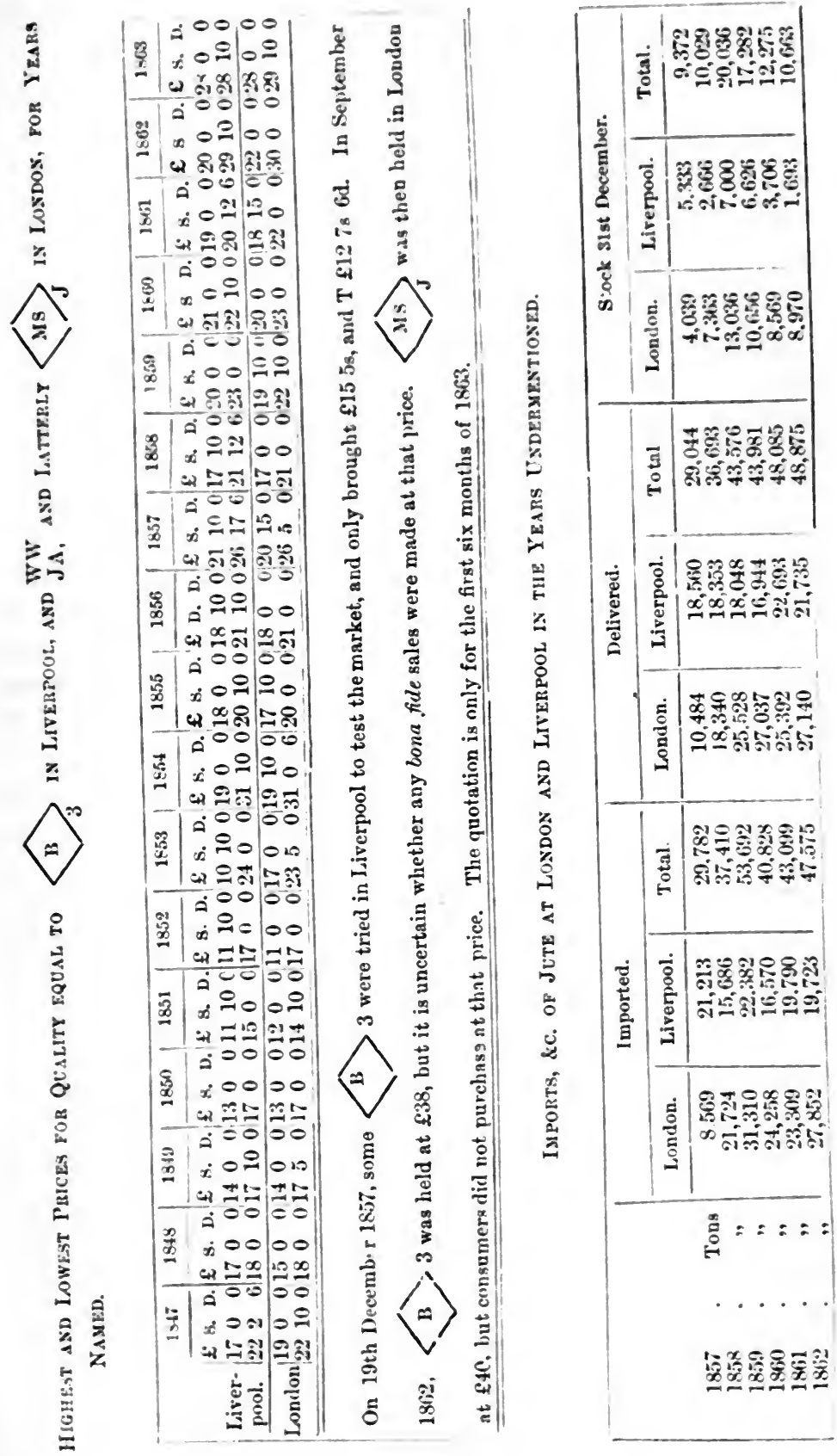




\section{CHAPTER IV.}

\section{S U N N C U L T U R E.}

Crotularia Juncea, Sana, or Sunn Hemp, is a native of India. The fibres of the plant are much used for cordage and for making sackcloth, and are very valuable for these purposes. There are two varieties of the plant; one, sown in May or June, often grows ten or twelve feet high; the other, sown in October, rises to the height of four or five feet.

After the earth is properly ploughed, cleansed and pulverized, the seeds of these plants are sown very thickly. The natives say that they should be sown so close together that a serpent cannot creep between them. This prevents the plant from throwing branches, which it is prone to do, but which are highly injurious to the fibre. As the growth of the tall variety is extremely rapid, the crops suffer little from weeds, but if the weeds should be numerous they must be extirpated by the hand, when the Sana is only a few inches in height.

The Sana (Suna, Sunna, or Sun, the Bengal name for Hemp), begins to flower in August, and when it has done flowering, and the seed vessels have already attained their full size, some time before the seeds ripen, it is cut down, or pulled up by the roots, and tied up in small bundles, each containing ten or a dozen plants. If a fine soft fibre is required it is pulled earlier, and if great strength it is allowed to stand until the seed is ripe. The bundles are then set upright in water, about a foot or a foot and a half of the lower part of the stalk being immersed, and they continue in that condition one day. By this means the upper and comparatively tender part of the stalk is somewhat dried. That produces a great similarity in the quality of the fibre throughout the whole stalk.

After the Sana or Hemp has thus stood erect for one day it is steeped in a pond or in some other receptacle for water, to promote 
the separation of the fibre from the stalk. 'This process is conducted as follows:-A number of the small bundles above mentioned are laid one upon another, so as to form a heap five or six feet high, on each side of which three or four stakes have previously been set to prevent it from falling down. $\Lambda$ quantity of cow dung, about two or three inches in thickness, is then spread over the heap. Upon this a layer of straw is placed about a foot and a half in depth, and over the whole a quantity of earth sufficient to sink the heap until the upper part is five or six inches below the surface of the water. In two and a half days, or three days at farthest, the putrid fermentation is carried to a sufficient extent.

The Sana is then taken out, and the fibre stripped from the stalk in the following manner:-A man, standing up to his knees in the water, takes a few of the stalks, and having broken them about a foot from the lower end, holds them with the large ends from him, and strikes them on the surface of the water till the stems are broken, separate, and fall off. Then turning them, he takes hold of the fibres, which are freed from the broken pieces, and beats the small ends in the same manner on the water, till the fibre is entirely separated from the stems. $A$ few strokes are sufficient, and by a few more it is cleared from any mucus or fragments of stalks which may adhere to it. It is then dried and packed up for the market.

The chief thing to be attended to in this process is the proper regulation of the putrid fermentation. If this be not carried to a sufficient extent, the fibre will not separate, and if carried too far, the quality is injured. The most experienced natives count two days and a half a proper medium. The fermentation is doubtless quickened or retarded by the state of the weather, but the difference occasioned thereby is so small, that the Bengal farmers entirely disregard it.

By this simple, easy, and short process do the natives of India accomplish, without the aid of machinery, the scutching of the Sana in a most satisfactory manner.

The mode of cultivating and preparing Sunn is not the same in every part of India, but the differences are not material. 'The above is perhaps the plan most generally adopted, and its description will suffice on this point. 
The Sunn is probably the earliest of the distinctly named fibres of India, as it is stated in the Hindoo "Institutes of Menu" that the sacrificial thread of the Rajpoot is directed to be made of Sana, cotton being reserved for the Brahmins. Under the name of Sana it is mentioned in many Sanscrit works, and by that of Sunn it is known in most parts of India. It is most extensively cultivated throughout the whole of India, and is much used by the natives, for cordage, sacks, and a great variety of other purposes, as well as exported largely to England and other countries.

Sunn belongs to the family of plants yielding the pulses of India, and the peas and beans of Europe. It is an annual, with a straight stem branching toward the top when growing singly, but with few branches when close, as it is usually cultivated. The leaves are scattered, from two to six inches long, with a small bristle like point, and covered on both sides with soft silvery coloured hairs. The flowers are of a beautifully bright yellow colour, and the seeds, which are numerous, are kidney shaped. The seeds, when ripe and loosened, rattle within the pods, whence the genus has been named from the Greek word krotalos.

In the end of last century small quantities of Sunn were imported into this country from India, and it was often experimented upon both in India and here. When properly prepared it possesses considerable strength, and is well suited for some sorts of cordage. Early in the century some of it found its way to Dundee.

In the Advertiser some notices of Sunn Hemp appeared at differrent times. It is mentioned that in March, 1804, some Indian Hemp, which had been imported into Dundee, met with general approbation, and that some parts of the fibre, tried against Russian Hemp, proved beyond all demonstration that it was an article of the first consideration. This may refer to the Brown Hemp of commerce, which comes from India, and in many respects resembles Russian Hemp. It may, however, refer to Sunn Hemp, which was long an article of considerable importance in the trade of the town. Sometimes it rose in favour, and at others it was declared unsuitable, but this may refer as much to the purpose to which it was applied 
as to the fibre itself. In May 1811, it is said, "The Sunn Hemp of India, after a variety of experiments, appears not to have answered the public expectations, and the persons who had been sent out to Bengal to cultivate it have been recalled." In October 1506, a quantity of Sunn Hemp lying in Dundee was advertised for sale by Nelson and Co. In 1819 the article was again advertised for sale in Dundee. For some years about that period India Hemp cotton batrging appears in the Dundee prices current in the Advertiser, the price being generally $1 \frac{1}{2} \mathrm{~d}$ a yard below Hemp bagging, and $34 \mathrm{~d}$ a yard below Tow warp bagging. The India Hemp referred to was Sunn.

Since then it has often been tried, but the fibre is not well adapted for being spun by the machinery in use in Dundee, and for a long period very little of it has been used in the manufacture of textile fabrics there. No doubt machinery could be made to spin it, but there has never been sufficient inducement to do so, as Jute nearly answers all the purposes for which Sunn can be applied, and it can generally be bought at a less price. Another objection to Sunn Hemp is, that when wet it is weak and tender, which renders it unsuitable for many textile purposes, whilst Jute, on the contrary, is as strong when wet as when dry. This is perhaps the chief cause why Sunn has not retained its place among the fibres used there.

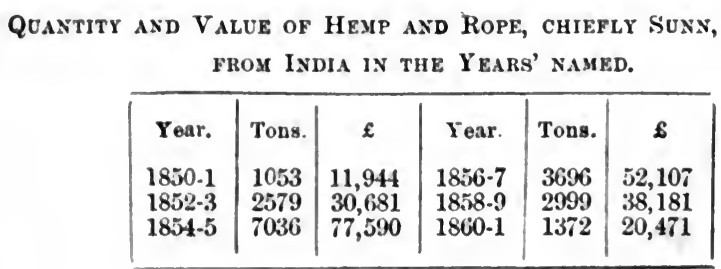


CHAPTER V.

\section{VARIOUS FIBRES.}

The great staple of the Linen Trade is Flax, the cloth made from this fibre being alone entitled to be called Linen. From various causes the cultivation of this plant has not kept pace with the demands of the world for Linen, and substitutes have been sought for to supply the void. The oldest of these is Hemp, and for many fabrics it is perhaps the best that has yet been tried. The culture and nature of this valuable fibre have been already treated of in a separate chapter. Neither Flax nor its twin sister Hemp have hitherto been grown in sufficient quantity for the wants of the trade, and prices of both have consequently continued high. Indeed so limited has been the supply of these fibres that the Linen trade, had it been confined to them, must have been circumscribed within narrower dimensions, and the Dundee branch of it could never have attained its present colossal proportions.

In a happy hour a cheap substitute for either Flax or Hemp was introduced into Dundee, and since then its progress has been most rapid. Jute, a native of the sunny climes of India, although a babe in years in the Linen trade, has become a full grown man in importance, and already it has supplanted both Flax and Hemp for many fabrics to which they were long supposed to hold a prescriptive right. This useful and beautiful, although not sterling Linen fibre, is fully elucidated in previous chapters. Its oriental sister Sunn, although it has never yet risen to much importance in this country as a substitute for Flax or Hemp in the manufacture of Linens, is a valuable plant, both in its native country and elsewhere. Its pro- 
perties and qualifications for the fabrication of cloth have not perhaps been sufficiently tried in the United Kingdom, and when it becomes better known it may be more appreciated. 'T'he mode of culture and preparation of this fibre has also been given.

In aldition to these there are other fibrous plants and substances which have been used for fabrics akin to Linen, or by parties engaged in the Linen trale, and a few of these will now be shortly referred to.

The NErTLE (Urticace) is a very common weed in this and in many other countries. It is shunned on account of its well known sting, and also from the forbidding nature of the places in which it generally gruws, yet it is nearly allied to the Hemp family, and possesses some of its properties. 'Thread, cloth, and paper have all been made from the common nettle of Europe, and some of the Indian speeies have long been noted for their fibre. In the hill country of India the large nettle grows to the height of 14 or 15 feet, and produces a very strong and useful fibre. The natives steep it for three days cnly, and then strip off the fibre, which is done by breaking off the top of the plant and pulling the fibre down from the thin end, which is the contrary way from Hemp stripping. Other species are prepared by different methods, but it is generally done by a simple mode. Some of these plants could probably be made more available in the manufactures of this country than they have hitherto been, and as they grow freely and might be proluced in quantity they deserve to be experimented upon.

China Grass (Urtica nivea) is another species of nettle, and perhaps the most famous of the tribe. Although the beautiful fabric called China Grass Cloth has long been known, the plant producing it, was, until quite recently, altogether unknown to Europeans. 'The subject has now been satisfactorily determined, and the mode of cultivation and preparation of the plant is accurately known. The manner of preparing the fibre is fully described in Chinese works, and the following précis will explain it. A light sandy soil near a river or well is the best for sowing the seeds in, and the ground should be dug, made into beds of one foot by four, again dug, pressed down and raked smooth. 
After a day they must be watered, raked, and again levelled, and they are then ready for the seed. One pint of seed should be well mixed with four pints and a-half of moist earth, and this will sow six or seven beds. The seeds should be sprinkled on the surface of the soil, and not covered with earth, or ther will not germinate. Light mats must be placed over the beds, and after the seed has sprung, when the sun's rays are powerful, straw must be laid over the mats, or the young plants will be destroyed by the heat. Before the young leaves appear the beds must not be watered, but the mats should be wetted to keep the ground underneath moist, and removed at night that the plants may get the dew. If parasitical plants appear they must be removed, and when the grass is two inches high the roof may be laid aside, and the earth moistened when dry, either at night or on a cloudy day. The young plants are then transferred into stiffer soil, placed four inches apart, a little earth being retained around the roots, which must be excluded from air and light, and the ground well watered and hoed. Every two or three days the watering must be repeated. Shortly after being transplanted the grass must be covered with fresh horse or cow dung. The plant then throws off new shoots, which may be removed and planted elsewhere, and the species can be propagated in this way as well as by seed. Young plants are also raised from layers which spring very quickly. In a few years the roots cross each other and intertwine, when the stems must be separated and replanted.

The first year, when the plants are a foot high, they are gathered, and the fibres of the cut straw are fit for spinning. 'The Tchou-ma or China grass may be gathered three times a-year, and when the stems are cut the little shoots springing up from the root stock should be about an inch high. After the large stems are cut the suckers spring up with more vigour, and soon furnish a second crop. The seed should be sown in February ; within four months the first crop may be reaped, two months thereafter the second is ready, and in other two months the third and last crop may be cut. The stems of the second crop grow faster than the others, and yield the finest quality of fibre. After reaping the crop the stocks must be covered with manure, and immediately watered 
The stems are split longitudinally with knives, the bark being first removed; then the lower layer is scraped off, and the under fibres are displayed, and removed by boiling in water. The first layer is coarse and hard and only fit for common materials, the second is finer and more pliable, and the third is the best, and is used for the finest purposes. After peeling the fibres they are tied up in skeins, steeped for a night in a pan of water, and then dried. They are then again steeped in water containing ashes of burnt mulberry wood, then in water and chalk, and then boiled in water containing straw, which makes them white and supple. 'They are then dried in the sun, again boiled in pure water, washed, and once more dried in the sun, after which they are joined end to end and spun on a wheel, and the long threads thus formed make the warp and woof of the cloth to be manufactured. Others prepare the stems by boiling in lime water, and washing, \&c.; others by wetting with dew at night, and sun-drying by day; and others by the steam of boiling water, so that the mode of softening and bleaching the fibre is not uniform.

The seeds are gathered in October, from the main shoots, dried in the sun, mixed with damp sand, and kept in a basket carefully covered with straw to keep them from frost, which destroys the germinating power. Before sowing the seeds are put in water. Those which sink are used, the others being useless. The best seeds are those which are spotted black. They should be sown thin or the plants will come up weak and sickly.

China grass is cultivated extensively in China and in several other countries in India. It is a most beautiful fibre, possessed of great strength, and admirably adapted for various purposes. China grass cloth has been long known and highly valued for the beauty of its texture. Of late years improvements have been effected in the preparation of the fibre, and in its adaptation to the manufactures of this country. Very beautiful specimens, both of the fibre and of the cloth were shown in the Exhibition of 18.51, and much care was bestowed on their preparation. In 1862 excellent specimens of both were also exhibited in the International Exhibition. Like Hemp, however, but in a greater degree, it is hard and not well adapted for spin- 
ning on Flax machinery, and little progress has yet been made in introducing it largely into the trade. From the expense of its cultivation and the comparatively small quantity produced, it has hitherto commanded so high a price in the market, as to put it beyond the reach of the general trade, and make the consumption insignificant.

The Rheea of Assam is perhaps identical with China grass, and the same fibre under different names is grown to some extent in the district of Rungpore in Burma, in Siam, and in other eastern countries. Its strength has been frequently tested, and found to be considerably greater than Russian Hemp, it would therefore appear to be a very suitable material for twines and ropes, although too harsh and hard for anything but the coarser kinds of textile fabrics.

The Neilgherry or Himmalay mountains abound in other species of nettle valuable for their fibres. The plants of India have each their distinctive varieties, and every oriental country has members of the same extensive family. Little has yet been done to make them available to the industry of this country, but that little is now being directed to practical ends, and in a few years the nation may expect to reap the advantage.

New Zealand Flax, (Phormium tenas) was discovered by Captain Cook in New Zealand, and he says "The country produced a grass plant like flags, of the nature of Hemp or Flax, but superior in quality to either; of this the natives make clothing, lines, nets, \&c." It is indigenous to these Islands, and grows in various districts of them. In 1798 it was introduced into the South of Ireland, and it has also been found to flourish on the west coast of Scotland, but it is not now cultivated in either of these places. It is a hardy plant, and would thrive in any temperate climate, but the heat of an Indian summer and the cold of a Russian winter are too great extremes for it. It prefers swampy lands, and is sometimes met with in its native country growing some feet under salt water, and also in places at some distance from the sea shore.

The leaves of the plant are perennial, hard, sword-shaped, and from five to seven feet in length, with a flower-stalk rising four or fire feet above them, and bearing a profusion of yellow 
flowers, followed by triangular seed-vessels, filled with flat and thin black shining seeds. 'Three-year-old plants are said to yield on an average thirty-six leaves, besides offsets from the roots. An acre planted with them, three feet apart (but that is too close), will yield about fifteen or sixteen hundredweight of scutched and cleaned fibre, as six leaves produce one ounce of them. The leaves are cut when full-grown, macerated in water for a few days, and then passed under a heavy roller. The natives, however, cut the leaves when full grown, and separate the fibres while yet green.

The leaves are scraped with a shell, the fibres separated with the thumb-nails, and then combed still farther to part them. Instead of the fibre surrounding a woody stem like common Flax, New Zealand Flax is a mass of fibre on the lower side of the leaf', stretching from the bottom to the top of the leaf in perfectly parallel lines, with a green covering on the upper surface, which, when dried, becomes yellow, and is easily removed in the scutching mill. In cleaning it wastes very little in weight, and it increases in bulk, which is very different from ordinary Flax. After the fibres have been subdivided by the comb, they are dried in the sun, and become perfectly white. Some of them are coarse and strong, others fine with a silky appearance, and which are capable of being heckled to an almost inconceivable fineness. It is said the plant may be shorn of its leaves in the morning, and be ready for weaving before evening, but it is the same with some other endogenous fibres, which are naturally white.

The fibres of this Flax are possessed of great strength, and under a direct strain will, if dry, support a heavy weight; in a damp or wet state their strength is much impaired, but when again dried they regain their original tenacity. It has the great disadvantage of many of the white fibres, of breaking at a knot. For spinning and weaving purposes the extreme brittleness of the fibre is its primary defect, and it is really so very serious a one, that until some means be found to overcome this and make it more pliable, it will never be employed in quantity for those purposes. Many attempts have been made from time to time to give it spinning quality, and a person named Burns, by some process inrented by him, prepared samples, one half of which G 2 
were left in the natural state to show the contrast. The others were of a beautiful soft texture, with the brittleness completely overcome. The cost of this process was too great for being turned to practical account, but a less costly mode may yet be discovered, which will bring the fibre within the range of the operations of both the spinner and weaver.

In experiments made with the fibre it has been spun over ordinary Flax machinery as fine as one pound per spindle, but until a cheap softening process be adopted little of it will be spun even into considerably heavier sizes than that, as it cannot be wrought profitably. It is, however, well adapted for lines, twines, and cordage, and for these purposes it will give satisfaction to the consumer. Sail-cloth, sacking, \&c., are also made of it, and the sails, cables, and running rigging of the beautiful model frigate presented by King William the Fourth to the King of Prussia were entirely formed of it.

The fibre is easily dyed, and takes on a good bright colour, although it may be fugitive. It was at one time supposed that it would not unite with tar, but it has been found to imbibe it in equal proportions with Russian Hemp. Murray, in his pamphlet on this plant, had it printed on paper made from its leaves. It would therefore appear to be applicable to many purposes, and it may yet prove a valuable plant both to its native country and to its antipodes, Great Britain.

Manila Hemp, (Musa textilis,) has of late years come into great favour in this country, and it now supplants Russian Hemp for a variety of purposes. The plant is a native of the Philippine Islands, and is there called Abaca. It is found both in a wild and cultivated state, but the natural groves are considered as property. The plant is of the same family as that which yields the plantain and banana fruit. With the produce of the Abaca the natives of some of the villages in these Islands purchase the necessaries of life, clothe themselves, and pay taxes, \&c. Some of these villages furnish yearly 1500 arobas (about 17 tons) each of the fibre, and others export as much cordage made of it.

The first export of Manila Hemp from the Philippine Islands was about 14 tons in 1818. After this there was no more demand until 1822, when a regular trade began, and since then 
it has gradually progressed. In 1844 the exports had reached 6234 tons, and by 1852 the total quantity amounted to 15,296 tons, of which 13,782 was for the United States. In 1854, the export to Great Britain was 5805, and to the United States 13,751, making 19,556 tons in all. By 1856 the exports to the United States had increased to 19,528 tons, but to Britain (including 43 tons to Singapore and India), it had decreased to 2363 tons, making the total exports for that year 21,891 tons. The total quantity shipped from Manila in the year from 21st May 1862 to 21st May 1863 was, to Great Britain, 15,625 tons ; to America, 11,581 tons ; to other places, 359 tons; making a total of 27,565 tons.

Manila Hemp imported into Great Britain from the Philippine Islands :-

$\begin{array}{ccccc}1857 . & 1858 & 1859 . & 1860 . & 1861 . \\ \text { Cwt. 55,861 } & \text { Cwt. 144,593 } & \text { Cwt. 168,893 } & \text { Cwt. 77,538 } & \text { Cwt. 208,980 } \\ £ 90,541 & £ 198,288 & £ 208,321 & £ 88,801 & £ 226,114\end{array}$

The plant which yields Manila Hemp is sometimes called a tree, but it is in fact only a large herbaceous plant. It is abundant in the volcanic region of the Philippine Islands from Luzon to Mindanao, as well as in the neighbouring Islands, even as far south as the Moluccas. It may therefore be easily cultivated in other countries where the soil, moisture, and climate nearly assimilate to those within this range. The plants of the Abaca were subjected to experiment by Dr Roxburgh in the beginning of the century, and his specimens are still in the East India Museum.

The Abaca is cut when about one year and a half old, just before its flowering or fructification is likely to commence. If cut afterwards, the fibres are said to be weaker, and if earlier they are shorter but finer. It is cut near the roots, and the leaves are taken off just below their expansion. It is then slit open longitudinally, and the central peduncle separated from the sheathing layers of fibre, which are the petioles of the leaves. Of these layers the outer are hard and strong, and employed in the fabrication of cordage. The intermediate layers are finer and suitable for coarse cloth, adapted for elothing purposes, and the inner layers consist of still finer fibres, which are used for the manufacture of more delicate textures. Muslin and grass cloth are made from the finest fibres of Manila Hemp, 
and some of them are so very fine that a garment made of them may, it is said, be enclosed in the hollow of the hand.

The stem-like mass consists of cellular tissue and fibres, with a thickish, watery fluid, which must be pressed out. The fibrous coats, when stripped off, are left for a day in the shade to dry, and are then divided lengthwise into strips, three inches wide. The petioles are stripped off one by one, and an incision made across on the inside with a knife, to take off the bark which covers them. They are then scraped or made to undergo a sort of heckling until only the fibres remain, and when sufficiently scraped the bundles of fibres are shaken into separate threads; they are then washed, dried, and picked up by women, who separate the finest with great dexterity. Those for cordage require no farther preparation, but those for fine weaving are made up into small bundles, and beaten with a wooden mallet until they are soft and pliable. Their ends are then gummed together, and the connected thread wound into balls, when it is then ready for the weaver.

The stuff when woven is soaked in warm water for twentyfour hours, after which it is steeped in cold water, then in rice water, and again washed, which makes it soft, lustrous and of a white colour. Some of the cloths are dyed of various colours, and others are embroidered.

Very little of the Manila Hemp imported into this country is of the finest description of fibre, but some of it can be formed into small threads, and it is of a fine light cream colour, lustrous, and very sightly. It is chiefly used for a species of matting, which is both beautiful and durable, and for twines and cordage, for which purposes it is very suitable. The finest qualities imported command a high price in this country, and, as its valuable properties become better known, it is getting into more general use and greater favour. Although possessed of great strength, like New Zealand Flax and some other fibres, the single fibres cut when knotted, and they do not possess the qualities requisite for being spun over Flax or other small machinery. Could they be rendered suitable for this purpose the fibre would, from its strength and lustre, be very valuable, and it would be highly prized throughout the linen manufacturing districts. 
The Lime or Linden Tree, (Tilia Europaea), although classed by botanists in the some family with Jute, is so very different in appearance that an ordinary observer would place it in quite another genus. This tree is well known, and a general favourite in the parks and public places of this country, both for the beauty of its appearance, and the fragrance of its flowers. It abounds in the forests of Europe, but especially in those of Russia, where it is highly prized for its many valuable properties. The wood is light and white, and used for carved works, furniture, and other purposes. After the trees are cut down in summer and the bark removed, some of them are burnt into charcoal, and the sap when drawn off and evaporated yields sugar. The honey of the sweet scented flowers is much sought after by the bees, and at this season their hum is heard throughout the entire day, as they ply their busy labour among the branches. The bark of the tree is made into ropes and mats, and of this the well-known Russia mats of commerce are manufactured.

The Lime trees intended for being cut down for their bar: are allowed to grow from four to sixteen years, the older one: being used for the better and larger kinds of mats, and the young stems where size is not essential. They are cut down when from six inches to one foot in diameter, and the trees are selected in the woods a little before the season for cutting. The proper time for cutting them is in the early summer, in the months of May and June, when the trees are full of sap, and the bark is most easily detached from the stem. When they are cut the bark is immediately separated, both from the tree and the branches, being first cut longitudinally in lengths of six or eight feet, then raised with an instrument made of bone, and afterwards torn off by the hand. The bark on being removed from the tree is laid on the ground to dry, two or three strips being placed one over the other, and kept straight by being tied down to long poles. When required for use they are steeped in water until the layers readily separate from each other, and from the bark. The coarse layers are on the outside; and the finest in the interior. After being steeped, the bark is taken out and separated into ribands or strands, which are hung up in the shade, generally in the wood where the trees 
grew, and in the course of the summer the ribands are manufactured into mats. They are also made into a coarse sort of rope, and they are used for making matted shoes, which are much worn by the Russian peasantry.

For every pair of shoes the bark of from two to four young Linden shoots are required, and although the stems again shoot up more rapidly as they are cut, the destruction of the tree for this purpose alone is immense; and when to this is added the enormous quantity of mats made annually, both for home consumption and for export, the total number of trees which must yearly be cut down is something prodigious.

A few mats are made in some parts of Sweden, but the vast bulk of them are produced in the Government of Viatka, and some of the contiguous Governments of Russia. During the period for barking, the villages in the places where the trade is carried on are nearly deserted, almost the whole population being then in the woods, employed in stripping the trees. After this operation is performed they again return to their homes, and work up the fibre or bast into mats From careful investigation it is estimated that the average annual production of mats in European Russia is as follows :-

\begin{tabular}{|c|c|c|c|c|c|}
\hline Governn & $t$ of Viatka, & & • & $6,000,000$ & eces. \\
\hline Do. & of Kostroma, & - & . & $4,000,000$ & ", \\
\hline Do. & of Kasan, . & $\cdot$ & . & $1,000,000$ & ", \\
\hline Do. & of Nijni Novgorod, & - & - & $1,000,000$ & $"$ \\
\hline Do. & of Vologda, Tamboff, & limbirsk, & \& Penza, & $2,000,000$ & ,• \\
\hline & & & - & $14,000,000$ & " \\
\hline
\end{tabular}

It is further estimated that of this extraordinary quantity about three-fourths are used in Russia, and one-fourth exported chiefly from Archangel, St Petersburg, and Riga. These mats will average perhaps fully three pounds each, making a total weight of about 20,000 tons annually.

In the vegetable world there are a vast number of fibre producing plants, in some of which the fibrous parts are in the leaves, in others in the bark, while some have them around the fruit, and others are fibrous throughout their entire structure. The appearance of these plants, their construction and habits, and the soil and climate which produce them, vary as much as 
the characteristics of the fibres produced. In Endogens the fibres grow inside the stem or leaves, and are pushed outwards by new growths, while in the Exogens the fibres grow outside the stem, and form a bark or outer covering to it. In many of the former the fibrous parts are separated by pressure and washing in water, and in the lattor the separation is generally effected by steoping in water, after which the stem or woody part is readily removed.

The fibres of many endogenous plants are harsh and coarse, and not at all adapted as substitutes for any description of linen. 'I'he want of propor machines for scutching even the softest and most pliable of them has tended to prevent them from being experimented upon in connection with the linen trade. With suitable machinery to clean and prepare the fibre, it is probable that some of this class of plants may yet be made available for mixing with, or as a substitute for Flax fabrics. In the International Exhibition of 1862 some machinery for this purpose was shown, and much lauded, especially an American invention, which Sandford and Mallory, the parties producing it, and Alex. Guild of Dundee, their agent in this country, assert to be the desiderated machine. Practical experience of some duration will alone test this, and until it has undergone the ordeal it would be premature to speak confidently on such a subject, however promising the machine may appear to be.

It is to exogenous plants, therefore, that the Linen manufacturer must yet look for a supply of the raw material of his trade. Already some of them have been rendered subservient to his purpose, but there is no doubt that very many more exist in the floriculture of nature, although hitherto unknown to man. The discoverer and introducer into the manufactures of his country of a single useful fibre is a public benefactor. Such a discovery creates new fabrics, opens up new markets, employs more people, and, by making trade less dependent on old branches, gives steadiness to it, and raises the general comfort of the people.

Some of the fibres already mentioned, though comparatively new to the trade and commerce of this country, have already done much to add to its general prosperity. Many others might be noticed which are known to exist, though not yet experimented upon and made available for useful purposes. It does not, how- 
ever, appear to be needful to do so, as those described give a pretty general idea of the culture of fibrous plants, and the mode of preparation of their filaments for manufacturing purposes. Those who have the desire and may be favourably situated for experimenting upon such plants ought to do so, and if what has now been written on the subject prompts any one to action and produces practical results, it will not have been written in vain.

G. and J. A. Noble of London, in their monthly circular of 4th March, 1861, make some observations with regard to the fibres of India, which being pertinent to the purpose, are given entire :-

"In 1857 we sold by auction various parcels of Indian fibres entrusted to us by the East India Company, and forwarded as samples to introduce them to the notice of those interested. Unfortunately the Insurrection in India prevented the development of the results then obtained, the sale was numerously attended, several purchases being made for the continent. We extract particulars of a few of the fibres, that can be relied upon as certain to meet with ready demand, which will afford some index to their practical value, although the prices obtained for many of the lots were we consider, higher (on the account of the competition for experimental purposes,) than would be realized with regular supplies.

"The Himalayan, or True Hemp from the Punjaub, known also as Kemaon, Kote Kangra, and Kooloo, from the various distrites that have hitherto produced it, is perhaps the most important; it possesses all the good qualities of Russian Hemp, is naturally strong, whilst it can be reduced to a fibre fit for most Flax purposes. The samples, consisting of 63 bales, realized from $£ 2615$ s to $£ 32$ per ton.

"The Rheea fibre is more valuable, and perhaps more urgently required than the last; this also is known by several names, indigenous to nearly the whole southern coast of Asia; it is principally known in Bengal as Kunkhoora in Sumatra, Calooe; in Singapore and Bankok, Taleh Rameh; in Japan, Karao; in China, Chu-ma; in Europe frequently as China Grass; some hundred bales have been imported at different periods ; the method of reducing it to its silky condition has not long been perfected, but the whole of the samples ( 64 bales) 
were sold for various experimental purposes, at from $£ 30$ to $£ 46$ per ton.

"The Aloe fibre, 55 bales, sold at from $£ 37$ to $£ 40$ per ton, partly taken for the continent, fromw hence we have had several subsequent inquiries.

"The Hibiscus, known in Bengal as Ambaree, attracted the attention of spinners of Jute, to which it bears a great resemblance, it is sometimes coarser in quality, and generally much stronger. Prices range from $\mathfrak{f} 11$ for very common to $\mathfrak{E 2 5} 15 \mathrm{~s}$ per ton, the latter price being obtained for a sample of fibre superior in every respect to Jute, and for which it would prove a very welcome substitute to our manufacturers.

"There was, amongst several other common fibres fit only for paper-makers, a sample of "Gharoo," from Malacca and Arracan, growing there, it is stated, very abundantly, and easily procurable; being in a rough state it fetched only $£ 105$ s per ton, it has, however, been since inquired after by the manufacturer.

"We ought to observe that these fibres were shipped, for the most part, in a very rough condition, without any attempt to assort the qualities, the packing also was invariably very defective; this inattention materially depreciated the value of the whole of the samples sold, and we believe that they have been upon different occasions the chief cause of disappointment to those who have imported fibre. It is to be feared that the extreme prices paid for Flax during 1854 induced a belief that fibre of any description, and however prepared, would sell here readily ; this caused shipments to be made of parcels hastily and badly selected, which, when received here, were found suitable for none but the most ordinary purposes, discouraging to the shippers, and unsatisfactory to those manufacturers who tested them. As the cost of importation is the same upon produce badly prepared, as when in good condition, it is very palpable that a great mistake is committed in not attending to this important matter in all shipments of fibre, more especially if we remember that good quality is generally the most saleable and the most remunerating.

"As a general rule, it is useless to look for any important practical results to follow the importation of a small parcel of any new fibre; manufacturers are not disposed to incur expenses 
in modifying their machinery, and testing the quality of a new material, unless it be offered in a sufficient quantity to enable them to ascertain its comparative merits and qualifications by placing it on the market in a manufactured condition."

The following list of prices of various fibres is taken from Messrs Noble's Prices Current, dated London, 3d July, 1863. The various statistical tables which follow have been collected from official and other reliable sources, and great care taken to have them accurate. The same remarks apply to the other statistical tables given throughout the volume:-

\section{PRICES CURRENT.}

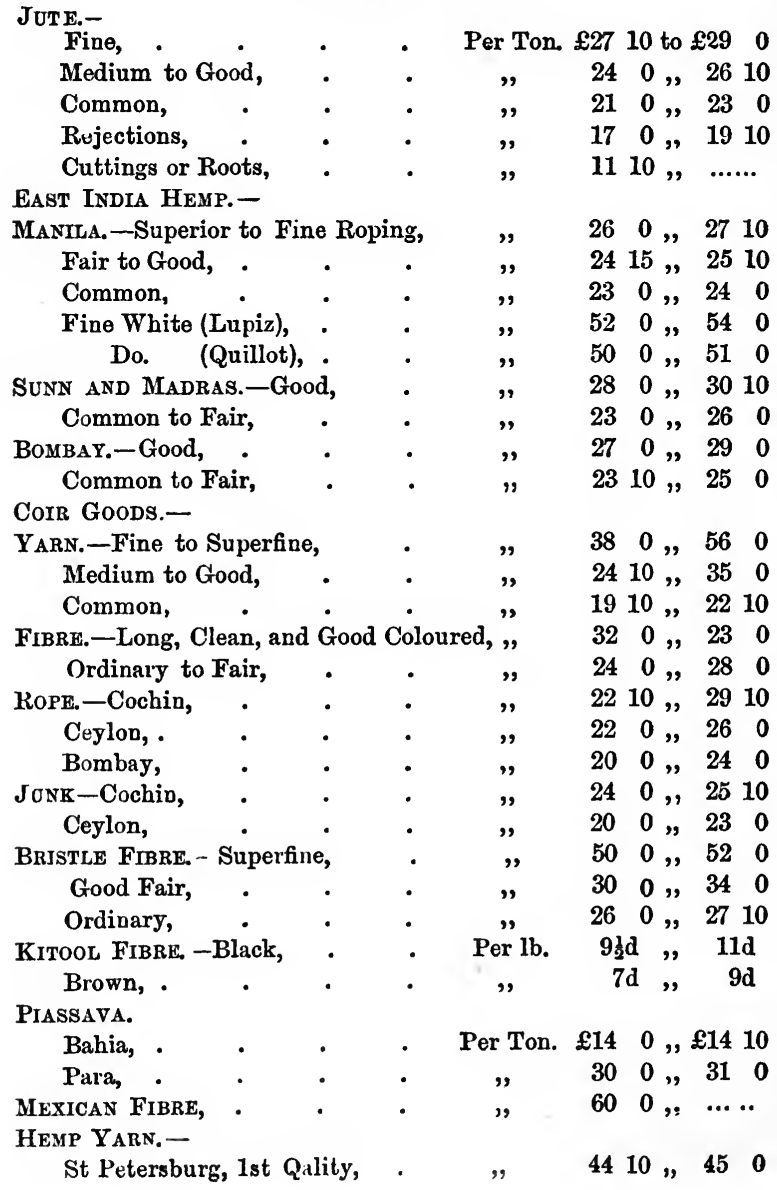


St Petersburg, 2d Quality, - Per Ton. $£ 30 \quad 0$ „, $£ 320$

Paly Lear,

HEMP-EUROPEAN. -

St Petersburg-Clean .

$90, \ldots, \ldots$

3910,4015

Outshot, . ", 3710,3810

Polish-Rhine,

Hulf clean, .

Outshot, .

Pass, . . .

Italian-lst Quality, Roping, .

$2 d$ do. do.

lst do. Spinning,

$2 d$ do. do.

1st do. Dressed,

$2 d$ do. do.

$3 d$ do. do.

Hungarian-Dressed, .

$$
\text { Undressed, }
$$

$37 \quad 0, \ldots .$.

$4210, \quad 4410$

4110,4210

$41 \quad 10,4210$

$40 \quad 0,4 \quad 4110$

$\begin{array}{lllll}38 & 0 & \text {, } & 39 & 0\end{array}$

460,480

430,2440

$70 \quad 0,, 73 \quad 0$

$\begin{array}{lllll}60 & 0 & , & 63 & 8\end{array}$

$54 \quad 0 \cong 57 \quad 0$

$\begin{array}{llll}38 & 0,40 & 0\end{array}$

300,310

FLAX. -

\section{Riga-WFPK, · \\ WFPHD,
WZK (Zins) .}

St Petersburg-12 Head, .

9 do

6 do.

Archangel-3d Crown,

Zabrack, .

Egyptian-Clean Scutched. .

Half clean do.,

Government Dressed,

Hand Dressed,

Common, .

New Zealand-Dressed, good,

Tow.-

Undressed,
Archangel-No. 1 Tow,
No. 2 do., 2d Codilla, $3 d$ do.,
Vologda-No. 1 Tow, No. 2 do.,
St Petersburg-Codilla,
Itulian-1st Bologna, . $2 \mathrm{~d}$ do., . . 1st Ceuto, . $2 d$ do.,

$620,, 720$

$620,, 680$

$610, \ldots .$.

$490, \quad 4910$

4310,4410

3310,340

$620,, 630$

$\begin{array}{lllll}56 & 0 & \prime & 57 & 0\end{array}$

$\begin{array}{lllll}58 & 0 & , & 66 & 0\end{array}$

$\begin{array}{lllll}48 & 0, & 54 & 0\end{array}$

$54 \quad 0,, 60 \quad 0$

$\begin{array}{lllll}39 & 0 & , 46 & 0\end{array}$

$250,, 30 \quad 0$

$\begin{array}{lllll}28 & 0 & , & 30 & 0\end{array}$

200, , 230

$48 \quad 10,4910$

$4710, " 4810$

$48 \quad 0, \ldots$.

3510,3610

$4510,, 4610$

$40 \quad 0,410$

140,21410

$\begin{array}{llll}36 & 0, & 3610\end{array}$

$3310,, 34 \quad 0$

$\begin{array}{lllll}37 & 0 & \text {, } & 38 & 0\end{array}$

3210,3310 
Imports, \&c. of East India HeMp into London in the Years UNDERMENTIONED.

Imported. Delivered.

Stocks 31st December.

\begin{tabular}{|c|c|c|c|c|c|}
\hline Tons, & 2,846 & 3,114 & Bombay. & $\begin{array}{l}\text { Sunn. } \\
2,388\end{array}$ & Manils \\
\hline 1858 & 5,331 & 3,263 & 139 & 498 & 3,861 \\
\hline 559 & 5,825 & 2,650 & 223 & 263 & 7,182 \\
\hline 1860 & 1,664 & 3,938 & 50 & 28 & 5,397 \\
\hline 61 & 4,436 & 4,225 & 69 & 18 & 5,602 \\
\hline & 4,200 & 4,640 & & & 5,155 \\
\hline
\end{tabular}

Quantities and Computed Real Value of Flax, Hemp, and Jute, Imported INTO THE UNITED KINGDOM FOR THE YeARS 1854 TO 1862, INCLUSIVE, AND the Rate at which the Value of the Jute from Calcutta is Calculated.

\begin{tabular}{|c|c|c|c|c|c|c|c|}
\hline \multirow{4}{*}{1854} & \multicolumn{2}{|c|}{ FLAX, TOW, \&C. } & \multicolumn{2}{|c|}{ HEMP, TOW, \&c. } & \multicolumn{3}{|c|}{ J U T E } \\
\hline & Tons. & 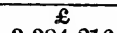 & Tons. & $£$ & Tons. & Rate. & 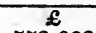 \\
\hline & 65,161 & $3,384,216$ & 37,312 & $1,817,905$ & 24,087 & $25 \mathrm{~s} 6 \mathrm{~d}$ & 553,993 \\
\hline & 64,672 & $3,317,122$ & 36,419 & $1,471,649$ & 26,965 & $16 \mathrm{~s} 7 \mathrm{~d}$ & 447,167 \\
\hline & 84,352 & $3,633,194$ & 39,831 & $1,319,907$ & 36,555 & $16 \mathrm{~s} 9 \mathrm{~d}$ & 612,290 \\
\hline 1857 & 93,312 & $3,524,767$ & 40,978 & $1,216,664$ & 30,942 & $20 \mathrm{~s} 11 \mathrm{~d}$ & 646,356 \\
\hline 1858 & 64,195 & $3,020,879$ & 45,014 & $1,222,393$ & 36,904 & $16 \mathrm{~s} \mathrm{10d}$ & 619,668 \\
\hline 1859 & 71,602 & $3,769,058$ & 54,935 & $1,469,360$ & 53,064 & $14 \mathrm{~s} 11 \mathrm{~d}$ & 790,383 \\
\hline 1860 & 73,240 & $3,836,770$ & 39,620 & ],203,869 & 40,839 & $16 \mathrm{~s} 2 \mathrm{~d}$ & 660,913 \\
\hline 186. & 66,684 & $3,423,137$ & 41,079 & $1,153,915$ & 45,205 & $15 \mathrm{~s} \quad 9 \mathrm{~d}$ & 709,961 \\
\hline 1862 & 89,918 & $4,693,928$ & 49,088 & $1,445,004$ & 48,497 & & 807,952 \\
\hline
\end{tabular}

Note.-The rate for 1862 is not known, as the details for that year were not published when this sheet went to press. The want of these details occasions a few blanks in some of the other Tables in the volume. 
VARIOUS FIBRES.

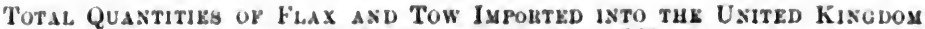
IN EACH YEAR, YROM 1801 to 1862.

\begin{tabular}{|c|c|c|c|c|c|c|c|}
\hline \multirow[b]{2}{*}{ Year. } & \multicolumn{3}{|c|}{ F I. A X. } & \multicolumn{2}{|c|}{$\begin{array}{l}\text { Average yrly. Importw for } \\
\text { thes yrs eniling as under. }\end{array}$} & \multicolumn{2}{|c|}{ НЕМP, JUTF, \&C. } \\
\hline & $\begin{array}{c}\text { From } \\
\text { Russia. }\end{array}$ & $\begin{array}{l}\text { From oth: } \\
\text { or Parts. }\end{array}$ & $\begin{array}{l}\text { From all } \\
\text { Parts. }\end{array}$ & $\begin{array}{l}\text { From } \\
\text { Russia. }\end{array}$ & $\begin{array}{c}\text { From all } \\
\text { l'arts. }\end{array}$ & $\begin{array}{l}\text { From } \\
\text { Russia. }\end{array}$ & $\begin{array}{l}\text { From all } \\
\text { Parts. }\end{array}$ \\
\hline 1801 & $\begin{array}{l}\text { Tons. } \\
9,405\end{array}$ & $\begin{array}{l}\text { Tons. } \\
4281\end{array}$ & $\begin{array}{l}\text { Tonn } \\
13.686\end{array}$ & Tous. & Tons. & $\begin{array}{l}\text { Tons. } \\
34.109\end{array}$ & $\begin{array}{l}\text { Tons. } \\
37467\end{array}$ \\
\hline 1802 & 10,754 & 3,376 & 14,130 & ….. & ...... & 22,288 & 25,370 \\
\hline 1803 & 10,760 & 3,822 & 14,582 & $\cdots \cdots$ & $\cdots \cdots$ & 34,339 & 37,884 \\
\hline 1804 & 13,091 & 4,539 & 17,630 & ?......" & & 35,801 & 36,957 \\
\hline 1805 & 18,493 & 5,094 & 23,587 & 12,600 & 16,723 & 30,788 & 31,583 \\
\hline 1806 & 15,306 & $2,6: 39$ & 17,945 & 13,681 & 17.575 & 37,119 & 37,404 \\
\hline 1807 & 18,918 & 2,221 & 21,139 & 15,313 & 18,976 & 37,591 & 38,884 \\
\hline 1808 & 6,824 & 4,015 & 10,$8 ; 39$ & 14,$524 ;$ & 18,228 & 12,007 & 13,122 \\
\hline 1809 & 19,761 & 6,743 & 26,504 & 15,800 & 20,003 & 39,804 & 42,792 \\
\hline 1810 & 23,805 & 1,919 & $2 \%, 724$ & 16,923 & 20,430 & 42,215 & 48,030 \\
\hline 1811 & 11,202 & 537 & 11,739 & 16,102 & 19,189 & 22,629 & 23,444 \\
\hline 1812 & 17,813 & 317 & 18,130 & 15,881 & 18,587 & 36,699 & 43,180 \\
\hline 1813 & \multicolumn{7}{|c|}{ The Recorls of this Year were Destroyed by Fire. } \\
\hline 1814 & 19,497 & $5,5: 29$ & 25,026 & 18,415 & 21,424 & 86,324 & 28,436 \\
\hline 1815 & 11,671 & $4,6 \geq 3$ & 16,294 & 16,797 & 19,382 & 36,135 & 37,639 \\
\hline 1816 & 7,516 & 3,117 & 10,633 & 13,540 & 16,364 & 18,459 & 18,773 \\
\hline 1817 & $14,7: 23$ & 6,015 & 20,733 & 14,244 & 18,164 & 22,926 & 23,764 \\
\hline 1818 & 14,330 & 7,052 & 21,382 & 13,548 & 18,814 & 32,971 & 34,210 \\
\hline 1819 & 16,775 & 3,714 & 20,489 & 13,003 & 17,907 & 24,250 & 24,639 \\
\hline 1820 & 15,774 & 3,345 & 19,119 & $13,8: 3$ & 18,472 & 20,792 & 21,309 \\
\hline 1821 & 18,254 & 6,673 & 24,927 & 15,971 & 21,331 & 12,671 & 12,789 \\
\hline 1822 & 20,993 & 9,512 & 30,505 & 17,225 & 23,284 & 29,188 & 30,823 \\
\hline 1823 & 14,892 & 12,805 & 27,697 & 17,337 & 24,547 & 32,658 & 33,357 \\
\hline 1824 & 22,445 & 14,682 & 37,127 & 18,471 & 27,875 & 27,868 & 28,596 \\
\hline 1825 & 33,314 & 19,448 & 52,762 & 21,979 & 34,603 & 28,932 & 29,754 \\
\hline 1826 & 26,395 & 8,036 & 34,431 & 23,608 & 36,504 & 23,254 & 24,466 \\
\hline 1827 & 33,497 & $11,8.57$ & 45,954 & 26,108 & 39,474 & 26,243 & 28,669 \\
\hline 1828 & 32,157 & 11,652 & 43,809 & 29,561 & 42,696 & 22,715 & 25,206 \\
\hline 1829 & 34,198 & 11,904 & 46,102 & 31,912 & 44,491 & 16,369 & 18,747 \\
\hline 1830 & 35,179 & 12,026 & 47,205 & 32,285 & 43,380 & 23,055 & 25,338 \\
\hline 1831 & 31,163 & 15,658 & 46,821 & 33,239 & 45,858 & 25,340 & $26,54 \mathrm{l}$ \\
\hline 1832 & 33,393 & 15,732 & 49,125 & 33,218 & 46,612 & 24,618 & 29.678 \\
\hline 1833 & 33,843 & 17,039 & 56,482 & 34,555 & 49,147 & 23,498 & 26,373 \\
\hline 1834 & 28,141 & 12,445 & 40,586 & 33,344 & 48,044 & 29,192 & 33,690 \\
\hline 183.5 & 21,924 & 15,116 & 37,040 & 30,693 & 46,011 & 30,526 & 34,378 \\
\hline 1836 & 51,851 & 24,605 & 76,456 & 34,830 & 51,938 & 27,823 & 29,302 \\
\hline 1837 & 34,101 & $15,9 \cdot 12$ & 50,043 & 34,972 & 52,121 & 29,584 & 881 \\
\hline 1838 & 54,478 & 26,836 & 81,314 & 38,099 & 57,088 & 29,050 & 36,519 \\
\hline 1839 & 35,285 & 25,899 & 61,184 & 39,528 & 61,207 & 39,073 & 49,785 \\
\hline 1840 & 43,520 & 19,142 & 62,662 & 43,847 & 66,332 & 29,954 & 34,203 \\
\hline 1841 & 48,473 & 18,869 & 67,342 & 43,171 & 64,509 & 27,138 & 32,608 \\
\hline 1842 & 42,236 & 15,052 & 57,288 & 44,798 & 65,959 & 20,778 & 29,295 \\
\hline 1843 & 54,469 & 17,388 & 71,857 & 44,796 & 64,066 & 23,153 & 36,787 \\
\hline 1844 & 55,601 & 23,573 & 79,174 & 48,859 & 67,664 & 32,798 & 45662 \\
\hline 1845 & 42,981 & 27,935 & 70,916 & 48,752 & 69 , & 30,164 & 46,592 \\
\hline 1846 & 37,020 & 20,3335 & 57,355 & 46,461 & 67,318 & $31,03: 3$ & 44,145 \\
\hline 1847 & 34,058 & 18,546 & 52,604 & 44,826 & 66,351 & 27,143 & 40,578 \\
\hline 1848 & 54,287 & 18,896 & 73,183 & 44,789 & 66,646 & 26,820 & 42,288 \\
\hline 1849 & 67,616 & 22,717 & 90,333 & 47,192 & 68,878 & 31,847 & 53,095 \\
\hline 1850 & 62,033 & 29,108 & 91,146 & 51,004 & 72,924 & $30,0-19$ & 52,431 \\
\hline 1851 & 40,934 & 18,775 & 59,709 & 51,786 & 73,395 & 33,229 & 64,670 \\
\hline 1852 & 47,495 & 22,940 & 70,435 & 54,474 & 76,961 & 26,856 & 53,407 \\
\hline 1803 & 64741 & 30.382 & 95,123 & 56,565 & 81,349 & 40,315 & 61,804 \\
\hline 18,44 & 9,290 & 55,871 & $6.5,161$ & 44,897 & 76,315 & 1,043 & 61,399 \\
\hline 1855 & 86 & 64,586 & 64,672 & 32509 & 71,020 & 1,589 & 63,384 \\
\hline 1856 & 54,008 & 30,344 & 84,352 & 35,124 & 75,948 & 27,008 & 76,386 \\
\hline 1857 & 63,745 & 29,576 & 93,312 & 38,374 & 80,524 & 29,035 & 71,920 \\
\hline 1858 & 46,544 & 17,651 & 64,195 & 34,734 & 74,338 & 30,624 & 81,918 \\
\hline 1859 & 53,723 & 17,879 & 71,602 & 43,621 & 75,626 & 36,583 & 107,999 \\
\hline 1860 & 52,486 & 20,754 & 73,240 & 54,101 & 77,340 & 29,929 & 80,459 \\
\hline 1861 & 47,630 & 19,054 & 66,684 & 52,825 & 73,807 & 24,017 & 86,284 \\
\hline 1862 & & & 89,918 & & 73,128 & 30,450 & 97,585 \\
\hline
\end{tabular}




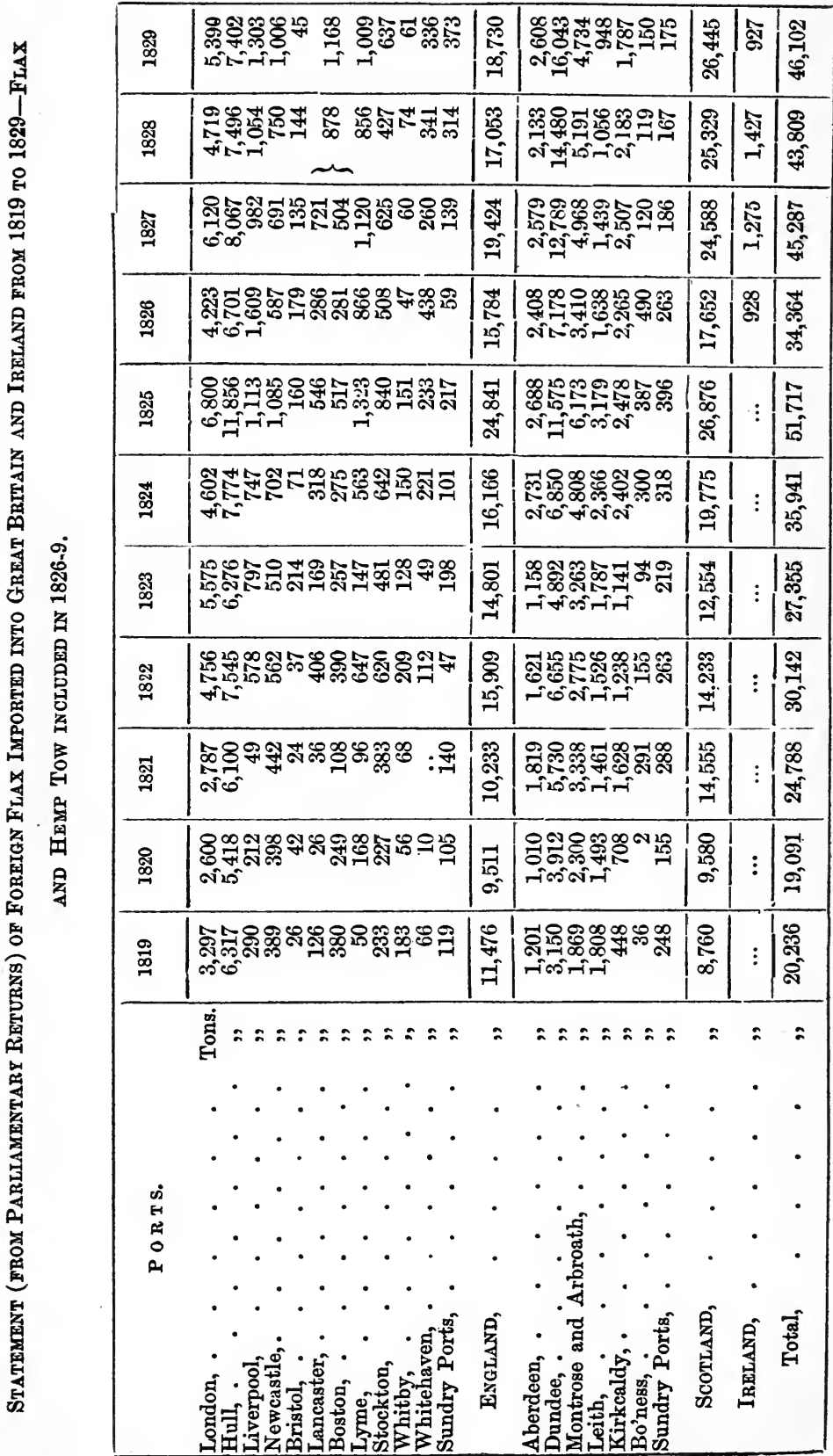


VARIOLS FIBRES.

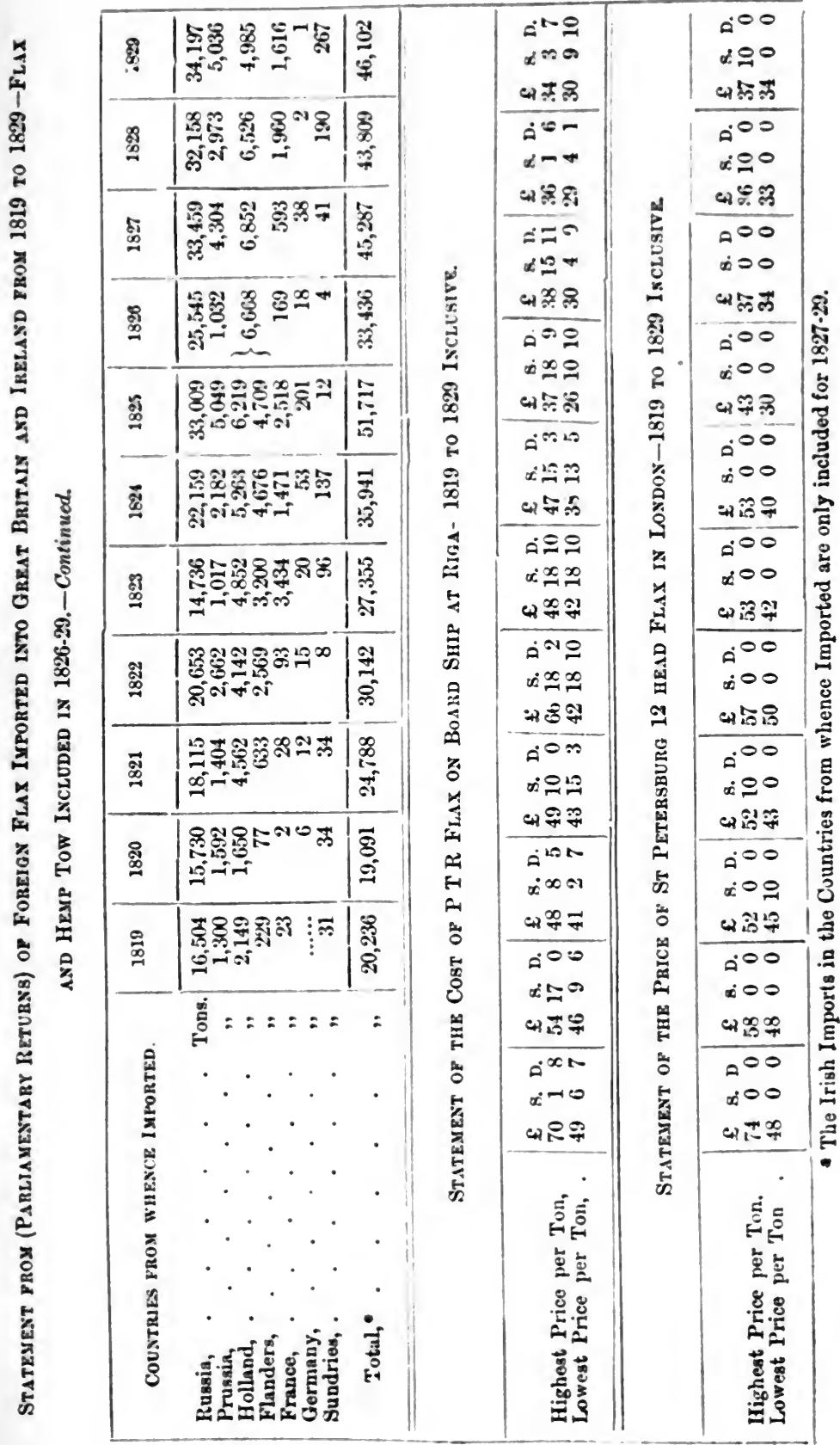




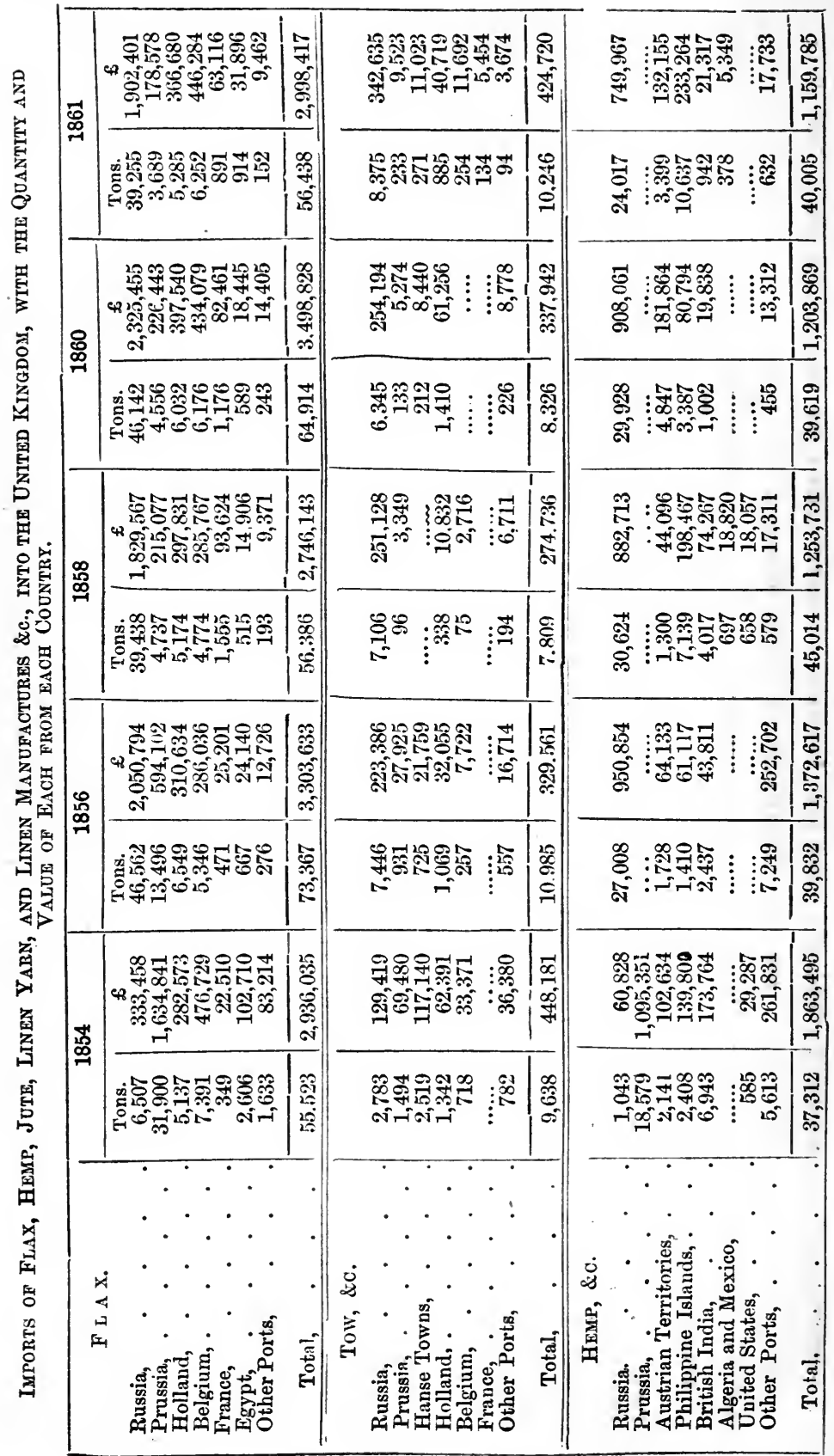


VARIOUS FIBRES.

\begin{tabular}{|c|c|c|c|c|c|c|c|c|}
\hline & 4 & : & $\begin{array}{l}\overrightarrow{\mathrm{S}} \\
8 \\
8\end{array}$ & & करำ & $\mid \begin{array}{l}3 \\
3 \\
0 \\
0 \\
0\end{array}$ & 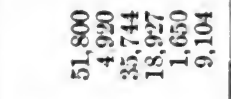 & 象 \\
\hline & : & 总す & $\begin{array}{l}19 \\
8 \\
15 \\
40\end{array}$ & & 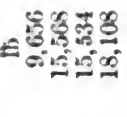 & $\mid \begin{array}{l}0 \\
0 \\
0 \\
0 \\
0 \\
\vdots\end{array}$ & 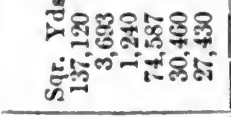 & | \\
\hline & 4 & 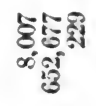 & $\mid \begin{array}{l}2 \\
6 \\
8 \\
8\end{array}$ & & 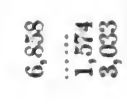 & $=$ & 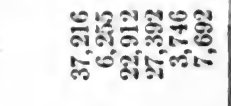 & $\begin{array}{l}\frac{m}{4} \\
28 \\
\frac{1}{6}\end{array}$ \\
\hline & : & 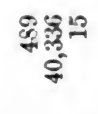 & 웅 & & 푸 ${ }^{\infty} \stackrel{\infty}{ }$ & 3 & 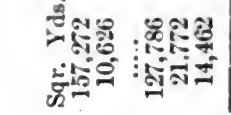 & $\mid \begin{array}{l}\infty \\
\stackrel{m}{m}\end{array}$ \\
\hline & 48 & 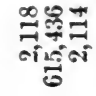 & 总 & & 웅요 & $\left|\begin{array}{l}\infty \\
\multirow{3}{3}{} \\
\infty\end{array}\right|$ & 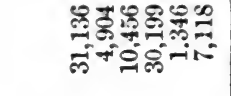 & $\begin{array}{l}8 \\
30 \\
180\end{array}$ \\
\hline & $\stackrel{\text { हैं }}{\dot{H}}$ & 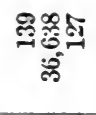 & $\mid \begin{array}{l}\dot{\circ} \\
\text { के }\end{array}$ & & & 8 & 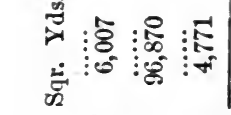 & $\left|\begin{array}{l}\infty \\
0 \\
5 \\
5 \\
-5\end{array}\right|$ \\
\hline & 4 & 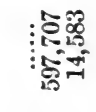 & 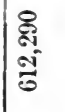 & & 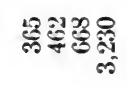 & 斻 & 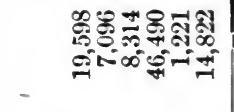 & $\begin{array}{l}17 \\
15 \\
5 \\
5\end{array}$ \\
\hline & $\stackrel{\text { : }}{\stackrel{0}{\circ}}$ & 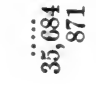 & 售 & & ๓ッレッ & $\vec{m}$ & 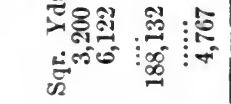 & 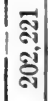 \\
\hline & 4 & 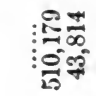 & 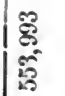 & & 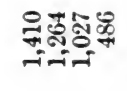 & $\stackrel{\infty}{=}$ & 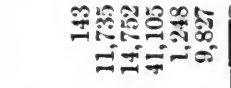 & $\left|\begin{array}{l}0 \\
\infty \\
\infty \\
\infty \\
\infty\end{array}\right|$ \\
\hline & : & : & की & & 엉이 & $\bar{\infty}$ & 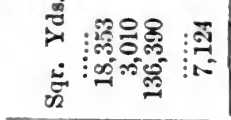 & $\left|\begin{array}{l}0 \\
\infty \\
0 \\
0 \\
0 \\
0\end{array}\right|$ \\
\hline & $\begin{array}{c}4 \\
5 \\
0 \\
2 \\
2\end{array}$ & . & $\begin{array}{c}\cdot \\
\cdot \\
\cdot \\
\text { हैं } \\
\text { हैं }\end{array}$ & 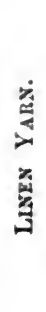 & 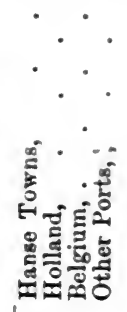 & · & 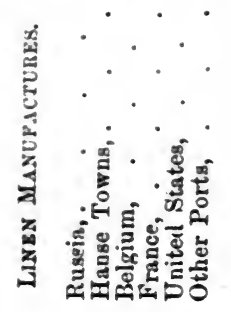 & . \\
\hline
\end{tabular}


Exports of Flax, Jute, and HeMp from the United Kingdom to Various Countries.

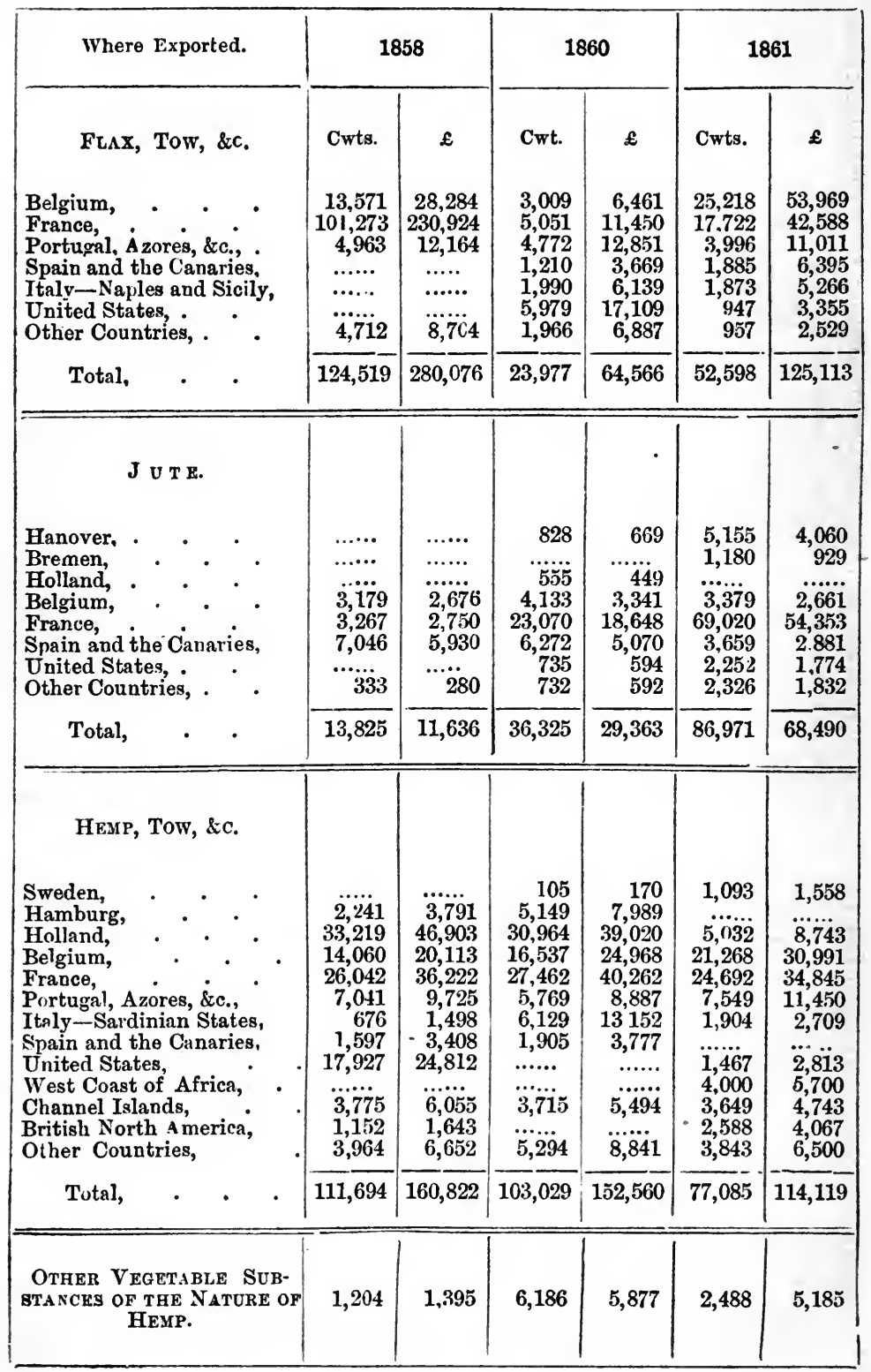


Prisolfal Pukts ixto Whi'h F'lix, Henp, JUt火, \&C., Were lyported iNto thK UNited Kingdos in the Yeahs NaMed.

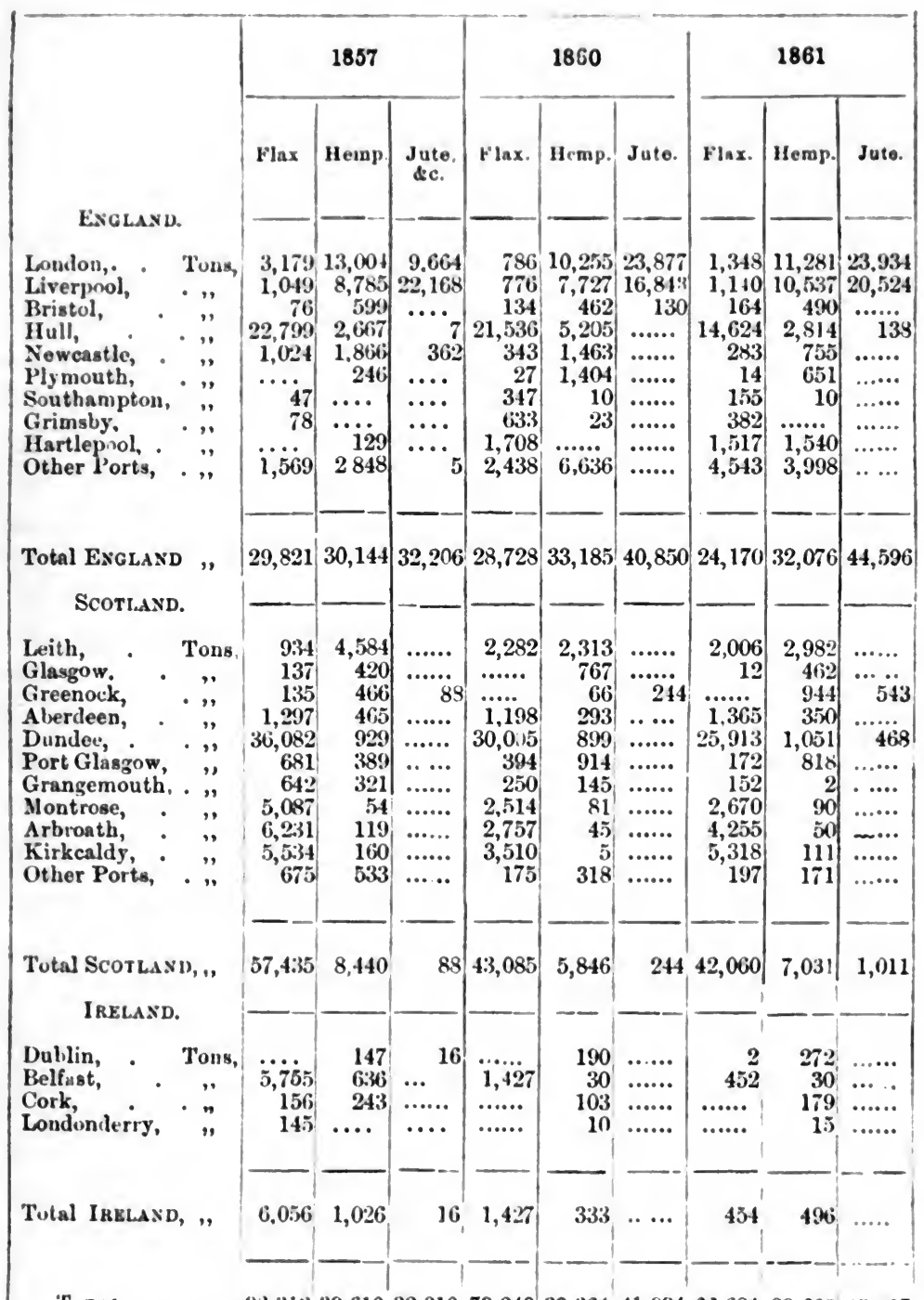

'Tuт.1., , $\quad 93,31239,61032,31073,240 \quad 39,364$ 41,094 66,684 39,603 4.,607 


\section{S E C T I O N II.}

\section{A N C I ENT L I NEN.}

IF Linen is not the oldest of textile fabrics, it is second only to woollen, and both were made at a very remote period. The Bible is the most ancient of written records, and it contains many references to Flax and Linen, and to the transformation of the one into the other. Before Moses wrote the first books of the Sacred Volume, before Joseph was sold as a slave to Potiphar, before even the patriarch Abraham visited Pharaoh, the Egyptians had attained to great perfection in the fabrication of Linen. The pictorial representations and explanatory hieroglyphics of the cultivation of Flax and its manufacture into Linen, found in the palaces, temples, and tombs of Egypt, carry back the trade for full four thousand years. Even this remote age may not have seen the invention of the art; but when, or where, or by whom, Linen was first made, is not known, and cannot now be ascertained.

It is probable that Linen owes its origin to a period not long subsequent to the creation of man. In antediluvian ages separate trades appear to have been assigned to, or appropriated by, each person or family. The manufacture of fibrous substances into articles of clothing, and for other domestic purposes, must then have had its representatives, as well as the other trades or professions which are incidentally mentioned in the Bible.

The knowledge of this branch of manufacture as of others would pass from the antediluvian age through the Ark, to the posterity of Noah in post-diluvian times. Probably to Ham had been assigned the duty of providing the family of Noah with the requisite textile fabrics, and his family would continue to do so while the people dwelt together. If so, Ham had no 
doubt learned to spin and weave before the Flood, and soon thereafter Flax would be grown and Linen woven in Armenia. Afterward, as the family migrated southward, they would carry the art with them, practice it at Babel, and thence convey it to the land to which they emigrated, when the people were dispersed at the confusion of tongues. Some branches of the family settled in Canaan, and others in Egypt, and in both countries, especially in the latter, the Linen trade speedily took root and grew up.

The sub-division of labour is not new, as it was approved and practised long before the Flood. The posterity of Ham seem, from the period of their settlement in Egypt, to have adopted the same system there. The Linen manufacture had with them its special representatives, whose sole business was to grow, and spin and weave the Flax. Long continued practice and careful application by hands and heads devoted to the trade would speedily perfect the manufacture, and enable them to transform the Flax into the "fine Linen of Egypt." That country may, therefore, with propriety, be called the cradle, if not the birthplace, of the Linen Trade. There the manufacture attained a perfection, perhaps never equalled, and certainly never surpassed, elsewhere, either in ancient or in modern times. From that land the art travelled northward, and westward, and Greeks and Romans, Germans and Britons, owe their knowledge of it to the ancient Egyptians-a people living in a highly civilized state long ages before even Greece was a nation.

The Bible, from its high origin and truthful character, demands and commands priority in treating of ancient Linen. 'To Egypt, from the great antiquity and wondrous perfection of its manufactures, the next chapter will be devoted. Other ancient countries, famous for their Linen, will then be shortly noticed, and this section will conclude with chapters on the linen of Greece and Rome. Unfortunately statistics are wanting to tell of the quantity of Linen produced in any of these countries, but some idea of its extent and value may be formed from a consileration of the many purposes to which it was applied, and the teeming population who daily used it. From the earliest period the trade has been of great magnitude, and it has exercised no little influence for good upon mankind. 


\section{CHAPTER I.}

\section{B I B L E I I N E N.}

Man, in the state of purity in which he was at first created, required no clothing, for it is said, "They were both naked, the man and his wife, and they were not ashamed." When they fell, "The eyes of both of them were opened, and they knew that they were naked, and they sewed fig leaves together and made themselves aprons," or things to gird about their loins. This was unquestionably the first fibre manufactured by human hands, and it was formed because man required to hide his shame. Manufacturing and sorrow were thus closely united at first, and labour and sorrow have too often been combined since. At the first interview between man and his Maker after the fall, it is said, "unto Adam also, and to his wife, did the Lord God make coats of skins, and clothed them," or, as it might more correctly be rendered, cause them to make, God being often represented in the Bible as doing what he directs to be done. The word translated "coats" might more properly be written tunics, a close garment that was usually worn next the skin, reached to the knees, and had sleeves. In after times it was made of woollen or Linen.

\footnotetext{
Fig leaves

They gathered, broad as Amazonian targe, Aud with what skill they had together sewed To gird their waist-vain covering, if to hide Their guilt and dreaded shame! Oh, how unlike To that first naked glory!
}

The spider may be regarded as the earliest spinner and weaver on this earth. Doubtless she had attained to as great perfection in her own particular manufacture at the time of our First Parents' expulsion from the gluries of the garden of Eden, as in these rlays of spinning frames and power-looms. This perfection surpasses even the "woven air" of antiquity, or the rarest skill yet attained in modern times, and were it reached, the nomenclature of the trade would require to be enlarged, ade- 
quately to define its exquisite quality. She was, and is an extraordinary monopolist. She grows her own raw material, spins it into yarn, and weaves it into cloth, solely by means of her own delicate little organs. The strength of the workmanship may not be great, but it is admirably adapted for the purpose this ingenious little manufacturer intends it to serve. Britain's power is vast, her mechanical skill is unrivalled, and her textile fabrics clothe all nations, but it is beyond the power of the most expert of her sons to form wheels and pinions or other mechanism to produce a texture to rival the spider's web. Indeed, the most expert of her fair daughters, even in the palmy days of the spinning wheel, (and then their supple fingers could fabricate a thread fine far beyond the reach of machinery), could not spin yarn fine enough to weave a fabric that would equal the web of the spider in catching flies. "The hypocrite's trust shall be a spider's web." "The spider taketh hold with her hands, and is in king's palaces." The wicked "weare the spider's web." So saith the sacred record.

Whether or not the spider's web would convey to the mind of Adam some idea regarding a woven fabric, can only be conjectured; but there is no doubt that, after being driven from the garden of Eden, he and his posterity continued tocover themselves with some description of clothing. The change from this blissful abode to less favoured regions rendered a more substantial covering necessary. Their merciful Creator provided their first dress, or taught them how to provide it, and this knowledge would enable them to prepare clothing in the future, both for thenselves and family. That God does so instruct his creatures is expressly stated by Isaiah, and it may be safely asserted that Adam got all needful instructions to fit him for his new and fearfully altered position.

Probably their clothing at first was formed of skins, it may be of the animals offered in sacrifice to God, and these would be followed by some sort of woven substance. Although there is no positive record of what material that was composed, it is very likely to have been wool. Abel, the second son of Adam, was "a keeper of sheep," and the flock supplied a ready material of which to make clothing, the fleece requiring comparatively little preparation to adapt it for being made into 
coarse cloth. Food and clothing were the first wants of fallen man, and the flock offered a natural and ready supply of both.

In the antediluvian age, as in the ages after the Flood, some of the people dwelt in houses, while others led a nomadic or pastoral life, and lived in tents. It is said of one of Lamech's wives, "Adah bare Jabal, he was the father of such as dwell in tents and have cattle." Nomades must wander from place to place in search of fresh pasturage for their flocks and herds, and their tents, while impervious to wind and rain, require also to be light and portable, that they may be easily removed. No other than a woven fabric is well adapted for such a purpose, and therefore it is certain that the spinning and weaving of cloth suitable for clothing and tents, and for other domestic purposes, formed one of the very earliest arts acquired by man.

There is no mention of Linen in the antediluvian age, but there is little doubt that it was then known and used. It is recorded that there were then musicians, and artificers in iron and brass, and shipbuilders, and tillers of the ground. Such notices imply a knowledge of the productions of nature, and of the art of applying them to the use of man. They also infer that the people lived in a state of luxury, and sought to enjoy the pleasures of life. Linen forms a cool, clean, and comfortable article of clothing, more especially in warm climates, and even then it would probably be sought for as a substitute for woollen garments in the hot season of the year.

It is certain that it was known and manufactured at a period not long subsequent to the Flood, and therefore it is very likely to have been known and in use before that event occurred.

The facility of changing body linen in temperate climates in -modern times, has added at once to health and longevity, and has greatly contributed to the comfort of the wearers. The same feeling must have existed among mankind in early ages, especially in hot and sultry climes, and this would cause such a material as Linen to be sought for, and highly valued when found. By the experiments made by Mr Thomson, afterward referred to, it appears that every Linen thread presents only the sides of cylinders, while that of cotton is surrounded by an innumerable multitude of exceedingly minute edges. This may explain the 
reason why the effects of Linen and cotton upon the health and feelings of those who wear them are so different. Ininen is much more lustrous than cotton, and the reason would seem to be because the lucid surfaces on the fibres of Linen are much larger than on those of cotton, and therefore more bright and shining.

It is related that Noah, shortly after the Flood, was uncovered in his tent, and that Shem and Japheth, two of his sons, took a garment and covered their fither. Noah and his family must have had their elothing and tents with them in the Ark, as this event appears to have happened shortly after the Flood subsided, and when, as yet, there was no time to prepare such articles. For a considerable period after this event the Bible makes little mention of woven fabrics, although they must have been in constant use. It is stated that Abraham pitched his tent near Bethel; that he sat in his tent door in the heat of the day ; that he would not take from a thread even to a shoe latchet of the spoil of the four kings whom he discomfited; and such like passages.

The Arab tent is composed of a cover of black goat's hair, compactly woven, with sides of coarse wool, spun at home by the women. Those in use by Abraham and others in patriarchal days were probably of a similar description, as there is little change in the manners and customs of these primitive people since the earliest records. A curtain of white woollen or Linen stuff, sometimes embroidered, divides the tent in two, the outer being for the men and the inner for the women.

When Rebekah met Isaac, she lighted off the camel, and took a veil and covered herself. 'The Eastern veil is a large sheet, which being thrown over the head, descends to the heels, and when gathered in front envelopes the whole person. In this early age they were almost always of Linen, and in some instances, as in the case of Ruth, of a coarse strong texture, capable of containing a considerable quantity of grain. This is the first time that a fabric, which it is almost certain was Linen, is mentioned in the Bible, although there can be no doubt that it was in use in Phœnicia before this period, as Egypt, a neighbouring country, was celebrated for its manufacture hundreds of years before $A$ braham went there.

Rebekali took goodly raiment of her eldest son Esau, which was with her in the house, probably of her own manufacture, 
and put it on Jacob her youngest son. When Jacob went near to his father and kissed him, Isaac blessed him and said the smell of my son is as the smell of a field which the Lord hath blessed. This would seem to imply that the garment was made of Linen, which is the produce of the fields, as to none other could the expression used be so applicable.

Woven fabrics are also mentioned in other passages of the Bible in these early times, such as the following:-Laban searched for his goods among the household stuft of Jacob; Tamar, Judah's daughter-in-law, put off the widow's garment; and Jacob made for Joseph a coat of many colours. About this coat there is considerable diversity of opinion, but it is generally supposed to have been composed of patch-work, and very probably of different colours of woven cloth. Such a dress was highly esteemed in Eastern countries in early times. The mother of Sisera, anticipating the return of her son victorious, says, "Have they not sped, have they not divided the prey, to every man a damsel or two? To Sisera a prey of divers colours of needle work, of divers colours of needlework on both sides, meet for the necks of them that take the spoil." In the days of David, kings' daughters, who were virgins, wore a garment of divers colours. In those times the art of interweaving a variegated pattern in the original texture was little known, and such dresses must therefore have been scarce and very valuable. Asiatics are still fond of dresses in which various fabrics are interwoven, and Mr Roberts states that in India it is customary to invest a beautiful or favourite child with a coat of many colours, which are often tastefully sewn together.

When Joseph's brethren took his coat of many colours, which they had dipped in the blood of the slain kid, and brought it to their father, he knew it and was very sorrowful. It is added that "Jacob rent his clothes and put sackcloth upon his loins, and mourned for his son many days." This sackcloth was probably a coarse fabric of Linen cloth, used for the purpose of holding grain and other commodities, very much as it is at the present day. It was often used, even in these early times, in seasons of deep affliction, when pleasure was burdensome, and the suffering body soothed the afflicted mind.

Sackcloth is often associated in Scripture with times of great 
suffering and sadness. When Sennacherib invaded Judea, Hezekiah rent his clothes, and covered himself with sackcloth, and went into the House of the Lord to implore his guidance and help. Mordecai rent his clothes and put on sackcloth and ashes when Haman decreed the destruction of the whole of the Jews; and many of the Jews lay in sackcloth and ashes on that mournful occasion. Daniel set his face unto the Lord God to scek by prayers and supplications, with fasting and sackcloth and ashes. At the preaching of Jonah the people of Nineveh put on sackcloth from the greatest of them even to the least. And the king arose from his throne and laid his robe from him, and covered him with sackcloth and sat in ashes. Sackcloth is repeatedly mentioned by Isaiah, and in other passages in the Bible, and for a very long period it must have been used as a symbol of grief by God's ancient people. 'That it was used for a similar purpose by other nations as well as by the Israelites, is shown in the case of the repentance of the Ninevites. Indeed, from the most remote times it seems to have been worn in seasons of deep affliction by the inhabtants of all Eastern countries.

It is, however, to be noticed that cloth made of goat's hair was used for sacks by the Greeks and Romans. "The Hebrew, Chaldee, and Syriac term for cloth made of this material is Shac or Sac, translated Saccus in the Vulgate version of the Scriptures. The Latin Sagum appears to have had the same origin. In English, sack and shag differ little from the oriental terms either in sound or sense." It may be, therefore, that the sackcloth spoken of in Scripture was of goat's hair, and not of Linen, and that the sacks which Jacob's sons took to Egypt to contain the corn, and those of the wily Gibconites, were also of that material. If the sacks which the brethren of Joseph took down with them to Egypt to contain the corn which they went to buy were not made of goat's hair, they were probably made from Flax, it being the strongest and most suitable material of which they could have been formed. It is possible that they may have been the manufacture of Egypt, as various qualities of Linen had found their way into Phonicia long before that time.

The first mention of Linen by name in the Scriptures is when Pharaoh exalted Joseph to the second place in the land of 
Egypt:- "And Pharaoh took off his ring from off his hand, and put it upon Joseph's hand, and arrayed him in vestures of Linen, and put a gold chain about his neck." Although this is the first time the term Linen appears in the Bible, it is well known to have been a common article of clothing at a much more remote period. The first portion of the earth occupied by man was in Asia, not far from the banks of the Euphrates, and it was near to the same river that the Ark settled on the subsidence of the water after the Flood. There the heat is so great, especially in summer, that woollen clothing is very burdensome. The only other fibre adapted for being formed into cloth, with which the early inhabitants of the world seem to have been acquainted, was Flax. That this plant was known and made into cloth at a very early period, is fully established, because specimens of Linen have been discovered in Egypt, which are proved to be fully 4000 years old. Linen may have been made at as early a date in other countries, but, so far as known, there is no record of this extant, the first mention of the article, either in sacred or profane history, being in connection with that country. As the Linen of Egypt will be treated of in the following chapter, it will be referred to here only in so far as is necessary to elucidate Bible Linen.

The vestures with which Joseph was arrayed were probably a kilt, suspended from the shoulders by straps, fastened round the middle, and reaching below the knees, with a large full shirt over it. Both articles were composed of fine white Linen, the upper being of a very beautiful and transparent texture, and fringed at the bottom. This was the usual dress of the king of Egypt, and it may have been one of Pharaoh's dresses which was put upon Joseph, that having sometimes been done in Eastern countries when the king desired to show a very special mark of respect to a favourite subject.

In embalming the dead in Egypt many folds of Linen were wrapped round the body, the quality of the fabric varying with the rank of the deceased. Jacob, and afterwards Joseph, were both embalmed in the usual way, and their bodies carried up from Egypt to the promised land, for the purpose of being buried in the Cave of Machpelah, the former shortly after his death, and the latter when the Israelites went up to take posses- 
sion of Canaan. No doubt the Linen which was employed for embalming so great personages was of fine texture, somewhat corresponding to their exalted position. It may still be about these bodies in that celebrated cave, but the Moslem guards it with so great jealousy that its wonders are all unknown.

Flax is first noticed in Seripture (indeed this is the earliest mention of Flax by any author), in the record of the plagues inflicted upon Egypt, when it is stated that " the Flax and the barley were smitten ; for the barley was in the ear and the Flax was bolled." Flax was a large and valuable crop in that country, and its destruction would be a serious loss to the people, because, in addition to the intrinsic value of the Flax, those who manufactured it into yarn and cloth would lose their employment until another crop was grown, as it is improbable that a year's spare stock would be on hand. Flax was also grown at this period near the Jordan, in Canaan. It is reported that Rahab brought the spies when they visited Jericho "up to the roof of the house, and hid them with the stalks of Flax, which she had laid in order upon the roof." This was literally "Flax of the wood," undressed Flax with its ligneous parts, placed on the roof to dry, preparatory to being scutched, the flat roofs of Oriental houses being well suited for laying out vegetable products which required to be aired in the sun, and it shows that the Flax had then but recently been gathered.

Job, who lived at an early period, complained that his days were swifter than a weaver's shuttle. The staff of Goliath's spear was like a weaver's beam, so also was the staff of his brother's spear. In the hand of the Egyptian who was slain by one of David's mighty men was a spear like a weaver's beam. 'These and other passages show that Flax was cultivated, prepared, spun into yarn, woven into cloth, and considered an important article of merchandize in very remote ages, not only in Egypt, but also in the adjoining countries. It has been satisfactorily proved that Linen was manufactured by the Israelites shortly after their settlement in Canaan, and for ages long subsequent to that event. The common, the hairy, and the knotted species or varieties of Flax were all grown from an early period in Palestine, 
and for long ages it was cultivated very extensively in that country. In the wilderness, and after their settlement in Canaan, it was the women chiefly who span the yarn, wove the cloth, and embroidered it, not only for domestic purposes, but also for sale. The Linen manufactures of Palestine were generally of the coarser descriptions, the finer qualities having been imported from Egypt. The Hebrews having in view the formation of a national establishment of their own, would no doubt learn the art of spinning and weaving before they left Egypt, and it is certain they improved and perfected the knowledge so acquired during their sojourn in the wilderness. The furnishings of Linen for the temple and for the robes of the priests appear to have been marvels of art in spinning, in weaving, in dyeing, and in embroidery, and they show the great progress which the Israelites had then attained in this branch of manufacture.

When the Israelites quitted Egypt they carried with them a vast quantity of valuable and costly articles. This is clearly shown by the varied and extensive offerings of the people for the furnishings of the tabernacle, among which was "blue and purple, and scarlet, and fine Linen, and goat's hair." The inner curtains of the tabernacle were composed of fine soft Linen, splendidly embroidered with figures of cherubim, and fancy work in scarlet and purple, and light blue. They were put round the pillars, and hung down in a loose and flowing manner from their chapiters. Cords were put through rings in the pillars to keep the tabernacle from being shaken with the wind, and these were no doubt of Flax, as were also the loops on the edges of the curtains. The veil of the "holy of holies" was of the same texture, and, according to Josephus, it was embroidered with all sorts of flowers which the earth produces, and interwoven with various ornamental figures, excepting the forms of animals. The outer covering of the tabernacle was formed of a plain hanging of fine twined Linen, which seems to have been wrought in an open or net work texture, to permit the people without to see the interior. The door curtain was of a different fabric from the general hanging, being a great curtain of fine twined Linen, embroidered with blue and purple and scarlet.

Josephus says that another veil of like magnitude, and tex- 
ture, and colour, covered the entrance to this holy place, from the top half way down the pillar. Over this was another veil of Linen of a like size, drawn this way and that way by cords, that it might be no hindrance to the view of the sanctuary on solemn days ; but on cold or wet days it was expanded, and protected the veil of divers colours. Josephus adds, "Whence that custom of ours is derived of having a fine Linen veil after the temple has been built to be drawn over the entrances."

The high priest's garments were also chiefly composed of Linen, upon which the various ornaments and symbols were fixed. The ephod was a close robe or vest, reaching from the shoulders to the loins, and made of a rich cloth of fine Linen, embroidered in blue, purple, scarlet, and gold. The girdle of the ephod and the breastplate were formed of the same rich material. The robe of the ephod was a long Linen gown of light blue, reaching to the middle of the leg, or perhaps to the feet. It was woven all of a piece, without seam, and with an opening at the top for the head to pass through. At the bottom of the skirt were figures of pomegranates wrought with blue, purple, and scarlet yarn. The mitre was a turban of fine Linen, above which was another with swathes of blue embroidered, around which was a golden crown. The coat of fine Linen was the inmost of the sacerdotal garments, and was a long robe fitting close to the body, reaching to the feet, and with sleeves tied fast to the arms. This vestment was made of Flax doubled, and was called Chethone, denoting Linen, which was called by that name. It was embroidered with flowers of scarlet, and purple, and blue, and fine twined Linen; but the fabric was nothing but fine Linen. It was also worn by the other priests while officiating. The girdle of needle work worn by all the priests was a piece of fine twined Linen, embroidered in blue, purple, and scarlet, which went round the body, but so loosely woven that it is said to have resembled the skin of a serpent. Maimonides says it was three fingers broad, and thirty-two cubits long. The priests also wore bonnets or turbans of Linen cloth, which was doubled round the head many times and sewed together; and Linen breeches or drawers, reaching from the loins to the knee. The old robes of the priests were unravelled to burn as wicks for the lamps at the feast of tabernacles. 
It is related that " all the women who were wise hearted among the Israelites did spin with their hands, and brought that which they had spun, both of blue, and of purple, and of scarlet, and of fine Linen, an offering unto the Lord." Also that the Lord filled Bezaleel and Aholiab with the spirit of God in wisdom, and in knowledge, \&c., to work all manner of work of the cunning workman, and of the embroiderer in blue, and purple, and scarlet, and fine Linen, and of the weaver. This shows that the Israelites had constructed in the wilderness looms, and all the other necessary implements and machinery for the production of the articles required for the tabernacle, and other such purposes.

Linen would thus appear to have entered largely into the magnificent furniture and fittings of the tabernacle, and almost wholly to have composed the clothing and gorgeous robes of the priests, both on ordinary and on state occasions, even at the very beginning of the Jewish ritual. Aaron; when he entered the holy place, was required to "wash his flesh in water, to put on the holy Linen coat, to have the Linen breeches upon his flesh, to to be girded with a Linen girdle, and to be attired with the Linen mitre: These are holy garments."

For a long period Linen continued to be the clothing of the priests when they were serving in the sanctuary. Garments woven in one piece throughout, so as to need no making, were held in high repute; hence the Jews have a tradition that no needle was employed in the clothing of the high priest, each piece of which was of one continued texture. This idea throws light on the description of the coat of Jesus:- "The coat was without seam, woven from the top throughout." This seamless coat would seem to indicate that our Lord, knowing that his time was now come, had arrayed himself in vestments suitable to the dignity of His Messianic office.

Philo, who lived at Alexandria, says " the Jewish high priest wore a Linen garment made of the purest Byssus, which was a symbol of firmness, incorruption, and of the clearest splendour, since fine Linen is most difficult to tear, is made of nothing mortal, and becomes brighter and more resembling light the more it is cleansed by washing."

Josephus says the Jewish priests wore drawers of "spun Flax," and over the drawers a shirt with flowers woven into it, 
which were of three different substances. He also mentions that the curtains of the tabernacle were of the same materials, and in all these articles the ornaments were of splendid materials and colours, put upon a ground of fine white Linen.

Reymier says that the law which obliged the priesthood to be clothed in Linen garments, imposed on them an onerous obligation, but there is not on any ground the least pretence for such a strange assertion. If there had been no command on the subject, the Jewish priesthood, following the example of the Egyptian priests, would very probably have chosen Linen for their clothing, especially when employed in the service of the sanctuary, it being not only clean, and pure, and comfortable in itself, but also an emblem of purity, and nothing better could have been used in its stead. There was, howerer, a distinct revelation on the subject, which positively settled the matter. The divine mind ordered Linen clothing for the priests, because it was in every respect the most suitable, and no passage occurs in the Bible to prove the assertion that the priests considered the command burdensome, or that they wanted it changed.

That it also formed part of the ordinary clothing of the people in the wilderuess appears from the rules for cleansing the garment "that the plague of leprosy was in." Whether it was a woollen garment or a Linen garment, or whether it was in the warp or woof of linen or of woollen, it had to be shut up certain days, and if at the end of that period the disease stain had spread it was to be burned; but if not it was to be washed, and after other trials it might be cleansed and then used again.

The Israelites were forbidden to wear a garment mingled of Linen and woollen, or of Linsey-woolsey. Josephus assigns as a reason for this, that such clothing was allowed only to the priests, and such no doubt was the case in later times, although not in the days of Moses. Maimonides says it was to prevent idolatry, as heathen priests wore such mixed garments in the hope of a lucky conjunction of the planets bringing down a blessing upon their sheep and their Flax.

Flax was used for making cords and ropes, both by the Jews and neighbouring nations. Samson was twice bound with new ropes of Flax, as recorded in the Book of Judges, but with him the new Flax cord became as Flax that was burned with fire; 
and again, he brake them off his arm like a thread. Herodotus mentions that the Phœnicians furnished Xerxes with ropes of Flax for constructing his bridge across the Hellespont, while the Egyptians supplied ropes of papyrus, which were inferior to the others in strength.

Linen was frequently used in early times for writing on. Even long before the mention of papyrus, Linen books are noticed by Pliny, and Vopiscus, and Livy speaks of such books being found in the temple of Moneta. Some biblical scholars suppose that the original of the Pentateuch and of the other books of the Old Testament were written on rolls of Linen. The question is open to investigation, as the Bible does not say of what the rolls were composed. Very probably when a roll or book is mentioned it is to be understood as of Linen, or of the skins of animals. The Sibylline books were made of Linen, and many mummy cloths have hieroglyphics on them.

Samuel, when a child, ministered before the Lord, girded with a linen ephod. David, at the removal of the ark, "was clothed with a robe of fine Linen; and all the Levites that bare the ark, and the singers, and Chenaniah the master of the song, with the singers, were clothed with robes of fine Linen. David also had upon him an ephod of Linen." Solomon imported Linen yarn from Egypt, and it is added "the King's merchants received it at a price." The making of Linen in Israel appears to have been confined to certain families, as it is reported in the genealogies recorded in Chronicles that "the sons of Selah the son of Judah were, Er, the father of Lecah, and Laadah the father of Mereshah, and the families of the house of them that wrought fine Linen, of the house of Ashbea." The Hebrew literally is " the families (or perhaps the partnerships) of the manufactory of Byssus." Among the other workmen got by Solomon from Hiram, King of Tyre, to assist in the erection of the Temple, was Hiram, the son of a widow of the tribe of Dan or Naphtali, whose father was a man of Tyre, (or according to Josephus, his father was Ur, of the stock of the Israelites), skilful to work in gold, in purple, in blue, in fine Linen, and in crimson. He made the veil of the temple of blue, and purple, and crimson, and fine Linen, and wrought Cherubim thereon. Josephus says Solomon "had 
veils of blue, and purple, and searlet, and the brightest and softest of Linen, with the most curious of flowers wrought upon them," which were drawn before the doors of the most holy place in the temple. He also had Linen curtains drawn over the doors of the holy place, in the same manner as they were drawn over the doors of the most holy place.

It is recorded in Psalms that the clothing of the King's danghter is of wrought gold, and that she shall be brought unto the King in raiment of needle work. This is supposed to refer to Pharaoh's daughter, and if so, her costly dress was doubtless of Egyptian manufacture, and composed of fine Linen of an extraordinary light and gauzy texture, and beautifully embroidered.

In Proverbs the attire of an harlot is mentioned. In some nations these lewd women, these courtezans, were obliged to wear a dress different from other women. In Israel it is not certain what sort of habit this was; but as the Athenian Lawgiver who took many of his customs from the Jews, and very likely this among the rest, ordered that women of innocent conversation should never appear abroad except in grave and modest apparel, and that the rest should wear flowered garments, it is probable that in Israel they had to appear in a somewhat similar attire. This dress was very probably of the Linen of Egypt, coloured or embroidered in some distinctive way. The harlot is also said to have decked her bed with coverings of tapestry, with carved works, with fine Linen of Egypt. Perhaps this would be better expressed by saying, I have covered my couch with variegated coverings of Egyptian tapestry, as that would be more in accordance with the more probable interpretation of the text. The word used in the Septuagint would suggest that it was the same on both sides, and it may be supposed to apply to some rich figured stuff employed for coverings to divans or sofas (which must be understood in such passages instead of beds), and perhaps also to cover such thin mattresses or quilts, as now serve in Western Asia for coverlets or counterpanes. This forms in fact one of the chief articles of domestic luxury in the East, for as the best rooms have no other furniture than sofas and cushions, every one desires that the stuffs with which they are covered should furnish evidence of his taste and wealth. It 
may also extend to the curtains with which the doors were hung during warm weather ; and in general it may be said, that, studious as Orientals are of richness in their personal attire, they are perhaps still more anxious about the draperies of their principal apartments. It would appear to have been the same in ancient times.

The Medes and Babylonians were celebrated for their embroidered stuffs, and cloth of a like description. Their noted tapestries, \&c., were figured by the needle, and were very famous in these and other countries. The Egyptians rivalled the Babylonians in this class of fabrics, and if the variegated coverings mentioned in the text above referred to had been Babylonian, it might have been concluded that they were wrought by the needle. They, are, however, said to be Egyptian, and as the Egyptians not only excelled in needlework, but also produced variegated patterns in the loom, as well as by the subsequent' application of colours to stuffs that were woven plain, it is doubtful to which of these the passage refers, but there is no doubt that it refers to Linen of one or other of these descriptions.

In Proverbs a very different class of women is mentioned in connection with Linen than those referred to in the foregoing passage. The one is the harlot, the most debased of womankind ; the other is the virtuous woman, "one among a thousand" - "She seeketh wool and Flax, and worketh willingly with her hands. She layeth her hands to the spindle, and her hands hold the distaff. All her household are clothed with scarlet. She maketh herself covering of tapestry, her clothing is silk and purple. She maketh fine Linen, and selleth it, and delivereth girdles unto the merchants." These passages give the character and occupation of an industrious housewife among the Hebrews, and are very instructive and interesting. In the early history of nations, and before trade had been established with neighbouring countries, or home manufactures become objects of attention, every kind of drapery was manufactured at home by the women. In such times the women took a pride in boasting that their husbands and children were solely attired by the labour of their hands, and a very proper subject of congratulation it was.

Among the pastoral tribes of Asia, and among the peasantry 
in various parts of the world who can themselves raise the materials of manufacture, or who cannot purchase so conveniently or so cheaply as they can produce, this practice is still continued. Among such classes, ladies of high rank, then as now, took the sole management of the various branches of domestic economy, and assisted their maidens in the production of embroidery and other fine work. Homer represents some of the most distinguished ladies as so employed. Penelope plied the spindle and loom, and tasked her maidens. The royal mother of Nausicaa in the dawn of morning, worked beside the hearth, spinning soft fleeces dyed with the sea purple. Even the glorious Helen wove a gorgeous web representing the battles which nations waged for her sake.

The proximity of time of these examples of royal industry, and its distance from the present, render such illustrations all the more interesting. In this country, during the middle ages, if not at a comparatively recent period, such usages were common. It is much the same still in Normandy, and also in oriental countries.

The virtuous woman "maketh fine Linen and selleth it." This passage most probably means that she made under garments or shirts, girdles, and other articles of Linen, primarily for the use of the family; and that, when more were produced than supplied the wants of the household, she sold the surplus to the merchant or shopkeeper who dealt in' such products of female labour. By this means, bachelors, and families who had no manufactures in their houses, or not sufficient for their wants, were supplied from the superabundance of those who produced more than they required. This kept the domestic establishment of such ladies fully and profitably employed, and was at the same time a great advantage to those who had no such establishments of their own to supply these necessaries. At a time when such articles were not, as now, to be purchased any day by those who have thic means to pay for them, the products of the industry of the virtuous Hebrew women must have been a great boon to those who required them, while they were at the same time a high commendation of, and profitable to, those who produced them.

It is recorded in Esther, that King Ahasuerus made a feast in 
Shushan, the palace, in the garden of the king's palace. The hangings of the pavillion were of various colours, fastened with cords of Linen and purple to silver rings and pillars of marble. Also, that Mordecai, after his advancement, "went out from the presence of the king in royal apparel of blue (or violet) and white, with a great crown of gold, and with a garment of fine Linen and purple." This shows the use of Linen in Babylonia at this period, and the perfection which had then been attained in its manufacture; but it is uncertain whether the Linen had been made in the country or imported from Egypt by the luxurious Ahasuerus, although it appears most probable that it was made in Babyionia.

In the days of Isaiah, the daughters of Zion were haughty, wanton, and filled with pride, and to punish them the Lord threatened to destroy their beauty, and take away their gaudy attire. Some of the articles of dress and ornament worn by them are very curious and instructive, as showing the luxury of the Lord's chosen people in that early age. Several of the articles of clothing then worn by the women of Jerusalem were composed of Linen, and prove the extensive use of this fabric among the Israelites. The mufflers (or spangled ornaments) were no doubt a description of veil, and these, as already mentioned, were made of Linen, the Eastern women not wearing transparent veils as is done in this country. Veils are almost universally worn by women in the East, but it is remarkable that it does not appear from Egyptian paintings that they were then used by the females of Egypt, although they were in general use in many Eastern countries at that early period. The bonnets or turbans were sometimes composed of Linen wound round the head, and sometimes of rich handkerchiefs or shawls. Changeable suits of apparel denote beautiful or costly garments, of the richest stuff that could then be procured. Mantles and wimples were formed of various sorts of material, according to the circumstances of the weaver. Fine Linen here probably denotes shirts or inner garments. Hoods are supposed to have been handkerchiefs or pieces of Linen cloth, which, after covering the head, fell down behind the back, and were brought round in front to cover the bosom and lower part of the face, and thus also supply the place of a veil. The veil mentioned is probably 
the head veil worn within doors. It forms one of the most graceful articles of female attire in the East at the present day. The stomacher was a piece of wide Linen put loosely round the waist, with the corners hanging down either behind or in front. The dress and ornaments described by the prophet were very attractive and costly, and the changing of them for a girding of sackcloth must have been a sore trial to the beautiful daughters of Zion.

The ordinary clothing of the Hebrews was a coat or waiscoat and a cloak. The coat was of Linen, and the cloak of stuff or woollen cloth, and the Hebrews never changed the fashion of these garments. It is probable, therefore, that the same description of dress which was worn by them when they first entered into the promised land was continued until the time of the Babylonish captivity.

The beautif:l passage, in which the prophet, referring to the loving Saviour, says, "A bruised reed shall he not break, and the smoking (or dimly burning) Flax shall he not quench," displays an intimate knowledge of the nature of the fibre in a state of ignition. The ends of the bundles, if exposed to the air, will rise into flame, but farther in the fire will continue to burn dimly or smoulder until the whole be consumed. In this way fire may be lodged for days among Flax, and it is only when fanned by the wind that it will burst into flame. The Hebrews used Flax for wicks to their lamps, which makes the allusion to the smoking Flax all the more appropriate and beautiful.

In the prophet's burden of Egypt, among the misfortunes and desolations that were to befal that people, it is recorded thus :"Moreover they that work in fine Flax, and they that weave net works (or white works), shall be confounded." This shows that the manufacture of Linen was one of the most important carried on in Egypt, as it is specially singled out as a vulnerable point, which, if confounded, would bring great woe upon the people and the country.

Jeremiah, in describing the custom of clothing the idol statues in rich dresses, says, "blue and purple is their clothing. The vestments and decorations of the statues of the gods in heathen temples were frequently of the most gorgeous des- 
cription, testifying at once to the wealth and to the liberality of their votaries. The material was of the very finest texture, manufactured in the most skilful manner, and embroidered and ornamented with the most costly articles, the whole forming robes of the greatest delicacy and beauty. This was the common practice among heathen nations, and the Jews adopted it when they lapsed into idolatry. There were various reasons for this, such as that it told effectively upon the minds of the undiscerning multitude, and it was a matter of some importance to the priests, as they derived considerable profit from the robes and ornaments lavished upon the idols. Pausanias mentions a brazen statue of Neptune at Elis, which was about the size of a large man, and was clad sometimes in woollen raiment, and at others in Linen and Byssus. In the Apocryphal book of Baruch, it is said, the priests take off the garments from the idols to clothe their wives and children.

The prophet was told by the Lord to get a Linen girdle and put it upon his loins, and afterwards to hide it by Euphrates that it might be marred, implying that the pride of Judah should be so marred. Girdles were and still are of importance in the East. They are frequently of Linen, but often of other material, and the size and richness of the girdle marks the dignity of the wearer.

Ezekiel, in describing the goodness of God to his ancient people, says, "I clothed thee also with broidered work, and shod thee with badger's skins, and girded thee about with fine Linen; I covered thee with silk." "And thy raiment was of fine Linen, and silk, and broidered work." This shows that embroidered dresses and clothing of fine Linen and silk were tokens of wealth and dignity, and as such held in high favour, and much prized in those days. It also shows that Israel forgot the bountiful giver of such signal marks of greatness.

The Assyrians, the lovers on whom the Israelites doted, were clothed in blue. Blue colour, probably sky blue, was held by the Jews and other Oriental nations in high esteem. It is often mentioned in the Bible, and it formed one of the colours in the High Priest's robe, in the hangings of the tabernacle, \&c. Light blue is still a favourite colour among the Persians, in whose dress it is more extensively used than any other. The 
outer gown and the drawers are the articles most frequently worn of this colour, and among all classes these are usually of Linen. In Arabia the dress of the women commonly consists of an ample shift and drawers of blue Linen.

In the lamentation for Tyre the prophet beautifully and graphically describes the merchandize in which the merchant princes of that world-renowned city traded. Prominent among these were "fine Linen, with broidered work from Egypt was that which thou spreadest forth to be thy sail; blue and purple (or purple and scarlet) from the Isles of Elishah was that which covered thee."

Fine Linen was not a very suitable article for the sails of a ship in any other than holiday navigation, nor would it be very eligible even then. It is possible that the passage may refer to flags or ensigns rather than to sails, as these generally have some painting or device upon them. The description may, however, refer to the splendid pleasure-galleys of the merchant princes of Tyre, which, from the vast wealth of the owners, would be gorgeously fitted up, and for them such sails may have been adapted. In Egypt, while the ordinary sails were white, those belonging to the pleasure vessels of the king and the nobles were often painted with rich colours, or embroidered with fanciful devices. Some of them were striped, others chequered. Sails of this sort were also furnished with a strong hem or border, neatly coloured, to preserve them from injury, and a light rope was generally sewed round them for the same purpose.

Javan is the general title for the Greek nation, and Elisha was one of the sons of Javan. The Isles of Elishah may, therefore, be taken for a part of Greece, such as Elis, Hellas, or Peloponnesus. The Tyrians were the most famous dyers of purple, but next to the Tyrian was the purple of Laconia, and the purple cloth of that province was used because it was cheaper than that of Tyre, which was reserved for the use of kings. It was employed for awnings to the galleys, which were sometimes magnificent. The galley in which Cleopatra sailed down the river to meet Antony, had an awning of cloth of gold, and the description which historians and poets give of this vessel is explanatory of the prophet's descrip. tion of the splendour and magnificence of the Tyrian ressels. 
To this galley Shakspeare alludes in the following beautiful passage :-

\author{
The barge she sat in, like a burnished throne \\ Burnt on the water; the poop was beaten gold, \\ Purple the sails, and so perfumed that \\ The winds were love-sick with' 'em.
}

Syria or Aram, in Scripture sometimes means Mesopotamia, and sometimes Damascus and the country about Libanus, \&c. The merchants of that country attended the fairs or markets of Tyre with the produce of Persia and other lands, taking in return purple and broidered work, and fine Linen, and other productions of Tyre, or those supplied by her commerce.

In Ezekiel's vision of the temple, he mentions that the man had a line of Flax in his hand; the word line being derived from linea, Flax. He also records that when the priests the Levites " enter in at the gates of the inner court, they shall be clothed with Linen garments; and no wool shall come upon them whiles they minister in the gates of the inner court, and within. They shall have Linen bonnets upon their heads, and shall have Linen breeches upon their loins; they shall not gird themselves with anything that causeth sweat." They were required when they went forth into the outer court to put off the garments wherein they minstered, and put them in the holy chambers, and to put on other garments. It thus appears that the wearing of Linen by the priests during their holy ministrations was, and was to be, a standing ordinance among the Israelites while their ceremonial ritual lasted.

Daniel records in his last vision that the man who was upon the waters of the great river Hiddekel, and told how long it should be to the end of the wonders which had been revealed to Daniel, was " clothed in Linen, his loins being girded with fine gold of Uphaz, his body like the beryl, and his face as the appearance of lightning," \&c. Again and again the Linen clothing of this glorious one is mentioned, thus implying that Linen is an emblem of purity, and therefore it is represented as being employed as the clothing of the angels, yea, even of the King of Glory. The Jews believed that good angels always wore, or at least always appeared in white raiment of Linen.

Two passages in Hosea clearly indicate that wool and Flax 
were the materials of which the clothing of the Israelites was composed, and that these were articles of primary necessity with that people. The symbolical wife of the prophet said "I will go after my lovers who gave me my bread and my water, my wool and my Flax, mine oil and my drink." Not finding her lovers, she resolved to return to her first husband, "For then was it better with me than now," forgetting that it is the Lord who supplies the wants of His people. For her sin the Lord declared that he would "take away my corn and my wine in the season thereof, and will recover (or take away) my wool and my Flax given to cover my nakedness." He, for her sins, says he will now "discover her lewdness in the sight of her lovers, and none shall deliver her out of mine hand."

There has been no little controversy about the nature of the material translated Linen in the Bible, as four different Hebrew words have been rendered Linen in our translation. Pishta, which is sometimes rendered Flax and at other times Linen; Bad, which signifies Linen; Butz, Byssus; Shash, Cotton. When Pishta or Bad is used there is no doubt that Linen is implied. The one may mean the Flax plant, and the other the cloth made of it, and both may have been used, as Flax and Linen often are in this country, to mean Linen. The Hebrew word Shash is translated "Byssus" in the Septuagint version, and in our own "fine Linen," and Shash is the name applied at this day by the Arabs to fine muslin, which is of Cotton, and not of Linen.

The word "Butz" does not appear in the text of Moses, although the Greeks and Latins use the word Byssus, which came from Butz, to signify the fine Linen of certain habits belonging to the priests. "Butz" occurs only in three or four passages in the Bible. In Chronicles, David is described as dressed in a mantle of Butz, with the singers and Levites, and also with having on at the same time a Linen ephod. Solomon used Butz in the veils of the temple and sanctuary; Ahasuerus' tents were upheld by cords of Butz, and Mordecai was clothed with a mantle of purple and Butz when King Ahasuerus honoured him with the first employment in his kingdom. The word is generally understood to mean the fine Egyptian Linen of which priests' tunics were made. In the 
present day part of the clothing of the dignitaries of the English Church is of Lawn, which is a species of very fine Linen, although not known by the name of Linen, and in like manner Byssus may have been some very fine description of Linen known under that title. There was a manufacture of Butz in the city of Beersheba in Palestine. The mummy cloths said by Herodotus to be "of Byssine sindon," are now known to be invariably of Linen, therefore the Byssus cannot be Cotton. Probably he meant no more by this expression than fine cloth, without reference to the material of which it was made. This subject is more fully adverted to in describing Egyptian Linen, and need not be farther continued here.

Frequent mention of Linen is made in the Now Testament, both with reference to terrestrial and to celestial objects. St Mark mentions that a young man followed Jesus, "having a Linen cloth cast about his naked body; and the young men laid hold of him, and he left the Linen cloth, and fled from them naked." The Linen cloth it is very likely, was his ordinary dress, or it may have been hastily thrown around him when he heard the tumult created by Jesus passing by, and went out to see the cause. In the original, the word is the same as that which describes the "Linen cloth" in which the body of Jesus was wrapped and hastily laid in the sepulchre of Joseph of Arimathea. The cloth in which the body of Jesus was wrapped before being laid in the grave is described as a clean Linen cloth. Very probably it had been so much taken off a piece of new white Linen as was required for the purpose, as there was no time to prepare a shroud specially for the Lord's body. Indeed it is said by St Mark that Joseph "bought fine Linen, and took him down, and wrapped him in the Linen, and laid him in a sepulchre." The Linen was thus new, and bought expressly for the purpose of wrapping the body of Jesus in; and as "Linen clothes" are mentioned by St John, the piece had evidently been cut into portions, the better to wrap up the body in it.

It was the custom then in Judea, as it still is in Western Asia, to wrap the dead body tightly round with many folds of Linen cloth, generally from a piece, and then to sew up and fasten the ends to keep the whole compact. The face was 
covered with a Linen napkin, and it was the practice to use them of the same lind and value, whether for rich or poor. The body was buried on the day of the death, or on the day following it, no coftin being used to enclose it. The grave clothes and napkin with which Lazarus was bound were no doubt of Linen, and the description of Jesus raising him from the dead is explanatory of this custom. The rich man is described as clothed in purple and fine Linen, implying that Linen clothing was in common use among the wealthy Jews in the time of our Saviour. It was also used for other purposes, as it is mentioned that Jesus "took a towel and girded himself," that is, with the towel. It was customary for a servant to wash his master or his master's guests, and when he did so he girded himself with a long piece of linen eloth, the ends of which being left hanging loose supplied the towel with which the hands and feet were wiped after being washed.

In the Revelation of St John, it is said that the seven angels who came out of the temple having the seven last plagues were "clothed in pure and white Linen." The merchandize of mystical Babylon were "fine Linen, and purple, and silk, and scarlet," \&c. The merchants who traded in these things shall stand afar off viewing the destruction of Babylon, and shall say, "alas, alas! that great city that was clothed in fine Linen, and purple and scarlet, and decked with gold," \&c., " for in one hour so great riches is come to nought."

Linen was used by man for purposes of clothing at an early period in his history. Where cleanliness and purity were required it was ever the chosen fabric. It has continued in use till now, and while time lasts it will continue to be a favourite dress with many people. Nor will its use cease when time has passed, as the last mention of Linen in the Bible is in reference to the glorious hereafter-to the heavenly Jerusalem.

In the triumphant song in hearen the redeemed shall rejoice because " the marriage of the Lamb is come, and His wife hath made herself ready, and to her it was granted that she should be arrayed in fine Linen, clean and white (or bright), for the fine Linen is the righteousness of saints" In heaven the Lamb's wife would be arrayed in the most beautiful of dresses. She seems to have asked for one pre-eminently pure, and it was granted 
that she should get the one she most prized. The most glorious vesture in which she could be arrayed by the Lamb was fine Linen, so clean and white as to be a fit emblem of the righteousness of saints. Earthly Linen is made from Flax which springs from the earth, and when finely bleached is very white and clear, but the celestial fabric, the fine Linen of the heavenly kingdom, is washed in the blood of Jesus, and therefore infinitely bright and pure. It is the true holy garment of saints.

He whose name is called the Word of God, who was clothed with a vesture dipped in blood, and sat upon the white horse, went forth, and was followed by the armies who were in heaven upon white horses, clothed in fine Linen, clean and white. The Lamb, His wife, and His army, the soldiers of the cross who have fought the good fight of faith and won the prize, are all clothed in fine Linen, clean and white, and all supremely pure.

In all ages Linen has been considered by man as an emblem of spotless purity, and well it may be so, for what on earth is cleaner, what can be purer, than fine Linen clean and white? It was the purest material in which it was possible to clothe the priesthood when performing their sacred duties, and it was used for this purpose in the idolatrous ritual of Egypt, of Greece, and of Rome, as well as by the Aaronic priesthood who ministered at the altar of the God of Israel. In heaven, for want of a brighter and cleaner object familiar to man, the righteousness of saints is said to be fine Linen, and there, because no finer or purer covering is known to man, it is said to be the clothing of the followers of the Lamb. Fine Linen, clean and white, is thus a token of purity on earth and an emblem of glory in heaven.

In the present day there is little Flax grown in Palestine, and Linen is not now an article of much consumption by the inhabitants of that country. It appears to have been to a great extent supplanted by cotton, but why this should be the case it is difficult to say. The habits and tastes of nations frequently change, and articles which have been long in use, from various causes become obsolete. Palestine has been repeatedly overrun by new and stranger races, who would, no doubt, import their own customs in dress as in other things, and in this way the wearng of Linen may have fallen out of use. 
Egrpt was early peopled by a civilized race. Menes or Misraim, the son of Ham, the first king, founded the kingdom in the year of the world 1816 , or, according to the commonly received chronology, 2188 years before Christ. Egypt has ever been considered by the ancients as the cradle of the sciences, and the nursery of the arts. The wonderful monuments of antiquity in which it abounds are unequalled in any land, and far surpass the greatest works of modern times. Its pyramids, its palaces, its temples, and its tombs, are the astonishment and admiration of mankind. Its fertility, caused by the annual overflow of the mysterious Nile, was as famous as its noble works of art, and the teeming soil enabled an almost incredible multitude of inhabitants to reside within its circumscribed limits.

The population of Egypt, although all descended from Ham, their common father, was divided into various distinct classesthe king, the priest, the scholar, the warrior, the husbandman, the shepherd, and the artificer, had each their several duties and privileges. Their common origin stamped a kind of nobility on every person descended from the common stock, and each class was respected by all the others. None were allowed to change their profession, so that each, by practice, became expert in their own calling, and, profiting by the experience of their ancestors, attained the highest perfection in arts and sciences.

Egypt holds the first rank in the production of Linen, both from the antiquity and extent of the trade, and naturally takes the first place, after Bible Linen, in an account of this ancient manufacture. The Egyptians early excelled in the art, and they were justly celebrated for the superiority of their Linens more than four thousand years ago. The Flax plant, matured by the fertilizing slime annually spread over the country by the Nile, 
grew there in perfection. Pliny mentions three sorts of Flax which were grown in Egypt. He gives the first place to Abeston or Abestinem, (i.e.,) incombustible Flax; the second to Byssus, which was of very fine and small fibre; and the third to the common Flax. He says that Byssus was extremely fine and dear, and none but rich and wealthy persons could afford to wear it, and also that it often received a purple dye, and served as an ornament to the ladies.

The various processes employed in the preparation of the plant in Egypt are admirably depicted on the enduring walls of their ancient palaces, temples, and tombs, by the skilful hand of the artist. Drawings of the various implements employed; of the people in the act of sowing the seed; pulling the plant; carrying water to fill wooden vats, evidently for the purpose of steeping the Flax; putting it through the several processes requisite to produce the fibre ; spinning it into yarn ; and weaving the yarn into cloth, are all distinctly pourtrayed The several operations are delineated with a minuteness of detail and a beauty of colouring truly astonishing. Thanks to the dry pure air of that celebrated country, many of the sketches look as bright and fresh as if they had only yesterday got the last finishing touches from the artist, instead of having been painted from 2000 to 3000 , and, in some instances, even 4000 years ago.

In Egypt, Flax is sown at the present time about the midnle of November, in the plains which have been inundated by the Nile, and it is pulled in about $\mathbf{1 1 0}$ days. It is generally in the boll in February, and pulled in March. There is little change in the climate of that country since the earliest records, and it is therefore probable that seed time and harvest is the same now as it was in the days of the first of the Pharaohs. The cultivation of the plant, the pulling and steeping, were all carried on very much as at present, and not very different from the mode practised in this country. The scutching process appears to have been done by beating the straw with a mallet to break it and loosen the fibre, and then by driving off the shive with a knife, comb, or other instrument. After being scutched it was combed or heckled, to break open or split up the fibres and to remove the loose fibres or tow, after which it was ready for spinning. This was done by the distaff and spindle, nearly in the same way as 
was practiced in this comtry not a century ago. The looms for weaving the yarn into cloth were of a comparatively rude construction, and not well alapted for producing a uniformly fine texture, but the industry and skill of the Egyptians overcame all difficulties, and enabled them to weave even the finest qualities, both of plain and figured fabrics, on their simple looms.

Sir J G. Wilkinson, in his popular account of the ancient Egyptians, minutely describes many of the processes connected with the growth and manufacture of Flax, and gives numerous drawings of several of the operations, copied from the drawings in the tombs and temples of that famous land. At Beni Hassan, the mode of cultivating the plant in the square beds, still met with throughout Egypt, the process of beating the stalk and making them into ropes, and the manufacture of a piece of cloth, are distinctly delineated. It is, however, possible, that the part of the picture in which men are represented pouring water from earthen pots, may refer to the process of steeping the stalks of the plant after they were cut. The square pieces would then indicate the different pits in which the stalks were immersed, containing some less, some more, water, according to the quantity of Flax and the state in which the process then happened to be. 'This is rendered the more probable by the flight of steps for ascending to the top of the raised sides of the pits, which would not have been introduced if the level ground were intended.

In the grottos of Eileithyias, the gathering of the Flax is represented in one of the bas-reliefs, and Costaz says the Flax is recognised by its length, which does not rise above the hips of the workmen, by the green colour of the stalk, and by the round yellow colour of the grain. Four men and a woman are employed in pulling it, another man binds it into sheaves, using his left foot to press the sheaf tight, and another carries it to one whose business is to get out the seed. This man stands under a tree with a comb the stock of which rests on the ground, and it is kept steady by the feet of the workman. He takes a handful of Flax and pulls it through the teeth of the comb, which detaches the bolls without injuring the stalk. Rosselina gives a representation from a tomb at Koum-el Ahmar, in which the men are pulling the Flax with the hand, after which it is tied in bundles and carried off the field on the back of asses. 
The steeping and the subsequent process of beating the stalks with mallets shown on the walls of the tombs, illustrates the following passage of Pliny upon the same subject:- "The stalks themselves are immersed in water, warmed by the heat of the sun, and are kept down by weights placed upon them; for nothing is lighter than Flax. The membrane or rind, becoming loose, is a sign of their being sufficiently macerated. They are then taken out and repeatedly turned over in the sun until perfectly dried, and afterwards beaten by mallets on stone slabs. That which is nearest the rind is called tow, inferior to the inner fibres, and fit only for the wicks of lamps. It is combed out with iron hooks, until all the rind is removed. The inner part is of a whiter and finer quality. Men are not ashamed to prepare it. . . . After it is made up into yarn it is polished by striking it frequently on a hard stone, moistened with water. When woven into cloth it is again beaten with clubs, being always improved in proportion as it is beaten."

The Egyptians also parted and cleansed the fibres of the Flax with a sort of comb, probably answering to the iron hooks mentioned by Pliny. Two of these, found with some tow at Thebes, are preserved in the Berlin Museum, the one having twentynine and the other forty-six teeth. This comb was used instead of the heckle of the present day, for the purpose of removing the tow or loose fibres of the Flax, and also for breaking or splitting up the fibre to adapt it for being spun into finer sizes of yarn.

The Egyptian yarn seems all to have been spun with the hand, and the spindle is invariably seen in the pictures representing the manufacture of the cloth. Spinning, as in Scotland before the introduction of spinning by power, was chiefly the occupation of women, and Wilkinson mentions that "wife" is nearly related to "woof," "weaving," and "web." Men were also employed at the spindle and the loom, though not, as Herodotus would seem to imply, to the exclusion of women, who, he pretends, undertook the duties of men in other countries " by going to the market, and engaging in business, while the men, shut up in the house, worked at the loom." Men to this day are employed in making cloth in Egypt as well as in Scotland and other countries, but it cannot be said that they have relinquished their habits for those of the women. The paintings executed 
by the Eryptians themselves represent both men and women manufacturing cloth.

In the hieroglyphics above the representations of the persons employed with the spindle, the word suht, which in Coptic signifies to "twist," constantly occurs. The spindles were generally small, being about fifteen inches in length, and were made of various sorts of material, such as wood, cane split, wicker work, \&c., and of a variety of forms or shapes. Several spindles found at Thebes are now in the museums of Europe, and one of them had some of the Linen thread with it when found. In order to increase the impetus in turning, the circular head was occasionally of gypsum or comprition. Some were formed of light plaited work, made of rushes or palm leav́es, stained of various colours, and furnished with a loop of the same material, for securing the twine after it was wound. The mode of spinning very much resembled that anciently practised in Scotland, which will be more particularly described in the chapter on Flax-spinning.

The historian Herodotus mentions that other nations made cloth by pushing the woof or weft upwards, while the Egyptians on the contrary push it down. This is confirmed by most of the paintings which represent the process of manufacturing cloth. At Thebes, however, a man, who is engaged in making a piece of cloth with a coloured border or selvage, appears to push the weft upwards, the cloth being fixed above him to the upper part of the frame. The Egyptian loom somewhat resembles the hand-loom in common use in Scotland, but the weft was put in by the hand, with a long wooden needle, split at each end to carry the weft, and not thrown through by a shuttle, as in the old system of hand-loom weaving here. Part of a needle of bronze of a later date was found at Berenice. They had also the horizontal loom which occurs in the paintings at Beni-Hassan and other places. At El Bershek, the mode of taking up the increasing length of the cloth by pegs in the ground, as still practised in Ethiopia, is shown. There is also shown at same place the manner in which the women wound off threads from numerous balls placed within a slight framework, the fineness of the threads being indicated by the number taken to form one twist. From the representations of Egyptian looms which occur in the tombs at Thebes, it might be supposed that they would have been totally incapable 
of producing the fine Linen so much admired by the ancients. The paintings in which they occur were executed at a very early period, and improvements may have taken place in their construction in after times It was not, however, necessary that this should be the case, as it is well known that oriental nations, by very simple appliances, are in the habit of executing the most delicate and intricate fabrics in so perfect a manner, that Europeans with the most complicated looms, and the newest improvements in mechanism, cannot surpass them. It is therefore very probable that their far-famed fine Linen, mentioned in Scripture and by ancient writers, was produced from looms of the same construction as those represented in the paintings of Thebes and Eileithyias, and these are of a very rude and primitive description.

The process of smoothing or calendering the cloth is also represented in the paintings. This appears to have been done by means of wooden rods passed to and fro over the surface. From the appearance of some of the fine Linen found in the tombs, it may be conjectured that much greater pressure was sometimes used for this purpose, and such as could only be applied by a press, or cylinder of metal. For smoothing Linen a wooden substitute for what is called an iron in this country was also used, some of which have been found at Thebes, six inches in length, and made of tamarisk wood. This chiefly belonged to the washerwomen, who had also a wooden. instrument for goeffreying fine Linen, by which the waving lines were made, which are frequently seen in the dresses of the kings and priests.

Pliny mentions four qualities of Linen, particularly noted in Egypt-the Tanitic, the Pelusiac, the Butine, and the Tentyritic. $\mathrm{He}$ also states that the immense quantity of Flax cultivated in Egypt was accounted for by their exporting Linen to Arabia and India, and that the quality of the Linen produced by Egyptian looms was far superior to any other.

The quantity of Linen manufactured and used in Egypt in ancient times was very great. Independently of what was made up ints articles of dress, the numerous wrappers required for enveloping the mummies, both of men and animals, show how large a supply must have been kept ready for the constant home demand. In addition to this a very large quantity 
was regnlarly exported to foreign markets, where it was in great request, and eagerly purchased by all who could afford to do so. Not only was the fine Linen and broidered work highly appreciated by other nations, but Linen yarn was also bought by them. It is related in the Bible that Solomon brought Linen yarn out of Egypt, and there is no doubt he was not the only foreign buyer of this much prized and really valuable production. When the Israelites left Esgyt it is known that they were intimately acquainted with the art, not only of making fine Linen, but also of embroidery, and they were not long in putting their knowledge to a practical use in making hungings for the tabernacle and robes for the priests.

Flax in the scutched or dressed state formed also a considerable branch of Egyptian trade, much of it being purchased by merchants from Carthage and other countries.

In the weaving, and in all the processes connected with the manufacture of fine Linen, the Egyptians have not been surpassed in modern times. Their Linens were composed of different qualities and fabries, all of which hat a world wide celcbrity, and the more civilized the people the more highly were they appreciated What the rich silks of France, or the beautiful lace of Belgium is to us in the present day, the fine Linen and broidered work of Egypt was among contemporary nations, and the more luxurious their habits the more were these articles valued and used.

The manufacture of Linen in Egypt in very early times formed one of the principal branches of industry to the inhabitants, very many of whom were engaged in its production. 'T'he city of Thebes was carly celebrated for its Linens, and it is very probable, from the immense quantity which must have been made, that there may have existed distinct establishments for its manufacture in various parts of the kingdom, of a kindred nature to the hand-loom weaving shops not yet extinct in this country. It is, however, certain that it was made extensively in the households of many of the inhabitants, very much as it was in Scotland at a not very distant period. As already mentioned, the yarn was spun and the eloth woven chiefly by the women, and it was weaved plain, embroidered or figured, white or lyed, as recuured. 
Of the products of the Egyptian loom in remote times little more is known than what the mummy pits have disclosed to us, and it would be as unreasonable to look through modern sepulchres for specimens and pronfs of the state of manufacturing art in the present day, as to deduce an opinion of the skill of the Egyptians from those fragments of cloth which envelope their dead, and have come down almost unchanged to the present age. The curious and costly fabrics which adorned the living, and were the pride of the industry and the skill of Thebes, have probably all perished ages ago. Some idea may be formed of the vast accumulation of Linen in the mummy pits and sepulchres of Egypt, when it is mentioned that it was a speculation at one time in Europe whether it should not be collected for the purpose of making paper.

Some of the Linen produced in Egypt was of a very common or inferior quality, the yarn being coarse and unequally spun, and the reed or set thin and open. Specimens of such cloth are frequently met with upon the mummies which have been exhumed. On opening up a mummy it is found that the body is wrapped round with many folds of Linen cloth. The poorer people were encased in Linen of common quality, ranging from 30 to 40 porter $\left(6^{00}\right.$. to $\left.8^{00}\right)$. The yarn forming this cloth is frequently ill spun, but other specimens of it are level and regularly spun, and though woven through a thin reed the cloth looks well. This proves that there were good and bad spinners in Egypt, even in the days when it was celebrated for its fine Linen, as there still are in this advanced age

The great mass of the mummy cloth employed in bandages and coverings, whether of birds, animals, or the human species, for many animals and all human bodies were embalmed, is of a coarse texture. The folds which are next the body, and which are generally found impregnated with resinous or bituminous matter, are the coarsest, the upper bandages nearer the surface being finer. Sometimes the whole is enveloped in a coarse and thick covering, very like some of the sacking of the present day, and sometimes it is in coarse and open cloth like what is now used in cheese presses, for which it might easily be mistaken. In the College of Surgeons various specimens of these cloths may be seen, some of which are very curious. In some 
instances as many as seven different qualities of cloth, varying from fine muslin to coarse sail-cloth, have been found on one mummy.

The priests, and the wealthy and noble classes, were encased in Linen of a very different texture from that used for the mass of the people, many of the specimens being remarkably fine, and well deserving the name of "fine Linen of Egypt." Some of it is stout and well woven, and made of excellently spun yarn, quite equal to the productions of the present day. The kings and queens, especially those of the earlier dynasties, some of whom have been discovered, were embalmed in a most costly manner, and the Linen employed for wrapping round them was of the very finest texture, beautiful alike in the quality of the yarn and in the fabric of the cloth. Some specimens have been found so fine that the very finest productions of the looms in modern times will scarcely compare with them. The very finest cambric or lawn of the present day looks coarse beside these specimens of the Egyptian looms in the days of the early Pharaohs. Indeed, so fine and so beautiful are they, that it is wonderful how the yarn could have been produced, or a fine enough reed formed for weaving them through.

The beauty of the texture and peculiarity in the structure of a mummy cloth found by Belzoni are very striking. It is free from gum, or resin, or impregnation of any kind, and has evidently been originally white. The yarn of both warp and weft is remarkably even and well spun, and the cloth is close and firm, yet very elastic. The thread of the warp is double, consisting of two fine threads twisted together, but the weft is single. The warp contains 90 threads in an inch (about 80 porter or $16^{00}$ ), the woof or weft only 44 , being barely half as many. The fineness of the threads, estimated according to the count of cotton yarn is about 30 hanks in the pound.

It would appear that the disparity between the warp and weft of Egyptian cloth was a system of their manufacture, as it is found in almost every specimen of it which has been examined. Sometimes the warp counts twice as many threads in an inch as the weft, sometimes three times, and not seldom four times the number. Cloth containing 80 threads of warp 
in an inch had 40 of weft, others with 120 threads in the warp had 40 in the weft, and others with the same number of threads in the warp had only 30 in the weft or woof. This system, so different from modern eloth, which has the proportions nearly equal, originated probably in the difficulty and tediousness of putting in the weft when the shuttle was thrown by hand, as is still the practice in this country with some very coarse fabrics, or by the still more tedious process already mentioned.

Basil Montague, in his "Thoughts on Laughter," states the case of a party against whom an action was brought in the Court of Common Pleas, in 1821, for infringing a patent, defending himself in the following remarkable manner. The question was asked whether the plaintiff's mode of weaving canvas was new or not. A witness for the defendant was called, who stated that so far from the plaintiff's manner of doubling the thread being new, he could state with certainty that it had been known and practised for upwards of 2000 years. The Court was incredulous and even jocular at his knowledge of the ancient mode of thread-making, and the Chief Justice, quoting the adage, "when Adam delved and Eve span," asked him if he could favour them with some information as to the method of spinning practised by our general mother. But the witness, nothing daunted, produced a specimen of cloth taken from the cerement of an Egyptian mummy, and proved to the satisfaction of the whole court that the yarn of which it was made, had been spun and twisted exactly in the manner described in the plaintiff's patent.

Some of the bandages which have been unwound from mummies bear indisputable evidence of having been mended or darned; seams occur in others. Old napkins, shirts, and other articles of clothing, and domestic furniture, are often found, and in one an armlet hole was found with the seams around it very neatly sewn. This proves that the old and worn Linen in the house had sometimes been given to the embalmers for bandages for the bodies, but it may only have been done by very thrifty housewives. Doubtless there were people in those days, as there still are, who would be quite content to permit, it may be the body of a distant relative, to be entombed at the least possible expense consistent with public decorum. In one 
case a perfect vest was discovered on a mummy, but generally the bandages are of new Linen taken from the webs. The quantity of Linen required for bandages for mummies must have been immense. Some of those unrolled have been found to weigh from 20 to 30 and $40 \mathrm{lbs}$, and to measure upwards of 300 yards in length. The Linen taken from one mummy, including the outer sheet, weighed $29 \mathrm{lbs}$, and the total length of the pieces was 292 yards. In some as many as 40 thicknesses of cloth have been found, the inner bandages being composed of various widths and lengths. The breadth varies from a few inches to two or three feet, and the length from two or three yards, up to six, eight, or nine yards.

The many sorts of draperies painted in Egyptian tombs help to elucidate the nature of the material employed in encasing the bodies of the ancient inhabitants, and supply information from which inferences can be drawn which may be received with tolerable certainty regarding its texture These exhibit a large variety of qualities, colours, and patterns. Some sorts are of various degrees of thickness, and, so far as can be judged from paintings, of rich and delicate workmanship, while others furnish patterns and styles not unworthy of imitation in the present age, and of a brilliancy of colouring which can scarcely yet be rivalled. Some qualities again āre so fine and transparent, that every detail of the figure which they envelope is seen with perfect clearness through them, as through very thin muslin or gauze. So great was the tenuity with which Linen was occasionally made in Egypt that some of the specimens obtained the appellation of "woven air," and certainly the praise was not unmerited. Sometimes Linen bandages are found on mummies with writing upon them, showing that the Egyptians were acquainted with a mode of writing on cloth.

Herodotus, who lived 460 years before Christ, finely describes the process of embalming, and the various materials used in the operation. Very large quantities of Linen cloth were used for this purpose, as the body was enveloped from head to font in many folds, generally taken off a web or piece of cloth, of various degrees of fineness, depending on the wealth of deceased, or of the surviving relatives. He says that Linen was the ordinary dress of the ancient Egyptians, orer which was some- 
times worn a woollen cloak or shawl, with fringes. The king wore a kilt, apron, or skirt, fastened round the loins and reaching below the knees, something akin to the Highland kilt of the present day, over which was a shirt of remarkably fine texture. The queen wore a light skirt, with a full shirt over it of very fine Iinen. The nobles and upper ranks wore the kilt, and on some occasions the shirt over it, the texture of which was not so fine as that worn by the king. The lower classes wore only a coarse kilt without any other covering above it. In like manner the upper ranks of women occasionally wore the shirt over the light skirt, but the lower classes of females invariably wore the skirt alone. This kilt and shirt were always of Linen.

Both Celsius and Forster quote passages from ancient authors which concur to show the abundance and excellence of the Flax grown anciently in Lower Egypt, and more particularly in the vicinity of Pelusium, the general employment of it among the inhabitants for clothing, and the exclusive use of Linen cloth for the garments of the priesthood and other sacred purposes, and especially for the worship of Isis and Osiris. The same authorities mention that Egyptian Flax, and the cloth woven from it, were shipped in great quantities to all parts of the Mediterranean.

The shirt of the priest worn in the worship of Isis was of Byssus, adorned with flowers, and that of the high priest of the Jews was probably something similar. Paulinus, bishop of Nola, testifies to the great strength of Byssus,-

Cloth made of Byssus indicates firm faith,

For threads of Byssus, it is said, surpass

E'en ropes of broom in firmness and in strength.

The dress of the priests on ordinary occasions was of a simple description, consisting of an under garment like the usual apron or kilt worn by the Egyptians, and a loose upper robe with full sleeves, secured by a girdle round the loins; or of the apron and a shirt with short tight sleeves, over which was thrown a loose robe, like a modern sheet, leaving the right arm exposed. Sometimes a priest, when officiating in the temple, laid aside the upper vestment, and was satisfied to wear an ample robe bound round the waist, and descending over the apron to the ankles (which answers to the dress of the Stolistes mentioned 
by Clemens " covering only the lower part of the body"); and occasionally he put on a long full garment, reaching from below the arms to the feet, and supported over the neck with straps. Others again, in the sacred processions, were entirely covered with a dress of this kind, reaching to the throat, and concealing even the hands and arms. The material of these dresses was almost always Iinen.

The robes of ceremony worn by the priests were grand and imposing, and peculiarities of costume marked the respective grades. Of the high priests, the one who offered sacrifice or libation in the temple had the highest post, and he appears to have been called "the prophet." He wore a leopard's skin fitting over his Linen robes, and a like covering was worn by the king on state occasions. The costume of the hierogrammat or sacred scribe consisted of a large kilt or apron, either tied in front or wound round the lower part of the body, and the loose upper robe with full sleeves, which, in all cases, was of the finest Linen.

The distinction between the skirt and the shirt or sheet worn overit, as well as the reason why Linen was used for all sacred purposes, is clearly expressed in the following passage from Apuleius :- "Can any one, impressed with a sense of religion, wonder that a man who has been made acquainted with so many mysteries of the gods, should keep at home certain sacred emblems and wrap them in a Linen cloth, the purest covering for divine objects? For wool, the execration of a sluggish body taken from sheep, was deemed a profane attire, even according to the early tenets of Orpheus and Pythagoras. But Flax, that cleanest and best production of the field, is used not only for the inner and outer clothing of the most holy priests of the Egyptians, but also for covering sacred objects."

Plutarch says that the priests of Isis wore Linen on account of its purity, and he remarks how absurd and inconsistent would have been their conduct if they had carefully plucked the hairs from their own bodies and yet clothed themselves in wool, which is the hair of sheep. He also mentions the opinion of some who thought the Flax was used for clothing because the colour of its blossom resembles the etherial blue which surrounds the world; and he states that the priests of Isis were also buried in their sacred vestments. 
Pliny states that the priests sometimes wore, and were partial to, cotton garments. Herodotus and Plutarch affirm that Linen was always preferred, owing as well to its freshness in a hot climate, as to its great tendency to keep the body clean, and that a religious prejudice forbade the priests to wear vestments of any other quality. This, however, refers to the inner portion of the dress, and the prohibition of entering a temple with cotton or woollen garments led to the notion that none but Linen were worn by them at any time. The same custom was adopted by the votaries of Isis, when her rites were introduced by the Greeks and Romans, and Linen dresses were appropriated to those who had been initiated in the sacred mysteries.

Whatever restrictions may have been in force respecting the use of cotton among the priesthood, other classes were at liberty to consult their own choice, during life, and either wear clothing of cool Flax or of soft cotton, as was most agreeable to themselves. Notwithstanding this permission, the nobles and higher ranks generally were almost always habited in Linen clothing, but the lower classes occasionally wore woollen garments, although Linen was also their usual attire.

Cloth was sometimes made of Flax warp and cotton woof; and this quality of fabric is still manufactured by the modern Egyptians. Julius Pollux, after describing the cotton plant as an Egyptian production, and stating that cloth was manufactured of the "wool of its nut," mentions this mixed fabric. It is a kindred cloth to many of the unions made in this country at the present day. Pure cotton cloth, and also this mixed article, were used to a great extent for coverings of chairs and couches, and for various other purposes.

No one was allowed to be buried in a woollen garment, in consequence of its engendering worms, which would injure the body. After death the body was invariably enveloped in bandages of Linen, and this regulation accounts for the mummy cloths of even the poorest individuals being, in every instance, formed of that material.

The followers of the Orphic and Bacchic rites, which were, according to Herodotus, Egyptian, and the Pythagoreans also, were forbidden to enter any sacred edifice or to bury their dead in woollen vests. There is a sacred reason assigned for this, 
says the o!d traveller, and this sacred reason kept him from telling more.

Perhaps the only existing representative of an ancient article of dress which may in any degree be supposed to resemble the Linen robes formerly worn in Egypt, is one of the two Egyptian Linen tunics obtained by General Reymer, while in Egypt with the French expedition, from the Arabs of Sakharah, who said hey had found it in a hole filled with sand, which they had cleared out. It is of square form, being three feet one inch each way, and the sleeves are about sixteen inches long. There is an opening at the top for the head, and on the whole it resembles a common shirt more than any other article of our dress. There are two square pieces of embroidery let into the cloth both before and behind in the lower part of the shirt, and similar square pieces are on each shoulder. On each arm there are also two pieces of embroidery, and one on each side between the hole for the neck and the square patch on the shoulder, hanging down like a pair of braces both before and behind. These embroidered parts are sewed to the cloth. The embroidery contains nothing of a pictorial kind, being formed of squares and circles, \&c. The cloth is yellow and the embroidery brown. It is uncertain whether the material be Flax, cotton, or hemp, but it is most likely Linen, and the embroidery is supposed to be made of the hair of an animal. The body of the tunic is formed of two breadths, and the seams on each side, and also the bottom of the sleeves are covered with neat edgings. The opening for the neck could be contracted by some small ties which are still attached to it. From its ornamental appearance it is supposed to have been an outer covering, or perhaps it is only an article of dress for the upper part of the body during summer, and it was obviously intended to be compressed round the waist by a girdle.

It would appear that it was chicfly of the description of Flax which Pliny calls Byssus, that the fine Linen of Egypt was made which has been so much celebrated by the nations of antiquity. No doubt it was of this material that the fine filmy cloth formerly described was formed, the threads composing which were so fine as to be almost invisible to the naked eye. It is also probable that it was the same sort of Flax of which the rich and 
magnificent furnishings of the Hebrew tabernacle, and the beautiful and gorgeous dress of the high priest, were made. The Israelites must have taken the Linen, or else the Flax of which it was made, when they went out from Egypt, as they had no other means of getting the material of which the priestly robes and sacred vestments and furnishings for the tabernacle were formed.

What special sort of Flax this was is not now known, but perhaps it may only have been a finer variety of the common Flax plant, the fibre of which was rendered susceptible of finer sub-division by careful culture. It is well known that some soils, and some modes of cultivation and preparation of Flax, produce a much finer fibre than others. It may, however, have been an entirely different plant, the knowledge of which is now lost. Should this be so the loss is much to be deplored.

By some parties the cloth known as Byssus is said to have been composed of a species of silk which was found growing from a certain shell-fish called "pinna." By others it is supposed that the fine Linen was in reality silk, but this is also liable to considerable doubt. The earliest notice we have of silk is derived from China, and although it is known that the Egyptians traded with India at an early period, and may, and indeed in later times did, get silk from China through India, there is no evidence that they imported it, or were even acquainted with this material at the very remote period when it is certain the exquisite fabrics called "fine Linen" were first produced there.

All doubts regarding the character of the material in which the dead were wrapped has now been satisfactorily set at rest. The received opinion in Europe until lately was that it was composed of cotton, and it was forbidden to doubt that "the bands of Byssine Sindon," said by Herodotus to have been used for enveloping the mummies, were cotton. The unscientific inhabitants of Egypt never, however, questioned the fact that they were Linen, and they have been proved to be. perfectly correct.

Accurate experiments have been made by $\mathrm{Mr}$ Bauer of Clitheroe, one of the most experienced cotton manufacturers in the world, who obtained and experimented upon about 400 specimens of mummy cloth, Mr Thomson, Dr Ure, and others 
with the aid of powerful microscopes, on the nature of the fibres of Linen and cotton thread. These have shown that the fibres of Linen invariably present a cylindrical form, trancparent, and articulated, or jointed like a cane, while cotton fibres offer the appearance of a flat riband, with a hem and border at each edge. There is, therefore, no possibility of mistaking the fibres of either, except, perhaps, when the cotton is in an unripe state, when the flattening shape of the centre is less apparent.

The results having been found similar in every instance, and the structure of the fibres thus unquestionably determined, the threads of mummy cloths, both fine and coarse, brown and bleached, were submitted to the same test, and no single exception was found to their being Linen; nor was there even a single instance of a mixture of Linen and cotton thread found. The experiments on this point have been so numerous, and so carefully conducted by many parties, that there can be no room for farther doubt on this subject, all the mummy cloths, yet tested, being veritably Linen. The fact of the mummy cloths being Linen is therefore decided.

The name Byssus, it is true, presents a difficulty, owing to the Hebrew Shash being translated Byssus in the Septuagint version, and in our own "fine Linen ;" and to Shash being the name applied at this day by the Arabs to fine muslin, which is of cotton and not of Linen; but as the mummy cloths, said by Herodotus to be "of Byssine Sindon," are known to be invariably Linen, the Byssus cannot be cotton. Herodotus indeed uses the word "tree wool" to denote cotton; and Julius Pollux adopts the same name, distinguishing it also from Byssus, which he calls a species of Indian Flax. The use of the two words Byssus and Linen presents no difficulty, since they might be employed, like our Flax and Linen, to signify the plant and the substance made from it.

$\mathrm{Mr}$ Thomson mentions some fragments of mummy cloths sent to England by the late Mr Salt, which he saw in the British Museum. They were of different degrees of fineness, some fringed at the ends, and some striped at the edges. His first impression was that they were muslin, and of Indian manufacture, as it is mentioned in the "Periplus of the Erythræan Sea" (ascribed to Arrian, but more probably the work of some 
Greek merchant, himself engaged in the trade), that muslins from the Ganges were an article of export from India to the Arabian gulph in the days of the Ptolemies. This suspicion that they were cotton was soon removed by the microscope of Mr Bauer, which showed that they were all, without exception, Linen. Some were thin and transparent, and of very delicate texture. The finest appeared to be made of yarn of 100 hanks in the pound, with 140 threads in the inch of warp (about 125 porter or $25^{\circ 0}$ ), and about sixty-four in the weft or woof. A specimen of muslin in the Museum of the East India House, the finest production of the Dacca loom, has only 100 threads in an inch in the warp, and eighty-four in the weft, but the surprising fineness of the yarns, which, though spun by the hand, is not less than 250 hanks in the pound, gives to this fabric its unrivalled tenuity and lightness.

Some of the cloths examined by Mr Thomson were fringed at the ends, and one, a sort of scarf, about four feet long, was fringed at both ends. Three or four threads twisted together with the fingers to form a strong one, and two of these again twisted together, and knotted at the middle and at the end to prevent unravelling, formed the fringe, precisely in the same way as the silk shawls of the present day are fringed.

The selvages of Egyptian Linens are generally formed with the greatest care, and are well ralculated by their strength to protect the cloth from accident. Fillets of strong cloth or tape also secure the ends of the pieces from injury, showing a knowledge of all the little resources of modern manufacture. Several of the specimens, both of fine and coarse cloth, were bordered with blue stripes of various patterns, and in some of them these stripes alternated with narrow lines of another colour. The width of the patterns varied from half an inch to an inch and a quarter. In one piece examined were seen seven blue stripes, the broadest about half an inch wide, nearest the selvage, followed by five very narrow ones, and terminating by one one-eighth of an inch broad. Had this pattern, instead of being confined to the edge of the cloth, been repeated across its whole breadth, it would have formed a modern gingham, which there is little doubt was one of the articles of Egyptian industry.

A small pattern, about half an inch broad, formed the edging 
of one of the finest of these cloths, and was composed of a stripe of blue, alternating with three lines of a fawn colour, forming a simple and elegant border. These stripes were produced in the loom by coloured threads previously dyed in the yarn, but the nature of the fawn colour could not be ascertained, as it was too much faded by age, and the quantity too small to admit of being determined satisfactorily. Although there was no doubt that the colouring of the blue stripes was indigo, to prove it the threads were submitted to a careful examination. Boiled in water for some time the colour did not yield in the least, nor was it all affected by soap, nor by strong alkalies; sulphuric acid diluted only so far as not to destroy the cloth, had no action on the colour; chloride of lime gradually reduced, and at last destroyed it; strong nitric acid dropped upon the blue, turned it to orange, and in the same instant destroyed it. These tests prove the colouring matter of the stripes to be indigo.

This dye was unknown to Herodotus, for he makes no men-tion of it. It was known to Pliny, who, though ignorant of its true nature and the history of its production, has correctly described the most characteristic of its properties-the emission of a beautiful purple vapour when exposed to heat. Had his commentators been acquainted with the sublimation of indigo, it would have saved many learned doubts. The Periplus mentions that it was an article of export from Barbarike, on the Indus, to Egypt, where its employment by the manufacturers of that country, probably from a remote period, is clearly established by the specimens here described.

A piece of Linen eloth brought from Thebes offers a very good instance of the coloured border. It is of ordinary quality, ninety-six threads being in the inch of warp, and thirty-four in the weft. The border consists of one broad band and six narrow stripes, of a blue colour, evidently dyed with indigo. The band which is nearest the selvage, is one inch and one fifth in breadth, the others consist each of two threads, in the direction of the warp, with the exception of the innermost one, which is of five threads, and the dividing line between the fourth and fifth is varied by the introduction of a blue thread down the centre. The yellowish tinge upon the rest of the cloth is supposed to arise from some a stringent preparation cmL. 2 
ployed for its preservation, which imparts a similar colvur to water, but affords no trace of tannin. In none of the specimens examined by $\mathrm{Mr}$ Thomson did either gelatine or albumen, or solution of iron, afford any precipitate, but the subacetate of lead produced a cloud, indicating the presence of extractive matter.

It is evident that the colour was imparted to the threads previous to being woven into cloth, as the blue remains unaltered. The cloths with broad coloured borders are curious, as they illustrate the paintings, and show that they were similar to those made by the looms in the age of the Pharaohs of the 12th and 18th dynasties, the date of the former being reckoned about 2000 years before Christ. The Nubians wear shawls with the same borders, manufactured in the Valley of the Nile at the present day. The Egyptians also dyed old dresses in those days.

Another piece of Linen from Thebes has 152 threads to the inch in the warp, and seventy-one in the weft. It is of a much darker hue than the cloth just mentioned, and was perhaps dyed with the Carthamus Tinctorius, or safflower. But the most remarkable piece of fine Linen is one found near Memphis which justifies all the praise bestowed upon the manufacture in former times, and excites the admiration of all who see it in the present day. To the touch it is comparable to silk, and not inferior in texture to the finest cambric which has yet been made. Such a fabric well merits the name of "fine Linen," as it is of unrivalled fineness and really Linen. Some idea may be given of its texture from the number of threads in the inch which are 540, or 270 double threads in the warp, and only 110 in the weft. - It is also of a light brown colour, and is covered with small figures and hieroglyphics, so finely drawn that here and there the lines are with difficulty followed by the eye, and as there is no appearance of the ink having been run in any part of the cloth, it is evident that it had been previously prepared for the purpose. The perfection of its threads is equally surprising, as the knots and breaks, seen in the finest cambric, are not found in holding it to the light. This was a mode of proving fine cloth known to, and practised by the ancients. It gave rise to the beautiful Greek expression, signifying "Lincere," borrowed from test 
of light, and it is far superior to the Latin Lincerus, derived from honey, Line Cerî.

The threads used for nets by the Egyptians were occasionally remarkable for their fineuess. Pliny says "some of them were so delicate that they would pass through a man's ring, and a single person could carry a sufficient number of them to surround a whole wood. Julius Lupus, who died while governor of Egypt, had some of these nets, each string of which consisted of 150 threads; a fact perfectly surprising to those who are not aware that the Rhodians preserve to this day, in the 'Temple of Minerva, the remains of a Linen corslet presented to them by Amasis, King of Egypt, the threads of which are composed each of 365 fibres; and in proof of the truth of this, Mutianus, who was thrice consul, lately aflirmed at Rome, that he had examined it; and the reason of so few fragments remaining was attributable to the curiosity of those who had frequently subjected it to the same scrutiny."

Herodotus mentions this corslet, and another, presented by Amasis to the Lacedæmonians, which had been carried off by the Samians: "It was of Linen, ornamented with numerous figures of animals, worked in gold and cotton. Each thread of the corslet was worthy of admiration; for, though very fine, every one was composed of 360 other threads, all distinct; the quality being similar to that dedicated to Minerva at Lindus, by the same monarch."

Many of the Egyptian stuffs presented various patterns worked in colours by the loom, independent of those produced by the dyeing or printing process, and so richly composed that Martial says they vied with the Babylonian cloth, embroidered with the needle. The manner in which these tapestries were worked is entirely unknown, but it is very prebable that it was by a process similar to that in use in this country before the introduction of the jacquard machine, the pattern being produced by the aid of one or more draw boys, who raised the proper threads of warp to form the required design as the weaver progressed with the cloth. Notwithstanding the superiority which the Egyptians attained in fabricating patterns by the loom, the art of embroidery was commonly practised there at at very early period, and long prior to the exodus of the Israclites. 
Taking advantage of the knowledge so acquired, the Hebrews were enabled to make the rich tapestries for the service of the sanctuary in the wilderness.

The gold thread used for embroidered work is supposed to have been beaten out with the hammer, and afterwards rounded, as Moses relates that "they did beat the gold into thin plates and cut it into wires, to work in the blue, and in the purple, and in the scarlet, and in the fine Linen." Homer says that the delicate net made by Vulcan, which was so fine that the gods themselves were unable to see it, is represented to have been forged on an anvil with the hammer. Pliny mentions cloth woven with gold threads, sometimes entirely of those materials, without any Linen or woollen ground, as were the garment of Agrippina, the tunic of Heliogabalus, and that worn by Tarquinius Priscus, mentioned by Verrius.

Pliny says " coloured dresses were worn in the time of Homer, from which the robes of triumph were borrowed; and from the Phrygians having been the first to devise the method of giving the same effect with the needle, they have been called Phrygiones. But to weave cloth with gold threads was the invention of an Asiatic king, Attalus, from whom the name of Attalic was derived, and the Babylonians were most noted for their skill in weaving cloths of various colours."

It still remains undecided when silver thread came into use, and as no mention of silver stuffs occurs in the writings of ancient authors, it has been supposed that its introduction was of late date. Silver wire, however, was known in Egypt about 3300 years ago, being found at Thebes of the Third Thothmes, and there is no reason to suppose that it was then a novelty. It is very probable that it was known and used nearly as soon as gold wire, which is found attached to rings bearing the name of Osirtasen the First, who lived about 3900 years ago.

The wire is supposed to have been beaten out and rounded with the file, and not drawn, as in the present day, through holes in metal plates. The appearance of some found at Thebes would, however, justify the conclusion that a mode of drawing it was not unknown to the Egyptians. There is no representation of the process in the paintings, but this omission is no argument. against it, since they have also failed to introduce the casting of 
metals and various other arts, with which there is abundant evidence that they were acquainted.

Wire drawing was first attempted with the most ductile metals, gold and silver being used before brass and iron, because the wire was originally employed for ornamental purposes. Gold thread and wire were always made entirely of metal, even to the time of the late Roman Emperors. In Egypt there is no instance found of flattened wire being wound round silk or Linen threads, or of silver or other wire gilt, though gilding was so common on vases and other articles of bronze. That the Egyptians had arrived at great perfection in the art of making golden thread, is evident from its being sufficiently fine for weaving into cloth, and for embroidery; and the exceeding delicacy of the Linen corslet of Amasis, on which numerous figures of animals were worked in gold, required a proportionate degree of fineness for the purpose.

Mrs Lushington says that mummies have been found wrapped up in garments curiously wrought with gold lace. The Psalmist says " her clothing is of wrought gold ;" and as this is supposed to refer to Pharaoh's daughter, it is probable that this was one of the employments of high born dames in Egypt in ancient times. At the present day ladies of the highest rank in Egypt employ much of their time in embroidering Linen and cotton tissues, particularly veils and handkerchiefs, with threads of silver or gold, and silk, in various colours. It would thus appear that this custom of early days has been continued in modern times, as it may be for ages yet to come. Some of the ancient Egyptian paintings exhibit beautiful specimens of the rich embroidered dresses then in common use.

The coloured dresses worn by ladies of rank and by the deities, as represented in the Egyptian paintings, much resemble modern chintzes in the style of their patterns, though it is probable that they were generally of Linen, instead of cotton or ealico. Some of them appear to have been worked with the needle, and others woven in the loom with gold threads

Another very remarkable discovery of the Egyptians was the use of mordants. They were acquainted with the effect of acids or colours, and submitted the cloth they dyed to one of the same processes adopted in modern dyeworks and manufactories. 
Although Pliny, in his account of the process, appears to have understood very little of what he was describing, yet he gives the strongest evidence of its truth. He says, "In Egypt they stain cloth in a wonderful manner. They take them in their original state, quite white, and imbue them, not with a dye, but with certain drugs which have the power of absorbing and taking colour. When this is done there is still no appearance of change in the cloths, but so soon as they are dipped in a bath of the pigment, which has been prepared for the purpose, they are taken out properly coloured. The singular thing is, that though the bath contains only one colour, several hues are imparted to the piece, these changes depending on the nature of the drug employed, nor can the colour be afterwards washed off ; and surely if the bath had many colours in it, they must have presented a confused appearance on the cloth." From this it is evident that the cloth was prepared before being steeped. The momentary effect he mentions could only be produced by the powerful agency of mordants, which the Egyptians appear to have used, not only to make the cloth take the colour equally, but also to change the hues.

Whether the Egyptians really understood the principle on which the salts and acids of the mordants acted, or calculated their effects solely from the experience they had acquired, it is difficult to decide. They were long used in Europe before their chemical agency was properly understood, and when the term mordant was first applied by the French dyers, they imagined that the intention of passing the substances, which were to be dyed, through certain saline liquors, was to corrode something that opposed the entering of the colouring principle, and so enlarge the pores of the substances, the effect of acids in changing the colours being a later discovery. It cannot therefore, with certainty, be proved that the Egyptians had a knowledge of chemistry, though from their long experience, and their skill in the employment of the metallic oxides, there are strong reasons to infer it. It is probable, though they were at first ignorant of the reason of such changes, in process of time they were led to investigate the causes by which they were effected.

Many discoveries and even inventions are more the effect of chance than of studious reflection, and sometimes the principle 
is last to be understood. When men have, from long practice, observed a fixed and undeviating result, their curiosity becomes excited, and either their thirst for knowledge or the desire of benefiting by the discovery, prompts them to scrutinze the causes which produce the effect, and, when this is thoroughly examined by people at all advanced in the arts of civized life, they will sooner or later discover what they desire to know. It may therefore be supposed that some general notions of chemistry, or at least of chemical agency, were known to the Egyptians. The beautiful colours they obtained from copper, the composition of various metals, and the knowledge of the effects produced on different substances by the salts of the earth, all tend to confirm this opinion.

The sculptures, as well as some of the cloths which have been produced, perfectly bear out Herodotus in his statement that they had the custom of leaving a fringe to their pieces of Linen, which, when the dresses were made, formed a border round the legs, but they do not appear to have been universally worn. This kind of dress was called Calasiris, and specimens of it, found in the tombs, may be seen in the British Museum and other collections. When the fringe was wanting, the border was hemmed to prevent the unravelling of the cloth; and a fringe was sometimes sewed on, as in many modern imitation shawls. The Jews wore a similar kind of fringed dress, and Moses commanded the children of Israel to make them fringes in the borders of their garments, and to put upon the fringe of the borders a riband of blue.

The Egyptians invented the mannfacture of carpets at a very early date, as they are mentioned by Homer, who gives them the name they are still known by, Tapeta, whence tapestry. They were used in houses, and representations of them are painted amongst the other scenes on the walls of the tombs, and fragments of them have been discovered. A small rug, eleven inches long by nine broad, was brought to England, which is made like Brussels, tapestry, and some other carpets of the present day, with Flax yarn for warp, and woollen weft. In the centre is the figure of a boy in white, with a goose above it, and the hieroglyphic of a "child" upon a green ground; around which is a border composed of red and blue lines. The remainder is a ground of yellow, with four white figures above and 
below, and one at each side, with blue outlines and red ornaments. The outer border is made up of red, white, and blue lines, with a fancy device projecting from it, having a triangular summit, which extends entirely round the carpet. Its date is uncertain, but from the child, the combination of colours, and the ornament of the border, Sir J. Wilkinson, from whose work this description is taken, was inclined to think it really Egyptian.

The Egyptians made twine of various kinds, strings, and the better sort of ropes they used, of Flax, and their mode of twisting the yarn into a rope is well represented in some of their ancient paintings. Their large ropes for common purposes were made of the fibres of the date tree, as in the present day, and many specimens of this durable material have been found in the excavations both of Upper and Lower Egypt. Their nets, both for fishing and fowling, were made of Flax string, and portions of them have been discovered at Thebes. Isaiah mentions "they that work in fine Flax, and they that make net works." Sieves were often made of string, but some of an inferior quality were made of rushes or reeds.

Herodotus mentions that the Egyptians are provided with a remedy against gnats, of which there is a surprising number. Each person has a net with which they fish by day, and which they render useful by night. They cover their beds with their nets, and sleep securely beneath them. If they slept in their common habits or under Linen, the guats would not fail to torment them, which they do not even attempt through a net. It thus appears that the idea of musquito curtains, like wery many other modern appliances, is borrowed from the ancient Egyptians. The netting needles of the Egyptians were of wood, split at each end, and between ten and eleven inches in length, but some of them were of bronze with the point closed.

The Egyptians were as celebrated for their manufacture of paper, as for the delicate texture of their Linen. Their paper was made from Papyrus, and not of Linen as is now done in this country, that invention, so far as known, not having been discovered until a comparatively recent date, there being no positive proof that Linen paper was known prior to the eleventh century of the Christian era. The Chinese were acquainted with the 
secret of making paper from vegetable substances long before it was known in Europe, and t!ey carried the manufacture to a state of high perfection, but little is known positively on this subject.

Small boats were sometimes made of papyrus. Pliny says boats were woven of the papyrus, the rind being made into sails, curtains, matting, ropes, and even into cloth. Vessels of bulrushes are mentioned by Isaiah ; Lucan alludes to the mode of binding and sewing them with papyrus; and Theophrastus notices boats made of papyrus, and sails and ropes of the rind of the same plant. There is no doubt, however, that their larger Nile ships and boats, and all their sea-going vessels, were made of wood, strong and well built, and able to endure the sturms to which they were exposed at sea. It is impossible to believe that a people so noted for their Linen manufacture, and who made and exported sail-cloth to Phœnicia and elsewhere for that purpose, would themselves have preferred so imperfect a substitute as the rind of a plant. Herodotus says that Egyptian sails were at first made of rush mats and afterwards of papyrus. It is more probable that they were formed of a coarse Linen, resembling mats, as the people were well acquainted with Flax, and must have known that it was the strongest and most suitable material of which they could make their sails. The more natural explanation of the sails mentioned by Pliny and other ancient historians is, that those of papyrus may have attracted attention from their curious nature, while it was thought unnecessary to describe the Flax sails, from their being made of the most suitable material and in general use.

There was a kind of Linen cloth made in Egypt expressly for sails, which was bought by the Tyrians for the pleasure galleys of the king and high grandees. It was painted or embroidered with devices, representing flowers, \&c., or it was adorned with chequers, or striped in various colours. The ship in which Antony and Cleopatra went to the battle of Actium, was distinguished from the rest of the fleet by its purple sails, which were the peculiar privilege of the Admiral's vessel. The sails of the large ship of Ptolemy Philopater, mentioned by Atticus, were also of fine Linen, ornamented with a purple border. 'This custon was a rery ancient one, as the most highly 
decorated sails are those represented in the tomb of the third Remeses at Thebes.

There was no established rule for the decoration of the sails of a ship, as it depended on the fancy of the owner, and sometimes the same monarch had sails of different patterns. The cloth of which the embroidered sails was formed was not of a very strong texture, and the sails were therefore bound round with a strong hem or border, neatly coloured, to strengthen them and keep them from being torn. Ordinary sails were of white cloth, something like those in use at the present day.

Chemmis, the city of Pan, retained the credit it had acquired for the making of Linen stuff till about the period of the Roman conquest, and Strabo says that Panopolis was an ancient seat of the Linen manufacture.

Hasselquist says the Linen made in Egypt in his time was not so thick as the European, being softer and of a looser texture, for which reason it lasts longer than ours. He also says the common people in Egypt are clothed in Linen only, dyed blue with indigo, but those of better fortune have a black cloak over their Linen shirt.

The coarse Linen of the ancient Egyptians was made of thick Flax, and used for towels and for sails, and it was called by the Greeks by a word which may be translated canvas or sail-cloth, but which was probably originally Egyptian, and only adopted by the Greeks. The same remarks may apply to the Greek word for Fine Linen.

It is recorded in the Rosetta Inscription, that Ptolemy Epiphanes remitted two parts of the fine linen cloths which were manufactured in the 'Temples for the king's palace, and that he also remitted a tax on those which were not made for the king's palace.

The Egyptians were not themselves a commercial people, as they long had a great aversion to the sea. They were, however, extensive traders and manufacturers, and produced goods well worthy of being exported. Many of the neighbouring nations early engaged in this traffic, and the Ishmaelites, who bought Joseph and took him down to Egypt, traded between that country and Gilead 3600 years ago. They carried down balm and spices into Egypt, taking back Linen and other productions 
of that country in return. The Phenicians early cultivated the Egyptian trade, to the mutual advantage of both countries, and of the world at large.

Notwithstanding the many misfortunes which from time to time befell Egypt arising from war and other causes, the people still clung to their famous Linen trade. According to the author of the Periplus of the Erythrean Sea, in the days of the Ptolemies, the merchants of Egypt exported to Adulis and other ports on the west coast of the Red Sea, to the straits of Babelmandeb and the port of communication with Axuma, robes manufactured at Arsinoe, cloth dyed to imitate Tyrian purple, Linens, fringed mantles, \&c. At the same period they traded to Patala on the Indus; to towns up the Indus; the Punjaub; the Deccan, Canara, and other places on the west of Hindostan, sending Linen cloth woven in chequer work, \&c., \&c. In the days of the Cesars, Egypt supplied to Rome, Flax, fine Linen, paper, and cotton goods, some of which seem to have been coloured or printed, and which were shipped from Alexandria.

The only account which we possess of China and India between that given by two Mahomedan travellers who visited these countries in the ninth century, and that given by the embassies of the European Powers in the twelfth and thirteenth centuries, is that given by Benjamin, a Jew of Tudela in Spain. He describes many countries and cities, and the trade carried on by them. Nearly all the Jews, he says, in Thebes, Constantinople, Samarcand, \&c., were dyers of wool. In Thebes alone there were 2000 workers in scarlet and purple. After the conquest of the northern parts of China by Genghis khan, he fixed upon the city of Campeon in 'Tangrit for the seat of a great inland trade. To it Linens and many other goods were taken by the Chinese merchants, who sold them to the Muscovites, Persians, and others. Marco Polo says that the Khan of China got the tenth of all Hemp, Flax, and other produce of the earth, meaning no doubt, of what was grown in his own dominions. It is probable, from this remark, that the Chinese had then grown Flax, manufactured it, and sent it to Campeon for sale. It may be, however, that the Linens sold there were the manufacture of Egypt, sent through India, as a trade between Egypt and India existed many ages before this period. 
Sanuto, a Venetian traveller in the beginning of the fourteenth century, says that Egypt was then celebrated, as of old, for the fineness of its Flax. European Flax was considered far inferior to the Egyptian species in every respect, and of much less value. The Egyptian Flax and their manufactures of Linen, silk, and Linen and silk mixed, were then exported extensively to Turkey, the Black Sea, the western parts of Europe, and to Africa, in Saracen or Christian vessels, and they were much appreciated wherever they were sent.

After that period the Linen trade was for a while carried on with more or less success, but a time came when Flax ceased to be cultivated, and the shuttle was still. The rulers, despotic and barbarous, so oppressed the people that they had no security for the fruit of their industry, and therefore no motive to work. The people, servile and ignorant, lived only for the day, their property and their very bodies being at the command of their pachas and governors. Then the Linen manufacture sprung up and flourished in other lands; in countries which were uninhabited or wholly barbarous when Egypt led the van of civilization, and acquired wealth and fame from its fine Linen. Then the glory and the pride of Egypt was gone. Its fine Linen which had called forth the praise of the nations of antiquity, which had clothed the High Priest of the living God, and enclosed his sanctuary, was a thing of the past, and to the present inhabitants not even " to memory dear." The land was still there as of old; the mysterious Nile still overflowed its banks at the appointed season, rendering its soil rich and fertile as in early ages. The people were changed; changed in habits, in feelings, in industry, in intelligence, in everything that makes a people great or happy; and this sad change was visible in every acre of the soil, in every act of its inhabitants.

After ages of neglect, by the vigorous but despotic policy of the late Mehemet Ali, the culture of Flax was re-established in the land of its birth, about thirty years ago, and since that period it has been prosecuted with vigour, and once more become an article of great importance to the country. The cultivation of Flax is entirely in the hands, or under the control of the Government, who derive a large income from it. The ancient 
skill of the Egyptians in the rearing of Flax has long been lost, and the present inhabitants are, as it were, new to the business. The germ of fine Elax is, however, in it still, and by careful and intelligent cultivation the quality might be greatly improved. Some of the best parcels which have been received combine strength with fine fibre, but the great bulk of the exports are coarse, and not of more value, if of so much, as the average of Russian Flax. The high price which the best qualities of Government dressed Flax commands in this country, will no doubt in time stimulate the reigning pacha, who is the great producer, to improve the cultivation, and when this is done it will be advantageous alike to grower and consumer.

The quantity of Flax exported from Alexandria in 1835 was only eight tons; but the quantity gradually increased for a number of years. Latterly it has decreased again, which may be attributed either to a diminished cultivation, or to greater local consumption. If the latter, it would be a proof that the social position of the people was improved, and, as the report of one of the commercial houses in Alexandria on the trade for last year says, of the well-being of the country.

The following statement gives the export in tons of Flax from Alexandria for the years noted :-

$\begin{array}{ccccccccccccc}\text { Years. } & 1839 & 1840 & 1841 & 1842 & 1849 & 1850 & 1851 & 1852 & 1859 & 1860 & 1861 & 1862 \\ \text { Tons. } & 305 & 493 & 770 & 1626 & 5003 & 6489 & 7185 & 3277 & 772 & 634 & 908 & 1094\end{array}$

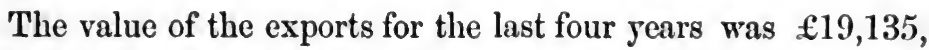

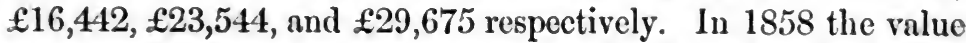
of the Flax exported was $£ 16,596$, of which $£ 14,211$ were to Great Britain, and $\mathfrak{E , 7 7 6}$ to Tuscany. In 1859 the value sent to Great Britain was $£ 10,714$, and to Tuscany, $£ 3,234$. Some farther details regarding this subject are included in the general tables given in another part of the work. 


\section{CHAPTER III.}

\section{P H E N I CIAN LINEN.}

The Phonicians, according to the Bible, the only authentic history of this remote period of the world, were among the first, if not the very first people who prosecuted commercial enterprise. Their country was admirably situated for such a purpose, and they appear to have taken full advantage of their local position, and carried on an extensive trade, both by sea and land, in the very earliest times. Profane writers furnish very scanty materials on the subject, but what they have said is entirely confirmatory of what is recorded in sacred history. They were not so much a manufacturing people as they were the carriers of other nations. The camel and the caravan on land, and the ship by sea, conveyed the productions of the east to western lands, giving western commodities in exchange to the natives of eastern climes. They were in fact the first merchants the world ever saw, and they prosecuted their traffic with a perseverance worthy of success. Their maritime enterprise has commanded the admiration of the world. Their civilization was far in advance of the age, and their learning was profound. To the Phœnicians we are indebted for the gift of letters. The art of making glass was first practised by them, and it is said that mirrors were first invented in Sidon.

The dealings of the Phœnicians with the Egyptians (who though the most ancient of manufacturers did not for a long period engage in commerce), began in the most remote times, and was carried on extensively for a very long period. The wealth acquired by their commerce with Egypt and other lands was so vast, as well entitled their traders to be called "merchant princes." That they were most luxurious in their domestic life is well established by all writers who have spoken on the subject. Linens, forming as they do one of the greatest luxuries as an article of clothing in warm latitudes, was early used by them for this purpose, and formed one of their most important 
articles of merchandize. They bought it in Egypt, not only for their own use, but also to export to other countries, where it was eagerly sought, and as much appreciated as it was by the Phœnicians themselves.

Sidon owed its foundation to Sidon, the eldest son of Canaan, and is one of the most ancient cities in the world. It possessed fleets 3600 years ago, but in later times the ships of old 'Tyre, which was a colony of Sidon, gained a world wide celebrity, and for long ages supersedel those of her ancient mother. More than 3100 years ago Phonician ships ploughed the Atlantic, and this maritime people founded the colony of Cadiz. Their vessels also sailed to Britain, and opened up the trade in tin and other minerals found in this country. England must thus have been peopled at a very early period, and her celebrated mineral wealth known and valued in very remote historic times. The Phœnicians had early discovered the use that might be derived from the wind, and employed sails of canvas to propel their vessels. For this purpose large quantities of strong Linen cloth was required, and also cordage of Flax for rigging to their ships. These articles of themselves would necessitate a considerable trade with Egypt, whence their supplies of such materials were drawn. No doubt Flax yarn would also be imported to a large extent, and manufactured into Linen by the Tyrians, for home use and for export in their trading expeditions. Such a favourite article as Linen then was must have formed an important portion of the merchandize of this trading community.

Homer, who lived 900 years before Christ, says that in the Trojan war the Phœnicians were famous for their purple stuff, and furnished other nations with many articles of luxury. The women of Sidon were especially celebrated for their skill in embroidery. This was before Tyre had risen into importance, as that city is not even mentioned in his works. According to Herodotus the Phonicians, before the destruction of Old 'Tyre, circumnavigated Africa, having sailed down the Red Sea and returned to Egypt by the Pillars of Hercules and the Mediterranean Sea, in the days of Necho, king of Egypt, who lived about 2500 years ago.

The Tyrians founded Carthage nearly 850 years before the II 
Christian era, at which time their fleets visited all the then known lands. In the days of Solomon, more than 150 years before that period, the vessels of Tyre traded in the Red Sea, and far south on the east coast of Africa as well as to the Persian Gulf and other parts. In those voyages an important part of the cargo consisted of the fine Linen of Egypt, both in the natural state as produced in that country, and also dyed of various shades of colour, particularly of the Tyrian purple, for which that people early acquired great fame.

Goguet and Heeren respectively collected much information regarding the purples of antiquity. They show that the preeminence given to purple, as a royal robe in the present day, is due to the ancient preference given to that colour because of its superiority in those days to all others. When the beautiful purple of Tyre was first discovered, the sovereign to whom it was presented appropriated it as a royal distinction, hence to "assume the purple" became significant with being chosen king. Homer mentions that purple was only worn by princes, and this limitation of its use was common among other nations. The king of Midian, defeated by Gideon, was clad in purple raiment. There were several shades of purple, and Pliny mentions some of them. The least esteemed was a faint red approaching to our scarlet; another a deep red approaching to violet; and a third was of a colour compared to coagulated bullock's blood, the most esteemed Tyrian purple being of this colour.

These dyes were obtained from different varieties of shell-fish found in the coasts of the Mediterranean Sea and in the Atlantic. The most celebrated were got from the coasts of Sicily, the Peloponnesus and Britain. Each fish only furnished a very minute quantity of puce, pressed from a white vessel in the neck of the animal, and which could only be obtained while the animal was alive. Hence the dyeing matter must have been very expensive. The puce of this fish is not now used in dyeing, and the art of preparing it is lost, but modern dyes are equally good and produced at much less cost.

The Phœnicians excelled all other people in the use of this colouring matter, hence the fame which the purples of Sidon and Tyre enjoyed in ancient times. Other countries were also celebrated for their purples, but none could equal Phœnicia. Linens 
were largely dyed of this colour, and the cloth so dyed was greatly esteemed among all the neighbouring nations, and formed an important item of the commerce of 'Tyre.

Another account of the world renowned Tyrian purple says it was got from two little shell-fish, the Buccinum and Murex, which were only found in perfection along the rocky coast of Phœnicia. Antiquity unanimously assigns to 'Tyre the discovery of the mode of obtaining two most beautiful tints of purple from these animals, and of employing it in dyeing wool and Linen. In a sac behind the head of these molluses is a very minute portion of a colourless creamy fluid which smells like garlic. It was extracted with a pointed pencil, and applied to the Linen, which was then exposed to a bright light, and became successively green, blue, red, deep purple, and by washing it in soap and water, of a bright and permanent crimson.

The first named fish was found on the rocks near the shore, and the other in deeper water, and the early spring was the best season for taking them. Other places made robes dyed of the same colour, but none could compare with the real Tyrian, and probably its merchants were possessed of some chemical secret by which the colour was made more brilliant, which made them so much more beautiful than those of other places. Both fish were used, the murex first to give depth and fastness, and then the buccinum to enliven by its lighter reddish tint. The most costly fabrics were twice dyed, which made it of so great beauty, and so very durable, that it brought fabulous prices in Rome and other luxurious places.

The capital of Justinian was supplied with the manufactures of Sidon fifteen centuries after they had been celebrated in the poems of Homer. The silks, which had been closely woren in China, were sometimes unravelled by the Phenician wrmen, and the precious materials were multiplied by a looser texture and the intermixture of Linen threads. Such garments are spoken of by Varro and Publius Syrus. It has been lately discovered by the Rev. C. Foster, that the ancient Arabians were skilled in the manufacture of sillen textures at as remote a period as within 500 years of the Flood, and perhaps the silk which found its way to Syria and to Europe may have been partly the produce of Arabia. 
It is mentioned in the Odyssey that the Phœnicians invariably sent a factor or supercargo with their vessels, who frequently traded by retail at the different ports, often stopping for months at one port for this purpose, and the voyage in this way extended over a long period.

Old Tyre, which was built on the continent, was destroyed by Nebuchadnezzar after a siege of thirteen years. The second Tyre was thereafter built on an island about a third of a mile from the shore. This city never attained the fame or importance of its predecessor, still it was powerful enough to stay the progress of Alexander's army for eight months, being longer than any other place under the dominion of the Persians. Long after this it continued to hold a name and place in the world, but like many other Eastern cities its sun has long set, perhaps never to rise again.

\section{CHAPTER IV.}

\section{CARTHA GEN I A N L I NEN.}

OF all the nations of antiquity Carthage, next to Tyre, was the most maritime and the most commercial. It was originally a colony of Tyre, at that time the most renowned city for commerce in the world. The Carthagenians inherited their trading habits, and their application to commerce, from their progenitors. In common with the Tyrians, the Canaanites, and the Israelites, they spoke the Hebrew tongue, or at least a language derived from it. The commonwealth was devoted to trade, and their fleets, sailing to all parts of the then known world, wafted the superfluities of one nation to barter them for those of another. The notices which we possess regarding the trade, \&c., of Carthage is almost all derived from Aristotle. 
Among their imports were fine Flax, sails and cables for ships, yarns and fine Linen from Egypt, purple and scarlet, tapestry and rich stuffs from Tyre and Phoenicia. These were consumed at home, or again exported to the western parts of the then known world, and other countries to which the Carthagenians traded, where they were exchanged for iron, tin, lead, copper, and other products of these lands. From this importation of fine Linen and yarns it may be inferred that the manufacture of Linens was carried on to a large extent in this great city. The climate was very similar to Egypt, and Linen would no doubt be much worn by the Carthagenians, and also form an important article for sending to foreign lands by its merchant citizens.

In time Carthage, like London of the present day, rose to be the centre of the trade of the world. The Carthagenians were for a long period the lords of the sea, and of that proud city it might then with propriety have been said that "Carthage rules the waves." Carthage was founded in the year of the world 3158 , when Joash was king of Judah, 79 years before the buildding of Rome, and 846 years before the Christian era. Some writers say it was founded 1233 years before Christ, but this is not the generally received opinion. It subsisted for a period of 700 years, having been destroyed in the 603d year of Rome, the 3859 year of the world, and 154 before Christ. It was founded by Dido, sister of Pygmalion, king of Tyre. Enervated by the great wealth acquired by their commerce and by the luxurious habits produced thereby, the Carthagenians at last became an easy prey to the warlike Romans. Mounds of debris and the ruins of some buildings are all that now remain of that once proud city.

The Babylonians, in the zenith of their power and glory, used considerable quantities of Linen as articles of clothing. A Linen shirt formed a part of the diress of almost all the people, and many of them had no other garments than those composed of Linen. Very little is known about the production of Linen in Assyria or Babylonia, but when so much of it was consumed it must have been largely manufactured at home. Very probably, however, the finer qualities were brought from Egypt, as that country was at that time the manufacturers of fine 
Linen for the world. Herodotus says that the dress of the Babylonians consisted of a Linen shirt, hanging down to the feet, and over it a woollen tunic, while a small white mantle or shawl was wrapped round the body.

Babylonian garments were in early times much prized. Achan coveted one, and his sin wrought much woe to the Israelites. Josephus says it was a royal garment woven entirely of gold, but they were not usually made of this costly material, although they were often embroidered with gold. This robe was manufactured in the plain of Shinar, not necessarily in Babylon, as this city was not at that early period of great importance, and it was not until many centuries afterwards that it was celebrated for its manufactures. It is doubtful of what these famous robes or mantles were composed, but it is supposed they were made of various colours, which seem to have been disposed in figures resembling those on Turkey carpets. From what the Roman writers say about them it is uncertain whether they were painted, woven in the loom, or embroidered by the needle. These robes from their glossiness and tasteful combination of colours, produced a very splendid and rich effect. They were very costly, and considered in the highest degree luxurious. Plutarch relates that Cato, on receiving one of them by inheritance, commanded it to be immediately sold, because he thought it too costly for a conscientious Roman to wear, thus showing his enmity to luxury. One of Nero's dining rooms was hung with Babylonian cloth at an expense, as mentioned by Pliny, of 4,000,000 sisterces, or upwards of $£ 32,300$ sterling. It is likely that gold and silver had entered largely into the composition of textures so extravagantly costly.

The Romans got their silks from Babylon in the days of Pliny. It is supposed that the Babylonians got them from the Indians, who in turn received them from China. China would thus appear to have been the early seat of the silk manufacture. Perhaps the Babylonian mantles may latterly have been formed of silk, but they were more likely to have made of Linen or woollen in these early times, as there is no certain proof that silk was then known in the western world. It is related that the Babylonian gods were arrayed in robes of purple, and very probably these were made of Linen. Strabo speaks of the same 
three articles of dress as worn by the Babylonians that are mentioned by Herodotus, and shows where they were chiefly made. He says that Borsippa, a city of Babylonia, sacred to Apollo and Diana, was a great place for the manufacture of Linen.

There is no doubt therefore that Flax was extensively cultivated in Babylonia, and that Linen was an article of very large consumption there. The growth of Flax in the region of the Euphrates may also be inferred from the use of the Linen thorax, as attested by Xenophon.

It is supposed, on good grounds, that large weaving establishments, approaching in many particulars to the cloth factories of the present day, were scattered throughout the whole of the provinces of Babylonia. Nineveh, and indeed all the cities which studded the banks of the Tigris and Euphrates, were famous for their woollen and Linen manufactures, and had been so in all likelihood from the time of the dispersion at Babel.

Now Babylon is not; Nineveh and the other great cities of that region, which formerly played so conspicuous a part in history have perished, and even the sites of some of them are unknown or only guessed at. With their fall trade and commerce in those once fair and fertile countries were extinguished, and Babylonian Linen and even the gorgeous Babylonian mantles now only historically exist.

\section{CHAP'TER V.}

COLCH I CA N L I N E N.

Accorving to Diodorus, Herodotus and other historians, the Egyptian King Sesostris, who lived 3500 years ago, had fleets both in the Red Sea and in the Mediterranean. Gibbon affirms that Sesostris, who carried on extensive wars, and extended his 
conquests to distant countries, planted a colony at Colchis on the banks of the Phasis, a river flowing into the eastern side of the Pontus Euxinus or Black Sea. The sailors employed by Sesostris were probably Phœnicians, because his own people were not then navigators, and their antipathy to the sea existed for many ages after this period.

It is certain that whether or not Colchis was a colony of Egypt, the people prepared their Flax in the same manner as the Egyptians, and in a way not practised by any other nation. They manufactured Linen on an extensive scale, built navies, and invented geographical maps. Phineus, king of Colchis, told the Argonauts of the maps, and exhibited them to the leaders of the Greeks.

Xenophon directs that nets should be made of Flax from the Phasis or from Carthage. Strabo testifies to the celebrity of Colchis for the growth and manufacture of Flax, and says that the Linen of this country was exported to distant places.

Hemp as well as Flax was grown extensively in Colchis, and they were exported to the ports of the Fgean Sea by the Ionians, who traded largely with the eastern and northern coasts of the Euxine, through the medium of their Milesian colonies.

The productions of Colchis, especially Flax, Hemp, and fine Linen, formed an important article of import into Rome in the days of Augustus, showing that the trade had been long and successfully carried on. Herodotus says that the Linen of Colchis was by the Greeks called Sardonian, and the Linen of Egypt Egyptian. This would imply that there was a difference between the manufactures of the two countries, as there would have been no occasion to give them distinguishing names had they been of a like quality.

For a long period after the reign of Augustus the country appears to have maintained its ancient pre-eminence for Linens. Larcher refers to Chardin as saying that the Prince of Mingrelia, a part of the ancient Colchis, paid in his time an annual tribute of Linen to the Turks.

Although Imeretia has long since lost her ancient and famous Linen trade, Flax and Hemp are yet grown abundantly in the country. The crops of Flax are in the present day described as 
being rich and luxuriant, but the plant is now grown for its oil alone, and the stalks are burned as soon as the seeds are gathered 'This destruction of valuable fibre is to be regretted, as it might yet be made what it was in ancient times, an important article of export, profitable alike to the growers and to the countries which import it. 'The subject is worthy of the attention of Turkish and other merchants trading to this part of the Black Sea.

\section{CHAPTER VI.}

\section{G R E C I A N L I N E N .}

Tue physical contour of a country influences to a great extent the particular kind of industry, and perhaps the very character, of the people. Egypt first, and Germany subsequently, were the great Linen producing countries of ancient times, because in these had been placed the splendid alluvial plains of the Nile and the Rhine. The Egyptian and German people were, as a rule, peace-loving and industrious. On the other hand, the inhabitants of mountainous districts were generally more noted for woollen manufactures, because their flocks yielded a ready supply of the raw material. They were also of a more turbulent and warlike disposition than the people who inhabited the neighbouring plains. Such was Greece in the earliest times. It had famous mountains and numerous hills, but it had no large rivers, and few great plains. It had its petty tribes, rugged as the country in which they dwelt, but war was more congenial to their tastes than industrial pursuits, and of trade and commerce it had none.

In some of the beautiful Islands which abound in the Grecian Seas, and which almost surround the mainland as it were with 
bright and lovely gems, a spirit of peaceful enterprise was early created. Their own little world at home being too small for their support or their ambition, they sallied forth in quest of fortune, and opened up a trade with distant lands. The Ionians had colonies at a very early period, and colonies imply interchange of commodities. Through their instrumentality the produce of distant countries was brought to Greece, and this gradually changed the tastes and habits of the people. Originally they were indifferent about dress, and content with the produce of their flocks, woven in native looms. As refinement progressed Linen would come into use, and the famous products of the looms of Egypt, of Phœnicia, of Babylonia, or of Colchis, would be more and more prized. The manners and customs of a people are not changed in a day, and in Greece these changes were progressive. This is borne out by the following account of the employment, dress, and habits of the people, especially with reference to the state of the Linen manufacture among them.

Greece was not a Flax growing country ; indeed, being intersected in every part by mountainous ridges, and possessed of no rivers or alluvial plains of any importance, it was not by nature adapted for the growth of the plant. The only part where it is recorded to have been grown in ancient times was Elis, a low lying plain on the extreme west of the Peloponnesus, watered by the rivers Alpheus and Igliaco. Pliny affirms that it was produced in that country. Pausanius speaks of the district of Elis as well adapted for growing the Byssus. He remarks that all the people whose land is adapted for it sow Hemp, Flax, and Byssus. In a third passage he says that the Byssus of Elis is not inferior to that of the Hebrews in fineness, but it is not so yellow. This Byssus of the Hebrews may have been so called because it was imported into Greece by them, and not because it grew in Palestine. It is well known, however, that Flax was grown extensively there, and that there was a manufacture of Byssus in Judah, and it may therefore have been veritably Byssus of the Hebrews.

If Flax was not extensively grown in Greece it must have been largely imported, as it was an article of great consumption from comparatively early times. In Greece weaving was a distinct trade, carried on by a separate class of persons; but, in addition to this, 
every considerable domestic establishment, especially in the country, contained a loom, with the other necessary apparatus for making cloth. The spinning of yarn was a common employment of the women, and the most noble in the land did not think it beneath them to join in the labour. When the farmhouse or the palace was sufficiently large to admit of it, a separate portion was devoted to this purpose. The work was principally carried on by female slaves, under the superintendence of the mistress of the house These occupations were all supposed to be carried on under the protection of Athena or some other goddess.

A lady in the Homeric age is described in the Odyssey as possessed of various articles of costly manufacture : "Her lyre had a silver frame, her basket is silver, and her distaff gold." Saffron was used as a spindle by the women of remote antiquity.

Homer mentions a distaff of gold given to Spartan Helen by Alexandra, the wife of Polybus, who lived in Thebes in Egypt, which he thus describes:-

And that rich vase, with living sculpture wrought,

Which, heaped with wool, the beauteous Philo brought.

Theocritus presented a distaff of ivory to Theugenis, the wife of his friend Nicias, the Milesian physician ; and he has given a very striking proof of the pleasure which the women of Miletus took in their employment in the verses which accompanied the gift. Among both the Grecian and Roman ladies the distaff and spindle were always of beautiful workmanship, and sometimes of costly materials. In addition to these articles they had also a basket for holding the wool or Flax, called a calathus or qualus. It was generally composed of wicker-work.

Catullus, in his description of the marriage of Peleus and Thetis, says :-

The softent fleeces, white as driven snow, Beside their feet, in osier baskets, glow.

Sidonian artists were most expert in the fabrication of embroidered works, but the high-born ladies of the court were apparently no mean proficients. Helen weaved a representation 
of a battle between the Greeks and the Trojans. Andromache copied flowers in a veil. The web of Penelope is proverbially known-that funeral offering for Laertes from the hand of filial affection; while another, which she presents to an unknown guest, is beautifully described by Pope.

In spinning and weaving the ancients evidently rivalled the present age, though without the aid of machinery. As far indeed as spinning is concerned no machinery can rival the human hand, which, from its slight oily exudation is enabled to communicate superior strength and evenness to the finest threads. Thus in Hindoostan muslins were formerly produced which, laid on the grass and wetted by dew, became invisible, and there is no room for doubting that the produce of the ancient Greek looms rivalled those of Dacca. The fabrics of Cos and Tarentum appear, in fact, from the testimony of the ancients, to have floated like a snowy mist around the female form, disclosing its whole contour like a gauze veil. It is related that the ambassador of Shah Sefi, on his return from India, presented his master with a cocoa nut set with jewels, containing a muslin turban, thirty English yards in length, so exquisitely fine, that it could scarcely be felt by the touch.

The employments of women in the Homeric times included the labour of the loom, to excel in which was considered one of their chief accomplishments, and most necessary duties. Carding and spinning also entered into the list of occupations. A Homeric princess thought nothing beneath her which could contribute to the comfort or elegant adornment of those she loved. Constant practice, and the delight which familiar and voluntary labour inspires, had already, in the heroic ages, enabled the Grecian ladies to throw much splendour and richness of invention into their fabrics. Probably the desire of excelling the ladies of Sidon in works of this kind gave an additional impulse to their industry and skill. At all events Homer makes it abundantly clear that they understood how to employ with singular felicity the arts of design, and to represent in varied colours, cities, landscapes, human figures, and all the complicated movements of war. No doubt allowance must be made for the poet's unrivalled skill in painting, but even then, enough remains to prove that at the period of the Trojan war, Greece 
had made remarkable progress in every art which tends to ameliorate and embellish human life.

In these occupations high-born ladies took refuge from anxiety and sorrow. 'To them Hector, as Homer relates in the Iliad, with rough tenderness, urged his beloved wife to have recourse, when her affection would withdraw him from his post. Telemachus, as told in the Odyssey, in a tone perhaps somewhat too authoritative, recommends the same course to his mother. The wife of Odysseus, famed for her household virtues, sat at her own door spinning the purple thread. Arete, queen of Phœacia, is likewise depicted sitting at the fire, distaff in hand, encircled by her maids. Even Helen, though frail as fair, is as laborious as Penelope, plying her shuttle or her golden distaff, and surrounded habitually by a troop of maidens - the she-manufacturers of the period.

The Greeks were famous for the beautiful patterns woven in their cloths, which were variegated with stripes, lozenges, the figures of birds and other animals, sprigs, flowers, and stars, interwoven into their texture, of the most brilliant and beautiful colours. Others were richly embroidered. Even napkins in Egypt were embroidered with golden flowers, as both these and all kinds of handkerchiefs still are throughout the East. In that age the warrior was to some extent indebted to the labours of the needle and the loom. Wild animals or other figures, the trophies of his dexterity in the chase, or his prowess in the fight, were embroidered in his belt. More ample robes were either received as the pledge of courteous hospitality, or worn as the prize of valour. In Greece the fine soft vests which warriors wore beneath their shirts of mail were usually figured with rich embroidery by the females of their family. Such occupations suited the secluded life and habits of oriental females, and the articles so wrought are graphically described by the mother of Sisera. Such garments were stored in the treasury of Priam.

One of the most extraordinary productions of the Grecian loom seems to have been that magnificent chlamys which was weaving for king Demetrius at the period of his overthrow. It is said to have been a long time in hand, and represented in one vast picture, both the face of the earth and heaven with all 
its constellations. But it never was completed, none of the succeeding sovereigns of Macedon possessing the gorgeous taste of the son of Antigonus.

It appears to be generally supposed that silver threads were not employed until a very recent period, either in weaving or embroidery. Mention, however, is made in Philo Sudæus of purple coverlets inwrought with silver and gold. At length the love of show and magnificence rose to such a height, that robes were woven entirely of threads of gold.

In the Homeric ages it is probable that the dresses of the Greeks had been almost entirely composed of woollen cloth, Linen being little used, and, if manufactured at all, only to a small extent at that early date. As refinement increased the articles of dress became more varied and costly, and Linen came to be generally worn, at least as underclothing, especially among the ladies of Attica.

It is probable, from the Greek word used for Linen in two passages in the Iliad, that the Linen was procured from Egypt, the term appearing to have been originally Egyptian and adopted by the Greeks. In the time of Homer the use of Linen cloth was certainly rare among the Greeks, and the manufacture of it was perhaps as yet unknown to them.

In a list of ladies tradesmen given in Plautus, mention is made of Linen weavers.

Being ignorant who was the inventor of weaving, the Grecians attributed the honour to Athena. She imparted a knowledge of it to Arachnè, a virgin of Mæonia, afterwards changed into a spider. But spiders were not long the only weavers among the Hellenes, as they speedily invented the upright and horizontal looms, which, in after times at least, were constructed from the wood of the Andrachnè.

The traditions of many ancient nations refer the invention of the art of weaving cloth to a very remote antiquity. According to Pliny, Semiramis the Assyrian queen, was believed to have been the inventress of this art. Minerva is in some of the ancient statues represented with a distaff, to intimate that she taught the art of spinning. This honour is given by the Egyptians to Isis ; by the Mahomedans to a son of Japhet ; by the Chinese to the consort of their Emperor Yas ; and by the 
Peruvians to Mamoella, wife of Manco-capac, their first sovereign. A decided majority of these names are those of ladies, thus associating women with the establishment of the useful arts in countries far apart and in very remote times. These traditions, says Yates in his "Textrinum Antiquorum," serve only to carry the invaluable art of spinning and weaving up to an extremely remote period, long prior to that of authentic history.

The same learned author has published a curious map designed to indicate the divisions of the ancient world, as determined by the raw materials produced, and employed in them for weaving. In China the chief manufacture has been from time immemorial silk; in India, cotton; in Egypt, Colchis in the Euxine, and the delta of the Rhine, flax; in Western Asia and Southern Europe, wool ; and in Northern Europe, hemp,

In Persia and other Eastern countries the taste for ladies to spin, weave, and make embroidered garments prevailed down to a later age. When Sisygambis, the captive Persian Queen, was presented by Alexander with purple and wool, she said, in an agony of grief and tears, they reminded her of happier days. The conqueror, misunderstanding her feelings, and desiring to remove the notion that he was imposing any servile task, observed:"This garment, mother, which you see me wear, is not merely the gift, but the work also, of my sisters." Similar presents passed between near relations in Persia, for it is related by Herodotus that Amestris, the queen of Xerxes, conferred upon her husband, as a gift of price, a rich, variegated, and ample pelisse, which the labours of her own fair hands had rendered valuable.

The Dorian style of dress formed the point of transition from the simple elegance of the Homeric period to the elaborate splendour of the historic age at Athens. Wealthy and fond of show they delighted in a style of dress curious and magnificent, appearing abroad in flowing robes of the finest Linen, dyed with purple and other brilliant colours.

As much dignity is supposed to belong to ample drapery, the citizen ladies in some of the districts of Greece took care not to be sparing of their stuff, their dresses trailing on the ground, and displaying numerous folds produced purposely at the extremity, by a band passing round the edge. These garments were 
generally of Linen. Snow white slippers of fine Linen, flowered with needle-work, were occasionally worn.

The dress of the men included many of the garments worn by women, for example the chiton, of which there were several kinds, some with and some without sleeves, were worn by both sexes in some parts of Greece.

According to Julius Pollux, the Athenians and Ionians wore a Linen shirt reaching to the feet. The Ionians cultivated Flax in their own country, as well as in colonies they had in the Euxine Sea, and on this account, as well as in consequence of the general elegance and refinement of their manners, for which they were proverbial, it is probable that they adopted this article of clothing long before the Athenians. Indeed it appears probable that the Linen first used by the Athenians was imported. Herodotus remarks that the Linen shift worn by the Athenian women was originally Carian.

Athena was considered to be the goddess who presided over spinning and weaving. A bride at the altar of Athena always presented one of her tresses cut off and twined round a spindle as a marriage offering.

The Athenian ladies wore a white tunic reaching to the ground (answering to the modern chemise), in some instances sleeveless and fastened on the shoulders with buttons; in others furnished with loose hanging sleeves descending to the wrist, and brought together at intervals upon the arm by silver or golden agraffes. It was gathered into close folds under the bosom by a girdle or ribband, sometimes fastened in front by a knot, and sometimes by a clasp. This inner robe, made in the earlier ages of fine Linen manufactured in Attica, or imported from Egypt, Tyre, or Sidon, came in after times to be of muslin from Tarentum, or woven at home from Egyptian cotton. The use of fine Linen, however, for this purpose was not wholly superseded by either of these fabrics.

Pliny says that among the finest and most elegant fabrics of Greece were those manufactured in the Achæan city of Patræ, where the women, being twice as numerous as the men, would alone appear to have worked in the factories, from which the greater number of the inhabitants doubtless derived their livelihood. The Flax from which the fine Linen and head nets of 
this town were suade, was not grown in the neighbourhood, but in the plains of Elis, where alone in Greece the plant attained the highest degree of perfection; not yielding in fineness to the best produced elsewhere, while it was possessed of superior whiteness. The fine cloths manufactured from it sold for their weight in gold.

A very beautiful kind from the Island of Amorgos, one of the Cyclades, was often substituted, down to a very late period, in place of the byssus or fine Linen of Egypt. 'This insular fabric, whether snow white or purple, would have rivalled the finest cambric, being of the most delicate texture, and semi-transparent, like the Tarentine and Coan vests of the Roman ladies, the Sandyx-coloured Lydian robe, or the silken chemises of the Turkish sultanas described by Lady Montague. It is in a tunic of this Linen that Lysistrata in Aristophanes advises the Athenian ladies to appear before their husbands, in order to give full effect to the splendour of their charms.

In imitation of the Egyptians they wove a sort of fine napkins, which were evidently used in the same manner as modern pocket handkerchiefs (for which, according to Aristophanes, the old men substituted a fox's tail.) The Flax from which these beautiful Linens was made was cultivated in the Island, and it was of remarkably fine quality.

Because the Amorginean Linen was often, perhaps commonly, dyed purple, the word amorgis has sometimes been supposed to denote purple stuff, and it has been inferred that none purely white was produced; but this, as Bochart observes, is probably a mistake, indeed it is believed that the fabrics of the Island were as often white as dyed. At all events, it was of extraordinary fineness, superior, in the opinion of Lindas, even to the byssus and carbasos or lawn of Cyprus, and it appears to have been of a thin gauze-like texture, like the drapery of " woven air," which Petronius throws around his female characters.

Over the chiton was worn a shorter robe not reaching below the knee, and confined above the loins by a broad ribband. This was also in some instances furnished with sleeves, and of a rich purple or saffron colour, generally ornamented like the chiton with a broad border of variegated embroidery. To these, in order to complete the walking dress, was added a magnifi- 
cent mantle, generally of purple embroidered with gold, which being thrown negligently over the shoulders, floated airily about the person, discovering the under garments, exquisitely disposed for the purpose of displaying all the contours of the form, particularly of the waist and bosom.

Diogenes Laertius tells a story respecting the philosopher Crates, which shows that at Athens it was not deemed proper for a man to wear Linen as an outer garment, but that persons were enveloped in it under the hands of the hairdresser. The Athenian police officer having charged him with wearing a Linen sheet for his outer garment, he said I will shew you Theophrastus himself habited in that manner, and, when they doubted the fact, he took them to see Theophrastus at the hairdresser's. Alciphron tells of the barber putting on him a Linen cloth in order to shave him, and Phaneas, in an epigram, says the cloth used in shaving is linen.

Herodotus says that, before an incident which he relates, "the women of Athens wore the Doric vest, which resembles the Corinthian; that they might have no occasion for clasps they obliged them to wear Linen tunics."

According to the same author, Xerxes provided cordage made of the bark of the biblos, and of white Flax, for constructing the bridges over the Hellespont. He says the Phœenicians used a cordage made of Linen, the Egyptians the bark of the biblos. In the second bridge the cables, he says, were made as follows: "For this purpose they did not employ a number of separate cables, but united two of white Flax with four of biblos. These were alike in thickness and apparently so in goodness, but those of Flax were in proportion much the more solid, weighing not less than a talent to every cubit."

Among the articles of armour enumerated by the poet Alcæus, as hung round his room, are "cuirasses of Linen, baldricks, and the short vest, which we wear beneath our armour, and a short Linen chiton descending to the middle of the thigh."

When a gentlemen first commenced housekeeping, or got a new set of domestics, he delivered unto the care of the proper individuaİs his kneading troughs, his kitchen utensils, his cards, looms, spinning wheels, \&c., and pointed out the place where 
each should be placed when not in use. Indeed, the implements of war, looms, spinning wheels, embroidering frames, \&c., were mixed up together in Greek houses, just as Homer describes them in the 'Thalamos of Paris at Troy.

Greece was not a manufacturing country, and although some of the states made their own clothing and even exported a little, others were indebted for it to neighbouring countries, and none of them exported textile fabrics to any great extent. At one period, and it continued for a long time, the Island of Delos was the grand mart, not only of Athens, but of all Greece, and of other countries on the Mediterranean Sea. It was the emporium for the then known world, just as Britain is at the present day. Neighbouring nations sent the products of their industry there to sell, taking back such necessaries or luxuries as their own country did not produce. It was an island of merchants, a depot for the goods of the world. Among other things it imported scarlet Linen tunics manufactured on the Island of Amorgos, and the rich purple stuff of Cos. Colchis traded with it, sending its Flax and fine Linen, and taking in return the products of other lands. The Egyptians, the Tyrians, the Romans, and many other nations and countries trafficked with the merchants of Delos, and Linens formed a very important article of the trade of the place. The war of Mithridates put an end to the trade of commercial Delos.

According to Thucydides, papyrus and sail cloth from Egypt, and carpets from Carthage, were among the importations of Corinth.

It is recorded that Alexander the Great took the turban from his head to bind up the wound of Lysimachus, showing conclusively that it was made of fine Linen. Turbans of fine Linen, with an encircling or front ornament of gold or precious stones, was the usual diadem of ancient kings.

Sails were manufactured from a variety of materials. In Egypt they sometimes consisted of numbers of hides sewed together, sometimes they were made of papyrus, and sometimes of Flax. In various countries they were plaited, as now in China, from reeds or rushes. But the sail-cloth of the Greeks was generally woven from Hemp, like some made in Britain at the present day. 
In ancient times the Greeks made very superior cloth from Hemp, and the Thracians, in whose country it was found both in a cultivated and wild state, used it extensively. It differed little from Flax, except in its superior height and thickness, and the fabrics manufactured were not to be distinguished from Linen, save by the most experienced judges.

Among the exports of Athens are enumerated soft fine wool, Linen, and woollen cloths, \&c. Elis exported Flax. Achaia exported all kinds of fine Linen manufactured at Patræ. Corinth exported Linen tunics. The Lacedæmonians distinguished themselves in dyeing and weaving, and their mantles and woollen garments were in much esteem throughout Greece. Linen, white and dyed, was brought from the Island of Amorgos to the various countries of Greece. Flax was imported from Egypt, and also paper, sails, curiously wrought Linen breastplates, Linen, \&c. Purple and broidered work and fine Linen was imported from Syria; in the most ancient times from Sidon, and later from Tyre and other places.

After the rise of the Roman power Greece gradually sank to a subordinate rank, and finally its States became provinces of Rome. Less account was then made of its manufactures and trade than when it was an independent power, and much is left to hypothesis and surmise. During that period the Linen manufacture held a place in some districts, and was prosecuted with greater or less success. Apart from the seat of government and power, and away from the anxiety and ruin which latterly overwhelmed Rome, they long followed their peaceful industry with comparatively little molestation.

Gibbon says that after the age of Justinian the Eastern Empire began to decay, and but for its trade and manufactures it would have sunk faster than it did. In the province of Pelo. ponnesus, mariners and the workers in parchment and purple were exempted from all personal taxes, which did much to encourage industry. Under this denomination may be fairly included the manufacture of Linen, woollen, and silk, the two former of which had flourished in Greece from about the days of Homer. These arts, which were exercised at Corinth, Thebes, and Argos, afforded good occupation to a numerous people, and the men, women, and children were distributed according to 
their ages and strength, and to each was assigned work suitable for their abilities.

The gifts which a rich and generous matron of Peloponnesus presented to the Emperor Basil, her adopted son, were doubtless fabricated in the Grecian looms. Danielis bestowed on him a carpet of fine wool, of a pattern which imitated the spots of a peacock's tail, and of a magnitude to overspread the floor of a new church. She gave 600 pieces of silk, and Linen of various denominations. The silk was dyed with the Tyrian dye, and adorned by the labour of fair hands with the needle, and the Linen was so exquisitely fine that an entire piece might be rolled in the hollow of a cane.

For centuries after this period the manufacture of Linen, silk, \&e., was earried on in Greece, but it gradually decreased and finally became extinet as the country fell under Mahomedan sway. In modern times it possesses no Linen manufactures that really deserve the name, and what Linens are required are, as they were in the very earliest times, imported from foreign countries.

When Colonel Leake was at Gastuni, near the mouth of the Peneus in Elis, after describing the mode of cultivating and preparing Flax, which he says, is one of the chief things produced there, he remarks, "contıary to its ancient reputation, the Flax of Gastuni is not very fine. It is chiefly used in the neighbouring islands by the peasantry, who weave it into cloth for their own use."

The imports of Linen manufactures into Greece for the years 1857 to 1860 were as follows :-

\begin{tabular}{lrrrr} 
& 1857 & 1853 & 1859 & \multicolumn{1}{c}{18160} \\
Tuns, & $\ldots \ldots$ & 65 & 85 & 143 \\
Value, & $£ 15,416$ & $£ 12.134$ & $£ 13,882$ & $£ 18,774$
\end{tabular}

In 1857 nearly five-eighths of the value was from Austria, the United Kingdom supplying little more than one-sixth, and France between one-fourth and one-fifth of the total. In 1860 the United Kingdom supplied more than the half, both in quantity and value, Austria one-third and France one-tenth. 


\section{CHAPTER VII.}

R O M A N L I N E N.

THE great desire of the Romans was the extension of their dominions, the aggrandisement of the state, and the consolidation of their power. At a very early period of their history they had colonies and dependencies in various parts of Europe and Asia, whence they drew supplies of many of the necessaries and luxuries of life. On this account it was not imperative on them to become a manufacturing people, as the labour of their colonies, and of tributary nations, provided them with the bulk of the textile fabrics they required. This the better enabled the Romans to devote themselves to military duty, and to seek martial glory, which was the great business of their life. Some of the subjugated countries and colonies were famous for one species of manufacture, and others for another, and all of them furnished their quota for the supply of the army, the navy, and the luxurious citizens of mighty Rome.

In the ancient history of the republic the Romans were almost entirely clothed in woollen garments, differing in quality and texture with the circumstances of the wearer and the seasons of the year, and it was not until the time of the Emperors that Linen came into extensive use. The Roman priests began to wear Linen garments at an early period, and in this they no doubt followed the example set them by the priesthood in Israel and in Egypt, who, from the earliest times, wore Linen clothing. Ovid and Juvenal call the Roman priests "Linen wearing," from the texture of the garments they wore. As greater refinement of manners began to prevail, and more luxurious tastes arose, woollen cloth failed to satisfy the wants of the wealthy Romans, and Linen fabrics came gradually unto use among them. Some of these, for every-day use, were no doubt of a common quality, but Linen of the most beautiful texture was largely consumed. 
Egypt, Phoenicia, Babylonia, Colchis, and Greece, all sent the marvellous productions of their looms to Rome, and found a ready market for them there. Spain, Gaul, Germany, and other countries famous for their Linens, also contributed their manufactures to satisfy the demands of the seven hilled city. Several districts in Italy were early distinguished for their Linens, and, as the consumption became more general, the production partook much of a domestic character, and many families span their Flax and weaved the Linen for their own use, after satisfying which, the superabundant production was bartered or sold.

An account of the Linen manufacture in some of the countries which supplied Imperial Rome has already been given, but it will not be out of place to advert to one or two of the Linen producing nations here. Their manufactures were, no doubt, to some extent used by the inhabitants of the country, but many of their most costly productions were specially made for Rome. The wealth and luxury of many of its noble citizens gave great encouragement to the fabrication of the very finest Linens. This stimulated the manufacturers to exert themsolves, and great excellence was attained, the beauty of many of the Linens produced being proverbial.

In ancient times some of the cities of Spain were highly celebrated for their manufacture of textile fabrics, and of these Linen was one of the most important. Strabo says there was a manufacture of Linen at Emporium in Spain, which lay in the Miditerranean not far from the Pyrenees. Tarraco (Tarragona) was famous for its fine Linen, which was remarkable for its shining whiteness, and the wonderful thinness of its fabric. Pliny, the natural historian, says that remarkably beautiful Flax was produced in Hispania Citerior, near Tarraco. He ascribes its splendour to the virtues of the river water flowing near Tarraco, in which the Flax was steeped and prepared. This is very likely to have been the case, as it is well known that the water in which the Flax is steeped has considerable influence on the quality of the fibre. On this account the Lys in Belgium has acquired a name and fame, and it has become the most celebrated river in modern times, for the valuable properties it imparts to the Flax steeped in it. 
Catullus, Pliny, and other authors say that Setabis, the modern Xativa, southward from Tarraco, but on the same coast, was celebrated for the beauty of its Linen, and especially for Linen sudaria or handkerchiefs. Pliny also mentions a kind of Flax called Zoelicum, from a place in Gallicia. Spain and Portugal at an early period manufacture dsuperior Linen for export. The Linens of Emporiæ and of the Saltioeti long continued to be famous. The Spartium or Spanish broom, principally used in the manufacture of cables, grew chiefly along the high arid plains of Valentia and Catalonia, through which passed the great high road to Italy.

Pliny relates that Flax was woven into sailcloth in all parts of Gaul; and that in some of the countries beyond the Rhine the most beautiful apparel of the ladies was Linen. Tacitus states that the women of Germany wore Linen sheets over their other clothing, that the dress of the men and women differed little excepting that the women wore more Linen than the men, and that the sleeves of their tunics were short, which left their arms bare, and also some part of their bosoms.

In the most inclement winter the hardy German was satisfied with a scanty garment made of the skin of some animal. The natives who dwelt towards the north clothed themselves with furs, and the women manufactured for their own use a coarse kind of Linen. Pliny speaks with ill-concealed contempt of the German ladies "who cannot desire to go more rich and costly in their apparel than to wear Linen." He mentions that the Germans wove their Linens in dwellings under the ground, and that a similar practice prevailed in some parts of Italy. It is well known that Flax does not spin or weave so well in a very dry place, as in one where the atmosphere is moist and cool, and it would appear that this had been known to, and taken advantage of by the Germans, and those of Italy, of whom mention is made.

It is mentioned by Paulus Diaconus, in the history of the Longobards, that the German ancestors of the Anglo-Saxons wore loose and flowing garments, chiefly made of Linen, adorned with broad borders, woven or embroidered with various colours. This must refer chiefly to the women, as it is hardly possible that all the garments of the men, especially the upper ones, would 
be made of Linen, seeing that they were so much exposed to storms, and so often engaged in military expeditions, in a country where warm clothing, in the winter season, is absolutely necessary.

Gibbon says that in A.D. 590 the Lombards of the 4th generation surveyed with curiosity and affright the portraits of their savage forefathers. Their dress consisted of loose Linen garments, after the fashion of the Anglo-Saxons, which was decorated with broad stripes of variegated colours.

The following passage from Equihart's life of Charlemagne, shows that during several succeeding centuries after the Roman age, the Franks wore Linen for their under garments:"Charles drest after the manner of his countrymen the Franks. Next to the skin he wore a shirt and drawers of Linen, over these he wore a tunic bordered with silk, and breeches." In the notes on this passage it is said that the Lombards and the AngloSaxons wore principally Linen garments.

From time immemorial some parts of Italy have been famous for their Flax. Pliny mentions various kinds of Flax which were produced in the plains of the Po and Ticino, in the country of the Peligni (in Picenum), and about Cumae in Campania. No Flax, he says, was whiter or more like wool than that of the Peligni. Professor Müller says "Flax was grown and manufactured in Southern Etruria from ancient times, and thus the Tarquinii were enabled to furnish sailcloth for the fleet of Scipio. Yarn for making nets was produced on the banks of the Tiber, and fine Linen for clothing in Falerii." This agrees with the views of those historians who maintain the Egyptian origin of the Etrurians.

Not only was Flax raised largely in Italy, but Spain, Gaul, and other provinces of ancient Rome were celebrated for the superior quality of what they produced, and Egypt contributed a full share of its fanous Flax to supply the extensive wants of the Roman people.

The warlike Roman disdained to occupy himself in tasks which he was accustomed to look upon as effeminate drudgery. His attention was more directed to the cultivation of the science of war than to the humbler but more useful industrial arte. 'To the women chiefly were assigned the labours of spinning 
and weaving, especially in the earlier ages of the Commonwealth.

Like Greece, Rome had its regular weaving establishments, conducted by a distinct class of people, and hired women used to weave in the open air at Rome. Men were also so employed at times. It also had its domestic manufacture, in which the mistress and her maidens both performed their part. Spinning and weaving were then considered honourable in themselves, and formed the chief occupation of females in every rank. The family loom long stood in the Atrium, the public apartment of the mansion, and there the lady of the house sat and toiled, surrounded by her maidens. No doubt as wool long formed the chief article of clothing of both sexes, it would be the material spun and weaved, but towards the end of the Republic, and under the Empire, Linen came more extensively into use, and mixed fabrics with either the warp or weft of Flax became general.

Although Flax was employed for many domestic purposes in Rome, it was not generally used until a late epoch for articles of dress, and the priests of Isis, who were always robed in Linen, were from this circumstance marked out to the eye as a distinct class. When it first began to be introduced it was almost entirely confined to the women, but gradually the men also adopted it, and at last Linen articles of clothing became common to both sexes.

Pliny has given some curious particulars as to the cultivation and preparation of Flax and the manufacture of Linen in his day. He appears to have looked upon it as an effeminate and even dangerous innovation, and to have considered that it would have been better to have retained the woollen clothing of former times. The arts of dressing and weaving Flax had been long practised in the east before they made their way into Italy and were practised in that country. Some of the great families among the old Romans boasted that they made no use of Linen in their houses or about their persons, and the use of it was long considered a mark of effeminacy and a piece of criminal luxury by that brave and hardy people. By - slow degrees, however, the use of Linen extended not only over all Italy, but also into Spain, Gaul, Germany, and Britain. 
Montfancon, from Pliny, says that the Romans had bedcoverings from Gaul (called Cadurcum, from the country whence they were made), of Linen as white as wool. If sheets are to be understood by stramenta, which in one sense signified underbed-clothes, sheets of this kind were used in Italy in the time of Pliny. Norrius defines plagae by sheets.

Fusus, the spindle, was always, when in use, accompanied by the colus or distaff, as an indispensible part of the same apparatus. The Flax or other material having been prepared for spinning, was rolled into a ball (glomus), sufficiently loose to allow the fibres to be easily drawn out by the hand of the spinner. The upper part of the distaff was then inserted into the ball, and the lower part was held under the arm in such a position as was most convenient for conducting the operation. The fibres were drawn out, and at the same time spirally twisted, chiefly by the use of the fore-finger and thumb of the right hand, and the thread (filum) so produced was wound upon the spindle. The spindle differed little from that used in Egypt. Its lower extremity was inserted into a small wheel called the whorl (vorticellum), of wood or other material, to keep the spindle more steady and to promote its rotation.

The distaff, spindle, balls of flax, and the bobbins spun, were usually held in a basket, called calathus. The distaff and spindle, with the wool or Flax and thread upon them, were carried in bridal processions. Without the yarn and material they were often suspended by females as offerings of religious gratitude, especially in old age, or in relinquishing the use of them. They were most frequently dedicated to Pallas, the patroness of spinning and of the arts connected with it. They were exhibited in the representations of the Three Fates, who were conceived by their spinning to determine the life of every man.

The method of spinning then in use was very similar to the mode practised in this country at no very remote period, and more fully detailed in the chapter on Flax spinning. It is still conducted in the same way almost universally throughout Southern Italy in the present day. A most graphic and charming description of the process will be found in Catullus, when he represents the Fates plying their task at the nuptials of Peleus and Thetis. 
The different parts of the loom and of the web are in like manner enumerated by Ovid, when describing the struggle of Arachne with the goddess Minerva, and they are frequently alluded to in the classics. The frame of the loom, which was generally placed vertically, and not horizontally, was called jugum, the web tela, the loops or holders were the licia, the warp stamen, the woof trama or subtemen, the reed arundo, the shuttle radius, and the lay or lath pecten. The warp was named stamen on account of its erect position in the loom. A transverse rod was passed through the threads of warp to divide it into two portions, the threads on one side of the rod alternating with those on the other side throughout the entire breadth of the warp. The warp was also divided into a number of parcels, a stone being suspended from each to keep the threads in a perpendicular position. The web as the work advanced was wound on a roller, turned by a handle. The warp was of strong, well twisted yarn. The weft was put on a spindle or a bobbin, and passed through the warp without any other contri. vance; or it was made to revolve in a shuttle, made of box brought from the shores of the Euxine, and pointed at both ends, that it might easily force its way through the warp. The licia or heddles were threads fastened at one end to a straight rod, and having a loop at the other through which a thread of warp was passed. The warp was divided by the arundo into two sets of threads, which were passed through the loops of the corresponding set of leashes. For a plain web two rods with the leashes attached were necessary, and the number of sets of leashes was increased according to the complexity of the pattern, which was called bilix or trilex, according as the number was, two, three, or more.

The warp was drawn through the heddles by two women, much in the same way as at present. In weaving, the warp was decussated by drawing forward the proper rod with one set of the threads of the warp, the woof was then shot across, the other set of the warp were then drawn forward, another shot of woof passed through, and so on, the continual repetition of this process interlacing the warp and weft. After the woof was conveyed by the shuttle through the warp, it was driven sometimes downwards, but more commonly upwards. Two different in- 
struments were used for this purpose. The simplest and probably the most ancient was a large wooden sword, spatha, but the most common was the comb, pecten, the teeth of which were inserted between the threads of the warp, and thus made by a forcible impulse to drive the threads of the woof close together, so as to make compact or firm cloth.

Although Linen appears to have been originally characteristic of the Egyptian and German nations, it came by degrees into general use among the Greeks and Romans. It was employed not only for articles of dress, especially those worn by women, and for sheets to lie upon, but also for table covers, and for napkins to wipe the hands, an application which was the more necessary on account of the want of knives, forks, and spoons. It was also used by those who waited at table, they being girt with towels, linteis. Linen towels were used at the baths for drying those who had bathed.

The Roman Emperors were at great pains to discover and procure the most excellent artificers of all kinds, particularly the best manufacturers of woollen and Linen cloth. These they formed into colleges or corporations, with various privileges, under certain officers and regulations, and settled in the most convenient places of the several provinces of the empire. In these Imperial colleges or manufactories, all kinds of woollen and Linen cloths were made for the use of the Emperor's family and court, and of the officers and soldiers of the Roman armies. All these colleges were under the direction of that great officer of the empire, who was called the Court of the Sacred Largesses, and every particular college or gynæceum was governed by a Procurator. From the vast extent of the Roman dominions useful and ornamental arts would be practised in one province which were quite unknown in others, and these colleges were the means of collecting, perfecting, and disseminating them over the mighty empire. By this means civilization and industrial knowledge were, as it were, carried with the Roman legions, and diffused among the subdued people in exchange for their freedom. In many instances they were perhaps the gainers, although they may not then have thought so. Such a system shows the wisdom of the Roman government, and the fatherly care of the Emperor for his many and varied peoples. 
Augustus, even when all simplicity of manners had expired with the Republic, affected still to bring up the females of his family upon the antique model-according to the fashion in Homeric ages, and wore no garments but such as were manufactured in his own house.

Pliny supplies many particulars of the Roman trade, and he wrote his account of it in the reign of Vespasian, when Rome was in its most flourishing state. In the days of Agricola, he says, Roman sails were made of Flax. About the time of Augusta, cloth, whether Linen or cotton is doubtful, was imported into Rome from Malta, but it is likely to have been Linen from Egypt, transhipped from Malta. The finest wool was imported from Colchis, and also Hemp, Flax, and fine Linens, which were shipped at the port of Phasis in the Euxine. Egypt supplied Flax, fine Linen, paper and cotton goods, some of which, as well as their Linens, seem to have been coloured or printed, and they were shipped from Alexandria. From the eastern part of the north of Spain Linens, \&c., were imported. Iinens were also imported from Gaul, and they were shipped from the port of Marseilles. Cicero and other historians confirm Pliny's statements.

Coarser Linen was used in great quantities for sails, and also for awnings to keep off the heat of the sun from the Roman theatres, the Forum, and other places of public resort. Pliny mentions that Linen awnings were first used in the theatre at the dedication of the temple of Jupiter by Catullus, 69 B.c.; that Linen was used to cover the Forum and Via Sacra at the gladiatorial show by Julius Cæsar, 46 в.c.; and that Linen awnings were extended over the Forum by Marcellus, on 31st July, 23 в.c.

For 200 years after the age of Pliny silk was only worn by females, but about this time it began to be worn by men, principally mixed with Linen or woollen. Pliny says that among the Roman ladies silk and a fine species of Linen, called byssimus, sold for their weight of gold.

The Emperor Alexander Severus, according to Elius Lampridius, was a great admirer of good Linen, and preferred that which was plain to such as had flowers or feathers interwoven, as practised in Egypt and in the neighbouring countries. He 
took great delight in Linen, and preferred it plain. "If," said he, "Linen clothes are made of that material in order that they may not be at all rough, why mix purple with them ?" But to interweave gold with Linen he considered madness, because this made it rigid in addition to its roughness.

The following passage from the life of the Emperor Carinus, by the historian Flavius Vopiscus, is remarkable as proving the value attached by the Romans of that age to the Linen imported from Egypt and Phonicia, especially to the transparent and flowered varieties:- "Why should I mention the Linen cloths brought from Egypt, or those imported from 'Tyre and Sidon, which are so thin as to be transparent, which glow with purple, or are prized on account of their laboured embroidery."

The same author, in his life of Aurelian, says:- "We have lately seen the consulate of Flavius Placidus celebrated in the circus with so great eagerness for popularity, that he seemed to give not prizes but patrimonies, presenting tunics of Linens and silks, pieces of Linen, and even horses, to the great scandal of all men." This would be about A.D. 343 .

The barbarous nations who overthrew Rome were regardless of dress, and lad no taste for the fine arts. Under their sway the wealth of the city and country disappeared, stern necessity dispelled luxurious habits, and utility took the place of show. In the Eastern Empire, as noticed under Greece, the peaceful and useful arts were for a time cultivated after they had been expelled from Italy, but there too they gradually sank and died. A period of barbarism overspread Europe, which is appropriately called "the dark ages," as they were indeed dark and benighted in an extraordinary degree. They overshadowed as with a black cloud former civilization; and during the middle ages, those dark ages which succeded the downfal of the Roman power, and kept the world in their grasp for several centuries, scarcely a vestige can be discorered of any considerable manufacture of articles of common utility, beyond what the necessities of the district required. Rich men kept domestic artizans among their servants, and even kings in the 9th century had their clothes made by the women upon their farms. There is no doubt, however, that every town had its handicraftsmen, such as weavers, smiths, \&c., and that the peasantry must have been supplied with 
clothing and other necessaries by those who made them, in exchange for the produce of their fields.

The production of textile fabrics during such a period must, at the best, have been insignificant, and scarcely deserving the name of a manufacture at all. This dark and heavy cloud overspread the entire Roman world, and everywhere extinguished science and art, and overthrew trade and commerce. The Linen manufacture shared in the universal chaos, and the curtain is thus drawn over the ancient trade. 
POIULAR LECTURES.

\section{SECTI O N I I I.}

\section{'IHE LINEN MANUFAC'TURLS OF 'IHE OLDEN}

\section{'T' I M E.}

Ten or twelve years ago, William Miller, banker, then of Dundee, now of Glasgow, devoted considerable time and research to the history of the Linen Trade, and collected a mass of valuable details and statistics regarding it, with the view of publishing a work somewhat similar to this. The popular part of the information which he acquired was then given in a series of lectures in Dundee, and in other towns throughout the district. These lectures were delivered in an easy yet attractive style, to crowded audiences, and proved a great success. Although much of the matter embraced in Mr Miller's lectures is given throughout the volume, yet from the graphic manner in which the sulject is treated in them, and the admirably condensed epitome of the progress of the trade which the Lectures cuntain, they are, with Mr Miller's consent, given entire, and this section is devoted to them.

Mr Miller having been prevented earrying out his design of publication-mainly by a long aud serious illness-in the most handsome manner, placed the manuscript containing the result of his labours at my disposal, and it has been of great assistance to me in the compilation of various parts of this volume. The chapters on Grecian and Roman Linen especially have been largely supplemented from it: and great part of the curious and interesting details and statistics extracted from the proceedings of the Board of Trustees for Manufactures in Scotland are the result of his investigations of their Transactions.

Some of the authorities from which Mr Miller quotes are mentioned in the course of the Lectures, but to have named them in all cases would have cumbered the text, and they have generally been omitted. The authorities to which he was chiefly indebted for his 
information are "Yates' Textrinum Antiquorum," "St John's Ancient Greece," “Smith's Roman Antiquities," “Anderson's History of Commerce," \&c., \&c.

To Mr Miller I an greatly indebted for the valuable aid he has rendered me, and most cordially do I thank him for his kindness.

THE Linen manufacture appears to have had its origin among the Egyptians. The Flax plant was indigenous to Egypt, and, from the mention made of it in the Book of Exodus, we may infer that it was extensively cultivated in that country so early as the days of Moses. "And the Flax and the barley was smitten (by the plague of hail); for the barley was in the ear and the Flax was bolled." Four hundred years before this, however, we learn from the same authority, that Linen cloth of superior quality was worn by at least the higher orders of the Egyptians.

Pharaoh, the king, we are told, arrayed Joseph in vestures of fine Linen. This occurred 1700 years before the Christian era, but there are good grounds for believing that the art of Linenweaving was practised in Egypt long before that time. Recent research has brought to light several very curious grottoes and tombs, excavated in the soft limestone rocks which border on the Nile-chiefly in Upper Egypt-the walls of which are covered with paintings, as distinct and brilliant as when first executed, which illustrate with remarkable fidelity and minuteness the various processes connected with the manufacture, from the pulling of the Flax to the weaving and finishing of the cloth. These paintings, which are acknowledged to be of the very highest antiquity, coupled with the traditions of the ancient inhabitants, who ascribed the invention of the art to their god Isis, and with the incidental references to the subject by the sacred historian, as above quoted, serve to carry back the manufacture in Egypt to a very remote period, long antecedent to that of authentic history. 
Herodotus, who visited Egypt about the year 460 B.c., makes frequent reference to the general prevalence of the art there in his time. He would have us believe, however, that the men alone engaged in it. "In this country" he says, "the women leave to the men the management of the loom in the retirement of the house, whilst they themselves are engaged abroad in the business of commerce." And Saphocles, very likely taking Herodotus as his authority, says in one of his poems-

"How like the unmanly sons of Egypt's clime, Where the men sit inglorious at the loom And to their wives loave each domestic care."

In the paintings, on the other hand, we see men and women alike employed in all the various operations connected with the manufacture, and doubtless they are more trustworthy than either the historian or the poet.

In spinning, the Egyptians used no distaff-the Flax, after being pulled, steeped, and scutched (all of which processes are clearly shown in the paintings), was roughly twisted by women into a long sliver by means of rubbing with the hand on a smooth round stone. After undergoing this process-which must have been somewhat equivalent to that of "roving" as practised in our mills-it was rolled up into a ball, and placed in a vessel resembling a modern flower-pot, and which, probably, contained water or some stiffening liquid. From this ressel, the spinner, mounted upon a slight elevation resembling in appearance a block of wood, brought the rove over his or her shoulder, and span it into yarn by means of a spindle, exactly resembling in shape that used among ourselves in days not yet long gone by. Sometimes the spinner used two roves, one over each shoulder, and at other times so many even as four. In such cases two spindles were used, one in each hand; and two roves were twisted into one double thread. It is difficult to understand by what sleight-of-hand so complicated an operation could have been accomplished by a single person.

Some very ancient spindles have been found in the tombs of the kings at Thebes. They are generally of wood, the circular head or whorl being of gypsum or other heavy material, in order to increase their impetus in revolving. Others are of a light o 2 
plaited work made of rushes or palm leaves, stained of various colours, and furnished with a loop of the same materials for securing the thread when wound up. Sir Gardner Wilkinson found one of these spindles at Thebes with some of the Linen thread upon it. It is now in the Berlin Museum.

The yarn, after being washed, dried, and beetled, was stretched as warp in the loom. This consisted merely of four pegs driven into the ground, two at one end and two at the other, each pair being connected by a cross rod. The warp, being first fastened to the nearest rod, was passed over the second, wrought back again to the first, fastened there, and cut off.

This peculiarity of the warp very much puzzled a gentleman in Dundee, to whom I showed a piece of mummy cloth, procured for me by a friend in London. He insisted that the cloth had three selvages, two at the sides and one at the end. A reference to a drawing from one of the paintings at once explained the difficulty. The web was generally about six yards long only, and being very narrow, somewhat resembled a scarf. The shortness would seem to be accounted for by their being ignorant of the plan of winding a long length of warp upon a beam that would enrol it as required; and by their having in consequence to stretch out the entire length of their web on a frame, as is practised at the present day by the Hindoos.

Judging from the paintings, there appears to have been three modes of weaving practised among the Egyptians. In one, a man sits upon the ground, somewhat after the manner of a dog, painfully interlacing the weft by means of his hands alone, and driving it home by a long thin rod running across the warp. He is weaving a checked pattern of different colours, probably sail-cloth. In another, two women are at work on the same web, one threads the weft, and the other drives it home. In neither of these is there any appearance of a shuttle. In a third painting the warp is stretched in an upright position, and a man interlaces the weft by means of a long netting-needlelooking instrument.

Of the quality of the yarn and cloth produced by these rude processes, we have satisfactory evidence in the mummy cloth, immense quantities of which have been discovered in the tombs. Belzoni observed cloth as fine as our common muslin, very 
strong, and of an even texture. Other qualities are as strong and coarse as sail-cloth. A remarkable peculiarity of mummy cloth is that the warp almost invariably contains a much greater number of threads than the weft. In some kinds the warp contains twice, in others thrice, and in some even four times the number of threads in the inch that the weft does. This structure, so different from that of modern cloth, we may suppose, was owing to the difficulty and tediousness of inserting the weft by the hand, as practised by the Egyptians. 'The same reason may perhaps account for another peculiarity in the Egyptian manufacture as compared with that of the modern loom, viz., that in both warp and weft the yarn was double, and in some instances even three plies are distinctly visible.

'The art of working complicated patterns in the loom seems to have been carried to great perfection among the Egyptians. Martial speaks of some figured cloth woven at Memphis, which surpassed in richness of execution the embroidery of Babylon. And Herodotus, speaking of a remarkable Linen corslet which had been given to the Lacedaemonians by Amasis, king of Egypt, describes it as having interwoven in the piece a great number of animals richly embroidered with cotton and gold. It was cloth of this kind from which the splendid robes worn by Aaron in the wilderness were made, as mentioned in Exodus. "And they did beat the gold into thin plates, and cut it into wires to work it in the blue, and in the purple, and in the scarlet, and in the fine Linen, with cunning work."

Large quantities of Linen yarn and cloth were yearly exported from Egypt to most of the countries bordering upon the Mediterranean. The prophet Ezckiel speaks of the "embroidered Linen from Egypt," which the Tyrians "spread forth to be their sail." Solomon, we are told, had Linen yarn brought out of Egypt; and Herodotus mentions that Egyptian Linen was in high repute and extensively used among the Greeks.

The dresses of the ancient Egryptians, whether rich or poor, were to a large extent composed of this kind of cloth, and their bodies when embalmed were uniformily incased in Linen. The quantity of cloth used for this latter purpose was very considerable. The length of the bandages round some of the mummies has been found to be from 290 to 300 yards, and on one opened 
at Leeds there were no less than 40 thicknesses of cloth discovered. The number of ancient Egyptians thus comfortably swathed must have been immense. Almost every museum in Europe of any pretensions contains one or more of these highdried human specimens ; and for many years, perhaps centuries, the caverns of Egypt have been mines of wealth to the Arabs in the neighbourhood, the bodies being used by them as fuel for cooking their victuals, and the wrappings made into clothes for themselves, or sold for the purpose of being made into paper for the use of the grocers and spice-dealers.

It is worthy of remark here that Linen has in all ages, and in every nation, been regarded as the only fabric suitable to be used for sacred purposes. The Egyptian priests were forbidden to wear anything but Linen while engaged in their religious observances, and it was strictly enjoined that no dead body should be buried in woollen. The Jewish priests were clothed in Linen when performing the most sacred services of the temple ; as, for example, on the great day of Atonement, according to the directions given in Leviticus, "Aaron shall put on the holy Linen coat, and he shall have the Linen breeches upon his flesh, and shall be girded with a Linen girdle, and with the Linen mitre shall he be attired-these are holy garments." Ezekiel, when describing the temple which he saw in his vision, says, "And it shall come to pass that when they enter in at the gates of the inner court that they shall be clothed with Linen garments, and no wool shall come upon them whiles they minister in the gates of the inner court and within." And the reason for this prohibition is immediately added, "They shall not gird themselves with anything that causeth sweat." In the book of Revelation we are told that the seven angels which came out of the temple were clothed in pure and white Linen, and that the fine Linen is the righteousness of the Saints. Plutarch remarks that the priests of Isis wore Linen on account of its purity, and Apuleius argues as to the reason for this preference after the following manner: "Can any one impressed with a sense of religion, wonder that a man who has been made acquainted with so many mysteries of the gods should keep at home certain sacred emblems, and wrap them in a Linen cloth, the purest covering for divine objects? For 
wool, the excretion of a sluggish body taken from sheep was deemed a profane attire, even according to the early teriets of Orpheus and Pythagoras. But Flax, that cleanest and best production of the field, is used not only for the inner and outer clothing of the most holy priests of the Egyptians, but also for covering sacred objects." The lawn of the bishop and the Linen surplice of the priest give evidence that a similar feeling has all along prevailed in the prelatical churches; and Geneva herself, jealous of symbol though she be, finds a fitness and propriety in this fabric for articles connected with some of her most solemn observances.

The people of Israel, at the time of their separation from Egypt, had attained to a high perfection in the manufacture of various kinds of cloth, as we learn from the very minute descriptions given in the books of Moses of the dresses of the high priest, and of the coverings and hangings of the tabernacle. This skill they had doubtless acquired during their long residence in the land of their bondage. In Palestine we know that Flax was from the very earliest times extensively cultivated and manufactured into Linen cloth. The spies sent by Joshua into Jericho were concealed by Rahab beneath "the stalks of Flax which she had laid in order upon the roof,"-doubtless for the purpose of drying them,-indeed Josephus expressly mentions that she was "drying the bundles."

In 1 Chronicles, iv. and 21 , there occurs a remarkable expression, which Yates supposes to refer to a iarge establishment for dressing fine Flax. The literal translation of the original, he says, is-"The families (or perhaps partnerships) of the manufactory of Byssus," Butz or Byssus being the word generally used to signify fine Flax. In the common version the sentence reads thus-" The families of the house of them that wrought fine Linen"; and the prophet Hosea twice mentions Flax as one of the chief materials used for clothing in his time.

Among the Israelites spinning would appear to have been practised chiefly by females. The virtuous woman spoken of in the book of Proverbs "seeketh Wool and Flax and worketh willingly with her hands; she layeth her hands to the spindle, and her hands hold the distaff; she maketh fine Linen and selleth it, and delivereth girdles unto the merchant." And Moses, 
when speaking of the manufacture of the furnishings of the tabernacle, says:- "And all the women that were wise-hearted did spin with their hands, and brought that which they had spun both of blue, and of scarlet, and of fine Linen. And all the women whose hearts stirred them up in wisdom spun goats' hair."

The loom used by the Egyptians we have seen was a very simple affair, scarcely deserving of the name. That in use among the Israelites was of a somewhat improved, but still very rude construction. It consisted, Dr Kitto supposes, merely of two upright posts driven perpendicularly into the ground, and united at the top by a cross- beam, from which the warp depended. The references in the Bible to the Jewish loom are very slight and uninstructive. Job complains that his days are swifter than a weaver's shuttle; the staff' of Goliath's spear was like a weaver's beam; and the locks of Samson's hair were woven by Delilah into the web and fastened with the pin of the beam. And this is almost all we learn as to the mode of manufacture among that people in ancient times.

Passing now to the classic regions of Greece and Italy, we find that in both the implements used in spinning were still the distaff and spindle. These were generally formed of wood, but those used by the females of the higher classes were sometimes of very costly materials and of beautiful workmanship. Theocritus presented a distaff of ivory to Theugenis, the wife of his friend Nicias, along with some complimentary verses, of which the following may serve as a specimen:-

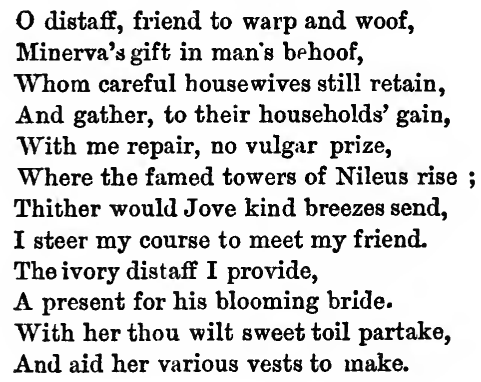

Homer mentions one of gold which was given to Grecian Helen by Alcandra the wife of Polybus who lived in Thebes:- 
Alcandia, consort of his high command, A golden distaff gave to Helen's hand; And that rich vase, with living sculpture wrought, Which, heaped with wool, the beauteoun Phylo brought, The silken tleece, empurpled for the loom, Rivalled the hyacinth in vernal bloom.

'The "rich vase" here mentioned was a basket for holding the Flax or wool which was to be spun. It was generally composed of wicker-work, but in this instance was of silver.

In preparing the Flax or wool for spinuing, it had first to be carded or heckled, and was then wrapped loosely round the top of the distaff in thin folds. This simple process would seem to have required considerable care and neatness in the execution of it, so as that the fibres might be easily and evenly drawn out by the hand of the spinner. Arachnes' skill in this art, no less than in those of spinning and weaving, excited, according to Ovid, the wonder and admiration of the neighbouring nymphs:-

\footnotetext{
Nor would the work when finished please so much

As while she wrought, to view each graceful touch,

Whetber the shapeless wool in balls she wound,

Or, with quick motion, turned the spindle round.
}

The modus operandi would seem to have been very much the same as that practised by our own grandmothers. The distaff was fastened to the person under the left arm, or held in the left hand, and the thread being attached to the top of the spindle by means of a small slit or cateh, a gyrating motion was communicated to the latter by the fair spinster rolling the upper end slightly along her right knee, and a slender fibre being then drawn out by the forefinger and thumb of the right hand, it was twisted into a thread by the rotatory motion of the spindle. As soon as the spindle reached the ground the thread was taken out of the slit or catch, wound quickly on the under part of the spindle, again fastened in the slit at the the top, and the spinning of a new length begun as before.

Catullus, in his poem on the marriage of Peleus and 'Thetis, describes these various operations very distinctly, thus:- 
From these the right hand lengthening fibres drew, Which, into thread, 'neath nimble fingers, grew. At intervals a gentle touch was given, By which the twirling whorl was on ward driven, Then, when the sinking spindle reached the ground, The recent thread around its spire was wound, Until the clasp, within its nipping cleft, Held fast the newly finished length of weft.

When the bobbin of the spindle was sufficiently loaded with the yarn, it was taken out of the whorl, and placed in a basket to await the operations of the weaver.

The Grecian and Roman loom was a very much better instrument than that of Egypt or Palestine, although, like the latter it still stood erect. The chief improvement was the use of leashes or treddles, by means of which the threads of the warp were decussated or drawn to either side alternately, so as to allow the shuttle to pass through between them at one stroke, and the weft to be fastened in its place by this reflex movement.

This operation, as all are aware, is now rapidly performed by means of treddles, which are moved by the feet, the hands being thus left free for throwing the shuttle; but among the ancients it was rudely, and of course slowly, executed by the hands. The weft was driven home originally by a flat piece of wood, called spatha, which was inserted into the opening through which the shuttle had passed, but afterwards by a reed or comb, called pecten, the teeth of which alternated with the threads of the warp, and were driven forcibly upwards, much in the same way that the reed of the modern weaver is driven hard up upon the cloth by the action of the lay. When we consider the various operations which the ancient workman had to perform with his hands alone-the decussating of the warp, the throwing of the shuttle, and the driving home of the weft-we can fancy how appropriate would be the application to him of the Roman proverb "Satigit serum suarum,"-He has his hands full at home.

We have said that the ancient loom stood erect, and of this we have very satisfactory evidence in the names given to its different parts. The warp was called stamen in Latin, and $\sigma \tau \eta \mu \omega \nu$ in Greek, on account of its upright position in the loom; the web when finished, but before it was cut down, was called vestis pendens, hanging garment, or pendula tela, be- 
cause it hung from the transverse beam or jugum. 'T'o set up

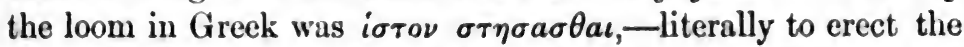
pole-being the same phrase which was used for setting up the mast of a ship-and so on.

Ovid has given us a very animated description of a contest of skill which he says took place between these famous sheweavers-Minerva and Arachne-in order to decide which was the most accomplished work-woman. The passage is interesting, as illustrating the ancient process of weaving.

\footnotetext{
Straight to their posts appointed both repair, And fx their thrended looms with equal care. Around the solid beam the web is ty'd, While hollow canes the parting warp divide, Thro' which, with nimble thight, the shuttles play, And for the wouf prepare a ready way.

The woof and warp unite-pressed by the toothy slay; Thus both, their mantles button'd to their breast, Their skillful fingers ply with willing haste,

And work with pleasure, while they cheer the eyo With glowing purple of the Tyrian dye ; Or, justly intermixing shades with light, Their colourings insensibly unite.

Then threads of gold both artfully dispose, And as each part in just proportion rose, Some antique fable in their work disclose.
}

As some of my fair hearers may be anxious to learn the result of this apparently unequal contest, I may mention that Arachne was declared the victor, which so enraged the goddess - who in this did not certainly give proof of her usual wisdomthat she first half killed the presumptuous maiden by striking her with a box-shuttle, and then repenting somewhat of the foul deed, permitted her to live, but changed her into a spider, and doomed her to incessant weaving during the rest of her mortal existence, as a warning to all earth-born females who should dare to show themselves more gifted than their celestial betters.

Among the Greeks and Romans we find that weaving had become a distinct trade, and was carried on by a separate class of persons called, in Latin Textores and Textrices, male and female weavers, or sometimes Linteones. At the same time, however, it is evident that almost every considerable domestic 
establishment, especially in the country, contained a loom or looms, with all the necessary apparatus for spinning and weaving. This department was under the special management of the mistress of the household, and ladies of the highest rank did not consider themselves above engaging personally in this useful occupation. In the larger houses a particular apartment,

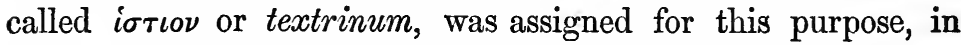
which the ladies sat, surrounded by their female slaves, directing and assisting in the cheerful toil, and doubtless keeping their tongues as busy as their spindles.

Alexander the Great informed Sisygambis, the captive Queen of Persia, that the garments which he wore were not merely the gift, but the workmanship also of his sisters.

Augustus Cæsar, when all simplicity of manners had expired with the Republic, affected still to bring up his family on the antique model, and wore no garment but such as was manufactured in his own house. The fair but frail Helen was laborious as Penelope, plying her shuttle, or her golden distaff in the midst of a troop of she-manufacturers. Arete, Queen of Phœacia, is depicted sitting at the fire, distaft in hand, encircled by her maids: and the wife of Odysseus, famed for her household virtues, is seen at her door spinning the purple thread. "In fine" says St John in his Ancient Greece, "the women of these ages were not creatures of mere luxury or show. Possessing considerable power and energy, and much skill in the elegant and useful arts of life, they were deterred by no false pride or ignorant prejudices from converting their capacity to the use of their families. The magnificence of their attire, their costly ornaments, or the consciousness of the highest personal beauty, no wise interfered with their thrifty habits. An Homeric princess even thought nothing beneath her which could contribute to the comfort or elegant adornment of those she loved."

Alas for these degenerate days! The romance of female industry has gone, we fear for ever. How unlike to the blooming maidens of classic Greece or Rome, twirling the dancing spindle under their own sunny skies, and singing or chatting merrily as they toil, are those dust-besprinkled females, breathing the noxious atmosphere of steam, and oil, and smoke, and moving listlessly about in the midst of a horrid uproar of grating wheels 
and clanking engines. The mighty monster steam, with his sinews of iron, and his breath of fire, has revolutionized the manufacturing world, has rendered the interesting appellation of "spinster" obsolete to all but session clerks and musty lawyers, and has driven our beauteous Helens, and our virtuous Penelopes to eke out a profitless existence in the irksome and ill-requited labour of Berlin-wool frames and crochet needles.

The perfection to which the manufacture of cloth was brought in Greece-if we are to believe the poets at least-appears to have been truly wonderful, especially when we consider the simplicity and even rudeness of their implements as compared with modern machinery. The most beautiful patterns were woven in their cloths. Stripes, lozenges, the figures of birds and other animals, sprigs, flowers and stars of the most beautiful and brilliant colours, were all produced in the loom. Others were splendidly embroidered. Even the fine soft vests which warriors wore beneath their armour were usually figured with rich embroidery by the females of the family. Homer represents Helen as weaving a representation of a battle between the Greeks and Trojans. Andromache copies flowers in a veil; the web of Penelope is proverbially known; Minerra and Arachne "some antique fable in their work disclose"; and the magnificent chlamys which was weaving for Demetrius at the period of his overthrow, represented in one vast picture both the face of the earth and heaven with all its constellations.

Flax was not largely grown in Greece-the mountainous character of the country being better fitted for sheep husbandry. As a consequence wool rather than Flax was commonly used in its textile manufactures. The only district of Greece in which Flax was cultivated was that of Elis, a low-lying plain on the extreme west of the Peloponnesus, watered by the rivers $\mathrm{Al}$ pheus and Igliaco; and the only place in which the manufacture of Linen prevailed to any extent was the seacoast town of Patre (the modern Patras). lying upon the gulf of that name, and near the entrance to the Gulf of Lepanto. A single glance at the map of Greece will shew that that country, intersected in every part by mountainous ridges, and possessed of no rivers or alluvial plains of any importance, was not by nature adapted for the growth of the Flax plant. Its romantic and beautiful 
mountains of Arcadia, on the other hand, were covered with flocks of sheep, the fineness of whose fleece was long proverbial.

It is interesting to observe how the particular kind of industry, and even perhaps the very attributes of a people, are influenced by the geographical character of their country. Egypt and Germany were the great Linen producing countries of ancient times, because in them had been placed the rich alluvial plains of the Nile and of the Rhine ; whereas Syria, Asia Minor, and Greece, being mountainous countries, were chiefly noted for their woollen manufactures. In our own Scotland, in the same way, it was in the basins of the Tay, of the Forth, and of the Clyde, that the cultivation of Flax, and the manufacture of Linen, so extensively prevailed in former times; while the districts of the Grampians and Lammermuirs were equally noted for their breeds of sheep, and the manufacture of woollen cloth. In the villages and small towns of the one there arose those independent and industrious burghers who, hating war and civil disturbance as their and the state's worst enemies, were content to remain at peace with their neighbours, and all the world besides, were their civil and religious liberties but secured to them; and, in the other, there was nursed that brave and hardy, but indolent and unambitious race, whose character has ever borne the true pastoral type, and whose memory will live longer in the romantic history of clan warfare and border forays, and in the sweet strains of their pastoral ballads, than in the records of social progress and industrial advancement.

The Flax grown in Elis was of the very finest quality, and the cloth manufactured from it was sold for its weight in gold. The Linen manufacture of Patræ was carried on almost wholly by women, their number, according to Pausanias, being thrice as great as that of the other sex. The articles made were caps or head-dresses of net-work, and very fine Linen intended for the use of the wealthier classes of the Grecian ladies. They imported the Flax from Elis and from Egypt. In the Island of Amorgos, in the Egæan Sea, a species of very fine Flax was grown, and from it were made Linens of the most delicate and beautiful texture, so fine indeed as to be semi-transparent, and to rival the finer cambric of the modern loom. It was sometimes dyed purple, from which the name Amorgos came occa- 
sionally to mean a purple cloth, but it was also frequently finished of the most brilliant and snowy whiteness. It is in a tunic of this Linen that Lysistrata in Aristophanes, advises the Athenian ladies to appear before their husbands in order to give full effect to the splendour of their charms.

In imitation of the Egyptians, the inhabitants of Amorgos wove a sort of fine napkins, which were evidently used in the same manner as our pocket handkerchiefs, at least by the ladies and youthful gallants, but for which, says Aristophanes, the old men substituted a fox's tail !

Among the Romans as among the Greeks, to the women chiefly were assigned the labours of spinning and weaving, especially in the earlier ages of the commonwealth; the warlike Roman disdaining to occupy himself in tastes which he was accustomed to regard as effeminate drudgery. For a similar reason the wearing of Linen garments was for many centuries wholly confined to females. Afterwards, as greater refinement of manners began to prevail towards the close of the Republic, and especially under the Empire, fabrics of Linen, cotton, and silk were generally worn by the wealthier classes, and by both sexes. These were not, however, manufactured at home, but were imported from those eastern countries to which the Roman conquests had by this time extended. Their price was in consequence very high. The biographer of the Emperor Alexander Severus considers it worthy of note that he took great delight in Linen, but preferred it plain instead of embroidered, as was the case with the Linen then imported from Egypt. "If," said he, "Linen cloths are made of that material in order that they may not be at all rough, why mix purple with them. And to interweave gold with Linen he considered madness, because this made it rigid in addition to its roughness." From this we may conjecture that his imperial Majesty was what we would call somewhat thin-skinued, and would not have made the most amiable of saints if elad in sackcloth or even in coarse flannel. What might have been the history of Christendom, we may profoundly inquire, had the Roman Pontiff of that day demanded the expiation of imperial sin in a haircloth shirt? 'The fineness of an emperor's epidermis might have postponed infallibility for centuries! 
Flax was grown to a considerable extent in various districts of Italy, especially in Etruria and Campania, and in the fertile plains of the $\mathrm{Po}$ and Ticino.

It was manufactured into articles of dress, sheets, table covers, table napkins (which were very useful among a people whose fingers were at once knives, and forks, and spoons), bath towels, and bakers' aprons. The coarser kinds were used for sails and for awnings for the theatres, forum, and other places of public resort.

Pliny, the natural historian, has given some curious particulars as to the cultivation and preparation of Flax, and the manufacture of Linen in his day, but appears to have looked upon it as an effeminate and even dangerous innovation upon the greater simplicity and purity of earlier times. He speaks, for instance, with ill-concealed contempt of the German ladies, "who cannot devise to go more rich and costly in their apparel than to wear Linen," and unfavourably contrasts their conduct in this respect with the women of the Serani, who were to be highly commended, he thinks, because they wore no Linen garments of any kind. He mentions that the Germans wove their Linen in dwellings under the ground, and that a similar practice prevailed in some parts of Italy. From the same author we learn that an exceedingly fine kind of Flax was grown in Spain, and that Setavis, the modern Xativa, was celebrated for the beauty of its Linen cloth, especially its sudaria or pocket-handkerchiefs. From these western nations of Europe it is easy to see how the manufacture and the use of Linen in dress would be imported into Britain.

Let me pause here, however, for but one reflection. At the period at which we have arrived the world was upwards of 4000 years old, and yet how little had been done in the improvement of the industrial arts! True, in those arts, such as sculpture, painting, architecture and the like, which appeal merely to the refined and cultivated taste, or those others which seek only to gratify the luxurious and voluptuous appetite, great perfection had been attained; but in those that provide for the comfort of the multitude and go to raise the character and standing of a people, there had been a deplorable stagnation and neglect. Take, for example, the textile manufacture of which we have been 
attempting to sketch the history. The spindles and looms of Egypt under the Pharaohs were rude enough, but they were not very far behind, indeed they differed little from those used by the luxurious Roman of the days of Augustus, and neither are they unworthy of comparison with those even now used by the descendants of the same haughty conquerors who rejoice to call the liberal and large hearted Pio Nono father. 'The Egyptian manufacturer, who lived seventeen centuries B.c., employed in his trade implements not much ruder than those used by his Italian brother tradesmen in the 19th century A.D. How is this to be accounted for? The only answer, I believe, is that commerce and manufactures cannot flourish either amidst the turmoil of war, or under the deadening influence of despotism; they are plants that may not be watered with blood, nor fostered beneath the shade of absolute power. Neither, however, ought they to be forced into unhealthy growth by artificial stimulants, nor confined within the narrow forms framed by empirical and ignorant rulers. Unless they breathe the pure air of freedom, and are uncontrolled in every twig and fibre, they will sicken and die. And hence we find that whenever a people are peaceable and free, they are industrious and inventive. Improvements in the arts, social advancement, and progress in civilization, in comfort, and in wealth, characterize the history of such a nation, but where tyranny and turbulence prevail, there are also to be found barbarism, poverty, and social debasement. This latter was the condition, generally speaking, of the nations of antiquity-( $\mathrm{I}$ speak, of course, of the great mass of the people),- - and hence it was that so little improvement was made in the industrial arts during the long period we have had under review. The prodigious advancement which has since been made in these was mainly owing to the peace-loving freemen of Flanders and Brabant - of the Hanseatic cities, and of the burgh towns of England, and Scotland, and Protestant Ireland-men who loved, and struggled for, and achieved civil and religious liberty for themselves, and for their children.

The history of the Linen manufacture in this country, will, as we shall find, elucidate the same truths, and teach the same lesson. For many centuries, tyrannical monarchies, and selfish oligarchies, foreign wars, and intestine disorders, discouraged and 
repressed the onward tendencies of the people's industry, and produced their natural fruits of monopoly and commercial restriction. The abolition of the Scottish and Irish Linen Boards, the Reform Bill, and Free Trade, were the Magna Charta of British industry, and gave freedom and impetus to British enterprise and skill. But we anticipate.

When the Romans invaded Britain in the year 55, they found the inhabitants, they say, in a state but little removed from barbarism. Some were clothed in the skins of animals, but many had no other garment but a coat of blue paint. Among such a people the textile arts could have made but little progress, the demand for manufactures being of necessity as limited as their wardrobes. It is believed, however, by some writers, that the arts of weaving and even of dyeing in different colours, coarse kinds of woollen and Linen cloth, were known and practised among the more civilized of the ancient Britons for, at least, a century before the first Roman invasion : but there can be no doubt that this event contributed materially to the improvement and more extended diffusion of those and many other useful arts among the conquered people. The Emperors of Rome were usually at great pains to improve the condition of their foreign subjects. They imported, or sought out amongst the inhabitants themselves, the most skilful artificers in every department, especially the best manufacturers of woollen and Linen cloth, and formed them into colleges or corporations, with various privileges, and under certain officers and regulations. The chief officer in each college was called the Court of the Sacred Largesses, and his business was to see that a certain quantity of cloth, of various kinds, was regularly produced for the use of the court, and of the army. Such an imperial manufactory was established, we learn, in England at Venta Belgarum, now called Winchester.

The arrival of the Saxons in England in the 5th century had at first an injurious influence upon trade and manufactures, in consequence of the unsettled state of the country which it produced. The skilful artizans of all kinds, dreading the depredations of their more warlike neighbours, gradually retired to the continent. So soon, however, as the new invaders became firmly established in their dominion, greater attention began again to be 
paid to the arts of peace. And, in the 7th century, we have evidence that the art of weaving had attained to considerable perfection, in the work of an ecclesiastical chronicler of the period, who speaks of "webs woven with shuttles filled with threads of purple and many other colours, flying from side to side, and forming a variety of figures and images in different compartments with admirable art." 'These were commonly executed by ladies of the highest rank, and were designed for ornaments to the churches and vestments for the clergy. The four daughters of Edward the Elder were highly celebrated for their skill in spinning, and weaving, and needlework, which was so far from spoiling the fortunes of these royal spinsters, that it procured for them the aldresses of the greatest princes then in Europe.

In the 10th century, the people of Flanders and Brabant began to be famous for their manufactures of wool and Flax, in which they were wisely encouraged by Baldwin the Younger, Count of Flanders, who established yearly fairs in several places, free of toll or duty, whether for goods imported or exported. In this century the town of Ypres in Flanders was built, which soon became celebrated for its manufacture of Table-linen, now called Diaper i.e. Cloth d' Ypres. Several towns in Germany began now also to rise into commercial and manufacturing importance -a position which they retained for many succeeding centuries. The English had also by this time very much improved their textile manufactures, and had become more reconciled to the use of Linen, which had previously been looked upon as somewhat effeminate. For underclothing especially it was deemed not only pleasant, but necessary as a remedy against cutaneous disease, which was then very prevalent. 'The wearing of a woollen shirt was in consequence considered doing deep penance for great sins. The ladies of this era, we are told, wore loose and flowing garments, chiefly made of Linen, adorned with broad borders, woven or embroidered with various colours; and persons of distinction began for the first time to wear a kind of stockings, which consisted of strips of woollen or Linen cloth wrapped round the leg like bandages.

The conquest of England by William of Normandy, (A.D. 1066 ,) gave a very considerable impulse to the manufactures of P 2 
that country. Great numbers of weavers came over in his army, and others followed on the invitation of the king, who promised them protection for their goods and persons. This immigration was soon afterwards greatly increased by a remarkable overflowing of the sea, which permanently inundated a large portion of Flanders, and forced many of the poor Flemings to take shelter in England. The skill of that people in weaving was then so great that an ancient historian remarks that "it seemed to be a peculiar gift bestowed on them by nature." In this reign the weavers in all the great towns of England were incorporated into guilds, and had certain privileges conferred on them by royal charters, in return for which they paid certain fines into the exchequer. The Linen made in England, however, was still very coarse-all the fine kinds being then, and for long after, imported from the continent.

David, king of Scotland, (12th century), who had passed his early youth at the Court of England, was the first to introduce the manufactures of that country into his own less favoured land. He brought English artizans with him into Scotland, and settled them in the burghs and towns to instruct the Scotch, who had as yet barely emerged from barbarism. From this date, however, their progress in the textile arts, at least, must have been considerable, for we learn that in the year 1410 Sir Robert Umfraville, Vice-Admiral of Encland, entered the Frith of Forth with ten ships of war, and carried off plunder of woollen and Linen cloth in such quantities, that the sale of them in England lowered the prices there very considerably; and hence Umfraville got the name of "Robin Mend-market."

The 12th century is famous for the origin of the Hanseatic League in Germany, which for long afterwards exerted so great an influence in the improvement of manufactures both on the continent and in England.

It would appear that the English of the 14th century dressed better than their neighbours of France; for Sir John Fortesque remarks that "The French weryn no woollyn, but if it be a pore cote under their uttermost garment made of grete canvas, and call it a frok. Their hosyn be of like canvas and passin not their knee, wherefor they be gartened and their thyghs bare. But the English wear fine wollyn cloth in all their apparell." 
'The Welsh, however, were not so well off, and their dress had apparently more of the French than of the English fashion, as we learn from Barbour, in his Life of Bruce, where describing the flight from Bannockburn, he says of Sir Maurice Barclay's Welshmen that

\footnotetext{
Wheree'r they yiol men might thern ken, For they well near all naked were, Or linen clothis hal but mare.
}

From all this we may gather that coarse Linen, worn as upper garments, was at that time a sign of poverty.

By the middle of the 16th century the Netherlands had attained to a high state of commercial and manufacturing prosperity. Antwerp, the chief town, was perhaps the most opulent city in Western Europe, and exported to all the neighbouring countries vast quantities of Linen both coarse and fine. It was manufactured there, and in the neighbourhood of Bois-le-duc, Nivelle, Cambray (from which came the name "cambric"), Courtray, Tiel, and Ghent. But this prosperity was not destined to be of long continuance. The religious persecution instituted against the industrious inhabitants by orders of the bigoted Philip II., king of Spain, to whom the country then belongel, and the horrible sacking of the town of Antwerp by the Duke of Alva, the regent, had the effect of driving into England great numbers of skilled weavers, who contributed largely to the progress and improvement of the manufactures of that country. "So great an antipathy," says Sir Wm. Temple, "there ever appears between merchants and soldiers." Might he not have added-So blind has religious bigotry ever been to its truest interests ; and so hostile to all useful arts and social advancement have all false religions ever shown themselves.

In the beginning of this century Russia was not known to any Europeans, except a few Flemings, who kept their own secret. In 1553 it was accidentally stumbled upon by an English ship, one of an expedition sent out from Gravesend in search of a north-east passage to China. This important discovery, so strangely made, led to the formation of a company of merchants for trading with that country, and it is remarkable that for sometime afterwards the only connection which the 
traffic thus opened had with the Linen trade of England, was that coarse Linens were exported to Russia, the only imports from thence being hides and furs.

The lights which fall upon the state of manufactures in Scotland at this period are very faint. The use of Linen, it is believed, was chiefly confined to the nobles, and perhaps, as the following incident would suggest, the priests. In one monastry in Perth, where only eight monks resided, the followers of Knox discovered eight puncheons of salt beef, with wine and beer in proportion, besides abundance of bedclothes, and table Linen of singularly delicate texture, but whether home-made or imported the record sayeth not.

In England, however, Linen cloth was not so much of a rarity, as is evident from a curious publication of the time, which relates the case of a man, who had been cited for offending against a law, then in force, to prevent the wearing of wide breeches, and who pleaded in defence the exceeding utility of this extravagant fashion In proof whereof he produced in open court from the proscribed garments, a number of sheets, two table cloths, ten napkins, four shirts, and other Linen articles, and was proceeding with the extraction of more, when the judge, amidst much laughter, stopped and dismissed him.

Shirts were then made of the finest Linen from Holland, and were sometimes so elaborately embroidered and otherwise adorned, as to cost so much as $£ 10$ a piece, a pretty fair price for a shirt it must be allowed, especially considering the value of money in those days. In the old ballad of "Lord Thomas and fair Annie," that lady says

\footnotetext{
My maids gang to my dressing room,

And dress me to my sark;

The one half is o' the Holland fine,

The other o' needle-wark.
}

While quoting ballads I may extract a stanza, appropriate to my subject, from one writteu about this time, referring to the forays which were so common in the border counties of England and Scotland before the accession of James VI. to the throne of England (in 1603) :-

They spuilzie puir men of their pakis (packs, goods), They leve them nocht on bed or bakis, 
Jaith hen and cock, with reel and rok, the "Landis Jok," All with him takin.

They leif not spendil, spone, nor spit, Bed, bolster, blanket, sark, nor sheit, "John of the Parke" rypis kyat and arke-for all sik warke, He is richt meit.

The revocation of the edict of Nantes in 1685 drove vast numbers of weavers and other skilled workmen (who were chiefly Protestants), out of France. Many of these settled in England, and brought with them their industrious, peaceful habits, and their skill in manufactures. Thus again did England benefit by the injury inflicted on foreign countries by the ignorant bigotry of their Popish rulers.

The 17th century was prolific in acts of Parliament having for their object the encouraging the growth of Flax, and the manufacture of Linen, both in England and Ireland. With this view the importation of these articles from France was strictly prohibited, and at one time the wearing of French cambric was punishable with heavy penalties, the reason assigned by the House of Commons being, that the trade with France was dotrimental to this kingdom! Anderson, in his History of Commerce, speaking of this prohibition, sagely remarks-"It was indeed more than time for England to interpose and save the almost expiring liberties of Europe "!!

This magnanimous and summary extinction of the rising fortunes of their Gallic neighbours did not long satisfy the intelligent political economists of England of that day. They began to be equally jealous of the upstart pretensions of their brethren in Ireland to compete with them in the race of industry. The woollen trade of that country had of late risen into alarming importance, and threatened, by rivalling that of England, to overthrow, according to $\mathrm{Mr}$ Anderson's reasoning, the British constitution. The English Houses of Parliament accordingly in the year 1698, memorialised the King (William III.) " to induce the people of Ireland to cultivate the joint-interest of both nations," as they said, by putting down the woollen manufacture in that country, and restricting themselves to the production of Linen cloth. The King replied, "I shall do all that in me lies to discourage the woollen manufacture in Ireland 
and to encourage the Linen manufacture, and to promote the trade of England." Strange to say, the Irish legislature agreed to the compact, and immediately imposed heavy duties upon the export of all woollen cloth. The consequence was, that this manufacture was completely ruined; many thousand families left the country; some of the southern and western districts were almost depopulated; and the whole kingdom was reduced to the utmost poverty and distress. On the other hand, and for the carrying fully out of this strange compact, an act was passed in the following year, 1699, for the special encouragement of the Irish Linen trade. A Board was established in Dublin, called " The Trustees for the Linen and Hempen Manufactures," and certain yearly revenues were assigned to them, according to the custom which then obtained in the management of the imperial finance These revenues at first amounted to about $£ 6000$ per annum, but soon rose to $£ 20,000$, at which latter sum the yearly fund at the disposal of the Board was fixed during a long subsequent period. The business of this Board was to encourage the Linen trade of the North of Ireland in every conceivable way-such as the awarding of premiums for the growth and importation of Flax seed; for the cultivation and preparation of the largest quantity of Flax fibre ; for the invention and distribution of new and improved implements ; for the erection of scutch mills ; and for the production of the best qualities of yarn and cloth. Inspectors, sealmasters, and superintendents were appointed and paid by the Board in the various localities where the trade was carried on: and inducements were held out to skilled weavers and Flaxdressers of foreign countries to settle in Ireland, for the purpose of instructing the native population in the mysteries of their art. This Board continued to hold the absolute control of every department of the Linen manufacture till the year 1828, when it was for ever swept away, with all its grievous restrictions and monopolies. That it accomplished much good in the infancy of the trade, when the want of skill and capital among the manufacturers rendered them very much dependent upon legislative aid and encouragement, cannot be doubted ; but its cumbersome regulations and irritating inquisitorial interferences were not suited to the genius of the 19th century, and so " The Board of 
Manufactures for Ireland" was numbered with the many other antiquated barbarisms of an unenlightened age, which the superior knowledge of the last fifty years has " decently interred."

- The spirit which dictated its original appointment cannot be commended. We have seen that a short-sighted selfishness had much to do in the matter, but a worse feature remains, I fear, to be noticed. The Linen trade of Ireland had its chief seat among the Protestants of Ulster, while the woollen trade was mainly carried on in the Popish districts of the south and west, and there are good reasons for believing that the suicidal compact of which I have already spoken, and which produced on the one hand the destruction of the woollen, and on the other the undue fostering of the Linen manufacture, had, in part at least, its secret origin in religious prejudice and bigotry.

Were other proof wanting, the records of the British Parliament itself would supply the deficiency: for in an Act, passed in the year 1704, the preamble commences in these words:"Forasmuch as the Protestant interest in Ireland ought to be supported by giving the utmost encouragement to the Linen manufacture of that kingdom-be it therefore enacted," \&c. If the Popish governors of the Spanish Netherlands, and the bigoted Louis XIV. of France, are to be condemned for their foolish and wicked expulsion of their most peaceful and industrious subjects, justice demands that we should equally reprobate the cruel and impolitic enactments of the British and Irish Legislatures of William and of Anne.

A Board of Manufactures for Scotland, similar to that for Ireland, was established in the year 1727. There was this difference, however, between the two, that whereas the one was given, as we have seen, partly to appease the selfish jealousy of the English nation, and partly to gratify the sectarian ambition of the northern Irish; the other was granted in fulfilment of a fair and open compact between two independent nations, and in satisfaction of what was then generally thought to be the just rights of one of the contracting parties. Both were undoubtedly economical blunders, but only one can be said to have been a political crime. By the Treaty of Union between England and Scotland (signed 22d July, 1706), it was stipulated that certain annuities should be paid out of the imperial purse, and applied 
specially for the benefit of the latter country, as equivalent for the greater advantages which, it was supposed, would accrue to the former by that treaty. The establishment of the Scottish Board of Manufactures was the tardy carrying out of that stipulation.

In the act or order in Council appointing the Board, and which was entituled "His Majesty's patent for improving Fisheries and Manufactures in Scotland," we accordingly find the preamble running thus :- " Considering that, by the 15th Act of the Treaty of Union, it is provided that an annuity of $£ 2000$ per annum be appropriated for seven years for promoting manufactures of Coarse Wool : Considering that, by Act 5th Geo. I., an annuity of $£ 2000$ per annum be payable out of the revenues of Scotland in lieu of the equivalent claimed by Scotland under the Treaty of Union, to be applied to the encouragement of the Fisheries and Manufactures of Scotland," and so on.

The Board was to consist of twenty-one commissioners appointed by the king. Their business was to take charge of the revenues and annuities granted for the purposes of the Act, to submit to the king in council a triennial plan for the apportionment of these revenues, and to frame regulations for the management and control of the different interests entrusted to their charge. The funds at their disposal were very considerable, but varied, of course, according to the produce of the revenues from which they were derived. The first triennial plan of distribution, which was for three years from Christmas 1727, provided for the payment of $£ 6000$ yearly in the following proportions, viz :-

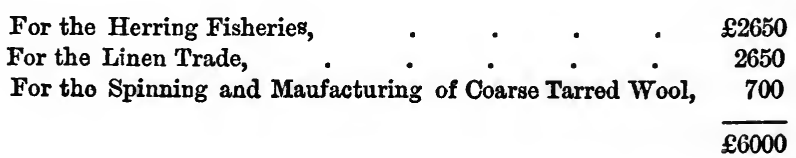

T'he particular plan for the distribution of the $£ 2650$ allotted to the Linen trade, embraces the following items of expenditure :-

Premiums for the growing of Lint and Hemp Seed at 15s per acre, . 
For encouraging Spinning Bchools for teaching Children to spin Lint and Hemp, . . . . .

For Prizes for Housewives who shall make the best piece of Linen Cloth, . . . . . . . $\quad 200$

For Salaries to the General Riding Officers at $£ 125$ each, . $\quad 250$

For Salaries to 40 Lappers aud Stamp masters at $£ 10$ each, $\quad 400$

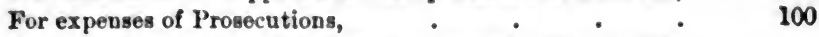

For procuring molels of the best looms and other instruments,

There are many curious facts, illustrative at once of the state of trade, and of the manners and customs of the people in the time of our great grandmothers, to be gathered from the perusal of the records of this Board. Perhaps the one which will sound strangest in our ears, deafened as they now are by the constant whir of many thousands of steam-impelled spindles, is that one of the very first acts of the trustees was to give orders for the establishment all over the country, but especially in the Highlands, of schools for teaching the polite art of spinning at the wheel. The sum of $£ 10$ per annum was allotted as the endowment of each seminary, of which the mistress received as salary $£ 5 ; £ 41$ s $8 d$ was allowed for the providing of 14 wheels for the use of the scholars, at the rate of $5 \mathrm{~s} 10 \mathrm{~d}$ each; $5 \mathrm{~s}$ was awarded for the "sustaining of pirns, bands," \&c. ; and the remaining $13 \mathrm{~s} 4 \mathrm{~d}$ was to defray the cost of coal and candle for the whole session, which extended from 13th October to 15th April, inclusive.

In a report on the industrial condition of the Highlands, presented to the Board by one of their inspectors, in the year 1754, it is mentioned that Henrietta Mackenzie, daughter of Sir Alexander Mackenzie had applied to be appointed one of the spinning-school mistresses for the purpose of encouraging the people to come to school. The inspector recommends that her application be granted, and thinks that her "being named in that capacity will have a very good effect." In the year 1729, a spinning-school was offered to the town of Dundee, but was refused, the Town Council considering that they had no funds to appropriate for such a purpose.

Immediately after the appointment of the Board, the trustees made proposals to Nicholas D'Assaville of St Quentin, cambric weaver, to bring over to Scotland ten experienced men, weavers 
of cambric, with their families, in order to teach their art to others. These proposals were ultimately accepted, and, in the year 1730, the Trustees bought from the Governors of Heriot's Hospital a piece of ground on which to build houses for the French weavers. A committee had been appointed to inspect the ground with a view to its purchase, and reported that they were well pleased with it, because of its nearness to the city and the villages of Broughtown and Coaltown, from all which they expected apprentices and spinners; and because they could procure stones out of the ground, or from the quarry of Broughtown, for building the houses. The extent of ground was five acres, and was purchased by the Trustees for the capital sum of $£ 273$, being the estimated value of the yearly feu-duty of $£ 10$ 18s 5d. It was sold in 1803 to Mr Burn, architect, for $£ 12,000$. The name of the place was changed, shortly after the purchase in 1730, from Broughton Loan to Little Piccardy, in honour of the native country of the French weavers. It now wears the more genteel appellation of Piccardy Place.

In the year 1745, the Trustees enter in their records that "a most wicked rebellion" had prevented their assembling during the latter part of the year, and also from making their usual report at Christmas, as the Patent directed, but express themselves agreeably surprised to find that the quantity of cloth stamped during the year had exceeded that of the previous year by $56,198 \frac{7}{8}$ yards, which they argue " is some evidence that the manufacturers had not quitted their work to dance after the Highland pipes." This minute, curiously enough, is signed by "Duncan Forbes, of Culloden, President."

From the Report on the state of the Highlands in 1754, already referred to, we learn that the inhabitants were very idle, and frequently to be seen "lying by dozens on the sides of the hills conversing and basking themselves in the sun beams." And again, "the people of the country have no employment but caring for their cattle or labouring their ground. They are for the most part idly inclined, and sleep away the half of their time." "In some places they live the whole summer on milk and the blood of their cattle, but have no meal nor grain of any kind." "Their clothing is poor like their food, their bodies being seldom all covered, and what clothes they have are never 
changed till worn into rags." Their houses are described as "extremely mean, especially those of the lower sort, which are so little that a man must almost creep on his hands and feet to get in at the door, and even after having got in he will scarcely be able to stand upright under the roof where the house is highest. In these houses they have no furniture, excepting one pot or pan, and a wooden dish. Their fire is placed in the middle of the house, around which they put large trees or branches, and behind these they lay heath for beds, where the family sleep promiscuously, few of them having any other covering than their body clothes."

I have not been able to learn when the spinning wheel was first introduced into Scotland, but it is clear, from the establishment of the Spinning Schools by the Board in 1727, that it was little known, or at least, little used, at that period in many districts of the country. And we do know that the good old fashioned rock and spindle had not been wholly superseded even so late as the beginning of the present century. Many can doubtless testify to this fact. I myself-although the century was a round dozen of years old at least ere I appeared upon its eventful stage-have frequently witnessed these implements at work in the hands of a certain old wife, who lived in the neighbourhood of my paternal home. The wheels of 1727 were single-handed, for the double-handed wheel was not invented till about the year 1764. It is spoken of as " $\mathbf{A}$ great improvement in the spinning-wheel, whereby a child can spin twice as much as a grown person can do with the common wheel."

At the date of the establishment of the Board, the returns of Linen stamped in the different counties shew that the manufacture was pretty generally prevalent over the whole of Scotland. Its chief localities, however, were in those counties lying in the great valley which extends from Lanarkshire in the west to Forfarshire in the east,-our own county (Forfarshire) being even then far ahead of all the others. Out of 2,183,000 yards stamped in Scotland in 1727, Forfarshire had 596,000; Perthshire, 477,000 ; Fifeshire, 362,000 ; and Lanarkshire, 272,000. Soon after this the manufacture began gradually to creep eastward, especially after the introduction of the cotton manufacture into the western counties about the end of last century ; the testi- 
mony of the Board being that wherever the manufacture of cotton was established, that of Linen sensibly declined; until, in 1822, the last year in which the returns were made, out of $36,268,000$ yards-to which quantity the trade had increased from $2,183,000$ yards in 1727-Forfarshire had 22,629,000 yards; Fifeshire, 7,923,000 ; Perthshire, 1,605,000; and Lanarkshire, 22,869. All the other counties, with the exception of Aberdeenshire, which had 2,500,000 yards, having only a few thousand yards each, and in some the manufacture had entirely disappeared.

The Board continued to exercise its functions with great vigour till the year 1823, when it also had to demit its authority, as far at least as the Linen Trade was concerned, at the indignant and oft repeated demands of the manufacturers themselves-a bill for that purpose having been brought in by the late $\mathrm{Mr}$ Huskisson, and passed by the Legislature, notwithstanding the most strenuous opposition of the Board, who urged that it was fraught with danger to all but a few capitalists, "who are probably aiming at obtaining a monopoly of the manufacture to themselves"! And thus passed away-let us hope for ever-all legislative interference with the Linen Trade of Scotland.

On the 5th July, 1746, the King's charter passed for establishing the British Linen Co. at Edinburgh, capital $£ 100,000$. One of the chief purposes intended to be served by this company was to supply the British merchants trading to Africa and the plantations in America with such kinds of Linen cloth as they hitherto were obliged to purchase from foreign nations, whereby it was hoped much money would be saved to the nation. This highly respectable company, I need hardly remind you, still exists, and continues as before to supply British merchants with Linens of its own making. The process of manufacture is, however, slightly different from that of former times. The Linen is now torn up and beaten into pulp, on which, when dried and stiffened, a very pretty and promising pattern is stamped, which gives it so extraordinary a value in the eyes of the merchants, that they believe, it to be worth its weight in gold.

The first mill for the spinning of yarn by machinery in Scotland was erected in Brigton near Glammis, in 1790, by Messrs James 
Ivory and Co., relatives, I believe of the present Lord Ivory. These gentlemen presented a petition to the Board of Manufactures in November of that year, setting forth "that they have erected one of the patent machines for spinning Linen yarn, to go by water, having purchased a license for that purpose from John Kindrew \& Co. of Darlington, the patentees, which, with the expense of the machinery and of a water mill, has cost them about $£ 1000$, and they pray that the Board will patronise and encourage them in the foresaid undertaking." The Board resolved by a majority, that "as this is the first undertaking of the kind which has been set on foot in Scotland, and as the undertakers have incurred a large expense in it, they shall be allowed a premium of $\mathfrak{£} 300$, payable in three moities of $£ 100$ per annum." Closely following this experiment, water mills were erected on the Dighty near Dundee, at Kirkland in Fife, and other places. In June, 1794, Alexander Aberdein \& Co. of Arbroath, presented a petition to the Board praying "for aid to erect a mill-house for holding machinery for spinning Linen yarn by water, which they propose erecting on the Brothock, the machinery to be constructed upon original principles of their own." I could not, however, find that their request was granted. The first mill erected in Blairgowrie was the Meikle Mill, or Blairgowrie Mill, in 1798.

At first spinning mills, being driven by water only, were erected, not in the towns, but in the country, on some river or burn where a good fall could be obtained. The introduction of steam power has now numbered these with the things that were, or at least is fast doing so, except in localities such as Blairgowrie, where the water power is sufficiently great and continuous to enable it still to cope successfully with its more formidable rival.

I have in my possession a curious list of the spinning mills which existed in Dundee and its neighbourhood in the year 1822. They were fifty-one in all, of which eighteen were in the town and thirty-three in the country, containing in all 15,102 spindles, the average number of spindles per mill being-in

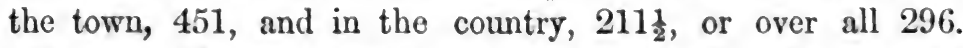
Of these fifty-one, twenty are marked as "newly erected." Deducting these there remains thirty-one, of which six only were 
in the town and twenty-five in the country, some of the latter having only about ninety spindles each. I have also been able to procure a correct list of all the spinning mills existing in Dundee and Lochee in the year 1851. They are in number forty-three, driving on the whole 109,000 spindles, and averaging 2500 spindles per mill. In Blairgowrie in 1851 there were thirteen mills, driving 13,000 spindles, or an average of 1000 spindles per mill.

The Quantity of Flax Imported into Dundee

\begin{tabular}{|c|c|c|c|c|c|c|}
\hline In 1745 & was & . & - & - & & Tons. \\
\hline , 1791 & ", & - & . & . & 2,444 & , \\
\hline , 1814 & ," & - & $\bullet$ & . & 3,000 & ", \\
\hline , 1830 & $"$ & • & • & . & 15,000 & " \\
\hline , 1843 & ," & - & . & . & 32,000 & ," \\
\hline :, 1853 & ", & - & & . & 34,052 & " \\
\hline & & & Cow. & & & \\
\hline 1853 & & • & $\begin{array}{l}\cdot \\
\text { UTE. }\end{array}$ & - & 10,820 & Tons \\
\hline 1853 & & • & . & . & 16,590 & Tons \\
\hline
\end{tabular}

Such details as these are perhaps uninteresting to my nonprofessional hearers, but they come strikingly to mark the rapid progress in this seven-league-booted century. What was a marvellous novelty yesterday is commonplace to-day, and will become a genuine relic of antiquity to-morrow. Water spinning mills were thought a wonderful invention in 1792, were thick as blackberries in 1822, and were set aside as old-fashioned in 1852. A few decades now-a-days bring about greater changes than centuries did before. The rock and spindle of our great grandmothers had held their place undisturbed since the days of the Pharaohs, but James Watt and his tea-kettles have now transferred them to the museum of the antiquary, and our children will regard them with much the same wondering as we do the mummies of Egypt.

Let me now, in conclusion, attempt to give a rapid sketch of the manners and industry of our Scottish peasantry of last century. 
The tenants of so many "Ploughgates" or farms, built their houses and farm offices in one group, called a "Toon," hence the phrase still common "a farm toon." A few acres were all that each possessed. The land was divided into two portions called " infield" and "outfield." The first which lay nearest the toon got all the manure and was constantly under crop, hence it was sometimes called the "croft," i.e. the cropped land. The other was pastured for several years in succession, and when thought to be sufficiently manured by the droppings of the cattle, was broken up, cropped for two or three years with oats, and then, without the sowing of grass seeds, which had not yet been introduced, the farmer trusted to the spontaneous production of nature for the pasture of the ensuing seasons. The infield was all in "run-rigg," i.e. the lands of one farmer intermixed with those of another; and the riggs were universally crooked, the result of ploughing so much with oxen. Every field contained a number of "balks," or waste places between the ridges, full of stones and bushes. The plough used was the old Scottish plough with wooden mould-boards, and was drawn by six, eight, ten, and sometimes so many as twelve oxen; or by oxen and horses together, or sometimes by oxen, cows, and horses, in one united team.

Bauldy, in the "Gentle Shepherd," sings-

I hae gowd and gear, I hae land eneugh, $I$ hae sax guid owsen ganging in a pleugh ; Gangin' in a pleugh, and linkiu' o'er the lea, And gin yo winna tak' me, I can let yo bo.

In some places the plough was drawn by four horses yoked abreast, the halters being fastened to a long stick in front, which the driver held in both hands, walking backwards, and guiding them so as to make them pull steadily together. Few carts were used at this time, the manure being carried out to the field in creels (curraghs) on the backs of horses, and the peats and corn brought home in the same manner. Carts when first introduced were merely small wooden frames, placed on low wheels of solid wood. The farm house was the low turf-walled, thatch-roofed erection still common in 
the Highlands, a byre and barn at one end, and a peat stack at the other.

\footnotetext{
A snug thatch-house, before the door a green, Hens on the midden, ducks in dubs are seen; On this side stands a barn, on that a byre, A peat-stack joins, and forms a rural square ; The house is Glaud's-there you may see him lean, And to his divot seat invite his frien.
}

The front wall of the house was usually graced during the day by a row of clean beech cogs and luggies, used in dairy operations. Inside was the "but" and "ben," the " ben" being drawing-room and best bed-room in one ; the "but" or " hallan" being kitchen, parlour, and dining-room. In this last the household lived and dined without distinction of caste between master and servant, and here the females span and reeled when not engaged in cooking or cleaning.

Every farmer in those days grew an acre or two of Lint, and it is worth mentioning, as illustrative of the manners of the age, that the wages of farm servants, whether male or female, consisted in part of so much ground for sowing Flax for their own use. In the parish of Fowlis for instance, the first Statistical Account remarks, that the wages of a maid servant were at that time $£ 3$, including bounties, such as two yards of Linen cloth, an apron, and as much ground as would sow two lippies of Lint seed.

The Lint when ripe was pulled up by the roots and rippled on the field to separate the straw from the bolls or seed, then steeped or " bogged," dried, beetled, scutched and hackled, and it was then ready for spinning, all which operations are so familiar to most of my hearers that I need not stay to describe them. At the time of which I speak it was customary for all unmarried females (gentle and semple alike) to occupy their whole leisure time in spinning, thus providing in the first place for the necessities of the household, and then for their own outfit in life when they came to be married. And she would have been considered a poorly-tochered bride indeed, whatever her rank, who had not a well-filled "kist" of snaw-white Linen, in table cloths, shirts 
and sheeting, of her own spinning and bleaching, to bring home on the marriage day. Hence arose, I doubt not, the name of "spinster" still applied to unmarried women; and hence also the practice, still prevalent when a young couple are married, for the lady to provide the "napery." In confirmation of this I have been informed by a near female relative of my own, that not only did she and all her sisters spend a large portion of their youth in "birrin" at the wheel; but also that the danghters of a noble Earl who lived in their neighbourhood, and whose family is, and has long been, one of the first in Scotland, spent much of their time in the sume delightful and intellectual employment.

Another fact worth noticing in connection with this subject is, that the spinning engines of these days were locomotive, that is to say, the country lasses, when visiting their friends would generally carry with them their rock and spindle or wheel, as the case might be, much in the same way, I fancy, as the ladies of the present day put their crochet needle or fine seam in their work-bag or box when they go to have an hour's chat with some friendly gossip. Burns* refers to this old fashion in one of his songs :-

\author{
There was a lass they ca'd her Meg, \\ And she gaed n'er the muir to spin ; \\ There was a lad that followed her, \\ They ca'd him Duncan Davison.
}

That Meg carried her wheel with her we learn from the subsequent verses, thus :-

\footnotetext{
The muir was dreigh and Meg wns skeigh,

Her favour Duncan couldna win,

For wi' her rock she would him knock,

And aye she shook the "temper pin."
}

* In making the following quotations from the lyric poetry of Scotland, I beg to explain that I do so merely for the illustration of my subject, my own feeling being that it is exceedingly interesting to be able to trace out the manners and customs of a bygone generation in these old songs, which, whatever their other merits or demerits, were undoubtedly a faithful impress of the age in which they were written : just as it is so interesting to read the history of a pre-adamic world in the frazments of fossil plants and animals which we find embedded in the rocks. 
The "temper pin," I may explain for the satisfaction of the uninitiated, was the wooden screw or pin which adjusted or "tempered" the bands of the wheel. This pin Meg would appear to have taken out and used in the most unkind and unlady-like manner as a weapon of defence, or perhaps offence, against the loving Duncan, a treatment very likely, I should think, to shake his temper. My only wonder is that he should have persisted in his suit to such a virago as she must have appeared, brandishing in one hand the rock and in the other this " temper pin," and " knocking " him considerably with both.

The phraseology of this song. can only be explained on the supposition that Meg was on her way to some spinning party such as I have mentioned. These re-unions were generally very merry affairs. The lasses would come early, bringing their rocks and spindles or wheels, as the case might be, in order to have an hour or two's gossip among themselves; but as gloamin' fell the lads would drop in and range themselves along one side of the spacious hallan, or perhaps, according to the discretion of the guidwife, interspersed among the lasses, weaving stockings and mitts, which was their branch of the domestic economy. Sometimes instead of the hallan, the barn, well swept for the occasion, would be the place of rendezvous. By and bye the wheels and stockings would be laid aside, and blind man's buff, story-telling, singing, dancing, and other amusements would succeed until it was time to go home. And then, of course, the gentlemen must convoy the ladies "o'er the muir" again, under the plausible pretext, doubtless, that they would need some one to carry their spinning graith for them. Such meetings were called "rockins," the term having originated evidently in the days of the rock and spindle. Burns hits off the scene capitally :-

\footnotetext{
On Fastern e'en we had a rockin, To ca' the crack and weave the stockin', And there was muckle fun and jokin' Ye needna' doot, And syne we had a hearty yokin' At sang aboct.
}

Indeed the whole of ancient Scottish song has frequent reference 
to the spinning wheel. Another of Burns', called "Bessie and her Spinning Wheel," begins thus :-

O leeze me on my spinning wheel, And leeze me on my rock and reel, Frne tap to tae that cleels ine bien, And haps ine fiel and warm at e'en.

And again :-

I bought my wife a stane o' lint, As gude as e'er did grow.

And a' that she has made o' that

Is ae puir pund $o^{\circ}$ tow.

The weary pund, the weary pund, The weary pund o' tow,

I think my wifo will end her lifo

Before she spin ber tow.

The "rock" comes in here again as a lethal weapon, for on the poor man remonstrating with his thriftless wife to "gae spin her tap o' tow,"

She took the rock, and wi' a knock,

She brak it o'er his pow.

In Allan Ramsay's beautiful pastoral we are introduced to Mause in the following prologue:-

\footnotetext{
A green kail-yard-a little fount, Where water poplin, springs, There sits a wife wi' wrinkled front, And yet she spins and sings.
}

And in the tussle which ensued between Madge and Bauldy, the lady's rock played a prominent part :-

Ye'll gar me stand? ye shevelling-gabbit brok, Speak that again, and trembling dread my rock.

From all this we learn that the rock, whether in the hands of coy maiden or irrate old wife, was at once an implement of industry and a formidable weapon of war. 
I have said that spinning was chiefly practised by the younger females of the family, but we have seen that it was not wholly confined to them. The married women, after passing through the middie period of mothers and housewives, and arriving at the venerable stage of "grannies," reverted to the less toilsome occupation of their youth :-

\footnotetext{
There was an auld wife had a wi' pickle tow, And she but gae try the spinnin' o't,

She linted her down and the tow gaed a low, And that was a bad beginnin' o't.
}

The yarn when spun, if intended for home use, was sent to the household weaver, who gave back the web when finished, charging so much per yard for weaving. It then underwent a mysterious process called " bookin'," which I shall not attempt to describe; and after being bleached by some bonnie burn side, the attendant nymph keeping the claith wet by means of a wooden "scupe," as I have myself often witnessed, was stored in the napery-kist for future use. An aunt of my own, now a greyheaded woman, of three-score and ten at least, informs me that when she was a girl she was long in very delicate health, and that, in consequence, to her was mainly assigned the care of the bleaching Linen, the general belief then being that the smell of wet Linen cluth was beneficial to consumptive patients.

The yarn made for sale was disposed of in small quantities of one or two spindles each to the yarn merchant, who attended the country markets for the purpose. These men again sold their parcels in the larger towns to the weavers and manufacturers.

In the same way the cloth when manufactured was brought into the country market-towns and villages, web by web, on the back of the weaver, (" hand-webs" these were called), where it was purchased by the hawker or agent, who again brought his lots into the larger towns, such as Dundee, on the weekly market days, where, after undergoing the careful inspection and stamping of the stamp-master, they were sold to the "green-cloth "merchant, who finally packed and exported them to England, or to the Plantations of America, as the United States were then called. 
An interesting description of these old times is given in a curious poem, or collection of poems, called the Piper of Peebles. It is as follows:-

Twa hunder year and mair sin syne

When fashions wer'na near sae fine, When common folk had scrimper skill, And gentles scarce had wealth at will, When nane but meadow girse was mawn, And nane bit hamit lint-seed sawn, When liut was beaten by the mell, And ilk ane swingl't till bimsel', When sarks were stark and no that saft, And lennel worn wi' washin's aft, And some had ane and some had twa, Any mony ane had nane ava, When wives wi' rocks and spindles span, And brawest lasses used nae can, When lasses wi' their rocks gaed out To ane anither nicht about, A full lang mile o' grund and mair, Sometimes no very free o' fear. Lang e'en o' nichts they countit half, When spinnels cuist their whorles aff Aye and upwards near the tap, They liked aye a bulky knap, Wi' threads cross-breadth'd aye to defend The rest frae ravelin' o'er the end ; On hand reels syne they reeled the yarn Before the use of wheel or pirn, Wi' double down comes, gig and whap, And scores, and so forth, as exact As reels can count that's made to chack. When knocked bear was Sunday's kail, And folk in pots brewed buthel (burial) ale. When men wi' greyheads played billie brack. Wi' younkers round about the stacks.

Mix't men, wives, lads, and lasses too, And herds, had neither hose nor shoe. But a' thing has a time atweel, $\Delta$ time to flourish, time to fail, So to the end of my Old Tale. 


\title{
SE C T IO N I V.
}

\section{0 D E R N L I N E N.}

\author{
P A R T I. \\ CONTINENTAL LINEN.
}

The overthrow of the Roman Empire in the fifth century completely destroyed all trade and commerce in the west of Europe. The new monarchies which sprang up from its ruins were founded in blood, and war was both work and pastime to their hardy sons. The necessaries of life were all they sought, luxuries, and even comforts being uncared for or unknown. For a time the Eastern Empire retained a considerable amount of civilization, and in some of the countries under the sway of the Emperors manufactures were encouraged-that of Linen, as ha been shown, flourishing for ages in Greece, where the trade was not wholly extinct in the beginning of the ninth century. The enlightened policy of the Christian sovereigns of Byzantium had no influence on the warlike tribes in the west. There darkness the most complete reigned for centuries, and during that period there was no Linen manufacture to describe, no progress to record.

The Great States, pre-occupied by war, left trade and commerce, the arts and sciences, to Petty States, or whoever chose to prosecute them. The free cities in Italy were the first to show 
signs of returning life. Those of the Netherlands and of the Hanse Towns afterwards sprang into existence, and they were mainly instrumental in spreading a knowledge of manufacturing industry throughout Europe. Venice, Pisa, Genoa, and other Italian cities became the medium of communication between the nations of the East and of Western Europe. They inported the precious productions of India, Egypt, and the various countries of the East, including silks, Linens, \&c., and exchanged them with the Germans, Franks, English, and other western nations, for the mineral wealth or the produce of the fields and forests of those lands. - By this means these cities acquired vast wealth and political importance, far beyond what the limited extent of their territories would otherwise have commanded. Sometimes one city was predominant in power and then another, and sometimes they rivalled each other in greatness, and, striving for pre-eminence, weakened each other, and rendered themselves an easy prey to the common enemy.

Charlemagne, who ascended the throne of France in 768, by an enlightened and liberal policy did much for the establishment of manufactures in Germany and France, and for the extension of civilization and the arts among his people. He introduced Christianity, founded Hamburg (in 804), and other cities which afterwards rose to great commercial importance, and encouraged trade as far as the genius of his age would permit. The city of Bruges, founded in 760, afterwards became famous in the manufactures of Flanders. Other maritime or manufacturing towns gradually rose up in Brabant, Flanders, \&c., which in time procured privileges from their feudal lords, especially the guidance of their own affairs, and pre-emption from arbitrary assessment by their feudal superior, and from following him in his wars. This freedom and these privileges were then of great avail in fostering commerce and manufactures while in their infancy. Now that trade has attained mature strength, exclusive privileges and national aid are only hindrances, which ought all to be swept away.

Baldwin, the younger (III.), Count or Earl of Flanders, was an enlightened prince, far in advance of his age. The Flemings were the first who began to earn their living by weaving, and, 
lying near France, says the Pensionary De Witt, they "sold the cloth to that fruitful land, where the inhabitants were not only able to feed themselves, but also by the superfluous growth of their country, could put themselves into good apparel." Baldwin, seeing the advantage to be derived from trade, both by himself and his people, set up annual Fairs, without tolls or duties, in several towns. The Flemish historians say that "he fortified several cities, and then invited into the country all manner of handicraftsmen for making of all manner of manufactures, to whom he granted great privileges, and established fairs at Bruges, Courtray, Tor- . bout, Mount Cassel," \&c., \&c. Through his instrumentality manufactures both of wool and Flax made rapid progress in Flanders, and from his enlightened policy much permanent good has flowed to all the nations of the world.

In Anderson's Commercial History it is said that "the woollen manufacture in all probability preceded the Linen, the former being in a manner absolutely requisite for preserving men from the inclemency of the weather, the latter being a species of luxury, many barbarous nations at this time living without any Linen at all. As men fell into commerce, and consequently grew richer and more elegant, they gave the greater encouragement to so cleanly and desirable a wear as Linen next their bodies. The Linen manufacture came first from Egypt into Greece and Italy, and thence travelled westward into France and Flanders, next probably into Germany and England, before it grew in the more northern and north-eastern parts of Europe, where it has since prospered very much. Others think that the Carthagenians first introduced it into Europe."

Whether the Linen manufacture came by way of Carthage, or direct from Egypt to Greece or Rome, it is certain that it originated in Egypt, and thence found its way into Europe. During the dark ages that succeeded the downfall of the Roman power it lay dormant, but it was again vivified and restored in the dawn of the new born civilization which gradually threw light over western Europe. The spread of Christianity tended much to withdraw the veil which had overspread the western world, and to introduce a relish for Linen as an article of apparel, and for household and sacred purposes.

According to Voltaire, in the time of Charlemagne there were 
manufactures of woollen stuff, but Linen was uncommon. In proof of this he relates that "St Boniface, in a letter to a German bishop, desires him to send him cloth with a large nap for him to make use of in washing his feet-probably," adds Voltaire, "this want of Linen was the cause of all the diseases in the skin known by the name of leprosy, at that time so general."

If Linen was uncommon in Europe at that period, the value of it very speedily became widely known, and its use general in many countries. The progress of the Linen manufacture in some of the nations on the Continent of Europe where the trade is carried on extensively will now be given.

In some of the European States the Linen trade is not in modern times of much consequence, it being wholly of a domestic character, and the Flax grown is spun by hand, and weaved at home for family use. In others recent details have not been got to so complete an extent as was or is desirable, in some cases because statistical accounts are not made up, and in others because access to them were not available.

Many of the statistics given are taken from the published reports by the Secretaries of Legation at the different courts, and from those of the Consuls at the various ports. Several of these reports are got up with great care, and contain much useful information, but others are very meagre and of little use. Unfortunately there are some Secretaries and many Consuls who do not appear to send in reports at all, and this is much to be regretted, as these parties have the means of acquiring a knowledge of the trade and manufactures of the respectire countries and ports not available to others. For easy reference the monies and weights and measures given in these reports have generally been calculated into British standards, and are so given. The letter-press has been collected from a great variety of sources, and it is as full as, from the nature of the work, could conveniently be given. 


\section{CHAPTER I.}

\section{T A L I A N L I N E N.}

THE rude and barbarous nations who overthrew the Roman power in Western Europe manufactured little and traded less. They came from lands where the necessaries of life alone were sought, where the gratification of their passions was their chief desire, and where might was right. The people, steeped in poverty and ignorance, felt few of the wants of civilized life, and despised its luxuries. Even with their leaders works of art were valueless, and luxurious habits and cultivated taste were looked upon as crimes. The normal condition of such nations was more allied to the savage than to the civilized state, and rudeness and barbarity were natural to them. When such was the social state of the dominant race, it is not surprising that their laws should have been arbitrary and cruel, calculated alike to oppress the body and deaden the soul; or that their government should have been despotic and tyrannical, extinguishing everywhere the light of civilization, and so producing universal gloom.

After centuries of darkness, benighted Italy was the first to re-open her eyes and usher in the dawn of brighter and better days. Her cities, grown independent and great, became marts of commerce, her citizens merchant princes. They opened up the trade with India through Constantinople, Trebizond, and Persia, and were for many ages the medium of communication between the warlike nations of Europe, and the luxurious and enervated inhabitants of the East. Venice, Genoa, and other Italian cities had vast fleets, with which they traded to all the countries bordering on the Mediterranean and Euxine Seas, to Western Europe, and to the Moorish cities on the Atlantic. Flax was imported from Egypt and other countries, or raised at home, and the Linen trade formed an important part of their domestic in- 
dustry. With the fall of the proud republican cities the manufactures of Italy languished and died, but in modern times it has somewhat revived, and the new regime may, by and bye, consolidate and extend it.

In various parts of Italy, Flax and Hemp are largely cultivated, not only for the native manufactures of the country, but also for export. Many of the listricts of that beautiful country, a land of sunny skies and fertile soil, are admirably adapted for the growth of these textile fibres, and some of them produce both Flax and Hemp of the very finest quality. 'The Hemp of Bologna, of Ferrara, of Cesena, of Ascoli, and of Naples, is highly esteemed. Not less so is the Flax of the provinces of Cremona, of Lodi, and of Brescia in Lombardy, and of other places. At Solerno, and in some other districts, the cultivation of Flax is of recent date, but it is making some progress. In the mountainous regions of Lombardy and Venetia, Flax and Hemp are grown chiefly for native use, but a little of both, and also some cloth, are exchanged with the Milanese and other low countries for the produce and fabrics of these places.

According to the Italian Statistical Annual for 1857, the production of raw Hemp had risen in Italy, in round number, to $40,000,000$ kilogrammes, which at $£ 217$ s the 100 kilogrammes gives an annual value of $£ 1,120,000$, one-half of which applies to Bologna, Ferrara, and Cesena. Some competent valuers estimate the total quantity raised at 50,000,000 kilogrammes, allowing to Piedmont and the Neapolitan Provinces about $10,000,000$ more than is given in the report. It would thus appear that the total quantity anuually raised in Italy is close upon 50,000 tons. About 16,000 tons are exported to Switzerland, Germany, France, Great Britain, Spain and Portugal, the remainder being required to supply the inland consumption.

The culture of Hemp, in order to be productive, requires numerous special conditions as regards soil, water courses, \&c., which very much restricts its limits, and localizes it in particular places, sometimes very remote from each other. The provinces of Bologna and Ferrara are not only the centre of the Hemp production in the north, but also that of the best methods of cultivation. They yield the best produce, and amongst them the 
giant Hemp (Canopa gigante), which has been much approved in the various International Exhibitions. The Bolognese Hemp almost rivals Flax, and is distinguished by its whiteness, brilliancy, softness, and divisibility of fibre. The Ferrarese Hemp is of long staple, more tenacious, and well adapted for sacking, sailcloth, and cordage. The Hemp of Cesena, Venice, Piedmont, and the south partakes more of the nature of the Bolognese.

In the Hemp growing districts of the north of Italy very great attention is paid to it in every stage of its progress. The preparation of the soil is of primary importance, as the crop always corresponds to the care bestowed upon it. It is ploughed and reploughed in autumn, and in many places spade husbandry, auxiliary to the plough, is adopted. Before sowing the soil is broken and levelled by machines adapted for the purpose, and then divided into beds. The refuse of the stable has always been considered as normal and necessary manure, but prepared and other manure is used by some growers. The management of the supply of water requires care, and various contrivances have been adopted for its proper regulation. Under favourable circumstances Hemp grows in some districts to a prodigious height, and some specimen stalks of Farrarese have been shown from sixteen to twenty feet in length.

Retting is the most difficult and the most important of all the operations with Hemp, and it is performed in lakes, ponds, and running streams. Artificial pits or pools are considered best, and almost every grower has his own pits, excavated in the lowest part so as to collect the rain water. When near rivers or canals the water in the pits is changed when the process of maceration has made some progress, which makes it easy to regulate the fermentation, and it prevents the matter formed during the maceration from being deposited. With the same object, where the water cannot be run off it is drawn off by pumps or other means, and fresh water supplied. The quality and quantity of the water, the temperature, the quality of the Hemp, and the care of the grower, contribute essentially to the success of the retting process. To prevent deterioration to the stalk, and to preserve the greatest suppleness and freeness to the 
fibre, is the great object to be attained, and to secure this with the greatest uniformity possible the Hemp is assorted into sizes. The earth of the retting pits is carried to the fields to furnish fertilizing matter, and thus the crop is less exhausting to the soil than it would otherwise be. The nauseous miasma given off while the Hemp is in the steep, although disagreeable, is not deleterious either to men or animals.

In scutching, the stems are first crushed by machinery, then beaten either by hand with the common brake, or by machinery constructed for the purpose and moved by animals. The latter operation detaches the fibres from the wood, after which they are straightened with a long toothed comb, and made up into bundles, which completes the practical operation of the grower. The wood is valuable for charcoal used in the manufacture of gunpowder and artificial fireworks. Before being exported the Hemp is carefully picked and selected into different qualities, suitable for the various purposes to which it is applied. It is then packed into bales by means of common or hydraulic presses, and this process gives the Hemp greater brightness and flexibility.

Hemp softening is carried on to some extent in Italy. large spinning work has been established for about twelve years near Bologna. It is now being extended, and will contain 4000 spindles, and consume nearly 900 tons of Hemp yearly. There are some small hand-loom weaving establishments in various parts of the country, but none of great extent. The trade, both in spinning and weaving, is almost wholly of a domestic character, and gives employment to a large number of people.

Flax has been cultivated in Italy for a much longer period than Hemp, it having been grown extensively before the Christian era, and when Hemp was but little known. It is now reared in many parts of the country, but not largely in any one district, and this renders it very difficult to collect complete statistical details respecting it. According to the Statistical Annual referred to, the production reaches in round numbers fully 20,000 tons. The Flax cultivated is of two kinds, the winter and the summer sorts. The winter Flax is sown in October and gathered in June, and it yields about six hundred-weight of seed and nearly three of fibre an acre. The summer Flax is sown in May and watered abundantly, and it produces only 
about four hundred-weight of seed and three of fibre an acre. In the rotation the winter crop is made to succeed the harvest of corn, and the summer Flax the grass crop.

The production of Flax, as well as the methods of cultivating it, differ greatly in different localities. In some districts the Flax when pulled is put into sheaves and dried in the sun, after which it is thrashed to get the seed. It is afterwards put into pits or in running water to steep. In some places where there is no water for steeping, the Flax is cultivated exclusively for the seed, and the stalks burned in the kilns.

In various districts the cultivation of the soil is divided among different parties, each of whom performs some special part of the operation. The farmer furnishes horses, pays the seed in advance, \&c.; the cultivator and his family sow the seed, root up the Flax, \&c.; and the peasants have each his allotted work under both. The quit-rent ground (terratico) is either a pertica or a half-per tica, in one of those fields in which the rotation of the Flax crop happens to take place. This part of the Flax serves the family of the peasant, and his women take exclusive care of the ground for it, and of its cultivation even until it is spun.

In the mountainous regions of Lombardy and Venetia some Flax and Hemp are grown for native use, and some cloth and Hemp is exchanged with the Milanese and other Low Countries for their produce and fabrics. In the eastern part of Lodi and Crema the finest Flax is cultivated, and it is exported to foreign countries by way of Venice and Genoa. The Flax of Cremona is shorter and coarser in the fibre than that of Lodi and Crema. In the Milanese and Pavian districts Flax forms one crop in a nine year's rotation, and after the Flax crop is reaped there comes the second harvest, called the minuto, or smaller crop, which comprehends millet, vegetables, and beans.

In Brescia, Mantua, Verona, Vicenza, and some other places, there are manufactures of Linen, but they are not sufficient for the domestic consumption of the country, and have to be supplemented by large importations. At the commencement of the seventeenth century the Flax trade was of greater importance in the province of Brescia than it now is, as at that period about 1500 tons were annually exported, while at the commencement of the present century it was only about one-fourth of that 
quantity. At present about 300 hand-looms are employed in weaving Linens in Brescia, the value of the cloth made being about $£ 20,000$ annually. T'wo centuries ago there was a great trade in Linen thread at Salo, but it has now been lost.

The separation of Venetia from Lombardy, and the Austrian tariff, have inflicted much injury on the Linen trade of these provinces, although M. Zanardilli states that the manufacture of Flax in Lombardy still gives employment to 300,000 women, who work at their own homes, spinning by the ancient mode of distaff and spindle, and earning scarcely twopence a day. There are, however, Flax-spinning mills at Capaccio, Olmè, and Melagnano in Lombardy, employing about 12,000 spindles, and making about 1100 tons of yarn yearly. There is only one linen power-loom work in Italy, and there both Flax and Tow goods are manufactured; but it is not of great extent.

In Modena, Hemp and some Flax are cultivated, and Linen and canvas are among the few manufactures of this district. Hemp and Flax are also raised in Lucca, and both these articles are exported to some extent. In Peidmont, some Hemp and a little Flax is produced, but not enough for the limited local consumption, as the importation exceeded the exportation in 1857 by about 880 tons. Common Linens, canvas, and cordage, are made in Genoa, and some other towns, but excepting for domestic purposes this is not a manufacturing country. In the Island of Sardinia a small quantity of Flax is grown, and about 1000 cantars (70 tons) of it exported annually, the rest being used in the Linen manufactures of the country. The quantity of Hemp annually produced in Continental Sardinia represents a yearly value of $£ 400,000$ to $£ 500,00$ ), but it is not sufficient for the wants of the country. 'The Flax grown there is of much less value than the Hemp. In Parma and Tuscany there are almost no manufactures of Linen, and very little Flax is grown in either place. Any manufactures of Flax are done in the country districts, and they are almost exclusively for the ordinary wear of the peasants.

In what was formerly the Papal States some Flax and Hemp are grown, and, both being indigenous to the country, are of very superior quality, but neither are cultivated to a great extent. Both Hempen and Flaxen cloth is made, chiefly in the public 
schools, orphan asylums, and private houses throughout the country and city. There being no factories, the fabrics made are generally of the lower or middling descriptions, but, from the fine quality of the material used, the goods are excellent of their kind. In the Fair at Sinigaglia considerable quantities of Linens from Germany, \&c., are sold.

In Naples, Flax and Hemp, equal to twice the consumption of the inhabitants might be grown, many districts being remarkably fertile, and admirably adapted to produce both plants in perfection, but agriculture of every kind is in a rude and backward condition. The various branches of manufacturing industry, among which are a few coarsely made Linens, are in as miserable a state as the agriculture of the country.

In the fine Island of Sicily, Flax and Hemp are grown with scarcely more culture than scratching the ground to let in the seed. Although the soil is so fruitful, and as it were wooing to be cultivated, such is the wretched state of agriculture and of manufactures that Sicily can scarcely export a ton of either, nor even supply sufficient linens for her own domestic consumption. In one of the psuedo Platonic epistles, mention is made of Linen shifts made for ladies in Sicily, but the material for making them may have been imported. In like manner the Linen of Malta was in ancient times exceedingly admired for its fineness and softness, but the raw material was in all probability imported.

The Linen manufactures of what was formerly the kingdom of the Two Sicilies only employ some 400 to 500 hand-looms. Perhaps the freedom now enjoyed under the more enlightened policy of the King of Italy will tend to develop the resources of the country, and if so the growth of Flax and the extension of the Linen manufacture will, no doubt, soon become of much greater importance.

Comparatively little Linen yarn is imported into Naples or Sicily from the United Kingdom. The British trade in brown and bleached Linens is now much cut up by Germany and Switzerland, and the importation of diapers and table Linen is almost wholly from Germany, with which country, it would appear, Britain cannot compete in these articles. Considerable quantities of plain and fancy drills are, however, got from England and Ireland, as their manufacture of these fabrics is 
preferred. The high duties upon Linen manufactures have not been sufficient to call forward the Sicilian or Neapolitan weavers, or to enable them to compete successfully with manufacturing nations. Several experiments were made some years ago to extend the manufactures of Linen in the country, both from foreign and native grown Flax, but all proved abortive.

According to an account made up in 1764 , Linens were exported from the following places in Italy, viz.-Verona, Brescia, Crema, Bolonia (damask), Ancona (fine Flax), \&c.

The causes of the backward state of agriculture, trade, and manufactures throughout Italy generally, is a sad commentary on the despotism and misrule which have so long afflicted that fine country. Italy teems with priests and sacerdotal classes of every rank, and it might have been expected that a peoplo with so many religious instructors would be enlightened, happy, and prosperous; but it is not so. Freedom of thought and action are absolutely necessary for the successful cultivation of manufacturing industry, and for the prosperous prosecution of commercial enterprise, but they appear to be incompatible with priestly rule, and, in Italy, both are suppressed-to the misfortune of the people, and to the ruin of the country.

In 1857 the Sardinian States imported 3300 tons of Flax and Hemp, and about the same quantity in 1858 , but in 1859 it fell below 1400 tons. In 1857 about 900 tons of Flax yarns were imported ; in 1858 nearly 1000 tons; and in 1859 nearly 1200 tons. The Hempen and Flaxen cloth imported in 1858 was about 270 tons, and in 1859, 240 tons. The exports of Hempen cloth from these States for the same year were quite unimportant. The average imports of Linens into the Island of Sardinia in the years from 1857 to 1861 were under 100 tons, of the value of about $£ 18,000$. 


\section{CHAPTER II.}

\section{S P A N I S H L I N E N.}

SpaIN has had a chequered history. Many parts of the country are exceedingly fair and fruitful. It only wants freedom from bigotry, intolerance, and oppression on the part of its rulers, lay and sacerdotal, and intelligent industry on that of the people, to make it rank high among the nations of the earth.

After the removal of the Roman legions, Spain was divided into small kingdoms, ruled by petty kings, jealous of and often at war with each other. This made the southern portions of it an easy prey to the Moors from Africa, and for many centuries half the country was overrun by them. During that period arts and sciences flourished in a much higher degree than they have generally done in countries under the sway of the Moslem, and good progress was made in manufactures and commerce. The ruins of the Alhambra, and other magnificent architectural works, still remain to attest the taste and skill of the Moors, who, though warlike in their nature and habits, yet industriously cultivated the arts of peace. Flax was largely grown by this extraordinary people, and Linens and other textile fabrics were manufactured by them on an extensive scale. Besides supplying the home demand, many of these fabrics were exported to Constantinople, and to other cities in the Mediterranean and adjacent seas, and even as far as India, and eastern produce was brought back in return. This trade enriched the chivalrous yet commercial Moriscoes, and enabled them long to maintain their hold of some of the finest provinces of Spain.

In 1450, Spain imported Flemish woollen cloth to a considerable extent. A century later she imported Linens, Flax, thread, \&c., from Antwerp.

The same year (1492) in which the Moors were finally expelled 
from Spain, Columbus discovered for her a new world. For a time wealth, vast wealth, flowed in from her American colonies, and unexampled prosperity gladdened every heart in what was then happy Spain. At that period manufactures flourished in many of her cities, and the ocean was covered with her fleets. Then Spain was a great nation, but this prosperity was not destined to be of long duration. In the $16 \mathrm{th}$ century she attained the zenith of her glory, but with it her sun set, and in the following century Spain sank into deep darkness. By the bigotry of the king and nobles, and the grasping character of the clergy, with which that fine country has long swarmed, a deathlike stupor came over the people, and trade sank to the lowest ebb. Spaniards, stung with shame, have abstained from writing the history of the ruin which befel their country at the close of the 17 th century.

With the expulsion of the Moriscoes manufactures were nearly extinguished. In the 16 th century Seville possessed upwards of 16,000 looms, which gave employment to 130,000 persons. When Philip V., ascended the throne in 1664 , the number had dwindled down to 300 looms. Toledo in 1550 had upwards of fifty woollen factories, and in 1665 only thirteen, almost the whole trade having been carried away by the Moors, who established it at Tunis. Owing to the same cause, the art of manufacturing silk, for which Toledo had been celebrated, was entirely lost, and nearly 40,000 persons who depended on it were deprived of their means of support. Other branches of industry shared the same fate. The manufacture of gloves, which in the 16 th and early in the 17th century existed in every city, and of which enormous quantities were made and exported to England, France, and the Indies, had in 1655 quite disappeared. In 1550 the navy numbered 140 galleys, and in 1656 it was reduced to three wretched galliots, which were with difficulty manned. In 1752 the Government determined to restore the navy, but to do this they were obliged to send to England for shipwrights, and they had to get persons from the same place to make ropes for their rigging and canvas for their sails.

Early in the 18th century a woollen manufactory was established by Government at Segovia, which had once been a prosperous manufacturing city, but the most common processes 
had been forgotten, and workmen had to be imported from Holland to teach the Spaniards how to make up the wool, an art for which in better days, they had been especially famous. In 1757 the Government constructed a similar work on a larger scale at Guadalaxara in New Castile. Soon after something went wrong with the machinery, and it was necessary to send to England for a workman to put it right, as the Spaniards neither knew nor cared anything about these matters.

In 1767 the Spanish Government became more alive to the importance of trade and commerce. The leading men in the Government then, and for some time previous, had been foreigners, and that year the Government expelled the Jesuits, curbed the power of the priests, and let the people breathe, which they could hardly be said to have done while the Inquisition reigned in all its terrors. Trade, commerce, and manufactures started into existence as it were by magic, and the foundation of a prosperity was laid such as had not been known since the Moors were expelled from Granada. Charles III. was conciliating the Spanish colonies while George III. was fomenting rebellion in those of Britain. In 1765 he conceded free trade to his West India Islands, and a few years afterwards he granted the same boon to the American continent. These wise grants gave an immense impetus to the prosperity of the magnificent colonies of Spain, to the vast benefit of the mother country. Such enlightened policy had a rich reward. The export of foreign commodities was soon tripled, the export of home produce was increased five-fold, and the returns from America, nine-fold.

Spain is a territory so fair and fertile, that the Moors called it an earthly paradise, but the beauty of its scenery and the fruitfulness of its soil have oft been blasted with a curse. In 1788 Charles IV. succeeded to the throne. He was a king of the true Spanish breed, devout, orthodox, and ignorant; and with him came intolerance and all its evils. True religion, when exercised in its purity, humanizes and elevates man, and makes him happy in the enjoyment of nature's gifts, and in the God of nature; but when performed in unmeaning forms and ceremonies, by an ignorant and debased priesthood, it brutalizes the mind, and makes man unfit for the duties required of him, either as regards the present or the future state. The Church soon 
became dominant, and, as it rose in power, freedom of thought and action were abrogated ; the people, oppressed, groaned under priestly tyranny, and the Inquisition, that worst instrument of Jesuitical rule, was again set up with all its horrors. Then trade, commerce, and manufactures were extinguished, and the rich and beautiful country of Spain once more became almost a commercial blank in Europe.

The present century has seen a great change in the condition of Spain. The Government now exercises more of its legitimate authority than it previously did. The comntry, although still greatly priest-ridden, is not so completely under the misrule of the hierarchy as it was. The people enjoy more freedom of action than when under bigoted priestly sway, and prosperity has begun once more to over-shadow bright, but ill-governed, and often cruelly persecuted and persecuting Spain.

Within the last quarter of a century the trade of Spain has made good progress, and of late years the manufacture of Linens has been carried on extensively in some of its provinces. This manufacture from imported yarns is of comparatively recent date, but since the revision of the tariff, framed with a view to protect home manufactures, Linen weaving has rapidly increased, and it still promises to do so daily. The great difficulty has been to weave fine linens for shirting, cambric, and the like, but this is now being gradually overcome. The weaving of Linens throughout Spain is principally by hand, but power-looms are now to be sesn in several districts. Labour there is not very plentiful at present, which makes manufacturers more willing to resort to power-looms, and as their capital accumulates these will increase in Spain, as they have done in other countries.

The weaving of all kinds of coarse Linens is carried on to a considerable extent in Seville. Formerly large quantities of British and German Linens were imported, but the native made goods have entirely superseded them, except for the finest class of fabrics. The manufacturers are almost entirely dependent upon the United Kingdom for their supplies of yarn, very little being spun in the country. Cadiz has long imported Linens, besides which it now imports Flax, Hemp, and Linen yarn.

From time immemorial Catalonia has been a Linen manufac- 
turing country, and it still retains its well-merited fame. Its Linens found their way to Rome in the days of the Empire, and perhaps since then the trade has never been wholly extinct. In a politico-commercial poem called the "Libell of English Policie," we learn that in 1437 there were flourishing manufactures of wool, cotton, Linen, and silk, in that province. Catalonia is perhaps the greatest seat of the Linen manufacture in Spain at the present time, and the Catalonians, as well as many other Spaniards, are a Linen-wearing people. Considerable quantities of Flax, Tow, and Jute yarns, chiefly from the United Kingdom, are imported into Barcelona for the Linen manufactures of Catalonia. That city is the first in importance in this branch of business, whether as regards importation or manufacture; and, being the principal producer of fine Linen goods, the value of its importation of yarns is almost one-half of all Spain. The works in that province are, both for spinning and weaving, on an extensive scale, and of late years several powerloom establishments have been erected there. The Flax and Hemp are mostly imported from Genoa and Leghorn, but some of the Northern States of Europe also supply a part of what is spun. Some Linens are also imported into Barcelona, the supply of the goods made in the province being insufficient for the wants of the district.

Bilboa is the seaport next in importance to Barcelona for the importation of linen yarns, although very little is manufactured in the neighbourhood. It is the receiving port for the yarns for nearly all the Linens manufactured in the north of Spain, and it supplies Valladolid, Madrid, Saragossa, and Pampelona, \&c. The importation of Linen yarn into Bilboa for the supply of these districts is on the increase. The manufactures are chiefly of coarse Linens for local purposes. In 1859, the value imported was $£ 136,877$, all from Great Britain, being a considerable increase over the previous year. In 1860, the importation of Linen yarns, a part being from France, but chiefly from Great Britain, was of the value of $£ 158,210$, and of Linens, also from Great Britain and France, $£ 13,437$. In addition to this there was imported from Great Britain, Jute cloth of the value of $£ 47,250$, and Jute yarns of the value of $£ 14,566$. In 1861 the importation included-Linen yarns, $£ 129,708$; Jute yarns, 


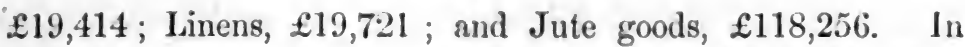
1862 , the imports embraced-Linen yarns, £147,076; Jute yarns, $£ 29,343$; Linens $£ 26,152$. The heavy importation of Jute Linens in 1861 were made prior to, and anticipatory of, the heavy increased duties on this article, which were imposed in August, 1861. The duties were then raised from 50 roubles to 250 roubles per quintal, which may be regarded as prohibitory. After that date the importation of Jute goods into Spain almost ceased. The Jute goods and yarns were almost wholly from Great Britain, the Linens and Linen yarns from Great Britain and France, but chiefly from the former.

Malaga is next in importance to Bilboa, and being the seat of one of the largest power-loom factories yet built in Europe, it consumes an immense quantity, both of Linen and cotton yarns. It is besides the receiving port for Granada, where hand-loom weaving is pretty extensively carried on.

Valencia ranges next in importance. Its consumption of yarns is of the coarser description, to supply home wants and sacks for the guano trade. 'This town is likely to become the centre of the Jute trade for the south of Spain. In 1860, 413 bales of yarn were imported into Valencia, and since then the quantity has largely increased.

There are also Linen manufacturing establishments in other provinces in Spain, two being in Sansebastian, which are on the increase, and one in Corunna. The imports into Sansebastian include Linen and Jute, raw and manufuctured.

The imports into Santander in 1861 embraced-Linen and

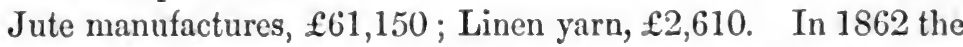

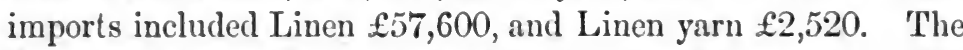
Jute goods were from Great Britain: the Linens from-1st Great Britain; 2d, France; and 3d, Belgium; the quantities from each being in the order stated.

In addition to the yarn imported into Spain a large quantity of Flax and Hemp is grown in the Basque provinces, and in nearly all the other provinces of the country, spun into yarn, and consumed in the native manufactures of the respective districts.

The Spanish colonies, like the mother country, are large consumers of Linen, and they are excellent customers of ours. In the Consular report from Havana for 1858 it is said that the 
Linens of the United Kingdom have deservedly superseded those of Germany in a great measure, and the coarse descriptions those of Russia.

The following is an account of the imports and exports of Linen manufactures and Linen yarns into and from Spain for the years from 1857 to 1860 inclusive :-

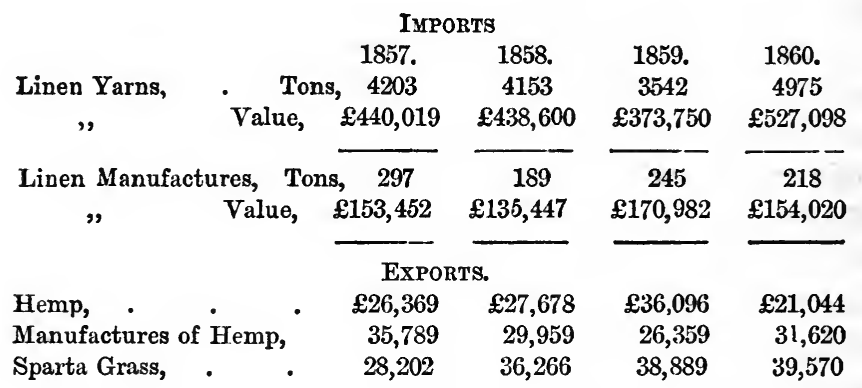

In 1826 there were no exports of any of these articles, and the imports for that year consisted of-

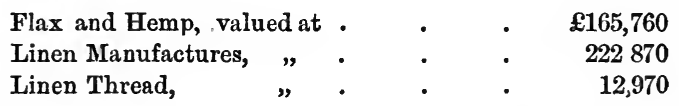

It would thus appear that the character of the trade has greatly changed since that period. Then little or no yarn was imported, but in $\mathbf{1 8 6 0}$ the quantity had risen to more than half-a-million sterling in value, and since that year, as will be seen by the tables of Exports from the United Kingdom, the quantity sent from this country alone very greatly exceeds that value.

\section{CHAPTER III.}

G E R M A N L I N E N .

THE manufactures of Germany are of ancient standing. Already in the 6th century several towns had sprung up in Germany, 
which were soon after to become famous for their manufactures and trade. The introduction of Christianity was highly instrumental in advancing the commerce of the country. By the beginning of the 9 th century a little progress had been made in general trade, and by the 11th century, Flanders and Brabant, and several German cities, had become important for their manufactures of Linen.

It is reported, on the authority of Helinoldus, that in the beginning of the 12th century (about 1109), Linen cloth was used as money in exchange for all other things in the Isle of Rugen, on the coast of Pomerania.

Early in the 14th century the Emperors began to infranchise certain German towns; whereupon these cities found it necessary to enter into a confederacy to defend themselves against their feudal lords. This union gave security to traders, and assisted greatly in the extension of manufactures in and around these cities, as well as throughout Germany.

The Linen trade is not only one of the oldest, but it is also one of the most important branches of industry in Germany. It gives employment to an immense nnmber of the inhabitants, and a vast capital is embarked in it. Many of the articles made in the United Kingdom were at first imitations of German Linens, and some of them are still familiarly known by their German names, or by the district in Germany where they were manufactured. Dowlas, Tecklenburgs, Creas, Platillas, Bretagnes, Silesias, Osnaburgs, \&c., \&c., have all a German origin, and most of these fabrics are still made there.

Some of the provinces of Prussia proper are integral parts of Germany, and its detached provinces are also German, the progress and present state of the Linen trade of Prussia will therefore be included in this chapter, as it will save repetitions which would otherwise be necessary.

Prussia has been a Linen producing country from a very early period. In 1450 she exported Flax, thread of Cologne, and canvas, principally to Flanders, which was then the great emporium of trade. The Italians, Hanse merchants, and Flemings, did the chief of business at that period.

The Linens of Silesia and Saxony have been long celebrated for their fine and durable qualities. Westphalia, Würtemberg, 
and several other of the sub-divisions of that great country have also been long deservedly famous for their Linen manufactures.

In 1764 Brandenburg had manufactures of canvas. Frankfort on the Oder had a tolerable Linen trade. Saxony had manufactures of fine and coarse Linen and ticking canvas, and made large quantities of thread. The persecution of the Protestants in Bohemia and Silesia forced great numbers to withdraw and settle in Upper Lusatia, where they introduced the Linen manufacture, particularly table Linen and tickings. Lower Lusatia, Dresden, Leipzic and neighbourhood, Chemnitz, Hamburg, and other places manufactured Linens. Bremen made large quantities of Osnaburgs. Esenbach, Harburg, SaxeLauenburg, Hanover, Hameln, Magdeburg, \&c., all had their Linen manufactures. Munster was much engaged in the Linen trade. Osnaburg or Osnabruck made Linen yarn and thread, and manufactured Osnaburgs to the value of upwards of a million of rix-dollars annually. Hamm was famous for its Linen bleacheries. Glatz had thread and Linen manufactures. Silesia manufactured twine and Linen of various kinds very extensively, including linen printing canvas, buckram, and damask, and exported these goods largely, particularly to England. Indeed nearly all the places named exported their manufactures to some extent, in addition to supplying the home demand. In 1755 there were 248 Linen looms in Berlin. In 1764 Hemp and Flax and their seeds, and also Linens and thread were exported from Prussia, and from Dantzic Hemp, Flax, and Linens.

Oddy, in his work on European commerce (1805), mentions that the produce exported from Prussia consisted of Flax, Hemp, \&c., chiefly from Memel and Konigsberg ; Linens from Silesia, either by the Elbe, or from Stettin. The value of Linen manufactures exported from Prussia, in 1799 was about $\mathfrak{E 2}, 000,000$, being fully a fourth part of all the exports from that country. Between that year and 1805 the Linen manufacture had increased to a surprising degree. This branch of manufacture was at that time the most important trade of the country, and Silesia had then gained a great reputation in the world for the durability and general excellence of its Linens. He goes on to say " that they are as good, or of better quality in Ireland, is certain; but they at one time were not equally considerate in 
the bleaching part. 'The chemical process for bleaching, once introduced into that kingdom, was wisely done away; while the gentle process in Silesia has been invariably used. Their cloth is generally three or four months in bleaching, and the lyes made very mild and moderately used. Experience has shown the reputation Silesian Linen has obtained in South and North America and the West Indies, but the Irish Linen must shortly command a preference to any other, as great care and attention is now paid to it.

"France, the United Provinces, and Switzerland, formerly carried on a very great trade in the Linen manufacture, but at present Silesia, Bohemia, Westphalia, Suabia, the Lausitz, and the countries belonging to the House of Brunswick, excel particularly in their Linen manufacture, the produce of which is exported to almost every part of the world. The greater part of the Silesian Linen goes through Higher Saxony and Luneburg, to Hamburg. It is likewise conveyed down the Oder, and from thence by means of canals which connect it with the Elbe. The Hamburg, merchants export it in great quantities to Spain, Portugal, England, and the United States of America.

"The striped and the checked sort of Silesian Linen, the stripes of which are formed of Turkey red yarn, are mostly exported to Italy on account of their fine quality, and are used for curtains, bed-ticks, \&c.

"The yarn of which the Silesian Linen is made is spun by means of the spindle, which makes it look like cotton, and requires less time to bleach than any other. The Silesian Linen of different manufactures is all of the same quality, and there is no other distinction in it than in the width and length of the pieces. The merchants of Hamburg, who are in that line, go twice a year to Silesia to make purchases. Dutch and Italians also go there to buy, and even the English, who generally buy lawns, dowlas, checked, and book Linen.

"In 1740 the export of Linen from Silesia amounted to only

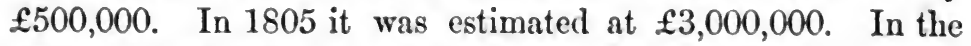
Prussian part of Silesia in 1792-3 there were 24,761 looms, em-

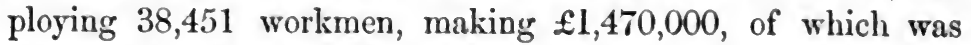
exported $£ 1,040,000$. The previous year the whole production

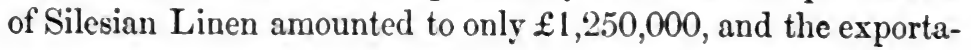


tion to $£ 810,000$, of which about nine-tenths consisted of bleached Linens, the remainder being unbleached, bleached and unbleached yarn, thread, unbleached linen ticks, damasks, handkerchiefs, \&c.

"To the value of the above exportation, made in 1791-2, is still to be added that of the following sorts:-Creas, Platillas, Bretagnes, Lawn, and the fine checked Linen.

"The Silesian Linen trade is the most important in the German Empire. The chief places of its manufacture are Hirschberg, Landshut, Schmiedeburg, Greiffenburg, Waldenburg, and Schweidnitz.

"Hirschberg is the first and most important trading city in Silesia, and is the seat of the lawn manufacture. So early as 1786 the exports amounted to $£ 254,000$. The raw long lawns; or what are now called double Silesias, are frequently sent to Haarlem, to be bleached for England. The patterns of the coloured lawns are sometimes mixed with red, blue, and green flowers. Other descriptions of lawns are made for the Italian market, and also still a different sort called cobweb lawns, probably from the fineness of their texture. The other towns mentioned manufactured Linens more or less extensively, and some of them made fabrics peculiar to themselves, such as ticks, damasks, checks and stripes, \&c.

"The manufacture of flowered damask and ticken had been brought to great perfection in Silesia and Lausitz. It was made in three different modes, plain, marbled, and white flowered, and consisted of table cloths, napkins, towels, \&c. The manufactures of Lausitz were chiefly exported to Cadiz, thence they were sent to the South American colonies of Spain. In 1795 the German manufacturers began to send goods to the United States, but the wars of this period frequently changed the nature of the trade, and caused great fluctuations in it."

In 1840 the value of the Linen manufactured in Silesia was estimated at $£ 1,230,000$. The principal localities of the Linen manufacture of Prussia at that period were in West Prussia; in Silesia, where it was, until near that date, all spun and woven by hand, the weavers living in small houses in the valleys between the mountains, but machinery for spinning had then been recently introduced; at Tecklenburg, and at Bielefeld in West- 
phalia ; and in some other places in the Rhenish provinces which were famed for Linen of fine and white quality. The annual consumption of Linen in Prussia was then estimated at nine or ten ells, or between seven and eight English yards to each individual. Bavaria grew about 15,000 or 20,000 tons of Flax annually, and she manufactured Linen for domestic use, which was all spun and woven by hand, but exported little. Würtemburg, in addition to the home supply, made some Linens and damasks of an ordinary description for export. Thuringia made them chiefly for domestic use. In Hesse-Cassel and Hesse-Darmstadt Linens were very generally inanufactured. Saxony was once famed for Linen fabrics, both for home use and for export, but although the trade had declined in 1840, the goods produced there were still of deserved repute. The Hanse Towns, Lubeck, Hamburg, and Bremen each manufactured small quantities of canvas, but they have long been rather commercial than manufacturing cities.

In Hanover, Flax was a most important article, as the cultivation and manufacture of it gave employment to nearly onehalf of the inhabitants. It was chiefly grown in the southern parts of the kingdom, and the quality was generally of a very good description, and well adapted for spinning. At the end of the serenteenth century, the Linen trade there was at its greatest height, but towards the middle of the eighthteenth century it fell off, as the Scotch and Irish Linens drove Hanoverian goods from the West Indies. During the American war it flourished again, but, in 1806, Napoleon's continental system nearly annihilated it. After the peace the trade again assumed a national importance, but it has never reached its former very prosperous condition. In 1843 the value of Linen and Linen yarn exported from Hanover was $£ 300,000$. Some Hemp was grown in Hanover, but it was not of very superior quality. The Osnabruck hempen Linen, known as Tecklenburgs, was bleached in the yarn, and it took a good colour. The quality of the Linen made in Hanover has considerably improved of late years, and as improvement progresses the trade may extend.

Mr Petrie, in his report, dated Hanover, July, 1863, says :"The total value of the Linen manufactures of Hanover (exclusiveof the export of Flax and Hempen yarns), in so far as they ap- 
pear in the returns for 1861, amounted to 1,748,080 dollars, about $£ 262,212$. The returns of the Linen industry of Hanover are only partial, as they record merely what is brought to the Government Linnen Leggen, which are offices where they are measured, stamped, and valued, for the purpose of facilitating their sale, but it is very likely that a cousiderable quantity is sold without passing through these marts. The returns for 1861 show an increase of 5624 pieces, measuring 612,553 ells of Linen cloth, value 98,310 dollars, upon 1860 . The three previous years there had been a constant and considerable diminution. The chief seats of the Linen industry in Hanover, are Osnabruck, Hildesheim, Luneburg, and Hamburg, and the greater part of it is carried on by hand-loom weaving, and gives employment to the rural population during the winter. The produce was formerly bought up for export to North and South America and the West Indies, but they now find their way to other states of the Zolverein, where their excellent and durable qualities procure them a ready sale."

Return of the quantities and value of Linen cloths taken to the Hanoverian Linnen Leggen :-

\begin{tabular}{|c|c|c|c|c|c|c|}
\hline 1857 & Pieces & 220,881 & Ells & $17,371,668$ & Value, Dollars & $1,684,849$ \\
\hline 1858 & $"$ & 197,396 & $"$ & $15,629,934$ & " & $1,505,375$ \\
\hline 1859 & ", & 183,232 & $"$ & $14,660,177$ & , & $1,409,210$ \\
\hline 1860 & , & 174,382 & " & $13,797,457$ & " & $1,321,113$ \\
\hline 1861 & , & 180,006 & , & $14,410,010$ & , & $1,419,443$ \\
\hline
\end{tabular}

Flax and Hempen yarns exported from Hanover and Hildesheim :-

$\begin{array}{lrrrr}1857 & \text { Bundles of } 37,500 \text { yards, } & 108,142 & \text { Value, Dollars } & 200,452 \\ 1858 & " & 98,276 & " & 194,666 \\ 1859 & " & 83,785 & " & 172,343 \\ 1860 & ", & 71,505 & " & 129,575 \\ 1861 & " & 68,491 & , & 123,152\end{array}$

Mr Corbet, in his report, dated Frankfort, 31st December, 1862, says:- "Excellent results are said to be attributed to the establishment of a school for weavers in the district of Lauterbach. The disproportionate import-duty of two rix-dollars charged on Jute yarn, and of twenty silver groschens on Jute 
weft, has exercised the unfavourable interest upon both the spinning and weaving interests which was to be expected; and its effect was especially felt in the district, where the demand for sackcloth is large, caused by the export of corn to France in 1861. There are numerous Linen manufacturing establishments in the districts of Upper Hesse."

$\mathrm{Mr}$ Baillie, in his report, dated Stuttgardt, 31st January, 1863, says:- "The Linen market has for a time benefitted by the high price of cotton, and the production of 1861 considerably surpassed that of 1860 . This manufacture, which had been abandoned of late years in some places, has now been resumed, and is likely to attain a still farther extension in Würtemberg, if not interrupted by political disturbances, and if peace is preserved. An establishment has lately been erected in Laichingen by a Stuttgardt house, in which about sixty looms for fine Linen and damask are now worked. Flax turned out well in most districts. The cultivation of Flax is advancing in Würtemberg, and derives additional stimulus from the circumstances which now affect the cotton industry. The attention of agriculturists has latterly been specially drawn to the necessity of a change in the system hitherto adopted for the production of Flax, before its cultivation can be extended and rendered remunerative. The Flax plant, when first gathered, contains an average of 12 to 15 per cent. of pure Flax capable of serving as raw material for spinning purposes, and, consequently, until the Flax has been prepared by the separation of its worthless parts, it is not current article of trade, and possesses no fixed market price, such as corn, \&c. This is a great inconvenience to many farmers in every Flax growing country ; aud, to obviate it, establishments have been started for purchasing the straw from the farmers after harvest, preparing the fibre, and selling the Flax in a marketable state to the consumer. Such an establishment has been started at Würtemberg, and it is expected that it will lead to a large increase to the growth of Flax, and be highly beneficial to all concerned," \&c.

In classification of the abundance and quality of the produce of the land in Bavaria, where 1 stands for super-excellent; 2, excellent; 3 , good or abundant ; 4, middling; and 5 , bad;-Flax and Hemp in 1862 stood thus: quality, 
2.34 ; quantity, 2.90, which ranges between excellent and abundant.

The following are the number of looms employed in the manufacture of Linen in Prussia in the years named :-

\begin{tabular}{|c|c|c|c|c|}
\hline $\begin{array}{l}\text { In 1822- Constantly Employed, } \\
\text { Employed part of the Year, }\end{array}$ & auxiliar & $\dot{y} t$ & arming, & $\begin{array}{r}33,169 \\
186,611\end{array}$ \\
\hline & Total, & & - & 219,780 \\
\hline In 1831-ConstantIy Employed, & - & - & - & 35,668 \\
\hline Auxiliary to Farming, & - & . & - & 216,780 \\
\hline & Total, & - & - & 252,448 \\
\hline In 1834-Constantly Employed, & - & - & . & 36,879 \\
\hline Ausiliary to Farming, & - & $\cdot$ & - & 220,343 \\
\hline & Total, & · & - & 257,222 \\
\hline In 1838-Constantly Employed, & • & 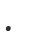 & • & 35,877 \\
\hline Auxiliary to Farming, & - & - & - & 246,294 \\
\hline & Total, & - & - & 283,171 \\
\hline
\end{tabular}

Of the whole number of looms, in 1838, 256,772 were in the valleys and villages of the country, and the remainder in the towns. In 1832, Linen yarns to the extent of 1700 tons, and in 1834 to the extent of nearly 2000 tons, were exported from Silesia, chiefly to Bohemia, where they were woven into Linens, and reimported in a brown state, to be bleached by the Silesian bleachers.

The following statistics of the Linen trade in Prussia refer to the year 1849 :-

Flax-Spinning Mills,.........11, with 38,729 spindles-2634 hands employed.

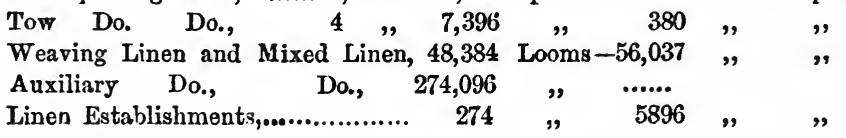

The average value of Flax and Hemp, \&c., annually exported from Memel prior to the Crimean war was about $£ 200,000$.

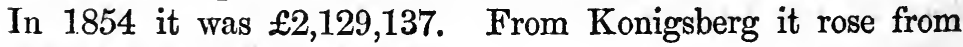

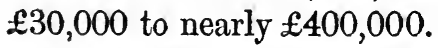

In 1850 there were in Prussia 38,254 first-class looms, and 
259,925 second-class looms, being considerably fewer than in 1849. In 1850 there were in Saxony 480 mills and manufactories, of which 35 were large, and 445 small.

Mr Campbell, on the trade of Memel for 1862, says:- "The business done in Flax was of a very fluctuating nature. 'Towards the end of May large arrivals came in from Russia and Poland, which overstocked the market. A lively demand sprang up in the English markets, and towards October stocks were cleared off. 4000 tons were exported during the year." "It is worthy of remark that the Flax which reached our market was the produce of the Russian provinces which lie immediately in our vicinity. Our merchants used their best endeavours to obtain parcels of the fine Wilna Flax, which formerly found its way to Memel, but they were unable to procure it, the Eydlkuhu railway having conveyed it to Konigsberg during the months our market was inaccessible."

Consul Huslet in his report on the trade of Konigsberg for 1861, says:- "The quantity of the Flax crop of 1860 was below an average, and the quality but second rate. The import from Russia was-in 1860, 4294 tons, and in 1861,4156 tons. The export by river and sea was insignificant, but that by railway to Germany was very important. Prices of Oberland crown Flax began with $£ 43$ per ton, rose to $£ 44$, and went down again to $£ 43$ 10s. The Russian crown sorts were quoted at $£ 44$ to $£ 49$ according to quality, but sank in autumn to $\mathfrak{E 4 3}$ to $£ 46$. The demand was languid in general; it was most lively from the beginning of August to the middle of September. The business in Linen is declining more and more, and no export worth mentioning." The consul, in his report of the trade at Konigsberg for 1862 , says that the "Linen manufacture in the province of Prussia is rapidly decreasing, and prices are almost too high for exportation."

In 1859, the Linen manufactures of Bielefeld in Rhine Prussia, were in a very flourishing condition, and extending greatly.

The following particulars are extracted from the report of $\mathrm{Mr}$ Lowther, Secretary of Legation at Berlin, dated 20th Jan., 1863: - "The export of Linen from Landesheet was unfavourable in 1861, owing to the American war, and the bad state of the money market in Havana. The trade with Hamburg was s 2 
small, but it was better with Leipzic and Saxony. Large quantities of diaper were sent to Denmark, and also strong raw Linen. In 1861 the number of weaving chairs at work on raw Linen were 1628 , on dowlas $1478 ; 563$ weavers worked on their own account on raw Linen, and 63 on dowlas; and for wages, on raw Linen, 774, and on dowlas, 1171. Male and female assistants on raw Linen; weavers, 622 , winders, 813 ; on dowlas, 727 weavers and 848 winders. The number of wefts and pieces of raw Linen, 93,663, and dowlas, 57,297.

"Erfurt contains factories for Linen goods, and bleachfields. Linen is only made in small quantities in Munster, and little is now exported to Holland. In Görlitz the manufacture of Linen did not diminish in 1861, and, notwithstanding the increased price of yarn, there was no want of employment.

"In Breslau the American war had a depressing effect upon the Linen trade. Silesia takes a large amount of Russian Hemp, and small quantities from Hungary. Little business is done in Flax. The Linen trade of Silesia was fully employed, and the goods found a ready sale, but the prices were low, and the quality of the Flax was not remarkably good.

"Bielefeld, Halle, and Wiedenbrück. - The Chamber of Commerce states that in 1861 as in 1860 the Linen trade had not a proper impetus. ' Flax suffered from the wet spring of 1861, but not so much as in other parts of Germany, Belgium, and Holland, and the prices were good for the seller. 'Tow and Hemp were plentiful. There was not much done in the spinneries, hand spinning being very much on the decrease. One spinnery in Bielefeld contains 8400 spindles, and occupied 600 people, and sold 17,392 centners (930 tons) of Flax and Tow. A spinnery in Rnavensberg set up 3000 spindles, in addition to the 16,000 , but could not make use of them in consequence of the want of work people. It employed about 1100 operatives, consumed 15,850 centners (850 tons) of F'lax, 22,850 centners (1220 tons) of Tow, and produced about 360,252 bundles of yarn. The Schönfeld spinnery employed 3000 spindles, and consumed 12,000 centners (650 tons) of Flax and 'Tow.' Of foreign machine yarn there were imported, according to the Westphalian Custom House Report, in 1861, 2911 centners ; in 1860, 3114 centners; and in 1859, 5329 centners. String-making 
suffered from the American war. There was but little difference in the Linen trade of 1861 as compared with 1860 ; it feels the want of a proper impulse from Russia. According to official lists, there were manufactured of Linen cloth and diaper-at Bielefeld, 35,618 pieces, and 31,103 in 1860 ; at Hereford, 5099 pieces, and 4495 in 1860 . 'Total 40,717 pieces in 1861 , and 35,598 in 1860 . About 500 persons are employed in the Herford district in the mixed Linen trade, which suffered from the high price of twist.

"Cologne.-The Flax harvest having been good the Linen trade was active, but on the whole the Linen trade has diminished within the last fifteen years one-third."

The exports of Flax and codilla from Prussia were as follows, viz :-

\begin{tabular}{|c|c|c|c|c|c|}
\hline \multirow[b]{2}{*}{ In } & \multirow[b]{2}{*}{1835} & \multicolumn{2}{|c|}{ Flax. } & \multicolumn{2}{|c|}{ Codilla. } \\
\hline & & Tons, & 3,595 & Tous, & 326 \\
\hline & 1840 & , & 4,920 & , & 1,400 \\
\hline & 1845 & , & 8,398 & 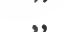 & 1,042 \\
\hline & 1850 & , & 11,236 & , & 1,022 \\
\hline & 1851 & , & 5,222 & , & 1,097 \\
\hline & 1852 & ," & 9,289 & , & 884 \\
\hline & 1853 & " & 11,781 & , & 1,028 \\
\hline & 1854 & ," & 33,386 & ," & 1,829 \\
\hline & 1855 & ," & 54,080 & , & 1,525 \\
\hline
\end{tabular}

The great increase during 1854 and 1855 was due to the Crimean war. The Russians could not export their produce from any of their own seaport towns, because their ports were all blockaded; but Prussia, who selfishly stood neutral during that war, taking advantage of her geographical position and her apparent neutrality, profited largely by the transit of Russian produce through the country, and its shipment at her ports. With the termination of the war the commerce of Russia again reverted to its old channels, and her produce was shipped from her own ports. Since then the average exports of Flax and Codilla from Prussia have ranged from 10,000 to 12,000 tons, a great part of which, however, is still grown in Russian provinces adjoining to Prussia.

In Prussia, the employment of children in textile factories is subject to the provisions of a law of the 9th March 1839, and of another of 16th May 1853. The labour of children under 
twelve years of age is prohibited, and when that age has been attained they must produce, prior to employment, satisfactory evidence of school attendance and acquirement. From twelve to fourteen they must not work more than six hours daily, and they must attend school for other three hours.

The statistics of Prussia, with regard to commerce are not given separately, but are included in the Zollverein calculation.

Imports for Constiption, Exports and Transit Trade of the Gebmanic UnION.

\begin{tabular}{rrrrrr}
\multicolumn{2}{c}{ Imports. } & \multicolumn{2}{c}{ Exports. } & \multicolumn{2}{c}{ Transit. } \\
1834. & 1840. & -1834. & 1840. & 1834. & 1840. \\
34,108 & 40,506 & 25,429 & 29,567 & 226 & 920 \\
7,976 & 6,671 & 6,348 & 2,140 & 1,282 & 578 \\
6,265 & 17,847 & 31,978 & 44,976 & 5,716 & 221 \\
5,619 & 39,571 & 15,059 & 14,257 & 4,172 & 402
\end{tabular}

Bleached, Dyed and Print. ed Ticking, including Damasks, Towelling,

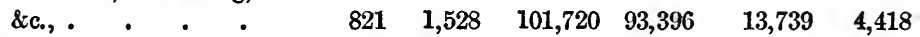
Flax, Hemp, and Tow, Cwts. 168,441 234,357 $\quad 126,629$ 162,009 $\quad 7,808 \quad 1,895$

The imports and exports of the Zollverein for the years 1850 and 1853 were as follows:-

\begin{tabular}{|c|c|c|c|c|}
\hline \multirow{2}{*}{ IMPORTS. } & \multicolumn{2}{|c|}{1850.} & \multicolumn{2}{|c|}{1853.} \\
\hline & Tons. & $£$ & Tons. & $£$ \\
\hline $\begin{array}{l}\text { Flax, Hemp, \&c. : } \\
\text { Linen Yarn, } \\
\text { Linens, }\end{array}$ & $\begin{array}{r}13,500 \\
3,350 \\
1,610\end{array}$ & $\begin{array}{l}815,750 \\
427,750 \\
358,390\end{array}$ & $\begin{array}{r}14,700 \\
5,340 \\
1,750\end{array}$ & $\begin{array}{l}\mathbf{5 7 6 , 7 4 0} \\
\mathbf{5 8 5 , 9 9 0} \\
442,220\end{array}$ \\
\hline ExpoRTs. & & & & \\
\hline $\begin{array}{l}\text { Flax, Hemp, \&c. } \\
\text { Linen Yarn -hand spun, } \\
\text { Do. mill spun, } \\
\text { Linens, . . }\end{array}$ & $\begin{array}{r}13,900 \\
6,600 \\
4,300 \\
5,700\end{array}$ & $\begin{array}{r}835,520 \\
70,000 \\
52,100 \\
2,222,100\end{array}$ & $\begin{array}{r}13,700 \\
2,900 \\
3,900 \\
6,100\end{array}$ & $\begin{array}{r}534,410 \\
44,200 \\
59,500 \\
2,264,400\end{array}$ \\
\hline
\end{tabular}

In 1859, the imports into the Zollverein of Flax, Hemp, \&c., amounted to 14,040 tons, and the export of same articles to 7480 tons. 
The quantity of Flax and Hemp imported into the Zollverein in 1861 was 343,969 centners (about 18,430 tons), and exported 269,750 centners ( 14,450 tons.)

Some farther details regarding the imports and exports of Linen manufactures from and to the United Kingdom and Germany will be found in the statistical tables given in various parts of this volume. They do not, however, shew the full extent of the trade with Germany, as many of the yarns and Linens destined for that great country go through Holland, Belgium, \&c., and are included in the exports to these countries.

Notwithstanding the large extent of the German Linen manufacture, and its importance to this country, it might be greatly increased were the absurd fiscal restrictions which trammel and seriously injure the trade removed, or judiciously modified, and the unwise, and in some cases prohibitory duties reduced. Each Petty State has customs regulations, scales of duties, monies, weights, and measures of its own, which mistify and confuse merchants trading with them. The conservative and absolutist views of some of these insignificant States hinder the liberal countries of Germany from assimilating the tariff of the Zollverein to that of other nations, and from making it more in accordance with the free trade principles of the age. A treaty for a new and more liberal tariff with France has been in progress for some time, but it has not yet been fully carried through. The government of this country should not rest until a commercial treaty, mutually advantageous to Germany and to the United Kingdom, is concluded, and the trade thrown open to the people of both countries. Were this done, and care taken to have Linens and Linen yarns, including Jute fabries, admitted at a moderate rate of duty, it would greatly benefit the Linen trade of this country, and be a boon to the people of Germany.

Consul Ward, in his report on the trade of Hamburg for 1861, says:- "The Zollverein expires on 31st December 1865. Prussia will then have her hand free to establish as liberal a customs tariff as she pleases. It remains to be seen whether she will have the courage to risk the dissolution of the Union, and proceed alone, if necessary, in the path of free trade. In Prussia and in all Northern Germany, public opinion sets in favour of the non-renewal of the Zollverein as at present constituted. 
The principle of the decision of a majority is desired to be substituted for that of an unanimity of votes." Were this alteration effected, the carrying of a liberal tariff by the more enlightened of the German States would follow as a certain result.

\section{G E R M A N F A I R S.}

IN Germany most extensive Fairs or markets are held periodically at several places, where merchandize to a great value changes hands. Some of the Fairs in Germany were established more than 1000 years ago, and have been continued ever since. Many goods of almost every description are taken there in stock, but, in addition to these, large transations are entered into for delivery afterwards. Merchants from all parts of Germany, and also from all the neighbouring countries, Russia, France, Britain, \&c., \&c., attend at some of these Fairs. In 1842, about 750 tons of Linen goods, at the average price of 200 thalers per centner, value about $£ 500,000$, were imported for sale at the Easter Fair at Leipzig, about two-thirds of which were disposed of. The total value of all the goods brought to that Fair was

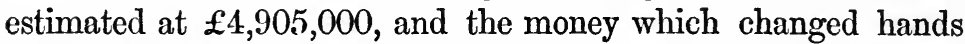
about $3 \frac{1}{4}$ millions sterling, an astonishing amount to turn over during the few days the Fair lasts.

The privileges which from time to time have been granted to the merchants attending those Fairs, and the exemption of the goods exposed for sale from many taxes which are levied on similar goods at other times, have drawn large quantities of merchandize to the Fairs. They have also tended to stimulate commercial enterprise, and to foster a spirit of freedom in Germany and in other countries, and they have helped to spread civilization throughout the world.

The extraordinary extent of business still transacted annually at the Fairs in Germany may be imagined when it is stated that the value of goods, the produce or manufacture of the German Customs-Union, imported for sale at the Easter, Michaelmas, and New Year's Fairs at Leipzig in 1856, was $£ 11,095,272$; 
and of foreign goods, $\mathfrak{f} 4,045,893$; total, $\mathfrak{1 5}, 141,165$. Twothirds of the German, and seventeen-twentieths of the foreign goods were sold. In these amounts are included Linens of German manufacture, of the value of about $\mathfrak{f} 6(0) 0,000$; bleached Linens of British manufacture, the whole of which were sold, of

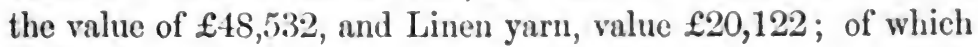
$£ 12,060$ was British manufacture.

In the Fairs at Leipzig for 1858 the sales of Linens were quite up to the average, and British and Irish bleached Linens were then reported to be gaining ground in Germany. British Linen yarn and thread were also in good demand, and a large business was done in them. In 1857 the Linen trade at the Fairs there rose to its maximum, having been about one-sixth more than in 18.56. In 1859 it had fallen about one-third from the point reached in 1857, but in 1860 it improved, the fall that year not being quite one-fourth below the highest point. In 1861 there was a slight improvement upon the previous year. This falling off in the imports into the Fairs did not arise from any diminution in the supply from this country, as the quantity of British made goods was even greater than before. The Germans had shaken public confidence in their manufactures by mixing cotton with their Linens, which limited the sale of their goods. There was a want of confidence in the Russians and Poles, and in some others who usually bought largely at these Fairs, which prevented sales being made on credit in 1860, and this tended to restrict business. The protective system of the German Customs-Union, which checks the importation of foreign Linen Yarn, worked unfavourably for the Linen manufacturers and artizans of Germany, and did injury to the trade at the Fairs. In 1860 , wages was so low as $2 \mathrm{~d}$ to $3 \mathrm{~d}$ for a day's work of sixteen hours, and the condition of the spinners by hand was even worse. In 1861 the home market had somewhat improved, but the export market had rather declined, or more business wotild have been done.

The supply of damasks at the Leipzig Fair of 1861, particnlarly from Gross Schonau, was large, but the business in that article, which is one of luxury, was dull. There was a brisk demand for the ready-male clothes and shirts, which Bielefeld furnishes in large quantities. English Linen of the dearer 
qualities had a fair sale, and Irish goods, notwithstanding the high duties, beat the native articles at the Fairs. In French and Belgium goods there was no business, but a little was done in Dutch Linen. Mill spun yarns were abundant and sold cheap, whilst hand-spun yarn maintained a higher rate.

The quantity of Linens, the manufacture of the States composing the German Customs-Union, brought to the Leipzic Fairs in 1862, was 1470 tons, and the sales were brisk. Of foreign Linen yarns the quantity at the Fairs was 110 tons, of which about 65 tons, value $£ 10,095$, were sold. About 70 tons of British bleached Linen, of the value of $£ 32,468$, was brought to the Fairs, and the whole was sold.

\section{H A N S A T IC LEAGUE.}

The Hanseatic League was established in 1169 between Hamburg and Lubeck, and they were shortly after joined by Bremen, and subsequently by other cities. The League was of great service in establishing and consolidating commerce in Germany and the north of Europe, and much of the prosperity of these countries is owing to the commercial enterprise of the Hanse Towns. Their sole aim and object was the cultivation and extension of trade and manufactures, of which Linen formed one of the most important articles, and the strength and energy of the united cities enabled the League to overcome aggression, oppression, and other difficulties which, singly, would have crushed the whole of them.

The cities forming the League were the depots of merchandize from all quarters, and their ships navigated every sea. At one time from seventy to eighty of the cities in Germany were members of the League, which was then powerful enough to defend itself against all aggressors. They planted factories in Tıondon, Bruges, Bergen, and Novgorod, at each of which they carried on a most extensive trade, exchanging the surplus commodities of one country for those of the others, and vice versa. Through their instrumentality and fostering care the dense forests of Sweden, 
Poland, \&c., gave place to smiling fields of corn, Flax, and Hemp; and the inhabitunts exchanged their dresses of skin for woven fabrics of Linen and wool.

For many centuries the League played an important part in the commerce of Europe, and for a time ruled its destinies; but by the progress of events, political and commercial, it was shorn of its ancient glory, and gradually its sun waned, and set. The Hanse towns now only comprise the three cities which first composed the League, and of these Hamburg alone can now be called a great city. Its trade is yet enormous, chiefly because it is the highway to a great part of Germany and central Europe; and, true to its former instincts, it still does extensively in Linen manufactures. The following is a statement of the imports and exports of Hamburg, in as far as regards the Linen trade, for the years named :-

\begin{tabular}{|c|c|c|c|c|c|}
\hline \multirow[b]{2}{*}{ IMPORTS. } & & \multicolumn{2}{|c|}{1850.} & \multicolumn{2}{|c|}{1855.} \\
\hline & & Tons. & 6 & Tons. & $£$ \\
\hline $\begin{array}{l}\text { Flax, Hemp, \&c., } \\
\text { Linen Yarn, \&c., } \\
\text { Linen, . }\end{array}$ & : & $\begin{array}{l}1,170 \\
2,830 \\
5,400\end{array}$ & $\begin{array}{r}43,400 \\
385,700 \\
800,500\end{array}$ & $\begin{array}{l}2,430 \\
3,540 \\
4,800\end{array}$ & $\begin{array}{r}87,200 \\
535,100 \\
754,900\end{array}$ \\
\hline Exponts & & & & & \\
\hline $\begin{array}{l}\text { Flax, Hemp, \&c. } \\
\text { Linen Yarn, } \\
\text { Linens, }\end{array}$ & : & $\begin{array}{l}1,030 \\
2,450 \\
3,310\end{array}$ & $\begin{array}{r}39,160 \\
353,400 \\
667,400\end{array}$ & $\begin{array}{l}1,880 \\
3,440 \\
3,830\end{array}$ & $\begin{array}{r}56,1: 30 \\
536,40) \\
670,0(0\end{array}$ \\
\hline
\end{tabular}

Of the Linen yarn imported into Hamburg in 18.50 , five-sixths was from Great Britain, and one-sixth from Altona. In 1855 about three-fourths the quantity was from Great Britain, and nearly one-fourth from Altona, Of the Linens imported nearly one-half is by the Berlin Railway, one-fifth from Great Britain, one-sixth from Harburg, and the balance from other countries. Of the yarn exported from Hamburg fully two-thirds goes by the Berlin Railway, nearly one-fourth to Altona, and the balance to other countries. Of the Linens exported in 1855 fully 22 per cent went to Cuba, 16 per cent. to Altona, 8 졸 per cent. to St Thomas and Porto Rico, 8 per cent. by the Keil Railway, $6 \frac{1}{2}$ per cent. to Venezuela, $6 \frac{1}{2}$ per cent. by the Berlin Railway, fully $4 \frac{1}{2}$ per cent. to Norway, nearly $4 \frac{1}{2}$ per cent. to Brazil, fully 
4 per cent. to the west coast of South America, and the balance to various other countries. In 1859 the Linens imported amounted to 5725 tons, of the value of $£ 916,759$. In 1860 the imports from the United Kingdom of Linen yarn and thread were 3820 tons, value $£ 522,700$, and Linen and Linen manufactures, value $£ 377,400$. The exports cannot be ascertained, because, since the export duty was abolished, no accounts, official or otherwise, have been kept, but they are supposed to bear the usual proportion to the imports, which are steadily on the increase.

The following reports, written from inspection, on the yarns and Linens from Germany shown in the International Exhibition of 1862 , give some idea of the state of excellence to which the manufacture has attained in that country.

"Hanover exhibits a small but very good assortment of Flax, yarns, and Linens. The Flax is in various stages of preparation, strong, of very fine fibre, and really excellent quality. The yarns comprise both Flax and tow qualities, and are very uniform and well spun. The Linens are of various qualities, brown and bleached, comprising sheetings, shirtings, damasks, \&c. They are well manufactured, highly bleached, the damasks of pretty designs, and all nicely finished and tastefully done up."

"Prussia takes a high rank among Linen producers, and makes an excellent appearance in the Exhibition. Numerous specimens of Flax are shown from different districts of that kingdom. It is well cleaned and heckled, and some of it of very fine quality. The yarns are shown in the green and bleached states, and spun from both Flax and Tow. Many of the samples are admirably spun, and well bleached. Of Linens there is an excellent display. Flax-sailcloth is shown in two or three qualities by different manufacturers. The quality is generally very good, and some of the specimens are highly superior, being made of excellent material, the yarn level and well boiled, and the cloth firmly and carefully manufactured. Sheetings, shirtings, ducks, diapers, damasks, and other Linens, in considerable variety, are exhibited. Some of them are in the rough or loom state, and others are bleached and finished. While some of the specimens 
do not possess great merit, others are of first-rate excellence, and not in any respect behind the same class of goods made in this country. Some of the damasks are of splendid designs, and the bleaching is remarkably good and clear. There are some very pretty specimens of indigo-dyed, and also of printed Linens. Many of the goods are highly finished, and got up with good taste. 'The display is altogether very creditable to Prussia, as it is really very excellent."

"Saxony has a small display of Linens, comprising sailcloth of very good quality; twilled sacking for railway covers, \&c., which are well and carefully made; dowlas, bleached, striped, and checked, made up as creas, lestados, \&c., and also sheetings, of beautiful colour and finish; and diapers and damasks of pretty patterns and designs, and of high colour and excellent quality."

\section{CHAPTER IV.}

\section{A U S T R I A N L I N E N.}

Austria has been long famous for its Linens, but it has never exported either yarn or Linens largely, the manufacture hitherto having to a great extent been confined to the supply of its local consumption. The high duties charged on the importation of these articles from other countries have been almost prohibitory, and comparatively few foreign Linens have found their way thither. Both the exports and imports of Linens have therefore been almost at zero hitherto The quantity of Linen yarn imported is also much smaller than might have been expected, considering the extent of the population of the country, and that many of them are a Linen wearing people. Details of the imports and exports are given below.

Austrian Flanders was among the first countries which, after the dark ages, began the manufacture of Linens in Western Europe Austrian Hainault and Brabant were also famous for 
their Linen manufactures at an early period, the city of Louvain alone having, in the 14th century, employed 150,000 weavers in its Linen and woollen manufactures. These countries are not now numbered among the dominions of Austria. In 1764, Vienna exported Linens, probably by the Danube and also through Trieste. Among the exports from the latter port in the present time are enumerated Hemp, Linen manufactures, and Linen bags.

Hemp is grown largely, and of good quality, in Hungary, Transylvania, \&c. Flax is cultivated largely in many districts of Austria, and in some of them to a very great extent.

The quantity of Flax and Hemp grown in the Austrian Empire in 1854 was 146,090 tons ; in $1859,147,840$ tons, and it is computed that the quantity has since increased to about 150,000 tons. The quantity of linseed and hempseed raised in 1854 was $5,372,680$ bushels ; and in 1859, 3,886,200 bushels.

Mr Fane, Her Majesty's Secretary of the Embassy at Vienna, in his report, dated 31st December 1862, says :- " A great part of the manufacturing industry of Austria has been created by artificial means, and is only maintained by high protective duties, and thus the community pay heavily for the benefit of the limited class of manufacturers."

It would thus appear that the Linen manufacture of Austria is not in a healthy position. The Government desires that Austria should be dependent on itself alone for its textile fabrics, and, while governed by such a spirit, neither an export nor an import trade of any extent need be looked for. Such a ductrine may do in an absolute country like Austria, but it is contrary to the spirit of the age, and with people living under such a law great progress is an impossibility, as fair competition only will stimulate to first-rate excellence in any branch of manufacture.

The Linen manufactures of Austria are not confined to any one province of that great empire, but they are established throughout nearly all of them. Kreusberg of Prague says, that in 1835 about 280,000 persons were employed in the Linen manufacture, including those in regular factories, as well as those in farm houses partially employed in husbandry, but probably the number now very considerably exceeds this, as the trade has been on the increase. 
'There are yet few large Linen spinning or weaving establishments by power in the Austrian Empire, but no doubt the manufacturers of that country, as they have hitherto done, will endeavour to keep pace with other nations, and extend with the wants of the trade.

In Austrian Silesia, there are spinning mills at Freudenthal, Engelsberg, and Schönlinde; and the first two places also make excellent Linens. Several towns in Bohemia have spinning-mills and Linen weaving establishments, such as Hohenelbe, Marklow, Gärten, Rumburg, Nachor, Liebenau, \&c. Linens are also made at Liebau, Sternberg, \&c., in Moravia, in Vienna, and in many other places of the Austrian Empire, and, from the great quantity of Flax grown, the total Linen manufactures of the country must be very large, and of the value of more than ten millions sterling per annum. Comparatively few of the Linens made in Austria are exported, their domestic consumption must therefore be enormous. A large proportion of the Linen manufacture of Austria is still carried on in the primitive method common to Scotland last century. The Flax is grown by small farmers, spun on the common hand wheel by their wives and daughters during the winter, and woven in the houses of the peasants, partly by those who follow weaving as a trade, but chiefly by hinds when not engaged in field work.

Linens when imported into Austria, but not including canvas or Linen thread and yarns, have to be entered under special permit, so that the Government may have the power of prohibiting their importation altogether, if so inclined.

Flax and Hemp passing through Austria pay a transit duty of 2 kreutzers (or the 15th part of a shilling) per centner of $123 \frac{1}{3} \mathrm{lb}$. Manufactures of Linen and Hemp, 27 kreutzers $\left(10 \frac{3}{4} \mathrm{~d}\right)$ per centner.

The imports and exports of Flaxen fibres and manufactures in the years 1856 to 1859 inclusive, were as follows:-

\begin{tabular}{|c|c|c|c|c|c|}
\hline \multicolumn{6}{|c|}{ IMPORTS. } \\
\hline $\left.\begin{array}{c}\text { Flax, Hemp, Manilla } \\
\text { Hernp, \&c., }\end{array}\right\}$ & $\begin{array}{l}\text { Tons, } \\
\text { Value, }\end{array}$ & $\begin{array}{c}1856 . \\
11,373 \\
\mathrm{~L} 309,438\end{array}$ & $\begin{array}{c}1857 . \\
10,637 \\
\text { L. } 289,392\end{array}$ & $\begin{array}{c}1858 . \\
10,676 \\
\text { L. } 385,438\end{array}$ & $\begin{array}{c}1859 . \\
9,635 \\
\text { I. } 347,372\end{array}$ \\
\hline Linen Yarn, . . & $\begin{array}{l}\text { Tons, } \\
\text { Value, }\end{array}$ & $\begin{array}{l}2,276 \\
\mathrm{~L} \\
193,339\end{array}$ & $\begin{array}{l}2,241 \\
\text { L. } 190,720\end{array}$ & $\begin{array}{c}2,895 \\
\text { 工 } 259321\end{array}$ & $\begin{array}{c}1,600 \\
\text { L. }_{6} 145,071\end{array}$ \\
\hline $\left.\begin{array}{c}\text { Linen Manufactures, } \\
\text { Lace, \&c., }\end{array}\right\}$ & $\begin{array}{l}\text { Tons, } \\
\text { Value, }\end{array}$ & $\mathrm{L}, 57,425$ & $\begin{array}{c}237 \\
\text { L. } 633,3: 66\end{array}$ & $\begin{array}{l}175 \\
\text { L.51,915 }\end{array}$ & $\begin{array}{c}159 \\
\text { I } 33,966\end{array}$ \\
\hline
\end{tabular}




\section{EXPORTS.}

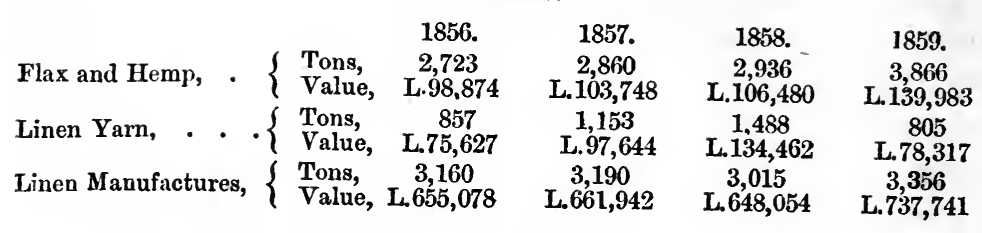

In 1860 and 1861 the imports and exports of yarns and woven fabrics, as given by $\mathrm{Mr}$ Fane, show an increase on the total; but as the report does not give the quantities of each textile fabric separately, it is uncertain what progress may have been made in Linen yarns or Linens.

The quantity and value of the Flax and Hemp, and of the Linen manufactures, conveyed in transit through the Austrian Empire for the same years, were-

\begin{tabular}{|c|c|c|c|c|c|}
\hline Flax and Hemp, & $\begin{array}{l}\text { Tons, } \\
\text { Value, }\end{array}$ & $\begin{array}{c}1856 . \\
8,479 \\
\text { L. } 230,670\end{array}$ & $\begin{array}{c}1857 . \\
7,118 \\
\text { L. } 193,686\end{array}$ & $\begin{array}{c}1858 . \\
7,910 \\
\text { L. } 286,924\end{array}$ & $\begin{array}{c}1859 . \\
7,940 \\
\text { L. } 288,064\end{array}$ \\
\hline Linen Mfanufactures, & $\begin{array}{l}\text { Tons, } \\
\text { Value, }\end{array}$ & $\begin{array}{c}760 \\
\text { L } 551,920\end{array}$ & $\begin{array}{c}761 \\
\text { L. } 552,320\end{array}$ & $\begin{array}{c}429 \\
\text { L. } 311,600\end{array}$ & $\begin{array}{c}256 \\
\text { L. } 186280\end{array}$ \\
\hline
\end{tabular}

In 1850 there were 1500 Flax spinning mills and manufactories in Austria, some of them of large and others of small size, and since then they have been largely increased, both in number and extent.

Some excellent specimens of Austrian Linen were shown in the Great Exhibition of 1862, and the following short report, written after an inspection of the goods, conveys some idea of the attainments of the Linen manufacturers in Austria at that period. From various causes Great Britain has little to fear from the competition of that Empire; still, even the most advanced of the manufacturers of Leeds, Belfast, or Dundee, may learn something from the study of Austrian Linens.

"A considerable quantity of Flax yarn and Linens, spun and manufactured chiefly in Bohemia and Silesia, are shown in the Exhibition. The yarns are exhibited in the natural, bleached, and dyed states. Some of the specimens are admirably spun, and would do no discredit to the mills of Dundee, Leeds, or Belfast. The art of bleaching and dyeing is well known in Bohemia and Silesia, the colours produced being' first-class. The Linens comprise sheetings, fine shirtings, diapers, damasks. 
and various other fabrics. They are manufactured with much care, the cloth being well driven up and uniform throughout, and the selvages neatly formed. Some of the goods are of common quality, and some of them of great fineness. The bleaching and finish of the finer goods are highly commendable, and contrast very favourably with similar goods made in this country. Some beautiful damask curtains and table Linens are shown, of very rich and lovely designs, and of most superior quality. The Linens exhibited in the Austrian department are possessed of much excellence, and do great honour to the various houses producing them, as well as to the sections of that empire in which they are made."

\section{CHAPTER V.}

D U T C II LI N E N.

HoLland, although a small and naturally a poor country, a land of sand hardly recovered from the ocean, was early celebrated for her trade and commerce, and for the great wealth which these brought her people. The indomitable love of the Flemings and Dutch for civil and religious liberty, and consequent hatred of tyranny and oppression, made them both feared and respected by other nations. They have ever been famed for industry and frugality, and for great perseverance in the pursuit of gain. The wealth, once acquired, was handed down from sire to son, increasing as it rolled on, until in many cases it attained colossal proportions. Their liberal and enlightened commercial policy enabled them to make the most of the vast capital at their disposal, until in time they became the richest people in Europe.

The history of Holland in the middle ages admirably exem- 
plifies the advantages which flow from commercial freedom, and from the absence of all restrictions on trade. Trade to be prosperous must be free, and if free, it requires no protection, no fostering care, no adventitious aid. The love of gain is sufficient stimulus to urge the merchant on to success, just as the desire for fame impels the warrior to deeds of glory. One country possesses a superfluity of some commodities, and another of others, the interchange of which is advantageous to both. The trader, if let alone, speedily discovers this, and becomes the medium of exchange, to the benefit of both countries, and to his own profit. In Holland, liberty and commerce went hand in hand, until her cities became the depots of the world, and all nations were her customers.

The Flemings enjoyed commercial freedom before the Dutch, and were justly jealous of their privileges. When Edward I. of England levied tolls and impositions on foreign merchants, vessels and goods, he solicited Robert, Earl of Flanders, to prohibit all trade with the Scots. The Earl replied "Our country of Flanders is common to all the world, and every person finds in it free admission." The reply is what might be expected from, and would be worthy of, Britain in the present day. It reflects immortal honour on the noble Earl who spoke it.

Austrian Flanders was perhaps the earliest of any country, without the Mediterranean, which began the manufacture of Linens on a large scale, after the dark ages which so long bound Europe as it were in a gloomy prison.

Before 1253 the Linen manufacture had been carried to great perfection in Flanders, and the material employed was of the finest quality. Many of the goods made were exported to England and to other countries. By the vast woollen and Linen manufactures of Flanders and Brabant, these countries acquired great commercial importance and much wealth during the 13th century, and their ports were crowded with shipping both of their own and of other countries.

The city of Bruges, which had been founded in 760 , gradually rose to great importance. In 1385 it attained the zenith of its prosperity, having been at that period the centre of all the commerce of Christendom. It then exported Linens largely, and in 1437 it was still noted for its export of fine Linen. About 1487 much 
of its commerce was removed to Dort, and thence soon after to Antwerp, which then began to be tho emporium of Europe. The cause was a dispute between the inhabitants and the Emperor, who, with the assistance of Antwerp and Amsterdam, blocked up Sluyce, its proper harbour, and so destroyed its commerce.

The city of Ypres in Flanders was built in 960, and has been long famous for its table Linen manufacture, commonly called Diaper (i.e.) Cloth D'Ypres. Lourain, in Austrian Brabant, was very celebrated for its woollen and Linen manufactures, which, in the beginning of the 14th century, maintained 150,000 weavers.

De Witt says, "the province of Holland enjoyed little trade before the beginning of the 14th century, because its feudal lords oppressed and overawed the people, and would not allow the citizens to wall their towns for security, as was the case then with Haarlem, Amsterdam," \&c. This statement shows the advantages which the trade of Holland derived from its municipal cities, and commerce in other lands has also benefited by the protection they afforded. They were a check and safeguard against the extortions of the barons, and enabled the people to prosecute their trade in peace. He also says that " in the 14th century the cloth halls of the Netherland cities, by making restrictive laws, under pretence of preventing deceit by the debasing of manufactures, drove much of the weaving trade into the villages, from which it was again driven by the wars between France and Flanders to Louvain and other towns in Brabant." And "that the Brabanters, in turn, no wiser than the Flemings, by the same means drove many of their weavers into England."

About the 10th century the woollen cloth manufactures of the Flemings had gained a high name in Britain and in Germany, and large quantities of them were exported in exchange for the products of these lands. About the beginning of the 14th century, the manufacture of woollen cloth was introduced into Holland by weavers from Brabant and Flanders, and before the end of that century the towns of Holland had become strong and had acquired great power and influence. For several centuries thereafter the Dutch and Flemish looms clothed the greater part of Europe, and it was from them that Britain and other countries learned the art of manufacturing textile fabrics. 
For a long period the Dutch imported the raw material for their manufactures, spun and weaved it, and returned the cloth to the countries whence it was received, in the same way as is done in Britain at the present day. In that early period they had no competitors for their woven fabrics, consequently they. had the control of the various markets of the world, and could command their own terms. It may therefore be imagined that their profits were handsome, and the trade well worth cultivating. Louis Guiciardini, in his description of the Netherlands in 1560, says:- " It has no wine growing in it, yet they have plenty of that fine liquor; nor Flax of their own growth, yet they make the finest Linen of any in the universe. They have no wool, either in good quality or quantity, yet make infinite quantities of good cloths. They grow no timber, yet they use more for ships, dykes, \&c., than perhaps all the rest of Europe together." Strong testimony of their industry and commercial enterprise.

The same writer says:- "Antwerp was then the great emporium of the world, $40 \mathrm{v}$ or 500 ships being in the harbour in one day, and merchants from the principal nations of the world resided there." In enumerating the exports, he says they sent Linen, tapestry, \&c., to Rome; to Ancona, English and Flemish cloths, stuffs, Linen, tapestry, \&c.; to Bologna, Naples, and Sicily, the same; to Milan, in addition to these goods, they sent English and Spanish "woolinens"? The same goods were exported to Florence, Genoa, \&c., \&c. Antwerp also exported Flax, \&c., to Italy. To Germany she exported a very large quantity of Linens, \&c. To Denmark, Norway, Sweden, Eastland, Livonia, and Poland, Linens, \&c. She imported from these countries, particularly Eastland and Poland, Flax, \&c., to a large amount. To France she exported great quantities of fine Linens, getting back in return immense quantities of canvas and strong Linens from Bretagne and Normandy. To England, Scotland, and Ireland, she exported Linens. He estimated the exports and imports to and from England at twenty-four million guilders, or $£ 2,400,000$. To Spain, Portugal, and Barbary, Linens and Flax thread," \&c., \&c.

$\mathrm{He}$ also says that "Bois-le-duc was then the seat of a great many manufactures, among others 20,000 pieces of Linen, 
worth, on an average, ten crowns each, were made anuually." At Novelle (five leagues from Brussels), he says "they made great quantities of very fine cambric, and also at Cambray, which originally gave its name to that fine manufacture. At Courtenay they made fine Linen for the table. At T'eel, Linen cloth and buckram. At Ghent, the cloth named from that city, Ghenting, in immense quantities, also fine Linen of many sorts, woollen also, and tapestries, fustians, buckrams," \&c.

Of Amsterdam, Guiciardini says they have no Flax of their own growth, yet make the finest Linen in the universe. This may be true, but in 1560 great quantities of Flax were raised in some parts of Holland.

Leyden was early distinguished for its woollen manufactures, and in order to maintain the reputation of Leyden cloths they were, in 1482 subjected to inspection by the Government authorities, something in the same way as Limens were in Scotland at a much later period.

In 1570 the revolt of the Netherlands against Spain began. In 1585 the sacking of Antwerp by the Spanish soldiery, drove the trade of that city, and of the manufactures of Brabant and Flanders, into England and Holland. Many of the woollen manufacturers settled at Leyden; the Linen spinners and weavers at Haarlem and Amsterdam; and more than one-third of those who worked and traded in serges, stockings, flannels, taffetas, silks, and damasks fled to England. Gerard Malynes says that four-fifths of the merchandize sold in Antwerp, before its sacking by the Duke of Parma in 1585, were English.

In 1595 the Dutch began to trade with India, and in 1601 they opened up a trade with Japan, sending out Linens, woollen cloths, \&c. ; but, by the end of the century, the trade was almost annihilated. In a manuscript, submitted by Sir Walter Raleigh, shortly before his execution, to James I., the great extent of the trade of Holland is graphically detailed, and had this monarch carried out the recommendations of that great man, they would have advanced the prosperity of Great Britain in a wonderful degree, but they were disregarded.

In the middle of the 17th century, although the Dutch had no native commodities of their own, having imported their Flax, Hemp, \&c., yet their commerce was greater than all the rest of 
Europe together. This prosperity was increased by the great influx of men from Germany, France, and England, whence they were driven by religious persecutions, and civil wars. The security afforded by the Government of Holland drew many of the best people thither, and as they had to work for their sustenance, it added to the general opulence. Each town had then its own particular commerce or staple, which they brought to the greatest height of improvement. Haarlem had the manufacture of Linen, mixed stuffs, and flowers.

Holland was not, however, destined to continue a great manufacturing country. The dearness of labour, high taxes, and circumstances peculiar to the country, were unfavourable to the production of woven fabrics. They owed their manufacturing prosperity to the commotions and persecutions in other lands, particularly in France, Spain, and Flanders. As more peaceful times dawned in England and France, manufactures, aided by improved machinery, took root and prospered there, As manufactures rose in these countries, they declined in Holland, until at last they only retained those which were not exposed to the competition of other nations. It is thus evident that Holland was more adapted by position, and by the commercial spirit of her citizens, for being a trading, rather than a manufacturing country.

The wars with Britain and other countries, which followed the season of prosperity in the Netherlands, did irreparable injury to her manufactures. These wars interrupted trade, caused heavy losses by captures at sea and otherwise, and greatly increased taxation. Voltaire says, "it is war alone that improvishes a nation," and certainly war all but ruined the Netherlands. Her trade declined, her capital had to seek employment abroad, and it nourished the growing trade of those countries in which it was invested, and enabled them to become rivals to the Dutch themselves.

In 1765 there was exported from Rotterdam 2500 to 2700 tons of Flax, and 17,000 hogsheads of Flax seed, value about 50 s each, or $£ 42,500$; and Dort exported from $5 C 0$ to 600 tons of Flax. At this time English printed Linens and calicoes, being the common summer dress in Holland, were in every shop in the country, and no attempts to imitate them had hitherto suc- 
ceeded. At this period Linens were exported from the province of Holland, Haarlem (and bleaching Linens), Amsterdam, and Friesland, the latter being specially noted for its Linens, then the finest in Europe.

In the palmy days of Holland its Linen trade was large and important, not only supplying the home demand, but affording, as above narrated, great quantities for export to other countries. It declined with the general trade of the country, which in 1795 had become completely paralyzed. After the peace of 1815 the Linen trade began to revive, and it subsequently increased to a very important extent, especially in Flanders.

The separation of Belgium from Holland, took place on 15th November, 1831. The two countries have since been distinct, and a short notice of Belgium, subsequent to the separation, will be given in another chapter.

There are still some Linens manufactured in Haarlem, but the quantity is unimportant, the bleaching of Linens is, however, still extensively carried on. In some other places a few are made, chiefly for home consumption. In Friesland a large quantity of superior Flax is grown, and at Leeuwarden and Harlingen canvas and Linen are manufactured, but not on a large scale. Some Linens are also made in $\mathrm{Zwolle.} \mathrm{The} \mathrm{province} \mathrm{of}$ North Brabant is the seat of a considerable Linen trade, chiefly for home use. It is made by the small farmers when not engaged in field labour, the yarn being spun by their wives aud daughters, by the common hand-wheel, and from their own Flax. Bois-le-duc, in that province, has long lost its former celebrity for Linens, but a considerable number of the peasants are still engaged in Linen weaving in their own cottages, and they bring the produce of their labour to an annual fair, which is held in that town on St John's day.

Holland not being now a manufacturing country, domestic fabrics receive little protection from its customs' tariff'. From and after 1st November, 1862, Linen and Jute yarns were admitted free of duty. Sail twine pays f. 1.00 per 100 lbs. Linen and all manufactures of Flax, Hemp, and Tow, pay 5 per cent. ad valorum, excepting sail-cloth, which pays f. 0.30 per roll of 42 ells, and when beyond that length, 60 cents. These particulars are taken from "The Tariff for the 
Netherlands," kindly suppled by Mr Thoms, the Vice Consul at Dundee. Linens can therefore be imported into Holland at a lower price than they can be produced there, and, as will be seen by the Board of Trade returns, given in another portion of this volume, the Dutch are very good customers to the United Kingdom.

In 1841 the value of Linen yarn and Linens imported, exported, and sent through Holland, was as follows :-

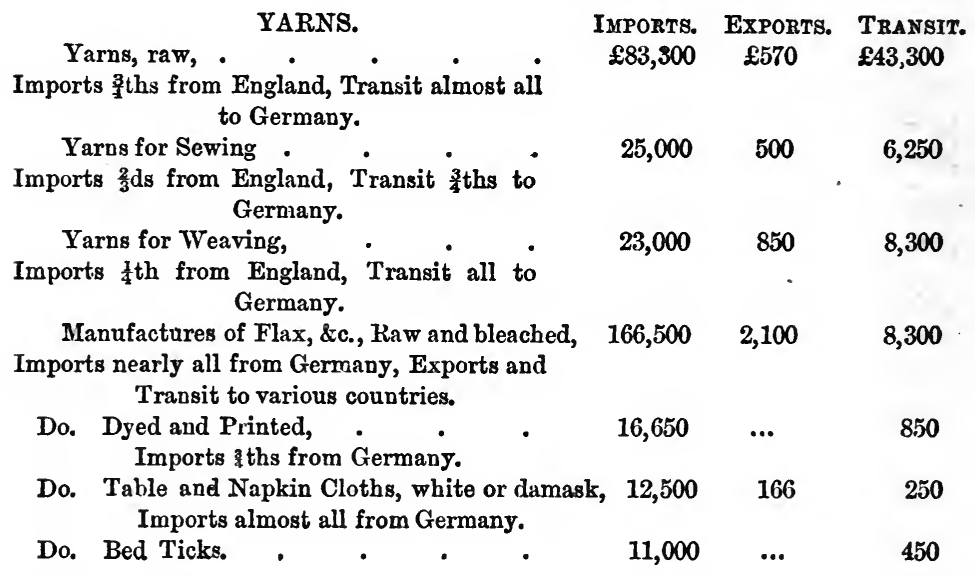

Some other manufactures of Flax, Hemp, \&c., came from Germany, Russia, England, \&c., and were chiefly used for home consumption. There were then no mills for spinning Linen yarns, or Linen weaving-factories in Holland, excepting a few in Overyssel and North Brabant, and they were not extensive.

The very large quantities of Jute yarn exported from the United Kingdom (chiefly from Dundee), to Holland, is wrought up into cotton and coffee bagging and other fabrics, to a great extent by those confined in the prisons and houses of correction. The bulk of it is sent out to the colonial possessions of the Dutch in the East Indies. The quantity required for this purpose is very great, and likely to increase. In 1858 there was imported into Holland 1,145,600 bags of East India, and 17,600 bags of West India coffee, of which the Netherland Trading Company imported 1,120,900 bags. The value of the ordinary Linen goods exported to Java and the other Dutch possessions 
in the Eastern Archepelago is 62 per cent. of the whole export; while the value of the imports in this branch is nearly double that of the exports.

Hitherto there had been no law in Holland akin to the Factory Act of this country, but recent enquiries have been made by some parties in that country regarding the working of the Act here, with the view of its introduction there.

In 1862 men and boys employed at weaving wrought 10 hours a day as a minimum, to 14 hours as a maximum; women and girls, 10 to 13 ; and children, $9 \frac{1}{2}$ to 13 hours. Men, lads, women, girls, and children, at spinning, 10 to 13 hours; less about $2 \frac{1}{2}$ hours a-day for meals. Wages-men, $10 \mathrm{~d}$ to $1 \mathrm{~s} 8 \mathrm{~d}$ a-day; women, $7 \mathrm{~d}$ to $1 \mathrm{~s} 8 \mathrm{~d}$; lads, $5 \mathrm{~d}$ to $1 \mathrm{~s} 8 \mathrm{~d}$; girls and children, $2 \frac{1}{2}$ to $8 \mathrm{~d}$.

The imports into and exports from Holland for the years noted, were as follows :-

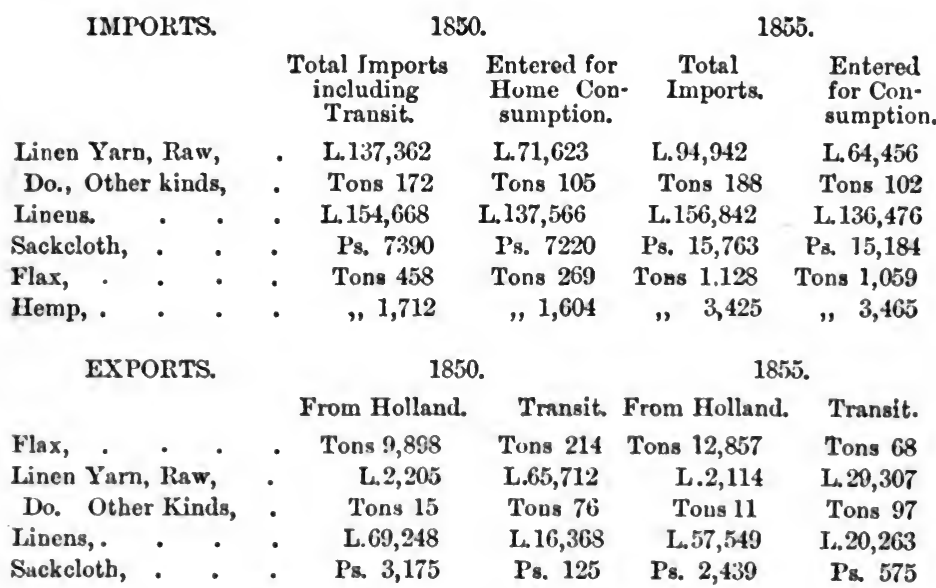

The quantity of Flax and Hemp grown in Holland for the years noted was as follows:-

$\begin{array}{lcccc} & & 1852 & 1853 . & 1851 . \\ \text { Flax, . } & \text {. } & \text { Tons } 12,918 & \text { Tons } 6,341 & \text { Tons } 6,586 \\ \text { Hemp, . } & \text { " } & 1,152 & \text {, } 1,210 & , " 1,568\end{array}$

The value of the Flax exported to Great Britain in 1859 was 
£254,802. The value of the Linens imported in 1860 was $£ 171,442$, and exported $£ 75,364$.

Mr Ward, Her Majesty's Secretary of Legation at the Hague, in his report dated 27th June, 1862, says:-" There are no statistics on the manufacturing industry of the Netherlands made up, and any abstracts got are necessarily imperfect and incomplete." No positive reliance can therefore be made on the figures given above, although they are believed to be, on the whole, substantially correct.

\section{CHAPTER VI.}

B E L G I A N L I N E N.

AFTER the separation of Belgium and Holland, the government of the former kingdom paid great attention to the manufactures of the country. The cultivation of Flax received much encouragement, and large quantities have long been regularly grown in both East and West Flanders, and in other provinces in the kingdom The quality of the Flax raised is highly extolled, and it commands a comparatively high price in all countries. Large quantities of the Flax grown is consumed at home, but it is also exported extensively to the United Kingdom, France, and other countries.

From time immemorial the Flemings have been famous for their mode of cultivating, preparing, and dressing Flax, which is not surpassed, if indeed equalled, in any other country. Some account of the various processes employed there having already been given in the chapter on Flax culture, it is unnecessary to say more on the subject here.

The farmers who grow the Flax have generally small holdings, and much of the work connected with its preparation is 
performed by the members of their own family. They also spin and weave a sufficient quantity of it for domestic wear, and sometimes also for sale in the home market. In addition to the quantity thus produced, there are lurge establishments for the spinning and weaving of Linens in various parts of the country. The chief seats of the plain Linen manufactures are Ghent, Oudenarde, Renaix, Grammont, Lokeron, and Alost, in East Flanders; Thielt and Roulers, in West Flanders; Malines, and Turnhout, in Antwerp, and Ath in Hainault. Courtrai, Brussels, and Bruges, are celebrated for lace, thread, ticking, and checks, \&c.

The machinery for the spinning and weaving factories in Belgium is of the best construction, and with all the recent improvements, a great part of it having been supplied by the best makers in Leeds and other towns in this kingdom. At one period large quantities of the yarn spun was exported to France, but the high duties charged by France nearly put a stop to the trade. The recent alterations in the French tariff will no doubt again open the door to the Belgium spinners, and enable them to send part of their surplus production thither. Considerable quantities of Belgian yarn are annually exported to this country, and used in some of the manufactures of Leeds and Belfast. Belgium also imports a good deal of Linen yarn from the United Kingdom, part of which is used in her manufactures, and part sent on to Germany.

The quantity of Linen manufactured annually in Belgium, exclusive of what is made in the houses and worn by the farmers of Flanders, was stated to amount to about 750,000 pieces in 1840 . Since then the production has increased very largely, and the increase would appear to be progressive. According to French official accounts the value of the imports from Belgium of the following articles entered for consumption in 1839 was-Flax,

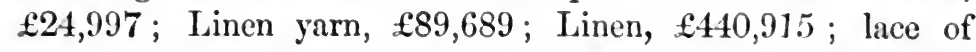

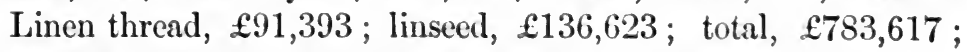
besides articles of same class introduced by contraband.

The process of bleaching in Belgium is much and deservedly extolled, as the colours produced are very pure and bright. The water in some of the rivers would appear to be admirably adapted, not only for steeping Flax, but also for bleaching both 
Linen yarn and cloth, and no doubt this circumstance helps to bring out the high colours for which the Belgian bleachers are so celebrated. There is a bleaching establishment worked by steam at Antwerp, and others in different parts of the country.

In 1856 the numbers engaged in the Linen and Hempen manufactures of Belgium amounted to 199,779 people, of whom 86,663 were males, and 113,116 females.

The quantity and real value of the Linen importations into Belgium for the five years ending 1860 were as follows :-

\section{F L A X.}

\begin{tabular}{|c|c|c|c|c|c|}
\hline $\begin{array}{l}\text { Quantity, Tons, } \\
\text { Real Value, }\end{array}$ & $\begin{array}{c}1856 . \\
\text { s, } \quad 6900 \\
\text { L. } 482,567\end{array}$ & $\begin{array}{c}1857 . \\
7420 \\
\text { L. } 452,291\end{array}$ & $\begin{array}{c}1858 . \\
10,710 \\
\mathrm{~L} .652,390\end{array}$ & $\begin{array}{c}1859 . \\
8425 \\
\text { น. } 581,600\end{array}$ & $\begin{array}{c}1860 . \\
9730 \\
\text { L. } 592,600\end{array}$ \\
\hline \multicolumn{6}{|c|}{ H E M P. } \\
\hline $\begin{array}{l}\text { Quantity, Tons, } \\
\text { Real Value, }\end{array}$ & $\begin{array}{c}1410 \\
\text { L. } 53,366\end{array}$ & $\begin{array}{c}2380 \\
\text { L. } 89,836\end{array}$ & $\begin{array}{c}1345 \\
\text { L. } 50,914\end{array}$ & $\begin{array}{c}2365 \\
\text { L. } 80,752\end{array}$ & $\begin{array}{c}1915 \\
\mathrm{~L}_{\llcorner} 65,289\end{array}$ \\
\hline \multicolumn{6}{|c|}{ L I N E N Y A R N S } \\
\hline $\begin{array}{l}\text { Quantity, Tons, } \\
\text { Real Value, }\end{array}$ & $\begin{array}{lc}\text { s, } & 616 \\
\text { L. } 101.990\end{array}$ & $\begin{array}{c}663 \\
\text { L. } 110,090\end{array}$ & $\begin{array}{c}1246 \\
\text { L. } 259,275\end{array}$ & $\begin{array}{c}618 \\
\text { L.125,694 }\end{array}$ & $\begin{array}{c}448 \\
\text { L. } 91,008\end{array}$ \\
\hline \multicolumn{6}{|c|}{$\mathbf{L} \mathbf{I} \mathrm{N} \mathbf{E} \mathrm{S}$} \\
\hline $\begin{array}{l}\text { Quantity, Tons, } \\
\text { Real Value, }\end{array}$ & L. 1101,076 & $\begin{array}{c}124 \\
\text { L. } 89,832\end{array}$ & $\begin{array}{c}116 \\
\text { L. } 73,306\end{array}$ & $\begin{array}{c}151 \\
\text { L. } 86,775\end{array}$ & $\begin{array}{c}293 \\
\text { L. } 119,173\end{array}$ \\
\hline
\end{tabular}

The quantity of Flax, and Hemp, and manufactures thereof, imported into Belgium ("Special Trade") was, in 1861, 19,006 tons, value, $£ 1,030,720$. In 1862 the quantity was 18,373 tons.

Of the Hemp imported nearly one-half was from Great Britain, about one-fourth from Russia, and about one-eighth from Austria. Of the Flax, about one-half was from Russia, and the bulk of the remainder from Holland. Almost the whole of the Linen yarn imported was from Great Britain.

The Linen exports for the same period consisted of-

\begin{tabular}{|c|c|c|c|c|c|}
\hline \multicolumn{6}{|c|}{ H E M P. } \\
\hline $\begin{array}{l}\text { Quantity, Tons, } \\
\text { Real Value, }\end{array}$ & $\begin{array}{c}1856 \\
421 \\
\mathrm{~L} 15,912\end{array}$ & $\begin{array}{c}1857 . \\
274 \\
\text { L. } 10,362\end{array}$ & $\begin{array}{c}1858 . \\
183 \\
\text { L. } 6943\end{array}$ & $\begin{array}{c}1859 . \\
218 \\
\text { L. } 7436\end{array}$ & $\begin{array}{l}1860 . \\
227 \\
\text { L.7745 }\end{array}$ \\
\hline \multicolumn{6}{|c|}{ F L A X. } \\
\hline $\begin{array}{l}\text { Quantity, Ton } \\
\text { Real Value, }\end{array}$ & $\begin{array}{l}12,600 \\
\text { L. } 869,631\end{array}$ & $\begin{array}{l}14,806 \\
\text { L. } 901,725\end{array}$ & $\begin{array}{c}14,941 \\
\text { L. } 910,555\end{array}$ & $\begin{array}{l}12,394 \\
\text { L. } 855.457\end{array}$ & $\begin{array}{c}16,840 \\
\text { L. } 1,025,561\end{array}$ \\
\hline
\end{tabular}




\section{N E N Y A R N S.}

\begin{tabular}{|c|c|c|c|c|c|}
\hline $\begin{array}{l}\text { Qunntity, Tons, } \\
\text { Real Value, }\end{array}$ & $\begin{array}{c}1856 . \\
1961 \\
\text { L. } 311,547\end{array}$ & $\begin{array}{c}5857 . \\
2480 \\
\text { L. } 403,606\end{array}$ & $\begin{array}{c}1858 . \\
1777 \\
\text { L } 355,856\end{array}$ & $\begin{array}{c}1859 . \\
2241 \\
\text { L. } 444,530\end{array}$ & $\begin{array}{c}1860 . \\
3273 \\
\text { L. } 623,481\end{array}$ \\
\hline ity, Tons, & 3344 & 3466 & 3358 & 3339 & 4306 \\
\hline
\end{tabular}

Real Value, L. 676,688 L.1,206,392 Is 1,136,011 Lo $1,096,193 \quad$ L. 1, 139,289

Besides Liwen, lace and tulle, of the average value of about, $\$ 40,000$ yearly.

The exports from Belgium in 1861 were-Flax and Hemp 17,792 tons, value $£ 1,134,440$; Linen yarns, 2610 tons, value

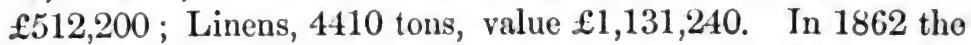
quantities were-Flax and Hemp, 19,340 tons; Linen yarn, 2860 tons ; Linens, 4240 tons.

$\mathrm{Mr}$ Barron, Secretary of Legation at Brussels, in his report, dated 25th Feb., 1863, (from which the above statistics relating to 1861 and 1862 are taken), says:- "In official parlance the 'special' trade comprises only imports for home consumption, and exports of native produce. My tables are all intended to depict the 'special' trade only; but great quantities of goods not liable to duty, especially Flax, \&c., pass in and out of Belgium as if intended for home consumption, and then as if native produce, and thus completely vitiate the returns of the special imports and exports." He farther says :- "The exports of Linen yarns and tissues alone amounted in 1861 to $\mathrm{f} .41,000,000$. If to this be added the value of Flax and Hemp exported, viz., f. 28,300,000, we should arrive at the prodigious amount of nearly f. $70,000,000$ as the aggregate value of these fibres exported from Belgium in a raw or manufactured state. It is true some foreign Flax is confounded with these exports. The finest Flax in the world is grown in Flanders. This is evidently the most important industry of Belgium in exportable value. It has profited largely by the cotton crisis.

"Another staple industry of Belgium, the Lace trade shares in the general languor. The manufacture of Valenciennes lace alone occupies 50,000 women in the two Flanders, and represents a value of nearly f. 20,000,000 per annum. De Bruxelles is another national lace which is unsurpassed in any other country, \&c.

"The extensive Linen mills existing in Ghent have afforded a resource to many cotton workers. 
"The new tariff on Linens is from 10 to 20 per cent. Although it offers no real reciprocity it is some improvement on the previous regime, and is even more liberal than the new French tariff, which has already proved beneficial to the English trade."

Of the Flax exported, on the average fully one-half is to France, and three-eighths to Great Britain. Of the yarns about one-half is to France, three-eighths to Prussia, and oneeighth to Holland; and of the Linens about one-third is to France, one-fourth to Holland, and one-fifth to Prussia.

The recent progress and present state of the Linen manufacture in Belgium was well exemplified by the goods shown in the International Exhibition of 1862. The yarns and Linens exhibited gave indisputable evidence of the skill displayed in their production, and the excellence which the manufacture has attained in that country, proving unquestionably that Belgium is no mean competitor with the United Kingdom in the markets of the world. The following short report on the Linen shewn by Belgium was written during the Exhibition, and after a careful inspection of the goods exhibited, and it is not without its lesson to all engaged in the trade:-

"There are comparatively few private exhibitors of Flax yarns and Linens from this country, the greater part of them being shown by the Belgian Grovernment, and produced at the various Flemish Apprentice Schools throughout the country. The private exhibitors are the present owners of what were lately Apprentice Schools, some Linen Societies, and a number of private firms. The Yarns comprise heavy Flax and Tow sorts. Some of them are shown in various stages of preparation, and of various qualities and sizes. The Linens exhibited are of many kinds, and comprise sail-cloth, sackings, ducks, sheetings, shirtings, ticks, diapers, damasks, \&c., \&c., forming altogether a large and varied assortment. Both Flax and Hemp sail-cloth is shown. The Hemp goods look rather coarse, and are not of great merit; but the Flax canvas is made of well-spun yarn, of good colour, and firmly driven up. Some excellent four-yard wide canvas is shown. Many of the Linens are shown in the rough or loom state; and they are very carefully manufactured and very excellent cloth. Others are shown in the bleached and 
finished state, and are of high colour, tastefully done up, and of most superior quality. They are of various degrees of fineness, from common Jute and Tow sacking to very fine lawn or cambric. The diapers are strong, useful, and pretty goods. The damasks, in table Linens, and for bed and window curtains, display extraordinary taste in design and finish. They are very lovely, of admirable quality, and some of them of particularly fine texture. In class No. 4, Belgium has also an admirable and large assortment of Flax and yarns. The Flax is exhibited in every stage of preparation, and from a common to the very finest quality. Some of the specimens are most beautifully dressed and made up, and of remarkably fine fibre. The yarns shown in both classes are of many sorts and qualities, 'Tow, Flax, and Hemp, but the greater proportion are in wet spun line. They are beautifully spun, and some of the specimens are of remarkable fineness, and equal, if they do not surpass, the finest examples of either the Leeds or Belfast mills. With such Flax and with such yarn, no wonder that Belgium makes so fine an appearance in Linens. The display in both these departments is of the very highest order, and worthy of the very greatest praise.

\section{CHAPTER VII.}

\section{F R E N C H L I N E N.}

THe soil of France is, in many districts, admirably adapted for the growth of Flax and Hemp, and both plants have from time immemorial been cultivated extensively in some parts of that empire. The manufacture of Linens in France also dates back to a remote period, and some cities and districts have long been celebrated for the large quantity and high quality of the 
Linens produced by them. The French are, and have long been, essentially a Linen wearing people, and the consumption of the various qualities for household and other purposes throughout the country is very large.

When the Romans swayed the destinies of France, Linens were extensively produced there, and since that period, although the manufacture may have fluctuated much in different ages, it has never been wholly extinct. Charlemagne, as has been mentioned, wore Linen, and his subjects were partly clothed in the same material. At this period, and perhaps for long afterwards, the making of Linen was chiefly confined to the labour of female servants, who span and weaved it for domestic use. What was not so required would be sold to those who manufactured none in their own establishments, but who could in this way supply themselves with this necessary article.

Rheims was famous for its Linen manufactures at an early period. In 1394 it is said the King of France sent "fine Linen of Rheims" to the Sultan, as part of the ransom of some noble prisoners who had fallen into his hands. Reynes or Rennes and Champagne were much celebrated about this period in romances and poems for the excellence of their Linens. Champagne has now lost its Linen trade, but it has acquired as wide a fame for its exhilarating wine as it ever had for its Linens, and probably the substantial benefits which it derives from its " champagne" is far greater than ever it got from its Linens. In 1422 Normandy had a considerable Linen manufacture. In 1437 Bretagne exported canvas. In 1453 France had an extensive foreign trade. She had then her wealthy merchant, Jacques Cour, who had 300 factors, and traded with the Turks and Persians. He exported large quantities of Linen and other goods. In an enumeration of the exports at this period, cloth and canvas are among the articles sent from Bretagne.

During the 16th century the commerce of France presents no feature of striking interest. She then exported Linens and other goods to England, and there seems to have been a great exchange between the woollens of England and the Linens of Bretagne.

Guicciardini in his picture of Antwerp in 1560, says that great quantities of fine Linens were exported from Antwerp to 
France, getting back immense quantities of canvas and strong Linens from Bretagne and Normandy. He also says that at the same period cambric was made at Cambray. The fabric got its name from this town, and it is therefore probable that it had first been made there. Giovani Bulero says that lrance, at the close of the 16th century, possessed four magnets, which attracted the wealth of other countries-one of which was Hemp and cloth, of which, and of cordage, great quantities were exported to Lisbon and to Seville. He adds that the exportation of the articles of this class was incredibly great.

In $1603 \mathrm{King}$ Henry IV. introduced foreign workmen into France for the improvement of manufactures, including tapestries, cloths and serges, silks and stuffs, gaups or thin Linen clotl, \&c. At this time, it is said, a Linen manufacture was set up-probably in some town where no establishment of the kind had previously existed. Early in the reign of Louis XIV. Colbert directed his attention to the improvement of manufactures and commerce in France, which were then raised to their greatest beight. In 1685 the value of Linen sail-cloth and canvas exported to England was $£ 400,000$, and to Holland $£ 160,000$; and the average value of Linens exported to England in the years 1686,1687 , and 1688 , was about $\mathfrak{£} 700,000$ sterling.

The Popish persecutions which followed the revocation of the edict of Nantes in 1685, drove about 600,000 protestants from France. These men were the pith and marrow of the country, and their removal proved a great blow to its manufactures, not only by the loss of their heads and hands, but by the stimulus which, by their skill and industry, was given to the same mann. factures in the countries to which they went. Subsequent wars had also the effect of gradually destroying some of the French manufactures, and of transferring them to other nations. "In this way," says Macpherson, " France was deprived of a most profitable manufacture of two species of Linen, viz., dowlas and buckram, chiefly made in Normandy and Brittany, of which England was said to have taken off to the value of $£ 200,000$ annually; for England, not being able to do without these two sorts of Linen, set the Hamburgers in imitating them so well, that the very names of these French Linens with us are buried in oblivion."

In 1753 the value of the Linens exported from France was 
911,465 livres. In 1764 Linens were exported from Lille and Cambray in French Flanders; Valenciennes in French Hainault; Amas in Artois; Amien, St Quentin (lawn), and Abbeville (sackcloth), in Picardy; Troyes (Linen and canvas), in Champagne; Caen in Normandy; and Mortagne (coarse Linens), in Maine. In Postlethwayt's Dictionary of Commerce, published in 1766, it is stated that "Flax abounds in France. They import large quantities, however, from Russia. Holstein and Flanders lint is of great esteem ; that of Picardy comes near it ; of others, Riga and Konigsberg are in most repute." $\mathrm{He}$ says the Linen trade of Europe is chiefly in the hands of the Russians, Germans, Swiss, Flemings, Hollanders and French. It would thus appear that Linens had been manufactured very extensively in France a century ago, because in addition to the large quantity of Flax grown at home, the importation of it, the growth of foreign countries, was also large.

The following extract, (taken from the Dundee Advertiser), from a decree by the Emperor Napoleon, shews the importance which he attached to the prosperity of the commerce and manufactures of France, and the large share which the Linen manufacture then formed of the trade of the country.

"Palace of St Cloud, 26th June, 1810. Napoleon, Emperor of the French, King of Italy, \&c., \&c., \&c. It being our intention to ascertain the opinion of the principal merchants and manufacturers of our empire upon everything relating to commerce and manufactures, we have decreed as follows:-That there should be established at Paris a general council of manufacturers, to consist of sixty members. The most useful members to obtain the title of Counsellor of Arts and Manufactures, and receive a brevet signed with our hand. The members to be manufacturers in employ." "Six of them shall be composed of those in the Flax and Hemp manufacture, one of whom must reside in Paris, \&c., \&c."

Since the termination of the war in 1815 the linen manufacture in France has progressed steadily. Fiscal regulations and commercial convulsions have now and again ruffled the tenor of its course, and checked its career, but it has overcome all obstructions and difficulties, and its extent is probably greater now than ever it was at any former period. As in most other countries, the Flax and Hemp raised by the farmers were 
dressed, spun, and woven for domestic use by the peasantry, many centuries before large manufactories were established. In course of time this system proved inadequate to supply the demand for Linens, and establishments were specially erected for weaving the cloth. Spinning by machinery was subsequently introduced, and latterly weaving by power, and these appliances have completely changed the aspect of the trade.

The value of Linen and Hempen cloth exported from France in 1800 was $34,866,000$ livres. In 1814 no Linen yarn was exported from the United Kingdom to France, and the quantity of Linen sent thither was only 37,314 yards, of the declared value of $£ 3703$. The exportation, both of Linen yarn and Linens, from this country to France was not of great extent prior to 1836. That year a new tariff of a more favourable nature came into operation, and the trade at once assumed gigantic proportions, showing the advantage to both countries of a moderate scale of duties, with the absence of undue restrictions upon commerce. In 1842, in order to encourage the native manufacture, the duties were again raised, and the trade fell off greatly. In 1847 the duties were still farther increased, and upon heavy sizes of Linen yarn and coarse Linens they were virtually prohibitory. As a natural consequence the trade became almost extinct, and for about twelve years only small quantities of the finest class of goods were exported to France. In 1860 a new and more liberal tariff came into operation, and great hopes were raised regarding its value to the Linen trade of this country. Hitherto, from exceptional causes, these have been only partially realized, and for some part of this year (1863) Dundee, instead of exporting her yarns and Linens to France, as it was expected she would do, has imported from that country large quantities of Flax, Tow, and Jute yarns, and also sailcloth and other linens. This may to some extent be accounted for by the high prices to which Linens rose in that town, consequent upon the scarcity of cotton, and the greatly increased consumption of heavy Linens in America, for war and other purposes there. These causes are not, however, sufficient to account for the phenomena of Dundee being undersold on her own streets by French yarns and Linens, and it would appear that the demand for such goods in France is not equal to the production, 
especially for Jute yarns and cloth. If this be the case, this country has little to hope from France as a market for her Linens, even in ordinary times after the trade has settled down into its usual channels again, as it implies that the French can spin and weave linens as cheaply as can be done in Dundee. Britain has therefore no compensating advantages to counterbalance the high duty still charged upon her Linen yarns and Linens imported into France, and thus far the Tariff is entirely one-sided.

The progress of the trade, and the impolitic effect of an adverse tariff are well exemplified by the following statement, taken from Parliamentary Returns, of the exports to that country for the years from 1830 to 1848. The effect of the new tarift for the first two years is shown by the value of the exports to France during 1860, the year in which that tariff came into force, compared with those for 1858 and 1862.

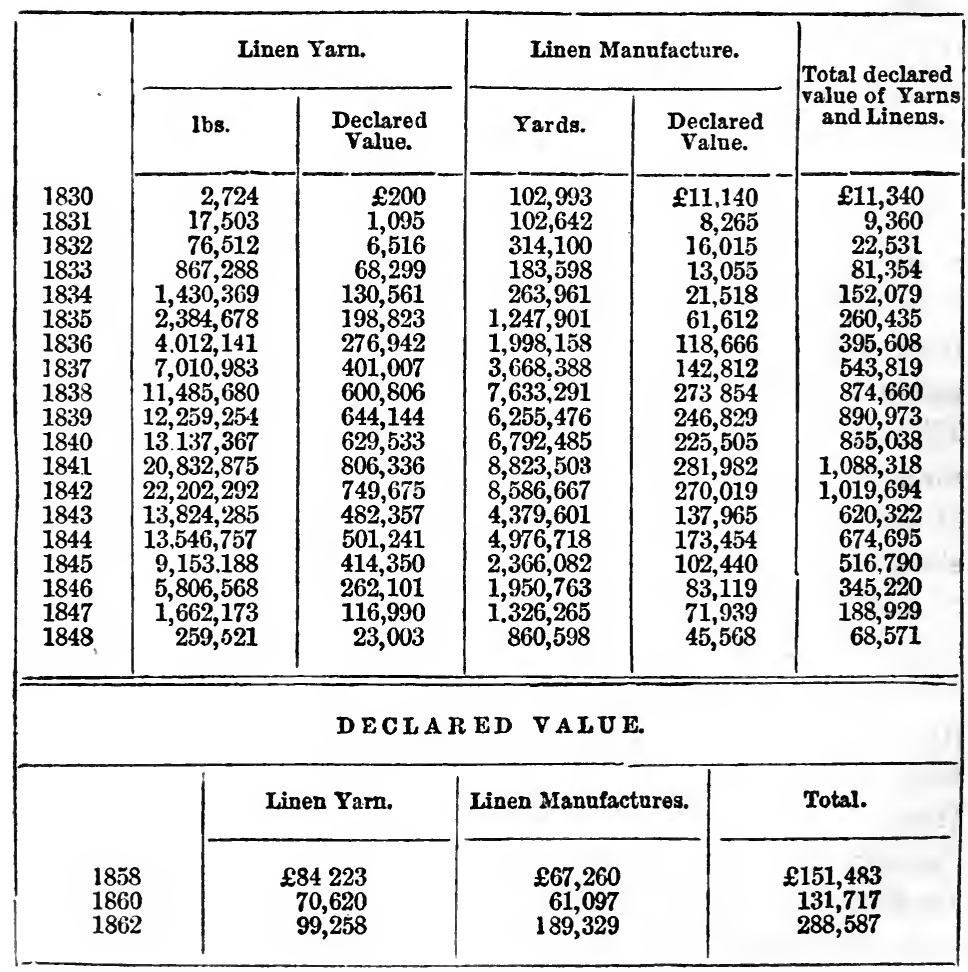


The proportion of Linens and Linen yarns which were sent from Dundee to France during the years given in the foregoing tables cannot be ascertained, because many of them were shipped to Hull, Iondon, \&c., and transhipped from these ports. The following table exhibits the quantities which were sent direct from Dundee to France, for the ten years from 1839 to 1848 inclusive. If the quantities sent indirectly were added, it would be seen that, for inany of these years, Dundee manufactures formed a very large proportion of the total exports to France :-

Exporty of Lisens axd Lisen Yakng sent dikect prom Dindeg to France.

\begin{tabular}{|c|c|c|c|c|c|c|c|}
\hline \multirow[b]{3}{*}{1839} & \multirow{3}{*}{$\begin{array}{c}\begin{array}{c}\text { Osna. } \\
\text { burgs. }\end{array} \\
\text { Pieces. } \\
1.740\end{array}$} & \multirow{3}{*}{$\begin{array}{l}\text { Sheetings } \\
\text { Pieces. } \\
5,750\end{array}$} & \multirow{3}{*}{\begin{tabular}{|l} 
Dowlas. \\
Pieces. \\
8,705
\end{tabular}} & \multirow{3}{*}{$\begin{array}{c}\text { Sun- } \\
\text { dries. } \\
\text { Pleces } \\
69\end{array}$} & \multicolumn{2}{|c|}{ Total. } & \multirow{2}{*}{$\frac{\text { Linen Yarns. }}{\text { L.bs. }}$} \\
\hline & & & & & I'ieces & Yards & \\
\hline & & & & & 16,264 & $2,363.160$ & $3,376,240$ \\
\hline 1840 & 3,872 & 3,566 & 9,020 & 57 & $16, \times 21$ & $2,497,610$ & $4,453,: 4 t$ \\
\hline 1841 & 3,245 & $8,9: 3$ & 21,220 & 159 & 33,547 & $4,913,165$ & $6,131,216$ \\
\hline 1842 & 5,294 & 18,312 & 28,137 & 205 & 51,978 & $7,551,960$ & $12,123,664$ \\
\hline 1843 & 1,434 & 5,432 & 12,450 & 226 & 19,542 & $2,839,300$ & $9,045,616$ \\
\hline 1844 & 3,380 & 1,146 & 3521 & .. & 8,047 & $1,223,660$ & $10,713,581$ \\
\hline 1845 & $1,7: 39$ & $90: 3$ & 2,652 & $\ddot{. .}$ & 5,324 & 802,445 & $8,860,321)$ \\
\hline $1846^{\circ}$ & 437 & 146 & 696 & 40 & 1,319 & $195,63)$. & $2,332,736$ \\
\hline 1847 & 260 & 205 & 626 & ... & 1,091 & 163,175 & $2,034,816$ \\
\hline 1848 & 72 & 63 & $\ldots$ & $\cdots$ & 135 & $2\}, 025$ & 260,624 \\
\hline
\end{tabular}

The two following years the direct exports totally ceased, subsequently a little yarn was sent occasionally, but the trade was almost extinct until the recent tariff came into operation, when shipments on a small extent were for a time resumed.

Statement of the duties on Linen yarns and Linens imported into France according to the tariffs of 1836,1842 , and 1860.

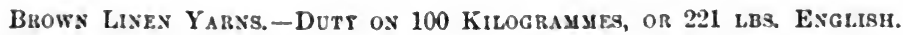

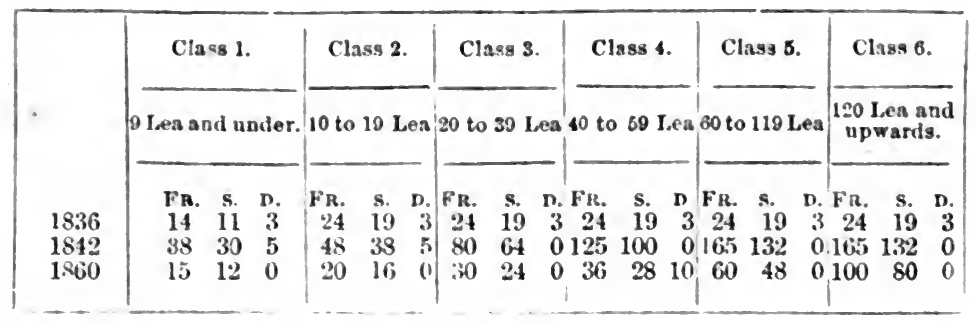


Unbleached Plain Linens-Duty on 100 Kils. or 221 lbs. English-Quality Fixed by the Number of Threads of Warp in one-Firth of an INCH.

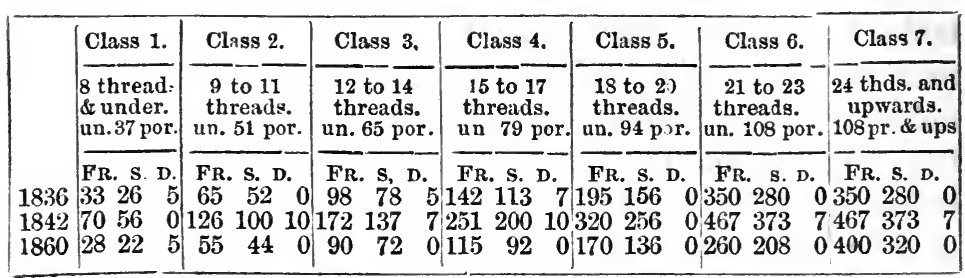

Jute Yarns--Natural Colour. - Duty on 100 Kils, or 221 lbs. English.

\begin{tabular}{|c|c|c|c|c|c|}
\hline & Class 1. & Class 2. & Class 3. & Class 4. & Class 5. \\
\hline & $\begin{array}{l}\text { Heqvier than } \\
21 \text { lb. per spdl. }\end{array}$ & $20 \mathrm{lb}$.to $8 \mathrm{lb}$. & 7 lb. & $\begin{array}{l}6 \mathrm{lb} \text { to } 5 \mathrm{lb} \text {. } \\
\text { inclusive. }\end{array}$ & 4 lb. to $2 \frac{1}{2} \mathrm{lb}$. \\
\hline $\begin{array}{l}\text { Old duty, } \\
\text { New do, }\end{array}$ & $\begin{array}{rrr}\text { Fr. } & \text { S. } & \text { D. } \\
60 & 48 & 0 \\
7 & 5 & 7\end{array}$ & $\begin{array}{lrl}\text { FR. } & \text { S. } & \text { D. } \\
6 \dagger) & 48 & 0 \\
9.20 & 7 & 4\end{array}$ & $\begin{array}{crr}\text { FR. } & \text { s. } & \text { D. } \\
60 & 48 & 0 \\
10.2 & 8 & 2\end{array}$ & $\begin{array}{lrr}\text { FR. } & \text { S. } & \text { D. } \\
60 & 48 & 0 \\
15 & 12 & 0\end{array}$ & $\begin{array}{ccc}\text { Fr. } & \text { S. } & \text { D. } \\
\text { t0 } & 48 & 0 \\
20 & 16 & 0\end{array}$ \\
\hline
\end{tabular}

Pure Jute Goods -Natural Colour-Duty on 100 Kils., or 221 lbs. EnglishQUALITY FIXED BY THE NUMber OF ThREADS OF WARP IN ONE.FIfTH OF $\triangle N$ INCH.

\begin{tabular}{|c|c|c|c|c|c|}
\hline \multirow[b]{3}{*}{$\begin{array}{l}\text { Old duty, } \\
\text { New do., }\end{array}$} & \multicolumn{2}{|c|}{ Class 1.} & Class 2. & Class 3. & Class 4. \\
\hline & $\begin{array}{l}\text { Mending B } \\
\text { Plain Sa } \\
\text { Double Wa } \\
\text { up to } 14\end{array}$ & $\begin{array}{l}\text { ging, } \\
\text { ing, } \\
\text {, do., } \\
\text { ter. }\end{array}$ & $\begin{array}{c}\text { Twilled Sack- } \\
\text { ing. }\end{array}$ & $\begin{array}{l}\text { Hessians, \&c. } \\
4 \text { and } 5 \text { threads. } \\
15 \text { to } 22 \text { por. }\end{array}$ & $\begin{array}{l}6,7, \& 8 \text { threads, } \\
23 \text { to } 36 \text { Porter. }\end{array}$ \\
\hline & $\begin{array}{cr}\text { Fr. } & \text { s. } \\
77 & 61 \\
13 & 10\end{array}$ & $\begin{array}{l}\text { D. } \\
7 \\
5\end{array}$ & $\begin{array}{ccc}\text { FR. } & \text { S. } & \text { D. } \\
77 & 61 & 7 \\
15 & 12 & 0\end{array}$ & $\begin{array}{ccc}\text { Fr. } & \text { s. } & \text { D. } \\
77 & 61 & 7 \\
21 & 16 & 10\end{array}$ & $\begin{array}{ccc}\text { Fr. } & \text { s. } & \text { D. } \\
77 & 61 & 7 \\
30 & 24 & 0\end{array}$ \\
\hline
\end{tabular}

Bleached or dyed yarns and linens pay considerably higher rates than brown or unbleached goods. Drills, both brown and bleached, pay higher rates than other Linens, and damasks pay 16 per cent. ad valorum. In 1864 a diminution of the duty on Jute yarns and Jute goods takes effect, amounting on the average, to about 30 per cent. on the rates charged up to that date.

There are not existing materials for the minute comparison of the growth of textile industry in France over a series of years, like that which is made up for the United Kingdom, but the following facts and figures relating to the Linen trade of France give some idea of its extent and importance.

The sirerage value of the Linen yarn imported into France from all countries for the five years from 1834 to 1838 was 


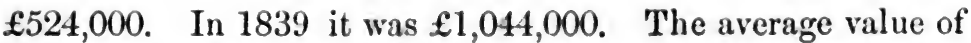
Linens exported from France to all countries for the same five years was $£ 1,104,000$, and for $1839 £ 1,208,000$. The average value of Flax exported from France for the same five years was $£ 48,000$, and for $1839 £ 180,000$.

The average annual imports of Flax into France for the three years ending as under were-

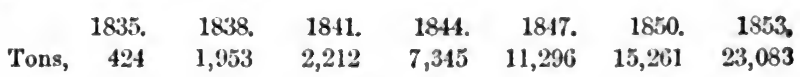

The imports of Hemp into France for the following years were-

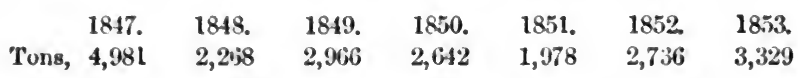

The quantity and real value of the Linen manufactures imported into France for the years named were as follows, viz. :-

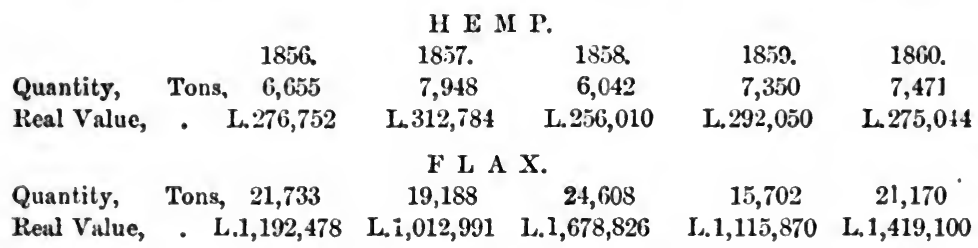

\begin{tabular}{|c|c|c|c|c|c|c|}
\hline $\begin{array}{l}\text { uantity, } \\
\text { eal Value, }\end{array}$ & Tons, & $\begin{array}{c}1,016 \\
\text { L. } 16,4,000\end{array}$ & $\begin{array}{c}1,243 \\
\text { L. } 164,000\end{array}$ & $\begin{array}{c}909 \\
\text { L. } 172,000\end{array}$ & $\begin{array}{c}1,212 \\
\text { L. } 172,000\end{array}$ & $\begin{array}{c}2,388 \\
\text { L. } 252,000\end{array}$ \\
\hline eal V & Tor & $\begin{array}{c}1,385 \\
.596,000\end{array}$ & $\begin{array}{c}1,321 \\
\text { L. } 656,000\end{array}$ & $\begin{array}{c}1,098 \\
\text { L. } 588,000\end{array}$ & $\begin{array}{c}1,414 \\
\mathrm{I}_{6} 644,000\end{array}$ & $\begin{array}{c}2,139 \\
\text { L. } 792,00\end{array}$ \\
\hline
\end{tabular}

LINEN AND HEMPEN YARNS.

About half the Flax imported is from Russia and the other half from Belgium; and the major part of the yarn and Linens imported is from Belgium.

The quantity and real value of the Linen manifactures exported for same years were as follows :-

\begin{tabular}{|c|c|c|c|c|c|c|}
\hline $\begin{array}{l}\text { Quantity, } \\
\text { Real Value, }\end{array}$ & $\begin{array}{l}\text { Tons, } \\
\text {. }\end{array}$ & $\begin{array}{c}1856 \\
452 \\
\text { L., } 21,374\end{array}$ & $\begin{array}{c}1857 . \\
600 \\
\text { L. } 27,703\end{array}$ & $\begin{array}{c}1858 . \\
674 \\
\text { L. } 35,565\end{array}$ & $\begin{array}{c}1859 . \\
837 \\
\text { I. } .39,062\end{array}$ & $\begin{array}{c}1860 . \\
713 \\
\text { L. } 30,535\end{array}$ \\
\hline $\begin{array}{l}\text { Quantity, } \\
\text { Real Value, }\end{array}$ & Tuns, & $\begin{array}{c}954 \\
\text { L. } 45,988\end{array}$ & $\begin{array}{r}\text { F L A } \\
1,793 \\
1,85,718\end{array}$ & $\begin{array}{c}2,481 \\
\text { L. } 131,410\end{array}$ & $\begin{array}{c}, 284 \\
\text { L. } 124,166\end{array}$ & $\begin{array}{c}2,661 \\
\text { L. } 128,423\end{array}$ \\
\hline
\end{tabular}

H E M P. 
LINEN AND HEMPEN YARNS.

$\begin{array}{lcccccc} & & 1856 . & 1857 . & 1858 . & 1859 . & 1860 . \\ \text { Quantity, } & \text { Tons, } & 409 & 457 & 618 & 698 & 996 \\ \text { Real Vulue, } & \cdot & \text { L.73,520 } & \text { L.89,989 } & \text { L.132,466 } & \text { L.135, } 639 & \text { L.226,528 }\end{array}$

\section{LINEN AND HEMPEN FABRICS.}

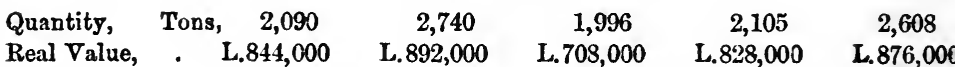

The greater part of the Linens exported are to the various colonies of France.

The acreage under Flax and Hemp, the produce thereof, and the value of the same in the years noted, were as follows:-

\begin{tabular}{|c|c|c|c|c|c|c|}
\hline Flax & 1841 & $\begin{array}{l}\text { Acres. } \\
245,603\end{array}$ & $\begin{array}{r}\text { Lin } \\
\text { Imp. Qrs. }\end{array}$ & $\begin{array}{l}\text { seed. } \\
253,479\end{array}$ & $\begin{array}{c}\text { Fibre. } \\
\text { Tons, } 36,216\end{array}$ & $\begin{array}{c}\text { Value Seed. Value Fibre } \\
\text { I. } 2,300,288\end{array}$ \\
\hline & 1852 & 200,840 & , & 186,743 & 33,049 & L.421,129 L.1,270,234 \\
\hline Hemp & 1841 & 440,371 & ", & 576,428 & 66,301 & L. $3,451,494$ \\
\hline " & 1852 & 125,357 & , & 316,482 & , 63,071 & L. 513,743 L. $1,986,239$ \\
\hline
\end{tabular}

In 1841 the average produce of Flax seed per acre was 8.3 Imperial bushels, and in 18527.43 , and the value per Imperial bushel for the two years respectively, $50 \mathrm{~s} 2 \mathrm{~d}$ and $45 \mathrm{~s} 1 \mathrm{~d}$. The average produce of Flax fibre in 1841 was 375 lbs., and in 1852 $368 \mathrm{lbs}$. avoir. per acre, and the value $46 \mathrm{~s} 10 \mathrm{~d}$ and $37 \mathrm{~s} 8 \mathrm{~d}$ per cwt. respectively.

The average produce of Hemp seed per acre in 1841 was $10 \frac{1}{2}$ Imperial bushels, and in 1852, 8 Imperial bushels, and the value $39 \mathrm{~s} 6 \mathrm{~d}$ and $32 \mathrm{~s} 5 \mathrm{~d}$ per Imperial bushel respectively. The average produce of the Hemp fibre in 1841 was $337 \mathrm{lbs}$; and in $1852450 \mathrm{lbs}$. avoir. per acre; the value being $36 \mathrm{~s} 8 \mathrm{~d}$ and 31 s per cwt. respectively.

The number of spindles employed in the Linen trade in France was given as follows:-

\begin{tabular}{|c|c|c|c|c|c|}
\hline In 1840 & 57,000 & Spindles. & In 1849 & 250,000 & Spindles. \\
\hline ,, 1844 & 120,000 & 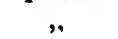 & , 1850 & 275,000 & " \\
\hline ,, 1847 & 170,000 & " & " $18 ; 1$ & 330,000 & , \\
\hline
\end{tabular}

These numbers are greatly in excess of those stated in the French Factory Returns for 1855, given below. How the discrepancy arises is unknown. It is improbable that the trade could have decreased so much between 1853 and 1855 , as it is 
understood to have rather increased considerably during these years, and to have gone on extending up to the present time.

From the Factory Returns published in France for the year 1855, it appears that there were 5576 factories engaged in the Flax and Hemp manufucture, with 210,282 spindles and 20,901 looms, driven by 64 steam engines, 90 water wheels, and other mechanical power 121 (it is not said of what nature), employing 33,067 men, 15,868 women, and 7232 children under sixteen years of age, making a total of 56,167 persons.

From this return it would appear that the term "factory" must designate in France something very different from its ordinary acceptation in this country. In the United Kingdom the number of factories in 1861-62 on Flax, Hemp, and Jute were 440, employing 94,003 persons, giving an average of 213 to each, while in France the average of persons to each factory on Flax and Hemp were only 10, showing that some of the works, designated factories, must be very insignificant affairs. It is probable that each building containing a few hand-looms may be included in the return as a factory, which would swell the number of them greatly, and may account for so many being given.

In France the employment of children in textile factories is governed by a law of $22 \mathrm{~d}$ March 1941 , framed partly on the model of the British law, but which extends to ordinary workshops as well as to fuctories possessing mechanical motive power, provided that not less than 20 workpeople are employed in them. By this law no child under eight years can be employed at all, and none batween eight and twelve can be employed during more than 8 hours out of every 24 hours, and those 8 hours must be divided by sufficient intervals of rest. From twelve to sixteen years of age, the hours of labour may extend to 12 , with similar intervals. No person under sixteen can be employed on Sundays or holidays. A subsequent law of 8th September $18+8$ limits the hours of labour of adults in factories of all kinds to 12 , reserving power to the government to declare exceptions to this enactment, in those cases where the nature of the work or the mechanism may require it. In $1855 \mathrm{Mr}$ Redgrave made a careful inquiry into the execution of these measures, and came to the conclusion that the law of 1841 had been obeyed very imperfectly, and that of 1848 fairly. 
Flax, as has been shown, is extensively grown in many Departments of France, and some districts are celebrated for the superior quality of what they raise. In the province of French Flanders, now the department of Nord, Flax is one of the most important crops cultivated, the quantity raised yearly being large, and the quality very superior. Consul Pringle, in his report of the trade of 1862, says that "a good deal of Flax is grown in the district of Dunkirk. Throughout the entire Department great care is paid to the cultivation and preparation of this valuable fibre, and the quality of what is produced will, in general, contrast favourably with what is grown across the border, in Flanders in Belgium." In the Department of Aisne, good Flax is grown, as well as in the Departments of Moselle, Voges, and others. In Maine (Departments of Mayenne and Sarthe), Flax of excellent quality is cultivated extensively. In Eure and other llepartments of Normandy superior Flax is grown. Bretagne has been long famous for its Flax, especially the Departments of Finisterre, Cote-duNord, and Morbihan, in all of which it is largely raised. Hemp is also grown to a great extent in these and in other districts of France, and the quality is generally very superior, much of it being woven into Linen, for many varieties of which, from its strength and durability, it is well suited.

Much of the Flax raised in France is characterized by fineness of fibre, and it is prised for its spinning qualities. A considerable part of it is well suited for being spun into the finer sizes of yarn, indeed some of it is so very superior that it is admirably adapted for cambric, lawn, and lace, fabrics for which France has long been famous. In addition to the Flax grown in the country, a considerable quantity is imported, the produce of the country not being sufficient for the consumption, The Belgium Flax imported is very similar in quality to the native article, and the Russian Flax bought by the French spinners is almost wholly of the higher marks, little of common quality being used in France.

The very smallest and finest sizes of yarn are still spun by hand, the human fingers being able to produce a thread finer than can yet be made by machinery. There are many Flaxspinning mills in France, where remarkably fine and perfect 
yarns are spun, and which will vie with any produced elsewhere. Lille, Valenciennes, Rouen, Abbeville, Dunkirk, Nantes, Rennes, and several other cities and towns have long been celebrated for their yarns, and others are following fast after them. The Departments of Finisterre and Cotes-du-Nord have several extensive Flax-spinning establishments, and the trade is extending there, as well as in the other districts in France where it has got a footing.

The Linen manufacture is chiefly confined to the northern and western provinces of France, but there are establishments both for spinning and weaving in other parts of the country. Although the trade, as already mentioned, was wholly of a domestic character in former times, and, as in Scotland last century, spread over a great part of the country, it is now gradually settling down in circumscribed localities, where the work is mainly performed in large establishments. The provinces at present most celebrated for their Linens, are French Flanders, Picardy, Isle of France, Normandy, Maine, and Bretagne or Brittany. In some of these the manufacture existed during the palmy days of Rome, and has never since been lost, and in others, although of more recent, it is still of ancient standing.

The towns chiefly engaged in the Linen manufacture are Lille, one of the oldest and most celebrated seats of the manufacture ; Dunkirk, which makes excellent sail-cloth ; Cambray, famed for its cambric, whence the name; and Valenciennes, noted for its lace and lawns, all situate in Nord, in which Department Linen is the most important branch of industry. Abbeville and Amiens, in Somme, make strong and coarse Linens; St Quentin in Aisne, fancd for lawus and lace; Vimoulier and Alençon, in Orne, in the latter of which, a kind of Hempen and Linen cloth is made largely, styled "Toiles d'Alençon," which are held in high estimation, and of which f.om 25,000 to 30,000 pieces are sold annually; Lisieux, Caen, and Bayeaux, in Calvados, famous for lace and lawns, in the manufacture of which they employ upwards of 50,000 hands; Beauvais, in Oise, which produces some of the best Linens made in France; Boulogne and St Omar, in Pay de Calais ; Dieppe, Fecamp, and Rouen, in Seine Inferieure; Bernay, in L'Eure; La Mayenne employs about 10,000 persons in the manufacture of sail-cloth, 
duck, and table Linen, all of excellent quality; Haute Rhine for fine broad Linen and Hempen cloth; Vosges for Linens and lace; Seine et Oise, and Seine et Marne, for Linen and cotton prints, \&c., \&c.

In all the Departments of Brittany, Finisterre, Cote-du-Nord, Morbihan, Ille et Vilaine, and Loire Inférieure, Linens are manufactured to a greater or less extent, and in some of them on a very large scale. The Iinen Company of Finisterre alone employs about 2400 hands, and other large establishments exist throughout that province. At these works sail-cloth; ducks, and almost every variety of fine and coarse Linens are made, the character of which stands very high for excellence of material, and for workmanship. Consul Barrow, in his report of the trade of Nantes, in 1862, says :- "There are three Hemp and Flax spinning factories at Nantes, and there are manufactures of Linen and canvas in the Departments of Loire Inférieure, at some of which several British operatives are engaged. For a number of years past many spinners and other operatives have gone from Britain to France, where they are employed in almost every town where Linen manufactures of any importance are carried on."

In the report of Mr Grey, Secretary to the Embassy, dated Paris, 20th February, 1863, he says "The Flax and Hemp trade feel that the high prices of cotton create an increased demand for these products ; and the raw material, as well as yarns and twists are rising in value." The value of the exports of Linen cloth, \&c., from France as given by Mr Secretary Grey, were in 1859 , f.108,900,000; in 1860, f.104,200,000; and in 1861 , f.79,900,000, which shows a great falling off, especially in the latter year. These figures are greatly in excess of the exports from France already given, and which were extracted from part viii. of the statistical tables relating to foreign countries, published by Government. Perhaps the values. as given by $\mathrm{Mr}$ Grey, embrace both imports and exports, although they are stated in his report as exports only.

In the report of the British Consul at Dunkirk, for 1861, he says that "since 1st June a great increase had taken place in the inport of Linen sheeting and yarn from England. There was a proposal among some of the dealers in these articles to 
import Irish Linen yarn, and after it had been woven into Linen, to send it back to Ireland to be bleached. 'The manufactures of Lille and other towns in this Department will now have the double competition of England and Belgium, and must exert themselves if they wish to maintain their ground. Every article in daily use was so expensive in France, that it was expected the relief to consumers would be great when the new tariff came into operation. 'The principal fuctory was Dickson $\&$ Co.'s for the manufacture of Linen, sail-cloth, and carpets, and which, in 1861 employed 866 hands, whose wages amounted

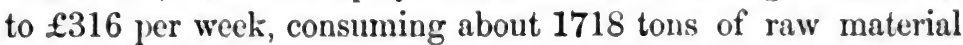

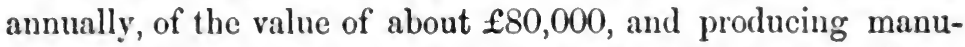
factured goods to the amount of $£ 120,000$, per annum. There was then another small Linen factory in Dunkirk, employing fifty-eight hands, and the product of which was reckoned at $£ 8000$ to $£ 10,000$ annually."

The following report on the Linens and Linen yarns exhibited at the Great International Exhibition of 1862 , written after a careful inspection of them, will conclude the chapter on the Linen trade of France. Under the Emperor Napoleon III. great progress has been made, not only in Linens but in other textile manufactures in France. The state of perfection they have already attained is wonderful, and under the wise and fostering care of so astute a man, they must prosper :-

"After the United Kingdom, and perhaps Belgium, France is the largest exhibitor of Linens. Not only is the collection extensive, but it is very varied in kind, and most excellent in quality. The goods are shown in handsome cases, which sets them off with good effect. 'The position in which some of the stalls are placed is unfortunate, as the cross gallery prerents the light from permeating among them, and throws a shade over some of the cases. Notwithstanding this, the goods have a very splendid appearance, and command much attention. In Class 3 , both Flax and Hemp are shown in the straw, and in various stages of scutching, cleaning, heckling, \&c. The quality of some of the specimens is very superior, and the dressed fibre well adapted for very fine yarns. Yarns spun both from the Flax and Hemp are shown. The Flax yarn is both dry and wet spun, and some of the samples are remarkably fine and well spun. Sail-cloth is 
exhibited made of Flax yarn, and also of Hemp yarn. The Hemp cloth is not very sightly, being rough, but the Flax cloth is well made, firm, and good. The Hemp exhibited, No. 450, is broke and scutched without retting. It appears to be well done, the fibre good, and very suitable both for making into cloth and also for fine twines, \&c.

"In Class 19, Flax and Hemp yarn and cloth of many descriptions are shown. The yarns vary from the finest cambric qualities, to coarse sizes both of Flax and Tow, for sail-cloth, sacking, \&c. In the quality of the spin there must necessarily be considerable variety, but on the whole the samples are very uniform and level. Some of them are remarkably fine, both in quality and spin, and quite equal to those shown from either Leeds or Belfast. Jute yarns are also exhibited, of very good quality, which would do no dishonour to Dundee. Beautifully prepared sewing thread, of many shades of colour, and of different qualities, are also exhibited. Many of the Linens shown are in the loom state, which makes them appear rough and unsightly, but the quality is generally very superior. The bleached and finished goods are got up with much care and taste, and are of great excellence. Twilled tow sacking, plain hemp sacking, double warp plain bagging, and other sorts of coarse goods, are exhibited, the quality of which is strong and good. They are made of well-spun yarn, well manufactured, and very suitable for the purposes intended, but like all Flax tow fabrics, they appear rough and coarse beside Jute goods. Sailcloth is shown by Dickson of Dunkirk and other firms, of remarkably superior quality. The material is excellent, the yarns are well spun, and the cloth is very firm and level, and admirably manufactured. It is shown in the various numbers from 7 to 0 , and in one instance to 00 , and some specimens are equal to any of the goods from this district. Some brown army ducks and similar goods of excellent quality, are shown. Sheetings, shirtings, cambrics, lawns, \&c., are exhibited, made of excellent yarn and finely woven. The cloth is very highly bleached and beautifully finished Very pretty cambric handkerchiefs and dresses, rich, yet chaste, both in colour and design, are shown. Damasks in table-cloths, towellings, dowleys, \&c., are exhibited in the white on brown, and in the full bleached state, the quality 
of which is truly admirable. The design of the damask, is in all cases, rich and beautiful, and, in some of the specimens, it is exquisite, and the finish of all is of the very highest merit. The display is altogether of so great excellence that our home spinners and manufacturers have difficulty in holding their own against their brethren in France. They will be entirely outdone in point of quality, design, bleach, and finish, at no distant day, should they at all relax in their efforts to maintain the superiority they have hitherto held."

\section{CHAPTER VIII.}

R U S I I N L I N E N.

Russra, although now a great country in respect of the vast extent of its territory, is in its intercourse with the other nations of Europe, of comparatively modern origin. Commercially little was known of it three centuries ago, and the trade between Russia and other countries was at that period quite insignificant. Since it first became known to the trading nations of the world, its commerce has extended greatly, and some branches of its trade is now of first-rate importance. Chief among these are its exports of Flax and Hemp, and their products, which now amount to several millions sterling yearly.

Russia has for a long period been the greatest Flax and Hemp growing country of the world. To its cultivation of these fibres the sereral Linen manufacturing countries of Europe have been largely indebted for their staple raw material. It is computed that the quantity of Flax annually raised in Russia is, on the average, about 150,000 tons, of which about one-third is consumed in its native manufactures, and the balance exported. Its Hemp is also largely used in Europe, and in other divisions of 
the world, for cordage, twines, and in many cases for textile fabrics, for the former of which, from its strength and tar absorbing qualities, it is admirably adapted.

In the beginning of the 16th century Russia was not known excepting to a few Flemish merchants, who found the trade profitable, and for a considerable period kept their own secret and the trade to themselves. The English discovered it by chance, after which they were not slow to avail themselves of its advantages. In 1553 an English ship, sent out in search of a north-west passage, touched at the place where Archangel now stands, and this led to the formation, in the following year, of a company of merchants for trading with that country.

In 1555, a treaty was entered into by Ivan Vassiliewitch II. of Muscovy, and Philip and Mary of England, by which a monopoly was granted to the English to trade with Russia. The trade was carried on almost exclusively between the English and the Russian Government itself, private individuals not being allowed the privilege of trading with the foreigners. The English established factories at Kolmogorod, near where Archangel now stands, Novgorod, Vologda, and Moscow, and ultimately extended their commerce by the Caspian Sea to Persia and Bokhara.

The Russia company was incorporated by charter of Philip and Mary, and it was sanctioned by act of Parliament in 1566. The statute 10 and 11, William III., cap. 6, enacts that " every British subject desiring admission into the Russian company shall be admitted on paying $£ 5$; and every individual admitted into the company shall conduct his business entirely as a private adventurer, or as he would do were the company abolished." Duties were payable to the Russian company on all goods imported into England, among which were the following, viz. :Flax, the ton, $9 \mathrm{~d}$; Hemp, $7 \mathrm{~d}$; mats, the $100,2 \mathrm{~d}$; Linen, the 120 ells-drillings, $1 \frac{1}{2} \mathrm{~d}$; diaper, $2 \mathrm{~d} ; 22 \frac{1}{2}$ to $31 \frac{1}{2}$ inches wide, $3 \mathrm{~d} ; 31 \frac{1}{2}$ to 45 inches, $4 \mathrm{~d}$; 45 inches and upwards, $6 \mathrm{~d}$; sailcloth, $3 \mathrm{~d}$; cordage, the cwt., $2 \mathrm{~d}$; linseed, the quarter, $2 \mathrm{~d}$; \&c., \&c. Goods not enumerated to pay one-eighth per cent. ad valorum, on the declaration of the importer.

The exports from Russia at first were chiefly hides, furs, \&c. The imports cloth, and what is remarkable, coarse Linens, which, 
for long after, constituted a large part of the exports to that country. In 165.5, the exports from Archangel were valued at

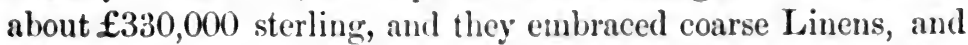
Linen yarns; but no Flax is mentioned, and the export of that article, if any, must therefore have been very small. In the century from the first opening up of the trade to the English until that period, great changes had taken place in the commerce of Russia. Iinens had now ceased to be imported, and were classified among the exports. Instead of the exports consisting of hides and furs, which imply a people dependent on their flocks and herds, or upon the wild animals of the country, and in a state of rude barbarism, they had changed to yarns and eloth, which infer a considerable degree of practical knowledge and skill. The skins and furs are grown to their hand, but the yarns and Linens require that the Flax shall be cultivated, deprived of its woody stem and the fibre cleaned, then spun into filaments, and these wrought into a textile fabric. All these changes indicate acquaintance with the productions of nature, the preparation of them for use, and the mechanical means necessary for accomplishing the alterations they must undergo to adapt them for the purposes they are intended to serve.

In 1724, the monopoly by the Russian Gorernment was totally broken up, and private merchants first established themselves at Archangel, duties being charged, for the benefit of the crown, on the importation of goods. In 1726 the first duties were laid on exports. Compared with the days of the monopoly by the Russian Government, this was a step in the right direction, and the country benefited greatly by this institution of free trade, as will be seen by the following return of the average value of the trule for successive decennial periods from 1724 to 1833 , being in all 110 years.

\begin{tabular}{ccr} 
Ten Years Ending & \multicolumn{2}{c}{ Imports. } \\
1733 & Roubles, 137,535 \\
1743 & , & 181,346 \\
1753 & " & 143,276 \\
1763 &, & 182,054 \\
1773 & " & 327,430 \\
1783 & " & 351,356 \\
1793 & " & 643,737 \\
1803 & " & 555,583 \\
1813 & " & $4,506,290$ \\
1823 & " & $1,215,322$ \\
1833 & "" & 878,364
\end{tabular}

\begin{tabular}{|c|c|c|}
\hline \multicolumn{2}{|c|}{ Exports. } & Average Value of Rouble \\
\hline Houbless & 279,113 & 30.1 to 40.1 \\
\hline ," & 386,728 & " \\
\hline , & $23 \times .410$ & , \\
\hline , & $457,9(9)$ & "' \\
\hline ", & $1,049,68.7$ & . \\
\hline$"$ & $1,385,780$ & $"$ \\
\hline " & $1.89:, 419$ & ", \\
\hline ", & $3,3331,743$ & , \\
\hline " & $6,125,247$ & 231 \\
\hline " & $9,930,434$ & $111 \mathrm{~B} . \mathrm{S}$ \\
\hline ," & $8, \pi 97, \pi 0 \pi$ & 10 \$ 1 \\
\hline
\end{tabular}


These figures, for the period up to 1803 , were extracted from an old manuscript, some time in the possession of a merchant in Archangel. They show that the trade must have declined after 1655 , as it was not until towards the end of last century that the value of the exports reached the same point at which they are stated to be for that year.

The following tables show the exports of Flax, Tow, and Codilla from Archangel, from 1823 to 1.853 ; also the same articles, together with the linseed and mats exported, from 1856 to 1863 :-

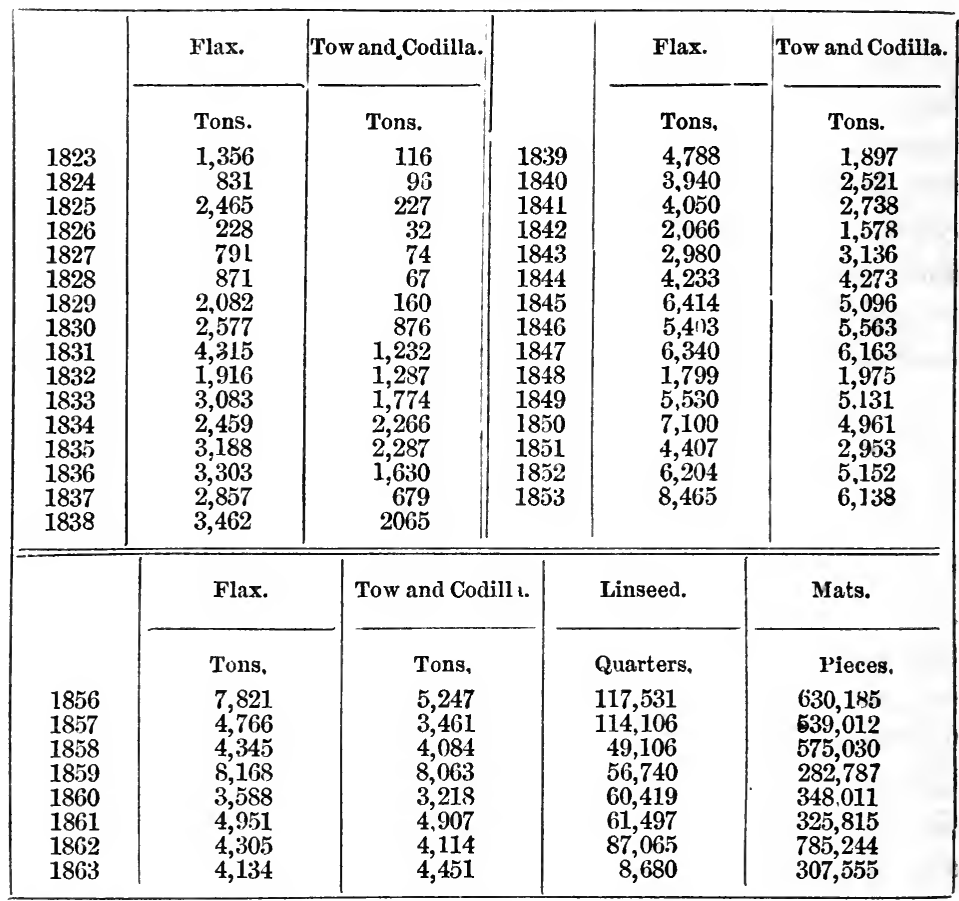

Whereof to Great Britain in 1862-Flax, 4051 tons ; Tow and Codilla, 3086 tons ; Linseed, 33,732 quarters; Mats, 669,574 pieces. In 1863-Flax, 3340 tons ; Tow and Codilla, 3274 tons ; Linseed, 4684 quarters ; Mats, 276,770 pieces.

The Flax goods shipped at Archangel bear a high character in the markets of great Britain. They are grown near the centre of Russia, in the Governments of Vologda, Viatka, Yaroslav, Kostroma, Novgorod, \&c., whence they are taken to Archangel. Some of the districts produce a quality of Flax much superior to others, although the general characteristics of all are the same. 
The Flax is all dew-ripped or retted, of a soft, silky nature, and the fibre reducible by heckling to a high degree of fineness. This makes it admirably adapted for being spun into the higher numbers of yarn. All dew-retted Flax is very apt to heat, both on the voyage and in the warehouse, if confined in a hot place without free circulation of air, and care should be taken to prevent this, as it weakens the Flax very rapilly, and soon totally destroys it.

The Flax grown in the Veligodski district has been long famous for its fineness and softness, and it bleaches well. Viatka has generally a longer fibre, but it is hard and not so well cleaned, and it does not subdivide so minutely on the heckle as the former. Yaroslav produces good serviceable Flax, and so do some of the other districts mentioned above.

Of late years the St Petersburg merchants have bought considerable quantities of Flax in these, which are called the Archangel districts, and there is no doubt that their purchases will yearly increase, because St Petersburg possesses advantages over Archangel by its better internal communications and as a port for shipment. 'The brack of Flax in Archangel, which is rery strict, is a guarantee of quality which shipments from St Petersburg do not possess; and while it continues to be as honourably performed as it has hitherto been, Archangel Flax will be preferred by buyers, even although the price is a little higher than at its rival shipping port. This may tend to preserve a part of the trade to Archangel, especially that of the districts lying nearest to it.

Archangel Flax is divided into Otborny and Crown, but little of the former is now shipped. The Crown is classed into 1st, 2d, and 3d sorts, 4th Crown and Zabrack. The first sort is beautifilly fine, but the quantity of this class is small, and the price relatively high. After laying aside any strikes fit for 1st sort, the next best is put into the $2 \mathrm{~d}$ sort, the next into $3 \mathrm{~d}$ sort, and the worst is 4th Crown. Untii 1862 there were only four classes in all, and the new classification has not yet had sufficient trial to test its merits. Zabrack was formerly the 4th sort of the growths, but it is now let down a step in the brack ladder. Zabrack is Flax too short, or which contains too much tow to be cleaned with the other qualities, and as it is thus the refuse of every growth it is not very uniform in quality.

Codilla is the loose fibres which come off in sorting the Flax in$\mathrm{x} 2$ 
tended for shipment, and it varies in quality with the district in which it is grown. 'The tow exported is taken off in heckling the Flax used in the home manufactures of the district whence it comes, (formerly it was taken off with a brush), and it also varies in quality with the Flax from which it is taken. Codilla is classed by the brackers into 1st, $2 \mathrm{~d}$, and 3 qualities, and tow into Nos. 1 and 2 qualities; and both tow and codilla, from their fine and soft fibre, possess superior spinning qualities.

The Flax shipped from Archangel is made up in small handfuls or strikes, and packed in mats of about five hundredweight. 'The tow and codilla are also packed in mats of about the same weight. The tow is in small handfuls, as it comes off the heckle, and the codilla generally in fleeces or flakes, rolled to gether at the one end and loose at the other.

Both Flax and tow from Archangel are clean, soft, and silky, and pretty free from shives. The codilla, which is longer and stronger in the fibre than tow, is also comparatively free from shives, excepting the $3 \mathrm{~d}$ sort, which is the coarsest of the scutchings taken off the Flax.

$\mathrm{Mr}$ Consul Renny, in his report on the trade of the district of Archangel for 1862, says:- "The export of Flax and Flaxtow shows a decrease for 1862, principally owing to the fact that in the farther districts which supply this port, the Archangel traders find themselves less and less able to compete with buyers for the St Petersburg market, and for the Russian factories. The advantages which St Petersburg possesses over Archangel are a lower scale of shipping charges (there being no charges for " brack," or indirect banking business), cheaper freights and rates of exchange. On the other hand Archangel boasts of an excellent Flax brack, which forms a guarantee of quality to foreign buyers, and where the difference of cost is not too great they prefer shipment from Archangel. This circumstance will, at all events, secure to this port the export of Flax from the nearer districts of its growth, and the quantity will probably be sustained about its present standard." The average rates paid for Flax per ton in 1862 was $£ 4810$ s, and for Flax-tow $£ 343$ s 6 d. In 1863 they were $£ 585 \mathrm{~s} 6 \mathrm{~d}$, and $£ 40$ 13s $6 \mathrm{~d}$, respectively.

At one period large quantities of Hemp were shipped at Archangel, sometimes extending to 1500 tons a year, but the article 
is now almost unknown in the exports from that port. 'The great shipping ports for the Hemp of Russia are now Riga and St Petersburg.

For a long period after the opening up of the trade of Archangel, that city was the only port accessible to Europeans, and the whole import and export trade of Russia was transacted there. The fort of Archangel, from its geographical position, is only open for about five months, being completely ice-bound during the remainder of the year, which is a great drawback to its trade, and confines it to comparatively narrow limits. Peter the Great felt this, and determined, so far as in his power, to obviate such a serious hindrance to the indefinite extension of the commerce of his country, by erecting cities on the Baltic. None of the Russian towns on that sea are open throughout the whole year, but the winter in some of them does not last more than three or four months, so that they are only sealed up about half as long as Archangel annually is.

The city of St Petersburg was founded in 1703, and, under imperial patronage, it speedily became a flourishing emporium of trade and commerce. From its position and from other causes, it attracted part of the trade to itself which had previously been all transacted at Archangel, anong which was the export of Flax, Hemp, and Linens. The city being erected at some distance up the Neva, Cronstadt, situated on a small island about twenty miles below, may, in some measure, be considered the port of St Petersburg, as only vessels with a small draught of water can get up to the city.

Large quantities of Flax and Hemp are now shipped at St Petersburg yearly, as well as canvas and various sorts of Linens, and these articles form a most important portion of the exports from that city, and from its port. The mode of bracking and making up Hemp has been detailed in the chapter which treats of that fibre. The Flax shipped there consists of the white sorts known as St Petersburg Flax, and of the St Petersburg Archangel qualities. 'The latter differs little from the real Archangel described above, excepting that among the dew-retted or brown Flax shipped from this port, there are varietics of an inferior quality, such as Rjeff, \&c., much of which is unfit for the purposes to which this description of Flax is usually 
applied. The white Flax, when assorted, is made up in bundles of 12,9 , or 6 heads, which are called bobbins; and they are tied up with strings, each sort having a stated number. It is not matted when shipped, as the other description is. It is known to the trade under these denominations, the 12 head being the best, and the 6 head the worst of the three qualities. This Flax is steeped in ponds to prepare it for the process of scutching, instead of being laid on the grass and dew-retted as the Archangel sorts are. It is grown in the Governments around St Petersburg, chiefly in Novgorod, \&c, and it is longer, broader, and stronger in the harle or fibre than the dewretted sorts; but it is not even, and therefore it yields less pure Flax on the heckle, and the fibre does not subdivide so much in heckling The Flax raised in some of the St Petersburg districts is much superior, and of a different character, to what is grown in others; thus Pskoff or Ostroff 12 heads is more valuable than ordinary 12 heads. The Flax shipped from Narva, a port in the Gulf of Finland, below Cronstadt, is made up in a similar manner, and under the same names as St Petersburg goods, and the quality is generally preferred to the latter. 'The shipments from Narva average about 2000 tons of Flax, and 500 tons of codilla yearly.

Formerly St Petersburg (white) Flax was much superior to what it now is, the 9 heads in former times being quite equal to the 12 heads of the present day. Then it was regularly classified according to its quality, and made up into bundles by sworn inspectors or brackers, appointed by Government. These functionaries for a time performed their duties with laudable impartiality, but latterly buyers lost confidence in them, and the brack was discontinued. Now it is made up in the interior by the dealers' own inspectors, who, of course, follow the instructions of their employers. Free on board buyers must therefore trust to the honour of the dealers from whom it is purchased, as the merchants see little of the Flax, and are very much at the mercy of those with whom they may have contracted for its delivery. These dealers go into the interior during the winter, purchase the Flax from the farmers and growers, and bring it down classified to the shipping port, where it is delivered over to the merchants, and by them shipped. Government inspection and all 
interference between the producer and purchaser of any commodity is bad in principle, and often injurious in practice, but there is no doubt that the excellent brack in Archangel, and the tolerably fair brack in Riga, have retained a character for the shipments from these places, which other ports, where the system has been discontinued, have lost.

The shipments from St Petersburg for the years mentioned were as follows:-

\begin{tabular}{|c|c|c|c|c|c|}
\hline & Flax, \&c. & Hemp, \&c. & & Flax \&c. & Hemp, \&c. \\
\hline & Tons. & Tons. & & Tons. & Tons \\
\hline 1825 & 7,324 & 32,367 & 1843 & 6.767 & 22,037 \\
\hline $1826 i$ & 7,432 & 29,339 & 1844 & $7,0,53$ & 27,530 \\
\hline $182 \%$ & 11,192 & 30397 & 1845 & $7,1: 35$ & 30003 \\
\hline 1828 & $10,8 \times 4$ & $29,1 \div 7$ & 1846 & 8,567 & 26,045 \\
\hline 1829 & 6,685 & 16.387 & 1847 & 9,362 & 28,395 \\
\hline $18: 30$ & 9,365 & 21,673 & 1848 & $14,79: 3$ & 24,629 \\
\hline 1831 & 4774 & 24,678 & 1849 & 16,689 & 30991 \\
\hline 1832 & 8,472 & 29,136 & 1850 & 15,070 & 28,$836 ;$ \\
\hline $18: 33$ & 5589 & 31,582 & 1851 & 9,650 & 29,970 \\
\hline $18: 34$ & 5,373 & 30,035 & 1852 & 13.311 & 26,562 \\
\hline 1835 & 3.595 & 32,215 & 1853 & 20,569 & 37,793 \\
\hline 1836 & 10,657 & 31,667 & 1858 & 18,764 & 22,945 \\
\hline 1837 & 8,565 & 31.579 & 1859 & 20,930 & 28,900 \\
\hline 1838 & 14,229 & 35,587 & 1860 & 19,117 & 27,820 \\
\hline 1839 & 3716 & 35,621 & 1861 & 20.593 & 25,293 \\
\hline 1840 & 7.919 & $28.88 \tilde{5}$ & 1862 & 26,450 & 28,233 \\
\hline 1841 & 7,505 & 22,781 & 1863 & 22,591 & 24,627 \\
\hline 1842 & 9.233 & 20,349 & & & \\
\hline
\end{tabular}

Very large quantities of Linens, the manufacture of Russia, were also exported from St Petersburg, but of late years the shipments have declined. The quantities for the years mentioned were-

\begin{tabular}{|c|c|c|c|c|c|c|c|}
\hline \multicolumn{8}{|c|}{ Of which to Great } \\
\hline Kavens ducks, & Pes., & 122,060 & 78,154 & Pcs., & 43,506 & Pcs., & 8,500 \\
\hline Flems, . & & 46,312 & 23,428 & "' & 65,327 & ", & 1,340 \\
\hline Sailcloth, & Arsb., & 64,204 & 310 & & 40,868 & , & 26,000 \\
\hline Diaper-broad, & , & 393,470 & 80,860 & Arsh., & $1,465,229$ & & \\
\hline ", -narrow, & , , & 117,806 & 87,988 & ", & 50,750 & Sh., & \\
\hline Linen-broad, & , & 56,000 & 56,000 & $"$ & 60 & ", & None. \\
\hline ", -narrow, & , & 203,540 & 191,540 & ", & None. & " & None. \\
\hline Crash, . & , & $1,081,830$ & $1,058,555$ & " & $1,111,301$ &, 4 & $4,425,090$ \\
\hline Drillings, & ", & 3,889 & 3,519 & , & 338,487 & , & None. \\
\hline Hemp-clean, & Pds., & $1,495,5222$ & $1,104,26 i$ & Pds., & $5,33,343$ & Pds, 1 & $1,258,527$ \\
\hline ", -outshot, & , , & 238,699 & 88,173 & ", & 532,731 & 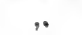 & 71,002 \\
\hline ," -half cleas & n, & $23 i, 837$ & 161 & ", & 303,716 & ", & 222,007 \\
\hline ," -codilla, & ' & 30,073 & 19.516 & " & 26,032 & $"$ & None. \\
\hline Flax -12 head, & ", & 456,743 & 431,307 & ", & 126,519 & ", & 504,996 \\
\hline , -9, & 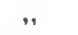 & $40,50 i$ & 32.761 & , & 252,265 & ," & 269,432 \\
\hline , $-6 \quad$, & "' & $32:$ & 323 & ", & 120,149 & , & 293,104 \\
\hline Tow and Codilla & , , & 15,481 & 8,519 & $"$, & 94,6533 & ", & 355,695 \\
\hline
\end{tabular}


Next to Narva, lower down the Gulf of Finland, is Revel and in the Gulf of Riga, Pernau, both of which are Flax shipping ports. The Flax shipped from Revel averages about 1000 tons a year, and the codilla about 200 tons. It is mostly grown in Esthonia, and the quality is strong and good. From Pernau the shipments of Flax average about 4500 tons a year. In 1863 they were about 5000 tons. It is chiefly raised in Esthonia and Livonia, and considerable attention is paid to the classification and sorting of the goods shipped. Pernau Flax therefore stands high in the estimation of consumers in Dundee, and deservedly so, as it is of good strong fibre, well cleaned, and possessed of superior spinning qualities The Flax shipped from Revel and Pernan consists of what was called Crown Marienburg, Marienburg Cut, Hoffs Threeband, and Risten Threeband. They are now called-M, Marienburg ; C, Cut ; R, Risten ; HD, Hoffs Threeband; D, Threeband; OD, ordinary or inferior Threeband.

Riga ranks next to St Petersburg in the extent of its exports, and in the important article of Flax it has long taken the lead in the superiority and regularity of the quality shipped, as well as in the quantity. Formerly the Flax was distinguished by a few well known names, either those of the provinces or estates in which it was grown, or arising from the manner in which it was tied up in heads or bundles. The following short description of the old Riga marks will not be without interest to modern dealers in Flax:-TR-Thiesenhausen Rakitzer, (grown on the estate of Count Thiesenhausen), was of a long harle, strong, even, clean, white and soft. From a custom which the country people had in wetting their hands in working or preparing this assortment, it made it unfit for long voyages in a warm climate, as it was apt to heat. The picked parcels of this description was called PTR. DR-Drujana Rakitzer, was rather finer in fibre, not quite so long, but clean, soft, white, and silver coloured, and fit for spinning into the finest yarns. It was not prepared with moist hands, and was generally shipped to Spain, Portugal, \&c. Lithuania and Courland Rakitzer was not so good in quality as the other sorts. It was commonly tied up in ban ls of four handfuls, doubled at one end. CM-Crown Marienburg, was a description a little superior even to the above marks with a very long stout harle, white, or of a bluish tinge of colour, 
and much liked in Britain. Since the names of the Riga Flax were changed a few years agro, these qualities are now represented by the different marks of Crown Flax, such as PK, FPK, \&c.

DC-Drujana Cut was the rejections made in bracking the Rakitzer, in consequence of not being so well cleaned, or from some other cause. Marienburg Cut was in like manner the refuse of the CM. This mark was made up in bundles, loose at both ends, and tied in the middle in such a manner as to leave a gash resembling the cut of a knife. They are now represented by the $\mathrm{W}$ marks. R'T-Risten Threeband was in like manner the refuse of the DC and $\mathrm{IC}$, and is now represented by the D marks. 'The Livonian Flax is denomnated at Riga, HD, Hoffs Threeband. This mark was tied up in bundles, loose at both ends, and fastened with two or three strings in the middle. Hoffs are still shipped extensively, and as the fibre is strong, and the yield on the heckle considerable, it is very suitable for sailcloth and other purposes where strength is required. The refuse of this Flax is LD, Livonian Threeband. The green ends on Livonian Flax is caused by tying the end, and hanging it over a rope or pole in bleaching or retting. DC cost about Ro. 5 less than TR, and RT from Ro. 3 to 4 less than DC. Riga Flax is generally shipped in mats of from 3 to $4 \mathrm{cwt}$. each. The Flax shipped the year it is raised is called fresh, and it possesses more elasticity, and spins better than when long kept.

The exports from Riga in the years noted were as follows:-

\begin{tabular}{|c|c|c|c|c|c|}
\hline & Flax, \&c. & Hemp, dec. & & Flax, \&c. & Hemp, \&c. \\
\hline 1825 & $\begin{array}{l}\text { Tons. } \\
23,701\end{array}$ & $\begin{array}{r}\text { Tons. } \\
11,828\end{array}$ & 1844 & $\begin{array}{r}\text { Tons. } \\
37,5288\end{array}$ & $\begin{array}{c}\text { Tons } \\
19,955\end{array}$ \\
\hline 1826 & 23,383 & 10,415 & 1845 & 21,052 & 15.286 \\
\hline 1827 & 24,758 & 11,587 & 1846 & 21,449 & 16,954 \\
\hline 1828 & 21,377 & $11,1 \leqslant 6$ & 1847 & 19,042 & 15,168 \\
\hline 1829 & 24,394 & $10+87$ & 1848 & 34,240 & 13,245 \\
\hline 1830 & 19,807 & 12.360 & 1849 & 45,344 & 16,239 \\
\hline 1831 & $1 \times, 19 \overline{5}$ & 11,833 & 1850 & 38,637 & 13,883 \\
\hline 1832 & 20,533 & 13,833 & 1851 & 27,529 & 17,967 \\
\hline 1833 & 25,474 & 11,797 & 1852 & 33,387 & 15,678 \\
\hline 1834 & 13,734 & 15,022 & 18.3 & 32,956 & 18,912 \\
\hline 1835 & $13,8: 6$ & 15,477 & 1856 & 40,617 & 24.901 \\
\hline 1836 & 28,415 & 13494 & 1857 & 44,829 & 20,412 \\
\hline 1837 & 20,128 & 13,875 & 18.98 & 31,777 & 20,747 \\
\hline 1838 & 30,322 & 15,166 & 1859 & 24,904 & 25,050 \\
\hline 1839 & 22,257 & 21,374 & 1860 & 31,327 & 21,267 \\
\hline 1840 & 23,735 & $20,14 x$ & $181 ; 1$ & $27,9.5 ; 3$ & 20663 \\
\hline 1841 & 26.802 & 17,424 & 1 wit2 & $33: 207$ & 20,295 \\
\hline 1842 & 29,185 & 19,275 & 1863 & 32,472 & 17,019 \\
\hline 1843 & 37.782 & 15,219 & & & \\
\hline
\end{tabular}


Destination of Flax and Hemp Shipped from Riga in 1860 and 1861, aNd of Crushing and Sowing Linseed and Hemp Seed For 1861.

Countries.

Flax.

\begin{tabular}{|c|c|c|c|c|c|}
\hline \multicolumn{3}{|l|}{ Countries. } & \multicolumn{2}{|c|}{1860.} & 1861. \\
\hline \multicolumn{3}{|c|}{ Great Britain, } & \multicolumn{2}{|c|}{ Tons, 25,277 } & 19,452 \\
\hline France, & $\cdot$ & • & ", & 5,687 & 4,306 \\
\hline Belgium, & . & • & , & 2,159 & 1,486 \\
\hline Sweden and & Norwa & & , & 206 & 412 \\
\hline Prussia, & . & . & , & 497 & 394 \\
\hline Portugal, & • & • & ", & 478 & 355 \\
\hline Denmark, & . & • & ," & 774 & 351 \\
\hline Holland, & . & . & , & 139 & 227 \\
\hline Lubeck, & . & . & $"$ & 153 & 129 \\
\hline Bremen, & . & . & , & & 3 \\
\hline Hanover, & . & . & , & 78 & $\ldots$ \\
\hline Spain, & - & - & , & 16 & $\ldots$ \\
\hline \multirow[t]{2}{*}{ America, } & - & - & $"$ & $\ldots$ & ... \\
\hline & & & & 35,464 & 27,115 \\
\hline
\end{tabular}

Hemp.

In 1861, Crushing linseed. Sowing Linseed.

Great Britain, Imp. Qrs., 73,147 Barrels, 45,345

Holland, 16,346

Holland, .

Belgium, . . " " $14,274 \quad$ " $\quad 50,401$

Denmark, . . $\quad " \quad 2702 \quad$ " 44

Sweden and Norway, ", $\quad 1,942 \quad " \quad 1,123$

France, . . " $\quad 1,532 \quad$ ", 24,450

Lubeck, . . " $\quad 278 \quad, \quad 21,795$

Prussia, . . " $\quad 5 \quad$ " 10,625

Portugal, . $\quad " \frac{2}{110,228} \quad " \frac{\cdots}{158,938}$

$1860 . \quad 1861$.

\begin{tabular}{crr} 
Tons, & 10,188 & 9,070 \\
, & 1,570 & 2,220 \\
$"$ & 2 & 442 \\
$"$ & 1,914 & 2,827 \\
$"$ & 595 & 780 \\
$"$ & 264 & 434 \\
$"$ & 1,026 & 949 \\
$"$ & 2,946 & 2,456 \\
$"$ & 883 & 1,068 \\
, & 300 & 135 \\
, & $\ldots$ & $\ldots$ \\
, & $\ldots$ & $\ldots$ \\
$"$, & 421 & 282 \\
\hline & 20,109 & 20,663 \\
\hline
\end{tabular}

Hemp Seed.

Imp. Qrs., 781

\begin{tabular}{rr}
$\prime$ & $\cdots$ \\
$"$ & 1406 \\
$"$ & 124 \\
$"$ & 118 \\
$"$ & 20 \\
$"$ & $\cdots$ \\
$"$ & $\cdots$ \\
\hline
\end{tabular}

Quantity of each Quality of Flax and Hemp Shipped from Riga IN 1861 AND 1862.

1861.

FLAX.-1st sort Poods, 810,967 or Tons, 12,872

$$
\begin{aligned}
& 2 \mathrm{~d} \quad, \quad 510,539 \quad, \quad 8,104 \\
& 3 d \quad " \quad 386,650 \quad " \quad 6,137 \\
& \text { 4th } \quad, \quad \ldots . . \quad, \quad \ldots . . \\
& \text { Poods, 1,708,156 ", 27,113 }
\end{aligned}
$$

Flax Codilla. - Poods, 52,909 or Tons, 840

$$
, \quad \longdiv { 1 , 7 6 1 , 0 6 5 } \quad \underline { 2 7 , 9 5 3 }
$$

HEMP.-1st sort Yoods, 650,105 or Tons, 10,319

$$
\begin{array}{rrrrr}
\text { 2d } " & 253,113 & & 4,017 \\
3 d \quad " & 398,598 & & 6,327 \\
& & & \\
\text { Total Poods, } & \underline{1,301,816}
\end{array}
$$

\begin{tabular}{|c|c|c|c|}
\hline " & $2,092,083$ & ", & 33,207 \\
\hline Poods, & 683,601 & Tons, & 10,851 \\
\hline , & 221,790 & , & 3,520 \\
\hline$"$ & 373,214 & " & 5,924 \\
\hline , & $1,278,605$ & ", & 20,295 \\
\hline
\end{tabular}

1862.

Poods, 1,159,902 or Tons, 18,411

$\begin{array}{rrrr}\text {, } & 524,547 & , & 8,326 \\ , & 181,221 & \text { " } & 2,876 \\ , & 151,375 & , & 2,403 \\ & 2,017,045 & & 32,016\end{array}$

Poods, 75,038 or Tons, 1,191 
The value of the exports of Flax, Hemp, and Linseed shipped from Riga in 1859 and 1861 was as follows :-

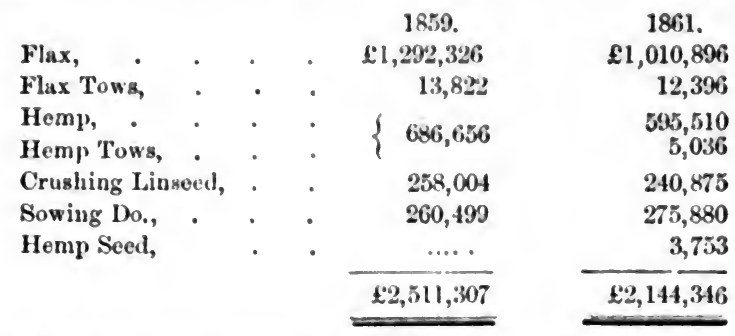

The total value of the exports from Riga in 1861 was Ro. 24,203,320, which at the exchange of $360 \mathrm{~d}$ is $£ 3,630,498$.

Libau is the Russian port farthest down the Baltic from which Flax is shipped. The growths are distinguished by Four Brand and Three Brand, the same as the ordinary Memel Flax. It was generally good, well prepared Flax, but not very fine in the fibre, and not well suited for spinning into the lighter sizes of yarn. It is chiefly raised in Courland, in which province Libau is situated, and the average quantity shipped from the port annually was about 2000 tons of Flax, and 200 tons Codilla. Of late years the quality of the Flax exported from Libau has deteriorated greatly, and the shipments have in consequence fallen off.

Pro forma Invoices of Flax, \&c., Shipped from Russia.

1. Flax from Archangel-

630 Poods, or 63 Berkz, or 10 tons, at 8. ro. 40 per Berkz.

8. ro. 2520.00

Duty 83 cop. per berkz. 52.29 ; 5 per cent. cent. thereon, 2.61

Customs, 7 per cent. thereon, . . . $\quad 3.84$

Shipping Charges, weighing, binding, bracking, lighterage, and watching, 16 cop. per pood, $\quad 100.80$

Mats, 80 at 19 cop., . $\quad$. $\quad$. 15.60

Town dues, d per cent. on cost, $\quad$. $\quad$. 1260

Brokerage, o " " $\quad$. . 12.60

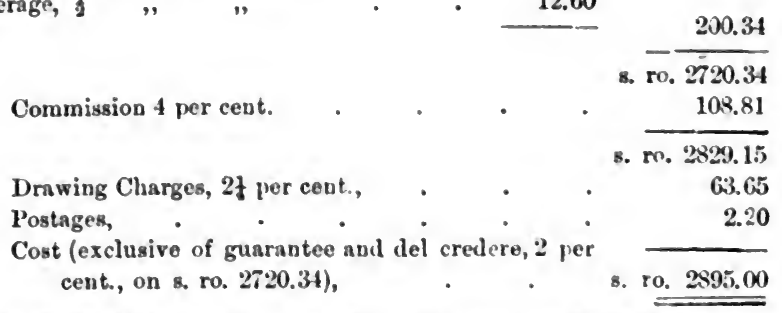

At Exchange, of $36 \mathrm{~d}$ per ro., $\mathfrak{1 4 4} 5 \mathrm{~s}$ per 10 tonk, or $£ 43836 \mathrm{~d}$ a ton. 
2. Tow and Codilla from Archangel-

630 poods at ro. 30 per berkz., or ro. 6 per 2 poods, viz.,

1 of lst sort and 1 of $2 \mathrm{~d}$ sort, . . .

Duty 5 cop. per pood, and 5 per cent. thereon, $\quad 33.05$

Customs, 7 per cent. thereon, . $\quad$. $\quad$. $\quad 2.31$

Shipping Charges, 16 cop. per pood, . $\quad$. 100.80

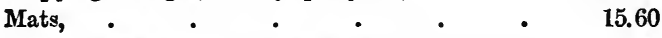

Town dues and Brokerage, $\frac{1}{2}$ per cent. each, $\quad 18.90$

8. ro. 1890.00

\begin{tabular}{|c|c|c|c|c|c|}
\hline & & & & & 0.66 \\
\hline & & & & s. & ro. 2060.66 \\
\hline Commission, 4 per cent, & - & - & - & • & 82.42 \\
\hline & & & & s. & ro. 2143.08 \\
\hline g Charges, $2 \frac{1}{4}$ per & cent., & . & . & • & 48.22 \\
\hline Postages, \&c, & . & . & . & • & 1.70 \\
\hline
\end{tabular}

At Exchange 36d per s. ro. $£ 328,19$ s per 10 tons, or nearly $£ 3218$ s a ton.

3. Flax from St Petersburg-

630 poods at s. ro. 40 per berkz. of 10 poods, .

s. ro. 2520.00

Duty $83 \mathrm{cop}$. per berkz., and 5 per cent. thereon, $\quad 54.90$

Entry and Custom House Charges, 4 per cent.

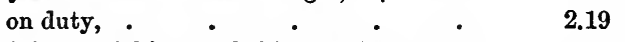

Receiving, weighing, and shjpping, 75 cop. per

$\begin{array}{llllll}\text { berkz., } & . & . & . & 47.25\end{array}$

Ship brokerage, and Cronstadt commission, 18

$\begin{array}{lllllllll}\text { cop. per ton, } & . & . & . & . & 1.80\end{array}$

Brokerage on Purchase, $\frac{1}{2}$ per cent., . $\quad$. $\quad 12.60$

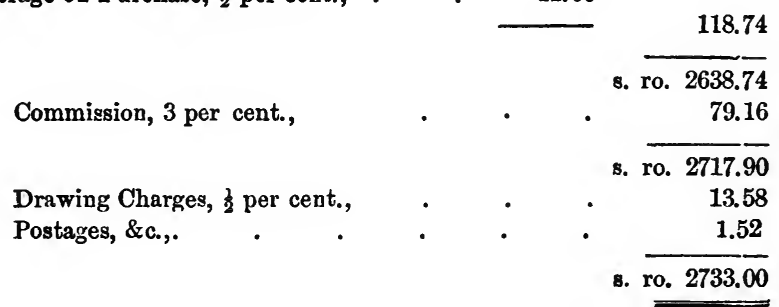

At Exchange 36d per s. ro. $£ 409$ 19s per 10 tons, or nearly $£ 41$ a ton.

4. Flax from Riga-

630 poods at s.ro. 40 per berkz. of 10 poods. . . s. ro. 2520.00

Duty 83 cop. per berkz., and 5 per cent. thereon, $\quad 54.90$

Shipping Charges, ro. 2.55 per berkz., $\quad$ - $\quad 160.65$

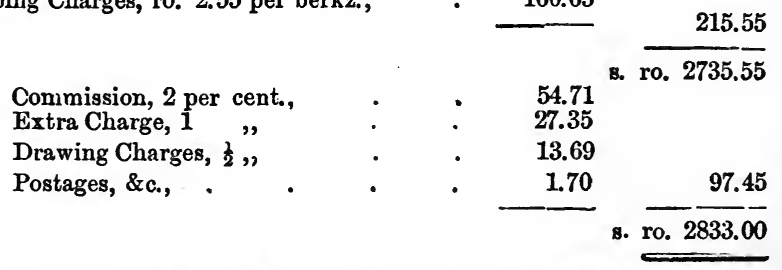

At Exchange 30d por 8. ro, $£ 42419$ s per 10 toris, or nearly $\$ 4210$ s a ton. 
List of the present marks, with English and German designations, of the various qualities of Flax shipped from Riga, with the relative value of the respective marks in 8 . ro. per berkz., taking s. ro. 40 for $\mathrm{K}$. I. as the standard.

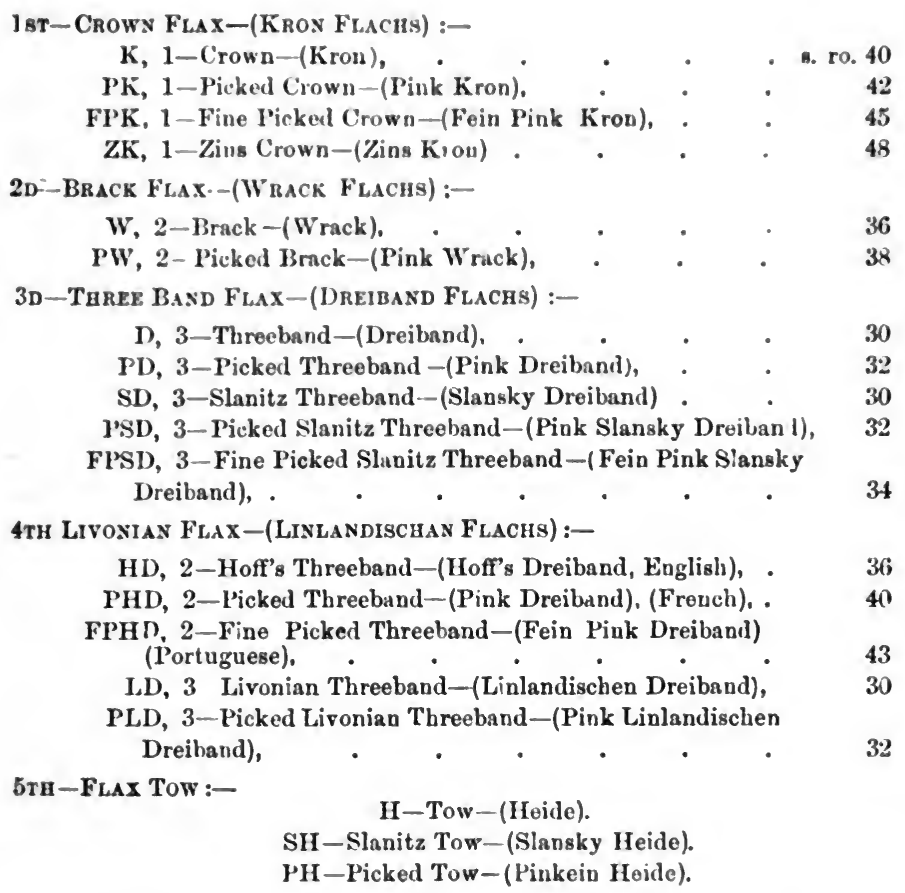

In these marks shippers have the liberty of adding to the above, as hitherto, viz.:-W, White, (Weiss)-H, Light, (Hell) -G, Gray, (Grau). DW, 4, Threeband Brack, (Dreiband Wrack) - the refuse of the Flax is likewise shipped. Nos. 1 and 2 are charged the lowest rate of freight, and Nos. 3 and 4 pay a little extra, as they are coarser and do not stow so well as clean Flax.

The following statement shews the total quantity of Flax and 'Tow exported from Russia and shipped at the ports already mentioned, viz., Archangel, St Petersburg, Narva, Revel, Pernau, Riga, and Libau, for the years named, and also the average shipments for the three previous years :- 


\begin{tabular}{lrrr} 
& & \multicolumn{2}{c}{ Average Three Previous Years. } \\
1835 & Tons, 27,158 & & \\
1838 & $"$ & 59,264 & Tons, 39,510 \\
1841 & " 52,166 & " & 48,686 \\
1844 & " 64,782 & & 55,613 \\
1847 & " & 76,874 & 54,017 \\
1850 & " 79,656 & " & 73,582 \\
1853 & & & 66,306
\end{tabular}

During the two years subsequent to 1853 , very few goods were shipped at Russian ports, in consequence of the blockade during the war. Large quantities of Flax and other Russian produce then found their way to Prussian ports, and were exported thence. After the war the shipment of goods direct from Russia was again resumed, comparatively little Flax, the growth of Russia, having then been sent via Prussia.

Previous to the war a good deal of the Flax grown in Wilna, and other Russian provinces adjoining Prussia had been purchased by Prussian merchants, and shipped from Memel and Konigsberg. The quantity of Russian Flax now shipped at these ports is on the increase, and from Konigsberg it is likely to go on extending year by year, as facilities are opened up for communication with the interior of Russia.

Already the Eydlkuhu Railway has brought Konigsberg much nearer to some of the central provinces of Russia than they are to any Russian port, and as railway ramifications extend into Russia, that port will become more and more an entrepot for shipping Russian produce. Konigsberg, from its position, is specially suited for becoming the port of Poland, as well as of the Russian provinces more to the south and east. From its geographical situation it is not long closed with ice, and shipments can therefore be made from it during the greater part of the year. This advantage has already drawn to that city some of the Flax usually exported from Riga, which is shipped under the regular Riga denominations or marks, and Flax from other districts will no doubt ere long find its way there also. In this way the Russian grower in the interior will be benefitted by quicker sales and better prices, and the consumer more quickly supplied with the raw material. Some details regarding the shipments of Russian Flax from Memel and Konigsberg are given in the chapter on German Linen. 
A considerable quantity of Russian Flax has for many years been conveyed over land to Silesia and other Linen manufacturing districts, where it is used in addition to the home grown production. Russia may therefore be said to supply with Flax, in whole or in part, many of the Linen producing countries of Europe. The total export of Flax and Tow from Russia by land and sea has not been obtained with accuracy, but it is believed rather to exceed than be under 100,000 tons a year on the average. The quantity of Flax annually grown in Russia is estimated, as already mentioned, at 150,000 tons, and if these computations are correct, it would leave about one-third of the quantity raised for consumption in the native Linen manufactures of the country. Of course the produce of the crop is subject to many fluctuations and changes, arising from the weather, political events, and other causes. The value of the Flax exported from Russia varies greatly in different years, but, on the average of the last ten years, perhaps $\mathfrak{£ 4 0}$ a ton would not be too much to estimate it at, and this would give a sum of about four millions sterling, paid annually to Russia by the Linen manufacturing countries, for Flax alone.

The value of the crushing and sowing linseed, and of the Hemp seed annually exported from Russia, may be fairly estimated at about one million sterling. Hemp and its products perhaps amount to about two millions, and Linen manufactures. mats, and other textile fabrics, to another million sterling. The value of these fibrous materials, and their products, exported annually from Russia, would, if these estimates are nearly correct, amount to about eight millions sterling. It is therefore of immense consequence to Russia, mighty though that empire be, to retain so lucrative and so vast a trade, and the government ought to encourage it by every means in their power. In this way Russia would retain the proud title which she has long held, of being the greatest Flax growing country in the world.

Although Russia has many facilities for manufacturing Linens, arising from the great quantity of Flax raised in the country, from cheap labour, and from fiscal protection, she has never attained to eminence as a Linen manufacturing nation. It is true she has supplied her own wants, the almost prohibitory tariff having prevented any foreign made Iinens, excepting small quantities 
of the very finest fabrics, from entering the country. She has also exported Linen for many years, but considering the capabilities of the country; her exports of these textiles when at the greatest would have been trifling although they had been quadrupled in quantity.

Linens to a greater or less extent are made in many of the governments of Russia, some of which are widely apart, which shows the universality of the trade, if not its magnitude. Yaroslav, Novgorod, Viatka, and all the Archangel Flax growing districts, make Linens extensively, chiefly for domestic purposes. The tow shipped at Archangel and St Petersburg is the produce of the Flax heckled, spun, and manufactured in those districts, and it is evidence of the large quantity of pure Flax goods made there. In addition to the tow exported, there are many spinning mills in these districts where Flax and tow are consumed extensively, the quantity of Flax used in the manufactures of these governments must therefore be great. A good deal of the yarn is yet spun by the hand-wheel, but this ancient mode of spinning is being rapidly superseded by Flax spinning mills, now scattered throughout these governments, the number of which is on the increase. The Linens are still mostly weaved by hand, but power-looms are not now unknown there, and their introduction is extending gradually and regularly.

One very large establishment, the Alexandrosky Works, not far from St Petersburg, was formerly worked by the Government, or under their anspices ; but the Government interest or patronage was recently terminated, and it is now conducted by private enterprise and skill. In the interior the great bulk of the Linens produced are required to supply the domestic wants of the various districts, but for many years a large quantity of the cloth made at the Government works near St Petersburg was exported. The goods chiefly made in Russia are sail-cloth, ducks, Russia sheetings, crash, and other fabrics, some of which are adapted more for local consumption than for export. In 1860 a Flax spinning-mill was started in the environs of Riga, being the first in that district. It then employed 118 hands, and the value of the manufacture for that year was $£ 5920$.

Linens are also manufactured in several of the provinces of 
central and southern Russia, as well as in some of those near the Baltic ; but perhaps the largest private establishment of the kind, which embraces both spinning and weaving, is that of Baron Steiglitz, near Narva, where sail-cloth is made to a large extent, as well as several other fabrics. In 1836 there were 3742 Flax mills and manufactories in Russia; in 1842, 3696 ; and in 1850, 3967. The number at the present time has not been ascertained, nor have any reliable particulars been got as to the number of spindles or looms in operation.

The Russian made Linens have generally been more celebrated for the superior quality of the Flax of which they were made, than for beauty of workmanship, or the sightly appearance of the cloth. The quality of the material used has always been remarkably good, but the yarn has neither been so well spun nor cleaned as in this country, and the appearance of some of the fabrics made is coarse and unsightly. They have not, consequently, been so well liked in this market, as, from their intrinsic merits, might have been expected. Some Russian Linens, however, are as good in appearance as they are excellent in quality. Real Russia sheetings are a well known article in many markets, and although they are now well imitated in this country by mixed fabrics, which can be sold cheap, many still prefer the genuine Russias, even at the additional price. Crash is another article which was and still is largely made in Russia, and it also has been successfully imitated in Dundee and elsewhere. Ravens-duck and sail-cloth have long been famous articles of Russian manufacture, but both fabrics, of a quality equal in material and superior in workmanship, have been made in the Dundee district, and in other parts of this country for many years. These imitations have of late years interfered so largely with the sale of Russian Linens in foreign markets, as greatly to curtail their manufacture in Russia for export. Jute, and mixtures of Jute, being cheap and sightly, have done much to banish Russian Linens from the markets of the world, and probably they are destined ultimately to supplant them entirely.

The absolute and arbitrary character of the Russian Gorernment, and their jealousy of the introduction of liberal ideas into the country, have done more to retard the progress of manufac- 
tures, including those of Linens, in Russia, than their prohibitory tariff has aided it, and so long as such a system exists, trade cannot prosper. The severe restrictions upon commerce, and the unwise fiscal regulations of government, curb private enterprise, and until more enlightened principles prevail, trade must languish, or die. Did the Government know its true policy, and study the best interests of the nation, it would allow the people freedom of thought and action. Manufactures and commerce would then extend rapidly, and Russia become great and exalted. The country would speedily grow rich in material wealth, and the Emperor happy in the love and affection of a prosperous and contented people.

By a recent ukase, the tariff on Jute goods has been arranged. Jute cloth may now be imported into the Russian Empire and into Poland, including the ports in the Black Sea, at a duty of $9 \mathrm{~s}$ the pood. Jute sacks are admitted at a duty of $9 \mathrm{~s}$ the hundred by the ports in the Baltic Sea, and $7 \mathrm{~s} 2 \mathrm{~d}$ by land, into Russia and Poland, and into the ports of the Black Sea they are admitted free.

The following report of the Linens from Russia, shown in the International Exbibition of 1862, will conclude the chapter:-

"Russia exhibits very many samples of Flax from the various Flax-growing districts of that country. Some of them are in the rough, and others heckled and ready for spinning. Many of the specimens are of fine quality, and such as would be very suitable for our manufactures, but very few of them could compare in money value with the French, Belgian, or Irish samples shown. A few samples of yarns are exhibited, but they are not of much importance in any respect, and some of the specimens of Linen shown possess little excellence. The display of sail-cloth made by Baron Stieglitz, is, however, well worthy of inspection. It is made both of Hemp and Flax material, bleached and boiled, 24 and 30 inches in width, in various qualities, and of all numbers. The material is generally very good, the yarns well spun, carefully boiled or bleached, and the cloth well manufactured. The collection is, on the whole, of great excellence, and well worthy of the famous establishment which produced them. Some indifferent specimens of sheetings and diapers are shown, but there are others of most superior quality 
in the spin of the yarn, bleach, manufacture, and finish of the goods. The damasks are generally good, and in some cases of very pretty designs."

[Some of the particulars given in this chapter were kindly furnished by William Wrongham and William Warden Renny of Dundee, gentlemen who resided long in Russia, and have $n$ thorough knowledge of the Flax trade there.]

\section{CHAPTER IX.}

\section{VA I IOUS COUNTRIES.}

Havisg now given some account of the progress and present condition of the Linen trade in the great Flax growing and Linen producing nations of continental Europe, only a few of the others will be mentioned, and that briefly, as the nature and extent of the trade, which is almost entirely of a domestic character in all of them, does not require a lengthenea notice.

\section{DENMARK, NORWAY, AND SWEDEN.}

These countries all manufacture Linens to a moderate extent, and the trade is no new one in Scandinavia. Flax was one of the chief articles of import into Bergen in Norway about the end of the 13th century, and since that period Linens have been manufactured to a greater or less extent in that country. In 1764, Sweden exported Flax and Hemp, canvas and Linen. Latterly the governments of Sweden and Norway have given much encouragement to the manufacture of Linens, but the trade has not been prosperous. The peasants cultivate Flax, but not extensively, and they spin and weave it, chiefly for home consumption, very little being exported. There are Linen manufacturing establishments at Copenhagen, Vordinborg, \&c., in Y 2 
Denmark ; Gothenburg, Gefle, Hernösand, \&c., in Sweden ; and Christiana, Bergen, \&c., in Norway. There are also Flax spinning mills at some of these places, but none of them are very extensive, and much of the Flax is still spun by the hand wheel, which is yet common in these countries. The goods produced are of fair quality, and will bear comparison with similar fabrics made in other countries. The linens manufactured throughout all the three great divisions of Scandinavia are almost wholly for the supply of the local demand, the trade may therefore be called a domestic one. Denmark does not grow much Flax, and her Linen manufactures are of little importance. The following statement of the quantity and value of the imports into Denmark, bearing on the subject, shows the nature and extent of the trade there :-

\begin{tabular}{|c|c|c|c|c|c|}
\hline & & \multicolumn{2}{|c|}{1859.} & \multicolumn{2}{|c|}{1860.} \\
\hline Flax, & & Tons, 525 & $£ 26,070$ & Tons, 553 & $£ 27,576$ \\
\hline Hemp, & - & 2568 & 80,050 & , 2668 & 83,260 \\
\hline Linen Yar & $\mathrm{n}$, & 304 & 48,486 & 345 & 53.675 \\
\hline Linen Man & nufactures, & 985 & 92,721 & , 1221 & 106,574 \\
\hline
\end{tabular}

In 1861, the quantity of Linen manufactures imported was 1243 tons.

The Linen trade of Portugal is of old standing, dating back to the time of the Cæsars, or perhaps to a period long anterior to it. When, or by whom, the manufacture was first introduced into the country is not known, but it may have been by the Phœnicians or Carthagenians, both of these maritime nations having traded with Spain and Portugal.

In more modern times Flax is grown and Linen manufactured in various provinces of the kingdom, although not extensively in any of them. In addition to the Flax raised in the country, a considerable quantity is annually imported, spun and weaved. There are several Flax spinning mills at work in Portugal, but a considerable quantity of the yarn manufactured 
is still spun by hand. The chief Linen manufacturing establishments are at Braga, Aveiro, Coimbra, Lisbon, \&c., and there various fabrics are made, some of which are of superior quality, both in point of material and workmanship. The goods manufactured are almost all consumed in Portugal, and being for local use, they are made to suit the taste and wants of the people. Only a small quantity of Linens are exported, and these go to the Portuguese colonies in Africa and elsewhere.

The extent of the external trade will be seen by the following statement, of the imports and exports of Flaxen fibres and fabrics, for the years 1855 and 1856, and although a little progress has been made since then, the differeuce is not very material.

I M P O R T S.

1855 .

1856.

Flax and Hemp, Tons, 2896 Value, $£ 110,592$ Tons, 2631 Value, $£ 82,891$

Linen Manufactures, " $403 \quad$ " $30,024 \quad$ " $437 \quad$ " 33,847

$£ 140,616 \quad £ 116,738$

Of the Flax and Hemp imported fully one-third is from Great Britain, fully one-half from Russia and Prussia, and the balance from Spain, \&c. About five-sixths of the total Linen manufactures are from Great Britain, and about one-twentieth, chiefly sail-cloth, is from Hamburg.

EXPORTS.

The total value of the Flax fibres, and manufactures thereof, exported for same years were-

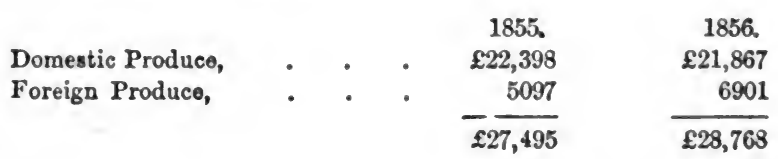

The Portuguese, by their continued prosecution of the nefarious slave trade in their African possessions, have miserably murdered myriads of the poor negroes, and brought indelible disgrace and infamy upon themselves. Were they to encourage the peaceful arts, and teach the natives to rear Flax and cotton, for which some of their territories there are admirably adapted, they would 
honourably enrich themselves, help to spread civilization in the dark places of the earth, and benefit mankind.

\section{S W I T ZERLA N D.}

The Swiss are an industrious people, and they have long made Linens, not only for their own use, but also for export. A century ago Zurich, Basle, and especially Appenzell, manufactured Linens, the latter extensively. At present the Linen manufacture takes an important place among their industrial pursuits, and large quantities are exported to Italy and to other countries. Much of the Flax is imported, and it is spun into yarn, and weaved in the different Cantons. The Linens made are varied in kind, and of praiseworthy quality. If the Swiss had a sea board of their own, or better means of transport, they would soon become formidable rivals to other Linen producing countries, as they are frugal and very industrious; but the Geographical position of the country is a serious obstacle in the way of their ever becoming a great Linen manufacturing people.

\section{T Ü R K E Y.}

The Turkish Empire includes some of the finest countries of Europe, and a large proportion of the central parts of Western Asia. Its territories are picturesque and beautiful, its soil rich and fertile, and its climate mild and salubrious. Under a liberal and enlightened government, the country might rank high among European nations, physicially, commercially, and socially. With all its natural advantages Turkey has never attained commercial distinction, nor is it likely to become a great trading nation, because the Moslem faith is antagonistic to progress in every shape.

In early times the Moors ruled the destinies of the greater part 
of Spain, and, pouring through the passes of the Pyrenees, penetrated France, but they were defeated with terrible slaughter, by Charles Martel and his Franks, in 732, and driven back to Spain, whence they were ultimately expelled 760 years thereafter.

In 1356 Solyman the Turk, with a few warriors, crossed the Hellespont one night, and seized a castle on the European shore ; and since then they have never lost their hold. In 1453 they captured Constantinople, when Constantine Palæologus, the last of the Caesars fell, and with him the Eastern Empire. For more than 200 years the Moslems pushed their way westward into Europe, until in 1683 John Sobieski of Poland defeated them before the walls of Vienna, and the cross once more triumphed over the crescent. Had Europe been overrun with the followers of the false prophet, either from Spain on the south or from Turkey on the east, it would have been blighted and blasted, and without a Linen trade, but Providence willed it otherwise. The tide of invasion was driven back, but the sick man still holds the lovely regions on both sides of the Bosphorus under his sway, and while he continues to do so their resources will not be developed, their manufacturing powers fostered, or their commerce unfolded.

Turkey, in many parts, is well adapted for growing Flax, but its capabilities are little tried. The people wear Linens largely and like the fabric, but they are not encouraged to manufacture them. A progressive government would draw wealth from the soil, and an enlightened people would enrich themselves by the sale of its products. The fatalism of the Turks makes too many of them live only for the day, and the rapacity and cupidity of the Pashas prevent or retard enterprise, the wealth acquired by labour and industry being too often made an excuse for treating its possessors with cruelty, and depriving them of what they have justly carned. Were the people secure in the possession of their gains, even the apathetic 'lurk might take courage, and benefit the world by learning to become rich. Dormant though the Linen trade be under Mahomedan rule, it is not altogether extinct, and the little life which it still displays proves that, under happier circumstances, it might be revived, and become as famous as it was under Christian sway in the days of the Eastern 
Empire. With fostering care Turkey might supply the mills of Western Europe with Flax, if she did not clothe the inhabitants with Linens.

In the Pashalick of Trebizond about 150 tons of Hemp and 50 tons of Flax are grown annually, and the lower classes manu-. facture Linen shirting, sheeting, and towelling for home consumption. All the beautiful Linens used in the harems of the rich are manufactured at Rizeh, to the extent of from 50,000 to 75,000 pieces annually. They are sent to Constantinople, Egypt, Bagdad, Mosul, and other Mahomedan countries and cities. 20,000 to 30,000 pieces of a coarser kind are annually consumed in this and other provinces. The finest is worth from $£ 7$ to $£ 9$ per piece of two shirts, and the coarse about $6 \mathrm{~s}$ or $7 \mathrm{~s}$ per piece of one shirt. Rizeh also manufactures about 1500 bales of Linen thread, and 250 bales of fishing nets annually, which are chiefly exported to Constantinople. In the province of Uscop, Hempen and Linen cloths are made of native produce. The Linens are bleached by repeated washing and exposure to the sun, and though coarse, they are durable. There are alsc manufactures made of silk and native Flax, and also some of silk, Flax, and English cotton twist, called "Meless," which is used for shirts and sheets, and wears well. The "Konapno," Hemp, and "Lineno," Linen cloths are also made and much used. These fabrics are manufactured by both Turks and Christians throughout the district. What is done there on a small scale might be done extensively in other parts of the country, and it would be well for Turkey if it were so.

Jute manufactures are finding their way into many new countries, in some of which they are applied to strange usages. In Crete twilled Jute sacks are now employed for packing soap in, and they have quite superseded the woollen sacks of native manufacture, which were formerly exclusively used for this purpose.

It was intended that this part should be devoted solely to the Continent of Europe, as distinguished from the British Islands. It will not materially alter the arrangement to include in this chapter a short notice of the great Saxon Republic of North America, and a brief paragraph upon an Asiatic city. 
This will accordingly be done. Several other countries, which are large consumers, if not producers of Linens, might with propriety have been noticed, but as the work has already extended greatly beyond what in the outset was proposed, they must be excluded. It is, however, the less necessary to enlarge on this point, as the extent of their trade in Linens with the United Kingdom is shown by the Board of Trade Returns, given in the volume.

\section{C $\mathrm{H}$ I N A.}

The city of Yarkand or Yarkiang, the capital of Chinese Turkestan, pays annually to the Government 34,000 sacks of corn, 57,569 pieces of Linen, and 15,000 pounds of cotton, besides some gold, silver, oil, copper, \&c. The population of the city is estimated at 200,000. It thus appears that Flax must be cultivated extensively in that country, and large quantities of Linen made in the city. It is a proper subject of inquiry by the merchants of this country, whether or not the Linens produced in the United Kingdon could be profitably introduced to this Linen wearing people. If their admission could be arranged, a wide door might be opened for their consumption, as it would appear that Linens must be largely used in that country.

China has not yet imported many Linens, but as trade progresses the consumption of Linen goods will, no doubt, increase. In 1860 there were imported into Shanghai 2343 pieces of Linen, valued at $£ 3045$, and 2718 pieces of canvas, valued at £6625. The importation into the other ports of China was altogether unimportant.

\section{THE UNITED STATES OF AMERICA.}

There are more Linens used in the United States, in proportion to the population, than in almost any other country in the world. 
For a long period a very large quantity of Flax has been grown in the United States, but the fibre is nearly all sacrified to the seed, very little of it being saved for textile purposes. The quantity of Flax raised in the States in 1850 was 3442 tons, but in 1852 it had decreased to 1688 tons. The linseed produced in 1850 was 562,312 bushels, and in 1852, 611,927 bushels. This shows that in the latter year the plant had been grown more for the seed than in the former, but in both years linseed appears to have been the great object for which Flax was cultivated.

In Ohio alone the crop of Linseed in 1862 was estimated at a million bushels, and in 1863 it was expected that, as grain prices being low; as much Linseed would be grown in the West as would supply the entire demand of the United States. How much this may be is unknown, but it must be very large, as between two and three million bushels are imported annually into Boston and New York from the East Indies alone. Were the fibre of the Flax grown in the United States all saved, as it ought to be, and might beas well as the seed, it would supply the material to keep many large spinning mills going either in that country or in the United Kingdom. The price which western linseed brought in New York in Sept. 1862 was $\$ 1.85$ per bushel, without bags.

In 1820 there were two Flax spinning mills in Paterson, New Jersey, wholly employed spinning yarn for sail.cloth, which then sold at $\$ 25$ a piece, being about double what British canvas of better quality could then have been sold for. It was chiefly made from Irish Flax, American being of bad quality, probably owing to its being allowed to stand too long in the ground in order to mature the seed. "The machinery," says a person from Dundee, who then visited the works, and sent a description of them to the Dundee Advertiser, "was in bad order, and the works were conducted in a slovenly manner. The yarn was doubled and twisted immediately after being spun, both for warp and weft, and instead of being retted or boiled, it was exposed to the action of steam, in a close vessel, three different times for fully a day each time. The cloth was coarse-looking but strong. Flax-dressers were paid $4 \mathrm{~s} 6 \mathrm{~d}$ per cwt., spinning girls from $9 \mathrm{~s}$ to $10 \mathrm{~s}$ a week, and weavers $13 \mathrm{~s} 6 \mathrm{~d}$ a piece. There were ten 
spinning frames in the one mill, and thirteen in the other ; and the two works used between them about three tons of Flax weekly."

In 1828 the Americans were making sail-cloth of cotton. It was said to be then preferred for fore and aft rigged vessels, because they could sail from a half to three quarters of a point nearer to the wind with it than with Hemp or Lint sails; and because it did not stretch nor shrink so much as Flax canvas. The stoutest sort weighed about $1 \mathrm{lb}$. a yard, and sold for $20 \mathrm{~d}$.

Some Flax and Hemp are still spun, and Linen weaved in the New England States, but the quantity is not large, the greater portion of the Linens consumed being imported.

Mr Stuart, Secretary of Legation, in his report, dated Washington, 25th May, 1863, says-" The manufacture of Linens in this country has made little progress, but Mr Kennedy, superintendent of the eighth Census Report of the United States, anticipates future success in the manufacture of fabrics from Flaxcotton, consequent on the invention of cheap machinery for the preparation of the Flax-cotton for spinning." Judging from the little progress hitherto made in the application of Flax-cotton to any practical textile manufacture, it is very doubtful if $\mathrm{Mr}$ Kennedy's anticipations of success from this article will ever be realized, either in the United States or elsewhere. To cottonize Flax is an unnatural process, as it is converting a superior fibre into an interior one, a proceeding which has no merit. Want of success in such experiments is perhaps real gain.

Gunny bags and gunny cloth have been articles of import into the United States for about seventy years. Some years the importation was of small extent, but at other times it rose to considerable magnitude. The cloth was used chiefly for cotton bagging, and the bags for a variety of purposes. Jute has also been imported for a long series of years, and it was begun to be manufactured there at an early period, perhaps before, but if not, certainly not long subsequent to its introduction into the manufactures of Dundee. The follorring tables and particulars regarding the trade in these articles for the last four years is taken from Consul Lousada's report, dated Boston, 20th February, $1863:-$ 
Imports into the United States of the ARtioles gpecified, during the Years named, aNd Stocks at 31st Dec. Each Year :-

\begin{tabular}{|c|c|c|c|c|c|c|c|}
\hline \multicolumn{8}{|c|}{1 M P O R T S. } \\
\hline & $\begin{array}{c}\text { Jute } \\
\text { Manila } \\
\text { Hemp, \&c. }\end{array}$ & \multicolumn{3}{|c|}{ Gung B ags. } & \multicolumn{3}{|c|}{ Gungy Cloth. } \\
\hline & Boston, \&c. & At Boston. & Other Prt & Total. & At Boston. & Other Prts. & Total. \\
\hline & Bales. & Bales. & Bales. & Bales. & B:lles. & Bales. & Bales. \\
\hline $\begin{array}{l}1859 \\
1860 \\
1861 \\
1862\end{array}$ & $\begin{array}{l}80,926 \\
66,049 \\
64,102 \\
59,561\end{array}$ & $\begin{array}{r}10,988 \\
8,480 \\
8,737 \\
11,071\end{array}$ & $\begin{array}{l}3,931 \\
3,073 \\
7,397 \\
4,280\end{array}$ & $\begin{array}{l}14,919 \\
11,553 \\
16,134 \\
15,351\end{array}$ & $\begin{array}{r}58,755 \\
32,381 \\
25,734 \\
7,375\end{array}$ & $\begin{array}{l}16,100 \\
32,847 \\
26,573 \\
10,500\end{array}$ & $\begin{array}{l}74,855 \\
65.228 \\
52,307 \\
17,875\end{array}$ \\
\hline \multicolumn{8}{|c|}{ STOCIS IN BOSTON. } \\
\hline \multicolumn{2}{|c|}{ At 31st Dec. } & \multicolumn{2}{|c|}{ Jute. } & \multicolumn{2}{|c|}{ Gunny Bags. } & \multicolumn{2}{|c|}{ Gung g Cloth. } \\
\hline \multicolumn{2}{|c|}{$\begin{array}{l}1859 \\
1860 \\
1861 \\
1862\end{array}$} & $\begin{array}{cc}\text { Bales } & 7, \\
, " & 1, \\
", & 2, \\
", & .\end{array}$ & $\begin{array}{r}7,350 \\
1,200 \\
2,186 \\
\ldots \ldots\end{array}$ & \multicolumn{2}{|c|}{$\begin{array}{cc}\text { Bales } & 6,808 \\
:, & 4,000 \\
, & 5,350 \\
" & 9,400\end{array}$} & \multicolumn{2}{|c|}{$\begin{array}{cr}\text { Bales } & 6,780 \\
" & 8,300 \\
" & 37,600 \\
, & 42,300\end{array}$} \\
\hline
\end{tabular}

In 1862 , the imports of Jute, Manila Hemp, \&c., were from the following places :-

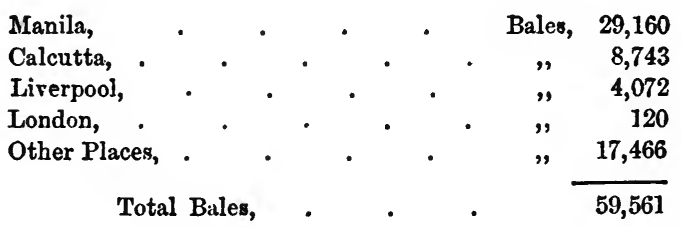

From January to September 1862, the price of Jute ruled from $\$ 100 @ \$ 115$; ton. Subsequently a speculative demand raised the price to $\$ 160 @ \$ 190$, duty paid. The lowest price of Manila Hemp in 1862 was 7 cents, and the highest 91 cents 78 1b. ; in 1861, $4 \frac{5}{8}$ and $7 \frac{1}{2}$; in $1860,5 \frac{5}{8}$ and $6 \frac{1}{4}$; and in $1859,6 \frac{1}{4}$ and 7 cents $73 \mathrm{lb}$. In the first eight months of 1862 gunny bags ranged from 12 to 14 cents. Afterwards the scarcity and high price of all kinds of bagging led to an active demand, partly for 
consumption and partly on speculation, and in the beginning of November they touched 25 cents cash, the highest price gunny bags ever reached in Boston. The sales and re-sales within a few weeks at that period reached 10,000 bales, but after the middle of November prices fell to $21 \frac{1}{2}$ to 22 cents a bag. In the beginning of 1862 there was a speculative demand for gunny cloth, and 10,500 bales changed hands, prices having advanced from 11 to 14 cents a vard. Afterwards sales became very dull, and prices fell to 11 cents. In Norember they again rose to $14 \frac{3}{4}$ to 15 cents.

The lowest price of gunny cloth in 1862 was 11 cents and the highest 15 cents per yard; in 1861, 7t and $11 \frac{1}{2}$; in $186: 0,8 \frac{1}{2}$ and 17 ; and in 1859,11 and 13 cents per yard ; and of gunny bags, in 1862, 12 and 25 cents ; in 1861, 101 and 14 ; in 1860, $8 \frac{8}{8}$ and 14 ; and in 1859,9 and $12 \frac{1}{2}$ cents per bag. In consequence of the war between the Federal and Confederate States, deliveries of gunny cloth for consumption in 1862 were very limited, the cloth being chiefly used for cotton bagging, \&c., the exportation of which was stopped by the blockade of the Confederate ports, and the stock on hand at the end of that year was, as shown above, 42,300 bales in Boston alone.

The following statement of the value of the articles enumerated, imported into America in the years ending 30th June 1859 and 1860 , is taken from official sources :-

1859.

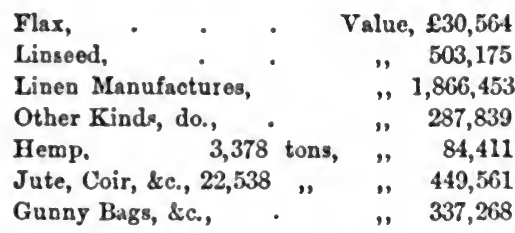

1860 .

Value, $\{44,518$

, 573,627

, $1,926,210$

" 335,366

2,273 tons, , " 67,884

$23,279 \quad, \quad$ " 409,530

433,884

Of the Linens imported in $1860, £ 1,871,856$ was from Great Britain. The Hemp exported from the United States in 1859 was 108 tons, value, $£ 1,933$; and in 1860 , 186 tons, vulue, $£ 1,935$. Linens re-exported in 1859 , value, $£ 7,122$, and in 1860 , $£ 24,871$.

The following table, taken from the United States Economist, shows the value of the Linens imported into New York, the great emporium of the commerce of the United States of America, for the periods specified :- 
Value of the Iinens Imported into NeW YoRK IN 1859, 1860, 1861, 1862, AND FROM 1st JANDARY TO 30Th NOVEMBER 1863.

\begin{tabular}{|c|c|c|c|c|c|}
\hline & $\begin{array}{c}\text { Entercd for } \\
\text { Home Consump- } \\
\text { tion. }\end{array}$ & $\begin{array}{l}\text { Entered for } \\
\text { Warehousing. }\end{array}$ & $\begin{array}{l}\text { Total Entered } \\
\text { at the Port. }\end{array}$ & $\begin{array}{c}\text { Withdrawn } \\
\text { from Ware- } \\
\text { house. }\end{array}$ & $\begin{array}{l}\text { Total Thrown } \\
\text { on the Market. }\end{array}$ \\
\hline & Dollars. & Dollars & Dolla's. & Dollars. & Dollars. \\
\hline 1859 & $10,173,127$ & $\begin{array}{r}947,357 \\
\end{array}$ & $11,120,484$ & $1,033,065$ & $\mathrm{j} 1,206,192$ \\
\hline 1860 & $6,415,345$ & $1,498,807$ & $7,914,152$ & 839,488 & $7,25 \pm, 833$ \\
\hline 1861 & $2,142,653$ & $1,437,650$ & $3,587,303$ & $1,878,081$ & $4,020.734$ \\
\hline 1862 & $6,711,360$ & 955,271 & $7,666,631$ & $1,612,414$ & $8,323,774$ \\
\hline 1863 & $6,630,049$ & 210,043 & $6,840,092$ & $2,304,644$ & $8,934,693$ \\
\hline
\end{tabular}

This tabular statement is important, as showing the effect of the unnatural, fierce, and protracted war in that cointry upon the Linen trade. At first the demand for Linens fell off greatly, and the value of the importation in 1861 was less than half the value the previous year, and less than one-third that of 1859 . In 1862 the stock of cotton goods became exhausted, and Linens had to be used instead, which greatly extended their consumption. The requirements of the army and navy meanwhile increased enormously, and vast quantities of Linens were used for war purposes. To supply these wants the importation of 1862 was greatly beyond that of the previous year, and almost equalled the value in 1860, when both the Federals and Confederates were consumers. The consumption continued to increase in 1863 , and, judging from the first eleven months of the year, to which this statement extends, the importation will be greater than for either of the complete years specified, excepting 1859 . What the future wants of the country may be it is impossible to predict, but the war hitherto, by curtailing the supply of cotton, has given a mighty impulse to the Linen trade of Great Britain and Ireland, especially to that branch of it, the centre of which is Dundee. This table does not show the full effect of the war on the Linen trade, because many Linens are sent to various places in the West Indies, \&c., which find their way into the Confederate States. The war has also indirectly increased the consumption of Linens in all countries, as the Board of Trade Returns show. 


\section{P A R T I I .}

\section{THE U N I T E D K I N G D O M.}

THE Linen trade is a very important branch of the industry of the British Isles. In each of the grand divisions of this great country, England, Ireland, and Scotland, the Linen manufacture is of ancient standing, and now of important extent. Though these countries are now politically united in one imperial whole, yet they were long separate kingdoms, with antagonistic interests, and while so, this branch of the trade possessed distinct features, in each peculiar to itself alone. In some respects the Linen trade in the respective sub-divisions of the kingdom are now identical, but in others they still differ, and it is perhaps better for the general prosperity that they should do so. Each has struck out a path for itself, which may be prosecuted successfully without injury to the others, and each can therefore without jealousy rejoice in the prosperity of their brethren, The general weal will be best served by each kingdom continuing to prosecute assiduously its own adopted fabrics. This will engender no rivalry, excepting the very legitimate one of each of three kingdoms trying which will cast the brightest halo around the Linen trade of the Empire.

Notwithstanding the union of Scotland, England, and Ireland into one empire, the history of the Linen trade in the United Kingdom naturally divides itself into its component parts. It will therefore be better and more clearly elucidated in distinct chapters. The introduction of the manufacture of Linen into the several divisions of the United Kingdom dates back to a far distant period, but little is known of the trade in either until comparatively modern times. England, from its proximity to the Continent, 
might naturally be expected to have acquired a knowledge of the art first, and history appears to support this conclusion. Of the three kingdoms it takes the highest rank in extent, population, wealth, and general importance, and to it therefore the first chapter will be devoted. Unlike England and Scotland, which draw the greater part of the supply of the raw materials for their Linen manufacture from abroad, and pay for much of it in hard cash, Ireland produces its Linen within itself. It grows its own Flax, spins and weaves it, and exports the products, thereby drawing many millions of gold to the country annually, and thus enriching both its agricultural and manufacturing populations. Some account of this trade, valuable not only to Ireland, but to the kingdom at large, will be given in the second chapter. The third chapter will relate to Scotland, and as it is intended to give a more minute account of the trade in it than in other countries, the chapter will contain such sub-divisions as may be necessary for the proper illustration of the subject. The last chapter in this part will contain details common to the United Kingdom, including general statistics not already given.

\section{CHAPTER I.}

\section{E N G L I S H L I N E N.}

It is well known that the Phœnicians visited England at a very remote period, and for many ages supplied the inhabitants with the productions of Eastern countries, in exchange for tin and other metals from the mines of Cornwall.

They were unquestionably the first people who visited Britain for the purposes of trade, as this is positively affirmed by Strabo, and acknowledged by many other authors. After visiting all the coasts of the Mediterranean they passed the Straits of Gibraltar about 1250 B.C., built Cadiz, sailed along the west coasts 
of Gaul, discovered the Cassiterides or Scilly Isles, and the south-west coast of Britain, Bochart says 904 B.C., but others think only 600 B.c. 'This much is certain that Herodotus, who lived 440 B.c., speaks of the Cassiterides as the place from which all the tin came, but declares he does not know where they are.

The Linen of Egypt was an important article in the trade of the Phœnicians, and no doubt formed one of the commodities given in barter for the highly prized metals and minerals of England, although Strabo only enumerates salt, earthenware, and brass trinkets, as then British imports. This Linen was much ralued by all the nations of antiquity to whom it was known, and doubtless the natives of Britain, although uncivilized, would also prize it. It is fair to suppose, therefore, that Linen may have been first introduced into England by this maritime people, although there is nothing certain kuown on the subject.

After the Phœnician commerce was destroyed, for many ages the rude and barbarous natives of this country had little intercourse with other nations, and the very existence of Linen, if ever known, seems to have been forgotten by many of them.

Casar says that the Britons in the interior of the country were clothed with skins. Pliny and others say that the ancient Britons still continued to besmear their bodies with paint long after the people of Spain, Gaul, and even Germany had abandoned that practice and were tolerably clothed. It would appear, however, that some of the people of Britain not only wore various kinds of cloth at the time the Romans first visited the country, but that they were then well acquainted with the art of dressing, spinning, and weaving both Flax and wool, and that they practised these arts much in the same manner as the people of Gaul. Not only was this the case, but they were even the inventors of some particular descriptions of cloth. One of these was made of fine wool, dyed of different colours, and woven in checks or squares, like the Scottish tartan of the present time. Of this the people made summer mantles and other garments. Pliny says the ancient Gauls and Britons were acquainted with the art of dyeing woollen yarn and cloth. The material chiefly used was the glastum or woad, with which in former times they had dyed their bodies; and deep blue long continued to be 
the favourite colour with which the ancient Britons, and also the Caledonians, dyed their clothes. The dress of the Druids was white, and probably of Linen cloth. Pliny mentions that the priest, arrayed in a surplice or white vesture, climbeth up into the tree (misletoe), and with a golden hook or bill cutteth it off, and they beneath receive it in a white soldier's cassock, or coat of arms.

Burnt bones have been found in British barrows, secured by a Linen cloth. Some specimens of the Linen were of a reddishbrown colour, the filaments at first appearing like hair. Sir R. C. Hoare found in a barrow some bits of cloth so well preserved that the size of the threads could be distinguished, and shewed it to be what is now termed a Kersey cloth.

The following description of the habit of the greatBritish heroine, Boadicea, is given by Dido and other historians. " "She wore a loose robe of changeable colours over a thick plaited kirtle, the tresses of her hair hanging down to her very skirts, with a chain of gold about herneck, and carrying in her hand a short spear or dart." What Tacitus says of the German women may also be true of the Britons-" Their dress differed little from that of the men, excepting that the women wore more Linen, but left their arms and part of their bosoms bare."

The art of making, and the custom of wearing Linen, were probably brought into England by the Belgic colonies, about a century before the Roman invasion, or perhaps earlier, and at the same time with agriculture, and it kept pace with that most useful of arts in its progress northwards. There is direct evidence that the Belgæ manufactured Linen, as well as cultivated their lands on the Continent, and there is thus good reason to conclude that they continued to do the same after they settled in this Island.

Although the Belgæ, the most civilized of the ancient Britons, were not altogether unacquainted with the most essential branches of the clothing art before they were subdued by the Romans, yet these arts were improved in England by that event. The Romans learned all the useful and ornamental arts practised in the different countries throughout their vast empire, and readily taught them to their subjects in other countries where they were unknown, or imperfectly practised. The Roman invasion of 
England must therefore have been the means of reviving and extending the use of Linen there, as the Britons were then, or very shortly afterwards, partial to Linen, and used it for many purposes.

Pliny describes the different qualities of Flax respectively produced by each country, with a minuteness which shows that the manufacture of Linen was then an important branch of trade among the Romans, and that wherever their arms penetrated Linen would soon be known. It appears from the Notitia Imperii that there was an Imperial college or manufactory of woollen and Linen cloth for the use of the Roman army in Britain established at Venta Belgarum, now Winchester. After the Romans left England, much of the civilization which they had introduced followed in their train, and again went with them; and the natives relapsed into at least semi-barbarism.

After the retreat of the Britons into Wales and Cornwall, and the establishment of the Saxons in England as masters of the country, greater attention began to be paid to the arts of peace, and particularly to trade and commerce. The retrograde movement which began with the withdrawal of the Roman legions was stopped, and a gradual improvement manifested itself in the country.

Macpherson in his "Annals of Commerce" says, that about A.D. 500 , it appears from the chronicles of the period fine Linen, (probably imported), was possessed by the inhabitants of Britain and Ireland. The bodies of the dead, at least those of eminent rank, were wrapped in fine Linen.

By the ancient laws of Wales, all the officers of the household were appointed to be clothed thrice every year, the King furnishing the woollen and the Queen the Linen cloth for that purpose. The several parts of the dress of the King and nobility are enumerated, among which are sheets, stockings, shoes, and boots. The stockings were of woollen or Linen cloth wound round the legs and feet, and fastened in different ways.

Before the end of the 7th century, the art of weaving had attained remarkable perfection in England, for in a book written by Bishop Aldhelm, about A.D 680, in praise of virginity, he speaks of "webs woven with shuttles, filled with threads of purple and many other colours, flying from side to side, and 
forming a variety of figures and images in different compartments with admirable art." These figures were sometimes embroidered upon the cloth with threads of gold, silver, and silk of purple and other colours, as the nature of the figures to be formed required; and to render them the more exact, they were first drawn with colouring matter by some skilful artist. They were commonly executed by ladies of the highest rank and greatest piety, and were designed for ornaments to the churches, or for vestments to the clergy.

The garments of the Anglo-Saxons were Linen and woollen, and the Flax and the fleece were spun in winter by the females of every family, from the highest to the lowest rank. From this universal practice the term spinster came to be applied to an unmarried woman, and the trace of this custom still remains. The Saxon ladies were very skilful with their needles, particularly in embroidery and ornamental work, and celebrated events were often represented by them with great truth on tapestried hangings and similar works.

The four princesses, daughters of King Edward the Elder, and sisters of King Athelstane, are highly celebrated by historians for their assiduity and skill in spinning, weaving, and needlework, which was so far from spoiling the fortunes of these Royal spinsters, that it procured them the addresses and the hands of the greatest princes then in Europe. William, of Malmsbury, mentions that Harold, King of Norway, sent to Athelstane of England a fine ship, with a gilded stern and purple sails.

The celebrated Bayeaux tapestry, executed by the Queen of William the Conqueror, and her maidens, in commemoration of the conquest of England, is of Linen cloth, worked with wool. It was presented by Queen, Matilda to the Cathedral of Bayeaux, of which William's brother was bishop. T'his tapestry is 20 inches wide by 214 feet long, divided into 72 compartments, and it is one of the most wonderful specimens of industry in existence. It is now in the possession of the municipality of Bayeaux, by whom it is highly valued and religiously preserved. It begins with the embassy of Harold to the Norunan court, A.D. 1065, and ends with his death at the battle of Hastings, the following year. The many important transactions of these two busy years are represented in the clearest and most regular 
order in this piece of needlework, which contains many hundred figures of men, horses, herds, trees, castles, churches, \&c., \&c., all executed in their due proportions and proper colours, with inscriptions over them to throw light on the history. 'Though Queen Matilda directed this work, yet the greater part of it was probably performed by Euglish women, as a contemporary writer says that the Anglo-Saxon ladies were so famous for their skill in needlework and embroidery in gold, that those elegant manufactures were called Anglicum Opus.

The Anglo-Saxons of this period were far from being strangers to the use of Linen, for all persons of any consideration among them wore shirts of it next their skin. These were considered so pleasant and necessary, that a woollen shirt was then, according to Johnson's Canons, reckoned among those things which constituted penance for very great sins. Above the shirt they wore a tunic, and Alcuinus says, "those of the soldiers are commonly made of Linen, and exactly fitted to the shape of their bodies." The Anglo-Saxons also wore breeches, either of Linen or woollen cloth, reaching below the knee, very much like the trousers of the sailors of the present time. 'The upper covering or mantle of princesses and ladies of distinction was made of silk or fine Linen. They had their sceta or sheets, and in a foreign charter, dated 1069, lintrius is a term used for bed Linen, and elsewhere lintheamina. It would thus appear that large quantities of Linens were consumed by the Anglo-Saxons, and it is probable that the manufacture had been chiefly of a domestic character. It may be, howerer, that part of them were imported, especially those of the finest quality.

The Flax plant appears to be indigenous to Britain. Its properties have been long known to the inhabitants, and it must have been raised from an early date. During the Roman, and also the Saxon period, it was grown to some extent, but the troubles consequent on the incursions and invasions of the Dames seem to have interfered with, and perhaps in a great measure to have stopped, its cultivation. It is reported that at the time of the Norman conquest very little Flax was grown. Very many manufacturers of cloth from Flanders came orer with the Normans and settled in England, and others followed at later periods. 
These industrious people pursued their trade with much assiduity, and with great advantage to their adopted country, as well as profit to themselves. The production of both woollen and Linen fabrics experienced considerable improvement soon after the Flemings arrived, and of the skill of this people an ancient historian has said that "The art of weaving seemed to be a peculiar gift bestowed upon them by nature."

In a list of titheable articles made out in 1070, being the fourth year of William the Conqueror, neither Flax nor Hemp are enumerated. It would thus appear that their cultivation had, for a time at least, been discontinued. They must, however, have been resumed within a century thereafter, as they are both enumerated by the Council of Westminster in 1175, among the things annually reproduced as subject to tithe.

William the Conqueror published a proclamation for the encouragement of trade, promising foreign merchants who frequented the ports of England the most perfect security for their goods and persons. King John, for the encouragement of the clothing arts, and the improvement of commerce, established in the great towns of England, guilds, or corporations of merchants, bestowing upon them, by royal charter, various privileges and immunities, for which they paid certain fines into the Exchequer; and the making and selling of cloth was regulated by statute. At this period the shirts of all persons of rank and fortune, and even of the great body of the people, were of Linen, which had then become so common that it was no longer taken notice of by historians as a singularity. As this part of dress is not much seen, it has been less affected by the tyranny of caprice and fashion than other parts of the clothing, and it still remains nearly what it then was.

It is related in Madox's " History of the Exchequer," that fine Linen was first made in Wilts and Sussex in 1253; and, in order to patronize the infant manufacture, Henry III. ordered the Sheriffs of each of these counties to buy for him one thousand ells of fine Linen, and to send it to his wardrobe at Westminster. Notwithstanding this royal patronage, woollen was worn in nearly all garments until the age of the Tudors, when Linen began to come into more general use. In 1272 it is recorded that Irish Linen was used at Winchester. 
In the latter part of the 13th century the people wore woollen shirts, but now (in the 14th century), says La Flamma, we wear Linen. Table Linen was then scarce in England. The manufacture of Linen must have been pretty generally established in Wales in the beginning of the 14 th century, as its use was then common in the country. Barbour, in his Life of King Robert Bruce, says that the men of Wales, in 1314 , were mostly clothed in Linen. During this century most of the fine Linen used in England was supplied by Rheims.

In 1331 Edward III. resolved to establish manufactures, and for that purpose invited over weavers from Flanders to settle in England. In 1351 the king regulated the places of meeting of the foreign weavers for the sale of their cloth. Those who had come from Flanders were to meet in the churchyard of St Lawrence, Pulteney, and those from Brabant in the churchyard of St Mary Somerset. Afterwards the cloth fair was removed to West Smithfield. It is stated in "I Londinopolis" that there were then weavers of divers sorts, viz., of drapery or tapery and napery, i.e. of woollen and Linen.

There is a regular account extant of the imports and exports which paid duty in England in 1354, an 1 among the former were Linen. In 1378 an Act was passed for the encouragement of foreign merchants, and Linens, canvas, \&c., are enumerated among the articles then imported. From these and similar notices it would appear that few Linens had then been manufactured in the country, the greater part of them having been imported, chiefly from Flanders and France. The principal manufacture of textile fabrics, before and for some time after this period, was woollen cloth, and considerable quantities of it were exported.

In 1386 a company or guild of Linen weavers was first established in London, consisting of such as hat been brought over from the Netherlands by Edward III. They were much molested by the weavers' company of London, and never attained a great degree of success.

The Tailors or "Fraternity of Scissors," now called "Merchant Tailors," dates as a chartered company in the city of London from the year 1399. Anciently they made all kinds of apparel, whether of wool or of Linen, and also the padding of 
armour, hence their designation in several charters as "Iinen armourers."

Many foreign merchants in England were at this time formed into companies, such as "Merchants of the Steel Yard," "Merchants of the Staple," \&c. The foreign trade was then on an extensive scale, and fine Linen was imported from Venice, Pisa, Genoa, Bretagne, Flanders, Holland, and other places, chiefly of Egyptian and German manufacture. The Linen cloth made in England would seem to have been generally coarse, and only worn by the very poorest, the fine Linens for the use of the rich being imported.

It appears from the roll of the king's wardrobe in 1415, that the greatest part of the Linen then used in England, especially by those of the higher ranks, was imported, and was chiefly from Reynes or Rennes and Champagne in France, and from Flanders and Brabant in the Netherlands. The excellence of these Linens is celebrated in many romances and poems composed shortly before this period.

In $1415 \mathrm{King}$ Henry V. invaded France with a fleet of large vessels, and gained the battle of Agincourt. The ship in which he himself embarked carried a sail of purple silk.

In 1445 the price of fine Linen for surplices and the altar, was $8 d$ an ell in England.

D'Amay says that linen was not common in the west in the 8 th century; that table Linen was very rare in England in the 13th and 14th centuries; and that La Flamma, a writer of the 14th century, says, the Emperors Frederick Barbarossa, and Frederick II. wore shirts of serge, not of Linen, at Milan.

Sturtt observes that the manufacture of Linen in this country was not carried to any extent before the middle of the 17th century, and was in its infancy even in the times of Charles II. At that time it was imported from Flanders, and was very dear. Gems were frequently inserted in Linen, and he says of cloth of Rayne, the

"Head shete of pery pight, With diamonils set and rubies bright"

Anderson, in his "History of Commerce," quoting from Richard Hakluyt, says, in 1430 England imported from Flanders, "fine cloth of Ypres and of Courtray of all colours, 
much fustian, and also Linen cloth;" Bretagne, "salt, wines, Linen, and canvas;" Cologne, via Flanders, "thread, woolcards, fustians, canvas and buckram;" Brabant, "mercery, haberdashery, and grocery ;" Ireland, "hides, fish, wool, Linen cloth, and skins of wild beasts." The same author says, in 1579 "there are persons in Persia who stain Linen eloth. It hath been an old trade in England, whereof some excellent cloths yet remain, but the art is now lost in this realm"

The silk manufacture was introduced about the beginning of the 15th century. At this period, according to a curious pamphlet called the "Prologne of English Policy," crest-cloth or Linen, and canvas were imported from Brittany ; Flax, Hemp, thread, and canvas from Germany and Prussia.

In an act passed in the twelfth year of the reign of King Henry VII., (1497), mention is made of the nature and extent of the foreign commerce of the country ; Linen forms but a very small part of the exports, as it is scarcely mentioned; nor does it hold a more prominent place among the exports of 1511. About this time Linen, even the very coarsest dowlas, was derived from Flanders. The English had then a fuctory at Antwerp, whence they had removed it a few years before from Bruges.

In "Nicholl's Illustrations" is an inventory of the goods of "John Port, late the king's servant," who died in 1524. His house consisted of " a hall, parlour, buttery, and kitchen, with two chambers, and one smaller in the floor above, a napery or Linen room, and three garrets besides a shop."

In 1531 the legislature seems to have become more alive to the importance of the Linen trade, a statute having been enacted requiring that, under certain penalties, "for every sixty acres of land fit for tillage, one rood should be sown with Flax and Hemp seed," and in the register of Pulham, St Mary, fines paid for the non-fulfilment of this law are recorded. By the 5th Elizabeth, c. 5, that Queen had power by her proclamation to revive this law in such counties as she should julgre proper, "for the better provision of nets for help and furtherance of fishing, and for eschewing of idleness," but no mention is made of the Linen manufacture.

About 1540 a trade was opened up by England with the Mediterranean and the coast of Africa, and the first article enu- 
merated amongst the exports is Linen. In 1553 the trade between England and Russia was begun, and among the exports to Archangel, and also to Narva, coarse Linen cloth is mentioned. In 1588 the first voyage from London to Benin was made, and Linens are the first of the commodities named among the exports to that country. As related in Guiciardini's picture of Antwerp, in 1560, England, Scotland, and Ireland, in common with many other countries, drew supplies of Linen from that city, which was then the great emporium of the Linen of Flanders. Missenden, in his "Circle of Commerce," mentions that in 1612, among the principal imports into England from Europe, Linens held a prominent place, and that during a great part ot the 16 th and 17th centuries, they were largely imported. In the 17th century England imported vast quantities of Hemp, Flax, \&c., from Carolina, in North America.

About the middle of the 16th century the growing of Hemp and Flax met with more encouragement from the Government than that of hops, yet it appears to have totally failed. Toward the end of this century (1597), the monopoly of the "steelyard" was abolished. The foreign merchants, in revenge, managed to force the English merchants to remove their staple town on the continent from place to place, until at last they found a kind reception at Hamburg. To this city they exported woollen cloth, \&c., and imported from the Hanse Towns, jewels, silk, Linen, tapestry, \&c.

In 1552 an Act was passed confirming the manufacture of dornocks, (coarse Linen diaper), and some other things to Norwich, and to all corporate and market towns in that county. To that and to the neighbouring counties the persecuted Flemish manufacturers fled in crowds, scared by the inhumanities of the execrable Duke D' Alva, his popish priestly bloodhounds, and savage soldiery. This act, passed by the amiable Edward VI., enabled these poor people, some twenty years afterwards, the more easily to prosecute their diligent labours in these districts; and to their industrious pursuits, among which was the making of Linen, England owes much of her present superiority in manufactures, trade, and commerce.

The manufacture of sail-cloth was established in England in 1590 , as appears by the preamble of 1 st James I , cap. 23 :- 
"Whereas the cloth called Mildernix and Powel Davies, whereof sails and other furniture for the navy and shipping are made, were heretofore altogether brought out of France and other parts beyond sea, and the skill and art of making and weaving of the said cloths never known or used in England until about the thirty-second year of the late Queen Elizabeth, about what time and not before the perfect art or skill of making or weaving of the said cloths was attained to, and since practised and continued in this realm, to the great benefit and commodity thereof."

In 1622 a special commission was appointed to enquire into the decline of trade in England:- "Consider also that whereas our Eastland merchants did formerly load their ships with undressed Hemp and Flax in great quantities, which set great numbers of our people to work in dressing the same, and converting them into Linen cloth, which kind of trade, we understand, is of late almost given over by bringing in Hemp and Flax ready dressed, and that, for the most part, by strangers. How may this be redressed? And as much treasure is yearly spent in Linen cloth imported at dear rates, and for that of the fishery so much desired by us be thoroughly undertaken, and our shipping increased, it will require a much greater production of Hemp for cordage, \&c., in the fishery, which would set an infinite number of our people to work. Consider how the sowing of Flax and Hemp may be encouraged."

Parliannent in 1643 laid a duty on damask table Linen. In 1663 statutes were passed for the encouragement of the Linen and tapestry manufactures of England, and the discouragement of the very great importation of foreign Linens and tapestry. In 1668 England was almost wholly supplied with Linens from France. At this time the French Protestants settled at Ipswich made Linen at $15 \mathrm{~s}$ per ell. In 1670 " the wear of flimsey muslin" was introduced into England, before which time our more natural and usual wear were cambrics, Silesia canvas, and such kinds of Flaxen Linens from Flanders and Germany.

Table cloths were sometimes made of very valuable Linen. Mrs Otter, in Ben Johnson's "Silent Women," mentions a damask tablecloth which cost 218 . The good man of the house sat at the upper end of the board "with a fayre napkin layde before him on the table lyke a master." It the close of 
Henry VIII.'s reign, the breeches worn were trussed out to an enormous size with horse hair, and a law was made against this. In the pedigree of the English Gallant, related that a man who was cited for disobeying this law, gave occular demonstration to the Judge that it was a storehouse for his spare Linen, and was dismissed. Shirts were articles of great expense and elegance. They were made of "Camericke Hollande lawn, or els of the finest cloth that may be got," and were so wrought with " needleworke of silke and so curiously stitched, with other knache besides," that their price would sometimes amount to $£ 10$.

These short notices of the import and export of Linens show that the manufacture in this country had been on a very trifling scale, and on the whole not sufficient to supply the home demand, as the imports seem to have exceeded the exports. Indeed from the passing of the statute in 1531, already referred to, up to the year 1767 many attempts were made to extend and improve the cultivation of Flax in England, and protection was afforded to the grower of the plant in various ways. Success does not appear to have attended the efforts of the Government, and in the latter year $£ 15,000$ were proposed to be distributed among the successful cultivators of the plant. For fitteen years no candidate came forward to claim a premium, which shows that little interest was taken in the matter; and that little Flax was grown, notwithstanding the encouragement offered by Government. About 1798 a bounty of $4 \mathrm{~d}$ a stone for the encouragement of the growth of Flax in England, was given to claimants.

Andrew Yarranton in a publication issued in 1677, entitled "Englands Improvement by Land and Sea," proposed "To outdo the Dutch without Fighting. To pay Debts without Monies," \&c. His plan was to establish the Linen manufacture in England, and by this means give employment to the people, and at the same time make the country independent of foreign nations. He mentions that vast quantities of Linens are yearly brought into England, some of it used there and the rest exported to our islands and other places ; as well as threads, tapes, twines, for cordage and wrought Flax.

Flax, he says, was grown in the upper parts of Germany, Saxony, and Bohemia, where victuals were cheap, and as the pulling, watering, dressing, spinning and winding the Flax gave much 
employment, there were no heggars there. In all the towns in Germany there were schools for little girls from six years old and upwards, where they were taught to spin, and by this early training they were enabled to produce a very fine thread more easily than if they had learned when older. The wheels were moved by the foot, and went easily with a delightful motion, and the mode of teaching the children was as follows:-Around a large room a number of benches were placed, in which sat perhaps two hundred children spinning. In the centre stood a pulpit, in which the mistress sat with a long white wand in her hand, watching the spinners. When any one was seen idle she was tapped with the wand, but if that did not do a small bell was rung, which brought out a woman, to whom the offender was pointed out, and who took her into another room where she was chastised. All this was done without speaking a word, and this training, the author thought, would do good in England, where the young women were so given to chatting. In an adjoining room a woman prepared and put the Flax on the distaffs, and when a maid had spun off the Flax, the bell was rung, the rod pointed to her, another distaff given, and the bobbin with the threads removed, and put into a box with others of the same size to make cloth. As the children learned to spin finer, they were raised to higher benches, and great care was taken to sort the thread and keep it uniform, and so to make regular cloth.

The thread or yarn was brought down the Elbe or Rhine in dry fats for Holland and Flanders, where it was weaved into fine Linen and bleached, and then exported. The people in these countries paid high rents for their houses and for provisions, but the weaving and bleaching of the cloth was not more than a tenth part of the labour, which made high charges for these processes less felt on the cloth. This vast trade it was said would continue in Holland and Flanders unless the Linen trade were promoted in England, and due care taken of the sorting of the yarn there, which had not been the case.

In England, a good housewife had six or eight spinners belonging to her; and sometimes she, her servants, and children span, the yarn being all put together, some for warp and some for weft to one piece of cloth, which made the Iinen unequal 
throughout. He recommended the training of the girls in spinning schools for three years as in Germany, which would teach them industrious habits, and by the time they reached their ninth year they would, he says, earn eightpence a day, and thus enrich their father instead of beggaring him, as they did when running about idle.

The author had, from 1665 until he wrote the book in 1677 , often travelled through Warwickshire on his way to London, and observed how suitable much of the soil there was for rearing Flax. $\mathrm{He}$ therefore recommended the establishment of the manufacture of Linens in Warwick, Leicester, Northampton, and Oxfordshires, because these countries had then no staple trade, and the land was rich and dry, and such as Flax grows best in. Bleachfields, he says, should be put down by the banks of rivers near the great towns, as it then was in Southwark by the help of the flowing of the Thames. He recommended each county to raise money to start the manufacture at first. After it was established in these counties and encouraged by a public law, they would soon become what Germany was to Holland and Flanders, as the yarn would be sent down the navigable rivers to the several towns to be woven, along with such of the Flax as was not spun in the counties.

In this way employment would be provided for the unemployed, of which there were so many in these counties, and at least two millions of money a year kept in the country, which was then sent out for Linen cloth. This, he supposed, would keep the people at home who then went beyond the seas, and it would make the country populous and rich, and greatly benefit the landlords and all classes of the community.

He thus shows that bleaching had then been carried on by the side of the Thames in Southwark, and that the central counties in England had no trade, and no means of employing the population, excepting at agricultural labour and work incidental thereto ; and as this did not yield employent to all the people, many had to emigrate to other lands. The author points to some large tracts of fine land suitable for growing Flax, and in one case mentions 3000 acres, near Stratford-upon-Avon, of the value of about $£ 3000$ a year, which exhibits the rent of such land at that period. This land, he says, would bear three cwt. 
of Flax an acre, which, well dressed, would make 1400 ells of cloth, worth three shillings the ell, or when manufactured sixty pounds an acre. Three people he says are required to manufacture the produce of an acre of Flax, and therefore these 3000 acres alone would employ 9000 persons. Thus by growing Flax extensively all the poor in England would be employed, and the country enriched.

'This is a very interesting account of the Linen trade at that period in Germany, Holland, \&c., and it would have been of immense advantage to England had the recommendation of the author been carried out. 'The description of the spinning schools is curious.

A regulation at one time existed in England, something akin to the stamping of Linens in Scotland. It was called a commission for the sealing lace, buttons, and Linen cloths, and it appears to have been abolished by King Charles I., in the following proclamation, made at York in 1639:- "Whereas divers grants, licenses, privileges, and commissions had been procured from him, on pretence for the common good and profit of his subjects, which since, upon experience, have been found to be prejudicial and inconvenient to his people, and in their execution have been notoriously abused, he is now pleased, of his mere grace and favour, with the advice of the Privy Council, to declare these following to be utterly void and revoked." \&c.

In 1685, the revocation of the Edict of Nantes, by Louis XIV., drove about 600,000 Protestant artificers from France, of whom about 70,000 settled in England. There they introduced new manufactures and improved old ones, Linen, for which they had been long famous, being among the latter.

An act was passed in 1678 prohibiting the importation of French merchandize; but on the accession of James II., who, for Popish ends, wished to conciliate Louis of France, this act was repealed, in consequence of which there was an inundation of French commodities. In 1686, as shewn by the Custom

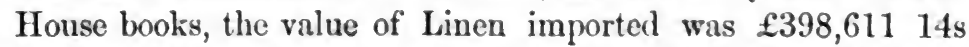
$10 \mathrm{~d}$, and the average annual importations of linen for that and

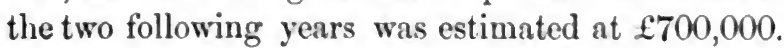

Anderson says that in 1696 " the English, Scotch, and Irish Linen manufactures met with all due encouragement, King 
William and the late Queen Mary honouring them with their names, which made their fame to rise. Abundance of people of condition came into them, some of lucre, and others from love to their country."

In 1698 Dupin, one of the French refugees, was instrumental in advancing the manufacture of fine linen, thread, ropes, lace, \&c.

About the end of the 17th century it was doubtful if the Linen trade would prove successful in England, and it was then a question if it would be for the benefit of the country that it should, as it might interfere with what was called "our noble and ancient woollen manufacture." It was said that it required about 20 acres of land to breed wool for setting on work the same number of hands which an acre of Flax would employ, and yet in the end the woollen manufacture would be found to employ by far the greatest number of hands, and yield the most profit to the public, as well as to the manufacturers. Even in Holland, where the Linen manufacture was so prosperous, it was said the Dutch had only the easiest and most profitable part of the trade, viz , the weaving and whitening of it. Most of the yarn was spun in Germany, Prussia, \&c., where the people, being poor, could spin cheaper than the people of Holland or England can do. But in countries where labour and land are cheap, as in Scotland and Ireland, the Linen manufacture had been found to be profitable to the community.

In 1669 Linen yarn weighing 23,680 lbs. was imported into the port of London from Scotland. In the month of May 1730 London imported-fine Linen from Holland, 66,286 ells; from Hamburg and Bremen, 1,232,209 ells ; Irish Linen, 179,114 yards ; and Linen Yarn from Hamburg, 73,450 lbs. On 23d October, 1738, 151,219 yards of Linen manufactured in Scotland, and 3000 sps. of yarn were imported into London. In 1731 the quantity of all kinds of Linen imported into the port of London alone was nearly 14,000,000 ells, the greater part of which was again exported to the plantations in America, and to the factories in Africa.

In 1703 a bounty of $£ 6$ a ton was allowed on the importation of Hemp from America. This must have been discontinued, because in order to obtain a cheaper and surer supply of Flax and 
Hemp, and to encourage their cultivation in the American colonies, the parliament granted a bounty of $£ 8$ on every ton of clean mercantile Hemp, or rough Flax, imported from the British American colonies from 24 th June, 1764, to 24 th June, 1771, from thence to $22 \mathrm{~d}$ June, $1778, \mathfrak{f} 6$; and thereafter to 24 th June, 1785, £4. The pre-emption of all such Flax and Hemp being offered to the commanders of the navy, and twenty days allowed for their determination, before the importer could be at liberty to sell it to a private buyer.

About 1605, Sir W. Morrison says that nearly all the nations of Europe, including England, took Flax, Hemp, \&c., from the Turks, and in Munn's treatise in favour of the East India trade, published in 1621, he makes the same statement.

In 1717 the duty of $6 \mathrm{~d}$ on every piece of forty ells of British made Linen exported, which had been laid on by the tonnage and poundage act, was taken off, " the said manufacture employing many thousands of the poor of this kingdom."

About 1720 great complaints were made by the weavers of the change of fashion in dress, caused by the French commercial treaty of 1713, and by the subsequent introduction of Indian cotton and cotton cloth. "The Weavers' True Cause" says, that instead of the women of the gentry wearing English brocades and Venetians as of late, they were now clothed with outlawed India chintz. 'The common traders' wives had changed their slight silk damasks for English and Dutch printed calicoes. The good country dames had supersided worsted damasks, flowered russets, and flowered calimancoes, with ordinary calicoes and printed Linens; and the meanest of them had given up plain worsted stuffs for ordinary printed Linens, whereby these famous branches of the weaving trade had almost become extinct. The weavers were stricken with horror at the growing frenzy of English women for printed calicoes, and declared that " the weaving of printed or painted commodities puts all degrees and orders of woman kind into disorder and confusion. The lady cannot be well known from her chambermaid. But when our womenkind were clothed with silk and woollen commodities, these mistakes were aroided, and a tolerable order observed." However fallacious such reasoning, it was powerful enough to procure an enactment in 1721 , which made it penal to sell or to 
weave calico. When that enactment was no longer tenable, it was in 1736 still penal to weave calico, unless the warp was wholly of Linen, and this continued to be British law until 1784.

On Sunday, 30th Dec., 1722, a woman was seized near London Wall, in the city of London, for wearing a gown faced with calico, and being carried before a magistrate, and refusing to pay the penalty inflicted by the statute, she was committed to the Compter. So says a London newspaper, published on Tuesday, 1st January, 1723.

To prevent the use of calicoes from interfering with the demand for Linens and woollens, a statute was passed in 1721 imposing a penalty of $£ 5$ upon the weaver, and $£ 20$ upon the seller, of a piece of calico. Fifteen years afterwards this statute was so far modified that calicoes manufactured in Great Britain were allowed to be worn, " provided the warp thereof was entirely made of Linen yarn." In 1774 a statute was passed allowing printed goods wholly made of cotton, to be used upon paying a duty of $3 \mathrm{~d}$ a yard, \&c. The statute continued in force many years.

In a report by Alexander Somerville of a journey made through the counties of York, Lincoln, Cambridge, and Norfolk, in 1773, to observe the management of Flax and Hemp there, the value of the quantity raised was estimated as follows :-

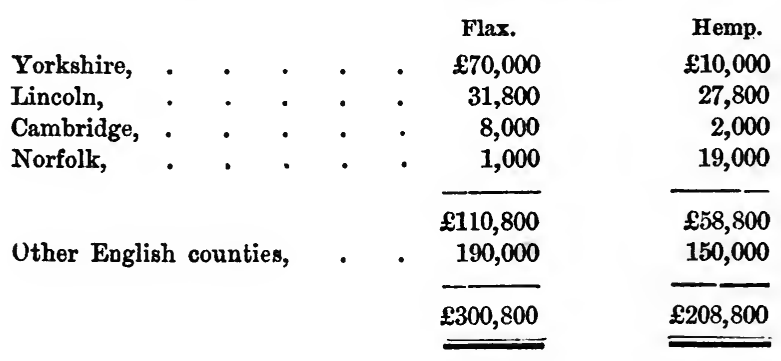

In 1745 , an act was passed, 18 Geo. II., c. 36 , for the encouragement of the native Linen trade, by which it was enacted "that it shall not be lawful for any person in Great Britain to wear any cambric or French lawn under the penalty of $£ 5$, and the like penalty on the seller thereof." Another short 
act, 21 Geo. II. c. 26 , was passed for explaining, amending, and enforcing the previous act, by farther extending the penalties to the vendors, and also to the milliners making up such fabrics. These acts, like many other which still cumber the statute book, must have been, in a great measure, inoperative, if indeed they were ever seriously intended to be enforced, and they ought never to have been passed.

In order still farther to encourage the manufacture of sailcloth in Great Britain, which was then in a prosperous and improved state, and had previously been fostered by many acts of parliament imposing duties on foreign cloth imported, \&c., an act was passed in $1746,19 \mathrm{Geo}$. II., c 27, confirming previous acts, and ordaining that every vessel built in Great Britain, and in His Majesty's plantations in America, must, at her first sailing, be furnished with one full and complete set of new sails made of sail-cloth manufactured in Great Britain, under the penalty of $£ 50$ : and any sailmaker in Great Britain or the plantations shall on every new sail affix in words at length, a stamp of eight inches diameter, whereon his name and place of abode shall plainly appear, under the penalty of $£ 10$.

A manufacture of cambric in imitation of the French cambric was established at Winchelsea in 1761 . In 1764, the English Linen Company was established as a corporate body, chiefly for the purpose of making cambric and lawns of the kind called French Lawns, with a joint capital stock which should not exceed $£ 100,000$; the goods, in order to certify them to be of English manufacture, to be sealed at each end of the piece by proper officers before they were taken out of the loom. This company may have been intended to supply the void caused by the prohibition to wear French cambric by the acts of 1745 .

This year, 1764, a great improvement in the spinning-wheel was invented by Mr Harrison, whereby it was said a "child may spin twice as much as a grown person can do with the common wheel." The Patriotic Society for the encouragement of arts and commerce gave him a premium of $£ 50$.

In 1764, Linens were exported from the following places in England, viz., as appears from a report made up at that time by Dr Busching, of Gottengen-Stafford, in Staffordshire; Darlington, in Durham; Manchester and Warrington, in Lancashire. 
In "The Progress of Commerce from 1700 to 1800 " it is mentioned that Great Britain imported Flax and Hemp, \&c., and exported Linen manufactures; that Ireland exported Linens to Portugal, and that German and Irish Linens were sent as far as to Timbuctoo!

For the establishment of a fund of $£ 15,000$ a year to encourage the cultivation and dressing of Hemp and Flax, additional duties ware in 1767 laid on foreign canvas and lawns, to be repaid on such as should be exported. In 1770 it was enacted that $£ 8000$ of this sum should be for England, and $£ 7000$ for Scotland. Should the funds fall short of $£ 15,000$, England to have 8-15ths and Scotland 7-15ths of the amount collected. By the thirteenth Report of the Commissioners for Examining the Public Accounts, dated 18th March 1785, it appears that no claims had at that date been made from England, but that a few had been made from Scotland.

In 1767 an additional duty of $3 d$ was laid on every ell of drilling and Linen above one yard wide imported.

Linens imported into England from foreign countries :-

\begin{tabular}{|c|c|c|c|c|}
\hline 1762 & $18.827,853$ & Yards. & Duty, & $£ 134,031 \quad 14$ \\
\hline 1765 & $25,497,795$ & " & " & $\begin{array}{llll}182,997 & 0 & 11\end{array}$ \\
\hline 1770 & $27,101,: 43$ & ," & " & $221,333 \quad 8$ \\
\hline 1771 & $28,243,121$ & , & , & $230,951 \quad 14$ \\
\hline
\end{tabular}

Total quantities of Flax, Hemp, Flax seed, and Linen yarn, imported into England from 5th January 1764 to 5th January 1772, being eight years:-

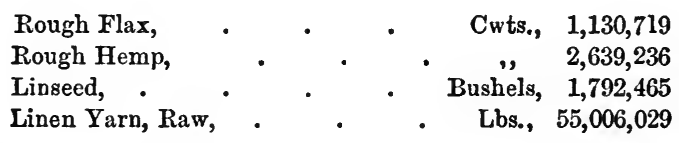

In 1773 there was great stagnation in the Linen trade throughout the United Kingdom, owing to serious over trading in 1771 , both at home and abroad, the loaded state of the foreign markets from excessive exports in 1770,1771 , and $177 \%$, and many failures in the latter year. Mr Paine, Governor of the Bank of England, in his examination before the House of Commons, estimated that the importation of foreign Linens, which in 1772 had been $27,000,000$ yards, had fallen in 1773 to $17,000,000$ yards. 
By the Act 22 George III., cap. 40 (1782), the crime of cutting or destroying woollen, silk, cotton, or Linen goods, or of any utensils used in their manufacture, was made a felony without benefit of clergy.

On an average of the three years, 1768 to 1770 , the quantity of Flax seed imported from America was

To Great Britain,
To Ireland,

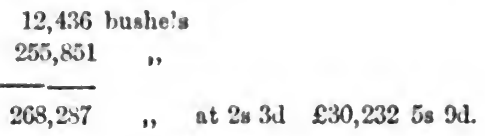

On the average of the three years from 1777 to 1779 , the value of Flax seed imported from the Continent of Europe, chiefly from Holland and Russia, was

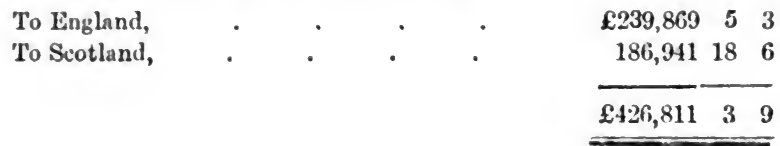

From the period of the introduction of the cotton manufacture into England in the early part of the 17th century, down to the year 1773, the weft or transverse threads of the web only were of cotton, the warp, or longitudinal threads being wholly of Linen yarn, principally imported from Germany, Ireland, and Scotland. In the early stages of the manufacture, the weavers, dispersed in cottages throughout the country, provided the yarn for their webs, and carried them to the market when they were finished. About 1760, Manchester merchants began to send agents into the country, who employed weavers, and furnished them with the Linen yarn for warp, and raw cotton for weft, the latter having to be carled, and then spun with the common spindle and distaff by the weaver's family. 'The latter was perhaps an improvement on the former plan, but both were slow and tedious, and the quantity of cloth which could be so produced was necessarily of limited extent. The invention of the spinning Jenny by James Hargraves, in 1767 , superseded the spindle and distaff, and subsequent improvements on it, and the invention of the spinning frame by Richard Arkwright, in 1770, obviated the necessity of using Flax yarn for warp. After this period calicoes and other fabrics were made wholly of cotton. 
The introduction of the cotton manufacture into England was a severe blow to the Linen trade in that country, and since that period cotton and Linen have, in a great measure, been antagonistic to each other. The invention of machinery for spinning the cotton made the competition all the stronger, and gave cotton a great advantage over Flax. At first, cotton strong enough for warp could not be spun by machinery, and for some time calicoes were made with Linen warp and cotton weft. While this continued large quantities of Flax yarn were used, but Arkwright's invention, and improvements thereon, speedily enabled cotton spinners to produce yarn strong enough for warp, and Flax yarn was then discarded. After that period King Cotton ruled supreme, until the fratricidal war in America compelled him to bow his head, and give his rival Flax a moment's breathing space. This has been of immense benefit to the Linen trade, and may prove of permanent advantage to it, although in many markets it cannot be expected to supersede cotton, should that article go back to the prices of 1860 again.

In a curious letter, signed Samuel Homespun, in the Gentleman's Magazine of 1742, some calculations are given to show the value of one acre of ground sown with Flax seed. He goes on to say "that though the quantity of Flax an acre will produce depends entirely upon the quality of the soil and cultivation of it, yet the fineness of the Flax depends almost solely on the conduct of reaping, watering, and grassing it. This fact is very little known, but it is absolutely certain. Great Britain produces not only the largest crop of Flax, but the toughest and finest of any in the world. Our soil is so proper for it, that unless the farmer mismanages his Flax in reaping, watering, or grassing, it is not in his power to raise coarse Flax."

On the supposition that the farmer employs suitable skill in choosing the land proper for a crop of Flax, an acre will pro. duce at a medium 50 stone Dutch weight of Flax. Some bad land will only produce 30 stone, but very superior he says will produce 100 stones. Suppose, he then says, the produce 50 stone Dutch weight of Flax per acre, this will produce 25 stone English of fine Flax, $12 \frac{1}{2}$ of medium, and $12 \frac{1}{2}$ of coarse. The 25 stone will yield 2000 spindles yarn, at 5 spindles in the $\mathrm{fb}$.; which 
wrought in the finest reed, viz., a 2400 , will produce 2838 yards cambric at 10 s a yard, or $£ 1,194$. The $12 \frac{1}{2}$ stone second sort will produce 200 spindles yarn, which wrought in a 1500 reed will yield 452 yards Linen, at $2 \mathrm{~s} 6 \mathrm{~d}$, or $£ 56$ 10s. The $12 \frac{1}{2}$ stone coarse spun into yarn, at $2 \mathrm{lb}$. a spindle, and wove in a 600 reed, will yield 1129 yards Linen, at $8 \mathrm{~d}$, or $£ 3210$ s, being

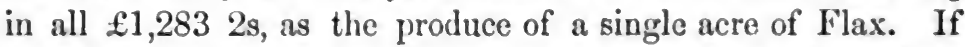
manufactured into coarser Linen, 50 stones of Flax will produce 25 stones of fine dressed Flax, $12 \frac{1}{2}$ stone of medium, and $12 \frac{1}{2}$ stone of coarse; 25 stone fine dressed Flax will yield 800 spindles of yarn, 2 spindles in the pound, which wrought in a 2100 reed, will yield 1238 yards of Linen, at $4 \mathrm{~s} 6 \mathrm{~d}$, or $£ 27811 \mathrm{~s} ; 12 \frac{1}{2}$ stone medium will produce 100 spindles, at 40 cuts to the pound, which wrought in a 1200 reed, will produce 266 yards of Linen, at $1 \mathrm{~s} 8 \mathrm{~d}$, or $£ 22 \mathrm{3s} ; 12 \frac{1}{2}$ stone coarsest will produce 60 spindles, at two pounds of Flax per spindle, which wrought, in a 400 reed, will yield 576 yards of Linen, and this made into buckram, at 7 d a yard, is $£ 1616 \mathrm{~s}$, or in all $£ 31710$ s an acre. For the truth of the yield of Flax to an acre he appealed to all the Flax raisers in Yorkshire and Lancashire; of the value of cambric he appealed to the Linen drapers in London; and of the produce of the yards from the quantities of Flax and yarn, he appealed to all the spinsters and weavers in Great Britain.

In 1781, the cultivation of Flax in England was recommended on the score of increasing the population, by inducing " numbers from the Continent to settle in England, as a great national advantage."

In the same year, a Dorsetshire gentleman wrote the Bath Agricultural Society, strongly recommending the cultivation of Flax and Hemp on the rich marshy lands lying west of the Mendiss Hills, for which it was very suitable. He said the vast quantities of these plants which had been raised on the same kind of land in the Lincolnshire marches, and in the Fens of the Isle of Ely and Huntingdonshire, were a full proof of it. In these places much land, which for grazing was worth 20 s to $25 \mathrm{~s}$ per acre, had been readily

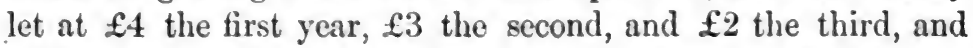
that the produce had been from 50 to 70 stone per acre, which, when dressed, brought from $7 \mathrm{~s}$ to $9 \mathrm{~s}$ a stone, or $£ 24$ an acre. Poor soils also grew Flax and Hemp well, and Spalding Moor 
in Lincolnshire, which although a barren sand, yet with proper care and culture produced the finest Hemp in England, and in large quantities. In the Isle of Axholme, in the same county, the culture and management of these fibres was the chief employ of the inhabitants, and large quantities were produced. According to Leland it was the same there so long ago as in the reign of Henry VIII.

The writer goes on to say that the Hemp raised in this Kingdom is not of so dry and spongy a nature as that from St Petersburg, and does not take in so much tar, but that of equal dimensions it is stronger and more durable. One peculiar advantage, he says, attending the cultivation of Hemp and Flax is, that a crop of the former prepares the land for the latter, and therefore a crop of Hemp was a clear gain to the farmer. That these plants impoverish the soil is a mere vulgar notion, a prejudice devoid of all truth, and unsupported by any authority, as these crops really meliorate and improve the soil. He farther stated that the quantity of Flax and Hemp yearly imported into this Kingdom about the year 1763 was estimated at 11,000 tons, to raise which in this country would require about 60,000 acres of land, and which could be grown at home, in the manner suggested by him, without interfering much with other crops.

A cultivator of Flax, in writing to the Dundee Advertiser, in February, 1803, recommends an extended cultivation of Flax, in order to give employment to women in weeding, \&c., and, as an inducement to do so, he says, "the trade in the west of England can at present get as much English Flax grown as they need, better and cheaper than St Petersburg 12-head. The extent to which the English have so successfully carried the raising the crops should encourage the folks here to do so also."

Much has been said and written from time to time about the propriety of growing Flax more extensively in Britain, and it is asserted by Warnes that it would be a great saving to the farmer, and at same time enrich the country. To attempt to grow cotton here, he says, would be fruitless, but the cultivation of Flax would be highly advantageous. He also says Flax is "a plant for which, including the seed, oil, and cake, $£ 400,000$ per wcek are expended with foreigners."

Samuel Druce, jum., of Evesham, furnishes the following statc- 
ment of the produce and expenses of Flax grown by him in 1845, on 4 acres, 1 rood, and 24 poles of land :-

\section{EXPENSFS.}

Ploughing, at $10 \mathrm{~s}$ an Acre,

\&2 40

10. Bushels of Linseed, 54 to $55 \mathrm{lls}$. per bushel, at

$7 \mathrm{~s} 6 \mathrm{il}$,

Sowing and Harrowing, do.,

Weeding,

Pulling and tying up the stalks, threshing, spreading aud turning, and preparing for scutchin :, 30 s per acre,

Fxpense of Carting, Stacking in Barn, \&c.,

Rent and Taxes, 50, per acre. .

Scutching $1.455 \mathrm{lb}$. of Flux, at $2 \mathrm{~d}$ per $1 \mathrm{~b}$. .

Do. $372 \mathrm{lb}$. of Tow, at ld per lb, .

\section{PRODUCF.}

1,349 lbs. Flax, sold in Leeds, for (after deducting expenses),

$106 \mathrm{lbs}$, do., sold in Evesham, . . . . 372 lhs. Tow, d"., . . . 104 bush. Linseed,54@55 lbs.per bush., @7s6d bushel,

Small quantities of tail Linseed, chaff, and refuse from Seutching,

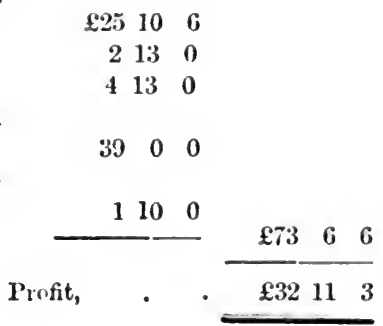

Warnes says regarding this statement, "the cost of dressing the Flax is excessive, and the quantity of tow and consequent waste immense."

The same author farther says that his late Royal Highness the Prince Consort at one time resolved to grow Flax upon his estates, not so much because the cultivation was in itself profitable, as because it gave enployment to the working classes, and if grown largely throughout the country would be highly advantageous to them, and also benefit the mercantile community, by providing the raw materials for their mills and factories.

Marshall \& Co. of Leeds, in writing to Warnes, says,- "We believe both the soil and climate of England are suitable for the plant. At one time the Flax grown in the east of Yorkshire was of as good quality as that grown in Belgium; but the growth since then has fallen very much off', chiefly owing 
to the farmers managing the cultivation and preparation in a slovenly manner, and partly to the landlords having a prejudice against the crop as an exhausting one, which would not be the case if your plan was adopted of using the seed for feeding cattle on the farm where the Flax was grown." They say the seed should be sown thick, ( 3 to $3 \frac{1}{2}$ bushels per acre) to produce fine Flax. The effect of retting on running water is to produce Flax of a light yellow colour, but the same effect is produced in large ponds or lakes of fresh water. This Flax fetches a higher price in the market than when retted in stagnant pools, \&c. This firm were reported to have imported Flax to the amount of one million sterling annually. Supposing the produce of an acre to be $£ 20$, it would thus take 50,000 acres to grow the Flax required by this one firm. Warnes calculated that it would require 500,000 acres annually to produce the Flax required in the United Kingdom.

Warnes also calculated that a woman could spin 20 s to 30 s of yarn for fine lace, lawn, cambric, \&c., out of $6 \mathrm{~d}$ worth of Flax, which shows the immense amount of labour the manufacture of this description of goods, if largely prosecuted, would give to females throughout the country.

For several years Warnes, both by precept and practice, urged the farmers of England to cultivate Flax, and he proved very satisfactorily that it was a highly profitable crop whether raised for its seed, or for its fibre, or for both. Notwithstanding his most laudable exertions, his very proper example has not been largely followed, and at the present time the quantity of Flax grown in England is insignificantly small. Many counties produce none at all ; Dorset, Somerset, Norfolk, and a few others grow small quantities, and in certain portions of Yorkshire a little more attention is paid to the cultivation, but even there the crop is not appreciated, and although the quality of what is raised is good, the quantity is very much less than it ought to be.

English grown Flax is very suitable for the mills of Leeds and other Linen manufacturing districts of the country, and it is therefore surprising that so little has been done by those engaged in the trade to induce farmers to grow the plant. It is true, as already mentioned, that Government at different times insisted upon a 
certain quantity being grown annually, but it may well be doubted if compulsion be the best mode of accomplishing such an object. A more legitimate plan is to show farmers that it is profitable to grow it, as the pocket is an excellent incentive, and the hope of gain would stimulate them to earn it.

Much of the land of England is admirably adapted for raising Flax, and to the agriculturists individually it is undoubtedly a profitable crop, and in a national point of view it is a highly necessary and proper one. Unfortunately there are no national statistics to show the quantity grown, or the districts which produce it, and this is much to be regretted, as it keeps the country very much in the dark regarding what it is doing, and makes it all the more difficult to extend the growth of this truly valuable national crop.

Mr Baker, the factory inspector, in his annual report, says:"We can neither produce from abroad nor induce our farmers to grow the raw material in sufficient quantity. The same complaint is made in the Federal States of America, where the production has fallen off enormously. It is to Ireland at present, and even eventually to India, that the Flax spinners are looking for a supply which, if ever the time arrives, is to render the Flax trade of comparative importance with cotton." Mr Baker thinks there is yet much to be learned in the manufacture of machinery adapted for general farming purposes, and to the scutching of Flax. He thinks the gradual introduction into Ireland of the Scotch and English system of tillage farming on a large scale, operates against an increase of Flax culture in Ireland.

In his first half yearly report for 1863 he says:-"The growth of Flax appears to be decreasing evorywhere whence we have hitherto been accustomed to be supplied; and though an annual knowledge of the acreage sown is as essential to the vitality of the Linen trade as where cotton is to come from is to the cotton trade, the growth of Flax is exciting no very extraordinary attention. The changes taking place in agriculture, and the diminution of cottier farms, which are peculiarly favourable to Flax cultivation, owing to the cheapness of home labour, and the facility with which Flax can be prepared in the first instance, make the matter more important. In England we 
have no statistics of Flax ; in Scotland they have been given up: in Ireland they have been collected for years by Mr Donelly in the most satisfactory manner-a proof of what might be done elsewhere. So with regard to English wool; we guess that there is a sheep to an acre on all the farm lauds in England, but whether it is so or not we are totally in the dark. But for Australia, and, even with Australia, but for rags reduced to wool again, and re-manufactured, many of our woollen mills would long ago have been at a stand-still ; and with regard to Flax, if there should be a Flax famine as there has been a cotton famine, we should again suffer extremely, with a consciousness that by a little timely forethought those sufferings might have been alleviated if not averted. A company was started in Yorkshire a few months ago, including some Flax millowners, for the purpose of collecting Flax in this country from the farmers, and preparing it for the trade, but the company has been broken up for want of encouragement even from the trade itself." It would thus appear that the trade is highly culpable for their indifference on so vitally important a subject.

From a table of the imports and exports of Great Britain in 1800 , it appears the imports bearing on the Linen trade were, -from

Russia-Flax anl Hemp ; Linens, viz., Diapers, Drillings, and Sheetings.

Poland-Some Linen.

Prussia-Flax and Hemp.

Germany-Flax and Hemp, Linens, viz., Cambrics, Lawns, Canvas, Hollands, Tablings, \&c., and 3,000,000 lbs. Linen Yarn.

Holland-Flax and Hemp, and a few Linens.

Ireland-Some Flax, and 32,152,399 yards of Linen Yarn.

The exports were-to

Denmark-Scotch Linens.

Russia, Germany, and Portugal-A few Irish Linens.

Madeira-Linens.

New England-Linens, and Irish Linens.

New York-Linens-Scotch, and Irish, and Russian.

Pensylvania-Linens and Sailcloth ; a few Irish and Russian Linens.

Virginia and Maryland-British, Irish, Russian, and German Linens.

South Carolina, Georgia, Newfoundland, Canada, New Brunswick, Nova Scotia, Bermuda, Bahama, aud British West India Islands-Some Linens-Irish, Russian, and German.

Florida and Bay of Bonduras-Irish Linens.

East Indies and China--Linens of all kinds and Sailcloth.

New Holland-Linens-British and Russian.

Africa, Sierra Leone, and Cape, of Good Lope- British, Irish, and othe!linens. 
Return of the number of square yards of calicoes, muslins, Linens, and stuffs made either of cotton or Linen, printed, painted, stained, or dyed in Great Britain (except such as shall have been dyed of one colour throughout), with the amount of Excise duties collected thereon in Lingland and Scotland, in the three years ending 5th January 1830 :-

\begin{tabular}{|c|c|c|c|c|c|}
\hline \multirow{3}{*}{$\begin{array}{l}\text { England, } \\
\text { Scotland, }\end{array}$} & \multicolumn{3}{|c|}{$\begin{array}{l}\text { Number } \\
\text { Calicoes and Muslin }\end{array}$} & \multirow{3}{*}{$\begin{array}{l}\text { Yards. } \\
\text { Linens and Stuffs. } \\
1,376,779 \\
31965\end{array}$} & A mount of Duty. \\
\hline & . & . & 115,$6 ; 36,321$ & & $\& 1,706,936 \quad 8 \quad 3$ \\
\hline & . & . & $22,863,883$ & & $333,897 \quad 15 \quad 8$ \\
\hline Year ending & 5 th Jan. & 2. 1828 & $138,500,204$ & $1,408,744$ & $£ 2,040,88 \uparrow \quad 311$ \\
\hline Eng'and, & . & • & $112,498,528$ & $1,654,457$ & $£ 1,665,110 \quad 12$ \\
\hline Scotland, & . & - & $25,971,724$ & 23,252 & $379,093 \quad 8$ \\
\hline Do. 5th & Ianuary & y. 1829, & $139,470,252$ & $1,677,709$ & $£ 2,044,204 \quad 0 \quad 1$ \\
\hline England, & . & • & $102,256,792$ & $1,704,761$ & $\boldsymbol{\varepsilon} 1,516,431 \quad 1410$ \\
\hline Scotland, & . & . & 26.105550 & 8,755 & $380,833 \quad 12$ \\
\hline Do. oth & anuary & 8,1830 & $128,362,342$ & $1,713,516$ & $£ 1,897,265 \quad 7$ \\
\hline
\end{tabular}

EXPORTS OF SAME-

To Foreign Coustries.

Yds. of Calicoes, Ifuslins, Amount of Linens, and Stuffs. Drawback.

\begin{tabular}{|c|c|}
\hline $\begin{array}{l}\text { Engladd, } \\
\text { Scotlaud, }\end{array}$ & $\begin{array}{r}81,193,826 \\
8,751,365\end{array}$ \\
\hline 1828. & $89,945,191$ \\
\hline England, & $82,609,216$ \\
\hline Scotland, & $7,410,349$ \\
\hline 1829. & $90,049,565$ \\
\hline $\begin{array}{l}\text { England, } \\
\text { Scotland, }\end{array}$ & $\begin{array}{r}81,449,096 \\
8,417,009\end{array}$ \\
\hline 1830. & $89,866,103$ \\
\hline
\end{tabular}

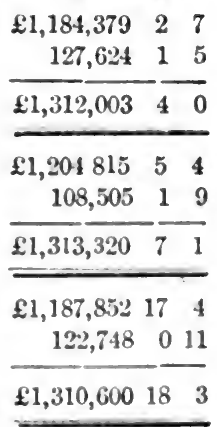

To IRELaNd.

Yds. of Calicoes, Muslins, A monnt of Linens, and Stufts. Drawback.

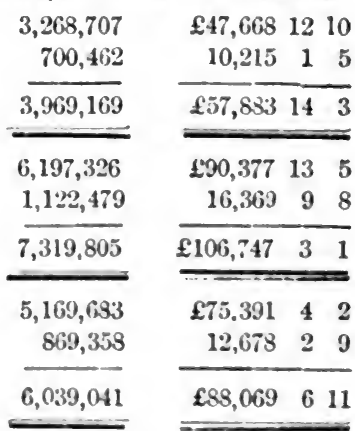

Before the introduction of Flax spinning by power into Englaud, the manufacture of Linens was general in many districts of the country. Since that period the trade has, in a great measure, become concentrated in a few localities, in some of which it is prosecuted vigorously and most successfully.

The invention of Flax spinning machinery by John Kendrew 
and Thomas Porthouse at Darlington in 1787, will be specially referred to in the chapter on Flax spinning. It was the beginning of a new era in the Linen manufacture, and mighty results have followed from the rude spinning frames first set in motion by these men. Their memory ought to be held sacred by every one interested in the trade, as their bloodless triumph of mind over matter has done more good to their fellow men than many warriors who have been ennobled for wading in the blood of the vanquished slain.

For many years subsequent to 1787 Flax spinning was carried on in the vicinity of its birth. So late as 1838 there was a small work at Darlington, and another at Houghton-le-Skerne, employing fifty to sixty hands each, and some others in different parts of the county, but all are silent now ; there being, according to the Factories' Return of 1862, no Flax spinning mills in Durham, and only two weaving factories, employing sixty-nine hands in all.

Shortly after the invention was brought out at Darlington, machinery on the same principle was started in Leeds and in other districts in the West Riding of Yorkshire. Within a comparatively limited period great improvements were effected on the original machinery in Leeds, and that town speedily became the head quarters of Flax spinning in England. John Marshall, a name famous in the annals of Flax-spinning, applied himself assiduously to the prosecuiion of the new trade, and by his ability and perseverance soon carried Flax spinning to high perfection, and to a vast extent. To that gentleman Leeds is indebted for much of its present prosperity. His spinning mills continue at this day a monument of enterprize and skill, and his family have hitherto maintained the superiority which he so long ago established. The name of the Marshalls of Leeds are houshold words in the Flax-spinning trade, and their works are the greatest in the world, whether as regards the number of spindles of yarn spun, or the value of their annual production. The celebrated Scotch Flax spinning firm, the Baxters of Dundee, perhaps surpass the Marshalls in the weight of material annually consumed in their works, but the yarn and cloth produced by them, being of a coarser description, is of comparatively less value in the manufactured state. 
The great Flax mill erected by the Marshalls is one of the most striking buildings reared by private enterprise in Leeds, and, from its unique character, the following description is given:-It is one hundred and thirty-two yards long and seventy-two yards wide (inside measure), and twenty feet high. 'The roof consists of seventy-two brick arches, supported on as many iron pillars, and secured together by strong iron work. The brick roof has a thick coating of composition, to prevent the water from coming through, and it is covered with earth from which has sprung up a beautiful grass sward. There are sixty-six glass domes in the roof, each forty-eight feet round, eleven feet six inches high, containing ten tons of glass, in iron window frames. The total weight of the roof is 4,000 tons. There are four steam engines, of 100 horse-power, and two of 80 horse-power each; and one engine of 7 horse-power, which does nothing but blow hot or cold air into the room. The building covers more than two acres of ground, and it is supposed that 80,000 persons might stand in the room. This hall is occupied for spinning and weaving by power, and the whole processes incidental to the trade subsequent to heckling is performed in it, the Flax going in in bundles and the Linen out in bales. To non-practical people it is one of the most interesting sights which can be witnessed, both as regards the beautiful machinery with its many and curious motions, and the immense number of active and apparently happy male and female workers who guide its operations, and turn out the beautiful yarns and Linens, the production of which have rendered the Marshalls of Leeds so famous. To those practically acquainted with the trade this work is a sight worth seeing, as even the most advanced would learn much both as to the construction of the machinery and its arrangement.

There are several large establishments deroted to the Linen, manufacture in Leeds besides those of Messrs Marshall, but none of them will at all compare with the one described, in extent or completeness; indeed there is no other work in the United Kingdom of a like description with it. The goods made in Leeds comprise the better class of Linens, and they are mostly of a strong durable character, well adapted for family use. They include sheetings, damasks, towellings, drills, sackings, and a variety of other descriptions 
of Linens of a highly superior quality, suited both for the home trade and for export. Very large quantities of the finer numbers of yarn are exported, and extensive manufactures of excellent thread have long been carried on in the town and district.

In 1821 there were in and around Leeds nineteen Flax spinning mills, with an aggregate steam power of about 700 horses, containing 36,000 spindles for spinning only, and producing about 9,000 spindles of yarn per day. The sorts chiefly spun were $1 \frac{1}{4}$ to $3 \mathrm{lb}$. line, and 3 to 7 or $8 \mathrm{lb}$. tow, mostly spun wet, on the long fibre cold water system. There were besides a number of twisting frames in the mills. From slow driving and hard twisting the production per spindle was only about half as much as was then taken off in Dundee, and therefore Leeds, with six times the number of spindles which Dundee possessed, only threw off from three to four times as much yarn. Of the Flax spinning: works in Leeds at that period, four of them belonged to $\mathbf{M r}$ Marshall, forming in extent one third of the whole, and equalling Dundee entirely.

For a number of years after the period referred to Leeds made slow progress in Flax spinning, as there were only twenty-four engines, with an aggregate of 705 horse-power at work in 1831 . Shortly thereafter the spirit of extension must have entered, because in 1838 the number of Flax mills had increased to forty. four, employing 2,127 males and 4,303 females, in all 6,430 hands. In all Yorkshire at the same period there were ninetyone Flax spinning mills, employing 3,230 males and 6,414 females, making together 9,644 persons.

Eight years ago there were thirty-seven works in Leeds devoted to the Linen manufacture, with an aggregate of 1831 horse-power, containing 198,076 spindles, and 140 power-looms, and employing 9,458 hands.

Previous to the erection of Flax spinning mills the manufacture was in a very distressed condition. The German and Belgian spinners were so much superior to the English, that the greater part of the Linen required for home consumption was imported from Flanders and the north of Europe. The introduction of machinery and the improvements made in bleaching, \&c., turned the scale in favour of England, and not only enabled the manufacturers to supply the home demand, but also to ex- 
port Linens largely. Flax spinning works were also erected at an early date in I ancashire, Dorset, Durham, Salop, and other counties, and they are still carried on to a considerbale extent in various districts.

The Linen manufucture is one of the most important branches of the trade of Barnsley. Part of the yarn manufactured is spun there, but large quantities are procured from Leeds, Barnsley being one of the best customers of that town. There are still many hand-looms at work in the town, but, as in other places, the power-loom is now fast superseding the handloom, and it is well adapted for the fabrics for which Barnsley has been so long famous. These are drills, strong sheetings, damasks, ticks, huckabacks, towelling, ducks, plain and fancy Hollands, and kindred descriptions of fine, heavy Linens. The trade of the district has enjoyed a considerable degree of prosperity throughout 1863 , and good progress has been made and is still making in it. Already there are a number of power-loom works in full operation, some of which are of large extent, and contain several hundred looms, and the trade is still extending.

Brown and bleached Linens are manufactured extensirely in several other places in Yorkshire. Doncaster, Northallerton, Hull, Whitby, and other torns produce superior goods of various descriptions. Indeed Yorkshire is the great seat of the Linen manufacture in England, as Forfarshire is in Scotland, and Antrim in Ireland. Establishments abound in various parts of each of these counties for spinning and weaving, Leeds, Dundee, and Belfast being respectively the centres of the Flax manufacture in the three countries. In 1850 there were sixty Flax factories in operation in Yorkshire, containing 82,768 spindles, and 911 power-looms. Since then great progress has been made, the present condition of the trade in the county is highly satisfactory, and the prospects for the future bright and encouraging.

Lancashire ranks next to Yorkshire in the extent of its Flax manufactures, the spinning of Flax having been long carried on extensively there. In 1838 there were seventy horse-power employed in Flax spinning in Salford. In Preston there were in the same year six mills at work, employing 1392 hands ; in Kirkham, two mills, with 542 hands; in Wigan, two mills, with 400 
hands ; in Boston, one mill, with 261 hands ; and in other parts of the county, five mills, employing in all 286 hands. Latterly the spinning of Flax has not made much progress in Lancashire, the number of works in operation having decreased, but there are still some large spinning mills at work, and power-loom weaving is on the increase. Within the last few years some Jute spinning mills have been established in Liverpool and other places in the county, one at least of which is conducted vigorously.

Norfolk has long grown Flax, but not to a very great extent. A small quantity of Hemp is also raised there, and also in a few other counties in England, but the quantity cultivated throughout the whole country is not large, and from various causes it is decreasing. Norfolk also manufactures a few Linens in one or two places, but the trade is now of little importance compared with what it was formerly. Gloucester, Hants, Devon, and several other counties have each a few small works, the bulk of the Linen made being for local consumption.

In Somerset some Flax is raised yearly, and there are a number of Flax mills and Linen manufactories, which produce a considerable quantity of sailcloth and other goods. In 1838 there were thirteen Flax mills in active operation, and three or four large weaving establishments, besides several smaller ones. Dorset contains many works, both for spinning and weaving, and it grows a good deal of Flax, and some Hemp, which are consumed in the local manufactures of the county. The number of spinning mills in the county in 1838 was eighteen, but they were all small, and placed in various distinct localities. At that period there were many weaving establishments in Dorset, and the sailcloth made in and around Bridport has long been highly celebrated for excellence of material and superiority of workmanship. In the year mentioned, $\mathrm{Mr}$ Austin, in his report on hand-loom weaving, remarks "that 80 tons of Flax were used weekly in a circuit of 20 miles round Bridport, one-tenth of which was home growth. Besides the Flax mills there were then 420 hand-looms in the Linen trade. The manufacture was principally sailcloth. Bridport is the chief seat of it, and that year employed 206 looms upon it; and 120 looms were employed at Beauminster and adjoining villages. Very little variation had taken place in the trade for 
many years. Canvas, ducks, \&c., were also woven, chiefly by women." The manufacture of sailcloth, twines, \&c., in Bridport has long been, and still is, in a very flourishing condition, and the present prospects of the trade are quite as encouraging as they have been at any previous period.

Cumberland had nine Flax spinning mills in 1838 , and many weaving factories. Sililcloth has long been made extensively in the county, and Cockermouth has acquired no little celebrity for the superior quality of its cloth. The sailcloth made there is really excellent, and the fame earned is well deserved. Westmoreland has long had some extensive Flax spinning works. In Newcastle there are several sailcloth factories, and other Linens are also made there to a small extent. Lincolnshire raises both Flax and Hemp, and considerable quantities of what is grown in the neighbourhood of Spalding are taken for sale to a Fair, held there on 27 th April yearly. Another Fair is held at same place, and for a like object, in December, and the bulk of the supply is purchased for account of the Yorkshire spinners, there being little Flax used in the county:

There are still some sackings and other coarse fabrics manufactured at Abingdon, but the trade there has decreased greatly within the last quarter of a century, and it is still waning. In London a few coarse Linens are made, but the quantity is unimportant. A work for spinning and weaving Jute is to be erected there this year (1864), which may be the nucleus of other establishments of a similar kind in the future.

Formerly Flas spinning occupied more attention than weaving in England, the chief works being deroted to that important branch of the trade; and the progress made, and excellence attained in it, has been of no ordinary character. Latterly the spindles employed have decreased, the number in 1857 being 441,759 , and in $1562,344,308$, showing a diminution of 97,451 between these years. While this is the case with spinning, power-loom weaving has taken a great start, the number of looms having increased from 41 in 1835 , to 1987 in 1857 , and 2160 in 1862 . Since then the number of power-looms has increased still faster, and the progress making is not likely to be soon arrested. Indeed the Linen manufacture, as already mentioned, is in a highly satisfactory state, not only throughout B b 2 
Yorkshire, but also in several other parts of England, and it gives good promise of continued extension year by year. The prospects of the future of the Linen trade in England were never brighter than now, and there is no doubt the intelligent gentlemen engaged in it throughout the various parts of the country will take full advantage of the present opportunity, and benefit the kingdom while enriching themselves.

Details regarding the extent of the trade in the various counties throughout the country, in the beginning of 1862 , made up up by the Inspector of Factories, will be given hereafter.

Comparative Note of Import of Flax, \&o., into Huli, for Year ending 31st DECEMRER.

\begin{tabular}{|c|c|c|c|c|}
\hline & 1860. & 1861. & 1862. & 1863. \\
\hline 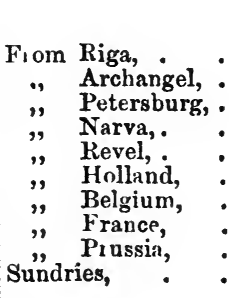 & $\begin{array}{r}\text { Tons. } \\
3,813 \\
103 \\
3,127 \\
405 \\
195 \\
4,081 \\
5,175 \\
856 \\
467 \\
52\end{array}$ & $\begin{array}{r}\text { Tons. } \\
2,840 \\
\ldots \ldots \\
1,355 \\
163 \\
\ldots \ldots . \\
2,791 \\
3,060 \\
556 \\
126 \\
190\end{array}$ & $\begin{array}{r}\text { Tons. } \\
3,958 \\
\ldots \ldots 71 \\
2,571 \\
371 \\
20 \ldots \\
2,898 \\
2,636 \\
1,466 \\
547 \\
316\end{array}$ & $\begin{array}{r}\text { Tons. } \\
\text { - } 3,902 \\
\dddot{1,520} \\
127 \\
78 \\
3,227 \\
2,673 \\
830 \\
165 \\
155\end{array}$ \\
\hline Total, & 18,274 & 11,081 & 14,763 & 12,677 \\
\hline
\end{tabular}

\section{CHAPTER II.}

I R I S H L I N E N.

The old Irish or Celtic name for Flax was Lhin, and the term poll a lhin, yet applied to places in the country, shows that the steeping of Flax in pools was practised in Ireland at a very remote period. It is probable that Linen was first introduced 
into the country by the Phonicians, but of this nothing certain is known. The Brehon laws enjoin the Brughaids or farmers to acquaint themselves with the method of cultivating and managing Flax; and it is stated that Linen dyed yellow was much worn by the ancient Irish.

Macpherson, in his "Annals of Commerce", says, "We learn from the chronicles of the period that about A.D. 500, fine Linen was possessed by the inhabitants of Britain and Ireland. The bodies of the dead, at least those of eminent rank, were wrapped in fine Linen."

Previous to the conquest of Ireland by the English in 1156, it would appear, from a list of exports furnished by Geraldus Cambrensis, that there were then no Linen manufactures.

Linen was woven in Ireland as early as the 11th century, but perhaps the first mention on record of Irish Linen occurs in the 13th century, it being said that in the reign of Henry III. in 1272 , Irish Linen was used in Winchester. It is recorded that Ireland exported Linen about the middle of the 15th century. In the "Picture of Antwerp," published in 1560, it is said that Linen were exported to Ireland. Leland states respecting Liverpool, that in 1545, "Yrisch merchants cum much thither, and moch yrisch yarn that Manchester men do by there."

About the year 1641 a considerable quantity of Flax yarn had been spun in Ireland, as Manchester then bought large quantities of Linen yarn from the Irish, and, weaving it, returned the cloth to Ireland for sale.

It does not appear that much improvement had taken place for some time, because in 1673 England imported from France Linen to the value of $£ 507,207$, which she would not have done if Ireland could have supplied it. Among the earliest notices extant of the Irish trade, Iinen and woollen cloths are mentioned as two of the most particular articles of export, but no details are given, so far as known, to show the relative extent of either. No doubt, however, the quantity, althongh perhaps large when compared with the other exports of the day, were trifling when contrasted with the exports of the present period. It was not until the 17 th century that the Linen trade attained any national importance in Ireland.

Although Ireland exported Linen goods at a very early period, 
yet this manufacture cannot be regarded as her staple one, or as having contributed much to her foreign commerce, until it flourished among the Scotch colonists in Ulster towards the middle of the 17th century. As soon as they entered into it with spirit, Linen yarn, instead of being exported to Manchester and other places of England to be weaved, was manufactured into cloth in Ireland. Iinen then formed the chief article of its commerce, and it entirely superseded and supplanted the woollen manufacture there.

Macpherson says that about 1670 , or perhaps a little later, the Linen manufacture began to be encouraged in Ireland. "It began among the Scots in the north of Ireland, where it has to this day flourished more than in any other part. The vast quantities of Linen which England takes of the Irish enables them to pay for almost every kind of our product and manufacture which we supply them with. Before they made much Linen cloth, the people in the north of Ireland sent their Linen yarn to England."

Sir William Temple in his "Miscellanies," published about 1681, says - "No women are apter to spin Linen thread well than the Irish, who, labouring little in any kind with their hands, have their fingers more supple and soft than other women of the poor condition amongst us. And this may certainly be advanced and improved into a great manufacture of Linen, so as to bear down the trade both of France and Holland, and draw much of the money which goes from England to those parts upon this occasion into the hands of his Majesty's subjects of Ireland, without crossing any interest of trade in England, for, besides what has been said of Flax and spinning, the soil and climate are proper for whitening, both by the frequent brooks and also winds in that country."

Macpherson says, "Great sums being continually carried out of England for Hemp, Flax, and Linen, which might in a great measure be supplied by Ireland, if proper encouragement were given to induce foreign protestants to settle in that kingdom, the Parliament, in 1696, passed an act for allowing Hemp, Flax, Iinen, and Linen yarn, the produce or manufacture of Ireland, to be imported into England by natives of England and Ireland, without paying any duty. And the manufacture of sail-cloth being already brought to good perfection in Eng- 
land, all English made sail-cloth was thenceforth allowed to bo exported without paying duty, either in the piece or made into sails."-7, 8, William III., cap. 39. Experience has shown that this law laid the foundation of the great and flourishing manufactures of Linen and cambric in Ireland.

During the reign of Charles II. the woollen manufacture made rapid progress in Ireland. This roused the jealousy of the English manufacturers, and they got an Act passed in the British Parliament prohibiting any export of wool from Ireland, excepting to England and Wales. Not content with this, in 1698, both houses of Parliament addressed his Majesty William III. representing that in consequence of labour being cheaper in Ireland than in England, the progress of the woollen manufacture there was such as to prejudice that of England, and that it would be for the public advantage were the former discouraged, and the Linen manufacture established in its stead. His Majesty replied, "I shall do all that in me lies to discourage the woollen manufacture in Ireland, and encourage the Linen manufacture, and to promote the trade of England." However illiberal and erroneous these notions were, Government had no difficulty in getting the legislature of England to second its views, by restricting the exportation of all woollen goods from Ireland, excepting to England, where prohibitory duties were laid on their importation.

In the Journals of the House of Commons, $177^{\prime} 2$ and 1774, it is recorded that in 1698 the Parliament of Great Britain recommended to the King a kind of compromise with Ireland, whereby England should enjoy exclusively the woollen manufacture and Ireland the Linen. Ireland accepted the terms and abstained from the woollen manufacture, and even imposed heavy duties on the exportation of woollen cloth. The effect of this was to ruin the woollen trade. Several thousand manufac turers left the kingdom, some of the southern and western dis tricts were almost depopulated, and the whole of the kingdom reduced to the utmost porerty and distress by these improvident measures.

By such unwise restrictions the woollen manufacture, which at an early period flourished in Ireland, was confined to the home consumption, and of course the trade rapidly declined. For- 
tunately for Ireland, its place was soon taken up by the Linen manufacture, which from that period until now may be said to have had a prosperous career.

It is to be feared that the ostensible reason for suppressing the woollen manufacture and establishing that of Linen in its stead was not the true one. The woollen trade had been in a great measure carried on in the south and west of Ireland, which were popish districts, whilst the chief seat of the Linen manufacture was in protestant Ulster. Protestant Linens were upheld and encouraged, whereas Popish woollens were suppressed. Besides other evidence of the spirit which dictated such proceedings, the records of the British Parliament prove it. In an act passed in the year 1704, the preamble commences thus: "Forasmuch as the Protestant interest in Ireland ought to be supported by giving the utmost encouragement to the Linen manufactures of that kingdom," \&c. It is unfortunate that such unjust enactments should have been passed by either the British or Irish legislatures of William or of Anne. They look more like the persecuting bigotry of the sovereigns of popish countries, than the enlightened spirit of protestant lands. The Linen trade deserved all encouragement, but not at the expense of the woollen manufacture, even though it was in the hands of papists, and it would have been far better had both been upheld and stimulated.

Louis Crommelin, after the repeal of the Edict of Nantes A.D. 1699, fled from France with a number of other refugees, and settled near Lisburn. These persons being acquainted with the French mode of manufacturing Linen, introduced the system into Ireland, and by this means greatly improved the trade there. At this period curious expedients were adopted to increase the demand for Linen, one of them being an order by the Lord-Lieutenant to wear hat bands and scarfs of Linen at funerals, a custom which still exists. The machinery then used in the Linen manufacture was of the simplest construction, and principally worked by hand, but in 1725 new machinery was invented and applied in some of the processes.

In Queen Anne's reign the Irish House of Commons sent a bill in favour of the Linen trade to Her Majesty, accompanied with an address requesting permission from the English Parliament to export Linens to the British colonies. The English 
ministers, after crushing the woollen trade, always appeared desirous to encourage and foster the Linen manufacture, in which the Irish had for competitors the French and Flemish artizans. Lord Strafford, while Lord-Lieutenant of Ireland, not only countenanced and protected this new branch of industry, but also embarked a considerable sum himself in the trade. Among other improvements originated by this nobleman, he brought over from the Continent a number of spinners and manufacturers, who taught the Irish the superior system of treatment in operation there.

By an act passed in the 9th year of the reign of Queen Anne, a "Board of Trustees of the Linen and Hempen manufactures" was appointed for the encouragement of the cultivation of Flax, and the improvement of the manufacture of Linen in Ireland. In 1707 the Irish Parliament confirmed the establishment of the Linen trade in Ulster, and this Board was formed to foster, encourage, and extend the rising manufacture. The most liberal means were placed at the disposal of the Board by Government, and for several years $£ 20,000$ were annually distributed under its management. 'The Trustees were almost always composed of the leading men of the country, and often the highest nobility and gentry were among their number. These parties always took an active interest in the proceedings of the Board, and often considerable share in its management. This shows the interest then taken in the nation by the great landowners of the country, especially in the infant Linen trade, and it speaks well for the patriotism and catholic spirit by which they were animated.

The establishment of the Royal Dublin Society also materially contributed to the introduction of improvements in the agricultural management of the Flax crop. This was the parent of Irish Industrial Institutions, and so early as 1739 the mem. bers held enlightened views of the advantages to be derived from the proper cultivation of the crop. They exerted themselves to instruct the farmers practically in the culture of Flax, and for that purpose persons trained under the skilful Flax growers of Belgium were sent among them, who circulated excellent directions for the management of the crop in all its stages.

The Trustees of the Linen Board met every Tuesday, at their house near the Linen Hall in Dublin, for the transaction of busi- 
ness. This Hall was, in the olden time, the mart to which all the merchants repaired with their cases of bleached Linen, finished and ready for sale, and there the English traders attended and made their purchases. It was, in these times, a great convenience, as the means of communication in the interior were few, and the system of one grand central market answered all parties admirably.

In going over the transactions of the Trustees, it would appear that many important subjects occupied their attention, and that the labour imposed upon them was considerable. They appointed intelligent inspectors in the country districts, to look after the interests of the Linen trade, and see that it was not interfered with prejudicially by any party ; and many of them were very zealous in the discharge of their duty, and no doubt did good service to their employers and to the country at large.

The following abstract of the amount expended by the Board of Trusteee in 1815, shows how the sum granted yearly by Parliament for regulating and improving the Linen manufacture in Ireland was applied :-

PREMIUMS.

Manufacturing Sail Cloth, Canvas, Duck, \&c., from mill spun yarn,

Manufacturing thread lace, . $\quad$ • $\quad$ •

Imitating Bristol Candle·wick, . . •

Spinning fine yarn,

\section{GRANTS.}

Total Premiums, . $\quad £ 11,5241410$

$£ 11,22918 \quad 4$

$\begin{array}{lll}77 & 6 & 0\end{array}$

53150

163156

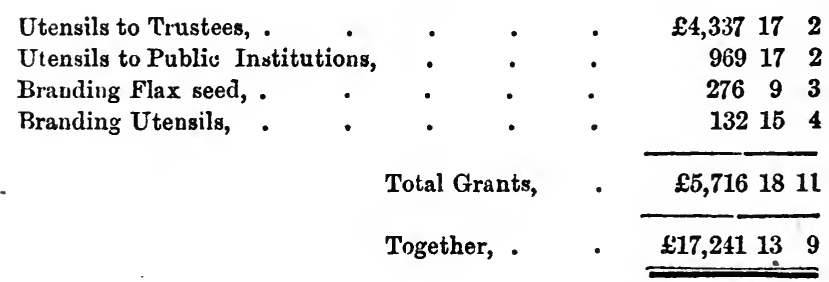

As the Linen trade concentrated itself in and around Belfast, the necessity of sending all the white or bleached goods to Dublin for sale became troublesome and inconvenient, and it was 
resolved to erect a white Iinen Hall in Belfast. In 1783 this hall was erected by subscription, and a considerable part of the Dublin trade was transferred to it. In 1810,159 packages, of the average value of $\mathfrak{f} 6.5$, were received in it; in 1812,247 ; in 1815, 636; and in 1818, 1241 packages. The greater part of these Linens were exported to America and the West Indies.

The brown Linen trade was almost wholly transacted in the provincial towns. The weavers, who were chiefly small farmers or cottagers, grew the Flax, spun the yarn at home, or purchased it, wove the cloth in their own houses, and took the pieces to the nearest market for sale, where they were purchased by the merchants. The purchasers bleached the pieces, then sent them to the white Linen Halls for sale. After these Halls were superseded they sent the cloth to England, or shipped it to foreign countries. For the regulation of these provincial markets, intelligent inspectors called "Sealmasters" were appointed by the Linen Board, for each district, whose duty it was to examine the Linen brought for sale, and to certify to the quality being sound and genuine. Each piece, before it could be admitted to the Hall, had to be stamped and sealed by the inspector, and he was responsible for the perfection of the pieces to the buyers; but should he be called upon to make compensation for faulty pieces, he had recourse against the weaver for the same. In many cases the manufacturers were allowed, under certain restrictions, to stamp their own cloth. As soon as he could find security, him-

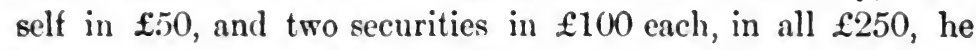
was instantly, and as a thing of course, directly invested with a seal to stamp his own cloth. From 1782 to 1816 no fewer than 1616 brown seals, and 1596 white seals, had been issued by the Board of Trustees, to manufacturers in the province of Ulster alone.

To show the thoroughly domestic nature of the Linen trade in Ireland, and the extent of the business done in the provincial towns, the following details, taken from page 36 of the Appendix to the Report of the Board of Trustees for 1816, is interesting. It is there stated that the average number of weavers who attended the weekly market, and the ralue of the Linens sold weekly in the undernoted places were- 


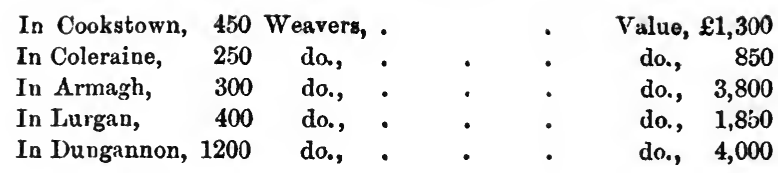

This market system still exists to a small extent, but it is gradually wearing out, and a very short period will no doubt see its total decay. The primitive fashion is still in existence at Ballymena, noted for light $\frac{4}{4}$ Linens; at Armagh, for heavy ditto ; at Lurgan, for lawns and diapers ; at Coleraine and Ballymoney for $\frac{7}{8}$ fine Linens; and at Magherafelt, for inferior ditto. In Belfast brown Linen market a few goods are still sold; but Lisburn lawn market, once so celebrated, is now extinct, and all the plain lawns brought by weavers for sale are taken to Lurgan. The trade is now generally carried on by large manufacturers, who give the yarn out to weave in the people's houses, and get the cloth returned to them; or who weave it in their power-loom factories. The superintendence of these provincial markets occupied a considerable portion of the time of the Linen Board of Dublin, and as they were extremely particular, it made the seal masters very attentive to their duties. This care conduced greatly to the production of regular and uniform goods, gave the merchants confidence in their purchases, and tended to the establishment and rapid increase of the Linen trade in Ireland.

With the view of fostering and encouraging the establishment of this new branch of industry, Government frequently granted a bounty, or paid a premium to the producers or exporters of Linens, to enable them to prosecute it successfully. No trade got more assistance of this kind than the Linen manufacture, and it was granted both to Great Britain and to Ireland. The bounties formerly paid on the exportation of Linens will form the subject of a subsequent chapter.

In an anonymous pamphlet, published by an Irishman about 1731 or 1732 , as to the Irish woollen and Linen trade, he ascribes the late increase of population in Ireland to the growth of the Linen trade. He argued that as sheepwalks decreased and tillage land increased, so did the population increase. The population returns certainly bear out this statement, as the increase of population was much more rapid during the quarter of a century 
following the passing of William III.'s statute in 1696 in favour of the Linen trade, than it had been for the like period before it.

It is stated by Macpherson that in Ireland, which had hitherto been famous for its woollen manufactures, it is found (in 1732), more profitable to grow Flax for the Linen manufacture. Sheep therefore are disappearing, especially from the northern counties, "whereas the Linen manufacture is now universally spread." At the accession of King William III. in 1689, Ireland did not export to the value of $£ 6000$ of Linen; whereas in 1741 , according to a letter from Ireland of this year, the export had increased

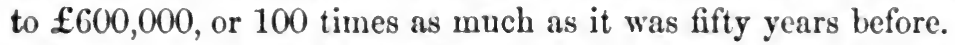

In $a$ book published in Dublin in 1760 , it is said that the Linen Hall in Dublin had been erected " under as just and nice regulations as any commercial house in Europe." Another account says:- "Since the year 1757 the exportation of Linen from Ireland has been gradually lessening, and the following is a private estimate of its state for two years past, ending Ladyday each year ":-

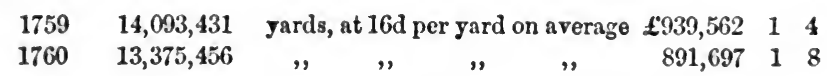

The same party estimates the quantity of Linen yarn exported to Great Britain in these years at nearly an equal value to the yarn worked up in the Linens exported. Possibly the increase in the Linen manufacture of Scotland at that time may partly, if not entirely account for the decrease in Ireland. To give more encouragement to the trade, the Irish Parliament in 1761 granted to the Trustees for the Linen manufacture $£ 80(00$ a-year for two years.

Postlethwayt says, "In 1766, the ports from which Linen yarn is chiefly exported from Ireland are Londonderry, Belfast, Newry, Drogheda, and in a less degree Dublin, Dundalk, and Coleraine. The port to which such yarn is exported is Liverpool."

The quantity of Linens exported from Dublin in 1768 , was $18,490,195$ yards ; and in $1769,17,790,705$ yards. The Linen trade both in Ireland and Scotland declined for some years after this date, and many people emigrated to America. The value of the exports of Linens from Dublin in 1771, was $£ 1,691,000$, 
in $1772, £ 1,300,000$, and in 1773 only $£ 900,000$. About threefourths of the looms in the north of Ireland were, in the latter year, standing idle for want of work, and in some places nearly the whole were silent.

Statement of the Linen cloth and yarn exported from Ireland, in the years specified, whereof about seven-eighths of the whole was to Great Britain :-

\begin{tabular}{|c|c|c|c|c|}
\hline \multirow{9}{*}{$\begin{array}{l}1710 \\
1720 \\
1730 \\
1740 \\
1750 \\
1760 \\
1770\end{array}$} & \multicolumn{2}{|c|}{ LiNen Cloth. } & \multicolumn{2}{|c|}{ LINEN YaRN. } \\
\hline & Yards. & $£$ & Cwits. & $\delta$ \\
\hline & $1,688,574 @ 1 \mathrm{~s} 3 \mathrm{~d}$ & 105,535 & 7,975 & 47,853 \\
\hline & $2,437,984,, 1 \mathrm{~s}$ Od & 121,899 & 15,722 & 94,334 \\
\hline & $4,136,203, " 1 \mathrm{~s} \mathrm{od}$ & 206,810 & 11,088 & 55,485 \\
\hline & $6,627,771,, 1 \mathrm{~s} 4 \mathrm{~d}$ & 441,851 & 18,542 & 111,256 \\
\hline & $11,200,460$, Is $2 \mathrm{~d}$ & 653,360 & 22,373 & 134,238 \\
\hline & $13,375,456,1 \mathrm{~s} 4 \mathrm{~d}$ & 891.697 & 31,042 & 186,254 \\
\hline & $20,560,754,, 1 \mathrm{~s} 6 \mathrm{~d}$ & $1,542,056$ & 33,417 & 200,502 \\
\hline
\end{tabular}

Bounties on the importation of Irish Hemp into England were established in 1779. In 1780 the Irisk Parliament rcsolved to give bounties on the exportation of Irish Linens to Africa, America, Spain, Portugal, Gibraltar, and Minorca; and on Irish sail cloth exported to any place excepting Great Britain. The English Board of Trade examine into this resolution, to see what effect it would have upon their own trade, and finally are of opinion that the Irish bounties "cannot possibly affect the interests of the Linen trade of this kingdom, and are, so far as bounties may in any case be expedient, wisely and providently applied by these new provisions, to promote the interest of the Irish Linen Trade." They also say that " our system of Linen bounties and Linen duties, though possibly in many cases exceptionable in the great scale of commercial policy, has proved an essential encouragment to the Irish staple, and has also been the means of forcing forward an extensive Linen manufacture in this kingdom, though struggling under a great disadvantage as to the growth and supply of the raw material."

In the Dundee Advertiser of 17th June 1808, it is said;"The Government had it in contemplation, for the encouragement of the growth of Flax in Ireland, to engage to pay for such Hemp as could be ascertained to be of the growth of Ireland, 
and which might be delivered into His Majesty's dockyards in the course of the following three years, whatever price that article might bear in the market on the day of its arrival in the dockyard. And in case the market price should be below $£ 60$ per ton, to pay that price for it, provided such Hemp should be deemed, upon delivery, good and merchantable, and shall be approved of and received by the officers as fit for His Majesty's service. Payment to be by bills made out at the Navy Office at ninety days' date, bearing an interest of $3 d$ per cent. per diem, upon certificates being granted, as usual, by the officers of the yard, of the quantities of Hemp they had received. This price referred to Plymouth, but should the officers want part of the Hemp grown in Ireland delivered at Portsmouth, an additional sum of $£ 110$ s a ton was to be paid for it; and $£ 2$ if delivered at Chatham or Woolwich."

In 1807 the quantity of plain Linen exported from Ireland to Great Britain was 40,870,283 yards, of the value of $£ 3,405,856$ $18 \mathrm{~s} 4 \mathrm{~d}$ sterling, besides a small quantity of drills, checks, \&c.

The following is an account of the quantity and value of the Linens exported from Ireland in the years named:-

\begin{tabular}{|c|c|c|c|c|c|}
\hline \multirow[t]{2}{*}{ Years. } & \multirow{2}{*}{$\frac{\text { To Great Britain. }}{\text { Yards. }}$} & \multirow{2}{*}{$\frac{\text { To Foreign Ports. }}{\text { Yards }}$} & \multirow{3}{*}{$\begin{array}{l}\text { Total. } \\
\text { Yards. }\end{array}$} & \multicolumn{2}{|c|}{$\begin{array}{l}\text { Amount of Bounty paid in } \\
\text { Ireland on Linen exported to } \\
\text { Foreign Paits. }\end{array}$} \\
\hline & & & & $f$ & 8. v. \\
\hline 1800 & $31,978,039$ & $2,585.829$ & & & \\
\hline 1805 & $40,707,267$ & $2,976,266$ & 43.683533 & 12,224 & \\
\hline 1810 & $32,584,545$ & $4,313,725$ & $36,898,270$ & 16,448 & \\
\hline 1815 & $37,986,359$ & $5,496,206$ & $43,482,565$ & 17,430 & \\
\hline 1820 & $40,318,270$ & $3,294,948$ & $43,613,218$ & $14,9: 8$ & 911 \\
\hline 1825 & $52,559,678$ & $2,553,587$ & $55,113,265$ & 12,015 & \\
\hline 1829 & $\cdots \ldots$ & $2,386,223$ & & 6,836 & 111 \\
\hline
\end{tabular}

After 1825 the quantities exported to Great Britain were not kept at the Custom-house, as the cross channel trade was thereafter assimilated by law to a coasting traffic. Of the exports from Ireland during the first thirty years of the century more than 12-13ths were to Great Britain.

The exports of Linen from the United Kingdom seem to have been at that period about equal to the imports from Ireland into Great Britain. During the year 1825, the last in which an account was kept of the Linen trade between Great Britain and Ire- 
land, there were exported from the United Kingdom of British Linen $35,993,038$ yards, the real or declared value of which was $£ 1,309,616$; and of Irish Linen, $16,087,146$ yards, the real or declared value of which was $£ y 18,385$, amounting together to $52,080,184$ yards, worth $£ 2,228,001$. The declared value of the imports of Irish Linen into Great Britain in 1825 was $£ 2,893,018$, and of the total imports $38,784,908$ yards were retained for home consumption.

The Linen Board was frequently occupied with suggestions and proposals for the improvement of Flax-preparing processes, and although some of these proposals were fallacious, others were of utility, and did good to the trade in various ways. Some of these are referred to in the section on Flax Culture, and are both instructive and interesting.

In 1821 the Trustees of the Linen Board made some reductions in their expenses, but the Parliamentary grant continued the same as usual, viz. :-

To encourage the raising of sufficient quantity of Hemp and Flax in Ireland for one year, . . . . . . For the encouragement of the Hempen and Flaxen manufacture in the provinces of Leinster, Munster, and Connaught, for one year, . $\quad$. $\quad$. $\quad$. $\quad$. . . . To encourage the growth of Flax in Ireland for one year, . . . 7,250

A farther sum for one year, to be applied by the Trustees in such manner as shall appear to them to be most conducive to promote and encourage the said manufacture, the said sum being instead of a like sum paid to the Trustees out of the produce of the dutics on teas and coffee, . $\quad$ - $\quad$. $\mathfrak{E 2 , 0 0 0}$

Old Irish currency, equal to about $£ 20,000$ sterling, $\quad \cdot \quad \cdot \quad \cdot \quad \overrightarrow{£ 21,600}$

In 1816 the Board sent one of their Inspectors on a tour through Scotland and Yorkshire for the purpose of obtaining and imparting information regarding the state and progress of the Linen manufacture in these countries. The Inspector in his report gives an account of the cultivation of the plant in Scotland, and recommends the great care taken by the producers and manufacturers there, especially in the scutching process. He recommended the scutching mill for which a premium of $£ 50$ was awarded by the Linen Board of Scotland. He also recommended the adoption in Ireland of a two-handed wheel for spinning, and took one of them over with him to Ireland. 
At that time a desire was felt in Ireland to supply Scotland with Irish Flax. The Inspector inquired in Scotland the reason for their not using it, and was informed that the system of kiln-clrying the Flax, so much practised in Ireland, and the imperfect scutching of the Flax there, made it inferior to the Continental Flax, although in some other respects it was superior to it. 'The best Flax at that time sent from Ireland was shipped at Belfast, and the quality shipper thence was yearly improving.

The following is the result of a trial made by the Inspector on Scotch and Irish Flax, the former dried by air in the field, and the latter by artificial heat:-

$1 \mathrm{cwt}$. Scotch, Heckled.

\begin{tabular}{|c|c|c|c|}
\hline Flax, . & & & \\
\hline First Tow, & ${ }^{\circ}$ & & \\
\hline Second Do., & & & \\
\hline Waste, & - & & \\
\hline
\end{tabular}

$112 \mathrm{lbs}$
$1 \mathrm{cwt}$. Irish, Heckled.

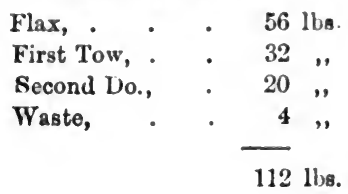

These parcels were heckled to the same quality for mill-spinning, and gave an advantage to the Scotch grown Flax of about 25 per cent. The reason of this difference was attributed to the fire-drying of the Irish Flax, which deprives it of the oil, makes it hard and brittle, and easily broken in heckling.

The improved scutching machinery recommended by the Inepector was to some extent introduced into Ireland, and among other parties who took an interest in improving the preparation of Flax on their estates in the north of Ireland, was the Drapers' Company of London.

In the report of the business done at Leipzic Fair in 1816, it is said, "The prospect for the first and most ancient manufacture of Germany, Linens, is the most gloomy of all. The Irish Linens were supplanting them in America, and cottons were taking their place in many places, because so much cheaper." This shows the progress which had then been made in the manufacture of Linens in Ireland, and the hold which they had taken in the American market. German Linens had long been held in great esteem by the Americans, but the superiority of Irish goods was, even at this time acknowledged, and they had nearly supplauted the German goods in that market. 
In 1820, a genuine improvement was invented and carried out, viz., the new patent temples for weaving, which holds the cloth to the proper width on the same principle as pincers; thus obviating the use of the teethed temples, which frequently punctured and tore the selvage, and thus injured the cloth. So favourably was this improvement viewed, that the Linen trade in Belfast ordered 400 pairs for gratuitous distribution among the weavers, and strongly recommended the patentee to the Linen Board as worthy of a pecuniary reward. He got $£ 100$. These temples are now in general use, and have tended to improve the quality of Irish Linens.

On 23d August 1821, George IV. visited the Linen Hall and Board Room in Dublin, and received a complimentary address.

Both merchants and farmers have from time to time been subjected to frauds and deceptions. About 1822 it was a common practice among weavers to put paste on brown Linens, for the purpose of giving them an artificial appearance of weight and strength. The practice of rubbing the cloth to such an extent as to injure its quality, especially at the selvage, was also common. This made the piece appear finer and richer than it really was, and thus deceived the buyer. These deceptions were thoroughly exposed by the merchants, and stringent measures adopted to keep up the reputation of the goods; and a test fluid was invented for detecting deleterious substances used in starching Linen cloth, but the trickery was not easily stopped.

It was quite a customary thing at this period to sell inferior Flax seed to the farmers, instead of genuine Dutch seed ; and the better to carry on the deception, empty barrels which had contained the real article were procured, filled with the counterfeit, and sold as genuine, although generally at a somewhat lower price. Greedy farmers bought the cheapest seed, and only discovered the fatal mistake when the crop produced turned out next to worthless. To prevent the serious consequences to the extension of the production of the plant, which the sale of bad seed had caused, an application was made to the Lord-Lieutenant for a grant of money to purchase genuine Flax seed for distribution among small farmers, unalle from poverty to purchase it. On 28th May 1822, the Lord-Lieutenant granted $£ 3000$ for this purpose, and the distribution of the seed did so much good, that 
an application was made for a renewal of the grant the following year, which was acceded to.

In 1822, the Linen Board despatched an intelligent inspector on a tour through Holland, Flanders, and France, and his report contained much useful information on various subjects in connection with the trade, especially with the cultivation and preparation of Flax.

In 1823, unions, composed of cotton warp and Linen weft, were first made, and a great outcry was raised against such goods. Government was petitioned to have this novel manufacture stamped in some peculiar style to distinguish it from genuine Linen, so as to keep up the fair fame of Irish Linens.

Same year the 'Trustees of the Linen Board brought over two Dutch agriculturists, to instruct the Irish farmers in the Continental mode of growing and preparing Flax; and the improve. ments introduced by these men were of great service, both to the farmers who were taught to produce better Flax, and to the trade who received the superior article.

Several improvements in the construction of looms and other weaving machinery were introduced from time to time about this period. Some of the:e were rewarded by the Trustees from the funds at their disposal. Among others, the Jacquard machine was tried for the production of damasks and diapers, and found to answer admirably.

Flax imported from foreign countries was allowed to be sold by auction in Scotland, if within a year of its importation, at one-half per cent. of duty, if sold for account of the original importers. Irish Flax could not be so sold, and in 1835 the Chamber of Commerce of Dundee wanted the same privilege extended to it, but the Commissioners of Excise would not grant their request.

The spinning of Flax by machinery was begun in England in 1787 , and it is also supposed to have been begun the same year in Scotland. For some years little progress was made, and as the machinery was rude and imperfect, the yarn produced was not well spun. From time to time improvements were introduced, by which the quality of the yarn spun was much improved, and the quantity taken off greatly increased. This enabled the spinners in these countries to purchase Flax in the Irish markets, manufacture it into Linen, and sell is below c c 2 
the price of Irish made goods. It is astonishing to think that the intelligent manufacturers of Ireland should so long have looked on, and allowed the enterprise of these countries almost to rob them of their trade; but such is the fact. It was not until the first quarter of this century had almost gone, that spinning by power was seriously thought of in Ireland, and it was fully forty years after the system had been introduced into England and Scotland until a mill was established in Ireland. Even then it was only the perilous position of the trade, arising from the competition in these countries, that forced it on. It was fortunate for the country that at such a time men of enterprise, energy, and sagacity equal to the emergency were ready to step in, and as it were chain the trade to Ireland. No doubt the superior excellence of the hand-spun Irish yarn, the low price at which it was spun, and the difficulty at first experienced in spinning by machinery the very fine numbers of yarn which is used in Ireland, all combined to delay the erection of spinning mills there; but these reasons do not sufficiently account for the start which the trade was allowed to get both in England and Scotland. After spinning by machinery was fairly established, its progress was exceedingly rapid, and the time lost appears to have been speedily made up.

In 1824 the idea of erecting a spinning mill on an extensive scale in Belfast was popular among many of the members of the Linen trade there, and some steps were taken to accomplish this object, but it eventually fell to the ground, and hand spinning went on as before. It was not until the year 1828, that Flax spinning machinery was started in Belfast, the Messrs Mulholland having in that year erected their mill, and they have continued the trade to the present day. Messrs Murland erected their work in the same year, and since then spinning has made immense progress.

In 1826 the Government, considering that the Linen trade of Ireland did not then require the encouragement necessary in its early stages, intimated to the Trustees of the Linen Board, that the grant for the following year would be reduced to $£ 10,000$, and that it would soon be wholly withdrawn.

In April, 1827, a Dublin newspaper mentioned that Government had determined to abolish the Irish Linen Board; a cir- 
cumstance "which, it said, "affords great satisfaction to those engaged in the Linen trade, as the Board tended, rather to cramp than encourage the Linen trade by its partial operation"

Following up this intimation, on 6th August, 1827, the Lord Lieutenant informed the Trustees that, in conformity with the directions of the Lords of the Treasury, and in pursuance of the principles previously intimated to them, it was not the intention of the Government to recommend that any grant should be proposed for the encouragement of the Linen manufacture for the year 1828. The Board was in consequence dissolved.

After the dissolution of the Board by Parliament, the production and management of the Flax plant in Ireland was, for many years, left very much to the intelligence and persererance of the private parties engaged in its growth and manufacture. Agricultural and other societies no doubt awarded premiums for good Flax, and for the best specimens of Linens, but these were, comparatively speaking, isolated and imperfect cases of help, and of little real utility. Notwithstanding the want of assistance, the trade made vast progress, and the production of yarns and Linen went on increasing with extraordinary rapidity.

In 1841 the Royal Flax Society of Ireland was established for the promotion and improvement of the growth of Flax in Ireland, and during an existence of eighteen years, it having been dissolved in 1859, it did good service in the cause for which it was started. The Queen and Prince Albert were patrons of this Society, and the Lord Lieutenant vice-patron. Government granted $£ 1000$ a year to assist in defraying the expenses, and local donations, and noble patronage and support, were accorded to it ; but, notwithstanding these advantages, it came to an end, and the void created by its dissolution has not yet been filled up.

In 1849 the Queen and Prince Albert visited Belfast, and inspected, in the Linen Hall there, a well-arranged collection of samples of Flax seed, green Flax straw, scutched Flax, heckled or dressed Flax, yarn and sewing threads, brown and bleached Linens assorted in every variety, damasks, lawns, handkerchiefs, cambrics, \&c. The royal personages expressed much gratification at the exhibition, and Her Majesty carried away in her hand several stems of Flax as a memento of their visit.

In 1835 the exports of Linen from Belfast amounted to 
$53,881,000$ yards, of the value of $£ 2,694,000$. According to official returns there were in Ireland in 1838 forty Flax mills, employing in all 9,017 hands. In 1841 there were in the town and immediatc vicinity of Belfast twenty-five steam mills for spinning Linen yarn, one of which employed 800 hands.

In 1853 there were eighty Flax spinning mills in Ireland, containing more than 500,000 spindles, producing fully $9,000,000$ bundles of yarn per annum, worth about $£ 2,250,000$ sterling.

As appears by the parliamentary return, given hereafter, there were in the beginning of 1862 , seventy-nine spinning mills in Ireland on Flax, and two on Jute, containing together 594,805 spindles. Since that period a considerable increase has been made to this number, and according to the "Review of the Irish Linen trade for 1862," in the supplement to the Linen Trade Circular, dated 12th January 1863, the number then employed was estimated at about 600,000 . In addition to these there might, from various causes, have been about 50,000 spindles in Ireland not then in operation.

In the "Review of the Trade for 1863," in Circular of 11th January 1864, it is said there had been no addition to the spinning mills in that year, but a considerable increase had taken place in the spindles employed, which were then estimated at 650,000 , but the exact number had not been correctly ascertained.

Before the introduction of spinning by power, the yarn required was all spun by hand, by females scattered throughout the country. This gave employment to a great number of industrious people, and the want of such labour was long severely felt. The concentration of labour in mills and factories has drawn many people from the country districts to the towns, where the females and young persons find ready employment at such works. How far this change in the mode of employment is to the advantage or disadvantage of the physical frame of the workers, or to their moral well-being, is not a subject coming within the scope of this work. The progress of trade, and the requirements of the world have led to these changes, but it is without doubt the duty of every mill-spinner and manufacturer to use every endeavour to make their works as little as possible hurtful to health, and to attend strictly to the moral training of the young under their charge. 
Until the establishment of spinning mills, the weaving of Linens was all, or nearly all, performed in the houses of the weavers. As already mentioned, the yarn was often spun by the one part of the family, from Flax grown by themselves, or bought in the neighbourhood, and weaved by the others; and the cloth was taken to the brown Linen markets for sale. After Flax spinning mills were once established, the yarn to be manufactured was provided by merchants, weaved in the houses of the weavers, or in factories erected for the purpose, and the cloth then taken to the merchant, who paid for the weaving of it. The introduction of power-looms into Ireland for weaving Linen is making great changes on this system.

The number of power-loom works in Ireland, and the looms they contained in 1859 and in April 1861, were given in the Linen Trade Circular, as follows:-

\begin{tabular}{rcccc} 
& & \multicolumn{3}{c}{ Power-Looms. } \\
Year. & Number of Works. & Employed. & Unemployed. & Total. \\
1859 & 28 & 3,124 & 509 & 3,633 \\
April, 1861 & 35 & 4,609 & 324 & 4,933
\end{tabular}

In 1862 , by the parliamentary return referred to, nineteen spinning mills had power-loom factories attached to them, containing 2,491 looms, and there were fifteen distinct powerloom works, with 2,175 looms, making together 4,666 looms. Since the date of that return a large increase has been made to the number of power-looms, as it is stated in the supplement to the Linen Trade Circular, 12 th January 1863, that the total number of power-looms employed in Ireland, in the weaving of Linen, in the end of 1862 , was estimated at 6,000 . This shows that great progress has of late been making in this branch of the trade, and there can be no donbt that the production of Linen in Ireland will, with a sufficient supply of the raw material, go on extending in the same ratio as the consumption.

The spinning-frame and the power-loom have greatly cheap. ened the cost of the common and medium qualities of Linen, and placed them within the reach of nearly all classes in every country. This has wonderfnlly increased the demand for these goods, because the lower the price at which such an article as Linen can be sold, the more of it will be used. Without the spinning mill and the power-loom factory, it would be impossible to produce in Ireland the quantity of yarn and cloth now 
made there, because to spin the yarn alone would require about $1,400,000$, women expressly devoted to the task all day and every day throughout the year. Improvements in weaving by power, as well as in spinning, have been going on since the introduction of power-looms and some of these by easing the tension on the yarn, and by lessening the cost of production, are of first-class importance,

In "Beeton's Dictionary" it is said that the exports of Linen from all Ireland in 1857 were supposed to amount to $106,000,000$ yards, valued at $£ 4,400,000$ sterling.

The yarn spun in Ireland consists both of Flax and tow qualities, partly dry spun, and partly wet spun, and the bulk of it is of the higher or lighter numbers, of fine quality, and suitable for the description of Linens manufactured there.

Some coarse or heavy yarns, chiefly made of scutching tow, are also spun, but the quantity is comparatively small. A con. siderable quantity of the yarn spun is exported to other countries, but the greater part of it is woren into cloth in Ireland. The finest spun for commercial purposes, is about 340 leas, of 300 yards each, to $1 \mathrm{lb}$. weight. It has been spun, and sometimes is spun, much finer, the very finest numbers being yet spun by hand. In the Exhibition of 1851, specimens of 760 lea yarn were shown, one pound weight of which would measure about 228,000 yards, or nearly 130 miles! The yarn is made up in bundles of $4 \frac{1}{6}$ spindles, or 60,000 yards. 120 threads on the reel of ninety inches, or 300 yards, form a cut or lea; twelve cuts are a hank or hesp; and 1673 hanks form a bundle. These bundles are tied up in bunches of three, six, nine, or twelve bundles, according to the fineness of the yarn.

The Linens produced are of very various degrees of fineness, quality, width, and description. It is only the lower qualities, say from $8^{00}$ to $16^{\circ 0}$, or from 40 to 80 porter, which are yet profitably produced in power-looms. Of course coarser fabrics than $8^{00}$ can be advantageously made in power-looms, but there are few of a lower class than this number made in Ireland. Fine goods, from $18^{\circ 0}$ and upwards, are still made by hand, as they cannot yet be so beautifully or cheaply made by power; but, as improvements in spinning and weaving progress, finer sets will, no doubt, be profitably made in the power-loom. 
For brown goods, or for light fabrics, the yarn is sent direct from the mill to the factory, but for heavy and superior bleached goods, the yarn is boiled before being weared. The cloth to be bleached is taken from the loom to the bleach-green, where it is boiled in large iron vessels, with the tops securely fastened to retain the steam, and thus prevent loss of heat, air, and reduction in the amount of liquid, which, with open vessels, would occur. The liquid used is alkaline lye, generally prepared from soda ash. The cloth is then washed, and exposed to the action of the atmosphere on the grass for two or three days. These processes are repeated until the goods are half white. To remove the straw of the Flax they are then put into a bath of water, having in solution chloride of lime, or soda, or potash (soda being now considered safest and generally used), and soured in sulphuric acid, reduced to 2 or 3 of Twaddel's alkalimetre, either before or after the chloride. Rubbing with plenty of soap is an excellent part of the bleaching process, and contributes to increase, rather than diminish the strength of the fibre. When the Linen is quite white it is starched, dried on rollers heated by steam, and finished on the beetles, the whole time occupied in bleaching being from four to seven weeks, according to the season, and weight of the cloth.

Great care has to be taken not to damage the goods during the frequent boilings and washing in chloride, \&c. Lime is now generally used in bleaching processes, and is a valuable auxiliary ; but in 1815, when it was first used at the bleach-greens, attempts were made to stop it by enforcing an old law which had been passed in former times to prevent its use. The Trustees of the Linen Board took a reasonable view of the subject, and informed those who wanted the act put in force, that they thought to do so would be to act injuriously to the trade; and they recommended that Parliament should rather be petitioned to amend or repeal the act. In or about 1816, the use of soap in bleaching was first adopted. This was a valuable improvement, because after the severe caustic preparations the Linen has to pass through in bleaching, soap restores the essential oil extracted by the alkalies and acids, and helps to keep the fibre in a mellow and heathly state.

Fifty years ago 2000 to 3000 pieces of Linen was a trade for 
one bleachfield or green for a year; it would not keep a large work going for a week now. Not long ago the bleaching of a piece of light yard wide Linen would have cost the merchant about $3 \mathrm{~d}$ a yard; now, in consequence of the introduction of soda ash, and centralizing the business in large concerns, it only costs about $1 \frac{1}{4} \mathrm{~d}$ per yard. Ireland possesses the best climate in the world for Linen bleaching, and it is this gift of nature which has given her so high a position in this branch of commercial industry. Lately those having the charge of bleachfields have made great progress in chemical knowledge, and the operations, before irregular, are now conducted with far more certainty.

A large quantity of the low priced Linens made are exported in the brown state. Some are slightly tinged yellow, others are dyed a slate colour, but the greater proportion are bleached. Some of the bleached goods are printed for dresses, handkerchiefs, \&c. ; and very beautiful productions they are.

According to the report of $\mathrm{Mr}$ Tremenheere, who was sent as a commissioner by Government to make inquiry as to the propriety of placing bleach-works under the Factory Act, the number of people employed at bleach-greens in Ireland was 1100 females, 271 boys, and 2812 adult males, total 4183 . Assuming that each adult male represents about 1000 pieces of cloth bleached annually, it would give $2 \frac{3}{4}$ million pieces bleached each year, worth about $£ 4,000,000$.

After Linens are bleached they are kept in cool store rooms until required. They are afterwards lapped in special lengths and styles, to suit the markets they are intended for, almost every country having a fold peculiar to itself, which alone will sell there. They are then ornamented with fancy ribbons and papers, and sometimes, especially for export, with handsome prints. Cambric handkerchiefs and other high class goods are often put into elaborately made boxes, having a most attractive appearance when displayed to advantage in shop windows, \&c. Probably this will often tempt people to purchase, whether they really require the goods or not.

Great taste was displayed in the getting up of many of the Irish Linens shown in the Great Exhibition of 1862, and, so profuse was the paper display in some instances, that very little of the cloth was to be seen at all. No doubt experience proves 
that such gaudy ornaments help to sell the goods, or they would not be so decorated, but the money so laid out adds nothing to the intrinsic value of the cloth.

Although great encouragement has for many years been given to the cultivation of Flax in Ireland, its extension has not been at all in keeping with the patronage it has received. The following table shows the number of acres grown yearly from 1812 to 1825 , with the hogsheads of Flax seed sown. From 1826 to 1846 no records of the land under Flax crop were kept; but from that year to the present period, a careful account has been made up yearly, and the acreage sown is now given:-

\begin{tabular}{|c|c|c||c|c|c|}
\hline Years. & $\begin{array}{c}\text { Hoggheads } \\
\text { Suwn. }\end{array}$ & $\begin{array}{c}\text { English Acres } \\
\text { So w n. }\end{array}$ & Years & $\begin{array}{c}\text { Hogsheads } \\
\text { Sown }\end{array}$ & $\begin{array}{c}\text { English Acres } \\
\text { Sown. }\end{array}$ \\
\cline { 1 - 2 } 1812 & 41,765 & 118,390 & 1819 & 44,431 & 125,950 \\
1813 & 29,945 & 84,885 & 1820 & 52,416 & 148,584 \\
1814 & 35,373 & 100,272 & 1821 & 45,163 & 130.858 \\
1815 & 52,254 & 148,124 & 1822 & 49,658 & 140,765 \\
1816 & 53,540 & 151,70 & 1823 & 54,636 & 154,877 \\
1817 & 32,873 & 93,184 & 1824 & 64,172 & 181,909 \\
1818 & 47,607 & 134,951 & 1825 & 49,181 & 139,412 \\
\hline
\end{tabular}

\begin{tabular}{|c|c|c|c|c|c|}
\hline Years. & $\begin{array}{c}\text { English Acres } \\
\text { Sown. }\end{array}$ & Years. & $\begin{array}{c}\text { English Acres } \\
\text { sown. }\end{array}$ & Years. & $\begin{array}{c}\text { English Acres } \\
\text { Sown. }\end{array}$ \\
\hline 1847 & 58,000 & 1853 & 174,579 & 1859 & 136,282 \\
1848 & 53,863 & 1854 & 151,403 & 1860 & 128,595 \\
1849 & 60,304 & 1855 & 97,075 & 1,661 & 147,957 \\
1850 & 91,040 & 1854 & 106,311 & 186.2 & 150,070 \\
1851 & 140,536 & 1857 & 97,721 & 1863 & 213,992 \\
1852 & 137,008 & 1858 & 91,646 & & \\
\hline
\end{tabular}

The statute acres under Flax in the several provinces in Ireland in 1860 and 1861 , were as follows:-

$\begin{array}{lccccr} & \text { Ulster. } & \text { Munster. } & \text { Leinster. } & \text { Connanglit. } & \text { Total. } \\ 1860 & 123,424 & 1,6660 & 1,289 & 2,216 & 1: 2,595 \\ 1861 & 143,206 & 1,529 & 1,134 & 2,088 & 14 \pi, 957\end{array}$

The following is the extent of land under Flax, in statute acres, in the provinces and counties of Ireland, in 1862 and 1863, with the total acreage in each county and province:- 
MUNSTER.

\begin{tabular}{|c|c|c|}
\hline Clare, . & 1862 & Acres, 441 \\
\hline 827,994 acres, & 1863 & מו \\
\hline Cork, . & 1862 & ", \\
\hline $1,849,683$ acres, & 1863 & $"$ \\
\hline Kerry, & 1862 & :, \\
\hline $1.185,917$ acres, & 1863 & " \\
\hline Limerick, . & 1862 & ", \\
\hline 681,112 acres, & 1863 & , \\
\hline Tipperary, . & 1862 & ", \\
\hline 1,061,731 arres, & 1863 & " \\
\hline Waterford, & 1862 & 93 \\
\hline 461,553 acres, & 1863 & $"$ \\
\hline Total Munster, & 1862 & , 1,2 \\
\hline $6,067,990$ acres, & 1863 & , \\
\hline Increase, & 1863 & $" 3$ \\
\hline
\end{tabular}

\section{LEINSTER.}

\begin{tabular}{|c|c|c|c|}
\hline Carlow, . & 1862 & Acres & s, \\
\hline 221,342 acres, & 1863 & " & 12 \\
\hline Dublin, & 1862 & פو & 1 \\
\hline 226,414 acres, & 1863 & " & \\
\hline Kildare, & 1862 & ", & 1 \\
\hline 418,436 acres, & 1863 & , & - \\
\hline Kilkenny, • & 1862 & ", & 19 \\
\hline 509,732 acres, & 1863 & " & 51 \\
\hline Kings, & 1862 & " & 162 \\
\hline 493,985 acres, & 1863 & $"$ & 337 \\
\hline Lüngford, . & 1862 & " & 192 \\
\hline 269,409 acres, & 1863 & " & 406 \\
\hline Louth, & 1862 & $"$ & 181 \\
\hline 201,722 acres, & 1863 & $"$ & 704 \\
\hline Meath, & 1862 & " & 139 \\
\hline 580,083 acres, & 1863 & " & 324 \\
\hline Queens, . & 1862 & " & 37 \\
\hline 424,854 acres, & 1863 & " & 63 \\
\hline Westmeath, & 1862 & " & 68 \\
\hline 453,468 acres, & 1863 & " & 158 \\
\hline Wexford, & 1862 & $"$ & 18 \\
\hline 576,588 acres, & 1863 & 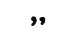 & 33 \\
\hline Wicklow, . & 1862 & $"$ & - \\
\hline 500,178 acres, & 1863 & $"$ & 4 \\
\hline Total Leinster, & 1862 & , & 821 \\
\hline $4,876,211$ acres & 1863 & $"$ & 2099 \\
\hline Increas & 1863 & 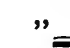 & 1278 \\
\hline
\end{tabular}

CONNAUGHT.

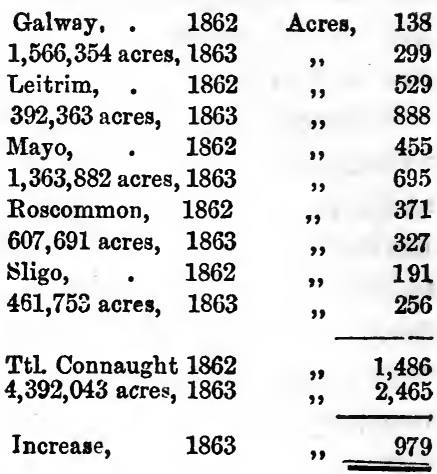

ULSTER.

Antrim, . 1862 Acres, 13,020

761,803 acres, $1863 \quad$ "21,548

Armagh, . $1862 \quad$ " 16,204

328,076 acres, $1863 \quad$ "24,066

Cavan, - $1862 \quad$ " 6,150

477,360 acres, $1863 \quad$, 10,279

Donegal, . $1862 \quad$ " 19,489

$1,193,443$ acres, $1863 \quad$ " 24,095

Down, . $1862 \quad$ " 30,532

612,495 acres, $1863 \quad$ " 44,859

Fermanagh, $1862 \quad$ " 2,273

457,287 acres, $1863 \quad$ "4,479

Londonderry, $1862 \quad$ " 19,698

522,350 acres, $1863 \quad$ " 25,868

Monaghan, $1862 \quad$ " 14,289

319,757 acres, 1863 " 20,051

Tyrone, . $1862 \quad$ " 24,834

806,296 acres, 1863 . 32,001

Total Ulster, $1862 \quad$, 146,489

$5,478,867$ acres $1863 \quad$,207,246

Increase, $1863 \quad, \quad 60,757$

To tal Ireland, $1862 \quad$ " 150,070

$20,815,111$ acres $1863 \quad$." 213,992

Increase, 1863
63,922

This table is taken from the abstract of agricultural statistics, Ireland ; kindly furnished by William Donnelly, Registrar General. 
In the Review of the Linen Trade for 1863, it is estimated that the Flax crop of that year will bring in to the growers the

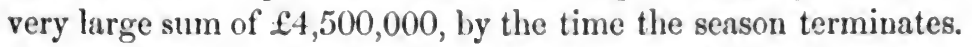
'The benefit of such a prodigious sum, expended in the country for this valuable plant in one year, cannot be estimated. Hopes are entertained, and on good grounds, that an area of 300,000 acres will, happily, be found to be devoted to Flax in Ireland in 1864. Were proprietors and tenants throughout the length and breadth of Ireland, to enter heartily into Flax cultivation, this acreage would very soon be doubled. The produce would raise the degraded peasantry in the south and west from their present state of abject dependence, and give them more substantial food than potatoes morning, noon, and night; more commodious dwellings than a pig-stye; and more comfortable clothing than the rags which are there to be seen in all directions.

The produce per acre varies with the season, the quality of the soil, and the cultivation, but the average crop will be close upon 5 cwt. of clean Flax, ready for heckling, per acre. The price of Flax varies with the supply and demand, but the Irish farmer has less competition with Flax than with any other crop he can raise, and in a series of years it will pay him very much better than grain, grass, or green crop; it is therefore well worthy the attention of every farmer in Ireland.

The following official account of the crop of Flax in Ireland in 1820 and 1821 is reported in the Dundee Advertiser, 19th October, 1821 : -

\begin{tabular}{cccc} 
& & Hhds. & Producing in Tons. \\
The quantity of Flax seed sown in 1820 was & $-52,416$ & 52,416 \\
Do. & 1821 " & 45,163 & 32,973 \\
& Tons deficient in 1821, & 19,443 \\
\hline
\end{tabular}

The paragraph goes on to say that the arerage of crop 1820 was 140 stones of Flax to the hogshead of seed, and in 1821 not more than 100 , so that the quality of crop 1821 was either much shorter or finer than the previous year's. It appears from this statement that nearly three times the amount of the average importation of Flax from the Baltic (20,000 tons), is annually raised in Ireland, and, it is added, "were that fine country governed as it ought to be, we should have no occasion to import a single ton from the magnanimous Alexander." 
The Flax is sometimes sold in the straw, but generally the farmers have it scutched on their own account, as they think, and perhaps truly, that they make more money out of it when they take the Flax to market themselves. There are numerous scutchmills scattered over the Flax-growing districts of Ireland, 956 being in operation in 1853, mostly driven by water-power. To these the straw is taken, and the Flax, after being scutched, is ready for market. There are a number of market towns for the sale of Flax in Ulster, and to the nearest of these the farmer generally takes his Flax for sale. At these markets buyers attend, examine the various parcels on sale, and make their purchases. Sometimes the Flax is bought by local parties who have commissions from the spinners in Belfast and elsewhere, and sometimes the spinners send their own inspectors direct from their works to buy for them. The purchases are generally paid for in cash as soon as the weight is ascertained, and delivery made, and a considerable amount of money changes hands at some of these towns on market days.

The following reports of the country Flax markets, are taken from the Belfast Trade Circular :-

Flax Markets as reported, with estimated Quantities and Prices, 22D LEC., 1862.

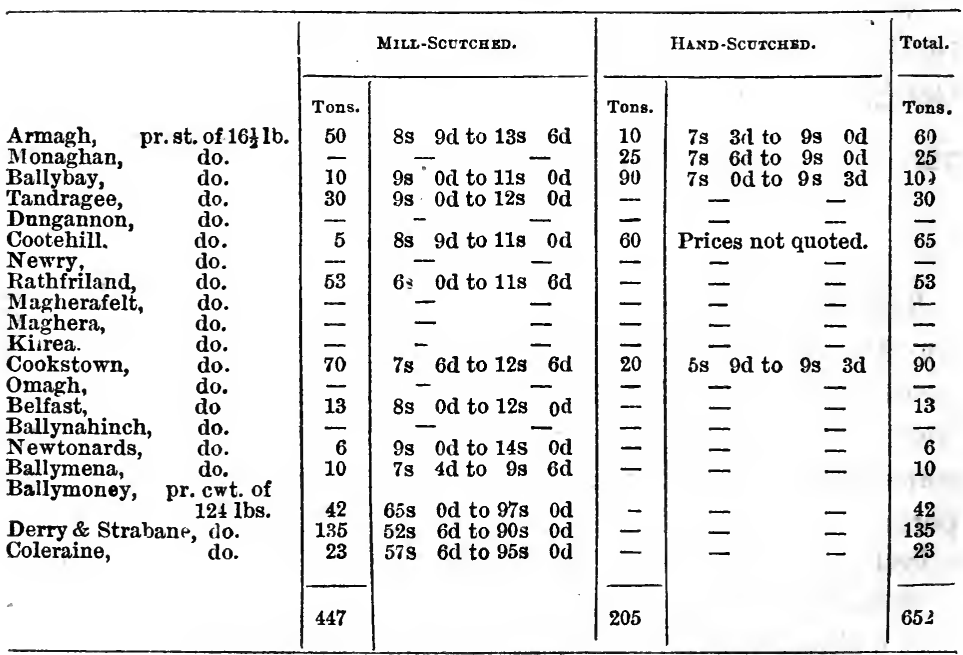


Do., do., 21 st Dec., 1863:-

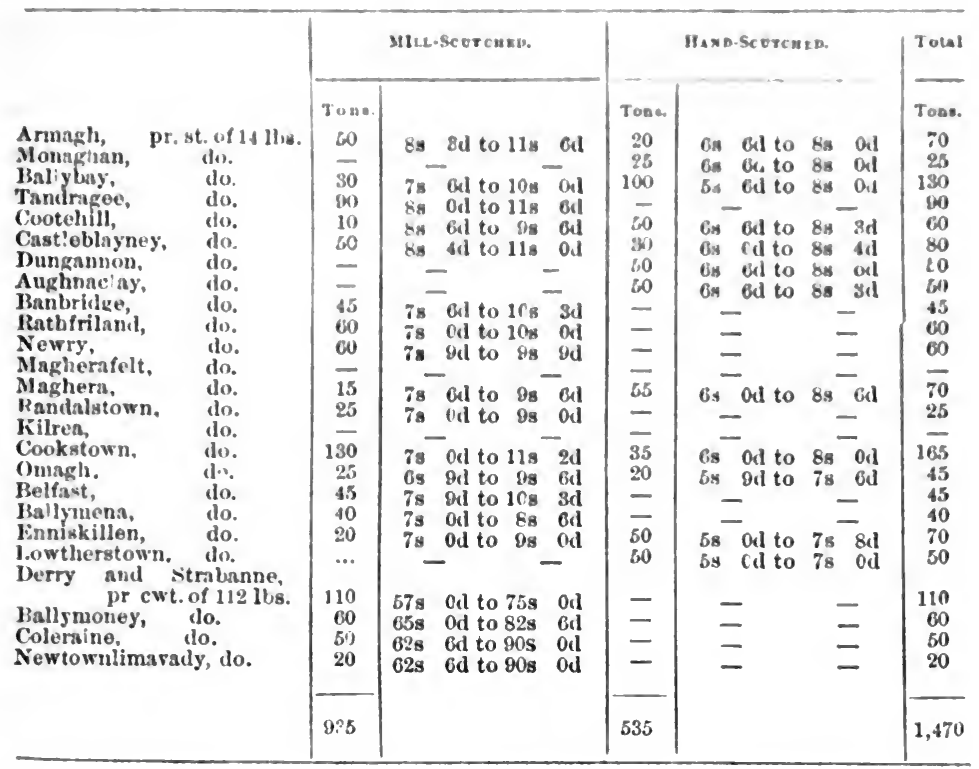

The Flax brought into the Irish markets is generally of a bright greenish colour, called "silvery clay," but some of it is nearly as white as the Courtrai Flax. The Flax varies very much and some of it brings a correspondingly high price, but all qualities find ready buyers, because the demand generally exceeds the supply. Unless the cultivation of Flax be yet very much increased, it is probable that the demand will continue greater than the supply, as the extension of machinery, and consequent consumption of Flax, is increasing rapidly in Ireland every year.

Hitherto the cultivation of Flax in 1reland has been almost entirely confined to the province of Ulster, but there is no good reason why it should be so. Much of the soil of Ireland is admirably adapted to the growth of the plant, and it might be cultivated over a great extent of the country, much to the advantage of the growers. The Linen trade in Ireland has progressed very rapidly of late years, but it might have extended still faster had the supply of the raw material been more 
abundant. It is therefore a point of the first importance to those engaged in the trade to have a plentiful supply of Flax, and no Flax is better adapted for the productions of Ulster than what is grown in Ireland. It is the duty of the spinners and merchants of Belfast to give the farmers every encouragement and assistance in their power, to foster the cultivation of Flax throughout the country. The ready market which is found for the sale of Flax in Ireland, and the high price which it brings, offer great encouragement to its growth. The great hindrance to its more extensive cultivation is the ignorance and prejudice of the farmers. These are not insuperable difficulties, and those engaged in the Linen trade ought to take instant and determined action to instruct the farmers, and to undermine and root out their prejudices. The result would prove beneficial alike to grower and consumer, and tend greatly to extend this most important trade in Ireland.

In the Review of the Irish Linen Trade for 1862, in the Trade Circular, it is stated that the difficulty which has hitherto existed in scutching Flax by an inexpensive process, is one of the retarding circumstances to progress in the cultivation of Flax in that country. Surely the intelligence, the skill, and the wealth of Ireland will speedily overcome this difficulty, and produce a low priced, portable, scutching machine, that will do the work cheaply, yet efficiently. The object is a worthy one, and it is possible to accomplish it, for what will genius not do in this enlightened age? Perhaps a reward that would command the attention, and be worth the ambition of the highest talent, might call forth the needed machine.

Great efforts have of late been made, both in the south and west of Ireland, to make the small farmers acquainted with the profitable nature of the Flax crop. These endeavours have in some quarters, met with much less encouragement than the importance of the movement deserved, and it is astonishing to find that some parties, of whom better things might have been expected, have actually opposed so beneficial a measure. Such opposition can only arise from ignorance or prejudice, and it says little for the intelligence of those from whom it proceeds. Notwithstanding the luke warmness of some who profess to be 
friends, and the hostility of open enemies, it is gratifying to think that, in 1863 , there was a material increase in the quantity of land sown with Flax seed, when compared with the extent of the crop in previous years. The enlightened noblemen and gentlemen who have been aiding in this good work deserve high commendation, as they are not only benefiting their tenants and dependents, but also adding to the industrial prosperity of Ireland, and conferring a boon on the United Kingdom.

In the prospect of an increased cultivation of Flax last season the importers of seed provided a plentiful supply of various qualities. The total quantity of Flax seed imported into Ireland for sowing purposes for 1863 was as follows :-Riga, 91,393 barrels; Dutch, 20,000 hogsheads; American via Liverpool, 5000 hogsheads. Home grown and English sowing seed, 10,000 bags. This quantity was sufficient for double the number of acres that were under Flax cultivation in 1862 . The quantity imported into Belfast in 1862 and 1863 is given hereafter. Should the quantity for 1864 be deficient, it will no doubt be supplemented by the time it is required.

The year 1863 gave a great impulse to the Linen Trade in the three kingdoms, and Ireland has reaped its full share of the increase. The cause is no doubt exceptional, but the hold which has been gained will not be soon lost, if an abundant supply of Flax can be provided at a moderate cost. It is therefore of the greatest importance to have a sufficient stock of raw material, and neither trouble nor expense should be spared to procure it.

The prosperity of the Linen Trade in Ireland in 1863 has had a centralizing effect. Many of the most eminent houses have found it for their interest to open sale rooms in Belfast, at same time conducting their operations as formerly in the localities where their manufactories and bleachworks are situated. The Linen Circular, in its review of the trade for that year, says, "Belfast may emphatically be said to have become the metropolis of the Linen Trade." This is no doubt true in as far as regards the Linen Trade of Ireland, but it is doubtful if Leeds and Dundee would accord their assent to its being the metropolis of the Linen Trade of the Kingdom.

The value of the Irish Linen manufacture has been estimated D D 
at $£ 10,000,000$ annually, and, for 1863 , this may not be far from the truth, but it cannot have come up to nearly that amount in former years. There is no data, however, from which a correct account of the value can be made up, and imaginary estimates are sometimes wide of the truth. It is supposed that about one-half the value of the production is exported, and the other half retained in the United Kingdom for home consumption.

To Dr Hodges, Professor of Agriculture, Queen's College, Belfast, and Chemist to the Chemico-Agricultural Society of Ulster, the trade are greatly indebted for the zeal and assiduity with which he has laboured to enlighten farmers and others on the nature and properties of the Flax plant, and the soil best adapted for its culture. The Society who have brought his talents and intelligence to bear on this important subject deserve well of their country, and so do all who have been aiding in the encouragement of so noble a cause.

The following figures show the progress of the Flax manufacture in the several counties where it exists in Ireland, estimated by the number of persons employed in the years specified, and in 1862 respectively:-

\begin{tabular}{|c|c|c|c|c|c|c|}
\hline Antrim, & . & • & 1839 & 5,876 & 1862 & 19,020 \\
\hline Armagh, & $\cdot$ & - & , & 518 & ",' & 3,582 \\
\hline Down, & - & . & ", & 572 & " & 5,162 \\
\hline Dublin, & - & . & , & 297 & ", & 810 \\
\hline Kildare, & . & . & ," & 205 & ,, & 704 \\
\hline Londonderr & $\mathrm{y}$, & . & $"$ & 214 & ", & 158 \\
\hline Louth, & . & . & $"$ & 589 & ," & 1,348 \\
\hline Meath, & . & . & , & 168 & ," & 177 \\
\hline Monagban, & . & . & ,, & 129 & , & 258 \\
\hline Tyrone, & . & . & ", & 159 & , & 1,487 \\
\hline Donegal, & . & . & 1850 & 185 & ", & 316 \\
\hline \multirow[t]{2}{*}{ Clare, } & . & . & 1856 & 569 & , & 497 \\
\hline & & & & 9,581 & & 33,525 \\
\hline
\end{tabular}

There were, in addition to the above, two factories engaged in the Jute mauufacture in Antrim in 1862, with a steam power of 150 horses, having 1824 spindles, and employing 338 persons. There are no returns regarding the numbers previously employed in this branch of trade. 


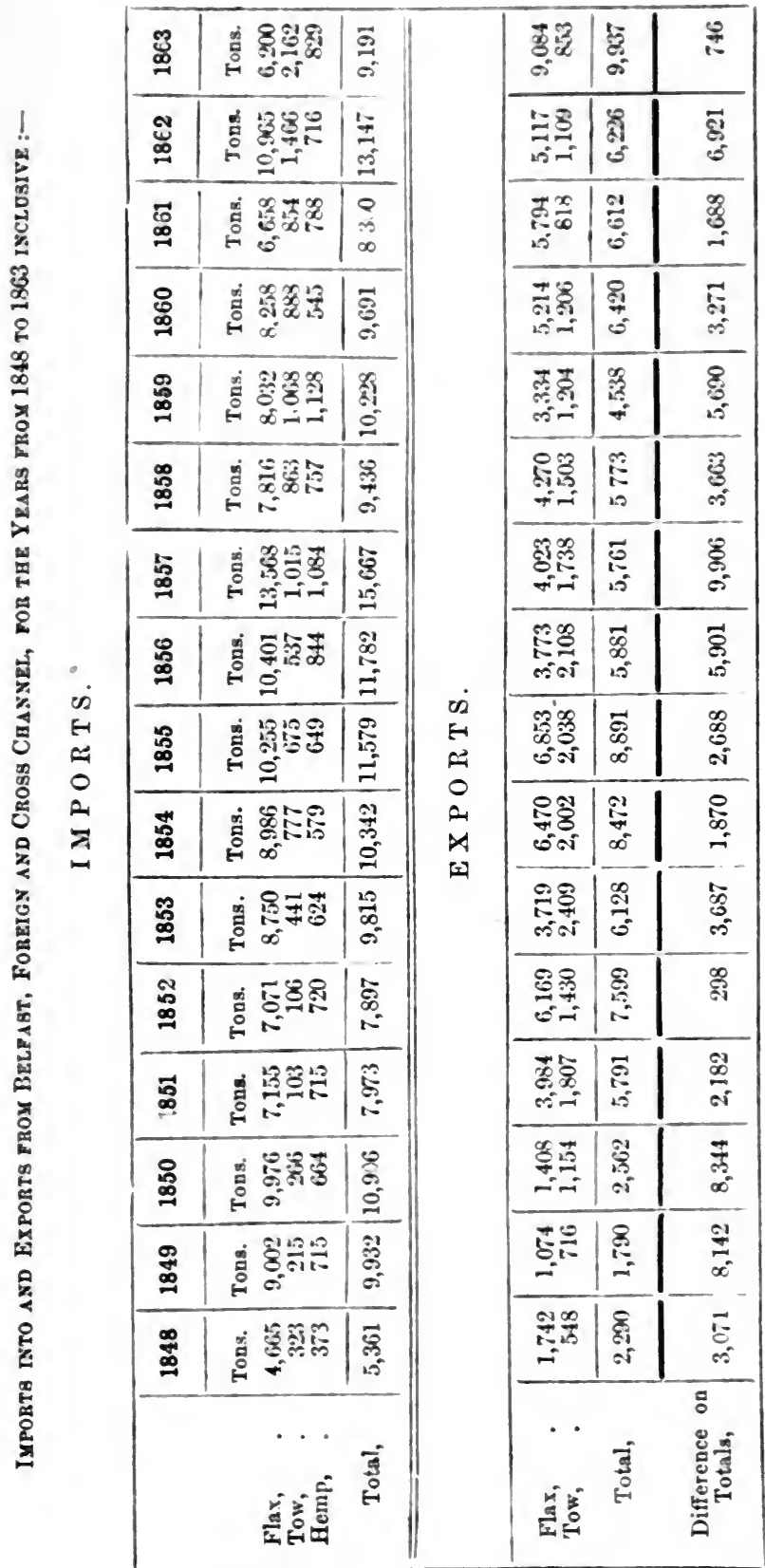

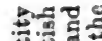
莒 을. ㄹ. 政 틀요 f. $\Rightarrow 2$ o. 再品

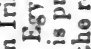
过

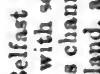
궁 을 되

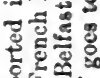
틀. 50 워요 㩆 

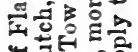

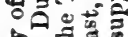
政造。 裙。 品 울 : 공요

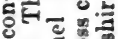
a

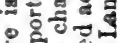

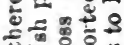
证 궁 ㄴ.

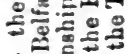

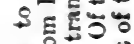
돈멸

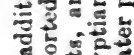

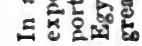
1
1
0
0
2
2 
FACTORY RETURNS FOR IRELAND IN 1857 AND IN 1862.

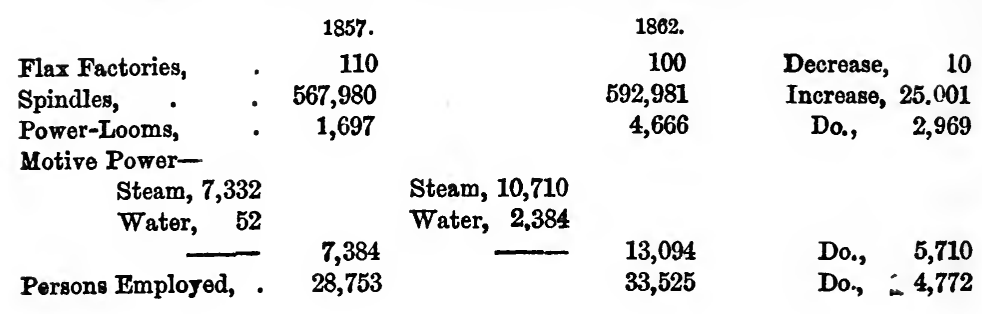

Imports and exports of the articles specified, into and from Belfast, for years 1862 and 1863.

IMPORTS.

1862.

\begin{tabular}{llrr} 
Linen Yarn, & \multicolumn{3}{c}{ Lbs., 6,420,400 } \\
Linens, & \multicolumn{3}{c}{ Yards, 3,721,000 } \\
& Tons. & Hhds. & Brls. \\
Flax seed, & 319 & 18,809 & 50,973
\end{tabular}

EXPORTS.
1863.

\begin{tabular}{ccc}
\multicolumn{3}{c}{ Lbs., $, 5,787,600$} \\
\multicolumn{3}{c}{ Yards, 4,048,000 } \\
Tons. & Hhds. & Brls. \\
265 & 10,689 & 33,919
\end{tabular}

Lbs., 20,622,560

" $1,183,526$

Yards, 78,475,000

Tons. Hhds. Brls.

$620 \quad 254 \quad 4,681$

Some of the details given in the chapter on Flax Culture, and also in this chapter, are taken from the admirable work on "Flax and its Products in Ireland," with the kind permission of the author, William Charley, J.P., \&c., Seymour Hill, Belfast, to whom I beg to express my thanks. 


\section{CHAPTER III.}

S COT TH LIN EN.

The history of the earlier stages in the existence of almost every nation is wholly confined to warlike operations of an offensive or defensive nature. At that period civilization, according to modern ideas, is altogether unknown and unthought offood and safety, no matter how obtained, being the primary and principal aim of all classes. Under such circumstances might is right, and the strong and powerful, reckless even of their own lives, have little respect for the feelings of others. In these remote times clothing was altogether a secondary consideration, comfort being a thing unknown, even to chiefs and nobles. Although the people had then been possessed of the requisite knowledge and skill to spin and weave fibrous substances, they had little opportunity and no inducement to do so, as they were wholly under the control of their feudal lord, and their substance was in reality his. The all engrossing subject was war; and war, either for aggrandizement or in defence, entirely fills the historian's page.

The earliest manufactures of any country are naturally those of the first necessity to the wants of the inhabitants. Local position and circumstances effect changes in these wants, many of the necessaries of an inland population being different from those living on the sea shore, and vice versa. Ordinary articles of clothing, in all countries, excepting perhaps those lying in very warm latitudes, after food, rank prominently among the first requirements of the people. The cold and variable elimate of Scotland would call for some covering, even to its early inhabitants, hardy and inured to privations although they undoubtedly were.

The ancient history of Scotland prior to the Roman period, can scarcely be other than apochryphal, there being no true re. 
cord of it extant. The people were comparatively rude and barbarous when the Roman legions first encountered them, and their clothing at that time was scant. A Roman historian says the Caledonians lived in a state almost approaching to nudity, but whether this was from necessity or choice cannot be satisfactorily determined. Dio represents them as living in tents, naked and without buskins; but Herodian speaks of them as wearing a partial covering.

According to Hollinshead, the apparel of the ancient Scots was hosen of Linen or woollen, which never came higher than the knees; breeches, for the most part of Hemp, with cloak of wool in winter, but of lighter material, probably Linen, in summer. If this report be true, the inhabitants of Scotland had been early acquainted with the manufacture of Linen.

In early times the women in the Highlands went with their heads bare until marriage, after which they wore a head dress, called a curtch or mutch, made of Linen, and tied under the chin. Martin says the head-dress was a fine kerchief of Linen, straight about the head.

At the battle of Bannockburn, it is related that " the carters, wainmen, lackeys, and women, put on shirts, smocks, and other white Linens, aloft upon their usual garments, and bound towels and napkins to their spears, staves, \&c. Then placing themselves in battle array, and making a great show, they came down the hill side in face of the enemy, with much noise and clamour. The English, supposing it to be a reinforcement coming to the Scots, turned and fled."

It thus appears that at an early period Linen had been extensively manufactured in Scotland, even although the inhabitants may not have been acquainted with the art at so remote a date as that to which Hollinshead refers.

The following is an inventory of the napery ordered to be carried to Wyngefield, near Sheffield, for the use of Mary Queen of Scots, on 20th December 1584, and ordered to be transported with her to Tutbury Castle, in Staffordshire, when she was removed there in January 1586, viz:- " 60 paire of sheetis ; 4 dozen and 4 pillowberes; 7 table-clothes of damaske ; 7 tableclothes of diaper ; 6 towells of damaske ; 7 towells of diaper; 6 dozen of damaske napkins; 7 dozen of diaper napkins; 4 
coberdclothes of damaske; 9 coberdelothes of diaper ; 12 plane table-clothes; 12 coarse table-clothes; 20 dozen of plane napkins ; 20 wiping clothes ; 30 dressours ; 12 plane towells." The scantiness of this inventory, particularly in the article of sheets, was grievously complained about by Sir Ralph Sadler, Kt., Chancellor of the Duchy of Lancaster.

About this period "The Interest of Scotland Considered" says " our manufactures were carried on by the meanest of the people, who had small stocks and were of no reputation. These were, for the most part, workmen for home-consumpt, such as masons, house-carpenters, armourers, blacksmiths, tailors, shoemakers, and the like. Our weavers were few in number, and in the greatest contempt, as their employments were more sedentary, and themselves reckoned less fit for war, in which all were obliged to serve, when the exigencies of the country demanded their attendance." A little farther on it is said "the manufactures of Scotland were confined to a few of the coarsest nature, without which the poorest nations are unable to subsist."

Darid Rizzio, who was a model of dress to the Scottish court, had upon his back when he was slain a night gown of damask furred, with a satin doublet, and a hose of russet velvet.

In 1598, Fynes Moryson, a gentleman who had travelled in most of the countries of Europe, being at Berwick, felt an earnest desire to see the King of Scots' court before returning home. The court was then at Falkland. He gives a full description of all he saw there, including houses, furniture, provisions, dresses, \&c., and among other things says, " the unmarried gentlewomen of all sorts did go bareheaded, and wore short cloaks, with most close Linen sleeves on their arms, like the virgins of Germany. The common sort, citizens' wives, and women of the country, wore cloaks of coarse stuff, of two or three colours of chequer work, vulgarly called plodan."

By the rental sheet of the Marquis of Huntly in May 1600, the rent appears to have been paid in money and in kind, and in the enumeration of articles paid to him by the tenants were " 990 ells of custom Linen." This shows that Linen was made to some extent for home consumption in the northern parts of the country, from native grown Flax, and as there was little 
money then current, part of the produce of the land was given to the feudal lord in payment of the rent.

Up to the end of the 16th century little cloth was made in the country, and manufactures were in a rude state, but at that period the principal article of export from Scotland to foreign countries consisted of Linen goods.

An effort was made by the burghs, in June 1601, to introduce an improved cloth manufacture into Scotland. Seven Flemings were engaged to settle in the country to set the work agoing, six of whom were for says and one for broad cloth. When they came to Edinburgh a delay arose, it being debated whether they should not be dispersed among the principal towns in order to diffuse their instructions as widely as possible. On 28th July the strangers complained to the Privy Council that they were neither entertained nor set to work, and that it was proposed to sunder them, "whilk wald be a grit hindrance to the perfection of the wark." The Council decreed that "the hail strangers brought hame for this errand should be kept together in Edinburgh, and put to work on the conditions made between them and the commissioners who engaged them." And until they should begin to work the Council ordained the bailies of Edinburgh to entertain them in meat and drink, though this should be paid back to them by the other burghs. The strangers were allowed at the same time to undertake any other work for their own benefit. On 11th September, the burghs had done nothing "to effectuat the claithworkers," and the Council declared that unless they should have made a beginning by Michaelmas, the royal privilege would be withdrawn.

In August, 1609, under favour of the King, a number of strangers had been introduced into the country to practice the making of cloth of various kinds. A colony of them had settled in the Canongate of Edinburgh, headed by one John Sutherland, and a Fleming named John Van Headen, and " are daily exercising their art of making, dressing, and litting of stuffs, and giving great light and knowledge to the country people." Notwithstanding the King's letter the Magistrates of Canongate wanted them to become burgesses and freemen. On appeal to the Privy Council they were exempted

This exemplifies the narrow minded policy of the age, when 
men who had been specially brought from a distance to instruct the people in a most important branch of manufacture, of which they were ignorant, were harassed and interrupted in the exercise of a public good. The same system was in active force in many towns, until the abolition of corporate privileges. A remnant of the same policy is still to be found among some of the Incorporated Trades of the present day. It is true they do not now have the power to compel tradesmen to join their trade, but they refuse to admit any to its privileges excepting handicraftsmen, and not even them, unless on terms almost prohibitory. Something, however, might be said in favour of the exclusive privilege of the 'Trades' Incorporation in early times, but it is not needful to enter into such a discussion.

Before this period cloth seems to have been made by members of the household for the use of the family, but now the manufacture was extended farther, goods being made for sale to the general public. 'These strangers appear to have been the first to attempt to manufacture cloth for sale.

On 11th July, 1616, Commissioners for a number of the burghs met to deliberate on a proposal of the King for working up within the country the whole wool produced in it " in stuffs, plaids, and kerseys." They expressed themselves as content that the exportation of wool should be prohibited, in order that a trial should be made, but they could undertake no burden in the matter "anent the home bringing of strangers," or for assurance that his Majesty's ends would be attained. A prohibition for the exporting of wool was soon after issued.

This paragraph shows a like narrow-minded policy, on the part of the then Government, in prohibiting the export of wool, thinking thereby to compel the manufacture of the whole of it in the country. That policy is now fortunately exploded, but for a long time after this period it was rigidly carried out on one commodity or another, which greatly retarded the extension of manufacturing industry.

On 11th August, 1618, John Taylor, the Thames waterman, visited Scotland, and took a highland tour to Morayshire, \&c. He says " the houses of the gentry are like castles, and the master of the house's beaver is his blue bonnet. He will wear no shirts hut the Flax that grows on his own ground, and of his wife's, 
daughters', or servants' spinning. His hose, stockings, and jerkins are made of his own sheeps' wool."

In this year footings were introduced by the servants of noblemen. The tanning of leather was also introduced into Scotland this year from Durham, Morpeth, Chester-le-Street, \&c., under royal patronage. It met with small success, but boots were raised to $20 \mathrm{~s}$ and shoes to $6 \mathrm{~s}$, which was considered a great grievance by the people.

In 1640 Covenanting troops, under General Munro, marched from Aberdeen to take rule of the estate of the Marquis of Huntly, who was then with King Charles I. in England. The men of the country, deprived of the presence of their chief, bowed to the General. Some joined the Covenanting army, others submitted to force. Among the spoil, Munro seized a great quantity of home-made Linen cloth, which he found bleaching about the country, hanging it over the walls of Strathbogie Castle to dry, "pity to behold," says the narrator. This home-made Linen was for domestic purposes. In those days bleaching by the present artificial mode was unknown, and instead of the operation being performed in two or three days, as it now is, it then took as many months, sun, air, and water being the agents employed.

In the reign of Charles $I$. there were cloth works on a small scale at Newmills in Haddingtonshire, at Bonnington near Edinburgh, and at Ayr. That at Newmills was in a thriving - condition until Dundee was stormed and sacked by Monk, in 1651, when a store of its cloth in that town was taken, and the troubles which followed soon after closed the work.

Articles of clothing in Scotland had before that period been almost wholly of home-manufacture. As in Sweden, \&c., to this day, the great bulk of the people span their own wool and Flax, each family for itself, and had the yarn woven into cloth by the village webster. There had been, as yet, but the merest attempts at a manufacture of cloth or Linen for general sale and use. A little later it could scarcely be said there was any general manufacture of articles of attire, excepting at Aberdeen. One George Pyper had a number of country people engaged there working stockings with the needles, for which he paid them at the rate of five groats (equal to $1 \frac{2}{3} \mathrm{~d}$ sterling) a-pair for making. It is said he raised the working to such a fineness in some instances, 
"that he hath given 20s sterling and upwards for a-pair." In that district there was a manufacture of "plaiden stuffs" and "fingrams" in operation on 1st March, 1681.

The Duke of York, who possessed considerable faculties for business, had consultations with the greatest mercantile spirits the country then possessed, about planting cloth factories in Scotland, similar to those in England. This was the more necessary, as the money sent to England for the better kinds of cloth was draining the country of its gold. English money was not to be had then under 6 and 7 per cent., and exchange between Edinburgh and London had risen against the former city as high as 12 to 15 per cent. The result of the Duke's patriotic deliberations was the passing of an act of Parliament, in Sept. 1681 , for the encouragement of trade and manufactures. Through his personal exertions a body of merchants was induced to associate for the setting up of a new work at Newmills, the produce of which was to be disposed of under peculiar regulations. The company had a monopoly, English goods being prohibited. They began with two looms, soon increased to eight, soon thereafter to twenty-five, and in 1683 it was still extending. The act was too sweeping and too stringent, as it forbade the importing of many kinds of cloth, including cambrics and damasks, which led to much smuggling.

Such were some of the early struggles of an important branch of industry in Scotland; but it was not, after all, to be in this age that good woollen cloth was to be produced in this northern clime. In 1697 it is said attempts were made to make several articles, but they were not so good as what came from abroad. Those who would propagate any new manufacture must lay their account to labour under several disadvantages at first.

The Legislature of Scotland generally did all in its power for the encouragment of the Linen trade in the country, but sometimes the policy of the Court changed, and the interests of those engaged in this faroured branch of trade were forgotten. In $1685 \mathrm{King}$ James II., in order to secure the friendship of the French king, repealed the prohibition against importing Linens into the country. For a time this had a discouraging effect on the Linen trade, and it is said that the manufacturers 
of this country were oppressed by the quantity of foreign Linens which flowed in upon them.

Morer, who was in Scotland in 1688 and 1689 says,_- "But that which employs great part of their land is Hemp, of which they have mighty burdens, and on which they bestow much care and pains to dress and prepare it for making their Linen, the most noted and beneficial manufacture of the kingdom."

In September 1681, Thos. Kennedy and Jno. Trotter, merchants, were proposing to set up a manufacture of Linen and woollen stuffs in the place called Paul's Work, in Edinburgh, where, so long ago as 1609, there had been an attempt at a woollen work. And, as an encouragement, the Council ordained them to have all the privileges offered to manufactories in Scotland, by the 12th act of their parliament regarding manufactories.

In November 1682, three merchants in Glasgow were arranging for the setting up of a manufactory "for making damaties, fustines, and striped vermiliones," expecting it would be "a great advantage to the country, and keep in much money therein which is sent out thereof for import of the same." As they would require a great stock and many servants, the enterprisers deemed themselves entitled to have their work declared a manufactory, so that it might enjoy the privileges accorded to such by act of parliament. This favour was granted by Council for nine years, "but prejudice to any other persons to. set up and work in the said work."

In December 1684, while strenuous measures were taken for preventing the free importation of English woollen cloths into Scotland, a petition came from persons interested in the Linen manufacture, complainiug of the usage which had lately been experienced by Scotchmen selling Linens in England. Hitherto there had been a free trade for Scotch Linen weavers in the south, and as from 10,000 to 12,000 persons were employed in such weaving, the results were important, not merely to the workers, but to the landlords for the payment of their rents; and to the Government, as each 1000 to 1200 packs exported to England paid a custom of $£ 3$ sterling. Latterly, however, the men selling Scotch Linen in England had been taken up and whipped as malefactors, and many were obliged to give bonds that they would discontinue their traffic. The Council 
recommended the Secretary of State to interpose with His Majesty, that merchants and others might have liberty to sell Linen in England as formerly; never once adverting to the fact that they had an act of parliament conceived in the same illiberal spirit towards English woollen manufucturers. Had the practice of whipping the Scotch who went to England to sell their Linens not been stopped, it would have been a severe blow to the Scotch Linen trade of the present age, as manufacturers would not have liked such a castigation in their journeys to the south.

In order to promote the making of Linen, an act was passed in 1686, ordaining that "no corpse of any person whatsoever be buried in any shirt, sheet, or anything else, except in plain Linen," the relatives of the deceased persons being obliged, under heavy penalties, to come to their parish minister within eight days of the burial, and declare on oath that the rule had been complied with.

On 14th June, 1693, another act was passed, ordaining that, for the same end as the act of 1686 , no lint should be exported from the kingdom; that lint imported should be duty free; and making sundry arrangements for a uniformity in the breadth of the cloth produced. Same year, an act was passed conferring particular privileges on two companies which carried on the Linen manufacture in Paul's Work, Edinburgh, and in the Citadel of Leith, as an encouragement which was required for their success.

On the 28th May, 1694, articles of agreement were concluded between Nicholas Dupin, acting for a Linen Company in England, and the royal burghs and others in Scotland, for the formation of a company to carry on the Linen manufacture in Scotland. It was arranged that " the enterprise should rest in a capital of 6000 shares of $£ 5$ each, one-half of which should be held by Englishmen, the rest by Scotchmen, the burghs each being allowed certain shares in proportion to their standing and wealth, the money to be paid in four instalments within the ensuing two years."

In July 1695 there was a farther act passed "anent burying in Scots Linen," ordaining that none should be used for sepulchral purposes above twenty shilling Scots (20d sterling) per Scots 
ell, and also commanding that the nearest elder or deacon of the parish, with one or two neighbours, should be called by the friends of the deceased persons, to see that the shroud was in all respects conform to the acts thereanent.

A rope manufactory had been established some years at Newhaven by James Deans, bailie of the Canongate, and one of his sons, but it was discontinued after considerable loss had been incurred. In November 1694, Thomas Deans, another son of the first enterpriser, expressed himself as disposed to venture another stock in the same work, provided he should have it endowed with the privileges of a manufactory, though not to the exclusion of others disposed to try the same business. His wishes were complied with by the Privy Council.

On the 7th May, 1696, the privileges of a manufactory, according to statute, were granted by the Privy Council to Patrick Houston and his partners, for a rope work in Glasgow. This copartnery was to set out with a stock of 40,000 pounds Scots, and to introduce foreign workmen to instruct the natives.

In 1696 the Linen manufacture is spoken of as established, and two years later the bleaching of Linen was executed at Corstorphine.

A pamphlet in favour of the African Company, published in 1696, remarked that Scotland had lately been falling upon true and lasting methods of increasing her trade, by erecting companies to "manufacture our own natural commodities, thus we have the woollen cloth manufactory at Newmills, the baise manufactory for our wools, the Linen manufactory, several for leather, and others." The company received an act of incorporation from the Scottish Parliament in June 1695, under the name of "The Company of Scotland Trading to Africa and the Indies." The truly unfortunate Darien adventure was a death-blow to the Company, and nearly ruined the half of Scotland. This Company was much encouraged by the celebrated William Paterson, the projector of the Bank of England. The last capital of the Company, $£ 229,6114 \mathrm{~s} 8 \mathrm{~d}$, was paid out of the Equivalent in 1707, and the Company then came to a close.

About the year 1695 Glasgow exported annually some hides, Linen, \&c., to Bristol, bringing back tobacco, sugar, and goods of the manufacture of England. In October 1696, James Mel- 
ville of Halhill, got a letter of gift from the Privy Council to encourage him in a manufacture of sail-cloth.

On 16th January, 1697, a case, which had been in the Court of Session for two years, in which a husband was sued for return of a deceased wife's "tocher," was decided. The Lords, after long deliberation, decided that annong other things, " under child-bed Linen, or Linen on the wife's person in child-bed, are paraphernal, but not the Linen on the child itself, nor on the bed or room, as they are common moveables, and so not to be returned."

Among the wedding clothes of Miss Smythe of Methven, who was married to the eldest son of Sir Thomas Moncrieff of that Ilk, in 1701, were 20 ells of Holland for 6 shirts, Linen for 6 shirts, Holland for 6 suits of night clothes, cambric for 6 hand napkins, Holland for 2 aprons, \&c., \&c.

On 10th July, 1701, in consequence of a mortality among lambs, many died, and the wool could not all be used in Scotland. Parliament had previously forbid the export of wool, in order that the woollen manufacturers might be encouraged. The Dean of Guild of Edinburgh petitioned the Privy Council to allow the surplus wool to be exported, as the return for the same would be in Lint, Hemp, \&c., but the petition was refused.

The Union, in 1707, produced remarkable effects on the industry and trade of Scotland. She ceased, in conformity with England, to export wool, and her manufacture of fine woollens was supplanted in England, but her coarse woollen manufactures flourished. The duties which had existed on the exportation of Scotch Linen to England were removed, and there was immediately so large an increase to that branch of the national industry, that it was said it seemed the poor could want no employment. Englishmen came north and established works for sail-cloth, damasks, and other Linen articles, heretofore hardly known in the north; and thus, it was remarked, there was as much employment for the poor as in the best days of the woollen manufacture. The colonial trade was also opened up to Scottish enterprise by the Union, and cargoes of Scotch goods, including Linens, went out to America in great quantities, in exchange for colonial produce brought in, thus creating, 
as it was then said, a prodigious vent for Linens and other goods. The quantity of Linen made in Scotland in $\mathbf{1 7 1 0}$ was $1,500,000$ yards.

In 1723 a writer of some ability travelled over Scotland, and wrote an account of his journey. Among other things he says, " many of the ladies were good housewives, and many gentlemen of good estate were not ashamed to wear clothes of their wives' and servants' spinning."

In 1725, Woodrow says, the merchants of Glasgow were beginning to think of ventures in other directions than formerly. "This summer there seems to be a very great inclination through the country to improve our manufactory, and especially Linen and Hemp. They speak of a considerable society in Glasgow, of the most topping merchants, who are about to set up a manufactory of Linen which will keep six hundred poor people at work. The gentlemen, by their influence seem much to stir up country people, and to encourage good tradesmen, and some care is taken to keep Linen and webs exactly to standard, and to see that the stuff be good and marketable. . . . What will come of it I know not. I have seen frequent attempts of this nature come to very little." This year really did become the epoch of that vast system of textile manufacture for which the city has since become so celebrated. The first efforts of the looms were confined to Linen cloth, lawns, and cambrics. Seven years later one of her enterprising citizens, Alexander Harvie, "at the risk of his life, brought away from Haerlem two inkle-looms, and a workman," and was thus enabled to introduce the manufacture of inkles into his native town, where it long flourished. The introduction of the cotton manufacture into Glasgow was the work of a subsequent age.

In 1720 , a public newspaper states there was annually exported, from Scotland into England the value of $£ 100,000$ in white Linen, and as much in brown, the Flax being of " a spunsie quality," which gave it a preference over the similar products of both Ireland and Germany. The same document estimated the English woollen cloths imported into Scotland at $£ 400,000$ per annum. About this period neither the manufacture of Linens nor woollens had been brought to great perfection in Scotland. 
By an act of parliament passed in 1727, a Board of Trustees was established in Scotland for the administration of an annual sum set aside for the encouragement of manufactories and fisheries. The sum at first given was $£ 4000$, which was calculated to go a great way in so poor a country. The activity and serviceableness of the Board was, in its earlier years, chiefly shown in the promotion of Linen manufacture, which, under the stimulus, rose greatly, but as this act had a most important effect on the Linen trade of Scotland, full details regarding it vill be given separately.

The conflicts between the Bank of Scotland and the Royal Bank, at this period, had its effect even upon the Board of 'Trustees. On 26th June, 1728, the Lord Adrocate, Duncan Forbes, wrote thus to the Duke of Newcastle on the subject:- "The 'Trustees appointed by His Majesty, for taking care of the manufactures, proceed with great zeal and industry; but at present credit is run so low, by a struggle between the bank lately erected by His Majesty, and the old bank, that money can scarcely be found to go to market with."

In 1730 the country may be said to have been in a state of transition from poverty to growing wealth, and from restricted to expanding views regarding matters of trade. For a generation the Linen manufacture had been passing through what might be called a prosperous infancy. The influx of commercial prosperity had fairly set in at Glasgow; and the Linen manufacture and other branches of industry were then making good progress.

A lady, born in 1714 , who has left a valuable set of reminiscences of her early days, among other things, says :-

"Linens being everywhere made at home, the spinning executed by the servants during the long winter evenings, and the weaving by the village webster, there was a general abundance of napery and underclothing. Every woman made her web and bleached it herself, and the price never rose higher than two shillings a yard; and with this cloth almost every one was clothed. The young men, who were at this time growing more nice, got theirs from Holland for shirts, but the old ones were satisfied with necks and sleeves of the fine, which were put on loose above the country cloth. Table Linens were reE E 
newed every day in gentlemen's families, and table napkins were always used. A few years after this, weavers were brought from Holland, and manufactories for Linen established in the west. Holland, being about six shillings an ell, was worn only by men of refinement. I remember, in the '30 or '31, of a ball, where it was agreed that the company should be dressed in nothing but what was manufactured in the country. My sisters were as well dressed as any, and their gowns were striped Linen at $2 \mathrm{~s} 6 \mathrm{~d}$ per yard. Their head-dresses and ruffles were of Paisley muslins, at $4 \mathrm{~s} 6 \mathrm{~d}$, with fourpenny edging from Hamilton; all of them the finest that could be had. At this time hoops were constantly worn four-and-a-half yards wide," \&c, \&c. The universal dress of the middle classes at this period was of plain country cloth, but gentlemen of figure wore English or foreign cloth, \&c.

On 9th April, 1732, the Caledonian Mercury says, "Died, John Gray, Master of the Rope and Sail Manufactory at Edinburgh ; eminent for his unparalleled skill in cutting whalebone." On 18th October in the same year, the Magistrates of Musselburgh, in riding the marches of the town's property, were attended by the burgesses, \&c., to the number of about 700 , in their best array. A dispute arose between the tailors and weavers, on the point of precedency of their respective corporations. The tailors said it had fallen to them by lot; the weavers that they were men, and as such preferable to the tailors. After engaging in fierce strife to settle the point, victory declared for the needlemen, who beat the weavers out of the field, and nearly captured their standard. This proves that weaving had been carried on to a considerable extent in Musselburgh at that time.

Dean Castle, an extensive ruin, formerly the property of the ill-fated Earl of Kilmarnock, stands in a hollow near that town. It was burned down in 1735 , by the carelessness of a servant girl, who, in preparing some lint for spinning, heedlessly let it catch fire, and the flames were not stopped until the castle was destroyed.

In 1739, the manufacture of Linen thread was introduced into Kilbarchan, and within a little of this period the same manufacture was established in several parts of the country, far removed from 
each other and totally disconnected. This is indicative of the existence of general causes which governed the whole movement, showing that the progress was essentially national. Bower, in his history of the University of Edinburgh, says, "Between 1750 and 1760 a great degree of patriotic enthusiasm arose in Scotland to encourage arts and manufactures, and the Edinburgh Society was established in 1755 for the express purpose of improving these."

In 1764, Linens were exported from the following places in Scotland, viz., Linlithgow, Paisley, Hamilton, Glasgow, Burntisland, Perth, Dunkeld, Dundee, Aberdeen, Old Meldrum, and Banffshire. Several of these places have long ceased to manufacture Linens, which shows the changes a century produces on the trade of a country in these progressive ages.

Postlethwayt, in his dictionary, 1766, says-"In the west of Scotland, where the finest cloth is made, they have a foolish notion that unripe Flax makes the finest Flax, they therefore pull the lint when the blossoin falls. This kind of lint heckles away almost to nothing, and is indeed very fine in appearance, but has no substance, and the yarn spun of it is weak and ouzy. It wastes much in the washing, and cloth made of it grows as thin as a cobweb in the bleaching, before it can be brought to a full colour." He also says the "French spinning school in Scotland had bred a great many good spinners of fine yarn, but many of them are persons of rank, and when they have gratified their curiosity in learning the art, give over the practice, and are of no more use to the manufacturer."

The same author says, "About this time the bounty on Linen exported having temporarily ceased, a great many weavers, about 8000 , were thrown out of employment, many of whom enlisted into the army, others into the Dutch service, and others left the country.

Another account says, "In consequence of the overtrading in 1770 and 1771, the demand for Linens fell off greatly, and 1773 was a year of great depression. In four counties in Scotland, out of 6000 looms, 2500 were unemployed; and in general a third part or more of the Linen looms in Scotland were standing idle."

The parties engaged in the woollen trade of the country often E e 2 
enveighed against the partiality shown by the Legislature to the Linen trade. It was said that from cheapness of raw material and labour, the natural seat of the Linen manufacture was Holland, Flanders, Germany, and France. Since its introduction into this country bounty had been added to bounty, and restriction to restriction, as each preceding regulation had been found inadequate to struggle with the difficulties of our soil and situation. Discouraged with the preference shown to the favourite trade, in $\mathbf{1 7 7 4}$ the woollen manufacturers of Norwich, Birmingham, Sheffield, Wolverhampton, \&c., petitioned the House of Commons against imposing an additional duty upon foreign Linens imported, which was then in agitation, on the ground that it would lead other countries, by a similar policy, to impose restrictions on their commodities, which were the more natural and profitable manufactures of this country.

Total quantities of Flax, Hemp, Flax seed, and raw Linen yarn imported into Scotland from 5th January 1764 to 5th January 1772-eight years :-

\begin{tabular}{|c|c|c|c|c|c|}
\hline Rough Flax, & • & & • & Cwts., & 533,749 \\
\hline Rough Hemp, & & $\bullet$ & & ", & $\mathrm{L1} 2,980$ \\
\hline Linseed, & & • & $\bullet$ & Bushels, & 455,243 \\
\hline Linen Yarn, & & • & . & Lbs., & 954,972 \\
\hline
\end{tabular}

In 1765, the Annual Value of the Flax and Hemp

imported into England was said to be about $\$ 700,000$

Into Scotland, do., do , do., 150,000

Linen Yarn imported into Britain, . . 450,000

$\overline{£ 1,300,000}$

About one-half of the Flax consumed in Scotland at this period was of home growth.

Pennant, in his tour in 1776 , says--" I cannot ascertain the time when the Linen manufacture arose. There could not be a great call for the commodity a century and a half ago, when people of fashion scarcely changed their shirts above once a week in England. But thanks to the luxury, or rather the neatness of the times, this article has become a most national advantage."

About this period the Linen manufacture was spread over a great part of the country, and some details will be given here- 
after regarding the trade in several parishes, under the head " Rural Districts." In some districts there was little more made than supply local wants, but in others the manufacture was carried on extensively, and large quantities of Linens were sent to England, as well as shipped abroad. Much of the Flax used in the manufacture was raised at home, and Riga and Dutch Flax were imported to supply the further requirements of the trade. The Flax was chiefly grown by the cottier farmers, and the preparatory processes to adupt it for being spun were performed by their families. Spinning Flax, on the hand wheel, formed the principal occupation of females of all classes, both in town and country, and some of them, from long practice, became great adepts in the art. The yarn was either weaved at home, or sold in the district markets, of which there were many throughout the country, to agents from the large towns, such as Dundee, Glasgow, Montrose, \&c. It was either made into Linen in these towns, or sent off to England and manufactured there. After the introduction of Flax spinning by power, the trade became completely changed. The spinster and the hand wheel of last century gave place to the factory girl and the spindle of the present; the manufacture ceased in many rural districts, and became concentrated in towns where spinning mills were erected, and in a few other places. It is not necessary to follow the progress of the trade in many of the country parishes, because in most of them it died a natural death. In a few of the chief towns where the trade is still vigorously conducted, a short account of each will be given under the head "District Trade." This course renders it unnecessary to say much more regarding the linen trade of the country here, a few general notices will therefore close this portion of the work.

In 1802, a tax was proposed to be imposed upon the imports and exports of Flax and Linen, cotton and cotton goods. Those concerned in the Linen trade in Edinburgh, Dundee, Montrose, \&c., applied to the Lords of the 'Treasury to have Flax and Linen exempted. They agreed in the meantime to exempt Linen from all duties at exportation; and the Mlinister stated that he was disposed to hold the impost as a temporary measure, and that he would endearour to get Parliament to repeal the act next session, if it could be shown that it endangered the 
prosperity of the trade. The bill, as finally passed, exempted Flax and yarn from duty on importation, but a considerable duty was imposed on foreign Linen imported. An equal duty was extended to Irish Linen exported from Great Britain, as on foreign Linen imported into it. The Dundee Advertiser of the day says " it was intended to propose to Parliament to impose duties on goods exported from Ireland, equal to those exported from Britain, and when this was done there would be nothing wanted, but that the excise duties paid by bleachers in Scotland should be the same as those paid by the bleachers in Ireland." This was considered to be reasonable, becouse the Linen trade in Ireland was then in a more advanced state than in Scotland.

In 1803, considerable correspondence was carried on in the newspapers about the saving of Flax seed, and it was shown that seed saved from a crop raised from Dutch seed, produced an equally good crop the following year, without injuring the Flax from which it had been taken. It was also shown that Flax, after grass, required no manure, and that Flax growing was profitable both to the cultivator and to the nation, especially when the seed was saved for re-sowing or cattle-feeding, and the fibre for Linen, and that this could and should be done without danger to either.

On 26th April, 1805, Government made the following intimation:- "Notice is hereby given that a convoy will be appointed to sail from Leith Roads, on 2d May." Such notices will appear strange in the present day, but at this period they were but too much required. The following paragraph, from the Dundee Advertiser of 24th January 1806, is of a more peaceable nature:- "A farmer at Gartsherrie erected a steam Flax mill and thrashing mill, which was found to answer well, and was the first of the kind put up in Scotland, to prepare and dress lint independently of the weather. It was expected to prove of great use to the country." On 4th April, 1806, the convoy for the Baltic sailed from Leith Roads, in all about 140 sail.

In consequence of the distressed state of the country in the beginning of 1811, many operatives were thrown out of employment. The gentlemen of Kinross-shire resolved to purchase, on their own account and risk, cotton and Linen yarn, to be given 
out to weavers to be manufactured into cloth, under the direction of a person appointed for the purpose. Upwards of $£ 4000$ was subscribed to carry out the measure. The result of this experiment could scarcely be otherwise than unfavourable, as the gentlemen of Kinross-shire, however good their intentions, could not be expected to compete profitably with those bred to the trade. It is doubtful how far such schemes are wise, as the competition they create is injurious to the fair trader, and does more harm to the operatives in other districts, than good to those whom the philanthropists are desirous to serve.

The quantity of Flax imported into Scotland in 1811 was 6094 tons. In 1813-4, there was a considerable discussion in the newspapers of the day about the repeal of the duties on Linens imported. The Glasgow merchants wanted the duty taken off, as they could not get assortments made up without German Linens.

In 1816, a London merchant petitioned Government to put a duty on cotton bagging, the manufacture of Brazil, or on the cotton wool imported in it from Brazil, in order to encourage the manufactures of Scotland, which were then depressed, "as this would cause Scotch bagging to be used for Brazilian cotton, as well as for American" The Government replied that they would take it into consideration. That year the machinery of a small spinning mill, which had been erected at the back of Edinburgh Castle, consisting of 8 spinning frames of 24 spindles each, \&c., was advertised to be sold.

The progress of the Linen manufacture in Scotland in 1863 is of the most gratifying description. By a return presented to the House of Commons in 1862, details of which will afterwards be given, there were in Scotland in the end of 1861, 192 works engaged in the Flax manufacture, driven by a moving power equal to 15,391 horses, of which, 14,337 steam, and 1,054 water, with 312,239 spindles and 8,510 power-looms, and employing 39,562 people. Since that return was made up the increase in every department of the trade in almost every town engaged in it has been continuous and rapid, and the number of spindles, power-looms, horses' power, and people enployed have been largely increased.

At one period a very large quantity of Flax was raised in Scotland but the cultivation has gradually decreased, until it is 
now all but extinct in many counties. In 1812 about 5000 acres were grown, worth at $£ 20$ an acre $£ 100,000$. In 1834 great complaints were made about the growth of Flax at home having ceased, and strong recommendations made to renew it. It was calculated that $£ 48$ to $£ 56$ a ton could then be got for Scotch Flax, which would pay the grower well.

Mr J. Hall Maxwell kindly furnished the following statement of the acreage under Flax in Scotland during the years when the statistical inquiry, made by the Highland and Agricultural Society, was in operation, from 1854 to 1857 . The quantity was as follows, viz :-

\begin{tabular}{|c|c|c|c|c|}
\hline Counties. & $1854^{\circ}$ & 1855 & 1856 & 1857 \\
\hline $\begin{array}{l}\text { Fife, } \\
\text { Stirling, }:\end{array}$ & $\begin{array}{r}\text { A cres. } \\
1,648 \\
1,372 \\
1,275 \\
725 \\
1,650\end{array}$ & $\begin{array}{r}\text { Acres. } \\
428 \\
770 \\
746 \\
432 \\
1,085\end{array}$ & $\begin{array}{c}\text { Acres. } \\
\mathbf{5 7 6} \\
\mathbf{5 4 8} \\
\mathbf{5 4 0} \\
\mathbf{3 5 2} \\
\mathbf{7 0 7}\end{array}$ & $\begin{array}{r}\text { Acres } \\
377 \\
438 \\
309 \\
210 \\
200\end{array}$ \\
\hline Total Acres, . & 6,670 & 3,461 & 2,723 & 1,534 \\
\hline $\begin{array}{l}\text { Proportional Number of } \\
\text { Acres under Flax, }\end{array}$ & .189 & .098 & .077 & .043 \\
\hline
\end{tabular}

Unfortunately this is a gradually diminishing statement, and it is to be feared that even the small acreage of 1857 has since then decreased, but no statistics have been taken up since that year, which is much to be regretted on many accounts.

The following paragraph, taken from a Letter in the Glasgow Journal, bears on the subject:- "In Scotland the growth of Flax is very limited. There are no authorised statistics published of the extent, but it is estimated not to be over 1,700 to 1,890 acres altogether, and is chiefly confined to the north-east portion of Lanarkshire and Stirlingshire. A small part is grown in Fife and Ayrshire.

"Scotch Flax always commands a very high price, and is readily sold to manufacturers of Linen thread who require great strength. The price of this season will range from $£ 60$ to $£ 85$ per ton, and cannot fail to remunerate the grower handsomely. A half-barrel of seed, costing 26 s to 30 s, should sow an acre of 
land, which should yield 40 to 50 imperial stone of Flax, value from $8 \mathrm{~s}$ to $10 \mathrm{~s}$ per stone. The cost of working is estimated at $£ 310$ s to $£ 4$ per acre.

"The two following results of their Flax crop last season are given by farmers in the neighbourhood of Glasgow:-One sowed $10 \frac{1}{2}$ acres with six barrels of Riga seed-he sold the produce for $£ 2047 \mathrm{~s}$. Another suwed $5 \frac{1}{2}$ acres with three barrels seed, and got $£ 1205 \mathrm{~s}$ for his crop. If proper skill is exercised in the preparation of the soil, and care taken in the selection of the seed, the success of the Flax crop is just as certain as any other; and, as to its being a profitable one, there is not the slightest doubt. For well-handled Scotch flax there is always a ready market and a high price.

"That a large and profitable field is open to the farmer, if he would lay aside his prejudices, is ascertained by those who have tried it, and it is undoubtedly his interest to take to Flax-growing with spirit, and to derote a field or two at seed time to the pretty blue-flowered plant."

In regard to the culture of Flax in the more improved districts of Scotland, Mr Sheriff " is convinced that, if grown as a crop and persevered in, it would prove destructive both to the tenant and to the soil he cultivates." Mr Kerr observes-"a real farmer has no time for the minute attentions required in this branch of husbandry, nor land to spare for laying it out to grass or dry."

These two sentences, taken from the preface to Sir John Sinclair's " Account of the Husbandry of Scotland," may represent the views of the gentlemen farmers of the present day, but there is no doubt they are fallacious in every point of view. The crop is not more exhausting than several others, if the rotation be at sufficient intervals, and if the refuse and steep water be put on the land. Where the seed is used for feeding purposes, as it can be with proper care without deteriorating the fibre, it is the very reverse of an exhausting crop. Large farms are inimical to Flax raising, because it does require a considerable amount of handling and care, which extensive farmers may not themselves, perhaps, be able to superintend ; but an intelligent foreman could soon be learned to do this in a satisfactory manner. The want of scutch mills in the various districts is also 
an obstacle to the increased cultivation of Flax in Scotland; but the greatest objection at present is the want of a ready market for the disposal of the Flax. This the spinners might obviate by employing competent parties to purchase the Flax in the country markets, as is done in Ireland; but until they take action in the matter, it is vain to look for farmers beginning to grow it on a large scale. Scotch Flax is a superior article, and admirably adapted for all the better class of Linens, and it brings a high price in the market. There is no doubt that, were farmers to grow Flax regularly, it would pay them better than any grain crop. It is for their interest, as well as for that of the spinners, that the plant should again take rank among the crops in Scotland, as it would tend to stimulate the Linen trade, and benefit the country.

BRITISH LINEN COMPANY.

Although the British Linen Company is now known only as a Bank, it was appropriately named on its first institution. On the suppression of the rebellion, caused by the last effort of the Stuarts to regain the throne of their ancestors, it was thought that the settlement and prosperity of Scotland would be assisted by the introduction and encouragement of such branches of industry as the circumstances of the country might point out. Among these the Linen trade appeared conspicuous. Accordingly, on 5th July, 1846, the King's charter passed for erecting the British Linen Company at Edinburgh, with a capital of $\mathfrak{1 0 0 , 0 0 0}$ sterling. The subscribers were actuated only by patriotic motives, and they consisted of all the eminent men of the city and country. The subscription list or contract is a remarkable document, and looks more like the Roll of Parliament than a list of traders.

One of the chief objects of the Company was to supply the British merchants trading to Africa and the British Plantations with such kind of Linen cloth as they had previously been obliged to purchase from foreign nations, whereby it was hoped 
much money would be saved to the nation. 'T'his was not the only object, however, which the promoters had in view, as they also intended to prosecute the Linen trade in its several departments. After the formation and incorporation of the Company, they entered into trade in the manner intended, and prosecuted it with great success.

Macpherson says, "by 1751 the Company had been instrumental in the advancement of the Linen manufacture in Scotland, by advancing ready money to the poorer manufacturers for their goods, whereby they are enabled to go on with much more spirit." He adds, " the Board of Trustees likewise bestow annual premiums for the best manufactures, whereby a spirit of industry increases more and more in Scotland."

Postlethwayt, in his "Dictionary of Commerce," published in 1766, says:- "Some years ago, his Grace the Duke of Argyle, and other lords and gentlemen, finding some difficulties to attend the spinners of Flax into yarn, as well as the weavers of the said yarn into different sorts of Linen, by reason of the want of a ready sale for their goods, and they being made to keep them on hand for a market, were often obliged to sell them at an under value, to the great prejudice of the manufacture. On these considerations they were incorporated by a charter from his present Majesty, under the name of the British Linen Company, with a capital of $£ 100,000$, for trading in all branches of this manufacture. They import Flax from abroad, linseed, pot and wood ashes for bleaching, and sell them on credit to proper hands, then buy the yarn and Linen, all at reasonable prices; which Linen, particularly the sort corresponding to Osnaburgs, \&c., fit for America and the West Indies, they keep in large warehouses both here and at London, where they are sold for exportation."

Although it is rarely safe to pronounce authoritaively on the reason of any social change, in which many causes and elements are usually combined, yet it is a fact that the Linen trade underwent a rapid development after the establishment of the British Linen Company; and no doubt part of that progess is due to the assistance they rendered to traders and others engaged in the manufacture. The Company were not long in discovering that their assistance could be best given by advancing money to the 
individuals engaged in it, and allowing them to prosecute the manufacture on their own account, free from the competition of a corporation. This led the Company to withdraw from the direct dealing in yarns and Linens, and to adopt banking as their sole business. As bankers, they are now only known in this country, and as such have been very prosperous. Their capital has been increased from time to time to $£ 1,000,000$, and yields a dividend of 10 per cent. per annum. The establishment in Dundee has occasional applications from parties at a distance for prices of yarns and Linens, and with proposals for business.

After the institution of the Company, they had an agent in Dundee, for the purchase and sale of goods, of the name of Palmer, but that agency was long discontinued before the present Branch Bank Establishment was opened there in 1811.

\section{BOARD OF TRUSTEES FOR MANUFACTURES.}

After the union of Scotland and England, in 1707, the Government of the day did much to encourage the manufacturing industry of the lesser kingdom. With this view various expedients were resorted to, some of which were of doubtful utility, but others proved really beneficial to the country. The culminating act of the Legislature was the institution of a Board of Trustees for Manufactures, with certain funds at their disposal for the encouragement of the objects contemplated, and certain privileges and powers for carrying out and fulfilling these objects.

The following details of the proceedings of the Trustees have been extracted from their Minutes and Annual Reports, and they are interesting as showing the means taken to foster the Linen trade in Scotland. Incidentally, the progress of the trade and the state of the country can be gathered from the proceedings of the Trustees in a clearer manner than from any other data extant, and an account of the Linen Trade in Scotland would have been incomplete without these valuable extracts :-

"His Majesty's Patent for Improving Fisheries and Manufactures in Scotland," Registered and sealed at Edinburgh, 18th July, 1727. 
Considering that by 15th article of the 'Treaty of Union, it is provided that an annuity of $£ 2000$ per annum be appropriated for seven years, for promoting manufactures of coarse wool: Considering that by act 5th, George I., an annuity of $£ 2000$ per annum be payable out of the Revenues of Scotland, in lieu of the Equivalent claimed by Scotland under Treaty of Union, to be applied to the encouragement of the Fisheries and Manufactures of Scotland: Considering that by act 12th, Geo. I., it is among other things provided that, should the Malt 'Tax of $3 \mathrm{~d}$ per bushel, levied in Scotland, produce a larger sum than, $£ 20,000$ clear of all charges of management, the surplus shall be applied to the encouraging of the Fisheries and Manufactures of Scotland: Considering that by act 13 th Geo. I., passed for encouraging and promoting the Fisheries and Manufactures of Scotland, it is provided that a plan may be luid down by His Majesty for that end, with proper Rules and Regulations for the distribution of the Funds available for the purpose; And that His Majesty may, by Letters Patent, appoint Commissioners, not exceeding twentyone, for managing and distributing these funds: We have, therefore, and for the good of our people, and for advancing and promoting such Fisheries and Manufactures in Scotland, as may most conduce to the general advantage of our United Kingdom, thought fit to ordain a letter, to be passed under the great seal, \&c., \&c., directing the several sums above mentioned, to be paid to the Receiver General of Scotland for the purposes above mentioned, viz.,- - the encouragement and improvement of the Fisheries and Manufactures of Scotland, in the manner and by the rules hereinafter mentioned, viz. :-

3. The $£ 14,000$, due under Treaty of Union for improvement of woollen manufacture, be lent out at interest.

4. $£ 6000$ of arrears of annuity (5th Geo. I.), to be also lent out.

5. Interest of said $£ 6000$, with future annuity of $£ 2000$, and surplus of Malt Duty, be equally divided between the Fisheries and Manufactures of Scotland.

6. Further arrears of said Annuity, and of surplus of Malt Duty which may not be yearly employed, may remain in the Receiver-General's hands for carrying out the general plan.

11. $£ 1500$ to be annually distributed on premiums at the rate of $15 \mathrm{~s}$ per acre for the sowing of Lint or Hemp seed.

12.- - 400 to be allowed amually as salaries to Lappers and Stamp-masters at $£ 10$ each.

13. $£ 250$ to be given as salaries for two "General Riding Officers" or Inspectors.

14. $£ 100$ to be allowed for expenses of prosecutions against those who shall transgress the rules. 
15. $£ 150$ " for encouraging Schools for teaching children from the age of 8 years to that of 14 years to spin."

16. $£ 50$ for models of best sort of Looms and other instruments connected with the Linen trade.

17. $£ 200$ in several small prizes to housewives "who shall make the best piece of Linen cloth."

22. Interest of $£ 14,000$ to be appropriated to encouragement of woollen manufacture.

23. Interest of $£ 6000$, and annuity of $£ 2000$, and surplus of Malt Duty, be apportioned by equal halves to Fisheries and Linen manufacture.

24. The Commissioners yearly to estimate, 1st, the funds which may for that year be at their disposal, and $2 d$, the amount which may for that year be necessary for carrying out the objects of the Trust.

25. Plan of distribution of funds to be for three successive years, and not for one year only.

26 to 36 . Commissioners to make necessary regulations; plan of distribution of premiums; how preferences for premiums are to be determined; and as to matters of detail.

37. Commissioners to render annual accounts.

38. Commissioners to submit plan of next year's distribution to His Majesty for approval.

39. Authorizes Commissioners to propose alterations.

40. When not a quorum of Trustees (by reason of death or resignation or otherwise), His Majesty to name 21 new Trustees by a new charter.

The others not given above relate to Fisheries, and to appointment and powers of Commissioners.

\section{Manner in which Funds were employed:-}

Premiums for lint seed sown at 15s per acre. Afterwards increased to 20 s per acre.

Premiums for best cloth manufactured.

Salaries of Stamp-masters and Inspectors.

Assistance to Bleachers in fitting up their Bleachfields.

Do. to Mill-scutchers for fitting up mills.

Awards for new discoveries or improvements.

Salaries to spinning school mistresses, and in some instances to weaving schools.

Salaries to foreign manufacturers for teaching best mode of weaving, preparing Flax, making reeds and looms.

Expenses of prosecutions for infraction of their regulations.

Distribution of Flax and Hemp seed to poor people.

Gifts of looms, wheels, reels, \&c., to poor people, to enable them to begin business.

Premiums for Flax seed saved, at 1s per peck. 
'Twisting mills furnished to women for commencing thread making.

Premiums paid for taking apprentices.

Extra fund for growth of Flax-granted in 1771. In premiums chiefly for the best and greatest quantities of Flax raised.

Regulations were contained in the Act of Parliament to be observed by the spinners, weavers, and stamp-masters from and after 1st November 1727, among which were- "Every weaver shall make all the Warp of every piece of Cloth of equal fineness, and the Weft of one Fineness, and proportionate to the Warp, and no piece of Cloth shall be made Coarser or Thinner in one place than another, and no Lint or Tow yarn shall be put in the same piece, upon pain of forfeiting their Security, and being disabled to be a Weaver until new Security be found by him." "Lappers may enter into Buck-houses, Bleach-yards, or other places, and Search the same for Lime, Pigeon's Dung, and Soap Dregs, and upon proof before one or more Justices of Peace, or 'Magistrat of Burrows,' that any of the above mateterials has been mixed or used with any Lees in Bleaching, the offender shall forfeit Five pounds sterling, and the cloth or yarn so Bleached to the Informer, and be rendered incapable to Bleach for two years following."

The distribution of the funds at the disposal of the Board for three years from Christmas 1727, is given in the "Popular Lectures," pages 234 and 235 . It is there shown that $£ 150$ was given for encouraging spinning schools. This sum was divided as follows:

To four Schools for introducing Spinning into the Highlands, or places where it is least understood, $£ 10$ per annum for each School,

To three Schools for teaching the dressing of Flax and Spinning thereof into fine yarn fit for thread or Cambrics, one at $£ 50$ and two at $£ 30$ per annum,

Conditions on which these four Schools are to be settled:-

1. Provides for mistress having a certificate of character from the Kirk Session, and of capacity to teach spinning from the Magistrates of the burgh or Justices of the Peace of the county in which she resides.

2. That in each school be taught at least fourteen scholars, aged from eight to fourteen years.

3. That they be taught six hours every lawful day, from 13 th Oct. yearly, to 15th April thereafter.

4. That the mistress shall furnish lint to such of the scholars as cannot provide themselves, and shall have the profit of their work. 
5. That when the scholars do furnish themselves with lint, or have it furnished on their account, the profit of the work shall be to the scholar.

6. That such scholars as do attend the said school for the three seasons contracted for, have their wheels which they have used for themselves.

7. That so soon as the mistress has provided a house and engaged scholars, the 14 wheels shall be delivered to her on receipt.:

\section{Extracts from the Minutes and Annual Reports of the Trustees.}

On 17th August, 1727, the Commissioners, among their first acts made the following proposals to Nicholas D'Assaville of St Quintin, cambric weaver:-

"To bring over ten experienced men, weavers of cambric, with their families, to settle in this country, and to teach their art to others."

Each master to be provided with a house, \&c., during life, and to be furnished with all materials for making up four looms for his own use, gratis. That each master shall be obliged to take an apprentice every five years, for five years, and to teach him his trade. That said N. D'Assaville shall bring over also a maker of brushes, cambs, \&c., to settle in this country.

1727.-David Donald invented a machine for beating and bruising Flax. Tried and approved of.

1728. - Proposal made by James Adair, Belfast, to introduce the Linen trade into Galloway, by bringing over his son and 20 weavers, and fitting up a bleachfield. Approved of.

Richard Holden, of Warrington, Ireland, writes Trustees as to his invention of a rolling press, and an engine for examining and measuring cloth.

Report complains that out of the 2000 acres expected to be sown with linseed, only 315 had been contracted for.

That they had offered premiums to those who should erect bleachfields, and that several parties having appeared to offer, they had agreed to devote $£ 2000$ among them in premiums, at the rate of $£ 50$ per acre so fitted up.

The Trustees finding that the art of preparing Flax for the heckle was little known in Scotland, sent over James Spalding, of Bonnington Mills, to inspect the mode practised on the Continent, who on his return invented a machine, by which the Trustees think Flax will in future be dressed better and more cheaply.

This year 7 spinning schools were set up.

The foreign reedmaker settles in the country.

1729. - Spinning school offered to Dundee, but refused, that town having no funds to devote to such a purpose. 
By several accounts it appeared that "the rollers made by D. Donald, as fitted up to go by water, did bruise the Flax exceedingly well, especially at Ceres in Fife."

Improvements made in machine for dressing Flax, and it was made to go by water, from which a considerable saving of expense was expected. On the report of a committee a premium was awarded Spalding for his lint machine set up at Bonnington Mills, as it did the work better than hand-beaters and scutchers.

Heckles were hitherto made "with short brass teeth, by a sort of strollers called tinkers." Some patterns with long steel teeth were this year brought from England and Holland, and an attempt was made in this country to imitate them.

'I'en Protestant cambric weavers, with their families, consisting in all of 33 persons, were this year brought from France, and maintained in Edinburgh at the public charge until proper houses and vaults could be got fitted up for them to carry on their trade. Next year they got houses at Broughton Loan.

Linen bleachfields were erected this year.

The 'I'rustees brought over from Ireland Richard Holden, skilled in several branches of the Linen manufacture (salary

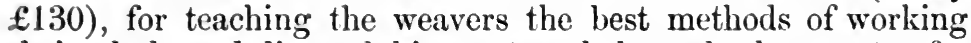
their cloth, and directed him to travel through the country for that end.

1730.-Two of the French women appointed to instruct the women in the spinning of fine yarn for cambric. A Dutchman brought over to instruct the weavers in the use of the Dutch loom.

Two processes for folding and lapping cloth brought from Holland and set up at Glasgow.

1731.-A deputation from Dunfermline wait on the Board, having inspected a new diaper loom fitted up by Richard Holden, at the Camerun, near Edinburgh, and find it very superior to those formerly in use. Board order it to be introduced at Dunfermline. The old loom required the use of a "draw boy" to assist the weaver in making the figure. By the new loom the weaver can make the figure himself.

A skilful Flax raiser from Flanders brought over to instruct in raising and dressing Flax, salary $\$ 254$ s. Some steps taken for introducing the manufacture of that kind of Linen used for shirting in the army.

1732. - Dean of Guild, Dundee, sends over to Board samples of coarse cloth, whitened with kelp by Richard Holden, being cheaper than other materials. 'Irustees propose to erect such bleaching fields at Dundee and Dunfermline. Holden fits up a bleachfield for this purpose at Pitkcrro, near Dundee. 
265 acres sown with linseed.

Dispute as to $2 \mathrm{~d}$ housewives' prize for cloth at Irving, settled by ordering it to be given to Mrs Semple, spouse of minister at Dreghorn, "whose piece on oath was adjudged to be the best."

1733.-More Flax dressers and hecklers brought over.

The Trustees state that the Linen manufacture was then in a flourishing condition, but they mention that great quantities of Linen yarn are daily bought up in Scotland and exported to Ireland and other parts, and that this practice has been growing for some years. They call His Majesty's attention to this, and say, "though it be beneficial at present, it may require to be put under some restraint by a law, as it raises the price of yarn, without which no cloth can be made." They add, "As the demand for yarn invites the poorer sort of people to spin, and is a means of propagating and rendering universal that branch of the trade, they thought the purchasing of it by foreigners may be winked at for some time, till, by the encouragement which the demand for yarn gives, the country be sufficiently stocked with spinners."

1734.-Considerable quantities of yarn began now to be exported to England.

The Trustees petition for an Act of Parliament, "exuming from duties the materials to be used in whitening at such bleachfields as should be licensed by the Trustees."

1737. - "The warping mill-a machine for warping webs, which was first brought over to this country a few years ago by the Dutch weavers, was this year considerably improved by an ingenious tradesman of this country."

"Our tradesmen did also this year acquire the perfect skill of the reed banks (brought over last year by the Dutch reedmaker), a very curious machine, without the help of which no proper weaving reed could be made."

1738. - 124 acres sown with linseed.

The Trustees caused patterns of the different sorts of coarse Linens made in the manufacturing countries of the Continent, and most in demand for low uses in the American Plantations, to be brought over here, and to be distributed over the country to be imitated by our weavers.

The Trustees this year give their countenance to some trials that were made for introducing into this country the manufacture of Tape and Inkle.

1739. - The Trustees observe that the coarse Linen manufacture improved but slowly in comparison with the fine.

1740.- The Trustees observing a taste for thread stockings prevailing in the country, applied for and obtained His Majesty's permission to offer encouragement for setting up stocking looms. 
The Trustees ordered several trials to be made for obtaining the skill of spinning that slack and gross kind of yarn that is fit for Osnaburgs and other coarse Linens used in the American Plantations, and directed sundry experiments to be made of making these kinds of goods from yarn spun in this country.

The manufacture of fine Linens began very much to prevail in Edinburgh.

'The coarse manufucture decreased this year, which was in a great measure owing to the vigour of the frost, which made it impossible for the weavers of coarse cloth, who are commonly but ill accommodated in houses, to carry on their work; and to the very great scarcity of provisions, which obliged many of them to leave their employments, and to enlist as soldiers in His Majesty's service.

1741.-A press set up by the Trustees for trimming and pressing thread stockings after the form of those in England.

1742. - The thread manufacture continued remarkably to improve and increase, which was attributed to a certain firmness or toughness in the Flax raised in this country which was not to be found in the foreign.

Some small quantities of Osnaburgs began now to be made, particularly at Dundee and Arbroath. An attempt again made in Parliament to take off the drawback on foreign Linens exported to the British Plantations, which failed of success.

1743.-A warping machine invented by Patrick M'Gillewie, merchant in Perth, by which one person can do as much as twenty formerly could by the old method.

The scheme of 1732 for promoting the cambric manufacture by erecting a warehouse, and impressing money into the warehouse keeper's hands for advancing to the toreigners part of the price of their cloth upon lodging it in the warehouse, to be replaced when the cloth was sold, having been found not to answer the purpose intended, was abandoned; and the balance of the money lying in the warehouse keeper's hands was lent to two yarn traders of this country, free of interest for six years, and to give them the $\mathfrak{1 1 0 0}$ per annum allowed to the warehouse keeper, on condition that they supplied the foreign weavers with yarn at prime cost, and made a considerable addition to the number of looms now employed in that trade.

1744 - The Trustces proposed to set up Lint Boors (as in Hol. land), whose business was to purchase the crop of Flax from the farmers, and prepare it for yarn themselves. This was carricd out in 1745 .

1745. - Report adverts to the Rebellion, as related in the "Popular Lecture,"

1746.-An ingenious method of throwing the shuttle in broad F 12 
looms invented this year by John Johnston, a Scotchman, for which he is awarded $\$ 50$.

1747. - Several improvements made in the different sorts of spiuning wheels.

A very remarkable change began now to be observable in the Linen manufacture. The fabric of the coarse cloth was much improved, and the quantity made greatly increased, which was attributed to the bounty lately granted on the exportation of coarse Linen; and to a great spirit for manufacture promoted over the country by means of the British Linen Company, which was erected last year by a charter from His Majesty.

1748. - The Trustees did this year. in consequence of the power given them by Law, alter the names of certain species of Linen manufactured in this country. Osnaburgs they called Edinburgs, cambrics were named Carolines, \&c. 936 acres sown with Flax seed.

1749. - 1094 acres sown with Flax seed.

1750.-Premiums for sowing seed discontinued, owing to want of funds.

1753. - This year an Act of Parliament was passed giving $£ 3000$ per for nine years (in addition to $£ 2000$ formerly granted), to the Trustees for improving manufactures in Scotland, to be applied by them for "the encouraging and improving the manufacture of Linen in the Highlands only. No part of said sum to be applied for any other use than for instructing and exciting the inhabitants of that part of Scotland to raise, prepare, and spin Flax and Hemp to be used in the manufacture of coarse Linens, and to weave yarn there spun into such Linen, and for providing the inhabitants with fit materials and utensils for these purposes, and for distributing rewards and prizes to the growers, preparers, spinners, weavers, and other manufacturers, in respect either to the quantity or excellence of the Flax or Hemp so raised or prepared, and of the yarn so spun, wove, or otherwise manufactured, and for such other like uses as the Commissioners shall think proper for promoting the true interest of this Act." This at the time was a judicious act, and calculated to wean the turbulent Highlanders from their predatory and warlike propensities, and to instil a spirit of industry among them instead.

1754.-By order of the Board; the General Surveyor of the Manufacture of the Highlands made a tour of inspection to Lochcarrron, Lochbroom, Glenmoriston, \&c., in August this year, with the view of establishing stations there for introducing the Linen inanufacture, so as to carry out the views of the Government in granting the $£ 3000$ per annum. He was accompanied by one of the managers of the British Linen Company. 
Their reports give a very curious account of the manners and mode of living in the Highlands at that time. As this is noticed in the "Popular Leeture," only a few circunstances not mentioned there will be given here. "The women generally spin what little wool is necessary for the use of the family on the distaff, in a very slow and imperfect manner. In summer they cut with a sickle what little grass grows round their houses, and it takes ten or twelve women a whole day to cut as much as a man would do in an hour or two with a scythe, which they are not at all acquainted with." "Men servants are engaged by the half-year, and are allowed for wages from 8 to 10 merks, with 3 pairs of shoes, each pair reckoned to be worth $1 \mathrm{~s}$. Women get 3 to 4 merks of wages per half-year, with an apron, \&c., to the value of 1 merk, and 2 pairs of shoes, valued at $8 \mathrm{~d}$ per pair." "The farmers' houses are much better than those of the poorer class. The side walls are made of stakes stuck into the ground, which are wattled with the branches of trees, outside of which is is wall of turf, with divots turned over it like slates. The roof is supported with coupled trees fixed in the ground. These are wattled with small wood, over which divots are laid, and then it is thatched with straw, stubble or ferns. The proprietor furnished the wood for the farm house; and, exclusive of the wood, the farmer reckons the cost of the house to be from $\mathfrak{£ 1}$ 10 s to $\& 310$ s, according to dimensions." "The fire in the houses of the lower rank is placed in the middle of the floor, around which they put trees or branches, behind which they lay heath for beds, where the family sleep promiscuously, few of them having any other covering than their body clothes. Nigh many of the villages is a little cornfield, not sufficient to maintain a fifth of the inhabitants. Few of them have any gardens, or know the use of roots and greens. On the sea coast in some places Irish beef, mutton, cheese, and butter, were plentiful, and the people fed well, but in others milk, and the blood of their cattle, supported them the whole summer. 'Their clothing seldom covered all their hodies, and it wis never changed till worn into rags."

1755.-The 'Trustees reported that the cambric manufacture established in Edinburgh by foreign weavers had not answered, the prohibition against the wear and importation of French cambric having greatly increased smuggling, and thron great quantities of French cambric into the comitry duty free.

1758. - The Trustees report that the malt duty had for several years yielded no surplus for the purposes of the Trust.

1761.-The Trustees complain that manufacturers are obliged to import great quantities of yaru from Hamburg, Flinders, and other places abroarl, the supply here nut being sufficient, and 
that this foreign yarn is in miny respects unsuited for the manufacture of Britain.

1762. - Complaints are made of violation of agreement between Great Britain and Ireland, of date 1718, whereby "All white and brown Linen cloth of the manufacture of Great Britain is to be imported into Ireland duty free, so long as it shall continue lawful to export from Ireland directly to the British Plantations all sorts of white and brown Linen cloth of the manufacture of Ireland."

"Account of surplus of malt duty, which have been received by us for promoting the Fisheries and Manufactures of Scotland-

From Midsummer 1726 to Midsummer 1733, being 7 years, $£ 19,168166$

From Midsummer 1733 to Midsummer 1751, being 18 years, $18,088102 \frac{1}{2}$

$£ 37,257 \quad 6 \cdot 8 \frac{1}{2}$

Since midsummer 1751 no surplus had been received." follows :-

"The account of funds received yearly at this time is as

1. The annuity of
Settled by Act of Purliament in discharge of

$\mathbf{2 0 0 0}$

the Equivalent due to Scotland by the Treaty of Union.

2. One year's Interest of $£ 40,000$, formerly applicalle to the said Improvements, lodged with the Royal Bank of Scotland

2000

$£ 4000$

And surplus of malt duty when any."

1763. - A new machine for swingling Flax invented, " of small expense and portable, that is wrought by the foot like a turning loom, is much safer for the Flax than the water mill, and subject to none of its inconveniences."

The woollen and cotton manufactures are gaining ground slowly, and the Trustees complain that many are deserting the Lineu trade for these others, "where, by the want of regulations, they have a greater opportunity to employ their ingenuity in fraudulent practices."

A weaving school at Coupar-Angus is mentioned.

A salary given to an agent in London for buying up insufficient cloth of Scotch manufacture, \&c.

1765. - A Linen Hall set up in Edinburgh, and four general markets are proposed to be held there annually. 
1766.-The appropriation made last session of Parliament of $£ 15,000$ per annum for promoting the growth of Elax and Hemp in Great Britain is noticed.

1768. - 'The prohibition of importation of foreign cambric, and additional duties on foreign lawn, have done injury to the home manufacture by increasing smuggling.

1772. - The Trustees propose to encourage the raising of Hemp, for the manufacture of Hempen Osnaburgs and shirtings, of which great quantities are yearly inported from abroad.

The Trustees purchase the west wing of the New Exchange, Edinburgh, for their offices, \&c., for the sum of $£ 1,33110 \mathrm{~s}$.

In 1772 there were 252 Lint mills in Scotland, distributed among the various countries as follows:-

\begin{tabular}{|c|c|c|c|c|c|c|}
\hline \multirow{2}{*}{$\begin{array}{l}\text { A berdeen, } \\
\text { Ayr, . }\end{array}$} & & \multirow{2}{*}{$\begin{array}{r}7 \\
\cdot \quad 22\end{array}$} & \multicolumn{3}{|c|}{ Brought Forward, } & \multirow{2}{*}{$\begin{array}{r}102 \\
\text {. } \quad 1\end{array}$} \\
\hline & & & Haddington, & & . & \\
\hline Bamff, & . & . 8 & Kincardine, & & . & - \\
\hline Caithness, & . & 1 & Kinrors, & $\cdot$ & . & . \\
\hline Dumfries, & - & 1 & Lanark, & . & . & 31 \\
\hline Dumbarton, & & 16 & Linlithgow, & . & $\cdot$ & - \\
\hline Edinburgh, & 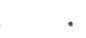 & 2 & Perth, . & . & . & 73 \\
\hline Elgin, & . & 3 & Renfrew, & • & $\cdot$ & . \\
\hline Fife, . & . & · $\quad 11$ & Ross, . & . & $\cdot$ & • \\
\hline Forfar, & - & 31 & Stirling, & - & $\cdot$ & 28 \\
\hline Carry for & rward, & . 102 & Total, & & $\cdot$ & \\
\hline
\end{tabular}

1773.-The Trustees notice the introduction of several new kinds of manufacture, such as the making of gauzes and thread at Paisley, and the making of several kinds of fine thread in imitation of what is made at Lisle in Flanders; and that the spinning of silk, cotton, and wool has been extended considerably.

1776. - Interest on $\$ 40,000$ in Royal Bank reduced to $4 \frac{1}{2}$ per cent. on 11th November 1776.

1779.-Paid William Alison \& Co., Dundee, towards expense of establishing an extensive manufacture of buckrams at Dundee, $£ 50$.

1782.-A Lancashire wheel for spinning cotton granted to Eleanor Tomlace, Strathmiglo.

1783.-Dyeing in Woad practised.

The making of thread, such as that made at Lisle, introduced into Renfrew.

John Mackie, Mormond Village, Aberdeenshire, petitions as to a machine he has invented "to spin double and twist Linen yarn" (a two-handed wheel.) Referred to Professor Copeland, A berdeen,-£10 a warded.

The convention of Royal Boroughs in Scotland had a considerable hand in establishing the Board of Trustees for manu- 
factures and the various Linen Acts in Scotland. The following are some entries connected therewith, extracted from the Book of the Convention, as reported in the Dunciee Advertiser, $3 \mathrm{~d}$ August 1821, which show that the Acts were solicited for, and obtained at the expense of the Convention:-

1727. - Commissioners' expense to London in soliciting acts for encouraging the Fisheries and Manufactures, and establishing the Board of Trustees for that purpose ; for expediting their patent,--in all .

$£ 825130$

1745. - Expense incurred in soliciting Parliament for increasing the bounty on exportation of Linen, . . . .

1748. - Expense incurred in prosecuting frauds committed in the importation of foreign Linen, and obtaining bounties on the exportation of British Linen, . . . . .

1756. -Expense of Commissioners at Londoh, in soliciting a renewal of the Linen bounty,-including "Solicitor's" bill, . .

1767 -Expense of soliciting an act for establishing a fund to promote the raising of Flax,

132102

$27318 \quad 6$

9621610

$516 \quad 0 \quad 2$

1783. - Expense of Commissioners' and Solicitors' bills, for their trouble in obtaining the Linen and cotton bounty act, .

$622 \quad 210$

1784.-Surplus from malt duty in $1780, £ 1,300$, being the first since 1751 .

The Trustees report that , preparations are making at present in different parts, for building five cotton water mills, with the proper machinery upon a very great scale."

$£ 50$ allowed Matthew Bar as a reward for introducing and establishing the manufacture of black silk Florentines; striped, spotted, and figured velvets for waiscoats ; silk and cotton mixture ginghams; silk and Linen stripes, dyed fustians, royal ribbs, and corduroys, which had formerly been peculiar to Spitalfields and Manchester.

The Trustees award $£ 22$ to John Squire, tenant of the Earl of Kinnoul, for a great improvement on the common two-handed wheel, and appoint the invention to be published in all the newspapers.

1785.- $£ 10$ 10s awarded to Alexander Cassills, one of the Board's itinerant Flax-dressers, for an invention of a wheel on a new construction, for spinning, doubling, and twisting either Linen, woollen, or silk yarn.

The Board authorises $£ 12$ to be given to Hugh Smith, Flaxdresser, to erect an oven for drying Flax, as an experiment, such an oven being generally used in Holland, as reported by A. Macdonald, Flax surveyor.

1787.-Premium of $£ 10 \mathrm{~J}$ awarded to Patrick Taylor, Edinburgh, for introducing into this country the figuring of Linen floorcloth for "carpeting. 
Petition from dames Ferguson, weaver, Aberdeen, asking reward for inventing method of working two webs at one time. Referred to Professor Copreland, Aberdeen, who reported that a man may by this loom weare ten yards per day instead of six, and that he believes the invention to be new. T'he Stamp-masters of Dundee, l'erth, and Glasgow, report that several looms of this construetion had been made there, but found not to answer so well as the single loom.

1788.-The report notices an act passed in twenty-seventh year of His Majesty's reign fixing the future annual fund for encouraging the growth of Flax and Hemp, which had formerly been fluctuating and dependant on the quantity of German Linen imported, at 22,956 13s $8 \mathrm{~d}$, being the average former produce of the fund. 'T'he 'Trustees resolve therefore to appropriate this sum by a triennial plan the same as the other fund.

Premium of $\mathfrak{f}^{2} 26$ awarded to Alexander Robb, at Tongland, for enabling him to make improvements on a weaving loom, intended to be wrought with water or any other mechanical power.

To Hugh Smith, at Cranworth, for experimenting on a new mode of watering Flax by means of boiled water,-£15. These experiments were next year found not to answer, "the whole oily substance beingr taken out of it."

1788.-Peport on a spinning-wheel, which fills the pirns without shifting the thread from tooth to tooth of the fly, invented at same time by Peter Duff, and Hutchinson and Drummond, both wheel-wrights in Auchtermuchty. Approved and ordered to be distributed in the county. Two dozen to be made for the Trustees themselves for this purpose.

An application for encouragement to some cotton manufacture in Inverness. The Board resolved that application be refused upon the ground that the cotton manufacture extends itself uniformly without public aid, and ought not to receive any so long as it continues to prosper as at present.

Gratis distribution of Flax seed to be discontinued.

1789. - The Trustees propose to sell the properties at Lochbroom, \&e., bought by them about 1754, "they having found that the plan has utterly failed, and the settlements been deserted." The 'Trustees remark that the manufacture of Linen decreases in those counties in which other manufactures have been introduced.

Premium of $£ 21$ awarded to Alexander Robb, Tongland, on the favourable report of Dr Hutton, Professor Robinson, Professor Playfair, and Mr Macvicear, manufacturer, for his invention of a loom to be driven by water or other mechanical power.

John Jocheal, weaver, Pollockshaws, awarded $£ 50$ for in- 
provement on common loom, the chief merit being to enable the weaver to place the threads of his woof or weft at equal distances, and at such distances as he pleased.

1790. - Trustees take notice in their report, of machinery now erected in different places to go by water for spinning Linen yarn, and of machinery for threshing corn.

On 16th February, letters were received from the Provosts of Glasgow, Dundee, and Dunfermline, to the effect that the Linen Hall in Edinburgh for the sale of Linens was not now deemed of consequence to the manufacturers. Board resolved to suppress it, the Hall not having been found to answer the purpose intended. Premiums, however, for cloth competed for still given.

On 17th November 1790, a petition from James Ivory \& Co., of Brigton, Kinnettles, setting forth that they had erected there one of the patent machines for spinning linen yarn to go by water, having purchased a license for that purpose from John Kindrew \& Co., of Darlington, the patentees, which with the expense of the machinery, and of a water mill, has cost them about $£ 1000$, was read to the Trustees. This subject is referred to in the "Popular Lectures," page 238. In the petition they state that "it is their intention upon this machine to try the spinning of heavy yarn fit for the Osnaburg manufacture, which hitherto had not been attempted," and as the succeeding in this experiment, and the success of this new mode of spinning, is highly interesting to the Linen manufacture of Scotland, they pray that the Board will patronise and encourage them in the foresaid undertaking.

1791.-On 19th January this year the Secretary acquainted the Board that samples of the coarse Linen yarn spun at the water mill at Brigton, and of the thread and cloth made from the yarn, have lately been sent to this office for inspection, and that the same had been accordingly inspected by four judges, whom the Secretary (by Mr Graham, of Fintray's desire), called for the purpose. The Secretary then presented the judges' report, in which they say that the yarn is well and regularly made, more so indeed than the generality of what is spun by hand, and that the cloth manufactured from the mill yarn is a good marketable article, and equal to anything of the kind they have seen; and the Secretary presented a certificate from a number of the principal manufacturers and dealers in Linen at Dundee, a letter from the Rev. Dr Small there, and one from Professor Playfair of the College of Edinburgh, all testifying the public spirit, and the probable utility that will result from the erection of this water mill, and the merit and ingenuity of Mr Ivory, the principal undertaker of the project, which being considered, the Board 
resolved by a majority, " as it would appear that this is the first undertaking of the kind which has been set on foot in Scotland, and that the undertakers have incurred a large expense in it, that they shall be allowed a premium of $£ 300$, payable in three moities of $\mathfrak{E} 100$ per annum, provided always it shall appear that the patent of the Darlington Company, hy whom the machinery was invented, does not extend to scotland, as to which the Secretary was directed to enquire and report."

On 26th January, Siecletary reported that he liad made inquiry at the Onice of Chancery, and that he finds that it loes extend to Scotland, whereupon it was resolved that "in consideration of the patent, they cannot confirm the premium proposed withont leviating fiom the constant and uniform practice of this Board."

The 'Trustees propose to purchase the vested rights of the foreign weavers in Picardy, these weavers having found it necessary to apply themselves to other trades, the cambric manufacture having failed them.

Awarded to Alexander Webster, damask and diaper weaver, on account of his having introluced and established that branch of manufacture at Dundee, $£ 20$.

1793. - William Allan instructed to do one pattern for the damask manufacture. This was done occasionally, he being bound to do two patterns every year, such as the Board may appoint, in ornamental manufactures or house work.

'Thomas Moncur, Yarn Inspector, Alyth, having been charged by $\mathrm{Mr}$ Nairn, of Drumkilbo, Mr Dalgairns, of Ingliston, Mr William Watson, Ochtertyre, Ec., of spreadiug seditious principles, especially of having drank at the Cross of Meigle, the toast of "Success to the French Liberty and Equality," ordered to return answers what he has to say for himself.

1794.-On 11th June, Alex. Aberdein \& Co., of Arbroath, petitioned the Board for aid to erect a mill house for holding machinery for spinning Linen yarn ly water, which they propose erecting on the Brothock, the machinery to be constructed upon original principles of their own.

1797. - Awarded to Henry Meldrum, waver, Dunfermline, for discovering an ingenious method of weaving Marseilled quilting with coloured sprigs, $£ 1010$ s.

1798. - Premium awarded to 'Thomas Arbuthnot \& Co. for encouraging a new establishment formed by them for carrying on the manufacture of sail cloth, \&c., at Peterhead. Wm. Ford, manufacturer, Montrose, applied for a reward for inventing a method of making sail cloth on a new plan-the warp being twisted and woven without any starch or tallow applied to it. On inspection, some manufacturers report that the method is new to them.

1799.-Patrick MLne. Edinhurgh, petitions for a reward for 
constructing a machine for calendering and glazing cotton, which performs the work in an excellent manner, and at one-third less than at Manchester. Messrs Gilchrist, haberdashers, Edinburgh, report that the machine is applicable to Linen as well as cotton, that it it the first machine of the kind which has been set up in Edinburgh, that he does their goods in all respects as well as they formerly had them done at Manchester, and upon more reasonable terms. Board grant premium of $£ 30$.

1800.-The Board refused application from Sir J. Sinclair for spinning schools at Caithness, in as much as spinning is now so generally known, and so easily acquired, as in their opinion to render spinning schools almost unnecessary.

1801.-Pemium of $£ 1010$ s allowed John Lamb, wheelwright, Dunkeld, for a decided improvement on the spinning-wheel. On 27 th November, 1805 , additional premium of $£ 10$ 10s allowed him.

1802.-To Andrew Steele, Alyth, a premium for his ingenuity and industry in weaving with a wooden arm and hand, £10 10s.

The Trustees report for many years an annual decrease of the quantities of Linen manufactured, thus- "The decrease is chiefly in the fabrics which are manufactured for exportation, and upon which a bounty is payable, without which bounty, as the Trustees have repeatedly thought it their duty to observe, it would be impossible for the Scottish manufacturers to contend with foreigners, while they are obliged to purchase from the latter a very large proportion of the raw material."

1803. - The Board approves of some very bad Linen, forfeited, being publicly burnt on the market-day at each of the towns of Forfar, Kirriemuir, Glammis, Dundee, and Brechin.

1804. - Thomas Parker, Edinburgh, petitions as inventor of a machine for recovering Flax out of the waste; allowed $£ 40$ to erect one as an experiment.

1806.-David Bonar, weaver, Dunfermline, took out a patent for improvements on the damask looms, and had sold the patent to the Operative Weaver Society there for $£ 350$.

In April, 1806, a quantity of faulty fereign Linseed was seized at Leith by an officer of the Board of Trustees, who brought an action before the Sheriff to have it forfeited, in terms of the Statute regulating the importation, and the Sheriff pronounced sentence of forfeiture. The owner appealed to the High Court of Justiciary, who affirmed the Sheriff's decision, and found the proprietor liable in expenses.

The premiums offered in January, 1807, by the Trustees for the best Ravens-duck, sheeting, diaper, huckaback, plain Linen, \&c., were from $£ 15$ to $£ 20$ each fabric for the best, and $£ 10$ to $£ 15$ for the second best in colour, fabric, and design, \&c. In December, same year, the names of the successful competitors 
were advertised;-five of them belonged to East Wemyss, three to Dunfermline, two to Edinburgh, and one to Culross, being eleven in all for Linen fabrics.

1807. - Cotton and coftee bagrging first mentioned. This year the Stamp-masters in Dundee were David Blair, Archibald Neilson, and John Alison.

'To William 'Taylor, Edinburgh, towards the expense of erecting machinery for preparing tow yarns for coarse Linen, called Duck (first mention of this), f2:5.

'The Trustees for Manufactures showed commendable care for the interests of the trade in the early years of the century. In consequence of complaints of false reel and false tale of Linen yarn, and putting up the yarn irregularly, intimation was given that the penalties enforced by law would be rigorously inflicted upon those infringing the law, and their officers were authorised to enter into shops. warehouses, \&c., to search for same. They also advertised that they would henceforth rigorously seize all faulty linseed, and aid in enforcing the penalties ordained by statute against selling old or bad-sowing seed. The seller was bound to deliver an account, subscribed by him, along with every parcel of linseed sold, specifying the quantity, price, port from which it came, year of its growth, and the country where grown. The Trustees recommended that none excepting Biga, Dutch, or Philadelphia seed should be sown, as none else was good.

In 1800 the Trustees had allowed importation of linseed for crushing for oil, on security being granted that it would be so used. In 1804 the liberty was removed, finding it injurious to sowing of lint. This appears from minute, 4th February, 1807.

1807.-Alexander Robertson, Pathhead, invented an improvement in heckles, the chief of which was attaching a spring to them, which makes them yield gently to the pull of the Flax-dresser, thus lessening the breakage of the Flax, and the consequent yield of tow-£25 premium allowed.

The Board of Trustees in April, 1809, intimated that the premiums for raising Flax and Flaxseed for crop 1807 were then payable. The premium on Flax was $9 \mathrm{~d}$ a stone, and on Flaxseed $9 \mathrm{~d}$ a peck, if it was certified by the surveyor to be fit for sowing.

4th July, 1810.-Joseph Crompton, of Manchester, presently residing in Dundee, asks premium for a sail-cloth loom, which he had invented to go by water or steam, and presenting a certificate from several manufacturers in farour of the loom; but $\mathrm{Mr}$ Blair reporting unfavourably-Petition refused. 
About 1813, and for a year or two thereafter, Lee's scutching machine engaged the attention of the Trustees.

2d June, 1813.-A Petition from millspinners in Fife to help them in getting bill to impose a duty on all foreign yarn imported was refused, "because the mills have hitherto been wholly employed in spinningyarn for the manufacture of Osnaburgs andother coarse cloth made in Forfarshire, while the greatest part of the manufactures in Fife and Perth are still dependant on handspinning at home, but chiefly what is spun in Ireland and Germany, which last is understood to be preferred to Irish by our manufacturers."

1813. - Reward of $£ 5210$ s given to Francis Blair, Linen manufacturer, Edinburgh, for invention of a sail cloth loom to go by water, the chief excellence of which is that it gives both an open and close stroke everything the shuttle passes through. Reported favourably of by Professor Playfair and others.

25th May, 1816. - Sunn Hemp or India Hemp for manufacturing into bagging first introduced into Dundee by $\mathbf{M r}$ Maberly, of London. Board resolve that the bagging shall be stamped "India Hemp," to distinguish it from Baltic Hemp, if the former be coloured to represent Baltic Hemp.

1816.- Several experiments having been made at Airdrie, by order of the Board, of Lee's machinery for scutching Flax without steeping - of the ordinary hand-scutcher and breaker from Yorkshire-and of the ordinary Flax mill; Reports decidedly in favour of the mill.

In 1817 instructions for growing Flax and for the culture and preparation of Hemp were published by the Trustees. For Hemp, 4 to 5 bushels the English acre were necessary for seed. It was said to be a most beautiful crop, and to leave the land clean. It grows more than six feet in eight weeks. In the morning the head of each plant is turned to the east to meet the rising sun, it follows it during the day, and in the evening it is found pointing to the west. In the night it collects a large quantity of dew, which falls to the ground, and keeps it in a moist state till the crop is pulled.

221 January, 1817.- - Reward of $£ 50$ given to George Dow, Panmure, for improvement in scutching-mill, chiefly because the farmers certify that he dresses their Flax so well.

Patent by Samuel Hill, of London, for new machinery for breaking, rubbing, and heckling Flax, whether watered or unwatered, brought before the Board, and recommended by Sir J. Sinclair ; ordered to be examined, and report.

No more applications. for twisting machines for thread manufacture made after this period.

'The manufacture of Forfarshire now very far exceeds that 
of any other county, consisting almost entirely of the coarse fabrics.

1818.-Of $31,283,1001$ yards stamped, 19,000,000 stamped in Forfarshire alone. Bounty still allowed on exportation of these.

Premium of es is, awarded to James Leitch, Galashiels, for improvement on two-handed spinning-wheel.

Last payment for spinning schools- to Miss Cunningham Ballantine for school at C'amphelton.

1819.-Premium of $\$ 30$ awarded to Henry Meldrum, weaver, and Robert M'Grewor, pattern-drawer, Dunfermline, for improvements in weaving diapur.

A trial of Hill's method of scutching Flax, made at Dundee, and statement drawn up by Messrs Brown, mill-spinners, in its favour -it producing more clean Flax than the mill. Board delay consideration till comparative expense, \&c., be ascertained.

Premium of $\mathfrak{f}^{2} 1$ allowed John Spence, Linlithgow, for great improvement in spinning-wheel, by which yarn is laid on piru evenly without stopping wheel to change from tooth to tooth

2d March, 1819. - The Trustees issued their annual Notice regarding the premiums on Flax and Hemp. In it they gave notice, that for the yoar 1819, they will distribute throughout Scotland, equally according to the Claims that shall be made,

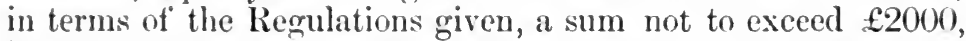
in premiums, on the Flax or Hemp raised, not exceeding one shilling per stone. The same to be clean scutched, and fit for the heckle. No claim to be admitted from any person sowing less than 16 pecks of seed, in ne farm, and one parish. Should the claims exceel $£ 2000$, the rate of preminms to be rednced in proportion. Persons sowing seed, with a view to the premium. to send intimation to the office in Eulinburgh before lst June, of the pecks and acres sown, farm, parish, and shire, each in separate lines, and to mention if it was solcly for his own behoof. A copartnery required 16 pecks for each person, and where the ground sown was not measured, 16 pecks was held equivalent to two acres. The same parties applying for the premiums had to send affidavit to the office betore the end of December 1820, in a prescribed form, specifying the acres and pecks sown, and the total produce in Flax or Hemp, farm, \&e. 'The crop might be sold while growing, but the buyer had to furnish the grower with the lint millers certificate of the produce. At the foot of each aftidavit the manager of the Flax mill was required to certify, from the book kept at the mill, the stones of clean produce, fit for the heckle, and free from tow. Growers were recommended to attend at the Flax mills while their Flax was heing scutched, and weigh ont equal quantities of rolled Flax to each worliman, so as to save waste in scutching, \&c. 
The premiums were paid shortly after the affidavits were given in, and notice of the time advertised in the Edinburgh newspapers and put on the parish church doors, and the parties getting premiums had to grant receipt in a prescribed form. The Notice also contained instructions about the quality of seed fit for sowing, and mode of buying it to prevent imposition on the part of the seller; directions for watering Flax; description of the best scutching mill, and other useful information.

1821.-Crop of Flax very much decreased, owing to the low price of the commodity.

In 1822 the King approves of $£ 15,000$ being expended on building an Institution at north end of Mound, Edinburgh. The total cost of building the Institution, as appears from the 'Trustees' Annual Report for 1828, was £20,424 0s 11d.

1823.-Flax seed sown for premiums-661 growers, 19,900 pecks of seed, on 2487 acres.

In 1824, 2861 $\frac{1}{2}$ acres were sown with Flax seed in Scotland; in $1825,1819 \frac{1}{2}$; in $1826,1350 \frac{1}{2}$; in $1827,865 \frac{1}{2}$; in 1828 , $811 \frac{3}{4}$; in 1829,778 .

26th May, 1825.-Weavers of Dunfermline in alarm at proposal by Mr Huskisson to take off the duties on the importation of foreign damask. The Board agree to request that these duties may not be taken off all at once, but gradually.

1827.-A Apropriation of funds at the disposal of the Trustees altered to such as may be specified in any Royal Warrant.

1829. — £1700 paid still for premiums to Flax growers.

The abolition, on 27th June, 1823, of the law for the Inspection and Stamping of Linen in Scotland, greatly abridged the duties of the Trustees, and their proceedings subsequently had little influence on the Linen 'Trade. It is therefore unnecessary to give farther extracts from their Minutes or Annual Reports.

By the Linen Laws those engaged in the Linen trade were relieved from all corporation fees. This in former times was a valuable privilege, as no Linen manufacturer was required to become a freeman in any town, or to join any Guildry or Trades' Incorporation; obligations which were very burdensome on merchants and other tradesmen. 


\section{T H E S T A M A C T.}

The Act of Parliament 13 George I, passed in 1727 , is frequently called "The Stamp Act." Some extracts from the annual reports and minutes of the Trustees of the Board of Linen Manufactures appointed by His Majesty in terms of, and as authorised by, that Act, have already been given, and the matters relating to the stamping of Linen might have been embodied with same; but as they refer to a distinct portion of the duties of the Trustees, some account of the working of the stamping laws, taken from the proceedings of the Trustees and other sources, are giren separately.

By this Act it was declared that no Linen cloth could be sold or exposed for sale till it had been inspected and stamped, under a penalty of $\mathfrak{f 5}$ on the seller and the same on the buyer. For the convenience of dealers in Linen, public officers were established in different districts under the authority of the Trustees whom His Majesty, by the same Act, was empowered to appoint for overseeing, directing, and improving the Linen manufacture in Scotland. These officers were called "Stamp-masters," and their duty was to superintend the measuring, inspecting, stamping, and lapping of all Linens manufactured for sale throughout the country. No Linens of any kind made for home use required to be stamped, as the law only extended to goods made for sale. The Trustees, in some instances, granted private seals, which authorised manufacturers to stamp their own cloth, according to the directions of the Act; but these seals were afterwards recalled by the Trustees, at the request of the stamp-masters, as they were found to be injurious to their pecuniary interests.

This Act contained some peculiar clauses, and it may be called the ground-work of the Linen Laws in Scotlanl. The preamble states the necessity of laws and regulations, on account of great frauds and abuses being daily committed, whereby the demand is lessened, and the credit of these manufactures distrusted. It imposed severe penalties on yaru irregularly reeled It 
regulated the width of the cloth, fixing the breadth at full $\frac{1}{2}$ yard, or full $\frac{5}{8}, \frac{3}{4}, \frac{7}{8}, \frac{4}{4}, 1 \frac{1}{4}$, or $1 \frac{1}{2}$; and if any part of any piece did not stand one or other of these widths, it was to be stamped as of the next narrower breadth. Each piece of broad, double, or single diaper, made for table cloths, had to be full two yards wide. All cloths to be whitened must contain at least $12 \frac{1}{2}$ yards. A weaver was required to run a coarse coloured thread through every 200 threads of the warp, to distinguish the number of hundreds of threads in the breadth of the cloth; and another coloured thread within a quarter of an inch of the former, through every 40 threads of the warp, to distinguish the number of beers or scores. By the statute no manufacturer was allowed to set up until he had given security that he would not weave any cloth contrary to these laws, failing which he would forfeit all the cloth woven by him. He was also obliged to take an oath, to be administered by the stamp-master every time he took cloth to the stamp-office, that all the goods were really the manufacture of Scotland or Ireland, and of no other place. The cloth was all to be measured by the "standard yard wand." The stamp-master or lapper might apply to a magistrate to forfeit the cloth if faulty, and, if so adjudged, it was cut into several pieces for the use of the lapper. The stamp-master was required to make good the value of the cloth to the party who bought it on the credit of the stamp, if faulty or wrong measured, and also pay $£ 5$ for each dereliction of duty, besides being dismissed. The stamper was required to stamp the cloth within twenty-four hours after being offered to him.

When the Act was passed actual measurement and inspection might have been frequently necessary. The Flax was home-grown and ill cleaned; the yarns, spun by the distaff or hand-wheel, variable in quality and weak; and the cloth "bleached on the gowan brae, and beetled in the burn." The manufacturer nearly corresponded to the weaver of the present day ; and, from his insignificance and the distance of his dwelling, little known to the purchaser of his cloth. These reasons did not warrant the imposition of such trammels and restrictions upon the trade, but at that early period fiscal regulations were common, and their injurious effect not fully understood. 
The fee for inspecting, measuring, stamping, and lapping Linen, was one penny sterling per 40 yards, not exceeding $10 \mathrm{~d}$ a yard, and '2d above that value, which fee went to the stampmaster. When required to beetle the cloth, double fees were authorised to be charged.

The different descriptions of Linens subject to stamping in 1727 were the following, viz. - White Linen, brown Linen, diaper and damask, striped Linen, checked Linen and Bengals, tykeus, checked handkerchiefs, muslin handkerchiefs, cambrics and lawns or Carolines, muslins or Glasgows, muslin cravats or Paisleys. In 1730 harns, straitzens, and tweels were added; and in 1731 calico, satinet, and cambric Holland.

Sail-cloth and vitries were exempted from the operation of the Stamp Act, but the Legislature required that manufacturers of these fabrics should make them of a defined description of yarn, and stamp his name on the cloth, under a severe penalty for non-performance. These restrictions were imposed by an Act coeval with the Stamp Act, and they were withdrawn by Par. liament in 1820. The bill for this purpose says, "Whereas an Act was made in the 9th year of the reign of Geo. II., entitled an Act for the further encouraging and regulating the manufacture of British sail-cloth, and for the more effectual securing the duties now payable on foreign sail-cloth imported into this kingdom; and whereas, in consequence of the great improvements, \&c., the Act should be repealed, be it enacted, \&c., that so much of the said Act as relates to the materials to be used in the manufacture of British sail-cloth, and the manner of manufacturing the same, shall be and is hereby repealed."

For a considerableperiod cotton bagging did not come within the operation of the Stamp Act, but great complaints were made by purchasers about the fraudulent manner in which it was frequently made up-a good sheet being put outside, while the great bulk of the piece was thin and of inferior yarn. By a decision of the Court of Session, given in the beginning of 1814 , cotton bagging was found to be subject to the fees of the stamp-master. The Trustees thereupon intimated that, in consequence of the decision of the High Court of Justiciary, cotton bayging should be inspected and stamped by the public stamp-master the same as other cloth, and that any pieces exposed to sale unstamped 
should be seized, and the vender fined. That makers might have time to dispose of their present stock, it was ordered that no seizure should be made before 1st June, 1814. The article thereafter continued to be stamped during the existence of the Act.

The Trustees, in their regulations to the stamp-masters, advised them to be careful in the discharge of their duties, as they were to look sharply after them, and to pay no regard to the common excuse of the first fault. Notwithstanding this standing regulation, in the course of time abuses crept into the system as practised by the stamp-masters, which gave rise to general and loud complaints. To obviate some of these wellfounded objections, respectable manufacturers were allowed to erect measuring reels in their own premises, and the stampmasters held their measurement of the goods as correct, and stamped them accordingly. This saved these manufacturers the trouble and expense of taking all their goods to the public stamp-office. Others commuted their fees for one-half, and in some cases for one-third of the price fixed by the Act.

The Glasgow merchants applied to the Board of Trustees to allow the national stamp to be cut from Linens exported to frreign countries, but they perempiorily refused their consent. These parties then applied to Government, who agreed to their request, and an Act was passed in 1814, 54 Geo. III., cap. 127, altering the law to the extent prayed for. After this change the national stamp was cut from nearly all the Linen exported, and the greater part of the pieces so cut off were sold for shoe lining.

About this period the mill-spinners made out an unanswerable case for being relieved from the odious seizure of their yarns under the antiquated statutes called the Linen Laws. It was shown that it was then impossible to reel every cut with precisely 120 threads, and that to seize yarn, as was frequently done, for having a thread too few or too many, was both vexatious and unjust. The Board of Trustees clung to their laws as if they were infallible, and not to be touched with mortal hands, and refused to permit any alteration. The spinners did not have the courage to go to Parliament with their case, or they might have been as successful in getting rid of such frivolous and useless restrictions as the Glasgow merchants were.

In 1820 a series of ably written letters appeared in the Dun- 
des Advertiser pointing out the abuses which then existed in the administration of the Act, and the injurious tendency which the law, however wrought, had upon the progress of the trade. It was shown that the stamp-masters regularly and systematically broke the law themselves in many ways: that, if it was to be enforced strictly, it would put a stop to the manufacture of Osnaburgs and sheetings, the then principal Linen fabries, as they were not of any of the widths authorised by the act: that other textile fabrics manufactured in Scotland were not subject to the operation of any such law, and yet they had prospered even more than the Linen trade: that the Linen manufactures of England were free from such restrictions, and yet they were in as flourishing a condition as those of Scotland: that even sail-cloth and vitries, branches of the Linen trade in Scotland, were exempt from the control of the stamp-master, but did not suffer in consequence: that the stamp was a stigma on the trade, as unnecessary as it was impolitic: and that, whether or not the Stamp Laws were founded on erroneous principles of legislation, they had outlived the period and the circumstances under which they were originally framed, and ought to be repealed. The charge for stamping, though small, was said to be as much on a piece as the expense of carrying it to London. It was a burden on a manufacture in which we have rivals that meet us almost on an equal footing, which was very different from one on an article in whieh we had an undoubted preeminence. It is a tax counteracted by a bounty, and the bounty " is exceptionable in the great scale of commercial policy."

The woollens of Yorkshire were at one time subject to sealing or stamping, much as Linens were in Scotland, but those made in the adjoining county of Lancashire were free from this law. In 1821 the subject was referred to a select committee of the House of Commons, who recommended the repeal of the Act; and, in bringing up the report, Mr Wortley, the chairman, said "competition was enough to keep every one honest." The Act was repealed and the manufacturers relieved from inquisitorial control.

The following extracts from the proceedings of the Board of Trustees have reference to the Stamping Laws, and are explanatory of the foregoing particulars on the subject:- 
On 13th July 1737, a web of Linen (insufficient) stamped by David Dalgleish, stamp-master, Dunfermline, having been discovered, he was dismissed, and the Magistrates of Edinburgh were desired " to cause burn publickly one part of the said web here, and the other part at Dunfermline."

20th November 1786.-The Linen and cotton printers of Glasgow petition the Trustees that the stamping of these fabrics be discontinued.

17th January 1787.-The Board determine that cloth made of Linen and cotton mixed, may be excluded from the operation of the law, but not cloth made wholly of Linen.

5th December 1787.-The Board agree, on the recommendation of the manufacturers of cambric in Glasgow, to discontinue stamping that kind of cloth.

8th July 1789.-Petition received from the Linen merchants of Dundee, complaining of the ignorance of the stamp-masters in Fife as to Osnaburgs, this manufacture having been lately introduced.

20th January, 1790.-A third stamp-master appointed to Dundee.

6th June 1792.-Board resolved that all sail-cloth shall be stamped, being specially influenced by a letter from William Sturrock, manufacturer of sail-cloth, A. Wilson, linen-dealer, and D. Blair, stamp-master, Dundee, setting forth the great necessity of sail-cloth being stamped to prevent frauds, especially in case " a manufacturer should mark his cloth with a No. it did not deserve, and a vessel is furnished with sails of such cloth, it may be the means of the vessel and cargo, and every person on board perishing."

11th July 1792.-Remonstrances against this resolution from the manufacturers in Dundee and Arbroath, "as it will not only put them to great inconvenience, but subject them to a kind of tax, from which the sail-makers in England are freed." The Board resolved to adhere.

22d May 1793.-Secretary reports that everything was ready for issuing orders as to stamping sail-cloth, but having heard that it would likely be very unpopular, and would be opposed at all places where the manufacture is carried on, he has thought right to ask the opinion of the Board. The Board is nonplussed, and defer consideration. On 11th December same year, Board finally determine that they have no power to enforce the stamping of sail-cloth, and cancel the resolution of 6th June, 1792.

28th May 1800.-Petition received from owners of water spinning-mills in Fifeshire, praying to have their mill spun yarn relieved from inspection by the Board's officers.

25th February 1801.-Various reports from manufacturing 
towns being read as to this, which were very contradictory, adjourned consideration of the petition sine die.

1805.-Reports that officers had seized a quantity of yarns, not reeled according to law, and that Sheriff of Fife had declared it forfeited. Appeal taken to Circuit Court at Perth, and sentence of Sheritt' confirmed.

1806. - 'The Proprietors of Kirkland Mill, Fife, refused admittance to the cupar Inspector to inspect their yarn, and officers accordingly instructed to insist on being admitted, and, if again refused, to prosecute for the penalty under 24 Geo. II., c. 24 .

Petition received from mill-spinners against present law, intimating that they intend applying to Parliament for alteration, and wishing Board's concurrence Wrote to them to print their Bill and send it for consideration. The purport of the Bill was -relieving spinners from control and inspection of the Board's officers, and giving the power of prosecuting for bad yarn to aggrieved purchaser only. 1)raft of the Bill sent.

In 1808.- Board resolve to resist change of law.

1811. - The opinions of various manufacturing towns in Forfar, Fife, and Perthshires, hostile to the change, public meetings being convened for the purpose at Dundee, Forfar, Kirriemuir, Brechin, Arbroath, Kirkcaldy, and Dunfermline; answer of the spinners thereto; and Mr Blair's own opinion on the subject before the Board. 'The whole matter having been taken into consideration, the Board find:-

1. That the proposed law, even though it were expedient that an alteration should be made, provides no sufficient check against fraud.

2. That the checks imposed by the present law are wholesome.

3. That there are spinning mills in Forfarshire where yarn is regularly made up according to law without inconvenience to the owners, and whose yarn has not been seized for years.

4. That the opinion of the great body of manufacturers in Forfar and Fifeshires is hostile to a change.

5. 'That these opinions have been freely expressed at public meetings called to consider the question.

1811.-Petition from John Melville, stamp-master, Dysart, to allow duck and sheeting, made in imitation of Russian, to pass unstamped, that they may pass for Russian. Petition refused.

1812.-David Lawson, of Dundee, appealed against seizure of bagging made of Hemp, because unstamped, and Sherift decided in his favour. 'Trustees appealed to Court of Justiciary, and Sherift"s sentence reversed. 
17th February 1813.-Memorial from certain Glasgow merchants against intended seizure of Linen cut up into short lengths and made up so as to resemble German and French Linen for exportation to South America, which used to be sent exclusively from Old Spain and Portugal. Of late years they were largely imported into Britain from Germany, and carried to these colonies by the Americans, but in consequence of the war with America, and other changes in our foreign relations, are likely to fall into the hands of British merchants The memorial represented that the people in the Spanish colonies in South America would not buy the Linen if stamped with Scotch or Irish stamps, which had to be cut off, so great was their prejudice in favour of French and German Linen. Board connive at this, being assured that the Linen had been originally stamped.

3d March.-Petition from Glasgow merchants asking the Board to recommend doing away with stamping Linen for exportation.

13th April. - The Board depone, on opinion of Mr Blair, that the Stamping Act is one of the wisest in the Statute Book, and give their reasons at length.

20th June. - Remonstrance from merchants and calender. ers, Glasgow, presented. The Board adhere to resolution of 13th April, but agree to dispense with oath of calenderers.

6th July 1814.-Bill introduced for doing away with Stamping Linen for exportation. The Board strongly disapprove and resolve to oppose. Bill passed 23d July, 1814.

December, 1817.-It appears that a recent act of Parliament authorises national stamp to be cut off Scotch Linen exportedand that manufacturers were in the habit of cutting stamp off, even before sending the Linen to London.

21st November 1820.-Mr Blair draws attention of Board to a motion made in the Convention of Royal Boroughs, to the effect that Linen stamping is useless, is a tax upon the manufacture, and ought to be abolished. Board resolve on a series of resolutions in defence of the practice, and the policy of its continuance, and send copies of these to the chief magistrate of each Royal Borough in Scotland.

19th December 1820.-Memorial from seventy merchants and manufacturers of Linen in Dundee, noticing resolutions in favour of the repeal of the Law for Stamping, passed at a public meeting of manufacturers, merchants, and flaxspinners, in Guild Hall of Dundee, on 30th November 1820, and urging that the meeting, though respectable, did not consist of more than sixty people-giving their opinion that the law was beneficial to the trade, and asking the Board to resist alterations. Ordered to lie on the table. 
1821. - Several resolutions received from Dundee for and acrainst the Stamp Act and the Stamp-masters; also from Custom-house at Greenock, urging that were stamping abolished, there would be great risk of framls as to the bounties, low-priced cloth leeing entered as of a higher value. 'The Board defend the stampmasters, and argne against any clange; and unanimously resolve to adhere to the present practice.

1822.- Report by their Secretary to the Linen Board in Ireland showing the good effect of public stamping. P'resented and laid on table.

25th March 1823.-Ietter from C'ommittee of Privy Council on 'Trade, mentioning that in consequence of representations from various manufacturers in scotland, their Lord:hips had under their consideration the several acts relative to the Linen manufacture; and their Lordships being of opinion that it may be alvisable to submit to Parliament, during the present session, a bill to repeal such parts of these acts as have reference to the measuring, lapping, and stamping such Linens, and affixing the name of the manufacturer to each piece, and requesting any remarks. Board send letter deprecating the repeal as "fraught with danger to all but a few capitalists of manufacturers, who are probably aiming at obtaining a monopoly of the Scotch Linen Trade."

5th May. - Secretary (in London) reports that Mr Huskisson had resolved to bring in a bill to repeal the laws for the stamping of Linen, or, as it is reported, to make it optional to the manutacturers to st:mp themselves, or have them stamped by public stamp-masters - that a Deputation of buyers from Dundee are in London, have printed their case, and are doing what they can to defeat the bill. Also presented a letter from J. B. Miller, on the part of the Deputies of the Dundee buyers, stating that in the interview which they had with Mr Huskisson, at which Mr C. (irant was also present, they found him fixed in his purpose of bringing in the bill, and that the facts and arguments which they brought into his view in support of the long established system of public stamping made no impression whatever on him.

20th May. - Secretary (in Isondon) reports that he and the Board's London solicitor, with one of Dundee Deputies, had waited on Mr Iluskisson, "that Mr H. could not be mored from his purpose," that the bill had been brought in and read a second time, and, from a copy which he had seen, it sweeps away the whole regulations of the Acts 13th Geo, I., and 2 th Geo. II. for the inspection of linseed, Linens, yarn, Linen cloth, and bleaching materials.

29th May--As to the optional clause, giving the manufac- 
turer power either to stamp himself or by stamp-master, $\mathrm{Mr}$ Blair's opinion read that it would be wholly nugatory or inefficient. Board pass series of resolutions deprecating the contemplated change, and foretelling the ruinous effects thereof.

8th July.- " The Secretary printed a copy of an Act of Parliament passed on 27th June, 1823, which puts an end to the inspection of lintseed, Linen yarn, bleaching materials, and the inspection and stamping of Linen by the officers appointed by the Board, and leaves it to manufacturers, sellers, and buyers, to act as they think proper."

"The Board directed the Secretary to transmit a circular to all the surveyors of lintseed, inspectors of yarn, stamp-masters, and general surveyor, informing them that they must immediately cease to act, and return their commissions, stamps, and types to this office."

The Trustees in their Annual Report for 1823 notice that the law requiring Linen to be stamped and inspected having been repealed, their duties ceased at midsummer 1823 .

For several years after the repeal of the Stamp Act, a system of inspection was in operation, but it was entirely voluntary, there being no law to enforce it. The inspectors, in most cases, were the same parties who had acted as stampers under the Act, and they were generally well qualified, from their knowledge and experience in examining Linens, for being inspectors. Manufacturers either took their cloth to the inspector, or, as was more generally the case, got the inspector to their own works to go over and examine the pieces; and if he was satisfied with the quality, the cloth was stamped with the name of the inspector, which was an evidence that it was of proper workmanship, and fair quality.

Such a system was liable to abuse, because, by collision between the manufacturer and inspector, inferior goods might have been stamped and sold for the genuine quality; but, in practice, this was rarely or ever done, as the inspectors were generally men of character, and they would have been personally responsible for any loss arising from such a dereliction of duty. The practice was continued for a number of years, but it ultimately died out. Merchants, by and bye, became better acquainted with the quality of the goods they were in the practice of buying, and were content to take them on their own judgment, without the intervention of inspectors.

The law requiring the stamping of Linen was no doubt founcted 
on apparent views of public utility, and probably in the infancy of the trade, when buyers, from want of experience, were ill able to judge of the quality of the cloth, it may have been of benefit to the trade. At the period of the passing of the Act, and for long afterwards, almost all manufacturers were simply weavers, who, with the assistance of the members of their family, or a few apprentices, produced a piece or two a week, which they took to the nearest market-town for sale. Such parties had less interest in keeping up the regular quality of their goods than the large producers of the present day, and probably on this ground the Act may have been at the time a judicious one. It is very doubtful, however, whether any advantage which could have been derived from it, even at the outset of the Linen manufacture, was sufficient to compensate for the inquisitorial annoyance, expense, and loss of time to which it subjected the manutacturer.

It could not have been expected that a person who had no connection with the trade, and whose emoluments depended on the quantity that he stamped, would be as scrupulous of affixing the seal of his approbation on the pieces as if his interest depended on the quality. In practice, especially after mill-spun yarns came into general use, the approbation of the stampmaster was not found to have much influence on the judgment of the merchant. If stamping was then requisite at all, the safest way for the public would have been to allow the manufacturer to stamp his own cloth, and his credit and interest was a guarantee that no improper goods would be sent into the market as genuine. 'This has virtually been the ease since the abolition of stamping, and the practice has been found to work well, and given satisfaction both to buyer and seller. The fewer trammels there are upon trade, and the less interference between the producer and purchaser of any article, the more will that trade prosper. "Let us alone unto ourselves" was the reply of an enlightened manufacturer to the great Sully, when he proposed to protect and encourage trade by a Royal edict; and trade and manufactures, let alone, have in all ages been found to prosper most.

The Act was beneficial in furnishing statistics regarding the extent and progress of the trade during its continuance, and the following tables, extracted from the proceedings of the Trustees, throw much light on the Linen Trade for a long series of years :- 


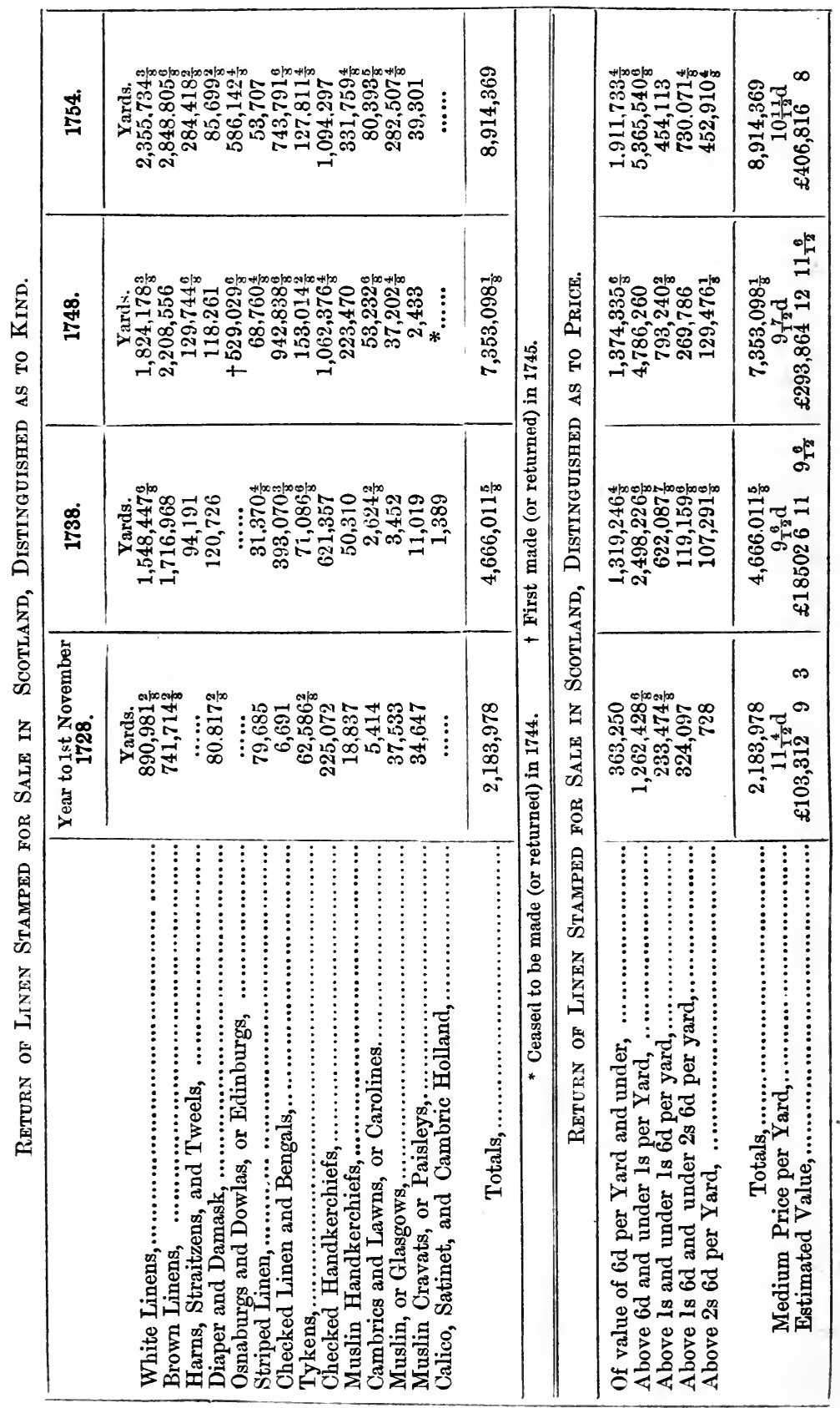




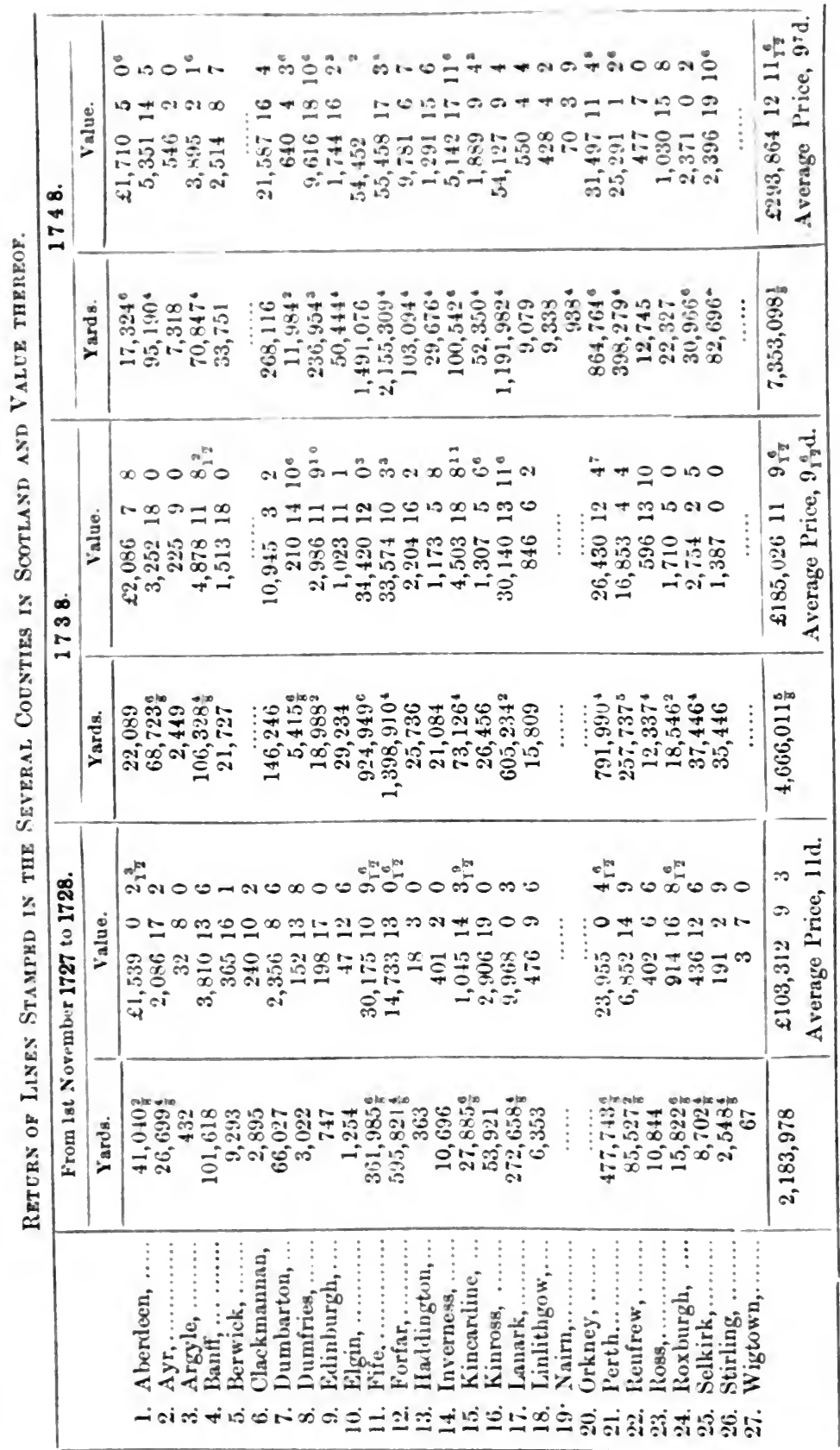




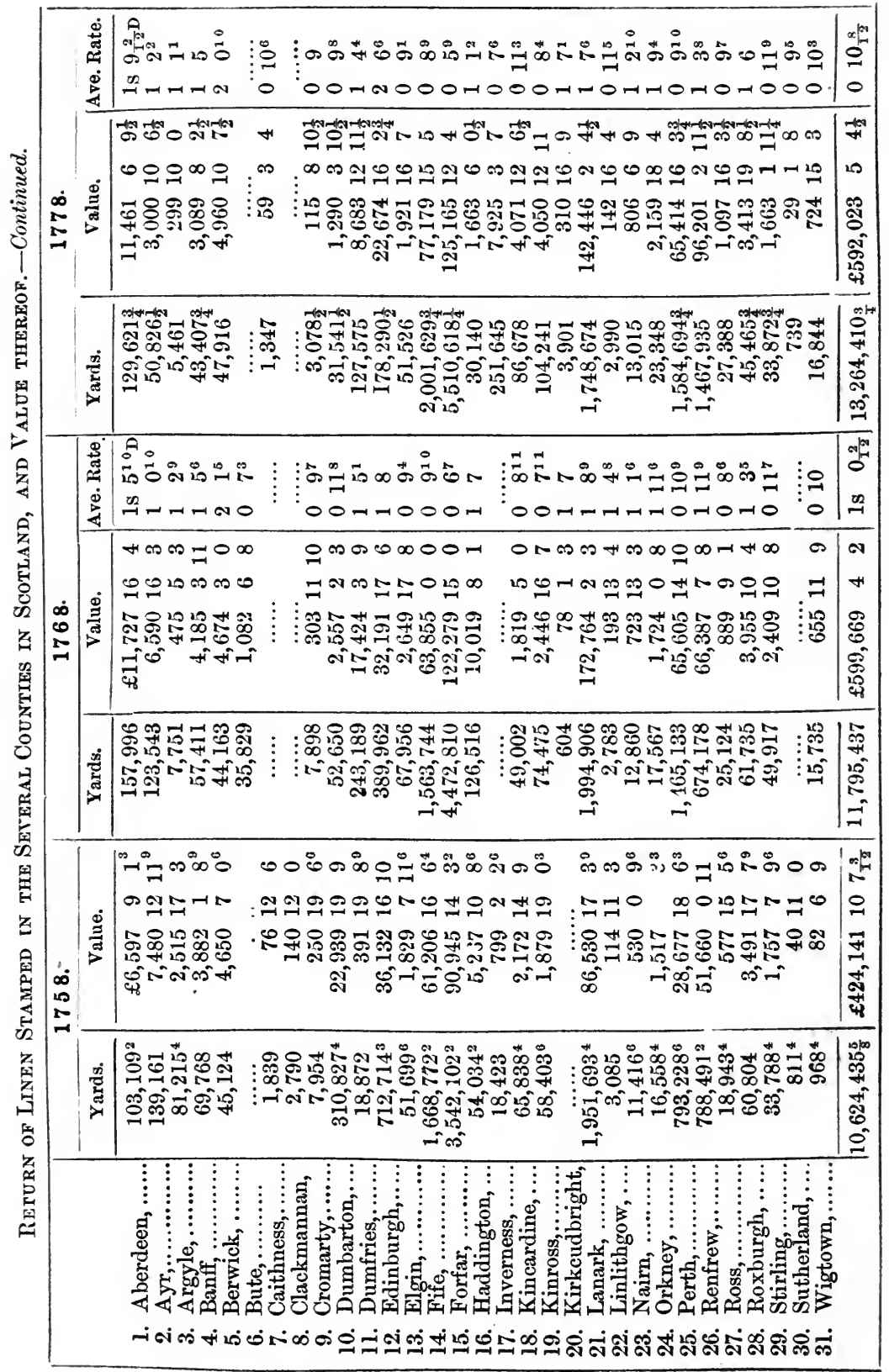




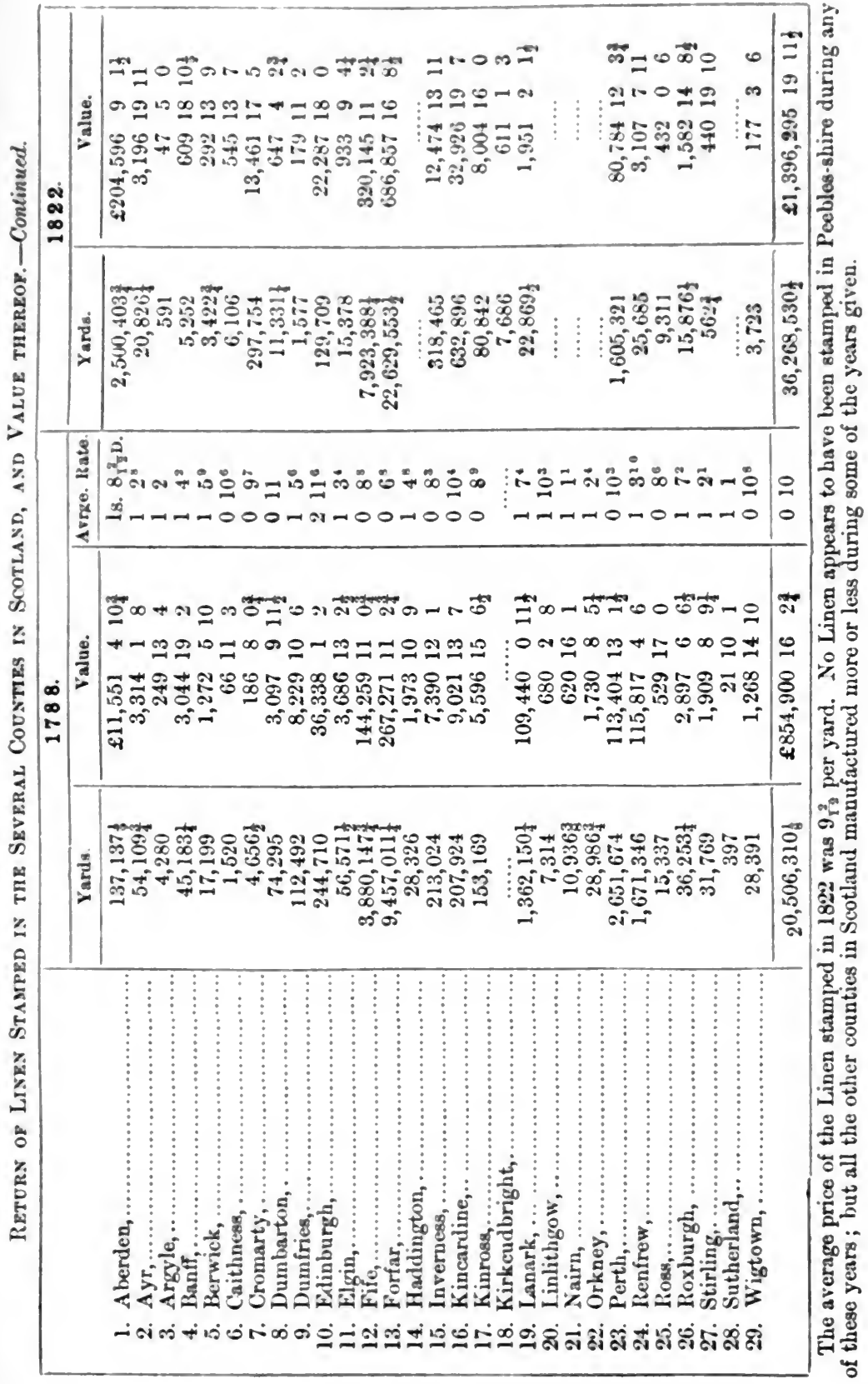


Quantity and Value of Linen Guods Stamped in Scotland.

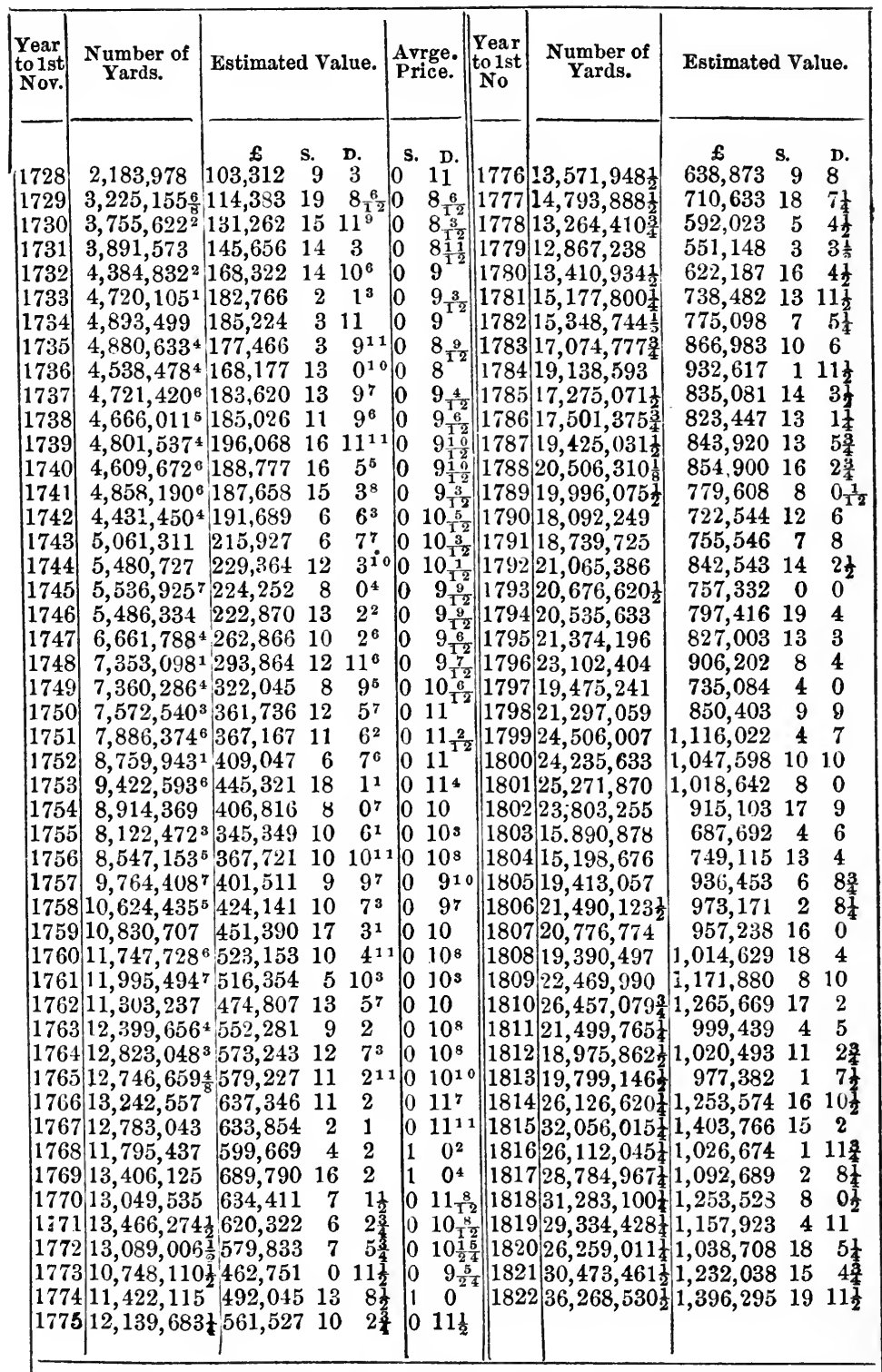

The Bounty Act was passed in 1742. Bounties ceased 6th April 1754. 


\section{KINI OF LINEN STAMPED.}

\section{2.}

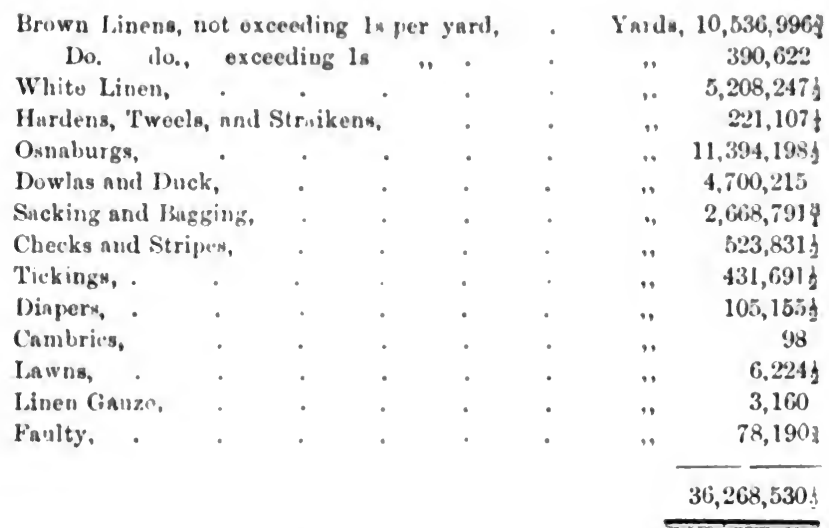

Until towards the end of the eighteenth century a large pro. portion of the Linen Trade of Scotland was of a domestic kind. In many parishes the Flax was raised, spun, weared, and bleached by the cottier farmer and his family. These processes were a source of pleasant and healthy employment to a large and industrious population, at seasons when other arocations did not require their attention. Flax was the rent-paying, luxury-providing crop; and as it was the only commodity which brought wealth into many parishes, it is well named "The golden crop."

In order to give a succinct view of the state of the trade. scattered as it then was throughout the rural districts of the country, an account of the processes practised in the various parishes where the manufacture was chiefly carried on will now be given. These details are taken from the "Statistical Accounts of the Parishes of Scotland," made up by the respective ministers (the phraseology used by them being generally retained), and a variety of other sources, and are interesting as pourtraying the manners and customs of a bygone age. In 
many of these parishes the manufacture died a natural death, consequent upon the changes which the spinning mill produced on the trade of the country, and it is unnecessary to follow in many cases the various phases which preceded its extinction, as the causes were generally the same in all. The spinning-mill, when fairly established, so cheapened spinning that the handwheel was driven from the contest. The young people, deprived of their usual employment, sought labour in the mills; and when these became concentrated in the manufacturing towns, the workers left the country districts; and became absorbed with the town population. Then the ancient manufacture waned and died, and in many districts where it had formerly been conducted with vigour, not a trace of it now remains.

In some of the country districts where spinning-mills were early erected, the rise, progress, and final extinction of the works have been briefly noticed, because their history is now little known, although highly interesting. At first the works were planted where water as a motive power could be rendered available, because the steam-engine was then rude in construction, uncertain in its operation, and costly to work. These country works were far from the market, and had many other disadvantages, some of them of a formidable character. As improvements in the steam-engine were discovered, the cost of spinning by steam-power decreased, and larger works were put up in the towns. The mills driven by water being limited in size by the available power of the stream, were generally of small extent. With the advance of steam they became less and less valuable; and many of them which at first rose like a rocket, and for a time flashed like a meteor, dazzling the country around, were at last burned out by an accidental fire, and only a heap of rubbish remains to mark the spot where once they stood. In several of the smaller towns and villages, chiefly in the counties of Fife and Forfar, the Linen manufacture, in some of its processes, is still a living one; and details regarding its present state in some of these are given.

For more easy reference the towns and parishes described are arranged alphabetically.

A short description of the former and present condition of the Iinen manufacture in a few of the larger towns in Fife and 
Forfar, shewing where the trade is still in active operation, will follow under the title "District 'Trade." These are also given in alphabetical order. 'Thereafter an account of the rise, progress, and present condition of the trade in Dundee, the great centre of the Linen manufacture of Scotland; together with various statistical tables in connection with the trade of the town and district, will conclude this portion of the work.

\section{RU R A L DISTRICTS.}

Abernethy.-In 1792 there were 82 male and female weavers in the parish, many of whom excelled in making all kinds of household Linen; but the greater number of them were employed in weaving Silesias for the Perth merchants. They got the webs warped and ready for the loom, and were paid so much a yard for weaving. The manufacture was then on the decline; but, some years before, the weavers were handsomely paid for their labour.

Abernyte.-About 1790 fully sixteen acres of Flax were annually grown, ten pecks being sown per acre, which produced a little over or under twenty-five stones of Flax. The seed of the Flax grown was generally saved and sold for about a shilling a peck to the oil mills, very little of it being fit for sowing again. 'There was then a Flax-mill in the parish, and the charge for scutching $1 \mathrm{~s} 6 \mathrm{~d}$ a stone. On the small stream which separates the parish from Longforgan there were, within the space of a mile, nine mills, of which four were for Flax-scutching. The manufacture of coarse Linens employed a considerable population before this period; but the number of weavers was then greatly reduced by the destruction of the cottrges which they had occupied. The kinds manufactured were coarse sheeting, and harn or pack-sheet. This stuff then sold for from $3 \frac{1}{2} d$ to $4 \frac{1}{2} d$ a vard, and an ordinary 
weaver was able to weave from 20 to 30 yards a day. The women not engaged in service were employed in spinning yarn for Linen and thread, for which they received from $1 \mathrm{~s} 2 \mathrm{~d}$ to 1s $3 \mathrm{~d}$ a spindle, and they span half a spindle a day. The statistical report of this parish says- "It appears from Boetius that Linen was very early a considerable manufacture of Dundee ; and it still continues the staple of this country."

Alyth.-Flax has been grown in this district from time immemorial ; and towards the end of last century, the quantity sown had increased, and the quality was generally good. Three, and often four stones, of $24 \mathrm{lbs}$ avoirdupois, was no uncommon return from the peck of seed; and there were then three lint mills in the parish, which were well employed. The chief articles made were yarn and brown Linen, of which a large quantity was spun and weaved in the town and district around, this manufacture having been established since the beginning of the 18th century. The quantity of Linensstamped from 1st Nov. 1787, to 1791 was, at an average, 258,639 yards yearly, and the medium value $£ 693910$ s $3 \mathrm{~d}$. This branch of the trade, although then much larger than in former years, was, it was thought, still capable of being much enlarged and improved, as it well deserved to be. Perhaps not half the yarn at this period spun in that part of the country was manufactured in it, although it might all have been weaved with advantage to all parties. The distance between Dundee and Alyth, where most of the cloth was sent, was compensated for by cheaper labour, and the intercourse was soon to be made more easy by the turnpike road between Meigle and Dundee, which was then nearly finished. At that time it was also in contemplation to erect a bridge over the Isla, and continue the road to Alyth, which, it was expected, would be of essential benefit to the district. The bridge was subsequently built and the road opened, which assisted to develop the resources of the country ; and although the growing and spinning of lint has long been discontinued, the weaving of Linen from mill-spun yarns has prospered and given employment to very many people. Twenty years ago the quantity of coarse Linen made exceeded 10,000 pieces a year; and the railway recently opened will still farther stimulate the exertions of the inhabitants, and add to the wealth of the town and dis- 
triet around. 'This year, 186, David Smith \& Son, extensive handloom manufictures, are erecting a power-loom weaving establishment, which will be driven by a steam-engine of 12 horse-power, and is intended to contain 100 looms. This will tend to give more regular employment to the labouring population, and thus be of great benefit to the town. The goods made in the district are now chiefly hessians, brown sheetings, and other coarse fubrics.

Anbirlot, - For several years prior to 1790 , the farmers in this parish paid considerable attention to the raising of Flax. and, as they received several premiums, it appears their labours had been crowned with success. That year 97 acres were sown with linsed in the parish, and procured the premium given by the Socicty for raising Flax in the country. The inhabitants were celebrated in a high degree for raising, watering, dressing, and spinning Flax ; but there were then no Linen manufactures in the parish.

Auchterarder. - Eighty years ago there were but one or two two-handed spinning wheels in use here, and the want of them was deplored, as they tended to increase the materials for the Linen manufacture, and better the condition of the workingclasses, especially the women, for which there was little employment in the parish. About the year 1770, a considerable manufacture of yarn and narrow Linen cloth was carried on, and it was bought, both in the brown and bleached state, by the Glasgow merchants; but the trade had declinel, and in 17.90 was almost extinct. Sale Linen continued to be manufactured in the town and neighbourhood, and also Linen of a fabric peculiar to the place, which went by its name. Near Auchterarler was the village of Borland Park, huilt by Government for the accommodation of the soldiers who were disbanded after the war in 1763 . They disliked the place, and soon left it; and in 1790 it was occupied by 140 people, mostly all of whom were weavers. Linen has now ceased to be manufactured in this parish.

Auchimauchty. - Abont 90 acres were annually appropriated for the growth of Flax in the parish, about 1790, and regret was expressed at the Board of Trustees having curtailed the bounty on it, as the crop was gencrally indifferent, 
and did not pay the farmer well. The chief manufacture was Linen, and the quantity made from 1st Nov. 1790 to 1791, as appears from the Stamp-master's books, was-

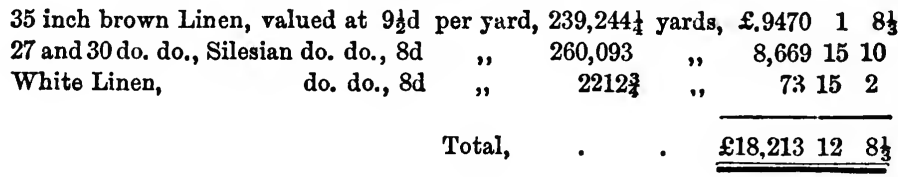

Great part of which was made in the town and neighbourhood. An ordinary journeyman weaver could work 9 spindles a week, but an expert hand could weave 17 spindles, at $1 \mathrm{~s}$ per spindle. About 1770 the ordinary price for weaving was $5 \frac{1}{2} \mathrm{~d}$ a spindle, and the rate had more than doubled within 20 years. About $\mathfrak{E 5 0 , 0 0 0}$ was annually expended by Linen merchants in the town in the end of last century. In 1817 a blight is said to have come over the manufacturing industry of the town, and the trade was thenceforward carried on chiefly by agents, instead of native manufacturers. In 1843 there were about 700 weavers in the parish, one-third of whom were females, who earned about $5 \mathrm{~s} 6 \mathrm{~d}$ a week. The Linen manufacture is still the staple of the town and parish, and in addition to weaving there is now a bleachfield belonging to Peter Skinner in active operation, which gives employment to about 30 hands, and is yearly increasing. The Linens now made include dowlas, sheetings of all widths, towelling, table-cloths, \&c., \&c.

Avoch.-In the end of last century a considerable quantity of Flax was raised by the tenants, which was spun and woven by themselves into Osnaburgs and other Linens. This brought in yearly from $£ 300$ to $£ 500$, and no foreign material was required excepting a few barrels of Dutch linseed. As much hemp was sown by the farmers as was sufficient to make sails and cordage to the fishing-boats.

BANFF.-The thread and Linen manufacture was carried on to a great extent in the parish from 1780 to 1790 . For the thread manufacture about 3500 mats of Dutch flax was imported annually, which, at an average price of $£ 35 \mathrm{~s}$, cost upwards of $£ 11,000$ sterling, and gave employment to about 60 men in heckling and other operations. The spinning 
employed about 4000 persons in the district, and the Flax yielded about 150,000 spindles of yarn, circulating about $£ 10,000$ yearly among the spinners. 'The doubling and twisting the yarn, which was done in Banff, employed about 200 women and children, and the bleaching about 40 more. The thread was sent to Nottingham and Leicester, and was valued at alout $£ 30,000$. Ultimately the trade gave place to the stocking manufacture, which was long carried on successfully, and the Linen manufacture at last became extinct in the district.

Barky. - "In the parish," says the Statistical Report, " almost every householder was a manufacturer, as weavers were then generally called, there being about a hundred of them in 1790. Exclusive of considerable quantities of home-yrown Flax, the manufacturers used yearly of foreign Flax from Riga and st Petersburg several tons, amounting in value to more

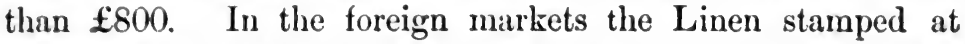
Aberbrothock had acquired a high reputation; and it could not be denied that, to the cloth made at Barry, which had long been distinguished for the goodness of its material, and the superiority of its workmanship, the stamp of that town was indebted for part of its fame. By introducing honour as a prompter to excellence, the manufacture of Barry had reached its then state of perfection. For more than 40 years the inspection of the weaving had, by the unanimous consent of the manufacturers, been assigned to an annual officer, who was allowed to choose two assistant councillors. 'The officer, with his assessors, were eagle-eyed to discover every blemish, and a pecuniary fine, or, what was more dreaded, the correction of ridicule, overtook every one who was in fault. 'These cireumstances had contributed to fix such habits of attention and accuracy, that some workmen had not had a piece cast at the Stamp Office for 20 years. The condition of the manufacturers might have been ameliorated by insuring to them at all times abundance of Flax at a reasonable rate, by continuing the encouragement to the Linen trade, and by rescuing them from a twofold combination of Flax and brown Linen merchants, by which they enhanced at pleasure the price of the foreign Flax they sold, and depressed the price of the cloth which they 
bought." It is doubtful if the people of Arbroath believed that so much of the fame of their town for Linen was owing to the superior manufactures of Barry, although there is no doubt that Barry Linens were really good. The condition of the manufacturers of the present day would be very much improved by having at all times abundance of material at a reasonable price; but this never has been, and it is to be feared never can be, guaranteed to any trade.

Since the period referred to Barry has risen into considerable importance for its manufactures. The village of Carnoustie, situated in the parish, which, at the beginning of the century was quite an insignificant place, is now a very thriving and populous village, and almost deserving to be classed among the towns of the county. It has long been celebrated for its manufacture of bleached sheetings, and similar goods, large quantities of which were produced by its weavers, who still rank high among those of their class in the county. In 1857 "Panmure Works" was erected there by the enterprising and respectable firm of James Smieton \& Son, merchants in Dundee, which is a perfect model of a power-loom work, not only for its handsome external appearance, but also for the excellent arrangement of its machinery within, and which is specially referred to in the chapter on Linen Weaving. The work is intended to contain, when finished, from 400 to 500 looms, with all the necessary preparing and finishing machinery, and to be driven by two engines of 25 horse-power each, with a third of 10 horse-power for driving the calendering machinery, \&c. At the present time, one of the large engines, and the small one, are going, and the number of looms now at work are 216 . The firm have also upwards of 100 handlooms, and they employ in all 400 hands, to whom they pay about $£ 8000$ in wages annually. The class of goods chiefly made are various qualities of ducks, paddings, sheetings and dowlas, and the firm have acquired high celebrity for the new class of mixed fabrics, cheap yet sightly, which they produce. Including goods purchased by them, there are about 3000 bales, containing $5,000,000$ yards, finished, packed, and sent off from the Works yearly; and the quantity is increasing rapidly. Messrs Smieton have erected a number of exccllent houses for the accommodation of their 
employees, to whose comfort every attention is paid. They are about to put up a handsome bnilding of two storeys for a literary Institute, to contuin reading room, elass-room, an industrial school for females, hall for lectures, \&c. This will be a great boon to the people employed, and the liberality and kindly spirit displayed by the firm is well worthy of imitation.

Benvik.-In the year 1750 a sail-cloth manufactory was established in Inverlervie hy a company of Montrose merchants, and long carried on with great success; but after an existence of about forty years, it wasentirely given up. After this the weavers bought flax, span, weaved, and bleached it, each for his own account. 'The quantity of Linen so male was not large; but the quality was so superior, that at country fairs, where much of it was sold, it brought a penny a yard more than cloth of a similar kind bleached at the regular bleachificlds. About 1785 the bleaching of cloth was a considerable trade there; but after that period it gradually declined About 1775 a thread manufactory was established in Bervie, and was long carried on successfully. Fully 50 people were employed in the trade, and the thread long found a ready sale in the London market. In 1787 a building was erected by Walter Sim and Walter 'Thom, under the firm of Sim and Thom, on the haughs of Bervie, for spinning Linen yarn; and it is almost certain that it was the first Flaxspinning mill in Seotland. This firm was granted a license, by Kendrew and Porthouse of Darlington, to put up machinery for spinning flax, on the principle for which they had that year taken out a patent. The machinery was procured from England, through the patentees, and they personally advised regarding the erection. 'The mill has now been at work for 77 years, and it is still in active operation. Its extent at first was eight frames or sides of 24 spindles each, in all, 192 spindles for spinning Flax yarn. 'Three years after its erection the mill had not been all filled with machinery; but when full, it would eontain from 600 to 700 spindles, and employ 20 to 30 men and women, and 60 boys and girls. The mill was originally driven by water-power, but a steam-engine was added many years ago to give additional power and a steadier motion. Now it contains 808 spindles, for spinning from three to four pound tow-yarn, the original machinery having been all dis- 
placed long ago. James G. Gibb, the present proprietor, in reply to an enquiry on the subject, says - "At what precise period the spinning actually commenced I cannot say, but it was in the same year, 1787 ; Linen thread being what the firm manufactured." In corroboration of this the following circumstances may be mentioned:- In "Leigh's Road-book of Scotland" it is stated that the town of Bervie presents two things to the notice of travellers-a small harbour for fishing-boats, and a machine for spinning Linen yarn, said to be the first of its kind in Scotland." No date is given. In the "Statistical Account of Scotland," under the title "Parish of Bervie," written by Walter Thom in 1790 or 1791, it is stated - "Three years ago, a machine was erected on the Haughs of Bervie for spinning Linen yarn, being the first of the kind in Scotland." On taking down part of the machinery for improvement, many years ago, it is stated in the " Reminiscences of Flaxspinning," "there was found within a driving-drum an inscription of date 1787, written by one of the mechanics who first fitted up the machinery, stating the work to have been erected that year; also some lines as to the nature of it and the offence given the handspinners of Bervie, whose living was endangered thereby, and whose rage consequently was bitter against all concerned in the erection." James Ivory and Co. of Douglastown, in their petition to the Board of Trustees, say they were to try the spinning of heavy yarn, fit for the Osnaburg manufacture, which hitherto has not been attempted. Sim \& Thom spen yarn for their thread manufacture. The assertion of Messrs Ivory is therefore correct, although they may not have been the first to spin by machinery in Scotland. Bervie may therefore well claim the priority of spinning Flax by machinery in Scotland. Although exceedingly imperfect at first, within a year or two considerable improvements were effected upon the machinery, and the yarn then spun was of good quality, and fit for any sort of manufacture. There are now other four spinning-mills in Bervie, containing 1024 spindles, all of which are adapted for spinning small sizes of tow-yarn. A sail-cloth manufactory was at one time erected in the town, where about 100 weavers were employed in Linen weaving; but bleachfield and sail-cloth factory have long since disappeared, and weaving 
is all but extinct. Little sign of manufacturing industry is now visible in the town, excepting the ancient spinning mill of Bervie, and the progeny which have risen up around the parent work.

Bexdocuy.-'I'owards the end of last century, about 43 acres of Flax was grown here. The linseed was sown about the end of April, after a slight shower, or when the ground was wet, about 10 pecks being allowed the acre. The Flax was pulled about the end of August, and yielded from 18 to 20 stones an acre. The Flax was steeped for five or six days in water, then laid on the grass for two or three weeks, and very little linseed was saved.

Benhocm. - At Johnshaven in this parish, a manufactory of sail-cloth was established about 1790 , by a company belonging to Dundee, and a few years thereafter they gave employment to about 50 men, besides a number of women. At that time there were 5 Flax-dressers, and 63 weavers in the parish. In 1836 about 230 people were employed in the Linen manufacture in the parish, and the trade is still carried on successfully, and by Dundee parties, although not so extensively as it once was.

Brisay and Harray.-From 1780 to 1800 the women span a great deal of lint, which was grown in Orkney, excepting an occasional bag of foreign which they bought, and for which they paid a guinea. Besides making a good many pieces of Linen, both of fine and coarse quality, for themselves, a considerable quantity was weaved for sale, generally through an $8^{\circ 0}$ reed. It was sold in Newcastle, Edinburgh, and other places, and brought $11 \mathrm{~d}$ a yard.

Blatr Atholt.-Among the principal crops in the parishes of Blair Athole and Strowan in 1792, Flax is mentioned, and one of the chicf exports was Linen yam. It was spun from homegrown lint, and almost every person had a share in the business. There was then little ready money in the parish, and what little there was, was the produce of the Linen yarn, which went to pay the rents.

CaIrie. - About 1790 the rents in the parish were chiefly paid by the women spinning Linen yarn. A piece of land was regularly allotted for sowing with Flax seed, which always turned out to good account. The proprietors were recommended to encourage that branch of trade, as it would increase the riches and 
prosperity of the country. In Fowlis-Wester the weavers, besides household Linen, made scrims, a thin narrow Linen, for the Glasgow market. This manufacture ceased all at once on the commencement of the war in January, 1793, and as suddenly revived in June, 1794, on the capture of the French West India Islands, and the speculation which was thereby encouraged among the Glasgow traders.

Cambuslang.-The weaving of Hollands or fine Linen made from lint grown in the parish was begun about 1730, and it then gave employment to a few looms. About 1783 the art of weaving received a considerable improvement by the introduction of the fly or picker shuttle, which was then for the first time applied to the fabrication of Linen in the parish. Eight or ten years thereafter the weaving of lawns and cambric took the place of Hollands, the yarn being furnished by the merchants of Glasgow, who took back the cloth.

CAPUTH.-Flax was early grown, to some extent, in the parish, and the manufacture of Linen was the chief occupation of the people. In 1792 there were 10 flaxdressers and 130 weavers amongst the male population of the parish. In the year from 1st November, 1775 to 1776 , the quantity of Linen stamped by the stamp-master was 79,264 yards, value $£ 3,26515 \mathrm{~s} .7 \frac{1}{2} \mathrm{~d}$; in the year ending 1st November, 1785, it was 107,653 yards, value $£ 4,8310$ s $1 \frac{3}{4} \mathrm{~d}$; and in the year ending 1 st November, 1792 , it was 104,451 yards, value $£ 4,610$ 1s $8 \mathrm{~d}$. In the seventeen years from 1st November, 1775 , to 1 st November, 1792, the total quantity stamped was $1,680,938$ yards, valued at $\mathfrak{£ 6 9 , 5 5 5}$ $13 \mathrm{~s} 2 \frac{3}{4} \mathrm{~d}$. It consisted partly of bleached, but chiefly of brown Linen, the latter consisting of scrims and Silesias. About half the quantity stamped was made in the parish, but there was manufactured in it, in addition, about 12,000 yards for household use ; and about 20,000 yards, manufactured in the parish, were stamped at Dunkeld and Blairgowrie. The Board of Trustees, by bestowing well-judged rewards, and giving other encourage-, ments, had contributed much to the success of the trade in the parish. In the Statistical Report of the parish, written in 1839, it is said, "Happily for the peace and purity of our quiet rural population, no spinning mills have yet been erected, neither is any great public work going on at present in this parish." 
Ceres. - The soil is excellently calculated for Flax, and a good deal was cultivated about 1790 , the annual produce having been about 1500 stones. I'he Linen trade was then, as now, the principal one, and there were 7 flaxdressers and 138 weavers engaged in it. A spiming mill was erected at 'Tarvit in 1799 , and two at Pitscottie in 1827. In 1825 a bleachfield was established at Ceres, previous to the erection of which brown Silesias was the fabric chiefly made; but afterwards dowlas and sheeting were weaved, from 700 to 900 being engaged in the manufacture in 1839, the value of the goods made being from $£ 50,000$ to $£ 60,000$ yearly. The Stat istical Report says: "To any one who reads this statement of the manufacture, it will be evident that the works are most profitably arranged. 'The mills supply the bleachfield, and it the weavers; and while there is thus a saving of carriage, there is also an encouragement to the manufacture of the place. There is every likelihood that the manufactures of this flourishing place will, in a few years, become more extended, as there are some proposals of erecting another mill on a very extensive plan." How different these liberal sentiments from those expressed by the Minister of Caputh at same period. The Linen trade is still in a flourishing condition in the parish, spinning at Pitscottic and Tarvit Mills, bleaching by W. W. Yool, St Ann's, and weaving being carried on extensively and successfully. Upwards of $£ 1000$ is paid annually in wages by James Annan, Pitscottie Mill, alone.

Cuusy.-About eighty years agn Flaxspinning was the chief employment, but the people did not like it, as it required more confinement and exertion than knitting stockings, which they did for the manufacturers of Aberdeen. The dress of the common class was then cloth made from their own sheeps' wool, Dundee bonnets, and shoes of leather tanned by themselves. About that time an heritor of the district joined himself to the Camisars, a sect of enthusiasts from France, who were so called from the French word chemise, they being clothed in Linen garments as an emblem of purity.

Cosrie.-The staple manufacture, near the end of last century, was Linen yarn, of which a great quantity was spun and sold yearly, and with the money thus got, most of the furmers paid great part of their rents. The Flax yarn sold for $2 \mathrm{~s} 4 \mathrm{~d}$ 
a spindle, and from the tow of the lint was spun harn yarn, which, when made into cloth, brought from $9 \mathrm{~d}$ to $1 \mathrm{~s}$ a yard. The finer sorts of this harn were used by the men and women for shirts, and the coarser for sailors' jackets and trowsers.

Coupar-ANGus.-For more than one hundred years the manufacture of Linen has been carried on in this town and parish, and Coupar harn has been long a well-known article in the trade. In 1792 the quantity made within the bounds of the parish, and stamped at the stamp-office in town was 97,810 yards of brown Linen, weaved in about a 600 reed, and 116,793 yards of harn. These goods were sent to the English market. The harn was worth about $5 \mathrm{~d}$ a yard, and was used for packsheet; and the Linen, when bleached, was used for buckram and hat linings, and was of the average value of $9 \mathrm{~d}$ a yard. There was then a bleachfield at Balgersho, within the parish, which bleached about 200,000 yards annually, but in 1793 the quantity had decreased to 90,000 yards. In the neighbouring parish of Kettins there were at that period three bleachfields, two of which put through 100,000 yards each annually, and the other 30,000 yards. At that time there were 101 weavers, and 11 flax-dressers in Coupar, and in the parish of Kettins 100 looms and 3 flaxdressers. Flax was then cultivated to a considerable extent in both parishes, and in favourable seasons it succeeded well-the lippie of seed frequently giving a stone of dressed Flax. Bleaching has long been discontinued in both parishes, but in Cupar Linens are still manufactured to a large extent-one manufacturer, John Robertson, employing about 300 hand-loom weavers, about three-fourths of whom are females, on hessians, sackings; sheetings, drills, \&c. As in most country districts weaving is only an auxiliary employment, out-door labour in summer and household duties taking up much of the time, the number of hands is therefore no just criterion of the work done ; and this is pre-eminently the case with weavers in and around Coupar-Angus. A powerloom work on a small scale is now in course of erection there, which, when in operation, will help to give more vitality to the town.

CrAIL. - Towards the end of last century, the women were generally employed in spinning lint yarn for the manufacturers 
in other places, and they span to the extent of many thousands of spindles every year. Nearly 40,000 yards of sheetings, Usnaburgs, and coarse brown Linen were made by the weavers for sale, besides what was manufactured for private use.

Crifrs. - In the town and parish the manufacture of Linen was early carried on, and packsheet, sacking, and other coarse fabrics were chiefly made. In 1785 a bleachfield, with suitable machinery, was erected, and shortly after that time the manufacture of a thin lind of coarse Linen, called Silesia (vulgarly scrims), was commenced. They were male from 27 to 30 inches broad, were laid 92 yards longr, and measured from the loom about 106 yands. Each piece brought the weaver a guinea, and occupied about 24 days in weaving; but on the introduction of the fly shuttle in 1791, the same work was done in 14 days. 'This cloth was all sent to Glasgow, where it was bleached and printed. In 1790 only 2078 yards of this cloth was weaved and stamped in Crieft, but in 1792 it had increased to 14,777 yards, and the value was about a shilling a yard. The Linen manufacture in Crieff has long since been supplanted by that of cotton.

Cupar-Fife.-Flax was cultivated in this parish from a remote period, and the soil was well adapted for its growth, but for many years it may be said to have been a thing of the past. The Linen manufacture has long been the staple trade of the town, and the chief article made from 1780 to the end of the century was what was called "yard-wides" for buckram, glazed Linens, \&c. ; Osnaburgs, tow sheetings and Silesias, were also made at that period, and there was then about 500,000) yards annually stamped in Cupar, of the value of about $£ 20,000$. 'There were at that time six Linen merchants in the town, and the number of looms in the parish was 223. Cupar being the principal market in Fife for the yard-wides mentioned, webs to the value of more than $£ 20,000$ were brought in from the adjoining country, and sold there. The I inen merchants of the day were said to purchase annually from the manufacturers and weavers to the value of between $\mathfrak{1} 40,000$ and $\mathfrak{5} 50,000$ of linens, which they paid in ready money, and sent to London, Glasgow, and other markets. The Linen was bleached at a field on the Eden, which was then in good repute for bleaching. The prosperity which attended the 
Linen trade some time prior to 1793 had been the means of increasing the population considerably, and there were then few begging poor in the parish. In 1836 there were three flaxspinning mills in the parish, employing in all 236 hands. There were then ten manufacturers in the town, employing about 6010 weavers there, besides many others in the various villages around Cupar. Since then manufacturing industry has had its seasons of distress and prosperity, but it is still the staple of the parish, and the mill-spinners and manufacturers at present give employment to very many hands in the town and district around. Russell Mill, belonging to Smith, Laing \& Co., has a waterpower of about 50 horses. It contains 2200 spindles, and employs 200 hands, who reside in comfortable houses near the work. Their physical comfort, moral well-being, and mental culture are carefully attended to by the firm. Cupar Mill employs nearly 100 people, and belongs to William Smith \& Son.

Cucles. - The Earl of Findlater, who presided at the Board of Trustees in Edinburgh, resolved to introduce the Linen manufacture into Cullen about 1748. He took to that town two or three young men, sons of gentlemen in Edinburgh, who had been regularly bred to the business, and who had some patrimony of their own. To encourage them to settle so far north he gave them $£ 600$ for seven years, the money to be then repaid by yearly instalments, free of interest during the whole period of the loan. He also built weaving shops and furnished every accommodation at reasonable rates. From his position at the Linen Board he obtained for the young manufacturers premiums of looms, heckles, reels, and spinning-wheels, with a small salary to a spinning mistress. So good a scheme and so great encouragement could not fail of success, and in a few years the manufacture was established to the extent desired. All the young people were engaged in the business, and even the old found employment in various ways in the manufacture. Thus a spirit of industry was diffused over the place and neighbourhood in a very short time, which soon appeared in their more comfortable mode of living and better dress. The manufacture, as in other places, had its vicissitudes owing to good or bad markets or demand, but still it contiuued long on the whole in a prosperous state. In 1791 there were in the town 65 looms constantly employed in 
weaving Linen, a few of them being on damask. The manufacturers also gave out a great many webs to be woven in the country. Flax cultivation had been tried in the parish, but the soil and climate was too dry, and it was only in moist seasons it did well. This is one of the most interesting experiments which was ever made to introduce the Linen manuficture into Scotland. The success which for some time attended the attempt gradually waned, and the trade at last became extinct. Now even the title of the good Earl who male it is dormant; but his deeds are still to menory dear.

Dekr.-In this parish about 16 hogsheads of linseed, mostly American, were sown annually in the last decade of last century. This was reckoned a sufficient quantity for 36 acres, and the produce was about 1000 stones of scutched Flax. 'The tenant of one of the lint mills had for several years about that period received the greatest premium for raising Flax of any one in the county of Aberdeen.

Dowally.-From a peck of linseed, on the average, three stones Dutch weight of dressed Flax was grown near the end of last century. Each tenant of half a ploughshare sowed eight pecks of Flax-seed yearly. They began to keep their own seed, and found it little if at all inferior to what was imported; and they generally had the best crop of Flax after grass.

Duskeld.-Linen yarn was long the staple commodity of the town and district around, and the merchants there dealt in it extensively, not less than 200,000 spindles being bought yearly. The price varied greatly in different seasons, according to the state of the Flax crop, and of the Linen market. In 1776 it brought from $1 \mathrm{~s} 8 \mathrm{~d}$ to $1 \mathrm{~s} 10 \mathrm{~d}$ a spindle, and in 1796 it was from $3 \mathrm{~s}$ to $3 \mathrm{~s} 3 \mathrm{~d}$, the rise having been gradual for some years prior to the latter date. 'The yarn bought in Dunkeld, and not manufactured there was sold in Perth, Dunfermline, or Glasgrow. Some improvements on the construction of the spinning-wheel had been invented, about 1790, by a wheel-wright in Dunkeld, which on trial produced easily about one-third more than the common wheel, and the Duchess of Athole patronized the invention. It was thoug! in the district that the Trustees wunld have found it a proper object for their encouragement, but it does not appear that they took any notice of the inrention, and it is uncertain in 
what it consisted. The Linen manufacture was then carried on by some spirited individuals to a very considerable extent. They employed such weavers as they could find accommodation for in the town, and many more in the country. They also purchased a great proportion of the Linen which was brought from the district around to the Stamp Office in Dunkeld. From the report of the stamp-master to the Board of Trade, the following statement of the progress of the trade is taken :-

\begin{tabular}{|c|c|c|c|c|c|c|}
\hline In 1789 & re Stamped & 34,441 & Tards, & Value & $£ 1,533$ & 1310 \\
\hline , 1790 & , & 63,244 & , & ", & 3,100 & 46 \\
\hline , $179 \mathrm{I}$ & $"$ & 89,605 & , & ", & 4,480 & 5 \\
\hline, 1793 & , & 115,215 & ", & ", & 480 & 1211 \\
\hline , 1794 & , & 117,752 & ," & , & 5,396 & 19 \\
\hline 1795 & , & 130,684 & $"$ & $"$ & 6,534 & 4 \\
\hline 1796 & , & 149,554 & , & ", & 7,477 & 14 \\
\hline
\end{tabular}

The ancient trade of Dunkeld has long ceased to flourish, and now scarcely a vestige of it is to be found in the parish.

DunNotTER.-Stonehaven and other parts of the parish of Dunnotter long abounded with the best spinners of Flax yarn, and in Stonehaven alone about $£ 2,650$ was paid yearly for spinning, from 1770 to the end of the century, chiefly on account of the manufacturers in Aberdeen, Montrose, and Arbroath. The manufacture of sail-cloth was begun about 1780, and for some years.carried on extensively and successfully, by an Aberdeen merchant, 75 looms having been employed, but on his death it was discontinued. In 1793 another on a smaller scale was commenced; and the previous year the manufacture of Osnaburgs, sheeting, Linen checks, \&c., had been established by Arbroath merchants. About that time a few small cargoes of Flax were annually imported from the Baltic.

Dunnichen.-Here, from 1780 to 1790 , about ten bolls wheat were raised on an acre; and sixteen stones of scutched Flax, worth $12 \mathrm{~s}$ the stone, was the average produce. The enclosed fields were let at from $40 \mathrm{~s}$ to $50 \mathrm{~s}$ an acre for pasture, and at $£ 5$ an acre for Flax. Many weavers, principally of coarse Linen, then inhabited the parish. The village of Letham has long been in repute for its Linen fabrics, and a considerable quantity is still made there.

Dysart.-The manufacture of checks and ticks was begun in 
the parish between the years 1710 and 1720. It progressed slowly until 1776 , when it did not exceed in value $\mathfrak{L} 8,500$ annually. Before the introduction of these fabrics, Linen for shirting and sheeting was made extensively, but they were ultimately entirely superseded. About 1780 , two or three of the established manufacturers got into the English trade, and having made goods suitable for that market, increased the manufacture beyond what their capital was equal to, and beyond what they could get hands in the town to execute. 'The manufacturers gave their orders for common goods to other makers in the neighbourhood who employed two or three looms. These parties by economy sived money and got more looms, but the value of the goods made increased more rapilly than the capital of the manufacturers, owing chictly to the too realy facilities offered by the branch banks. On this foundation about one-third of the goods were then made, and the cloth was of an inferior quality to what was made by nen of capital. Those who began the manufacture had had to work with the sweat of their brow for eight or ten years before they made the first hundred pounds of their capital, but it is stated in the Statistical Report (from which part of this article is taken) that towards the end of the century a weaver without capital could get credit for a few hundred pounds in yarn, or in cash on a bill with two or three names upon it. 'T'o retire these bills the groods had to be expeditiously manufactured, and to accomplish this the weavers of the established manufacturers were said to have been seduced by drink and extravagant wages, the consequences of which were obvious. About 1790 the sales of Linen in the parish were not

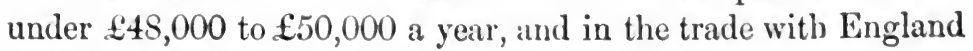
very few bad debts had been made. The sales exceeded the produce, because the manufacturers bought cloth from other parishes, and also employed workers there, but at the same time a number of the weavers of Dysart were employed by the manufacturers of Kirkcaldy, \&c. 'The number of looms in the parish at this period was 700 to 750 , employed on checks and ticks, and the quantity of cloth then manufactured annually was about 795,000 yards, which at a medium price of $11 \frac{1}{2} \mathrm{~d}$ a yard makes the value $£ 38,09315 \mathrm{~s}$, about one half of which was sold in London; one-fourth, chiefly the coarse kinds, in Glasgow ; and 
the other fourth in Manchester, Liverpool, Nottingham, Leeds, and some other towns in Yorkshire. In the Linen trade ten hands were reckoned to be employed by each loom, but as threefourths of the Flax consumed in the trade was foreign, seven to a loom might be a fair proportion, which for 725 looms gives 5075 persons employed, but a number of the hands lived in the adjoining parishes. Seven-eighths of the Flax used in making bleached yarn was imported from Russia, and spun in Fife. What was used for the blue stripes, \&c., was mostly made from home grown Flax, but as a sufficient quantity could not be got, Dutch Flax was imported and spun to make up the deficiency. Not above a fourth of the yarn used in the parish was spun in it. The great inconveniency the parish then laboured under was a scarcity of good weavers. The people took apprentices, but were unable to teach them, and the men grew up bad weavers, and of course made bad cloth. Shortly after the date referred to, the trade became bad, and little or no money could be got from the banks, which greatly crippled the manufacturers, and did injury to all classes in the town and district. Some time after that period trade began to revive again, and in 1836 the number of looms employed on checks and ticks in the town and parish was 2088, producing about 37,000,000 yards annually, of the value of fully $£ 150,000$. These goods were sold in Glasgow, London, Liverpool, Manchester, \&c., and to various parts of Europe, America, \&c. Including winders, warpers, weavers, \&c., from 5000 to 6000 persons were then employed in this department of trade in the parish, and in addition the Dysart manufacturers employed about 1000 looms in Ceres, Strathmiglo, and other places. Since then the trade has, with some interruptions, gone on steadily, and at present it is in a very prosperous state. There is a small spinning-mill to the east of the town, belonging to Thomas Millie \& Son, but the great establishment in the place is that of James Normand \& Son, who employ a steam power of 80 horses, driving about 300 power-looms, with all the necessary preparing and finishing machinery for these and for about 400 hand-looms. Within the walls of the work they employ close on 500 people, and pay upwards of $£ 8000$ a year in wages. The goods they make are chiefly hucks, diapers, damasks, \&c. This respectable firm are 
now erecting an excusive spinning-mill beside their powerwork, which, when in operation, will add greatly to the number of their employees, and to the importance of Dysart.

Elain.-In the reign of William the Lion, lint paid tiend in the parish, which shows that it had been grown to some extent at that early period. Prior to 1740 the trade was principally carried on with Holland, but after that date it was chiefly with London, and other English cities and towns. In 179() Linen yarn, to the value of $\mathfrak{2} 2000$ sterling, was exported; at $\mathrm{d}$ at that time the spinning of Flax had taken the place of the manufacture of gloves and woollen stuffs. In the country part of the parish there were then 19 Linen weavers, and in the town of Elgin 70. 'Twenty years before that date, wheat was much run upon; but it was then said to be justly on the decline, as the high price did not compensate for the injury done to the soil by so exhausting a crop. The same remarks were afterwards made about the Flax crop.

Falkind.-Flax was raised some years, from 1770 to the end of the century, in considerable quantities, but the whole produce was not sufficient for the consumption of the inhabitants The weaving of coarse Linen was the principal manufacture carried on in the parish. About 200 looms were then employed, which, at 300 spindles to each loom, is 60,000 spindles a year; the value of which, manufactured and taken to market, was, at $3 \mathrm{~s} 9 \mathrm{~d}$ a spindle, $£ 11,250$. An expert trades . man could weave 400 spindles in the year, which, at $9 \mathrm{~d}$ a spindle, the highest price given, is $\mathfrak{t} 15$; from which deluct winding 200 spindles weft, at $1 \frac{1}{2} \mathrm{~d}$ a spindle, $\mathfrak{f} 15 \mathrm{~s}$-leaving for the weaver's wages $£ 1315 \mathrm{~s}$ per annum. The markets for the green-cloth were Auchtermuchty and Cupar. William Lumsden \& Son, Freuchie, are now the largest manufacturers in the parish. In 1860 they erected a power-loom factory, with a steam-power of 25 horses, containing at present 100 looms; in addition to which the firm employ 320 hand-loom weavers, employing from 450 to 500 people, and paying in wages about $£ 12,000$ annually. Linen sheeting and hucks are the principal fabrics made; and of these about 1,000,000 yards are produced annually. John Scott's trustees have a small spinning-mill and 
power-loom factory, and the quantity of goods made by others in the parish is trifling.

Fordoun.-In 1795 a mill for spinning Flax yarn was erected at Auchinblae, in the parish of Fordoun, and it was long carried on with considerable success. The yarn was manufactured into Linen in the parish, and afforded employment to many of the inhabitants. In 1835 about 50 people were employed in the mill, and the yarns spun annually consisted of 45,000 spindles Flax, value $£ 6,200$, and 25,000 of tow, value $£ 3,800$; together, about 70,000 spindles, value $£ 10,000$. In addition to the employment given at the mill, about 29,700 spindles of yarn were weaved in the town, producing about 117,680 yards of Linen. The value of the yarn manufactured was about $£ 3,712$, and of the cloth made $£ 4,640$, the price paid for weaving being about $1 \mathrm{~d}$ to $1 \frac{3}{4} \mathrm{~d}$ per yard, as in quality. About seven years ago the machinery of the mill was sold, and the building applied to other purposes ; but it has been again filled with spinning machinery, and is now once more in active operation as a spinning-mill. Few Linens have been weaved in the parish for some years; but now that the mill is again at work, the quantity may be increased.

FordYCE.-The Linen manufacture would appear to have existed in this parish in the fifteenth century, for amongst other privileges granted to the weekly market at Fordyce, by charter from the Crown, that of Linteum latum et arctum was given in 1490. There was a bleachfield at Portsoy, which was stopped towards the end of last century. It employed a good many people; but after it was given over no manufacture of consequence was carried on in the parish; and in 1790, although most of the inhabitants raised as much Flax as make linen to serve the household, perhaps not more than 1000 yards of it were sold out of the parish.

ForaAN.-The women in the parish, towards the close of the century, were employed in spinning coarse yarn for Osnaburgs, of which the merchants of Dundee then exported large quantities. The war at that period for a time caused great stagnation in the trade, and the price of spinning fell from $1 \mathrm{~s} 6 \mathrm{~d}$ to $1 \mathrm{~s}$, and even to $10 \mathrm{~d}$ a spindle. While the encouragement was high it was difficult to get maid-servants. It was supposed that the 
constant sitting at the wheel, and the immoderate waste of saliva, was not favourable to the health of the young women. There were then 14 weavers in the parish.

Fonres.-In the parish and surrounding district Flax was an important article of cultivation during the latter half of last century. The Linen Board assisted in erecting lint mills, which encouraged the growth of that plant. The spinning of the Flax and manufacturing so much of the yarn as was required for domestic purposes, long employed a considerable number of the women, 'The merchants of the town bought the yarn and sent it to Glasgow, where it generally found a ready sale, unless when the market there was overstocked with Irish yarn; which, it is reported, was at certain times preferrel, but only on account of its cheapness. From 1760 to 1770 this trade brought a considerable supply of money to the district, and was of great advantage to the women who span it, as well as beneficial to the public. About 1784, owing to the increase of cotton-spinning, and the large importation into Glasgow of Linen yarn from Ireland, the yarn from this town fell greatly in price, and the trade began to decline. That year one of the merchants of the town sent to Glasgow 23,290 spindles of yarn, which had been collected in the neigbourhood, and the other dealers sent at least 47,000 spindles, the weaving of which, at $2 \mathrm{~s}$ a spindle, then the current rate, produced $£ 7,029$ sterling, a very important sum, indeed, to be brought into the district for wages from this article alone. After the decline of the trade, many of those who had formerly been employed in spinning yarn for sale took to spinning Dutch flax for the manufacturers of Aberdeen and Inverness. In 1790 there were 25 weavers in the town of Forres and 8 in the country part of the parish, The following was the wages paid in the parish about the two periods named:-

1750.

1790.
A labouring man-servant. yearly, $£ 1108$
£5 00 to $\begin{array}{llll} & 0 & 0 & 0\end{array}$
A woman-servant, do.,
$016 \quad 8$ to $20 \mathrm{~s}$
$116 \quad 0$ to $2 \quad 2 \quad 0$
A man during harvest,
$010 \quad 0$ and victurls 150 and 2 meals.

Galston.-About 1790, from 20 to 30 acres were generally sown with Flax, and the produce dressed by a watermill in the village. The quantity of Flax scutched there 
was from 900 to 1000 stones avoirdupois, and about half of it was heckled. Little Flax was then dressed in any other way than by the mill, although scutching by the hand was considered by far the safest method, and subject to much less waste than when the water-mills were employed.

GLAMis.-The manufacture of Linen has long been carried on in the parish. Before the end of last century a considerable quantity of Flax was grown, and the spinning and weaving of it gave employment to many of the inhabitants. In 1806 a mill was erected for spinning Flax and tow-yarn on the Glamis Burn, which was driven by a water-wheel of 16 horse-power; and in 1820 a steam-engine, of 10 horsepower, was added, to assist when the water was scarce. There was also a plash-mill, for cleaning yarn, upon the stream; and in 1836, about 66 persons, of both sexes, were employed in the works. The yarn spun in the mill was manufactured into Usnaburgs and sheetings in the parish, and produced about 4000 pieces annually. There were also manufactured in the parish, by parties not connected with the mill, about 7500 pieces of same description of goods yearly. Subsequently to that period, a new overshot-wheel, of about 40 feet in diameter, was erected, and great expenses laid out in the construction of a dam in the Den of Glamis, and in conducting the water to the wheel. Some years ago the lessee of the mill died, and the work was discontinued; and about three years since, the machinery was sold, and the mill dismantled. There is still a considerable quantity of Linen made in the parish for manufacturers residing in the district, or for those in Forfar; but since the stoppage of the spinning-mill, the village has never been its former self.

GLASGOw. - Not until after the Union of the two Kingdoms, were manufactures to any extent carried on in this city. Between 1725 and 1750, the spirit for manufactures become prevalent, and since then it has extended greatly. The Linen trade was begun in 1725, and for a long period it formed the staple manufacture, not only of the city, but of the west of Scotland generally. Cotton, after its introduction, to a great extent supplanted it; but up to the end of the century, lawns, cambrics, checks, diapers, and other Linens, continued to be made on a small scale. 
About 1780 nearly 3000 looms were employed in the Barony parish on these fabrics, and on Linen handkerchiefs for printing, and on "blounks," a cloth consisting of Linen warp and cotton weft, which was all printed for neck handkerchiefs, gowns, and bed-curtains. Ten years later this trade had completely changed, cotton having superseded Flax, and the looms were then on muslins, \&c. For a long period St Rollox Flaxmills, belonging to Alex. Fletcher \& Coy, have been in active operation in Glasgow. This large work is driven by steamengines of 520 horse-power, contains upwards of 20,000 spindles, and employs about 850 hands. Within the last two years W. \& J. Fleming \& Co. have put up a new work for spinning and weaving jute, with a steam-power of 150 horses, which, when filled with machinery, will be a large establishment. Some other details regarding the trade in Glasgow are given in other parts of the work.

Grange. - In this parish, a kind of short Flax was at one time grown, but no description of the plant is given, and it was entirely banished from the country, perhaps about a hundred years ago. The raising of Flax, and the various operations required to bring it into yarn and cloth, occupied many people, and brought much money into the parish. The products were sold in Keith market, which was then resorted to by purchasers of Linen cloth from all parts of Scotland. In 1791 spinning Dutch flax brought about $\mathfrak{1 5 0 0}$ a year into the parish, and it had then nearly superseded home-grown Flax.

Greesock.-In 1725 a rope-work was established here, and shortly after a duck or sail-cloth manufactory was commenced. Other works of a similar kind were soon erected in this district, large quantities of cordage and sail-cloth having been made, both for home consumption and for export. Since that early period the original rope-work has been enlarged from time to time, and it isstill in a prosperous condition, and with every modern appliance. Some other successful establishments of the same kind are also in active operation here. There has long been a large and wellconducted Flax-spinning work there, and the sail-cloth made from the yarn by the Gourock Rope-work Company is very highly celebrated, and it is, perhaps, second to none made in the whole kingdom. Latterly, jute-spinning and weaving by 
power has also been commenced by the Greenock Spinning Company, and already some progress has been made in both departments.

Huntly. - The Linen manufacture was introduced about the middle of last century, and was long carried on with much success and great advantage to the parish. In 1792 there were in the town 52 flaxdressers, who, at an average, dressed 40 mats of Flax, weighing $109 \mathrm{lb}$. each, in a year, the value being about $£ 3$ a mat. It was spun into yarn, of from 4 to 12 hanks to the pound, and worth, when spun, $£ 716 \mathrm{~s}$ a mat; or, in all, about $£ 16,224$ sterling. There were then 209 weavers in the parish, exclusive of those employed by the manufacturers of Huntly, \&c., who wrought, at an average, 73,150 yards of Linen yearly, which, at 2 s a yard, amounted to $£ 7315$ sterling. These details show the importance of the trade at that period; but it has long been lost to the district

INvERARY.-About the year 1748, the Duke of Argyle introduced the Linen manufacture into the parish. The manufacture made rapid progress, and for a long period it was attended with very beneficial consequences to the country, as it brought ready money into the parish, but it does not now exist.

INVERNESS. - In this town a hemp manufactory was early established, and in 1791 about 1000 hands were employed in spinning, dressing, and weaving the hemp (of whom 130 were weavers), for which they were paid from 1 s to $10 \mathrm{~s}$ a week of wages. The hemp was imported from the Baltic and manufactured into cloth for bags, sacking, and tarpauling, which was consumed in Britain and throughout the East and West Indies. About 1780 a white and coloured thread manufactory was begun, and it increased so rapidly that, within ten years, about 10,000 people were engaged in heckling, spinning, twisting, bleaching, and dyeing, for which the wages paid was from 1s to $12 \mathrm{~s}$ a week. The Company had then nineteen agents in the neighbouring districts to manage the spinning departments. The Flax was imported from the Baltic, and the thread sent to London, whence it was dispersed over the world. A bleachfield was established on the Ness, and, for some time, carried on successfully. The thread manufacture has long been lost to Inverness, and to many districts in Scotland where 
it once flourished, and it is now concentrated in a few spots, where the yarn is spun and the thread made by steam-power. The hemp manufactory acquired a name and fame in the country for the superiority of its cloth, and it still has a vigorous existence. Its products have long been celebrated and sought for in London and elsewhere, and they are still largely used for coal sacks, and other kindred purposes, for which they are specially adapted.

Keırн. - The chief trade in the parish was Flax-dressing, spinning, and weaving, lut between 1787 and 1790 the two first declined greatly, partly owing to the advanced price of Dutch Flax, from which the yarn had for sometime been made, but chiefly to the large importation of Linen yarn from Ireland into Glasgow, which had been the principal mart for Keith yarn. The yarn had besides deteriorated in quality, and got into disrepute, but a resolution was come to by the manufacturers to take no yarn thereafter from the spinners, but what was of the very best quality, and this was expected to revive the trade. A bleachfield, very complete in every respect, had been erected at considerable expense on the banks of the Isla, which it was said equalled in execution any field in the north.

KeмBACK.-Ceres Burn, although a small stream, drives a large quantity of Flax-spinning machinery. After leaving the parish of Ceres it enters Kemback, in which are Blebo Works, belonging to Alex. Watson \& Son. These works consist of three Flax-spinning mills, with all the necessaryadjuncts for carryingon the trade. The oldest of the three mills was erected early in the century, and the largest one in 1839. In winter the water-power, which is equal to 100 horses, drives the whole machinery, one of the wheels being 39 feet in diameter, and 10 feet wide; but there is also a steam-power of from 70 to 80 horses, which is employed in summer when the water is low. The mills contain 4500 spindles, and employ 300 hands. The situation of the works in the famed Dura Den, is one of the most beautiful in Fife; and the village attached to them, which consists of 80 houses, and contains 500 inhabitants, is pretty and picturesque. Twenty years ago only about 200 hands were employed, which shows that considerable extensions have taken place since then. In the adjoining parish of Dairsie is Iydox Mill, with between 
600 and 700 spindles for Flax-spinning. It belongs to $\mathrm{Mr}$ David Annan, and employs about 40 hands.

KENMORE.-In the parish Flax was cultivated to a considerable extent towards the end of last century, the return of lint being commonly a stone of Flax to the lippie of linseed. The Flax was spun in the parish, a portion of the yarn being made into cloth for household purposes, and the remainder sold to help to pay the rents of the small farmers, by whom it was chiefly grown. In 1794 there were 20 Flax-dressers and 63 weavers in the parish.

KETTLE. - About eighty years ago, the parish grew fully a hundred Scotch acres of Flax yearly. Linens were manufactured so early as in the beginning of the eighteen century, and in $\mathbf{1 7 9 0}$ there were 170 looms, belonging to about 60 masters, with their journeymen and apprentices. The gross produce of a loom per annum was about $£ 60$, but a good hand could fetch considerably above $£ 100$. The average gross expense to the masters for lint, spinning, boiling, working, \&c., was about $£ 46$ 15s, most of which was laid out in the parish and neighbourhood, and the manufacture circulated about $£ 10,000$ annually, the greater part paid in the parish. Of the Flax used about one-eighth was Dutch, one-eighth Riga, the remaining three-fourths being the produce of Kettle. The Linen brought from $7 d$ to $2 \mathrm{~s} 6 \mathrm{~d}$ a yard, a small part being bleached, but the greater part was sold as it came from the loom, in Cupar or Auchtermuchty, and thence sent to Glasgow, Leeds, or London. In 1836 there were $\mathbf{3 7 8}$ hand-looms in the parish, chiefly employed on weaving dowlas, \&c. Latterly the number of looms has greatly diminished, and nearly the whole are employed by Alex. Lawson, who manufactures sheetings for family use, and other bleached Linen fabrics extensively.

KrLBRIDE. - In strong clean land Flax succeeded well in the parish of West Kilbride, and the attention of parties had been so much directed to its cultivation nearly a century ago that greater quantities were raised there than in any of the neighbouring districts. It was commonly sown after potatoes. The only species of manufacture then in the parish was coarse Linen, of which considerable quantities were made every year by the peasants. The females span the yarn during the winter, and brought a consi- 
derable sum into the parish. The Linen was bleached at home by simple exposure to the sun. In June there was an annual market or fair for the sile of it, where it was bought by the Linen dealers in Glasgow and Paisley, who exported the greater part to the West Indies. Nearly 7000 yards of cloth were made yearly, which sold at from 1 s to $1 \mathrm{~s} 3 \mathrm{~d}$ a yard. The value of this and of the yarn sold, divided among farmers and housekeepers, enabled them to pay off their domestic debts with ease and punctuality. 'This idea may be correct, but it must have originated with the village shopkeeper.

Kilchoman, is IsLa.- The rearing of Flax was actively followed by the common tenantry, who, a century ago, paid great part of their rents by the produce. It was pre-eminently a Flaxen country, about 80 hogsheads being annually sown in the parish; and the cultivation of the plant and manufacturing the lint constituted the principal business of the people, they being much more given to the making of Linen than to any other work. Travelling merchants took the Flax seed, and gathered the yarn, which was mostly sold to the Glasgow manufacturers. Many of the more genteel families in the parish kept weavers employed for themselves all the year through, and the clearness of their linen showed how well the waters were adapted for bleaching.

KILLiN. - One of the principal crops raised in this parish about 1790 was Flax, the quantity grown being very considerable. It was sown about the end of $A$ pril, and the rotation of crops was oats in lea ground, or after fallowing, then potatoes or bear, and then Flax. The return of Flax varied from half a stone to a stone of Flax from the lippie of seed, the stone weighing $22 \mathrm{lb}$. avoir. The Flax was spun by the women of the parish during the winter months, and some of it weaved into linen for the wants of the district; but the greater part of it was sold at the fairs, six of which were held annually in the village of Killin, the purchasers taking it to Glasgow, and other manufacturing towrs. There were then in the parish 9 Flax-dressers and 36 weavers.

Kilwinnisg (for many hundred years famous for masonry and archery), about eighty years ago manufactured lawns and Linen gauzes for the Irish market. About 12 or 14 hogshead of Flax seed were sown in the parish annually, and the produce 
spun and manufuctured for home purposes; a part of it having been made into harn, a coarse kind of cloth which was sold for shirts to the common people. Great complaints were about that period made in the district regarding the high duty charged by the Irish upon Scotch goods, if they contained even a single thread of cotton yarn in them, while at the same time Irish Linen was admitted into Scotland free; and unless Ireland repealed this duty, it was proposed to petition the British Parliament to lay a proportionate duty on all Irish Linen brought into this country.

KINGHORN. - One of the first spinning-mills established in Fifeshire was in this town. The Statistical Account of Scotland says :- " About 1792 the teasing, rolling, and spinning of tlax by means of the Arkwright and Darlington machinery was started here." Shortly after that period, James Aytoun, who died on 8th February 1864, and who was in very truth the father of the Flax-spinning trade, started a work with four frames of 36 spindles each, being 144 spindles in all, at Kinghorn. Previous to this $\mathrm{Mr}$ Aytoun studied Flax-spinning, under Kendrew \& Co., the patentees of the spinning machines of Darlington, and agreed with them for a license to work the four frames, for which he paid them $£ 1$ a spindie. A third work was started there about the same time, the three trusting to the Loch of Kinghorn being sufficient to drive the spinning machinery of the three mills, the falls being in cumulo more than 100 feet. This was found not to be the case, as the Loch was speedily drained. $\mathrm{Mr}$ Aytoun put up a coal-work engine on the old principle, to assist in driving his machinery, but it proved so constant a source of annoyance to him that he left the (by him) hated place in 1802. The other parties erected Bolton and Watt's engines, only then coming into repute in Scotland for driving machinery, and succeeded better in their attempts. Twenty years ago there were three Flax-spinning mills in the town, employing 467 hands; and Tyrie bleachfield in the parish, having 70 workers, making a total of 537 people employed in these branches of the Linen trade. There were also a number employed in weaving, winding, \&c. Two of the mills, St Leonards and Mid Mill, and the bleachfield, all belonging to the respectable firm of Swan Brothers, of 
Kirkcaldy and Dundee, are still in active operation, and give employment to a large portion of the inhabitants.

Kinloch.-Flax was grown largely in the parish, and the raising, spinning, bleaching, and weaving of it occupied the labour of a considerable number of the inhabitants. It is said in the Statistical Account of the parish, that if Flax was sown for the second or third crop on marled ground (marl was largely used in the district about 1790 , having been got from some lochs in the parish)-that is, while the influence of the marl in the ground was most powerful, though the crop had a promising appearance till towards the middle of July, when the plant is about seven or eight inches long, the swelling and agitation of the earth, caused by the powerful operation of the marl under the strong influence of the sun, breaks the tender fibres of the plant while in its quickest growth, and causes it to decay.

Kinnetrtes. - Of 2065 acres cultivated in the parish in 1791, 28 were Flax. It was usually sown from 20 th to the end of April, and pulled from 12th to 25th August, but occasionally a few days later. If sown much earlier it was often injured by frost, and lay long in the ground before germinating; some of it being sickly nearly all the season, and not ready for pulling earlier than if it had been sown at the usual time. The women were generally occupied spinning the Flax during winter, and when their services were not required in farming or other operations. In 1791 there were 58 persons engaged in weaving green Iinen or Osnaburgs, which were chiefly disposed off in Forfar. It is stated in the Statistical Report that the fluctuations which affected the manufacture of Linen in the parish, arising from various causes, were sometimes distressing. About the years 1787 and 1788 the subject of spinning Flax by machinery was attracting very general attention, and some parties in Dundee resolved to try the experiment. $W$ ith that view arrangements were made with William Douglas, of Brigton, in this parish, for the use of part of a corn-mill which adjoined his mansion-house. The grinding machinery was removed, the building converted to suit its altered circumstances, and the spinning machinery and apparatus put up. The trial was to be made on a small scale, being for 120 pirns or spindles, and it was in the contemplation of the company 
to extend their plan, if the experiment was found to answer their expectations. In the end of 1788 or the beginning of 1789 the machinery had been so far put in order as to admit of a trial being made, and the yarn it threw off, which was intended for the manufacture of Osnaburgs, was then said to look well, and to be of very good quality. The work was carried on by virtue of a lease of patent privilege from Kendrew \& Co., of Darlington. The experiment must have come up to the expectation of the promoters, because, under the firm of James Ivory \& Co., they leased ground for a new mill and a village for the workers, for 45 years, from Mr Douglas, and, as the lease expired in 1834, it must have been entered into in 1789. The erection of the new mill and village, called Douglastown, was at at once proceeded with, and the buildings so far completed next year as to admit of the machinery being put in, and the spinning begun. This is shown by a petition from the firm to the Board of Trustees, dated 17th Nov. 1790, in which it is said the machine, \&c., was already erected. In an enumeration of the inhabitants, made up by the Minister in $\mathbf{1 7 9 1}$ for the statistical account of the parish, an artist, employed conducting a Flax yarn mill, is included. This new mill was of five stories in height, and a large structure for the infancy of the trade; and the village was commodious, and each house had a large garden attached to it. James Ivory, teacher in the Dundee Academy, a celebrated mathematician, who was afterwards knighted, was a partner and manager of the company, and Mr Douglas, the proprietor of the ground, was also connected with it. For a time the work was carried on successfully, but on the sudden death of Paul, the Emperor of Russia, in 1801, Flax fell greatly in price, and the company suffered so heavily that they broke up in 1803. Mr Douglas some time after paid the debts of the concern in full, and in 1804 bought the work at a public sale, and carried it on himself until 1808 , when he assumed some partners, each paying $£ 800$ for his share. This party carried on the mill for seven years, when, in consequence of losses by bad trade and bad debts, they stopped. Mr Douglas again paid the debts in full, and carried on the work on his own account until 1817, when he sold the machinery to the late James Watt, of Dundee, with the remainder of the original lease. The lease of the spinning-mill and village, and 
the machinery in the mill, was advertised in the Dundee Advertiser in 1817 to be sold by public roup, upset price $\mathfrak{f}^{3} 3000$. Not selling at this price, it was afterwards advertised to be sold on 13th August, 1817, at \pm 2000 ; and, as an inducement to a purchaser, it was siid that at the termination of the lease, at Whitsunday, 1834, the proprictor must either take the houses, waterwheel, and machinery of the first motion at a valuation, at a price not to exceed $\mathcal{E l ( 0 )}$, or allow the tenant other fifteen years of the property. 'The water-power being irregular, a small steamengine of seven horse-power was added about 1830. In 1834 the mill contained 14 frames of 30 spindles each, or 420 spindles in all, and threw off 234 spindles of yarn per day, or 1404 a week. It then gave employment to $10 \mathrm{Flax}$-dressers, 12 preparers, 16 spinners, 7 reelers, 2 turners, 1 engineman, and a clerk who superintended the whole. The yarn was generally manufactured into cloth, and exported to foreign markets by the proprietor. The mill was seldom profitable to any of those who span it, and shortly after 183.4 the engine and machinery were removed, and it ceased to be a spinning mill. It now stands gaunt and desolate, a monument of the mutability of the Linen trade. It has long since passed out of the hands of the Douglas family, and is now absorbed in the estates of the Earl of Strathmore. The villagers, along with the other inhabitants of the parish, are mostly employed in weaving shcetings and Osnaburgs for the manufacturers of Forfar. In 1835 the average wages for weaving a piece of Osnaburg, 150 yards long, was $8 \mathrm{~s}$; hessians, 124 yards long, $8 \mathrm{~s}$; bleached sheetings, 110 yards, $14 \mathrm{~s}$; brown sheeting, 104 yards, $11 \mathrm{~s}$. At the spinning mill the males received $15 \mathrm{~s}$ a week, and the females $4 \mathrm{~s} 6 \mathrm{~d}$, which at the period was considered good wages. 'The labouring population of the parish, when not employed at out-door work, are now chiefly engaged as formerly, in weaving Linen, the wages being regulated by the price paid in Forfar. Farther details regarding Douglastown Mill will be found in the "Popular Lecture;" in the proceedings of the Board of 'T'rustees; and in the account of the parish of Bervie. The subject is so fully referred to, because at this distant date anything relating to the pioneers of Flaxspinning by machinery must be interesting to all, but especially so to those engaged in the trade. 
KInRoss.-The principal manufacture was silesias, from 27 to 30 inches in width, some coarse tweels, harns and straikens. The quantity manufactured, as taken from the stamp-master's book in Kinross was, frorn 1st November 1780 to 1st November $1790,1,184,341 \frac{1}{2}$ yards, being 118,434 yards yearly, which at $9 \mathrm{~d}$ per yard at an average is $£ 4,4415 \mathrm{~s} 6 \mathrm{~d}$ per annum. About five-sixths of the whole was manufactured in the parish, and the rest in the neighbourhood. Besides this a great deal was made for shirts, bed and table Linen, \&c., for private use. The yarn was spun by the people in their own houses, mostly from Flax raised in the parish, and the number of looms in the parish was then about 200 . A patriotic experiment made by the landowners of Kinross during a season of distress has already been mentioned.

KIRKDEN.-For a crop of lint about $£ 5$ an acre was paid, but it sometimes rose as high as $£ 6$ 3s. Those who let the land, ploughed and harrowed it, and carried the Flax to and from the watering. There was hardly a house in the parish where one or more women were not employed in spinning yarn for the Osnaburg weavers, and of the many millions of yards of that cloth annually made in the country, this parish had its proportion. The women all span with both hands, and a good spinner could earn from $3 \mathrm{~s}$ to $3 \mathrm{~s} 6 \mathrm{~d}$ a week, and girls of 13 or 14 years of age $2 \mathrm{~s}$, and many of them $2 \mathrm{~s} 6 \mathrm{~d}$; and they reckoned that their board cost about $1 \mathrm{~s} 6 \mathrm{~d}$ a week. The weavers were scattered over all the parish, and most of them grew a little Flax and paid the current price for spinning it. Much of the Flax used was at one period grown at home, but before 1785 a great quantity was also brought from abroar. The manufacturers of the district used to go to Forfar or Arbroath for the stamping and sale of their webs, but about 1790 a fortnightly market for their purchase was begun in the neighbouring town of Letham. The spinning-mill at Gighty Burn in the parish of Kirkden was erected in 1796, but the work was discontinued about 20 years ago. Hatton mill was erected in 1807, and in 1838 contained 15 frames of 30 spindles each for Flax and tow, and span about 1300 spindles of from 3 to $5 \mathrm{lb}$. yarn weekly. Subsequently other two mills were erected, and in that year the three smaller works span about 1200 spindles of Flax yarn, neither of 
them having tow machinery. Three of them got small steam engines to keep up the power when water failed in summer, the stream being then very small.

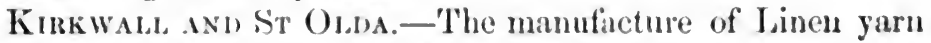
was introluced in 17+7. At first it was very unpopular, but it soon trimmphed over vulgar prejudices, and became diflused pretty generally over the islands. In years of extreme dearth and scarcity, it preserved the lives of many poor people, who otherwise would have died for want, and enabled others to live more comfortably. From 1770 to 1785 the trade flourished, and about 25,000 spindles were annually exported, the quality of which, in the opinion of the best judges, was as good as any in Scotland. After that period it began to decline, as the yarn lost the character it hal gained in the market, in consequence of the competition for spinning, and consequent carelessness of the spinners in spinning and reeling the yarn. Some lint continued for a time to be spun and sold in Elinburgh, Glasgow, or wherever the price of yarn was highest; but when the price was low, as had been the case for some years prior to 1790 , the yarn was manufactured into Linen cloth, chiefly for the English market. In that year, besides the yarn sold for the south, and the quantity bartered with the merchants who went over from Morayshire, about 30,000 yards of coarse Linen, intended for sale, was stamped at Kirkwall, in addition to what was used for private families.

LARGo.-In 1790 almost every weaver, and many others in the parish, had their bleaching-green where they prepared Linen, from the value of $9 \mathrm{~d}$ up to $4 \mathrm{~s}$ the yard. Linen and checks were the great articles of manufacture. Those who could afford to purchase yarn did so, and sold the cloth in Dysart, Kirkcaldy, Cupar, and Dundee; while others, with less stock, were employed making similar goods by the manufacturers of these towns. The great proportion of the Flax was imported, and much of it spun in the parish. A woman commonly span 2 hanks a day, for which she was paid $1 \mathrm{~s}$ to $1 \mathrm{~s} 2 \mathrm{~d}$ a spindle.

LesLik.-About 1760 the women universally span with one hand, a hesp being then a sufficient day's work for a woman, and mistresses required no more from the maid-servants when they sat all day at the wheel; after they had spun their hesp, the k k 2 
rest of the day was their own, and might be employed in their own work, or otherwise, as they thought proper, if in a rational way. Before 1770 a wheel for spinning with both hands was unknown in the parish, but by 1790 almost none else were to be seen in it. The price of spinning a spindle had been $10 \mathrm{~d}$, but in the latter year it was $1 \mathrm{~s}$; and women could then earn $2 \mathrm{~s} 6 \mathrm{~d}$ a week, while the men made from $7 \mathrm{~s}$ to $10 \mathrm{~s}$ at the loom. 'The weavers were the most numerous set of handicraftsmen in the parish, and the fabric woven was generally plain Linen. The women were chiefly employed in spinning Flax and Tow, both to supply the weavers and for sale. The changes which have come over Leslie since that period are wonderful. In 1836 there were six spinning-mills in the parish, about 260 weavers, and three bleachfields. The greatest works at present are those of John Fergus \& Co., Prinlaws, which embrace three spinning-mills, viz., Prinlaws, East Prinlaws, and Milldeans, also power-loom weaving and bleaching, all on an extensive scale, and employing numerous hands. 'l'hese works have now been carried on for many years, and they are still in active operation, the power looms being employed by the large London firm of D. Dewar, Son, \& Sons. Leslie lint mill, belonging to Alexander Gilchrist, contains 900 spindles for light tow yarn, and a small mill belonging to James Haggart, are both actively employed in the parish.

LETLENDY.-The green crops in this parish in 1792 consisted of nearly equal proportions of potatoes, turnips, pease, and lint, and the rotation of the latter was after oats. The annual produce was about 2.50 stones (Amsterdam) of lint. The parish was divided into small farms, of from six to ten acres; and the rent of the best land did not exceed 20s an acre, the greater part being below 15s. There were then 2 flaxdressers and 13 weavers in the parish.

Leuchars. - There were 90 looms in the parish in 1794, 34 of which were in the village. The weavers were employed in what is called "household work" of various kinds, and in brown Linen and single and double sail-eloth, which they made for the Dundee merchants. Several of the manufacturers had shortly before begun to buy yarn, weave it, and sell the cloth to the merchants in Cupar and Dundee. That description of business was 
then on the increase, and such a trale was thought so extraordinary, as to be worthy of being recorded in the Statistical Account of the parish. One man in the parish had gained a name and fame for working damasks and other table Linen. Handloom weaving has continued to be the chief occupation of the inhabitants, the cloth being sill made principally for manufucturers in Cupar, Dundee, \&c.

LitTle Dunkeld.-In this parish Flax was an article of great importance to the inhabitants in the last two decades of last century, potatoes and lint having been called the two feet which supported them. It was generally sown after barley, but sometimes after potaties; and in the latter case, when the land was somewhat moist, the ground did not get a seed furrow, as this was found to be detrimental to the lint, and it was sown in the state in which the ground was left at the digging of the potatoes, a little lime being sometimes mixed with the soil in hoeing them. In this way, the richest crop of Flax was obtained. Sandy ground produced the poorest crop, but the quality was finest. A peek of seed, Linlithgow barley measure, produced from 3 to 4 stones of 22 lbs. avoirdupois. 1426 pecks, producing 4296 stones, was the average yearly crop. The Flax was all spun by the women of the parish, and afforded them constant employment for six months in the year. A little of the yarn was weaved for domestic purposes; but the bulk of it was sold to hawkers and others for the great manufactories, and to weavers who sold webs when made. A spindle from the pound of heckled Flax was the usual size of the yarn spun for sa'e. The one fly-wheel was once chiefly used, but tho two-handed one had then become pretty general. The thread produced by it was coarser; but as the Flax was not so well heckled, it gave more pounds from the stone, and it was more profitable, Some young women, without much previous teaching, were able to spin a thread as fine as $3 \frac{1}{2}$ spindles from the pound avoirdupois. In 1790 there were 5 lint mills in the parish, with large sheds attached, roofed with slate, for stowing unseutched Flax; the Board of Trustees having given much encouragement to these erections. They also furnished one of the weavers with a diaper loom. There were at that period 23 flaxdressers in the parish, and 160 weavers. 
LOCHMABEN.-Nearly a century ago a considerable manufacture of coarse Linen was carried on in the town and country around. About 60,000 yards were made yearly, which were all sold in England, mostly unbleached, at from $6 \mathrm{~d}$ to $1 \mathrm{~s}$ or 1s $1 \mathrm{~d}$ a yard. There were then two lint mills in the parish ; but they were unable to do all the work they could have got, and part had to be scutched elsewhere.

Logerait.-In this parish, about 200 acres of Flax was grown. The staple article of manufacture and export was Linen yarn, which was spun by the women in winter, during which period they sat closely at their wheels. In 1783 famine prevailed in the parish, but the Linen yarn happened luckily to bring a very high price that year, which was a great assistance to the people. In 1787 corn was as dear and yarn one-third cheaper; the poor in consequence suffered more even than in the former period.

Logie-Pert. - Logie Bleachfield, on the North Esk, was started about 1760, and went on gradually extending, until, in 1790 , about 70,000 spindles of thread were bleached annually almost the whole produce being disposed of in the London market. This field has now been discontinued, Aberdein, Gordon \& Co., the proprietors, having erected a new work at Sunnyside, in the parish of Montrose, a little lower down the Esk. There they have a steam-power of itwelve horses, employ 50 hands, aud bleach fully 800 tons of yarn yearly. Logie spinning-mill was erected before 1805, and much enlarged about thirty years thereafter, employing, in 1835, about 130 hands. It was long carried on by the same firm, but they left it and the bleachfield together. and it was silent for some time. It is now possessed by James Ramsay \& Co., and busily at work again. 'The water-power is equal to 30 horses, and the mill contains 1400 spindles, and employs 70 hands. Craigo mill and bleachfield adjoins Logie. The field was begun shortly after Logie, and for a time also bleached thread; but before 1790 it was chiefly employed on cloth. Now yarn is bleached largely, the machinery being driven by a water-wheel of 20 horse-power, and the work affording employment to 110 hands. At both ficlds the yarn bleached is chiefly the property of the respectire firms, and spun at their own mills. Craigo spinning- 
mill, adjoining the field, has a water and steam-power of 34 horses, contains 1800 spindles, and employs about 150 hands. Both mill and field belong to Richards \& Co. of Montrose, who pay about 16000 a year of wages to the workers. In 1790 there was a mill in the parish for cleaning yarn for shoeting and ducks, with yarn-beaters, and Flas-breaking or scutching machinery, which put through about 1500 stones, all for home consumption. 'Then about 46 acres of Flax was grown in the parish yearly, and the women found excellent employment in spinning it. Factory yarn was also given out by shopkeepers, for spinning which from $1 \mathrm{~s}$ to $1 \mathrm{~s} 2 \mathrm{~d}$ a spindle was paid.

LongForgan.-About the year 1794, and for some years before, the inhabitunts had been remarkably successful in raising great crops of lint, and their practice was then said to be well worthy of imitation. The system adopted was to water the lint grounds in rainy weather with dung water, that from the cowhouse being preferred. So advantageous was this operation, that the then proprietor had a cart made specially for the purpose of conveying the liquid manure to the field, and it is minutely described in the Statistical Account of the parish. Iinens have long been, and still are weaved in haudlooms to a moderate extent in the parish.

MaIss.-Last century the farmers were averse to sow Flax, as they did not think the ground proper for it, and only about 20 acres were grown yearly. In 1760 , there was only one bleachfield, employing 10 persons, and one mill for washing and cleaning yarn; but in 1790 there were no fewer than nine bleachfields, employing about 10!) persons, three of which were carried on upon an extensive scale, and seventeen mills for washing and cleaning yarn, besides five mills for beating thread and eloth. In the latter year a mill for spimning flax was erected at Trot-

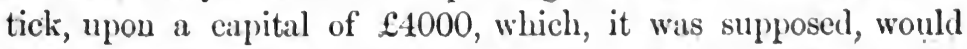
give bread to a great number of people, both young and old, and bring considerible emoluments to the proprietors. When the Statistical Report of the parish was written in 1791, one frame was working, by which a specimen of the yarn was produced. It is stated that the spindles ran with amizing quickness, and made very good yarn; only, as it was drawn out dry, it appeared rough. It was thought that this might have been obviated if 
a method of wetting the flax while spinning could have been invented, as it would make the cloth smoother, and give it a finer appearance. The mills were all on the Dighty river, which, it was then supposed, drove more machinery for its size than any other in Britain. The women in the parish found profitable employment in spinning Linen yarn, which they did by the twohanded wheel, and earned easily eightpence a day. $\mathrm{A}$ large quantity of coarse cloth, called soldiers' sarking, and Osnaburgs, was bleached at the fields, the most of which was exported. Some of it was weaved in the parish, but the greater part was sent out from Dundee to be bleached, and returned to the merchants. The report adds- "In short, a person has only to come to this water to see the happy eftects of industry and manufactures, and to what a height they may be carried. While the manufacturer enriches himself, he does a real benefit to society, by employing those hands who must have either become burdens upon the public by asking charity, or nuisances by worse practices." For nearly twenty years, the spinning-mill at Trottick was carried on with varied success, sometimes realising handsome profits, at others, making heavy losses. During that period it frequently changed owners, until, in December 1808, it finally became diverted from its original purpose, and was turned into a yarn-washing mill in connection with Claverhouse Bleachfield. In 1833 there were four bleachfields in the united parishes of Mains and Strathmartin, two of which were of great extent; and four Flaxspinning mills, all of which had steamengines in addition to the water-power. There were also five yarn-washing mills, where yarn was milled or prepared for the loom, and the weft softened by beating. There are now three bleachfields, viz., Claverhouse, Turnbull \& Co.; Dundee, Cargill \& Co. ; and Balmuir, A. J. Murdoch \& Co. The first two carry on a very extensive business, and the other, which has been recently erected, bids fair to do a large trade also. Several plash-mills are still in operation; but the Flax mills have disappeared or changed their occupancy, the last one having been burned down in 1861 .

MakKINCH. - A bleachfield was early established in the parish, and it was being carried on successfully about 1793. 'The manufacture of brown Linen had been introduced prior to 
that period, and a large quantity of goods were for some time manufactured, but the trade had declined, and the greater number of the people were then employed by manufaeturers on the coast in making checks and ticks. From the flourishing state of these manufictures, and the high wages paid to the weavers, the quantity male had then increased greatly. In 1794 Haugh spinning mill was erected, but after a varied fortune it was dismantled lately. Operations are now in progress to resume operations, and it will soon be started again. Balgonie Works, belonging to J. G. Stuart \& Co., are driven by water and steam power, equal to 150 horses, and contain 2976 spindles and 32 power-looms ; and Shythrum Mill, belonging to N. \& N. Lockhart, contains 820 spindles, chiefly on Hemp twines. These works, and several extensive bleachfields, give regular employment to a large number of hands, and greatly benefit the parish.

Meiglf.-In 1788 there were stamped at the Stamp Office here 147,024 yards of Linen; in 1789, 150,174 yards ; and in 1790, 136,998 yards. The Linen manufactured in this parish was of superior quality, and chiefly used for buckram, hat lining, \&c. It was the principal trade of the parish, and in 1791 there were 91 weavers, who produced every week about 4000 yards ot Linen,

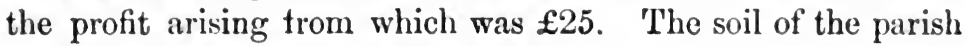
yielded excellent crops of Flax.

Melrose. - In the year 1668 the weavers in the town were incorporated under what was called a seal of cause from John, Earl of Haddington, then lord of the lordship, and bailie principal of the regality of Melrose. 'This town had long been famed for Linens, named "Melrose land Linens," for which commissions had been received from London and foreign countries, but after about 1770 the business began to decline. The quantity stamped, as shown by the stampmaster's yearly abstract, from 1st November 1754 to 1 st November 1755, was 33,2821 yards, valued at $\mathfrak{E 2 , 5 7 5} 10 \mathrm{~s} 11 \frac{1}{4}$. In the succeeding ten years the quantity and value continued much the same. From November 1764 to 1765 there were stamped $32,300 \frac{5}{8}$ yards, value $£ 2,49514 \mathrm{~s} 91 \mathrm{~d} d$; and from Nov. 1773 to $1774,20,789 \frac{3}{4}$ yards,

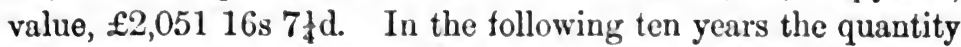
decreased, on the average, to 17,792 yards, value $£ 1,84512 \mathrm{~s} 4 \mathrm{~d}$. 
This decline was in a great measure owing to the rise of the woollon manufacture in the district, and the encouragement which the Board of Trustees had given to it in the shape of pre-. miums and otherwise. It was suggested by the manufacturers, that the Trustees should give premiums and extras on well made pieces of Linen, as had been done in Scotland about 40 years previously, and that spinning mistresses should be appointed in different towns in the parish to teach the young girls to spin, and offering prizes to the best spinners. 'There was then a bleachfield in the parish, the property in which was divided into $£ 5$ shares, but the trade had also been in a decaying state. The Linen trade, it appears, gradually gave way before the advance of the woollen manufacture, until it finally became extinct in the district. In 1780 the price paid for spinning was, 4 hanks of yarn from 1 pound of lint, 1s $2 \mathrm{~d}$; 5 hanks, $1 \mathrm{~s} 4 \mathrm{~d}$; 6 hanks, 1s $8 \mathrm{~d}$; 7 hanks, $2 \mathrm{~s}$. In 1790 , it had risen to $1 \mathrm{~s} 7 \mathrm{~d}, 1 \mathrm{~s} 8 \mathrm{~d}, 2 \mathrm{~s} 1 \mathrm{~d}$, and $2 \mathrm{~s} 4 \mathrm{~d}$ for these sizes respectively.

Menmuir.-The soil in several places was particularly favourable for raising Flax. It was sown about the beginning, but sometimes through the whole of April. In 1792, with the assistance of the Board of Trustees, a mill for dressing lint was erected on the water of Cruik. Shortly before that year four or five persons obtained premiums from the Trustees. for the quantity and quality of the Flax grown by them. The women span a great deal of lint into coarse yarn for the duck or sail-cloth factory. They span with both hands, a practice supposed in the district to be then little known in the south of Scotland, which enabled them to earn $3 \mathrm{~s}$ a week. There were three persons in the parish who took in the undressed Flax, and one of them kept two hecklers to prepare the lint for spinning, which, on being returned in yarn, was carried to Montrose, as the few manufacturers in the parish were principally employed in making Linen of a finer quality for home consumption.

METHVEN.-The principal manufacture of the parish was broad and narrow brown Linens, broad and narrow harns, and a few broad white Linens. By the books of the stampmaster the number of yards stamped in 1787 were 44,996 yards. The manufacture after that increased rapidly, and in 1792 there were 140,448 yards stamped for salc, which at an average price of 


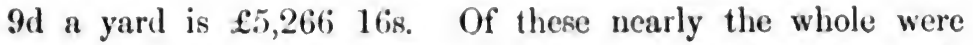
weaved in the parish. The following year the trade was bad, and many of the weavers were obliged to turn to other employments There were then $11 \mathrm{Flax}$-dressers and 159 weavers in the parish, Flax was a common crop, and the spinning gave employment to many of the women.

Monifietr.-In the parish there were, in 1790, about 38 weavers, who made household cloth when required, and at other times Osnaburgs, but the quantity of Linen woven could not be then ascertained. 'There were 3 Flax-dressers, 7 Flax millers, and 2 oil millers in the parish. In the oil mill the oil from about 800 bolls of linseed was extracted annually. A small part used in the neighbourhood, was sold at $1 \mathrm{~s} 3 \mathrm{~d}$ the Scotch pint, and the rest sent to London. Part of the oil dust was sold for the purpose of fostering the milk of the cows in spring, and the balance made up into cakes, and sent to Yorkshire to fatten cattle. A spinning mill was long in operation at Milton of Monifieth, but it has not been occupied for years, and the ruinons building will soon be numbered among the things of the past. Panmure bleachfield has been carried on for many years with great success by Daniel Drimmie \& Co., and it is now one of the largest for yarn in the conntry.

Monedre.-In the parish lint throve well, and was manufac-. tured by the small farmers into Linen, (most of them being also weavers), and Perth furnished a good market for the cloth. Some of the principal farmers then sowed a considerable quantity of lint, and exposed it to sale upon the field before it was fully ripe, generally getting from $£ 12$ to $£ 14$ an acre for it. In 1790 one farmer got as much as $\mathfrak{E 1 9}$ an acre. At that time all the women in the parish span Linen yarn, and it was mostly weaved by the old men.

East Monkland. - In this parish about 100 acres of Flax were raised for sale, for which the ground was let at from $\mathfrak{5 5}$ to $\mathfrak{£ 6}$ an acre. It was generally sown the second year after the land was broken up from pasture, and after a crop of oats or pease. There were then 227 weavers in Airdrie and other parts of the parish, who were chiefly employed by the Glasgow manufacturers in weaving Linen.

West Monkiand - A considerable quantity of Flax was 
raised, and it was generally sown on ground which had been well manured with dung or lime for the previous crop; such land being let at from $£ 4$ to $£ 7$ an acre. Riga seed was preferred, and it was sown in April and ready for pulling about 1st August. Nine women could pull an acre a day, and were paid $10 \mathrm{~d}$ each. The produce was 16 stones an acre, which sold at $12 \mathrm{~s}$ to $13 \mathrm{~s}$ a stone, and the scutching cost $2 \mathrm{~s} 6 \mathrm{~d}$ a stone, there being two mills for this purpose in the parish. From 1780 to 1790 the raising of Flax had greatly increased, one farmer growing 30 acres, and he had got several premiums from the Trustees. There were no less than 400 Linen weavers in the parish, who all wrought to Glasgow manufacturers, and their wages produced a circulation of about $£ 14,400$ annually. There were then two bleachfields, being the first in the country who bleached after the Dutch method, and for their diligence and ingenuity they obtained a considerable premium from Government.

Monzie.-The principal trade in the parish for the last two or three decades of last century was the weaving of Linen tweels and scrims for sale, of which they made a large quantity and are said to have bleached it excellently themselves. The tweels were of various degrees of fineness, worth from $1 \mathrm{~s}$ to $4 \mathrm{~s}$ a yard, and some families with only two looms weaved about 1000 yards per annum. The scrims were a very narrow linen cloth, of different qualities, and generally sold unbleached. They were all exported, and supposed to have been used for trousers. If so the country in which they were worn must have been very warm, but in any climate a scrim, if like the class of goods so called in the present day, could not form a very seemly pair of trousers. The women span a good deal of yarn, which they made into cloth for sale, and thus by their industry they raised great part of the rent.

Moulis.-The principal branch of manufacture during the greater part of the eighteenth century was the spinning of Linen yarn, which was the staple commodity of the country. The Flax was grown in the parish, and in 1790 there were seven lint mills, which enabled the people to get all their Flax dressed before the proper time for spinning it. The price of a stone of lint was at an average $13 \mathrm{~s} 4 \mathrm{~d}$, and this when dressed or heckled yielded about 11 lbs. of lint, the tow, backings, \&c., 
being equal in value to the price of dressing. From these 11 lbs. of lint 11 spindles of yirn were spun, which sold at the average price of $2 \mathrm{~s} 4 \mathrm{~d}$ the spindle, or $\mathfrak{2 1} 5 \mathrm{~s} 8 \mathrm{~d}$. The profit was therefore $12 \mathrm{~s}+\mathrm{d}$, or $1 \mathrm{~s} 1 \frac{1}{2} \mathrm{~d}$ the spindle, and as it generally took three days to spin a spindle, the daily wages was $4 \frac{1}{2} \mathrm{~d}$. A good spinner, employed sulely in spinning, might have earned 3 s a week, but the average spin was 16 cuts a day, and the size of the yarn was generally a spindle, or 48 cuts from a pound of lint. The spinning of lint was done in winter, woollen yarn having been spun in summer, and the spinning with both hands had then been introduced, and was coming into practice. A fair, held at Moulin in the end of February, had been the principal market for the sale of Linen yarn, and thither the weavers and yarn dealers from different parts of Scotland used to resort, and buy up, for ready money, the yarn which had been spun during the winter. For some years prior to 1791, the quantity sold in the fair had fallen off greatly, as shopkeepers and yarn-dealers had bought up the yarn in the course of the winter, and sent it to their employers in manufacturing towns. In 1741 Linen yarn sold at $1 \mathrm{~s}$ the spindle, and in 1756 the Linen used for shirts by the peasants cost $4 d$ a yard. In 1791 a man's shirt cost 3s $4 \frac{3}{4} \mathrm{~d}$, a woman's shift $2 \mathrm{~s} 9 \frac{3}{4} \mathrm{l}$, and children's shirts $2 \mathrm{~s} 5 \frac{1}{2} \mathrm{~d}$, all of Linen. Linen yarn sold then for $2 \mathrm{~s} 6 \mathrm{~d}$ to $2 \mathrm{~s} 7 \mathrm{~d}$ the spindle, which was considered a good price. The spinning season was from November to March, or about 21 weeks, and it was calculated that in the parish there were 272 spinners, who span one spindle each per week, and 414 who span two spindles, thus producing for sale 23,100 spindles, which at $2 \mathrm{~s} 4 \mathrm{~d}$ brought a return in cash of $£ 26836 \mathrm{~s} 8 \mathrm{~d}$. This quantity of yarn consumed about 2200 stones of lint as it was taken from the mills, the remainder of the produce of the parish having been used for household purposes, or sold to other districts less fertile in producing Flax. In 1790 there were 75 acres of Flax grown, producing 36 stones per acre, making 2700 stones, which at $13 \mathrm{~s} 4 \mathrm{~d}$ is $£ 24$ per acre, and in all $£ 1800$. That year there were 4 flaxdressers and 28 weavers in the parish.

Newbukgh, Fife.-Prior to the year 1780 the trade and manufactures of Newburgh were of comparatively limited extent, and Cunningham called it "a poor country village." In 
the statistical account of the parish in 1792, the place was of so small importance that it was said "no trader has yet appeared in Newburgh whose extensive transactions in commerce would entitle him to the name and character of a merchant, though, perhaps, the time is not far distant when many will be found here of that respectable description." The writer of that paragraph must have been able to dive into futurity, or rather he had been sagacions and far seeing, as his predictions have been fully verified. For many years subsequent to that date the individuals employed in the trade for the most part wove their own yarn, and disposed of their webs to merchants in Dundee, Perth, Cupar, Auchtermuchty, Glasgow, \&c. Afterwards the manufacturers began to operate more extensively, employing a number of weavers, and selling the cloth direct to the English buyers. In 1833 there were 342 people employed in winding; 564 looms were at work in town; the pieces manufactured 23,600 , containing about 826,000 spindles of yarn ; and the cost of the cloth, including weaving, bleaching, \&c., was $£ 128,325$. In addition to the quantity of Linens made in Newburgh, the manufacturers employed many weavers in the towns and villages for many miles around. The cloth made consisted of dowlas and sheetings - the latter from one to three yards wide, and in quality from fourteen hundred Linen downwards. The pieces were made about 140 yards long, and a yard wide sheeting was worth from $£ 510$ s to $£ 6$ a piece, while the three yard wide was sold at $3 \mathrm{~s} 6$ d a yard. In 1835 there were thirteen manufacturers in Newburgh. Since that period the trade of the town has not increased much, and the number of manufacturers are fewer than they then were, but some of them do a very large and important trade. The class of goods now chiefly made in the town and district are sheetings for household purposes, and for such the place has a high and well-merited reputation, as the Linen made is really of a superior description, and very suitable for the purposes for which it is intended. According to the Fifeshire Directory, published in 1862, there were upwards of 550 looms in the district, which varies little from the number in 1833, and the manufacturers now, as then, employ many hands in the neighbouring towns and villages, In the neighbourhood is Clunie Bleachfield, a prosperous concern, belonging to John Hendry. 
North Yed, and Fetrak. - In North Yell and Fetlar the Linen manufacture had been tried about 1790 , but it did not succeed, "because the fair sex were so accustomed to roam about the rocks that they could not apply themselves with diligence to the manufucturing business, and because the constant sitting was said to have brought on hysterical disorders." Another reason was that they could purchase Linen cheaper than they could afford to make it. 'The Shetland women must then have been very delicate and nervous fuir ones, but perhaps the true cause of the failure of the Linen trade was because the fair sex preferred pleasure to labour, and considered it beneath their dignity to spin or weave; or because other employments were more congenial to their taste.

Orpur.--Among the advantages which the parish of Orphir, in Orkney, was said to possess in the end of last century were "fire, water, and fine women." It appears from the statistical report of the parish, that these fine women were employed spinning Linen yarn, and that the country dealers allowed so poor a price for the commodity that the most expert spinner could hardly earn twopence a day, which would not furnish fine dresses for the fine womeu. The Linen manufacture, on a small scale, had shortly before that period been introducer into the parish, and it was said that since then rhuematism had become more frequent, it was supposed in consequence of the substitution of the Linen shirt for the woollen waistcoat formerly worn by the common people.

Paisley.- The manufactures of Paisley, from the Union to about 1760 , consisted at first of coarse checked Linen cloth and Bengals, afterwards of checked Linen handkerchiefs, some of them fine and beantifully variegated in colouring, according to the taste of the manufacturers. These wore succeeded by plain lawns and Linen gauze, for which the town was once celebrated. The manufacture of white sewing thread, known as ounce thread, to distinguish it from the different kinds of coloured and white thread then made in Aberdeen and Dundee, was begun about 1750. It was introduced into the neighbourhood from Holland in 1725, and carried on for a long time in the family of the lady who first learned the secret, and began the trade. As in Glasgow, the cotton manufacture finally supplanted that of Linen in Paisley. 
Perth.-The Linen trade of this city was begun at a distant period, but the time of its introduction is not accurately known. German merchants, or Flemings as they were called, very early frequented the port of Perth, and some of them who were acquainted with the Linen manufacture settled there, and were received as burgesses. The trade had its day of prosperity and also of adversity, as in other places; but, on the whole, for a long period, it went on gradually extending, until it became the staple manufacture of the place.

The Literary and Antiquarian Society of Perth nominated some of their number, well acquainted with trade, to give in a report upon it. The Committee took much trouble in collecting the materials, and on 10th June, 1794, gave in a report, from which the following particulars, bearing on the Linen trade, are taken:-

"The staple manufacture of Perth was Linen, and of late a considerable quantity of cotton. There are upwards of $\mathbf{1 5 0 0}$ looms employed in the town and suburbs on Linen and cotton, which manufacture goods annually to the value of about $£ 100,000$ sterling, Besides this there is at least $£ 120,000$ sterling more of Linen purchased in the Perth market by the dealers, all of which is woven in the surrounding country, making a total value of about $£ 220,000$ annually.

"The Linen goods comprise brown and bleached finethreaded Linens, called Silesias, chiefly printed for handkerchiefs, with Britannias, Kentings, \&c., for export, the estimated value of which is above $\$ 120,000$; (Perth had been long famed for the manufacture of these articles) stout Holland sheetings of various widths, with $\frac{7}{8}$ and $\frac{4}{4}$ Holland shirting, and a few long lawns, above $£ 12,000$; four-fourths brown and bleached country Linen, chiefly used for hat linings, buckrams, \&c.; brown Hollands, hessians, pack-sheetings, and other coarse fabrics made in the neighbourhood, including soldier's shirtings, with a few coarse sheetings and Osnaburgs, purchased, $£ 20,000$; fivefourths wide umbrella Linen, Linen for window blinds, \&c., above $\$ 8000$-making a total of Linen goods of above $£ 160,000$, which the Committee are confident is under-rated.

" There are three printing works in the neighbourhood, viz., Ruthven, Tulloch, and Cromwell-park, which is now 
doing business to at least the extent of $\mathfrak{E} 80,000$ annually, and the trade is on the increase. 'The produce of these works is shipped at Perth, chiefly for the London market. 'The printers there have " full command of the article of Silesia linen for handkerchief printing, the stuple manufacture of the town and neighbourhood. 'They likewise supply part of the country demand both in England and scotland.

"There are four bleachfields in the vicinity of Perth, which bleach cloth for the country around, and for the manufacturers in the principal towns of Scotland, and they even get cloth from England. At Luncarty about 600,000 yards of Linens aro bleached annually, two-thirds of which are low-priced Linens, with diaper and table Linens from Dunfermline, Edinburgh, Perth, \&c., and the other third consists of fine Linens and sheetings. At 'lulloch abont 300,000 yards, chiefly low-priced Linens for the public. At Huntingtower fully 600,000 yards, two-thirds of which are low-priced goods, and the other third diapers and fine goods. And at Stormont about 450,000 yards, two-thirds Silesias, Britannias, shirtings, \&c., and the other third diapers and fine goods. At Luncarty and Huntingtower there are sometimes in the throng season above 60 Scots acres of greens at each work covered with Linens.

"The imports from foreign countries comprises Flax and Flax seed, estimated at above $£ 9000$ annually. The following is the arerage importation of these articles for the five years from 10 th October, 1783 , to 1 (t) th October, 1788 :-

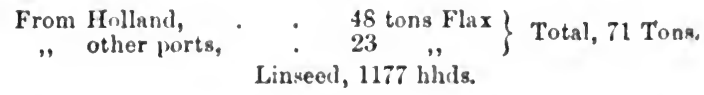

And for the five years from 10th October, 1788, to 10th October, 1793-

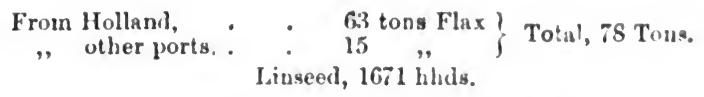

Since the period refer:ed to, great changes have overtaken the trade of Perth and vicinity. Flax-spinning was for some time prosecuted actively, but for a number of years it has been discontinued. The weaving of cotton fabrics by hand in the city and neighbourhood has long supplanted Linens, but of late years 
a large power-loom work, containing 230 looms, has been actively employed in the city ; and another, containing 100 looms, atCromwell-park. They both belong to J. Shield \& Co., and produce all kinds of damask and diaper table-cloths, towels, \&c., crash, padings, drills, dowlas, \&c., consuming about 500,000 spindles of yarn annually, and paying between $£ 8000$ and $£ 9000$ in wages. The power employed is steam in Perth, and water at Cromwell-park. There is another small power-loom work, with 33 looms, on hessians, Osnaburgs, and dowlas, at Milnhaugh, which pays nearly $£ 700$ in wages yearly.

Some of the old bleaching establishments in the vicinity of Perth continue to be carried on extensively. Tulloch, belonging to John Sandeman, still does a good deal of work ; and Luncarty, belonging to Marshall, Sandeman, \& Co., is a very large and prosperous concern. Stormontfield has been silent since 1861 ; but Pitcairnfield, belonging to David Lumsden, has a water-power of 50 horses, and employs between 50 and 60 hands on cloth bleaching, who are paid about $£ 1500$ in wages yearly. Mr Lumsden has a yarn bleachfield, Denburn, in Kirkcaldy, where about half this amount is paid in wages. Huntingtower, belonging to $W$. $\mathrm{S}$. Turnbull, is perhaps the most important bleachfield in the neighbourhood. It has been entirely re-built and renewed within the last ten years, when all the la test improvements were adopted. The machinery consists of six boilers, thirty-eight sets of beetles, and twelve pairs of wash stocks, with two calenders, and all other apparatus necessary for these machines. The machinery is driven by a water-power of from 90 to 100 horses, about 150 people are employed, and the wages paid is about $£ 5000$ yearly. Mr Turnbull has recently re-built the cottages for his servants, with every attention to comfort internally, and to architectural appearance without. These bleachfields are all for Linen, but Caird \& Co. have a thriving field for bleaching yarn at Cromwell-park.

Peterhead. - The manufacture of thread was carried on to a considerable extent in the end of last century. In 1794 there were 52 twist mills in the town, giving constant employment to 334 people in doubling, twisting, and making up the thread. About 800 women were employed spinning the yarn for the thread, fully $104,(100$ spindles of which were used annually. 
A considerable quantity of the yarns were bought in Banff, Huntly, Keith, \&c., and much of it was spun from Dutch Flax. The greater part of the thread was bleached, and it was almost wholly sent to the London market, where the article was in

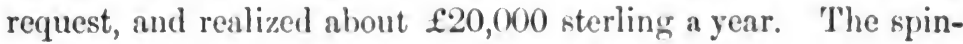
ners made about $2 \mathrm{~s} 6 \mathrm{~d}$ a week, the women employed in doubling, \&c., 2s $6 \mathrm{~d}$ to $4 \mathrm{~s}$, and the men in heckling, twisting, \&c., 5s to 88. The manufacture was at that period in a prosperous condition, and some of the manufacturers contemplated increasing their machinery. It was introduced into the town in 1764 by two young ladies, who began the manufacture of white thread on a small scale. When it was commenced no yarn could be found in the town finer than four hanks in the pound, but the young women were soon trained to spin it as fine as eight and ten hanks or hesps in the pound, and the two young ladies were so attentive to their business, that their thread became as much esteemed as any in the kingdom. They extended their bleachfield from time to time, and got a ready sale for all the threads they could manufacture. Aftcr being about a quarter of a century in the trade, they retired from business and left it to others, and, as above related, it continued to prosper for many years; but the trade has been long extinct in the town.

Rathen.-Thespinning of Flax was introduced into this parish by a cotton manufacturer in 1750 , and during the remainder of the century it was carried on to a great extent. 'The Flax was chiefly Dutch, and it was sent dressed from Aberdeen, Banff, Huntly, Keith, \&c., to agents, who gave it out to the women to spin, and took back the yarn, returning it to the parties to whom it belonged. The average price paid for spinning was about a shilling a pound. In 1793 about 38,900 lbs. were spun, the wages on which was $\mathfrak{1 9 4 5}$. The parish had long been famed for producing fine Flax, but more so before than after the introduction of marl. The farmers were, however, restricted from raising wheat or Flax in considerable quantities, because they had been found, or were supposed, to exhaust the soil. The cultivation of Flax has often been prohibited on this account, but the parties riho restricted the growth of wheat beyond a fair rotation on such a ground could not have been much acquainted with practical agriculture. This doctrine 
would not meet with much approval in the present more enlightened age.

St Boswells.-St Boswells' Fair is held in the parish annually, in July. Long prior to 1790 Linen was sold in it to a considerable extent, great numbers of the neighbouring country people being employed during the winter in spinning the yarn and weaving the cloth. The prices ranged, according to quality, from $10 \mathrm{~d}$ and $1 \mathrm{~s}$ to $3 \mathrm{~s}, 4 \mathrm{~s}$, and even $4 \mathrm{~s} 6 \mathrm{~d}$ a yard. Many persons provided themselves with Linen at this fair, thinking that they purchased it cheaper there than they could either make it themselves or buy it elsewhere. The fair is still continued yearly; but the change in the manufacturing trade of the country within the past seventy years has entirely stopped the sale of Linen, and this article is now unknown among the goods taken to it for sale.

SALTON - In the beginning of last century, the lady of Fletcher of Salton, animated with a sincere desire to increase the manufactures of her country, travelled in Holland, with two expert mechanics, in the habit of servants. Her rank procured her access, with her supposed domestics, to the manufactories; and; by frequent visits, the secrets of operation were discovered, and models of the various works were formed by the disguised artists; The parish in this way became acquainted with two discoveries, viz., the making of pot barley, and the weaving of Hollands; and for several years it supplied the whole of Scotland with these important articles, to the great emolument of the inhabitants. In the year 1750 the first bleachfield belonging to the British Linen Company was formed in this parish, under the patronage of Lord Milton. During his lordship's life it was conducted with much spirit, and, by procuring the most expert workmen from Ireland, it became so flourishing as to give employment to 100 persons. The bleachfield did not exist long, it having been converted into pleasure-ground, and the manufacture of Hollands was taken up by other places. Although this trade has been for a long time lost to Salton, these goods are yet common productions in the Linen districts of the three kingdoms.

Scoonie.-Although little Flax was produced, there were about 140 looms in the parish in 1792, mostly engaged in the manufacture of brown Linen, many of which were in the village 
of Leven. There was then a bleachfield near the village, the business of which was increasing, as the prejudices which had existed against public bleaching were then wearing off. 'The linen sold in the brown state brought from $8 d$ to $10 \mathrm{~d}$ a yard. What was bleached fetched from $10 \mathrm{~d}$ to $20 \mathrm{~d}$, and some of a fine texture from $2 \mathrm{~s} u$ to ts a yard. A fair was held in the spring for linseed, and one every month, from May to October, for white Linen. In 1836 there were five spinning-mills in the parish, employing 250 hands, and about 170 were employed in weaving ; but there is now only one firm, Boswell \& Co., engaged in Flaxspinning, and weaving has also decreased greatly.

STmacatrino.-The soil was generally adapted for growing Flax, which was raised to a considerable extent, usually the second crop after lea. Eight pecks of seed were sown on the acre, the return being about 32 stones of dressed lint. An acre of lint, sold on its feet, brought from $\mathfrak{£ 1 0}$ to $£ 14$. The Flax which the farmer raised was spun in his own family, and brought, when sold, about $£ 12$ s the stone. When given out to spin, 1s 1d a spindle was paid for the spinning.

Strankaer.-About the middle of last century, the manufacture of Galloway plaiding, a coarse fabric made for the Virginia market, used to be the staple of Stranracr. By 1770 it had been supplanted by the manufacture of coarse Linen, for which Flax was raised in greater quantities than formerly. The Linen was brought to market both green and bleached, and bought chiefly by the merchants from Glasgow and Kilmarnock. The following was the quantity stamped, as shown by the stampmaster's books for the years named, viz.:-In 178S, 28,391 yards - value, $\mathfrak{1} 1268 \mathrm{j} 4 \mathrm{~s} 10 \mathrm{~d}$; in 1789, 28,662 yards $£ 127614 \mathrm{~s}$; and in $1790,26,991$ yards-\{1181 8 s $3 \mathrm{~d}$.

Stratudon.-About 1770 the women were chiefly employed in knitting stockings; but some years afterwards that work gave place to the spinning of Flax. There was little lint raised in the parish, but the $A$ berdeen manufacturers, through the country shopkeepers, supplied Flax, and took back the yarn. The employment was considered exhaustive, in consequence of the quantity of saliva required; but, notwithstanding, it was prosecuted diligently. 'Two-handed wheels were used about $17: 12$, and the common stent of the women was from 20 to 24 cuts $?$ 
day, although some of the best spinners, and in Strathdon they were generally capital hands, could on a stretch spin double that quantity. The wages for a spindle was $1 \mathrm{~s}$, and the spinning brought a good deal of money into the parish.

Strathmiglo.-This parish has long been noted for diapers, domestic dowlas, and other Linens, in the mannfacture of which, about twenty years ago, 500 weavers were employed. A bleachfield belonging to George Walker has long existed in the parish; and now a power-loom work has been established by Alexander Troup, with an engine of 16 horse-power, and containing nearly 100 looms, the wages paid annually being close

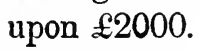

STrichen.-The culture of Flax was reckoned an important object in the parish of Strichen near the end of last century. It had been very much promoted by the encouragement of the Board of Trustees for Manufactures, in giving a premium for erecting a lint mill and distributing linseed gratis; but more effectually by the appointment of yarn markets in the beginning of March and middle of May, at which the principal manufacturers and dealers attended, and bought for ready money, and at the full market value, the yarn which the country people brought for sale The Trustees gave premiums of $£ 10$ per annum, for five years, to the person who bought the greatest quantity of yarn in these markets, made from Flax the growth of the country. 'This occasioned a competition amongst the buyers, to the advantage of the sellers. Upwards of 4000 spindles had for some years been sold by the country people at these markets, and they were of great benefit to the parishioners, and gave promise of becoming more valuable when better known.

Thurso.-About 1790 the weavers in the parish were principally employed in the manufacture of Linen cloth. The spinning of Flax for the south country manufacturers employed many hands, but it was not considered to be of much real benefit to the country. It appears from the Custom House books, that for the three years preceding January 1797, the average quantity of dressed Flax brought to Thurso was $84,583 \mathrm{lbs}$. per annum. This quantity would produce 53,114 spindles of yarn. The

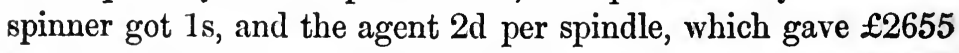
to the spinners, and $\mathfrak{1} 443$ to the agents or factors $=£ 3098$ 
yearly. "How inferior this," it is remarked in the Statistical Account of the parish, "to the profit which would have accrued to the country, if this quantity of Flax had been manufactured into sewing thread, or into cloth."

TunnfF.-In 1767, a manufacture of thread and Linen was begun in the town, and a bleachfield for the linen was erected in the neighbourhood; but the manufacture turning out unprofitable, it was discontinued, after having been carried on for about ten years. Subsequently the thread manufacture and bleachfield were again established on a small scale; and another thread work was begun in the neighbourhood about 1793. That year from 400 to 500 pieces of cloth, and about 666 yards of Linen, were bleached at the field; and 6696 yards of harn or brown Linen were stamped in the parish for sale, about twothirds of which was made out of the parish, and only brought there to be stamped. Some Flax was then grown and spun in the parish, in addition to which, foreign lint was given out to be spun by the manufacturers, this being one of the principal articles which brought money into the place. The wages paid in the parish in the years noted were as follows:-

\begin{tabular}{|c|c|c|c|c|}
\hline & & 1744. & 1774. & 1794. \\
\hline A ploughman, per annum, & & $£ 188$ & $£ 410$ & $£ 7 \quad 10 \quad 0$ \\
\hline A woman-farm-servaut, & - & $\begin{array}{lll}0 & 18 & 0\end{array}$ & 110 & $\begin{array}{lll}215 & 0\end{array}$ \\
\hline A man, for harvest, & • & $\begin{array}{llll}0 & 11 & 4\end{array}$ & 19 & $\begin{array}{lll}1 & 15 & 0\end{array}$ \\
\hline A woman for do., & . & $\begin{array}{lll}0 & 8 & 9\end{array}$ & 017 & $\begin{array}{lll}1 & 3 & 0\end{array}$ \\
\hline
\end{tabular}

Wém.-A considerable quantity of Flax was annually grown in the parish, in the latter half of last century, the usual quantity of seed sown being about fifteen hogsheads. The yield was from three to four stones of scutched Flax for the peck sown. The Flax was dressed in water-mills erected in different parts of the parish, and the owner of the lint paid 1s $4 \mathrm{~d}$ the stone for scutching. The whole of the Flax was spun into yarn of 4,5 , or 6 hanks in the pound, and it was all sold in that state to merchants from Perth and Glasgow, excepting the little required for home use.

Wemrss.-Almost every substantial family used to make a few pieces of good Linen aunually, from yam of their own spinning, which was wrought by weavers in the parish, bleached by themselves, and sold in the public markets held for the pur- 
pose in this and the neighbouring parishes. In this way the weavers had been employed from time immemorial, till about 1750. At that time some parties in Easter Wemyss became regular manufacturers of Linen; and since then this business has extended and improved. Much of the Linen was made from Scotch Flax, spun in the parish, and the quality was superior to the bulk of what was made in the country. The premiums given by the Trustees of the Linen Board for Linen and sheeting were adjudged to the parish for five years successively, viz., to one party for 1785 and 6 , and to another for 1787,8 , and 9. After that period the number of looms increased, the weaving of checks and ticks for manufacturers in this and the neighbouring parishes began; and in 1794 there were about 120 looms so employed. Since then hand-loom weaving has greatly decreased in the parish, and by and bye it will probably be extinct. East Wemyss has continued up to the present time to manufacture various sorts of Linens extensively. Twenty-five years ago considerably more than a million yards of dowlas, duck, and sheeting were made annually; but now this quantity is very much within the mark. Druggets, composed of Linen warp and woollen weft are now made in moderate quantities, and the trade is extending. One firm here, G. \& J. Johnston, employ about 200 hand-looms, which are scattered throughout a wide district; in addition to these they have recently erected a handsome power-loom work, driven by steam-engine of 25 horse-power, which already contains above 100 looms, being about half the quantity it is intended to hold. The firm make sheetings, dowlas, hucks, diapers, drills, ticks, \&c., employ fully 300 hands, and pay $£ 4000$ to $£ 5000$. annually in wages. The great establishment in this parish is Kirkland Worlss, on the Leven. They were begun in 1788 by some gentlemen belonging to London and Dundee, for the purpose of spinning cotton ; but very shortly afterwards were adapted for Flax-spinning, which has ever since been carried on. Great attention was from the first paid to the spinning, and even in the last century the yarn was considered of good quality. Soon after Flax-spinning was fairly established, the manufacture of sail-cloth and other fabrics was commenced; and a large quantity of the yarn spun is still manufactured on the premises. 
In 1794 about 300 people were employed at the works, and the Company then imported Flax direct from Russia. On Thursday, 25th January, 1810, Kirkland Works, which shortly before had been improved and enlarged, was, for the first time, lighted with gas. The apparatus for lighting the Works was constructed by Bolton and Watt; and this was the first introduction of gas into any spinning-mill in Scotland. In 1838, 392 hands were employed in Flaxdressing and spinning, 48 in bleaching, and 241 at hand-loom weaving, being 681 in all. About 280,000 spindles of yarn were spun, of which two-thirds was weaved intocanvas, sheeting, sacking, \&c., and the remainder sold; and the wages paid yearly was then about $\mathfrak{E} 17,000$. The works now belong to $H$. \& T. Peter, are driven half by water and half by steam, the aggregate power being 150 horses. They employ about 500 hands, who receive about $\mathfrak{i} 10,100$ a year in wages, and the quantity of material, Flax, Hemp, and Jute annually consumed is about 1500 tons. For many years after its erection, Kirkland was one of the leading establishments in the country, both in extent and importance, and the work has continued to keep pace with the improvements of the age. The raw material is heckled spun, bleached, weaved, now partly by power-looms, and the Linen, packed in bales, sent off to all parts of the country. The establishment has been long celebrated as a model work, complete in all its parts.

Wick.-Flax throve well in the parish near the end of last century, and most farmers grew as much as served their own use, but it had never been carried to such an extent as to procure premiums from the Trustees. Watering it was found to be a very precarious and troublesome process, requiring constant and regular attention, and taking up much valuable time. 'The experiment of boiling the Flax instead of watering it had been tried in the parish, and seemed to answer. The Linen manufacture in Wick has long ceased, and catching and curing herring are now the chief occupations of the inhabitants. 


\section{I S T ICT TRADE.}

\section{A berdeEn.}

The principal manufacture, prior to 1745 , was knitted stockings, which were mostly exported to Holland, and thence dispersed throughout Germany. After that period the Linen manufacture was introduced, and brought to considerable perfection. The spinning of Linen yarn for manufactures arose from a small beginning. Some patriotic gentlemen, a few years after the battle of Culloden, being desirous to spread this useful art more extensively in the northern districts, applied to the Board of Trustees in Edinburgh, who sent a woman qualified to instruct others in the art of spinning, and she took with her all the implements necessary for her purpose. She was very successful in her exertions, and from that period the production of Linen yarn went on increasing. In 1795 about 100,000 spindles were made, mostly by the wives and daughters of mechanics and labourers, for the spinning of which they were paid $£ 5000$ sterling. About the same period, much Linen yarn was taken to Aberdeen from the country around, and sold there. Very little Linen cloth was, for a considerable time, made in Aberdeen, the bulk of the yarn spun, especially the coarser sorts, being exported to Perth, Dunfermline, Glasgow, and other towns in the south. At this period the Irish, it was said, "engrossed the greater part of the Linen trade both in the English and in foreign markets not on account of the superiority of their goods, but in consequence of the encouragement given by their Parliament to the Linen manufacture, which enabled them to under-. sell the Aberdeen manufacturers, even in Scotland."

About 1790, a Company was formed in Aberdeen for the manufacture of brown sheetings and Osnaburgs, and in 1795 the firm began to make sail-cloth also. For some time the sail-cloth was almost all used by the sailmakers of Aberdeen, who approved of the quality, and thought it equal to any made in the south. The sheetings and other goods were shipped 
to London, whence they were chiefly sent to the $W$ est Indies and America. By unremitting attention to the manufacturing, these goods were equal to those made in other parts of Scotland, and the works were long prosperous. The Flax then used in the Linen manufactured for home use was chiefly imported from Holland and from England; but for Osnaburgs, brown sheetings, and other goods, Baltic Flax was chiefly used.

The manufacture of Linen thread, particularly white and coloured, was early begun in Aberdeen, and carried to so great perfection that for a long period it was almost unrivalled. At one time, towards the end of last century, Aberdeen made more thread than any other town in Scotland. It was all for the English market, the greater part of it going direct to London, whence it was shipped abroad. A considerable quantity of finer thread, called ounce or nun's thread, from its having formerly been made by nuns in France and Flanders, was at same period made in Aberdeen. About 1795 this thread manufacture employed nearly 100 boys, who earned from 1s $8 \mathrm{~d}$ to $2 \mathrm{~s} 6 \mathrm{~d}$ a week, 600 men earning from $5 \mathrm{~s}$ to $12 \mathrm{~s}$, and fully 2000 women, who had constant employment in spinning yarn, doubling and twisting the thread, \&c., and earned, when employed in the manufactories, from $5 \mathrm{~s}$ to 6 s a week; but when employed at home, rather less, as their time was partially occupied with household duties. In addition to those mentioned, who dwelt in the city and suburbs, fully 10,000 women were occasionally employed in the country around, spinning the Linen yarn for the thread.

In Sir John Sinclair's Statistical Account of Scotland, from which part of the above is taken, the following paragraph occurs-" At a period when the aids wanted by Governmeut are so considerable, the Legislature ought to do everything to encourage and strengthen the manufactures of the country. In 1782 , Parliament granted a drawback of the duty on soap used in bleaching and cleaning Linen and other goods. But a farther drawback is yet necessary with respect to ashes used in bleaching, which drawback, although very trifling to Government, would be of consequence to manufacturers in many respects. The member of Parliament who will give himself the trouble to examine into the utility of this drawback, and step forward to 
procure it, will deserve better of his country than the man who, by a continual opposition to Government, endeavours to raise a name to himself by pretending to be the people's friend. The people's best friend is the man who contrives to secure their property, and increase their trade by unfettering their manufactures."

In an acconnt of the exports from Aberdeen in 1712, it is stated that 7 trusses worsted stockings were sent to Norway, 104 trusses woollen cloth and worsted stockings to Holland, 12 trusses worsted stockings to Portugal, 31 parcels worsted stockings to Spain, and 2 boxes stockings to Germany; but no Linens were then exported, at least none are enumerated. The quantity of tow exported from Aberdeen to foreign countries in 1790 was 955 cwt. ; in 1791, 1,127 cwt. ; an l in 1794, 2,5931 cwt.

Flax-spinning by machinery was begun before the end of last century on the Don, not far from Old Aberdeen, and until a recent date, some very large establishments were carried on there and in Aberdeen. For a long period these works were in a highly flourishing condition, and the partners ranked among the elite of the city. Death and other casualties changed the seeming prosperity into positive adversity, and for years the music of the spindle in some of these mills has ceased, and the merry laugh of the factory girl is heard no more. The cessation of these works was a sad blow to Aberdeen, from which it has hardly yet recovered. In 1851 there were three large establishments in Aberdeen, and neighbourhood, viz. :-

Milne, Cruden, \& Co., Spring Gardens, and Gordon's Mills on the Don,. . . . . . 80 horse-power.

Lees, Masson, \& Co., Grandholm, . . . . 150 do.

Richards \& Co., Broadford, . . . . . . . 230 do.

Total, . . . . . $\frac{.}{460}$ horse-power.

There is now only one work engaged in the Linen trade in Aberdeen, but it is of gigantic proportions. It is driven by steam engines working up to 785 horses, contains 16,814 spindles for Flax and tow spinning and 428 power-looms, and it employs 2,175 hands. In connection with the mill is a bleachfield, also a calender and other adjuncts. Indeed, the Flax is imported, spun, weaved, bleached, calendered and packed within the establishment by Richards \& Co., the 
proprictors. The same frm have extensive works in Montrose and neighbourhood, all of which formerly belonged to Maberly $\&$ Co., but were acquired hy the present firm after the bankruptey of their predecessors about 1830 .

The causes which have produced such sad changes in Aberdeen are not difficult to discover. By intelligence and steady perseverance great works were reared up, but their builders forgot to raise up sons or other successors in industrious habits to conduct them when they were no more. The new generation, without the active, careful habits of their predecessors, became men of the world, and forgot their mills, thereby spending money instead of making it. Their business neglected, became unprofitable; their fortunes were soon dissipated ; and, as a natural consequence, misfortunes came and overwhelmed them. Thus it was in Aberdeen, and thus it will be everywhere, unless the families of the rising great be trained in habits of industry.

\section{Arbroath.}

Before 1736 Arbroath had little or no commerce, and no manufactures. Any pieces of cloth then made were carried to Montrose for sale, and Flax was purchased from the merchants of Montrose and Dundee. In 1738 or 1739, a weaver in or near Arbroath having got a small quantity of Flax, unfit for the kind of cloth then usually brought to market, made it into a web, and offered it to his merchant as a piece on which he would be willing to lose something. The gentleman, who had been in Germany, immeliately remarked the similarity between the pice of cloth and the fabric of Osnaburgs, and urged the weaver to undertake the manufacture of other pieces of the same kind, which he reluctantly agreed to do. The experiment succeeded to a wish, and many hands were soon employed in the neighbourhood of Arbroath. In this accidental manner was the manufacture of Osmaburgs first introduced into Scotland, and for many years they gave employment to a vast number of people in this and the neighbouring counties, and they are still made to a very large extent. Soon after this a company was formed by several gentlemen of property, who jointly undertook to establish a manufactory of Osnaburgs and other brown linens, and to import their own Flax. They laid out consider- 
able sums of money on different kinds of machinery, which were executed on a very complete and extensive scale. Success attended their spirited exertions, and, partly through their instrumentality, Arbroath fabrics attained great superiority, and for very many years commanded a sale in preference to any others of a similar kind made elsewhere. The gentleman alluded to, and who took the management of the company, was John Wallace, merchant, and sometime provost of the town; and for many years afterwards all the Osnaburgs manufactured in the neighbourhood centred in his shop. Before the end of the century the manufacture of this cloth had been extended to almost every town, village, and parish in the county, and far beyond it, and a very large amount of money was brought into the county by that branch of business.

In an account of Arbroath, written by the Town Clerk in 1742, he says, "The weavers are as numerous as all the other trades put together, and the grcatest manufacture is coarse Linen, which is commonly sold green, the greater part of which is sent to London. Of late the most considerable merchants have set up a manufacture of white and check Linens, which they are in good hopes to bring to perfection." Pennant in his Tour in 1776 says, "Osnaburgs were made in Arbroath before any encouragement was given by Government, or the Linen Company erected at Edinburgh. The merchant who first introduced the manufacture is still alive, and has the happiness of seeing it overspread the country."

From these early attempts are to be dated the rise and progress of the trade and manufactures of Arbroath, which, with occasional seasons of prosperity and adversity, have, on the whole, made wonderful advances up to the present time. Sail-cloth,Osnaburgs, and other brown Linens were long the chief articles of manufacture. In the year from November 1791 to November 1792 , as appears from the books of the stamp-master, there were stamped of the latter two articles 1,055,303 yards, of the value of $£ 39,6606 \mathrm{~s} 10 \frac{7}{8} \mathrm{~d}$. At that period nearly 500 looms were employed upon sail-cloth, the quantity produced being about of an equal value to the other Linens. The greater part of the Linen and sail-cloth manufactured was then shipped to London, the remainder being sent to Dundee and Glasgow. The principal 
articles of importation were Flax and Hemp from Russia, \&c.

About that period "the manufacture of a particular kind of cloth for coachmakers and upholsterers was begun in Arbroath. The parties who established the manufacture opened a shop in London for the sale of it, and in 1793 they had 18 looms working in Arbroath. One of the kinds was remarkable for its thinness, and more deserved the name of gatuze than Linen. A weaver was able to weave about 40 yards of it a day, and the selling price was $4 \mathrm{~d}$ per yard." 'The introduction of the manufacture of scrims into Arbroath seems to have created some surprise, but it was not long before the people became familiarized with the fabric, when it ceased to be an object of wonder. Owing to the flourishing state of the manufactures of the town, the increase of the population had been rapid for the ten or twelve years prior to 1793 , and it kept pace with the extension of trade That year the Harbour dues, exclusive of the Guildry dues, brought at

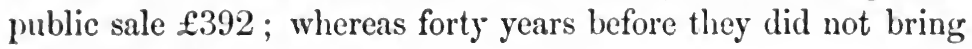
more than $\mathfrak{e 7 0}$, Guildry dues included.

In 1793 three elders went round the parish of St Vigeans, part of the town of Arbroath being in this parish, and took up the statistics of the population. Out of a population of 1,369 there were then engaged in the Tinen trade, 12 Flax-dressers, 2 dyers, and 225 weavers. There was in the parish a washing mill; a mill for beating dry yarn, with eight stamps; and a bleachfield where about 1000 spindles of yarn and 5,500 yards of Linen were bleached annually.

In 1740 a thread manufactory was established in Arbroath, and carried on for many years successfully, and thousands of people gained a livelihood by it. Owing to the high price of Flax, the great rise in the cost of spinning, the high wages allowed to weavers and others engaged in the manufacture of Osnaburgs and other Linens, and the want of a proportionate rise in the price of thread in the London market, where the bulk of it was sold, the manufacture, after an existence of nearly fifty years, began to decline. In 1792 , from the causes enumerated, the thread trade in Arbroath was facetiously said to be "thread bare."

In 1793, a small mill for spinning Flax was erected on the Brothock at Letham. It was at first driven by water-power, but a 
small steam engine was ultimately added to increase the power. It was an experimental attempt, and underwent constant alterations, but never prospered. Many years ago the work was abandoned, and the buildings allowed to go to ruins. In 1807 or 1808 some machinery for Flax-spinning was put into Inch mill, which was driven by a steam-engine of 16 horse-power, but the major part of the building was then used as a flour mill. About 1815 the whole building was converted into a Flax and tow mill, and in 1842 the work had been greatly extended, and included bleaching, \&c. The building is still occupied as a spinning mill, but owing to the vicissitudes of trade it has had its seasons of rest, and after having stood for some time it was in 1863, with all the machinery, sold by auction for $£ 5,300$. It has since again changed hands, and now its machinery is once more in active operation.

The trade of Arbroath continued to increase rapidly. From 1820 to 1825 was a season of great prosperity in the Linen manufacture. The effect of this halcyon era was the erection of many spinning and other works of an extent greatly beyond the means of the proprietors, and very much beyond the legitimate requirements of the trade. There was then a plethora of banks in the town, and in their competition for business unwarrantable facilities were afforded to men without capital; and many of them without experience or judgment. The natural consequences followed, when, in the beginniug of 1826 (a year memorable in the annals of trade for the dire calamity which then burst upon the commercial world), the manufactures of the place were all but unsaleable, money became scarce, credit failed, and almost the whole manufacturing community, adventurer and honourable merchant alike, were engulphed in one common ruin. This melancholy season was long remembered with feelings of sorrow, and it is not yet entirely forgotton by many in the trade.

At that period almost every mill and factory were si'ent, universal distress prevailed throughout the town, and it was some time before Arbroath became its former self again. A day of prosperity did, however, dawn, and trade once more resumed its wonted course. By July, 1827, the weavers which had been thrown out of employment by the stagnation of 1825 and 
1826 were again at full work, and wages had risen greatly. T'he price paid for weaving dowlas was then $12 \mathrm{~s}$, and in some instances $13 \mathrm{~s}$ per piece, but not many months before it had been as low as 9 s per piece. The experience of 1826 had the salutary effect of lieeping production within the demand, and when some years afterwards misfortunes overtook Dundee and other places the merchants and manufacturers of Arbroath were enabled to withstand the shock, and bear up arainst a season of bad trade.

In 1831, the quantity of Flax, Hemp, and Codilla imported into Arbroath was 2,096 tons. In 1832 there were in the parish of Arbroath 4 spinning mills, employing 393 hands; and within same bounds 1,173 weavers, 316 of whom were upon sail-cloth. The wages then paid was, for boys and girls in mills, $3 \mathrm{~s} 3 \mathrm{~d}$ to $3 \mathrm{~s} 6 \mathrm{~d}$ per week, women, $4 \mathrm{~s} 6 \mathrm{~d}$ to $5 \mathrm{~s} 3 \mathrm{~d}$, men, $10 \mathrm{~s} 6 \mathrm{~d}$ to $15 \mathrm{~s}$. Weavers earned on the average about $6 \mathrm{~s}$ a week, and winders, of whom there were then 372 , about $3 \mathrm{~s}$. 'There were at that time 25 warpers at $12 \mathrm{~s}, 31$ starchers at $10 \mathrm{~s} 6 \mathrm{~d}$, and 25 lappers and overseers at $15 \mathrm{~s}$ a week.

Even after the severe lesson of 1825, Arbroath has not been exempt from periods of depression, caused by overtrading. After one of these periodical convulsions the following paragraph, taken from the Dundee Advertiser, of 14th June 1833 , is significant-" It gives us pleasure to notice, that $\mathrm{Mr}$ Goodall, agent for the British Linen Company's Bank in this place, has received instructions from the Directors in Edinburgh to renew the discounting of bills, \&c., which for some time past, in consequence of the gloomy appearance of business with our merchants, had been suspended." At that period, according to statistics got up in connection with the then proposed Dundee and Arbroath Railway, there were about 360 spinning frames in Arbroath and neighbourhood, averaging 37 spindles each, which were calculated to produce 19 spindles yarn each, or 6,840 spindles per day. Of this yarn one-half was Flax, averaging $3 \frac{1}{2} 1 \mathrm{~b}$, and the other half tow, averaging $6 \mathrm{tb}$. per spindle, consuming nearly 275 cwt. a day, or in 310 working days, about 4,260 tons a year.

In 1832 , there were 12 spinning-mills in the parish of $\mathrm{St}$ Vigeans, and by 184:2 they had increased to 15 , driven by 20 steam-engines of 250 horse-power, giving employment to 275 
men and boys in heckling, \&c., and, inside the mill, 250 males and 715 females, being a total of 1,240 , besides those indirectly engaged in the trade. The quantity of Flax spun in these mills was close upon 5,500 tons, of the value of about $£ 200,000$, which after being spun, was estimated at $£ 264,000$. At that period about 1,500 tons may have been spun in the parish of Arbroath, making, for the whole town, 7000 tons per annum. The wages then paid in the preparing departments was from $3 \mathrm{~s}$ to $6 \mathrm{~s}$, and spinners and reelers earned from $5 \mathrm{~s}$ to $6 \mathrm{~s} 6 \mathrm{~d}$ a week. The price paid for weaving a piece of Linen, which in $1825 \mathrm{had}$ been $17 \mathrm{~s} 6 \mathrm{~d}$, was in 1842 reduced to $9 \mathrm{~s} 6 \mathrm{~d}$. Sheetings, \&c., were mostly weaved in the houses of the operatives, but sail-cloth was woven in large weaving shops. There were then employed in Arbroath 732 Linen weavers, of whom a third were women, and 450 canvas weavers, of whom about a fifth were women, besides starchers, warpers and foremen, and also a large number of women engaged in winding the warp and weft yarns. At that period there were two bleachfields in the town, but for some time past only one of them, belonging to Webster \& Co., has been in operation. There are, however, three extensive and well conducted fields in the neighbourhood, viz., Kellyfield, Charles Dowall ; Panbridefield, John F. Dickson; and Waulk Mill, on the Brothock, which are mostly employed by the manufacturers of Arbroath.

The average yearly quantity of Linen stamped in Arbroath during the years 1805,1806 , and 1807 , were $1,287,233$ yardsthe average fees paid the stamp-master being $\$ 1341 \mathrm{~s} 9 \mathrm{~d}$. In the years 1816,1817 , and 1818 , the average yearly quantity stamped had increased to 2,055,208 yards, and the stamp-master's fees to $£ 2141 \mathrm{~s} 8 \mathrm{~d}$. This does not show the extent of the trade of Arbroath in these periods, because sail-cloth, which was then made to a moderate extent, was not stamped at all.

The following prices-current show the leading fabrics manufactured in Arbroath in the years specified, and the current quotations of the day for same. It was not until some years after sail-cloth began to be entered in the prices-current that it was made extensively, but the manufacture, when once fairly established, made good progress, and of late years it has been the great staple of the town. The sterling merits of Arbroath 
canvas is now widely known, and the cloth is much appreciated by the sailmakers and shipowners who like to supply their ships with superior sails. The manufacturers of this important article know well the advantage to be derived from keeping up the character of their goods, both in material and workmanship, and no doubt they will endeavour to maintain their well-merited reputation.

\section{Armonti Pricks Currext.}

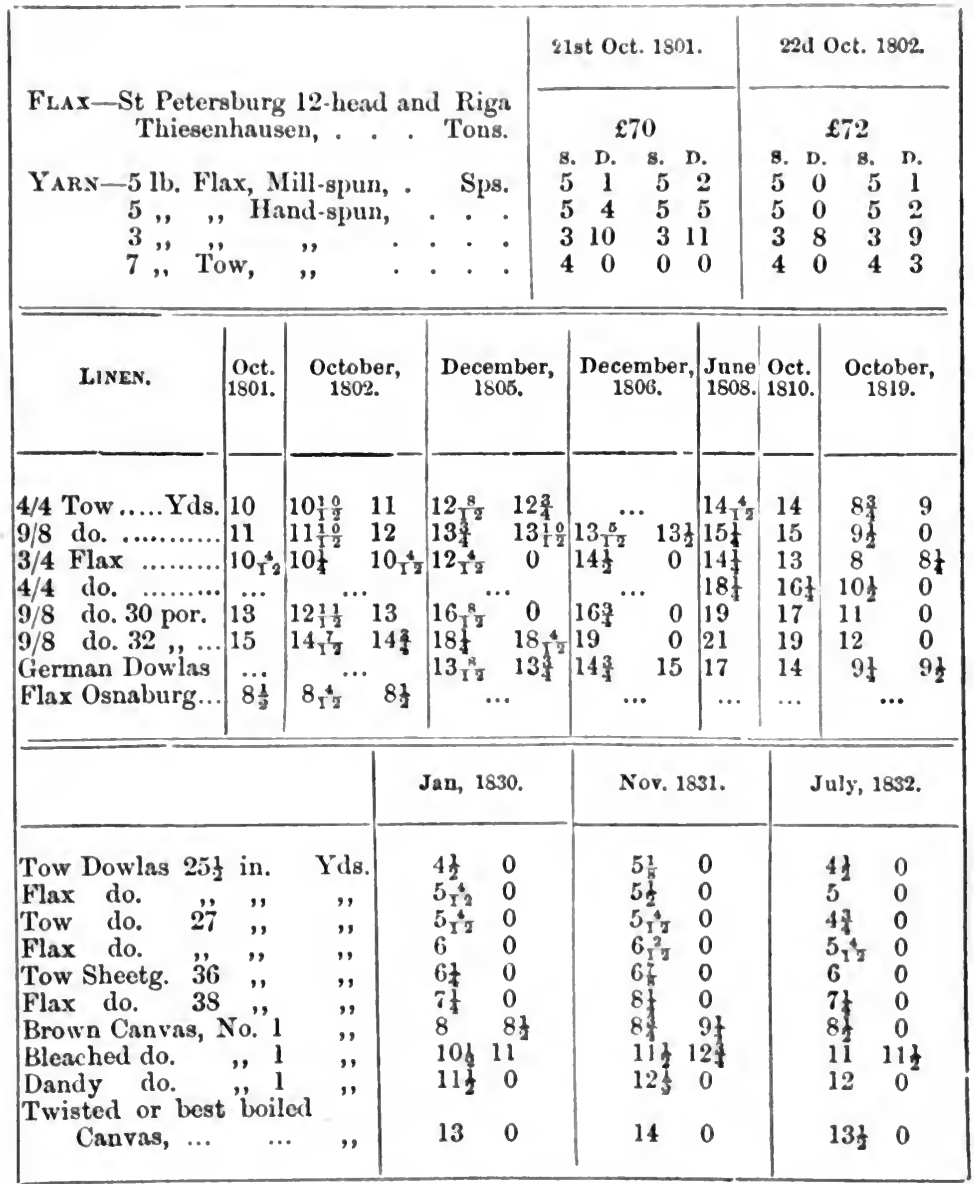

In 1851 there were eighteen firms engaged in the staple trade in Arbroath, with an aggregate of 530 horse-power, and ranging M $\mathrm{m} 2$ 
from 90 down to 8 horse-power employed by the various parties. Now there are seventeen firms engaged in Flax-spinning or power-loom weaving, employing in the aggregate 39 steamengines (including one water-wheel), of 792 horse-power. The works contain 30,342 spindles, and 836 power-looms, and give employment to 4,620 people. Some of the firms are going on with extensions on a moderate scale, to meet the requirements of their increasing trade. The quantity of canvas produced annually by these looms is about 420,000 pieces, in addition to which about 15,000 pieces are made by the hand-looms which are still in use. There are also about 8,000 pieces of Linen of other descriptions, such as hessians, sheetings, \&c., made in the town yearly. Most of the mills have establishments of their own for Flax-dressing, but in addition to these there are about 80 men employed by master Flax-dressers. Altogether there may be fully 4,000 people in the town engaged in the Linen manufacture, and during the last year the trade was in a highly flourishing condition, giving full employment to all who were willing to work, and returning a fair remuneration for the labour and capital of the employers. Some of the firms in Arbroath have long held an honourable position in the trade, and are deservedly respected. As in all prosperous manufacturing towns, younger parties are rising up, who, by their industry and energy, are steadily and surely commanding success. The future of Arbroath is therefore very hopeful.

\section{Blairgowrie.}

At an early period in last century Flax was grown in the parish to a moderate extent, and it was long continued to be cultivated. The whole of the quantity raised was spun in the parish during the winter months, and the rents of many of the smaller farmers were mostly paid with the money got for the yarn. For a long time the husbandry was of the rudest kind, but about 1780 an improvement took place, after which more land was cultivated, and better crops raised. The Flax was generally sown about the end of April, in a portion of the division for oats, and when the season was suitable, a fair crop was produced. Besides the home-grown Flax, considerable 
quantities of foreign Flax were spun, and the yarn was either woven in the parish, or sent to Dundee. The women, about 1790 , used the two-handed wheel, but in early times they only span with one hand. Considerable quantities of household work were made in the town and parish, and about 50,000 yards of "yard-wides" were annually weaved. l'art of these goods were bleached at a field in the parish of Rattray, but the greater portion were sold in Blairgowrie at about $8 \frac{1}{2} d$ a yard, and sent in the green or unbleached state to London. In addition to these, some of what was called "Hessian Stuff" were also woven in the district at that time.

A stamp-office was early established in the town; and after being in existence for some time, it was discontinued for several years, but was again opened in 178.5. The quantity of cloth stamped for the first eight years after its re-establishment was as follows:-

$1785 \ldots . . .17,197$ Yards.
$1786 \ldots . .50,380 \quad "$
$1787 \ldots \ldots .128,559 \quad "$
$1788 \ldots . .130,602 \quad "$

$1789 \ldots \ldots 165,364$ Yards.
$1790 \ldots \ldots 190,682 \quad "$,
$1791 \ldots \ldots .220,371 \quad "$
$1792 \ldots \ldots .252,485 \quad "$

This table comprises the Linen woven in Blairgowrie, what was brought from the neighbouring parishes, and also the quantity bleached at Rattray, and it shows a steady increase for these years. In 1790 there were 100 weavers, 8 Flax-dressers, and 7 lint millers in the parish. The wages of a maid-servant were then $£ 3$, and the produce of two lippies of linseed, sown in her master's ground, or an equivalent for it if he was not a farmer.

Before 1798 a small building in the Haughs of Rattray, below Blairgowrie, which had previonsly been occupied as a lint mill, had some machinery put into it for spinning Flax. This was the nucleus of the now large establishment called Ericht Works. The Flax is taken into these works in the raw state, and the Linens sent out packed in bales; the whole processes, heckling, spinning, bleaching, weaving, calendering, and packing being carried on therein. 'These works have been greatly enlarged of late years, and further extensions are now in progress. Ericht Works belong to John Adamson, and have been a prosperous concern since he acquired the property, now a good many 
years ago. In 1798 another Flax-spinning mill, on a more extensive scale, was erected farther up and on the opposite bank of the Ericht, which, in contradistinction to its lesser and lower predecessor, was called the "Meikle Mill." It was, perhaps, large for its day, but when compared with some of the extensive mills recently erected, it is small indeed. It now also belongs to Mr Adamson, but for sometime past has ceased to be occupied as a spinning mill. On the Lornty, a picturesque tributary to the Ericht, a spinning mill was erected by the late David Grimmond, in 1814. It is now in the occupation of his son, David, and has produced its quota of yarns weekly for fifty years without yet showing many signs of decay. Since the erection of "Meikle Mill," the banks of the beautiful and romantic Ericht have been studded with spinning mills, and the rush of its waters affords employment to a large population. In 1851 there were twelve mills in the neighbourhood of Blairgowrie, having an aggregate water-power of 257 horses. At the present time there are eleven works in operation, with 319 horse-power, whereof water 289 , and steam 30 . The works contain 13,200 spindles, and 250 power-looms, and employ about 1,600 hands. A new mill, now in course of erection at Keithbank, will shortly add to the power, and bring the spindles up to more than 1,400 .

At page 71, it is stated that the late James Grimond, of Oakbank Mill, Blairgowrie, was one of the pioneers of Jute spinning. Since that portion of the work was in print it has been ascertained that he was the first spinner Mr Watt got to make trial of the fibre; that he cut it into lengths, heckled it, span the line into $3 \mathrm{mb}$. yarn (16 lea), the quality of which was excellent. The Jute first used by him was of remarkable fine fibre, soft and silky, with spinning properties superior to the bulk of what is now imported. At the present time two or three of the mills spin Jute to the extent of 200 to 300 bales a week, the others being all upon Flax or Tow.

Throughout many parts of the country the Flax-spinning mills driven by water-power have, from a variety of causes, been demolished or turned to other purposes; but this does not apply to the district of Blairgowrie. Here the water-power is sufficient to drive moderate-sized mills steadily and profitably, but it is not so large as to admit of great extensions, and many 
of the mills therefore remain as they were originally erected. Hitherto the works have generally prospered, and at present they have a vigorous existence, and give promise of a successful future. The proprietors are a very respectable body of spinners, most attentive to business, and well worthy of the wealth which many of them have acquired. The beauty of the scenery and the salubrity of the climate make Blairgowrie liked by the workers, to whose comfort, physically and morally, great attention is paid by the millowners. 'They labour under the disadvantage of having to attend the markets in Dundee once or twice a week, for the purchase of the raw material and the sale of its produce; but this is a disadvantage shared by the spinners and manufacturers residing in other towns, and it is more than counter-balanced by the cheap motive power supplied by the Ericht.

Of late hand-loom weaving has not been prosecuted largely in Blairgowrie, and it is not likely to be more actively carried on hereafter, as power-looms are everywhere supplanting them.

\section{Brechin.}

Flax has long been cultivated in the parish of Brechin, but it was not until after the rebellion of 1745 that much attention was paid to the subject. After the introduction of the manufacture of Osnaburgs into Arbroath, the discovery of the fabric was soon heard of and its utility appreciated throughout the country, and the article became a general favourite. Among other places, Brechin went early into the trade, and for a long period Osnaburgs were the chief fabric made there. To provide material for this important manufacture, the growth of Flax in the parish was encouraged, but the total quantity raised was never very large.

From various causes the quantity of Flax grown in the parish, as in other districts of the country, gradually dwindled down, until only a few acres were raised for domestic purposes. Now the plant is little seen here, and young people would scarcely know it, though they saw its beautiful flowers waving in the wind before them. 
'Towards the end of last century the merchants of Brechin were then, as now, much engaged in the Linen trade, and large quantities of yarn and Linen were bought and sold every market day. At that period the grcater number of the women were employed in spinning, and the two-handed wheel was commonly in use, although a short time previously Flax had been wholly spun with one hand. The men were engaged in weaving, and both men and women were well paid for their labour. There was then a bleachfield in the city, which gave regular and healthy employment to a number of people of both sexes.

Spinning by machinery was commenced in Brechin about the end of the last, or the beginning of the present century, and the mill first built was then considered a large one. The building is still standing, and now forms part of the premises of the East Mill Company, being occupied by them as warehouses. The spinning firm issued a copper coinage of their own, and Fast Mill bawbees are still in existence, having a view of the mill on one side of the coin. The original mill came into the hands of the present Company in 1836, after which they erected a large new fireproof mill. Since that period several considerable additions have been made to the work, and in 1858 another mill was added to it. In 1852 an extensive bleachfield was started by the Company, and the following are details of the works of this respectable firm at the present time:-'The motive power is partly steam and partly water, the might of the beautiful river South Esk being impressed to aid in turning the machinery. The spinning mill is of eighty horse-power, contains 4,300 spindles, and gives employment to 400 hands, who receive in wages about $£ 7,400$ annually. The consumption of Flax is about 1,300 tons a year, the produce being 670,000 spindles of from $1 \frac{1}{4}$ to $5 \mathrm{lb}$. Flax yarn, and from 3 to $8 \mathrm{lb}$. tow yarn. The bleachwork requires 20 horse-power, employs 100 hands, who are paid $£ 2,600$ of wages annually, and the quantity of yarn bleached is fully 1,900 tons. The establishment is complete in all its parts, and in a prosperous condition; and considerable attention is paid to the comfort of the hands by James Ireland, who energetically manages the entire work.

There is another bleachfield in the town, belonging to the Inch Bleaching Company, who carry on an extensive business, 
employing about 100 persons, and finishing about 1,600 tons of yarn annually.

The Linen stamped in Brechin in 1805, 1806, and 1807 averaged 52:3,163 yards yearly, for which the stamp-master's fees averaged $\$ 549 \mathrm{~s} 11 \mathrm{~d}$. In 1816,1817 , and 1818 the quantity and the fees averaged respectively 749,481 yards, and 2781 s 7 d.

A quarter of a century ago, there were thirty persons in the town and parish engaged in heckling Flax, 200 in spinning, chiefly in the large spinning-mill, which had been erected some time before, 40 to 50 in bleaching, and perhaps 1,200 to 1,500 in weaving. Another spinning mill was at one time erected in Brechin, but it was converted into a paper-mill in 1852 . In 1851 there was not a steam-engine in the town. Now there are five connected with the Linen trade, of the aggregate of 95 horse-power; and very shortly the number will be increased.

The manufactures of Brechin have changed considerably since the century began. Before then it was almost wholly Osnaburgs, but other fabrics had been early introduced, and in 1811 the stock of a manufacturer, which was sold by auction, consisted of the following goods:-

96 Pieces 27 -inch plain Hemp Bagging.

21 " " Twilled Do.

42 "32-iuch Do. Flax Tow Sheeting.

$4, \quad 27$-inch Tow Osnaburg.

2 " 39-inch Flax and Tow Sheeting.

100 sacks and bags, with yain suitabl of for such gools.

Flax, Hemp, tow, codilla, \&c., starching berths, fire-carts, \&c., \&c.

At one period the greater part of the Linen made in Brechin was given out to be woven by agents acting for manufacturers resident in other towns, but in the latter part of 1835, new fabrics were introduced, and since then the trade has been chiefly in the hands of native manufacturers. A respectable firm, Lamb and Scott, at that date erected a manufactory for these new fabrics-viz., canvas and hessians, and considerable employment was given to females in spimning the yarn. A correspondent, writing to the Dundee Advertiser on 20th November, 1835, mentions these as gratifying circumstances, but laments that the expense of conveying such heavy mate. rial to and from Dundee, the great central market, would 
be against the stability of the manufacture of such goods in Brechin. Time has proved that the lamentation was not without sufficient cause. Although these fabrics have been long discontinued, the firm who attempted their introduction are still in existence, and carry on perhaps the largest manufacturing business in Brechin at the present day. They employ fully 600 hand-looms in the town and neighbourhood, and have now in course of erection a power-loom work which will contain fully 300 looms.

A small power-loom factory, of eight horse-power, was erected about ten years ago, and contains 48 looms. It belongs to J. and J. Smart, who also employ fully 140 hand-loom weavers. D. and R. Duke employ about 400 hand-looms in Brechin and throughout the district, and pay about $£ 8,000$ annually in wages. This firm are also erecting a power-loom work, which will contain 308 looms. There are other manufacturers in Brechin who carry on considerable trade.

The principal fabrics now made in Brechin are bleached sheetings, dowlas, and similar goods, and for these the district has acquired an extensive and justly merited celebrity.

\section{Dunfermline.}

This ancient town has long been distinguished for the manufacture of diaper and table linen. In the infancy of the trade it was the custom to weave diaper only during the summer, and checks in winter, but why such a custom should have been established it is difficult to determine. The practice was continued until about 1749 , when the manufacture of ticks and checks was almost relinquished, and for many years diaper was the only article made. This trade long went on satisfactorily, showing a gradual yearly increase, until in 1788 the looms employed numbered about 900 , and in 1792 they had increased to 1,200. For some years before the latter date the value of the goods made annually was from $£ 50,000$ to $£ 60,000$, and it was then on the increase.

In the chest of the Incorporation there is preserved a very curious specimen of the weaving art. It is a man's shirt, wrought in the loom near the end of the seventeenth century, by a weaver 
named Inglis. 'The shirt is without seam, and was finished by the ingenious artist without assistance from the needle, the only necessary part which he could not accomplish being a button for the neck.

In 1792 a mill for spinning yarn from Flax, Hemp, and Tow, was erected at Brucefield, near Dunfermline, and the Flaxyarn spun in it, even in the first year of its existence, gave satisfaction. In the Statistical Account of Scotland this mill is said to have got the second patent for spinning yarn by machinery, but it was not the second erected in Scotland, several others having had precedence of it. The mill span for many years, but it has long been numbered among the things that were.

Within the previous half century astonishing progress had been made in the art of weaving table Linen. In the early stages of the trade sometimes three persons were requisite in weaving a web of diaper, but after the introduction of the fly shuttle, and what was called a frame for raising the figure, a single weaver could work a web $2 \frac{1}{2}$ yards wide without the least assistance.

Much taste and skill is necessary in designing the patterns of diapers, but by thought and practice some of the tradesmen acquired considerable genius in this art, and a century ago obtained premiums from the Board of 'Trustees for their draughts. Table-cloths could then be furnished of almost any breadth, length, and quality, and coats of arms, mottos, or other devices were wrought in them if wanted; but compared with the present state of the manufacture the cloth was coarse, and the designs at best rude and without taste, and much inferior to foreign specimens. They consisted chiefly of the British flag, the national Scottish arms, gentlemen's coats of arms, and sometimes flowers, birds, \&c., all very unnatural and extravagant. Afterwards more ingenuity and taste in design and execution were displayed, and latterly rich and varied patterns were produced, equal if not superior to German goods, which had long been the favourites in Britain. The damask loom, with its Jacquard machine, is now capable of producing any figure, however complicated, and there are several individuals in the town wholly devoted to design painting, the artistic merity of whose patterns are deserving of high praise. 
For a long period Dunfermline has been the chief seat of the table Linen manufacture of Scotland, but until the introduction of the Jacquard machine in 1824, the progress made was comparatively slow. This admirable machine, by greatly simplifying the weaving of even the most complex design, has given an immense impetus to the trade of the town. Through its use the appearance and quality of the goods have been much improved, and the saving of time in weaving has cheapened the cost of the fabric produced, the while adding to the comfort of the weaver. A prettier design and a better quality of table Linen at a reduced cost has greatly extended consumption, to the vast benefit of Dunfermline.

The following figures show the number of looms employed, and the value of the produce in the years specified :-

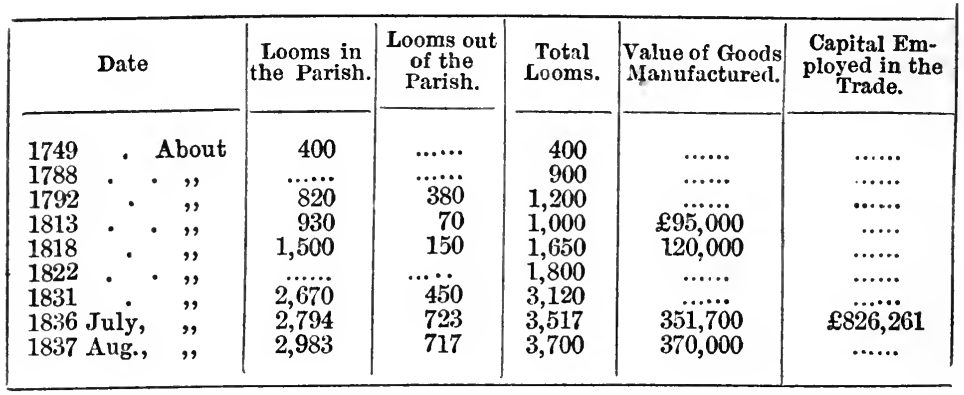

The total number of people employed in the various departments of the trade in July 1836 was 5,044. The weekly wages of weavers averaged $10 \mathrm{~s}$; warpers, $15 \mathrm{~s}$; winders, $4 \mathrm{~s}$; yarn boilers and bleachers of yarn, chiefly women, $7 \mathrm{~s}$; bleachers of cloth, $8 \mathrm{~s}$ $6 \mathrm{~d}$; lappers, 9s $6 \mathrm{~d}$; pattern cutters, 10s; dyers, 18s. Of the 3,517 looms then employed, 770 were on single diaper, which do not require Jacquard machines ; 1,880 on single damask, and 369 on double damask, which may have them; 445 on table covers, 13 on worsted warps, 15 on Linen, full harness, and 17 on bed quilts, all of which have them. The worsted warps and Linen full harness looms had greatly increased by 1843 . The rate of wages per spindle of warp had fallen on one fabric from $7 \mathrm{~s} 8 \frac{1}{2} \mathrm{~d}$ in 1807 to $2 \mathrm{~s} 5 \mathrm{~d}$ in 1844 , and on another from $6 \mathrm{~s} 3 \mathrm{~d}$ to $2 \mathrm{~s} 3 \mathrm{~d}$, but the weaver had much less compulsory idle time at 
the latter date, so that his weekly wages were not so much reduced as the difference in the rates indicate.

Until a recent period the Linens made in Dunfermline and its vicinity were chiefly woven by hand in the houses of the weavers, almost every master of a house being owner of his own loom, and sometimes of two or three more, which he let to journeymen and apprentices. A good many years ago the factory system was commenced, and several larire hand-loom weaving shops were erected by the manufacturers, where it was thought the work could be more efficiently carried on than when distributed, as of old, among swarms of cottages. 'The recent introduction of power-loom establishments has again changed the mode of production, and hand-looms, whether in cottages or in large shops, are fast disappearing, and will in the course of time become extinct, excepting for some descriptions of goods for which powerlooms may not be adapted.

At present there are four power-loom establishments in operation in Dunfermline, and others are in course of erection. Erskine Beveridge and Co., St Leonards Works, employ 709 power-looms, which are driven by steam-engines of 210 horsepower, with 220 hand-looms in the factory, and more than this number outside; the number of hands employed by this respectable firm being about 1,500 , and the wages paid annually about

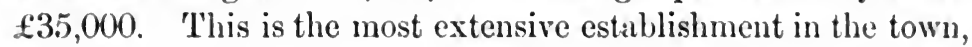
but, large though it be, it is proposed still farther to extend it. Some of the other works, both hand-loom and power-loom, are on a large scale. D. Dewar, Son, and Sons, of London, a firm of established reputation (whose concise and correct monthly reports on the Linen trade are highly valued), are presently erecting a power-loom work in the town, which when completed will be an extensive concern. It is intended to contain 580 looms, with all the necessary adjunets for preparing and finishing the superior class of goods required in their trade. 'The manufactures of Dunfermline being mainly confined to one class of goods, the fluctuations which periodically befall every trade tell with great severity upon this town, because when depression comes it comes to all, and all classes suffer. Power-looms strike out for themselves new branches of trale, and by being kept constantly at work afford regular employment to the hands en- 
gaged; their extension will therefore be of great advantage to the town aud district.

The goods manufactured in Dunfermline consist of diapers of various kinds, single and double damasks, white on brown table Linen, table-covers, floor-covers or crumb-cloths, cloutings, sheetings, \&c., \&c. The quality of the goods made varies with the market for which they are intended, but the town has attained great celebrity for the beauty and excellence of its table Linens, and the chaste and lovely specimens shown in the Great Exhibition of 1862 added to its former fame in this department. No doubt the respectable firms who are engaged in the manufacture of the ancient town will continue to maintain the high character their productions have already acquired, and keep pace with their competitors, both home and foreign.

Very little of the yarn consumed in Dunfermline is spun in the district, there being only one mill in the place, and it is not on a large scale. The coarser sorts are got from Kirkcaldy, Dundee, \&c., and the finer numbers, of which much of the manufacture consists, chiefly from Yorkshire and Ireland. There are four bleachfields in the neighbourhood, where part of the yarn consumed is bleached, but much of the cloth is sent to the fields near Perth to be cleared and finished, after which it is returned, and made up for a market.

\section{Forfar.}

The first Statistical Accouut of the parish, written about 1792 , states that about the year 1745 or 1746 the manufacture of Osnaburgs was commenced in Forfar by the brother of the merchant who first, from an accidental cause, discovered the fabric and began the trade in Arbroath. It says:- "From a small beginning, this branch of manufacture speedily became the staple manufacture of Forfar, and it is pleasing to add that the gentleman who first introduced it into the town acquired a comfortable independency by it, and was long spared to enjoy it among his fellow townsmen. Before that period the Flax was dressed by women, and there was no cloth made in the town, excepting a few yard-wide scrims. Then the number of incorporated weavers did not exceed forty, and 
there were not more than sixty looms employed in the town. In consequence of the Act for encouraging weavers, the trade increased so rapidly that before 1750 there were upwards of 140 looms in Forfar, and now there are between 400 and 500 . The knowledge of this art is easily acquired, and the call for hands is so great, that almost every young man betakes himself to it. He receives a part of the profit on his work from the very day his apprenticeship begins, and in a year or two he is qualified to carry on the business for himself, and able to support a wife; and so he marries and multiplies, and this rapidly increases the population. The Osnaburg trade rapidly spread, and gave employment to vast numbers of people throughout the country, but it was a very fluctuating one, and when the demand slackened at any time, it brought many of the young and improvident into difficulties. When it is good-and for some time before this year it has been more stable and flourishing than has ever been known before-the profits on it, together with the Government bounty, are sufficient to support the sober and industrious weavers against the influence of a falling market. Manufacturers are now giving $15 \mathrm{~s}$ to 20 s for working the piece of ten dozen yards, which a man of good abilities as a weaver can accomplish in nearly as many days; and a man working his own web had been known to produce eighteen such pieces by his own hand in nineteen weeks. This, however, is allowed by all to be extraordinary, although it shows what sobriety and diligence can do." After this period, the manufacturing trade went on progressively, with occasional checks arising from various causes. Sometimes the fluctuations were both violent and sudden, and the following details of the wages paid at different times in the year from October, 1814, to October, 1815, show this clearly:-At the former date, the weaving of a 24 por. 25 inch Osnaburg, 146 yards long, as measured and stamped by the Government Inspector; the warp of $3 \mathrm{fb}$. Flax, and wefted with $7 \mathrm{sp}$. of $6 \mathrm{tb}$. Flax yarn, was $21 \mathrm{~s}$. In November the weaving rose to $28 \mathrm{~s}$; in December it fell to $14 \mathrm{~s}$; and by October, 1815 , it had fallen as low as $6 \mathrm{~s}$ the piece.

During the years 1805, 1806, and 1807, the quantity of Linen stamped in Forfar averaged 1,765,70-4 yards yearly, the stamp-

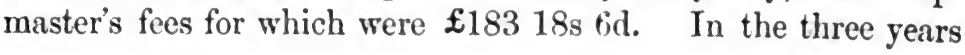


1816,1817 , and 1818 , the average quantity stamped yearly was $2,611,776$ yards, and the average yearly fees $£ 272 \mathrm{1s} 2 \mathrm{~d}$, which shows a marked increase over the former period.

Twenty years ago, about 3000 individuals were employed in Forfar and neighbourhood in weaving sheetings, Osnaburgs, dowlas, and kindred fabrics. About 2000 pieces were then made weekly, of the value of from $£ 4,000$ to $£ 5,000$, or from $£ 200,000$. to $£ 250,000$ annually. After that date the trade continued to make considerable progress, and the production increased yearly. Within the last year or two, important changes have been introduced into the manufacturing industry of the town by the establishment of power-loom factories. Of these there are now four distinct works, with an aggregate of 77 horse-power, contaihing. at present 482 looms, and giving employment to fully 600 hands. Some of these firms are adding to the number of their powerlooms, and several other Forfar manufacturers contemplate: erecting power-loom works, as they find it impossible, with hand-looms only, to compete successfully with their more enterprising rivals. At present there are about 4500 hand-looms in and around Forfar, chiefly employed by the Forfar manufacturers, and, including 3,000 warp and weft winders, 100 warpers, \&c., the number employed in the hand-loom trade in the town and district may amount to about 7,600 people. In the course of a few more years, this branch will probably become a thing of the past, as the fabrics manufactured are admirably adapted for power-looms, and steam seems destined to supplant manual labour in the weaving of Linen. Some of the hand-loom manufacturers have now small steam-engines for driving warp and. weft winding machines, finishing the cloth, \&c.

There is one large public calender and bleachfield in the town, belonging to Charles Norrie and Sons, of Dundee, in which there is also yarn winding machinery, where the manufacturers who have not such conveniences of their own can get their winding done. This work is of 20 horses-power, employs nearly 100 hands, pays about $£ 2000$ of wages annually, and it has been highly conducive to the prosperity of Forfar. Some of the new power-loom works have yarn cleaning and bleaching establishments attached to them, which is found to be a convenience to the proprietors. 
In round numbers the wages paid annually to the handloom weavers, winders, אe., in the Forfar district, amounts to

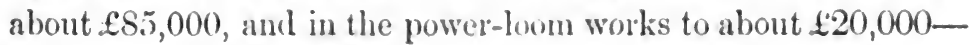
making more than $\mathfrak{L 1 0 0 , 0 0 0}$ in all The class of goods made in Forfar comprise Osnaburgs, sheetings, spriggs, towelling, German dowlas, and similar Linens, mostly brown or milled, fow of them being bleached. The Forfar manufacturers have long been justly celebrated for the uniform and sterling quality of their goods, and the fame which they have thus acquired is worldwide. Merit in their case has received its proper reward-many of the older manufacturers heing now in easy circumstances, and enjoying the fruits of their honest industry.

\section{Kinkcatint.}

This town was long noted for its shipping and commerce, and it is known that a considerable number of its vessels were taken in the harbour of Dundee when that town was stormed and sacked by General Monk. The inhabitants of Kirkealdy, as of some other places, had in these troublous times deposited many of their valuables in that town, as a place of security, and about 5000 , value of their property, was then carried away or destroyed, a particular account of which is preserved among the records of the burgh. In $16+4$, tradition relates that 100 ships belonged to the port; and between that year and the Revolution, 94 vessels belonging to Kirkcaldy (of which a detailed and authentic account is preserved), were lost at sea or taken by the enemy. Subsequently the town had its full share of the disasters and troubles of the period, and its customs nayable to the Crown fell to less than half of what they had formerly been.

When the commerce of Kirkcaldy declined, the inlabitants turned their attention to manufactures, particularly that of Linen. The description of goods first made were bed-ticks, checked and striped Linen, and a low-priced lind of plain Linen. These appear to have been imitations of the goods made in Holland and Flanders, and they were known as striped Hollands, Dutch checks, Dutch ticks, and Flanders checks and ticks. It is not exactly known when the manufacture of these 
articles was first introduced, but they can be traced back to the beginning of last century, and the probability is that the manufacture began about two hundred years ago.

For a long time manufactures made little progress, and, in 1733, the whole amount of cloth stamped in Kirkcaldy was only 177,740 yards. In 1743 it had risen to 316,550 yards, the computed value of which was about $£ 11,000$; but in this was included the cloth made in the parishes of Abbotshall, Dysart, Leslie, \&c., which were all stamped in Kirkcaldy. The local authorities showed a laudable desire to extend the trade, and, in 1739, appointed an annual market for Linen cloth, \&c., to be held on the first Wednesday of July, and to be customfree for three years. In the same year, the Council, "considering how much it will be for the benefit of the town and country that a heckler of lint be established, they, therefore, unanimously resolve to make application to the Trustees that a heckler be settled here, with such a salary, and under such regulations, as the Trustees judge proper." Bleachers had also advantages held out to them to induce them to settle in the district. The Linens made at this time consisted of common checks, which were sold to the Glasgow merchants for exportation; and handkerchiefs, checks, and a coarse description of ticks; all for the home trade. The goods were conveyed by the manufacturers on horseback to the various towns of Scotland, and were mostly sold at fairs.

During the commotions attending the rebellion in 1745, the trade was in a great degree suspended; but afterward it was prosecuted with diligence, until the war of 1755 interrupted the communication with the West Indies and America, which was at that time almost the only market for the goods of this district. The effect of this was that the value of the manufactures, which had risen to $£ 20,000$, fell in 1773 to

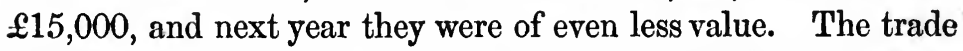
became so bad, that some manufacturers thought of turning their capital into another channel. Before doing this an attempt was made by James Fergus to produce ticking for the English home trade, and thus to introduce the manufactures of the town into the internal consumption of that country. After he had discovered the tweel and provided materials, he had 
difficulty in fincling weavers who could give the cloth the requisite stiffness and smoothness; but a weaver, by discovering "the open stroke," enabled him to produce the required fabric. 'This opened up a new trade, and since then ticking has been one of the staple articles in the manufactures of Kirkcaldy. Before this experiment was tried the manufacture of checks and ticks had given place, in many parts of England, to finer and more protitable articles. There was thus a door open for Mr Fergus, and the attempt proved eminently successful, and for many years the trade advanced progressively, without almost a single interruption.

In 1792 the manufacturers of Kirkcaldy employed about 810 looms, of which 266 (being triple the number in 1788) were in the parish, 300 in Abbotshall, 100 in Dysart, 60 in Largo, and the others in the neighbouring parishes. In the whole district about 2000 looms were employed, the produce of which for the year ending 1 st Nov. 1793, was estimated at $£ 110,000$. 'The average annual amount of a weaver's work was from 10 to 12 pieces of 110 yards, or about 1,200 yards, worth at 1s a-yard £60. The annual produce of the looms employed by Kirkcaldy manufacturers might thus be nearly $1,000,000$ yards, worth about $£ 50,000$. Reckoning 22 spindles as the average quantity of yarn to a piece, nearly 200,000 spindles were annually woven into cloth at that time. The price of checks was from $6 \mathrm{~d}$ to $1 \mathrm{~s}$ 6d per yard; ticks, $7 \mathrm{~d}$ to $2 \mathrm{~s} 6 \mathrm{~d}$; plain Linen was cheaper, but very little of it was then made. The whole Linen made in the county of Fife for the year ending 1st November 1793, was $5,013,089$ yards. The average quantity of Linen stamped yearly in Kirkcaldy during 1805,1806 , and 1807 was $1,641,403$ yards, for which the stamp-master drew fees amounting to $\$ 170$ $19 \mathrm{~s} 7 \mathrm{~d}$ a year. In 1816,1817 and 1818 , the average quantity

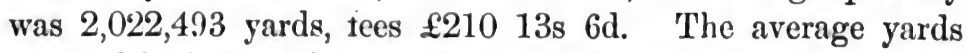
stamped in Cupar-Fife, and fees paid on same, for these years, were 967,186 yards, $\mathfrak{L} 10014 \mathrm{~s} 11 \mathrm{~d}$, and $1,422,687$ yards, $£ 148$ 3 s $11 \mathrm{~d}$ respectively.

Towards the end of last century there was a little cotton yarn used in some of the fabrics, but the greater part was made of Flax yarn, spun by the hand. At that time there were five cot$\therefore \geq 2$ 
ton manufactories in Kirkcaldy, called "Spinning Jennies," the heavy parts of which were driven by a horse-engine; but the trade was shortly after discontinued. About 1793 three Flax mills were erected in Kinghorn, after the Darlington model, but although the yarn thrown off was of good quality, very little of it was produced. Of the whole Linen yarn manufactured, about one-seventh was spun from Flax grown in the country, and six-sevenths from Flax imported, chiefly from Riga, at the average price of $£ 45$ a ton. After the Flax was heckled, the manufacturer sent it to agents in different districts, who gave it out to be spun by the housewives and maidens throughout the country, getting a small commission on the yarn returned by them. In this way the total expense of spinning; charges included, was on the average $1 \mathrm{~s} 3 \mathrm{~d}$ the spindle. Besides the yarn spun on manufacturers' account, parcels were regularly bought in the neighbourhood, and also in Montrose, Brechin, Coupar-Angus, the north of Scotland, and even in Ireland. Notwithstanding these supplies, it was with considerable difficulty that a sufficient command of yarn suitable for the manufactures of Kirkcaldy could be got previous to the introduction of mill-spun yarns, and parcels continued to be imported up to about 1832. For some years a considerable quantity of yarn had been imported from Bremen and Hamburg, amounting in one year to $441,400 \mathrm{Hbs}$., which at $3 \mathrm{Hb}$. to the spindle made 147,133 spindles. Of this, however, only a small quantity was used in the parish, the greater part being sent to Perth, Dunfermline, Falkland, Auchtermuchty, and other inland towns in which coarse Linen was manufactured.

Of the yarn used in making ticks and checks, about threefourths was bleached and the remainder dyed. Most of the principal manufacturers bleached and dyed their yarn themselves, and the others employed public bleachers and dyers. The various operations of heckling, spinning, dyeing, bleaching, winding, warping, and weaving, was computed at $5 \frac{1}{2}$ hands to every loom, which would give a total of 4,455 hands employed in the trade. Deducting the price of materials (Flax, cotton, bleaching and dyeing stufts, \&c), which, when those of the best quality were used would be about one-third of the value of 
the cloth, there remained about $£ 33,000$ for labour and profit. This sum divided among the whole productive hands, gives fully $: 7$ to each.

In addition to the quantity of Linen made by the manufacturers of Kirkcaldy, they purchased annually a considerable quantity in the neighbouring district. In 1792 more than $£ 30,000$ worth of cloth was purchased. Of the whole cloth so made and purchased, about three-fourths was sold in England, a small portion of which was exported to the West Indies and America. Of the remaining fourth, about one-half was sold in Glasgow for exportation, and the other half consumed in the country.

In 1793, the stagnation in trade caused by the war was severely felt in Kirkcaldy, and caused great loss and suffering to both the manufucturers and their workers. The demand fell off greatly, prices of goods declined rapidly, and heavy losses upon stocks and otherwise were incurred. On some fabrics the rate of weaving fell from 10 to 20, and, on coarse goods, as much as 40 per cent., and even at this reduction work was scarce and difficult to be had, and many weavers underwent great hardships. About this period females began to weave Linen, the whole having formerly been performed by men.

Abbotshall, which, although a separate parish, really furms part of the town of Kirkcaldy, had then about 300 looms, the greater number of which were employed by three manufacturers on checks and bed.ticks. Two of these parties had bleachworks in the neighbourhood, chiefly employed on their own yarn. The manufacture of sail-cloth was introduced in 1811, and has been carried on to a greater or less extent ever since.

Early in 1821 a trial was made in Kirkcaldy to weave Linen by machinery, and the experiment eren then promised to be beneficial to the trade. The building was intended to be driven by a steam-engine, to contain 40 looms, and in October of that year 24 looms were at work in it. The following calculation of the estimated produce and expense of the work when the proposed 40 looms were all in operation was made at the time, and is interesting as referring to perhalys the first power-loom factory ever erected for linen :- 
Producr of 40 Looms, Driven by a Steam-Engine of Six Horse-power.

60 Pieces of White Dowlas per week, 120 yards

each, at 18s per piece, . . . .

ExPENSE.

Interest on sunk capital, $£ 2000$, at 10 per cent., $£ 400$

Coals, \&c., for steam-engine, . . . . 500

Wages of 40 girls, at $5 \mathrm{~s} 3 \mathrm{~d}$ per piece of Linen, $\quad 15150$

Overseer, . . . . . . . . . 200

Dressing the warps, . . . . . . 200

Winding the wefts, . . . . . . 500

Oil and repairs, $\quad . \quad$. $\quad . \quad 2 \quad 250$

Profit, $\quad \ldots \quad \ldots \quad \frac{36}{£ 18}$

This statement shows that the weaving of a piece of Linen which cost $18 \mathrm{~s}$ by hand could be done by the power-loom at $12 \mathrm{~s}$ -a difference which it was then considered would be sufficient to induce others to enter into the trade on an extensive scale.

In 1838 about 1100 looms were employed by the Kirkcaldy manufacturers, of which about two-fifths were in the town. The net weekly wages then paid the weavers, taken from the Reports of the Hand-loom Weavers' Commission, 18th August, 1838 , averaged $7 \mathrm{~s} 3 \mathrm{~d}$ for ticks, $5 \mathrm{~s} 11 \mathrm{~d}$ for fine sheeting, 3s to $6 \mathrm{~s} 6 \mathrm{~d}$ for dowlas, and $9 \mathrm{~s} 3 \mathrm{~d}$ for sail-cloth. The value of the Linens annually made in the town at that period was not less than $£ 200,000$. After supplying the home demand, the balance of the production was exported to America, the West Indies, Australia, \&c. The expense of weaving ticks was then nearly one-third of their cost ; sheetings, one-fourth ; dowlas, one-fifth ; coarse fabrics, one-sixth ; and best sailcloth, one-eighth.

In 1807, a steam-engine of six horse-power was applied to Flax-spinning in Kirkcaldy, and at that period a girl attended 24 spindles, and produced seven spindles of yarn a day. The price of mill-spinning was at first from 1s to $2 \mathrm{~s}$ a spindle, but by 1840 it had fallen to from $3 \mathrm{~d}$ to $5 \mathrm{~d}$. In 1842 the mills in the town and neighbourhood, belonging to Kirkcaldy spinners, contained 13,000 spindles, which produced 6000 spindles a day, and cost in erecting about $£ 90,000$.

The late James Aytoun, for many years the father of the spinning trade, and who died at a good old age on 8th February, 1864, erected a mill for spinning tow in 1822. Tow 
spinning had previously made comparatively little progress, but he introduced important improvements, and was so successful that he put up a second mill in 1826, and a third some time after. In the end of 1832, or beginning of 1833, Mr Aytoun commenced to spin Jute, and he was among the first who did so. Since then it has been spun regularly in his works, and they are the only ones in Kirkcaldy where it has ever been used extensively. The great staple spun by the mills here is Flax and tow, fine yarns being required for the ticks and other superior Linens made in the parish. There are now nine firms engaged in spinning and weaving by power in Kirkcaldy. Their works are of 338 horse-power, contain 11,914 spindles, and 398 power-looms, and employ 1,462 hands. The number of power-looms will shortly be increased, as some other works are in course of erection.

For many years past the Linen manufacture has, with some ups and downs, kept a steady course, but no great extension has taken place, and the statistics of the trade in 1864 do not show a marked increase over those of 1842 . The class of goods now made in Kirkcaldy are ticks and checks, hucks, towelling, dowlas, sheeting, sail-cloth, floor-cloth up to eight yards in width, \&c. Much of the cloth manufactured requires bleached or dyed yarn, and there are several dyeing establishments and bleachworks in the town and surrounding district for supplying the wants of the trade. Some of the bleach-works are on an extensive scale, and, besides supplying the home demand, furnish large quantities of finely bleached yarn for export. The firms engaged in the staple trade in Kirkcaldy carry on a large business, and they are generally much and deservedly respected.

\section{Kírriemuir.}

After the rebellion of 1745 , the brown Linen manufacture was introduced into the parish. Before that period Flax had been grown for home use, but more attention was afterwards paid to its cultivation, which increased the quantity and improved the quality of the crop. Where plenty of manure could be got, the rotation was generally six years, but where this was not supplied an eight years' rotation was considered best. 'Two fairs were held in the town yearly, at which the Flax and yam were sold. 
David Sands, a famous household weaver, lived in the town about 1760 . He was an ingenious man, and invented a mode of weaving double cloth for stay or corset-makers, stitched at the proper parts, which required little labour to prepare them for use; and he supplied the staymakers of Kirriemuir and other towns with his cloth. Later in life he succeeded in weaving and finishing in the loom three shirts without seam. Not only did he weave the cloth, but he hemmed and stitched them, wrought button-holes, put on buttons, and also put ruffles on the breasts, all in the loom. These wonderful productions of the loom were exhibited among his acquaintances, and then sent, one to the Board of Trustees for Manufactures, another to the Duke of Athole, and a third to the King. Whether any of the shirts are still in existence is unknown, but their ingenious maker died shortly after having accomplished this extraordinary work, poor in purse, though rich in local fame.

The manufacture of Osnaburgs, scrims, birdies, and other coarse Linens has long been carried on in the town to a considerable extent. The value of the cloth made from September, 1791, to September, 1792, was $£ 38,000$ sterling. 'This is more than had ever been manufactured before in one year, and was owing to the then flourishing condition of the trade, which had never been better than in the end of the latter year. The number of weavers in the parish at that date was 228 , and a journeyman, it was said, could with ease gain $1 \mathrm{~s} 4 \mathrm{~d}$ a day. The common wages of women at spinning was $8 d$, but to such perfection in the art had they arrived that many women could, if they chose to exert themselves, earn from $1 \mathrm{~s} 2 \mathrm{~d}$ to $1 \mathrm{~s}$ $3 \mathrm{~d}$ a day. It is reported that a weaver, on a wager, had woven a web of birdy, 91 yards long, in 18 hours and 20 minutes, the price for weaving which was then $8 \mathrm{~s}$. The prosperous state of the Linen trade, and the high wages paid for spinning and weaving at that period, had greatly raised the price of all kinds of labour in the town and parish.

From November, 1798, to November, 1799, the quantity of Linen stamped in the town was $1,814,874$ yards, and in the following year 1,846,516 yards. During the years 1805, 1806, and 1807 , the quantity stamped averaged $2,226,200$ yards yearly, and the fees paid the stampmaster averaged $\mathfrak{2} 231 \mathrm{17}$ s 11d. The 
average quantity for the three years 1816,1817 , and 1818 , was

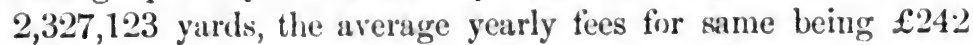
8 s 2 d. The quantity stamped in Kirriemuir during the first of these periods was greater than in any other town in Forfarshire, with the exception of Dundee, and it was more than half the quantity stamped even there. In the latter years Kirriemuir stood third in rank among the towns in the county, Dundee and Forfar alone exceeling it in the quantity stamped. 'This shows the importance which Kirriemuir had attained as a manufacturing emporium in the early part of this century. The manufacture went on extending, until in $18: 33$ it was supposed that not fewer than 3000 individuals were engaged in the trade, and that the number of webs woven annually was about 52,000, containing $6,760,000$ yards, being nearly four times the quantity stamped in 1799, and about three times as much as the average in the other years stated.

The Kirriemuir manufacturers now give employment to fully 2000 weavers, of whom about 1,500 are in the town and suburbs, and the remainder in the country around. The number of warp and weft winders, warpers, lappers, and others employed will not fall very far short of 2000 , so that the total number employed in the Linen manufacture in the district approaches 4000 people. The wages paid in the various branches of the

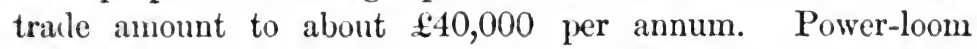
wearing has not yet been introduced into Kirriemuir, but no doubt a very few years will see works of this kind started there, as well as in the neighbouring towns. The manufacturing trade of Kirriemuir has had its fluctuations as other places have, but, notwithstanding, the increase has been on the whole progressive and stealy. This may, perhaps, be owing to the fuct that the manufacturers have been all along practical tradesmen, well qualified to judge of the work when executed, and they have generally been careful, industrous men. Some of them have acquired a moderate competency, and they conduct their business in a quiet, unobtrusive manner, very much to their own comfort and profit. The description of goods now made in the district is ehiefly Osnaburgs, hessians, de. 


\section{LOCHEE.}

A considerable part of the united parishes of Liff and Benvie adjoins to, and forms part of Dundee, and is embraced in the account of the town. Lochee, formerly a small village in the country part of the parish, is now an important manufacturing place, and although municipally connected with Dundee, it is yet so distinct and so important, as to demand a separate notice. For a very long period the manufacture of Linen had been carried on in the parish of Liff, but the trade received a considerable impulse between the years 1735 and 1740 , when part of the parish, suitable for manufactures, was feued in small plots. Houses were speedily put up, and many of the new inhabitants were weavers, who prosecuted the trade diligently, although on a very small scale. The population rapidly increased, and, with its increase, the manufacture extended and became established. Every hamlet had its weavers, but the chief seat of the trade in the parish was at Lochee, which had several advantages and attractions for manufacturers. Ground on a certain tenure was attainable in small portions; a small brook furnished the necessary supply of water for boiling and bleaching yarn and cloth ; and it was in the vicinity of Dundee, where a ready market could be found for its manufactures. In 1791 the number of looms employed in the Lochee district were 276 , and the number of apprentices and servants 104. Little household Linen was then made, nor were many Osnaburgs manufactured. The staple trade was in coarse Linens, named after their width, as yard-wide, three-quarters-wide, thin Linens, \&c., the price of which was regulated according to the quantity and quality of the yarn in the piece. Very little of the yarn manufactured was spun in the district, although many women busily plied the wheel, the weavers being, for the most part, supplied in Dundee. Nearly half the cloth was bleached before being sold, and the manufacturers had adopted the method of dry bleaching, which was to boil the cloth in water mixed with pot-ashes, wash out the lees, and then leave it on the ground to bleach by the action of the sun and weather, without, as formerly, sprinkling water upon it. By this means much labour and expense was saved, and the cloth was raid to have been equally well bleached. 
The following is a pretty accurate statement of the cloth manufactured in 1792 , and the prices at which it was commonly sold bythe manufacturers :-

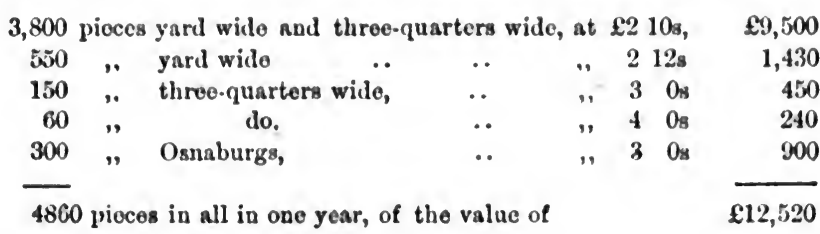

Of this quantity, 2,830 pieces were bleached, and in that state fit for shirting and other important uses, and the profit upon them was more than upon green or unbleached cloth.

There was no stamp-office in the village, and the cloth had to be taken to Inchture (which then had its stamp-office and its weekly corn-market!) or to Dundee, to be stamped, and some of it was sold in these places.

The want of a stamp-office in the village was much felt and complained of, and certainly it is curious to think that one should have been established at Inchture, where few Linens were made, and none in Lochee where the manufacture was large and important. Subsequently the Dundee stampers paid periodical visits to Lochee and stamped the cloth, which saved the manufacturers much unnecessary trouble.

Besides many operative manufacturers, there were then five merchant manufacturers in Lochee, who bought from the weavers much of the cloth weaved in the neighbouring country parishes. 'The one who bought to the greatest extent sent all his cloth to London, partly for consumption throughout England, and partly for exportation. The others disposed of their stock in Dundee, Perth, or Coupar-Angus, as they preferred a smaller profit at home to the chance of a greater one from London. The first of these merchant weavers, as mentioned in the Statistical Account of the parish, was a family of the name of Cox, who, in 1793, "still continued in the same line, much to the credit and advantage of themselves, and to whose industry and example the district is principally indebted for its present flourishing condition." The descendants of this family still continue in the same line, much to the credit and 
advantage of themselves and the community; and were the writer of the Statistical Account to awake and see the gigantic and magnificent works of the family, he would change the designation from merchant weavers to that of merchant princes. This family can trace their uninterrupted connection with the Linen trade farther back than any other in the Dundee market. The following short sketch of their history is given, because, from their antiquity, the family has become venerable in the trade, and the name a household word in their own immediate district.

The family now known under the firm of Cox Brothers has been connected with the Linen trade in Lochee and its vicinity for about 150 years, five generations in direct lineal descent having thus followed the calling of their fathers. The first in the series, as far as certainly known, conducted business for many years as a merchant manufacturer, or green cloth merchant, by buying cloth from the neighbouring weavers, and bleaching it at his premises, called Lochee-field. This person died in 1741, and was succeeded by his son David, who prosecuted and extended the business until 1793, when it was resigned to the management of his son James, the third in the succession. James Cox was of considerable enterprise and standing, having along with other merchants and county gentlemen become one of the original shareholders and partners of the Dundee Banking Company, when the association assumed that name in 1777 . In 1816 the fourth generation entered upon possession of the works, which at that time had become greatly extended, the bleaching-greens covering not less than 25 acres. Three years afterwards, in the month of August 1819, at the conclusion of the bleaching season, when the warehouses were filled with finished cloth, the works were almost entirely consumed by fire, causing enormous loss to the owner. The buildings were temporarily repaired to run out the lease, but at its expiry the establishment was given up, and the works, with many groups of weavers' cottages, were razed to the ground, and have since been converted into a portion of the home farm of the Earl of Camperdown. The proprietor then moved to the most populous part of the village of Lochee, and turned his attention to weaving the rlifferent fabrics for which the district was famous. 
It may be worthy of notice that on his premises the first broad hessian for the Manchester market was woven in 1815, and although it was only 45 inches wide it caused great excitement, and many visits were made by the surrounding operatives in wonder and curiosity to inspest the loom and its work.* This gentleman was succeeded in 1827 by his eldest son, who in 1841, became united along with thrce of his brothers in the copartnery of Cox Brothers. As hand-loom weaving at this time began gradually to be superseded and displaced by power-looms, this firm, about 1845) commenced to establish weaving by steam power, and in the course of a few years after they erected on the side of the stream formerly used by their family, a new work for spinning and weaving in all its departments, which was named "The Camperdown Linen Works." The old trade of bleaching, both in yarn and cloth, is still retained, and the dyeing of yarns for Jute carpets, of which they are extensive makers, is also carried on within the works. They are perhaps the only firm in the district who take in the raw material and send out the cloth in bales from their own premises, the whole operations, spinning, bleaching, dyeing, weaving, calendering, packing, \&c., \&c , being performed within the gates of their extensive works. 'Their principal spinningmill is entirely fire-proof, and from its great height and collossal proportions is a commanding object in the district. There are several engines in this building, but the giant of the structure, although nominally of 100 horse-power, actually works up to about the power of 500 horses, and that too with a smoothness, steadiness, and regularity truly astonishing. Camperdown Linen Works are built on a regular plan, and though intersected by various streets within the gates, the several parts are so connected that the material in its progress goes from department to department in a systematic manner, without wasting either time or labour. Three years ago this firm con. structed a branch line of railway from their works to join the leading line from Dundee to England, and the year following they established a telegraphic communication between the works and their office in Dundee and elsewhere. The recent progress

\footnotetext{
- The direct descendants of the weaver, son, grandson, and great grandson, hase been continuously employed by this family, and the two last are still in their works.
} 
of this enterprising firm has been amazing, and the dimensions of their present establishment is so vast that the works cover $13 \frac{1}{2}$ acres or thereby. The steam engines on the premises are estimated at 1,335 indicated horse-power, and upwards of 3,200 persons are constantly employed in the different branches of their manufactures.

There are other two spinning and weaving establishments by power in the village. Pitalpine Works, belonging to James Donald, are driven by two engines, together of 70 horse-power, and contain 1,802 spindles and 85 power-looms, and give employment to 300 hands. West Mills, belonging to Edward Parker, are driven by two engines, together of 40 horse-power. They contain 1,124 spindles and 12 power-looms, and employ 170 hands. In addition to these works a great many hand-looms are employed in the village and district around by these firms, and by other manufacturers located in Lochee.

The village is now a most important place, and branching out very rapidly, and it will probably soon be united in fact, as it is already politically, with Dundee.

\section{Montrose.}

In the beginning of last century, and until about 1744, Montrose was distinguished for its shipping. It was also famous for an annual market for Linen yarn, which was brought from all parts of the counties of Angus and Mearns, and even from Aberdeenshire and more distant places, and sold here. The yarn was either manufactured into Linen or thread in the town, or sent to other places for sale, and some of it found its way to London, Manchester, and other places in England. The first manufacture of any consequence in Montrose was sail-cloth. It was begun by a company in 1745 , and carried on for many years, with considerable success. Another company, on a larger scale, soon after followed, and subsequently a number of smaller concerns were started, some of them during the war which terminated with the Peace of 1783 . After this Peace the article was so much overdone, that the great companies, and most of the smaller ones, gave up the trade. Two companies set up the manufacture of thread, and, as before with canvas, their example was soon followed by others on a smaller scale, and the trade was 
long carried on extensively and profitably by some of these concerns. The canvas, and much of the thread manufactured were sold in London, the balance of the latter being chiefly sent to Manchester, and, for a while, all found a ready market. Some brown sheetings and Osnaburgs were also made by manufacturers here, and a considerable trade was carried on in the commission line in Osnaburgs and yarns sent to Glasgow. Pennant, in his 'Tour in 1776, says-" Montrose has increased one-third since the year 1745 . At that time there was not a single manufacturer. At present the manufactures have risen to a great pitch ; for example, that of sail-cloth, or sail-duck, as it is here called, is very considerable. In one house 82,566 pieces have been made since 1755. Each piece is 38 yards long, and numbered from 8 to 1 . No. 8 weighs 24 lb., and every piece, down to No. 1, gains $3 \mathrm{lb}$. in the piece. The thread for this cloth is spun here, not by the common wheel, but the hands. Women are employed, who have the Flax placed round their waist, and twist a thread with each hand as they recede from a wheel turned by a boy at the end of a great room. Coarse cloth for Linen for the soldiery is also made here; besides this coarse Linens, which are sent to London or Manchester to be printed ; and cottons for the same purpose are printed at Perth. Great quantities of fine Linen, lawns, and cambric, are manufactured in this town, the last from $2 \mathrm{~s} 6 \mathrm{~d}$ to $5 \mathrm{~s}$ a yard. Diapers and Osnaburgs make up the sum of the weavers' employ, which are exported to London, and thence to the West Indies. Much thread is brought here by the rural spinners to be cleaned and made into parcels, and much of it is coloured here. The bleaching is very considerable, and is the property of the town. It is not only used by the manufacturers, but by private families for the drying of their Linen. The men pride themselves on the beauty of their Linen, both weaving and household, and with great reason, as it is the effect of the skill and industry of their spouses, who fully emulate the character of the goodwife so admirably described by the wisest of men."

In the years 1805 to 1807 the quantity of Linen stamped averaged 198,375 yards yearly, the fees which the stamp-master drew for same being $£ 2013 \mathrm{~s} 3 \mathrm{~d}$. For the three years from 1816 to 1818 the quantity had increased to an average of 465,369 yards yearly, and the fees to $£ 689 \mathrm{~s} 6 \mathrm{~d}$ 
In 1789 Nontrose had 53 ships, of 3543 register tons: In May 1815, the Board of Trustees for Manufactures in Scotland agreed to give $£ 30$ per annum for three years towards the support of a lace-school in Montrose. The Board also presented the Dowager Lady Ramsay of Balmain with a very handsome gold medal, as a mark of the approbation they entertained of her meritorious exertions in establishing so useful a manufacture in Scotland. After the introduction of Flax spinning by machinery, Montrose was not long in engaging in the trade, and, in 1805, the first mill was built. Others followed, but success did not in all cases attend them. On 11th July 1817, Ford's Flax spinning-mill, of four storeys and attics, with two engines of 12 and 25, together 37 horse-power, was advertised for sale. It contained 38 spinning frames for Flax, and 22 for tow, of 30 spindles each, being 1800 spindles in all, together with 4 thread or twisting frames of 30 spindles each, or 120 in all, making a total of 1,920 spindles. In 1834 there were four large works in the town moved by steam, and one in the parish, on the North Esk, driven by water. There were also other two mills on the same river, in the neighbouring parish of Logie, both driven by water, and belonging to Montrose firms. The steam-power of the mills in Montrose was equal to 129 horses, producing annually 854,869 spindles, and the two in Logie 302,224 spindles. Part of the yarn was manufactured in the town and district, and part sold to manufacturers in other towns, or shipped to foreign countries. That year the Linen woven in the town and neighbourhood consisted of 4200 pieces bleacher sheeting, 21,443 bleached dowlas, 2,225 brown sheeting, 7,106 bleached duck, 2,253 bleached canvas, 2,716 brown canvas, 191 Navy canvas, 1,690 hessian, 204 tarpauling, 2,057 hop bagging, 32 sacking, 2,635 Osnaburg, and 241 of sundries; making in all, 46,993 pieces. The importation of Flax into Montrose same year was 2,496 tons, and 44 tons of hemp, and the shipping belonging to the port numbered 108 vessels, 11,000 tons.

Since the period referred to the trade of the town has gone on steadily, and the fluctuations and vicissitudes of other towns have been less felt here, chiefly owing to the firms engaged in the business not having extended their establishments beyond the wants of the trade, nor beyond their ability to maintain the control over them, and to buy and sell when and 
where they ean do it to most adrantage. At the present time there are four firms engaged in Flax-spinning in Montrose. The motive power is steam, of the agrgregate of 305 horse-power; and the mills contain 27,500 spindles, and give employment to 1,855 people. In 1851 the number of firms engaged in the trade was the same, and the power differed little from what it now is. One of the firms, Richards and Co., have now also a steam engine of 26 horse-power, driving 122 power-looms, with all the necessary preparing and finishing machinery for their extensive production, 240 hands being employed in this department. The quantity of Flax, Tow, \&c., now consumed anuually is close on 5,000 tons, and the wages paid to those engaged

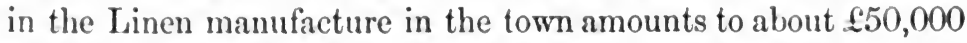
yearly. There are a good many hand-loom weavers in the town and district around, and the fabrics chiefly woven by them, and in the power-looms, are ducks, sheetings, dowlas, hessians, canvas, and floor-cloth, the quality being remarkably good, and the bleach and finish of some of the fabrics of a high order. James Mudie employs about 130 to 140 hands in making floor-cloth in all widths up to 8 yards, and broad sheetings. He contemplates erecting a power-loom factory in Montrose shortly. The yarn spun in Montrose has long had a high reputation, both for superiority of material and excellence of spin. Messrs Aberdein spin from 8 to 70 lea, and Messrs Paton have spun as high as 30 lea dry tow, and 90 lea dry Flax. Part of the yarn spun, and not manufactured by the spinners, is sold to manufacturers throughout the county, and part of it is exported to Germany, Spain, and other countries. 'The firms in the trade are of long standing and high respectability.

The "District Trade" is in a very prosperous condition. spinners and manufacturers are getting a satisfactory return for their capital and labour. Operatives have steady employment and good wages. Provisions are abundant and cheap. All classes are satisfied and happy contentment reigns. Never at any previous period was there more cause for gratitude than now, as the present is all that could be desired, aud the prospects for the future are rery hopeful. 


\section{U N D E E.}

DundeE, the centre and great seat of the Linen manufacture in Scotland, is beautifully situated on a rising ground on the north bank of the Tay. It is a town of great antiquity, and has often taken a prominent part in national affairs. One of the earliest notices of Dundee occurs in Hollinshead's History of Scotland, where it is stated, "The Roman general Agricola, during the reign of Domitian, near the end of the first century, defeated Karanach or Catanach, King of the Picts in Fife, and chased him to the Tay. He got a boat, and escaped to the other side, and abode at Dundee or Alectum, whither a great many of the Pictish nobility, who had escaped from the Romans, resorted to him."

"A little later, 10,000 Danes and Norwegians, under Gildo, landed in the Tay, and Garnard, King of the Picts, who succeeded Karanach, hearing of their arrival, left Dundee with his nobles, and went to meet him. He led Gildo to Dundee, and lodged him in the Castle. Shortly afterwards he was visited by Gald, the Galgacus of the Roman historians, King of the Scots, who remained certain days in Dundee. The two kings, accompanied by Gildo, then departed to the Castle of Forfar, where they entered into a league, and held a council of war against the Romans."

The town of Dundee is occasionally mentioned by ancient historians after the period referred to, but it is not certain that these early notices are historically true. It is not, however, the history of the place that is proposed to be given here, but only such notices regarding its early trade as have been met with. That it was a place of some commercial importance at. a remote period. there can be no doubt. In the charter granted to the town on 20th January, 1358, by King David Bruce, which confirms for- 
mer privileges and confers new ones, the following passage occurs:- "Wherein there is great trade of merchandise, and whereunto there is made great resort and repair of people." It may thus be inferred that at and prior to this date a considerable and profitable trade had been carried on in the town, and that it was frequented by many people, no doubt both from the neighbouring country, and from distant places, both for pleasure and business.

Hector Boctius, the historian and Principal of King's College, Aberdeen, who was a native of Dundee, and flourished in the reign of James V., about 1526, says of the Dundee of his day, "In which the people travel very painfully about, weaving and making of cloth," which shows that the inhabitants were then a manufacturing people, and very probably they made both Linen and wooller goods.

One of the first notices of Dundee as a port is when David, Earl of Huntingdon, landed in the harbour on his return from the Holy Land in the beginning of the 13th century. In 1341 Walter Curry, a shipmaster belonging to Dundee, as related by Fordun, was a leading party in a strategy whereby Douglas of Liddesdale got possession of the Castle of Edinburgh, then in the possession of the English. The celebrated naval commander Andrew Wood, in 1489, defeated the English Fleet off the Bell Rock, and carried the prizes into Dundee.

In the reign of James III., about 1467, as quoted by Skene in his glossary of the Regiam Magestam, an Act of Parliament was passed, which imposed a certain duty on all kinds of ships resorting to the port or harbour of Dundee, for the repair and support of the harbour works, the pier or shore, and bulwarks. In 1491 a disputed case about a ship called the Maré, of Dundee, came before the Lords Auditors of Parliament. In 1556 the wealth of the town must have been great, as it was then assessed $\mathfrak{1 0 5} 9 \mathrm{~s} 3 \mathrm{~d}$ sterling, being nearly half as much as Edinburgb, and very much more than any other town in the country. In 1569 the Magistrates were ordered by the Regent Murray to send three vessels to join the fleet appointed to pursue Bothwell, and these vessels formed the principal part of the fleet. A barque belonging to Dundee, carrying goods from Camphire, was wrecked near Dunbar. The tradesmen of the town, farmers in the neigh० 02 
bourhood, and others, cut a hole in the side of the ressel, took . away the whole cargo, and sold it to the country people. Among the articles carried off were ten pieces of Holland cloth. On 27th January, 1636, the Privy Council fined the wreckers from fifty merks to fifty pounds each. In 1583 the exportation of sheep skins to Flanders was prohibited, Edinburgh, Perth, and Dundee "having done the like."

In 1645 Dundee was then the second town in Scotland, having a population of 11,160, while Edinburgh had 34,440, and Glasgow and Perth 6,600 each. In 1651 the town was taken by assault by General Monk, at a vast cost of blood and treasure to the inhabitants, and to the many strangers who had then taken shelter within its walls. The vessels belonging to the port at that time amounted to one hundred, of which sixty were in the harbour, and the plunder taken in the town was shipped in them, and sent off to Leith; but the vessels were lost in sight of the town, and none of them passed out of the Tay. After this calamity, the population decreased greatly. In the sack of the town, a store of cloth, belonging to the manufactory which had been established at Newmills in Haddingtonshise, was taken, and the works were shortly after closed.

In 1654 the town of Dundee, as reported to Cromwell by Tucker, "was much shaken and abated of her former grandeur, but she was still, though not glorious, yet not contemptible"

The Magistrates and Council applied to Parliament for assistance, in consequence of the damage done to the town by Monk; and in 1669 , besides some other relief granted, an Act was passed authorizing a general collection to be made throughout the kingdom for the purpose of repairing the harbour. In pursuance of this Act, a collection was made in all the churches throughout the country, by authority of the General Assembly.

It thus appears that the sack of Dundee by Monk was not only a terrible calamity to the inhabitants themselves, but that it was viewed as a national misfortune. Before the assault the town was only second to Edinburgh, both in population and importance; but afterwards it fell to the fourth rank annong the towns in the country, both Glasgow and Aberdeen rising above it. In 1692 the Convention of Royal Burghs, in making up each $£ 100$ Scots of their annual expenditure, assessed Edinburgh $£ 326 \mathrm{~s} 8 \mathrm{~d}$; 


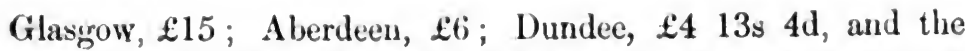
other towns in lesser sums. In 1695 a list was made up for a monthly cess to defray the expenses of the war, and Edinburgh

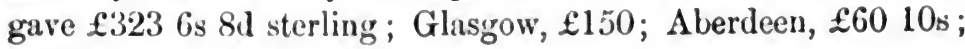
and Dundee, $54613 \mathrm{~s} 4 \mathrm{~d}$.

Although no precise accounts are known to exist regarding the early trade of Dundee, it is quite certain that the Linen manufacture was early introduced into the town, and carried on to an extent at least equal to the wants of the district; and before the end of the seventeenth century, some of it was mado for exportation.

In September, 1689, James Broich, skipper, of Dundee, was proceeding in his scout to Norway, with a small parcel of goods, and a thousand pounds Scots wherewith to buy a larger vessel. In mid sea he fell in with a French privateer, who took both cargo and cash, and was to sink the vessel and put the crew in their boat, in which case they must have perished. The privateer consented to let Broich go in his ship on obtaining a bond for 600 guelders, to be remitted to Dunkirk, and taking the shippers as a security for the money. On the return of Broich his case excited much commiseration, more especially as he had suffered shipwreck and capture four times before. On his petition the Privy Council ordained a voluntary contribution to be made for his relief in Edinburgh, Leith, Borrowstounness, Queensferry, and in the counties of Fife and Forfar.

In 1699 Roderick M'Kenzie, of Prestonhall, wanted to take sume victual from his land in Forfarshire to Mid-Lothian, but he was prevented by the Magistrates of Dundee, upon pretence of a late act of Privy Council. He petitioned, and the Council allowed him to transport the victual, enjoining that " he should not be troubled or robbed within the said town of Dundee, or liberties thereof, as they shall be answerable."

On 23d December, 1700, the Magistrates applied to Parliament by petition, craving an imposition for building and repairing the harbour, but it does not appear that the prayer was granted.

In 1707 , the Parliament, in consideration of the great sufferings of the town of the Dundee in the time of the troubles, and at the revolution, and of "the universal decay of trade," especially 
in that burgh, granted it an imposition of two pennies Scots on every pint of ale or beer made or sold in the town for twentyfour years. This was one of the last acts of the Scottish Parliament.

At the period of the Union (1727), 1,500,000 yards of Linens were manufactured in Dundee annually.

The manufacture of sewing thread was at one time an important branch of trade in Dundee. Christian Shaw, daughter of the Laird of Barganan (she was the cause of five women being burned for witchcraft in Paisley, in 1697), was the first who introduced the spinning of fine Linen thread into this country in the beginning of the 18th century. She acquired a remarkable dexterity in spinning fine yarn, and conceived the idea of making it into thread. She bleached the material and did all the processes herself at first. Some of her thread was taken to Bath, and sold to the lace manufacturers there at a good profit. A friend of the family happening to be in Holland, learned the secrets of the thread manufacture, which was carried on to a great extent there, particularly the art of sorting and numbering the threads, and packing them for sale, and also the construction and management of the twisting and twining machines. This knowledge he communicated to his friends in Barganan, which greatly assisted them in the manufacture. The young women in the neighbourhood were taught to spin fine yarn, twining mills were erected, and the trade extended until it became a leading manufacture in the district. It was subsequently taken up in Dundee, and for a long period it gave employment to a large population here and in other places throughout the country.

Soon after the Bank of Scotland was established in 1696, branches were opened in Dundee, Glasgow, and other places, but proving unsuccessful they were speedily withdrawn. In 1731 when the country was making advances in industry and wealth, a new attempt was made to establish branches in Glasgow, Dundee, and other towns. It was found, however, that the effort was premature, and after two years' trial these branches were all recalled.

In 1720 the mob took possession of two vessels loading bear in the harbour, in order to prevent the exportation of the grain, 
and also gutted the holise of the merchant, George Dempster. In 1729 a similar aftair took place in Dundee.

The harbour in these early times was composed ot small piers formed of wood jutting out from the shore, at which vessels lay to load and discharge, with break waters of stone outside to keep the water smooth within. It extended from the Castlehill on the east, westward by the Butcher Row to St Nicholas Craig.

In the letter from Samuel Homespun in the Gentleman's Magazine for 1742 , referred to in page 374 , some remarks are made which throw considerable light on the manufactures of Dundee at that period. He says "I shall now compute how much an acre of the worst Flax will produce when manufactured into the meanest sort of Linen; a case that though it can scarcely happen in this country, yet for argument's sake I shall admit.

"It will not be denied that of all Flax the Riga and Petersburg is the coarsest ; that of all Linens the fabric of the Dundee Linens is the poorest and meanest; that Riga and Petersburg Flax is of a sufficient quality, and is commonly used for the fabric of the Dundee Linen; and lastly that 30 stone of Flax to an acre is a very bad crop. This 30 stone of Flax then, supposed to be the produce of an acre, will yield 240 spindles of yarn, at two pounds to the spindle, and this 240 spindles wrought in a 400 reed, will produce 1,152 yards of Linen, which, when whitened, and made into buckram, is worth $7 \mathrm{~d}$ per yard, and amounts to $\mathfrak{E} 674 \mathrm{~s}$.

"But as this supposition consists merely in speculation, and cannot be so low in fact, because the worst Flax that grows in Great Britain is of infinitely a finer quality than the Riga and Petersburg Flax, and as the refuse or tow of the worst British Flax is of a sufficient quality for the fabric of Dundee Linens, I shall proceed to show what sum the produce of an acre of Flax may be supposed, at a medium, to save or yield to these kingdoms." This is shown by the second series of calculations in the former reference to this letter. The letter is certainly not flattering to the manufacturers of Dundee at that early period.

After the rebellion of 1745 the Government resolved to put an end to the arbitrary system of hereditary jurisclictions, and in 1747 an Act was passed resting them in the Crown. The Duke 
of Douglas was paid $£ 1800$ for his constabulary rights and privileges in Dundee. The town thus freed from control began to emerge out of the gloom in which it had so long been shrouded, and a brighter day soon dawned upon her.

In Brice of Exeter's "Universal Geographical Dictionary," published in London in 1759, it is said "Dundee is one of the best ports for trade in all Scotland, particularly for foreign, yet has it considerable inland business also, especially for corn and Linen cloth, which makes the country round about rich and populous, being maintained by the great quantities of goods which the merchants of Dundee buy for exportation."

By this time the liberality of Parliament in granting a bounty on brown Linens for exportation was beginning to be felt. Formerly the trade could not be carried on without loss, partly from the weight of the fabrics made, and partly from the lowness of the prices got for them. Now the industry of the inhabitants was stimulated, manufactures were established, and prosecuted with a success that operated in a most beneficial manner on the domestic habits and comforts of the people.

Pennant, in his tour in 1776, says, "Dundee used to be celebrated for the manufacture of plaiden, which was exported undressed and undyed to Sweden, Germany, \&c., for clothing the troops in these countries, but this was superseded by the manufacture of Osnaburgs in 1747, and it is now the staple of the county of Angus. In $17734,488,460$ yards of Linen were stamped."

The Rev. Dr Robert Small, in his Statistical Account of Dundee, published in 1762, gives an interesting account of the manufactures of the town at that period. He says- "The principal and staple manufacture of Dundee is Linen of various kinds:-1st, Osnaburgs, and other similar coarse fabrics of different names, for exportation, and which alone, till lately, were subjected to the national stamps. The quantity of these stamped between November, 1788 and 1789, amounted to $4,242,653$ yards, valued at $£ 108,78214 \mathrm{~s} 2 \mathrm{~d}$; and subtracting from this a fourth part, supposed to be brought from six neighbouring parishes into Dundee Stamp Offices, there will remain for the quantity made in this parish, $3,181,990$ yards, in value

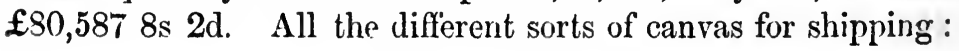


This fabric is entirely confined to the town, and the quantity annually made may be rated at 704,000 yards, and valued at $£ 32,000$. The cloth of this kind made by some of the principal manufacturers is thought to be superior in quality to any other in Britain, and by a regulation now introduced, and for which we are chietly indebted to Mr Graham of Fintry, of subjecting it to public stamp-masters, will probably retain its character. A process is also known by which the buyer, at a small additional expense, may have it effectually securod from mildew. 3d, Sack-cloth, principally for the consumption of the neighbouring country: The quantity annually made may amount to 16,000 yards, and may be valued at 2800 . 4th, Bagging for cotton wool, in quantity 165,000 yards, and in value $£ 5,500$. 5 th, Some diaper by one Company lately established. 6th, 'T'he greater part of the Linen necessary for household purposes; but the quantity and value of this I cannot pretend to give.

"Besides all these kinds of Linen, the manufacture of cotton has been lately introduced, and will probably soon become a very important branch of business. Several Companies are already engaged in it; they employ about 400 men, women, and children in spinning cotton into yarn for woof; they are supposed to spin annually $135,000 \mathrm{lbs}$. of y:rm, valued at $\mathfrak{2} 20,250$; anl, with warp which they buy from distant cottonmills, most of these Companies have begun to work up their yarn into calicoes, handkerchiefs, and coarse waistcoats. One Company also spins yarn for muslin, to the annual value of

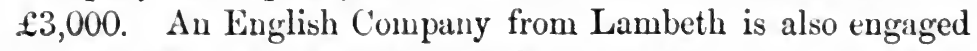
in establishing an woollen manufacture, where every branch of the business, from the wool to the finished cloth, is proposed to be carried on. The looms employed in all the kinds of weaving, and in all parts of the parish, are from 1800 to 1900.

"The manufacture of coloured thread has been established in Dundee for 50 or 60 years, and was for a considerable time peculiar to it. 'This business is in the hands of seren different Companies or masters, who use 66 twisting mills, and employ about 1,340 spinners, and 370 servants to make the yarn into thread. The quantity annually made is computed at 269,568 lbs, and valued at $£ 33,696$. The spinners live in different parts of Scotland, where labour is cheaper than in Dundee." 
"Two Companies are engaged in manufacturing cordage of all kinds for shipping, and ropes for all the various uses of the country. They employ about 30 persons, and they also carry on the whole business of ship-chandlers."

In addition to these branches of trade, Dr Small mentions that leather was tanned in Dundee, the computed annual value of which was $£ 14,200$. About 32 persons were employed in tanning, who used $£ 5000$ of oak bark; 12 curriers in dressing upper leather to shoes; 150 in making boots and shoes for exportation, and 200 for home consumption. The value of the boots and shoes exported was about $£ 6,923$. Soap-making was an art known in Dundee in the 16 th century, and the manufacture was at one time carried on extensively, but in 1791 the duty to Government had declined to $£ 1,82819$ s $0 \frac{1}{4} \mathrm{~d}$. The manufacture of glass had then been introduced three or four years, and two glass-houses, one for bottles and the other for window-glass, had been erected, employing 100 persons, and yielding a duty to Government in 1791 of $£ 3,406$. Many persons were engaged in the manufacture of tobacco and snuff. A sugar-house, with three pans, employed 15 persons. There was also a foundry and salt-works. Two native banks and two branch banks, one from Edinburgh, the other from Paisley, did business in Dundee, with an estimated circulation of $\$ 166,000$; and a Fire Insurance Office, which, although established only a few years, had then assurances current to the extent of $£ 800,000$

In 1751 the Excise duties collected in Dundee were-Malt, $£ 811$ 13s $1 \frac{1}{4} \mathrm{~d}$; Ale and Beer, $£ 1,21415 \mathrm{~s} 3 \frac{1}{2} \mathrm{~d}$; Candles, $£ 160$ $4 \mathrm{~s} 2 \mathrm{~d}$; Hides, $£ 28311 \mathrm{~s} 8 \frac{1}{4} \mathrm{~d}$; in all, $£ 2,4704 \mathrm{~s} 3 \mathrm{~d}$. In 1791 they had risen to $£ 10,01511$ s $0 \mathrm{~d}$; and the Custom House duties; and other items paid to Government by Dundee same year, amounted to $£ 56,84514 \mathrm{~s} 3 \frac{3}{4} \mathrm{~d}$. In 1745 the tonnage cleared inwards from foreign ports was 1,280 tons; outwards, 500 tons. No account of the inward coasting was kept, but the outward was 3,000 tons. In 1791 it was, inward foreign, 10,520 tons, outward, 1,276; inward coasting, 40,923, outward, 20,055 tons. On 5th January, 1792, 116 vessels, navigated by 698 men, and measuring $8,550 \frac{1}{2}$ tons, belonged to the port, of which 34 were employed in the foreign, 78 in the coasting, and 4 in the whale-fishing trade. 
GUODS INHORTED YRON FUREIGN.

\begin{tabular}{|c|c|c|c|c|}
\hline \multirow{3}{*}{\multicolumn{2}{|c|}{$\begin{array}{l}\text { Flax from Russia, , } \\
\text { Do. from Holland, }\end{array}$}} & \multicolumn{2}{|r|}{ I) 1745} & \multirow{3}{*}{$\begin{array}{c}\text { In } 1791 . \\
2,348 \text { Tuns. } \\
72 \text { " }\end{array}$} \\
\hline & & .. & None. & \\
\hline & & .. & 74 tons. & \\
\hline H mp, & .. & .. & None. & $299 \quad$, \\
\hline Tow or Codilla, & .. & .. & None. & 24, \\
\hline Clover-sced, & . & .. & $100 \mathrm{lbs}$. & 5112, \\
\hline Linseed, & .. & • & 1,906 buds. & 1,036 hhds. \\
\hline Fir Timber. & .. & .. & 98 loads & 1,706 loads. \\
\hline Fir-balks, & . & .. & 100 & 6,300 \\
\hline Deals, & .. & .. & 10,500 & 13,100 \\
\hline Swedish Iron, & .. & .. & 50 tons. & 45 tons. \\
\hline
\end{tabular}

Goods brovght Constwisk

$\begin{array}{lllll}\text { Cotton Wool, } & . & . & \text { None, } & 35 \text { Tons. } \\ \text { Tea from London, } & . & . . & \text { None. } & 47,743 \text { lbs. } \\ \text { Porter, } & . . & . & \text { None. } & 1,080 \text { hhds. } \\ \text { Coals from the Forth, } & . . & \text { No account. } & 28,021 \text { tous. } \\ \begin{array}{l}\text { Sugar, in } 1745 \text { no account, but } \\ \text { in } 1756,\end{array} \quad \text {.. } & \text {.. } & & 52 \text { tons. }\end{array}$

Goods SENT CoAstwise.

$\begin{array}{lllll}\text { Linen, brown and white, .. } & 1,000,000 \text { yards. } & 7,842,000 \text { yards. } \\ \text { Thread, white aud coloured, } & 12,544 \text { lbs. } & 130,952 \text { lbs. } \\ \text { Sall-cloth, } & . & . . & \text { None. } & 280,000 \text { yards. } \\ \text { Cotton Bagging. } & . & . . & \text { None. } & 65,000 \text { " } \\ \text { Barley or Big, } & . & . . & 3,393 \text { qrs. } & 23,917 \text { qrs. } \\ \text { Wheat, } & . & . . & 350 \text { qrs. } & 3,097, ",\end{array}$

Dr Small says "the particular cause of the increase and prosperity of Dundee is undoubtedly the bounty allowed by Parliament on Linen manufactured for exportation. By this the industry of the inhabitants was first set in motion and encouraged ; and their consequent prosperity, if it be not an evidence in favour of bounties in general, is at least a decisive one that, in some cases, they are wise and judicious, and may be productive of the greatest benefit. Whether the Linen manufacture could now be supported without the bounty, or whether the spirit of industry which is now awakened could be easily and profitably diverted into other channels, is a question on which it would be presumption in any private person to pronounce, and perhaps any experiment on the subject might be dangerous."

For some years prior to 1793 the average price of 12 -head 
Flax in the Dundee market was from $£ 38$ to $£ 40$ a ton, and for a considerable period it neither fell much below, nor rose much above these figures. During that time the price of 3 1b. lint yarn fluctuated from $2 \mathrm{~s} 10 \mathrm{~d}$ to $3 \mathrm{~s} 2 \mathrm{~d}$ per spindle, according to the rate paid for spinning, which then varied from $1 \mathrm{~s} 0 \mathrm{~d}$ to $1 \mathrm{~s} 10 \mathrm{~d}$ a spindle. The spinning of $6 \mathrm{lb}$. lint yarn then cost $2 \mathrm{~d}$ a spindle less than $3 \mathrm{lbs}$., and for spinning 7 lb. tow yarn from $1 \mathrm{~s} 6 \mathrm{~d}$ to $2 \mathrm{~s}$ a spindle was paid. Tow was at that time of so little value, that it was barely sufficient to pay the heckling of the Flax; but the quantity taken off was small, as the quality of the Flax was then superior to what it is now. At that time it was no uncommon thing to have 25 to 26 spindles of $3 \mathrm{lb}$. yarn from the hundred-weight of 12 head St Petersburg Flax. It must be remembered that a fine quality of Flax, if carefully handled and little broken in the scutching and preparing, has naturally little tow upon it. It is rough usage in the preparation that breaks the fibre and produces tow, the normal condition of the fibre being Flax. The descriptions of Linen chiefly made in Dundee about this period were Osnaburgs and sheetings. The warp of both was three pound lint yarn, and the weft either six pound lint or seven pound tow yarn. Osnaburgs were almost wholly Flax warp and weft, the tow yarn spun being chiefly put upon some of the qualities of sheetings then made. The sail-cloth manufactured was wholly of Flax, and the little cotton bagging produced was of hemp. After 1793 the price of Flax rose, and from 1795 to 1799 St Petersburg 12-head remained, with little fluctuation, at about $£ 52$ a ton. In 1796 the quantity of Flax and Hemp imported was 3,336 tons, of the value of $£ 160,128$.

Shortly after Dr Small wrote his Statistical Account of Dundee, a new element of material prosperity was introduced into the town. Up to that period all the Linen yarn used in the manufacture had been spun by hand. About the year 1787-8, Flax spinning by machinery was commenced at Bervie, and, nearly contemporaneously therewith, at other localities in the country. About 1792-3, a small Flax-spinning mill, to be driven by a steam-engine of perhaps 10 horse-power, was erected by Fairweather \& Marr, in Chapelshade. It was the first attempt of the kind made in Dundee, but it did not succeed. 
The next effort to establish spinning by machinery was made by the late David Birnie in Guthrie Street (atterwards the Flour Mill), to the west of the present Bell Mill, the engine being of 12 horse-power. It was also unsuccessful, and both mills ultimately ceased to spin. In $1798 \mathrm{Mr}$ Wilkie of Auchlishie ereeted a mill in Guthrie Street, where the East Mill now stands, with a steam-engine of 20 horse-power; and about the same period mills were erected on the east side of North Tay Street, of 12 horse-power ; and, in the Dens, of 6 horse-power, the five mills being in all of about 60 horse-power.

William Brown, in his "Reminiscences of Flax-spinning," referring to the works in operation in Dundee for Flax-spinning, previons to 1800 , says - "Works had been erected there in Guthrie Street, in 1793, and in the same street, where the mill called East Mill now stands, which was formed out of a tan-work in 1798; at North Tay Street; at Chapelshade, previously a cotton-work, and at Dens, under where Messrs Baxter's larger work now stands; in all, five mills, having about 60 horse-power of steam, driving about 2,000 spindles, and spinning about 5,000 spindles per week of Flax yarns, five to six pounds per spindle. No tows were then spun, or merely small quantities on trial." The total production of mill-spun yarns in J)undee at the end of last century was therefore very trifling, but it was the commencement of a new era in the history of the Linen marufacture of the town. From this period mill-spinning is intimately connected with the other branches of the trade; but it may not be out of place to trace consecutively the onward progress of spinning, and incidental references to it will afterwards suffice.

No farther progress was made in the erection of mills for spinning by steam-power until 1806, when James Brown of Cononsyth erected the Bell Mill in Guthrie Street. Indeed, before that ye?r, spinning had rather retrograded, as want of success had closed the two mills which had been first started. A new description of spinning machines had in the meantime sprung up in various parts of the town, of a very light construction, driven by manual labour, and in some cases by real horse power. These concerns generally consisted of two or three frames of 20 to 30 spindles each, with a preparing frame of two heads, 
which served for both drawing and roving. Each frame was driven by a man with a crank connected with a moving board under his feet to ease the labour, which, being continuous, was very severe. The yarn spun on these machines was chiefly $3 \mathrm{lb}$. Flax, the hire price for spinning being about one shilling a spindle. Horses were soon abandoned, being more costly as a moving power than men; but the rise in the price of Flax in 1809 , and the increase of works driven by steam and waterpower, put a stop to this primitive mode of mill spinning. Afterwards, some of these spinners started small steam-engines, but they, too, were ultimately relinquished, as they were unable to compete with the larger works subsequently built.

The Bell Mill, formerly called West Ward Mill, was a weighty undertaking for the age. The proprietor of it was concerned in Trottick Mill, Arrott Mill, and Friockheim Mill, and as he felt much interested in Flax-spinning, he wished to have a work superior to either of these. Cotton spinning was then in a very prosperous condition, and he was almost persuaded to construct his new mill for cotton. Providence had otherwise decreed, and the mill was put up for Flax. This decision perhaps finally established the Flax manufacture in the town, and thus, to some extent, determined the destinies of Dundee as to its future trade. The plans of the mill and the machinery were procured from Leeds, then, as now, the headquarters for Flax-spinning and machinemaking in England. The building was 97 feet long, 40 feet wide, four storeys and attic in height, and chiefly fire-proof. The machinery consisted of forty spinning frames or sides for Flax and tow yarns, with some twisting frames, mostly of 30 spindles a side, and ample preparing machinery for all the spinning-the whole being driven by a steam engine of 25 horsepower. For twenty years the mill stood unmatched in the town, but now it is as far surpassed by recent erections as it then outstripped its compeers. The building cost $£ 7000$, and the steam engine and machinery $£ 10,000$, an outlay showing some adventure on the part of the proprietor, but he was a shrewd and intelligent man, far in advance of his age. Spinning operations were commenced on 1st May, 1807, the yarns produced being 2, 3, and $6 \mathrm{fb}$. Flax, and 4, 6, 8, and $10 \mathrm{mb}$. tow. The $2 \mathrm{fb}$. yarn was from Dutch or English Flax, and intended for sewing 
thread, then largely made in Dundee, the thread-makers twisting and finishing it in their own premises. Paltic Flax of good quality was required for the 3 and $6 \mathrm{Ib}$. yarn, and the tow yarn was made from the tow taken from the Flax heckled at the work; but tow-spinning was then in a very backward state, and it was not until long after that yarn at all satisfactory to a spinner could be produced. The weekly production of yarn was 2700 spindles, and the cost of spinning was-wages, 5d ; coals, $1 \frac{1}{2} \mathrm{~d}$; oils, repairs, rent, and charges, $3 \mathrm{~d}$, being in all $9 \frac{1}{2} \mathrm{~d}$ per spindle, exclusive of interest, leterioration of machinery, \&c. At present $3 \mathrm{~d}$ a spindle covers these charges.

The Flax-spinning mills in operation in the end of 1807 were the following:--

\begin{tabular}{|c|c|c|c|c|}
\hline est Ward Mill, James & wn, & & & \\
\hline East Mill, George Wilkie, & . & ," & $2 c$ & ", \\
\hline Tay Street, David Cathro, & 1 & , & 12 & , \\
\hline Dens, Peter Hution, & . & , & 6 & , \\
\hline Tutal, & . $\quad \overline{4}$ & & $\overline{63}$ & \\
\hline
\end{tabular}

In 1811, the consumption of Flax by these four mills was $1 \frac{1}{2}$ tons a day, or 468 yearly, and the produce 224,640 spindles of yarn. The whole capital then invested in spinning machinery did not exceed $\mathfrak{2} 22,000$, and the whole Flax imported into Scotland was then about 6000 tons yearly. For a part of this year the only mills in operation in Dundee were East Mill and the one in the Dens, the other two having been stopped. At a subsequent period they were started again.

The troublous times before this period were most inauspicious to Mill-spinning On 1st March, 1811, the Advertiser contained an advertisement-"For sale, the Flax-spinning mill in West Ward, erected in 1807 by the deceased James Brown ofCononsyth, of 25 horse-power, containing 31 spinning-frames, with 900 spindles for Flax ; 14 spinning frames, with 372 spindles for tow; and 4 twisting frames, containing 120 spindles for thread twisting. Apply to Brown \& Co., at the Mill." The Bell Mill is still in the family of the projector. In external appearance it remains unchanged, but the original machinery has been long removed, and the mill is now in full operation as a Jute spinning and weav- 
ing concern, and it is in every way substantial and complete. On 19th June, 1812, Tay Street Mill was advertised for public sale. It had a 12 horse steam-engine, 8 frames of 30 spindles each, being 240 spindles for Flax yarn, and the like number of frames and spindles for tow yarn, making 480 spindles in all. The advertisement mentioned that David Cathro had put in machinery to the value of $£ 8000$ in 1809 and 1810 . The upset price was $£ 4000$. A plan of the mill was to be seen on applying to Archibald Crichton, a gentleman, who (April 1864), is still alive. In same newspaper Lochty Mill, Carnoustie, was advertised to be sold or let; and a Flax-spinning frame and preparing frame, to be driven by manual labour, were advertised for public sale in a house in Rosebank. On 13th August, 1812, the spinning-mill then going in Dens was advertised for public sale, with steamengine, 8 new roller spinning frames, and preparing machinery to put same on either Flax or tow. Next year the spinning-mill at Bullionfield, containing 5 frames, 2 carding-engines, \&c., was advertised for sale. Such advertisements show the unhealthy state of the trade, as there would not have been so many mills in the market had spinning been prosperous.

The progressive increase in mill spinning by steam-power from 1807 to 1832 was as follows:-

$\begin{array}{llll}\text { Mills in Operation in } 1807, & . & \text {. } \\ \text { Do. added } & \text {, } 1813, & \text {. } & \text {. } \\ \text { Do. added } & \text {, } 1818, & \text {. } & \text {. } \\ \text { Do. added } & \text {, } 1820, & \text {. } & \text {. } \\ \text { Do. added } & \text {, } 1821, & \text {. } & \text {. } \\ \text { Do. added } & \text {, } 1822, & \text {. } & \text {. }\end{array}$

Total in 1822, as in detailed statement, Mills added in 1823,

Do. do. , 1824,

Do. do. ,, 1825,

Do. do. , $\mathbf{3} 826$,

Do. do. ,, 1828,

Do. do. ,, 1829,

Do. do. ,, 1830, 1 and 2, .

Total in Dundee in 1832,

Do. , Lochee

Do. Dighty Water,"

Do. do., driven by water, equal to

Total in Duudce and Neighbourhood in 1832, Engines, 48

$\begin{array}{cc}\text { Engines, } & 4 \\ \text {,, } & 1 \\ \text {, } & 1 \\ \text {, } & 1 \\ \text {, } & 3\end{array}$

Engines, 17

,$\quad 3$

,. 1

, 3

, 1

, 8

, 5

Engines, 40

,, 3

, 5

,

,
, 2
Horse-pow̄er, 63

\begin{tabular}{lr}
, & 6 \\
,, & 6 \\
, & 6 \\
, & 38 \\
, & 59 \\
\hline
\end{tabular}

Horse-power, 178

\begin{tabular}{lr}
, & 36 \\
, & 14 \\
, & 64 \\
, & 20 \\
, & 121 \\
, & 49 \\
, & 201 \\
\hline
\end{tabular}

Horse-power, 683

$\begin{array}{ll},, & 41 \\ , & 56 \\ , & 20\end{array}$

Horse power, 800 
Table of Spinsivg Milla in Dundeg at Martingas 1822, with tue Propaletors' Nayes, and the Horse-Power aNd SPINDles EMploted, aNd tuR Probable Year in which the MItllo weme Started.

1. William Baxter and Son,

2. Bell and Balfour,

3. Henry B!yth,

4. Andrew Brown,

5. J. and W. Brown,

6. James Curmichuel,

7. Chalmers and Hackney,

8. Do. Do.,

9. P. Davie and W. Boyack,

10. George Gray,

11. Janes Hynd,

12. Kinmond and Co.,

13. David Lawson,

14. Alexander Milue,

15. Mrs John Scott,

16. John Sharp and J. Preston,

17. William Shaw,
Dens Mill,

Chapelshade,

Wurd Road,

Bell Mill,

East Mill,

Upper Dens,

Thy Street (East),

Do. (West),

South Dudhope Mill,

Anchor Mrill,

Ward Roal,

Iower Dens,

Ward Road,

Scouringburn,

North Dudhope Mill,

Ward Road,

Cuwgate,
When started Horne-Power. Spindles

\begin{tabular}{rrr}
1822 & 15 & 600 \\
1821 & 12 & 600 \\
1820 & 6 & 300 \\
1807 & 25 & 1,152 \\
1798 & 20 & 900 \\
1798 & 6 & 240 \\
1798 & 12 & 600 \\
1821 & 20 & 1,056 \\
1818 & 6 & 420 \\
1822 & 8 & 294 \\
1822 & 4 & 210 \\
1822 & 12 & 360 \\
1822 & 4 & 163 \\
1821 & 6 & 240 \\
1813 & 6 & 288 \\
1822 & 10 & 283 \\
1822 & 6 & 228 \\
& 178 & $\underline{7,944}$ \\
\hline 8, & $\underline{17}$ & $=$ \\
\hline
\end{tabular}

In March 1826, there wete 166 foremen and overseers, 247 hecklers, and 1,688 preparers, spinners, and shifters, in all 2,101 hauds eniployed in these 17 mills.

Table of the Spinsivg Mills withis 5 Miles of Dundef, and also or thosk in the Neighbourhood but more Distant from Dundee, with the Proprietors' Names, and the Number of Spindles at Martivyas 1822.

First-Within Five Miles of Dundse.

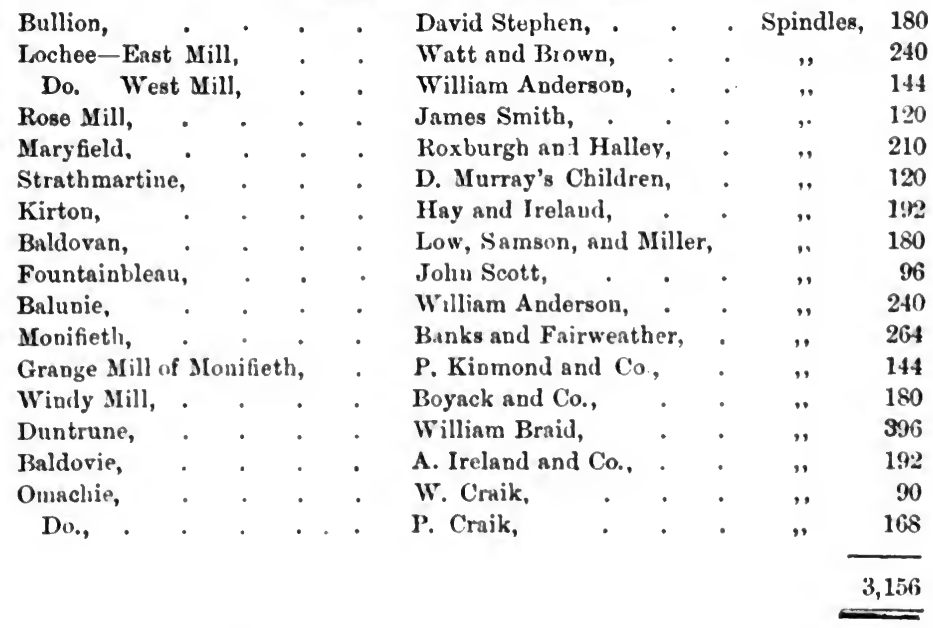


Second-In Neighbourhood, but beyond Five Miles fiom Dundee.

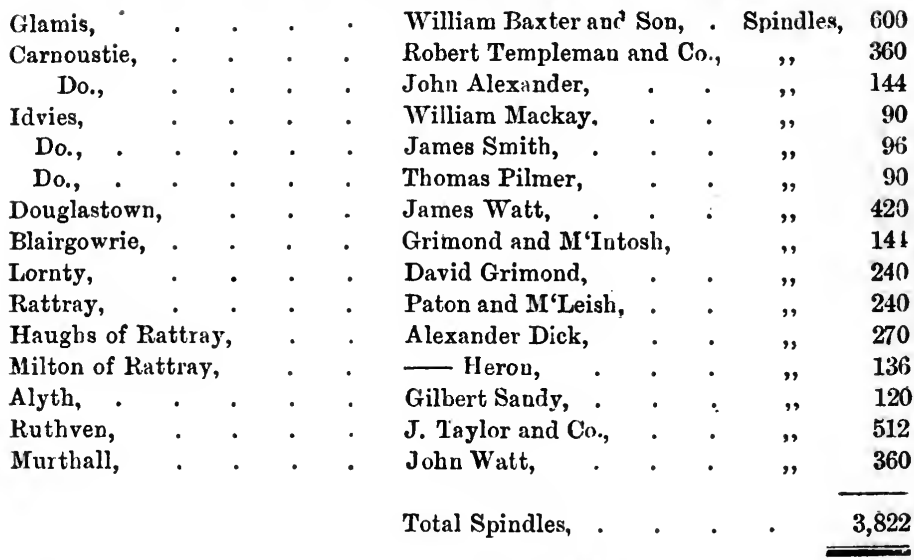

Subsequent to 1832 the increase in Mill-spinning was more rapid than before, and Jute, in Dundee, began to take its place among the fibres spun. In 1835 the trade had become widely developed in and around Dundee, and in December that year, the horse-power (steam and water), employed in Flax-spinning, and in the course of erection, in the district of which Dundee is the centre, or which came into competition with Dundee, was as follows, viz. :-

Dundee, llorse-Power Horse-Power
Employed.
Erecting.

Arbroath and Neighbourhood, . $\quad$. $\quad 297$

371

$\begin{array}{lrr}\text { Montrose and Neighbourhood, } & \text {. } & 210 \\ \text { Brechin and Neighbourhood, } & \text { - } & 78\end{array}$

Letham,

Bervie,

Total.

Aberdeen-Estimated to come into Competi-

tion with Dundee,

Perth,

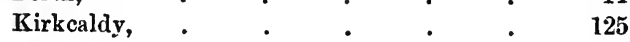

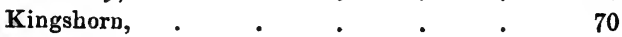

Cupar Fife and Neighbourhood, . . $\quad 67$

St Andrews, . • 6 
In 1851, the moving power (steam and water), employed in Flax-spinning and power-loom weaving was as follows, viz. :-

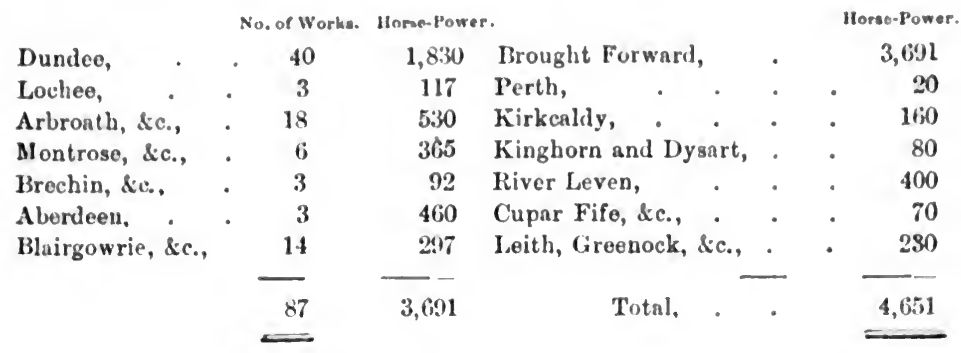

The steam-power employed by the several firms in Dundee and Lochee in 1851 ranged from 205, the highest, down to the lowest, 14 horse-power. For some years subsequent to this date little progress was made here, but the great demand occasioned by the Crimean war gave an impulse both to spinning and powerweaving. Details regarding the various spinning mills and power-loom factories in the several counties throughout the lingdom, in the beginning of 1862 , will be found in the Abstract of the Factory Returns, prepared by the Inspectors for presentation to Parliament, and given afterwards. Since then marked progress has been made in Dundee, both in spinning and in power-loom weaving, but especially the latter, and some particu-lars relative to the extent of machinery now in operation will be given hereafter.

It was the practice, from time immemorial, for the housewives and maidens of the surrounding district to bring the produce of their spindles and spinning-wheels into Dundee for sale on the market days. The market-place was the "Luckenbooths" and West End of the High Street, and there they assembled weekly with their stock of Linen-yaru. The manufacturers attended the market as regularly, and made their purchases; the business being carried on very much in the same way as is still done in the Butter Market. 'The yarn was generally brought to market as taken off the reel, and the quantity exposed for sale by the several parties varied from a spindle to perhaps ten or a dozen spindles. This retail mode of procuring supplies restricted the business of the manufacturers; and the many qualities offered P P 2 
for sale (the yarns of the various spinners varying greatly both in quality and size), made it tedious to assort them properly, and thus difficult to produce many pieces alike, or even one piece uniform throughout. Indeed, at one period the manufacturer was simply a weaver, who bought his own yarns, wove them in his own dwelling, took his piece upon his shoulder to the stampoffice, and, when stamped, carried it in the same primitive way to the shops of the recognised buyers, going from door to door until he found one willing to give a price to his mind.

As trade extended it became customary for dealers to traverse the more distant districts of the country to buy up the yarn, which they brought into the town and sold to the larger manufacturers. Others bought Flax, had it spun by hand, and sold the yarn to the manufacturers. Some manufacturers bought Flax on their own account, and emplnyed the women in town to spin it; or they sent it to agents in the country, who gave it out to the women in the district to be spun, getting a commission for the trouble on the yarn returned. These systems were all resorted to until a regular and abundant supply of mill-spun yarns were procurable, when they were discontinued; but it is little more than thirty years since these modes of collecting supplies had to be resorted to, and since the traffic in yarns on the High Street altogether ceased.

The class of goods made in the town, even in early times, was chiefly confined to coarse fabrics, and although the description has often changed to suit the demands of the markets for which they were intended, their prevailing character is still the same. The spinning machinery first erected in the town and neighbourhood was adapted for heary yarn, suitable for the quality of goods made. Perhaps it was well fur the success of the attempt that it was so, as it might have been more difficult to get machinery for fine yarns started in the experimental days of mill-spinning, and serious difficulties then would have retarded the progress of the trade. The many improvements which have now been effected in machinery adapt it for spinning very varied sizes of yarn, even from material which at one time would have been thought incapable of being spun at all, and thrown aside as useless.

In the early days of mill-spinning it was with difficulty that 
a sufficient number of hands could be got for preparers, spinners, or reelers, and it was then the practice in and around Dundee for the owners of mills, or their managers, to attend the neighbouring country fuirs to engage hands, and sometimes open tent had to be kept all day as an inducement to the people to come to terms. Engagements were generally made for six or twelve months, as with farm and household servants at the present day, and arles given as earnest of the bargain. The system has been entirely changed for many years. Then work in mills was new and little understood, and the prejudices against it, and those who took employment in them, very strong. 'The hours of labour were long, ranging from fourteen to fifteen a day, in towns, and, in some cases, they were even longer in country mills. Indeed, in some mills the hours were altogether arbitrary, and depended upon the caprice or whim of the manager, and the cupidity of the owner. Holidays were rare, and when they were granted the time was subsequently made up by working extra hours. Now employment in mills is a regular and recognised species of labour, and the hours precisely defined by the Factory Acts. Wages are higher for the shont hours of the present, than they were for the long weary hours of the early days of the trade. Six complete holidays must be allowed yearly, as well as the weekly half-holiday on Saturday, and no making up of lost time is allowed, with a slight exception in the case of works driven by water-power. The lofty and well ventilated mills of the present age, where every appliance of modern skill is impressed for the comfort and convenience of the hands, tends to make them healthy and happy.

Half a century ago it was with much difficulty that the various articles and materials required in carrying on the work, such as pressing rollers, bobbins, flyers, belts, lists, \&c., conld be got, and at best they were not well suited for the purpose. Now the stores required are supplied at a moderate cost, ready-made and of first-rate quality, by parties who make a trade of furnishing such articles. Before the introduction of coal gas the mills were lighted by whale oil lamps. As may be supposed, this mode of lighting was imperfect, troublesome, unhealthy, and dangerous. The substitution of gas did much to render employment in mills more attractive to the hands, and, by removing obstacles to the prosecution of the trade, tended to make success more certain. 
Indeed, without gas, Flax-spinning would not so soon have attained its present perfection.

Night spinning by relays of hands was, previous to 1824 , carried on to some extent in Dundee ; but it was found in practice not to be profitable ; and, as it was attended with many disadvantages, it has long since been entirely discontinued. $\mathrm{Mr}$ Brown mentions that the machinery first put into mills was not soon superseded. At a mill in Dundee the first set of machines, made on the spot in 1798 , continued in use till 1822 , when the spinning-frames were displaced, part of them being sold for same use in other works. Some of the Flax-spinning machinery in that mill continued working till 1830, at little disadvantage for some purposes.

Hand-heckling was long an important branch of the Linen trade in Dundee, and the Flax.dressers, numerically, once bore a much higher proportion to the total hands employed than they have done of late years. Early in the century they in some measure controlled the trade, dictating the rate of wages, number of apprentices, \&c., and enforcing their demands, however unjust, by strikes. This high-handed policy compelled employers to seek substitutes, and heckling machines were invented and introduced as competitors with the men. Now they have in a great measure supplanted them, a large proportion of the work being done by machinery. It is nearly sixty years since machines were erected for heckling Flax in Leeds, but it was many years later before they were started here, and for some time they made little progress, as they could not be adapted to humour strong or weak Flax like the human hand. The late John Sharp invented and patented a heckling machine, which was much approved, and, through his instrumentality, and that of others who sought the same clbject, difficulties were surmounted, and now the work is as well, and considerably cheaper, performed by the machine than by hand. For this result, and for the generally fallen condition of the hecklers as a class, the men have only their own, or their predecessors' illtimed tyranny to blame.

In the beginning of the century there were several small cotton works in town, but although they occasionally had their seasons of prosperity, they gradually declined, and the cotton spinning trade was ultimately abandoned here early in the century. The 
cotton work on north side of King Struet was advertised to be sold on 20th November, 1801, with all its machinery, consisting of a double 20-inch carding engine, with billy-picker, \&c., about a dozen "spinning-jennies," and four looms, \&c., \&c. In May 1802, it is reported in the Advertiser that there was a great demand for weavers of coarse cotton cloth in Dundee, and that this was seasonable, as then the Linen trade was very dull, and weavers could, in a few days, after changing from one manufacture to another, make excellent work at either. In July, 1802, it says, "hundreds of families are now supported by the manufacture of coarse cottons, which still continue in great demand."

After the peace of Amiens the sail-cloth manufacturers were crushed by the high price of material, and the want of demand ; and it was recommended that the cloth should be made of Hemp instead of Flax, as it had fallen 50 per cent. since the Peace, while Flax kept about double the price it had been a few years before. A Fifeshire manufacturer, in recommending Hemp, said "Russian and German Linens, and the finest foreign diapers, are of Hemp entirely, and a little extra bleaching makes them look like Flax, and I recommend an application to the Legis.

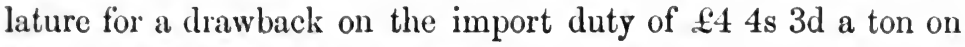
Hernp, which would be granted as soon as Hemp was shown to have been used successfully instead of Flax for Linens."

In the beginning of the century, and for many years thereafter, bleachfields were more numerous on the Dighty and in other districts than now, and their chief work was in bleaching home-made Linen, or what was called " customer work." Long advertisements from the various fields often appeared in the newspapers; and the regular prices were, "for all plain Linen, yard wide and under, bleached in the best manner, wove in a 900

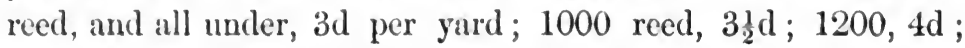
$1400,4 \frac{1}{2} \mathrm{~d} ; 1500,5 \mathrm{~d} ; 1600,5 \frac{1}{2} \mathrm{~d} ; 1700$ and upwards, 6d; tweels, $4 \mathrm{~d}$ to $6 \mathrm{~d}$; diapers, $4 \mathrm{~d}$ to $5 \mathrm{~d}$; damasks, $6 \mathrm{~d}$; plain Linen, bleached half white, $2 \frac{1}{2} \mathrm{~d}$; $2-2 \mathrm{ds}$ white, $3 \mathrm{~d}$; coarse tweels, same price; and sheetings, \&c., more than yard wide, at reasonable prices." There is now little or no "customer work" done at the fields, this branch of the trade having ceased with the manuficture of household Linen by the peasantry, farmers, and others. 
In the end of 1802, a seller of Dundee cotton bagging sued a purchaser in the Court of King's Bench, London, for the price. The defender pleaded that he had always been supplied with this article from Inverness, but in this instance, in consequence of not getting it from there in time, the seller had prevailed on defender's clerk to take some Dundee bagging, which proved unfit for his purpose. It was said in reply, by the pursuer's agent, that Dundee bagging was universally known to be inferior to Inverness, but if a person chose to take it instead of the other, he must do so with all its known imperfections. The defence was that it was not a merchantable commodity, nor fit to carry home cotton. The matter was left to the arbitration of one of the jury. The Dundee Advertiser of 21st December, 1802, in commenting on the trial, says "that the bagging must have been made long ago, when it was notorious that an inferior article was made here. The cotton bagging made in Dundee for the previous year was equal to Inverness or any other, and the quality was daily improving. It was perhaps to be regretted that the stamping of this article, as well as of Linens, properly so called, had not been enforced by the Trustees, for it was unquestionable that the stamping of Linens had prevented many frauds which would have ruined the staple trade of the place. The baneful effects of such mean practices have been bitterly experienced in the article of sail-cloth, to which, unluckily, the stamps do not attach."

In December, 1802, three Waulk mills, with lofts and utensils, situate at the Dens, were advertised to be let, and it was said they would suit for a brewery or barley mill. The Dens are now used for very different purposes than making beer or barley.

In the beginning of 1803 great complaints were made in Dundee and other places, that the Russian merchants managed the Flax market so that the manufacturers were entirely at their mercy ; and it was expected that this would drive the farmers to cultivate the plant more extensively, so as to make the trade less dependent on these parties. That complaint has often been made since then, not without much truth. The only means of checking such an abuse of power is the more extensive cultivation of Flax in other places. Until spinners receive supplies of Flax from other countries than Russia and Prussia, or until the quantity raised in these countries, available for consumption. 
in the United Kingdom, exceed the requirements of the trade here, the merchants there will have the control of prices; and there is no doubt they will continue, as they have hitherto done, to turn it to the best possible account for their own advantage. The same principle guides sellers of every commodity, as prices are regulated by the supply and demand, and it is right that they should be so.

On 1st April 1803, a vessel sailed from Dundee for New York with 125,583 square yards cotton bagging; 60,466 yards Osnaburgs ; 695 yards chequered Linen; 3,680 yards striped Linen mixed with cotton; 13,149 ells sail-cloth; 1,224 1bs. thread; and 40 hhds. Dundee porter and strong ale, \&c.

On 27th .July, 1804, "arrived the Mary Anne from Davis' Straits, brimful of blubber. Besides having all her casks full, nearly two large whales were stowed in bulk, and her punps were choked with oil." The whale fishing has long formed an important branch of the trade of Dundee, and from its nature, with varying success. Sometimes two prosperous years have followed each other, but more frequently a successful season has been succeeded by one or more bad or indifferent oncs. In 1827, out of nine vessels from the port, the Achilles, Captain William Valentine, came in with 22 fish; Princess Charlotte, Captain William Adamson. with 21 ; Three Brothers, Captain William Stiven, with 20; Fairy, Captain Welsh, with 19; and Thomas, Captain G. Thoms, with 15 fish; all being full. The other four were also well fished, the total quantity of oil being about 1,600 tons. Next year the same nine vessels brought 195 fish, about $1, \succ 00$ tuns of oil, valued, with bone, $\mathcal{d}$., at $£ 60,000$ to

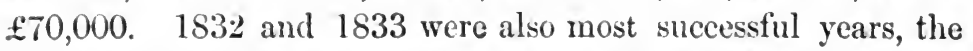
nine vessels belonging to Dundee having 235 and 219 fish in these years respectively. In the latter year the produce was about 100

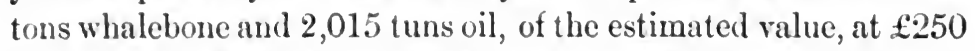
and $£ 20$, of $£ 65,300$. In 1833 the gross produce of the year's fishing by British vessels was estimated at 15,000 tuns of oil. Since then some very fortunate years have rewarded the exertions of the whale-fishers, but on the whole the trade has not been so profitable as it formerly was. 'This year, 1864, a more valuable fleet has gone to the fishing from this port than ever left before, the whole having steam-power to aid them. May success attend their latours! 
In 1804 many complaints were made about the sail-cloth then manufactured for Government being subject to mildew, partly, it was said from having been woven in shops rather below the level of the ground, and partly by the unequal application of the large quantity of ashes with which it was beeched. It was proposed to beech it twice instead of once, with less lee each time, washing it between the beechings. Other modes were suggested, but it is doubtful if any of them proved effectual, as the starch used in weaving the cloth would mildew when it got damp, however the yarn was prepared.

The Advertiser says the practice of purloining Flax, yarn, \&c., entrusted to parties to heckle, wind, or weave, was common, and much complained of. In November 1804, a woman was brought before the Justices of the Peace of this district, charged with selling the materials entrusted to her, and a man with having purchased same. Under the statute 22, George II., the woman was sentenced to be imprisoned for fourteen days and publicly whipped, and the man was fined $£ 20$, and in case of non-payment, to be imprisoned and publicly whipped. He paid the fine. In July 1805, six embezzlers of Flax and Hemp, confided to them for spinning, and twelve resets, including four manufacturers, were each fined by the Justices $£ 20$, or to be publicly whipped at the market-cross, in terms of the Act of Parliament. By a more recent Act, 7 and 8 Geo. IV., c. 29, it is declared that any person stealing, to the value of $£ 10$, any Linen, woollen, silk, or coftton goods, whilst exposed during any stage of the manufacture in any building, field, or other place, shall, upon conviction, be liable, at the discretion of the court, to be transported beyond seas for life, or for any term not less than seven years, or to be imprisoned for any term not exceeding four years, and, if a male, to be once, twice, or thrice publicly or privately whipped, as the court shall think fit. The theft of Flax, yarn, \&c., is but too common in the present day, but if purloiners or resets knew that they run a risk of being publicly whipped, under these statutes (if still in force), it would deter them from the commission of such crimes in future, and this would confer a boon on the trade.

The Act 15, Charles II., cap. 15, is not of the sanguinary character of those referred to. It ordains that any person, 
native or foreigner, may, without paying anything, set up in any place, privileged or not, corporate or not, any branch of the Linen manufacture; and foreigners practising the same shall, on taking the oath of allegiance, \&c., be entitled to all the privileges of natural born subjects. This Act, if unrepealed, is of some importance to the many foreign gentlemen who now settle in this country with the intention of engaging in the Linen trade.

$\mathrm{Mr}$ Brown mentions that about 1810 or 1811 , an engineering establishment was commenced in Guthrie Street, which supplied at first small steam-engines for the spinning frames previously worked by hand. The size begun with was two horse-power, but soon several of four to six horses were wanted for enlarged works. When the first steam-engine of two horse-power was put into hands, being the first made in the district, it was talked of as a wonder. Now splendid engines of 100 horse-hower are turned out of the same establishment by J. \& C. Carmichael, the proprietors, and even these leviathans are not the limit of the size at which engines could be furnished by them.

On 5th February 1813, three per cent. consols were quoted in Advertiser at 591; P'TR Flax, $£ 115$ to $\mathfrak{1 2 0}$, or about double consols; oatmeal, $2 \mathrm{~s} 6 \mathrm{~d}$ per peck; and quarten loaf, $1 \mathrm{~s} 5 \mathrm{~d}$. On 19th March same year, "In consequence of the changed aspect of the political atmosphere, some fine ships belonging to the town sailed for the Baltic. Six summers have passed without such a gratifying sight before; the trade to the Continent having been carried on by the ruinous intervention of licenses, and of neutrals."

In 1814 there was eonsiderable discussion about abolishing the duties on the importation of Linen. 'Those who opposed it said "the duties had induced parties to invest an astonishing capital in mills and bleachworks, which would be lost if they were removed, and Dundee, without its manufactures, would degenerate into a maltry village." 'The merchants, manufacturers, and shipping interest were recommenderl to meet and establish a Chamber of Commerce to watch over the interests of the trade, and to devise means to oppose the abolition of the duties.

In December 1816, the high price of provisions and the stagnation of trade caused the meal mobs in Dundee.

On 14th May 1817, the shore-dues were let by public roup to 
Thomas Neish for $£ 5,605$, being $£ 245$ above the upset price. The Advertiser, on 16th mentioned, that W. Hackney was to join him, and that Mr Hackney's grandfather had had the shore-dues and public warehouse together, fifty or sixty years before, for $£ 100$ a year. Before 1793 Bell and Balfour had the shore-dues by private bargain at $£ 560$ yearly. That year they were put up to auction for three years, and the same firm took them at $£ 965$ a year. In 1796 they were again put up to auction for other three years, and taken by William Wilson at $£ 1,550$ a year. Since 1822, excepting 1825-6, they have been collected by the 'Trustees, and in the year ending 31st May, 1863, the amount of shore-dues collected by the Harbour 'Trustees was £23,564.

Among the exports from the Harbour in 1818 were "yards of plain bounty Linen, ells of sailcloth, lbs. thread, square yards of diaper, hucks, and sheeting, square yards of cotton bagging, and lbs. cotton thread and yarn."

The following is a statement of the Linen stamped in Dundee in the years specified:-

\begin{tabular}{|c|c|c|c|c|c|}
\hline & $\begin{array}{l}\text { Yards } \\
\text { Stainped. }\end{array}$ & $\begin{array}{c}\text { Fees paid } \\
\text { Stamp-master. }\end{array}$ & & $\begin{array}{l}\text { Yarns } \\
\text { Stamped. }\end{array}$ & $\begin{array}{c}\text { Fees paid } \\
\text { Stamp-master. }\end{array}$ \\
\hline $177: 3$ & $4,488,460$ & & 1789 & $4,242,653$ & \\
\hline 1805 & $3,909,948$ & $\begin{array}{lll}£ 407 & 5 & 8\end{array}$ & 1816 & $7,296,007$ & $\begin{array}{lll}£ 760 & 0 & 0\end{array}$ \\
\hline 1806 & $4,727,178 \frac{3}{4}$ & $\begin{array}{lll}492 & 8 & 3\end{array}$ & 1817 & $7,958,071 \frac{3}{4}$ & $828 \quad 19 \quad 3$ \\
\hline 1807 & $4,604,167$ & $\begin{array}{llll}479 & 12 & 0\end{array}$ & 1818 & $8,600,363 \frac{3}{4}$ & $89517 \quad 5$ \\
\hline
\end{tabular}

In 1789 the estimated value of the Linen stamped in Dundee was $£ 108,78214 \mathrm{~s} 2 \mathrm{~d}$, and in $1818, £ 302,24512 \mathrm{~s} 11 \mathrm{~d}$. The average yearly quantity stamped in Forfarshire during the years 1805 to 1807 was 11,536,656 yards, the Stamp-master's fees for which was $£ 1,20114 \mathrm{~s} 8 \mathrm{~d}$ yearly on average. For the years 1816 to 1818 the yearly average was-yards, $17,485,794$, fees, $£ 1,821$ $8 \mathrm{~s} 8 \mathrm{~d}$, being an increase of fully 50 per cent. in the latter years over the previous ones. The average yearly fees paid the Stamp-masters in Scotland for the five years ending 1780, were

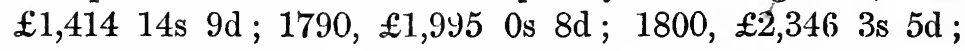
$1810, £ 2,30316 \mathrm{~s} 10 \mathrm{~d} ; 1818, £ 3,007$ 11s $1 \mathrm{~d}$ respectively.

On 19th October 1821, the Advertiser gave a report of the state of the staple trade of the district, and, as it is very interesting, it is given nearly entire. "Since the beginning of 1820 there has been little variation in the prices of the Linen manu- 
factures of Forfarshire, the fluctuations being only from to to $\frac{1}{2} d$ a yard, a steadiness new in the history of Linens. Formerly Strelitz Flaxen Osnaburgs varied from $6 \frac{1}{2} \mathrm{~d}$ to $9 \mathrm{~d}$, while tow of same description varied from $6 \mathrm{~d}$ to $8 \mathrm{~d}$. Dundee 24 por. $4-4$ th sheetings now sell at $7 \frac{1}{2} \mathrm{~d}$, and the variation in them is fully a $1 \mathrm{~d}$. Owing to prodigious over-production, cotton bagging, for three years prior to 1821, had almost ceased to be named among the staple productions, but the mamufacture of bagging has now resumed its place on a moderate scale. Baltic hemp bagging now sells at $9 \mathrm{~d}$ to $9 \frac{1}{\mathrm{~d}} \mathrm{~d}$, and Sunn hemp at $8 \mathrm{~d}$ to $8 \frac{1}{2} \mathrm{~d}$ a yard. The manufacture of bleached sheeting, dowlas, \&c., in Fife and Forfar shires, in point of extent and value, now exceeds that of Osnaburgs and brown sheetings. The Linen trade has been enriched by the addition of bleached sheeting and raven-ducks in imitation of Russian Linen, and dowlas in imitation of German do., and the imitation Linens are now carried to those very markets of which our Continental rivals had before the monopoly. Bleached imitation Russia sheeting may be quoted at $12 \mathrm{~d}$ to $15 \mathrm{~d}$, ducks, $9 \frac{1}{2} \mathrm{~d}$ to $10 \frac{1}{2} \mathrm{~d}$, dowlas, $10 \mathrm{~d}$ to $10 \frac{1}{2} \mathrm{~d}$. Hempen and tow sackings, hessians, and various other fabrics, have also been introduced within about five years. The introduction and improvement of spinning machinery has been a principal agent. It has increased the quantity, improved the quality, and diminished the price of the yarns brought to market. Yarns are now spun on the arerage at half the price which used formerly to be paid for hand-spinning. In the early stages of the manufacture, the difficulty of procuring yarns necessarily limited the trade, and Osnaburgs and sheetings were almost the only descriptions made in this neighbourhood. Six months had formerly been allowed for spinning and manufacturing the Flax into Linen, now two months does it. The improved quality of the Linens has increased the demand for them, which bad goods never do." It is added-" Every improvement requires caution, and should not be embarked in rashly. It requires an intimate knowledge of the principles and details of machinery, and perseverance to encounter and orercome difficulties."

The Advertiser of 3d February 1822, says-" Two Flax-spinning frames of 30 spindles each, made by Daniel Duff \& Co., were yesterday morning set a working at St Roque Mill for the 
first time, and in the short space of thirteen hours and a half turned off 66 spindles of yarn."

In October 1822, the wages paid to spinners in mills was from $7 \mathrm{~s}$ to $9 \mathrm{~s}$, and children from $2 \mathrm{~s}$ bd to $4 \mathrm{~s}$; spinners of hemp yarn by hand from $5 \mathrm{~s}$ to $6 \mathrm{~s}$, and weavers from $12 \mathrm{~s}$ to $15 \mathrm{~s}$, all per week. In 1826 Flax-dressers were paid 2 s per cwt., and in 1827 the rate rose to $2 \mathrm{~s} 6 \mathrm{~d}$ per cwt.

In 1823, there were shipped at Dundee 82,250 pieces Osnaburgs, $12,008,580$ yards, the bounty on which was $\mathfrak{E} 75,05312 \mathrm{~s}$ $6 \mathrm{~d}$. It was at this time estimated that about one million was laid out as fixed capital on buildings and machinery for the manufacture of Linen in Forfarshire.

Quantity and official value of the Linens and sailcloth exported from Dundee for the years ending 5th January 1824 to 1827 :-

\begin{tabular}{|c|c|c|c|c|}
\hline Year Ending. & Linens Exportd. & Value. & Sailcloth Exptd. & Value. \\
\hline $\begin{array}{cc}\text { 5th Jan. } & 1824 \\
,, & 1825 \\
, & 1826 \\
,, & 1827\end{array}$ & $\begin{array}{c}\text { Yards. } \\
2,331,127 \\
2,873,005 \\
2,610,234 \\
2,852,922\end{array}$ & $\begin{array}{ccc}\text { f } & \text { s. } & \text { D. } \\
71,300 & 16 & 9 \frac{1}{2} \\
74,175 & 12 & 10 \frac{1}{2} \\
70,180 & 4 & 10 \\
69,049 & 1 & 9\end{array}$ & $\begin{array}{c}\text { Ells. } \\
18,922 \\
69,379 \\
58,426 \\
2,001,496\end{array}$ & \begin{tabular}{rrc}
\multicolumn{1}{c}{$\boldsymbol{f}$} & S. & D. \\
951 & $\mathbf{5}$ & 19 \\
3,325 & 11 & 1 \\
3,233 & 14 & $8 \frac{1}{2}$ \\
41,877 & 17 & 9
\end{tabular} \\
\hline
\end{tabular}

The bounty on Linens having been reduced periodically, great exertions were made, previous to the days when the different instalments came off, to have all the goods possible shipped in time to secure the higher rate, and some ludicrous scenes occurred on these occasions.

The Advertiser of Thursday, 7th July, 1826, says:- "Yesterday being the last day that the description of Linen known by the name of canvas, No. 10, was entitled to bounty on exportation, large quantities were shipped. Clerks, packers, carters, porters, seamen, were all actively engaged in making the shipments, and it is said that an old merchant renewed his youth for the day, and wrought miracles. He had purchased largely of No. 10's at $3 \frac{1}{2} \mathrm{~d}$ per yard, and got them all on board in time, which entitles him to receive $2 \mathrm{~d}$ per yard of bounty. The original cost of the Linen shipped to him, deducting the bounty, is therefore $1 \frac{1}{2} \mathrm{~d}$ per yard. The bounty on the whole shipments amount to about $£ 11,000$." 
'The bustle and activity among the exporters of Linens from Dundee during the week preceding the 6th July, 1828, when another per centage of the bounty came off, was unprecedented. The total quantity exported for the week from $29 \mathrm{th}$ December, 1827 , to 5th Jamiary, 1828, was as follows:-

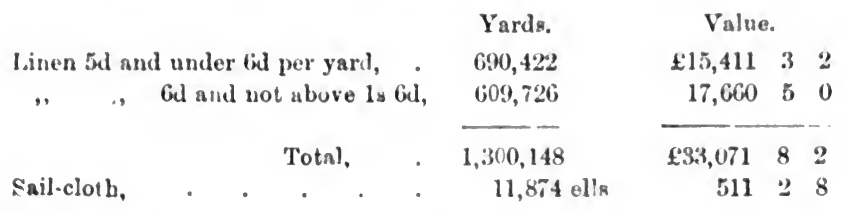

In December, 1828, ressels sailed from Dundee for Mobile, New York, and St Domingo; and ressels were then loading for Rio de Janeiro, Bahia, Pernambuco, New Orleans, Charleston, Savannah, New York, \&c., with Linens. The direct export trade has been all but lost to Dundee since facilities were afforded by railways in carrying goods quickly to Liverpool, \&c., where frequent opportunities are got for shipping them.

The fifth reduction of 10 per cent. from the bounty on the export of Linen took place on 5th January, 1829. From 6 th December, 1828, to 5 th January, 1829 , but particularly on the last day, there were upwards of 31,000 pieces shipped for foreign ports, the value of which was upwards of $£ 78,600$. The total value of Linens and sail-cloth exported from Dundee for bounties in year ending 5 th January, 1829, was £308,768 3s 9d.

At a meeting of merchants, Flax-spinners, and others interested in the Linen trade, held in the Town Hall, Dundee, 27th June, 1831, it was agreed, by a majority, that no application should be made for a continuance of the Bounty on Linen.

The shipments of Linen for the week ending 5th January, 1832, were very extensive, the time for the payment of bounty having expired on that day. Considerable quantities which could not be got shipped were put into bond, the Lords of the Treasury having been pleased to allow Linens entitled to bounty to be lodged in warehouses under the King's lock, on condition that such were exported within three months, and that the Crown be not subjected to any expense-the bounty only to be paid after the goods were duly shipped. The following details of the bounty Linen exported from Dundee for the quarter ending 5 th 
January, 1832, are taken from the Custom-House Books. The quantity for this quarter was much beyond the average, as extraordinary efforts were made to get goods off by 5th Jan., to secure the bounty, which then ceased entirely.

\begin{tabular}{|c|c|c|c|c|}
\hline $\begin{array}{l}\text { To what Place } \\
\text { Exported. }\end{array}$ & $\begin{array}{l}\text { From } 5 \mathrm{~d} \text { to } 6 \mathrm{~d} \\
\text { per Yard. }\end{array}$ & $\begin{array}{l}\text { From } 6 \mathrm{~d} \text { to } 1 \mathrm{~s} 6 \mathrm{~d} \\
\text { per Yard. }\end{array}$ & $\begin{array}{c}\text { Exceeding } \\
\text { 1s 6d per Yd. }\end{array}$ & Sailcloth. \\
\hline \multirow{9}{*}{ 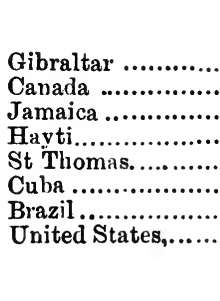 } & Yards. & Yards. & Yards. & Ells. \\
\hline & 33,781 & 486.873 & $\ldots$. & 36,243 \\
\hline & 42,985 & 215,112 & ........ & 46,638 \\
\hline & 280,798 & $1,260,164$ & $\ldots \ldots$ & 9,856 \\
\hline & 634,177 & $1,121,640$ & ...... & 2,878 \\
\hline & 206,227 & 527,039 & $\cdots \cdots$. & ...... \\
\hline & $\begin{array}{r}36,223 \\
836,798\end{array}$ & $\begin{array}{l}373,793 \\
890,640\end{array}$ & 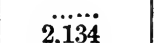 & $40 \dddot{478}$ \\
\hline & 968,998 & $3,361,257$ & 55,617 & $\begin{array}{r}48,468 \\
382,958\end{array}$ \\
\hline & $3,039,987$ & $8,236,518$ & 57,751 & 519,051 \\
\hline
\end{tabular}

The total value of Linen exported from Dundee for bounty, and the amount of bounties paid thereon, for the year ending 5 th January, were as follows :-

\begin{tabular}{|c|c|c|c|}
\hline $1830 \ldots \ldots$ & Value Exported, & $£ 277,977 \quad 0 \quad 0$ & Bounties, $£ 39,04312 \quad 8$ \\
\hline $1831 \ldots . . .$. & Do. & $\begin{array}{llll}365,595 & 0 & 11\end{array}$ & $\begin{array}{llll}41,359 & 0 & 11\end{array}$ \\
\hline $1832 \ldots \ldots$ & Do. & $596,424 \quad 0 \quad 0$ & $\begin{array}{lll}46,854 & 7 & 2\end{array}$ \\
\hline
\end{tabular}

The total value of British manufactures exported from Dundee in the latter year was as follows:-

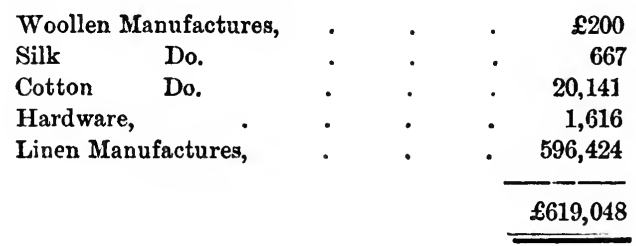

In 1800 the price of St Petersburg 12. head Flax in Dundee rose from $£ 52$ to $£ 73$ a ton; in 1801 it averaged $£ 71$; in $1802, £ 60$; $1803-4$, returns defective ; 1805, £65; 1806, £62; 1807, £65 ; $1808, £ 103 ; 1809, £ 118 ; 1810, £ 85$ 10s; 1811, £77; 1812, $£ 105 ; 1813, £ 88 ; 1814, £ 80 ; 1815, £ 73 ; 1816, £ 51 ; 1817$, $£ 5210$ s; 1818, £66 10s; 1819, £65; 1820, £54; 1821, £5ก. 
The average price for the seven years prior to 1815 was $t^{2} 94$. and for seven years subsequent to the war £59, showing a fall of $£ 35$ after the conclusion of the war. This was caused partly by the fall in freights (at one time, as related by the late David Martin, he paid the extranrlinary freight of $\mathfrak{2} 28$ a ton for Flax, from Riga to Dundee), and insurance, which in 1821 did not amount to one fourth of what they were during the war, and partly to the increased value of the currency, which depressed the price of Flax and all other materials. Another cause was the increased supply of Flax received from Ireland. Prior to the Revolutionary war, Flax had

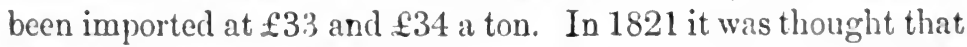
when 12-head St Petersburg Flax fell to $\mathfrak{A} 40$ per ton, it might be considered to have attained its level; and that $£$ :38 was the minimum price at which it could be landed here to pay all parties.

In the first decade of the century, the sorts of Flax principally used in Dundee were St Petersburg 12-head, Riga Thicsenhausen, and Dutch, and English, and the prices of all these descriptions were then nearly the same. In February, 1809, theso Flaxes on the average adranced to $\mathfrak{E} 150$ a ton, being the highest point they ever reached. During these years the fluctuations were sudden and violent, somctimes rising or falling $\mathfrak{f 2 0}$ a ton in a few days, chiefly caused by erents of war. Yarns varied as much as the raw material. The highest price paid for yarns was in the spring of 1809 , when $3 \mathrm{lb}$. Flax was $7 \mathrm{~s}$ a spindle $; 6$ tb. do., $11 \mathrm{~s} 9 \mathrm{~d}$; and 6 tb. Tow, $10 \mathrm{~s} 3 \mathrm{~d}$.

In the end of June 1826 the price of Flax fell greatly, and at that time it Petersburg 12-head was quoled at $£ 29$ to $£ 2910 \mathrm{~s}$,

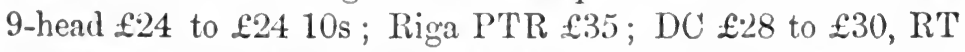
$£ 2210$ s to $£ 23$; Libau $£ 27$; Archangel qualities, 227 to $£ 35$. These are, perhaps, the lowest prices which Flax erer touched in Dundee. $3 \mathrm{lt}$. Flax yarn then fell to $1 \mathrm{~s} 10 \mathrm{~d}$ (a) $2 \mathrm{~s} ; 4 \mathrm{lb}$. do., $2 \mathrm{~s} 3 \mathrm{~d} @ 2 \mathrm{~s} 5 \mathrm{~d} ; 6$ and $7 \mathrm{fb}$. tow yarn, 2s 4d@3s; 10 to $12 \mathrm{lb}$. do., $3 \frac{3}{4} \mathrm{~d}$ to $4 \frac{1}{2} \mathrm{~d}$; prices at which they had never been quoted before.

The price of Jute has fluctuated greatly since its introduction into the trade, arising from scanty or superabundant supplies, or the result of speculation. The finer qualities have been sold here as low as $£ 10$, and as high as $£ 35$ a ton. The price of 
fine Jute for the twenty years preceding 1853 averaged about $£ 16$, and since then it has averaged about $£ 26$; the average price of all qualities since 1853 being about $£ 22$ a ton.

A prices-current of the raw materials, yarns and Linens, in the Dundee market, for each year from the beginning of the century, is appended. Excepting when otherwise stated, the prices were those current about the end of October in the respective years, and as the leading articles of the period are quoted, the class of goods then made, as well as the approximate price, is shown. In the early decades of the century the prices are taken from the Market Reports of the Advertiser; subsequently they have been made up from various sources, and with considerable care.

In 1809 Flax-dressers were paid 3s 6d per cwt. for heckling Baltic Flax, yielding $50 \mathrm{lb}$. for $3 \mathrm{lb}$. yarn, and $6 \mathrm{~s}$ per cwt. for Dutch and English Flax, yielding $60 \mathrm{lb}$. for $2 \mathrm{lb}$. yarn.

In the beginning of 1819 great complaints were made about the low wages paid for weaving. The goods then made were of two classes, sheeting and Usnaburg, and sail-cloth and bagging. Working fourteen hours a day, the quantity weaved by a man in a year, on the average, as taken from the books of many manufacturers, was-

Osnaburgs, 26 pieces, 3,796 yards, Sheetings, 26 " 3,276 ,"
Sail-cloth, 78 pieces, 3,120 yards,

Bagging, 78 , 4,680 ,

On Osnaburgs, \&c., a common hand could earn about $£ 10$ 17s $8 \mathrm{~d}$ a year, and a dexterous person about double ; and, on sailcloth, \&c., a common weaver could make about $£ 152$ s, and a first-rate one-half as much more. The women were employed spinning and winding. Three-pound Flax yarn, and coarse Hemp and tow yarn were chiefly spun, two spindles a week being the average quantity spun, which, at $8 \mathrm{~d}$ a spindle, made $1 \mathrm{~s} 4 \mathrm{~d}$ a week. At that time, low as wages were, manufacturers were then said to be losing on every piece, not a bale having been exported excepting on speculation for several months. Tho Advertiser adds - "So flourishes the staple trade of Dundee !"

Early in 1820, a Committee on the State of the Labouring Poor gave in a Report, showing that the wages then paid for weaving, \&c., in Dundee were as follows, viz. :- 
Sail-clotb, 2 wobs per wook, at ts $3 d$ onuh,

8. $6 \mathrm{~d}$

Bagging, 2 webs do. do.

8. 61

Sacking, 5 pieces in threo weeks, at $4 \mathrm{~s}$ il each (por woek), 7s 6d

Sheeting, 1 piece in 10 days, $\quad \ldots \quad \ldots . \quad \ldots \quad$ 10s 0 d

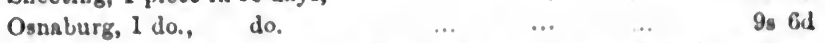

Less winding, rent, \&c., about $2 \mathrm{~s}$ dgl por piece of uheeting and Onuaburg.

The women employed in mills earned about 58 a week; best hand-spinners, when fully employed, $2 \mathrm{~s} 6 \mathrm{~d}$; but, on the average, from scarcity of work, \&c., 1s $2 \mathrm{~d}$ a week. About 1500 women were then employed in hand-spinning in Dundee. It was said that the women were only paid $4 \mathrm{~s}$ for spinning as much yarn as would extend from Dundee to Aberdeen in a direct line. (The distance is $65 \frac{1}{2}$ miles, and as a spindle, 14,400 yards, is upwards of eight miles long, the rate per mile is about three farthings, which scarcely allows sixpence for spinning a spindle.) A weaver then put the same quantity of weft in his web, in the same space of time as it took to spin it, for about double the money.

On 22d May 1822, a meeting of merchants and others interested in the Linen trade was held in Dundee to resuscitate the Forfarshire Chamber of Commerce, when office-bearers were elected, \&c.

The length of the webs given out to be weaved has often been a source of great dissatisfaction to the weavers. The price of weaving throughout the town was nearly uniform for the respective fabrics, but some manufacturers warped their webs longer than others, which gave their weavers extra work, without a corresponding increase of pay. Previous to 1824 , the length of webs were as follows, viz. :-

\footnotetext{
4.4ths and 9.8ths sheetings, 126 5ards, White wheetings, 115 to 116 yurds, Osnaburgs, 116 yardx,

Hessian sheetings, 115 yards,

Danily sheetings, 96 to 93 yards.

In 1833 the webs given out by rarious manufacturers were publicly measured on the Magdalen Green. The greatest differences were found to be upon hessian sheetings, which varied from 123 to 150 yards ; Liverpool sacking, from 99 to 113 ; canras, from 45 to 52 ; and cotton bagging from 65 to 78 ; but all fabrics differed considerably, showing that the wearers had good ground of complaint. That year the manufacturers met and resolved upon a uniform standard of lengths as follows:-4-4th Q 2 
and $9-8$ th brown sheeting, 22 por., 131 to 132 yards; 4-4th and 9.8th imitation do., 24 and 26 por., 106 to 108; 4-4th and !)-8th brown or bleached sheeting, 28 to 36 por.-short lengths, 108, long do., 132; hessian sheetings and sand bagging, 32 to 72 inches wide, 132 to 134 ; mending bagging, 34 inches wide, 103 io 105 ; do. 40 inches, 66 to 68 ; Osnaburgs, 22 to 26 por., 148 to 150 ; Dowlas, 25 to 27 inches, 22 to 28 por., 148 to 150 ; do. 30 to 40 porter, 134 to 136 ; Liverpool sacking, 12 to 16 porter, 100 to 102 ; farmers' do., 14 to 16 porter, 94 to 96 ; factory fabrics, viz., sacking, cotton bagging and pimento, $1 \frac{1}{2} \mathrm{Hb}$. per yard, 62 to 64 ; do., $1 \frac{1}{4}$ Hb., 66 to 68 ; hop-pocketing, 82 to 84 ; tarpauling, 42 to 44 ; canvas, 40 to 42 .

This list shows the class of goods then made in Dundee, some of which have ceased to be woven here, and are now the staple fabrics of the district towns. It is curious to mark the changes which time makes upon the trade of a locality. Dundee was once famous for its bonnets, its bottles, and its buckles; but now the Bonnethill, the Bucklemaker Wynd, and the Bottle-work are all that remain (excepting the ancient Incorporation of Bonnetmakers, whose yellow banner floats in the centre of the Nine Trades), to tell that these ancient trades once flourished here. The thread manufacture once employed many people in town, but it, too, has been long lost. The Soap-work Lane, and the Sugar-house Wynd tell of works that were. Its great leather trade is kept in remembrance by the Tannage Court, \&c., and, though long almost extinct, it is once more prosecuted vigorously, Henry Henderson \& Sons having tan-works and currying premises here, perhaps unequalled in extent by those in any other town in Scotland

In 1831 there were, by the census returns, 363 manufacturers here, and 6,828 persons employed in the Linen trade, of whom 700 belonged to Lochee. The wages then paid were-flaxdressers, $10 \mathrm{~s}$ to $12 \mathrm{~s}$; girls and boys, $3 \mathrm{~s}$ to $6 \mathrm{~s}$; women, $5 \mathrm{~s}$ to $8 \mathrm{~s}$; weavers, $7 \mathrm{~s}$ to $10 \mathrm{~s}$; mechanics, $14 \mathrm{~s}$ to $18 \mathrm{~s}$ a week, the total amount paid yearly being $£ 156,000$. Since that period the wages paid to the operatives engaged in the staple industry of the town have fluctuated with the rising or falling fortunes of the trade, and with the supply and demand in the labour market. Sometimes low wages and dear provi- 
sions have caused dire distress, and sometimes high wages and cheap provisions, as at present, have afforded many comforts to the prudent. Prosperity never benefits the improvident. The wages now paid in some of the leading departments of the trade are as follows:-Spinning-nills-preparers, is $3 \mathrm{~d}$ to $8 \mathrm{~s} 3 \mathrm{~d}$ : spinners, $8 \mathrm{~s} 3 \mathrm{~d}$ to $8 \mathrm{~s} 9 \mathrm{~d}$; shifters, $5 \mathrm{~s} 9 \mathrm{~d}$ to $6 \mathrm{~s}$; boys, $4 \mathrm{~s} 6 \mathrm{~d}$ to $9 \mathrm{~s}$; reelers and warpers, piece work, 9s to $14 \mathrm{~s}$; overseers, $21 \mathrm{~s}$ to $24 \mathrm{~s}$. Power-loom factories-winders, picee work, $7 \mathrm{~s}$ to $9 \mathrm{~s}$; weavers, piece work, $9 \mathrm{~s}$ to $11 \mathrm{~s}$; tenters, $22 \mathrm{~s}$ to $26 \mathrm{~s}$. Hand-loom factories-warpers, $15 \mathrm{~s}$ to 16 s; weivers, piece work, $5 \mathrm{~s} 6 \mathrm{~d}$ to $6 \mathrm{~s}$ for sacking; hessians, $1 \mathrm{~s}$ per spindle of weft put on, and $1 \mathrm{~s}$ per picce additional. Flax-dressers, 2s 6 d per cwt. Mechanics, $17 \mathrm{~s}$ to $25 \mathrm{~s}$. Calenderers, $15 \mathrm{~s}$ to $16 \mathrm{~s}$; lappers, $15 \mathrm{~s}$ to $17 \mathrm{~s}$.

- In 1832 the mills in operation in Dundee and the immediate neighbourhood (599 horse-power) consumed 15,600 tons of Flax, and produced $7,488,000$ spindles of yarn. 'The sum then invested in machinery was estimated at $\$ 240,000$. In these mills about 3000 persons were employed, of whom 600 were under 14 years of age, 1,073 under 18, some under 12, and a few from 6 to 7 , the others being 18 or more.

In Thomson's History of Dundee the value of the articles imported into the town, and cliefly used in the manufactures, for the three years ending 31 st May 1838 , is stated at $23,: 84,585$,

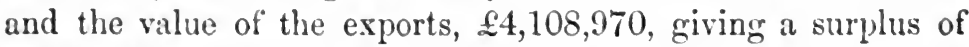
$£ 824,385$, or between 25 and 26 per cent. on the imported value. In the year ending 31 st, May 1838, the value of the imports is stated at $£ 782,513$, and of the exports, $\$ 1,172,669$, being an increase of nearly 50 per cent. After adding about 30 per cent. to the value of the raw material, of which the manufactured articles consisted, fur additional cost of labour, it leaves a profit of 20 per cent. According to the same authority there were in Dundee in 1846 , at least 36 mills, with a motive power on the aggregate of 1,242 horses, driving not less than 71,670 spindles.

On 7 th Sept. 1821 the Advertiser states that in Dundee "a power-loom is about to be used, by way of experiment, in the weaving of our staple fabric of Linens." Probably this experiment had not turned ont well, as it was not followed up. Other experiments were subsequently made, but no power-looms were regularly worked in town for many years thereafter. 
In 1826, when Wm. Baxter \& Son put up their second mill in Lower Dens, they proposed to put in ninety power-looms, as well as spinning machinery, but this intention was abandoned, and it was not until ten years thereafter that they carried out their early proposal of erecting a power-loom work. Towards the end of 1836, Messrs Baxter erected a power-loom factory at their Upper Dens works, and it was the first work of the kind started in Dundee. In a report of the New Factory which appeared in the Advertiser, it is mentioned that the weaving shop or shed alone is $\mathbf{1 5 0}$ feet long by $\mathbf{7 5}$ in width, lighted from the roof, and it is expected that from 300 to 400 people will be employed in weaving, and in the subsidiary processes. It is added"This mode of manufacturing has for a considerable time been carried on successfully in Aberdeen, and is extending there. It has also been introduced into several manufacturing towns in England." Shortly after this period, Alexander Rowan erected Dudhope Works, and John Laing Dens' Road Factory; and a little later A. and D. Edward and Co. erected a factory at their Logie works. For a considerable period, these four were the only power-loom factories in Dundee.

Within the last few years a new era has dawned on the trade. Many power-loom works have been put up; others are in course of erection, and others contemplated, some of them of great magnitude. Judging from the changes which have taken place within the last ten years, a very few years more will see handlooms almost entirely supplanted, as they cannot compete'successfully with power-looms, excepting for a few fabrics for which they still seem to be best suited.

Calendering and press-packing Linens were unknown in Dundee during the first two decades of the century. Previous to the introduction of calenders a few of the outside sheets of the piece were beetled, $i$. e. beaten on a large stone with wooden mallets by two men, who then lapped up the piece, and; tied it with two or more cords depending on the width of the piece, The goods were then generally shipped loose, or hand-packed and shipped. The bales were so light, compared with their bulk, that the traders had to carry a large quantity of ballast to put their vessels into sailing trim. This is not required with bales packed by hydraulic pressure, as they are compact and heary. 
In 1822 , William Shaw, who was then erecting a small spinning-mill at East Port, was recommended by some of the merchants of the town to turn part of the premises into a calendering and press-packing establishment, there being nothing of the kind here at that period. He went to Glasgow and purchased a calender and a hydraulic press, and had them erected in his work, and the press was the first to be worked by steam-power. For somo time the new finishing machinery was not appreciated, and for two years it was barely employed four days a week. This was discouraging, but Mr Shaw persevered, and subsequently, as the advantages of calendering became better known, work flowed in upon him. In 1819, William Sandeman had a calender at Douglasfield for finishing his bleached goods, and a packingpress, wrought by manual labour, but packing by it was a slow process, and the pressure comparatively light.

Few goods are now sent off without undergoing some process of calendering, as it greatly improves the appearance of the fabric, without injuring its quality. The calenders employed are heavier, make a more powerful impression, and put a better finish upon the goods than those used in the infancy of the trade. They are of four, five, or six bowls or rollers, two of which are made of paper and the others of iron. Calendering machinery is now made of the most approved construction, and excellently suited for the purpose. The hydraulic packing presses are powerful constructions, and capable of exerting a pressuro on the bales of from 1,000 to 2,000 tous, and upwards. The goods are beetled, sarceneted, cylindered, chested, or mangled, \&c., as may be desired, the different style of finish giren the goods being the effect of putting them through between the rollers in particular ways. The goods are cropped, then slightly damped, preparatory to the calendering process. Afterwards they are measured, lapped, or made up to suit the special taste of the market for which they are intended, then packed, and shipped. In most processes of calendering the goods are slightly contracted in width and extended in length. Few coarse Linens, excepting those specially finished for padding, receive any starch or other extraneous substance, preparatory to calendering, to gire them an appearance of having more body than they really possess. The firmness and consistency of Linen is chiefly owing to the 
quantity of fibrous material in the cloth, and this adds value to Linen goods. There are now seven public calenders here, which belong to highly respectable proprietors, and the works are large airy, and well ventilated, great attention being paid to the com.fort and well-being of the men. There are no women or children employed in any of the works. The works are under most careful management, every thing in and about them being maintained in admirable condition. In addition to the public calenders, many of the large manufacturing concerns have calendering and packing establishmeats of their own, upwards of a thousand hands being employed in the calendering department of the trade. Extensions in calendering necessarily keep pace with manufacturing progress.

The staple trade of Dundee has been subject to violent periodical convulsions, some of which have been local in their character, and others national. In the early years of the century these changes were chiefly caused by the sudden rise or fall in the price of the raw material, which moved up or down with the varying fortunes of the combatants in the wars of the period.

Flax, which in 1809 , rose to $£ 150$ a ton, fell in 1810 to $£ 80$. The loss on stock, and the stagnation in trade which accompanied and partly produced the fall, ruined nearly all the merchants, manufacturers and spinners, and for a time there were only two spinning-mills at work in the town. In 1812 Flax again rose greatly, but only to fall the farther the two following years, it being $£ 45$ a ton lower in 1814 than in 1812. Many failures, and contracted employment were the inevitable result. In 1815 prices again rose considerably, but next year they fell to a much lower point than they had touched at any previous time this century, and caused many bankruptcies. Each of these changes, by the compulsory stoppage of production, threw many of the operatives idle, and produced great suffering throughout the town.

For a long period prior to the autumn of 1825 , trade had been in a healthy state in Dundee, but, towards the end of that year, a great commercial panic occurred in London and quickly spread over the country. Many bankers failed, consols fell to 79, and trade became completely paralysed. About Christmas William Sandeman, bleacher, Douglasfield, and merchant in 
Dundee, who in 1810 had stopped for the then large sum of

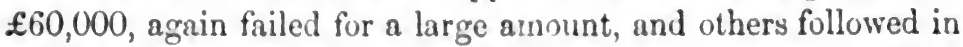
rapid succession. Dundee had its full share of the terrible calamity, and the hardships and privations whish the people then suffered were most distressing. So great was the stagnation in business here, that Government came to the help of the merchants, and, on getting a deposit of goods, granted Exchequer bills upon them. Many of the largest merchants took advantage of the aid so proffered, and it proved a great relief to thein, and benefit to the trade. Early in 1827 the American trade revivel. 'This gave an impulse to business, and those who had weathered the storm of 1826 speedily made up their losses again; but even yet that calamitous year is remembered with sorrow by all who suffered the fiery ordeal.

In 1834 bagging was in great demand for the United States, and handsome prolits were realised by exporters. This stimulated the manufacture, which was continued on an extensive scale during 1835. In the end of that year a great fire occurred in Niew York, destroying property to the extent of $20,000.000$ dollars, including a large quantity of bagging, and ruining nearly all the American insurance offices, some of which only paid from 20 to 50 per cent. on the claims upon them. To supply the roid caused by this fire, great exertions were made to send bagging out in quantity, and the article was so overdone, that many goods lay over for years, and did not ultimately pay freight and charges. The loses thus sustained brought ruin upon many of the manuficturer's and merchants, the first who stopped being a son of the man who failed for large amounts in 1810 and 1825. In this crisis the banks, as in 1816 , opened warehouses, received goods in deposit, and made adrances upon them, which did much to allay the panic and alleviate the distress. For many months at this trying period great hardships were endured by the operatives, and it was some years before business was again in a really prosperous condition.

The next serious disaster was the effect of the railway speculations in 18t7. During the mania produce of all kinds rose to fictitious prices; and, when the bubble burst, goods became unsaleable, and fell far below their intrinsic value. The vast losses by the fall in shares, in which all had speculated, and in 
the value of merchandise, brought so many to ruin that a general bankruptcy for a time seemed inevitable. Some of the previous panics had been greatly intensified in Dundee by overtrading, and by the undue extension of mills and factories, but the misfortunes of 1847 were chiefly owing to speculations apart from the regular trade. This town having been longer in catching the fever than others, had little time to get helplessly involved, still the ruin among merchants was wide-spread and most serious, and the distress among the working population, which was aggravated by the then high price of provisions, was extremely severe.

During the Crimean War an immense demand sprang up for coarse Linens, and the manufactures of Dundee were largely consumed by both beligerents during the seige of Sebastopol. The profits then realised stimulated enterprise, and led to the erection of extensive new works for spinning and weaving by power, and to great additions to previous ones. In this way the production was extended greatly beyond the legitimate wants of consumers, and much money was locked up in buildings and machinery which ought to have been conserved and retained in the trade. In 1857 the report of the failure of a Trust Company in America, followed by a panic there, reached this country. Suddenly the storm burst over the kingdom; merchant princes succumbed to the tornado, and banks of good repute gave way before it.

In Scotland two banks closed their doors, unable to stand the run which was made upon them, a thing before unknown in the history of the country, and one of them was then closed for ever. The Bank of England raised its discount to 10 per cent., but this did not check the demand for gold ; and unless the Government had interposed its authority, and permitted the Bank to violate the Bank Charter Act of 1844, it also would have been compelled to suspend. Had this not been averted, most disastrous results would have followed. In Dundee the prices of goods fell seriously, in some cases 50 per cent., many failures occurred, and much distress was endured by the working-classes. After that period trade went on regularly, but quietly, until the second year of the war in America. Cottons, which had risen to five times their cost before the war, could not be 
got in quantity, and the roid was in many cases supplied by linen, which increased the demand throughout the world. The extensive requirements of the armies in America, both Federal and Confederate, have absorbed an immense quantity of coarse and heavy Linens, and caused the pressing demand for them which has kept the mills and factories in full operation for the last two years. The immediate effect of this unparalleled activity has been to add greatly to the wealth of almost every house engaged in the Linen trade here, and to the prosperity and importance of the whole town. Part of the wealth thus acquired has been laid out in extending old works or in building new ones. If these extensions are kept within legitimate bounds they will be profitable to the builders and beneficial to the community, but if not they will do injury to all. One marked effect of the increased means at the command of those engaged in the trade is, that instead of payments being made as formerly by long dated bills, they now generally in cash. This shows that the wealth is not fictitious but real.

The following paragraph is taken from the Dundee Commercial and Shipping Gazette of 2d May 1840:-

"Direct Trade with India.-We have this week to record an important event connected with the trade of our port-the arrival of the barque Selma, Luckie, from Calcutta direct. This is the first arrival of any vessel from the East Indies with a cargo for Dundee. The Selma is the property of Mr William Davidson, shipowner, and was built here some years ago. She has a miscellaneous cargo, consisting chiefly of Jute hemp, sugar, rice, \&c. We regard this as honourable to the enterprise of our merchants, and trust it is only a beginning to a prosperous trade with the British dominions in the East. The Selma casst anchor in Carolina Roads on Sunday morning, 26th April, after a passage of 156 days, and was towed into Earl Grey's Dock on Wednesday, in presence of a crowd of spectators, who had assembled to witness the arrival of the East Indiaman." The following are the particulars of her cargo:-'Selma, (258, of Dundee), Luckie, from Calcutta, with 850 bales Jute hemp, 400 bags rice, 200 bags sugar, 197 bags linseed, 40 buffalo horns, 1 box preserves, 4 cases preserved ginger, 5 canisters arrow root, 1,900 cocoa nuts, 12 coils rope, 29 pieces teak wood, 
100 pieces bamboo, 7 bundles country twine, 2 boxes tea, 6 hhds. wine, and 3 boxes, 2 baskets shells, for Williain Davidson; 376 bales Jute hemp, for David Keith; 100 bags rice, 25 bags black pepper, 3 bags cloves, and 1 bag nutmegs, for Geo. R. Baxter; 135 bags rice, and 75 bags linseed, for $\mathrm{D}$. and $\mathrm{J}^{-}$ Moncur, \&c., \&c., \&c."”

In April 1864, twenty-four years after the arrival here of the first vessel from Calcutta with Jute, there were nine ships in the port which had arrived direct from Calcutta, the united cargoes of which were 44,276 bales of Jute, and a few hundred bales of cuttings, besides linseed, \&c. Other two vessels would have been here at same time with a farther quantity of 8,560 bales, but they were unfortunately stranded or lost when almost at their destination. One vessel with 2,641 bales had come in the previous month, and seven other ships are known to be on the way, the cargoes of which amount to 41,850 bales, making a total of 97,327 bales of Jute. It is expected that several other vessels will yet come direct from Calcutta to Dundee in the course of the year. So great has been the increase of the trade since the remarks on the subject-page 65 -were written, that it is estimated the direct shipments this year will be about 110,000 bales, of the value when landed here of $£ 400,000$.

The more direct any trade can be carried on between the producer and consumer, and the fewer hands the material passes through in its various transformations from the raw to the manufactured state, the cheaper will the goods be produced. This vast extension of so legitimate a branch of trade is therefore gratifying. Messrs Gilroy and Messrs Cox, the largest consumers, now employ their own ships in this trade, and the "East Indiamen" belonging to Dundee are already a large and valuable fleet.

From a statement of the quantity of Jute consumed here, kindly furnished by John Mitchell, of Arngask, it appears that in 1851 there were only five firms here who used more than 100 bales a week, the largest consumers being Gilroy Brothers, put down at 200 bales. Now, of the about forty houses in Dundee and neighbourhood who spin Jute, seven-eighths of them cut up more than 100 bales a week, and some firms, as alrearly mentioned, use about ten times this quantity. 
The Flax trade is chiefly in the hands of a few respectable firms, agents for houses at the various shipping ports in Russia, Prussia, \&c. Sometimes the spinners contract with the agents during the winter for Flax to be shipped by their constituents on the opening of the navigation in spring, at a frec-on-board price, or otherwise as may be agreed on ; and sometimes orders are given by the spinners to be executed if they can be done within certain prescribed terms. Unlimited orders are now rarely entrusted to the foreign merchants. Large quantities of Flax, tow, $\& c$, are annually consimed by the merchants abroad to their constituents here, who sell it to consumers, charging a commission for their trouble, and this is the most legitimate mode of con. ducting the business, and the most convenient to the spinner. An approximation to the quantity used in the district is sup. plied by the tabular statements appended.

Of late years great improvements have been made in the structure of the spinning-mills in Dundee. It was difficult to make much alteration upon the outward appearance of some of the older works, but where this was practicable it has been done. Internally much attention has been paid to ventilation, conveniences of various kinds for the comfort of the workers have been provided, and the employment rendered as healthy as possible. The recently built mills have been constructed on the most approved principle, with every modern appliance for the physical comfort of the operative; and the danger to health, consequent upon the nature of the employment, has been reduced to the minimum point. Some of the new works, entirely fireproof, are most imposing structures, palatial in appearance, colossal in extent, and, in durability, magnificence, or comfort, unsurpassed by the mills in any other town in the kingdom, or of any other country in the world

Although a tabular statement of the proprietors of spinningmills and power-loom factories, with some letails of the respective works, are given, a distinct notice of a few of the larger establishments, employing more than one thousand hands, and whose recently erected works are unusually imposing, will not be altogether a work of supererogation

The most extensive spinning and manufacturing concern here is that of Baxter Brothers \& $\mathrm{C}_{0}$. The head of the firm is Sir. 
David Baxter, bart., of Kilmaron, the chief of the merchant princes of Dundee. Sir David has performed many generous deeds to his native town, but his crowning act of princely munificence, in conjunction with his sisters, in presenting the noble Baxter Park to the people of Dundee, has raised him high in the admiration of the good and great of the land. In the beginning of the century, William Baxter, the father of Sir David, was engaged in the Linen trade. $\mathrm{He}$ was an intelligent and much respected merchant, and during his long and honourable career he was highly esteemed by his compeers. In 1822 he, along with his eldest son, Edward, as Wm. Baxter \& Son, erected a spinning-mill, of 15 horse-power, in the lower Dens. Before this date the family had a mill at Glamis. In 1825, Baxter Brothers \& Co. (other sons having been assumed as partners) put up another, and a larger work, to the northward, of 30 horse-power. Subsequently additions were made to it, and an engine of 90 horse-power substituted for the others. In 1833 the erection of Upper Dens Works was commenced, and for the last thirty years progress and improvement there have been constant.

As already mentioned, the firm experimented in power-looms so early as 1826 , and in 1836 went largely into them. It is mentioned in Thomson's "History of Dundee," that in 1846 the firm had in operation in Lower Dens Mills, 1 engine of 90 horse-power, driving 3028 spindles for dry spun Flax and tow ; Upper Dens Works, 2 engines of 70 and $35=105$ horsepower, driving 2,136 spindles on dry tow, and 5,872 of wet spinning-together, 8,008 spindles; being a total of 11,036 spindles. Also, 2 engines of 30 horse-power coupled $=60$ horse-power, driving 256 power-looms, intended to be increased to 420 ; and a calender work, with an engine of 10 horse-power, the total power being 265 horses. Since that date the increase has been continuous and rapid. They now contain 16 steamengines, of the aggregate of 615 nominal horse-power, 20,000 spindles, and 1,200 power-looms, and employ about 4,000 hands.

The material used by Messrs Baxter consists chiefly of Flax and tow, with a little Hemp. This firm is perhaps the only one here who have never, at any period, spun Jute in their works. In point of consumption of raw material they are the 
largest Linen manufacturers in the world, no firm using nearly as much weight of Flax, \&c., as they do. The goods made by them consist of sail-cloth, sheetings, dowlas, ducks, \&c., for the excellent quality of which they have an established reputation. In addition to the yarn spun in the works, the Messrs Baxter purchase largely from other spinners; and the whole goods produced by them are calendered and made up within the work, and sent out in bales, or as may otherwise be required by their customers; the value being about a million sterling a year. There are several distiuct spinning-mills in the Dens Works, but the larger one, on the north side of and fronting Princes Street, is a noble structure, of about 250 fect in length and four lofty storeys in height, besides attics. The engines are placed in the centre of the building, and over them is a fine statue of James Watt. Within the works there is a foundry and mechanic shops, where much of the spinning and weaving machinery used in the works are made. The ground upon which the works are erected extends to upwards of 10 acres, and it is nearly all covered with the mills, factories, warehouses, and other necessary premises required for carrying on so extensive an establishment. The buildings are most substantial and the machinery of the highest class, the internal arrangements admirable, and the management of the works perfect. This excellence has been attained by Peter Carmichael, the partner, who for many years has taken the superintendence of the works.

Logie Works, belonging to A. \& D. Edward \& Co., situated at the west end of Scouringburn, were begun in 1828, the first steam-engine being of 30 horse-power. In 1833 the work was enlarged; and subsequently several additions were made. In 1846 it contained two engines, of 90 and $70=160$ horsepower, driving in all 14,068 spindles; but it has since then been again and again extended. The mill fronting the Scouringburn is about 300 feet long, and is of four storeys and attics in height. Though not quite so lofty as one or two of the more modern structures, it was spacious for its day, being then the largest building in town, and it is still a most imposing and handsome erection. This mill forms one side of a large open quadrangular court; the buildings on the opposite sides, which 
are high and extensive, are used as heckling and preparingrooms, and the whole are fire-proof throughout.

In 1846 forty power-looms were put in operation in the range forming part of the north side of the mill court, but as it was found impracticable to make room here for the continued increase, a large fire-proof power-loom factory was erected in 1851 on the nursery grounds immediately to the south and west of the spinning-mill. This factory is a handsome building of four storeys, and the power-looms being all placed on one open floor, partly in the main building, and in a line of parallel sheds running behind it to the south. The two upper storeys of the main building are used as winding, warping, and preparing flats. Adjoining the power loom factory is the fire-proof calender lapping and packing. house. Contiguous to the works, and fronting Milnbank Road and Scouringburn, are the requisite warehouses for Flax, Jute, \&c.

The machinery now in operation consists of 17,000 spindles and 600 power-looms, with the necessary preparing, calendering, mangling, and packing machines, employing altogether about 2,500 hands. The works are driven by 5 engines of 260 horsepower.

For a long time the Messrs Edward spun only Flax and tow, but latterly they have added the spinning and manufacture of Jute. Their machinery keeps pace with the times, modern inprovemenits being readily adopted, and the whole kept in firstrate working order. The yarns produced are dry spun Flax, tow, and Jute, and wet spun Flax and tow of all sizes. The goods manufactured are sail-cloth, duck, dowlas, shirtings of all widths, up to three yards wide, diapers, hessians, and indeed all descriptions of Linen or Jute goods, suited either for the English or foreign markets. Linen damasks of various widths and qualities are also manufactured, and this is the only establishments in the district where figured Linens are produced to any extent by power.

The internal arrangement and adaptation of the works is excellent. The material of which the manufactured article is to consist goes from department to department systematically, until it is despatched from the packing-house in bales, either for the English trade or for the remote markets of the world. The 
situation of the works is very good and healthy, being almost in the country, bounded on the south and west by green fields and nursery grounds.

Unquestionably the largest and most imposing building set apart for spinning and weaving is that recently erected by Gilroy Brothers \& Co., in Lochee Road, and forming part of 'Tay Works. This building is 392 feet in length, the wings of four storeys in height, besides attics, and the centre of five storeys, the altitude to the top of the pediment being 90 feet. The masonry is built in regular courses, the centre and wings being ornamented by rustic corners, the whole building being of the most substantial character, and fire-proof throughout. In the frieze of the pediment orer the centre portion, the Dundee arms, on a large scale, are sculptured in stone; and on the apex is a splendid colossal statue of Minerva (upwards of ten feet high), with the spindle and distaff, which aptly crowns this magnificent structure. Internally every thing is in keeping with the grandeur of the exterior, and the spirited proprietors have left nothing undone which could add to the comfort of the employés within. This stately pile only forms a portion of Tay Works, which extend in all nearly 1000 feet along the Lochee Road, with mills, power-loom weaving factory, and other erections necessary for the subsidiary branches of the establishment, behind. The works contain five steam-engines of 240 horse-power, 10,096 spindles, and 300 power-looms, and give employment to 1,700 hands; and within a short period these figures will be considerably increased. In 1851 the power employed by Messrs Gilroy was only 80 horses, so that the progress since made has been very great. 'The clusses of goods manufactured are chiefly of' Jute, and comprise hessians, sacking, bagging, \&c., which are calendered within the works, and sent out in bales ready packed for market. The firm have also many hand-looms, and employ in all upwards of 2000 people. Tay Works are arranged on the most approved principle, the machinery is of the best description, and no expense is spared to keep it in first rate order. 'The internal economy of the work is as near perfection as it is possible to attain, and every department is conducted with clock-like regularity.

The spinning mill at Bow Bridge Works, built by J. and R R 
A. D. Grimond in 1857 , is perhaps the finest structure of its kind in existence, and with its erection a new era in spinning mills was inaugurated. It only forms a portion of the proposed buildings, but from its great elevation, and noble parts, it is a magnificent instalment of the complete work. This erection, entirely fireproof, is 190 feet in length, 110 in width on the basement floor and 52 on the others, and 71 feet in height to the easing. The four floors are respectively $18,17,16$, and 16 feet high, and the attic has the full height of the roof thrown into it. The basement storey is built of rock rustic, and the others of best square rubble. The engine-room is a model of stability and elegance, lighted by plate-glass windows on two sides. The windows in the mill. are 10 feet by $5 \frac{1}{2}$, with circular tops, which open for ventilation, and the building is beautifully painted. The engines, two of 50 horse-power each, work together, with a large cog-wheel between them, which turns the machinery, at same time acting as a fly-wheel. Economy of labour, being an important matter, has been a guiding principle, and with that view the material travels from machine to machine with the least possible amount of manual labour, not stopping in its course until it is transformed from the original fibre to the finished thread, warped or prepared for the loom. The boilers are in a fire-proof building apart from the mill, and were the largest here at the time they were put in. The engines and boilers were made at Bolton, and are of superior construction and finish. The mill was designed with great care, and is altogether, both externally and internally, a model work, and can hardly be surpassed for stability, simple grandeur, superiority of machinery, or admirable arrangement throughout. Messrs Grimond have for some years had large hand-loom factories at Maxwelltown, $\& c .$, for the supply of goods for their home trade, having warehouscs in London, Manchester, Belfast, \&c., and recently they have added power-looms, both at their Bowbridge and Maxwelltown establishments. Their works now contain five steamengines of 132 horse-power, with 3,600 spindles, and 136 powerlooms; about 600 hands being employed in these departments. At their extensive hand-loom works they employ nearly 1000 people, making about 1,600 hands in all. The goods Messrs Grimond make are hessians, sacking, carpeting, matting, hearth 
rugs, \&c. 'They have lately put up a calendering work, and will now be enabled to send off the groods ready packed for shipment.

The several mills belonging to Oliver Gourlay Miller spin more yarn on the aggregate, with one or two exceptions, than those of any other firm in Scotland. Mr Miller is successor to the oldestablished firm of $\mathrm{J}$. \& W. Brown, who in 1846 had three mills, of 75 horse-power, containing 3,576 spindles. He is son-in-law to the junior partner of that firm, who was a practical spinner in 1809, and from whose "Reminiscences of Flaxspinning" various extracts and details are, with the kind permission of the author, given in this volume. The works were extensive when $\mathrm{Mr}$ Miller entered into possession of them, but he has recently extended and improved the old mills, and erected a large new one. They are all contiguous, and comprise the following mills, viz.:-Arch, 2 engines of 46 horse-power, and 3,728 spindles; East, 2 engines, 38 horse-power, and 1,200 spindles; North, 1 engine, 25 horse-power, 1,740 spindles ; Column, '2 engines, 46 horse-power, 2,606 spindles; and South Mills (old and new together), 3 engines, 105 horse-power, 5,760 spindles ; -in all, 10 engines, 260 horse-power, 16,970 spindles. $\mathrm{Mr}$ Miller's great staples are Flax and tow, but he also spins a little Jute. The organization of the several works is complete, the machinery of the most approved construction, and it is kept quite up with the age in every modern improvement. Mr Miller has attained celebrity for the quality of his yarns, the whole of which he sells in the market, in the raw state, or bleached, creamed, or otherwise prepared, as he does not manufacture any of them into cloth. The prize medal for quality of dry spun yarn was awarded to $\mathrm{Mr}$ Miller at the Great Exhibition of 1862.

St Roque's Spinning-work and Wallace Power-Loom Work, belonging to W. R. Morison \& Co, are extensive establish.. ments. The spinuing mills contain 3 steam-engines, with an aggregate of 92 horse-power, and 4,000 spindles ; and the powerloom works, which are at some distance from the mills, two engines, together of 100 horse-power, and 510 power-looms, with the necessary calendering machinery for finishing the Linens made at the works. The power-loom factory has a handsome frontage of about 360 feet in length, and as it stands R R 2 
on a rising ground, fronting the south, it has a commanding appearance. These works were recently acquired by the firm, and are now in active operation. Together they are most suitable for the trade, and efficiently conducted; and they employ about 1,700 hands.

Seafield Works, belonging to Thomson, Shepherd, and Briggs have risen with surprising rapidity, having been begun little more than ten years ago, and now they contain seven steam-engines of 165 horse-power, 6000 spindles and 120 power-looms. The works also contain upwards of 450 hand-looms, the total number of people employed being 2,000. The older portions of theseworks have been quite eclipsed by the new mill and power-loom shed, which have been built to the south of them. This mill is a splendid building, about 300 feet in length, and four storeys and attics in height, and the factory, which communicates with the mill, is of the same length and nearly square. The machinery is only in course of being put into the new erections, but when completed the productive powers of the works will be doubled. The firm spin Jute chiefly, and manufacture carpeting, cocoanut-matting, sacking, bagging, \&c., which are calendered and made up on the premises.

Several other firms have large spinning and weaving establishments, which, had space admitted, it would have been desirable to refer to specially, as the organization of these works is, in every respect, quite equal to those detailed. Indeed, the spirit of the age is so thoroughly bent on utilitarian improvements, that every spinning and weaving establishment in town has made wonderful progress, and the description of those given is, to some extent, applicable to all, even the most unpretending, and all are worthy of high commendation.

The warehouses in which the raw material sent here for sale is stored were, at one time, very temporary erections A most serious fire occurred about eight years ago, by which several warehouses and their contents, to the value of nearly $£ 50,000$, were destroyed or injured. This caused more attention to be paid to their construction. Subsequently several fires occurred in Flax warehouses, and the fire offices adopted a tariff specially for them, which has compelled proprietors to effect improvements upon the buildings, and thus lessen the risk of fire, but they are 
still far from being perfect. A very handsome range of ware. houses has been built by Robert Fleming, on the site of some of those destroyed, which do credit to the proprietor.

Although there is apparently great risk from fire in spinningmills, yet, for many years, there have been fewer serious fires in them than in Flax warehouses. A few months ago, the Royal Insurance Company, taking this fact into consideration, resolved, with that spirit of liberality for which the office has been so long proverbial, to give the spinners the advantage, and reduced the premium on this class of risks to the extent of fully 30 per cent. This large reduction effected a saving of several thousand pounds a year to the spinners, and they, to show their appreciation of the boon, have very generally given the Royal a full share of their insurances.

Some of the spinners have their counting-rooms at their mills, but others have them in and around the "Corgate," which is the common market-place for the Linen trade of the town; and all attend that mart daily, much of the business being transacted on the street. As stocks of yarn and Linen are now usually kept at the mills and factories, or in the public calenders, where the goods can be inspected, extensive premises near the "market" are unnecessary, and a plain room or two generally suffice for counting-houses. A few years ago Alexander Easson erected a range of elegant offices adjoining the Royal Exchange, and with it forming a handsome square, far more suitable for the merchants meeting for business purposes than the public street, but it is not taken advantage of, as "use and wont" attaches them to the old resort, the far-famed "Cowgate."

Jaffe Brothers, merchants, have recently erected in Seagate, in the vicinity of the "Cowgate," a magnificent warehouse, with splendid counting-rooms and other conveniences for carrying on their extensive business. It would add to the architectural embellishments of the town were others to follow their spirited example, and put up equally useful and ornamental premises.

The Royal Exchange is a handsome building, unfortunately built on a bad foundation, which has hitherto rendered it impracticable to complete the elegant tower intended to have been put up, and which would have added greatly to the beauty of the structure. The reading-room in the building is a chaste and pretty apart'nent, but it would hive been more con- 
venient had it been on the ground floor, instead of up a flight of stairs. The Chamber of Commerce, under whose auspices the Exchange is conducted, was recently Incorporated by Royal Charter, and it is expected that the stability thus given it will increase its importance and extend its usefulness.

The Linens manufactured in Dundee comprise Flax, Hemp, and Jute goods, line and tow, and mixtures of them in varions proportions, and formed in many ways. Several of the fabrics are made in imitation of the Linens originally produced in Germany, Russia, Spain, and other countries. The classes of Iinens made are numerous; and as every quality is finished and lapped in a variety of ways, to suit them for the different markets of the world, their names are legion. It is not necessary to cnumerate the various sub-divisions of each class of Linens, but the following are a few of the leading fabrics manufactured:- Sail-cloth, brown, boiled and bleached; Duck; Spriggs ; Canvas Padding; Sheeting, brown, creamed, checked, bleached, \&c. ; Dowlas ; Diaper and Damask; Hessian Sheeting ; Sacking ; Hop-pocketing ; Bagging ; Tarpauling; Hammocking ; Scrims ; Carpeting; Hearth Rugs ; Matting, \&c., \&c. In the manufacture of many of these Linens the art of the bleacher and dyer is taxed to produce snowy whiteness or brilliant hues; and the beauty and excellence of some of the fabrics produced can scarcely be excelled.

It was intended to give a tabular statement of the steam-engines, horse-power, spindles, power-looms, hand-looms, and persons employed in the Linen manufacturing establishments in Dundee and in the manufacturing towns. In consequence of many of the hand-looms being placed in the dwellings of the weavers, it was not practicable to ascertain their number, and they have been excluded from the statement. Perhaps there may be 5,000 hand-looms still in operation in Dundee, but, as the distaff and the spinning-wheel have been superseded by the spindle, so in like manner the power-loom is fast displacing those wrought by manual labour, and in a few years hand-looms, in this district, will be numbered with the things that were.

It will be seen by the table that there are, in May 1864, 160 steam-engines engaged in the staple trade of Dundee and Lochee, of the aggregate of 4,621 horse-power. The number of spindles are 170,552, and the power-looms, 6,709 The total number of 
hands employed, according to the table, are 36,020 ; but the figures do not, in many cases, represent those only who are employed in the spinning mills and power-loom factories. Several of the houses have many hand-looms in operation, and the weavers and others employed in and about them are included, because, from the intimate union between the two classes in several of the works, it was not possible to separate them into component parts-workers at machinery and by hand.

The manufacturers who employ hand-looms only are not included in the table, and the number of operatives in their employ could not be correctly ascertained and are not given. Many of the hand-loom manufacturers have recently got small steamengines to drive winding machinery, cylinders, \&c., but even with these adjuncts it is with difficulty they can, in many fabrics, compete with those who have power-looms.

The consumption of Flax, Tow and Codilla, Hemp, and Jute in Dundec, isat present about 70,000 tons per annum, which at an average value of $£ 35$, makes the cost of the raw material $£ 2,450,000$.

The quantity of yarn now spun here weekly may be about 500,000 spindles, or $25,000,000$ per annum, which at $3 \mathrm{~s}$ per spindle, is $£ 3,750,000$. No data exists whereby an approximation even of the quantity of yarns exported from Dundee can be arrived at, but it must be considerable. Neither is there any data to assist in estimating the yards of Linen manufactured here, or their value, but perhaps the total value of the yarns and Linens produced in Dundee, for home and foreign consumption,

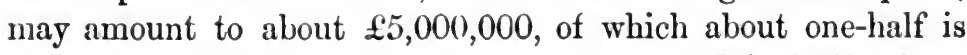
exported, and the other half consumed in the United Kingdom.

The wages paid to those engaged in the staple trade can only be guessed at. Perhaps, in round numbers, it may not be very wide of the mark to estimate the people directly engaged in the Linen manufacture here at 50,000 , and the wages paid to them weekly at $£ 20,000$, or say $£ 1,000,000$ per annum. The total population of Dundee now considerably exceeds 100,000, and if the estimate given be correct, it shows that about 50 per cent. of the inhabitants are employed in the staple trade of the town. In addition to the hands directly employed in the Linen trade, a large number are engaged in auxiliary branches in and around the town, viz., engineers and machine-makers, flaxdres- 
sers, bleachers, dyers, calenderers, carters, \&c., \&c. ; indeed, a large proportion of the population are directly or indirectly engaged in, or supported by, the Linen trade.

The amount of capital embarked in the spinning and power-loom works in Dundee and Lochee may be estimated at $£ 2,000,000$. 'The Flax, tow, \&c., bought by spinners and others in Russia, Prussia, \&c., and the Jute imported direct from Calcutta, as well as what is purchased in London and Liverpool, are almost wholly paid for in cash. The credit system in the purchase of gnods on the spot is latterly all but extinct, cash payments being now the rule and bills the exception. Many of the merchants export yarn and Linen. but especially the latter, to the various markets of the world, and it is from six to twelve or eighteen months, and sometimes even longer, before remittances are received for same. These several operations, from their magnitude, necessarily imply large means, but what the floating capital now engaged in the trade here really is, it is impossible to say, as no approximation even can, with any approach to certainty, be given.

It was a fortunate circumstance for Dundee that Jute was introduced into its manufactures. Since then the extension of the town has been in some measure dependent on the progress made in incorporating this fibre into its staple trade. During the last two years, in consequence of the cotton famine and the American war, the demand for Linen, as already mentioned, has increased amazingly. Flax has been an important article, as genuine Linens have been largely consumed, and this branch of the trade has enjoyed universal prosperity. Its Oriental sister, Jute, has, however, been a more important fibre here, as its products are cheap yet sightly, and they have afforded a ready means for supplying the extraordinary demand for low class Linens. The consumption of this article has therefore increased enormously, and is still extending, and it may now be called the great staple of Dundee. Notwithstanding the high price of Jute for the past two years, this trade has been very remunerative, and some parties have realized handsome fortunes in it. The superstructure of the prosperity of Dundee may therefore be said to be founded on Jute. May the building be as stable as it is stately! May the halo which surrounds the Linen trade of Dundee long continue to shine with undiminished lustre! 
I H PORT INTO DUNDER,

FROM 1815 TO 1863.

\begin{tabular}{|c|c|c|c|c|c|c|c|c|c|}
\hline Year. & Flax. & $\begin{array}{c}\text { Flax } \\
\text { Codilla. }\end{array}$ & Hemp. & $\begin{array}{l}\text { Hemp } \\
\text { Codilla. }\end{array}$ & $\begin{array}{l}\text { Total } \\
\text { Tong. }\end{array}$ & \multicolumn{2}{|c|}{$\begin{array}{l}\text { Flax and Tow } \\
\text { and Codilla of } \\
\text { Hemp \& Flax. }\end{array}$} & Hemp. & $\begin{array}{l}\text { Tl. Tons } \\
\text { Imprtd. }\end{array}$ \\
\hline 1815 & ....... & ..... & & 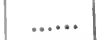 & & \multicolumn{2}{|c|}{1,221} & 966 & 2,187 \\
\hline 1816 & $\ldots \ldots$ & ....... & ....... & ........ & ….... & \multicolumn{2}{|c|}{2,015} & 851 & 2,866 \\
\hline 1817 & $\ldots . .$. & $\ldots \ldots$ & $\ldots \ldots$ & ...... & ........ & \multicolumn{2}{|c|}{2,989} & 1,735 & 4,724 \\
\hline 1818 & $\ldots \ldots$ & $\ldots \ldots$ & $\ldots . .$. & ...... & ....... & \multicolumn{2}{|c|}{3,509} & 1,418 & 4,927 \\
\hline 1819 & ....... & ....... & $\ldots \ldots$ & $\ldots$ & ....... & \multirow{2}{*}{\multicolumn{2}{|c|}{$\begin{array}{l}3,150 \\
3,911\end{array}$}} & 321 & 3,471 \\
\hline 1820 & $\ldots$. & $\ldots \ldots$ & $\ldots \ldots$ & $\ldots \ldots$ & ....... & & & 1,047 & 4,958 \\
\hline 1821 & . . . & ........ & $\ldots . .$. & $\ldots \ldots$ & $\ldots . .$. & \multicolumn{2}{|c|}{5,736} & 716 & 6,452 \\
\hline 1822 & $\ldots \ldots$ & $\ldots \ldots$ & $\ldots \ldots$ & $\ldots \ldots$ & ....... & \multirow{2}{*}{\multicolumn{2}{|c|}{$\begin{array}{l}6,655 \\
4,892\end{array}$}} & 3,136 & 9,791 \\
\hline 1823 & $\ldots \ldots$ & $\ldots \ldots$ & $\ldots . .$. & $\ldots \ldots$ & ....... & & & 3,032 & 7,924 \\
\hline $18: 4$ & $\ldots . .$. & $\ldots . .$. & $\ldots . .$. & $\ldots \ldots$ & $\ldots .$. & \multicolumn{2}{|c|}{$\begin{array}{l}\mathbf{4}, 892 \\
6,850\end{array}$} & 2,150 & 9,000 \\
\hline 1825 & $\ldots . .$. & $\ldots \ldots$ & $\cdots \cdots$ & $\ldots \ldots$ & ........ & \multicolumn{2}{|l|}{11,575} & 2,327 & 13,902 \\
\hline 1826 & $\ldots \ldots$ & $\ldots \ldots$ & $\ldots \ldots$ & $\ldots \ldots$ & ........ & \multicolumn{2}{|c|}{7,178} & 1,092 & 8,270 \\
\hline 1827 & $\cdots \cdots$ & $\ldots \ldots$ & ...... & $\ldots \ldots$ & ...... & \multirow{2}{*}{\multicolumn{2}{|c|}{$\begin{array}{l}12,789 \\
14,524\end{array}$}} & 1,260 & 14,049 \\
\hline 1828 & & & & & & & & 582 & 15,106 \\
\hline 1829 & 12,501 & 2.753 & 1,204 & 317 & 16,775 & \multicolumn{2}{|l|}{$\ldots \ldots$} & $\ldots \ldots$ & 16,775 \\
\hline 1830 & 13,045 & 3,760 & 2,131 & 1,560 & 20,496 & & $\ldots$ & 20,496 \\
\hline 1831 & 11,212 & 3,740 & 1,573 & 1,465 & 17,990 & \multicolumn{2}{|l|}{$\ldots .}$. & $\ldots . .$. & 17,990 \\
\hline 1832 & 16,112 & 2,985 & 2,588 & 513 & 22,198 & \multicolumn{2}{|l|}{$\ldots .}$. & ....... & 22,198 \\
\hline 1833 & 15,691 & 4,233 & 2,504 & 552 & 22.980 & \multirow{2}{*}{\multicolumn{2}{|c|}{$\ldots . .}}$. & ....... & 22,980 \\
\hline 1834 & 11,871 & 5,455 & 3,880 & 950 & 22,152 & & & ....... & 22,152 \\
\hline 1835 & 11,963 & 6,521 & 7,434 & 1,208 & 27,130 & \multicolumn{2}{|l|}{ ….... } & $\ldots \ldots$ & 27,130 \\
\hline 1836 & 30,653 & 8,721 & 1,974 & 1931 & 43.279 & ....... & & $\ldots . .$. & 43,279 \\
\hline 1837 & 10,503 & 2,934 & 939 & 861 & 15,237 & ....... & & $\ldots \ldots$ & $15, \approx 37$ \\
\hline & & & & & & & J u t e. & & \\
\hline & & & & & & By sea. & By Rail. & 'Total. & \\
\hline 1838 & 21,217 & 7,620 & 1,227 & 786 & 30,850 & 1,136 & & $\ldots$ & 31,986 \\
\hline 1839 & 13,012 & 5,720 & ], 174 & 891 & 20,797 & 2,411 & & ....... & 23,208 \\
\hline 1840 & 15,680 & 8,244 & 612 & 699 & 25,235 & 2,745 & ....... & ......... & 27,980 \\
\hline 1841 & 17,497 & 7,364 & 556 & 277 & 25,694 & 2,661 & $\ldots . .$. & ....... & 28,355 \\
\hline 1842 & 15,633 & 6,205 & 495 & 827 & 23,160 & 2,740 & $\ldots . .$. & ....... & 25,900 \\
\hline 1843 & 18,048 & 7,146 & 612 & 462 & 26,268 & 4,858 & ........ & ….... & 31,126 \\
\hline 1844 & 20,038 & 8,731 & 963 & 470 & 30,202 & 5,515 & $\ldots \ldots$ & …..... & 35,717 \\
\hline 1845 & 23,402 & 9,033 & 1,110 & 86 & 33,631 & 8,313 & ........ & ....... & 41,944 \\
\hline 1846 & 12,399 & 8,771 & 1,045 & 119 & 22,334 & 9,230 & ....... & …..... & 31,564 \\
\hline 1847 & 13,104 & 9,209 & 1,455 & 84 & 23,852 & 6,966 & & & 30,818 \\
\hline 1848 & 21,976 & 7,648 & 927 & 34 & 30,585 & 8,885 & 20 & 8905 & 39,490 \\
\hline 1849 & 26,091 & 10,024 & 1,124 & 18 & 37,257 & 7.946 & 4,196 & 12,142 & 49,399 \\
\hline 1850 & 31,572 & 8,962 & 996 & 108 & 41,638 & 6,3335 & 7.745 & 14080 & 55,718 \\
\hline 1851 & 20,301 & 8,192 & 1.543 & 110 & 30,146 & 7,386 & 9,542 & 16,928 & 47,074 \\
\hline 1852 & $20, \therefore 79$ & 6,094 & 518 & & 26,991 & 9,874 & 7,109 & 16,983 & 43,974 \\
\hline 1853 & 34,052 & 10,820 & 1,979 & 261 & 47,112 & 8,165 & 7,235 & 15,400 & 62,512 \\
\hline 1854 & 25,470 & 5,368 & 929 & 96 & 31,863 & 6,224 & 10,366 & 16,590 & 48,453 \\
\hline 1855 & 23.018 & 5,112 & 1,418 & 2 & 29,550 & 12,333 & 13,561 & 25,894 & 55,444 \\
\hline 1856 & 27,561 & 6,732 & 802 & 26 & 35,121 & 16,948 & 14,083 & 31,031 & $66,: 52$ \\
\hline $185 \pi$ & 30,351 & 6.926 & 995 & 28 & 38,300 & 8,158 & 16,184 & 24,342 & 62,642 \\
\hline 1858 & 18,698 & 3,731 & 3,113 & 300 & 25,842 & 13,828 & 16,258 & 30,086 & 55928 \\
\hline 1859 & 24,615 & 8,141 & 1,382 & 20 & 34,153 & 21,683 & 16,722 & 38,405 & 72,563 \\
\hline 1860 & 28,644 & 4,302 & 987 & $\ldots \ldots$ & 33,933 & 22,829 & 14,136 & 36,965 & 70,898 \\
\hline 1861 & 23,801 & 4,455 & 1,192 & ........ & 29,448 & 17,924 & 17,792 & 35.716 & 65,164 \\
\hline 1862 & 32,102 & 6,142 & 784 & ........ & 39,028 & 19,825 & 18,452 & 38.277 & 77,305 \\
\hline 1863 & 23,474 & 4,536 & 978 & $\ldots \ldots$ & 28,988 & 32,273 & 14,710 & 46,983 & 75,971 \\
\hline
\end{tabular}




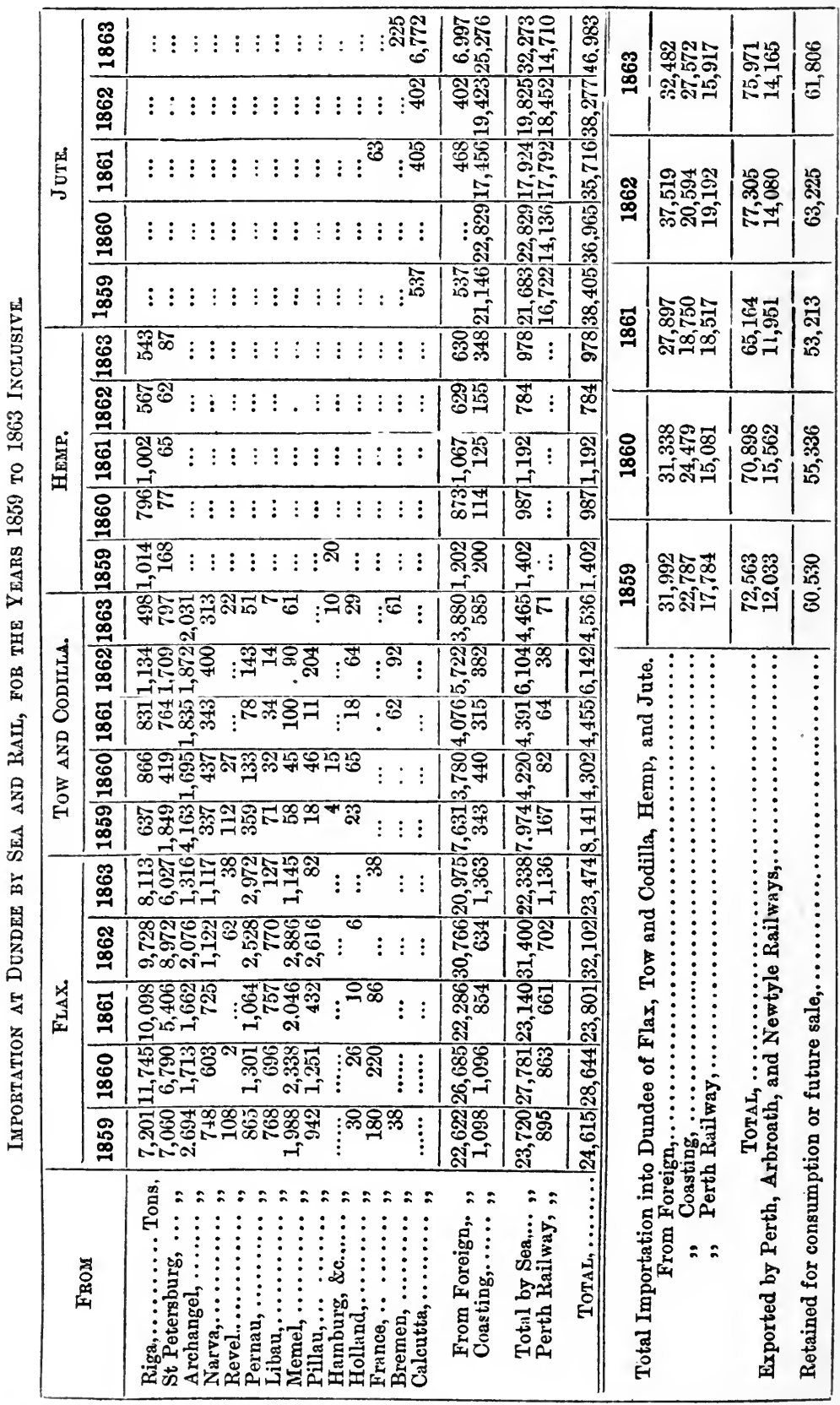


SCOTCH IINEN.

\begin{tabular}{|c|c|}
\hline 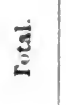 & 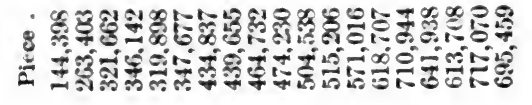 \\
\hline 竞 & 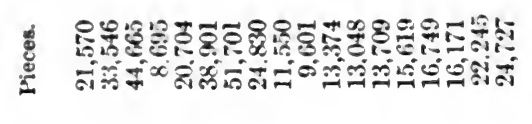 \\
\hline 尊 & 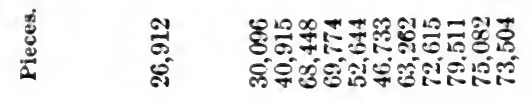 \\
\hline 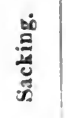 & 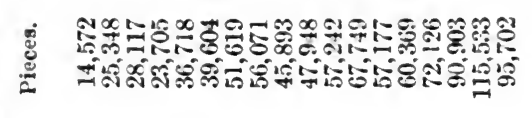 \\
\hline 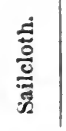 & 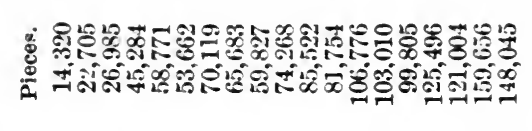 \\
\hline 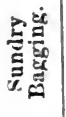 & 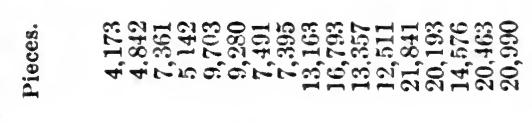 \\
\hline 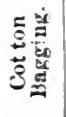 & 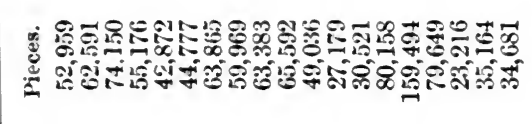 \\
\hline 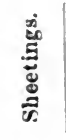 & 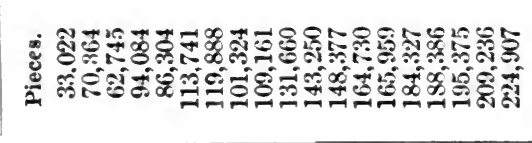 \\
\hline 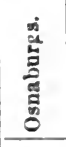 & 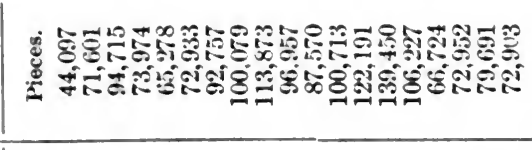 \\
\hline 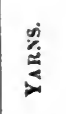 & 임ำ \\
\hline 赵 & 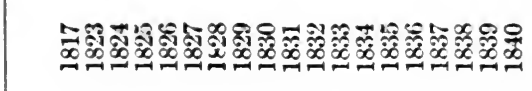 \\
\hline
\end{tabular}

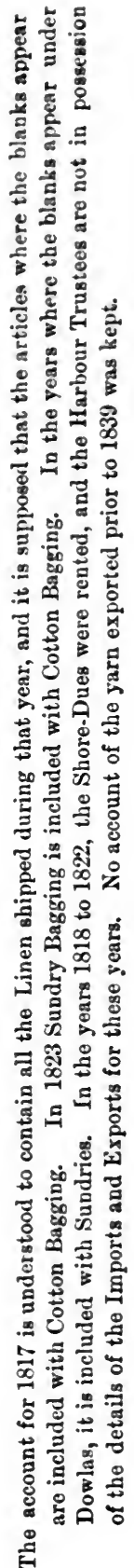




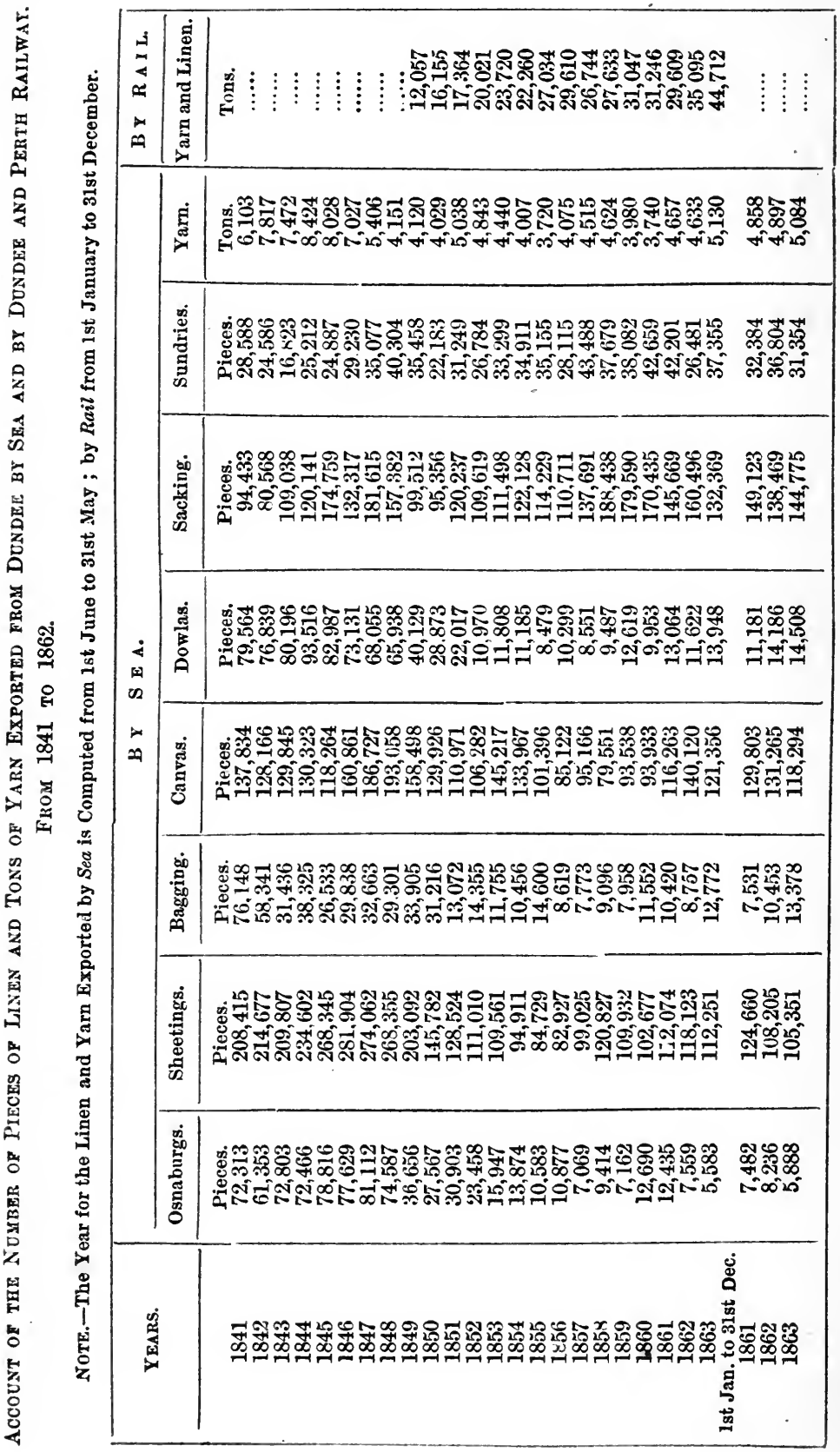




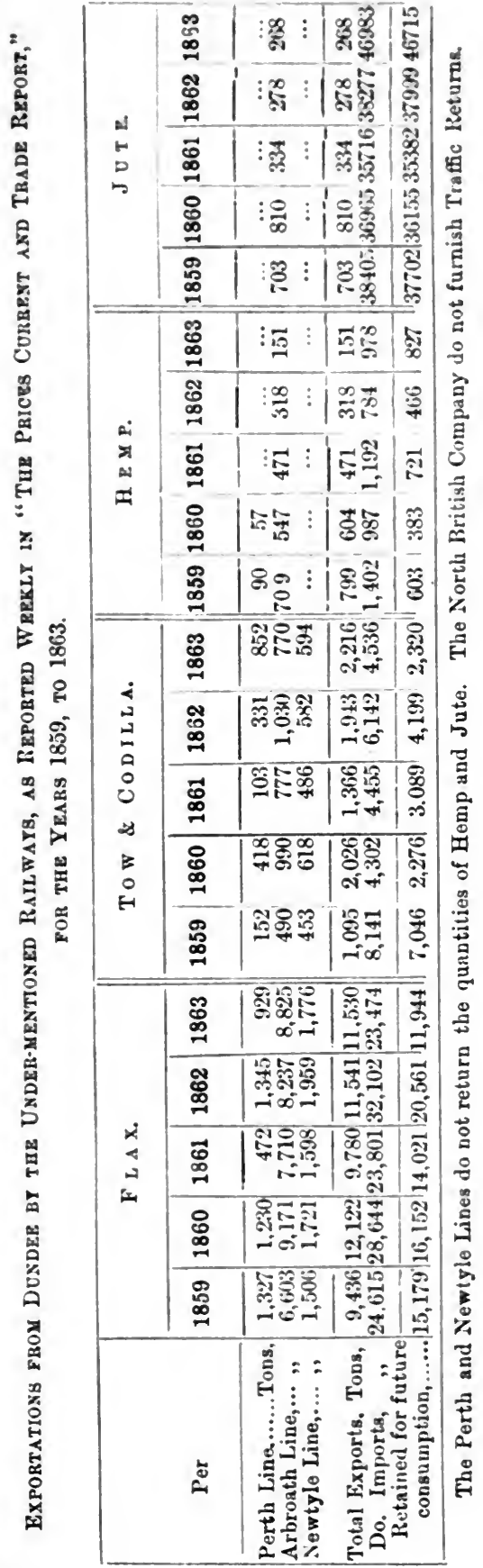

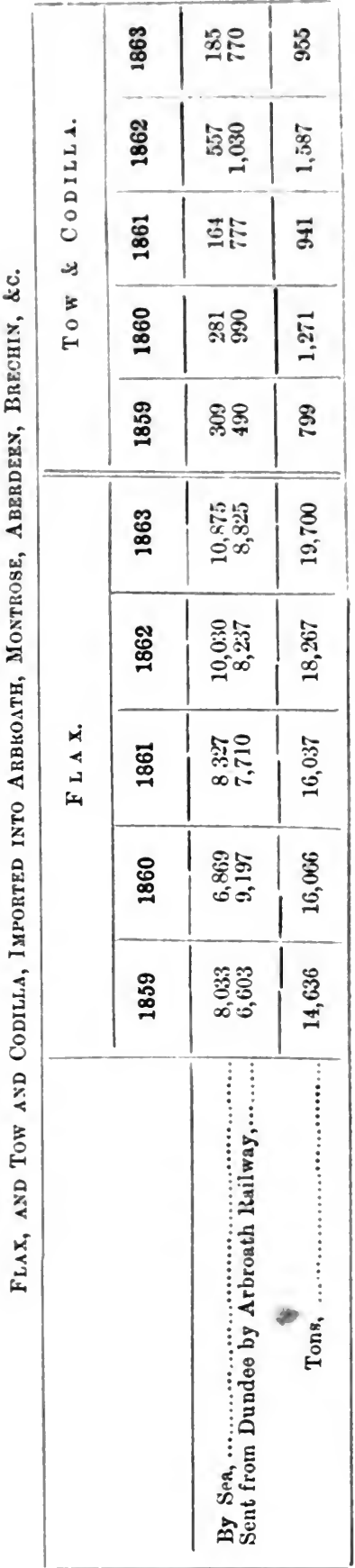




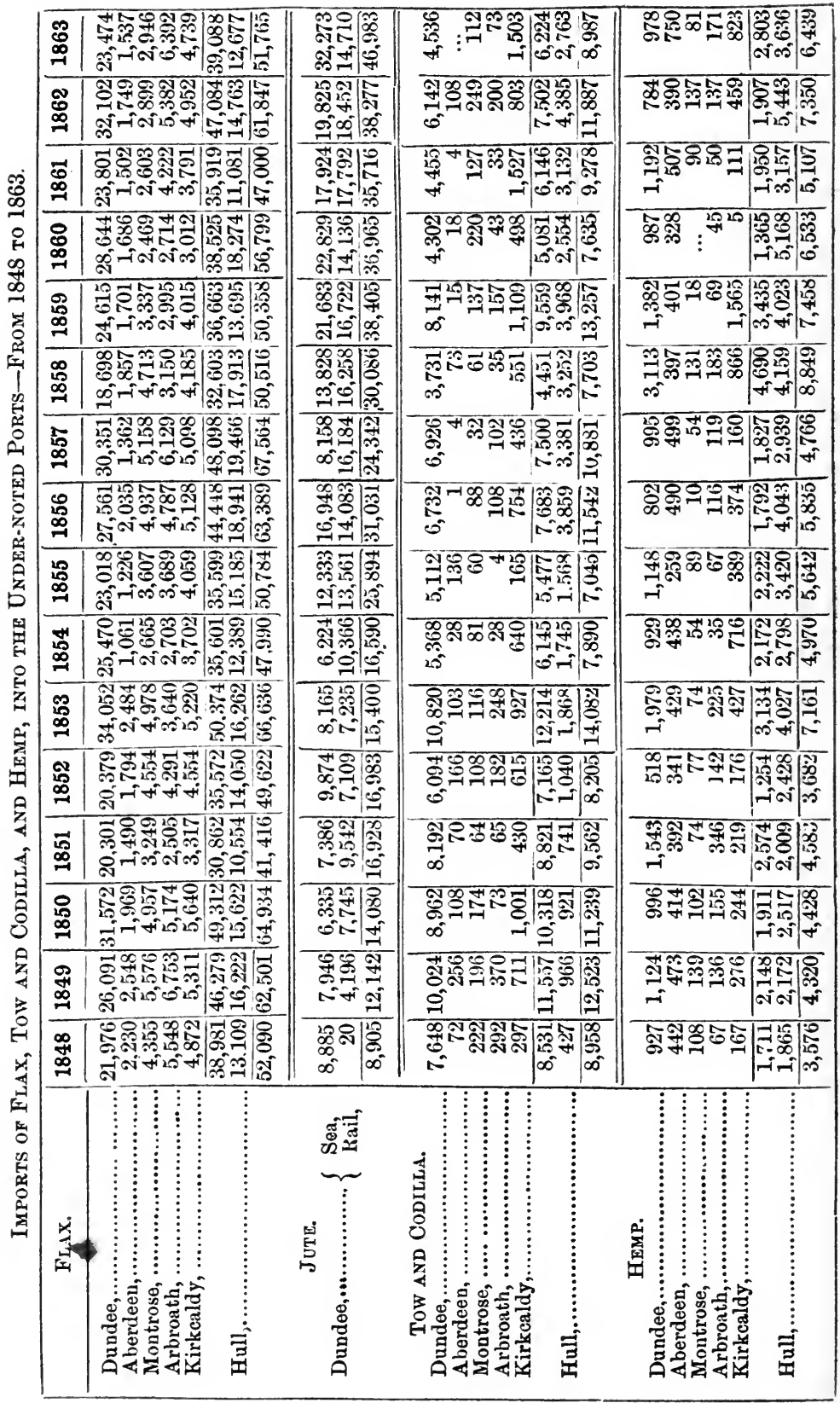




\begin{tabular}{|c|c|c|c|c|}
\hline $\begin{array}{l}\mathscr{8} \\
\infty \\
\infty\end{array}$ & 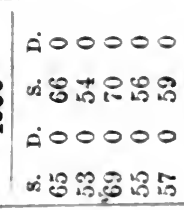 & $\begin{array}{l}0000 \\
400 \% 5 \\
0000 \\
075015\end{array}$ & 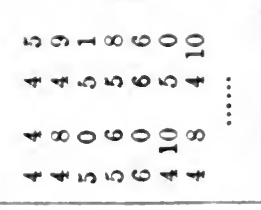 & 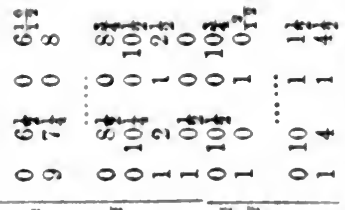 \\
\hline శ్ & 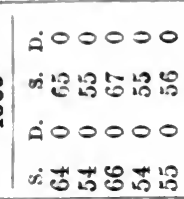 & 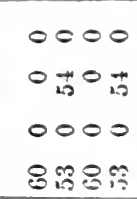 & 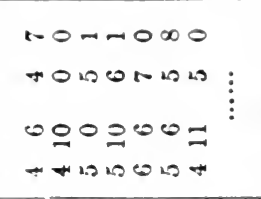 & 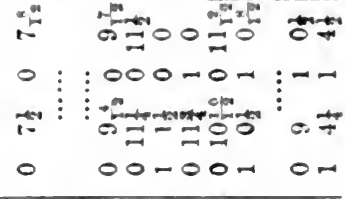 \\
\hline$\underset{\infty}{\infty}$ & 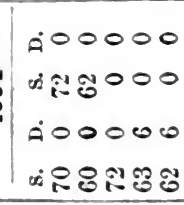 & $\begin{array}{l}0000 \\
8 \text { iो } 8 \text { in } \\
0000 \\
8.08 \%\end{array}$ & 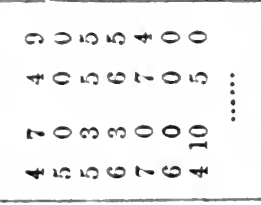 & 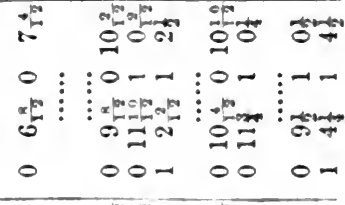 \\
\hline ஜ & 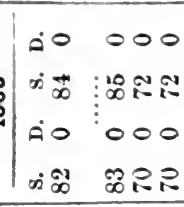 & $\begin{array}{l}0000 \\
0: 150 \\
0000 \\
8.5 \% \text { : }\end{array}$ & 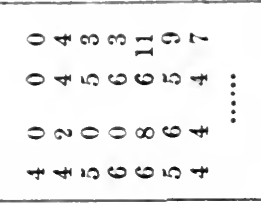 & 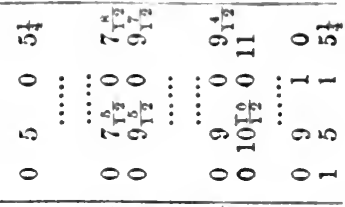 \\
\hline 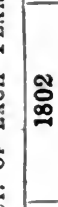 & 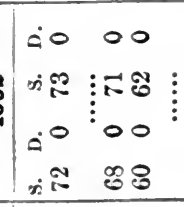 & 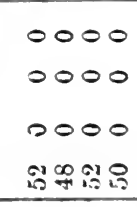 & 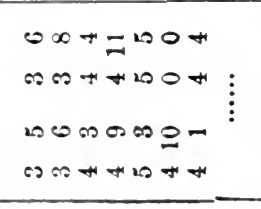 & 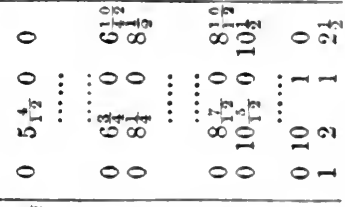 \\
\hline$\overbrace{0}^{\circ}$ & 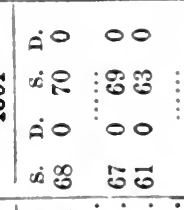 & & 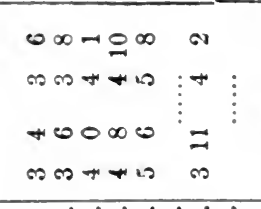 & 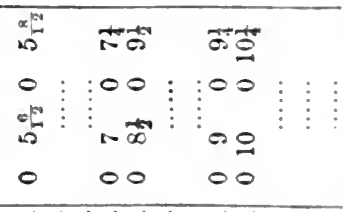 \\
\hline & 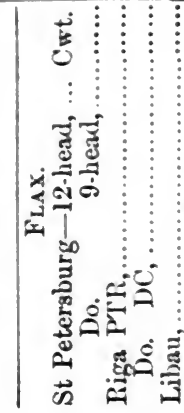 & 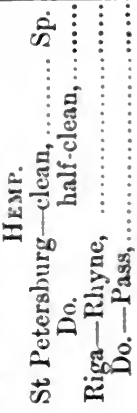 & 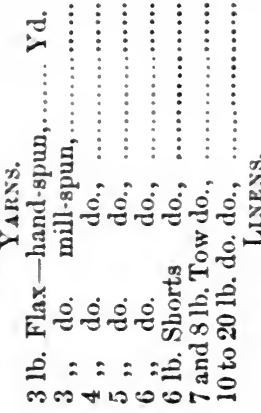 & 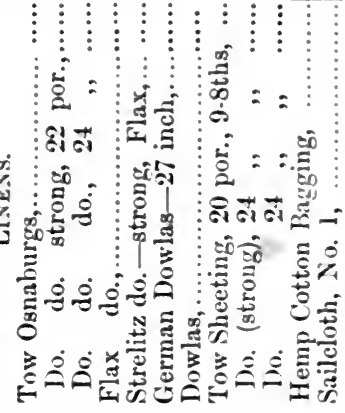 \\
\hline
\end{tabular}




\begin{tabular}{|c|c|c|c|c|}
\hline 옹 & 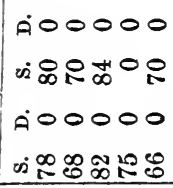 & 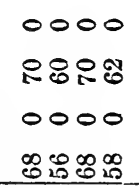 & 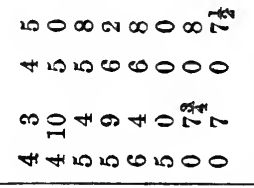 & 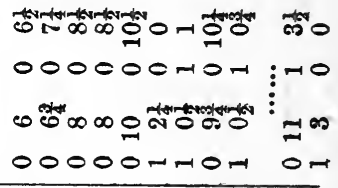 \\
\hline \begin{tabular}{c}
0 \\
0 \\
\hdashline
\end{tabular} & 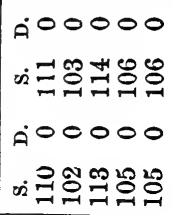 & $\begin{array}{l}0000 \\
8585 \\
0000 \\
28 \% 88\end{array}$ & 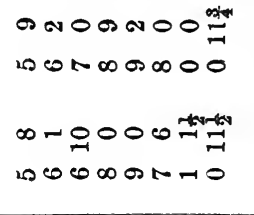 & 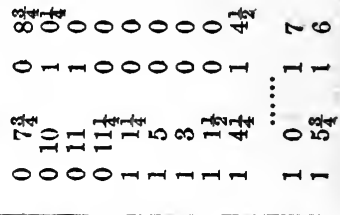 \\
\hline & 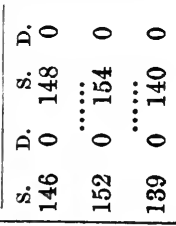 & 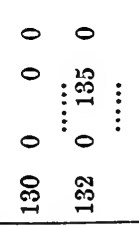 & 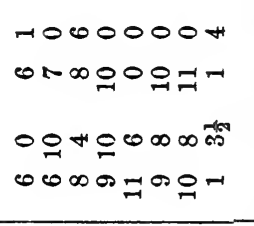 & 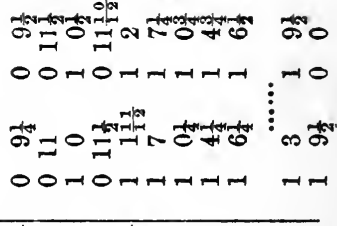 \\
\hline$\left|\begin{array}{c}0 \\
0 \\
0 \\
-1\end{array}\right|$ & 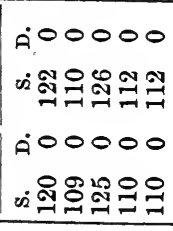 & 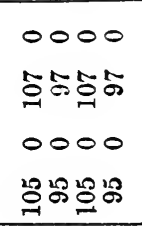 & 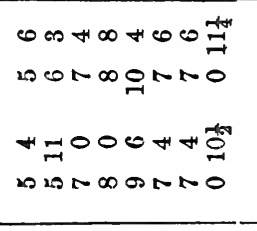 & 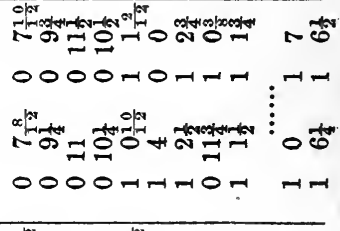 \\
\hline 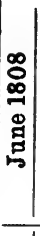 & 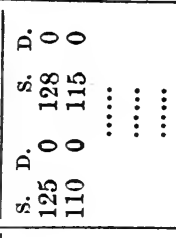 & 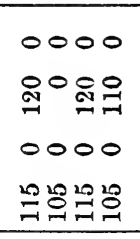 & 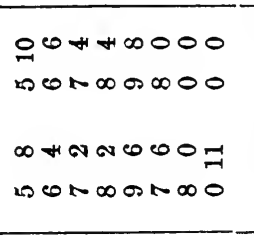 & 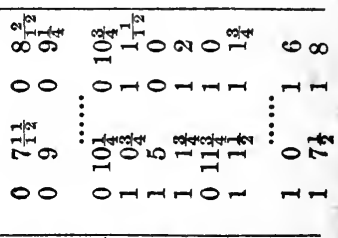 \\
\hline $\begin{array}{c}5 \\
\mathbf{\infty} \\
-1\end{array}$ & 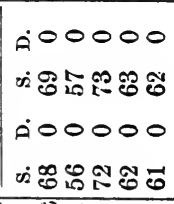 & 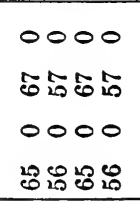 & 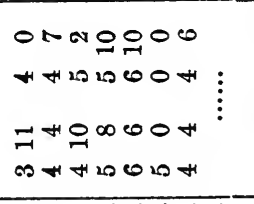 & 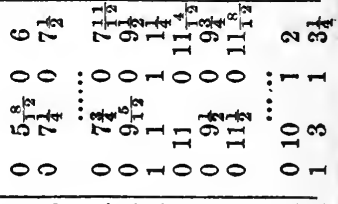 \\
\hline & 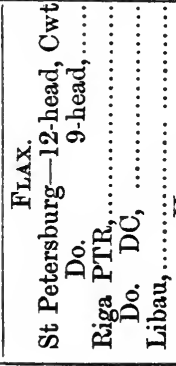 & 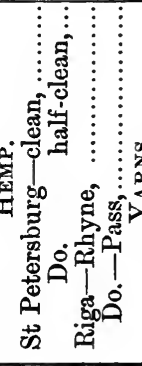 & 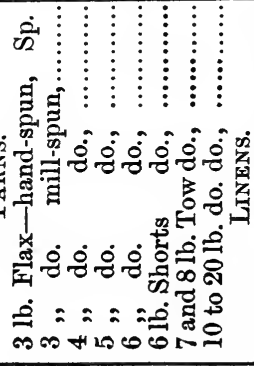 & 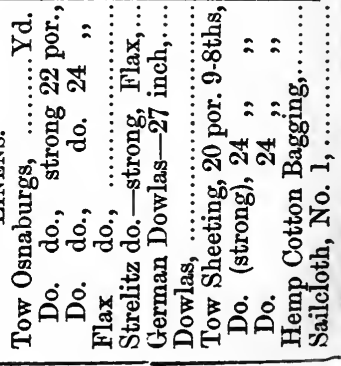 \\
\hline
\end{tabular}




\begin{tabular}{|c|c|c|c|c|}
\hline 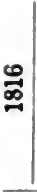 & 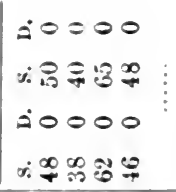 & 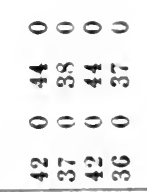 & 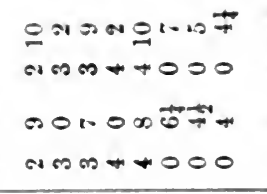 & 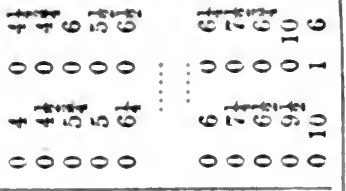 \\
\hline$\underset{\sim}{\infty}$ & 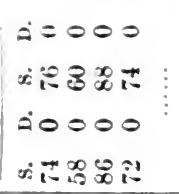 & 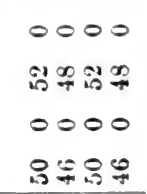 & 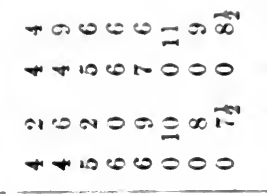 & 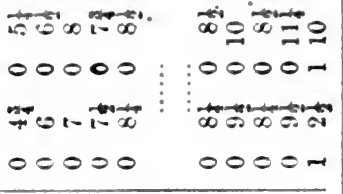 \\
\hline$\underset{\sim}{\vec{D}}$ & 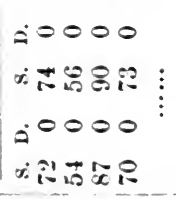 & 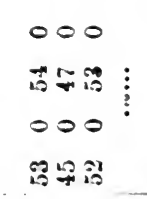 & 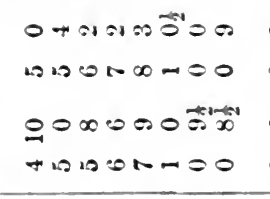 & 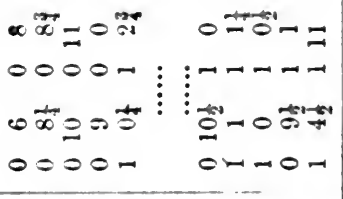 \\
\hline$\underset{\infty}{\infty}$ & 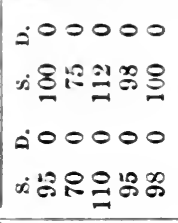 & 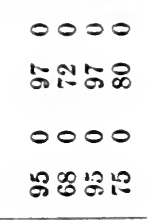 & 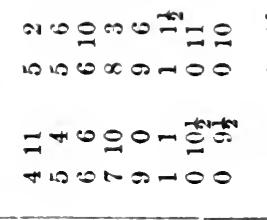 & 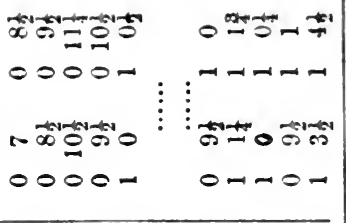 \\
\hline$\underset{\infty}{\infty}$ & 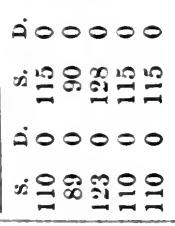 & 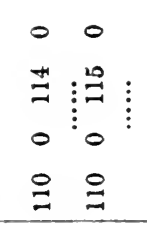 & 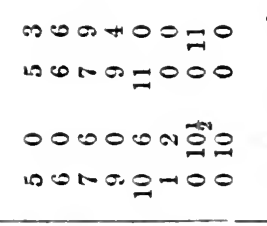 & 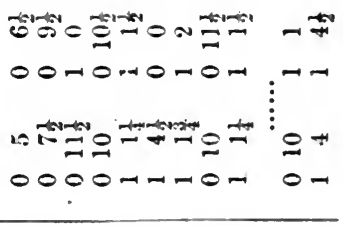 \\
\hline 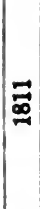 & 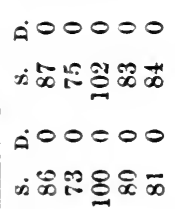 & $\begin{array}{l}0000 \\
\text { N:요 } \\
0000 \\
\infty: \infty R\end{array}$ & 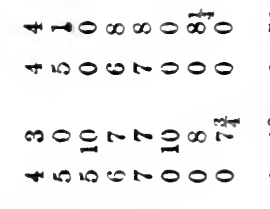 & 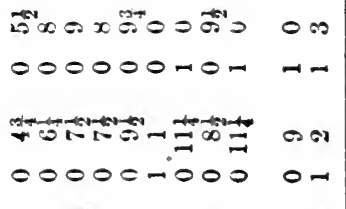 \\
\hline & 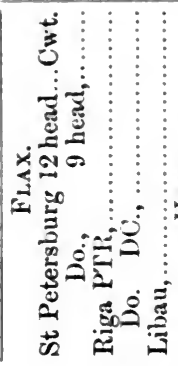 & 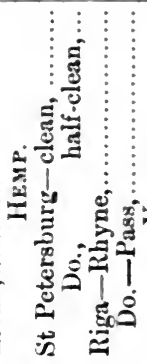 & 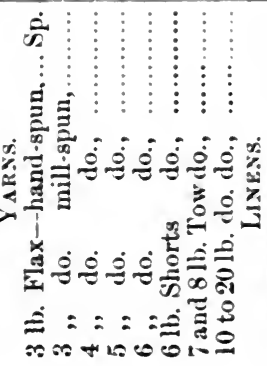 & 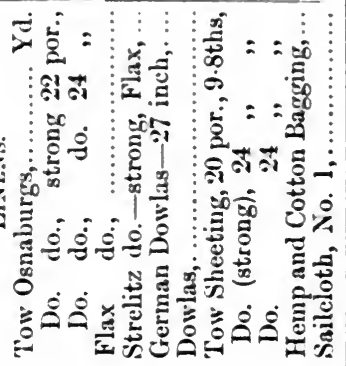 \\
\hline
\end{tabular}




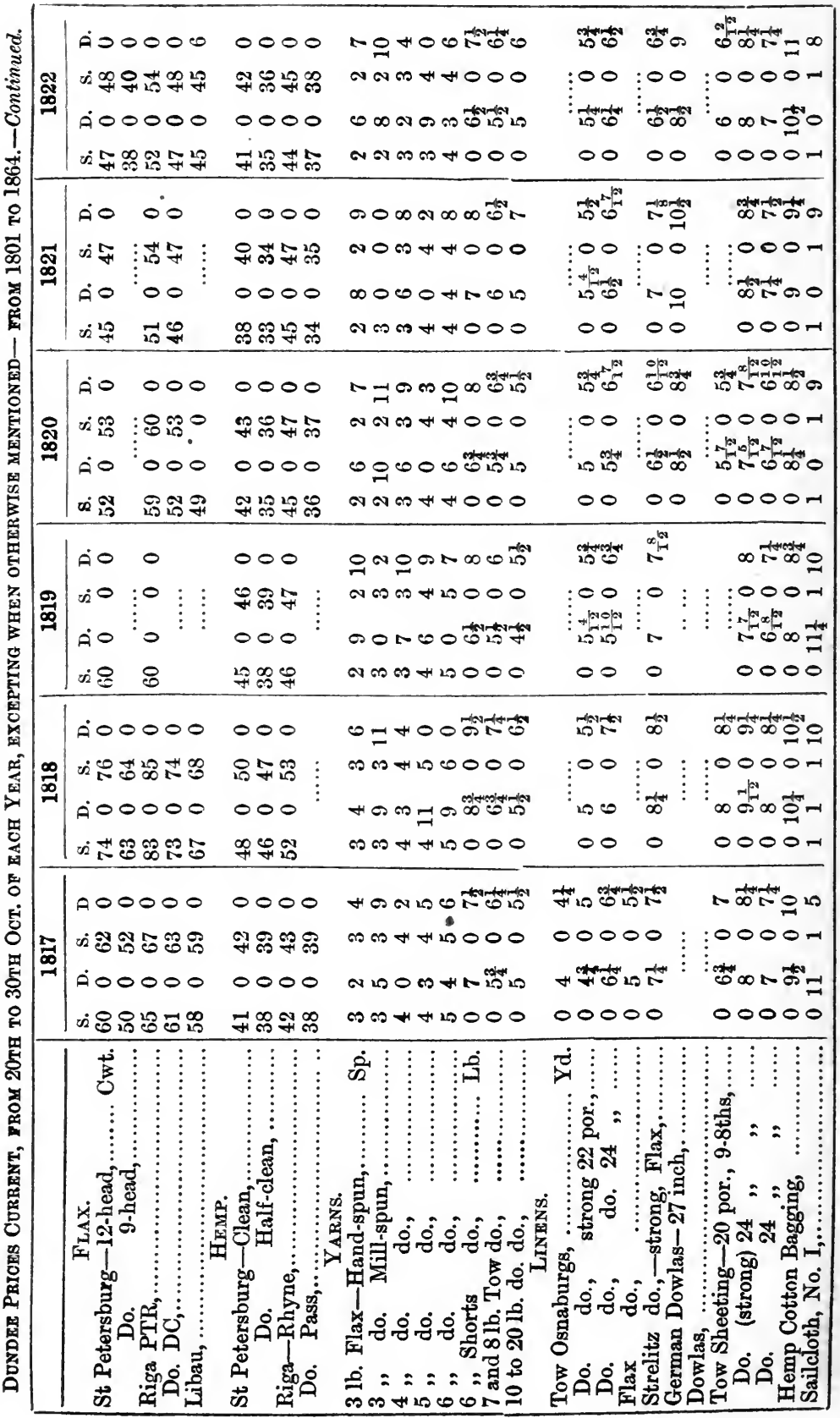




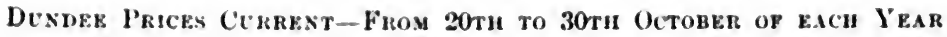
-From 1801 ro 1864 -Continuel.

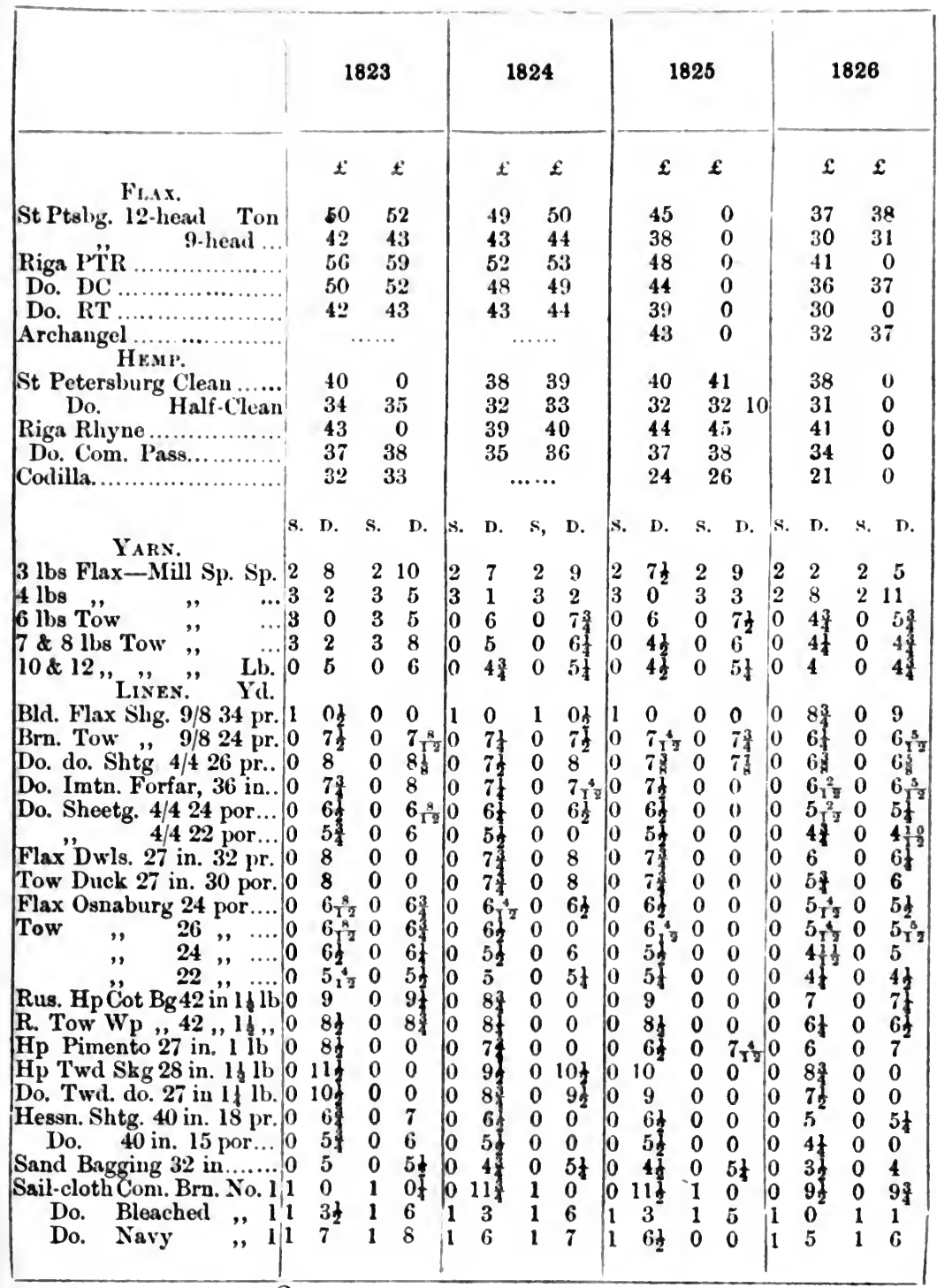


Dundee Prices Current-From 20th to 30th October of each Year -From 1801 то 1864-Continued.

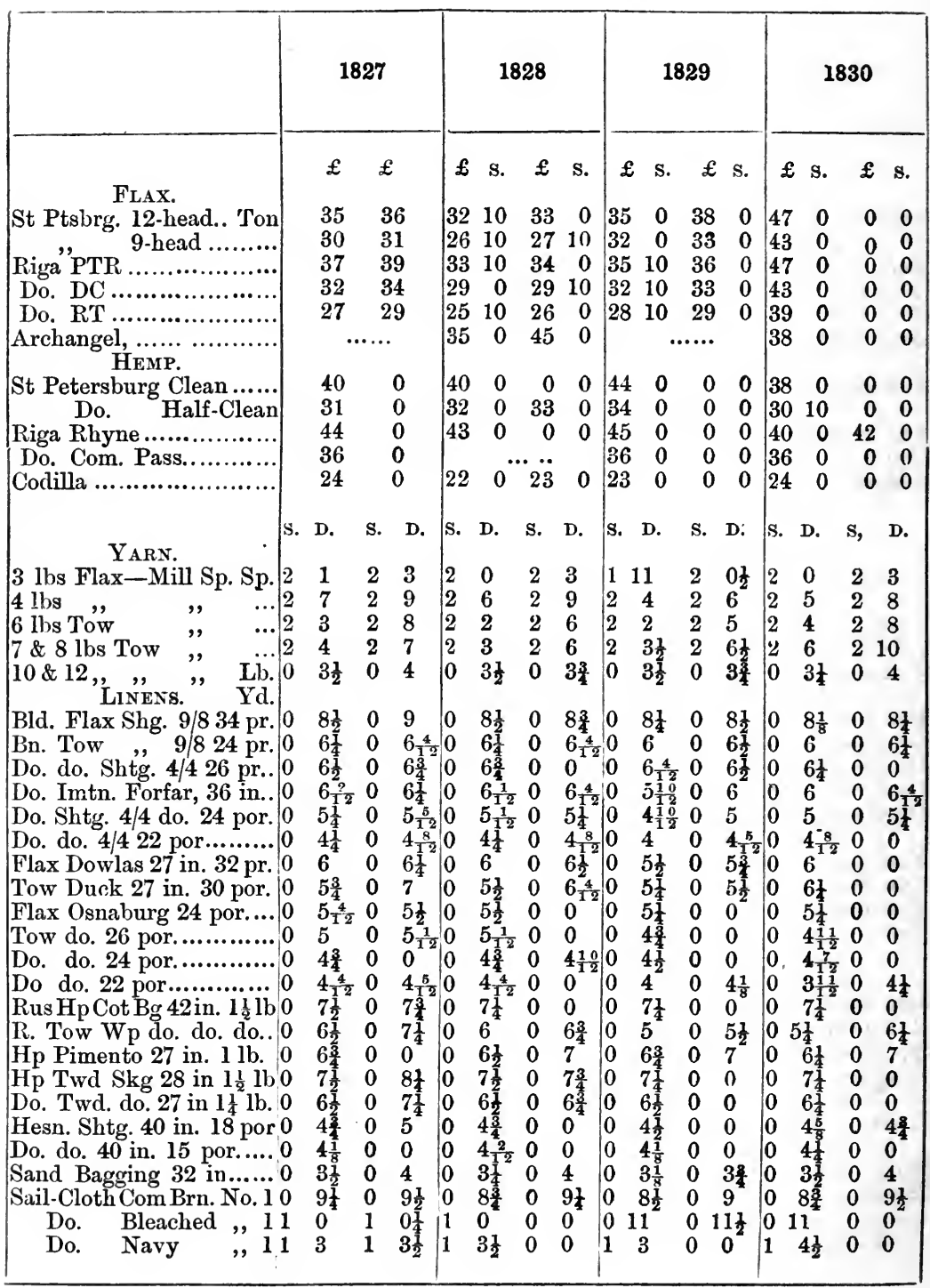


Dundee Prices Ceriest-From 20tu to 30tu Octuler of kacu YeakFros 1801 to 1864. - Continued.

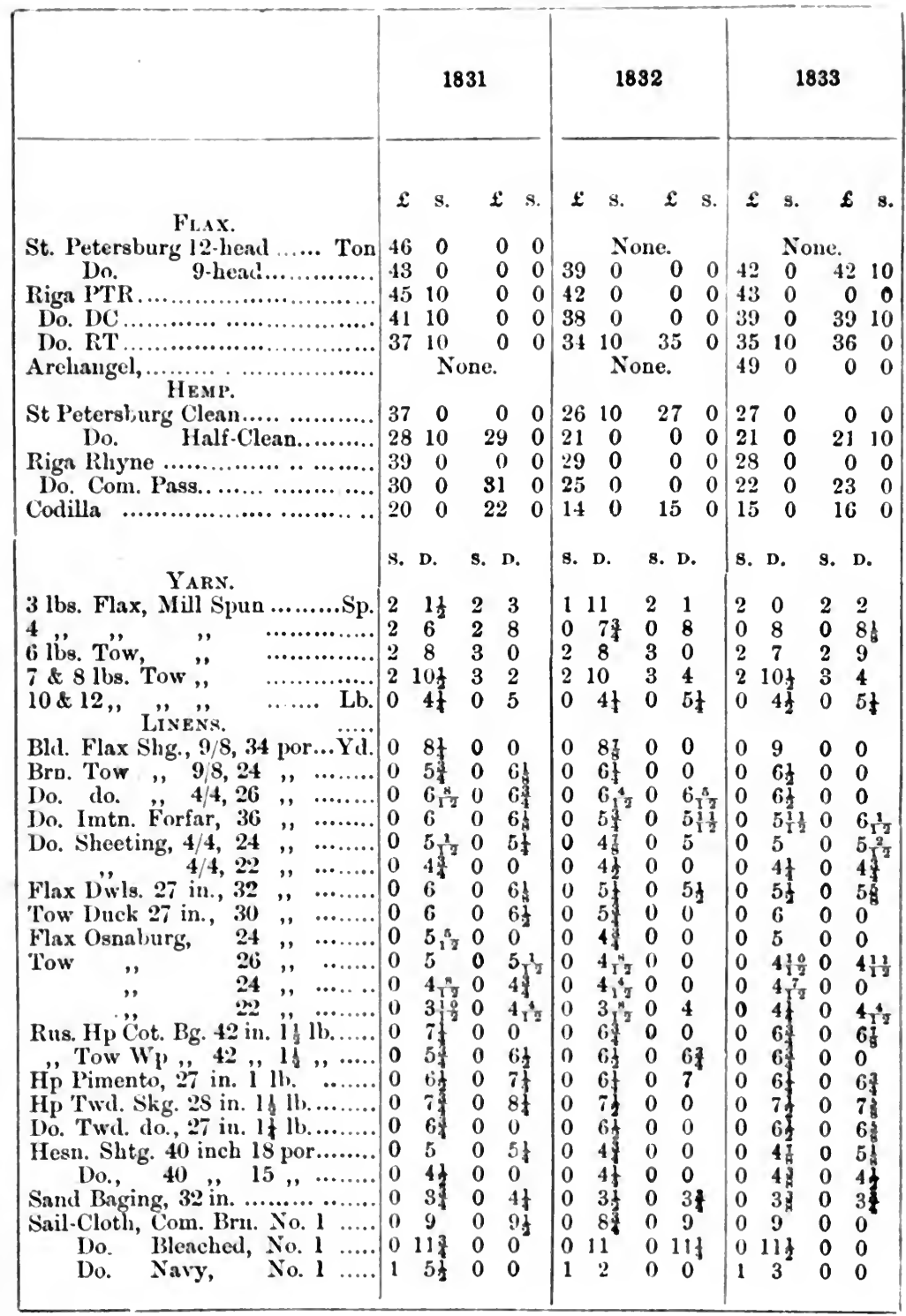


Dundee Prices Current, from 20th to 30th October of each YearFrom 1801 to 1864.-Continued.

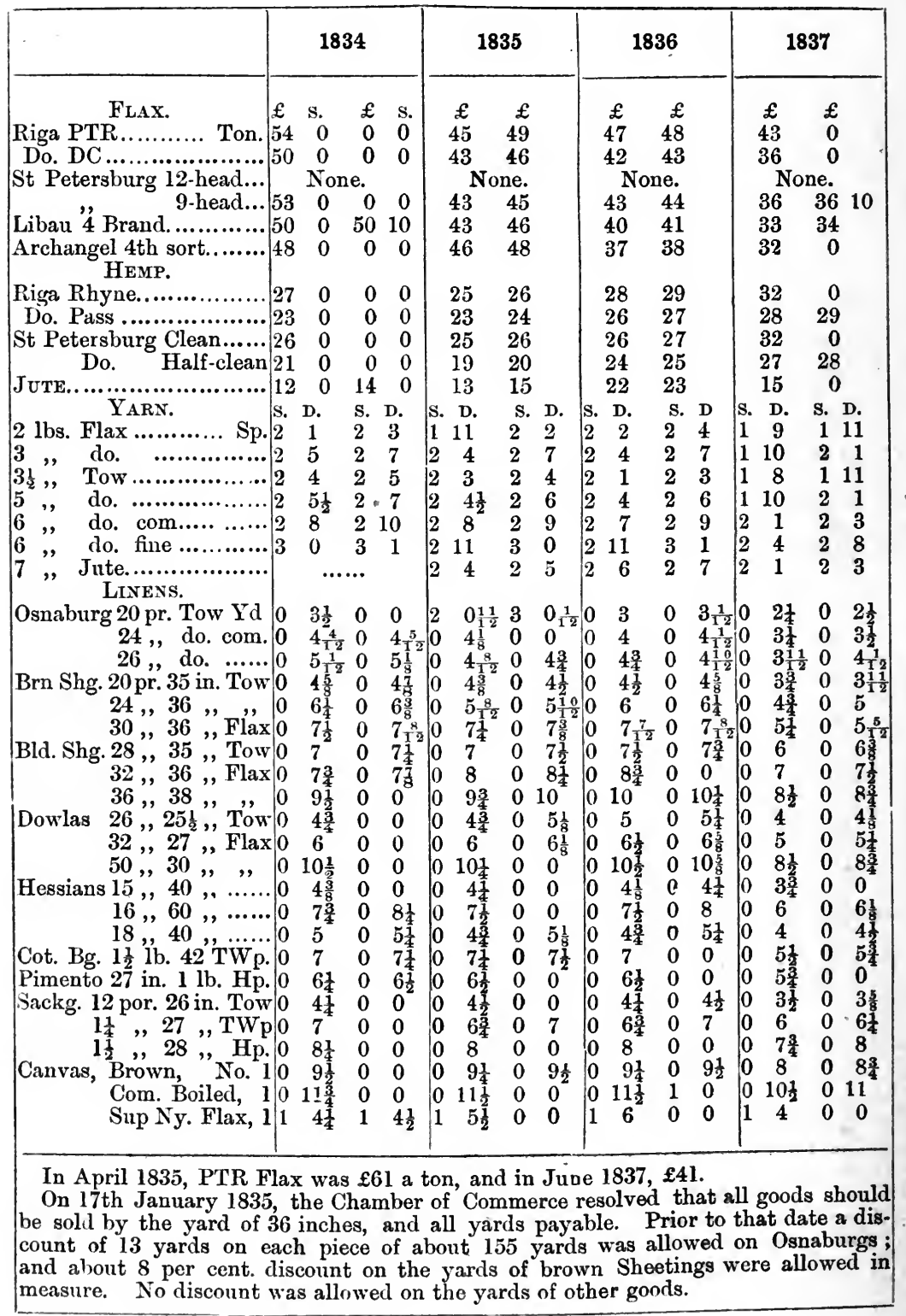


Dundee Prices Currext, frog 20th to 30th October of each Year-

From 1801 to 1864.-Continued.

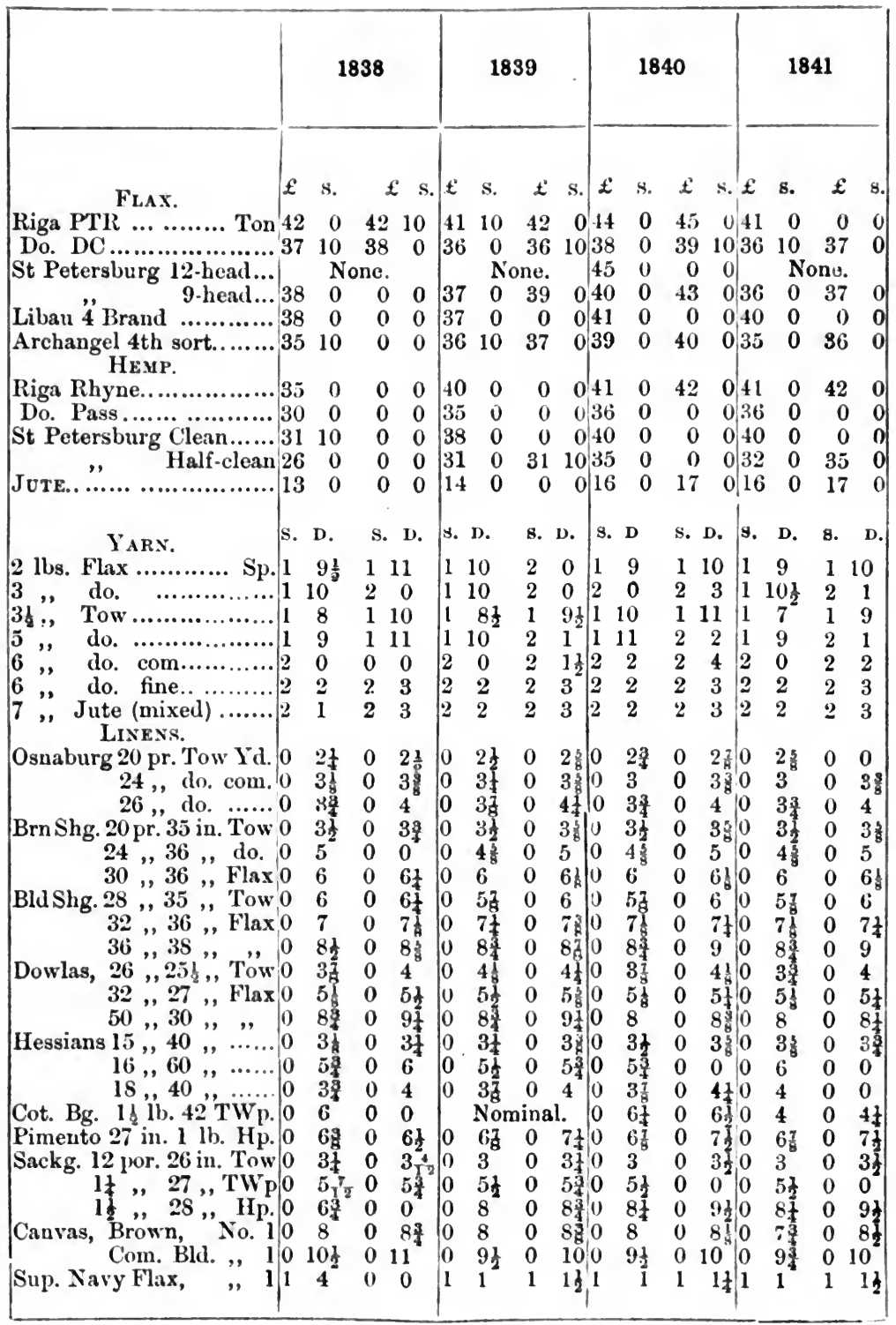


Dundee Prices Current-From 20th to 30th October of each Year -From 1801 to 1864.-Continued.

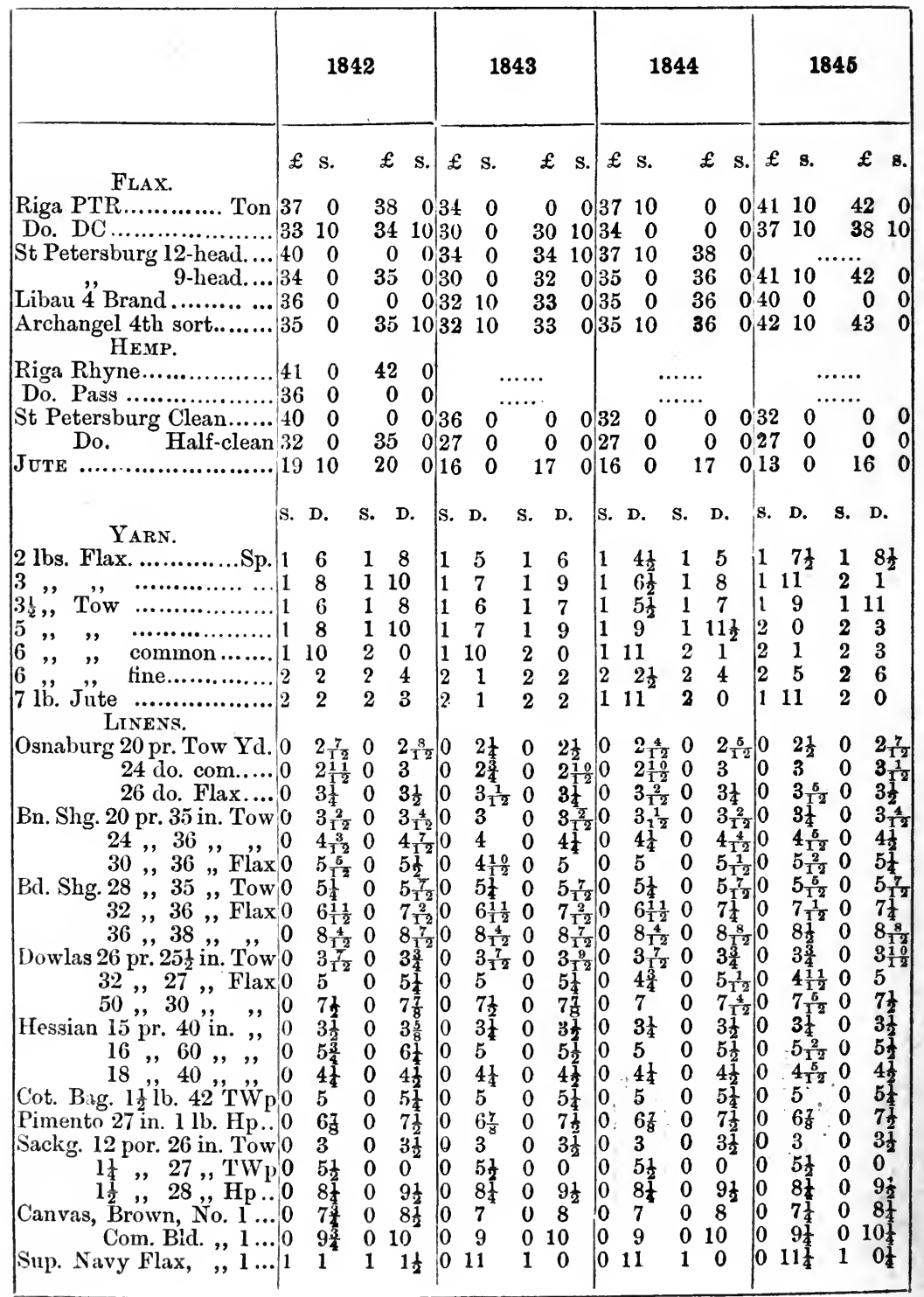


Dundee Prices Currext-Frus 20th to 30ru October or rach YearFrom 1801 to 1864. - Continued.

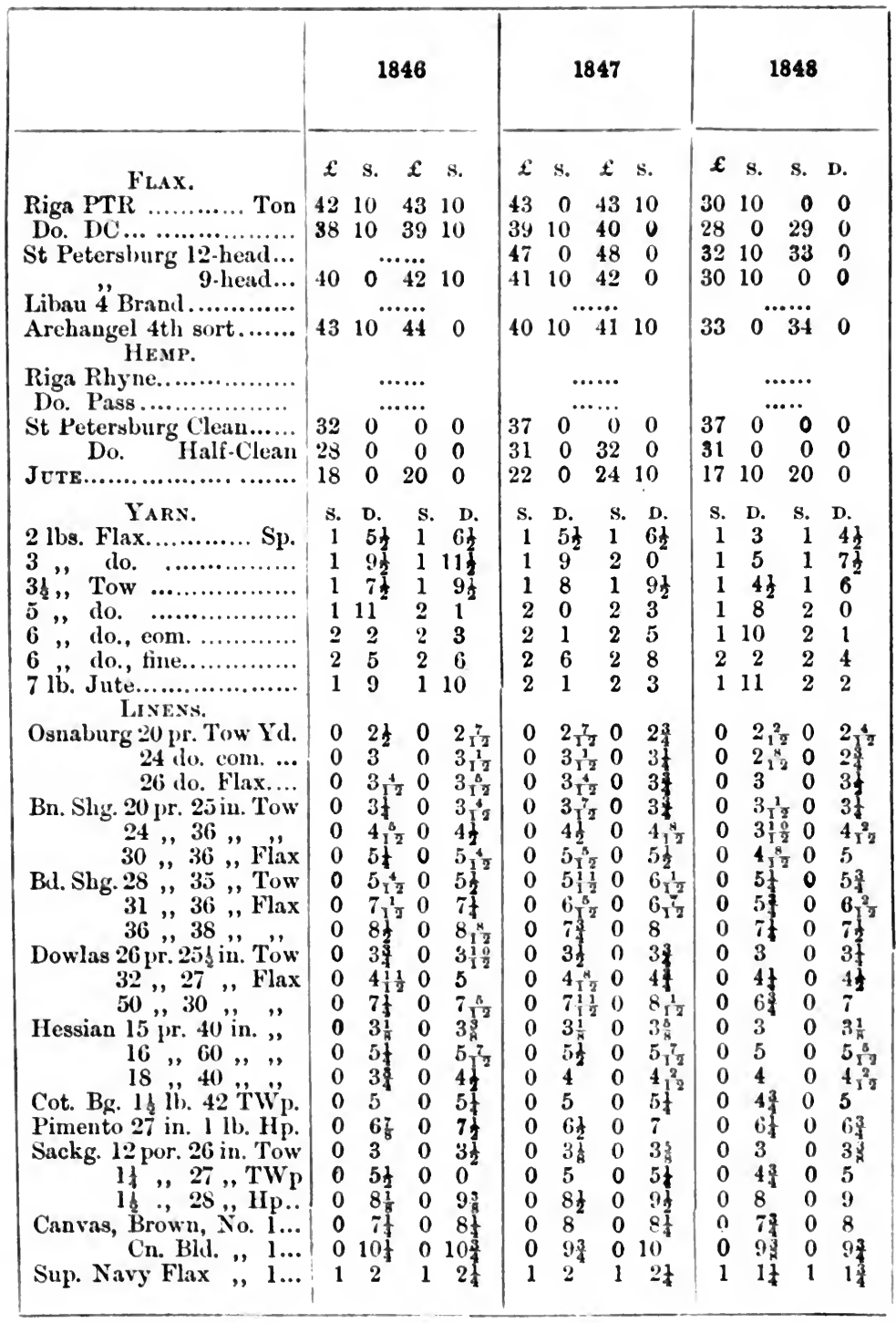


Dunuee Prices Current, mom 20th to 30th October of each YearFrom 1801 to 1864.-Continued.

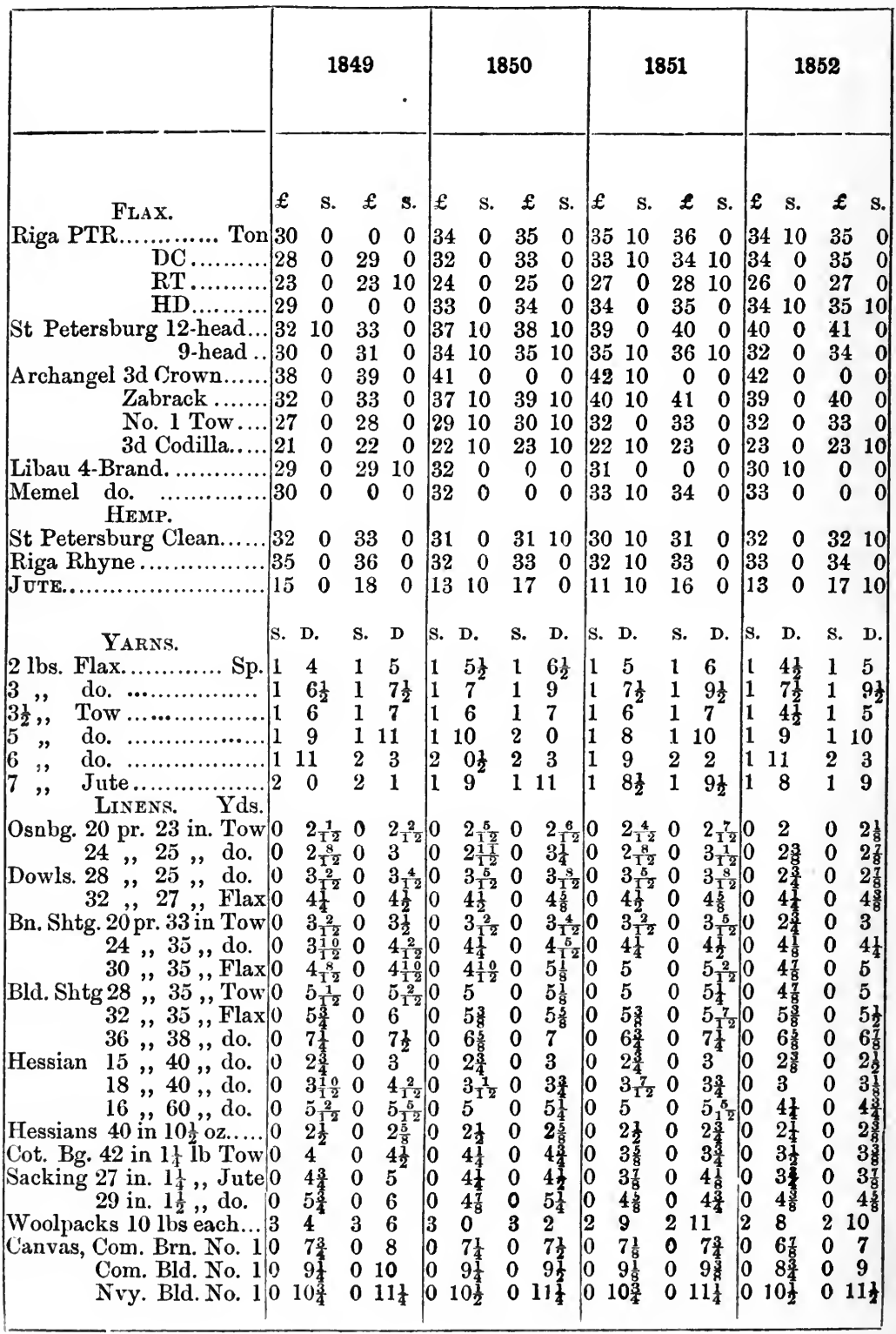


Dundee Prices Cerrest, from 20tu to 30th October of each Year-

From 1801 to 1864.-Continued.

\begin{tabular}{|c|c|c|c|c|c|c|c|c|c|c|c|c|c|c|c|}
\hline & \multicolumn{4}{|c|}{1853} & \multicolumn{4}{|c|}{1854} & \multicolumn{4}{|c|}{1855} & \multicolumn{3}{|c|}{1856} \\
\hline Ton. & $\mathcal{E}$ & s. & $\mathfrak{E}$ & s. & $£$ & s. & $\mathfrak{E}$ & s. & $£$ & s. & \pm & s. $£$ & s. & $£$ & s. \\
\hline Riga PTR 1853 then PLCM & 47 & 0 & 0 & & 50 & 0 & 52 & & 46 & 0 & 48 & 040 & 0 & 41 & 0 \\
\hline DC........................... & 401 & 10 & 41 & & 43 & 0 & 45 & & 41 & 0 & 42 & 034 & 0 & 34 & 10 \\
\hline RT.. & 34 & 0 & 35 & & 37 & 0 & 33 & & 36 & 0 & 37 & 028 & 0 & 30 & 0 \\
\hline HD. & 39 & 10 & 40 & 10 & 42 & 0 & 43 & & 40 & 0 & 41 & 033 & 0 & 34 & \\
\hline St Petersburg 12-head.... & 46 & 0 & 48 & & 49 & 0 & 50 & & 44 & 0 & 46 & 038 & 0 & 39 & 0 \\
\hline 9-head & 40 & 10 & 42 & & 45 & 0 & 46 & & 39 & 10 & 40 & 1034 & 0 & 35 & \\
\hline Archangel 3d Crown. & 48 & 0 & 48 & 10 & 53 & 0 & 54 & & 52 & 0 & 57 & $0 \mid 44$ & 0 & 45 & 0 \\
\hline Zabrack & 45 & 10 & 46 & & 46 & 0 & 50 & & 49 & 0 & 53 & 040 & 10 & 41 & 0 \\
\hline No. 1 Tow.... & 36 & 10 & 38 & & 43 & 0 & 44 & & 46 & 0 & 48 & 035 & 10 & 36 & 0 \\
\hline 3d Codilla.... & 30 & 10 & 0 & & 37 & 0 & 0 & & 38 & 10 & 39 & 029 & 10 & 30 & 0 \\
\hline Libau 4-Brand ............. & 39 & 10 & 40 & & 41 & 0 & 42 & & 39 & 0 & 40 & 036 & 10 & 37 & 10 \\
\hline $\begin{array}{l}\text { Memel do. ......... } \\
\\
\text { HEMP. }\end{array}$ & 38 & 0 & 39 & & 39 & 0 & 41 & & 41 & 0 & 42 & 036 & 0 & 37 & 0 \\
\hline St Petersburg Clean. & 38 & 0 & 39 & & 50 & 0 & 56 & & 43 & 0 & 45 & 034 & 0 & 0 & 0 \\
\hline Riga Rhyne .................. & 38 & 0 & 39 & & 60 & 0 & 61 & & 44 & 0 & 45 & $0 \longdiv { 3 5 }$ & 0 & 0 & 0 \\
\hline 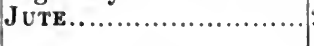 & $\because 0$ & 0 & 25 & & 19 & 0 & 24 & & 16 & 0 & 23 & 015 & 0 & 24 & 0 \\
\hline YARNS. & s. & D. & s. & D. & & D. & s. & D. : & s. 1 & D. & s. & D. s. & D. & & \\
\hline 2 lbs. Flax. & 1 & $6 \frac{1}{2}$ & 1 & 7 & 1 & 6 & 1 & 7 & 1 & $6 \frac{1}{2}$ & 0 & 011 & 7 & 0 & 0 \\
\hline 3, & & $11^{2}$ & 1 & $11 \frac{1}{2}$ & & 10 & 1 & 112 & & 11 & 2 & \begin{tabular}{l|l}
0 & 1
\end{tabular} & $11 \frac{1}{3}$ & & $0 \frac{1}{2}$ \\
\hline $3 \frac{1}{2},$, Tow .. ..... & 1 & 7 & 1 & $8^{\circ}$ & 1 & 9 & 1 & $11 \frac{\pi}{2}$ & 110 & $10 \frac{1}{2}$ & 2 & \begin{tabular}{l|l}
0 & 1
\end{tabular} & $10 \frac{1}{2}$ & & $11 \frac{1}{2}$ \\
\hline 5, , do. .... & 11 & 10 & 2 & 2 & 2 & 2 & 2 & 3 & 2 & 3 & 2 & 92 & $1 \frac{1}{2}$ & 2 & $5 \frac{1}{2}$ \\
\hline $6, "$, do. $\ldots \ldots \ldots . . .$. & 2 & 1 & 2 & 5 & & 4 & 2 & 9 & 2 & 8 & 3 & 32 & $4 \frac{1}{2}$ & 2 & 9 \\
\hline 7 , Jute ................ & 2 & $1 \frac{1}{2}$ & 2 & $2 \frac{1}{2}$ & 11 & 11 & 2 & 1 & & $11 \frac{1}{2}$ & 2 & 12 & $0^{\circ}$ & 2 & 1 \\
\hline Osnbg. 20 pr. 25 in. Tow & & $2+$ & 0 & 23 & 0 & 25 & 0 & & 0 & $2 \frac{5}{8}$ & 0 & $2 \frac{7}{8} 0$ & 25 & 0 & \\
\hline $24,, 25,$, do. & 0 & 25 & 0 & $3 \hat{i}$ & & $3 \frac{1}{\mathrm{i}}$ & 0 & 3 & 11 & $3 \frac{1}{8}$ & 0 & $3 \frac{3}{4} 0$ & $3 \frac{1}{8}$ & 0 & 3 \\
\hline Dowls. 28 , 25, , do. & 0 & 3 & 0 & $3 \hat{k}$ & & $3 \frac{i}{2}$ & 0 & $33_{4}^{3}$ & 0 & 3 & 0 & $3+0$ & $3 \frac{5}{5}$ & 0 & $3 \frac{3}{4}$ \\
\hline $32,, 27,$, Flax & & 4 & 0 & 43 & 0 & 4 & 0 . & 4 & 0 & $4 i$ & $\mathbf{0}$ & 40 & $4 \frac{1}{2}$ & 0 & $4 \frac{3}{3}$ \\
\hline Bn. Shtg. 20 pr. 33 in Tow & & $2 \frac{3}{4}$ & 0 & & & $3 \frac{i}{2}$ & 0 & & 0 & $3 \frac{5}{8}$ & 0 & $3 \frac{3}{4} 0$ & $3 \frac{5}{8}$ & 0 & $3 \frac{3}{4}$ \\
\hline 24,35, , do. & & 41 & 0 & $4 !$ & 0 & $4 \frac{1}{2}$ & 0 & 5 & 0 & 5 & 0 & 510 & $4 \frac{1}{4}$ & 0 & $5 \frac{1}{4}$ \\
\hline $30,, 35$, Flax & & 5 & 0 & 51 & & 51 & 0 & $5 \frac{3}{4}$ & 0 & 53 & 0 & $5 \frac{i}{8} 0$ & $5 \frac{1}{2}$ & 0 & 53 \\
\hline Bld Shtg $28,, 35$, , Tow & & $4 \pi$ & 0 & 5 & $\theta$ & $4 \frac{3}{4}$ & 0 & 5 & 0 & $4 \frac{3}{4}$ & 0 & 50 & $5+$ & 0 & $5 \frac{1}{2}$ \\
\hline 32,35, , Flax & & 53 & 0 & $5 \frac{1}{2}$ & & $5 i$ & 0 & $5 \frac{1}{8}$ & 0 & 5 & 0 & $5 \pi 0$ & 6 & 0 & 6 \\
\hline $36,38,$, do. & 0 & $6 \%$ & 0 & $6 \frac{7}{8}$ & 0 & 64 & 0 & $7 \hat{A}$ & 0 & $6 \frac{3}{4}$ & 0 & 70 & $6 \frac{3}{4}$ & 0 & $7 \frac{1}{8}$ \\
\hline Hessian 15,40, , do. & 0 & 27 & 0 & 3 & (1) & $3 f$ & 0 & $3 \frac{1}{2}$ & 20 & 3 & 0 & 30 & 38 & 0 & $3 \tilde{i}$ \\
\hline $18,, 40,$, do. & 0 & $3 \frac{3}{4}$ & 0 & 4 & 0 & $3 \frac{i}{4}$ & 0 & 4 & 0 & $4 \frac{3}{2}$ & 0 & 40 & $4 \frac{1}{4}$ & 0 & 43 \\
\hline 16,60, , do. & & 5 & 0 & $5 \frac{1}{2}$ & 0 & $5 \frac{3}{4}$ & 0 & 6 & 0 & 6 & 0 & $6 \$ 0$ & $5 \frac{1}{2}$ & 0 & $5 \frac{3}{3}$ \\
\hline Hessians $40 \mathrm{in.} 10 \mathrm{oz} . .$. & & 23 & 0 & 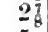 & 0 & 3 & 0 & $3\rfloor$ & 0 & 33 & 0 & 3 हु 0 & 34 & 0 & $3 \frac{1}{2}$ \\
\hline Cot Bag. 42, , l If Tow & & $4 \frac{3}{4}$ & 0 & 5 & 0 & 43 & 0 & $4 \pi$ & 0 & 41 & 0 & 410 & 4. & 0 & $4 \frac{1}{1}$ \\
\hline Sacking 27, if ,, Jute & & $5 i$ & 0 & 5. & & 4 & 0 & 5 & 0 & 4 & 0 & 50 & 44 & 0 & 5 \\
\hline $29,, 12$, , do. & & $5 \frac{1}{8}$ & 0 & $6 \hat{1}$ & & $5 \frac{1}{2}$ & 0 & 57 & & $5 \underline{1}$ & 0 & $5 \div 0$ & $5 \frac{1}{8}$ & 0 & $5 \frac{3}{4}$ \\
\hline Woolpacks 10 lbs each... & & 6 & 3 & 8 & 3 & 3 & 3 & 5 & 3 & 3 & 3 & 53 & 4 & 3 & 6 \\
\hline Canvas, Com. Brn. No. 1 & 0 & it & 0 & is & & إ & 0 & 偍 & 30 & it & 0 & $7 \leqslant 0$ & 7 & 0 & $i \frac{1}{2}$ \\
\hline Com. Bld. No. 1 & 10 & 9 & 0 & 98 & 0 & $?$ & 0 & 98 & 30 & !t & 0 & 970 & 91 & 0 & 91 \\
\hline Nvy. Bld. Ni & 101 & Int & 1 & & 1 & 0 & 1 & 0.6 & $\$ 01$ & 11 & 1 & 00 & 107 & 0 & $11 \frac{1}{4}$ \\
\hline
\end{tabular}


Dundee Prices Current-From 20th to 30th October of each Year -From 1801 то 1864.-Continued.

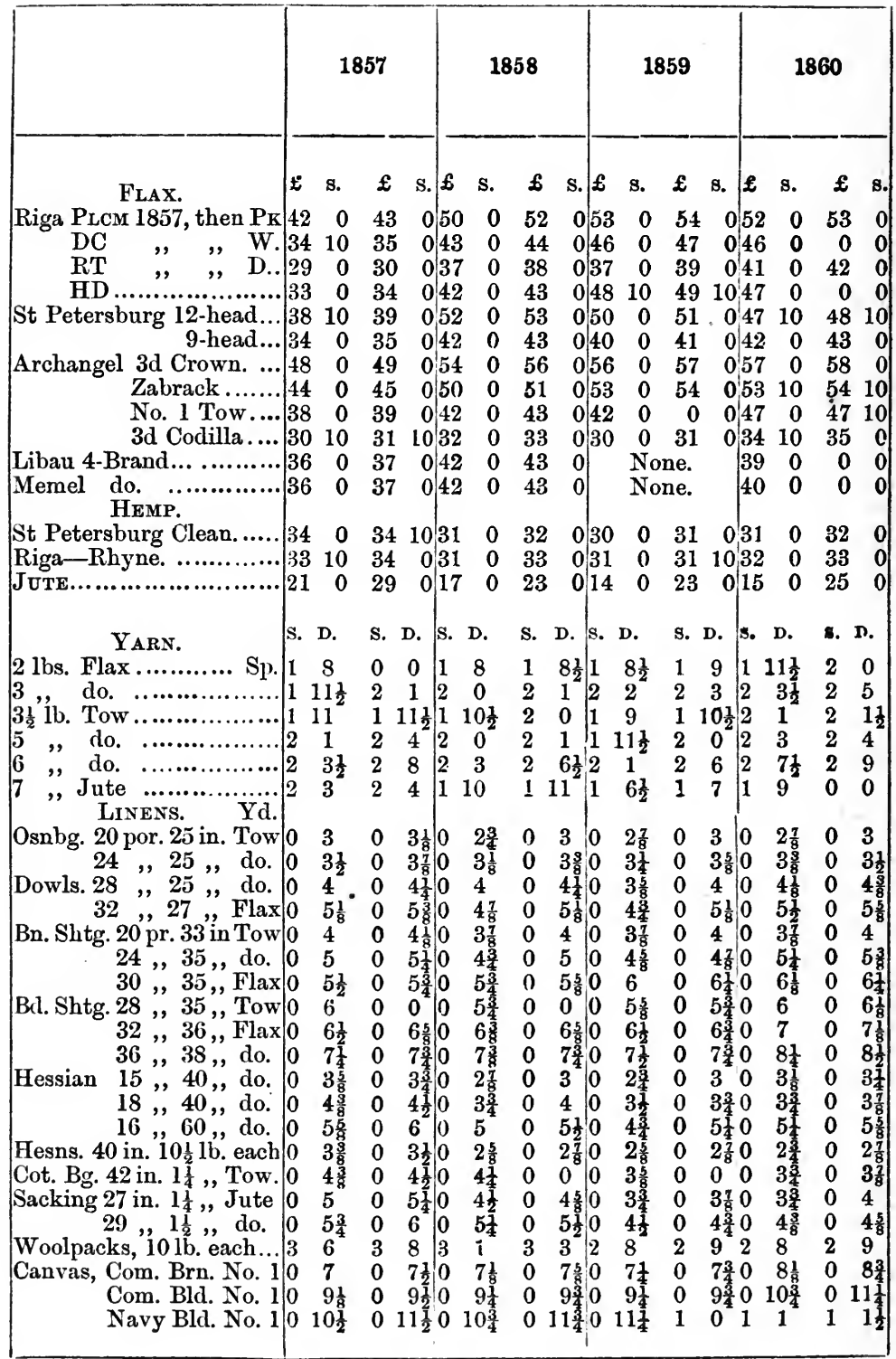


Dundee Prices Current-From 20tu to 30tu Octomer of each Year -From 1501 to 1863, and 26ti April 1864.-Contimued.

\begin{tabular}{|c|c|c|c|c|c|c|c|c|c|c|c|c|c|}
\hline \multirow{2}{*}{ FlaX. } & \multicolumn{4}{|c|}{1861} & \multicolumn{2}{|c|}{1862} & \multicolumn{4}{|c|}{1863} & \multicolumn{3}{|c|}{1864} \\
\hline & $£$ & s. & $\mathfrak{L}$ & s. $£$ & s. & $£$ & s. $\mathscr{L}$ & s. & $\mathfrak{E}$ & s. $£$ & s. & $\mathfrak{E}$ & s. \\
\hline Riga PK. & 48 & 0 & 49 & 057 & 70 & 0 & 050 & 0 & 57 & 055 & 0 & 56 & P \\
\hline W & 43 & 0 & 44 & 049 & 90 & 50 & 0.52 & 20 & 53 & 050 & $\begin{array}{ll}0 & 0\end{array}$ & 51 & \\
\hline & & & & & & & & & & 42 & 20 & 44 & \\
\hline $\mathrm{H}$ & 44 & 0 & 4.4 & 1048 & $8 \quad 10$ & 49 & 1050 & $0 \quad 0$ & 51 & 051 & 1 & 32 & \\
\hline ox & 45 & 0 & & 1050 & $\begin{array}{ll}0 & 0\end{array}$ & 52 & 051 & 10 & 53 & 044 & & 8 & \\
\hline & 38 & 0 & 39 & 045 & 50 & 46 & 044 & 40 & 47 & $0: 37$ & 70 & 41 & \\
\hline rchangel 3 & .54 & 10 & 55 & 1062 & 20 & 63 & 067 & 70 & 0 & 070 & 0 & 1 & \\
\hline " & 48 & 0 & 50 & $05 t$ & 60 & 7 & $0.50^{\circ}$ & $\dot{0} 0$ & 59 & 0.55 & 50 & 8 & \\
\hline $\mathbf{N}$ & 43 & 0 & 44 & 051 & 10 & 32 & 057 & 70 & 58 & 050 & 00 & 3 & \\
\hline & 31 & 0 & 1 & 1038 & 80 & 9 & 037 & 0 & 38 & 037 & 0 & 8 & \\
\hline Bral & 39 & 0 & 40 & 04 & +0 & 46 & 0 & & & & Nomi & ainal & \\
\hline $\begin{array}{l}\text { do. } \\
\text { HES }\end{array}$ & 40 & 0 & 41 & 045 & 50 & 0 & 047 & 0 & 48 & 47 & 70 & 40 & \\
\hline 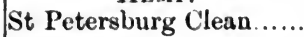 & 31 & 0 & 0 & 038 & 80 & 0 & 0 39 & 9 & 0 & 037 & & 0 & \\
\hline & 32 & 10 & 33 & 1039 & $\begin{array}{ll}9 & 0\end{array}$ & 40 & $0+1$ & 1 & 0 & 039 & & 0 & \\
\hline UT & 15 & 0 & 25 & 020 & $\begin{array}{ll}0 & 0\end{array}$ & 30 & 023 & 310 & 33 & 1019 & 90 & 33 & \\
\hline $\mathbf{Y}_{0}$ & 8. & D. & s. & D. s. & D. & 8. & D. $s$. & D. & s. & J). s. & - D. & 8. & \\
\hline $\operatorname{Tarn}-2 \mathrm{lb} . \mathrm{F}$ & 15 & 9 & 1 & $9 \frac{1}{2} 2$ & 2 & 2 & $2 \frac{1}{2} 2$ & 8 & 2 & $8 \frac{1}{8} 2$ & $6 \frac{1}{2}$ & 2 & 7 \\
\hline 3 & & 1 & 2 & $22_{2}^{2}$ & 7 & 2 & \begin{tabular}{l|l}
8 & 3 \\
5 & 3
\end{tabular} & 4 & $\begin{array}{l}3 \\
3\end{array}$ & \begin{tabular}{l|l}
5 & 3 \\
2 & 3
\end{tabular} & $\begin{array}{l}1 \frac{3}{2} \\
01\end{array}$ & 0 & 0 \\
\hline 5 do & & $\begin{array}{l}1 \\
2\end{array}$ & $\begin{array}{l}1 \\
2\end{array}$ & $\begin{array}{r}112 \\
212\end{array}$ & $\begin{array}{l}4 \frac{1}{2} \\
9\end{array}$ & $\begin{array}{l}2 \\
3\end{array}$ & \begin{tabular}{l|l}
5 & 3 \\
0 & 3
\end{tabular} & $\frac{1}{2}$ & $\begin{array}{l}\mathbf{0} \\
3\end{array}$ & $\begin{array}{l}2 \\
113 \\
3\end{array}$ & $\begin{array}{l}0 \frac{1}{2} \\
11\end{array}$ & 3 & $\begin{array}{l}1 \\
2\end{array}$ \\
\hline 6, & & 52 & 2 & 812 & 11 & 3 & 23 & 3 & 3 & 63 & 31 & & 6 \\
\hline $\begin{array}{l}\text { Jute........ } \\
\text { Ns. }\end{array}$ & 1 & 71 & 1 & $8^{2} 2$ & 4 & 2 & $\begin{array}{ll}5 & 3\end{array}$ & $1 \frac{1}{2}$ & 3 & $2 \frac{1}{2} \cdot 3$ & 2 & 3 & 3 \\
\hline snbg. 20 por. 25 in. Tow & & $2 \frac{7}{8}$ & 0 & 0 & 3 s? & 0 & $3 \frac{1}{2} 0$ & 41 & 0 & 430 & 41 & & \\
\hline . & & $3 \frac{3}{2}$ & 0 & 0 & $3 \frac{7}{8}$ & 0 & 40 & 5 & 0 & $5 \frac{1}{1} 0$ & 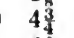 & & \\
\hline Jowls. 28 & 0 & 48 & 0 & 40 & $4 \frac{7}{8}$ & 0 & 50 & 7 & $\mathbf{v}$ & 710 & 68 & & \\
\hline Whe & & 54 & 0 & 530 & 6 & 0 & $6 ! 0$ & $8 \frac{1}{2}$ & 0 & 8 & $7 \frac{7}{8}$ & 0 & \\
\hline $\operatorname{tg} .2$ & & $3 \frac{5}{8}$ & 0 & 0 & 4 & 0 & 40 & $6 \frac{1}{2}$ & 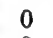 & 0 & 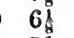 & & \\
\hline • & 0 & 5 & 0 & 510 & $5 \frac{8}{4}$ & 0 & $5 \frac{2}{2} 0$ & 81 & 0 & $8 \div 0$ & 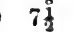 & 0 & \\
\hline 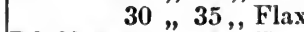 & & $5 \pi$ & 0 & 60 & $6 \frac{8}{8}$ & 0 & 60 & 93 & 0 & $9 \frac{1}{2} 0$ & $8 \frac{3}{4}$ & & \\
\hline d. Shtg. 28 & & $5 \frac{1}{8}$ & 0 & 60 & $6 f$ & 0 & 630 & $9^{\circ}$ & 0 & 90 & & 0 & \\
\hline$x$ & & $6 \frac{7}{9}$ & 0 & & $7 \pm$ & 0 & 750 & 103 & 0 & $10 \frac{8}{8} 0$ & 9 & 0 & \\
\hline & 0 & $8 i$ & 0 & 830 & $9 \frac{3}{3}$ & 01 & 101 & $0 \frac{3}{4}$ & 1 & $1 ! 1$ & 0 & & \\
\hline Hessian 15, & 0 & 3 & 0 & 310 & $3 \hat{s}$ & 0 & 330 & $5 \frac{1}{8}$ & 0 & $5+0$ & $4 \frac{3}{4}$ & 0 & \\
\hline & 0 & 39 & 0 & 330 & 4 & 0 & 40 & $5 \frac{5}{8}$ & 0 & $5 \frac{3}{0}$ & & & \\
\hline & & 5 & 0 & $5 \frac{1}{2} 0$ & $6 \frac{1}{3}$ & 0 & $6 \frac{10}{2} 0$ & $8 \frac{1}{2}$ & 0 & 90 & 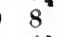 & b & \\
\hline $0:$ & & 2 & 0 & & $3 \pi$ & 0 & 30 & 5 & 0 & $5 \frac{3}{4} 0$ & $4 \frac{1}{4}$ & & \\
\hline & & 33 & 0 & 310 & 4 & 0 & 50 & $6 \frac{3}{4}$ & 0 & 0 & & & \\
\hline g 27 & & 33 & 0 & $3 \sqrt[3]{3} 0$ & $4 \frac{3}{8}$ & 0 & 510 & $6 \frac{7}{8}$ & 0 & 70 & 51 & 0 & \\
\hline 29 & & 43 & 0 & $4 \frac{1}{2} 0$ & & $J$ & $5 \frac{1}{2} 0$ & $7 \frac{8}{4}$ & 0 & $7 \frac{7}{6} 0$ & 6 & 0 & \\
\hline cks, & & $6^{\circ}$ & 2 & $8^{2} 3$ & 4 & 3 & 64 & 9 & 4 & $11^{8} 4_{4}^{4}$ & $1 \frac{1}{2}$ & 4 & \\
\hline as, Co & 10 & 8 & 0 & $8 \ddagger 0$ & $8 \frac{1}{2}$ & 0 & 90 & $9 \frac{1}{2}$ & 0 & 100 & $10^{2}$ & 0 & 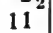 \\
\hline Co & & 99 & 01 & $10 \frac{1}{2} 0$ & $10 \frac{2}{2}$ & 01 & $11 \frac{1}{2} 0$ & $11 \frac{3}{4}$ & 1 & 011 & 0 & 1 & 1 \\
\hline Navy & & ii & 1 & $1 \frac{1}{2} 1$ & 2 & 1 & 31 & $3 \frac{1}{2}$ & 1 & $4 \frac{4}{2}[1$ & 4 & 1 & 5 \\
\hline
\end{tabular}


Table of the Horse-Power, Spindles, Power-Looms, and Hands employed in Spinning and Power-Loom Weaving Establishments in the onderNOTED TOWNS, IN APRIL, 1864. COMPILED From RETURNS, EXCEPTING IN A vert few Cases, supplied by the Proprietors.

ARBROATH.

\begin{tabular}{|c|c|c|c|c|c|}
\hline & Engines. & $\begin{array}{l}\text { Horse- } \\
\text { Power. }\end{array}$ & Spindles. & $\begin{array}{l}\text { Power- } \\
\text { Looms. }\end{array}$ & $\underset{\text { Employed. }}{\text { Hands }}$ \\
\hline $\begin{array}{l}\text { 1. Balfour \& Cumming.... } \\
\text { 2. Corsar Brothers.......... } \\
\text { 3. David Corsar \& Son.... } \\
\text { 4. William Curr \& Co..... } \\
\text { 5. Douglas Fraser \& Son... } \\
\text { 6. James Rait................. } \\
\text { 7. George Gordon........... } \\
\text { 8. G. \& A. Gordon.......... } \\
\text { 9. James P. Kyd.............. } \\
\text { 10. Andrew Loowson.......... } \\
\text { 11. Robert Lumgair......... } \\
\text { 12. Alexander Nicoll \& Co } \\
\text { 13. John Ogilvy \& Co....... } \\
\text { 14. Wm. Salmond \& Co. } \\
\text { 15. John Smith.............. } \\
\text { 16. John Walker \& Co...... } \\
\text { 17. F. \& W. Webster....... }\end{array}$ & $\begin{array}{l}1 \\
3 \\
5 \\
1 \\
5 \\
1 \\
1 \\
4 \\
1 \\
8 \\
1 \\
2 \\
1 \\
2 \\
1 \\
1 \\
1 \\
\end{array}$ & $\begin{array}{r}10 \\
50 \\
90 \\
12 \\
93 \\
25 \\
12 \\
110 \\
20 \\
225 \\
8 \\
22 \\
20 \\
50 \\
10 \\
10 \\
25 \\
\end{array}$ & $\begin{array}{r}1, \dddot{908} \\
2,502 \\
616 \\
3,384 \\
584 \\
750 \\
7,030 \\
10,004 \\
400 \\
904 \\
900 \\
1,360 \\
\cdots \\
\cdots \\
\cdots \\
\end{array}$ & $\begin{array}{r}34 \\
80 \\
140 \\
\ldots ̈ \\
110 \\
\ldots \\
\dddot{32} \\
104 \\
120 \\
\dddot{16} \\
\ldots \\
50 \\
40 \\
30 \\
50 \\
\end{array}$ & $\begin{array}{r}60 \\
440 \\
560 \\
70 \\
640 \\
55 \\
80 \\
620 \\
180 \\
1,230 \\
45 \\
110 \\
90 \\
240 \\
65 \\
55 \\
80 \\
\end{array}$ \\
\hline & 39 & 792 & 30,342 & 836 & 4,620 \\
\hline
\end{tabular}

\section{BLAIRGOWRIE.}

\begin{tabular}{|c|c|c|c|c|c|}
\hline & & 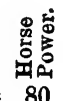 & 兽 & 免密 & 密苛 \\
\hline $\begin{array}{l}\text { John Adamson, Ericht Works, Steam, 30; } \\
\text { John Baxter, Ashbank Mill, } \\
\text { David Grimond, Lornty, Brooklin, and }\end{array}$ & $\begin{array}{l}\text { Water, } \\
\text { Water, }\end{array}$ & $\begin{array}{l}80 \\
18\end{array}$ & $\begin{array}{r}3,040 \\
960\end{array}$ & $\begin{array}{c}250 \\
\ldots\end{array}$ & $\begin{array}{r}800 \\
70\end{array}$ \\
\hline Oakbank Mills, & $"$ & 50 & 2,160 & $\ldots$ & 290 \\
\hline Matthew Low, Keithbank Mill,* . & 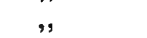 & 12 & 660 & $\cdots$ & 40 \\
\hline John Moncur, Westfield Mill, & ,, & 65 & 2,540 & ... & 160 \\
\hline $\begin{array}{l}\text { James Morrice, East and West Mills, } \\
\text { George Saunders \& Sons, Craig, and Bram- }\end{array}$ & " & 36 & 1,500 & ... & 90 \\
\hline blebank Mills, & $"$ & 58 & 2,340 & $\bullet \bullet$ & 200 \\
\hline & & 319 & 13,200 & 50 & 650 \\
\hline
\end{tabular}

FORFAR.

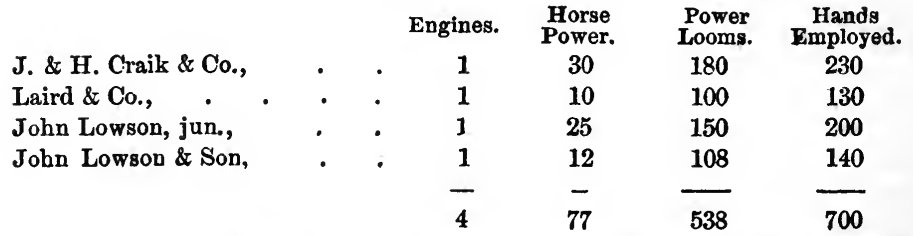

* To be supplanted by a new mill, now in course of erection, of more than double the size of the present work. 


\section{KINGHORN.}

\begin{tabular}{|c|c|c|c|c|}
\hline & & $\begin{array}{c}\text { Horse } \\
\text { Power. }\end{array}$ & spindles. & $\begin{array}{c}\text { Hands } \\
\text { Employed. }\end{array}$ \\
\hline Swan Brothers, St Loonarrl's & . & 83 & $3,4: 2$ & 250 \\
\hline Mid Mill, & . & 45 & 1.172 & 150 \\
\hline & & 128 & 4,624 & 400 \\
\hline
\end{tabular}

\section{KIRKCALDY.}

$\begin{array}{lllllllll}\text { R. \& A. Aytoun, } & . & . & . & . & 60 & 1,600 & \ldots \ldots & 150\end{array}$

Power. Spindles. Power Hands

Andrew Blair \& $\mathrm{Co}, \quad$. $\quad$. $\quad 16 \quad \ldots \ldots, \quad 40 \quad 50$

Louis Cheffelle,

J. \& W. Hendry,

John Jeffrey,

Archibald Nacdonald, . . . . .

A. G. Malcolm,

$\therefore \cdot(1738$ (.)

Swan Bros., Coal Wynd, $\begin{array}{lllll}36 & 1738 & \ldots . . . & 120\end{array}$

Park Mill, $\quad 28 \quad 1400 \quad \ldots . . .100$

Linktown, $\quad \begin{array}{llll}16 & 600 & \ldots . . . & 80\end{array}$

R. Wemyss,

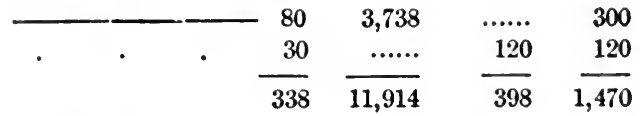

MONTROSE.

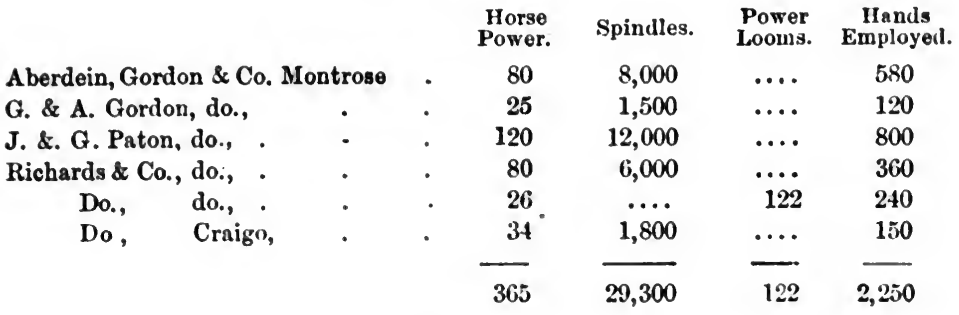

A BSTRACT.

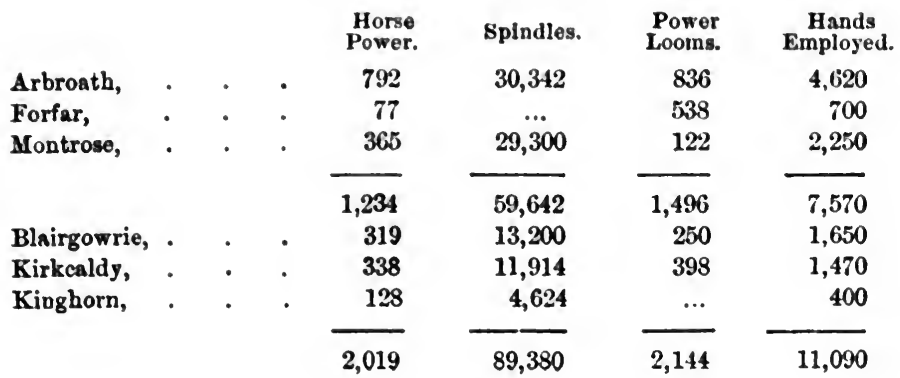




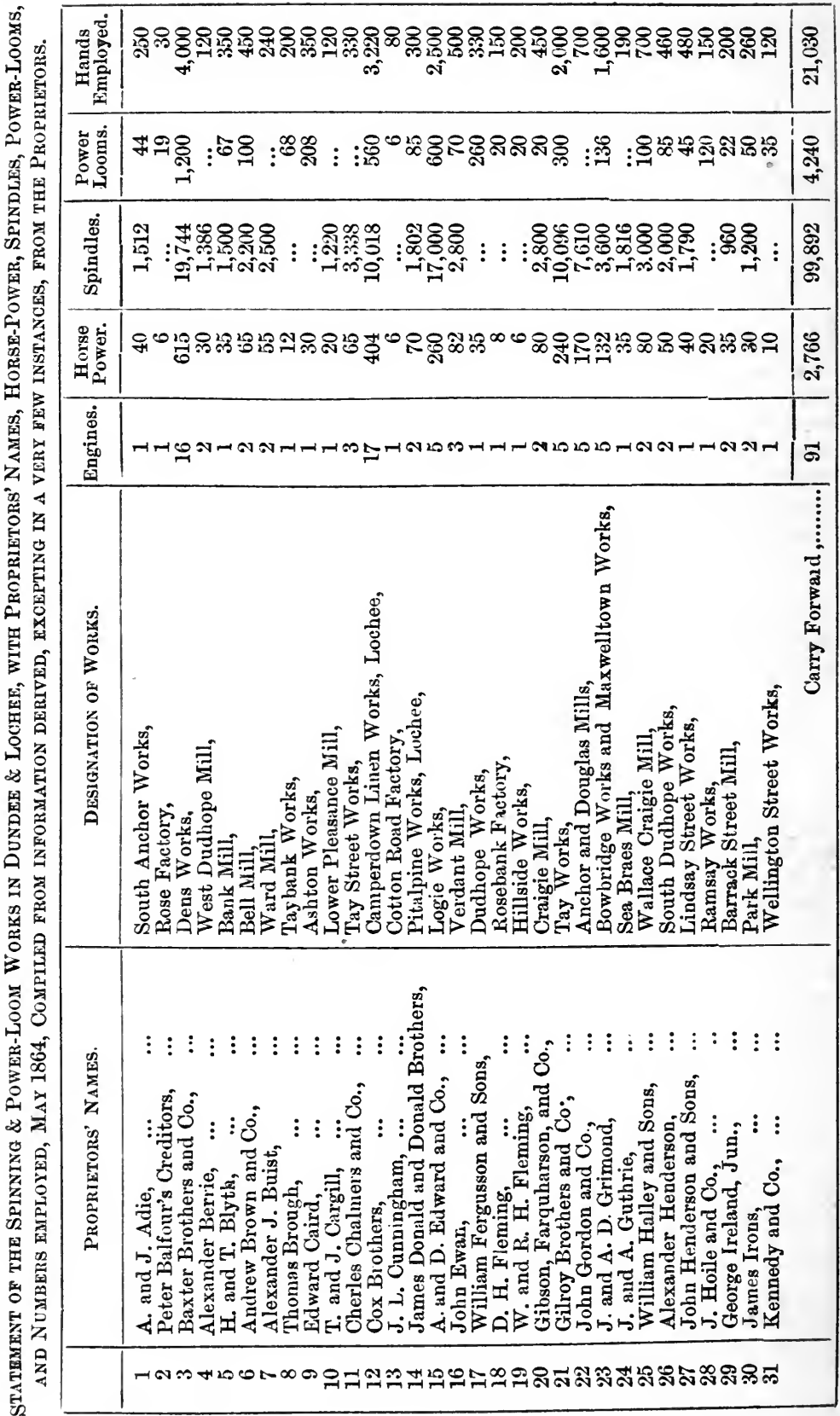




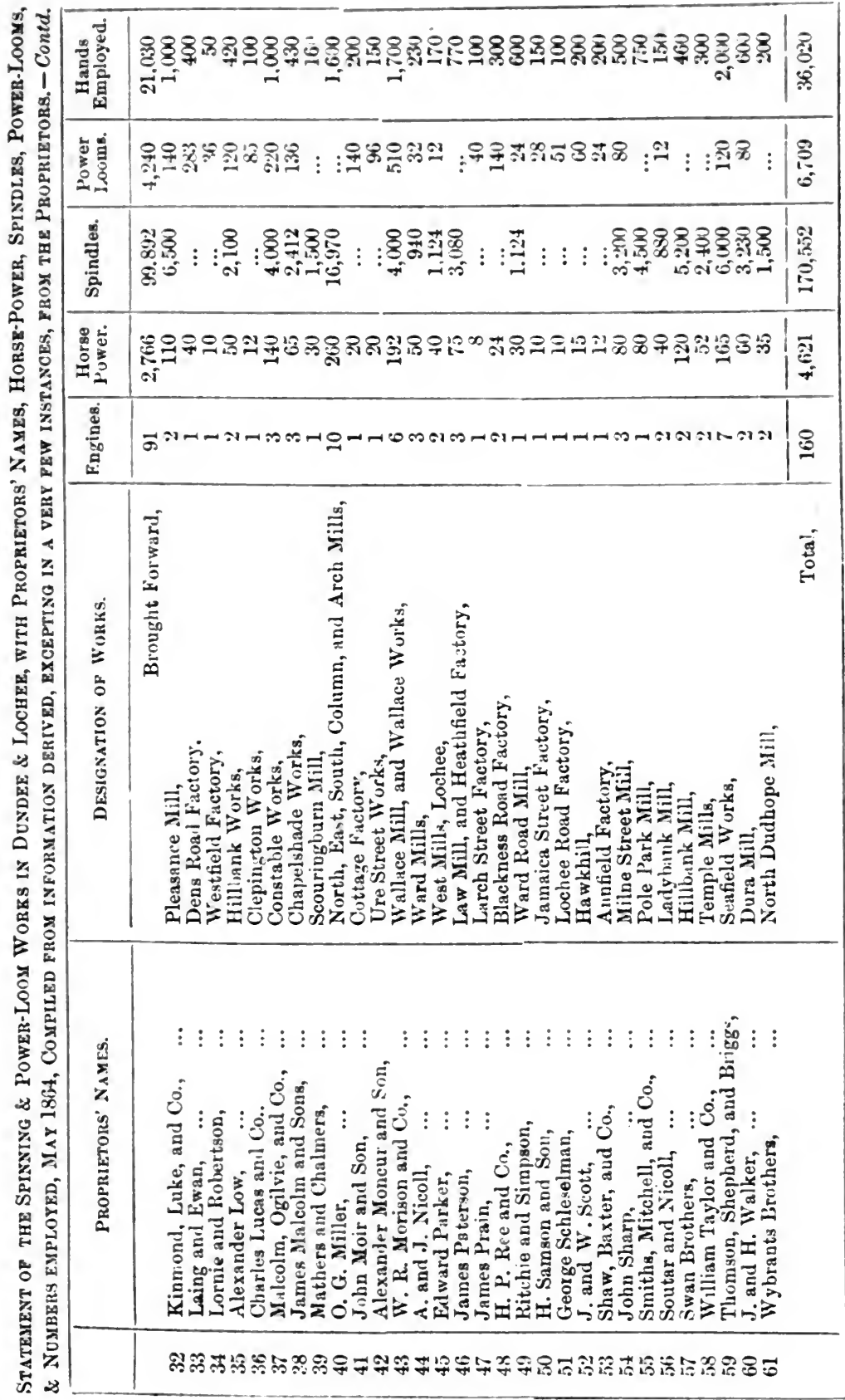




\section{CHAPTER IV.}

\section{U N I T E D K I N G D O M.}

$I_{T}$ is of high importance for those engaged in any branch of trade or manufacture to be furnished with reliable statistical information regarding the recent progress and present extent and condition of the same. It is to be regretted that no details are made up periodically of the regular production of any of the great staples of the country. This might be done by Government at no great cost, and its value not only to the individual trade, but to the nation at large, would be inestimable.

No means exist for ascertaining, with any degree of accuracy, the quantity of Linen manufactured yearly, either in England, Ireland, or Scotland. The only details made up by Government, bearing on the subject, are the importation into the Uuited Kingdom of the raw material, \&c., and the exportation of yarn and Linen, \&c., to foreign countries. These, so far as they go, are highly interesting, and their value is seen in the avidity with which the periodical returns are examined, as they are issued by the Board of Trade. These tables give no information regarding the consumption of Linens in the United Kingdom, of the real extent of which, and whether on the increase or decrease, little is absolutely known. Estimates of the production in the different localities may be formed, but at best they are only a guess, and as likely to be wide of the truth as near it; and any assumption of the yards, or value of the Linen made in the United Kingdom must be vague, and cannot be relied upon. Some details of the quantities of Flax, Hemp, Jute, \&c., imported into the United Kingdom have been given in the section on fibres.

The following is the importation into Great Britain of the articles mentioned for the years specified :-

$\begin{array}{lrrrr} & \text { Flax. } & \text { Hemp. } & \text { Linen Yarn. } \\ 1788 & \text { Tons, 12,997 } & \text { Tons, 18,455 } & \text { Tons, 4,188 } \\ 1799 & \text { "6,490 } & \text { " } 22,681 & \text { " } 4,203 \\ 1799 & \text { " } 19,269 & \text { " 31,335 } & \text { ", } 420\end{array}$


Qcantity and Valug or Flax and Hemp, and the phoducz thekeo, Im.

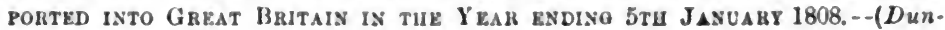
dee Advertiser, 17th Juno 1808.)

FiaX AND ITS Products.

Flax,

Canvas,

Drillings,

German Plain Linen,

Russian do. do.

Cambric

Damask and Viaper, Tabling and Napkining, Yards, 49800

Irish Plain Linen,

Holland, Flanders, and Frevch Linen,

Silesia Lawns

Thread, viz. sisters, wheeled, brown, and Bruges, Lbs., 6,261

Yarn, viz. Linen raw, total value of.

Total ralue of Flax and the produce thereof,

HeMP AND its Products.

Hemp

Tow,

Cordage,

Sailcloth,

Sails,

Tutal value of Hemp and the produce therenf,

Total Flax,

Total Hemp.

Grand Total,
Quantities.

Cwts. 420,769217

" 8,98013

Cwts. 621119

,. $23,187 \quad 0 \quad 12$

, $\quad 32,59030$

Pieces, 18,729

, $40,870,283$

Ells, 143,622

Pieces, 12,511

(n....

\section{$£ 5.719,693 \quad 8 \quad 0$}

Value.

$£ 1,891,076 \quad 4 \quad 4$

$19,445 \quad 7 \quad 10$

9,600136

$4,012 \quad 8 \quad 0$

$27,953 \quad 4 \quad 1$

The value of the articles enumerated imported into Great Britain from foreign countries in 1814 and 1815, was-

1814

Flax, rough, $\ldots \quad \ldots \quad \ldots \quad \ldots 949,981$

Hemp, do. $\quad . . \quad \ldots \quad \quad \ldots \quad 463,573$

Livens, $\quad \ldots \quad \ldots \quad \ldots \quad \ldots \quad 216,649$

Limen Yarns, raw, $\quad \ldots \quad \ldots . \quad 272,502$

$$
£ 1,902,705
$$

1815

$£ 633,040$

621,822

136,933

250,757

The value of the exports of British and Irish Linen manufactures for same years, was-

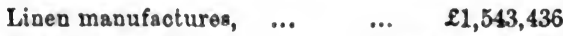

$£ 1,618,575$

Linen Yarn do. ... None enumerated. T T 2 
The value of foreign goods re-exported from Britain in same years was as follows:-

\begin{tabular}{llllrr} 
& & & & 1814 & \multicolumn{1}{c}{1815} \\
Flax, rough, & $\ldots$ & $\ldots$ & $\ldots$ & $£ 96,280$ & $£ 40,032$ \\
Hemp, do., & $\ldots$ & $\ldots$ & $\ldots$ & 40,752 & \\
Linens, & $\ldots$ & $\ldots$ & $\ldots$ & 177,342 & 103,501 \\
& & & & & \\
& & & & $£ 314,374$ & \\
Total value of Linen Exports, & $\ldots$ & $£ 1,857,810$ & $£ 1,804,191$
\end{tabular}

The revenue paid to Government on the importation into England and Scotland of the goors enumerated. for the year ending 5th January 1816, was-

England.

$$
\begin{array}{lllrrrr}
\text { Flax, } & \ldots & \ldots & £ 4,168 & 14 & 1 \\
\text { Hemp, } & \ldots & & \ldots & 274,677 & 5 & 3 \\
\text { Linens, } & \ldots & & \ldots & 77,336 & 8 & 1 \\
& & & & & & \\
& & & & & &
\end{array}
$$

A statement of the Flax, Hemp, and Jute imported yearly

\begin{tabular}{|c|c|c|c|c|c|}
\hline & From & Tons. & Total Tons. & Computed Value. & Total Value \\
\hline Flax, \&c., & $\begin{array}{l}\text { Kussia, } \\
\text { Other Countries, }\end{array}$ & $\begin{array}{l}61,728 \\
28,190\end{array}$ & $\ldots \ldots$ & $\begin{array}{r}£ 3,381,818 \\
1,824,174\end{array}$ & ........ \\
\hline Hemp, \&c., & $\begin{array}{l}\text { Russia, } \\
\text { Other Countries, }\end{array}$ & $\begin{array}{l}30,450 \\
18,638\end{array}$ & $\begin{array}{l}\ldots \ldots . . \\
\ldots \ldots . . \\
49,088\end{array}$ & $\begin{array}{r}£ 1,114,548 \\
590,326 \\
\end{array}$ & $\begin{array}{l}\ldots \ldots \\
\ldots \ldots \\
1,704,874\end{array}$ \\
\hline Jute, \&c., & $\begin{array}{l}\text { India, } \\
\text { Other Countries, }\end{array}$ & $\begin{array}{r}47,067 \\
1,122 \\
\end{array}$ & $\begin{array}{l}\ldots \ldots . \\
\ldots \ldots . . \\
48,189\end{array}$ & $\begin{array}{r}£ 906,834 \\
23,800 \\
\end{array}$ & $\begin{array}{l}\ldots \ldots . . \\
\cdots \ldots . \\
930,634\end{array}$ \\
\hline \multirow{2}{*}{\multicolumn{2}{|c|}{ Other Vegetable Materials, }} & ....... & 128 & ...... & 4,610 \\
\hline & & Tons, & 187,323 & & $£ 7,846,110$ \\
\hline
\end{tabular}
during the century, up to 1862 , is given in page 111. In that year the details of the Importation of Flax, Tow, \&c., was as follows :-

The rate at which Jute is calculated is $19 \mathrm{~s} 4 \mathrm{~d}$ per cwt.

The importation in 1863 included 72,948 tons of Flax, \&c. 51,908 of Hemp, \&c., and 62,939 of Jute, \&c.- total, 187,495 tons; and for the first four months of 1864 it was-Flax, \&c., 
22,396 tons, Hemp, \&c., 7,857, Jute, \&c., 31,208. 'l'otal, 61,461 tons, against 29,129 tons in same period in 1863 .

An account of the Linen yarn and Linens exported from the kingdom for several years has been extracted from the "Blue Books" published periodically by the Board of 'Trade, showing the yards and value shipped to each country. In the monthly and yearly abstracts of the Exports which are published, only some of the countries taling large quantities of these arti cles are enumerated, the balance being put down to "ot?er countries." This head has been sub-divided as far as can be done from the Blue Books, but, owing to the way in which they are made up, it is impossible to give the precise ralue sent to several of the countries of the world. These Tables shew the relative importance of each country as customers of the Linen manufacturers of the kingdom. 'The abstract only is given for 1863, and the first four months of 1864, as the full details are not yet published.

Sir F. M. Eden estimated the entire value of the Linen manufacture in 1800 at $£ 2,000,000$. The annual value of the Linen manufacture of Great Britain, and the number of people employed in the trade, chiefly founded on official returns published in 1806 , was-

Manufactures of Flax, value $£ 3,000,000$

Do.

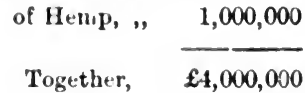

People employed, 95,000

Do.

35,000

Tot.1, 130,000

Bcing about six per cent. of the total manufactures of the country, and seven and one-hilf per cent. of the total people then employed in them. In 1843 the value of the Linen manufacture was estimated at $£ 10,000,000$. Setting aside one-third for raw material, and another third for profits, wages of superintendence, tear and wear of buildings and machinery, coals, \&c. it leaves the remaining third, or three and one-third millions, to be divided as wagres. Supposing each individual to earn on an average $\mathfrak{1} 18$ per annum, the total number employed would be 150,000 .

A few years ago it was estimated that the entire value of the Jinen manufactures of the United Kingdom was upwards of $£ 12,000,000$, of which about onc-halt' wis exported. 'The quau- 
tity exported in 1863 was, Linen yarn, $£ 2,535,728$, Linen, $£ 5,921,308$; together, $£ 8,457,036$. If the quantity exported be about half the quantity made, this would show the total value of the Linen manufactures for 1863 to be about $£ 17,000,000$ sterling. The value of the Flax and Jute imported, of the Hemp imported which is used in the Linen manufacture, and of the Flax grown in Ireland and other divisions of the Kingdom, in 1863, will not be over-stated at

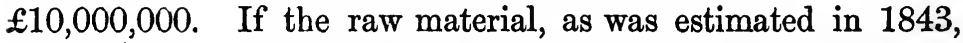
forms only one-third part of the value of the Linen manufactures of the country, this would make their total value in 1863 $£ 30,000,000$. This, however, is probably greatly beyond the real value, and a medium amount between the sums, as estimated by these two modes, or, say $£ 25,000,000$, may approximate to the true value. In any event, the Linen Manufacture forms one of the most important branches of the trade of the cointry. Its extension has of late years been marvellously rapid, and its elasticity is commensurate with its importance.

According to the Report of the Inspector of Factories, the num. ber of power-looms employed on Flax manufactures in 1835 were as follows:-In England 41 looms, Ireland 100, and Scotland 168, being a total of 309 looms. In 1850 the number had increased to 3,670 ; and in $186 \%$, as shewn by the Return made up by the Inspector of Factories, and given in to the House of Commons in 1862, the numbers had increased to 15,347. According to the same return the spindles employed in the Flax manufacture were 1,252,236.

The number of persons employed in the spinning-mills and power-loom factories engaged in the Linen trade in the different portions of the kingdom in 1839 and 1862 were as follows :-

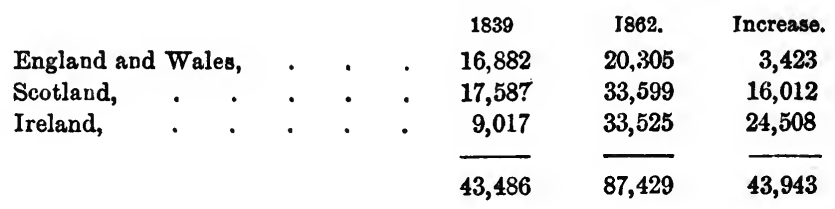

The distribution of the spindles, power-looms, and operatives employed in the several countries, forming the three grand divisions of the Kingdom, will be seen by reference to the Returns. 
THE very limited extent, and the purely domestic character of the Lineu manufacture in Scotland in the beginning of last century, may be learned by considering the condition of the country at that date. The turbulent character of the people, the imperious and avaricious spirit of the nobles and fendal superiors, and the despotic sway of the King, all tended to make property insecure, and to stifle, if not to extinguish, manufacturing industry. After the union of Scotland and England, a more peaceful day dawned upon the former country. The Government, anxious to conciliate the inhabitants and elevate their social position, sought to do so by extending the manufactures of the country. The Linen Trade was peculiarly a national one in Scotland, with the germs of prosperity already in it, and it was supposed that it only required to be fostered and encouraged to make it really beneficial to the country at large. The sagacity and wisdom of such an idea is undeniable, however much the mode adopted to carry it into practice may be questioned.

With the view of working out so desirable an object, laws were from time to time passed for the encouragement of the trade. 'The first of the Linen Acts, passed in 1727, was, after trial, found not to be sufficient to answer the purpose intended, and it was thought that the trade of the Kingdom might be stimulated, and perhaps rendered permanently progressive, by granting a bounty on the Linens exported to foreign countries. An Act having this object was accordingly passed in 1742 , and the payment of a bounty on Linen exports from Great Britain was continued, with some interruptions, until it finally ceased in 1832 .

In the early part of last century there was little energy in the country, especially among those engaged in its trade, manufactures, or commerce, and it was supposed that without Gorernment support no progress could be made. The spirit of self- 
reliance was then little understood, and seldom acted upon, and without adventitious aid manufactures would perhaps have remained stationary, or even retrograded. If pecuniary assistance from Government to aid in the establishment of any trade be defensible, it is so in this instance, because, at such a dormant period, it may be doubted if the trade would otherwise have taken root and made progress. It is certain that, without the patronising and subsidizing hand of Government, the progress of the Linen trade would, at best, have been very slow. To many, therefore, the encouragement so afforded seems right and proper, as the end, they say, in such a case, justifies the means.

The principle of bounties cannot, however, be defended, as it is unfair to tax the nation at large for the benefit of a section of it; or rather to supply the foreign customer with goods below prime cost. This is virtually what the payment of all bounties on the exportation of home manufactures shipped foreign really do, and the case of Linen has no special peculiarity in its favour. The best aid the Government can give to any manufacture is to repeal all import duties on the raw material, and let it reach the manufacturer at the lowest possible rate; to remove restrictions of every kind from all the processes of the manufacture; and to permit the exportation of the manufactured article free of duty and other national imposts. If the mode of manufacture, in all its operations, be left to the ingenuity, energy, and cupidity of the manufacturer, these will be sufficient to stimulate his exertions without public aid. The fears which were expressed by many that the withdrawal of a bounty on the exportation of Linen would ruin the Linen manufacture of the country have, happily, not been realized. Bounties are now a thing of the past, but the Linen trade still lives, and at the present time it flourishes more vigorously than ever it did before. Experience has proved that this manufacture, in common with all others, prospers best when left to the superior skill, enterprise and industry of those engaged in it, and the history of all businesses, carried on in this country by the aid of bounties, proves that they are neither advantageous to those engaged in them, nor to the nation.

In 1742 an Act of Parliament was passed (15 and 16 Geo. 
II., c. 29), laying an additional duty on foreign cambric of $1 \mathrm{~s} 5 \mathrm{~d}$ for every half-pice, and $2 \& 10 \mathrm{~d}$ for every whole piece imported; and for allowing thereout a bounty of $\frac{1}{2} d$ per yard on British and Irish Linen under the value of $6 \mathrm{~d}$ per yard, and 1d per yard on those of the value of $6 \mathrm{~d}$ and not exceeding 1s per yard, which should be exported to Africa, America, Spain, and Portugal.

A statute was passed in 1745 , to prevent frauds from being committed in counterfeiting the stamps put on British and Irish Linen, in order to receive the bounty allowed on their exportation, and for effectually preventing the exportation of foreign Linen under the denomination of British or Irish.

Same year another Act was passed, increasing the bounties on exportation of British and Irish Linen to the colonies or foreign countries. The new rates, payable at the Customhouses on duly certified invoices, were as follows:-

Linen of value under $5 d$ per yard a bunnty of $\frac{1}{2} d$ per yard,

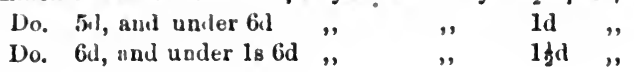

With sundry regulations for preventing frauds.

In 1749 an Act was passed continuing the bounty on lowpriced Iinen for three years longer. On 6th April 1754 the bounties ceased. In 1756 they were renewed. From the accounts laid before Parliament when the renewal of the bounty was under consideration, it appears that the

Yards. Yards.

Aunual consumption of Linen in Great Britain and the oolonies at

$\begin{array}{lllllll}\text { that period was } & \ldots & \ldots & \ldots & \ldots & \ldots\end{array}$

Of which imported from abroal, $\quad \ldots \quad \ldots \quad \ldots \quad 32,230,767$

But re-exported to foreign countries, $\quad \ldots \quad 2,230,767$

$80,000,000$

$30,000,000$

Inported from Ireland, $\quad \ldots . \quad \ldots \quad \ldots \quad \ldots \quad 12,230,767$

Mantifactured in Scotland, $\quad \ldots \quad \ldots \quad \ldots \quad \ldots \quad 12,000,000$

Manufactured in England, $\ldots \quad \ldots \quad \ldots \quad \ldots \quad 25,769,233$

$80,000,000$

In 1770 a new Act was passed, regulating the bounties on Linen exported. 
Total QUantity of British and Irish Linens Exported in the Years npecified from 1743, when Bounties began, up to 1773 ; with Bounty paid on same.

\begin{tabular}{lrrrrr} 
& $\begin{array}{c}\text { British. } \\
\text { Yds. }\end{array}$ & \multicolumn{1}{c}{$\begin{array}{c}\text { Irish. } \\
\text { Yds. }\end{array}$} & \multicolumn{2}{c}{ Bounty paid. } \\
1743 & 52,779 & 40,907 & & & \\
$1745^{*}$ & 56,240 & 101,928 & 7383 & 10 & 8 \\
1746 & 175,928 & 695,002 & 747 & 17 & 6 \\
1750 & 588,874 & 742,032 & 4,188 & 10 & 9 \\
1754 & $1,382,796$ & 843,973 & 8,308 & 16 & 8 \\
1760 & $1,413,602$ & $2,352,585$ & 13,905 & 7 & 11 \\
1765 & $2,095.933$ & $1,663,670$ & 23,538 & 13 & 1 \\
$1770 \dagger$ & $3,216,506$ & $2,707,482$ & 23,497 & 10 & 4 \\
$1771^{+}$ & $4,411,040$ & $3,450,224$ & 36,972 & 18 & 4 \\
1773 & $3,279,808$ & $2,832,246$ & 44,738 & 8 & 10
\end{tabular}

In 1778 the bounties determined, but were renewed. For a long time subsequent to this date the bounty on Linen exported, both British and Irish, continued to be paid, without much complaint from the nation, but early in this century the injustice of such payments began to be animadverted upon, and their continuance condemned. This condemnation sealed their doom, and they were at last, but not without much opposition, withdrawn in Scotland, as the following notes taken from the minutes of the Board of Trustees shew :-

15th June, 1819.-The Chamber of Commerce, Dundee, petitioned the Privy Council that the bounty on exportation of sail-cloth be continued, even although it was said, "it is and has long been the practice to make the cloth not in conformity with law, i.e., without the triple threads directed (by the Act 9, Geo. II., cap. 37) to be put at the distance of every two feet in each bolt of the first four numbers." A copy of the petition was sent to the Board of Trustees, asking their support. Board agree to recommend petition to their Lordships.

11th January, 1820.-Letter from Chamber of Commerce, Dundee, to the Board of Trustees, asking their support of a bill which Mr Maberly proposes introducing into House of Commons for renewing bounty on the exportation of Linens.

8th February, 1820.-Petition by manufacturers and others in Aberdeen, praying the Board to lend their aid to have the

- This year Bounty extended to all Linens from $5 d$ to $186 d$ per yard. The rates are given in page 665.

$\uparrow$ The Bounty of $1 \frac{1}{2} d$ now extended to Sheetings and Table Linens, and a new Bounty of $1 \frac{1}{2}$ per yard allowed on British checks and stripes from $7 \mathrm{~d}$ to $1 \mathrm{~s} 6 \mathrm{~d}$ per yard.

I No similar record from Scotland this year, but Gibson's History of Glasgow says that from that port alone there was exported 2,668,000 yards of Scotch, and 731,000 yards of Irish Linens, in 1771. 
bounty on exportation of British and Irish Linen, which expires on 25th March, 1821, renewed. 'The Board are of opinion that if the aforesaid bounty be withdrawn, it would be impossible for the manufacturers in Scotland to compete with the foreign manu-. facturers of the Continent, considering the superior advantages which the latter enjoy in the lightness of taxation, and cheapness both of labour and of the raw material. That, therefore, the continuance of the bounty seems to the Board to be of vital importance to the preservation of the manufacture, and to the many thousand persons employed in its various branches, as well as to the prosperity of the country at large. Resolve, therefore, that the application of the manufacturers be recommended to the particular attention of the Lord Advocate.

Ist March, 1821.-Letter from John Baxter, chairman of the Chamber of Commerce, Dundee, praying the Board to urge continuance of bounties. Board agree to do so, and prepare a letter accordingly to the Board of 'Trade.

A letter to the same effect was sent to the Board by the manufacturers of Kirkcaldy, and the Board resolved to write the Lords of the Treasury, asking renewal of the bounty on Linen. The bounty was again renewed.

In 1823 Government proposed to abolish the bounty on all Linen under $7 \mathrm{~d}$ a yard at once, and all above $7 \mathrm{~d}$ at the rate of 10 per cent. per annum. This would have excluded Osnaburgs, brown sheetings, sackings, \&c., which were under $7 \mathrm{~d}$ a yard. It was represented to Government that, under ordinary circumstances, it was impolitic to direct the national wealth of the country in particular channels by means of bounties and duties, yet great good had resulted from the departure from this sound principle in the manufacture of Linen. A periodical reduction of bounty on all qualities was asked. In 1824, the Chancellor of the Exchequer agreed to make the reduction of these bounties applicable, by a per centage, to every class of Linens.

Great complaints were made at various times about the exporters having taken advantage of Government, by misrepresentations regarding the value of their goods, and in some cases the complaints were not without sufficient cause.

In May, 1824, a letter from Liverpool was laid before a mee:ing of the Forfarshire Chamber of Commerce and Manufactures, 
mentirning that, as reported in a letter received from Scotland; Osnaburgs of Flax tow, 25 inches wide, value only $5 \frac{1}{4} \mathrm{~d}$ a yard, made at Dundee, had been exported from Liverpool, claiming and receiving the bounty of $1 \frac{1}{2} \mathrm{~d}$ a yard, which had been invoiced at only $3 \frac{1}{4} \mathrm{~d}$. The Chamber thought that it reflected great disgrace on some exporters of Dundee Linens, and offered to give all information to the Collectors of Customs at Liverpool, to prevent all such frauds thereafter.

In June 1826, the searchers in the Custom-House of London stopped shipments of large parcels of coarse Linens, on the plea that the exporters put a false value on their goods. Goods valued from $6 \mathrm{~d}$ to $1 \mathrm{~s} 6 \mathrm{~d}$ a yard were entitled to a bounty of $1 \frac{1}{2} \mathrm{~d}$ a yard, and by the usage of the trade the goods in question were entitled to this bounty, but the searcher said that "through the depression of trade, though nominally worth $8 \mathrm{~d}$, yet in the present distress they might be bought for less than $6 \mathrm{~d}$, and so were entitled to a smaller rate of bounty." The exporters took their ground on the usage of the trade, and contended that the searcher was exceeding his authority, and putting difficulties in the way of the trade, uncalled for and unjust.

In a letter from London in August 1826, it was said that Osnaburgs had fallen from $6 \mathrm{~d}$ to $4 \mathrm{~d}$ a yard, which would have reduced the bounty from $1 \mathrm{~d}$ to $\frac{1}{2} \mathrm{~d}$ a yard, less 20 per cent. which had been taken off the bounty; but by making them into No. 10 canvas prior to 5 th July, they were all shipped at $2 \mathrm{~d}$ per ell, free of any deduction. A kind of packsheet called hessians, worth from $4 \frac{1}{2} \mathrm{~d}$ to $4 \frac{3}{4} \mathrm{~d}$ a yard, were also shipped as canvas, and the shippers drew $2 \mathrm{~d}$ an ell of bounty on them also.

The Linen manufacture had, for about eighty years, been propped up by a bounty of from 15 to 20 per cent. on the value of the articles exported, but the time had now come when these were to be abolished. In Ireland, the withdrawal of the bounty began on 5th January 1825, and it finally ceased on 5th January 1830. In Britain they also began to be withdrawn in 1825, but they did not wholly determine till 5th January 1832.

The rates of bounty on Irish Linens exported to foreign parts, from the year 1780 to 5th July 1805, were-

Plain Linen, of the breadth of 25 inches or more, and under

the value of $4_{13}^{8} d$ per yard,

$0_{\frac{6}{3}} d$ per yard. 
Of the value of $4{ }_{13} d$, and under 61 per yaril,

Of the value of 61 , and not exceeding is $6 d$ per yard,

Checked or Striped linen not exceeding is 6ul, and not under $6_{1}^{\circ}$ d per yard,

Diaper, Sheeting, and other Linen upwards of one yard in brealth, and not exceeling ls 6d the square yard in value,

Sail-cloth,
$0 \int_{3}^{2} d$ per yard.

$l_{13}^{B} d, \quad$,

$00^{6} \mathrm{~d} \quad$,

$1_{1}^{8} \mathrm{~d} \quad, \cdot$

$2 d$ per ell.

\section{From 5th July 1805 to 5th January 1825-}

Plain Linen, of the breadth of 25 inches or more, and under the value of $5 \mathrm{~d}$ per yaril,

Of the value of $5 i l$ and unler $b i l$ per yard,

Of the value of $6 \mathrm{~d}$ and not exceeding ls $6 \mathrm{~d}$ per yard,

Checked or Striped linen not exceeding $1 \mathrm{~s} 6 \mathrm{~d}$, and not under $6_{\text {igd }}$ per yard,

Diaper, Sheeting, and other Linen, upwards of one yard in breadth, and not exceeding is $6 \mathrm{~d}$ the square yard in ralue,

Sail-cloth,

Oद̧l per yarl.

ld ,

$1 \underline{\text { lqd }}$,

oţd .

$1 \frac{1}{d}$,"

2d per ell.

From Jan. 5, 1825, to Jan. 5, 1826-9-10ths of the rates inmediately preceding.

$\begin{array}{lllll}", & 1826, & , & 1827-8-10 \text { ths of same. } \\ " & 1527, & , & 1828-7 \cdot 10 \text { ths } & , \\ " & 1828, & , & 1829-6-10 \text { ths } & \text { ", } \\ ", & 1829, & , & 1830-5-10 \text { ths } & \text { ", }\end{array}$

The bounty then ceased entirely.

The bounties paid on British Linen exported prior to 1825 were the same as on Irish from 1805 to 1825 . In 1825, twotenths or 20 per cent. of the amount was withdrawn. Thereafter one-tenth, or 10 per cent. of the amount, ceased on 5th January each year, until 5th January 1832, when the whole remaining bounty was withdrawn, and the adventitious aid which had been afforded to the manufacture for ninety years finally ceased.

The amount of bounty paid on British Linens exported in

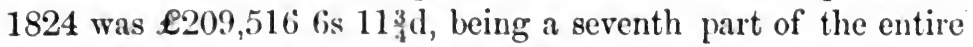
value of the exports, which was $£ 1,309,616$. The bounty on Irish Linen exported same year was $£ 87,54916 \mathrm{~s} 3 \mathbb{3} \mathrm{d}$, being about a tenth part of the value of the exports, which amounted to $£ 918,385$. 'This is one of the most glaring instances of the system of bounties, and it was surely high time that so costly a mode of upholding any manufacture came to a close. 
By 1828 the amount paid in bounties on Linens exported was much reduced, as will be seen from the following statement of the imports and exports for the year ending 5th January 1829 :-

I M P O R T S.

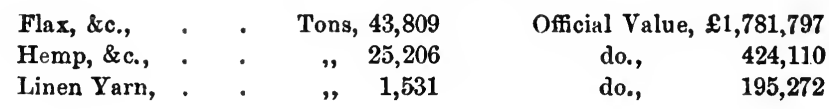

E X P O R T S .

\begin{tabular}{|c|c|c|}
\hline Total Quantity, & Yards, 48,258,333 & Yards, $12,029,481$ \\
\hline Official Value, & $£ 2,457,815$ & $£ 648,047$ \\
\hline Declared Value, & $2,456,385$ & 663,891 \\
\hline Bounty Paid upon & Yards, $46,235,012$ & 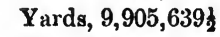 \\
\hline Ainount of Bounty, & $£ 166,0387 \mathrm{~s} 9 \mathrm{~d}$ & $£ 36,69617 \mathrm{~s} 8 \frac{1}{2}$ \\
\hline
\end{tabular}

Simultaneously with the abolition of the bounties, Government began the reduction of duties on Linens imported, and they were extinguished nearly at the same time.

On 27th July 1832, Lord Althorpe said the abolition of the Linen bounties was a saving to the country of $£ 100,000$ a year.

\section{F A C T O R Y L A W S.}

THE introduction of what is called the Factory system effected a vast change in the social condition and position of many of the operatives employed in mills and manufactories throughout the country. Before that period the manufacture of textile fabrics of every description continued to be of a domestic nature. The yarn was spun and the cloth weaved in the dwellings of the operatives, or in small rooms adjoining, where at most but a few persons were congregated together for this purpose. Generally these parties had their time very much at their own disposal, and, therefore, Legislative enactments to regulate their hours of labour were altogether unnecessary. 'The factory system drew the women and children from the homes of their fathers, and 
assembled them in large numbers within extensive buildings specially built for the new trade. In them these people were beyond the control of their natural guardians, and under the charge of men whose interest it was to take the greatest profit out of their labour. This, as might naturally be supposed, speedily led to great abuses, and the Act of the first Sir Robert Peel (42, Geo. III., cap. 73, passed 22d June, 1802,) checked some of the evils, but it made no provision against many others. At that period factory labour was little developed, and as the system extended itself, this act was so regularly and systematically evaded, that it became altogether inoperative with respect to its legitimate objects. Indeed so much was this the case that until within a period of about thirty years, it may be said there were no laws in the United Kingdom to regulate the hours of labour of women and children employed in factories.

The next law on the subject, called The Factory Act, was 3 and 4, William IV., cap. 103, passed 29th August, 1833. Until then, notwithstanding the Act of 1802 , the hours of labour in factories were left to the private arrangement of the employer and the employed, and the latter, being the weaker power, had frequently to submit to extremely long hours. The working hours in the various factories were not then uniform, nor were regular hours kept from day to day at many of the works, some of them being worked beyond the stated hours, until a certain amount of work was performed, and this at the discretion, and not unfrequently according to the caprice, of the employer or his manager. In some country districts the evil became so clamant that the interference of the Legislature was a positive necessity, young people having been continuously employed for 15 or 16 hours a day, with scarcely an interval for meals. In towns the hours, although not so long as in the country mills, were so continuous as to be highly detrimental to health, and they were very irregular, and far from uniform.

Since the passing of the Factory Act, the Factory Amendmeut Act, 4 and 5 William IV., cap. 1 (20th February, 1834), the Factories' Regulation Act, 7 and 8, Vict., cap. 15 (6th June, 1844), the Rope Works Exemption Act, 9 and 10 Vic., cap. 40 (3d August, 1846), the Factory Labour Limitation Act, commonly called the Ten Hours Act, 10 and 11 Vict., cap. 29 (8th 
June, 1847), the Children's Labour Act, 16 and 17 Vict., cap. 104 (20th August, 1853), the Factory Act, 19 and 20 Vict., cap. 38 (30th June, 1856), Bleaching and Dyeing Works Act, 23 and 24 Vict., cap. 78 (6th August, 1860), and other Acts have been passed for the protection of women and children employed in factories, bleaching and dyeing works, calenders, \&c., and for the regulation of the hours of labour in these works.

The law as it presently stands provides that the word "Factory" shall include all prenises within which any mechanical power shall be used to work any machinery employed in any process incidental to the manufacture of cotton, wool, hair, silk, Flax, Hemp, Jute, or tow, either separately or mixed together. That no child under 8 years of age shall be admitted into textile factories; that from 8 to 13 they shall work only $6 \frac{1}{2}$ hours a day, and shall receive educational instruction at prescribed hours, for three hours daily at the least. That no young person under the age of 18 , and no female above the age of 18 , shall be employed in any factory more than 10 hours in any one day, nor more than 60 hours in any one week; nor be employed before six o'clock in the morning, nor after six in the evening, excepting to recover lost time in country mills driven by waterpower, and then not later than seven in the evening. The laws also regulate the meal hours, make provision for the sanitary condition of the works, and compel employers to give at least six holidays in the course of a year.

By these laws provision is also made for the safety of the persons employed in factories, by making it imperative on employers to fence in a sufficient manner all dangerous machinery. Penalties are imposed for all breaches of the Factory Acts, and Inspectors are appointed for the purpose of regularly visiting the works to see that the requirements of the laws are fully complied with.

Enactments have of late years been made for the regulation of the labour of females and young persons in bleaching and dyeing works, but excluding those works where the open-air system of bleaching is practised as is the case in Linen yarn bleachworks. Two years ago an act was passed prohibiting the labour of women and young persons in such works between the hours of eight o'clock evening, and six in the morning, and last 
year calender works employing women, children, and young persons, have been placed under the Factory 1 ct, 26 and 27 Vict., cap. 38 (29th June, 1863).

'There cannot be a doubt that the Factory Iaws have not only prevented many abuses, but they have also been productive of much good to the health and comfort of the operatives employed in Factories, and that without doing serious injury to the millowners. At same time the Legislature ought to interfere as little as possible between master and servant in healthful employments, unless the necessity for such interference be very clearly proved.

\section{TABULAR STATEMENTS.}

Lisey Manufactures, Yarns, axd Flax Exporten froy the Uxitzo KisgDoY FROM 1831 To 1863.

\begin{tabular}{|c|c|c|c|c|c|}
\hline \multirow[t]{3}{*}{ Years } & \multirow{2}{*}{\multicolumn{2}{|c|}{$\begin{array}{l}\text { LINE. MaNUfactirfig. } \\
\text { Entered by the Yaril }\end{array}$}} & \multirow{4}{*}{$\begin{array}{c}\begin{array}{c}\text { Thread, Tapes } \\
\text { and sinall } \\
\text { Wares. }\end{array} \\
\text { Declrd. Value. }\end{array}$} & \multirow{2}{*}{\multicolumn{2}{|c|}{ IINEN YARN. }} \\
\hline & & & & & \\
\hline & Yards. & Declril. Value & & Ills. & Declrd. Value \\
\hline 1831 & $69,283,892$ & $£ 2,400,043$ & & & \\
\hline 1832 & $49,531,0 ; 7$ & $1,716,084$ & 58,643 & 110,188 & $£ 8,705$ \\
\hline 1833 & $63,232,509$ & $2,097,273$ & 69,751 & 935,682 & 72,006 \\
\hline 1834 & $67,8: 34,305$ & $2,357,991$ & 85,355 & $1,533.325$ & $13 i, 312$ \\
\hline 1835 & $77,977,089$ & $2.89: 139$ & 99,004 & $2,611,215$ & 216.635 \\
\hline 1836 & $82,088,760$ & $3,238,031$ & $8 x, 294$ & $4,574,504$ & 318,772 \\
\hline 1837 & $5 \times, 426,3333$ & $2,(063,425$ & 61.020 & $8.373,100$ & 479,307 \\
\hline $18: 38$ & $77,195,894$ & $2,717,979$ & 102.293 & $14,923,329$ & 746,163 \\
\hline 1839 & $85,256,542$ & $3,292,220$ & $1: 2,747$ & $16,314,615$ & 818,485 \\
\hline 1840 & $89,373,431$ & $3,194,827$ & 111,261 & $17,733,575$ & 822,876 \\
\hline 1841 & $90,321,761$ & $3,200,467$ & 147,088 & $25,220,290$ & 972,466 \\
\hline 1842 & $69,232,682$ & $2,217,373$ & 129,376 & $29,490,987$ & $1,025.551$ \\
\hline 1843 & $84,172,585$ & $2,615,566$ & 187,657 & $23,358,3 \div 2$ & 898,829 \\
\hline 1844 & $91,283,754$ & $2,801,609$ & 223,191 & 25970,569 & $1,050,676$ \\
\hline 1845 & $88,401,670$ & $2,830,784$ & 205,586 & $23,238,725$ & $1,060,566$ \\
\hline 1846 & $84,799,369$ & $2,631,804$ & 198,999 & $19,484,20: 3$ & 875,405 \\
\hline 1847 & $89,329,310$ & $2,759,094$ & 199,757 & $12,688,915$ & 649,893 \\
\hline 1848 & $89,002,431$ & $2,597,573$ & 205,216 & $11,722,182$ & 493,449 \\
\hline 1849 & $111,259,183$ & $3,209,639$ & 284,290 & $17,264.033$ & 732,065 \\
\hline 1850 & $122,342,516$ & $3,589,439$ & 358,243 & $18: 20,658$ & 881,312 \\
\hline 1851 & $129.106,753$ & $3,822,935$ & 284,461 & $18,841,326$ & 951,426 \\
\hline 1852 & 143,192627 & $3,872,4 ! 11$ & 359.295 & $23,928,592$ & 1.140 .565 \\
\hline 1853 & $134,165,291$ & $4,34,, 600$ & 412,832 & $22,893,586$ & $1,154,977$ \\
\hline 1854 & $111,648,657$ & $3,780,894$ & 339,149 & $17,696,867$ & 944,502 \\
\hline 1855 & $118,039,721$ & $3,823,691$ & 294,322 & $18,177,484$ & 932,981 \\
\hline $18 \% 6$ & 146.410 .188 & $4,506.110$ & 381,670 & $25,118,349$ & $1,365,950$ \\
\hline 1857 & $133,687.197$ & $4,194,742$ & 322,133 & $28,847,811$ & $1,647,953$ \\
\hline 1858 & $122,561,748$ & $3,802,213$ & 322,143 & $32,047,492$ & $1,746,340$ \\
\hline 1859 & $138,120,498$ & $4,300,026$ & 290, ti72 & $27,290,387$ & $1,674,602$ \\
\hline 1860 & $143,996,773$ & $4,434,8 \pi 8$ & 339,811 & $31.210,612$ & $1,801,272$ \\
\hline 1861 & $116,322,469$ & $3,571,131$ & 269,778 & 27981,042 & $1,622,216$ \\
\hline 1862 & $156.871,020$ & $4,648,270$ & 482,834 & $32,584,676$ & $1,854,866$ \\
\hline 1863 & $180,395,967$ & $5,921,308$ & 526,818 & $38,553,643$ & $2,535,728$ \\
\hline
\end{tabular}




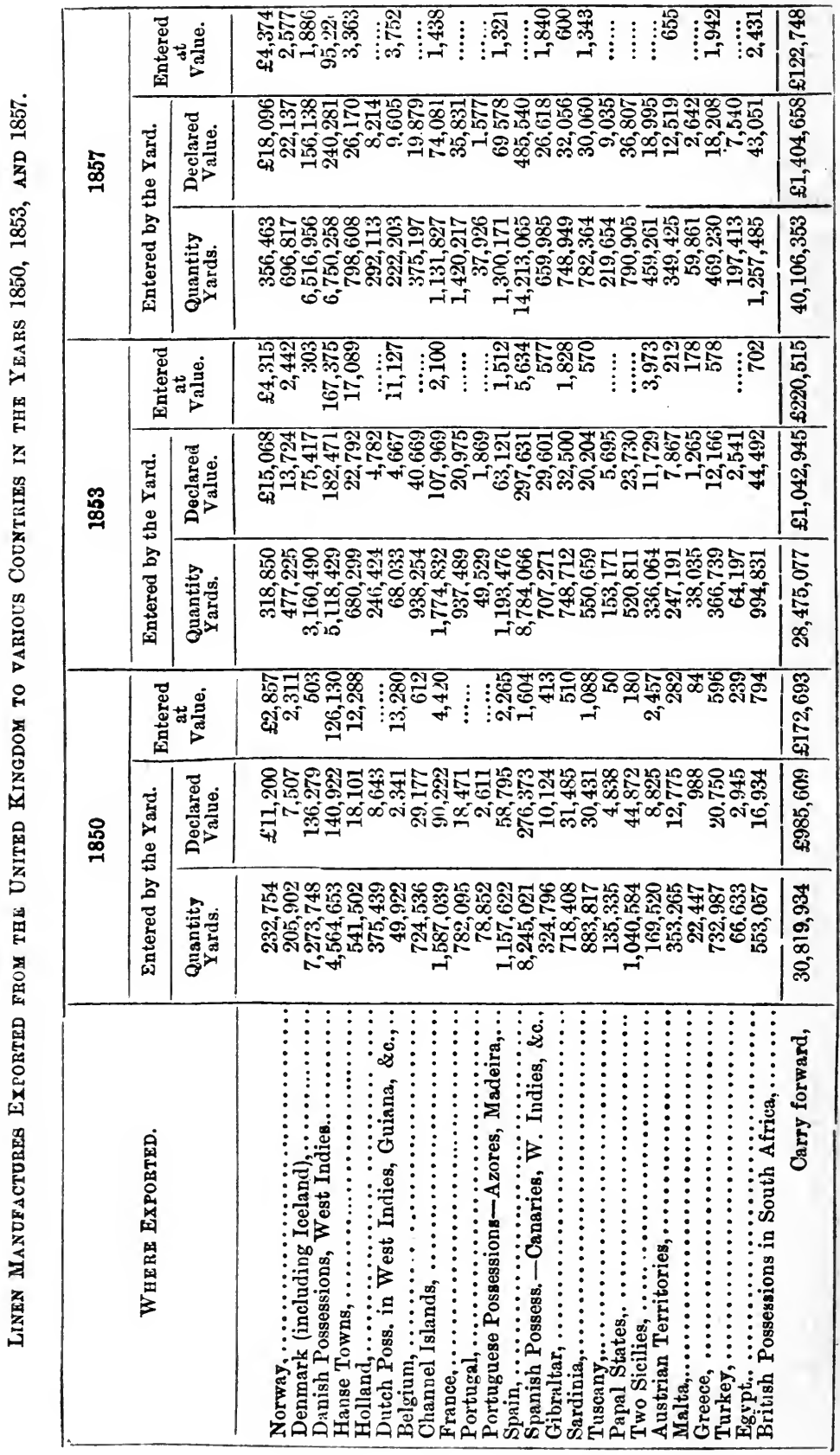




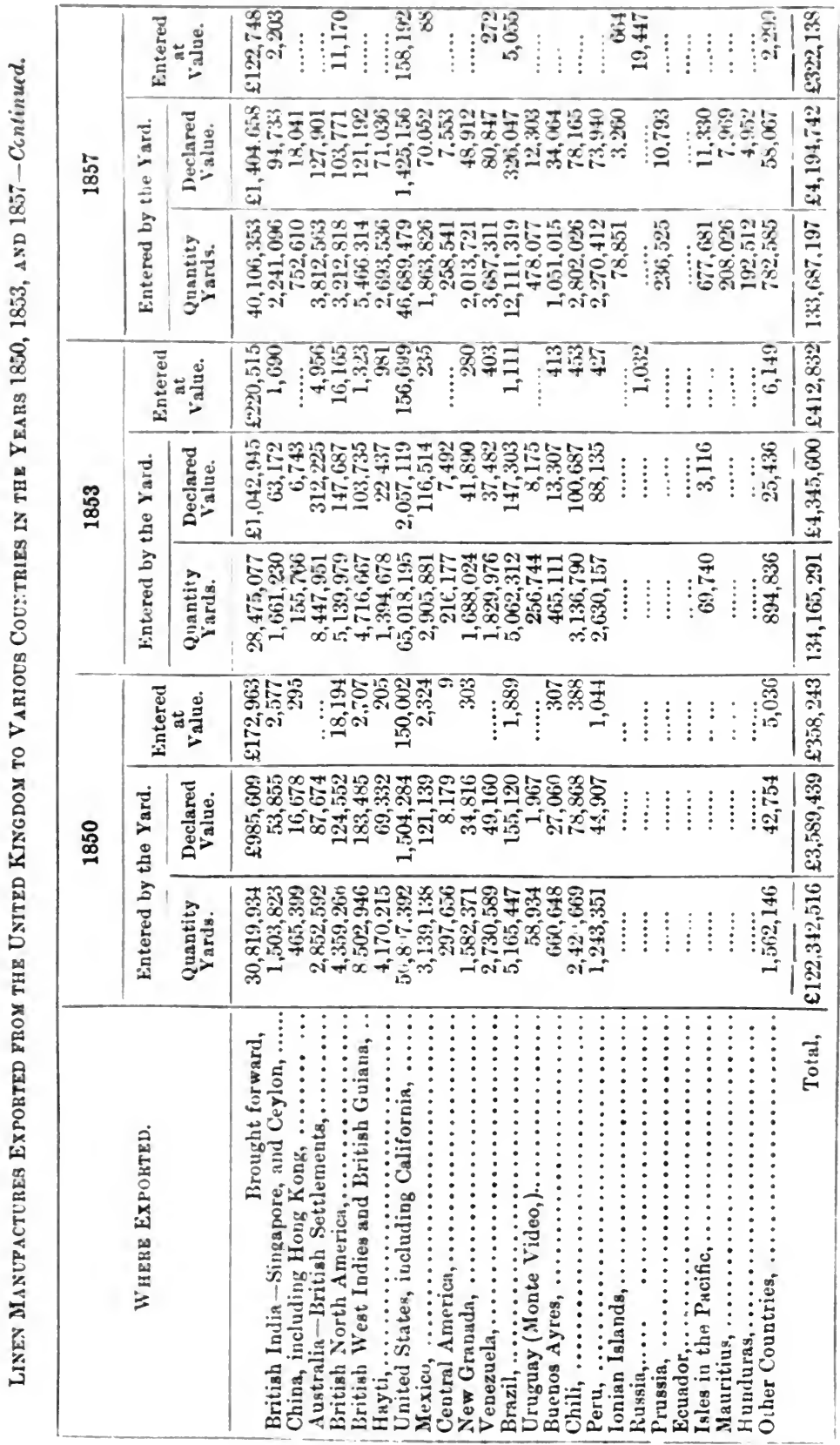

U U2 


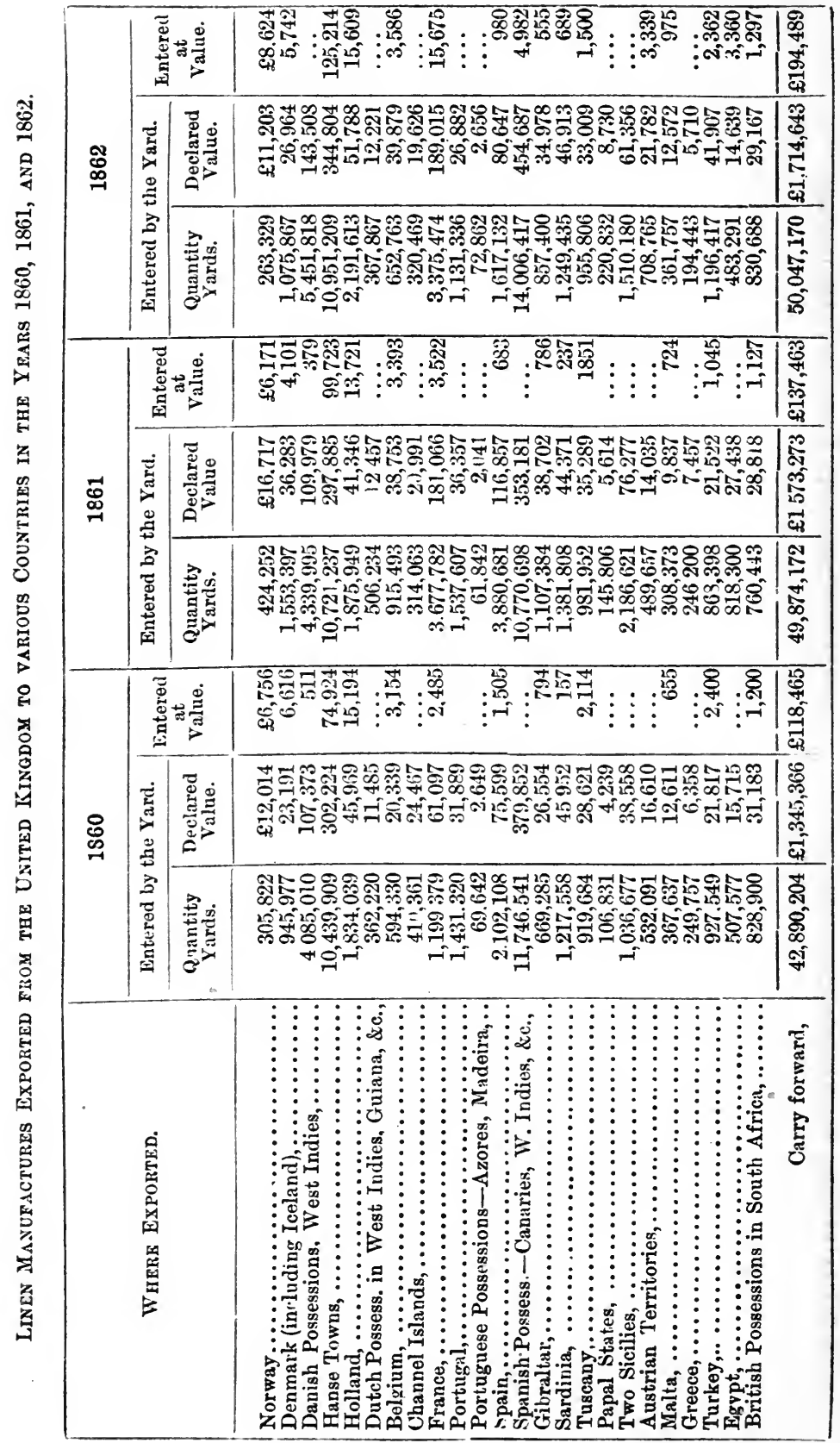




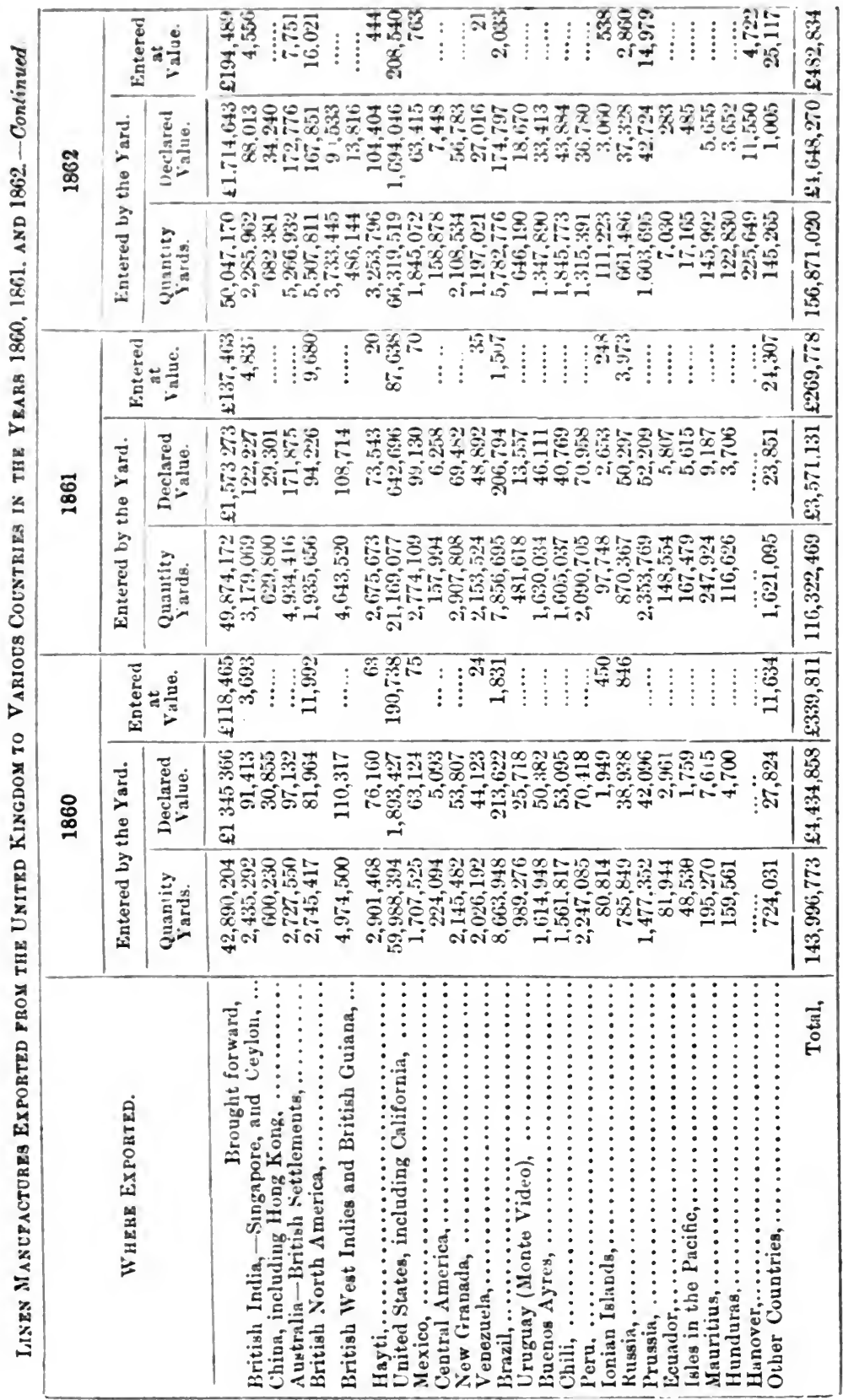




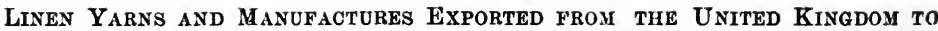
various CoUNTRIES FOR 1863, AND FOR FOUR MONTHS ENDING 30TH APRIL 1863 AND 1864.

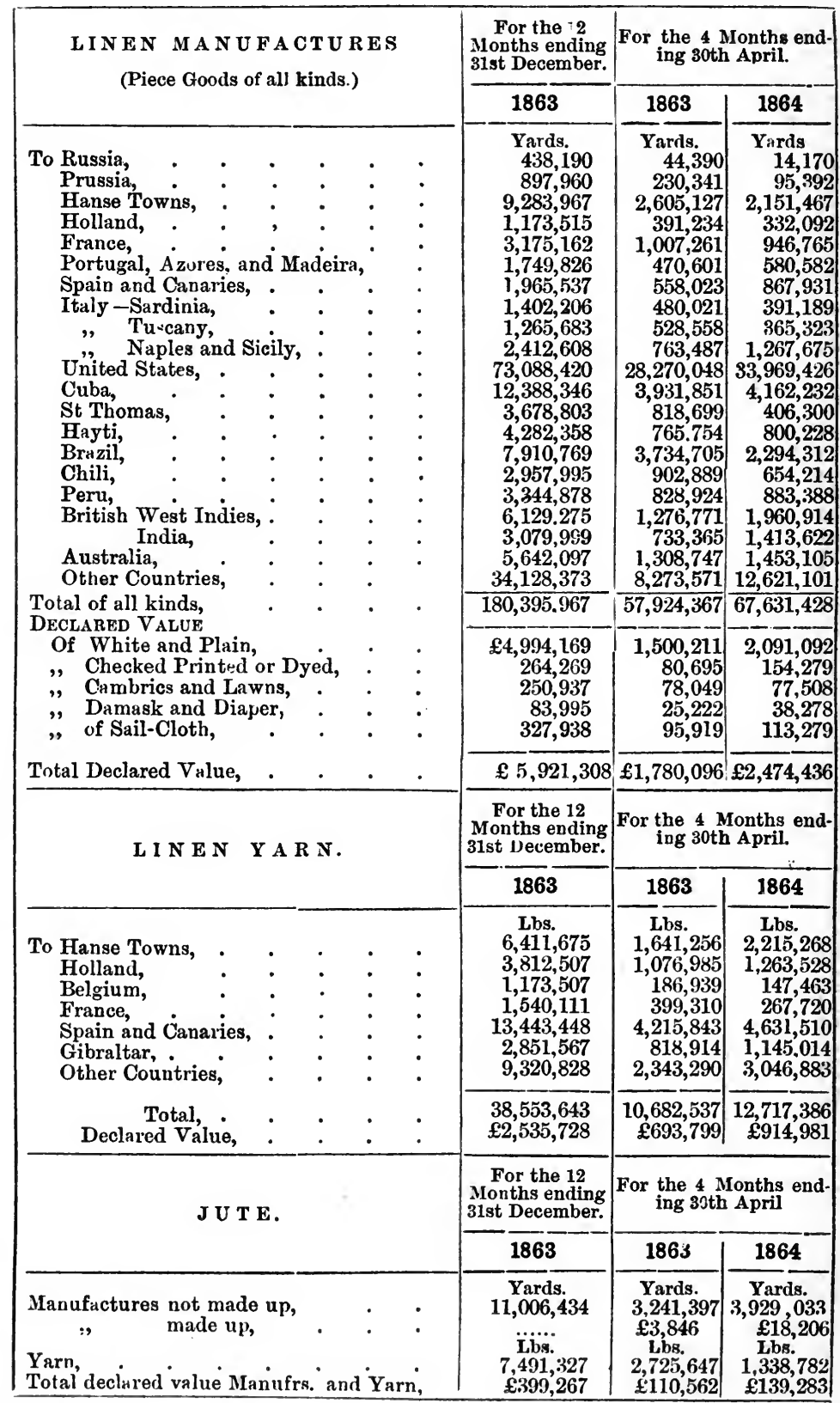


UNITEI) KINGiDOM.

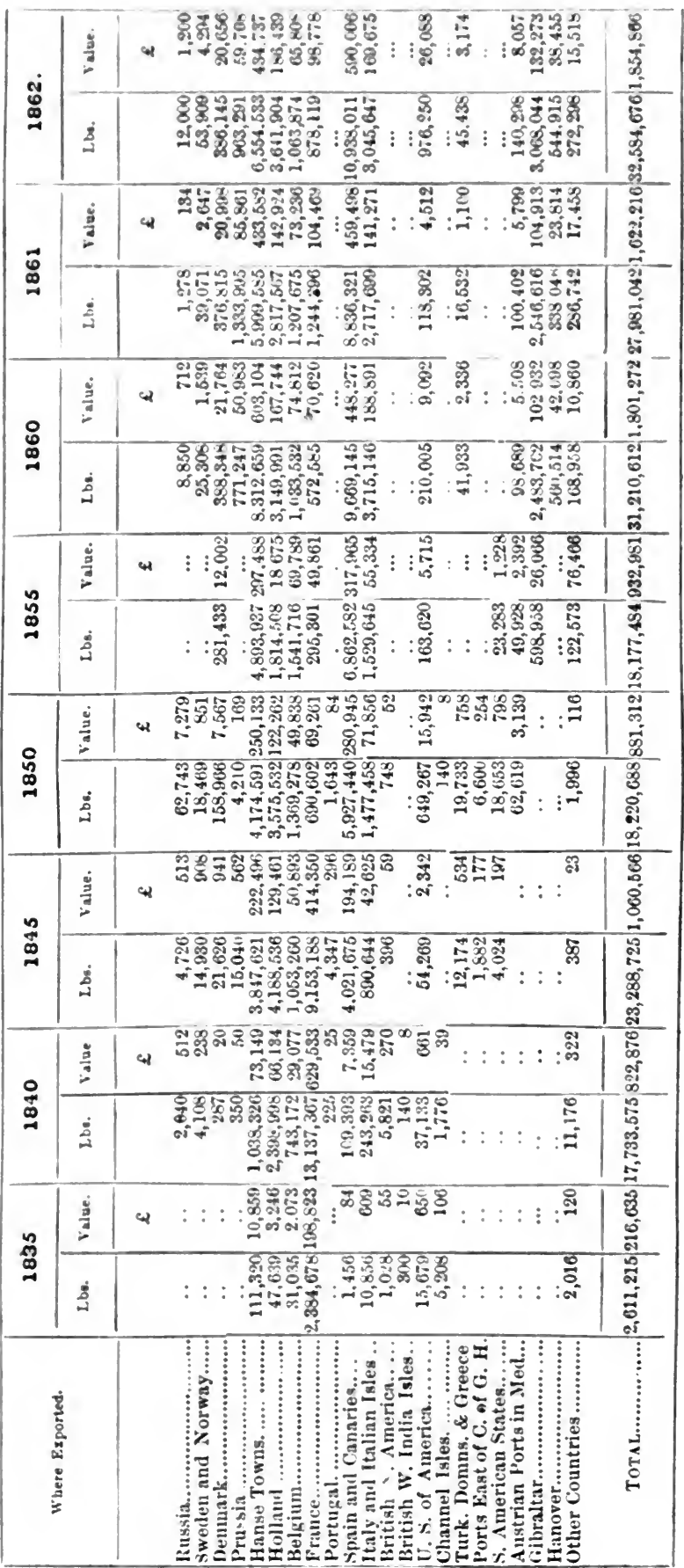


Retury of the Number of Flax, Hemp, aNd JUte Factories, sUbject to the Factory acts, in the tinited Ringdom, presented to the House of Commons, 11tr February 1862.

\section{ENGLAND AND WALES.}

Flax Factories.

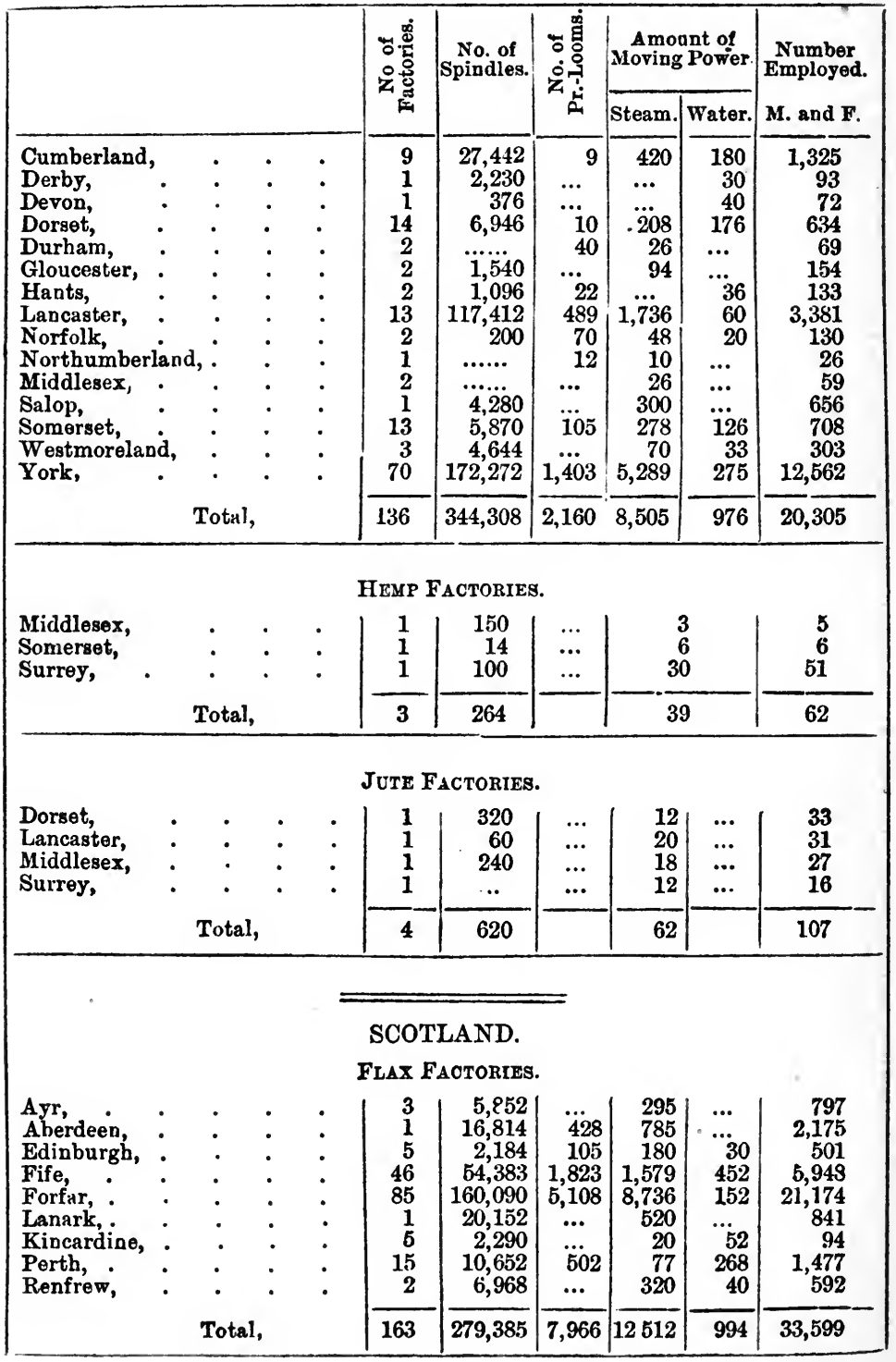


Retirn of Fiax, Hemp, and Jute Factories Continued.

SCOTLAND-Continued.

Hеур FАотоніеs.

\begin{tabular}{|c|c|c|c|c|c|c|c|c|c|}
\hline & & & & & \multirow{2}{*}{ 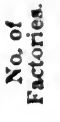 } & \multirow[t]{2}{*}{$\begin{array}{c}\text { No. of } \\
\text { rpindles. }\end{array}$} & \multirow{2}{*}{ 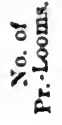 } & $\begin{array}{c}\text { A mount of } \\
\text { Moving Power. }\end{array}$ & \multirow{2}{*}{$\begin{array}{l}\text { Number } \\
\text { Employ } 6 \text {. } \\
\text { M. and F. }\end{array}$} \\
\hline & & & & & & & & Steam. Water. & \\
\hline \multirow[t]{2}{*}{$\begin{array}{l}\text { Ediuburgh, } \\
\text { Lanark, }\end{array}$} & • & - & - & $\dot{\bullet}$ & $\begin{array}{l}1 \\
1\end{array}$ & $\begin{array}{r}2,116 \\
200\end{array}$ & $\cdots$ & $\begin{array}{r}80 \\
8\end{array}$ & $\begin{array}{r}542 \\
3\end{array}$ \\
\hline & & & & & 2 & 2,136 & & 88 & 545 \\
\hline
\end{tabular}

JUTE FACTORIES.

\begin{tabular}{|c|c|c|c|c|c|c|c|c|}
\hline \multirow[t]{2}{*}{$\begin{array}{l}\text { Forfar, } \\
\text { Lanaik, } \\
\text { Renfrew, }\end{array}$} & \multirow{2}{*}{. } & $\dot{0}$ & $\begin{array}{r}24 \\
2 \\
1\end{array}$ & $\begin{array}{r}28,094 \\
1,000 \\
1,444\end{array}$ & $\begin{array}{r}406 \\
48 \\
100\end{array}$ & $\begin{array}{r}1,494 \\
153 \\
90\end{array}$ & $\begin{array}{r}20 \\
\cdots \\
{ }_{4}\end{array}$ & $\begin{array}{r}4,828 \\
216 \\
374\end{array}$ \\
\hline & & & 27 & 30,538 & 554 & 1,737 & 60 & 5,418 \\
\hline
\end{tabular}

IRELAND.

Flax factories.

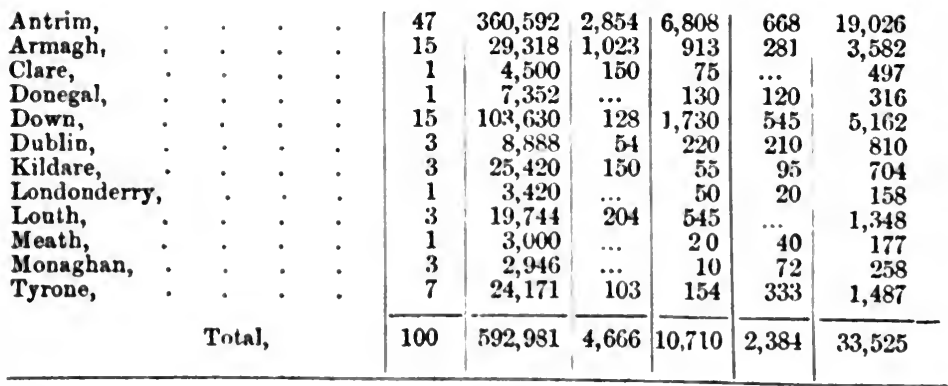

JUTE FAOTORIES.

Antrim, Down,

\begin{tabular}{|c|c|c|c|c|c}
3 & 1,824 & $\cdots$ & 194 & $\cdots$ & 385 \\
2 & $\cdots$ & $\cdots$ & 65 & $\cdots$ & 57 \\
\hline 5 & 1,824 & & 249 & & \\
\hline & & & &
\end{tabular}


Returs of Flax, Hemp, and Jute Factories. - Continued.

SuMMARY OF THESE RETURNS.

Flax factories.

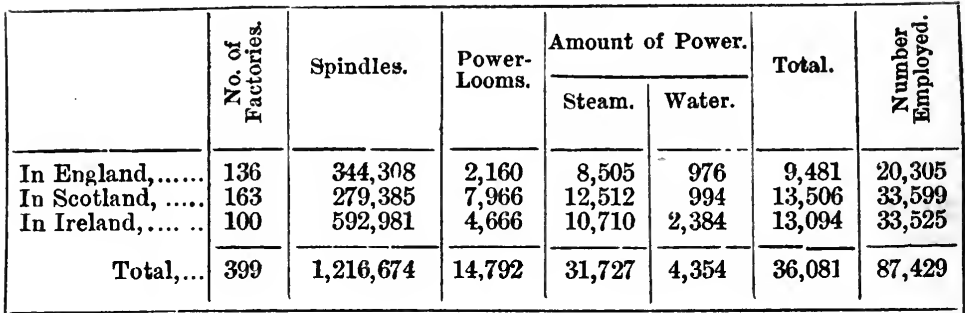

JUTE FACTORIES.

\begin{tabular}{|c|c|c|c|c|c|c|c|}
\hline $\begin{array}{l}\text { In England ....... } \\
\text { In Scotland ...... } \\
\text { In Ireland........ }\end{array}$ & $\begin{array}{r}4 \\
27 \\
5\end{array}$ & $\begin{array}{r}620 \\
30,538 \\
1,824\end{array}$ & $\begin{array}{c}554 \\
\ldots\end{array}$ & $\begin{array}{r}62 \\
1,737 \\
249\end{array}$ & $\begin{array}{l}60 \\
\ldots\end{array}$ & $\begin{array}{r}62 \\
1,797 \\
249\end{array}$ & $\begin{array}{r}107 \\
5,418 \\
442\end{array}$ \\
\hline Total... & 36 & 32,982 & 554 & 2,048 & 60 & 2,108 & 5,967 \\
\hline
\end{tabular}

HeMp Factories.

\begin{tabular}{|c|c|c|c|c|c|c|c|}
\hline $\begin{array}{l}\text { In England....... } \\
\text { In Scotland ...... }\end{array}$ & $\begin{array}{l}\mathbf{3} \\
\mathbf{2}\end{array}$ & $\begin{array}{r}264 \\
2,316\end{array}$ & $\begin{array}{r}1 \\
\ldots\end{array}$ & $\begin{array}{l}39 \\
88\end{array}$ & $\ldots$ & $\begin{array}{l}39 \\
88\end{array}$ & $\begin{array}{r}62 \\
545\end{array}$ \\
\hline Tota & 5 & 2,580 & 1 & 127 & $\ldots$ & 127 & 607 \\
\hline
\end{tabular}

Factories in England.

\begin{tabular}{|c|c|c|c|c|c|c|c|}
\hline 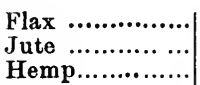 & $\begin{array}{r}136 \\
4 \\
3\end{array}$ & $\begin{array}{r}344,308 \\
620 \\
264\end{array}$ & $\begin{array}{r}2,160 \\
\cdots_{1}\end{array}$ & $\begin{array}{r}8,505 \\
62 \\
39\end{array}$ & $\begin{array}{r}976 \\
\ldots \\
\ldots\end{array}$ & $\begin{array}{r}9,481 \\
62 \\
39\end{array}$ & $\begin{array}{r}20,305 \\
107 \\
62\end{array}$ \\
\hline Tota & 143 & 345,192 & 2,161 & 8,606 & 976 & 82 & \\
\hline
\end{tabular}

Factories in Scotland.

\begin{tabular}{|c|c|c|c|c|c|c|c|}
\hline 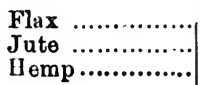 & $\begin{array}{r}163 \\
27 \\
2\end{array}$ & $\begin{array}{r}279,385 \\
30,538 \\
2,316\end{array}$ & $\begin{array}{c}7,966 \\
554 \\
\ldots\end{array}$ & $\begin{array}{r}12,512 \\
1,737 \\
88\end{array}$ & $\begin{array}{r}994 \\
60 \\
\ldots\end{array}$ & $\begin{array}{r}13,506 \\
1,797 \\
88\end{array}$ & $\begin{array}{r}33,599 \\
5,418 \\
545\end{array}$ \\
\hline Total. & 192 & 312,239 & $8, \tilde{0} 20$ & 14,337 & 1,054 & 15,391 & 39,562 \\
\hline
\end{tabular}

\section{Factories in Ireland.}

\begin{tabular}{|c|c|c|c|c|c|c|c|}
\hline 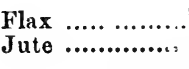 & $\begin{array}{r}100 \\
5\end{array}$ & $\begin{array}{r}592,981 \\
1,824\end{array}$ & $\begin{array}{c}4,666 \\
\ldots\end{array}$ & $\begin{array}{r}10,710 \\
249\end{array}$ & $\begin{array}{c}2,384 \\
\cdots\end{array}$ & $\begin{array}{r}13,094 \\
249\end{array}$ & $\begin{array}{r}33,525 \\
442\end{array}$ \\
\hline Total... & 105 & 594,805 & 4,666 & 10,959 & 2,384 & 11,343 & 33,967 \\
\hline Grand Total... & 440 & $1,252,236$ & 15,347 & 33,902 & 4,414 & 38,316 & 94,003 \\
\hline
\end{tabular}




\section{SEC'TION V. \\ MANUFACTURING OPERATIONS.}

Haring traced the Linen Trade from its origin in ancient times, and shown the important place it holds among the manufactures of the world at the present day, this section will be devoted to an account of the modes by which Flax was and is transformed into Linen. It is foreign to the intention of this volume to make it a hand-book to practical manufacturers; and it is not possible, without drawings, to give non-practical people an intelligible description of complicated mechanical operations. A short popular account of spinning, weaving, and bleaching is therefore all that will be attempted.

\section{CHAPTER I.}

F L A X-S P I N N I N G.

Each fibre of Flax is, on minute examination, found to be made up of a number of small parallel filaments, bound together, the separation of which to a considerable extent is necessary in successful Flax-spinning. 'To effect this to a partial extent, and to separate the tow, it is heckled. In heckling, the operator takes a stripe of Flax in his hand by the one end, throws the other end spread out over the heckle, or many steel-toothed comb, and draws the stripe towards him, repeating the process so long as necessary; after which the other end of the stripe undergoes the same operation. This process removes the coarser fibres of the tow, and partially subdivides the filaments of the Flax. The same operation is then repeated on a finer leckle, the teeth of which are smaller and closer set; and if the fibre of the Flax is required to be very fine, as it must be if intended to be spun into yarn for cambric, lawn, $\mathcal{d c}$, the same process is repeated orer still finer heckles. These operations thoroughly 
remove the tow, and split up the fibre of the Flax into very minute hairs; but where very small yarn is wanted, Flax of a fine, soft, silky fibre must be used, as a coarse strong quality cannot be sufficiently broken down, and yet retain sufficient strength to bear spinning, weaving, \&c. Machine heckling is now practised extensively, and recent improvements have so far perfected the machines that the Flax can be heckled to a medium degree, both cheaply and well. Various machines have from time to time been patented, one of the most recent being that of Combe \& Co., of Belfast, which is well approred by spinners; but although the construction of the machines by different makers varies considerably, the Flax in all, as in hand heckling, is drawn over toothed combs, or else the combs are drawn through the Flax, the object being to produce the largest yield and finest fibre of dressed Flax, and at same time to give the tow thrown off good spinning properties.

After the Flax has been heckled to the desired fineness, the fibres require to be united into a continuous line or thread, before they are adapted for being woven into cloth. In the case of China grass and some other Indian fibres, this is done by gumming the end of one fibre to that of another, and operators by long practice do this with a celerity truly astonishing. Flax is not well adapted for such a process, the fibres being soft, and so short that the joinings would necessarily be too frequent and the threads irregular in size. Such a mode of joining fibres together can never make either a very even, or a very strong thread, and it is never practised excepting with long and strong substances.

From the most remote periods the fibres of Flax have been drawn out and twisted or spun into yarn or thread for the purpose of being made into a woven fabric. The earliest appliance for that purpose of which mention is made in either sacred or profane history is the spindle Drawings of these are still to be seen in the paintings of the tombs at Thebes, and in other places in Egypt, and several of the spindles have been found there, and are now deposited in the various museums of Europe. One found by Sir J. Wilkinson at Thebes, and now in the British Museum, had some of the Linen thread upon it, thus putting its use beyond a doubt. 
'The Egyptian spindles were about fitteen inches in length, generally of wood, with the circular head of gypsum or composition, in order to increase their impetus in turning. Some were of light plaited work, made of rushes or palm leaves, stained of various colours, and furnished with a loop of the same materials, for securing the thread after it was wound. 'They are generally in shape bulbous near the one end, whence they taper to a point on the short end like a boy's top, and lengthen out into a handle at the other. The thread was attached to the handle of the spindle, which was laid on the right thigh, and made to revolve or spin like a top, by drawing the right hand quickly orer it, as it lay on the thigh. The spindle is then allowed to spin in the air, or on its narrow point on the floor, so long as the motion of the hand keeps it revolving, the fibres meanwhile being drawn from the bundle of Flax, in order to form the thread. The re. presentations of this process are beautifully distinct and clear, and render the mode of spinning in Egypt very intellicrible. The distaff, a piece of wood round which the Flax to be spun was lapped, was soon added to the spindle, which made the process easier and more expeditious than by the spindle alone. The distaff was held in the spinner's left hand, while the right was engaged in drawing the fibres from the bundles of Flax, and ever and anon giving fresh impetus to the motion of the spindle. The same system of spinning had been common in Palestine, as it is related in Proverbs, that the virtuous woman layeth her hands to the spindle, and her hands hold the distaff.

For thousands of years this rude mode of spinning was the only one known, and it was practised in every country where the manufacture of Linen was carried on. Until a comparatively recent period, and until the introduction of the spinningwheel, the same plan was in universal use in this country. The following description of the method followed here up to nearly the end of last century, is very little different from the oriental system of three or four thousand years ago, and it shows the little progress which had been made in this useful branch of industry during that long period of time.

The distaff and spindle in use, until superseded by the rock (Dan. rote, distaff) and spinning-wheel, were generally of simple construction. The distaff was a piece of light wood, fifteen to 
twenty inches long, round which the Flax to be spun was wound, leaving a portion of the distaff clear of the Flax. This portion was stuck into the apron-string of the spinner, or into a belt fastened round her waist to receive it. The distaff slanted out from the left side of the spinner, so as to be convenient for drawing the Flax from it in forming the thread. The spindle was a round piece of wood, about a foot in length, thick at the middle, and tapering toward each end, the lower one somewhat like the point of a cone, and the upper longer and less pointed, with a ring or belt of some heavy substance round the middle. A short thread formed of the Flax was fixed in a notch in the upper end of the spindle, and the spindle was then turned smartly by the right hand pressed upon it against the right thigh, and allowed to dangle in the air, hanging by the thread from the distaff. The centrifugal motion thus given to the spindle was kept up for some time by the heavy ring upon it, which acted as a kind of balance-wheel, and kept the circular motion somewhat steady. While this whirling of the spindle was going on, the spinner was busy drawing out the fibres of the Flax from the distaff with the left hand, and forming them into an equal thread with the right. When the spindle reached the ground and stopped, or when the impetus given to it by the hand was lost, care being taken not to let it retrograde, as by that means part of the twist given the thread spun would be lost, the yarn spun was wound upon the upper part of the spindle. The same process was repeated again and again, until the spindle was full, from one to two yards being spun at each movement given the spindle. The yarn was then reeled off into cuts, heers, hesps, and spindles, when it was ready for the market, or for being woven into cloth. This primitive system of spinning would appear strange to either maid or matron of the present day, but it was well-known in Scotland to the grandmothers or great-grandmothers of this generation. It was sometimes practised within and sometimes without doors, as the spindle and distaff could be easily carried about, and it was no uncommon sight to see a girl herding the cows and plying her spindle busily the while. All females were then learned to spin in their girlhood, and with care and assiduous application, but not without both, they soon became expert at it. It required a nice 
and well-practised hand to spin very small sizes of yarn; but as all women, in those days, prided themselves on their talent for spinning, many of them could form an astonishingly fine thread.

As the demand for yarn increased, this slow and tedious mode of spinuing would, doubtless, be often complained of, but it was not until the fourteenth century that any improvenent was effected. An apparatus called the "Torn" was then introduced. It was merely a sort of frame for supporting the spindle and distaff, apart from the spinner. In 1533 a wheel for spinning Flax was invented by a citizen of Brunswick. At first the spindle was mounted on a frame, and driven by a belt passing over a larger wheel. 'This was further improved by using a treddle, worked by the foot of the spinner to effect the movement of the wheel, by which her hands were left free to regulate the motion of the thread. Shortly thereafter a more perfect apparatus, called the Saxon wheel, took the place of those of simpler construction for spinning Flax. It had on its spindle a bobbin, on which the thread was wound, and a flyer, revolving with greater rapidity than the bobbin, to give the thread the necessary twist. The Flax was loosely wrapped round a distaff or rock, which was fixed at a little distance above the spindle. The treddle was moved by the foot of the spinner, and, by means of a crank shaft, gave a rotatory motion to the wheel, she, meanwhile, drawing out the fibres of the Flax in the requisite numbers to form the grist or size of the thread desired. In doing this the fibres were from time to time moistened with saliva to make them more readily combine.

For a long period after the introduction of this wheel into Scotland it had only one spindle, but, about the year 1764, the two-handed wheel, having two spindles, was invented, and shortly after it began to be used in some districts, although its use did not become general until toward the end of the century. Indeed, the one-handed wheel had long powerful opponents in the spindle and distaff, so difficult is it to root out received notions or antiquated ideas. Gradually, however, the wheel supplanted the spindle and distafi, and gradually the one-handed wheel gave way to, and was superseded by the more productive two-handed instrument.

The spinning-wheel, as well known to and much used by the 
maidens and dames in the first quarter of this century, may be thus described:-The frame of the machine stood on three feet, on the right of which, facing the spinner, was a spoked wheel, of about two feet in diameter, with the rim slightly hollowed outside. Rapid motion was given to the wheel by a wooden rod or crank, connecting the axle of the wheel to the treddle or footboard, and moved at will by the foot of the operator, much in the same way as a turning-lathe is moved. On the left were two pirns or spindles, one for each hand, for receiving the yarn as it was spun, driven by means of bands of gut, or cords of Flax or woollen yarn, highly-twisted, passing round the rim of the wheel and their axles. Each pirn or spindle had a flyer for twisting and guiding the thread before it was wound upon the bobbin, which was a hollow reed slipped over the axle and fitting rather closely to it. The fly went round with great rapidity, while the bobbin being kept back by the strain of the thread, turned round on the axle only as fast as it was let out by the spinner. This depended on the degree of twist intended to be given to the thread, and the expertness of the operator. The rock or distaff, with the Flax wound round it in the ruanner best adapted for admitting of the filaments being readily drawn out by the spinner, was placed above the pirns, and both hands were employed in drawing out the fibres and forming the threads. The threads, after being carried through a throttle or opening in the end of the spindle, were from time to time shifted along the flyer by means of small pieces of bent wire attached to it, for the purpose of filling the bobbin regularly with the yarn as it was spun. During the operation the spinner moistened the threads regularly with saliva, the better to unite the fibres and improve the appearance of the yarn. When full the bobbins were put on a pin or wand held in the left hand, and the yarn wound off from it by the right, round a reel of ninety inches in diameter, attached to which was an indicator to show when 120 rounds, which constituted a cut, were reeled. Wlen this quantity was told off, it was tied with a thread and another cut begun, and so on until a hesp or hank was completed, when it was removed from the reel to make way for farther reeling.

Some of the wheels used by the upper classes-and in those. dilys all females span, from the highest of the nobility to the 
lowest of the peasantry in both town and country-were made of fancy wood, finely polished, and had rather a liandsome appearance, quite suited for either the parlour or drawing-ronm. The great majority were, however, made of common material, and, though highly useful, they were not very sightly as articles of furniture. 'The last improvement on the Saxon or Flaxspinning hand-wheel, was the application of Arkwright's principle, by rendering the flyer antomatic in spreading the yarn on the bobbin, which saved the time necessary in moving the thread from one of the small bent wires on the flyer to another, and at same time performed the operation more equally. This, though a great improvement, was not sufficient to enable the Saxon wheel to hold its own against all comers. A new and mighty rival was, by the ingenuity of man, raised up in competition, and although for a time it had many checks and made way slowly, yet, surely and steadily it held on its course, until it triumphed over every competitor. Not only did it silence the birr of the spinning-wheel on the domestic hearth, but it totally changed the nature and character of the textile manufactures of the country, and, along with this, the social habits of the whole people.

Larly in the last century thinking minds were actively at work trying to discover some way of bringing machinery to do, or assist in doing, both the work of the hands and of the head of the spimner of yarn from fibrous substances. In 1738 Lewis Paul discovered the principle of roller-spinning, and took out a patent for a macline for this purpose. This machine was experimented upon, and improved by various parties, and it is said that in 1741 or $17+2$ a mill, turned by two asses walking round an axis, was erected in Birmingham for spinning cotton on this plan, and ten girls employed in attending the work. Paul's invention contained the germ of a self-acting and selfregulating principle, and the means which he used were so unlike any previous performance by the hands, that he is well entitled to the admiration of posterity for the originality of his genius.

Many of those who first embarked in spinning by machinery did not prosper, but others took their place, and good progress was made, and various improvements were from time to time introduced. It was left for the genius of Pichard Arkwright to 
give a practical solution to the problem of automatic spinning; and after he, by his talents and perseverence, had overcome the difficulty, the onward course of machine spinning was astonishingly rapid.

The successful application of machinery to the spinning of cotton induced men to turn their attention to the spinning of Flax by like means. Accordingly, in the year 1787, John Kendrew, optician, and Thomas Porthouse, clockmaker, both of Darlington, in the county of Durham, applied for and got a royal patent for "a mill or machine, upon new principles, for spinning yarn from hemp, tow, Flax, or wool." A specification of this patent, with figures, is inserted in the Repertory of Arts and Manufactures, vol. xvi. "The figures," says William Brown, in his Reminiscences of Flax-spinning (a pamphlet published privately by him at Dundee in 1862, and containing much valuable information on the early history of Flax-spinning by machinery), "shew merely a spreading or driving machine, consisting of a cylinder three feet in diameter by ten inches broad, smooth on the surface, with some small cylinders or rollers in connection for holding and drawing the Flax and other fibrous materials put upon it for operation. Also a spinning machine or frame, having four spindles, consisting likewise of a plain cylinder, but of smaller diameter, with rollers for holding and drawing the untwisted sliver of Flax or other material passing there. Intermediate drawing machines are alluded to, but not described further than as to their being on same plan as the others.

"These machines, plain in construction as they seem to have been, are to be looked upon as having given rise to all those more refined and effective ones, still much on same principle, which have gradually come into use since, and which have spread widely over Europe, almost entirely superseding the ancient modes of spinning by distaff and spinning wheel."

Kendrew is supposed to have been the inventor, as he had seen cotton machinery, and probably took the idea from it; but whether this be so or not, he was ably seconded by Porthouse, who was an expert workman. By much perseverance they, together, fitted up their machines in a small building called the "Low Mill," situated on the river Skerne, at Darlington. The 
building had previously been occupied by Kendrew for enlass grinding, and a part of it is still standing. The work, which commenced spinning, as is generully believed, in 1787 , the same year in which the patent was granted, is considered, and with propriety, to be the first regular work got up for the spinning of Flax by mill machinery. After a few years the work was discontinued, and the partners separated to commence individual concerns. Kendrews erected a work near Honghton, and Port house procured a building near Coatham, both on the Skerne, and near Darlington. James Aytoun of Kirkcaldy, who died this year, and was in very truth the father of the Flax-spinning trade, having been a spinner for more than the threescore and ten years allotted as the measure of man's days, visited the firm in Darlington in 1792-3, and studied what they could teach, imperfect though it was. Mr Aytoun was an ardent spinner, and when not bowed down by pain or bodily infirmity, took pleasure in recounting his experience of the trade in its infant days. The following information regarding this, the first Flax-spinning mill, and other interesting details interspersed throughout the volume, were kindly and readily furnished by him.

In $1792, \mathrm{Mr}$ Aytoun, at the age of seventeen, went to Manchester to be instructed in cotton-spinning, whicli was then making rapid progress. Hearing of the patent taken out by the Darlingtou firm for spinning Flax, and of the work which they had established there, he left Manchester and proceeded to that place, and, as already said, studied under the firm. Their spinning frames were of 36 spindles, divided into six distinct heads, each of which could be stopped. Thirty-six camnisters of small diameter were put at the back of the frame, and a soft sliver passed over an 18inch wooden cylinder to the front, with lever weights to carry it along. His knowledge of cotton spinning being greater than theirs, he suggested roving or twisting the sliver, which must have been a great improvement on the plan they had adopted, but it was a considerable time before it was introduced by the firm.

After acquiring a knowledge of the new trade, he agreed with them for a license to work four frames of 36 spindles each, being 144 in all, for which he paid them a royalty at the rate of one pound. These frames he erected at Kinghorn, as already mentioned in the notice of that town.

All the Flax-spinning mills 
first erected in Scotland, including those in Bervie, and at Douglastown in Kinnettles, appear to have done so by virtue of licenses granted by the patentees, for each of which they were paid a royalty. The patent must therefore have been a profitable one for them.

In their separate establishments the two patentees succeeded moderately well, although, from the small extent of their works, their prosperity could not be very great. Kendrew died in 1800 , but Porthouse survived him some years. In 1805 the concern at Coatham appeared, to a party from this district who then visited it, to be in a thriving state. Some of the original machines from Darlington were then at work, and were plain and ancient looking when compared with others of later construction standing beside them. The grounds around the work were laid out with shrubs and flowers, and the place had an air of cleanliness and comfort about it pleasant to behold. Porthouse was a quiet, retired man, and left the management of the mill chiefly to his wife, who was an able, active woman. She attended the work daily from morning till night, going about with tools in hand, shifting pinions, and doing other little and necessary pieces of work as an ordinary manager would. Shortly after the invention of Flax-spinning at Darlington, mills were erected at Leeds and neighbourhood, and ever since that locality has been the headquarters of Flax-spin:ning in England; steam having, from the first, been the motive power employed.

Unless steam power had been successfully applied to the production of a better class of yarns, and a more adequate supply than the distaff and spindle or the spinning-wheel could have provided, the Linen trade would never have attained to any great extent, nor could Britain have been able to cope successfully, either in the home or foreign markets, with countries where provisions and wages are low, and where the raw material is largely grown, or can be procured at less cost than here. The spinning frame is the starting point from which all improvements in the trade have rapidly advanced, and wonderful has been the progress, made since the first frame was set up in 1787.

The first Flax-spinning mills erected in this country were small, and in general they turned out unfortunate concerns. 
The machinery wits bally constructed, and the managers of the works were new to the trade, and ignornnt of the right principles of spinning. Some of them were speculative, unstealy men, without experience or capital, and their downfall reacted upon, and injured the infant trade. Few efforts of skill or ingenuity have ever been completely suceessful at their commencement, as the ingenious contrivers often want some of the elements necessary for that industrious perseverance which begets success, and it is often left to the succeeling generation to reap the fruit of their predecessors' exertions. It was so with Flaxspiuning; and it was only after years of probation, and the successful introduction of various improvements, that the trade proved profitable to those engaged in it.

Every species of manufacture has its day of small things, and time and a hard struggle are required to give sustaining vitality. No great branch of national industry ever started into a prosperous existence at once, but scientific skill and steady perseverance overcomes all difficulties. The machinery first applied to the production of textile fabrics cannot be otherwise than rude and imperfect. Enlightened experience gradually discovers and introduces more suitable appliances, until at last a high degree of perfection is attained.

During the first decade of this century Flax-spimning machinery continued rude and imperfect, but as the trade became more developed, and its value better understool, attention was directed to the machinery and improvements began to be effected. As improvements progressed, the quality of the yarn spun became better, and by and bye it was preferred to, and at last completely supplanted, hand-spun yarn. This preference, added to the elastic and expanding progress of the Linen trade, stimulated spinning enterprise, and many new mills were erected in various parts of the country.

The Flax-spinning machinery was not adapted for spinning tow, and for a long time this article was of comparatively so little value that it was only used for making ropes and other miscellaneous purposes. About the beginning of the century, experiments were made in tow spiming, but for some time little real progress was made, as the first trials were not very successful. Improvements were, however, introduced from time to 
time, and after repeated experiments more satisfactory results were attained, and tow-spinning became a fact. In August, 1821, the Advertiser says-" In 1814 it was considered a good day's work to spin twelve spindles of $6 \mathrm{lb}$. tow yarn on a frame of 30 spindles, but now the quantity taken off is not only largely increased, but the quality is so greatly improved that the difference of price between Flaxen and tow Osnaburgs, which had formerly been $1 \mathrm{~d}$ to $1 \frac{1}{2} \mathrm{~d}$ a yard, is now only from $\frac{1}{4} \mathrm{~d}$ to $\frac{1}{2} \mathrm{~d}$."

William Brown, of Dundee, an intelligent and enterprising spinner, took the lead in effecting these valuable improvements in tow-spinning, and he was ably seconded by the late George Moon, of Russell Mill, in Fife, and the late James Aytoun. Although Mr Brown has retired from his favourite trade, he is still an enthusiastic spinner, and takes delight in witnessing the onward progress of mill-spinning. Mr Brown became a Flax-spinner about fifty-five years ago, and he is now the father of the trade. May he be still spared for many years, and able to recount his triumphs, glorious though bloodless, in the spinning cause!

The great object of the Flax-spinner, whether by hand or by machinery, is to draw out and arrange the fibres in one continuous thread of uniform thickness, and with an equal twist throughout its entire length. On this depends the quality of the yarn, and the beauty and value of the cloth to be made of it. By much practice and nice manipulation many hand-spinners became adepts in the fabrication of yarn, and some of them could spin a thread of extraordinary fineness with great regularity. Others were unable to acquire such perfection in the art, and never became so expert as to be able to make the thread uniform throughout. The quantity which any one person could spin was necessarily small, it therefore required the united production of several spinners to form a piece of cloth. As the yarn was from these causes very unequal in size, colour, and quality, it required much sorting before being given out to the weavers, and even the greatest care was insufficient to produce a piece in perfection.

Any plan by which the yarn could be produced of uniform quality was therefore a boon to the trade, and this mill-spinning, from its very nature, was calculated to do. The nice judgment 
of the most superior hand-spinner, if practical by this process at all, could, by it, be applied and made available without limit. Superior minds felt the truth of this, grappled boldly with the sulject, and finally triumphed. The victory was not won in a day or a year, but the fight was maintained until success was gained. 'To Kendrew and Porthouse the honour belongs of originating the application of machinery to the spinning of Flax, and their invention has been productive of mighty results.

After the Flix has been heckled, it is ready for the spinningmill. The first process in spinning is to place the Flax in handfuls, with the ends over-lapping each other, on a small table, whence it is made to pass between two fluted rollers (retaining rollers), and traverse a series of heckles, worked on an endless chain, the ingenious apparatus for which purpose is called the gill, from the name of the inventor. After passing through these heckles, it is caught by another pair of rollers (drawing rollers), whence it passes in a continuous ribbon, called a sliver, into a high tin can. The endless chain works over rollers, and the points of the heckles are made to move through the sliver with a speed a little greater than the retaining rollers, and have thus a double action. Entering the sliver immediately on its emission from the retaining rollers, and moving faster than it does, the heckles split down the fibres of the Flax, and allow the sliver to be extended by the drawing roller. As the Flax proceeds onward, the action of the drawing rollers makes the extending sliver move many times faster than the heckles, and by this means straightens and lays parallel those fibres which may happen to be doubled, or lie obliquely in the sliver. The drawing rollers move at a different speed from the retaining rollers; they must, therefore, be fully the length of the fibre apart, or they would break it, but yet not at too great a distance, or the sliver would not follow, as it would separate at the middle part from the great attenuation there.

The drawing process is repeated over and over again by placing a stated number of these slivers together through the retaining rollers, whereby inequalities in any of them are equalized, and an even and uniform sliver produced. The process which succeds these repeated drawings, whether made by the simple rollers or by the gill, is twisting the sliver into a rove or loose thread, and for this purpose an addition of a boblin and 
a flyer is male to the drawing machine. The bobbin is made to revolve with such speed as wind or roll up the rove as fast as it is yielded by the last pair of rollers, and the flyer with so much additional speed as to give the sliver the desired twist while moving between the roller and bobbin. As the diameter of the bobbin is constantly increasing by the accumulation of the rove, and as the speed of the roller remains constant, it is necessary to vary the speed of the bobbin, so that, as it increases in diameter, it may diminish in speed and wind up the rove at the same rate throughout. In some roving frames the machinery to accomplish this is very complicated. The rove on the bobbin is ready tor the spinning-frame.

In tow-spinning the tow is spread as equally as possible on an endless cloth attached to a breaker carding engine, and as the cloth revolves it carries the tow to the card, through which it passes for the purpose of separating the fibres, unravelling those which are entangled, and presenting the whole in a continuous sliver or ribbon of an equal width and density throughout its whole extent. For the better accomplishing this object several of these slivers are made to pass together inhough another carding engine, called a finisher, the tecth on the rollers of which are finer and closer set than in the breaker, and they are also delivered by this card in a continuous sliver. The fibres composing the sliver are extended by drawing them out without breaking, several slivers being made to pass over the gills or other preparing machinery together, with the view of making the size of the sliver more uniform. The fibres are combined by slightly twisting them in the drawing, so that the tortion will generate a certain compression among them, which will make them extend farther without breaking, and thus by continued drawing and twisting the sliver will be attenuated to the required point. This operation is limited by two circumstances-when the fibres end together, and which it is one of the objects of carding to prevent, and when the friction produced by twisting becomes so great that the fibres will sooner break than slide on each other. After the last drawing the sliver is twisted into a rove, and put on a bobbin as with Flax.

In spinning, the bobbins with the rove are placed on pins fixed in a slightly angular position on the top of the spinning 
frame, whence the rove is passed between rollers on to other rollers moving at a greater speed than the first, and thence down through the throttle of the spindle, over the arm of the flyer, and on to the spiuning bobbin. The rove in this process is extended to the greatest degree of attenuation required, and at same time twisted so hard that when the operation is finished, and the thread perfectly formed, the fibres will sooner break than separate by sliding on each other. The thread is then reeled off the bohbin into cuts, heers, hanks, and spindles, a spindle being 14,400 yards in length; or it may be formed in the warping-mill into chains ready for the loom.

Early in the century, after some progress had been made in Flax preparing, the draw or elongation stood as follows:-At the spreading table ly hand, 6 to 1 ; at each of the three drawing machines, 10 to 1 ; and at the spinning frame, 15 to 1 making in all 90,000 to 1. A strike of Flax, therefore, measuring a foot in length, was drawn out or elongated to the extent of 17 miles ere forming its portion in the finished thread of yarn. In systems of the present day, where additional opera. tions are in use, a strike of Flax is drawn out to the extent of several hundred miles.

Wet spinning differs chiefly from this description of dry spinning in having the spinning frame furnished with a receptacle for holding water, which is heated by steam, the rove passing through the water on its way from roller to roller. The hot water still farther subdivides the fibres, which permits them to be drawn out into a finer thread than if spun dry, and the water makes the loose fibres combine better with the body of the thread than they do when dry.

Economy of space and labour are two very important elements to the Flax-spinner. Formerly this was not so much considered, and the arrangement of the machinery in the older mills is in consequence not so perfect as in those of modern construction. Improvements in these respects, where practicable, have been introduced into all works, so as to make them more convenient, and reduce the working expenses to the minimum.

The most approved arrangement is, to have the carding engines and other preparing machinery on the ground floor; or, if there is not room for the whole there, to put the more advanced portion, such as the drawing frimes, on the second floor. The 
spinning frames are placed on the second and third floor, and the reeling and warping in the upper storey. The material to be spun is stored, in a state ready for the machinery, or batched where this is necessary, in close proximity to the first machine through which it has to pass, viz.- - the rough Flax, to the heckling machine; the longs of either Flax or Jute, to the spreading machine; the Tow to the breaking engine; and the Jute, when not heckled, to the teaser, for the purpose of being made into Tow ; and each sort of material is taken from the store to the several machines as required.

After passing over the spreading table, the longs, formed into a sliver, is either allowed to fall into cans or wound round a beam, whence it is passed through the drawing machines, the first of which is placed immediately beyond the spreading machine, with just enough space between them for the necessary cans and the hands required to attend the operation. 'The other drawing frames are placed in a line at regular distances, and the material goes over each successively, until it is finally twisted into a rove and wound on a bobbin. The bobbins, when the roving has been performed on the ground floor, are carried by an elevator, worked by machinery, to the second floor, and placed on the spinning frames, where the rove is spun into yarn or thread. The yarn is then raised by an elevator to the upper floor, reeled, and made up into bundles for the market, or warped into chains ready for the loom, or wound on bobbins or otherwise for wett. The Tow, after passing through the breaking engine or card, is put through the finishing carding machine, which is placed at a little distance behind the breaker, and from the finisher it passes over the drawing machinery, which is placed in a line behind the last carding engine, and is successively changed from a sliver to rove, and from rove to yarn, \&c., as in the case of the line yarn. In this way the material passes from machine to machine until it is transformed into yarn, almost every process being performed by machinery, much of which, is automatic, and with the least possible amount of manual labour.

It is of vast importance to the spinner to provide an abundant supply of the most suitable material for the yarn he intends to spin, and great care should be taken to assort it properly so as to produce a uniform quality of yarn, as its value is greatly de- 
pendant on its uniformity. 'The construction of the preparing and spinning machinery, and keeping the whole in the most eflicient order, is another matter of essential importance, because, unless the machinery be not only of the most approved description, but kept up to the mark, it is impossible, even with the finest material, to make superior yarn. Of late years great improvements have been made on the carding engines, and those recently constructed are ponderous machines with the card cloth on a different principle from what was formerly used, and with more workers, \&c., around the eylinder. 'These machines perform their work better, and in greatly larger quantity than the old carding engines. Many and highly important alterations and melioratious have been made in the drawing machines, and perhaps more real improvements have taken place in this department than in any other. The spinning frame has also received its share of attention, and in all its parts, framework, cylinders, spindles, flyers, fic., \&c., modifications and beneficial changes have been made. The conical spindle, invented by David Caincross, Blairgowrie, in 1865, was one of the earliest and most important of these improvements. The machinery of the present day, when compared with that in use half a century ago, shows such a wonderful advance towards perfection, that it may be doubted if improvements can go on in the same ratio, or if the progress which can be made in the future will at all compare with what has taken place in the past.

Some machine making firms have been long celebrated for the Flax-spinning and weaving machinery they produce. Others of shorter standing, are fist rising into fame, and bid fair, at no distant period to rival their older compeers. Peter Fairbairn and Co., Leeds, and Combe and Co., Belfast, are famous for drawing and roving frames and other preparing machinery. Thomas Robinson, Leeds, for heckling machines. James F. Low, Monificth, for carding engines and spinning frames In Dundee, Rohertson and Orchar, Pearce Brothers, and Charles Parker and Son, for power-looms and for winding and other preparing machinery for weaving. John Kerr and Co., for calendering machinery, and J. Carmichael and Co, and Gourlay Brothers and Co., for stcam engines, boilers, \&c. 


\section{CH A P T E R I I.}

\section{LINEN WEAVING.}

WEAVING is the art of regularly interlacing thread or filaments into cloth. It is performed by the alternation of one series of threads over and then under another, or by the intermittent but regular crossing of the threads, as the cloth to be woven may be wanted plain or twilled. There are also various kinds of fancy weaving; but as few Linens are so made, excepting damasks and kindred fabrics, which will be referred to, it is unnecessary to mention them.

Pliny allows that the Egyptians invented the art of weaving, and Athanæus ascribes it to Pythmias, the Egyptian. This may or may not be the case, but certainly there is no handicraft more ancient and more universal than weaving. Representations of both horizontal and upright looms are found in the Egyptian tombs, at some of which men are employed, and at others women. The looms appear to be of rude construction and simple in detail. The upright looms are not unlike those still in common use in this country, as the framework consists of upright posts connected by cross-beams, with a lay and other appurtenances. The weaver, in one of the paintings, sits low on the loom, and is in the act of putting in with the hand a long shuttle, having a hook on each end of it. The shuttle is not thrown, as here, which must have made the work very tedious. 'The horizontal loom was a square frame, on which the yarn was stretched; and in some of them the increasing length of the cloth is taken up by pegs in the ground, a mode still practised in Ethiopia. In some of the Egyptian representations of weaving the warp appears as if suspended from the top to the bottom of the loom, and the woof or weft is pushed upwards, a practice, says Herodotus, common among other nations, but not in Egypt, where it was pressed downwards. The weaving implements of Egypt were no doubt a type of those in use among other nations of antiquity; but it 
would scem, from the expression of Job, "My days are swifter than a weaver's shuttle," that the shuttle must then have been thrown in working, as in no other way would the expression have been appropriate. Frequent mention of the weaver occurs in the Scripture, such as Bezaleel and Aholiab being taught to work all manner of cunning work, and in fine linen of the weaver, \&c. 'The staff of Goliath's spear was like a weaver's beam. The expression of Isaiah, "My life is cut off as by the weaver," \&c. These notices show not only that the Israelites, but also the neighbouring nations, were early acquainted with and practised the art of weaving. Indeed, all nations, however uncivilized, both in ancient and modern times, testify to the antiquity and universality, in some form or other, of textile industry.

The natives of India, at a very remote period, were well acquainted with the arts of spinning and of weaving, as may be proved by a reference to their Vedas. In India many of the manners and customs of the inhabitants have undergone little change for a very long period, and the looms of the present day are counterparts of those in use in early times. They are exceeding rude in construction, and have few of the appliances to facilitate the process with which in this country even the simplest and most ordinary looms are provided. With little more than a few pegs stuck into the ground, and some pieces of wood crossed over them to contain the warp and the cluth, does the industrious native of India sit on the ground, under the shade of a wide-spreading tree, and weave some of those beautiful fabrics which are the admiration and delight of the nations of Europe.

According to the representations of Ciampini and Montfancon, the looms of the fourth and fifth centuries are, in many respects, different from the modern. The threads of warp are not strained longitudinally, but perpendicularly, the weaver standing instead of sitting. The treadles are at each side of the loom, which is insulated. There is no appearance of the lay and reed, which divides the thrcads, and drives the cruss thread or weft close. There is a boat-fashioned shuttle. The weights appear, and the womin, besides the shuttle in one hand, has in the other a stick to rectify the threads. Isidore and others 
mention the insubulus about which the cloth was rolled, the reel, the slay, the threads diluted with water to render the finer sort more firm. In the Anglo-Saxon dictionaries there are the slay, lathe or lay (sloe), the weaving-house (tow hus), beam $(a m a)$, and female workers or weavers (webstres).

The common hand-loom of the present day does not differ much from those used by the Egyptians, Greeks, Romans, and other ancient nations. In all there are the four upright posts, bound together by cross-rances or ties. In front there is generally a breast-beam, with a cloth centre-beam under, but a little behind it, and the yarn-beam at the back of the frame, which can be elevated or depressed to suit the height of yarn upon it. Near the front, the lathe or lay is suspended from the top of the frame for the purpose of driving home the weft. Behind the lay are the heddles or camb, hung from pulleys at the top of the loom, and connected with the treddles which are placed underneath the frame-work. The heddles are composed of as many pieces of twine, with loops or mails in the centre of each through which the threads of warp are passed, as there are threads in the warp.

For plain weaving two heddle leaves are sufficient, although four, attached two and two, are used for some fabrics, for the purpose of spreading the warp more regularly, but only two treddles are required. For twilled cloth three or more treddles, with distinct heddles for each, are required, depending on the description of twill wanted, and which is known as threefeet, four-feet, eight-feet twill, \&c. Each heddle being connected with a treddle, the pressure of the weaver's foot raises one and depresses the other continuously and alternately, consequently, in plain weaving, raises half the threads of warp and depresses the other half, making an opening in the warp called the shed, through which the shuttle with the weft passes in front of the lay. The lay is composed of two sides, called swords, connected with a heary piece of wood below, when the shuttle is thrown from side to side by the hand; and, when the picker shuttle is used, by a race-course, in each end of which is a recess for the shuttle. In each recess is an iron rod, on which move small pieces of wood or buffalo-hide, called pickers, to which strings are attached which meet in a handle. This the 
weaver takes in his right hand, and, by a sharp jerk, projects the shuttle along the shuttle-race; thus he impels the shuttle with the weft from side to side alternately, the lay being drawn forward firmly by the left hand at each crossing of the shuttle, to drive the weft home.

Immediately above the race-course or bottom of the lay is placed the comb-like frume called the reed, composed of a number of thin pieces of cane or steel, the flat sides of which run parallel with the threads of warp, and the narrow edges face the front and back of the loom. 'The threads of warp are drawn through between the picces of cane or steel in regular order, two in each space, one of which rises with the motion of the treddle alternately. By the number of splits in a given space of the reed, the fineness of the cloth is determined. Above the race-course of the lay is the cape, a piece of wood which can be moved up and down the swords, and which rests on the top of the reed to keep it in its place and perpendicular to the warp. When the lay is drawn forward the reed pushes the thread of weft, which has just been thrown across, close up to the previously thrown thread. And as the alternate treddle is moved after each thread of weft is thrown, the warp threads thus bind it, and the fabric of the cloth is formed.

The picker was the invention of John Kay, of Bury, by whom it was patented in 1733. By means of it the threads of weft are passed in with more rapidity than when the shuttle is thrown from hand to hand by the weaver, and much wider cloth can be weaved by one person than by the old mode, which is limited by the stretch of the weaver's arms. The weft is wound on a small bobbin, which is placed in a hollow made for the purpose in the shuttle, and allowed to run off freely as the shuttle is passed from side to side. $\Lambda$ new mode has recently been introduced of winding the weft on a spindle, from which it is removed and placed on another in the shuttle, thus rendering the small bobbin unnecessary and saving time to tie weaver.

Before the threads of warp can be wound on the yarn beam on the loom, they must undergo a preliminary eperation called warping. For convenience and the saving of room the yarn in the hank is wound upon large bobbins, which are placed on a vertical frame so constricted as to allow the bobbins to revolve 
easily, and to keep the threads of yarn apart from each other. The threads are made to pass through guide-pins in a heck-box, and then round a large reel or warping mill, six or eight feet in height and of a diameter varying with the length of the warp required, the reel being turned by an endless rope passing round it and a wheel turned by the warper. The heck-box moves up and down a post, the motion being regulated by a cord passing over a wheel or pulley and wound round the axle of the reel, and unwound alternately, as the box moves up or down the post. By this means the warp is wound spirally and regularly on the reel, from top to bottom, or the reverse as the heck moves down or up, and the process is continued until the proper number of threads of warp for the intended web are given.

The heck-box is composed of two pieces, which can be raised on slides, and through the guide-pins of which the threads are passed alternately. In commencing to wind the yarn on the reel, the threads which pass through each of the two pieces of the heck are separated by raising one piece on its slide, and they are then passed the one portion over and the other under a guide-pin attached to the reel. The other piece of the heck is then raised and the threads in it passed over another pin on the reel, while those in the other piece pass under same. This process is repeated each time the chain or warp is wound up or down the reel, by which means the whole warp is separated thread by thread, which facilitates their alternate arrangement in the heddles in the loom. At the bottom of the reel a few of the threads are alternately passed together in pinfuls over and under other two pins, which enables the weaver by means of an evener or very open reed, with a moveable top, in each opening of which a pinful of the yarn is placed, to spread the warp regularly in winding it upon the yarn beam of the loom. Before the warp is taken off the reel, a piece of cord is passed carefully through the yarn, close to the pins, to preserve the separation of the threads at both ends of the warp, which separation is called the lease and without which it would be very difficult to weave the warp into cloth. The warp is marked on the reel in stated lengths, either by coloured threads or other means, to enable the weaver to know how he is progressing with the weaving of it, and to put on the weft regularly. In rolling 
the warp on the yarn beam, it is begun at the end where it is divided into suall pin-fulls, and terminated where it is separated into alteruate threads. 'This arrangement is necessary for the operation of drawing the threads through the heddles and reed; and the weaver takes care to preserve the lease perfect throughout the entire wearing of the web, by passing two lease rods between the alternate threads and keeping them there.

In winding the warp on the yarn beam of the loom, called beaming, a roller with weights attached is made to pass over the yarn to make it tight and hard, in order that the tension may be uniform while the weaver is working it off, as the cloth would otherwise be irregular and unsightly.

In weaving, the warp is kept extended by weights hung on the beam, and taken off gradually as the weaver proceeds, or it is let off by means of a ratched wheel and catch; and the cloth is wound round the cloth beam as it is woven, the yarn and cloth being kept tight by a finer toothed wheel and eatch on the cloth beam, wrought by a lever at the pleasure of the weaver. To have the loom in good working order it is necessary that it be made perfectly level and square, and properly fixed in its position. The lay should be hung mid-way between the heddles or camb and the woven portion of the work, and so poised as to return to its position by its own weight as soon as the stroke is made. It should also be hung at the proper height to permit the due elevation and depression of the threads of warp by the heddles, and if not so hung it will overstrain the weaver, and not do the work so perfectly. 'The loops of the hoddles must be hung at the proper elevation to keep the warp, when at rest, horizontal with the top of the yarn beam and breast beam; and they are suspended over a pulley, or in such other way as permit them to be raised and depressed alternately. The treddles move on a pivot at one end, and are attached to, and suspended from the heddles, with such an elevation as make the tramp of the weaver raise the heddle sufficiently to let the shuttle pass freely through the shade in the warp. In the connection between the camb and treddles, spring-staves, comiter-marches, \&c., are generally used to ease the nperation, steady the motion, and make the threads of warp pass each other the more readily, \&c.

In the trim of the loom even for weaving plain eloth, some I Y 
fabrics require a difference in the arrangement from others. Heavy goods, such as sail-cloth, require more lever power in the treddles, and the lay must describe a greater arc than in weaving Osnaburgs or other light fabrics. Other appliances than those mentioned are used to give motion to the shuttle, and in some of the other minor details, but the principle is the same in all cases.

Twilled fabrics are extremely various, and some of them very complex in their character, and difficult to explain to one not practically acquainted with the process. In twills the warp yarns, instead of interlacing alternately with the weft threads, cross them at regular or irregular intervals of every third, fourth, or other threads, depending on the number of heddles employed, and the way in which the threads of warp are drawn through them. The object in twills is to show more than half the warp on the surface of the cloth, and by this means improve its appearance; or to form diamonds, squares, or other figures upon it. The number of combinations which may be thus formed are very numerous, and in many instances the strength and durability, as well as beauty of the fabric is increased, by making the same quantity of yarn into twilled cloth than it would be if made plain. Squares, and other simple figures can be formed on the surface of the cloth, in plain weaving, by a different drawing of the threads through the heddles. If three threads be drawn through one heddle or leaf of the camb in succession, and one through the other, it will form a figured surface. If coloured yarn be introduced in either warp or weft of plain cloth, or in both, many patterns can be produced, and that in a variety of ways and of various figures. But if coloured yarns be employed in the manufacture of twills, there is scarcely a limit to the patterns which may be formed. In ordinary de. scriptions of Linen little diversity of colouring is resorted to, but beautiful specimens of what can be done in this way are shown in the variety of styles, and numerous patterns of Jute carpeting which are made. Ordinary twilled sacking, drills, \&c., exhibit one style of twills, while towelling, diaper, \&c., show another, and a very different description, and others differ from both of these.

In figure weaving, whether the draw-loom, the Jacquard, after 
wards described, or other means be employed, every thing depends on the proper arrangement of the warp yarns, as a single thread misplaced necessarily renders the figure imperfect. 'The taking up of the proper threads of warp, and drawing them through the approprinte mail or heddle, must therefore be dono with great care. 'I'o facilitate the operation it is necessary, in some complex patterns, to have the design drawn on paper, divided into squares, like those for German embroidery work. In this way the drawing of the warp threads for each shot of weft, so as to produce the intended pattern, can readily be made by an intelligent weaver, with a person to count off and call out the pattern as the drawing proceeds.

The beautiful specimens of damask made in Dunfermline, Belfast, and other places, are now chiefly produced by the Jacquard machine, invented by Joseph Marie Jacquard, and first shown at the National Exhibition of Industry, held at Paris in 1801. This very perfect, but simple machine, was at first received with much bad feeling by the artizans of France, many machines having been destroyed, and the inventor's life threatened. Its merits were too valuable and too apparent to be entirely kept back, even by such furious and frenzied opposition, and when it did emerge it revolutionized the trade. Previously, figures which could not be produced by combinations of twilling and colouring, were formed by the aid of the draw-boy, and such, or otber appliances, or by the cumbrous and tedious modes known in tapestry work as high and low warp, but by neither mode were they so perfectly brought out as by this beautiful invention.

'The value of Jacquard's most ingenious and truly admirable machine has long been universally acknowledged. He was, beyond all doubt, a benefactor, not only to those engaged in the manufacture of textile fabrics, but to the world at large. The Chamber of Commerce at Lyons recently erected a white marble tomb over the grave of Jacquard, in the cemetery of Oullins, near that city, but a more endearing and more enduring monument has been erected in the hearts of all who derive benefit from Jacquard's invention, and of all who know and can appreciate true genius.

The Jacquard engine is fixed at the top of the loom, in a direction perpendicular to the harness, and it may be attached Y Y 2 
to almost any kind of loom; but without diagrams it is nearly impossible to give a description at all intelligible to the general reader. Each cord of the harness is distinct, with a small leaden weight attached to the lower end to keep it extended. The upper ends are attached to lifting hooks, each of which goes through an eye in a corresponding needle. This harness answers the purpose of the heddles or camb of the common hand or power-loom, the threads of the warp being passed through an eye in the cords of the harness, each thread having its respective cord, which are raised by the treddles operated upon by the foot of the weaver. The needles lie in rows in a frame, horizontal to the warp, with their points projecting from the frame, and they are kept extended in their position by spiral springs placed in cavities at the end of the frame. In front of the points of these needles a square metallic box is placed, perforated on each side with holes exactly corresponding in number and position with the needle points. The box turns by a fourth of a revolution at each tramp of the treddle, and at the same time its side is pressed forward on the points of the needles, which enter it and are lifted by it, together with the lifting hooks, cords of the harness, and corresponding threads of warp, and they are held in position until the weaver throws a thread of weft. He then removes his foot from the treddle, when the box is drawn back from the needles, and the harness cords are allowed to drop, and with them the warp. This process, if repeated, would not produce tigured patterns on the cloth; but this is done in the following manner.

In order that the whole warp be not lifted at once, it is necessary to prevent all the needle points from entering the holes in the box. 'To accomplish this a number of perforated cardboards are made to pass over it in endless succession with its revolutions. These cards are only perforated in certain parts, according to the design intended to be produced, and where there are no openings in them the needles are pressed back and drop, the corresponding lifting hook, cord, and thread of warp dropping with them, the only threads kept up being those wanted to be shown on the surface of the cloth to produce the desired pattern. As the perforation of the cards is the means by which 
the harness is raised, and the absence of perforation determines the part of the warp not to be lifted, it is necessary to have one card for every shot of weft, until the whole pattern is described. 'The cords are exactly fitted to the box by means of studs upon the latter corresponding with larger holes in the former, and the whole are loosely looped together at the corners, so as to form an endless chain, one whole revolution of which completes the pattern.

There are contrivances to withdraw the box and make it revolve regularly, to throw the lifting-liooks out of gearing, and to connect the whole with the motion of the treddles, \&c., which it would be too tedious to describe. The cards are perforated by an ingenious machine, a sort of counterpart of the engine itself, which performs the operation both expeditionsly and correctly. The pattern rlesired is first drawn on paper ruled in small squares, denoting the respective threads of warp and weft, which enables the perforator to determine the proper spots to punch out on the card, so as to raise the necessary threads of warp to produce the design.

This machine is used in the manufacture of silk, cotton, woollen, and Linen, and is alike suitable to all. Patterns of endless design and of wonderful beauty can be produced by it, by the mere change of the cards passed over the surface of the perforated box, the particular pattern depending wholly upon them. Improvements have from time to time been effected on this engine, and it has now been made so astonishingly perfeet for the various fabrics for which it is adapted that it will be verv difficult to supersede it by anything more suitable.

It is nearly two centuries since power-loom weaving was first thought of, the idea having originated with M. Gennes, a French naval officer, who communicated the plan to the Academy of Sciences there in 1678 , and it was translated into our Philosophical Transactions in June that year. It was not, however, until about the end of last century that Cartwright solved the same problem with memorable success, and since then an extensive series of improvements have been conducted by various parties, and the machines have now heen brought to a high degree of perfection.

Shortly after power had been successfully applied to the weav- 
ing of cotton, Linen manufacturers and others began to turn their attention to weaving Linen by power, but for a long time the difference between the nature of the two fibres presented a serious barrier to its adoption. A cotton thread is so elastic that it will stretch a long way before it breaks, and threads of silk and wool have also considerable elasticity, but a Linen thread will break if extended one thirty-sixth part of its length.

It is mentioned in the proceedings of the Board of Trustees for Manufactures in Scotland that in $\mathbf{1 7 8 8}$ a loom was made by Alexander Robb, to be driven by water or other mechanical power. It appears from the proceedings of the Trustees that in 1810 Joseph Crompton, then residing in Dundee, had invented a loom to go by water or steam, but neither of these looms seem to have been brought into practical use, as no farther mention is made of either of them.

The first really successful manufactory for weaving Flax goods by power was established in London in 1812 or 1813, when this country was in the very height of the struggle with Bonaparte. The factory was connected with the extensive ropemaking works of Charles Turner \& Co., at Limehouse. The warp yarns were starched, and went through a laborious preparation, and the entire process would be reckoned very slow in the present day, but, for the period, displayed much mechanical skill and ingenuity. The yarns were chiefly spun by Neilson $\&$ Co., Kirkland Works, but towards the close of the war Messrs Turner erected a mill for spinning their own yarns. At the Peace of 1815, the demand for their goods ceased, and the spinning-mill was stopped. The power-looms, however, were. kept on, and in 1832 they were still working, and at that time making good canvas, but not long after they were stopped. One of the partners of this establishment was the inventor of the ingenious machine for weighing sovereigns, and another was celebrated for other inventions, so that the firm had been mechanically inclined.

In 1821 mention is made of a power-loom being about to be used in Dundee for Linen, but if the experiment proved successful, it was not followed up. The next successful application of the power-loom to Linen fabrics was made in Kirkcaldy in 1821. Some details of the work are given in the notice of that 
town. At the time these were written the previous existence of the London establishment was unknown to the author.

Shortly after that period Maberly \& Co. began to experiment upon weaving Linens by power, which, having proved successful, induced them to go into the trade In Mr Maberly's evidence on the Linen trade, taken in Parliament in 1824-5, he stated that he had then 200 power-looms erecting in Aberdeen for Linen weaving. He calculated that on fabrics of $10 \mathrm{~d}$ a yard there would be a saving of upwards of 25 per cent. in weaving by power, compared with the expense of weaving the same description of Linens by hand in England.

The power-loom Linen weaving establishment which $\mathrm{Mr}$ Maberly commenced in Aberdeen in 1824, was continued in active operation during the existence of his firm. On the stoppage of Maberly and Co., Richards and Co. stepped in and took up the Linen manufacturing branches of the business, and since then the power-loom factory at Aberdeen has been continuously and successfully carried on, and, as already mentioned, it now contains 428 looms. This establishment may be called the parent of the Linen power-loom works of the country, because, from the great talent and mechanical skill which the proprietors employed, and the strong efforts they perseveringly made to adapt machinery to Linen weaving, the obstacles which had previously barred its progress were obviated, and success attained. This work is therefore, perhaps, the oldest Linen weaving establishment by power in existence.

A firm in Preston put up a number of power-looms for the finer class of Linens, when the demand for such goods in France was so great, but after the increase of the duties there in 1842 , the trade ceased, and this, and some other factories which had been started, were closed.

Messrs Baxter of Dundee, as previously mentioned, intended to have erected power-looms in 1826 . In 1828 they actually commenced power-loom weaving, but their success was not such as to induce them to continue, and the looms and other machines were laid aside. In 1836 they again, or, rather, their new firm, Baxter Brothers and Co., determined to go into Linen power-loom weaving, and built a factory to contain 216 looms. Since that period the firm have most successfully perre- 
vered in the trade, and they now employ more power-looms on Linen than any other firm in the world. One of the partners, Peter Carmichael, has devoted much of his time in maturing. and perfecting the looms and preparing machinery, and to his success is orving, in a great measure, the admirable suitableness of the power-looms of the present day to the weaving of Flax and Jute goods. Mr Carmichael has improved heckling machines, spinning machinery, weft winding machinery, powerlooms, \&c., and he is the patentee of several inventions for these objects, which have been, and still are, in practical use, and highly valued.

It was some time after these experimental trials before Linen power-loom weaving made mtich head-way, but of late years astonishing progress has been made in the various Linen manufacturing districts in the kingdom. The trade may even yet be considered in its infancy; but, judging from the many factories in course of erection, and the great magnitude of some of them, it bids fair to attain maturity at no distant day, and to possess a vigorous, prosperous existence.

The superstructure of a power-loom is a frame-work of castiron, standing on a solid foundation, and made of such strength as to bear the weight of the web, and the heavy strain which the loom undergoes in working. There is the breast beam in front, over which the cloth passes in its way to the cloth beam or roller placed below, around which it is wound by the machinery as the work proceeds. 'The warp beam is placed behind, with a roller over it and parallel with the breast beam, to keep the yarn in a horizontal position; and the warp is kept at a proper tension by weights or other appliance attached to the yarn beam. The treddles are suspended from the top of the loom by two or more belts working on pullies if the cloth is narrow, or winks if broad -the wide cloth requiring the heddles to be hung from more points than the narrow, to give strength to the gearing and steadiness to the motion of the heddles in the operation of weaving. 'The lay is put in motion by two cranks, one at each side close by the frame of the loom, that they may not interfere with the space for the warp. The shuttle is thrown by a whip-lever in the centre of the loom, moving alternately to the right and left or by two whip-lerers, one at each side of the loom within the 
framing, to which the picking-cords are attached, and which move the picker with a jerk. The motion of the treddles is produced by two eccentric wheels acting on two levers or treddles furnished with friction rollers, the short radius of the one whecl allowing its corresponding treddle to be raised at the time the long radius of the other depresses its treddle, and thus the treddles are raised and depressed alternately.

The motion is communicated to the various parts of the loom by means of a driving shaft, to which teethed wheels, cranks, $\& c$, are attached or connected. 'These move the lay, shuttle, treddles, \&c., with unerring regularity, and the whole operations go on simultaneously and uniformly. The loom is thrown out of gearing by means of fast and loose pullies, one of which is connected with the driving shaft, and the other unconnected, the driving belt being moved by a lever from the one to the other at the pleasure of the weaver.

At first the mechanism of the power-loom was very imperfect, and so far from precision that each loom had its own particular character, and was individualised,-as, she would only work a certain kind of work; she took a stubborn tit and required to be coaxed, often for half a day at a time, before she would throw the shuttle, or take up, \&c. Under these circuinstances the looms could not do much work. The speed did not exceed eighty picks a minute, and a weaver was required for each loom ; indeed, with the shifting of the temples, and the rubbing of the cloth, both of which processes are now obsolete or superseded, one loom was hard work for a strong woman. Practical experience has introduced so many really beneficial alterations and improvements that power-looms are now in a high degree perfect and complete. Some fabrics of Linen require a very different construction of loom from those suitable for others, but the science and skill which have been brought to bear on the subject have overcome all difficultics, and looms are now made admirably adapted for every deccription of goods. So complete are they now constructed in all their parts that the weaver has little more to do than keep the shuttles supplied with weft, and repair any threads of warp which mily get broken, and one weaver is quite able to attend to two looms at once, although they are now running at more than twice the speed of twenty years ago. 
Some of the recent improvements in the construction of the power-loom are both ingenious and useful, among which may be noted the following:-By a simple mechanism the loom is stopped when the weft in the shuttle is run out, or in its breakage from any cause. By another the loom is stopped whenever the shuttle does not get clear of the shed. The rubbing machine was invented and patented in 1845 , and by this machine the work of one hundred looms can be rubbed in a superior manner by one person. The warp is retained at the proper tension by levers and springs, \&c., \&c. By a self-acting process the several shuttles required in working checks. and such goods are changed regularly at the proper time for producing the desired pattern. In the International Exhibition of 1862 several most complex looms for weaving Brussels carpeting were shown, in some of which the wires which form the looped surface of the cloth are inserted and again withdrawn by a novel and ingenious contrivance, which performed the work admirably. But perhaps the greatest curiosity in mechanical weaving is the electric loom of Chevalier Bonelli of Milan, from which there are good grounds for anticipating very brilliant results-more especially in its application to the principle of the Jacquard looom.

Preliminary to the warp or chain going into the power-loom, the yarn has to undergo the operations of winding, warping, and starching or sizing, all of which are now performed by means of machinery.

In the preparing machinery great advances to perfection have been made-several patents have been taken out for improvements in winding both warp and weft yarns. Some of which, such as those of Mr Cox of Lochee, Mr Carmichael, and Robertson and Orchar, of Dundee, are really valuable. The introduction of the "flatterer" or parallel motion into the dressing machines, by means of which the warp threads are made of uniform length, though never patented, greatly facilitated weaving. So many other improvements have been from time to time introduced, both in preparing machinery and in looms, that some machinery and some looms have been broken up and re-made again and again during the last twenty years. For instance the weft winding machines, which at first required the yarn to be wound from the hank on large bobbins, and then 
removed from these on to the weft pirns, passed through five stages of development previous to the patent taken out for it in 1853. The best weft winding machines have a separate building apparatus for each spindle, to stop the spindle when the thread breaks, one to prevent doubling or two ends going on at once, and mechanism to make the yarn run at the same speed at the thick part of the pirn as at the small, an apparatus for stopping the spindle when the pirn has received its proper quantity of yarn, \&c., \&c.

Want of space prevents any description from being given, as was intended, of winding, warping, dressing or beaming machines, and of other machines connected with the Linen manufacture.

It is most important to have the machinery of a powerloom work of the best construction, and kept up in first. rate order. It is no less important for the success of the manufacturer that he keeps up a sufficient supply of the best and most suitable quality of yarn, which is his raw material, without which superior Linens of uniform quality cannot be produced. Having the machinery and yarn what they ought to be, the next point is to make the one transform the other into superior cloth, quickly and cheaply. To do this requires it well arranged work, so that the yarn may pass through the various processes without loss of time, or waste of labour. Panmure Works have been referred to-page 488-as a model in this respect. There the railway waggon with the yarn is taken into a gateway in the centre of the work, and the yarn removed to the warehouse on the one side of the gateway, whence it is taken by an elevator as required to the floor above and wound. 'The warp yarn is taken down again by the elevator to the warping and dressing house, and the weft yarn by other elevators to the weaving shed. After being warped and starched, the chains are beamed, drawn through the heddles and reed, all in succession, and taken into the weaving shed, which forms the centre of the work. From the loom the cloth passes into the picking, damping, and calendering house, which is placed on the opposite side of the weaving shed from the warping house. Thence the cloth passes into the lapping house, on the opposite side of the gateway from the yarn warehouse, and is there lapped and 
packed into bales. These are put on the waggon in the gateway and sent off to the customers. In this way the yarn makes the circuit of the work, and in its course it is transformed into cloth in the shortest possible time, and with the least amount of labour, consequently at the minimum cost. It may be mentioned that the extension of Panmure Works are now in progress, and that in a few months the number of looms will be increased to about 420 . The building of the Institute is nearly completed, and the erection is an ornament to the village and an honour to the proprietors.

Much of the success of Linen weaving in Dundee is due to the workpeople. They have shewn a readiness to adopt improvements for lessening labour and facilitating the various processes which is highly honourable to them. They have also shewn a remarkable facility for acquiring the skill and dexterity necessary to work the machines with quickness and ease, to the advantage alike of their employers and themselves. Perhaps it is the same with the people engaged in Linen power-loom operations in other places, and if so all deserve commendation. It is gratifying to think that the wages of the operatives are in every department about double what they were in 1842 , and it is to be hoped that in the future they will be as well remunerated for their labour as now.

\section{CHAPTER III.}

\section{I N E N B L E A C H IN G.}

Bleaching is an ancient art, but it is not known by whom it was first discovered. In the writings of the old historians it is mentioned that the early inhabitauts of Asia employed certain earths and alkaline plants in washing and scouring their garments, and that they were acquainted with a method of making their Linen extremely white. No doubt, when the knowledge of the whitening and detersive properties of these substances was o ice acquired, the art would be prosecuted until a consi- 
derable degree of proficiency had been attuined, as cleanliness is one of the handmaids of civilisation.

Theophrastus, who was the son of a fuller in the Isle of Iesbos, and who wrote 300 years before the Christian era, mentions that lime was then employed in bleaching. He relates that a ship, partly loaded with Linen and partly with lime for bleaching it, was destroyed by the accidental access of water to the lime. Parkes doubts this, and in his essay on bleaching, says "it is stated by Theophrastus that lime was used by the ancients in bleaching, but this has not been proved, and it is very much doubted by scientific men."

Pliny mentions that white Linen was esteemed above the azure blue-coloured curtains of the Emperor Nero. He says the Greeks and Romans used sereral kinds of earths and plants in scouring Linen. Pliny also mentions that the ancient Gauls and Britons were acquainted with the art of bleaching I.inen cloth, though their process seems to have been verys imple and imperfect. He says, "They sometimes put certain herbs, particularly the ronts of wild poppies, into the water, to make it more efficacious in bleaching Linen. But, as this kind of cloth is very apt to contract stains and impurities in the using, so nothing is more necessary to those who wear it than the art of washing and cleansing it from time to time. To this art the Gauls and Britons were not strangers, for soap, made of the tallow or fat of animals and the ashes of certain vegetables, was not only very much used, but was even invented by the ancient Gauls."

For a long period little adrance seems to have been made in the art of bleaching, either in the materials employed or in the manner of their application to the yarn or cloth.

In the beginning of last century the Dutch were esteemod the best bleachers in Europe. Their method was to steep the cloth in waste ley, then in new ley, which was run on the cloth hot, and in a clear, pure state. In this it was allowed to steep for eight days, then washed with black soap, and wrung by a machine. 'The cloth was then steeped in a wooden ressel containing butter-milk. A little of the mi!k was first poured into a ressel, then a piece of the cloth was tread in, more milk and cloth were then added altemately until the vessel was nearly full, the ressel being closcd with planks firmly werlged from a 
beam over it. After steeping from six or seven days to two or three weeks, according to the notion of the bleacher, the cloth was taken out, washed with black soap, wrung, then spread on the grass for two or three weeks to bleach. During the time the cloth was exposed it was regularly watered with clear water, supplied from small canals conveniently led through the bleaching-ground. The water was thrown over the cloth with a long wooden shovel, so contrived that with it the worker could throw the water to a great distance over the cloth. The operations of "bucking," i.e., pouring boiling ley over the cloth, souring in butter-milk, grassing or crofting, was repeated five or six times, the strength of the alkaline ley used being lessened each time, until the cloth was bleached to the whiteness required. Souring in butter-milk was the only mode then known and practised in Holland. The time occupied in whitening the goods was from six to seven months, in summer only, and goods commenced in the middle or latter part of the year had to stand over half bleached until next spring. The excellence of the colours produced by the Dutch was partly owing to the purity of their water, an abundant supply of which was of primary necessity to them in their bleaching operations.

The mode of bleaching fine Linen practised at Picardy and St Quentin about the middle of last century differed considerably from that of the Dutch. The following description of the operations there is from Postlethwayt's "Dictionary of Commerce :"

"After being taken from the loom they are put to soak in clear water for a whole day. They are then taken out and thrown into a bucking tub filled with cold ley, made of wood ashes and water, which has served already. Then washed in clear water and spread out in a meadow, where they are watered with scoops called gieters out of the river. After lying some time on the ground they pass through a fresh ley poured on hot, then washed in clear water and laid again on the meadow, all which operations are repeated till the Linen has acquired the desired degree of whiteness. They next rub them with black soap to take out the grease, wash out the soap, and put them to soak in sour milk, the cream being first taken off. Being taken out of the milk they are washed in clear water for the last time. Then dip them in water in which a little starch has been steeped 
with smalt or Dutch lapis-next fastened on poles to dry-when near dry (three quarters and a half) they take them from the poles and beat them on marble blocks with smooth wooden mallets, folded into small squares and pressed. The merchants then put their numbers on them, which are written or stamped on small bits of parchment, and tied to the selvage of the piece with silks of different colours, according to the merchant's fancy, who calls that silk his livery, each merchant having his own colour which he never changes. After this they wrap them up, very neatly in brown paper of Koan, well beat, tied with small packthread which they commonly get from Holland. They are then ready for sale."

'I'he bleaching of common Linen, as practised at Anjou is similar, but less complicated, and with this addition that they are first put into wooden troughs, full of cold clear water, where with wooden mallets, which are moved by a water mill, they are so well agitated and beat that they are insensibly cleaned of all filth and harshness. The calender, from I'ostlethwayt's description, would seem to be nothing more than the well-known mangle.

The Board of Trustees for manufactures in Scotland, soon after their appointment, took into consideration the subject of bleaching, as it was intimately connected with the Linen manufacture. The Trustees resolved to grant assistance to parties willing to establish bleachfields, and they made stringent regulations anent the use of what was then considered improper materials for bleaching. The first bleachfield set up under their auspices was Dalquhorn Field, near Dumbarton, by Patrick Seton and partners. It consisted of 12 acres, and on 18 th February, 1729 , a grant of $£ 50$ an acre, being $£ 600$, was paid to the firm. On 18th March 1741, a farther sum of $£ 300$ was paid them. In 1729 grants were also made for Cameron Field, near Loch Lomond; field of 7 acres at Gray's Green, Glasgow ; field of 6 acres at Georgie Field, near Edinburgh; Cupar-in-Fife Field; Aberdeen Field, \&c., \&c. The Board paid for experiments in bleaching to James Spalding, $£ 180$, Dr Wm. Cullen, Glasgow; f21, and Dr Francis Home, $\_100$. The Board subsequently, and at various times, assisted to establish bleachfields in other parts of Scotland.

The first important improrement made in bleaching in this 
country was the substitution of water, acidulated with sulphuric acid (in place of the butter milk previously employed), which was introduced by Dr Home about a century ago. This discovery was probably made by him in the course of his experiments at the request of the Board of Trustees. By it souring was elliciently performed in twelve hours instead of the days or weeks required when milk was used; and when the sulphuric acid is properly diluted it is safe, and does no injury to the goods.

The next, and perhaps the most important discovery ever made in bleaching, was the application of chlorine in the whitening of cotton and Linen goods. Some time after the application of sulphuric acid as a souring agent in bleaching, it was discovered that oxymuriatic acid possessed the property of destroying vegetable colours. This led the celebrated chemist, Berthollet, to experiment upon the subject, and in April 1785, he read a paper on this acid before the Academy of Sciences in Paris. Doubts were at one time entertained regarding the priority of the discovery, but these were ultimately decided in favour of Berthollet. Chlorine gas is produced from a combination of common salt, black oxide of manganese, sulphuric acid, and water. Dr Thomson recommends the following proportions as the most economical and advantageous, viz. :-Salt, 1 part ; manganese, 1 part ; vitriol, 2 parts ; and water, 2 parts. Scheele, a Swedish chemist, in experimenting on manganese and muriatic acid, discovered this new modification of that acid in 1774, and Berthol. let, who subsequently repeated the experiments of Scheele, discovered that the mixture was a compound of muriatic acid and oxygen, and gave it its shortened appellation, "chlorine." The acid, he thought, might be introduced with advantage into the art of bleaching, and shorten the process greatly. This discovery quite revolutionised former processes of bleaching, and from it a new era dates.

In 1786 Berthollet exhibited the experiment before Mr Watt, the person who first introduced the new method of bleaching into Great Britain. Early in 1787 Professor Copland, of Aberdeen, was shown by M. de Saussure, in Geneva, the dissolving property of this acid, and on his return home, in July that year, he repeated the experiment before some bleachers in the neighbourhood of Aberdeen, who at once began the application of 
the process to the bleaching of Linen on a large scale. The party referred to, Messrs Milnes, of the firm of Gordon, Barron, and Co., commenced the use of chlorine in bleaching linen at Aberdeen in 1787, and they were the first who began the trade in this country; but several other parties commenced its use in the same and following year, and its extension was very rapid. Chlorine was at first only known in its gaseous state, and considerable difficulty was experienced in applying it to the material to be bleached. The cloth had to be exposed to its action in a close receiver, with appliances to raise and lower the cloth in water, and thus expose it to the alternate action of the gas and water, as the chlorine, which would not act on the cloth in the dry state. This plan continued to be practised until 1790 , when it was ascertained that chlorine combined with a solution of pearl ashes, and in that state could be conveniently applied in bleaching.

Another great discovery was made in 1798 by Mr Tennant, of Glasgow, who combined chlorine with a solution of lime, and followed up his invention by combining chlorine with dry lime, in which state it was very convenient for transport. Chloride of lime, or bleaching powder, has since then been regularly used by bleachers of Linen and cotton cloth and yarn, and it will not be easily superseded.

The Board of Trustees for Scotland, in their minutes, February, 1800 , mention that bleaching by steam had been invented by Mons. Chaptel, "the celebrated French chemist." In 1817 a bleaching foreman was advertised for in Dundee, "acquainted with all the new improvements made in making and using oxigenated muriatic acid."

Alexander Drimmie, an intelligent bleacher in Aberdeen, and father of Daniel Drimmie, of Panmurefield, Dundee, made some important discoveries and improvements in Linen bleaching. The following extracts from his note-book, written about 1850 , refer to his substitution of soda ash for potash ley about 1820 , and his invention of washing machinery about 1825 :- "Bleaching.-This branch of the Linen trade has improved at an extraordinary rate. Formerly fine Linen was sent to Holland to be bleached. It required a whole summer to do so, and hence was called Scotch Hollands. 
"The first bleachfield in Scotland was near Perth. Barrilla was used in part, and also pearl ashes from Russia. Potash from America was afterwards introduced, and cost at one time about $9 \mathrm{~d}$ per $\mathrm{Hb}$. About 30 years ago I began bleaching with soda ash, made from the residuum of the chlorine stills, and that can now be made at one sixteenth of potash at $9 \mathrm{~d}$ per $\mathrm{fb}$. The introduction of this alkali was quite an era in the trade. By various improvements since in the manufacture of chlorine, this alkali, now called soda ash, has superseded the use of potash, and was exported last year to the amount of $£ 400,000$ in value.

"Alkali being now so cheap, the quantity used in proportion to the weight of the goods is much greater, and much time is saved. Indeed, by the use of plenty of ley, and using only chloride of soda, Linen cloth may be bleached almost without exposure, and in a few days, if the proper plan be taken. It costs more money, but saves time. All bleaching materials have been brought very low in price, and machinery has also helped to reduce the cost of bleaching."

"Washing by machinery was introduced by me about 25 years ago. It saves labour, and does the work well."

A calender, to give a finish to bleached Linens, was erected at Douglasfield, in the parish of Dundee, in 1819, and since then the calendering has been applied to the finish of almost every class of Linens. Cloth bleaching was carried on largely at Douglasfield before the end of last century, and the work is still in active operation, W. A. M'Intyre and Co. bleaching both Linens and yarns there. Baluniefield, belonging to John M'Intyre, is also in Dundee parish, and is a large and prosperous yarn bleachfield.

Of late years further improvements have been introduced in the preparation of bleaching materials, in the machinery employed in bleaching, and in the mode of conducting the operations, whereby bleaching Linen cloth and yarn has been simplified, expedited, and cheapened. It is now a large branch of the Linen trade, and, as conducted by the bulk of the bleachers, perhaps the most healthy. Bleachfields or greens abound in all the great Linen districts in the three kingdoms, and the bleachers are, as a class, an intelligent and respectable body of men, and many of them are excellent chemists. The 
trade gives employment to many thousand male and female operatives, and as many of the processes are carried on in the open air, or in lofty, well-ventilated bleaching-houses, the hands are noted for being robust and healthy. Formerly all bleachfields required a great extent of greens for exposing the yarn or cloth, to facilitate the process and whiten the colour; but now many goods are bleached without exposure at all, and others are grassed for only a short period, so that extensive greens are not so much required. Indeed the character of bleaching has greatly changed, recent improvements having facilitated operations, and enabled the various bleachers the better to meet the increased requirements of the extending Linen trade.

\section{BLEACHFIELDS IN FORFARSHIRE.}

1. Aberdein, Gorlon, and Co.,

2. Cargill and Co., .

3. John Carmichael,

4. Cox Brothers,

5. John F. Dickson,

6. Charles Dowall,

7. Daniel Drimmie and Co.,

8. David Duncan and Co.,

9. East Mill Company,

10. Inch Bleaching Company,

11. John Lowson, Jun.,

12. John Lowson and Son,

13. John M'Intyre,

14. W. A. M'Intyre and Co.,

15. A. J. Murdoch \& Co.

16. Charles Norrie and Sons,

17. Richards and $\mathrm{Co}$.

18. Tuinbull and Co.

19. Webster and Co.,

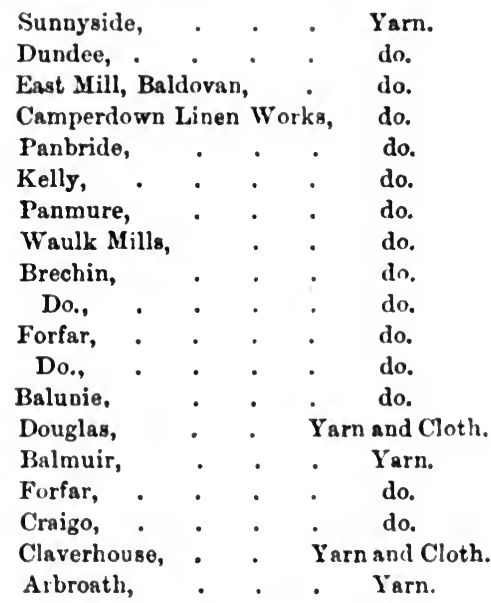

In addition to the above, several firms in Dundee bleach the yarn required in their Carpet Manufactures. 


\section{$(724)$ \\ A P P ENDIX.}

FraX.-Very little progress is making on the Continent of Europe to increase the area of land under Flax, and no great hopes of an extended supply need be entertained from that source. In some of the English counties a little more attention is being paid to this important subject, which the high price of Flax and the low price of grain may deepen, but as yet the benefits to be derived from this is only prospective. Scotland is quite asleep, and no hopes of the resumed cultivation on an extensive scale of what was once a favourite and a very general crop are entertained. Ireland is this year alive to the importance of growing Flax, and nobly has she done her part. In Ulster a greatly increased acreage has been sown with this, to the farmer, most profitable plant, and even the central, southern, and western counties are entering with spirit into the golden crop. It is calculated that upwards of 300,000 acres are now under Flax in Ireland, and as the crop is now (June) in a healthy state, it is probable that the produce may be about 80,000 tons, which, at present prices for seed and fibre, will bring to the growers nearly six millions sterling.

The India Flax Company, formed a few years ago, was most unfortunate in its first attempts to improve the culture of the fibre in India. The seed sent from Europe lost its germinating powers on the royage, and one year's progress was thus arrested. Now the prospects are more hopeful, and in another season or two it is expected that India will produce a considerable quantity of good sound common Flax, fit for the trade of Dundee and neighbourhood, if not for Belfast or Leeds. A good deal of Flax continues to be grown in the United States, but much of the fibre is still unwisely sacrificed for the seed. In Canada some progress is making in the cultivation of Flax, and hopes 
are entertained that it will receive more attention as its value becomes better known, and that the country will yet produce the fibre largely, as the quality is very suitable for spinning purposes.

JUTE. - In Scott's Magazine, vol. lxiv. for 1802, some interest ing details regarding Jute and other Indian fibres are given. On 23d December 1794. Dr Roxburgin, superintendent of the East India Company's Botanical Garciens in Calcutta, laid before the Governor-General samples of dressed and undressed Jute and other fibres, which he thought suitable for the Linen manufacturers of Scotland, and for papermakers. He subsequently made experiments in the cultivation and preparation of Jute. On 27th May 1796, the Board of Trade wrote the Governor-General, for transmission to the Court of Directors, that they had forwarded in a bale some Jute, sent them by Dr Roxburgh, as a specimen of an attempt to improve its quality by a mode of cultivation and dressing different from the practice of the natives, and requesting that the samples might be referred to manufacturers in England for trial, and their opinion communicated to the Board in India. Along with the samples the Doctor sent drawings and descriptions of the two plants, the fibres of which are called Jute, and an account of his method of cultivation of the plants, and preparation of the fibres. He says he thought the fibres might be rendered much finer, even fit for cambric and lawn, by being sown thicker and cut earlier than usual, and steeping it in pure soft clean water well exposed to the sun's beams, instead of in the muddy water of the tanks which the natives used, and which is always discoloured by the leaves of trees and other putrid vegetable matters.

In 1802 material for paper making must have been scarce and dear, as the above details were published by J. Sewell, 32 Cornhill, London, in what appears to be an advertisement recommending the East India Company, captains, officers, supercargoes, importers of rice and India bale goods, grocers, drapers, $\& c$. , to collect sugar, rice, pepper, and other bags, as they made superior paper, samples of which were exhibited. The first idea of this was communicated to $\mathrm{Mr}$ Sewell by an ingenious literary gentleman, long resident in India, whose attention was called to the subject from secing an adrertisement on the covers 
of the European Magazine, recommending ladies not to destroy their Linen rags. Jute, it was said, was largely used in Bengal for making coarse sacking (called gunny cloth), ropes, twines, and many other purposes. It cost in Bengal about 5s a cwt., and had been sold in England at 20s to 29s a cwt. The advertisement goes on to say, "Jute and Sunn offer a very good material for the owners of rice ships to fill up their cargoes with, or as dunnage, or if packed in gunny bags it will be more convenient, without risking much capital." Sunn, which cost $7 \mathrm{~s}$ to $8 \mathrm{~s}$ in Bengal, sold in England at 35s.

'These particulars shew that some attention had been paid to Jute, and that its nature and value, as a textile fibre, was not unknown in England nearly seventy years ago. It is wonderful therefore how its introduction in quantity into the manufactures of the country is of so recent a date. That its extension has been rapid since its real value was known is shewn in the chapters on Jute. The following tables bring down the exportation from Calcutta to the present time, viz. :-

Exports of Jute from Calqutta.

To Great Britain. France, \&c. America. Total.

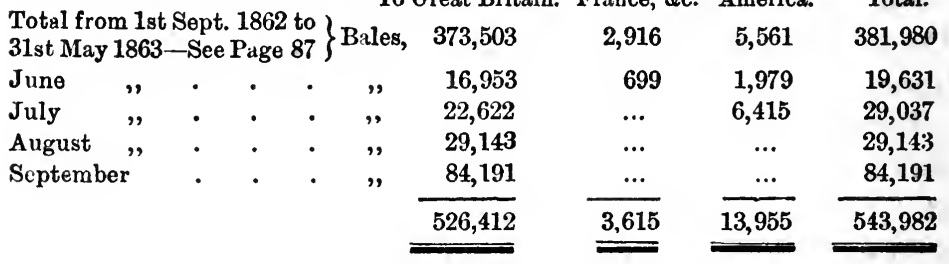

Comparative Statement of Clearances and Sallings of Jute from Calcutta to Great Britain in the first Seven Months of Season 1863-4.

\begin{tabular}{lcrrrr} 
& \multicolumn{2}{c}{$\begin{array}{c}\text { Reported Clearances. } \\
\text { Jute and Cuttings. }\end{array}$} & $\begin{array}{c}\text { Jute. } \\
\text { Jual Shipments. } \\
\text { Cuttings. }\end{array}$ & Total. \\
September, Bales, & 82,138 & 28,290 & 1,704 & 29,994 \\
October, ", & 120,796 & 101,204 & 6,596 & 107,800 \\
November, ", & 143,911 & 85,335 & 3,608 & 88,943 \\
December, ", & 121,958 & 157,111 & 10,806 & 167,917 \\
January, ", & 62,733 & 98,880 & 9,620 & 108,500 \\
February, ", & 38,240 & 43,395 & 3,400 & 46,795 \\
March, & ", & 49,172 & 39,007 & 5,310 & 44,317 \\
April, & 21,511 & 30,720 & $\underline{4,530}$ & $\mathbf{3 5 , 2 5 0}$ \\
& & $\underline{640,459}$ & $\underline{583,942}$ & $\mathbb{4 5 , 5 7 4}$ & $\mathbf{6 2 9 , 5 1 6}$
\end{tabular}

Owing to steam communioation being now open with the principal Jute-growing districts, the new crop commences to arrive in Calcutta a month earlier than heretofore. Shipments are therefore now calculated from 1st September to 31st August, instead of 1st October to 30th September, as formerly. 


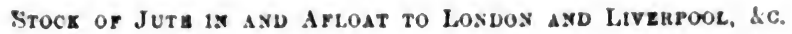

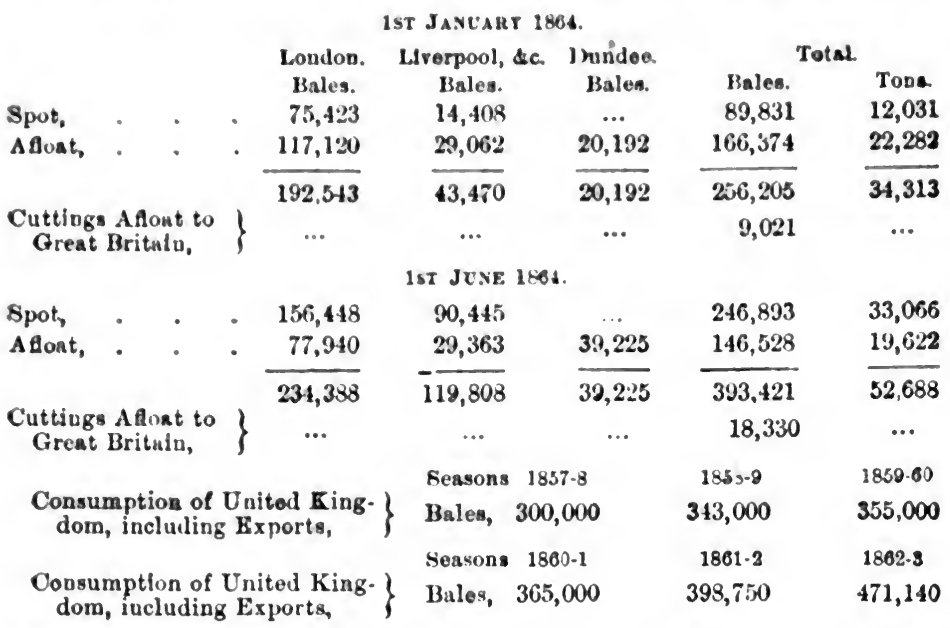

Some of the figures regarding Jute are taken from the excellently got up Weekly Repurts of Barber, Nepbew, and Co., of London.

Late accounts from Calcutta advise that a very greatly increased area of ground is sown with Jute this season, and that the appearance of the crops is promising. There is therefore no fear of a short supply of fibre for next season's trade.

IRELAND.-Abstract of Return of Flax-spinning Mills and Linen power-loom factories in Ireland, with spindles and looms in 1859, and in May 1864, and looms in 1861, compiled from information derived (save in a very few instances) from the proprietors, by the Linen Trade Committee :-

\section{SPINNING-MILLS.}

$\begin{array}{cccccc}\text { Muls. } & \begin{array}{c}\text { Splndles } \\ \text { Employed. }\end{array} & \begin{array}{c}\text { Spindles } \\ \text { Unemployed. }\end{array} & \begin{array}{c}\text { Total } \\ \text { Spindles. }\end{array} & \begin{array}{c}\text { Proposed } \\ \text { Extension. }\end{array} \\ 1859 . & 82 & 560,642 & 91,230 & 651,872 & \ldots \ldots . \\ 1864 . & 74 & 641,914 & 8,860 & 650,774 & 50,638 \text { Spindles. }\end{array}$

In aldition to the preceding, there are employed in twist-

ing thread, . . . . . . .

Five Mills are in cuurse of erection, capable of containing

$14,648 \quad$,
$45,000 \quad$,

Power-Loom Factories.

$\begin{array}{cccccc}\text { Factories. } & \begin{array}{c}\text { Looms } \\ \text { Employel. }\end{array} & \begin{array}{c}\text { Looms } \\ \text { Unemployed. }\end{array} & \begin{array}{c}\text { Total } \\ \text { Ioom. }\end{array} & \begin{array}{c}\text { Proponed } \\ \text { Extension }\end{array} \\ 1859 . & 28 & 3,124 & 509 & 3,633 & \ldots \ldots \\ 1861 . & 35 & 4,609 & 324 & 4,933 & \ldots \ldots \\ 1864 . & 42 & 7,929 & 254 & 8,187 & 1,685 \text { looms. }\end{array}$


The trade of Belfast is in a most flourishing condition, and extensions to old mills and factories, and the erection of new ones, are being carried on with great vigour.

France.-The following table of the articles enumerated, imported into France, and taken out of bond for consumption, for 1861, 1862, and 1863, is taken from the French Board of Trade Returns :-

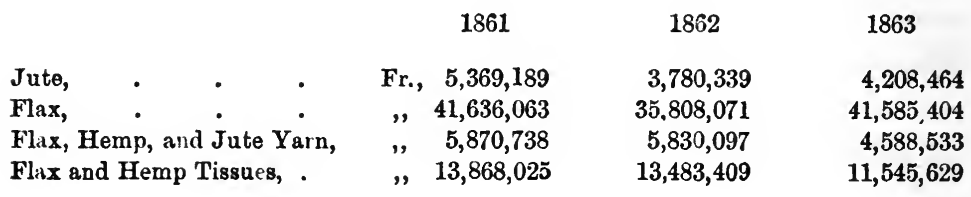

Exports of French productions, for same years and from same source :-

$\begin{array}{lcrrr}\text { Flax, } & \text { Fr., } & 3,146,870 & 11,611,606 & 9,568,182 \\ \text { Flax and Hemp Yarn, . } & \text { " } & 1,577,086 & 3,126,707 & 22,091,454 \\ \text { Flax and Hemp Tissues, . } & \text { " } 14,871,869 & 14,467,086 & 18,602,740\end{array}$

These tables show a remarkable extension of the exportation of yarn in 1863, when compared with the previous two years. In 1863 , the sterling value was about $£ 880,000$, being seven times the value in 1862 , and eleven times the value in 1861 . Of the yarn exported in 1863 , it is estimated that $2,200,000$ spindles were sent direct to Dundee, besides indirect shipments via Hull, \&c. The total value of yarn imported into the United Kingdom from France in 1863 is estimated at $£ 600,000$, of which about two-thirds found its way, directly or indirectly, to Dundee. This is a curious illustration of the effects of the late French Treaty, and it is convincing evidence that the protection accorded to the French spinners by a large import duty on yarns spun in this country ought never to have been agreed to, and should at once be taken off. Then the competition between the spinners of France and the United Kingdom in both countries would be on fair terms, but at present the advantages are manifestly all on the side of the French. Of late the Linen manufacture has been making rapid progress in the northern districts of France, and the productive powers both of spinners and manufacturers have been and still are greatly on the increase. 
Russia.-The Russian Government have promulgated a decree, authorising nearly every description of goods, the produce of the country, to be exported free of duty. 'This is a commendable policy, and if the Emperor would follow it up by removing the prohibition against certain imports, and reducing the duties on all to reasonable rates, and by removing the many restrictions with which the trade of the country is trammelled, he would do much to encourage legitimate commerce, and to enrich the empire.

U N I T E D S T A T ES.

Valog of the Linens Imported into New York from 1at JaNuary to 31st DECEMBER 1860 TO 1863.

\begin{tabular}{|c|c|c|c|c|c|}
\hline & $\begin{array}{l}\text { Entered for Hom } \\
\text { Consumption. }\end{array}$ & $\begin{array}{l}\text { Entered for } \\
\text { Warehousing. }\end{array}$ & $\begin{array}{l}\text { Total Entered } \\
\text { at the Port. }\end{array}$ & $\begin{array}{l}\text { Withdrawn frotn } \\
\text { Watrehouse. }\end{array}$ & $\begin{array}{l}\text { Total Thrown } \\
\text { on the Market. }\end{array}$ \\
\hline 30 & $\$ 6,415,345$ & $\$ 1,498,807$ & $\$ 7,914,152$ & $\$ 839,483$ & $\$ 7,254,833$ \\
\hline 661 & $2,142,653$ & $1,437,650$ & $3,580,303$ & $1,878,081$ & $4,020,734$ \\
\hline 662. & $6,711,630$ & 955,271 & $7,666,901$ & $1,612,144$ & $8,323,774$ \\
\hline 863. & $8,022,270$ & $3,044,742$ & $11,067,012$ & $2,465,564$ & $10,487,834$ \\
\hline
\end{tabular}

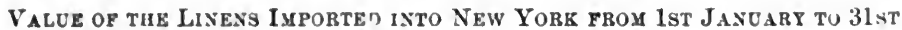
MAY 1862 To 1864.

$\begin{array}{rrrrrr}1862 . & \$ 2,415,241 & \$ 365,615 & \$ 2,780,856 & \$ 877,472 & \$ 3,292,713 \\ 1863 . & 3,523,772 & 1,537,538 & 5,061,310 & 673,107 & 4,126,879 \\ 1864 . & 4,690,970 & 1,614,007 & 6,304,977 & 1,856,893 & 6,547,863\end{array}$

The same causes which have so vastly stimulated the progress of the Linen trade in the United Kingdom within the last two years, have been at work in the various Linen manufacturing countries in the world, and all have to a greater or less extent felt the increased demand, and shared in the golden harvest.

The following extract from the admirable monthly Report of D. Dewar, Son and Sons, for July 1864, is so pertinent and so appropriate, that it may fitly conclude this volume:-

"The trade of this country generally is in a very prosperous condition. For this prosperity, however, we are chiefly indebted to the operation of free trade and the maintenance of peace-so essential to the proper development of that commercial policy which has proved to be so great a blessing to the country. Never, at any time, has trade been more active than at the present moment. In every branch of business-both for the home and the forcign markets-the most buoyant feeling pre- 
vails. The recent reduction in the Bank rate has infused additional life into commercial operations ; so that, up to the present time, everything appears to be progressing in a very satisfactory manner. Of this, some proof will be found in the fact that the value of the exports, for the five months ended 31st May last, amounted to $£ 64,069,060$, as compared with $£ 50,742,670$ in the corresponding period of last year, and with $£ 47,545,238$ in the preceding year.

"But the question now uppermost in everybody's mind is, shall we have war or not? At this time the interruption of peace and the extension of the Danish war, to other parts of Europe, should we become actively involved in the dispute, would be a sad calamity indeed. We are very reluctant, however, to believe in such an event. No Government will venture, under existing circumstances, to plunge this country into a war involving such sacrifices as must inevitably be made to support it. It is, of course, difficult to say what effect would be produced on our trade by a general war in Europe. That it would be followed by severe commercial depression there can be no doubt, aggravated in a high degree by the increased prices of provisions, in addition to increased taxation. During the Crimean war, when the foreign supply of corn and provisions was in no way affected, the price of wheat averaged, on several occasions, as much as 80 s per quarter. It is now only $40 \mathrm{~s}$, but with a general war in Europe, affecting, as it undoubtedly would, all the corn-producing countries, it is no exaggeration to esti-. mate the probable average price at $100 \mathrm{~s}$, an additional annual cost to the nation of $£ 60,000,000$ on this one item only.

"The British trade with European countries is now of a very extensive character. During the last year the real value of the goods imported from northern Europe and France amounted to $£ 70,795,575$; but, including all Europe, the total value was $£ 94,567,234$. On the other hand, the declared value of the British goods exported to the north of Europe and France was $£ 37,479,009$; while to all Europe the aggregate value amounted to $£ 59,641,568$. This, of course, is exclusive of the value of foreign and colonial goods re-exported to the different European countries. It will, therefore, be seen that the value of our exports to Europe during the last year was greater than to all 
the world in the year 1848, during which the aggregate value amounted only to $£ 52,849,445$. A war in Europe would, for the time being, affect trade to an extent equal to the total destruction of that of the year 1848 ; so that the loss which would be sustained by the destruction of trade, the enhanced cost of provisions of all kinds, and the increased public expenditure, would scarcely be less than $£ 200,000,000$. Setting aside all other considerations, what Goverument will venture to incur the responsibility of entailing so great a loss as this upon the country?

"'The effects of a war would of course be felt in every department of trade; but few to a greater extent than the Linen trade. For nearly the whole of the foreign supply of the raw material we are dependent upon the north of Europe; while, at the same time, a very large proportion of the Linens exported is for European consumption. On a former occasion we estimated the annual consumption of Flax in this country at 100,000 tons a year; this has since been confirmed by the last report of the Government Inspector of Factories, and according to whom, after the most careful inquiry, the average consumption for the last seven years has been 100,400 tons. During the last year the total quantity imported was 72,948 tons; but as the acreage under Flax in the United Kingdom during the last year was wider, and the yield heavier, the home supply has been estimated at 64,227 tons; making, in all, 137,175 tons for the past year. For so far, the account of the crop up to the present time is most favourable. There is, at least in Ireland, a still greater breadth of land under the crop, and as the yield of fibre promises to be equally as good as last year, we have little doubt the supply from our own sources will be fully 70,000 tons.

"It will be seen, however, that this quantity will fall far short of the total consumption of last year. In the quantity imported there is a very considerable increase up to the present time; according to the returns just issued, the total of the Flax received during the five months ended 31st May last, was 638,174 cwt., compared with 317,821 cwt. in the corresponding period of last year, and with $334,165 \mathrm{cwt}$. in the year preceding. We must, however, take into our consideration the steadily increasing demand for Linens, which, if not interrupted hy war, neces- 
sarily involves an increased demand for the raw material. Should, therefore, the present pacific relation of this country be interrupted, it will easily be seen to what an extent trade will suffer. But we are not amongst those who believe that anything serious will occur; and the steady progress of our foreign trade at this moment, as well as the condition of the foreign markets, indicate clearly enough that there is no great fear existing in the minds of people generally, that the question of peace or war, so far as this country is concerned, admits of any other than a pacific solution only.

"In any case, however, we find ourselves in considerable difficulty with regard to the supply of Flax. The consumption of Linens at home is extending rapidly ; it is, in fact, limited only by the supply-for the demand cannot be met; while the value of the piece goods exported during the five months ended 31st of May last, was $£ 3,138,863$, compared with $£ 2,270,878$ during the same period of last year, and $£ 1,722,705$ in the preceding year.

"With respect to the supply of Flax, we are much gratified to find that the attention of the Government is now being directed to the matter. This question is more now than ever of paramount importance, considering the increased supply of the raw material necessary for the requirements of the additional spinning mills about to be erected for supplying the excessive demand for yarns, which are sold at such unprecedentedly remunerative rates.

"Mr Baker, the inspector of fac'ories, in his last official report to the Home Secretary, states:-'In 1862 Messrs Dewar estimated the average consumption of Flax at 100,000 tons a year, stating also that fully as much more was required.' According to the result of the most careful inquiry on the part of Mr Baker, 'the average consumption for the last seven years was 100,400 tons ;' and of the accuracy of his statement there can be little doubt. He goes on to state that, 'the entire acreage of England and Wales is $37,324,883$, which, divided into farms, gives an average of 149 acres each. Adding the number of farms in Scotland and Ireland, and supposing that every farmer could $\cdot$ be induced to grow five acres of Flax, for one year as an experiment, the produce of a low average rate of $4 \mathrm{cwt}$. per acre would be equivalent to 511,850 tons.' 
" But supposing only half the land, or half the inclinations of the farmers, would admit of this growth, we should still have a production of $: 55,925$ tons, which would be more than twice as much as Mr Dewar's estimate; and, without interfering with the cotton trade at all, would give the odd day and a half's employment to the cotton districts which, according to $\mathrm{Mr}$ Ashworth's calculations, will be wanting in 1865, and perhaps in 1866 ; and would distribute to the farmers themselves between two and three millions of hard cash, which otherwise they would never touch. Moreover, of this we may be sure, that without this home growth, should there ever be a time when we cannot obtain foreign Flax, we shall then have a Flax famine, as we have lately had a cotton famine; and whether there is ever such a time or not, the Flax-spinning spindles of the European continent have, within these late years, so largely increased, that much of the Flax grown abroad will be wanted for home consumption; and though we may possibly obtain some of it, the prices will be enhanced, and our own farmers had better, therefore prepare to help us under the contingency.'

"These remarks are so truthful, and they bear so fully on the present position of the trade, that we deem it right to give them all the publicity we can. They are evidently the result of careful observation and inquiry ; no practical person will dispute their accuracy; and it would be fortunate indeed if those most interested would follow the advice given; for certain it is that something must be done to render us less dependent on the foreign supply." 


\section{$734)$}

\section{N D E X.}

\section{A}

Aberdeen-Manufactures, 426.

Yarn and Linen made, 538.

Thread made, 539-Mills, 540.

Exports, 540-Spindles, 540.

Decline of Trade, 541.

Aberdein, Gordon and Co., 518, 577, 655, 723.

Abernethy, 483-Abernyte, 483.

A bingdon, 66, 387.

Achan's Covetousness, 182.

Adam, 120, 121.

Adamson, John, 549, 654.

Adie, A. and J., 656 .

African Company, 430.

Agricola, 206, 578 .

Alexander the Great, 180, 191, 195, 220.

Alexander Severus, 206, 223 .

Alexandrosky Works, 336

Aloe Fibre, 107.

Alva, Duke of, 362.

Alyth, 484.

Amestris, Queen of Xerxes, 191.

Amiens, 315.

Amorgos, 193, 195, 196, 222.

Amsterdam, 291, 293.

Anderson, A. B., 67.

Anderson, William, 67.

Anderson's History of Commerce, 360.

Anglo-Saxons, 356, 357.

Anne, Queen, 392, 393.

Annan, David, 508-Annan, James, 493.

Antwerp, 292, 393, 304, 362.

Appendix, 724 .

Arachnè, 190, 219.

Arab Tent, 123.

Arbirlot, 485 .

Arbroath-Jute spun, 80.

Osnaburgs first made, 541.

Town Clerk's Account, 542.

Pennant's Tour, 542.

Linen Stamped, $542,546$.

Sailcloth made, 542.

Elders of St Vigeans, 543.

Scrims and Thread made, 543

Spinning Mills, 543, 545.

Vicissitudes of Trade, 544 .

Bleachfields, 545.

Discount of Bills, 545 .

Dundee and Arbroath Railway, 545.

Prices Current, 547.

Power-Looms and Spindles, 548, 654.

Flaxdressers, 548.
Production of Linens, 548.

Archangel-First Russiau Port, 320.

Imports and Exports, 321, 322 .

Character of Flax shipped, 322, 324.

Brack and Classification of Flax, 323 .

Consul Renny's Report, 324.

Linen made, 336.

Arete, Queen of Phoeacia, 189.

Argyle, Duke of, 443.

Aristophanes, 193, 223.

Ark wright, Richard, 373.

Assaville, Nicholas D', 448.

Athelstane, King, 356.

Athena, Goddess of Weaving, \&c.,190, 192.

Athenian Ladies, 192, 223.

Athens, 191, 194.

Attica, 192.

Auchterarder, 485-Auchtermuchty, 485.

Augustus, 206, 220.

Aurelian, 207.

Austria-Made Linens early, 285.

Flax and Hemp grown, 286.

Dependent on itself, 286.

Manufacturing Industry Arlificial, 286.

Imports and Exports, 287.

Goods in Transit, 288.

Spinning Mills, 288.

Linens in Exhibition, 288.

A voch, 486.

Aytoun, James, 71, 79, 510, 566, 691.

Aytoun, R. and A., 655 .

Awnings of Linen, 206.

\section{B}

Babylon-Magnificence of, 136.

Fabrics costly and prized, 182.

Silks, 182.

Flax grown, 183.

Weaving Establishments, 182.

Baker, Mr, Inspector of Factories, 379, 732.

Baldwin, Earl of Flanders, 249.

Balfour and Cumming, 654 .

Balfour and Meldrum, 65, 68, 72.

Banff, 486.

Bank of England, 430.

Bank of Scotland, 433

Bannockburn, Battle of, 229, 422.

Barber, Nephew, and Co., 727.

Barcelona, 264.

Barnsley, 385.

Barry, 487. 
Basil, linperor, 197.

Bnsque l'rovinces, 263.

Havaria, 273.

Baxter Brothers and Co., 382, 614, 621, 711.

Baxter, John, 6rH.

Bayeaux Tapestry, 356 .

Belfast-Linen Trade settled in, 394.

Linen Hall erecter, 395.

Spinning Mille, 404, 4(5).

Queen and Prince Albert's Viait, 405.

Metropolis of linen Trude, 417.

Imports and Exports, 419,420 .

Belgw introducel Linen to Brituin, 354.

Belgium - Flax Culture, 23, 39, 298.

Spinning and Weaving Factories, 299.

Linens made, 299. Bleaching, 2:99.

Imports and Exports, $30 \mathrm{~m}$.

Linens in Exhibition, 302.

Benholm. 491-Bendochy, 491.

Benjamin of Tudela, 173.

Berlin, 275.

Berrie, Alexander, 656.

Berthollet, 720.

Bervie, 489, 692.

Beveridge, Frskine and Co., 557.

Bezaloel, 130 .

Bilboa, 264.

Bielefield, 275, 276.

Birnie, David, 589.

Birsay and Harray, 491.

Blair, Andrew and Co., 655.

Blair-Athole, 491.

Blairgowrie-Jute-Spinning, 80, 550.

Spinning Mills, 239, 549.

Linens Stamped, 549.

Spindles and Power-looms, 550, 654.

Bleaching-Greece. 193-Spain, 199.

Holland, 295, 717-Be]gium, 299.

England, 366-Irelaud, 409.

Scotland, 426, 430, 447, 449, 720 .

With Kelp, 449--Diy Bleaching, 570.

Dundee, 599, :22.

Linen, 716-France, 718, 719.

Grants to Bleachfields, 448, 719.

Chlorine. 720-Chloride of Lin", 721.

Steam, 721-Soda Ash, 721.

Washing by Machivery, 721.

Forfarshire, 723 .

Blue Books, 661.

Blyth, H. and T., 656 .

Boadicen, 354 .

Bosrd of Trustees for Scotlanil.

Patent for Appointment, 445.

Rules and Regulatious, 445.

Extracts - Minutes and lieports, 448.

Boetius, Hector, 484, 579.

Bohemia, 287.

Bois-le-duc, 292.

Bologna, 253, 255 .

Bolton and Watt, 510 .

Bonelli, Chevalier, 714.

Borneo Company, 81.

Borsippa, 183.

Boston, 3H8.

Boswell, St., 533.

Bothwell, Earl, 579.

Bounty-On Hemp and Flar Impoiter, 368.
Ohject of (irnting, 603 .

Acts Authorising, 663, 664, 665.

Injudicious, 664, 668, 669 .

(On Exports, 666, 670 .

Frouds of Merchants, 668.

Abolition, 667, 669 .

Boyack, William, 71.

Brabant, 227, 286, 2200, $29 \%$.

Brechin-Osuaburg Manufacture, 551.

Spinning Mills, 552.

Bleach fiuth, 552.

Linen Stamped, 553.

Power-Isoms, 554.

Brehon Laws, 38!9.

Bretagne, 304, 314, 315.

Brice's Universal Geography, 584.

Brillport, 386.

British linen Company, 238, 442.

Britons - Noticed by old Historians, 353.

Clothed in Skins, 353.

Yainted their Bodies, 353.

Span and Weaved Tartan, \&c., 353.

belga introduced Linen, 354.

Romans introduced Civilization, 354 .

Wrapped their dead in Linen, 35.5.

Retreat into Wales and Cornwall, 355.

Brough, Thomas, 656.

Brown, Andrew and Co., 656.

Brown, James, 589.

Brown, William, 589, 690, 694.

Bruce, King I avid, 578.

Bruce, King Robert, 359.

Bruges, 249, 290.

Brussels, 299, 301.

Buist, Alexander J., 656.

Butter Milk, 718, 720 .

Byssus, 130, 141, 186, 215.

C

Cadiz, 263.

Casar mentions the Britons, 353.

Caird and Co., 530.

Cuird, Edward, 656.

Cairnie, 491.

('airncross, David, 699.

Caledonians, 42:.

Calendering Machines, 460, 614 .

Calico-With Flax Warp, $370,374$. Penalties on Weaving, 369.

Cambray, 293, 306-315.

Cumbric, 293, 314, 315, 363, $3 \pi 1$.

Cambuslang, 492-Caputh, 492 .

Cargill and Co., 520, 723.

Cargill, T. and J., 656.

Carimus, Emperor, 207.

Carmichael, J. and Co., 603, 199.

Carmichael, John, 723.

Carmichael, Peter. 712, 714.

Cassiteridis, The, 353 .

Catalonia, 2ti3.

Carthage-Hebrew spoken, 180.

Founded by Dido, 181 .

Inported Flax, 181.

Emporium of Trade, 181.

Taken by the Romans, 181.

Introduced Linen to Eurvipe, 2:0.

Catullus, 187, 200, 217.

Ceres, 493.

Chalmers, Charles and Co., 650. 
Champagne, 304.

Charlemagne, 201, 249.

Charles II., 391.

Charles III. of Spain, 262.

Charles IV. of Spain, 262.

Charley, William J. P., 420.

Chaptel, Mons., 721.

Cheffelle, Louis, 655.

Chemmis, 172.

China, Early Acrount of, 173. Flax, 173, 345. Linens, 345.

China Grass-A Nettle, 95. Cultivation, 95-Preparation, 97. Not suited for Spinning, 98.

Chlorine, 720, 721.

Ciampini, 701.

Cleopatra's Gallery, 139.

Cluny, 493.

Colchis-An Egyptian colony, 184. Grew Flax and Hemp, 184, 185. Exported Linen, 184, 195.

Cologne, 277.

Combe and Co., 684, 699.

Commercial Restrictions, 231.

Companies of Merchants, 360 .

Comrie, 493.

Constantine Palæologus, 343.

Convoys from Leith Roads, 438.

Copenhagen, 339.

Copland, Professor, 720.

Corinth, 196.

Corsar Brothers, 654.

Corsar, David and Sons, 654 .

Corslet of Amasis, 165, 213.

Cos, Fabrics of, 188, 195.

Cotton Bagging, 439, 467, 600, 617.

Cotton Manufacture, 373, 374, 563, 598.

Cotton Sailcloth, 347.

Council of Westminster, 358.

Coupar Angus, 454, 494.

Courtrai, 299.

Cox, James, 572.

Cox Brothers, 573, 620, 656, 714, 723.

Crail, 494.

Craik, J. and H. and Co., 654.

Crete, 344.

Crichton, Archibald, 592.

Crichton, James, 58.

Crieff, 495.

Crommelin, Louis, 392.

Crompton, Joseph, 710.

Cromwell, 580.

Cronstadt, 325.

Cruelties of the Spaniards, 229, 263, 293, 362.

Cullen, 496

Cumberland, 387.

Cunningham, J. L., 656

Cupar-Fife, 495.

Curr, Willianı and Co., 654.

Curry, Walter, 579.

\section{D}

Dacca-Jute grown around, 60 . Cloth made, 162. Celebrated Manufactures, 188

Daniel's Vision, 140.

Darien Compnny, 430.
Darlington, 382, 692.

Davidson, Williarn, 619

Dean Castle burned, 434.

Deer, 497.

Delos, 195.

Demetrius, Chlamys of, 189.

Denmark, 340.

Dewar, D., Son and Snns, 516, 557, 729.

Dickson, John F., 546, 723.

Dickson and Co., 317, 3:8.

Dio, 422.

District Trade, 483, 538, 577.

Domestic Trade, 481.

Donald, James, 574, 656.

Dorian Dress, 191.

Dorset, 386.

Dorsetshire Gentleman, 375.

Douglastown Mill, 512, 692.

Douglas, William, 511.

Dowall, Charles, 546-723.

Dowally, 497.

Drimmie, Alexander, 721.

Drimmie, Daniel and Co., 523, 721, 723.

Druce, Samuel, jun., 376.

Druids wore Linen garments, 355.

Duncan, D. and Co., 723.

Dundee-Dirtet Jute Imports, 65, 619, 620.

Jute introruced, 67, 69, 71.

Imports, 240, 587, 613, 633 .

Exports, 309, 587, 601, 606, 608, 613, 635.

Chamber of Commerce, 403, 603, 611, $630,666,667$.

Stormed by Monk, 426, 580 .

Offered a Spinning School, 448.

Bleaching with Kelp, 449.

Antiquity of, 578.

Second Town in Scotland, 580.

Decay of Trade, 581 .

Manufacture of Thread, 582, 612.

Could not support a Bank, 582.

Harbour, 579, 580, 583.

Mobs in, 582, 603.

Account of, by S. Homespun, 583--

Brice, 584 - Pennant, 584-Dr Small, 584,

Hereditary Jurisdiction, 584.

Various Trades, 585.

Price of Flax, 587, 608, 609, 616.

Mill-spinning, 589, 591, 592, 613, 630, 656.

Bell Mill, 590.

Capital in Spinning Mills, 591, 632.

Mills for Sale, 591 .

Mills in Neighbourhood, 593, 654.

The Luckenbooths and Hand spinning, 595.

Difficulties of early Spinners, 596.

Night Work, 598-Heckling, 598.

Cotton Manufacture, 598.

Bleaching Prices, 599.

Russian Merchants, 601.

Whale Fishing, 601.

Manufacture of Sailcloth, 602.

Punishment for Theft, 602 .

Foreigners may be Free, 603.

Engineering, 603-Shore-duen, 603.

Ijiven Stamped, 604. 
Wages, Gon, 610, lill, 61:2, 61s, lisl. buunty on Linen, (i)t.

Length of Welw, 6ill.

Mucubility of Trule, 612.

Power-Lnom, 613.

Calendesing Machinery. 615.

Convulsions in T'rule, ilti.

Bagging and Railway Manius, 617.

Crimean amd Americul Wars, 618.

'rusprerity, til!).

Inprovements in Mills, ti21, 625.

The Fiax liade, 621

Flax Warehouses, 6:2.

The Cow rate, 6i29.

Fabrics Manufactureel, 630.

statistics of 'Trad"., (53), 631.

Con-umption of Ruw Miterial, Gi3l.

Production of Y Yrns and Cloth, 631.

13.nefits lerivel from Jule, $C^{*} 32$.

l'rices Current, 639.

situtistics of Mills and Fuctories, fint. 6 in6.

Dundee Adrertiser, 22, 75, 93, 306, 346, $376,398,413,438,456,4139,513,545$. $553,591.599,600,612,603,604,605$, $616,610,613,614,659$.

Duff, Dauiel, 71, 605.

Duff, Thomsa, 81 .

Duke, D. and N., 5.5.

Dunfermline-New Diaper L)om, 44.

Table Linen, 5.5.

Suecimen of Art 554 .

Spinning-Mill, 55j.

Tyste in Manufactures, 5.55

Iroomจ, 556-Wages, 5i.6.

Pow, r Loom Works, 5i.7.

Fabries made, 558.

Dunkeld, 497.

Duskirk-Flax grown, 314 .

Masufactures, 315

Dickson aud Co's Work, 317 .

Iunnichen, 498-Dunnoter, 494.

Jupiu, Nicholas, 429.

Dura Den, 507.

Julch Government use Jute Yarn, 75.

1) utch not Flax growing, $292,293$.

Dyeing - Jute, 73, 573 .

E:yptian, 162, 167--Phwuicin, 178.

Babylonian, 182-Cirecian, 193.

England, 353-Itelant, $\$ 10$.

1)ysart, 498 .

\section{$\mathrm{E}$}

Easson, Alexauder, 58, 639.

Eistland Merchunts, 36:3.

Fist Mill Company, 5.52, 723.

Ellen, Sir F. M., Gil.

Elict of Nuntes, 231, 305, 367,392 .

Edinburgh, 424, 42x, 421, 439, $44 \%$.

Elinbuigh society, $43 \%$.

Fiward $A H, \mathrm{n}, 65$.

Edward, A. and D. and Co., 614, 623, 656 - Elwart. The Eliler, 3 ix;.

Edward III., 359. - Elwanl VI., 362.

Egyıt-Antiquity, 115.

Trades Her ditary, 145.

Aucient Priutings, 146, 210.

Flax Preparations, $146,148$.

Spinilles nul Spinning, 148, 211. 31
Loouns and Wenvine, 14\%, 21\%.

Cialundoring, 150.

Qunlity uf lincus, 1:50, 152, 153, 155, 161213.

lineu usut for Einbalming, 15 !, 153.

Linen Exported, 150.

1)ress of dilferent rinks, 153, 136, 213.

Meuded Mummy Cloths, 154.

Embalming, 126, 155

Finx Abundant, 156-"Uni ms," 158.

Ancieut (iarmients, 159.

Mummy Cloth all Linen, I60.

I)ell linen, 16:2, 16.4 .

Nets and l'ulterns of Linen, 165

Fold und silver Linbroidery, l6t;.

Wirc Drawiug, 167.

Morilauts used, 167.

Fringes and Carpets, 169.

Twines and Puper, 170.

Gnats, remedy against, 170 .

Papyrus Buats, 171 -Sails, 171.

Lituen male in ' l'emples, 17:.

Flax Exportel, 175 .

Eileitlyins, Grottus of, 147 .

Elgin, 501-Flis, 186, 221, 222.

Elizalieth, Queen, 361.

Emliroilered Work, 128, 133, 159, 1i:;, $182,189,196,213,356$.

Employment for the Unemployed, 366.

Endogens, 105.

Englind-1'eople rude, 220 .

S. $x$ Inn Invsion, 2:6.

F'rogress in Weaving, 227.

Williann of Norman ly, 227.

Visitel by Pløenicial:s, 35:

Flax indigenou*, $3 \% 7$.

Guilis establishel, 358 .

Lineu Imports, $360,372$.

Egyptian, German, and Flemish Linen, 360 , 361 .

Flax from Carolina, 362.

liussian 'Trm e begum, 3 i2.

Flax Culture encourngod, $362,363$.

linen Manufarture encouragel, 3 i3.

Stagnation io Trate, 372.

Inports and Exports, 380 .

Flux-Spiuning, 381 .

Spivdles and Power-Looms, 387.

lish l'ruduce duty free, 39 .

Wuollens assignid to, 391 .

Piemium on Irish Hemp, 399.

Whipping the scotch, $4: 2 x$.

Union with scolland, 431.

Complaints of Woollen Manufacturers, 430.

Fanglish Gallant, 364 .

English Linen Compuny, 371, 499.

Equivalent, The, $430,4.14$.

Encht, River, 550.

Euphraies, River, 18:3.

Ewun, John, Gin.

Excise Dutiea, 381 .

Exogens, 105.

Ez.kiel's Vision, $14 \mathrm{C}$.

\section{F}

Factory Iaws-France. 31.3.

United Kingl, m, fiil. 
Factory Returns, 420, 662, 683.

Fairbairn, Peter and Co., 699.

Falkland, 423, 501.

Fashions, Change of, 369.

Fergus, John and Co., 516.

Feryusson, William and Sons, 656.

Fibres of Plants, 4, 273, 683.

Findlater, Earl of, 496 .

Finisterre, 316.

Flanders, 227, 285, 290.

Fraser, Douglas and Son, 654 .

Flatterer, The, 714 .

Flax - Names, 4-Án Annual, 4. Description, 4.

Varieties, 5, 127, 146, 255.

Climate required, 6.

Seed Valuable, 7 .

Sowing Seed, 10, 33.

Produce per acre, 11, 255, 374, 377.

Composition of Plant, 12.

Soil required, 13, 32.

Rotation of Crops, 14, 33, 256.

Sowing, 16, 33, 146-Manure, 16.

Weeding, 17, 34

Pulling, 17, 34, 146.

Steeping, 19, 23, 28, 37, 147, 143, 378.

Rippling, 20, 35,

Preparing-Lee's Patent, 21, 22Shenck's, 26- Watt's, 27.

Spreading, 26, 38.

Dew Retting, 26, 323.

Scutching, 29, 39, 146.

Manage ment of Crop, 31

Courtrai System, 23, 39.

Prices, Riga and London, 113.

Antiquity, 126, 127, 146.

Where Grown-Canaan, 127, 215-

Egypt, 145, 210-China, 173, 345

- Babylon, 183 - Colchis, $184-$

Greece, 186, 197, 221-Italy, 201, 253, 255, 258-Spain, 199, 224, 260,

265-France, 201, 303, 312, 314, 358

- Germany, 267, 271, 275-Austria.

286-Holland, 295, 297-Belgium,

298-Russia, 323, 326-Portugal,

340-Turkey, 344-America, 346-

England, 357-Ireland, 388-Scot-

land, 242, 439.

Fibre in straw, 273.

scotch and Irish Contrasted, 401.

Progress of Cultivation, 724.

Flax and its Products in Ireland, 420.

Flax Seed-Food for Cattle, 7, 20, 378.

Yield of Oil, 7-Imports, 8, 373.

Should be Saved, 19, 20, 438 .

Flax Heckling, 683.

Flax-Spinning, 130, 134, 187, 188, 215, $223,243,246,683,684,692$

Fleming, David H.. 656 .

Fleming, Robert, 629.

Fleming, W. and J. and Co., 50.5.

Fleming, W. and R. H., 656 .

Flemings-Love of Lib rty, 289.

Enjoyed Commercial Freedom, 290.

Weaving a Gift to, 358 .

In Scotland, 424.

Fletcher, Alexander and $\mathrm{C} \%$., 50\%.

Fordoun, 502-Fordyce, 502.

Forfar-Osnabuigs made, 558.
Fluciuations in Tra 'e, 559.

Linen Stamped, 559.

Wages, 559, 561 .

Value of Limens made, 560.

Hand and Power-Lonms, 560.

Bleachifield and Caleuder, 56?.

Fabrics made, 561-Castle, 578.

Forfarshire, 385, 463 .

Forgan, 502-Forres, 503.

France-Imports aud Exports, 80, 81, 305, 306, 307, 311, 728.

Soil adapted for Flax, 303.

Linens early made, 304 .

Popish Persecutions, 30 i.

Yarn to Duudee, 307, 728.

Exports, Uuited Kinglom to. 30 .

Do., Dundee to, 309-Tariffs, 309.

Acreage under Flix, 312.

Spindles, 312, 313.

Factories and Factory Laws, 313.

Fine Flax grown largely, 314.

Prosperous under Napoleou, 316, 317.

Linen in Exhibition, 318.

Fraternity of Scissors, 359.

French Cambric prohibited in England, 370.

Friesland, 295-Frist stops Wearing, 451.

G

Ga'gacus, 578-Galston, 503.

Garments, Seamless, 129, 130, 554, 568.

Gaul, 199, 200, 203, 353.

Gas introduced into mills, 537.

Gennes, M., 709-Geutle Shepherd, 241.

Genoa, 256, 257, 264-George IV., 402.

Geraldus, Cambrensis, 389.

Germanic Union, 278.

German Ladies, 224, 354.

German Fairs, 280.

Geı many - Linen wuve under ground, 200

Manufactures Ancient, 266.

German names of Linens, 267.

Linen Manufactures, 279 ,

Fiscal Regulations, 279.

Linens in Exhibition, 284.

Ghent, 299, 301-Gibbon, 166.

Gilchrist, Alexander, 516.

Gibson, Farquhirson and Co., 656.

Gilroy Brothers, 65, 79, 620, 625, 656.

Giovani Bolero, 305.

Glasgow, Manufactures established, 428.

Exported Linen to BristoI, 430.

Rol'e Work erected, 430.

Woodrow's Account, 432.

Manufacturing Progress, 433, 504.

Lapping Machines, 449.

Glamis, 504-Gordon, George, 654.

Gordon, Barron and C.., 721.

Gord ( $n$, G. and A, 654, 655 .

Gordon, John and Co., 656.

Gourlay Brothers, 699.

Gourock Rope Work Company, 505.

Grange, 505.

Great Britain -

Importations from Ireland, 398-399.

Imports and Exports, 658, 659, 666 .

Revenue from Flax, \&o., 660.

Consumption of Linen, 665 .

Greece-Description, 185. 
Giew Flax, 186--Iadien of, 187.

Fimployment of Woinen, 188.

Needle Work, 189.

Hemp Fabric, 196.

Manufuctures, 196;-- Fixjoits, 196.

Infrorts of Linen, 1:\%.

Gienock Spinning Compuny, 506.

Crimond, Divid. 550-6.i4.

Grimonil, Jumes, 71. Jiv.

Grimond, J. and A. D., 6:5. 6.36.

Gunny Cloth, 53, 60, 84, 347, 348.

Guthrie, J. nnil A., 653 .

\section{$\mathrm{H}$}

Haarlem, 291, 244, 295.

Huddington, Farl of. 5\%l.

Haggart, Janes, 516-Haller, John, 71.

Halley, William and suns, 656.

Hamburg-Iniports and Exports, 50, 66, 283-Founded, 249.

Han's Faniiy male Linen, 118.

Hanover-Famed for Isinen, 267, 271.

Napuleon and Trale, 271.

"Linn.n Ieggen," 272

Exports, 2\% 2 -Stamp Act, 272.

Linen in Exhibition, 254.

Hansestic Lengue-Funation, 228, 282. Extent of Trale, 283.

Hargraves, James, 373.

Harlots - Distinctive Dress, 133.

Harold, King of Norway, 356.

Hasselquixt-Egyptian Linen, 172.

Hebrew Clothing, 137.

Heckling, 598, 683.

H-ckling IInchine, 684-Hertor, 189.

Helen-Industry of, $135,187,189$.

Helespunt, Bridge over, 194.

Henip-Names, 41 -Male and Feinale, 41. Exhilarating Propertic s, 42.

Thracian Garment 42 .

Sowing, 43, 45, 25.4.

Soil, 44 -Pulling, 46 .

Stcepine, 47, 254-Grassing, 47.

Scutching, 48, 255-Produce, 48.

Various qualioins, 44, 4i, 45, 25:3.

Imports and Expurts, 110, 111, 116, $117,610-10$ ty paid, 660.

Henderson, Alexader, 6isi.

Henderson, H.nry and son", 612 .

Henderson, John and Sons, 656 .

Hendiy, John, 5izf.

Hendry, J. and W., 65\%.

Henry, Thonias. 67-Menry III., 358.

Henry IV. of Frauce, 305.

Henry VII., itil.

Henry VIII., 3ij-Merodian. 422.

Herolotus, 149, 177, 182, 1-3.211, 3\%3, 700 -Hikiscus, Descrifitim, 117.

Highlanls - Manufacture's tried, 4.2.

High Pri-st's Garnents, I:29.

Hiram, 132.

Hodges, Professor, 11, 12, 418.

Hoile, J. and Co., tist.

Holland. Love of liberts, 289. Privileges of the Flemings, 290

Clo:h Hulls. :291.

I $2 x$ nfull of Trade, 294

Litnited Manufactures. 20.5.

Imports and Exporta, 29ti.
Jute Yinrms manufactureil, 296, :97.

l'lax und Hemp grown, $2 y 7$.

No Statisticn of 'Trade, 298

Hullinshead, 4:2: 578.

Humespun, Samuel, $374,583$.

Homer, 135, 177, 187, 18!, 2115.

Horen's Prophecy, 140.

Housrkeeping in Greece, 19.1.

Hull Imports, $38 \%$.

Huntingdon, liarl of, 579-11uutly, 505.

Huntly, Marquis of, $4: 3,4: 6$.

Idol' dress, 137-Illiad, 183 .

Ireh Blonching Company, 5.22, 723.

Inlia, Anc ent trade with, 162.

India Flax Company, 724 .

Inverary, 50i-Invernesk, 50d.

Ireland-Lejislition, 231 .

Lineo Board appointerl, 232, 393.

Iuspectors appointed, $232,395$.

Trade settled in Ulster, 233.

Flax steeperl in remote tiues, 388.

Erportenl Linens carly, 38.

Women goud spinners, 390.

Linen Manufacture encouraged, 390.

Fixports of wool prohibited, 391 .

Ruin of Woollen Trale, 391.

Linen Trade assigned to, 39L.

Protestant Linens encouraged, 392.

Linen Scarfs at Funerals, 392.

Premiums and Granıs, 394, 400.

Transactions of Trustres, 394.

Seals Issued, 395.

Domestic nature of Trade, 395.

Distıict market $\mathbf{3 9}$;.

Bounty to Linen producers, $\mathbf{3 9 6 .}$

Exports and Import. 3!7, 398, 399, 408 - Bounty on Irish H'mp, 398.

Bounty on Lines exported, 398

Cross Channel Trade Coasting, 399.

Tour of Inspection, 400, 403.

Two-handed Wheel, 400 .

Kilu-drying Flax, 401 .

Inferior flax seed, 402.

Dntch Agriculturists, 403 .

Late Introduction of Mill-spinning, 404-First Spinuing Mills, 404.

Grants to Trustees withdrawn, 404 , 405 - Roval Flax Soci.ty, $40 j$.

Victoriand Allee $t$ visit lic fust, 405.

Spinning Mills, 40\%, 727.

Vulue Linen Mannfacture, 406,418

II. rielspun Yaro, jOt.

Spindles, 40i, $4: 20,727$.

lower-Ioom $407,420,727$.

Quality of larn and Linen, 408.

Linens in (ireat Exhibition, $\$ 10$.

Acreage of $\mathrm{k}$ la $\mathrm{x}$ grown, 411,412 .

Value Flax Crop. 413.

Market Rejurts, $114,415$.

Progress of cultivation, 415.

Quality of Irish Flax, $\mathbf{4 1 5}$.

Fin Seed, 417 .

Trade centralised, $\$ 17$.

lervous employed, 418.

Flax and its Prudisct.a \$2

Ireland, fieorge, jun., 6ini.

Irnus. James, 6.j6. 
Isaiah-Zion's daughters, 136.

Italy -Flax grown, 201, 253.

Free Cities, 248, 252.

Flax Cultivation, 253, 256.

Districts where grown, 256.

One Power-Loom, 257.

Priests, 259.

Imports and Exports, 259.

Ivan Vassiliewitch II., 320 .

Ivory, James and Co., 238, 458, 490, 512.

\section{J}

Jacob's Garments, 124.

Jacquard Machine. 556, 707.

Jaffe Brothers, 629.

James II., 367, 427.

James III., 579-Jeffrev, John, 655.

Jesus, Seamless Coat, 130.

John, King, establishes Guilds, 358.

John, Saint, 143.

Jolnson, Ben, Silent Women, 363.

Johnston, G. and J., 536.

Joseph's Coat, 124, 126. - Josephus, 129.

Jute-Long grown in India, 49.

First importation of, 50 .

Experimental Cultivation, 50, 725.

Varieties and Description, 51, 83.

Names, 51, 52, 53-Job, 52.

Sowing. Soil, and Climate, 53.

Roots, 54-Kunners, 55.

Reaping, 55 --Steeping, 55.

Scutching, 56-Produce, 56.

Grown in Dundee, 58.

Stalk or Stem useful, 58.

Colour, 59-Uses in India, 59.

Gunny Clotll and Bags, 60 .

Whisky made of Roots, 6i).

Transport to Calcutta, 61.

Bazaars, 61.

Public Packing Houses, 61.

Size of Bales, 61-Packing, 62.

Shipment from Calcutta, 62.

Sold by B: okers in England, 62.

Auction Sales, 63.

Intermediate Agents, 64.

Direct Shipments to Dundee, 65.

Selma, first direct Ship, 65.

Spun on Hand-wheel, 67.

Disliked by Mill-spinners, 70, 77.

Bad repute of, $71,76,78$.

Carpeting, 72-Dyeing, 73.

Iruports into Dundee, 76 .

Batching, 77.

Fibres, Hard and Dry, 78.

Weaved without Starch, 79.

Appearance sightly, 79 .

Fabrics made, 79 .

Extending Consumption, 80.

Inıports into France, 80.

Cotton, 82-Wool, 82

Extent of Crop, 83 .

May be Washed or Briled, 83, 84.

Esports from Calcutta, 8t, 86, 726.

London Stutistics, 85.

Stock, 88, 727.

Imports, 89, 110, 111, 115, 117, 66 .

Price», 89, 108,110

Countries whence Inınorterl, 115.

Exports, 116.
Ports it: to which Impoited 117.

Manufictures Exported, 678.

Consumption, 727 .

Jute Fuctories, 680, 681, 682.

Jute Yarns-Largely used in Holland, 296-Expirts, 678.

\section{$\mathbf{K}$}

Kay, John, 703

Keith, 507--Kemback, 507.

Ken lrew and Porthouse, 239, 381, 458, $489,510,512,690,695$.

Kenmore, 508 -Kettle, 508.

Kennedy and $\mathrm{C}_{\text {o., }} 656$.

Kerr, John and Co., 699.

Kill'archan--Thread Manufacture, 434

Kilbride, 508-Kilchoman, 509.

Killin, 509-Kilwinning, 509.

Kilmarnock, Earl of, 434.

Kinghorn, 510, 655-Kinloch, 511.

Kinmond, Luke, and Co., 657.

Kinnettles, 458, 511.

Kinross-P itriotic experiment, 433, 514.

Kirkcaldy-Shipping, 561.

Linen Manuf acture established, 561.

Fluctuations in Trade, 562, 565.

Linens Stamped, 562, 563.

Ticking Manufacture, 562 .

Looms employed, 563.

Power-Looms erected, 565.

Spindles and Power-Looins, 567, 655.

Kirkden, 514.

Kirkland Wurks, 22, 239, 536, 710 .

Kirkwall and St Olda, 515 .

Kirriemui -Flax Cultivation, 567.

Curious articles made, 568.

Linen Fabrics, 568, 569 .

Linens Stamped, 569 .

Looms, 569-Wages, 569.

Kitto, Dr, 216.

Konigsberg -Flax Exports, 274, 275.

Convenient Shipping Port, 334 .

Kyd, James P., 654.

\section{$\mathbf{L}$}

Lace, 299, 301-Lacedemonians, 196.

Laing, John, 614-Laing and Ewan, 656.

Laird and Co., 654 .

$L \cdot \mathrm{mb}$ and Sco t, 554 .

Lancashire, 385-Largo. 515.

Lawson, Alexa : der, 508 .

Leadbetter and Co., 11.

Leather Tanning, 426.

Lee's Flax Preparation, 21.

Leghnrn, 264-Leeds, 378, 382, 383, 384.

Leipsic Fair, 280, 401.

Leland, 389-Leprosy, 131.

Leslie, 515--Lethendy, 516.

Leuchars, 516-Ley.len, 293.

Libau, 331 -Lille, $31 \tilde{\text { D. }}$

Lime or Linden Tree-Ornamental, 103. Yields Sugar, 103,

Raw Material for Mats, 103.

Cut Young, 103- Steeping. 103.

Uses to which Bark is applieı, 104.

Large production of Mats, 104.

Lin-u-Antiquity, 1, 118, 126, 210.

Countries whence Imported, 115. Healthy to Wear, 122. 
Fist mentioned in Scripiures, 125. Wrapped nround the Deid, 126, 142. C'urtains of the 'Tubernule, 128. Veil of the Holy of Hulies. 12s.

Sicerlotal Girments, 129, 144, 157, $198,214,215,3 i-1$.

An linblem of Purity, 130, 131, 140. $144,2 ' 4$.

Thed in the Willerness, 131.

Hooks, 132-Jiphods, 129, 132.

V:1 ptian, 1:32-H. brew Numes, 141. Whete Mado - Egypt, 145, 210lisyptian Temples, 17:2-C - Cina, 173, 345-Carthnge, 1-1 -- Baby. Jotia, 183 Colchis, 181-Ciecer, 187. 188, 192, 193-spaiv, 199.

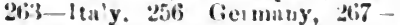
Prussin, 20i7-silesia and Suxuny, 267,269 -Hulland, 290-Belgium, 209-Fınce, 303, 31:-Russia, 336 -Turkey, 344-By the Belgn, 35-Imperial Colloge, Wunchester, 35i-Englant, 355-Irelund, 359 -Scotland, 4\%2.

Texture tine, $188,193$.

(iernan Numes, 267.

Imports und Exports Bel:ium, 300 - France, 311 - Russia, $32 \%$-Delsmark, 340--Portugul. 341-New York, 350, 729-Uuited Kingilom, $673,678$.

Found in British Burrows, 354.

Exported from kingland, 361.

Manufacture neouraged in England, 363-Qumlity mule in Irvlın!, 403.

Manufac' ure established in Sent!and, 430--Stamped in scotland, 476.

Wenving, 700 .

Dis, by wliom Invented, 700.

Linen Bl, aching. 716 .

Jinen Hall, $343,3: 7,402,405,451,4$,

Linen Tradu Circular, 406, 407, 414, 416, 417.

Linen Yarn-Countries whence Imporlel 115 linported by Sol.min, 132.

Imports an! Exports, 300, 311, 37:, $398,673,678,679$.

Iinseor, 8-Liuseed ()il, 7,8 .

linsey Woolsey, 131

I.nt B.ors, 21, 451 .

Liitle D'unkelil, 517-Iivy, 132.

Wuchee- Barly Linen Manufucturn, ni,

Linen fubrics made, 571.

Alicient family history, 5id.

Camperduwn Linen Wuk*, 573.

Other Wurk" 5ït.

Iorkhart, N. and $\mathbf{N}, 521$.

L gremit, 5ls - L vie l'ert, jls.

lomharly, 2it; -London, 3in, 38i.

Longforsan, 519 lornty,

Loon-Figyptin1, 149, 21:, 225, T(x).

Isr.iclitish, 1:30, 216.

Kuman, 204, 218, 225.

In Prussia, $2 \pi 4$.

II Englanil, 387, 680, 6i:.

In Ireland, 407 , 6is 1 , $08 \%$

In Siotlund, 439, 680 6:2.

Improventents, fo:

Indian, 701,713 .
Hand, 70:-Power, 712.

Lornie and Cu., 657.

Low, Alexuniler, 657 .

Low. Andrew and Son, 71 .

Inw, Jnmes F., 69.

Low, Matthew, 654.

Louvain, 28ci, 291.

low son, A nilrew, 654.

L)wson, John, Jun., fiit, 72 ,

luwson, John und Sou, ti54, 723.

Lucis, Charles and Cu., 657.

Iumgair, Robert, tist.

L.umsilen, David, 530.

Lumslen, William and Son, 5(11.

цун, River, 23, 199.

\section{M}

Maberly anl Co., 6i, $5 \$ 1,711$.

Macelunuld, Archinald, 6is.

Muphersun, $355,389,390,397,413$.

Mudox-History of Exchequer, 35.8.

Mulaga, large Power-Loum Wirk, 26i.

Mains, 519-Malcolın, A. G., (jis.

Inlculm, James und Suns, 657

Malcolm, Ogilvie, and Co., 657.

Manchester, $373,3.49$.

Manill. Hemp-Indigenous to Mhillipine's Islanils. 100.

Description of 1 lant, 101.

Ireparation of Fibre, 101.

Increase of Exportation, 101.

Purposis adapted for, $10^{*}$.

Mataufacturung Operatives, $6 \div 3$.

Mirco Polo, 17:3-Markinil, 52 )

M. rshull and C'o., 377, 352, 35.3, 351

Marslaall, Sandeman, an! ('o., 5iso.

Martin, David and Co., 65.

Mary, Queen of Scots, $42 \%$.

Matilda, Queen, 3iti.

Mathers anil Chilmers, 657.

I: $\mathrm{x}$ we!l, J. Hall, 440.

II Culluch's Dictinnary, 83.

M'Intyre, John, 7\%2, 7:3.

M'Intyre, W. A. and Co., 7:2*, 7:3.

II'Kenzie, Kuderick, Sis

Hoh+met Nli, 174 .

Muigle, 5:1-Heir ose, 5:21.

Mem.

Menmuir, 522-Metliven, 523.

Miller, 1\%. G., 6i27, tio

Miller, Willinm, $2(y)$.

Miller Thomas, 500.

Min rva, 204, 21!, (i25.

Mitchell, John, 620.

Mithridates, 19\%.

Muir, Jilut and Son, $65 \%$

Honcur, Al xamler and s in, bit.

Moncur, 1), and J., 620.

Mesucur, John, 6.H.

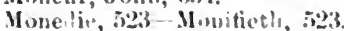

Monk Siermel Dumlere, $420,501,580$.

Vonklaml, Fast, 5ou-Do., West, i2:

Iontanue, Lady, 193.

Montruge-Innual I.inen Maket,

Sailcloth Companu.s, its.

Pennunt's Tour. ifo.

Linen - tampel, 5io.

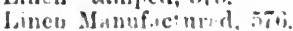

Lace Shonl, 5 is 
Flax Mill for Sale, 576.

Spindles and Power-Looms, 577, 655. Goods made, 577-Wages, 577.

Monzie, 524-Moon, George, 694.

Moors of Spain eucouraged 'I'rade, 260.

Noravi:1, 287-Mordecai's A pparel, 136.

Morer's Account of Crops in Scotland, 428.

Morison, W. R. and Co., 627, 657.

Morrice, John, 654.

Moryson, Fynes, 423.

Moscow, 320-Moulin, 524.

Mudie, James, 577.

Mulholland and Co., 404.

Munro, General, 426.

Murdoch, A. J. aud Co., 520, 723.

Murland and Co., 404.

Murray, Regent, 579.

Musselburgh-Riding the Marches, 434.

\section{$\mathrm{N}$}

Naples, 258.

Napoleon, Emperor, 271, 306.

Napoleon III., 317 Narva, 326.

Nebuchadnezzar, 180.

Needl-work, 124, 129, 133, 192, 357.

Neilson and Co., 710-Neish, James, 74.

Neish, Thomas, 68, 69-Nero 182.

Netherlands-Cloth Halls, 291.

Revolt, 293-Trade Injured, 294.

"Iariff, 295-Trading Company, 296.

Nettle, 95-Newburgh, 525.

New York, 350.

New Zealanil Flax-

Discovered by Captain Cook, 98.

Description, 98-Pı eparation, 99.

Strength of Fibres, 99.

Spun into fine yarn, 100.

Corilage for Moilel Frigate, 100.

Nicol, Al-xander and Co., 654.

Nicoll, A. and J., 657-Nineveh, 183.

Noah and his Family, 118, 123.

Noble, G. and J. A., 80, 106, 108.

Nomadic Life, 122-Norfolk, 386.

Normand, James and Son, 500 .

Normandy, 304-Norrie, Charles, 75.

Norrie, Charles and Sons, 560, 723.

North Yell and Fetlar, 527.

Norwich, 362-Novgorod, 320, 322, 336.

\section{$\mathrm{O}$}

Odyssey, 180, 187.

Ooilvy, John and Co., 654.

O-nal urgs, 451, 541, 558.

Osnaburg Yarn orilered, 451.

O: phir, 527- Ovid, 219.

\section{$\mathbf{P}$}

Paisley, 527-Panmure Works, 488, 715. Paral States, 257.

Parker, Charles and Son, 699.

Parker, Edward, 574, 657.

Paterson, James, 657.

Paterson,William--Bank of England, 430.

Paton, J. and G., 577, 655-Putræ, 192.

Pearce Frothers, 699 -Piedmont, 257,

Penelope's Industry, 135, 188, 189.

Prnnan's Tour, 436, 542, 575, 584.

Periplue of the Erythiain Sea, 173.

Peruau, 328.
Perth, 528-Peterhead, 531.

Peter, H. and T., 537.

Pharaoh's Daughter, 133.

Philip and Mary, 320.

Phœnicians-First Merchants, 176.

Fleets visited Britain, 177, 353 .

Circumnavigated Africa, 177.

First used Canvas Sails, 177.

Founded Carthage, 177.

Traded in Red Sea, 178.

Tyrian Dye, 139, 178.

Silk Manufactures, 179.

Picker Lay, 703-Plutarch, 157.

Picts, The, 578-.Plowgates, 241.

Pliny, 146, 147, 166, 200, 224, 353, 355, 700, 717-Poland, 334, 338.

Popish Persecutions, 229, 263, 305, 362, 367, 392-Popish Wonllens, 392.

Port, John, Inventory of, 361 .

Portugal-Aocient Linen Trade, 200, 340. Flax grown, 340 .

Hand and Mill Spinning, 340.

Native Consumption, 341.

Imports and Exports, 341.

Slave Trade, 341 .

Postlethwayt, 397, 435, 443, 718.

Power-Looms-In England, 387, 680, 682.

In Ireland, 407, 681, 682.

In Scotland, 439, 680, 682.

Invention of, $457,461,462$.

Description, 712.

Personified, 713.

Improvements, 714 .

Prain, James, 657.

Premiums on Flax and Hemp, 463.

Preston, 385-Priam, 189.

Prince Consort, 377, 405.

Printed Calicoes, 369.

Protestant Linens, 392.

Prussia-Linen Manufacture, 267.

West Prussian Manufac ures, 270.

Exports, 268-Looms, 274.

Expiry of Zolverein, 279.

Linen in Exhibition, 284.

Ptolemy Epiphrnes, 172.

Pythmias invented Weaving, 700.

\section{$\mathbf{R}$}

Rait, James, 654.

Raleigh, Sir Walter, 29:3.

Ramsay, Lady, 576.

Ramsay, $J$ ames and Co., 518.

Rathen, 531-Rebecca's Veil, 123.

Rebellion in Scotla od, 451.

Ree, H. P. and Co., 657.

Reed-maker Settles in Sco'land, 448.

Renny, Consul, 324.

Renny, William Warden, 329.

Revel, 328-Rheea of Assam, 98, 106.

Rheims, 304, 359 .

Richar ds and Co., 519, 540, 577, 6.55, 711, 723.

Riga--Impnr'ant Shipping Port, 328.

Clas-ification of Flax, 329.

Exports, 329, 330.

Marks of Flax, 333.

Richie : Inl Simp : (1). 657.

Rizeh, 344- Rizzio, D.tvid, 42:3. 
Rubh, Alexander-Firat Powrr-I.oom, 457, 710-Kolertson, John, 494.

Robertson aml Orchar, 699, 714.

Kobinson, 'Thomas, 699.

Rome-l'riesls wore Linen, 198.

Manufucturing efferninate, 201, 223.

Weaving Eatablinhm.nts, 202.

Manufucturing Implementa, 203.

Imperial Mnufactories, 20\%, 206.

Court of Sacred Largesses, 205, 226.

A wnings of Linen, 206.

Overthruw, 207

Rope Woks frected, 430.

Rotterdam, 294.

Rowan. Alexauder, 72, 614.

Royal Bank, 433.

Koyal Bur:hs, Convention of, 4 it6. 472.580.

Royal Dublin Society, 393 .

Royal Exchange, 629.

Koyal Insurance Company, 629.

Rugen-Linen used for Money, $27 \%$.

Rural Districts, 437, 483.

Russia-Anciently little known, 229, 319, 320 .

Discrvered ly the Eng!ish, 229.

Greatest Flux-gruwing Country, 319.

Production of Flax, 319.

Pioduce originally exported, 320 .

Government Monopoly, 320.

Monopoly brokew up, 321.

Exports and Impurts, 321, 322, 32\%, $329,330,334$.

Proforma Invoices, 331.

Exports via Prussia, 3:34.

Do. to Silesia, 335.

Value of Exports, 335.

Linens made, 335.

Linens of fine material, 337.

Arbitrary Government, 337.

Tariff on Jute Goods, 338.

Linens in Exhibition, 338.

Removal of Duty on Exports. 729.

Russia Company, 320 .

S

Suckcloth, 124.

Sacred Largesses, Cuurt of, 225, 226.

Sailcloth, 171, 17i, 200, 362.

St Boswell, 532.

St Petersburg - Founded, 325.

Sorts of Flax Shipped, 325.

Classification, 325.

Deterioration of Quality, 326.

Exports, 327.

Salford, 385-Salt on, 532.

Silmond. William and Co., 654.

Samson, Hugh and Sins, 657.

Sandeman, Juhn, 5i30.

Sundeman, Wiliun, 615, 616.

Sandford and M.llory, 8., 105.

Sanuto, a Venetian Iraveller, 174.

Sardinia, 257.

Saunders, George nnd Sons, Girt.

Saussure, M. de, 7:20-Six iny, 267, 287.

Scandionvia, 3:39, 340-Scheele, 720.

Schleselnan, George, 6.57-Sconie, 5332.

Scotland-Manuf.icture introduced. 228.

Linen little used, 230.

Bouril of Trustees, $233,433,444$.
Rebellion of 1745, 236, 451 .

Spinning Schools, 237.

Ijinen Stamped, $237,476$.

Flax grown, 242, 440.

Manufacture encouraged, 371, 427.

Stute of Flux Crop, 400.

Ancient Histury Apochryphal, 421.

Liben early made, 422 .

I)ess worn, 423, 425.

Flemings brought, 424 .

Illiberal I'olicy, 4:25.

English Money sonrce, 427.

Morer's on Flax Crop, 42R,

Scotchmen Whipped in Eigland, $42 \times$.

Corpses Buried in Linen, 429, 430.

Flax Exportation Prohibited, 429.

Linen Manufacturing Company, 429.

Union with England, 431.

Linens nade in Scotland, 432.

Inkle lonms introluced, 432, 450.

Moncy reportel scarce, 433.

A Lady's Account of Country, 433.

Linen from Hulland, 434.

Depression in 'Trade, 435.

Woollen Manufactuier * Cumplaint. $4: 36$ - $1 \mathrm{ml}$ olts, $4: 36,4: 39$.

liural Districts, 437, 483.

State of Trude, 437.

Linen Duties Inplosed, 438.

First Steam Mill, 438.

Spindles and Power-Looms, 439, 680, (i82-Bıtish Linen Company, 44:.

Linen Trale Flourishing, 450.

'Trustees' Surveyor's Tour, 452.

Country Described, 453.

Lint Mills, 455.

The Stamp ict, 465 .

Di trict T'r ide, 483, 538.

Scotr, James, 69.

Scott, James and William, 6.57.

Scutching Marbinery, 30, 39, 400, 401, 416-St lma, 619.

Semiramis Inveuts Weaving, 190.

Sesostris-Fleets of, 183.

Colony at Culchis, 184.

Suilors Phoenicians, 184.

Severuy, Alexander, 206, 223.

Seville, 263-Sharp, John, 657.

Sliaw, Baxter, und Co., 657.

Shaw, William, 615.

Sheets of Serge worn, 360.

Shuttle, 12\%, 149, 204. 452, 703, 712.

Sicily 258 -Sily lline llooks, 132.

Sidon-Must Ancient City, 17i.

Culebrated for Manufactuies, 179.

Fintroidery, 187.

Silesia-linen early made, 267 .

Yarn kpun by the Spindln, 269.

Manufut $t$ ring Details, 269.

Linen 'Tiade important, 270.

Mannfactures, 287.

Silk - An ient Manufacture of, 179.

Got from Indin, 182.

I'sed in Babylon, 18:.

Worn in Rome, :065.

Silken Sails, 310.

Intıoduced into Britain, 3il.

Sinclair, SıJ John, 441. 
Sisera-His Mother's Song, 124.

Small, Di, 458, 584.

Smart J. atid J., 554.

Smieton, James and Son, 438.

Smith, David and Son, 485.

Smith, Jolın, 654

Smith, Laing and Co., 496.

Smiths, Mitchell and Co., 657.

Smith, Peter, 79.

smith, William and Son, 496.

Smythe, Miss-Her Wedding Outfit, 431.

Sobieski, John, of Poland, 343.

Soda $A$ sh, 721.

Solomon imports Linen Yarn, 132.

Solyman, the Turk, 343.

Somersetshire, 386 .

Soutar and Nicoll, 6.57.

Spain-Noted for Linen, 199.

Chequered History, 260.

Flax grown by the Muors, 260 .

Moors expelled, 260, 343.

Decline of Manufactures, 261.

Pievival of Trade, 262.

Fer ility of Country, 262.

Linens marle in Seville, 263-Citta lonia, 263- -Bilboa, 264 - Malaga, 265 - Valencia, 265 - Santander, 265.

Linens largely consumed, 265.

Imports and Expurts, 266.

Spiller's Web, 121.

Spinning-Jute, 77, 78.

In the Wilderness, 130.

Juder, 134, 215-Egypt, 148, 211.

Greece, 187- Rome, 203.

France, 314-Gerına::y, 365.

Employment of Womea, 128, 223, 246.

Locomotive machines, 243.

Introduction of Machiuery, 689.

Spindles-France, 312, 313.

England, 387-Ireland, 406.

Scotland, 439-Aberdeen, 540 .

Arbroath, 548- Blairgowrie, 550.

Brechin, 552-Kirkcaldy, 567.

Montio 1 , 577-Dundee, 630 .

Spindle and Distaff, 134, 149, 187, 203,

685-Spiunin' Machinery, 691, 693.

Sp,inning Mil's -

Douglastown, 238, 458, 511.

Darlington, 382-Yorkshire, 382, 384.

England. 387--1 reland, 406.

Bervie, 4S9 - Fordoun, 502.

Glamis, 504-Kirkd.n, 514.

Mains, 519-Monifieth, 523.

Kirkland, 536-Ar'roath, 541, 543.

Blairgowrie, 549 Brechiu, 552.

Dunfermline, 555.

Dundee, 589, 591, 592, 613, 630.

Internal Arrangements, 621, 628, 694, 696, 697.

Outward Appeara:ıce, 621.

Spinning Process, 694.

Spinning Schools, 365, 4:35, 447.

Spirning Wheel, 371, 400, 687.

Spinster-Origin of term, 356 .

Stimp masters, 465,468

Stamping-Abolisherl, 464, 474.

Instituted, 46.5.

Fabries Stimpel, 497 Fees, 477.
Fabries Exempted, 467.

Stamps cut off, 468 .

Proceedings of Board, 470.

Abuse8, 474.

Returns of Linen Stamped, 476.

Steiglitz, B:ron, 337, 338.

Stocking $\mathrm{L}$ om, 450 .

Strabo, 184, 352, 353

Stracathro, 5:33.

Strafford, Lord, 393.

Stranraer, 5:33-Strathdon, 533.

Strathmiglo, 534-Strichen, 534.

Stuitgardt, 273.

Stuart, J. G. and Co., 521.

Sunn-Description, 90.

Cutting and Steeping, 90.

Scutching, 91.

Early known in India, 92, 726.

Tried in Dundee, 92.

Found Unsuitable, 93.

Shipments from India, 93.

Swan Brothers, 510, 655, 657.

Switzerland, 342.

\section{$\mathbf{T}$}

Tab rnacle, Curtains of, 128.

Tacitus, 35̃4-Tailors of London, 359.

Tailor's $v$. Weavers, 434 .

'Tanning Leather, 426-Taws, James, 72.

Taylor, John, the Thames Witerman, 425.

Taylor, William and Co., 77, 657.

Telemachus, 189.

'Temple, Sir William, 229, 390.

Temples, 402-Tennant, M., 721.

Thebes-Celebrated for Linen, 151. Numerous Dyers, 173.

Theophrastus, 717.

Thom, Wa'ter, 489, 490.

i hums, Vice-Consul, 296

Thomsen, Shepherd and Briggs, 628, 657.

1 homson's Expe:iments, 122, 160, 162.

Thracians-grew Hemp, 196.

Thread Manufacture, 434, 451, 486, 490. 527, 531, 539, 543, 574, 582, 585.

Thucydides, 195-Thurso, 534.

Timbuctoo-Iinens exported to, 372

Tocher, A Wife's, 431.

Tow-Imports, 114-Trebizond, 344.

Tremenheere, Mr, 410.

Triumphant Song, 143.

Trojan War, 188.

Troup, Alexauder, 534.

Turkey-Beautiful Country, 342.

Solyman crossed Hellespont, 343 .

Moslem Aggression Checked, 343.

Ciimate suitable for Flax, 343.

Li:ıen laige!y Worn, 343.

Flax Grown, 344.

Fine Linen of Rizeh, 344

T'urkish Sultana's Dress, 193.

Turnloull and Co., 520, 723.

Turnbull, W. S., 530.

Turner, Charles and Co., 710.

Turriff, 535.

Tyre-Merchant Princes, 139.

Purple Dye, 139. 178.

Dycd Lis ens, 179.

Dye o!ttaivel from Fish, 179. 
Destruction of, 130 .

Alexander Arrosted, 180.

\section{U}

Ulster, 390, 392, 393.

Unions, 178, 370, 374, 40.3.

United Kiugelun-

Iniports of Jute, \&c., 110, 6tio.

Inpoits of Flax, Sc., 110, 111, 11:. bitio.

Imports-From whence, 11:3, 114

Do. Where Landed, $112,117$.

Exports, Flax, Juto, \&c., 116. Do. to France, 308 .

Linen Trade Sub.diviled, 351.

Wunt of Stutistics, 658 .

Value Linen Male, 661.

Employed in Manufacture, titi2.

Mills and Fnctories, 662.

Fuctory Iaws, 671.

Exports of Yarn and Linen, 673, 178. Filctory Retilins, 6\$0.

United States of America-

Inports of Jute, 50 , 64; 81, 347, 345 .

Grows Flax, 346

Fibre Sactificed, 346.

Flax-spinning Mills, 346.

Progress Linen Trade, 347

Pices of Jute, \&c., 348.

Value of Imports, 349 .

The War and the Linen Trade, 350.

Value Jinen Imports into New York, $350,729$.

Valencienues Lace, 301, 306, 315.

Vedas of India. 701.

Veil of Holy of Holies, 128.

Veils, Eastern, 12:3-Veligolski, 323.

Venice, 252, 256-Vespasian, 206.

Vexments of the Gols. 137.

Vesture dipped in Blood, 14.

Vintka, 322, 336-Vienna, '286, 34:3.

Village Webster, 426.

Virtuous Woman, 134, 135.

Vologila, 320, 322-Volt:iire, 250.

\section{IV}

Wages Contrasted, 503, 535.

Wages paid, 539, 545, 556, 563, 564, 606, 610,612 -Wales, 35., 359.

Walker, J. and H., 657 .

Walker, John and Co., G54.

Warnes, 376, 377, 378.

Warping Mill-Introduced, 451. Deseription, 703.

Watson, Alexander and Son, 507 .

Watson, Dr J. F., Repurt on Jute Crop, 83.

Watt, James, jun., purchases Jute, 69. Extended Operitions, 70 . Warehouse Burned, 71.

Weavers $v$. Tailors. 4:34.

Weaving - Mode in Egypt, 149, 212, 700 Establishme uts in Judea, 15:.
Fogypt, 15] Babylunia, 163.

Grecce, 18t, 192, 219.

Rome, 202, 205, 219-Spain, 194

Ciermany, $200 \rightarrow$ England, $227,35 \%$.

Invented bv, 19(), 700.

A Gift to the Flemings, 358 .

Indian Mode, 701 - Hand-Ioum, ive

Twilled Fubries, 706.

Figures, 706 -Dimak, 707.

Jacquard Machine, 707.

Arrangement of a Wurk, 715.

Weavers' Company of, London, 359.

Weaving by l'ower, 457, 4(i1, 46:2, 701.

Weaving schoul, 4irt.

Webster and Co., 5.16, 723.

Webster, F. and W., 654

Weem, 535 - Wemyss, 535.

Wemyss, R., 655 -Westphalia 247.

Whale Fishiug, 601-Wick, 537

Wilkie, George, 589.

Wilkinson, Sir J. G., 147

William I11., 391, 397.

William and Mary, 368 .

William, the Conplueror, $227,354,356$.

Wils'u, Professur, 13, 27-Wilts, 358.

Winchester-Imperial Cullege, 355.

Irish Linen used, 358389.

Women Syan in Israel, 130, 134, 215.

Wood, Audrew, 579.

Wodrow's Account of Glangow, 432 .

Woollen Manufacture, 368 .

Wortley on Stamping, 469.

Woven Air, 120.

Wurtemberg, 267, 271, 273.

Wy brants Brothers, 6:7.

\section{$x$}

Xenoplinn, 183, 184.

Serxes, 132, 191, 194.

\section{Y}

Yarkand, 345.

Yarn-Whence Imported, 115.

Imported by Solomon, 132 .

Imports and Exprorts-Beläiun, 300. Do., France, 311.

False Reel of, $461,171$.

Exports-United Kingdom, 678.

Yaroslinv, 3:2, 3:36.

Yarranton, Andrew, 364.

York, Duke of, 4:\%

Yorkshire, 382, 345.

York whire Woollens Stanped, 469.

Yool, W. W , 19;

Ypres, $227,291$.

Z

Zion's Ditughters, Iress of, $13 i$.

Zullverein-Imports and Exports, 278.

Fi-cal Regulations, 279.

Expires, 279. 


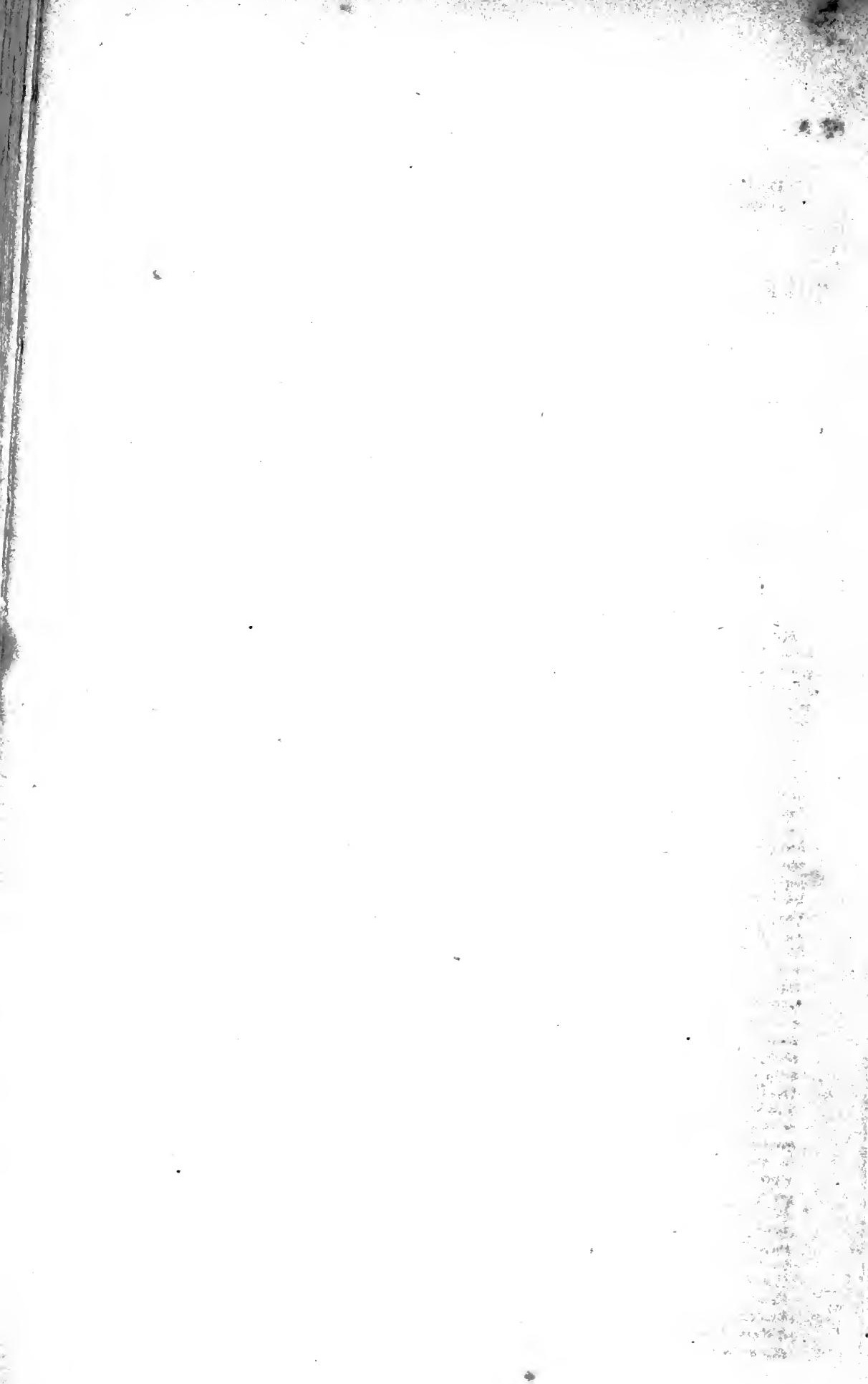




\title{
THE LINEN TRADE: ANCIENT \& IODERN.
}

\section{BY ALEX. J. WARDEN, DUNDEE.}

\author{
LONDON: LONGMAN \& CO.
}

8vo., Cloth Boards, 18s ; Gilt, $20 \mathrm{~s}$.

EXTRAOTB FROM OPINIONS OF THEPRESG.

\author{
Fros the "Dundere Advratiser," 20tr Joly, 1864.
}

Mr Warden's book on the linen Trade will become the standard work of reference for information on every subject connected with the raw material, the processes of manufacture, and more especially with the history and statistics of every branch of the Linen and Jute Trades. Combining rare diligence with continued and systematic effort, he has brought together in one volume an extraordi. nary urray of facts, many of them curious, and all of them more or less important as throwing light on the development of a large branch of national industry. Written with remarkable fluency, in a simple and easy style, distinctly arranged in chronological order, and with a copious index, the volume is, in fact, a cyclopredia of all that relates to the Linen Trade, and will take its place on the office desk along with M'Culloch's Dictionary of Commerce and Baines's History of the Cotton Manufacture. Nor will it interest bnsiness men alone. Mr Warden, in his gleanings from all available sonrces of everything connected with the growth and manufacture of flax and jute, bas noted many remarkable passages, throwing light on the social progress of our own and other nations, and many parts of his book may be read with pleasant interest, quite apart from the subjects to which they more directly relate. - . - Mr Warden has collected a great num. ber of very curious facts with respect to the means taken to promote the Linon Trade, and of the jealousy subsisting between different towns and countries with regard to the manufacture and sale of goods. Our Sootch forefathers were very much opposed to English woollens coming into Scotlaud, bat the Finglish of the period took their revenge by whipping as malefactors our pedlar who were found selling Scotch linens in England, and Mr Warden pawkily remarks, "had the practice of whipping the Scotch who went to England to sell their linens not been stopped, it would have been a severe blow to the Scotch Linen Trade of the present age, as manufacturers would not have liked such a castigation in their journeys to the South." The Parliament of Scotland in 1686, in order to encourage the Linen Trade of the period, passed an Act denying burial to any corpse of any person whatever "in any shirt, sheet, or anything else except plain linen," and by a suh. sequent Act the nearest elder or deacon, with one or two neighbours, was required to see that the law was complied with. At that time it was the pride of the women to have large chests full of linen of their own spinning - the fashion of going to the shop and ordering their marriage outfits not having then set in. . . We bave directed attention to only one or two chapters of Mr Warden's valuable work. It would far exceed onr limits were we to attempt to notice them all in the same way. Suffice it to say that no one professing to be well-informed with regard to the Linen and Jute Trades can dispense with this compendious work. The chapters on the raw material, on ancient linen, and particularly on the Linen Trade of the different conntries in Europe, are all valuable: while about two hundred pages of the work are occupied with accounts of the Linen Trade of tho different towns and villages in Sootland, which, from their special local interest, are sure to be engerly read. 


\section{From the "Dundee Courier and Argus," 20th July, 1864.}

Mr Warden has chosen happily his time for a history of the Linen Trade. The Linen Trade in these latter days is worthy of a historian. It is among the very oldest of human enterprises. When that sad necessity for clothing arose, consequent upon the misconduct of the first man and woman, the linen trade was obviously at hand. The fig-leaf was an arrangement of a most temporary character. The coat of skins was a step in advance, but it also was unsatisfactory. Visibly it had no higher aim than to keep poor homeless man from the cold, till his necessity had time to give birth to some of those inventions of which she is truly said to be the mother. Nature provides no ready-made clothing. From the day that Adam fell the loom was inevitable. To what forgotten son of genius it first occurred to discard the sheep's skin and clothe himself in its wool we shall never know. In like manner the man who first utilised the fibres of the flax plant is a benefactor whose memory is unhonoured because his name is unkuown. That he lived at a very early period in the world's history is all we can tell. Mr Warden conjectures that linen was in use among the ante-diluvians. Very certainly it was largely used in Egypt at no very great interval after the deluge. The Egyptians living and dead were a linen-wearing people. From $\mathrm{Pharoah}$ in his palace to the beggar in his hovel, every Egyptian dressed himself in linen; and when he died his friends wrapped his body in linen, and put it away to await the expected return of his soul to its former dwelling-place. The production of Egyptian looms must have been very considerable, for there was a large export as well as a large home trade. Mr Warden thinks there may have been large handloom weaving-shops, similar to our own, in the city of Thebes, for example, which was much famed for its cloths. Are our readers not conscious of a feeling of brotherhood with those ancient and long-embalmed Pagans, who were the skilled linen weavers of antiquity? That poor mummy, whom we stare at in a museum, spent his days in that remote time, and in that mysterious and awful valley of the Nile, very much as we do by the waters of the Tay, in continual thought and converse about the quality of linen yarns and the texture of linen cloth! Ever from his time to ours, the Linen Trade has been an institution upon the earth. After a duration nearly cœval with that of man himself, it has in our day entered upon a new and widened stage. Almost always until quite recently, linen weaving bas been carried on in the dwelling-house of the weaver, and upon a comparatively limited scale. Ours is the era of large factories. It is the era, too, of expansion hitherto undreamed of. Till our time, the Linen Trade has been one of the most humble and unobtrusive of the arts, ministering in meek silence to the comfort of man. To the surprise of all-chiefy of those engaged in it-the Linen Trsde has suddenly claimed its rightful place as one of the greatest of human industries. Never before has the world rewarded its makers of linen with the lavish generosity which it is our good fortune to experience. The great enemy of the Linen Trade is cotton. That enemy having been overthrown, the course of the Linen Trade recently has been one splendid triumph. In such a well-chosen time, Mr Warden undertakes to write the history of the Linen Trade, from the days when Pharoah cansed Joseph to be arrayed in fine linen down to the latest extension of spinning and power-loom weaving among ourselves. We are bound to say, after a somewhat careful examination, that he has done his work well. The mass of information collected is immense. The arrangement is natural and pleasing. The risk of books of this description is that they are unreadable by reasen of extreme dullness. Mr Warden has kept perfectly clear of this great evil. His book is lively and interesting in a high degree. We are now in possession of what has long been desired, and never desired so urgently as since recent events have thrust greatness upon us-a thoroughly well-executed History of the Linen Trade. Any man dealing in linen products who does not immediately buy this book, and read every word of it with the deepest interest, thereby proves himself unworthy of that kind fortune which has given him "the goodly heritage" of a place in the Linen Trade during this its most lucrative era. We must remark farther, that, although Mr Warden's book is published in London, it has been not only composed, but also printed and bound in Dundee, and a most creditable specimen of native workmanship it is.

From the "Leeds Mercury," 15th August, 1867.

The history of the cotton trade, published some years ago, was recently followed by the publication of the History of the Silk Trade, the History of the Woollen Trade, and the History of the Worsted Trude, and to these Mr Alex. J. Warden, 
of Dundee, has added, under the above title, a History of the Linen Trade. The work is a very comprehensive one, and though nocessarily dry in many of its details it embodien a mass of most valuable and interesting information. The writer describes not only the cultivation of the $\mathrm{mw}$ material in its various forms, but traces the manufacture and the uses to which the manufactured article bas been put from the earliest times, interspersing the historical record with sketches of the rise and progress of the trade in Fingland, Scotland, and Ireland. The work is a valuable addition to the histories already publiahed of the other branobea of textile industry.

\section{From the "Times," 17 th August, 1864.}

Among recent commercial publications has been "The Linen Trade, Ancient and Modern," by Mr Alexander Warden-a practical history, abounding in carious details, commencing with the linen manufacture in Biblical times, and tracing ita progress to the present day.

\section{Froy the "Leeds Intelligenoer," 20th Auoust, 1864.}

This work is, we believe, the first of any importance published on this subject, and to those who are in any way interested in or conuected with this manufacture it will be found a reference book of the highest value. After making a fow comments on the antiquity of the growth of hemp and flax and the fabrication of linen, the writer strikes at the root of the subject, and Chapter One furnishes us with a carefully written and full account of of the culture of flax. The seed, the nature of the plant, its product, with tables of its ohemical composition, the proper soil and rotation, preparation of the ground, sowing, weeding, pulling, rippling, watering, spreading, lifting, drying, breaking, and soutohing, all these are treated of at a greater or less length, with careful notices of improvements that have beon made of late, and the merit and demerits of modern innovations. Chapter Two is occupied with the culture of hemp, from the first mention of it by Herodotus to the present time. The production of jute, its culture in the field and treatment in the factory, occupy some space; while the vast amount of business done in this article of commerce from the years 1840 to 1863 is clearly set forth in carefully arranged tables; and another set of tables gives the highest and lowest prices from the year 1847 to 1863 . There is also a short article on Sunn Hemp. Various fibres are treated of at some length, with a list of prices. Linens of the Bible, Egyptian Linen, Phœnician, Carthagenian, Colchican, Grecian, and Roman linen, under the general head of ancient linen, are all separately treated of. Modern linen is divided under two heads, Continental and the United Kingdom. In the latter the articles on Scotch and Irish linen will be found especially interesting. Having at length and with an infinite amount of pains traced the Linen Trade from the most anoient times to its position in manufactures and commerce at the present time, the author naturally comes to the manufacturing operation by which the raw material was and now is converted from its crude state to the beantifully fine fabrics with which we are all familiar. The great compass of the work bas rendered it a most difficult and arduous task to arrange the various beads so as not to permit one subject tn trench upon another; but the writer bas, we think, been exceedingly bappy in his arrangement, and the infinite pains he has taken as regards the very numerous statistical tables, together with the businesslike manner in which he has throughout, as a rule, treated this entirely business subject, will make it a most valuable book in the hands of all engaged in any part of this increased and widely-spread trade; and it will also prove of use to any who may wish to experimentalise either in the growth or manufacture of flax, hemp, jute, or any of the other numerous fibres treated of in this volume.

\section{From tue "Barssley Curonicle," 20tu August, 1864.}

A very valuable work under the above title has just been added to the existing histories of the other branohes of English textile industry. The work, which is a most comprehensive one, and contains a vast amount of interesting and important information, is from the pen of Mr Alex. J. Warden, of Dundee, and is published by Messrs Longman \& Co. It comprises not merely a description of the cultivation of the raw material, but minately traces the various modes of its manufacture, and the uses to which the manufactured article has been put from the earliest times. 


\section{From the "Athendum," 27rh August, 1864.}

In this bulky volume we have all that the compiler designed,-namely, a fulf and reliable record of the rise, progress, and present condition of a very important department of manufacture and commerce. Mr Warden plays with statistics as easily as Hercules might with modern quoits. The volume closes, naturally enough, with an urgent recommendation for the increase of the culture of flax. If the farmers of the United Kingdom could be induced to grow but $2 \frac{1}{2}$ acres of flax for one year, as an experiment, the produce, at the rate of $4 \mathrm{cwt}$. per acre, would amount to about 256,000 tons; the cotton trade would not be impeded, the cotton districts would find the odd day and a half's employment which the workers are likely to want, and between two and three millions of hard cash would go into the pockets of the farmers. Without this home growth, we may live to see a flax famine.

\section{From the "Northers Whig," 30th AUgust, 1864.}

The goodly octavo, with its 745 pages of matter, and the title of which is given as the heading of this notice, conies out at a time when every detail connected with the linen trade possesses a special interest. $\mathrm{Mr}$ Warden has supplied a great want in the history of manufactures, and in the accomplishment of his task he has exhibited not only immense research in the collection of materials, but he has given as at once an exceedingly valuable and very graphic account of the progress of the linen trade from its early date and down to the present. The first section of the work goes into various and very interesting details of flax culture in different parts of the world; then we have a well-written account of the growth of hemp; and, finally, a highly interesting detail of the production of jute-that now very important Indian fibre, which, for years past, has occupied a large space in the manufactures of Scotland. In the second section, our author enters very fully into the consideration of the linen trade of Egypt and Canaan. Great difference of opinion exists respecting the quality of the article spoken of in Leviticus and Deuteronomy as fine linen, and some writers have gone so far as to state that the description of the finest article woven in the days of the Pharaohs was hardly equal to that of medium fabrics in the present day. Now, so far as can be ascertained from the earliest and most authentic records of the East, it would appear that the fine linen worn by the nobles was really what its name implies, and the very high prices at which it was valued show that only the superior classes were able to use it as an ornamental gal ment. . - Previous to going into the history of the trade in its modern aspect, and as it exists in the United Kingdom, Mr Warden gives several chapters on the state of the manufacture in continental nations-those which refer to Italy, France, Russia, and the Germanic States being especially interesting. This section will by many persons be considered as the most valuable in the entire work, seeing that it treats of the current condition of the trade in a portion of Europe of which there has hitherto been very little known in this country; and every passage in that series of annals teems with important information, filling up as it does a vacunm that has long existed in the general history of the manufacture. No large space of Mr Warden's volume has been devoted to the English linen trade. Even the far-famed factories of the Messrs Marshall of Leeds, are passed over with much less attention than we could have desired. Neither have the manufacturers of Barnsloy been treated with more ceremony; and the entire details given of the Irish linen manufacture only occupy two and thirty pages. To make amends for this, however, our author, with the national love of fatherland which ever distinguishes the North Briton, has devoted nearly half of his work to the history of Scotch linens. Much, therefore, as we may be disposed to grumble at the condensation of the annals of the other parts of the Kingdom's flaxen enterprise, we must congratulate $\mathrm{Mr}$ Warden on having in this instance given to the public the most comprehensive view ever taken of that department of Scotland's industry... It would be impossible in the space which we have at our command to give any lengthened extracts from this very valuable work, and we must just refer our readers to the volume itself, every chapter of which abounds with information that cannot fail to be almost equally interesting to the student of industrial history as to the members of the linen trade. Mr Warden's work will prove an important addition to a department of literature which is every day taking a higher stand in public estimation.

$$
\text { From the "Glasgow Daily Herald," 3D SePt. } 1864 .
$$

Mr Warden's bulky volume shows a vast amount of researoh, and will be found 
full of interesting information, not only to the manufacturer and those interestod in the linen trade, but to the general reader; for besides dwelling at length on the statistics and technicalities of the manufacture, there are long and curious accounts of the flax cultivators of the most ancient times. The linen trade is one of the oldest, and as it is so often poetically referred to by Grecian and Roman authors, ample materials exist in their works for the modern hintorian. Mr Warden has made good use of these, aud hence his chapters on Eyyptian, Phonician, Grecian, and Roman linens are really worthy of perusal. A small scction of the volume is devoted to a comparison of the lineu manufactures of ancient and modern times, and is the substance of a series of lectures delivered in Dundee by Mr William Mfiller of this city. These lectures are a valuable addition to the work. The great bulk of the volume, however, is taken up with modern linen and its modern manufactures, in which the author reviews in quite an exhaustivo manner the progress and prospects of the manufacture in Italy, Spain, Germany, Holland, France, Russia, England, and Scutland-the Scotch trade, of course, being expounded with great circumstantiality of detail. This latter portion is necessarily dry and statistical, but we have no doubt that it is accurate, as it bears all the narks of careful industry, and it will in consequence be the most valuable portion of the book to those readers engaged in this ancient trade. Mr Warden writes fluently, and if not always with the greatest accuracy, yot in a lively and intelligent manjer.

\section{Froy the " Mlanchester Courier and Lancashire Greral advertiser," 7ta SEPT., 1864.}

The manufacture of linen is one of the most ancient of industries, and may, indeed, be said to have a classical reputation, since references to it will be found in abundance in the works of the Greek and Roman poets. In modern times, and especially in this country, it has made remarkable progress, and at the present moment is one of the most valuable branches of manufacture. . . . It is somewhat strange that, excepting in cyclopædias and works of a similar character, no descriptive history of so important a branch of industry should until now have made its appearance; but such sppears to be the fact. Mr Warden, of Dundee, a gentleman connected practically with the trade, has essayed to supply the defi. ciency. The work is well done, thoroughly trustworthy in its details, and his immense collection of facts and statistics has been arranged with care, and in a clear, readable form. Commencing with an account of the culture of the raw material, and a history of the manufacture as carried on in ancient Greece, Egypt, and Kome, our author proceeds to a comparison of the trade as it was conducted in early times, with its nore recent development, and then describes the progress and prospects of the manufacture in France, Spain, Germany, Russia, Italy, and the United Kingdom. Some of the chapters on the trade in Scotland are perhaps more minute and their interest too exclusively local for a work of the geneml obaracter aimed at by $\mathbf{M r}$ Warden; and compression and revision might be applied with great advantage, in a literary sense, to other portions of the volume. But, as a whole, the work will be one of great value to those engaged in the trade. As regards the future, Mr Warden's remarks on the inportance of an increased culture of flax, and his anticipations of a flax famine should farmers continue to neglect the cultivation of this valuable raw material, are worthy of the thoughtful consideration of agriculturists. In Ireland. the subject has of late been taken up with earnestness; but in England and Scotland the crop, though proved to be a profitable one, is becoming smaller every year.

\section{From the "Belfast News-Letrer," 13th Sept., 1864.}

In his preface to his book, Mr Warden craves indulgence for possible literary faults, on the score that he is not so practised in literature as in all that concerns the linen trade in all its various branches. The indulgence is not needed. The author must indeed be skilled in linens if he is more at home in the warehouse than the study; for he has contributed to manufacturing science a work which is hardly more remarkable for its fulness of detail and accuracy of information than for its pleasing style and the scholarly research which is evinced in many of its pages. Mr Warden divides his work into sections, in each of which he has an astonishing amount of information to afford the public. The raw material first occupies his attention, and in separate chapters he discusses the botanical peoulisrities and the modes of culture and preparntion of flax, hemp, iute, and other 
fibres. How amply this part of the work is accomplished may be judged when wo gay that it occupies nearly 120 pages. The chapter on jute is peculiarly interesting, and might be read with profit by many of the merchants and manufacturers of Ireland. It was so recently as 1833 that $\mathrm{Mr}$ James Watt, of Dundee, first, and not without much difficulty, introduced it into the trades of that town. It is now a most important and lucrative branch of manufacture both there and in Lancashire, and we cannot see why it might not be successfully introduced into Belfast. The same energy that has given us a linen trade so extensive might well be employed in creating other sources of employment and profit. In a literary sense, the sections most interesting are those which treat of "Ancient Linen, and the Linen Manufactures of the Olden Time." In reviewing ancient linen, the art of weaving fabrics of flax is traced back to the ancient Egyptians. For although a chapter is properly devoted to "Bible Linens," it is to be noticed that the firmt mention of linen by name in the Bible is when Pharaoh exalted Joseph to the second place in the land. It is argued, and it is arguable, that raiments previously spoken of in general terms were made of the flax fibre; but if we stop at the point indicated we have gone back far enough to prove the high antiquity of the linen trade. Phœnician, Carthagenian, Grecian, and Roman lines are each separately treated, and the chapters devoted to them are highly readable. The modern linen section leads, however, to the more practical part of the work; and in it the progress of the trade in Italy, Spain, Germany, and other countries is traced; a second part of the section being devoted to English, Irish, and Scotch linen, but especially to the latter; the manufactures of every town being separately treated. The author has made these chapters peculiarly interesting, not merely to persons engaged in the trade, but to the general reader. The fifth and last part is wholly occupied with an account of manufacturing operations, which are fully and intelligibly described. Statistical tables are interspersed through the work, and add no little to its value. We congratulate the members of the linen trade and the public on having such a history placed within their reach. The labour of merely compiling the information in a book of 740 pages was immense. But the book is no mere compilation, but a well and carefully-written work, arranged with the utmost clearness, and written in a style of more than ordinary attractiveness.

\section{From the “"Morning Post," 19th Sept., 1864.}

The history of an industry so important was worth compiling; and it proves to be far more interesting in a popular point of view than could be supposed at first sight. Mr Warden brings to the task an intimate acquaintance with every branch of the trade, and apparently a natural aptitude for the collection and arrangement of details, whilst in point of literary style the bulky volume he has produced is more than respeotable. He devotes over 100 pages to a minute description of the various fibres produced from the flax, hemp, jute, and sunn plant, and gives an account of the best methods of growth and preparation in each case. In a section on ancient linen he furnishes a very pleasing treatise on Bible linen, and he traces the manufacture to Egypt, Phœnicia, Greece, Carthage, and Rome. The history and position of the linen trade in Italy, Spain, Germany, and France are treated in separate chapters; and the portion of the work which is more immediately interesting at home is then commenced. Mr Warden has spared no trouble to tell his readers how the linen trade was introduced into the British Islands, and to what causes its progress was due. . . . The history of the trade in Scotland is traced by the author with much minuteness of detail, and many very interesting factsare mentioned. . - After the Union the trade began to flourish, and was spread over all the country ; but, as in England and Ireland, the improved methods of manufacture and the erection of spinning-mills and power-loom factories have tended to localise it. An account of those improved methods is given by the author in the last seetion of his book, and he seems to augur a bright future for a trade which has certainly made immense strides within these few yeare. It ean hardly be disguised, however, that much depends upon the continuance of the American war. The high price of cotton is one of the conditions that has stimulated the linen manufacture ; and it is natural to assume that when cotton is once more cheap flax fabrics will not be so much in demand as they at present are.

From the "Daily News," lst Oct., 1864.

The title of this book dnes not promise much entertainment to the general reader; ho will be disposed to say, "It is a class publication, intended for men 
engaged in that branch of trude, and can have no interest for me." In this ho will fall into a great error. The volume is no doubt intended for the trade in one sense, and contains all the information whoh a linen manufacturor or draper can possibly require; but it is much more than a commercial manual-it is a very able and learned history of the most anoient of all the arts. The earliest records of mankind make mention of linen as an article of oommon ase. It was familiar to the sacred writers, and Herodotus, the earliest of profane historians, notices the high perfection to which the art of linen weaving was brought in Ėyph. An art so anoient and so closely associated with the progress of mankind in civilisa. tion must bo a theme full of curious and pleasing interest to every thinking person, and the manner in which Mr Alexander Warden has treated it in this publication is well calculated to commend it to the notice of all classes of readers. The first part of the work is devoted to the natural history aud chemistry of the flax plant, and other fibrous vegetables, such as hemp, jute, phormium tenax, and many others. The author investigates the geographical distribution of these plants, their elementary constituents, their commercial value, the methoda adopted in their culture and manufacture. The whole of this part of the volume is well arranged and clenrly elucidated, the general results being placed before the reader in tabular forms which we think must be of immense value to every one engaged in the linen industry. The author passes on to the consideration of the antiquity of linen weaving, and with much research and good store of Hebrew and Greec learning, clearly traces it up to the very dawn of human history. Egypt was no doubt before Palestive in this as in all other arts; and there can be little doubt that some of the mummy wrappings and documents which any one may see in the British Museum are very nearly, if not quite four thousand years old. Our author next traces the art into Phoenicia, Carthage, Babylon, Colchis, Greece, and finally to Rome. The Romans found the Britons almost ignorant of textile arts, and among many other good things taught them to spin and weave, and to exchange the skins of beasts, and the dye of woad, which previously had been their only vesture, for linen and woollen garments. The rude fighting Danes and Saxons did not wholly neglect so useful a branch of industry. . . . From hence downwards to the close of the last century the linen trade was gradually assuming an increasing importance among the different nations of the earth. The introduc. tion of cotton into textile fabrics in the 17 th century was not unfavourable to the flax trade, cotton could not by the old methods be spun strong enough for the warp or longitudinal threads of the texture, and down to 1773 it was used only for the weft or transverse threads. The inventions of Hargraves, Arkwright, and others obviated the necessity of using flax threads for the warp, and enabled the manufacturers to make the whole fabric of cotton. This proved a heavy blow and great discouragement to the more ancient industry, the flax trade drooped, and was in many places barely kept alive by the unwholesome stimulation of govern. ment bounties, until the civil war in America deposed King Cotton, when it experienced a sudden revival, which it is hoped will be permanent. The author gives a history and description of all the great seats of the manufacture, not only in the three kingdoms, but throughout the world. The importance of the linen trade to Ireland is very great, if we may judge of the immense increase in her export within the last few years. The progress of Scotland is, however, very much greater, and England, which never before took kindly to the business, has of late turned her attention to it with telling effect. The author, whilst giving his readers a thorough knowledge of everything connected with flax and linen, does not neglect to relieve the dryness of his statistics by pleasant pictures of society in old times, of the employment of ladies in the labours of needle and shears and embroidery, of the marvellous linen pictures produced by help of the Jacquard device, and of the lovely damasks and diapers which were the prifle of chatelaines and prinoesses in ages gone by. We no longer live in times when the maidons of the houschold spent their evenings in the great hall, spinning and sewing by the light of a crenset lamp or a wood fire; the art thus practised in primitive sin. plicity has becone the chief business of the nation, the great staple of its industry, the greatest source of its wealth and power. We have looked through Mr Alexander Warden's book with attention, and feel compelled in common justice to say that it is remarkable for its fulness, as well as for the pains that have been taken to make it accurate and trustworthy. It is also written in a style which entirely saves it from the monotony that might be thought inherent in a commercial topio. We have, it is true, all manner of statistics and tabular statements connected with the trade in every country under the sun; but we have also that touch of nature which awakens human sympathy and curiosity, for the autbor connects bis theme througbout with the advance of mankind from barbarism to civilisation. 


\section{From the "Illustrated Lonbon News," 1st October, 1864.}

Mr Alexander J. Warden's new work on the "Linen Manufacture" not only contains interesting historical matter relating to the linen of the ancients and moderns, and copious comnercial details, but also very much valuable scientific information respecting flax, hemp, jute, sunn, \&c., now of such great national importance. In regard to flax, we are instructed respecting its botanical character, various species, methods of culture, the chemical constituents of the plant, and the soils in which it is grown, British and foreign, the preparations for the manufacture, \&c. The history of the gradual introduction of the now important jute into Britain, and the methods of bleaching, spinning, and dyeing it, will be quite new to the general public, who may not be aware that it has led to great commercial prosperity in Dundee since the decline of the cotton manufacture in Lancashire. Jute is the fibre of the Corchorus olitarius (pot herb, or Jew's mallow) and Corchorus capsularis; herbaceous annuals, which in India grow from five to fourteen feet high. The former derives its name from the leaves having been eaten by the natives as a kind of spinach. The stems yield the fibre known in commerce. Sunn hemp (Crotularea juncea), sana, belongs to the family of plants yielding the pulses of India. The fibre obtained from its stalks has been employed in corlage, but for textile purposes it has given way to its formidable rival jute. $\mathrm{Mr}$ Warden gives interesting particulars respecting other fibres which may hereafter become of national importance. Mr Warden's book is undoubtedly the best modern book on the subject, and will form a companion to Ure's "History of the Cotton Manufacture."

\section{From thr " Edinborgh Revirw," Oct. 1864.}

In the course of an admirable Review of several works bearing on the History and Antiquities of Angus or Forfarshire, which appeared in the $E$ dinburgh Review for Oct. 1864, from the accomplished pen of the Right Rev. the Bishop of Brechin, the learned Prelate says - "Since the above has been written, we have met with Mr Warden's accurate and exhaustive 'History of the Linen Trade.' He first goes at great length into an account of the raw material, describing the flax, hemp, and jute culture. Then he gives the result of an interesting investigation into the ancient history of linen in Palestine, Egypt, Phœnicia, Greece, and Rome ; and pursuing the subject, he treats of modern linen in the different countries of Europe down to the present time. He supplies a mass of carefully compiled statistics as to the actual condition of the trade in England, Ireland, and especially Scotland. Altogether the work is a most laborious and valuable hand-book of this interesting branch of industry."

\section{From the "Edinburgh Evening Courant," 15th Oct., 1864.}

The history of the linen trade, and the culture and manufacture of flax and kindred plants, form the subject of a goodly and attractive volume by $\mathbf{M r} \mathbf{A}$. J. Warden, of Dundee. The work, partaking in a great degree of a technical character, nevertheless contains a large amount of information that is of interest to all. Mainly written for the sake of those who are engaged in the linen trade, its value is not confined to the counting-house, whether at Dundee, or Loeds, or Lille. It is worthy of a place in every general library, and is not unfitted, with its showy cover, to appear on the drawing-room table. Mr Warden, himself a merchant of experience and standing, familiar with the processes of linen manufacture and with the routine of its commerce, has employed his leisure for some years in a historical investigation of the subject. In this volume he has compiled from various and scattered sources the traces and records of past uses and forgotten modes, as well as the particulars of the recent progress and present extent of the vast enterprises connected with this branch of modern merchandise. He has gone into the task with a diligence and success that leave nothing to ke desired, and he presents to the public as the result of his labours a book of 740 pages. In the copiousness and attractiveness of his subject, $\mathbf{M r}$ Warden has no doubt been extremely fortunate. At the beginning he has to deal with one of the greatest wonders of beneficent Nature-namely, the production of flax. A plant suited to all temperate climates, rapid in its growth, attractive in its beauty, and rich in its harvesting, flax contributes to man a fibre which, when woven into a garment, evill wear for an age, and which when not subject to wear has been known to exist 
for a hundred generations. Besides this valuable raiment whioh man has used from the earliest times, and which has in all nations been regariled as the symbol and agent of cleanness and purity, the fax plant expresses an oil and yields a seed possessing high medioinal properties, and also most nutritive qualities for the food of the lower animals. With its assnciated plants it produces fabrics of tho most widely various kinds, from the delicate texture of Freuch cambric to the rough material of sail-cloth, cordage, and rope. The bishop in his spolless lawo, and the ship spreadiug her white suil to the brees", alike contribute ar customers to the linen trade. Throughout the Seriptures of noth Old and New Testament, the record inore or less explicit of $\mathbf{4 0 0 0}$ years of the world's history, in tho Egyptian tombs, on the Assyrian sculptures, in Greek and Roman literature, wo tind con. stant reference to and illustration of the uses of this remarkable plant, and so highly is it spoken of in the sacred volume that we find prieste, angels, and the redeemed saints spoken of as clothed with gurınents of "fine lineo." All these things are to Mr Warden the fruitful subjects of observation, elucidation, and suggestion. Opening with a series of chapters explanatory of the botanical character, agricultural processes, and mereanule values of flux, hemp, and jute, he goes on to speak of Bible linen, Egyptian linen, Ruman linen, \&c., in regard to all of which be deeply engages the interest of the reader by his eloquent passages and suggestive comments. Although deprecating any pretence to literary style, he sustains with great skill the interest of the reader, and makes him continue as a pleasure what he probably began as a study or as prosecuting a dry field of inquiry. Following up the historical summaries, Mr Warden proceeds to incorporate with his work the substance of several lectures on the "linen manufactures of the olden time" delivered in Dundee about twelve years azo by Mr William Miller, now of Glasgow, to whom Mr Warden expresses his obligations for "a mass of valuable details and statistics," which have helped him with various parts of his volume. Coming to the subject of modern linen, he enters upon the more techni. cal portion of the work. But the details of invention, commerce, and enterprise are, nevertheless, full of instruction, throwing great light not ouly on the imme. diate question, but on the habits, occupations, and trade of various European nations. Then we come to a series of chapters still more copious, devoted to the linen trade of the United Kingdom, and especially the northern part of it. The origin and objects of the British I,inen Company's Bank, still a yreat bank, but no longer a linen company, are stated; un abstract is given of the minutes of the Board of Trustees for Mauufactures in Sontland, to whose fostering care wo no doubt in great part owe the present prosperity of the linen manufacture here; and also a brief histury of the stamping laws. Of the linen manufacture in the rural districts of Scotlanil we have also abundant historical and stativtical details. A long chapter is then devoted to the linen trade of Dundee, which, from small beginnings, has risen to be one of great magnitude, employing vast capital and great numbers of people. We quote a couple of pages from this part of the work as presenting a curious example of how times ohauge and trades change with them. The jeony bas now so completely superseded the distaff, that modes of labour within the memory of many havo been completely absorbed into the proviuce of history ; and the term of "spinster," is forgotten by all save the parish clerk and the district registrar. The spinster is replaced in the industry of society by the poor mill-girl, and the profitless pursuits of crochet and embroidery are alone left for those of our young ladies who would not be altugether idle, and who would still rejoice in the labour of their hands. . . . In the examination of this subject of the linen trade, the question will naturally occur, why with a climate so well fitted wo the production of tlux, do we entirely (excepting partially in Ire. land) depend upon our imports of the crop? Mr Wurden states that where it has been fairly tried it has yielded nearly twice the pecuniary return of other cropa to the farmer, and that its alleged "scourging" of the land is somewhat unreason. ably dreaded. One reason for its non-introduction is the want of scutching mills on or near the ground, but these would no doubt be supplied were there any disposition ahown on the part of farmers to cultivate che flax. But the land of this country being comparatively limited in area, and the abundant quantity in which flax is obtainel from the Netherlands and other countries, where it is cultivated with the greatest skill and success, it is probably unnecessary to consider the propriety of establishing any home competition in the matter of production. The rise of the jute trade of Dundee is one of the most remarkable chapters of $\mathbf{M r}$ Warden's book. It is scarcely thirty years since this Indian fibre was introduced, in circumstances of great difficulty and discuuragement, into the trade of Dundee, whereas now it is one of the great staple mauufactures of the town, employing 
thousands of the population. In conclusion, we would cordially recommend $\mathbf{M r}$ Warden's book for its fulness, perspicuity, and research in regard to a subject which affects the immediate welfare of many thousands of our conntrymen, and which in a more general sense is fraught with interest to all classes of the community.

\section{Froy the "Mechanics' Magazine," 2D Dec., 1864.}

At last linen has its history. It has been hitherto considered enongh for the majority of people to buy, sell, and wear linen. Now, in addition to these, they can learn its histery, from the earliest records of man's invention-from the days, in fact, when "Adam delved and Eve span" to the present age, when nearly every nation of the earth is more or less interested in its manufacture and use. - . Mr Warden writes well and to the point, and the greater portion of his volume cannot fail to be deeply interesting to even the general reader. In flax spinning, to which Mr Warden devotes a capital paper, each separate fibro has to be unravelled; this is called "heckling." The same process is gone through a second time, but with a finer heckle. A great number of machines have been invented for this purpose. . . . The desired fineness having been obtained, the flax is ready for being spun. The spindle was the earliest appliance for this purpose, the distaff being added to it, making the process easier. "The virtuons woman layeth her hands to the spindle, and her hands hold the distaff," said Solomon ; - -a plain description of the Oriental method of spinning. Few appliances have continued in use so long as the spindle and distaff. It remained in use until the introduction of the spinning wheel. The English spindle, introduced so often in books as illustrating the acme of country happiness and industry, aided too by the pleasant pictures drawn by such poets as Cowper and Wordsworth, was very like the Egyptian spindle. We have no occasion to describe it, as it is familiar to nearly every one. . . . One of the first important innovations upon the old system was that of a machine invented by Lewis Paul in the middle of the eighteenth century. This person discovered the principle of rolling-spinning. "Paul's invention," remarks Mr Warden, "contained the germ of a self-acting and self-regulating principle, and the means which he used were so unlike any previous performance by the hands, that he is well entitled to the admiration of posterity for the originality of his genius." To Richard Arkwright the country is indebted for the practical solution which he gave to the problem of automatio spinning. By this principle, the flyer was rendered automatic in spreading the yarn on the bobbin. From the introduction of machines for cotton spinning to the invention of machinery for the spinning of flax, was but one step. Two men, one a clockmaker and the other an optician, patented, in 1787, a machine, "consisting of a cylinder three feet in diameter by ten inches broad, smooth on the surface, with some small cylinders or rollers in connection for holding and drawing the flax and other fibrous materials put upon it for operation. Also- (we are quoting from the specification) - a spinning machine or frame, having four spindles, consisting likewise of a plain cylinder, but of smaller diameter, with rollers for holding and drawing the untwisted sliver of flax or other material passing there." Rapid was the progress that followed the introduction of these machines of Kendrew and Porthouse. At first they were very small, somewhat awkward, and for some time, notwithstanding their pretty general introduction, unprofitable to the purchasers. It is true that steam was used from the first as a motive power, but during the first decade of the present century, perfection was not attained. Then followed improvements close upon the heels of each other; and, as $\mathbf{M r}$ Warden says, as the machinery was improved, the quality of the yarn became finer until it supplanted hand-spun yarn. . In bringing down the history of these manufacturing operations, $\mathrm{Mr}$ Warden describes at length the machinery used in the present day. . . The second chapter of that portion of the book detailing the history of the manufacturing operations in the production of linen for the market, treats us to an account of the rise and progress of weaving. Of fancy weaving there is no mention, as few linens are so made. Into the ancient history of this venerable handicraft, we do not intend following the author. - . The process of warping before the threads of warp can be wound on the Jard beam on the loom is fully described in a pleasant manner by Mr Warden. . . The art of bleaching is a distinct branch, though of course a necessary one, of linen manufacture. The earliest inention wo have of bleaching is that of Theophrastes, who, three hundred years before Christ, refers to the use of lime in this process. Buttermilk was originally employed in this country, but water, acidulatod with 
sulphuric acid, was substituted a century ago by Dr Home. Chlorine was after. wards used, Mr Watt being the tirut to introduce this suggestion of M. Berthollet into England. - . . It must strike the reader of Mr Warden's exoedingly interesting book how much may be done by the pressure of uecessity towards obtaining something like accuracy and perfection in machinery, \&o.

\section{Froy the "Practical Mechanics" Joursah" Ist Feb., 1865.}

Ttis goodly volume, withal its unpretending title, contains net only the most complete and comprehensive account of the linen trade, to which, by its title, one would suppose it limited, but also an excellent account of almost all the other fibrous materials that have been proposed or employed as the basis of textilo fabrics analogous to linen. The author has obviously worked at bis history as at a labour of love, and produced a work that almost no one could take up witbout becoming interested in its historioal and topograpbical details, and that must long remain of sterling value to all concerned in the produotion or sale of linen, as a ropertory andauthority. The 6rst Section, of 110 pages, is devoted to "The Raw Mato. rial," and in this we have not only the vatural history and distribution in space of all the fibre-growing plants, but an extremely good resume of the agriculture and the conditions for success and for securing special qualities of fibre, as respects all the more important fibrous materials. In Sections II. and III. we bave the archwology of linen, beginning with "Bible linen" and coming down to modern day". Mr Warden is evidently an orthodox churchman of some Scottish form, and does not hesitate to take the start point of linen history from "the first interview between man and his Maker after the fall," wher "unto Adam aod his wife did the I.ord God make coats of skins and clotbe them." Coats, he says, might be better transluted tunics, and "these were afterwards (by an easy change, no doubt, as the etymologists say,) made of woollen or of linen." Though the author, in his opening sentences, tells us that linen was fabricated more than four thousaud yours ago, he sppears never to have entertained a question whether this transition from heavon-descended skins, to the wide-spread flax cultivation and manufacture of fine linen in Egypt, was likely to have taken place within much less than two thousand years, in accordance with doctrinal chronology. But however Mr Warden's method of writing history may be behind modern modes pour verifier les dates in logical rigidity, we may well follow his narrative with interest, aud feel pleased, if nothing more, with the truthful piety of the author. His historical lucubrations cannot deprive his work of its great practical value. The fourth Section, in its first and second parts, is devoted to the description of the modern linen manufacture all over the world; the fifth, and last, to the manufacturing operations whereby the fibre becomes linen oloth : all which is ably, lucidly, and exhaustively given. Whatever opioion may be arrived at as to the archroological part of the history in Mr Wardon's book, there can be but one formed as to the able way in which be has traced the growth and change of locality of the linen manufacture in nodern times. The long chapter in which (p. 359 et seq.) he traces the origines, the rise and progress, and present state of the linen manufacture of the north of Ireland, should be studied by Irish Members of the House of Commons, and by all others who are still desirous that the great and prosperous staple trade of the north should overflow and spread over the south and west. The attempts hitherto made to effect this have been singularly unsuccessful and discouraging. Some of the causes of this which are of anterior, if not of historical origin or date, and which do not quite lie on the surface, may be more or less discerned by a reflective reader, who, boing personally well acquainted with the social condition of the south and west of Ireland, shall take up and study this chapter of Mr Wardeo.ED.

\section{From tue " ScotsMan," 16Th Nov., 1864.}

Mr Warden might almost have designated his book "The Linen and Jute Trades, Ancient and Modern." It is true, the word " ancient" could scarcely have been applied to the jute trade; but that trade is virtually described in this volume, fully and well; and modern though it be, so far as this country at least is con. cerned, it is running its race so rapidly and strongly, that it is vot only already of vast importance to Scotland, but to the country generally, and we have no doubt it will develop itself, and inerease so much as to be quite worthy of being described as fully as the linen trade. It is practically, by its rapid extension and the variety 
of purposes to which it is being applied, almost abreast of the older branch already. Although Mr Warden no doubt commenced the compilation of this work before the beginning of the recent prosperity in the linen and jute trades, he could not have brought it out at a more opportune time than when that prosperity, after running on uninterruptedly for two years, has attained an elevation never before reached. Not only is every manufactory and spinning-mills and every pieee of machinery, and every power-loom fully occupied, but very considerable additions and extensions are being made, as well in Fifeshire as in Forfarshire. The first impression of the book, looking at its siz, is that surely all that could be written about the linen trade might bave been compressed into a smaller space. We fail to discover, however, where the volume could have been judiciously curtailed. Mr Warden has accomplisked his task comprehensively and well; and he writes fluently and clearly. In a book devoted to a dry technical subject, such as the "Linen Trade, Ancient and Modern," may be supposed to be, the geveral reader cannot be expected to look for much to interest him ; but he will find himself in this instance agreeably mistaken, and a perusal will gratify him as much almost as it must do persons more immediately engaged in the trade. To no portion of his subject does Mr Warden appear to have devoted himself more energetically and lovingly than to that portion designated "Bible Linen," which will generally be read with interest. - . - The modern linen trade, particularly as it has developed itself in Forfarshire, is very fully described; and although the portion of the volume devoted to an account of the jute trade is comparatively small, that arises, no doubt, more from its recent introduction than from its want of interest or magnitude, as compared with the linen trade. The linen trade is more spread over our own country, as well as the continent of Europe, than the jute trade is; the north of Ireland, having Belfast as the centre, is as importantly occupied in the production of flax and its manufacture into linen as Scotland is, with its centre of the trade in Dundee; but the manufacture of jute into yarns and cloth is almost entirely confined to Forfarshire, No trade has so rapidly risen into importanoe in this country-none bas proved more beneficial to the locality in which it is carried on; and as there seems to be no limit to the production of the raw material at a moderate cost, there seems as little reason to doubt that this trade is only yet in $i$ ts infancy, when it is considered to how many and various useful purposes the manufactured article can be applied. It is interesting to follow the progress of the linen trade from its position fifty years ago, with the old spinning-wheel-the occupant alike of the mansion and the cottage-and the "customer" weaver, to the modern spinving-mills aud power-loom factories. She was then considered a "handless" maiden who conld not spin the yarn for her own "providin';" and there is still much more of private spinning and weaving at the present day on the continent of Europe than Mr Warden serms to be aware of. So much do old customs and habits adhere to a people, that it is . only last summer we saw in a town in France, within easy reach of two days' railway travelling, the old distaff and spindle at work in the hands of an old woman; and in the country parts of Germany the linen is yet almost altogether produced for private use by the cottage spinning-wheel and the "customer" weaver. In a late excursion through Saxon Switzerland we had such a "customer" weaver for our guide, and a more intelligent person could scarcely be met in the same rauk of life. He possessed a good house and a piece of land, as many of our Scotch weavers formerly did, and as some of them still do. But we cannot regret the advance of the power-loom, for weaving is not only a monotonous but a severe labour; and both man's and woman's strength and intelligence can be more suitably and profitably employed than at the weary driving of a shuttle. It may be added, that the rapid progress of steam, as applied to machinery and railroads, has effected great changes in the customs of those employed in the trade. There are yet living men who have walked from Brechin to Dundee on a market day, "stood the market," and walked home again in the afternoon.

From the "Illustrated Times," 29Th OOT., 1864.

"The Linen Trade, Ancient and Modern," does not at once strike the arerage reader as a lively subject for a large and thick volume. But $\mathrm{Mr}$ Warden claims indulgence for being no professional bookmaker, and he may certainly be acquitted of being a title-maker. The title is the faintest indication of the contents of a volume which is historically interesting to all readers, whilst it cannot fail to have 
opecial claims on a large section of manufacturers and their workmen. The early part of the brok is taken up with an account of the growth of flax, the general foundation of linen, with especial reference to its cultivation in respect to rotation of crops, \&c, subjects which the growers shouldalready know, or should study completely under Mr Warden's able guidanoe. Hemp and jute are similarly describer, as they undonbtedly belong to the same genus, and have, or have had, much more to do with linen than most people would imagine. India nettle and China grass are also subjects of discussion, as well as the New Z and which now obtains no cultivation. "Bible lineu" forms an excellent ohapter, leading the way to linen as known to the ancients. In "the years long still" ladies would spin, instuad of "doing" crochet or worse. "In these occupations high-born ludies took refuge from anxiety and sorrow,"saps the author. Hector recommended it to Mra Hector, and Telemachus to his mother; and even "Helen, though frail as fair, was laborious as Penelope, plying her shuttle or her golden distaff, and surrounded habitually by a group of maidens, the she-manufacturers of the period." Such stories must read strangely in Lancashire aud anongst distressed neollewomen everywhere. The early accounts are full of interest. The ancient Romans stuck to woullen garments, but the more effeminate period of the Empire was not satisfed without fine linen to its purple. Italy and Spain were great in its growth, importation, and manufacture; but with their general decay decayed the flax idea. In the present day, however, Italy is so rich in the plant as to export large quantities; and in Spain the linen trade is reviving, as every. thing else seems to be doing. In Frasce the emigrution of workmen oonsequent upon the revocation of the Edict of Nantes in 1685 gave a great blow to trade, and set Hamburg in ompetition. Russia has for a lin; period been the greatest flax and hemp growing country in the world. In Turkey it is but little thought of. Coming nearer home-whilst necessarily omitting much, even in the bilefest glance. of this volume's contents - we find that flax was iodigenous to Britain, and that in the reign of John the uve of linen was familiar to the great body of the people. In 1643 Parliament laid a duty on damask table-linen; and a few years fater, despite every encouragement given, we were almost wholly supplied with linens from France. In Ben Jonson a tablecloth is described as costing $£ 18$. Byand-bye came the grievances, of course. The silk-weavers complained that the use of printed stuff was so common that there was no distinction of classes-which meant that the silk people were being ruined; and in $1770 \mathrm{Arkwright}$ invention, obviating the necessity of using $\mathrm{fl}$ ix yarn for warp, put cotton fairly upon her nntil lately flourishing legs. In Ireland, although linen was known there at a very early period, the accounts are vague and unsatisfactory; until, about the close of the seventeenth century, a stipulation with England with respect to the woollen trade produced an activity which has led the flax culture and manufacture to its present flourishing condition. With respect to Scotland, Mr Warden has collected a vast mass of information, always useful, sometimes amusing. In early times the Scotch were as badly off as their neighbours, but they had much to do with the Irish success, and soon saw the utility of establishing a suocess for themselves. One-third of Mr Warden's book is devoted to very minute details of the Scotoh trade, and the very minuteness of the account is quite sufficient to render it impos. sible to give any general sketch here. But it is a most important subject, and han naturally rcceived the best attention from its author.

\section{From the "Journal of hariculture," March, 1865.}

The Journal of Agriculture, for March 1865, after noticing "The Horse and His Rider," by Sir Francis B. Head, says-But, with all deferenoe to Sir Francis Head, we venture to submit that much may be said in praise of linen; and, with the help of Mr Warden's admirable work, and of information derived from other sources, we doubt not that our farming friends, however fond of "the woolly people," will be led to doubt whether they do well in negleoting the cultivation of flax, and in annually spending enormous sums in importing from foreign countries material for rearing animals which mav readily be found at home. Mr Warden's book merits their special attention, and not theirs only, but that of all interested in our national prosperity. The manufacturer and the agriculturist will find it full of matter specially bearing on their respective callings. The merely literary student, also, will be attracted by its multifarious topics, embracing things new 
and old. Nay, we know a young lady who seized on it with avidity, charmed, probably, with the sections, "Ancient Linen," in which "Bible Linen," and the Fine Linen of the Egyptians, figure conspicuously, and "The Linen Manufactures of the Olden Time," in which we have a pleasant account of the primitive customs of our forefathers, some of which lingered on to no very distant date. Mr Warden thinks that the history of civilisation, as exemplified by the progress of the arts and sciences, should interest us more than the recorded exploits of those who, in popular esteem, are the heroes of our age. Assuredly, Milton had reason to denounce them as "destroyers rightlier called, and plagues of men." It is to be regretted that manufactures, trade, and commerce are only mentioned incidentally by ancient authors, and that few of them give an intelligible account of the manufacture of linen. Most praiseworthy, therefore, is Mr Warden's endeavour to gather into a connected history notices scattered through detached sentences and paragraphs. - . Mr Warden handles his pen with a grace and a freedom which rendier unnecessary his deprecation of criticism on his work as a literary effort. We shall give a resume of its multifarious contents, and then invite onr agricultural readers to settle the question whether they do well in omitting flax from their rotation of crops. It used to be largely grown in Scotland, and the enlarging growth of it in Ireland demonstrates how important it is there deemed as a branch of rural industry. . . . Not in the least open to scepticism are his observations on the fine linen so profusely employed by the Hebrew priesthood, and in the magnificent furniture and fittings of the Hebrew sanctuary. We fear, however, that the Bishop of Natal will not allow that "the Israelites had constructed in the wilderness looms and all the other necessary implements and machinery for the articles required for the tabernacle, and such other purposes." Whether Dr Colenso demurs to the possibility of this statement or not, it is certain, we believe, that " all the women who were wise-hearted among the Israelites did spin with their hands, and brought that which they had spun, both of blue, and of purple, and of scarlet, and of fine linen, an offering unto the Lord." . " Singularly minute, curious, and interesting is the chapter on Eoyptian Linen. . Bearing in mind the extreme tenuity of the hand-made yarns of the modern natives of India, and the gauze-like fabrics produced by their simple lonms, we need not be incredulous when informed that some specimens of Egyptian linen were termed " woven air ;" and that some of the linens wrapping up the embalmed bodies of kings and queens are found to be so fine that the very finest cambric or lawn of the present day looks coarse beside these specimeos of the Egyptian looms in the days of the early Pharaohs. . . We have only touched on a few of the curious matters so amply illustrated in the long chapter on Egyptian linen, and regret that we must pass over all that $\mathrm{Mr}$ Warden has go industriously compiled regarding Phœnician, Carthaginian, and Babylonian, Colchican, Grecian, and Roman linen. . . . Omitting much very interesting matter, we pass on to the seventeenth century, which was prolific in Acts of Parliament intended to encourage the growth of flax and the manufacture of linen, both in England and Ireland. - . A Board of Manufactures for Scotland was established in 1727, and, as an example of political shortsightedness, it is amusing to read that, by the Treaty of Union between England and Scotland (anno 1706), it was stipulated that certain annuities should be paid out of the Imperial purse, and applied for the benefit of the latter country as an equivalent for the greater advantages likely to accrue to England from the said treaty! In this stipulation originated the Scottish Board of Manufactures. - . The chief localities of the linen trade at the date of the establishment of the Board were in those counties extending from Lanarkshire to Forfarshire, the latter county being even then far ahead of all the others. The Board, so far as the linen trade is concerned, was deprived of its functions in 1823 by Act of Parliament, against which it vigorously protested, declaring the Act fraught with danger to all but a few crpitalists, "probably aiming at obtaining a monopoly of the manufactures to themselves." The Act, however, passed at the indignant and reiterated demands of the linen manufacturers, who by experience had learned the worthlessness of bounties and protections which only trammelled the progress of industry; which only craves from Governments freedom to develop its resources naturally, in supplying the growing demands of the populations of the world. . . As might be anticipated, our "Dundee Merchant" enlarges on the history of the linen trade in Dundee, and gives numerous details of great interest to the people of this ancient town, now the centre of the Scotch linen manufacture, and proud of its recently acquired distinetion as "the motropolis of jute." 


\section{Fros the "Eoovosist," 29tu APHL, 1865.}

The author of this book. Mr Alex. Warden, hinself a linen merobant of Dundee, has been moved he tells us to undertake the task by the conviction "that the history of so ancient and iruportant a manufacture as that of linen, and of the com. merce connected with it, ought to be given to the world." He modestly professes his consciousness of his own deficiencies with respect to mere literary qualifications, but hopes that the results of his many years' intimate practioal acquaintance with the trade in all its branches may, in some sort, atone for them; and would ask "that the book may bo received and judged of not as a literary effort, but as an attempt to compile a full and reliable record of the rise, progreas, and present condition, of an important department of manufacture and commerce."

We think Mr Warden may fairly besaid to have acconplished his object, and that this thick volume of 700 odd pages contains all that any man is likely to want to know abont lineu and the commerce connected with it. . . . In his tirst section Mr Warden treats of the raw material of the linen manufacture. The three principal fabrics, flax, hemp, and jute, are described at some length. The native country of the first of these flax-is, we are told, unknown, but it is probably of Oriental origin, whence it has travelled Westward aod Northward into Europe. It has been cultivated from the very earliest times, since, though it requires careful nurture to produce it of a superior quality, it is not difficult to rear, and it is capable of being grown throughout a great range of latitude. It is grown extensively and protitably in the Northern districts of Russia, as well as in the plaios of India and Egypt. But it undoubtedly thrives best in a temperate climate, and one having a regular supply of genial moisture in spring, without an excess of wet in antumn, and where the temperature is pretty equable throughout the season. Short hot summers induce too rupid a growth, and althongh the quantity of fibre produced is large, the quality is never fine. Thus Mr Warden informs us that the climate of Egypt as well as the hot summers of Russia and Prussia are inimical to the fineness of the fibre, and the flax of these countries wants that elasticity, pliancy, and oiliness which is found in that of Belgiunı for instance or Ireland. The flax plant is valuable not only for its fibre but also for its seed; and Mr Warden pro. ceeds to make some remarks on the methods that should be employed for insuring that both should be produced by the samecrop-an object which, he says, necessitates great care. He adds some minute directions on the soil and rotation of crops, on the preparation of the soil, on sowing, pulling, rippling, watering, \&c., \&c., issued by the North-Eastern Agricultural Association of Ireland. Of hemp he spoaks more brietly, seeing, that although in former times it was largely used in the manufacture of linens, very little of it is now consumed in that way. Its fibre is too harsh and strong for the finer class of goods, and, indeed, must undergo some softening process before it can be properly spun over machioery at all. As from various causes the cultivation of flax has not kept pace with the demand of the world for linen, so that its price has continued high, and had the linen trade been confinerl to it, it must have beon circumscribed within narrow dimensions, it was in a happy hour that jute, a cheap substitute for either flax or hemp, was introduced into Dundee. Since then, "this useful and beautiful, though not sterling linen fbre,"-a native of India, - has made most rapid progress, and has already supplanted both flax and hemp for many fabrics to which they were long supposed to hold a prescriptive right. 47,575 tons of it were imported at London and Liverpool in the year 1862. Mr Warden is, however, of opinion, that all attempts to cottonise jute, so as to adapt it to be spun over cotton machicery, must be unavailing, - at least, until radical changes are introduced into the cultivation and preparation of the plant.

Mr Warden devotes his second section to an account of ancient linen, -its manufacture and use in Egypt, Palestine, Greece, Rome, Colchis, and other countries. This he does by carefully collecting and arranging the detached sentences or short paragraphs referring to the subject which may be found in ancient writers, sacred and profane. . . . Under the head of "Mlodern Linen," Mr Warden gives a sketch of the rise, progress, present condition, and prospects of the linen trade in the various countries of the world in which it is pursued, concluding with the United Kingdom. Scotland, in particular, is treated at great length, as is natural, both from the important place the manufacture there holds, and from the anthor's special information. . . M M Warden estimates the present probable value of the linen manufactures of the United Kingdom at about $£ 25,000,000$, of which about one-half is exported. This, as he says, "is enough to show that it forms one of the most important branehes of the trade of the conntry. Its extension has of late years been marvellously rapid, and its elasticity is commensurate with its im. portance." 
We may add in conclusion, that in addition to the points already specified, the volume contains ample tabular statements of imports and exports, prices current, factories, \&c., \&c., besides a complete account of the processes of manufacture.

anatysis of the Volome on the Linen Tradi, ancient and Modern. Br ALEX. J. WARDEN, DUNDEE.

\section{From Mrssha Longuan's "Notms on Books."}

This volume comprises full details of the cultivation and preparation of flax, jute, and the other raw materials of the linen manufacture; the history of the trade in Ancient Egypt, Judea, Greece, Rome, \&c. ; its present condition in the various nations of Continental Europe; in England, Ireland, and Scotland, from the earliest times; notices of parishes in Scotland formerly devoted to the linen manufacture ; a particular account of the trade in Dundee and in the manufacturing towns around; a Dundee Prices Current for every year of the present century. particulars relating to spinning and weaving establishments ; imports, exports, and many other statistical tables; spinning, weaving, bleaching, \&c., in ancient and modern times; followed by a copious lndex to the whole work.

In the Leisure Hour for September, 1867, page 602, the Editor soys :-We have been greatly indebted, in the preparation of this article, to $\mathrm{Mr}$ Warden's volume. It does its author great credit. We hardly know a monograph on any particular subject to compare with it. If any reader wants to know all about linen in all its departments, in all countries, in all the ages of the world, all that he can desire is gathered in this volume. Perhaps the style wants what an author might call "finish," but the facts are all there, and they are told in a light, intelligent, olear, and manly way. The manner in which the writer deals with "Bible Linen" does him much credit. 

$\mathrm{HD}$

9930

A2W2 iarden, Alexander Johnston

The linen trade, ancient and modern.

2d ed. Longman, Green, Longman, Roberts and Green (1867)
PLEASE DO NOT REMOVE CARDS OR SLIPS FROM THIS POCKET

UNIVERSITY OF TORONTO LIBRARY 


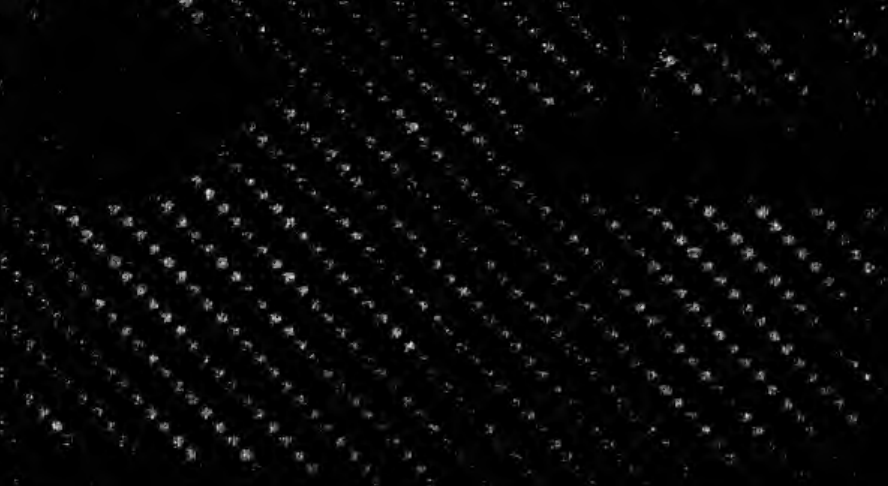

$\frac{5}{3}-\frac{2}{2}$

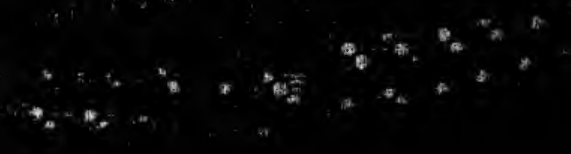

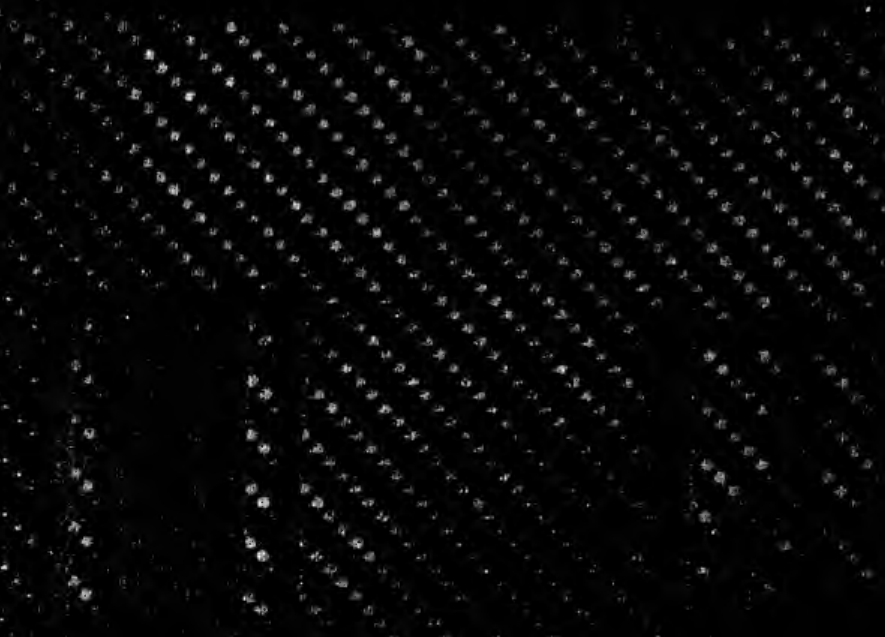

, 